\title{
Metal Waste Form Corrosion Release Data from Immersion Tests
}

\author{
Chemical Engineering Division
}

Argonne National Laboratory 


\begin{abstract}
About Argonne National Laboratory
Argonne is operated by The University of Chicago for the U.S. Department of Energy Office of Science, under contract W-31-109-Eng-38. The Laboratory's main facility is outside Chicago, at 9700 South Cass Avenue, Argonne, Illinois 60439.For information about Argonne and its pioneering science and technology programs, see www.anl.gov.
\end{abstract}

\title{
Availability of This Report
}

This report is available, at no cost, at http://www.osti.gov/bridge. It is also available on paper to U.S. Department of Energy and its contractors, for a processing fee, from:

U.S. Department of Energy

Office of Scientific and Technical Information

P.0. Box 62

Oak Ridge, TN 37831-0062

phone (865) 576-8401

fax (865) 576-5728

reports@adonis.osti.gov

This report was prepared as an account of work sponsored by an agency of the United States Government. Neither the United States Government nor any agency thereof, nor The University of Chicago, nor any of their employees or officers, makes any warranty, express or implied, or assumes any legal liability or responsibility for the accuracy, completeness, or usefulness of any information, apparatus, product, or process disclosed, or represents that its use would not infringe privately owned rights. Reference herein to any specific commercial product, process, or service by trade name, trademark, manufacturer, or otherwise, does not necessarily constitute or imply its endorsement, recommendation, or favoring by the United States Government or any agency thereof, Argonne National Laboratory, or The University of Chicago. 


\section{ANL-04/15 \\ METAL WASTE FORM CORROSION RELEASE DATA FROM IMMERSION TESTS}

by

C. T. Snyder, L. A. Barnes, and J. K. Fink

Contributing Authors:

D. P. Abraham and L. Leibowitz

Chemical Engineering Division

Argonne National Laboratory

9700 S. Cass Avenue

Argonne, IL 60439

May 2004 



\section{TABLE OF CONTENTS}

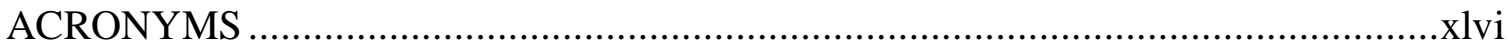

ACKNOWLEDGMENTS xlvii

I. INTRODUCTION 1

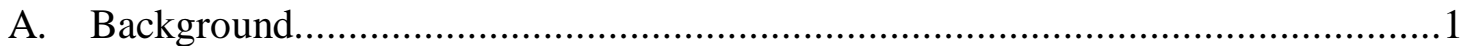

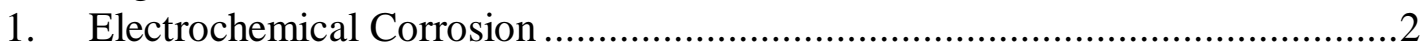

2. Role of Passive Oxide Layer ................................................................. 18

3. Review of Releases from Existing Immersion Tests ............................... 19

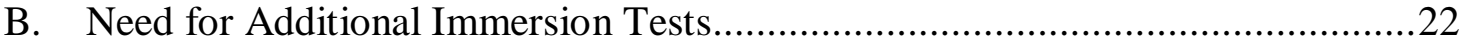

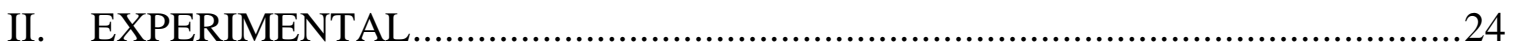

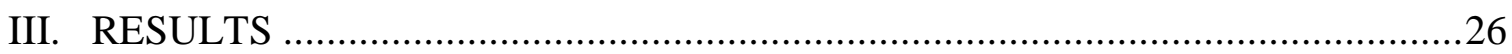

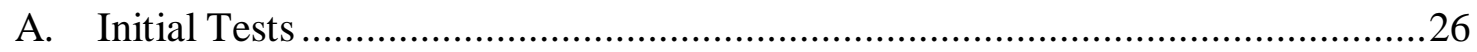

1. Releases of Elements from Each Test .................................................26

a) Effect of Reuse of Teflon Vials on Releases of Major Elements ................26

b) Effect of Variation of Detection Limits on Reported Releases ....................28

c) Sample Contamination of Minor Elements \& Mo .....................................30

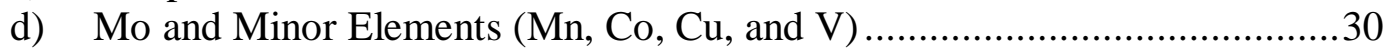

2. Cumulative Releases at $90^{\circ} \mathrm{C}$ for Each Solution.......................................... 31

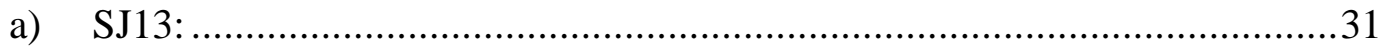

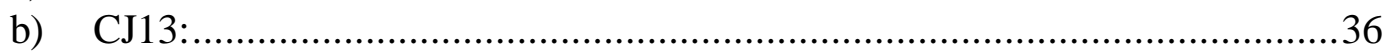

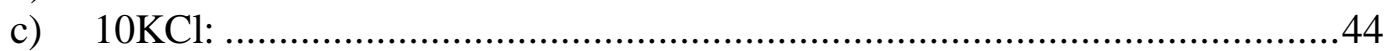

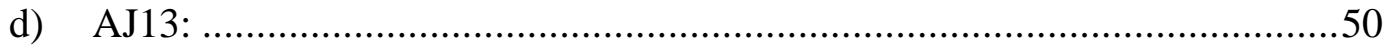

3. Comparison of $90^{\circ} \mathrm{C}$ Cumulative Releases as a Function of Solution ..............57

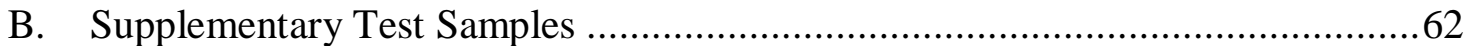

1. Releases of Elements from Each Test .....................................................62

a) Sample Contamination of Minor Elements and Mo ...............................62

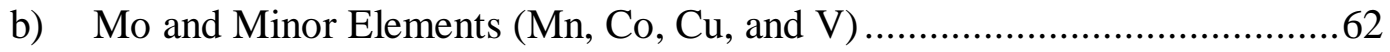

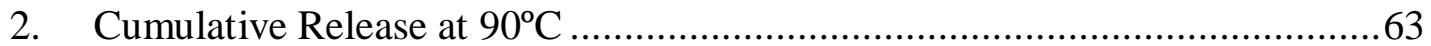

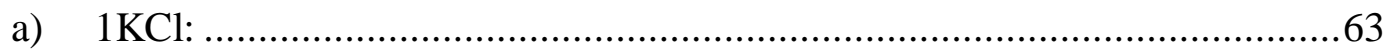

3. Cumulative Release at Ambient Temperature:..........................................66

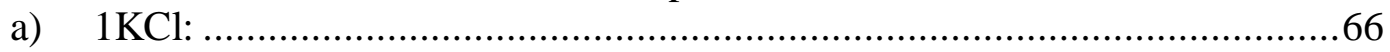

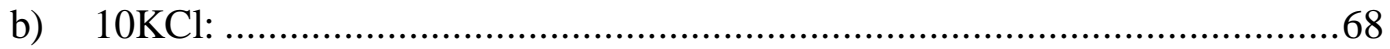

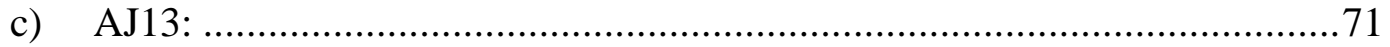

4. Comparison of $90^{\circ} \mathrm{C}$ and $25^{\circ} \mathrm{C}$ Results as a Function of Solution .................... 72

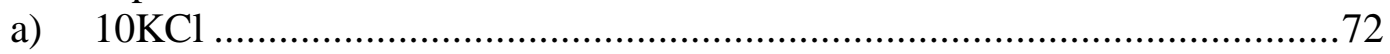

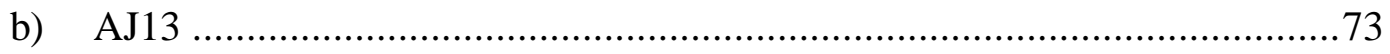

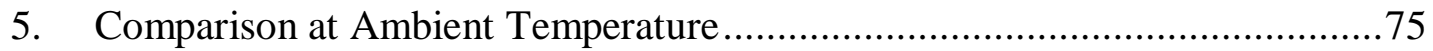

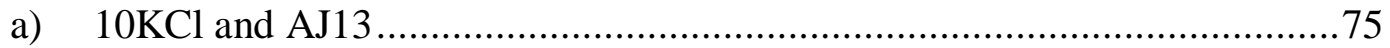

C. Comparison of $90^{\circ} \mathrm{C}$ Releases with Electrochemical Corrosion Data ..................77

D. Comparison of Releases from the MWF and High Level Waste Glass................80

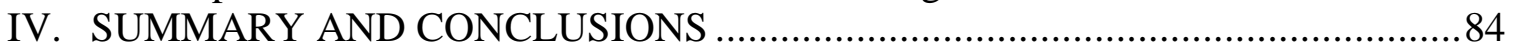

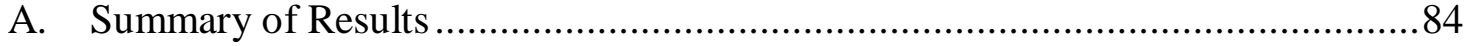

1. Results of Test Matrix Experiments............................................................ 84 
2. Results from Additional Tests ............................................................. 85

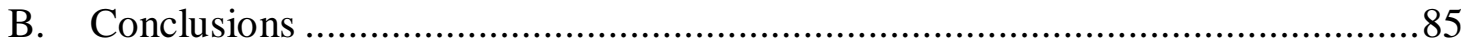

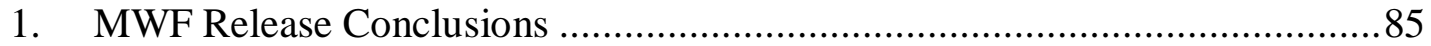

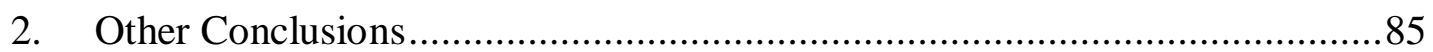

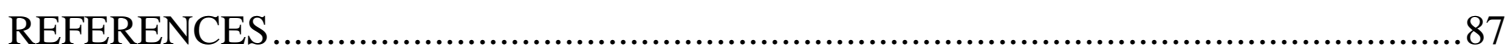

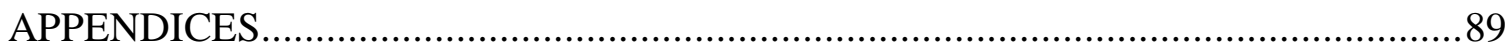

A. Data from Electrochemical Corrosion Tests .....................................................91

B. Publications by D. P. Abraham on the Metal Waste Form Alloy and Protective

Oxide Layers ............................................................................................ 103

C. Data from 7, 14, 28, 60, 95, 182 and 365 day Immersion Tests at $90^{\circ} \mathrm{C}$ in $1 \mathrm{KCl}$ and

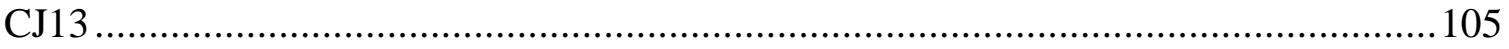

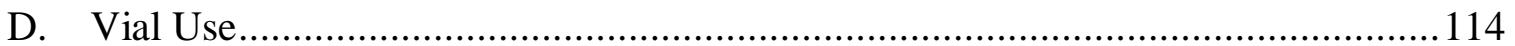

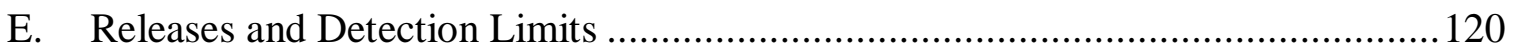

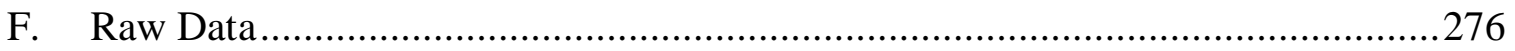

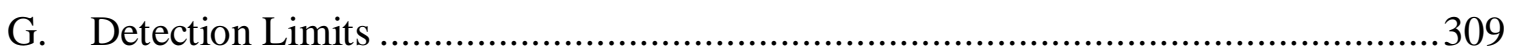

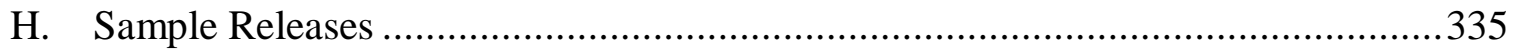

J. Supplementary Tests—Releases and Detection Limits .......................................360

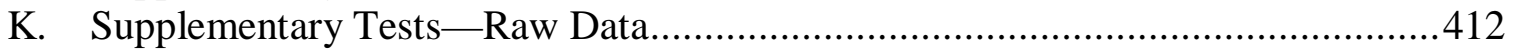

L. Supplementary Tests_Detection Limits ..................................................... 418

M. Supplementary Tests—Sample Releases ..................................................... 427

N. Normalized Loss Formula with No Correction for Blanks ..................................453 


\section{LIST OF FIGURES}

Page

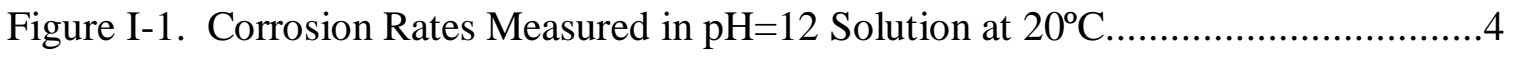

Figure I-2. Corrosion Rates Measured in Concentrated J-13 (pH=8.2) Solution at $20^{\circ} \mathrm{C} . .5$

Figure I-3. Corrosion Rates Measured in 10,000 ppm Chloride $(\mathrm{pH}=6.3)$ Solution at

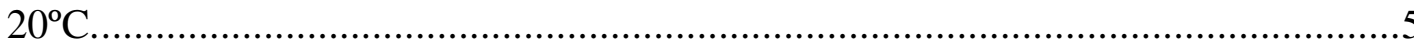

Figure I-4. Corrosion Rates Measured in 1,000 ppm Chloride $(\mathrm{pH}=5.8)$ Solution at $20^{\circ} \mathrm{C}$.

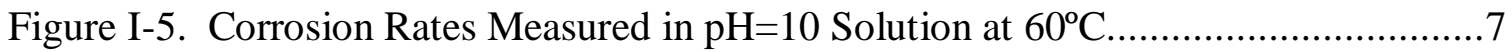

Figure I-6. Corrosion Rates Measured in Concentrated J-13 (pH=8.2) Solution at $60^{\circ} \mathrm{C} . .7$

Figure I-7. Corrosion Rates Measured in 10,000 ppm Chloride ( $\mathrm{pH}=6.3$ ) Solution at

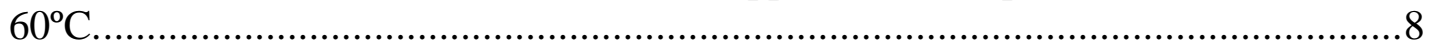

Figure I-8. Corrosion Rates Measured in 1,000 ppm Chloride $(\mathrm{pH}=5.8)$ Solution at $60^{\circ} \mathrm{C}$.

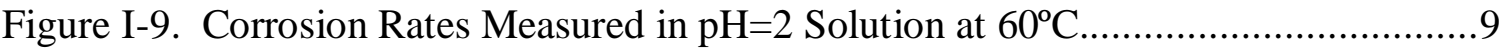

Figure I-10. Corrosion Rates Measured in $\mathrm{pH}=10$ Solution at $90^{\circ} \mathrm{C}$...........................

Figure I-11. Corrosion Rates Measured in $\mathrm{SJ} 13$ (pH=9) Solution at $90^{\circ} \mathrm{C} \ldots \ldots \ldots \ldots \ldots \ldots . . . . . . . .10$

Figure I-12. Corrosion Rates Measured in CJ13 ( $\mathrm{pH}=8.2$ ) Solution at $90^{\circ} \mathrm{C} \ldots \ldots \ldots \ldots . . . . .10$

Figure I-13. Corrosion Rates Measured in 10,000 ppm Chloride ( $\mathrm{pH}=6.3$ ) Solution at

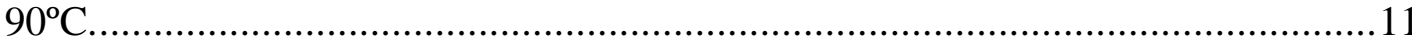

Figure I-14. Corrosion Rates Measured in 1,000 ppm Chloride ( $\mathrm{pH}=5.8$ ) Solution at

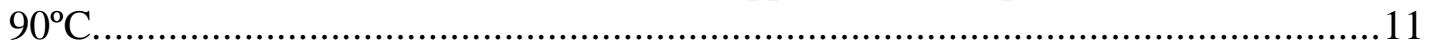

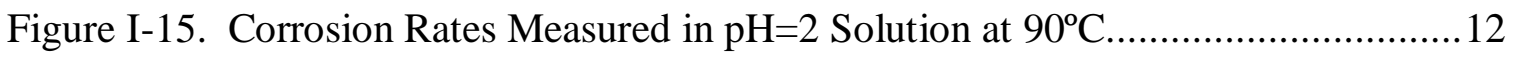

Figure I-16. Average Corrosion Rates Measured in $\mathrm{pH}=10$ Solution. .........................13

Figure I-17. Average Corrosion Rates Measured in Concentrated J-13 (pH=8.2)

Solution.

Figure I-18. Average Corrosion Rates Measured in 10,000 ppm Chloride ( $\mathrm{pH}=6.3$ )

Solution.

Figure I-19. Average Corrosion Rates Measured in 1,000 ppm Chloride (pH=5.8)

Solution.

Figure I-20. Average Corrosion Rates Measured in $\mathrm{pH}=2$ Solution. ..........................15

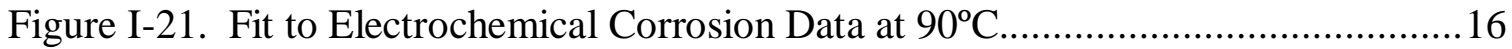

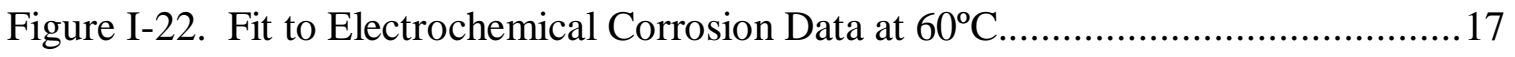

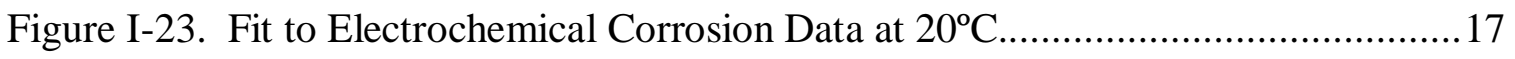

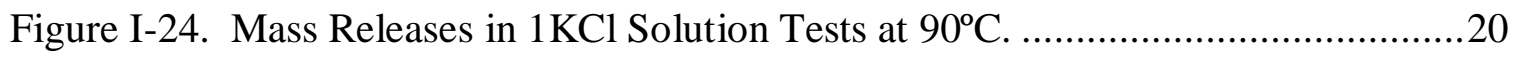




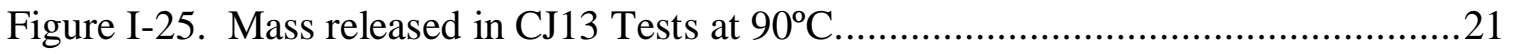

Figure I-26. Comparison of Fe Release with Total Release in CJ13 at $90^{\circ} \mathrm{C}$................21

Figure I-27. Comparison of Corrosion and Release Rates from $90^{\circ} \mathrm{C} \mathrm{CJ} 13$ Tests.........22

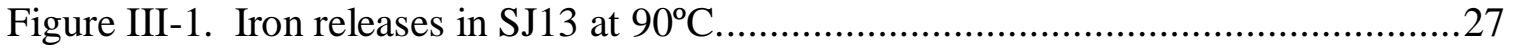

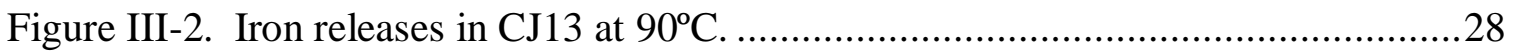

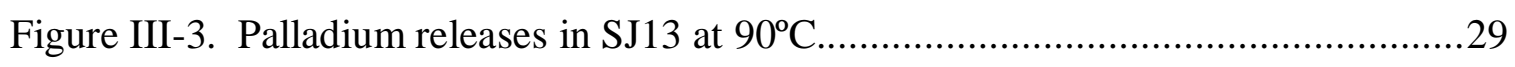

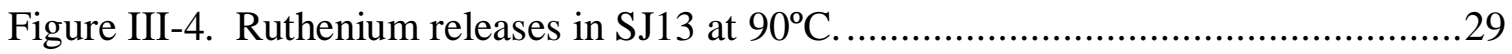

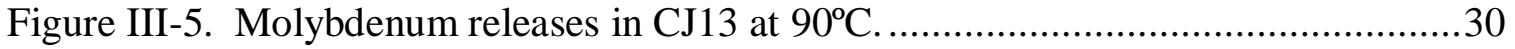

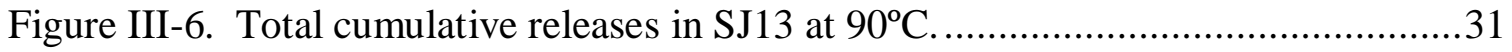

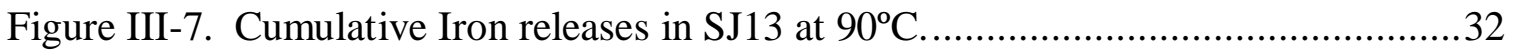

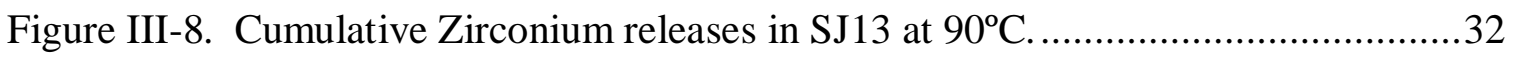

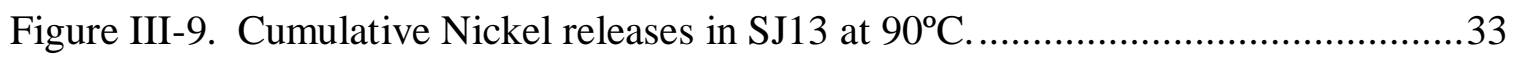

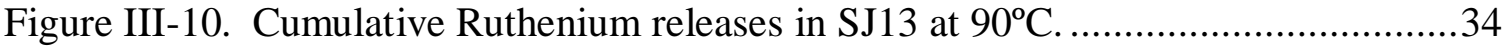

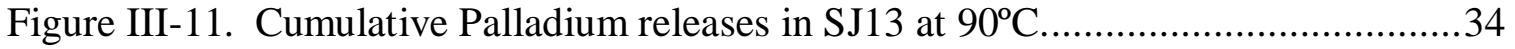

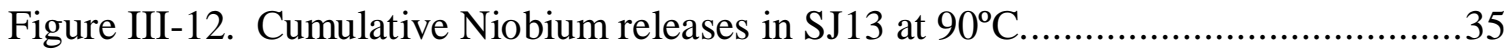

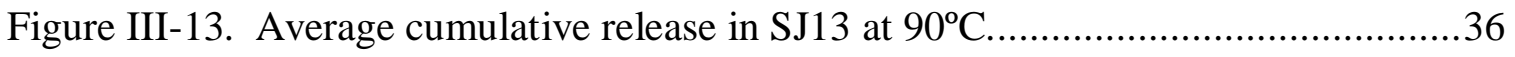

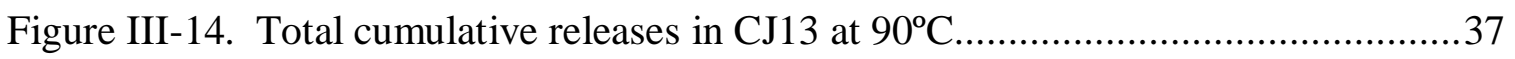

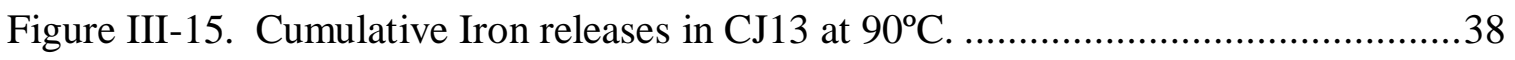

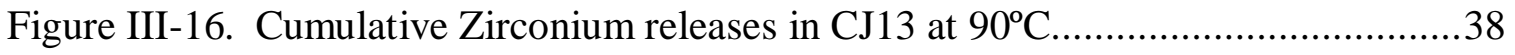

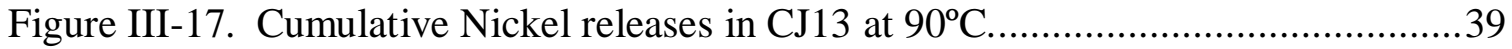

Figure III-18. Cumulative Chromium releases in $\mathrm{CJ} 13$ at $90^{\circ} \mathrm{C}$................................39

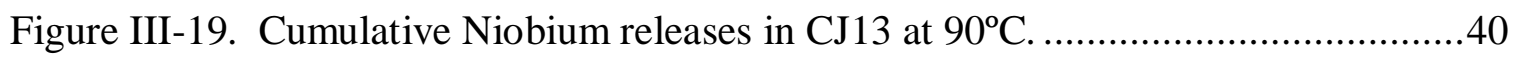

Figure III-20. Cumulative Palladium releases in $\mathrm{CJ} 13$ at $90^{\circ} \mathrm{C}$...............................41

Figure III-21. Cumulative Ruthenium releases in $\mathrm{CJ} 13$ at $90^{\circ} \mathrm{C}$...............................41

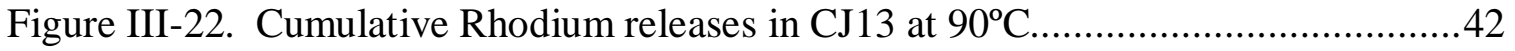

Figure III-23. Average cumulative release of polished samples in $\mathrm{CJ} 13$ at $90^{\circ} \mathrm{C} \ldots \ldots \ldots . . .43$

Figure III-24. Average cumulative release of oxidized samples in $\mathrm{CJ} 13$ at $90^{\circ} \mathrm{C}$..........43

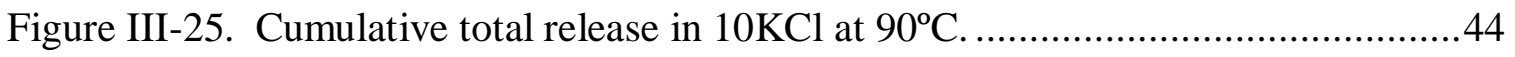

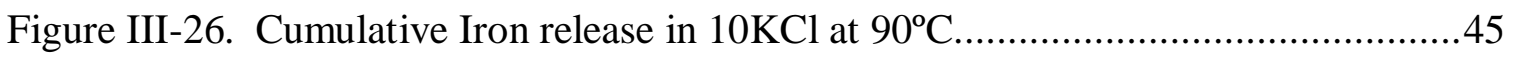

Figure III-27. Cumulative Chromium release in $10 \mathrm{KCl}$ at $90^{\circ} \mathrm{C}$..............................45

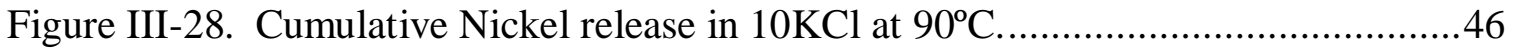

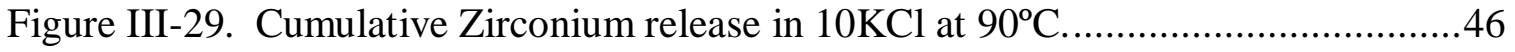

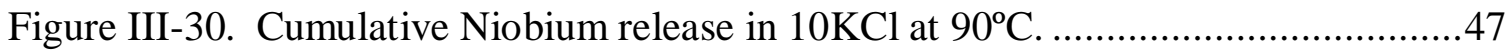


Figure III-31. Cumulative Palladium release in $10 \mathrm{KCl}$ at $90^{\circ} \mathrm{C}$..............................48

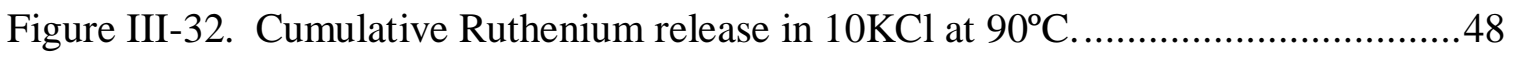

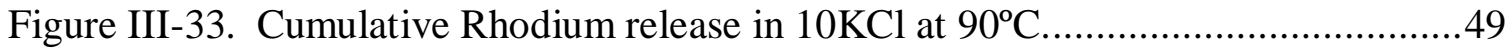

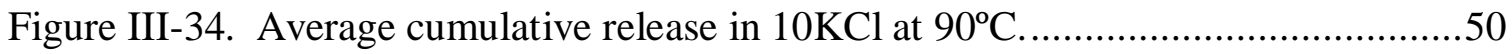

Figure III-35. Cumulative total release in $\mathrm{AJ} 13$ at $90^{\circ} \mathrm{C}$........................................51

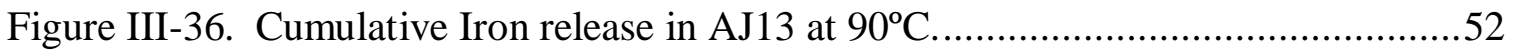

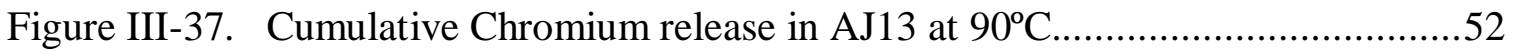

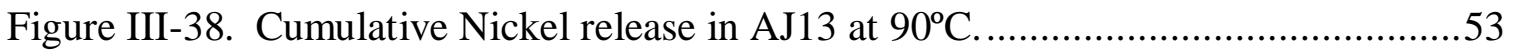

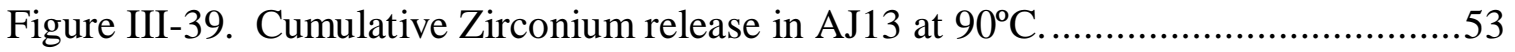

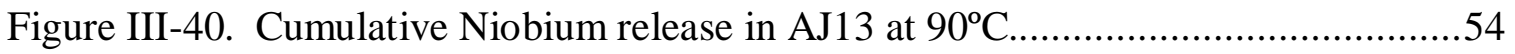

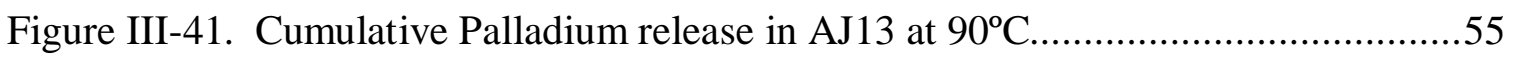

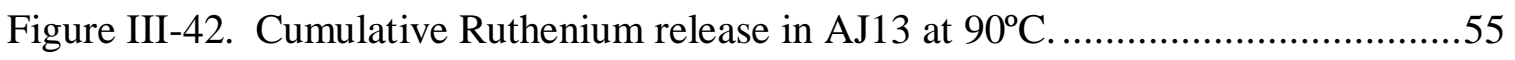

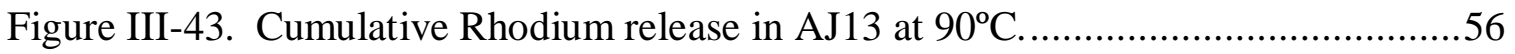

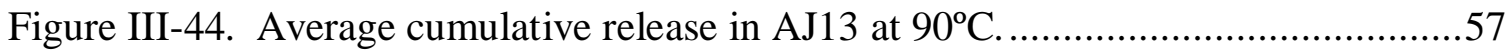

Figure III-45. Average cumulative total release at $90^{\circ} \mathrm{C}$ in four solutions....................58

Figure III-46. Average cumulative Iron release at $90^{\circ} \mathrm{C}$ in four solutions. ...................58

Figure III-47. Average cumulative Zirconium release at $90^{\circ} \mathrm{C}$ in four solutions.............59

Figure III-48. Average cumulative Niobium release at $90^{\circ} \mathrm{C}$ in four solutions. .............60

Figure III-49. Average cumulative Palladium release at $90^{\circ} \mathrm{C}$ in four solutions. ...........60

Figure III-50. Average cumulative Ruthenium release at $90^{\circ} \mathrm{C}$ in four solutions...........61

Figure III-51. Average cumulative Rhodium release at $90^{\circ} \mathrm{C}$ in three solutions. ..........61

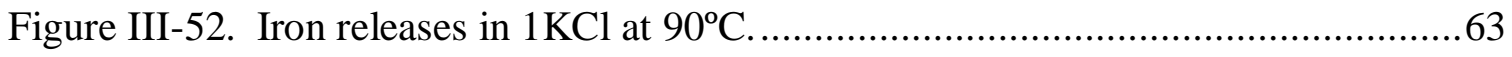

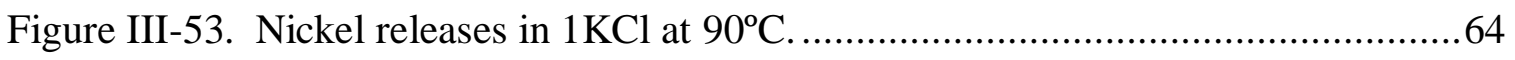

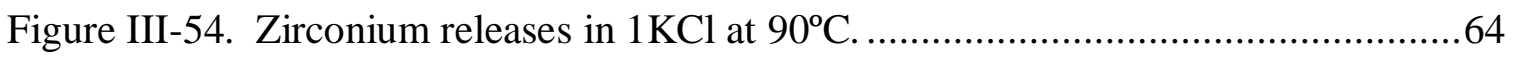

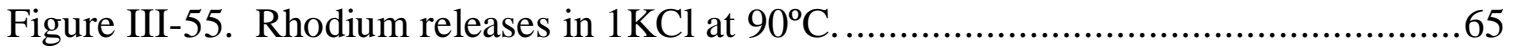

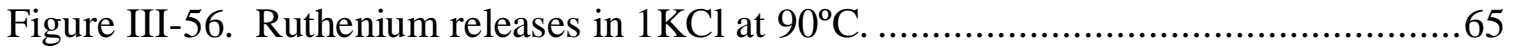

Figure III-57. Iron releases in $1 \mathrm{KCl}$ at room temperature. ....................................66

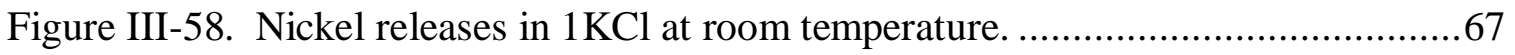

Figure III-59. Zirconium releases in $1 \mathrm{KCl}$ at room temperature. ..............................67

Figure III-60. Iron releases in $10 \mathrm{KCl}$ at room temperature. ....................................68

Figure III-61. Chromium releases in $10 \mathrm{KCl}$ at room temperature.............................69

Figure III-62. Nickel releases in $10 \mathrm{KCl}$ at room temperature. ................................69

Figure III-63. Zirconium releases in $10 \mathrm{KCl}$ at room temperature ............................70 
Figure III-64. Palladium releases in $10 \mathrm{KCl}$ at room temperature .............................70

Figure III-65. Iron releases in AJ13 at room temperature .......................................71

Figure III-66. Cumulative releases in $10 \mathrm{KCl}$ at room temperature........................... 72

Figure III-67. Cumulative Loss of Iron in $10 \mathrm{KCl}$.................................................. 73

Figure III-68. Cumulative releases in AJ13 at room temperature...............................74

Figure III-69. Cumulative Loss of Iron in AJ13 solution...................................... 74

Figure III-70. Cumulative releases in $10 \mathrm{KCl}$ and $\mathrm{AJ} 13$ at Room Temperature...............75

Figure III-71. Curve Fitting with Cumulative Loss of Iron in $10 \mathrm{KCl}$ solution at room

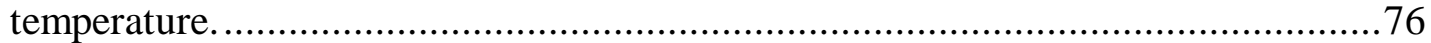

Figure III-72. Curve Fitting with Cumulative Loss of Iron in $1 \mathrm{KCl}$ solution at room

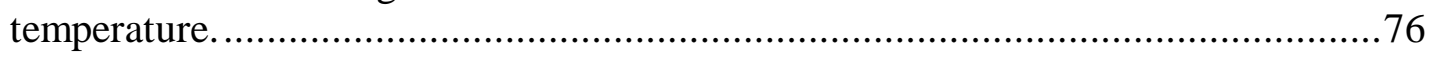

Figure III-73. Comparison of MWF Electrochemical Corrosion and Total releases in $\mathrm{SJ} 13, \mathrm{pH}=9.2$, at $90^{\circ} \mathrm{C}$.

Figure III-74. Comparison of MWF Electrochemical Corrosion and Total releases in $\mathrm{CJ} 13, \mathrm{pH}=8.3$, at $90^{\circ} \mathrm{C}$.

Figure III-75. Comparison of MWF Electrochemical Corrosion and Total releases in $10 \mathrm{KCl}, \mathrm{pH}=6.9$, at $90^{\circ} \mathrm{C}$.

Figure III-76. Comparison of MWF Electrochemical Corrosion and Total releases in

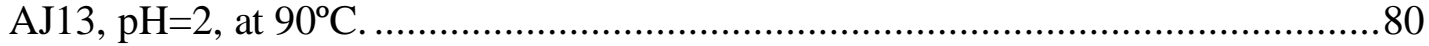

Figure III-77. Fits to the Average Cumulative Fe Normalized Losses at $90^{\circ} \mathrm{C}$.............81

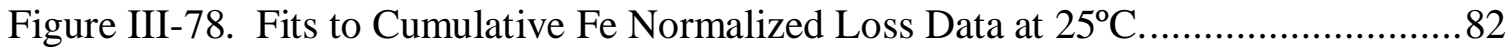

Figure III-79. Comparison of $\log _{10}$ of the release rates of the MWF and HLWG..........83

Figure E-1. Iron Releases in Solution, on Walls, and in Residue from Polished Sample 1 in SJ13 and Average Detection Limits for Leachate and Acid Strip.................... 120

Figure E-2. Iron Releases in Solution, on Walls, and in Residue from Polished Sample 2 in SJ13 and Average Detection Limits for Leachate and Acid Strip.................... 120

Figure E-3. Iron Releases in Solution, on Walls, and in Residue from Polished Sample 3 in SJ13 and Average Detection Limits for Leachate and Acid Strip.

Figure E-4. Iron Releases in Solution, on Walls, and in Residue from Oxidized Sample 4 in SJ13 and Average Detection Limits for Leachate and Acid Strip.

Figure E-5. Iron Releases in Solution, on Walls, and in Residue from Oxidized Sample 5 in SJ13 and Average Detection Limits for Leachate and Acid Strip.

Figure E-6. Iron Present in Solution, on Walls, and in Residue from SJ13 Control and Average Detection Limits for Leachate and Acid Strip. 
Figure E-7. Iron Releases in Solution, on Walls, and in Residue from Polished Sample 1 in CJ13 and Average Detection Limits for Leachate and Acid Strip.

Figure E-8. Iron Releases in Solution, on Walls, and in Residue from Polished Sample 2 in CJ13 and Average Detection Limits for Leachate and Acid Strip. 123

Figure E-9. Iron Releases in Solution, on Walls, and in Residue from Polished Sample 3 in CJ13 and Average Detection Limits for Leachate and Acid Strip. 124

Figure E-10. Iron Releases in Solution, on Walls, and in Residue from Oxidized Sample 4 in CJ13 and Average Detection Limits for Leachate and Acid Strip. 124

Figure E-11. Iron Releases in Solution, on Walls, and in Residue from Oxidized Sample 5 in CJ13 and Average Detection Limits for Leachate and Acid Strip. 125

Figure E-12. Iron Present in Solution, on Walls, and in Residue from CJ13 Control and Average Detection Limits for Leachate and Acid Strip. 125

Figure E-13. Iron Releases in Solution, on Walls, and in Residue from Polished Sample 1 in $10 \mathrm{KCl}$ and Average Detection Limits for Leachate and Acid Strip...... 126

Figure E-14. Iron Releases in Solution, on Walls, and in Residue from Polished Sample 2 in $10 \mathrm{KCl}$ and Average Detection Limits for Leachate and Acid Strip. 126

Figure E-15. Iron Releases in Solution, on Walls, and in Residue from Polished Sample 3 in $10 \mathrm{KCl}$ and Average Detection Limits for Leachate and Acid Strip. 127

Figure E-16. Iron Releases in Solution, on Walls, and in Residue from Oxidized Sample 4 in $10 \mathrm{KCl}$ and Average Detection Limits for Leachate and Acid Strip.

Figure E-17. Iron Releases in Solution, on Walls, and in Residue from Oxidized Sample 5 in $10 \mathrm{KCl}$ and Average Detection Limits for Leachate and Acid Strip. 128

Figure E-18. Iron Present in Solution, on Walls, and in Residue from $10 \mathrm{KCl}$ Control and Average Detection Limits for Leachate and Acid Strip. 128

Figure E-19. Iron Releases in Solution, on Walls, and in Residue from Polished Sample 1 in AJ13 and Average Detection Limits for Leachate and Acid Strip.

Figure E-20. Iron Releases in Solution on Walls and in Residue from Polished Sample 2 in AJ13 and Average Detection Limits for Leachate and Acid Strip.

Figure E-21. Iron Releases in Solution, on Walls, and in Residue from Polished Sample 3 in AJ13 and Average Detection Limits for Leachate and Acid Strip.

Figure E-22. Iron Releases in Solution, on Walls, and in Residue from Oxidized Sample 4 in AJ13 and Average Detection Limits for Leachate and Acid Strip.

Figure E-23. Iron Releases in Solution, on Walls, and in Residue from Oxidized Sample 5 in AJ13 and Average Detection Limits for Leachate and Acid Strip. 
Figure E-24. Iron Present in Solution, on Walls, and in Residue from AJ13 Control and Average Detection Limits for Leachate and Acid Strip. 131

Figure E-25. Chromium Releases in Solution, on Walls, and in Residue from Polished

Sample 1 in SJ13 and Average Detection Limits for Leachate and Acid Strip. ..... 132

Figure E-26. Chromium Releases in Solution, on Walls, and in Residue from Polished

Sample in SJ13 and Average Detection Limits for Leachate and Acid Strip......... 132

Figure E-27. Chromium Releases in Solution, on Walls, and in Residue from Polished

Sample 3 in SJ13 and Average Detection Limits for Leachate and Acid Strip. ..... 133

Figure E-28. Chromium Releases in Solution, on Walls, and in Residue from Oxidized

Sample 4 in SJ13 and Average Detection Limits for Leachate and Acid Strip. ..... 133

Figure E-29. Chromium Releases in Solution, on Walls, and in Residue from Oxidized

Sample 5 in SJ13 and Average Detection Limits for Leachate and Acid Strip. ..... 134

Figure E-30. Chromium Present in Solution, on Walls, and in Residue from SJ13 Control and Average Detection Limits for Leachate and Acid Strip. ............................. 134

Figure E-31. Chromium Releases in Solution, on Walls, and in Residue from Polished Sample 1 in CJ13 and Average Detection Limits for Leachate and Acid Strip...... 135

Figure E-32. Chromium Releases in Solution, on Walls, and in Residue from Polished Sample 2 in CJ13 and Average Detection Limits for Leachate and Acid Strip...... 135

Figure E-33. Chromium Releases in Solution, on Walls, and in Residue from Polished Sample 3 in CJ13 and Average Detection Limits for Leachate and Acid Strip...... 136

Figure E-34. Chromium Releases in Solution, on Walls, and in Residue from Oxidized Sample 4 in CJ13 and Average Detection Limits for Leachate and Acid Strip...... 136

Figure E-35. Chromium Releases in Solution, on Walls, and in Residue from Oxidized Sample 5 in CJ13 and Average Detection Limits for Leachate and Acid Strip...... 137

Figure E-36. Chromium Present in Solution, on Walls, and in Residue from CJ13 Control and Average Detection Limits for Leachate and Acid Strip.

Figure E-37. Chromium Releases in Solution, on Walls, and in Residue from Polished Sample 1 in $10 \mathrm{KCl}$ and Average Detection Limits for Leachate and Acid Strip.... 138

Figure E-38. Chromium Releases in Solution, on Walls, and in Residue from Polished Sample 2 in $10 \mathrm{KCl}$ and Average Detection Limits for Leachate and Acid Strip.... 138

Figure E-39. Chromium Releases in Solution, on Walls, and in Residue from Polished Sample 3 in $10 \mathrm{KCl}$ and Average Detection Limits for Leachate and Acid Strip.... 139

Figure E-40. Chromium Releases in Solution, on Walls, and in Residue from Oxidized Sample 4 in $10 \mathrm{KCl}$ and Average Detection Limits for Leachate and Acid Strip.... 139 
Figure E-41. Chromium Releases in Solution, on Walls, and in Residue from Oxidized

Sample 5 in $10 \mathrm{KCl}$ and Average Detection Limits for Leachate and Acid Strip.... 140

Figure E-42. Chromium Present in Solution, on Walls, and in Residue from $10 \mathrm{KCl}$

Control and Average Detection Limits for Leachate and Acid Strip.

Figure E-43. Chromium Releases in Solution, on Walls, and in Residue from Polished

Sample 1 in AJ13 and Average Detection Limits for Leachate and Acid Strip...... 141

Figure E-44. Chromium Releases in Solution, on Walls, and in Residue from Polished

Sample 2 in AJ13 and Average Detection Limits for Leachate and Acid Strip...... 141

Figure E-45. Chromium Releases in Solution, on Walls, and in Residue from Polished

Sample 3 in AJ13 and Average Detection Limits for Leachate and Acid Strip...... 142

Figure E-46. Chromium Releases in Solution, on Walls, and in Residue from Oxidized

Sample 4 in AJ13 and Average Detection Limits for Leachate and Acid Strip...... 142

Figure E-47. Chromium Releases in Solution, on Walls, and in Residue from Oxidized

Sample 5 in AJ13 and Average Detection Limits for Leachate and Acid Strip...... 143

Figure E-48. Chromium Present in Solution, on Walls, and in Residue from AJ13

Control and Average Detection Limits for Leachate and Acid Strip.

Figure E-49. Nickel Releases in Solution, on Walls, and in Residue from Polished Sample 1 in SJ13 and Average Detection Limits for Leachate and Acid Strip. ..... 144

Figure E-50. Nickel Releases in Solution, on Walls, and in Residue from Polished Sample 2 in SJ13 and Average Detection Limits for Leachate and Acid Strip. ..... 144

Figure E-51. Nickel Releases in Solution, on Walls, and in Residue from Polished Sample 3 in SJ13 and Average Detection Limits for Leachate and Acid Strip.

Figure E-52. Nickel Releases in Solution, on Walls, and in Residue from Oxidized

Sample 4 in SJ13 and Average Detection Limits for Leachate and Acid Strip. ..... 145

Figure E-53. Nickel Releases in Solution, on Walls, and in Residue from Oxidized

Sample 5 in SJ13 and Average Detection Limits for Leachate and Acid Strip. ..... 146

Figure E-54. Nickel Present in Solution, on Walls, and in Residue from SJ13 Control and Average Detection Limits for Leachate and Acid Strip.

Figure E-55. Nickel Releases in Solution, on Walls, and in Residue from Polished

Sample 1 in CJ13 and Average Detection Limits for Leachate and Acid Strip...... 147

Figure E-56. Nickel Releases in Solution, on Walls, and in Residue from Polished Sample 2 in CJ13 and Average Detection Limits for Leachate and Acid Strip...... 147

Figure E-57. Nickel Releases in Solution, on Walls, and in Residue from Polished Sample 3 in CJ13 and Average Detection Limits for Leachate and Acid Strip...... 148 
Figure E-58. Nickel Releases in Solution, on Walls, and in Residue from Oxidized

Sample 4 in CJ13 and Average Detection Limits for Leachate and Acid Strip...... 148

Figure E-59. Nickel Releases in Solution, on Walls, and in Acid Strip from Oxidized

Sample 5 in CJ13 and Average Detection Limits for Leachate and Acid Strip...... 149

Figure E-60. Nickel Present in Solution, on Walls, and in Acid Strip from CJ13 Control and Average Detection Limits for Leachate and Acid Strip.

Figure E-61. Nickel Releases in Solution, on Walls, and in Residue from Polished Sample 1 in $10 \mathrm{KCl}$ an Average Detection Limits for Leachate and Acid Strip...... 150

Figure E-62. Nickel Releases in Solution, on Walls, and in Residue from Polished Sample 2 in $10 \mathrm{KCl}$ and Average Detection Limits for Leachate and Acid Strip.... 150

Figure E-63. Nickel Releases in Solution, on Walls, and in Residue from Polished Sample 3 in $10 \mathrm{KCl}$ and Average Detection Limits for Leachate and Acid Strip.... 151

Figure E-64. Nickel Releases in Solution, on Walls, and in Residue from Oxidized Sample in $10 \mathrm{KCl}$ and Average Detection Limits for Leachate and Acid Strip. ..... 151

Figure E-65. Nickel Releases in Solution, on Walls, and in Residue from Oxidized Sample 5 in $10 \mathrm{KCl}$ and Average Detection Limits for Leachate and Acid Strip.... 152

Figure E-66. Nickel Present in Solution, on Walls, and in Residue from 10KCl Control and Average Detection Limits for Leachate and Acid Strip. 152

Figure E-67. Nickel Releases in Solution, on Walls, and in Residue from Polished Sample 1 in AJ13 and Average Detection Limits for Leachate and Acid Strip...... 153

Figure E-68. Nickel Releases in Solution, on Walls, and in Residue from Polished Sample 2 in AJ13 and Average Detection Limits for Leachate and Acid Strip...... 153

Figure E-69. Nickel Releases in Solution, on Walls, and in Residue from Polished Sample 3 in AJ13 and Average Detection Limits for Leachate and Acid Strip...... 154

Figure E-70. Nickel Releases in Solution, on Walls, and in Residue from Oxidized Sample 4 in AJ13 and Average Detection Limits for Leachate and Acid Strip...... 154

Figure E-71. Nickel Releases in Solution, on Walls, and in Residue from Oxidized Sample 5 in AJ13 and Average Detection Limits for Leachate and Acid Strip...... 155

Figure E-72. Nickel Present in Solution, on Walls, and in Residue from AJ13 Control and Average Detection Limits for Leachate and Acid Strip.

Figure E-73. Zirconium Releases in Solution, on Walls, and in Residue from Polished Sample 1 in SJ13 and Average Detection Limits for Leachate and Acid Strip. ..... 156

Figure E-74. Zirconium Releases in Solution, on Walls, and in Residue from Polished Sample 2 in SJ13 and Average Detection Limits for Leachate and Acid Strip..... 156 
Figure E-75. Zirconium Releases in Solution, on Walls, and in Residue from Polished

Sample 3 in SJ13 and Average Detection Limits for Leachate and Acid Strip. ..... 157

Figure E-76. Zirconium Releases in Solution, on Walls, and in Residue from Oxidized

Sample 4 in SJ13 and Average Detection Limits for Leachate and Acid Strip. ..... 157

Figure E-77. Zirconium Releases in Solution, on Walls, and in Residue from Oxidized

Sample 5 in SJ13 and Average Detection Limits for Leachate and Acid Strip. ..... 158

Figure E-78. Zirconium Present in Solution, on Walls, and in Residue from SJ13 Control and Average Detection Limits for Leachate and Acid Strip. ............................. 158

Figure E-79. Zirconium Releases in Solution, on Walls, and in Residue from Polished Sample 1 in CJ13 and Average Detection Limits for Leachate and Acid Strip...... 159

Figure E-80. Zirconium Releases in Solution, on Walls, and in Residue from Polished Sample 2 in CJ13 and Average Detection Limits for Leachate and Acid Strip..... 159

Figure E-81. Zirconium Releases in Solution, on Walls, and in Acid Strip from Polished Sample 3 in CJ13 and Average Detection Limits for Leachate and Acid Strip...... 160

Figure E-82. Zirconium Releases in Solution, on Walls, and in Acid Strip from Oxidized Sample 4 in CJ13 and Average Detection Limits for Leachate and Acid Strip..... 160

Figure E-83. Zirconium Releases in Solution, on Walls, and in Residue from Oxidized Sample 5 in CJ13 and Average Detection Limits for Leachate and Acid Strip...... 161

Figure E-84. Zirconium Present in Solution, on Walls, and in Residue from CJ13 Control and Average Detection Limits for Leachate and Acid Strip. 161

Figure E-85. Zirconium Releases in Solution, on Walls, and in Residue from Polished Sample 1 in $10 \mathrm{KCl}$ and Average Detection Limits for Leachate and Acid Strip.... 162

Figure E-86. Zirconium Releases in Solution, on Walls, and in Residue from Polished Sample 2 in $10 \mathrm{KCl}$ and Average Detection Limits for Leachate and Acid Strip.... 162

Figure E-87. Zirconium Releases in Solution, on Walls, and in Residue from Polished Sample 3 in $10 \mathrm{KCl}$ and Average Detection Limits for Leachate and Acid Strip.... 163

Figure E-88. Zirconium Releases in Solution, on Walls, and in Residue from Oxidized Sample 4 in $10 \mathrm{KCl}$ and Average Detection Limits for Leachate and Acid Strip.... 163

Figure E-89. Zirconium Releases in Solution, on Walls, and in Residue from Oxidized Sample 5 in $10 \mathrm{KCl}$ and Average Detection Limits for Leachate and Acid Strip.... 164

Figure E-90. Zirconium Present in Solution, on Walls, and in Residue in 10KCl Control and Average Detection Limits for Leachate and Acid Strip. .164

Figure E-91. Zirconium Releases in Solution, on Walls, and in Residue from Polished Sample 1 in AJ13 and Average Detection Limits for Leachate and Acid Strip...... 165 
Figure E-92. Zirconium Releases in Solution, on Walls, and in Residue from Polished

Sample 2 in AJ13 and Average Detection Limits for Leachate and Acid Strip...... 165

Figure E-93. Zirconium Releases in Solution, on Walls, and in Residue from Polished

Sample 3 in AJ13 and Average Detection Limits for Leachate and Acid Strip...... 166

Figure E-94. Zirconium Releases in Solution, on Walls, and in Residue from Oxidized

Sample 4 in AJ13 and Average Detection Limits for Leachate and Acid Strip...... 166

Figure E-95. Zirconium Releases in Solution, on Walls, and in Residue from Oxidized

Sample 5 in AJ13 and Average Detection Limits for Leachate and Acid Strip...... 167

Figure E-96. Zirconium Present in Solution, on Walls, and in Residue from AJ13

Control and Average Detection Limits for Leachate and Acid Strip.

Figure E-97. Niobium Releases in Solution, on Walls, and in Residue from Polished Sample 1 in SJ13 and Average Detection Limits for Leachate and Acid Strip. ..... 168

Figure E-98. Niobium Releases in Solution, on Walls, and in Residue from Polished Sample 2 in SJ13 and Average Detection Limits for Leachate and Acid Strip. ..... 168

Figure E-99. Niobium Releases in Solution, on Walls, and in Residue from Polished Sample 3 in SJ13 and Average Detection Limits for Leachate and Acid Strip. ..... 169

Figure E-100. Niobium Releases in Solution, on Walls, and in Residue from Oxidized Sample 4 in SJ13 and Average Detection Limits for Leachate and Acid Strip. ..... 169

Figure E-101. Niobium Releases in Solution, on Walls, and in Residue from Oxidized Sample 5 in SJ13 and Average Detection Limits for Leachate and Acid Strip. ..... 170

Figure E-102. Niobium Present in Solution, on Walls, and in Residue from SJ13 Control and Average Detection Limits for Leachate and Acid Strip. 170

Figure E-103. Niobium Releases in Solution, on Walls, and in Residue from Polished Sample 1 in CJ13 and Average Detection Limits for Leachate and Acid Strip...... 171

Figure E-104. Niobium Releases in Solution, on Walls, and in Residue from Polished Sample 2 in CJ13 and Average Detection Limits for Leachate and Acid Strip..... 171

Figure E-105. Niobium Releases in Solution, on Walls, and in Residue from Polished Sample 3 in CJ13 and Average Detection Limits for Leachate and Acid Strip...... 172

Figure E-106. Niobium Releases in Solution, on Walls, and in Residue from Oxidized Sample 4 in CJ13 and Average Detection Limits for Leachate and Acid Strip...... 172

Figure E-107. Niobium Releases in Solution, on Walls, and in Residue from Oxidized Sample 5 in CJ13 and Average Detection Limits for Leachate and Acid Strip...... 173

Figure E-108. Niobium Present in Solution, on Walls, and in Residue from CJ13 Control and Average Detection Limits for Leachate and Acid Strip. 
Figure E-109. Niobium Releases in Solution, on Walls, and in Residue from Polished Sample 1 in $10 \mathrm{KCl}$ and Average Detection Limits for Leachate and Acid Strip.... 174

Figure E-110. Niobium Releases in Solution, on Walls, and in Residue from Polished Sample 2 in $10 \mathrm{KCl}$ and Average Detection Limits for Leachate and Acid Strip....174

Figure E-111. Niobium Releases in Solution, on Walls, and in Residue from Polished Sample 3 in $10 \mathrm{KCl}$ and Average Detection Limits for Leachate and Acid Strip.... 175

Figure E-112. Niobium Releases in Solution, on Walls, and in Residue from Oxidized Sample 4 in $10 \mathrm{KCl}$ and Average Detection Limits for Leachate and Acid Strip.... 175

Figure E-113. Niobium Releases in Solution, on Walls, and in Residue from Oxidized Sample 5 in $10 \mathrm{KCl}$ and Average Detection Limits for Leachate and Acid Strip.... 176

Figure E-114. Niobium Present in Solution, on Walls, and in Residue from $10 \mathrm{KCl}$ Control and Average Detection Limits for Leachate and Acid Strip. 176

Figure E-115. Niobium Releases in Solution, on Walls, and in Residue from Polished Sample 1 in AJ13 and Average Detection Limits for Leachate and Acid Strip...... 177

Figure E-116. Niobium Releases in Solution, on Walls, and in Residue from Polished Sample 2 in AJ13 and Average Detection Limits for Leachate and Acid Strip...... 177

Figure E-117. Niobium Releases in Solution, on Walls, and in Residue from Polished Sample 3 in AJ13 and Average Detection Limits for Leachate and Acid Strip...... 178

Figure E-118. Niobium Releases in Solution, on Walls, and in Residue from Oxidized Sample 4 in AJ13 and Average Detection Limits for Leachate and Acid Strip...... 178

Figure E-119. Niobium Releases in Solution, on Walls, and in Residue from Oxidized Sample 5 in AJ13 and Average Detection Limits for Leachate and Acid Strip...... 179

Figure E-120. Niobium Present in Solution, on Walls, and in Residue from AJ13 Control and Average Detection Limits for Leachate and Acid Strip.

Figure E-121. Paladium Releases in Solution, on Walls, and in Residue from Polished Sample 1 in SJ13 and Average Detection Limits for Leachate and Acid Strip. ..... 180

Figure E-122. Paladium Releases in Solution, on Walls, and in Residue from Polished Sample 2 in SJ13 and Average Detection Limits for Leachate and Acid Strip. ..... 180

Figure E-123. Paladium Releases in Solution, on Walls, and in Residue from Polished Sample 3 in SJ13 and Average Detection Limits for Leachate and Acid Strip. ..... 181

Figure E-124. Paladium Releases in Solution, on Walls, and in Residue from Oxidized Sample 4 in SJ13 and Average Detection Limits for Leachate and Acid Strip. ..... 181

Figure E-125. Paladium Releases in Solution, on Walls, and in Residue from Oxidized Sample 5 in SJ13 and Average Detection Limits for Leachate and Acid Strip. .....182 
Figure E-126. Paladium Present in Solution, on Walls, and in Residue from SJ13 Control and Average Detection Limits for Leachate and Acid Strip. 182

Figure E-127. Paladium Releases in Solution, on Walls, and in Residue from Polished Sample 1 in CJ13 and Average Detection Limits for Leachate and Acid Strip......183

Figure E-128. Paladium Releases in Solution, on Walls, and in Residue from Polished Sample 2 in CJ13 and Average Detection Limits for Leachate and Acid Strip......183

Figure E-129. Paladium Releases in Solution, on Walls, and in Residue from Polished Sample 3 in CJ13 and Average Detection Limits for Leachate and Acid Strip...... 184

Figure E-130. Paladium Releases in Solution, on Walls, and in Residue from Oxidized Sample 4 in CJ13 and Average Detection Limits for Leachate and Acid Strip...... 184

Figure E-131. Paladium Releases in Solution, on Walls, and in Residue from Oxidized Sample 5 in CJ13 and Average Detection Limits for Leachate and Acid Strip...... 185

Figure E-132. Paladium Present in Solution, on Walls, and in Residue from CJ13 Control and Average Detection Limits for Leachate and Acid Strip.

Figure E-133. Paladium Releases in Solution, on Walls, and in Residue from Polished Sample 1 in $10 \mathrm{KCl}$ and Average Detection Limits for Leachate and Acid Strip.... 186

Figure E-134. Paladium Releases in Solution, on Walls, and in Residue from Polished Sample 2 in $10 \mathrm{KCl}$ and Average Detection Limits for Leachate and Acid Strip.... 186

Figure E-135. Paladium Releases in Solution, on Walls, and in Residue from Polished Sample 3 in $10 \mathrm{KCl}$ and Average Detection Limits for Leachate and Acid Strip.... 187

Figure E-136. Paladium Releases in Solution, on Walls, and in Residue from Oxidized Sample 4 in $10 \mathrm{KCl}$ and Average Detection Limits for Leachate and Acid Strip.... 187

Figure E-137. Paladium Releases in Solution, on Walls, and in Residue from Oxidized Sample 5 in $10 \mathrm{KCl}$ and Average Detection Limits for Leachate and Acid Strip.... 188

Figure E-138. Paladium Present in Solution, on Walls, and in Residue from $10 \mathrm{KCl}$ Control and Average Detection Limits for Leachate and Acid Strip.

Figure E-139. Paladium Releases in Solution, on Walls, and in Residue from Polished Sample 1 in AJ13 and Average Detection Limits for Leachate and Acid Strip...... 189

Figure E-140. Paladium Releases in Solution, on Walls, and in Residue from Polished Sample 2 in AJ13 and Average Detection Limits for Leachate and Acid Strip...... 189

Figure E-141. . Paladium Releases in Solution, on Walls, and in Residue from Polished Sample 3 in AJ13 and Average Detection Limits for Leachate and Acid Strip...... 190

Figure E-142. Paladium Releases in Solution, on Walls, and in Residue from Oxidized Sample 4 in AJ13 and Average Detection Limits for Leachate and Acid Strip...... 190 
Figure E-143. Paladium Releases in Solution, on Walls, and in Residue from Oxidized

Sample 5 in AJ13 and Average Detection Limits for Leachate and Acid Strip...... 191

Figure E-144. Paladium Present in Solution, on Walls, and in Residue from AJ13

Control and Average Detection Limits for Leachate and Acid Strip.

Figure E-145. Rhodium Releases in Solution, on Walls, and in Residue from Polished

Sample 1 in SJ13 and Average Detection Limits for Leachate and Acid Strip. ..... 192

Figure E-146. Rhodium Releases in Solution, on Walls, and in Residue from Polished

Sample 2 in SJ13 and Average Detection Limits for Leachate and Acid Strip. ..... 192

Figure E-147. Rhodium Releases in Solution, on Walls, and in Residue from Polished

Sample 3 in SJ13 and Average Detection Limits for Leachate and Acid Strip. ..... 193

Figure E-148. Rhodium Releases in Solution, on Walls, and in Residue from Oxidized

Sample 4 in SJ13 and Average Detection Limits for Leachate and Acid Strip. ..... 193

Figure E-149. Rhodium Releases in Solution, on Walls, and in Residue from Oxidized

Sample 5 in SJ13 and Average Detection Limits for Leachate and Acid Strip. ..... 194

Figure E-150. Rhodium Present in Solution, on Walls, and in Residue from SJ13 Control and Average Detection Limits for Leachate and Acid Strip.

Figure E-151. Rhodium Releases in Solution, on Walls, and in Residue from Polished Sample 1 in CJ13 and Average Detection Limits for Leachate and Acid Strip...... 195

Figure E-152. Rhodium Releases in Solution, on Walls, and in Residue from Polished Sample 2 in CJ13 and Average Detection Limits for Leachate and Acid Strip...... 195

Figure E-153. Rhodium Releases in Solution, on Walls, and in Residue from Polished Sample 3 in CJ13 and Average Detection Limits for Leachate and Acid Strip...... 196

Figure E-154. Rhodium Releases in Solution, on Walls, and in Residue from Oxidized Sample 4 in CJ13 and Average Detection Limits for Leachate and Acid Strip...... 196

Figure E-155. Rhodium Releases in Solution, on Walls, and in Residue from Oxidized Sample 5 in CJ13 and Average Detection Limits for Leachate and Acid Strip..... 197

Figure E-156. Rhodium Present in Solution, on Walls, and in Residue from CJ13 Control and Average Detection Limits for Leachate and Acid Strip.

Figure E-157. Rhodium Releases in Solution, on Walls, and in Residue from Polished Sample 1 in $10 \mathrm{KCl}$ and Average Detection Limits for Leachate and Acid Strip.... 198

Figure E-158. Rhodium Releases in Solution, on Walls, and in Residue from Polished Sample 2 in $10 \mathrm{KCl}$ and Average Detection Limits for Leachate and Acid Strip.... 198

Figure E-159. Rhodium Releases in Solution, on Walls, and in Residue from Polished Sample 3 in $10 \mathrm{KCl}$ and Average Detection Limits for Leachate and Acid Strip.... 199 
Figure E-160. Rhodium Releases in Solution, on Walls, and in Residue from Oxidized

Sample 4 in $10 \mathrm{KCl}$ and Average Detection Limits for Leachate and Acid Strip.... 199

Figure E-161. Rhodium Releases in Solution, on Walls, and in Residue from Oxidized

Sample 5 in $10 \mathrm{KCl}$ and Average Detection Limits for Leachate and Acid Strip....200

Figure E-162. Rhodium Present in Solution, on Walls, and in Residue from 10KCl

Control and Average Detection Limits for Leachate and Acid Strip. ....................200

Figure E-163. Rhodium Releases in Solution, on Walls, and in Residue from Polished

Sample 1 in AJ13 and Average Detection Limits for Leachate and Acid Strip......201

Figure E-164. Rhodium Releases in Solution, on Walls, and in Residue from Polished

Sample 2 in AJ13 and Average Detection Limits for Leachate and Acid Strip......201

Figure E-165. Rhodium Releases in Solution, on Walls, and in Residue from Polished

Sample 3 in AJ13 and Average Detection Limits for Leachate and Acid Strip......202

Figure E-166. Rhodium Releases in Solution, on Walls, and in Residue from Oxidized

Sample 4 in AJ13 and Average Detection Limits for Leachate and Acid Strip......202

Figure E-167. Rhodium Releases in Solution, on Walls, and in Residue from Oxidized

Sample 5 in AJ13 and Average Detection Limits for Leachate and Acid Strip......203

Figure E-168. Rhodium Present in Solution, on Walls, and in Residue from AJ13

Control and Average Detection Limits for Leachate and Acid Strip. .203

Figure E-169. Ruthenium Releases in Solution, on Walls, and in Residue from Polished

Sample 1 in SJ13 and Average Detection Limits for Leachate and Acid Strip. .....204

Figure E-170. Ruthenium Releases in Solution, on Walls, and in Residue from Polished

Sample 2 in SJ13 and Average Detection Limits for Leachate and Acid Strip. .....204

Figure E-171. Ruthenium Releases in Solution, on Walls, and in Residue from Polished

Sample 3 in SJ13 and Average Detection Limits for Leachate and Acid Strip. .....205

Figure E-172. Ruthenium Releases in Solution, on Walls, and in Residue from Oxidized

Sample 4 in SJ13 and Average Detection Limits for Leachate and Acid Strip. .....205

Figure E-173. Ruthenium Releases in Solution, on Walls, and in Residue from Oxidized

Sample 5 in SJ13 and Average Detection Limits for Leachate and Acid Strip. .....206

Figure E-174. Ruthenium Present in Solution, on Walls, and in Residue from SJ13

Control and Average Detection Limits for Leachate and Acid Strip. ....................206

Figure E-175. Ruthenium Releases in Solution, on Walls, and in Residue from Polished

Sample 1 in CJ13 and Average Detection Limits for Leachate and Acid Strip......207

Figure E-176. Ruthenium Releases in Solution, on Walls, and in Residue from Polished Sample 2 in CJ13 and Average Detection Limits for Leachate and Acid Strip......207 
Figure E-177. Ruthenium Releases in Solution, on Walls, and in Residue from Polished

Sample 3 in CJ13 and Average Detection Limits for Leachate and Acid Strip......208

Figure E-178. Ruthenium Releases in Solution, on Walls, and in Residue from Oxidized

Sample 4 in CJ13 and Average Detection Limits for Leachate and Acid Strip......208

Figure E-179. Ruthenium Releases in Solution, on Walls, and in Residue from Oxidized

Sample 5 in CJ13 and Average Detection Limits for Leachate and Acid Strip......209

Figure E-180. Ruthenium Present in Solution, on Walls, and in Residue from CJ13

Control and Average Detection Limits for Leachate and Acid Strip. 209

Figure E-181. Ruthenium Releases in Solution, on Walls, and in Residue from Polished

Sample 1 in $10 \mathrm{KCl}$ and Average Detection Limits for Leachate and Acid Strip....210

Figure E-182. Ruthenium Releases in Solution, on Walls, and in Residue from Polished

Sample 2 in $10 \mathrm{KCl}$ and Average Detection Limits for Leachate and Acid Strip....210

Figure E-183. Ruthenium Releases in Solution, on Walls, and in Residue from Polished

Sample 3 in $10 \mathrm{KCl}$ and Average Detection Limits for Leachate and Acid Strip....211

Figure E-184. Ruthenium Releases in Solution, on Walls, and in Residue from Oxidized Sample 4 in $10 \mathrm{KCl}$ and Average Detection Limits for Leachate and Acid Strip....211

Figure E-185. Ruthenium Releases in Solution, on Walls, and in Residue from Oxidized Sample 5 in $10 \mathrm{KCl}$ and Average Detection Limits for Leachate and Acid Strip....212

Figure E-186. Ruthenium Present in Solution, on Walls, and in Residue from $10 \mathrm{KCl}$

Control and Average Detection Limits for Leachate and Acid Strip.

Figure E-187. Ruthenium Releases in Solution, on Walls, and in Residue from Polished

Sample 1 in AJ13 and Average Detection Limits for Leachate and Acid Strip......213

Figure E-188. Ruthenium Releases in Solution, on Walls, and in Residue from Polished

Sample 2 in AJ13 and Average Detection Limits for Leachate and Acid Strip......213

Figure E-189. Ruthenium Releases in Solution, on Walls, and in Residue from Polished

Sample 3 in AJ13 and Average Detection Limits for Leachate and Acid Strip......214

Figure E-190. Ruthenium Releases in Solution, on Walls, and in Residue from Oxidized

Sample 4 in AJ13 and Average Detection Limits for Leachate and Acid Strip......214

Figure E-191. Ruthenium Releases in Solution, on Walls, and in Residue from Oxidized

Sample 5 in AJ13 and Average Detection Limits for Leachate and Acid Strip......215

Figure E-192. Ruthenium Present in Solution, on Walls, and in Residue from AJ13 Control and Average Detection Limits for Leachate and Acid Strip.

Figure E-193. Molybdenum Releases in Solution, on Walls, and in Residue from Polished Sample 1 in SJ13 and Average Detection Limits for Leachate and Acid

Strip. 216 
Figure E-194. Molybdenum Releases in Solution, on Walls, and in Residue from Polished Sample 2 in SJ13 and Average Detection Limits for Leachate and Acid Strip.

Figure E-195. Molybdenum Releases in Solution, on Walls, and in Residue from Polished Sample 3 in SJ13 and Average Detection Limits for Leachate and Acid Strip.

Figure E-196. Molybdenum Releases in Solution, on Walls, and in Residue from Oxidized Sample 4 in SJ13 and Average Detection Limits for Leachate and Acid Strip.

Figure E-197. Molybdenum Releases in Solution, on Walls, and in Residue from Oxidized Sample 5 in SJ13 and Average Detection Limits for Leachate and Acid Strip.

Figure E-198. Molybdenum Present in Solution, on Walls, and in Residue from SJ13 Control and Average Detection Limits for Leachate and Acid Strip.

Figure E-199. Molybdenum Releases in Solution, on Walls, and in Residue from Polished Sample 1 in CJ13 and Average Detection Limits for Leachate and Acid Strip.

Figure E-200. Molybdenum Releases in Solution, on Walls, and in Residue from Polished Sample 2 in CJ13 and Average Detection Limits for Leachate and Acid Strip.

Figure E-201. Molybdenum Releases in Solution, on Walls, and in Residue from Polished Sample 3 in CJ13 and Average Detection Limits for Leachate and Acid Strip.

Figure E-202. Molybdenum Releases in Solution, on Walls, and in Residue from Oxidized Sample 4 in CJ13 and Average Detection Limits for Leachate and Acid Strip.

Figure E-203. Molybdenum Releases in Solution, on Walls, and in Residue from Oxidized Sample 5 in CJ13 and Average Detection Limits for Leachate and Acid Strip.

Figure E-204. Molybdenum Present in Solution, on Walls, and in Residue from CJ13 Control and Average Detection Limits for Leachate and Acid Strip.

Figure E-205. Molybdenum Releases in Solution, on Walls, and in Residue from Polished Sample 1 in $10 \mathrm{KCl}$ and Average Detection Limits for Leachate and Acid Strip.

Figure E-206. Molybdenum Releases in Solution, on Walls, and in Residue from Polished Sample 2 in $10 \mathrm{KCl}$ and Average Detection Limits for Leachate and Acid Strip. 
Figure E-207. Molybdenum Releases in Solution, on Walls, and in Residue from Polished Sample 3 in $10 \mathrm{KCl}$ and Average Detection Limits for Leachate and Acid Strip.

Figure E-208. Molybdenum Releases in Solution, on Walls, and in Residue from Oxidized Sample 4 in $10 \mathrm{KCl}$ and Average Detection Limits for Leachate and Acid Strip.

Figure E-209. Molybdenum Releases in Solution, on Walls, and in Residue from Oxidized Sample 5 in $10 \mathrm{KCl}$ and Average Detection Limits for Leachate and Acid Strip.

Figure E-210. Molybdenum Present in Solution, on Walls, and in Residue from $10 \mathrm{KCl}$ Control and Average Detection Limits for Leachate and Acid Strip.

Figure E-211. Molybdenum Releases in Solution, on Walls, and in Residue from Polished Sample 1 in AJ13 and Average Detection Limits for Leachate and Acid Strip.

Figure E-212. Molybdenum Releases in Solution, on Walls, and in Residue from Polished Sample 2 in AJ13 and Average Detection Limits for Leachate and Acid Strip.

Figure E-213. Molybdenum Releases in Solution, on Walls, and in Residue from Polished Sample 3 in AJ13 and Average Detection Limits for Leachate and Acid Strip.

Figure E-214. Molybdenum Releases in Solution, on Walls, and in Residue from Oxidized Sample 4 in AJ13 and Average Detection Limits for Leachate and Acid Strip.

Figure E-215. Molybdenum Releases in Solution, on Walls, and in Residue from Oxidized Sample 5 in AJ13 and Average Detection Limits for Leachate and Acid Strip.

Figure E-216. Molybdenum Present in Solution, on Walls, and in Residue from AJ13 Control and Average Detection Limits for Leachate and Acid Strip. .227

Figure E-217. Manganese Releases in Solution, on Walls, and in Residue from Polished Sample 1 in SJ13 and Average Detection Limits for Leachate and Acid Strip. .....228

Figure E-218. Manganese Releases in Solution, on Walls, and in Residue from Polished Sample 2 in SJ13 and Average Detection Limits for Leachate and Acid Strip. .....228

Figure E-219. Manganese Releases in Solution, on Walls, and in Residue from Polished Sample 3 in SJ13 and Average Detection Limits for Leachate and Acid Strip. .....229

Figure E-220. Manganese Releases in Solution, on Walls, and in Residue from Oxidized Sample 4 in SJ13 and Average Detection Limits for Leachate and Acid Strip. .....229 
Figure E-221. Manganese Releases in Solution, on Walls, and in Residue from Oxidized

Sample 5 in SJ13 and Average Detection Limits for Leachate and Acid Strip. .....230

Figure E-222. Manganese Present in Solution, on Walls, and in Residue from SJ13

Control and Average Detection Limits for Leachate and Acid Strip. .230

Figure E-223. Manganese Releases in Solution, on Walls, and in Residue from Polished

Sample 1 in CJ13 and Average Detection Limits for Leachate and Acid Strip......231

Figure E-224. Manganese Releases in Solution, on Walls, and in Residue from Polished

Sample 2 in CJ13 and Average Detection Limits for Leachate and Acid Strip......231

Figure E-225. Manganese Releases in Solution, on Walls, and in Residue from Polished

Sample 3 in CJ13 and Average Detection Limits for Leachate and Acid Strip......232

Figure E-226. Manganese Releases in Solution, on Walls, and in Residue from Oxidized

Sample 4 in CJ13 and Average Detection Limits for Leachate and Acid Strip..... 232

Figure E-227. Manganese Releases in Solution, on Walls, and in Residue from Oxidized

Sample 5 in CJ13 and Average Detection Limits for Leachate and Acid Strip......233

Figure E-228. Manganese Present in Solution, on Walls, and in Residue from CJ13

Control and Average Detection Limits for Leachate and Acid Strip. .233

Figure E-229. Manganese Releases in Solution, on Walls, and in Residue from Polished Sample 1 in $10 \mathrm{KCl}$ and Average Detection Limits for Leachate and Acid Strip....234

Figure E-230. Manganese Releases in Solution, on Walls, and in Residue from Polished Sample 2 in $10 \mathrm{KCl}$ and Average Detection Limits for Leachate and Acid Strip....234

Figure E-231. Manganese Releases in Solution, on Walls, and in Residue from Polished Sample 3 in $10 \mathrm{KCl}$ and Average Detection Limits for Leachate and Acid Strip....235

Figure E-232. Manganese Releases in Solution, on Walls, and in Residue from Oxidized Sample 4 in $10 \mathrm{KCl}$ and Average Detection Limits for Leachate and Acid Strip....235

Figure E-233. Manganese Releases in Solution, on Walls, and in Residue from Oxidized Sample 5 in $10 \mathrm{KCl}$ and Average Detection Limits for Leachate and Acid Strip....236

Figure E-234. Manganese Present in Solution, on Walls, and in Residue from $10 \mathrm{KCl}$ Control and Average Detection Limits for Leachate and Acid Strip. .236

Figure E-235. Manganese Releases in Solution, on Walls, and in Residue from Polished Sample 1 in AJ13 and Average Detection Limits for Leachate and Acid Strip......237

Figure E-236. Manganese Releases in Solution, on Walls, and in Residue from Polished Sample 2 in AJ13 and Average Detection Limits for Leachate and Acid Strip......237

Figure E-237. Manganese Releases in Solution, on Walls, and in Residue from Polished Sample 3 in AJ13 and Average Detection Limits for Leachate and Acid Strip......238 
Figure E-238. Manganese Releases in Solution, on Walls, and in Residue from Oxidized

Sample 4 in AJ13 and Average Detection Limits for Leachate and Acid Strip......238

Figure E-239. Manganese Releases in Solution, on Walls, and in Residue from Oxidized

Sample 5 in AJ13 and Average Detection Limits for Leachate and Acid Strip......239

Figure E-240. Manganese Present in Solution, on Walls, and in Residue from AJ13

Control and Average Detection Limits for Leachate and Acid Strip. ..................239

Figure E-241. Cobalt Releases in Solution, on Walls, and in Residue from Polished Sample 1 in SJ13 and Average Detection Limits for Leachate and Acid Strip. .....240

Figure E-242. Cobalt Releases in Solution, on Walls, and in Residue from Polished Sample 2 in SJ13 and Average Detection Limits for Leachate and Acid Strip. .....240

Figure E-243. Cobalt Releases in Solution, on Walls, and in Residue from Polished Sample 3 in SJ13 and Average Detection Limits for Leachate and Acid Strip. .....241

Figure E-244. Cobalt Releases in Solution, on Walls, and in Residue from Oxidized Sample 4 in SJ13 and Average Detection Limits for Leachate and Acid Strip. .....241

Figure E-245. Cobalt Releases in Solution, on Walls, and in Residue from Oxidized Sample 5 in SJ13 and Average Detection Limits for Leachate and Acid Strip. .....242

Figure E-246. Cobalt Present in Solution, on Walls, and in Residue from SJ13 Control and Average Detection Limits for Leachate and Acid Strip. .... .242

Figure E-247. Cobalt Releases in Solution, on Walls, and in Residue from Polished Sample 1 in CJ13 and Average Detection Limits for Leachate and Acid Strip......243

Figure E-248. Cobalt Releases in Solution, on Walls, and in Residue from Polished Sample 2 in CJ13 and Average Detection Limits for Leachate and Acid Strip.....243

Figure E-249. Cobalt Releases in Solution, on Walls, and in Residue from Polished Sample 3 in CJ13 and Average Detection Limits for Leachate and Acid Strip.....244

Figure E-250. Cobalt Releases in Solution, on Walls, and in Residue from Oxidized Sample 4 in CJ13 and Average Detection Limits for Leachate and Acid Strip..... 244

Figure E-251. Cobalt Releases in Solution, on Walls, and in Residue from Oxidized Sample 5 in CJ13 and Average Detection Limits for Leachate and Acid Strip.....245

Figure E-252. Cobalt Present in Solution, on Walls, and in Residue from CJ13 Control and Average Detection Limits for Leachate and Acid Strip. 245

Figure E-253. Cobalt Releases in Solution, on Walls, and in Residue from Polished Sample 1 in $10 \mathrm{KCl}$ and Average Detection Limits for Leachate and Acid Strip....246

Figure E-254. Cobalt Releases in Solution, on Walls, and in Residue from Polished Sample 2 in $10 \mathrm{KCl}$ and Average Detection Limits for Leachate and Acid Strip....246 
Figure E-255. Cobalt Releases in Solution, on Walls, and in Residue from Polished

Sample 3 in $10 \mathrm{KCl}$ and Average Detection Limits for Leachate and Acid Strip....247

Figure E-256. Cobalt Releases in Solution, on Walls, and in Residue from Oxidized

Sample 4 in $10 \mathrm{KCl}$ and Average Detection Limits for Leachate and Acid Strip....247

Figure E-257. Cobalt Releases in Solution, on Walls, and in Residue from Oxidized

Sample 5 in $10 \mathrm{KCl}$ and Average Detection Limits for Leachate and Acid Strip....248

Figure E-258. Cobalt Present in Solution, on Walls, and in Residue from 10KCl Control

and Average Detection Limits for Leachate and Acid Strip. .248

Figure E-259. Cobalt Releases in Solution, on Walls, and in Residue from Polished Sample 1 in AJ13 and Average Detection Limits for Leachate and Acid Strip......249

Figure E-260. Cobalt Releases in Solution, on Walls, and in Residue from Polished Sample 2 in AJ13 and Average Detection Limits for Leachate and Acid Strip......249

Figure E-261. Cobalt Releases in Solution, on Walls, and in Residue from Polished Sample 3 in AJ13 and Average Detection Limits for Leachate and Acid Strip......250

Figure E-262. Cobalt Releases in Solution, on Walls, and in Residue from Oxidized Sample 4 in AJ13 and Average Detection Limits for Leachate and Acid Strip......250

Figure E-263. Cobalt Releases in Solution, on Walls, and in Residue from Oxidized Sample 5 in AJ13 and Average Detection Limits for Leachate and Acid Strip.....251

Figure E-264. Cobalt Present in Solution, on Walls, and in Residue from AJ13 Control and Average Detection Limits for Leachate and Acid Strip. 251

Figure E-265. Copper Releases in Solution, on Walls, and in Residue from Polished Sample 1 in SJ13 and Average Detection Limits for Leachate and Acid Strip. .....252

Figure E-266. Copper Releases in Solution, on Walls, and in Residue from Polished Sample 2 in SJ13 and Average Detection Limits for Leachate and Acid Strip. .....252

Figure E-267. Copper Releases in Solution, on Walls, and in Residue from Polished Sample 3 in SJ13 and Average Detection Limits for Leachate and Acid Strip. .....253

Figure E-268. Copper Releases in Solution, on Walls, and in Residue from Oxidized Sample 4 in SJ13 and Average Detection Limits for Leachate and Acid Strip. .....253

Figure E-269. Copper Releases in Solution, on Walls, and in Residue from Oxidized Sample 5 in SJ13 and Average Detection Limits for Leachate and Acid Strip. .....254

Figure E-270. Copper Present in Solution, on Walls, and in Residue from SJ13 Control and Average Detection Limits for Leachate and Acid Strip.

Figure E-271. Copper Releases in Solution, on Walls, and in Residue from Polished Sample 1 in CJ13 and Average Detection Limits for Leachate and Acid Strip......255 
Figure E-272. Copper Releases in Solution, on Walls, and in Residue from Polished

Sample 2 in CJ13 and Average Detection Limits for Leachate and Acid Strip......255

Figure E-273. Copper Releases in Solution, on Walls, and in Residue from Polished

Sample 3 in CJ13 and Average Detection Limits for Leachate and Acid Strip......256

Figure E-274. Copper Releases in Solution, on Walls, and in Residue from Oxidized

Sample 4 in CJ13 and Average Detection Limits for Leachate and Acid Strip......256

Figure E-275. Copper Releases in Solution, on Walls, and in Residue from Oxidized Sample 5 in CJ13 and Average Detection Limits for Leachate and Acid Strip......257

Figure E-276. Copper Present in Solution, on Walls, and in Residue from CJ13 Control and Average Detection Limits for Leachate and Acid Strip. .257

Figure E-277. Copper Releases in Solution, on Walls, and in Residue from Polished Sample 1 in $10 \mathrm{KCl}$ and Average Detection Limits for Leachate and Acid Strip....258

Figure E-278. Copper Releases in Solution, on Walls, and in Residue from Polished Sample 2 in $10 \mathrm{KCl}$ and Average Detection Limits for Leachate and Acid Strip....258

Figure E-279. Copper Releases in Solution, on Walls, and in Residue from Polished Sample 3 in $10 \mathrm{KCl}$ and Average Detection Limits for Leachate and Acid Strip....259

Figure E-280. Copper Releases in Solution, on Walls, and in Residue from Oxidized Sample 4 in $10 \mathrm{KCl}$ and Average Detection Limits for Leachate and Acid Strip....259

Figure E-281. Copper Releases in Solution, on Walls, and in Residue from Oxidized Sample 5 in $10 \mathrm{KCl}$ and Average Detection Limits for Leachate and Acid Strip....260

Figure E-282. Copper Present in Solution, on Walls, and in Residue from $10 \mathrm{KCl}$ Control and Average Detection Limits for Leachate and Acid Strip. 260

Figure E-283. Copper Releases in Solution, on Walls, and in Residue from Polished Sample 1 in AJ13 and Average Detection Limits for Leachate and Acid Strip......261

Figure E-284. Copper Releases in Solution, on Walls, and in Residue from Polished Sample 2 in AJ13 and Average Detection Limits for Leachate and Acid Strip......261

Figure E-285. Copper Releases in Solution, on Walls, and in Residue from Polished Sample 3 in AJ13 and Average Detection Limits for Leachate and Acid Strip.....262

Figure E-286. Copper Releases in Solution, on Walls, and in Residue from Oxidized Sample 4 in AJ13 and Average Detection Limits for Leachate and Acid Strip......262

Figure E-287. Copper Releases in Solution, on Walls, and in Residue from Oxidized Sample 5 in AJ13 and Average Detection Limits for Leachate and Acid Strip......263

Figure E-288. Copper Present in Solution, on Walls, and in Residue from AJ13 Control and Average Detection Limits for Leachate and Acid Strip. 
Figure E-289. Vanadium Releases in Solution, on Walls, and in Residue from Polished

Sample 1 in SJ13 and Average Detection Limits for Leachate and Acid Strip. .....264

Figure E-290. Vanadium Releases in Solution, on Walls, and in Residue from Polished

Sample 2 in SJ13 and Average Detection Limits for Leachate and Acid Strip. .....264

Figure E-291. Vanadium Releases in Solution, on Walls, and in Residue from Polished

Sample 3 in SJ13 and Average Detection Limits for Leachate and Acid Strip. .....265

Figure E-292. Vanadium Releases in Solution, on Walls, and in Residue from Oxidized

Sample 4 in SJ13 and Average Detection Limits for Leachate and Acid Strip. .....265

Figure E-293. Vanadium Releases in Solution, on Walls, and in Residue from Oxidized

Sample 5 in SJ13 and Average Detection Limits for Leachate and Acid Strip. .....266

Figure E-294. Vanadium Present in Solution, on Walls, and in Residue from SJ13

Control and Average Detection Limits for Leachate and Acid Strip. 266

Figure E-295. Vanadium Releases in Solution, on Walls, and in Residue from Polished Sample 1 in CJ13 and Average Detection Limits for Leachate and Acid Strip......267

Figure E-296. Vanadium Releases in Solution, on Walls, and in Residue from Polished Sample 2 in CJ13 and Average Detection Limits for Leachate and Acid Strip......267

Figure E-297. Vanadium Releases in Solution, on Walls, and in Residue from Polished Sample 3 in CJ13 and Average Detection Limits for Leachate and Acid Strip......268

Figure E-298. Vanadium Releases in Solution, on Walls, and in Residue from Oxidized Sample 4 in CJ13 and Average Detection Limits for Leachate and Acid Strip......268

Figure E-299. Vanadium Releases in Solution, on Walls, and in Residue from Oxidized

Sample 5 in CJ13 and Average Detection Limits for Leachate and Acid Strip......269

Figure E-300. Vanadium Present in Solution, on Walls, and in Residue from CJ13 Control and Average Detection Limits for Leachate and Acid Strip.

Figure E-301. Vanadium Releases in Solution, on Walls, and in Residue from Polished

Sample 1 in $10 \mathrm{KCl}$ and Average Detection Limits for Leachate and Acid Strip....270

Figure E-302. Vanadium Releases in Solution, on Walls, and in Residue from Polished

Sample 2 in $10 \mathrm{KCl}$ and Average Detection Limits for Leachate and Acid Strip....270

Figure E-303. Vanadium Releases in Solution, on Walls, and in Residue from Polished

Sample 3 in $10 \mathrm{KCl}$ and Average Detection Limits for Leachate and Acid Strip....271

Figure E-304. Vanadium Releases in Solution, on Walls, and in Residue from Oxidized Sample 4 in $10 \mathrm{KCl}$ and Average Detection Limits for Leachate and Acid Strip....271

Figure E-305. Vanadium Releases in Solution, on Walls, and in Residue from Oxidized Sample 5 in $10 \mathrm{KCl}$ and Average Detection Limits for Leachate and Acid Strip....272 
Figure E-306. Vanadium Present in Solution, on Walls, and in Residue from $10 \mathrm{KCl}$ Control and Average Detection limits for Leachate and Acid Strip....

Figure E-307. Vanadium Releases in Solution, on Walls, and in Residue from Polished

Sample 1 in AJ13 and Average Detection Limits for Leachate and Acid Strip......273

Figure E-308. Vanadium Releases in Solution, on Walls, and in Residue from Polished

Sample 2 in AJ13 and Average Detection Limits for Leachate and Acid Strip......273

Figure E-309. Vanadium Releases in Solution, on Walls, and in Residue from Polished

Sample 3 in AJ13 and Average Detection Limits for Leachate and Acid Strip......274

Figure E-310. Vanadium Releases in Solution, on Walls, and in Residue from Oxidized

Sample 4 in AJ13 and Average Detection Limits for Leachate and Acid Strip......274

Figure E-311. Vanadium Releases in Solution, on Walls, and in Residue from Oxidized

Sample 5 in AJ13 and Average Detection Limits for Leachate and Acid Strip......275

Figure E-312. Vanadium Present in Solution, on Walls, and in Residue from AJ13

Control and Average Detection Limits for Leachate and Acid Strip. ..................275

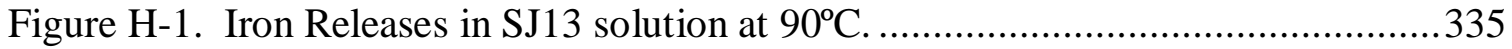

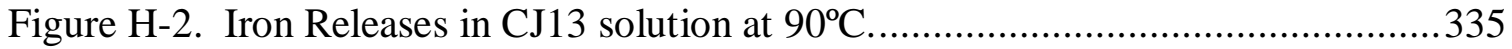

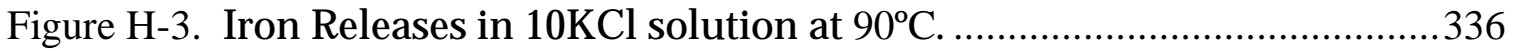

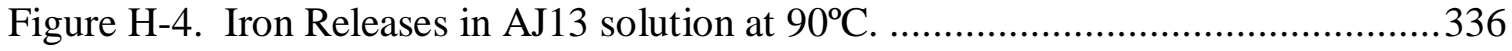

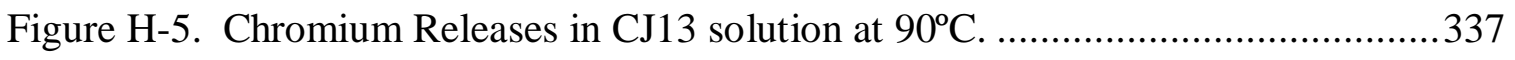

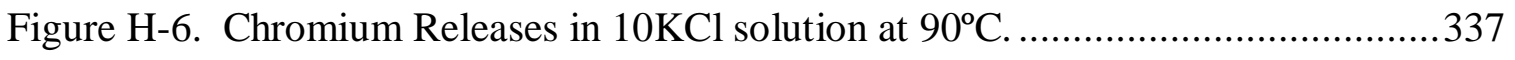

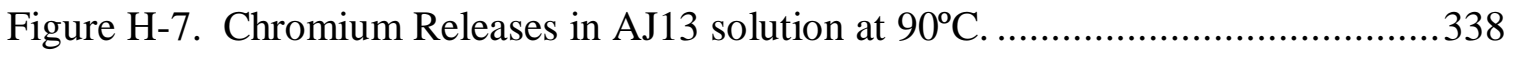

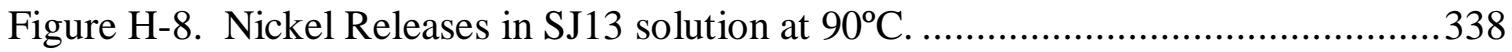

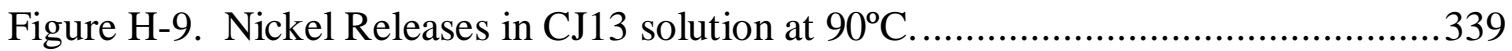

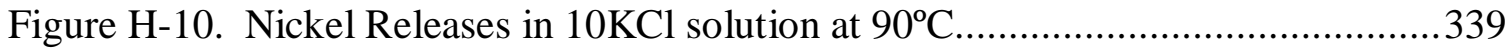

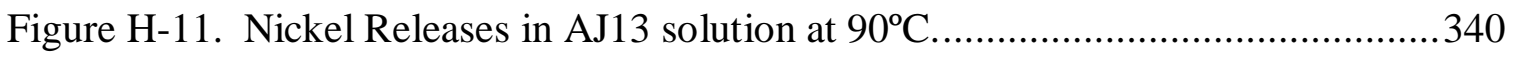

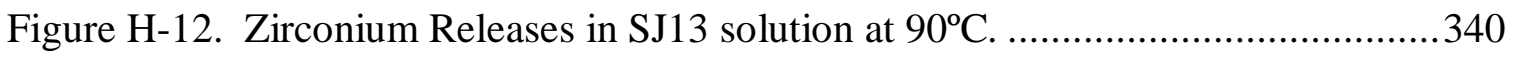

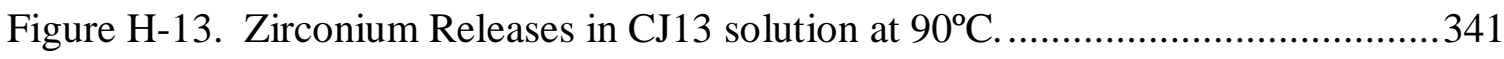

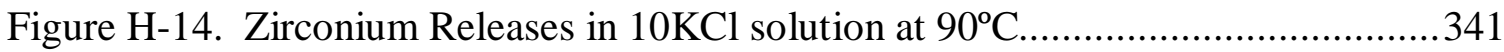

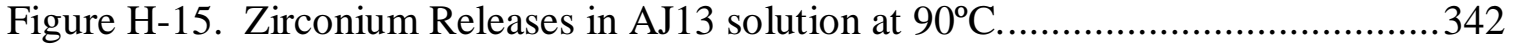

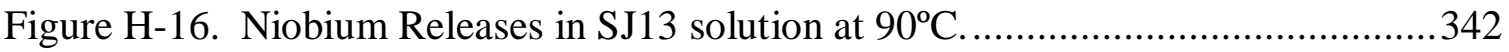


Figure H-17. Niobium Releases in CJ13 solution at $90^{\circ} \mathrm{C}$. 343

Figure $\mathrm{H}-18$. Niobium Releases in $10 \mathrm{KCl}$ solution at $90^{\circ} \mathrm{C}$. 343

Figure H-19. Niobium Releases in $\mathrm{AJ} 13$ solution at $90^{\circ} \mathrm{C}$. .344

Figure H-20. Paladium Releases in SJ13 solution at $90^{\circ} \mathrm{C}$. 344

Figure H-21. Paladium Releases in CJ13 solution at $90^{\circ} \mathrm{C}$.. .345

Figure H-22. Paladium Releases in $10 \mathrm{KCl}$ solution at $90^{\circ} \mathrm{C}$. 345

Figure $\mathrm{H}-23$. Paladium Releases in $\mathrm{AJ} 13$ solution at $90^{\circ} \mathrm{C}$. 346

Figure H-24. Rhodium Releases in $\mathrm{CJ} 13$ solution at $90^{\circ} \mathrm{C}$. 346

Figure H-25. Rhodium Releases in $10 \mathrm{KCl}$ solution at $90^{\circ} \mathrm{C}$ .347

Figure H-26. Rhodium Releases in AJ13 solution at $90^{\circ} \mathrm{C}$. 347

Figure H-27. Ruthenium Releases in $\mathrm{SJ} 13$ solution at $90^{\circ} \mathrm{C}$.. 348

Figure H-28. Ruthenium Releases in $\mathrm{CJ} 13$ solution at $90^{\circ} \mathrm{C}$. 348

Figure $\mathrm{H}-29$. Ruthenium Releases in $10 \mathrm{KCl}$ solution at $90^{\circ} \mathrm{C}$. 349

Figure H-30. Ruthenium Releases in AJ13 solution at $90^{\circ} \mathrm{C}$. 349

Figure H-31. Molybdenum Releases in SJ13 solution at $90^{\circ} \mathrm{C}$. 350

Figure H-32. Molybdenum Releases in CJ13 solution at $90^{\circ} \mathrm{C}$........ 350

Figure H-33. Molybdenum Releases in $10 \mathrm{KCl}$ solution at $90^{\circ} \mathrm{C}$. 351

Figure H-34. Molybdenum Releases in AJ13 solution at $90^{\circ} \mathrm{C}$. 351

Figure H-35. Manganese Releases in SJ13 solution at $90^{\circ} \mathrm{C}$. .352

Figure H-36. Manganese Releases in $\mathrm{CJ} 13$ solution at $90^{\circ} \mathrm{C}$. 352

Figure $\mathrm{H}-37$. Manganese Releases in $10 \mathrm{KCl}$ solution at $90^{\circ} \mathrm{C}$. 353

Figure H-38. Manganese Releases in AJ13 solution at $90^{\circ} \mathrm{C}$. 353

Figure H-39. Cobalt Releases in $\mathrm{SJ} 13$ solution at $90^{\circ} \mathrm{C}$. .354

Figure H-40. Cobalt Releases in CJ13 solution at $90^{\circ} \mathrm{C}$. 354

Figure $\mathrm{H}-41$. Cobalt Releases in $10 \mathrm{KCl}$ solution at $90^{\circ} \mathrm{C}$ 355

Figure H-42. Cobalt Releases in AJ13 solution at $90^{\circ} \mathrm{C}$. 355

Figure H-43. Copper Releases in SJ13 solution at $90^{\circ} \mathrm{C}$. .356 


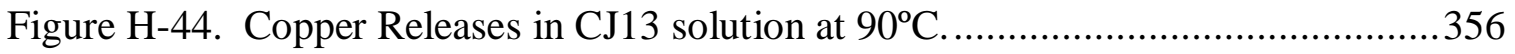

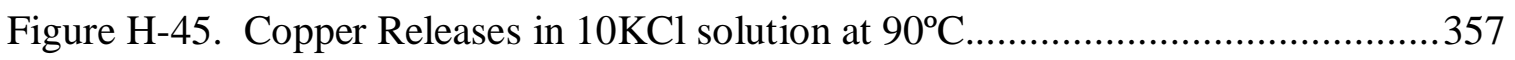

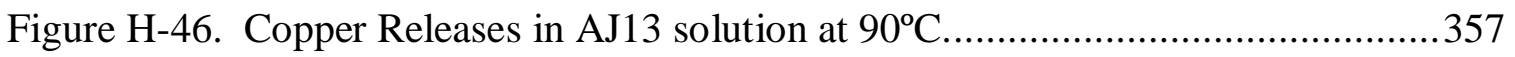

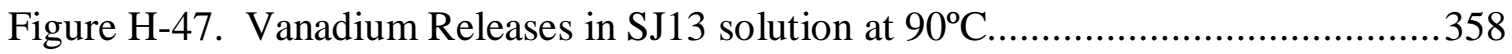

Figure H-48. Vanadium Releases in $\mathrm{CJ} 13$ solution at $90^{\circ} \mathrm{C}$........................................358

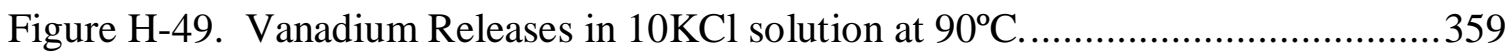

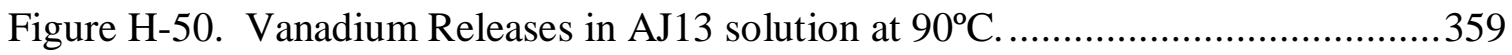

Figure J-1. Iron Releases in Solution and on Walls from Polished Sample 25 in $1 \mathrm{KCl}$ Solution at $90^{\circ} \mathrm{C}$ and Average Detection Limits for Leachate and Acid Strip.........360

Figure J-2. Iron Present in Solutions and on Walls in $1 \mathrm{KCl}$ Solution Control at $90^{\circ} \mathrm{C}$ and Average Detection Limits for Leachate and Acid Strip..........................................360

Figure J-3. Iron Releases in Solution and on Walls from Polished Sample 27 in $1 \mathrm{KCl}$ Solution at Room Temperature and Average Detection Limits for Leachate and Acid Strip. 361

Figure J-4. Iron Present in Solution and on Walls for $1 \mathrm{KCl}$ Solution Control at Room Temperature and Average Detection Limits for Leachate and Acid Strip...............361

Figure J-5. Iron Releases in Solution and on Walls from Polished Sample 29 in $10 \mathrm{KCl}$ at Room Temperature and Average Detection Limits for Leachate and Acid Strip...362

Figure J-6. Iron Present in Solution and on Walls for $10 \mathrm{KCl}$ Control at Room Temperature and Average Detection Limits for Leachate and Acid Strip...

Figure J-7. Iron Releases in Solution and on Walls from Polished Sample 31 in AJ13 $\mathrm{pH}=2$ at Room Temperature and Average Detection Limits for Leachate and Acid Strip.

Figure J-8. Iron Present in Solution and on Walls for $\mathrm{AJ} 13 \mathrm{pH}=2$ at Room Temperature and Average Detection Limits for Leachate and Acid Strip.

Figure J-9. Chromium Releases in Solution and on Walls from Polished Sample 25 in $1 \mathrm{KCl}$ at $90^{\circ} \mathrm{C}$ and Average Detection Limits for Leachate and Acid Strip.. .364

Figure J-10. Chromium Present in Solution and on Walls from $1 \mathrm{KCl}$ Control at $90^{\circ} \mathrm{C}$ and Average Detection Limits for Leachate and Acid Strip.

Figure J-11. Chromium Releases in Solution, on Walls, and in Residue from Polished Sample 27 in $1 \mathrm{KCl}$ at Room Temperature and Average Detection Limits for Leachate and Acid Strip. 
Figure J-12. Chromium Present in Solution and on Walls from $1 \mathrm{KCl}$ Control at Room Temperature and Average Detection Limits for Leachate and Acid Strip. .365

Figure J-13. Chromium Releases in Solution and on Walls from Polished Sample 29 in $10 \mathrm{KCl}$ at Room Temperature and Average Detection Limits for Leachate and Acid Strip. 366

Figure J-14. Chromium Present in Solution and on Walls from 10KCl Control and Average Detection Limits for Leachate and Acid Strip Data.

Figure J-15. Chromium Releases in Solution and on Walls from Polished Sample 31 in AJ13 at Room Temperature and Average Detection Limits for Leachate and Acid Strip.

Figure J-16. Chromium Present in Solution and on Walls from AJ13 Control at Room Temperature and Average Leachate and Acid Strip Data.

Figure J-17. Nickel Releases in Solution and on Walls from Polished Sample 25 in $1 \mathrm{KCl}$ Solution at $90^{\circ} \mathrm{C}$ and Average Detection Limits for Leachate and Acid Strip........368

Figure J-18. Nickel Present in Solutions and on Walls in $1 \mathrm{KCl}$ Solution Control at $90^{\circ} \mathrm{C}$ and Average Detection Limits for Leachate and Acid Strip.

F Figure J-19. Nickel Releases in Solution and on Walls from Polished Sample 27 in $1 \mathrm{KCl}$ Solution at Room Temperature and Average Detection Limits for Leachate and Acid Strip.

Figure J-20. Nickel Present in Solutions and on Walls in $1 \mathrm{KCl}$ Solution Control at Room Temperature and Average Detection Limits for Leachate and Acid Strip.....

Figure J-21. Nickel Releases in Solution and on Walls from Polished Sample 29 in $10 \mathrm{KCl}$ Solution at Room Temperature and Average Detection Limits for Leachate and Acid Strip.

Figure J-22. Nickel Present in Solutions and on Walls in 10KCl Solution Control at Room Temperature and Average Detection Limits for Leachate and Acid Strip. .. 370

Figure J-23. Nickel Releases in Solution and on Walls from Polished Sample 31 in AJ13 Solution at Room Temperature and Average Detection Limits for Leachate and Acid Strip.

Figure J-24. Nickel Present in Solutions and on Walls in AJ13 Solution Control at Room Temperature and Average Detection Limits for Leachate and Acid Strip.

Figure J-25. Zirconium Releases in Solution and on Walls from Polished Sample 25 in $1 \mathrm{KCl}$ Solution at $90^{\circ} \mathrm{C}$ and Average Detection Limits for Leachate and Acid Strip.

Figure J-26. Zirconium Present in Solutions and on Walls in $1 \mathrm{KCl}$ Solution Control at $90^{\circ} \mathrm{C}$ and Average Detection Limits for Leachate and Acid Strip. 
Figure J-27. Zirconium Releases in Solution and on Walls from Polished Sample 27 in $1 \mathrm{KCl}$ Solution at Room Temperature and Average Detection Limits for Leachate and Acid Strip.

Figure J-28. Zirconium Present in Solutions and on Walls in $1 \mathrm{KCl}$ Solution Control at Room Temperature and Average Detection Limits for Leachate and Acid Strip...373

Figure J-29. Zirconium Releases in Solution and on Walls from Polished Sample 29 in $10 \mathrm{KCl}$ Solution at Room Temperature and Average Detection Limits for Leachate and Acid Strip.

Figure J-30. Zirconium Present in Solutions and on Walls in 10KCl Solution Control at Room Temperature and Average Detection Limits for Leachate and Acid Strip...374

Figure J-31. Zirconium Releases in Solution and on Walls from Polished Sample 31 in AJ13 Solution at Room Temperature and Average Detection Limits for Leachate and Acid Strip.

Figure J-32. Zirconium Present in Solutions and on Walls in AJ13 Solution Control at Room Temperature and Average Detection Limits for Leachate and Acid Strip...375

Figure J-33. Niobium Releases in Solution and on Walls from Polished Sample 25 in $1 \mathrm{KCl}$ Solution at $90^{\circ} \mathrm{C}$ and Average Detection Limits for Leachate and Acid Strip.

Figure J-34. Niobium Present in Solutions and on Walls in $1 \mathrm{KCl}$ Solution Control at $90^{\circ} \mathrm{C}$ and Average Detection Limits for Leachate and Acid Strip.....

Figure J-35. Niobium Releases in Solution and on Walls from Polished Sample 27 in $1 \mathrm{KCl}$ Solution at Room Temperature and Average Detection Limits for Leachate and Acid Strip.

Figure J-36. Niobium Present in Solutions and on Walls in $1 \mathrm{KCl}$ Solution Control at Room Temperature and Average Detection Limits for Leachate and Acid Strip. .. 377

Figure J-37. Niobium Releases in Solution and on Walls from Polished Sample 29 in $10 \mathrm{KCl}$ Solution at Room Temperature and Average Detection Limits for Leachate and Acid Strip.

Figure J-38. Niobium Present in Solutions and on Walls in $10 \mathrm{KCl}$ Solution Control at Room Temperature and Average Detection Limits for Leachate and Acid Strip...378

Figure J-39. Niobium Releases in Solution and on Walls from Polished Sample 31 in AJ13 Solution at Room Temperature and Average Detection Limits for Leachate and Acid Strip.

Figure J-40. Niobium Present in Solutions and on Walls in AJ13 Solution Control at Room Temperature and Average Detection Limits for Leachate and Acid Strip...379 
Figure J-41. Palladium Releases in Solution and on Walls from Polished Sample 25 in $1 \mathrm{KCl}$ Solution at $90^{\circ} \mathrm{C}$ and Average Detection Limits for Leachate and Acid Strip.

Figure J-42. Palladium Present in Solutions and on Walls in $1 \mathrm{KCl}$ Solution Control at $90^{\circ} \mathrm{C}$ and Average Detection Limits for Leachate and Acid Strip......

Figure J-43. Palladium Releases in Solution and on Walls from Polished Sample 27 in $1 \mathrm{KCl}$ Solution at Room Temperature and Average Detection Limits for Leachate and Acid Strip.

Figure J-44. Palladium Present in Solutions and on Walls in $1 \mathrm{KCl}$ Solution Control at Room Temperature and Average Detection Limits for Leachate and Acid Strip...381

Figure J-45. Palladium Releases in Solution and on Walls from Polished Sample 29 in $10 \mathrm{KCl}$ Solution at Room Temperature and Average Detection Limits for Leachate and Acid Strip.

Figure J-46. Palladium Present in Solutions and on Walls in $10 \mathrm{KCl}$ Solution Control at Room Temperature and Average Detection Limits for Leachate and Acid Strip...382

Figure J-47. Palladium Releases in Solution and on Walls from Polished Sample 31 in AJ13 Solution at Room Temperature and Average Detection Limits for Leachate and Acid Strip.

Figure J-48. Palladium Present in Solutions and on Walls in AJ13 Solution Control at Room Temperature and Average Detection Limits for Leachate and Acid Strip...383

Figure J-49. Rhodium Releases in Solution and on Walls from Polished Sample 25 in $1 \mathrm{KCl}$ Solution at $90^{\circ} \mathrm{C}$ and Average Detection Limits for Leachate and Acid Strip.

Figure J-50. Rhodium Present in Solutions and on Walls in $1 \mathrm{KCl}$ Solution Control at $90^{\circ} \mathrm{C}$ and Average Detection Limits for Leachate and Acid Strip.

Figure J-51. Rhodium Releases in Solution and on Walls from Polished Sample 27 in $1 \mathrm{KCl}$ Solution at Room Temperature and Average Detection Limits for Leachate and Acid Strip.

Figure J-52. Rhodium Present in Solutions and on Walls in $1 \mathrm{KCl}$ Solution Control at Room Temperature and Average Detection Limits for Leachate and Acid Strip...385

Figure J-53. Rhodium Releases in Solution and on Walls from Polished Sample 29 in $10 \mathrm{KCl}$ Solution at Room Temperature and Average Detection Limits for Leachate and Acid Strip.

Figure J-54. Rhodium Present in Solutions and on Walls in $10 \mathrm{KCl}$ Solution Control at Room Temperature and Average Detection Limits for Leachate and Acid Strip...386 
Figure J-55. Rhodium Releases in Solution and on Walls from Polished Sample 31 in AJ13 Solution at Room Temperature and Average Detection Limits for Leachate and Acid Strip.

Figure J-56. Rhodium Present in Solutions and on Walls in AJ13 Solution Control at Room Temperature and Average Detection Limits for Leachate and Acid Strip...387

Figure J-57. Ruthenium Releases in Solution and on Walls from Polished Sample 25 in $1 \mathrm{KCl}$ Solution at $90^{\circ} \mathrm{C}$ and Average Detection Limits for Leachate and Acid Strip.

Figure J-58. Ruthenium Present in Solutions and on Walls in $1 \mathrm{KCl}$ Solution Control at $90^{\circ} \mathrm{C}$ and Average Detection Limits for Leachate and Acid Strip.

Figure J-59. Ruthenium Releases in Solution and on Walls from Polished Sample 27 in $1 \mathrm{KCl}$ Solution at Room Temperature and Average Detection Limits for Leachate and Acid Strip.

Figure J-60. Ruthenium Present in Solutions and on Walls in $1 \mathrm{KCl}$ Solution Control at Room Temperature and Average Detection Limits for Leachate and Acid Strip. .. 389

Figure J-61. Ruthenium Releases in Solution and on Walls from Polished Sample 29 in $10 \mathrm{KCl}$ Solution at Room Temperature and Average Detection Limits for Leachate and Acid Strip. 390

Figure J-62. Ruthenium Present in Solutions and on Walls in $10 \mathrm{KCl}$ Solution Control at Room Temperature and Average Detection Limits for Leachate and Acid Strip...390

Figure J-63. Ruthenium Releases in Solution and on Walls from Polished Sample 31 in AJ13 Solution at Room Temperature and Average Detection Limits for Leachate and Acid Strip.

Figure J-64. Ruthenium Present in Solutions and on Walls in AJ13 Solution Control at Room Temperature and Average Detection Limits for Leachate and Acid Strip. .. 391

Figure J-65. Molybdenum Releases in Solution and on Walls from Polished Sample 25 in $1 \mathrm{KCl}$ Solution at $90^{\circ} \mathrm{C}$ and Average Detection Limits for Leachate and Acid Strip.

Figure J-66. Molybdenum Present in Solutions and on Walls in $1 \mathrm{KCl}$ Solution Control at $90^{\circ} \mathrm{C}$ and Average Detection Limits for Leachate and Acid Strip.

Figure J-67. Molybdenum Releases in Solution and on Walls from Polished Sample 27 in $1 \mathrm{KCl}$ Solution at Room Temperature and Average Detection Limits for Leachate and Acid Strip. 393

Figure J-68. Molybdenum Present in Solutions and on Walls in $1 \mathrm{KCl}$ Solution Control at Room Temperature and Average Detection Limits for Leachate and Acid Strip...393 
Figure J-69. Moybdenum Releases in Solution and on Walls from Polished Sample 29 in $10 \mathrm{KCl}$ Solution at Room Temperature and Average Detection Limits for Leachate and Acid Strip. 394

Figure J-70. Molybdenum Present in Solutions and on Walls in 10KCl Solution Control at Room Temperature and Average Detection Limits for Leachate and Acid Strip.

Figure J-71. Molybdenum Releases in Solution and on Walls from Polished Sample 31 in AJ13 Solution at Room Temperature and Average Detection Limits for Leachate and Acid Strip. 395

Figure J-72. Molybdenum Present in Solutions and on Walls in AJ13 Solution Control at Room Temperature and Average Detection Limits for Leachate and Acid Strip...395

Figure J-73. Manganese Releases in Solution and on Walls from Polished Sample 25 in $1 \mathrm{KCl}$ Solution at $90^{\circ} \mathrm{C}$ and Average Detection Limits for Leachate and Acid Strip.

Figure J-74. Manganese Present in Solutions and on Walls in $1 \mathrm{KCl}$ Solution Control at $90^{\circ} \mathrm{C}$ and Average Detection Limits for Leachate and Acid Strip..... 396

Figure J-75. Manganese Releases in Solution and on Walls from Polished Sample 27 in $1 \mathrm{KCl}$ Solution at Room Temperature and Average Detection Limits for Leachate and Acid Strip.

Figure J-76. Manganese Present in Solutions and on Walls in $1 \mathrm{KCl}$ Solution Control at Room Temperature and Average Detection Limits for Leachate and Acid Strip...397

Figure J-77. Manganese Releases in Solution and on Walls from Polished Sample 29 in $10 \mathrm{KCl}$ Solution at Room Temperature and Average Detection Limits for Leachate and Acid Strip. 398

Figure J-78. Manganese Present in Solutions and on Walls in $10 \mathrm{KCl}$ Solution Control at Room Temperature and Average Detection Limits for Leachate and Acid Strip...398

Figure J-79. Manganese Releases in Solution and on Walls from Polished Sample 31 in AJ13 Solution at Room Temperature and Average Detection Limits for Leachate and Acid Strip. 399

Figure J-80. Manganese Present in Solutions and on Walls in AJ13 Solution Control at Room Temperature and Average Detection Limits for Leachate and Acid Strip...399

Figure J-81. Cobalt Releases in Solution and on Walls from Polished Sample 25 in $1 \mathrm{KCl}$ Solution at $90^{\circ} \mathrm{C}$ and Average Detection Limits for Leachate and Acid Strip.......400

Figure J-82. Cobalt Present in Solutions and on Walls in $1 \mathrm{KCl}$ Solution Control at $90^{\circ} \mathrm{C}$ and Average Detection Limits for Leachate and Acid Strip. 400 
Figure J-83. Cobalt Releases in Solution and on Walls from Polished Sample 27 in $1 \mathrm{KCl}$ Solution at Room Temperature and Average Detection Limits for Leachate and Acid Strip. 401

Figure J-84. Cobalt Present in Solutions and on Walls in $1 \mathrm{KCl}$ Solution Control at Room Temperature and Average Detection Limits for Leachate and Acid Strip..... 401

Figure J-85. Cobalt Releases in Solution and on Walls from Polished Sample 29 in $10 \mathrm{KCl}$ Solution at Room Temperature and Average Detection Limits for Leachate and Acid Strip.

Figure J-86. Cobalt Present in Solutions and on Walls in $10 \mathrm{KCl}$ Solution Control at Room Temperature and Average Detection Limits for Leachate and Acid Strip...402

Figure J-87. Cobalt Releases in Solution and on Walls from Polished Sample 31 in AJ13 Solution at Room Temperature and Average Detection Limits for Leachate and Acid Strip.

Figure J-88. Cobalt Present in Solutions and on Walls in AJ13 Solution Control at Room Temperature and Average Detection Limits for Leachate and Acid Strip. 403

Figure J-89. Copper Releases in Solution and on Walls from Polished Sample 25 in $1 \mathrm{KCl}$ Solution at $90^{\circ} \mathrm{C}$ and Average Detection Limits for Leachate and Acid Strip.

Figure J-90. Copper Present in Solutions and on Walls in $1 \mathrm{KCl}$ Solution Control at $90^{\circ} \mathrm{C}$ and Average Detection Limits for Leachate and Acid Strip. .404

Figure J-91. Copper Releases in Solution and on Walls from Polished Sample 27 in $1 \mathrm{KCl}$ Solution at Room Temperature and Average Detection Limits for Leachate and Acid Strip.

Figure J-92. Copper Present in Solutions and on Walls in $1 \mathrm{KCl}$ Solution Control at Room Temperature and Average Detection Limits for Leachate and Acid Strip...405

Figure J-93. Copper Releases in Solution and on Walls from Polished Sample 29 in $10 \mathrm{KCl}$ Solution at Room Temperature and Average Detection Limits for Leachate and Acid Strip.

Figure J-94. Copper Present in Solutions and on Walls in $10 \mathrm{KCl}$ Solution Control at Room Temperature and Average Detection Limits for Leachate and Acid Strip...406

Figure J-95. Copper Releases in Solution and on Walls from Polished Sample 31 in AJ13 Solution at Room Temperature and Average Detection Limits for Leachate and Acid Strip. 407

Figure J-96. Copper Present in Solutions and on Walls in AJ13 Solution Control at Room Temperature and Average Detection Limits for Leachate and Acid Strip...407 
Figure J-97. Vanadium Releases in Solution and on Walls from Polished Sample 25 in $1 \mathrm{KCl}$ Solution at $90^{\circ} \mathrm{C}$ and Average Detection Limits for Leachate and Acid Strip.

Figure J-98. Vanadium Present in Solutions and on Walls in $1 \mathrm{KCl}$ Solution Control at $90^{\circ} \mathrm{C}$ and Average Detection Limits for Leachate and Acid Strip..... 408

Figure J-99. Vanadium Releases in Solution and on Walls from Polished Sample 27 in $1 \mathrm{KCl}$ Solution at Room Temperature and Average Detection Limits for Leachate and Acid Strip.

Figure J-100. Vanadium Present in Solutions and on Walls in $1 \mathrm{KCl}$ Solution Control at Room Temperature and Average Detection Limits for Leachate and Acid Strip...409

Figure J-101. Vanadium Releases in Solution and on Walls from Polished Sample 29 in $10 \mathrm{KCl}$ Solution at Room Temperature and Average Detection Limits for Leachate and Acid Strip.

Figure J-102. Vanadium Present in Solutions and on Walls in $10 \mathrm{KCl}$ Solution Control at Room Temperature and Average Detection Limits for Leachate and Acid Strip...410

Figure J-103. Vanadium Releases in Solution and on Walls from Polished Sample 31 in AJ13 Solution at Room Temperature and Average Detection Limits for Leachate and Acid Strip.

Figure J-104. Vanadium Present in Solutions and on Walls in AJ13 Solution Control at Room Temperature and Average Detection Limits for Leachate and Acid Strip...411

Figure $\mathrm{M}-1$. Iron Releases in $1 \mathrm{KCl}$ solution at $90^{\circ} \mathrm{C}$.

Figure $\mathrm{M}-2$. Iron Releases in $1 \mathrm{KCl}$ solution at room temperature.

Figure M-3. Iron Releases in $10 \mathrm{KCl}$ Solution at room temperature. .428

Figure M-4. Iron Releases in AJ13 Solution at room temperature. .428

Figure M-5. Chromium Releases in $1 \mathrm{KCl}$ solution at $90^{\circ} \mathrm{C}$.

Figure M-6. Chromium Releases in $1 \mathrm{KCl}$ solution at room temperature.

Figure M-7. Chromium Releases in $10 \mathrm{KCl}$ solution at room temperature. 430

Figure M-8. Chromium Releases in AJ13 solution at room temperature. .430

Figure M-9. Nickel Releases in $1 \mathrm{KCl}$ solution at $90^{\circ} \mathrm{C}$. 431

Figure $\mathrm{M}-10$. Nickel Releases in $1 \mathrm{KCl}$ solution at room temperature. .431

Figure M-11. Nickel Releases in $10 \mathrm{KCl}$ solution at room temperature. 432

Figure M-12. Nickel Releases in AJ13 solution at room temperature. 432 
Figure $\mathrm{M}-13$. Zirconium Releases in $1 \mathrm{KCl}$ solution at $90^{\circ} \mathrm{C}$. 433

Figure M-14. Zirconium Releases in $1 \mathrm{KCl}$ solution at room temperature. .433

Figure M-15. Zirconium Releases in $10 \mathrm{KCl}$ solution at room temperature. .434

Figure M-16. Zirconium Releases in AJ13 solution at room temperature. .434

Figure M-17. Niobium Releases in $1 \mathrm{KCl}$ solution at $90^{\circ} \mathrm{C}$. .435

Figure $\mathrm{M}-18$. Niobium Releases in $1 \mathrm{KCl}$ solution at room temperature......................435

Figure M-19. Niobium Releases in $10 \mathrm{KCl}$ solution at room temperature...................436

Figure M-20. Niobium Releases in AJ13 solution at room temperature.....................436

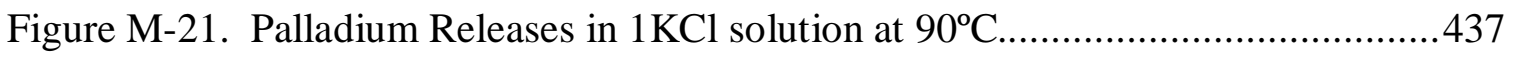

Figure M-22. Palladium Releases in $1 \mathrm{KCl}$ solution at room temperature ...................437

Figure M-23. Palladium Releases in $10 \mathrm{KCl}$ solution at room temperature..................438

Figure M-24. Palladium Releases in AJ13 solution at room temperature...................438

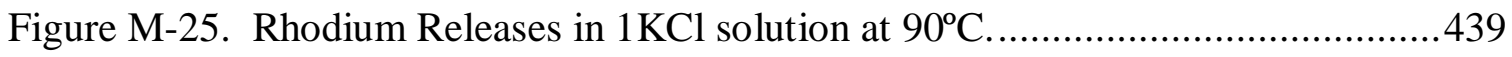

Figure M-26. Rhodium Releases in $1 \mathrm{KCl}$ solution at room temperature....................439

Figure M-27. Rhodium Releases in $10 \mathrm{KCl}$ solution at room temperature..................440

Figure M-28. Rhodium Releases in AJ13 solution at room temperature ....................440

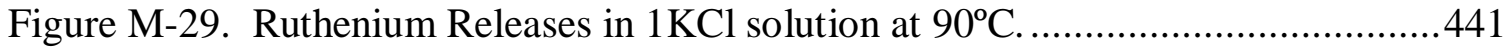

Figure M-30. Ruthenium Releases in $1 \mathrm{KCl}$ solution at room temperature .................441

Figure M-31. Ruthenium Releases in $10 \mathrm{KCl}$ solution at room temperature. ................442

Figure M-32. Ruthenium Releases in AJ13 solution at room temperature. .................442

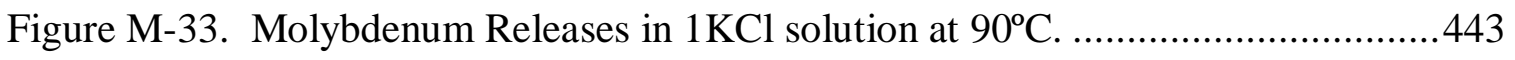

Figure M-34. Molybdenum Releases in $1 \mathrm{KCl}$ solution at room temperature ...............443

Figure M-35. Molybdenum Releases in $10 \mathrm{KCl}$ solution at room temperature..............444

Figure M-36. Molybdenum Releases in AJ13 solution at room temperature................444

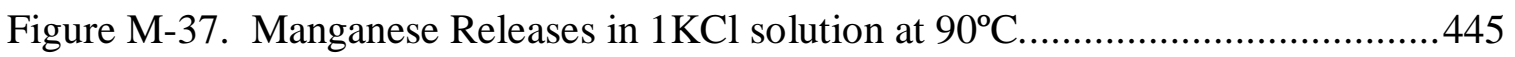

Figure M-38. Manganese Releases in $1 \mathrm{KCl}$ solution at room temperature..................445

Figure M-39. Manganese Releases in $10 \mathrm{KCl}$ solution at room temperature................446 
Figure M-40. Manganese Releases in AJ13 solution at room temperature. 446

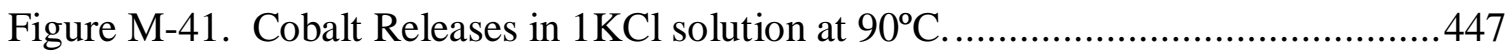

Figure M-42. Cobalt Releases in $1 \mathrm{KCl}$ solution at room temperature. .......................447

Figure M-43. Cobalt Releases in $10 \mathrm{KCl}$ solution at room temperature......................448

Figure M-44. Cobalt Releases in AJ13 solution at room temperature. ........................448

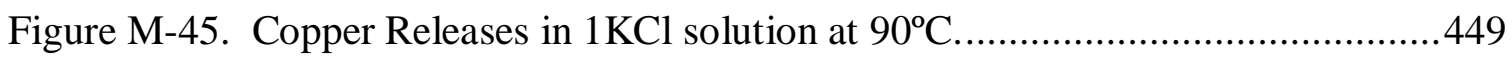

Figure M-46. Copper Releases in $1 \mathrm{KCl}$ solution at room temperature.......................449

Figure M-47. Copper Releases in $10 \mathrm{KCl}$ solution at room temperature.....................450

Figure M-48. Copper Releases in AJ13 solution at room temperature ......................450

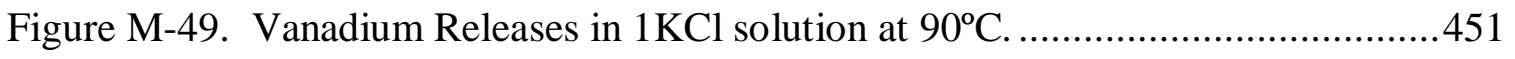

Figure M-50. Vanadium Releases in $1 \mathrm{KCl}$ solution at room temperature. ..................451

Figure M-51. Vanadium Releases in $10 \mathrm{KCl}$ solution at room temperature. .................452

Figure M-52. Vanadium Releases in AJ13 solution at room temperature....................452 


\section{LIST OF TABLES}

Page

Table I-1. Comparison of One Representative Composition of J-13 Well Water with the Composition of Simulated J-13 Water Used in Immersion Tests. .1

Table I-2. Typical Composition of $20^{\circ} \mathrm{C}$ Electrochemical Testing Solutions....................2

Table I-3. Typical Composition of $60^{\circ} \mathrm{C}$ Electrochemical Testing Solution.....................2

Table I-4. Typical Composition of $90^{\circ} \mathrm{C}$ Electrochemical Testing Solutions.....................3

Table I-5. Composition, Density, and Equivalent Weight of Alloys Tested by the

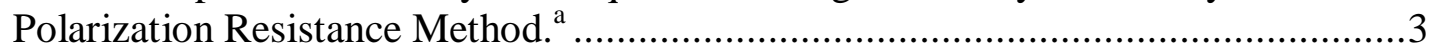

Table I-6. Composition (wt \%) of SS15ZR25 Alloy Samples ${ }^{\mathrm{a}}$.....................................19

Table I-7. Composition of Solutions used for Immersion Tests ${ }^{\mathrm{a}}$ …............................19

Table III-1. Parameters used in Equation (1) to Fit Fe Normalized Losses .....................82

Table A-1. Composition and Density of Alloys Tested.................................................91

Table A-2. Typical Composition of Solutions Used for Electrochemical Testing at $20^{\circ} \mathrm{C}$.

Table A-3. Corrosion Rates $(\mu \mathrm{m} / \mathrm{y})$ Measured in $\mathrm{pH}=12$ Solution at $20^{\circ} \mathrm{C} \ldots \ldots \ldots \ldots \ldots \ldots \ldots . . .92$

Table A-4. Corrosion Rates $(\mu \mathrm{m} / \mathrm{y})$ Measured in $\mathrm{pH}=12$ Solution at $20^{\circ} \mathrm{C} \ldots \ldots \ldots \ldots \ldots \ldots \ldots . . .93$

Table A-5. Corrosion Rates $(\mu \mathrm{m} / \mathrm{y})$ Measured in CJ13 Solution ${ }^{\mathrm{a}}$ at $20^{\circ} \mathrm{C} \ldots \ldots \ldots \ldots \ldots \ldots \ldots . . . .94$

Table A-6. Corrosion Rates $(\mu \mathrm{m} / \mathrm{y})$ Measured in $10 \mathrm{KCl}$ Solution at $20^{\circ} \mathrm{C} \ldots \ldots \ldots \ldots \ldots \ldots . . . . .95$

Table A-7. Corrosion Rates $(\mu \mathrm{m} / \mathrm{y})$ Measured in $1 \mathrm{KCl}$ Solution ${ }^{\mathrm{a}}$ at $20^{\circ} \mathrm{C} \ldots \ldots \ldots \ldots \ldots \ldots \ldots . . . . .96$

Table A-8. Typical Composition of Solutions Used for Electrochemical Testing at $60^{\circ} \mathrm{C}$.

Table A-9. Corrosion Rates $(\mu \mathrm{m} / \mathrm{y})$ Measured in $\mathrm{pH}=10$ Solution at $60^{\circ} \mathrm{C} \ldots \ldots \ldots \ldots \ldots \ldots \ldots . . . .97$

Table A-10. Corrosion Rates $(\mu \mathrm{m} / \mathrm{y})$ Measured in CJ13 Solution ${ }^{\mathrm{a}}$ at $60^{\circ} \mathrm{C} \ldots \ldots \ldots \ldots \ldots \ldots . . . .97$

Table A-11. Corrosion Rates $(\mu \mathrm{m} / \mathrm{y})$ Measured in $10 \mathrm{KCl}$ Solution ${ }^{\mathrm{a}}$ at $60^{\circ} \mathrm{C} . \ldots \ldots \ldots \ldots \ldots . . . . .98$

Table A-12. Corrosion Rates $(\mu \mathrm{m} / \mathrm{y})$ Measured in $1 \mathrm{KCl}$ Solution ${ }^{\mathrm{a}}$ at $60^{\circ} \mathrm{C} \ldots \ldots \ldots \ldots \ldots \ldots . . . .98$

Table A-13. Corrosion Rates $(\mu \mathrm{m} / \mathrm{y})$ Measured in $\mathrm{pH}=2$ Solution at $60^{\circ} \mathrm{C} \ldots \ldots \ldots \ldots \ldots \ldots \ldots . . . .98$

Table A-14. Typical Composition of Solutions Used for Electrochemical Testing at $90^{\circ} \mathrm{C}$............. 
Table A-15. Corrosion Rates $(\mu \mathrm{m} / \mathrm{y})$ Measured in $\mathrm{pH}=10$ Solution at $90^{\circ} \mathrm{C}$. 99

Table A-16. Corrosion Rates $(\mu \mathrm{m} / \mathrm{y})$ Measured in SJ13 Solution ${ }^{\mathrm{a}}$ at $90^{\circ} \mathrm{C} \ldots \ldots \ldots \ldots \ldots \ldots . . . . . . .99$

Table A-17. Corrosion Rates $(\mu \mathrm{m} / \mathrm{y})$ Measured in CJ13 Solution ${ }^{\mathrm{a}}$ at $90^{\circ} \mathrm{C}$................. 100

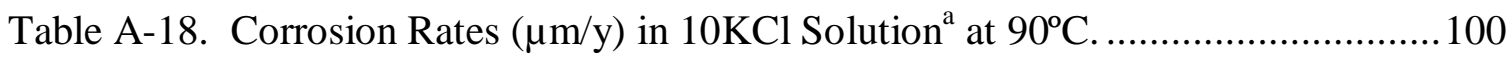

Table A-19. Corrosion Rates $(\mu \mathrm{m} / \mathrm{y})$ Measured in $1 \mathrm{KCl}$ Solution ${ }^{\mathrm{a}}$ at $90^{\circ} \mathrm{C} \ldots \ldots \ldots \ldots \ldots . . . . . .100$

Table A-20. Corrosion Rates $(\mu \mathrm{m} / \mathrm{y})$ Measured in $\mathrm{pH}=2$ Solution at $90^{\circ} \mathrm{C} \ldots \ldots \ldots \ldots \ldots . . . . . .101$

Table A-21. Comparison of Corrosion Rates ( $\mu \mathrm{m} / \mathrm{y})$ Measured at $90^{\circ} \mathrm{C}, 60^{\circ} \mathrm{C}$, and $20^{\circ} \mathrm{C}$

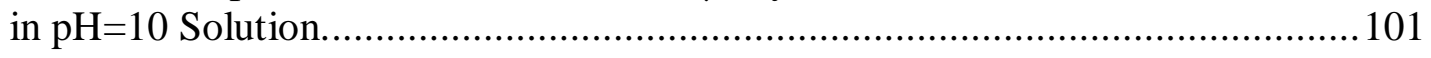

Table A-22. Comparison of Corrosion Rates $(\mu \mathrm{m} / \mathrm{y})$ Measured at $90^{\circ} \mathrm{C}, 60^{\circ} \mathrm{C}$, and $20^{\circ} \mathrm{C}$

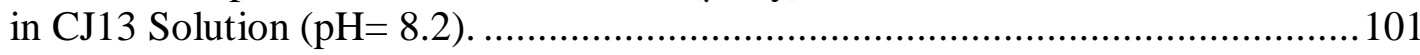

Table A-23. Comparison of Corrosion Rates ( $\mu \mathrm{m} / \mathrm{y})$ Measured at $90^{\circ} \mathrm{C}, 60^{\circ} \mathrm{C}$, and $20^{\circ} \mathrm{C}$

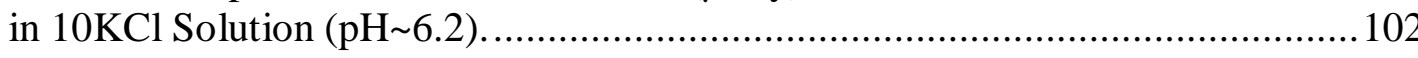

Table A-24. Comparison of Corrosion Rates ( $\mu \mathrm{m} / \mathrm{y})$ Measured at $90^{\circ} \mathrm{C}, 60^{\circ} \mathrm{C}$, and $20^{\circ} \mathrm{C}$

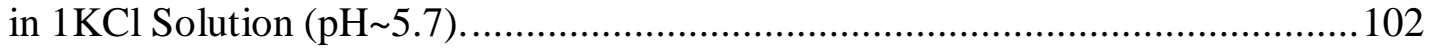

Table A-25. Comparison of Corrosion Rates $(\mu \mathrm{m} / \mathrm{y})$ Measured at $90^{\circ} \mathrm{C}, 60^{\circ} \mathrm{C}$, and $20^{\circ} \mathrm{C}$

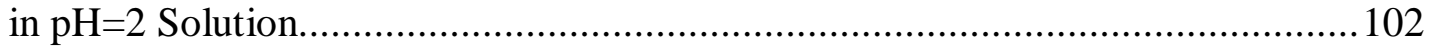

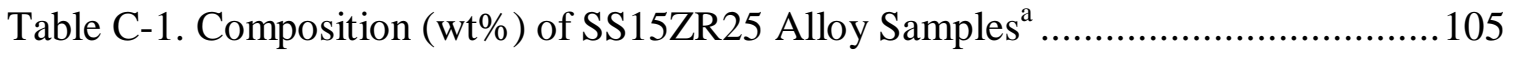

Table C-2. Composition of Solutions used for the Immersion Tests ${ }^{\mathrm{a}} \ldots \ldots \ldots \ldots \ldots \ldots \ldots \ldots . . . . . . . . . . .105$

Table C-3. Weight Change Data and Surface Examination Results from Specimens

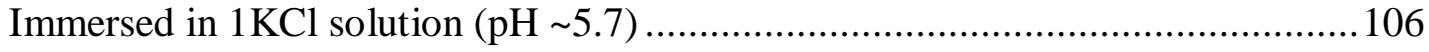

Table C-4. Weight Change Data and Surface Examination Results from Specimens

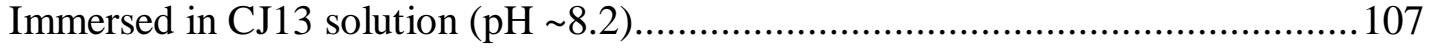

Table C-5. Leachate Data $(\mu \mathrm{g} / \mathrm{L})$ for $90^{\circ} \mathrm{C}$ Immersion in $1 \mathrm{KCl}$ Solution .................... 108

Table C-6. Acid Strip Data $(\mu \mathrm{g} / \mathrm{L})$ for $90^{\circ} \mathrm{C}$ Immersion in $1 \mathrm{KCl}$ Solution ................... 109

Table C-7. Leachate Data $(\mu \mathrm{g} / \mathrm{L})$ for $90^{\circ} \mathrm{C}$ Immersion in CJ13 Solution...................... 110

Table C-8. Acid Strip Data ( $\mu \mathrm{g} / \mathrm{L})$ for $90^{\circ} \mathrm{C}$ Immersion in Modified J-13 Solution....... 111

Table C-9. Total Concentrations and Mass Releases in Leachate and Acid Wash in $1 \mathrm{KCl}$ Solution at $90^{\circ} \mathrm{C}$

Table C-10. Total Concentrations and Mass Releases in Leachate and Acid Wash in CJ13 at $90^{\circ} \mathrm{C}$ 
Table C-11. Normalized Loss $\left(\mathrm{g} / \mathrm{m}^{2}\right)$ for Specimens Immersed in $1 \mathrm{KCl}$ Solution at $90^{\circ} \mathrm{C}$ 113

Table C-12. Normalized Loss $\left(\mathrm{g} / \mathrm{m}^{2}\right)$ for Specimens Immersed in CJ13 Solution at $90^{\circ} \mathrm{C}$

Table D-1. Table of Vial Use. 115

Table F-1. Leachate Data $\left(\mathrm{ng} / \mathrm{mm}^{2}\right)$ from SS15ZR26 Specimens Immersed in 363K $\left(90^{\circ} \mathrm{C}\right)$ Solution for 7 days. .276

Table F-2. Acid Strip Data (ng/mm²) from SS15ZR26 Specimens Immersed in $363 \mathrm{~K}$ $\left(90^{\circ} \mathrm{C}\right)$ Solution for 7 days.

Table F-3. Residue Data $\left(\mathrm{ng} / \mathrm{mm}^{2}\right)$ from SS15ZR26 Specimens Immersed in $363 \mathrm{~K}$ $\left(90^{\circ} \mathrm{C}\right)$ Solution for 7 days.

Table F-4. Leachate Data $\left(\mathrm{ng} / \mathrm{mm}^{2}\right)$ from SS15ZR26 Specimens Immersed in 363K $\left(90^{\circ} \mathrm{C}\right)$ Solution for 14 days.

Table F-5. Acid Strip Data (ng/ $\left.\mathrm{mm}^{2}\right)$ from SS15ZR26 Specimens Immersed in $363 \mathrm{~K}$ $\left(90^{\circ} \mathrm{C}\right)$ Solution for 14 days.

Table F-6. Residue Data $\left(\mathrm{ng} / \mathrm{mm}^{2}\right)$ from SS15ZR26 Specimens Immersed in $363 \mathrm{~K}$ $\left(90^{\circ} \mathrm{C}\right)$ Solution for 14 days. .281

Table F-7. Leachate Data $\left(\mathrm{ng} / \mathrm{mm}^{2}\right)$ from SS15ZR26 Specimens Immersed in 363K $\left(90^{\circ} \mathrm{C}\right)$ Solution for 21 days. .282

Table F-8. Acid Strip Data (ng/mm²) from SS15ZR26 Specimens Immersed in $363 \mathrm{~K}$ $\left(90^{\circ} \mathrm{C}\right)$ Solution for 21 days.

Table F-9. Residue Data (ng/mm²) from SS15ZR26 Specimens Immersed in $363 \mathrm{~K}$ $\left(90^{\circ} \mathrm{C}\right)$ Solution for 21 days

Table F-10. Leachate Data $\left(\mathrm{ng} / \mathrm{mm}^{2}\right)$ from SS15ZR26 Specimens Immersed in 363K $\left(90^{\circ} \mathrm{C}\right)$ Solution for 28 days

Table F-11. Acid Strip Data ( $\left.\mathrm{ng} / \mathrm{mm}^{2}\right)$ from SS15ZR26 Specimens Immersed in $363 \mathrm{~K}$

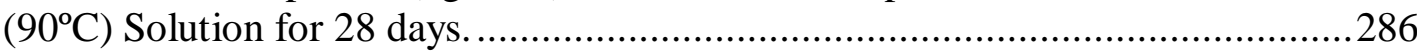

Table F-12. Residue Data (ng/ $\left.\mathrm{mm}^{2}\right)$ from SS15ZR 26 Specimens Immersed in $363 \mathrm{~K}$ $\left(90^{\circ} \mathrm{C}\right)$ Solution for 28 days.

Table F-13. Leachate Data $\left(\mathrm{ng} / \mathrm{mm}^{2}\right)$ from SS15ZR26 Specimens Immersed in 363K $\left(90^{\circ} \mathrm{C}\right)$ Solution for 42 days. 288

Table F-14. Acid Strip Data $\left(\mathrm{ng} / \mathrm{mm}^{2}\right)$ from SS15ZR26 Specimens Immersed in $363 \mathrm{~K}$ $\left(90^{\circ} \mathrm{C}\right)$ Solution for 42 days. 
Table F-15. Residue Data $\left(\mathrm{ng} / \mathrm{mm}^{2}\right)$ from SS15ZR26 Specimens Immersed in $363 \mathrm{~K}$

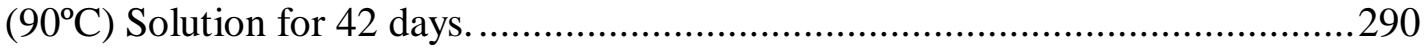

Table F-16. Leachate Data $\left(\mathrm{ng} / \mathrm{mm}^{2}\right)$ from SS15ZR26 Specimens Immersed in $363 \mathrm{~K}$ $\left(90^{\circ} \mathrm{C}\right)$ Solution for 56 days.

Table F-17. Acid Strip Data $\left(\mathrm{ng} / \mathrm{mm}^{2}\right)$ from SS15ZR26 Specimens Immersed in $363 \mathrm{~K}$ $\left(90^{\circ} \mathrm{C}\right)$ Solution for 56 days.

Table F-18. Residue Data $\left(\mathrm{ng} / \mathrm{mm}^{2}\right)$ from SS15ZR26 Specimens Immersed in $363 \mathrm{~K}$ $\left(90^{\circ} \mathrm{C}\right)$ Solution for 56 days.

Table F-19. Leachate Data $\left(\mathrm{ng} / \mathrm{mm}^{2}\right)$ from SS15ZR26 Specimens Immersed in $363 \mathrm{~K}$ $\left(90^{\circ} \mathrm{C}\right)$ Solution for 70 days.

Table F-20. Acid Strip Data $\left(\mathrm{ng} / \mathrm{mm}^{2}\right)$ from SS15ZR26 Specimens Immersed in $363 \mathrm{~K}$ $\left(90^{\circ} \mathrm{C}\right)$ Solution for 70 days.

Table F-21. Residue Data $\left(\mathrm{ng} / \mathrm{mm}^{2}\right)$ from SS15ZR26 Specimens Immersed in $363 \mathrm{~K}$ $\left(90^{\circ} \mathrm{C}\right)$ Solution for 70 days.

Table F-22. Leachate Data $\left(\mathrm{ng} / \mathrm{mm}^{2}\right)$ from SS15ZR26 Specimens Immersed in $363 \mathrm{~K}$ $\left(90^{\circ} \mathrm{C}\right)$ Solution for 98 days.

Table F-23. Acid Strip Data $\left(\mathrm{ng} / \mathrm{mm}^{2}\right)$ from SS15ZR26 Specimens Immersed in $363 \mathrm{~K}$ $\left(90^{\circ} \mathrm{C}\right)$ Solution for 98 days

Table F-24. Acid Strip Data $\left(\mathrm{ng} / \mathrm{mm}^{2}\right)$ from SS15ZR26 Specimens Immersed in $363 \mathrm{~K}$ $\left(90^{\circ} \mathrm{C}\right)$ Solution for 98 days

Table F-25. Leachate Data $\left(\mathrm{ng} / \mathrm{mm}^{2}\right)$ from SS15ZR26 Specimens Immersed in $363 \mathrm{~K}$ $\left(90^{\circ} \mathrm{C}\right)$ Solution for 154 days.

Table F-26. Acid Strip Data $\left(\mathrm{ng} / \mathrm{mm}^{2}\right)$ from SS15ZR26 Specimens Immersed in $363 \mathrm{~K}$ $\left(90^{\circ} \mathrm{C}\right)$ Solution for 154 days.

Table F-27. Residue Data (ng/mm²) from SS15ZR26 Specimens Immersed in $363 \mathrm{~K}$ $\left(90^{\circ} \mathrm{C}\right)$ Solution for 154 days.

Table F-28. Leachate Data $\left(\mathrm{ng} / \mathrm{mm}^{2}\right)$ from SS15ZR26 Specimens Immersed in $363 \mathrm{~K}$ $\left(90^{\circ} \mathrm{C}\right)$ Solution for 224 days.

Table F-29. Acid Strip Data $\left(\mathrm{ng} / \mathrm{mm}^{2}\right)$ from SS15ZR26 Specimens Immersed in $363 \mathrm{~K}$ $\left(90^{\circ} \mathrm{C}\right)$ Solution for 224 days.

Table F-30. Residue $\left(\mathrm{ng} / \mathrm{mm}^{2}\right)$ from SS15ZR26 Specimens Immersed in $363 \mathrm{~K}\left(90^{\circ} \mathrm{C}\right)$ Solution for 224 days.

Table F-31. Leachate Data $\left(\mathrm{ng} / \mathrm{mm}^{2}\right)$ from SS15ZR26 Specimens Immersed in 363K $\left(90^{\circ} \mathrm{C}\right)$ Solution for 308 days. 
Table F-32. Acid Strip Data $\left(\mathrm{ng} / \mathrm{mm}^{2}\right)$ from SS15ZR26 Specimens Immersed in $363 \mathrm{~K}$

$\left(90^{\circ} \mathrm{C}\right)$ Solution for 308 days.

Table F-33. Residue $\left(\mathrm{ng} / \mathrm{mm}^{2}\right)$ from SS15ZR26 Specimens Immersed in $363 \mathrm{~K}\left(90^{\circ} \mathrm{C}\right)$

Solution for 308 days. 308

Table G-1. Iron Detection Limits in Leachate Data $\left(\mathrm{ng} / \mathrm{mm}^{2}\right)$. 309

Table G-2. Iron Detection Limits in Acid Strip Data $\left(\mathrm{ng} / \mathrm{mm}^{2}\right)$. 310

Table G-3. Chromium Detection Limits for Leachate Data $\left(\mathrm{ng} / \mathrm{mm}^{2}\right)$. 311

Table G-4. Chromium Detection Limits for Acid Strip Data $\left(\mathrm{ng} / \mathrm{mm}^{2}\right)$. 312

Table G-5. Nickel Detection Limits for Leachate Data $\left(\mathrm{ng} / \mathrm{mm}^{2}\right)$. 313

Table G-6. Nickel Detection Limits for Acid Strip Data (ng/mm²). 314

Table G-7. Zirconium Detection Limits for Leachate Data $\left(\mathrm{ng} / \mathrm{mm}^{2}\right)$. 315

Table G-8. Zirconium Detection Limits for Acid Strip Data (ng/ $\left.\mathrm{mm}^{2}\right)$. 316

Table G-9. Niobium Detection Limits for Leachate Data (ng/ $\left.\mathrm{mm}^{2}\right)$. 317

Table G-10. Niobium Detection Limits for Acid Strip Data (ng/mm²). 318

Table G-11. Paladium Detection Limits for Leachate Data $\left(\mathrm{ng} / \mathrm{mm}^{2}\right)$ 319

Table G-12. Paladium Detection Limits for Acid Strip Data $\left(\mathrm{ng} / \mathrm{mm}^{2}\right)$. 320

Table G-13. Ruthenium Detection Limits for Leachate Data $\left(\mathrm{ng} / \mathrm{mm}^{2}\right)$. .321

Table G-14. Ruthenium Detection Limits for Acid Strip Data (ng/mm²). .322

Table G-15. Rhodium Detection Limits for Leachate Data $\left(\mathrm{ng} / \mathrm{mm}^{2}\right)$. .323

Table G-16. Rhodium Detection Limits for Acid Strip Data $\left(\mathrm{ng} / \mathrm{mm}^{2}\right)$. .324

Table G-17. Molybdenum Detection Limits for Leachate Data $\left(\mathrm{ng} / \mathrm{mm}^{2}\right)$. 325

Table G-18. Molybdenum Detection Limits for Acid Strip Data (ng/mm²) 326

Table G-19. Manganese Detection Limits for Leachate Data (ng/mm²). 327

Table G-20. Manganese Detection Limits for Acid Strip Data (ng/mm²). 328

Table G-21. Cobalt Detection Limits for Leachate Data $\left(\mathrm{ng} / \mathrm{mm}^{2}\right)$ 329

Table G-22. Cobalt Detection Limits for Acid Strip Data (ng/mm²) .330

Table G-23. Copper Detection Limits and Leachate Data $\left(\mathrm{ng} / \mathrm{mm}^{2}\right)$ .331

Table G-24. Copper Detection Limits for Acid Strip Data (ng/mm²) .332 
Table G-25. Vanadium Detection Limits for Leachate Data $\left(\mathrm{ng} / \mathrm{mm}^{2}\right)$ 333

Table G-26. Vanadium Detection Limits for Acid Strip Data $\left(\mathrm{ng} / \mathrm{mm}^{2}\right)$.

Table K-1. Leachate data $\left(\mathrm{ng} / \mathrm{mm}^{2}\right)$ from SS15ZR26 specimens immersed in room temperature solution for 14 days.

Table K-2. Acid Strip data $\left(\mathrm{ng} / \mathrm{mm}^{2}\right)$ from SS15ZR26 specimens immersed in room temperature solution for 14 days.

Table K-3. Leachate data $\left(\mathrm{ng} / \mathrm{mm}^{2}\right)$ from SS15ZR26 specimens immersed in room temperature solution for 28 days.

Table K-4. Acid Strip data $\left(\mathrm{ng} / \mathrm{mm}^{2}\right)$ from SS15ZR26 specimens immersed in room temperature solution for 28 days.

Table K-5. Leachate data $\left(\mathrm{ng} / \mathrm{mm}^{2}\right)$ from SS15ZR26 specimens immersed in room temperature solution for 42 days.

Table K-6. Acid Strip data $\left(\mathrm{ng} / \mathrm{mm}^{2}\right)$ from SS15ZR26 specimens immersed in room temperature solution for 42 days.

Table K-7. Leachate data $\left(\mathrm{ng} / \mathrm{mm}^{2}\right)$ from SS15ZR26 specimens immersed in room temperature solution for 56 days.

Table K-8. Acid Strip data $\left(\mathrm{ng} / \mathrm{mm}^{2}\right)$ from SS15ZR26 specimens immersed in room temperature solution for 56 days.

Table K-9. Leachate data $\left(\mathrm{ng} / \mathrm{mm}^{2}\right)$ from SS15ZR26 specimens immersed in room temperature solution for 84 days.

Table K-10. Acid Strip data (ng/mm2) from SS15ZR26 specimens immersed in room temperature solution for 84 days.

Table K-11. Leachate data $\left(\mathrm{ng} / \mathrm{mm}^{2}\right)$ from SS15ZR26 specimens immersed in room temperature solution for 140 days.

Table K-12. Acid Strip data $\left(\mathrm{ng} / \mathrm{mm}^{2}\right)$ from SS15ZR26 specimens immersed in room temperature solution for 140 days.

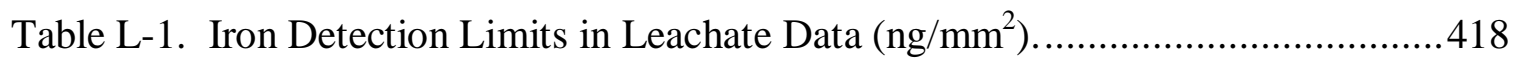

Table L-2. Iron Detection Limits in Acid Strip Data $\left(\mathrm{ng} / \mathrm{mm}^{2}\right)$..............................4 418

Table L-3. Chromium Detection Limits in Leachate Data $\left(\mathrm{ng} / \mathrm{mm}^{2}\right)$. ........................418

Table L-4. Chromium Detection Limits in Acid Strip Data $\left(\mathrm{ng} / \mathrm{mm}^{2}\right)$. .................... 419

Table L-5. Nickel Detection Limits in Leachate Data $\left(\mathrm{ng} / \mathrm{mm}^{2}\right)$.............................419

Table L-6. Nickel Detection Limits in Acid Strip Data $\left(\mathrm{ng} / \mathrm{mm}^{2}\right)$...........................419 
Table L-7. Zirconium Detection Limits in Leachate Data (ng/mm2). ...................... 420

Table L-8. Zirconium Detection Limits in Acid Strip Data $\left(\mathrm{ng} / \mathrm{mm}^{2}\right)$......................420

Table L-9. Niobium Detection Limits in Leachate Data $\left(\mathrm{ng} / \mathrm{mm}^{2}\right)$. .........................420

Table L-10. Niobium Detection Limits in Acid Strip Data $\left(\mathrm{ng} / \mathrm{mm}^{2}\right)$........................421

Table L-11. Paladium Detection Limits in Leachate Data $\left(\mathrm{ng} / \mathrm{mm}^{2}\right)$........................ 421

Table L-12. Paladium Detection Limits in Acid Strip Data $\left(\mathrm{ng} / \mathrm{mm}^{2}\right)$.......................421

Table L-13. Rhodium Detection Limits in Leachate Data $\left(\mathrm{ng} / \mathrm{mm}^{2}\right)$.........................422

Table L-14. Rhodium Detection Limits in Acid Strip Data $\left(\mathrm{ng} / \mathrm{mm}^{2}\right)$....................... 422

Table L-15. Ruthenium Detection Limits in Leachate Data $\left(\mathrm{ng} / \mathrm{mm}^{2}\right)$.......................422

Table L-16. Ruthenium Detection Limits in Acid Strip Data $\left(\mathrm{ng} / \mathrm{mm}^{2}\right)$................... 423

Table L-17. Molybdenum Detection Limits in Leachate Data $\left(\mathrm{ng} / \mathrm{mm}^{2}\right)$. .................423

Table L-18. Molybdenum Detection Limits in Acid Strip Data $\left(\mathrm{ng} / \mathrm{mm}^{2}\right)$.................423

Table L-19. Manganese Detection Limits in Leachate Data $\left(\mathrm{ng} / \mathrm{mm}^{2}\right) \ldots \ldots \ldots \ldots \ldots \ldots \ldots . . . . . . . . . . .424$

Table L-20. Manganese Detection Limits in Acid Strip Data $\left(\mathrm{ng} / \mathrm{mm}^{2}\right)$....................424

Table L-21. Cobalt Detection Limits in Leachate Data $\left(\mathrm{ng} / \mathrm{mm}^{2}\right)$. ...........................4 424

Table L-22. Cobalt Detection Limits in Acid Strip Data $\left(\mathrm{ng} / \mathrm{mm}^{2}\right)$.........................425

Table L-23. Copper Detection Limits in Leachate Data $\left(\mathrm{ng} / \mathrm{mm}^{2}\right)$...........................425

Table L-24. Copper Detection Limits in Acid Strip Data $\left(\mathrm{ng} / \mathrm{mm}^{2}\right)$........................425

Table L-25. Vanadium Detection Limits in Leachate Data $\left(\mathrm{ng} / \mathrm{mm}^{2}\right)$.......................426

Table L-26. Vanadium Detection Limits in Acid Strip Data $\left(\mathrm{ng} / \mathrm{mm}^{2}\right)$.....................426 


\section{ACRONYMS}

ACL Analytical Chemistry Laboratory

AJ13 Acidified J13 (well water) (solution)

ANL Argonne National Laboratory-East

ANL-W Argonne National Laboratory-West

CJ13 Concentrated J13 (well water) (solution)

CMT Chemical Technology Division

HLWG High level waste glass

ICP-AES Inductively coupled plasma-atomic emission spectroscopy

ICP-MS Inductively coupled plasma-mass spectrometry

ID Identification

MCC-1 Materials Characterization Center-Protocol \#1

MWF Metal waste form

NIST National Institute of Standards and Technology

NL Normalized elemental mass loss

RSD Relative standard deviation

SJ13 Simulated J13 (well water) (solution)

SS Stainless steel

TRU Transuranic

WASRD Waste Acceptance System Requirements Document

$1 \mathrm{KCl} \quad 1,000$ parts per million of chlorine (solution)

$10 \mathrm{KCl} \quad 10,000$ parts per million of chlorine (solution) 


\section{ACKNOWLEDGMENTS}

The authors would like to acknowledge A.S. Hebden, J. Kuppy, N. Katyal, D.G.

Graczyk, F.P. Smith, S. Lopykinski, and A. Essling.

This research was funded by the U.S. Department of Energy, Office of Nuclear Energy, Science and Technology. 


\section{EXECUTIVE SUMMARY}

\section{Purpose and Scope}

The compilation of Metal Waste Form (MWF) immersion test data in this document is part of the effort initiated to qualify the stainless steel-15\% zirconium (SS-15Zr) alloy for repository disposal. The SS-15Zr alloy was developed as part of the waste stream from the Argonne National Laboratory (ANL) electrometallurgical process for spent nuclear fuel. There were four areas of significant relevance concerning MWF performance in a long-term repository setting addressed in the test model. The areas encompassed the study of the effects of (1) the solution aggressiveness [simulated by concentrated J13 solution (CJ13)], (2) high-chloride content of the solution [simulated by 10,000 ppm chloride solution $(10 \mathrm{KCl})$ ], (3) solution $\mathrm{pH}$ [simulated by acidified J13 solution (AJ13)], and (4) the state of the metal surface-polished vs. oxidized on the releases. The simulated J-13 solution was intended to replicate the groundwater in the J-13 well at the Yucca Mountain geologic repository. A fifth area of interest was to determine if the releases were limited by iron saturation of the solution. The data obtained from the entire study will be compared with the data from the High Level Waste Glass (HLWG) form previously qualified for repository disposal.

\section{Methods}

Immersion corrosion tests were initiated on nonradioactive samples of polished and oxidized SS-15Zr-1Nb-1Ru-1Pd-1Rh metal waste form at $90^{\circ} \mathrm{C}$ and ambient temperature $\left(25^{\circ} \mathrm{C}\right)$ in May and October, 2000. The tests were based on Materials Characterization Center Protocol \#1 (MCC-1) (ASTM C 1220), a static leach test procedure initially developed to evaluate glass-based waste forms. The procedure measured selective leaching of elements from the waste form into representative test solutions, and provided chemical durability and corrosion resistance information.

After each sampling interval, the total release of the metal waste form major elements ( $\mathrm{Fe}, \mathrm{Zr}, \mathrm{Cr}$, and $\mathrm{Ni}$ ), the fission product elements ( $\mathrm{Nb}, \mathrm{Pd}, \mathrm{Ru}, \mathrm{Rh}$, and $\mathrm{Mo}$ ) and the minor elements $(\mathrm{Mn}, \mathrm{Cu}, \mathrm{Co}$, and $\mathrm{V})$ was determined from the release to the solution, the release to the walls (obtained from the acid strip wash), and the detected residue. The control data provided useful information regarding the uncertainties in the tests.

Due to contamination problems for $\mathrm{Mo}, \mathrm{Cu}$, and $\mathrm{V}$, and the lack of interest in the low released minor element, $\mathrm{Mn}$, releases of these elements will not be discussed. All elemental release and control blank concentrations were converted to normalized loss.

Comparison of the data with high level waste glass data, a waste form previously qualified for repository disposal, was possible when in this form. 


\section{$\underline{\text { Results and Conclusions }}$}

Even though the MWF samples used in these tests contained no actinides and no Tc, conclusions can be made with respect to the releases of the noble metal fission products and the stainless steel constituents.

- Fe releases are an order of magnitude or higher than the releases of the noble metal fission-product elements in all solutions.

- Releases of noble metal fission products and Cr and Ni in SJ13 and CJ13 solutions at $90^{\circ} \mathrm{C}$ are close to the limits of detection.

- Solution concentration increased the $\mathrm{Zr}$ release. $\mathrm{Zr}$ releases from CJ13 were about a factor of 2 lower than the Fe release. In $\mathrm{CJ} 13, \mathrm{Zr}$ releases from oxidized samples were higher than from polished samples.

- Releases of all elements increased in the $\mathrm{AJ} 13, \mathrm{pH}=2$ solution. Total cumulative releases as a function of time continued to increase for the 308 days of tests unlike the behavior in other test solutions. Tests in solutions with $\mathrm{pH}$ between 2 and 8 are needed to understand the different behavior.

- Except for high chloride solutions, $(10 \mathrm{KCl})$, release rates of stainless steel elements and noble metal fission products from the MWF samples are lower than release rates from HLWG. 


\section{INTRODUCTION}

\section{A. Background}

The June 1999 Metal Waste Form Handbook [1] provided data on the Metal Waste Form

1. Processing,

2. Compositions and Microstructure,

3. Mechanical and Thermophysical Properties, and

4. Corrosion Behavior.

Corrosion behavior studies included vapor hydration tests, galvanic corrosion tests, pulsed-flow immersion tests, static immersion tests, and electrochemical corrosion tests.

The immersion tests were done using deionized water and simulated J-13 well water. Simulated J-13 well water is water similar in composition to water from well J-13, which is located near the Yucca Mountain Repository. The composition of the water in well J13 and the composition of water from nearby wells vary considerably. Table I-1 shows a comparison of the composition of the simulated J-13 well water used in the metal waste form (MWF) tests with one of the many analyses of the water from well J-13 [2]. The main difference between the simulated J-13 solution and the analysis of the water from the $\mathrm{J}-13$ well is the presence of $2.2 \mathrm{mg} / \mathrm{L}$ of fluoride in the $\mathrm{J}-13$ well water that has not been included in the simulated solution. Static immersion tests consisted of immersion of different alloys and slag in deionized water and simulated J-13 well-water at $90^{\circ} \mathrm{C}$ for 90 days or 365-days. No measurable mass loss or gain or corrosion could be determined from these tests.

Table I-1. Comparison of One Representative Composition of J-13 Well Water with the Composition of Simulated J-13 Water Used in Immersion Tests.

\begin{tabular}{|c|c|c|}
\hline Species & $\begin{array}{c}\text { Typical J-13 } \\
\text { water }(\mathrm{mg} / \mathrm{L})\end{array}$ & $\begin{array}{c}\text { Simulated J-13 } \\
\text { water }(\mathrm{mg} / \mathrm{L})\end{array}$ \\
\hline Nitrate, $\mathrm{NO}_{3}{ }^{-}$ & 9.6 & 10.1 \\
\hline Sulfate, $\mathrm{SO}_{4}{ }^{2-}$ & 18.7 & 18 \\
\hline Chloride, $\mathrm{Cl}^{-}$ & 6.9 & 4.31 \\
\hline Fluoride, $\mathrm{F}$ & 2.2 & --- \\
\hline Calcium, $\mathrm{Ca}^{2+}$ & 12.5 & 10.2 \\
\hline Magnesium, $\mathrm{Mg}^{2+}$ & 1.9 & 2.09 \\
\hline Sodium, $\mathrm{Na}^{+}$ & 44 & 50.9 \\
\hline Potassium, $\mathrm{K}^{+}$ & 5.1 & 5.21 \\
\hline Silica, $\mathrm{SiO}_{2}$ & 58 & 33.8 \\
\hline Bicarbonate, $\mathrm{HCO}_{3}{ }^{-}$ & 125 & 109 \\
\hline $\mathrm{pH}$ & 7.6 & 9 \\
\hline
\end{tabular}




\section{Electrochemical Corrosion}

The electrochemical corrosion behavior of metal waste form samples with a range of alloy compositions was measured using the polarization resistance method (also known as linear polarization) based on ASTM G-59 [3]. Polarization resistance is the resistance of a metal or alloy to oxidation during the application of an external potential. The measurement technique and the equations relating the corrosion rate to the polarization resistance of the corroding species are given in the 1999 Metal Waste Form Handbook [1], which contains figures and tables of the corrosion rates determined from polarization resistance measurements on radioactive and nonradioactive samples at $20^{\circ} \mathrm{C}$ in solutions with $\mathrm{pH}=2,4,9$ (simulated $\mathrm{J}-13$ ), and 10 .

Additional polarization resistance measurements on polished nonradioactive samples have been completed at $20^{\circ} \mathrm{C}, 60^{\circ} \mathrm{C}$ and $90^{\circ} \mathrm{C}$. Solutions used in these additional tests and previous tests at $20^{\circ} \mathrm{C}$ are given in Table I-2 in order of decreasing $\mathrm{pH}$. Solutions used in the tests at $60^{\circ} \mathrm{C}$ and $90^{\circ} \mathrm{C}$ are given, respectively, in Tables I-3 and I-4. Compositions of alloys tested at $20^{\circ} \mathrm{C}$ are listed in Table I-5. Alloys listed in Table I-5 in bold print, (ingots SS15ZR17, SS5ZR18, SS20ZR19, and SS15ZR25) were also tested at $60^{\circ} \mathrm{C}$ and $90^{\circ} \mathrm{C}$. More extensive data on the electrochemical corrosion tests using the polarization resistance method are provided in Appendix A.

Table I-2. Typical Composition of $20^{\circ} \mathrm{C}$ Electrochemical Testing Solutions.

\begin{tabular}{|c|c|c|c|c|c|c|c|c|c|c|}
\hline \multirow[b]{2}{*}{ Solution } & \multirow[b]{2}{*}{$\mathrm{pH}$} & \multicolumn{9}{|c|}{ Solution Composition (mg/L or $\mathrm{ppm})$} \\
\hline & & $\mathrm{Na}$ & $\mathrm{K}$ & $\mathrm{Ca}$ & $\mathrm{Mg}$ & $\mathrm{Si}$ & $\mathrm{SO}_{4}^{-2}$ & $\mathrm{Cl}^{-1}$ & $\mathrm{NO}_{3}^{-1}$ & $\mathrm{HCO}_{3}{ }^{-1}$ \\
\hline $\mathrm{pH}=12$ & $\sim 12$ & 396 & 57 & 1.07 & 0.99 & 36.4 & 18.2 & 3.93 & 10.9 & 89 \\
\hline $\mathrm{pH}=10$ & $\sim 10$ & 65.2 & 5.32 & 10.4 & 2.18 & 37.9 & 18 & 4.33 & 9.5 & 88 \\
\hline Sim. J-13 & $\sim 9$ & 50.9 & 5.21 & 10.2 & 2.09 & 33.8 & 18 & 4.31 & 10.1 & 109 \\
\hline Conc. J-13 & $\sim 8.2$ & 5300 & 510 & 6 & 1.9 & 30 & 22 & 727 & 11 & 12700 \\
\hline $10000 \mathrm{ppm} \mathrm{Cl}$ & $\sim 6.3$ & 6270 & - & - & - & - & - & 10000 & - & - \\
\hline $1000 \mathrm{ppm} \mathrm{Cl}$ & $\sim 5.8$ & 607 & - & - & - & - & - & 1000 & - & - \\
\hline $\mathrm{pH}=2$ & $\sim 2$ & 49.1 & 5.1 & 10.9 & 2.12 & 35.1 & 17.8 & 443 & 10.5 & 4.4 \\
\hline
\end{tabular}

Table I-3. Typical Composition of $60^{\circ} \mathrm{C}$ Electrochemical Testing Solution.

\begin{tabular}{|c|c|c|c|c|c|c|c|c|c|c|}
\hline \multirow[b]{2}{*}{ Solution } & \multirow[b]{2}{*}{$\mathrm{pH}$} & \multicolumn{9}{|c|}{ Solution Composition (mg/L or $\mathrm{ppm})$} \\
\hline & & $\mathrm{Na}$ & $\mathrm{K}$ & $\mathrm{Ca}$ & $\mathrm{Mg}$ & $\mathrm{Si}$ & $\mathrm{SO}_{4}^{-2}$ & $\mathrm{Cl}^{-1}$ & $\mathrm{NO}_{3}^{-1}$ & $\mathrm{HCO}_{3}^{-1}$ \\
\hline $\mathrm{pH}=10$ & $\sim 10$ & 65.2 & 5.32 & 10.4 & 2.18 & 37.9 & 18 & 4.33 & 9.5 & 88 \\
\hline Conc. J-13 & $\sim 8.2$ & 5300 & 510 & 6 & 1.9 & 30 & 22 & 727 & 11 & 12700 \\
\hline $1000 \mathrm{ppm} \mathrm{Cl}$ & $\sim 5.8$ & 607 & - & - & - & - & - & 1000 & - & - \\
\hline $10000 \mathrm{ppm} \mathrm{Cl}$ & $\sim 6.3$ & 6270 & - & - & - & - & - & 10000 & - & - \\
\hline $\mathrm{pH}=2$ & 2 & 49.1 & 5.1 & 10.9 & 2.12 & 35.1 & 17.8 & 443 & 10.5 & 4.4 \\
\hline
\end{tabular}


Table I-4. Typical Composition of $90^{\circ} \mathrm{C}$ Electrochemical Testing Solutions.

\begin{tabular}{|c|c|c|c|c|c|c|c|c|c|c|}
\hline \multirow{2}{*}{ Solution } & & \multicolumn{8}{|c|}{ Solution Composition $(\mathrm{mg} / \mathrm{L}$ or $\mathrm{ppm})$} \\
\cline { 3 - 12 } & $\mathrm{pH}$ & $\mathrm{Na}$ & $\mathrm{K}$ & $\mathrm{Ca}$ & $\mathrm{Mg}$ & $\mathrm{Si}$ & $\mathrm{SO}_{4}^{-2}$ & $\mathrm{Cl}^{-1}$ & $\mathrm{NO}_{3}^{-1}$ & $\mathrm{HCO}_{3}{ }^{-1}$ \\
\hline $\mathrm{pH}=10$ & $\sim 10$ & 65.2 & 5.32 & 10.4 & 2.18 & 37.9 & 18 & 4.33 & 9.5 & 88 \\
\hline Sim. J-13 & $\sim 9$ & 50.9 & 5.21 & 10.2 & 2.09 & 33.8 & 18 & 4.31 & 10.1 & 109 \\
\hline Conc. J-13 & $\sim 8.2$ & 5300 & 510 & 6 & 1.9 & 30 & 22 & 727 & 11 & 12700 \\
\hline $10000 \mathrm{ppm} \mathrm{Cl}$ & $\sim 6.3$ & 6270 & - & - & - & - & - & 10000 & - & - \\
\hline $1000 \mathrm{ppm} \mathrm{Cl}$ & $\sim 5.8$ & 607 & - & - & - & - & - & 1000 & - & - \\
\hline $\mathrm{pH}=2$ & $\sim 2$ & 49.1 & 5.1 & 10.9 & 2.12 & 35.1 & 17.8 & 443 & 10.5 & 4.4 \\
\hline
\end{tabular}

Table I-5. Composition, Density, and Equivalent Weight of Alloys Tested by the Polarization Resistance Method. ${ }^{a}$

\begin{tabular}{|c|c|c|}
\hline Ingot & Alloy Description & Density $(\mathrm{g} / \mathrm{mL})$ \\
\hline SS316 & SS316 & 8 \\
\hline SS15ZR12 & SS-15Zr-2Ru-1Pd-1Ag & 7.8 \\
\hline SS15ZR14 & SS-15Zr (annealed) & 7.65 \\
\hline SS15ZR15 & SS-15Zr-2Ru-1Nb-0.5Pd-0.5Ag & 7.8 \\
\hline SS15ZR17 & SS-15Zr (as-cast) & 7.65 \\
\hline SS05ZR18 & SS-5Zr-2Nb-1Ru-1Pd & 7.8 \\
\hline SS20ZR19 & SS-20Zr-2Nb-1Ru-1Pd & 7.7 \\
\hline SS05ZR20 & SS-5Zr-1Nb-0.5Ru-0.5Pd & 7.8 \\
\hline SS05ZR21 & $\mathrm{SS}-5 \mathrm{Zr}$ & 7.9 \\
\hline SS15ZR23 & $\mathrm{SS}-15 \mathrm{Zr}\left(\right.$ cooled at $\left.10^{\circ} \mathrm{C} / \mathrm{min}\right)$ & 7.65 \\
\hline SS15ZR24 & $\mathrm{SS}-15 \mathrm{Zr}\left(\right.$ cooled at $\left.5^{\circ} \mathrm{C} / \mathrm{min}\right)$ & 7.65 \\
\hline SS15ZR25 & SS-15Zr-1Nb-1Ru-1Pd-1Rh & 7.8 \\
\hline SS15ZR26 & SS-15Zr-1Nb-1Ru-1Pd-1Rh & 7.8 \\
\hline SS15ZR27 & $\mathrm{SS}-15 \mathrm{Zr}\left(\right.$ cooled at $\left.1^{\circ} \mathrm{C} / \mathrm{min}\right)$ & 7.65 \\
\hline SS00ZR28 & SS-2Nb-1Ru-1Pd-1Ag & 8 \\
\hline $\mathrm{Zr}$ & $\mathrm{Zr}$ & 6.5 \\
\hline ZR08SS02 & Zr-8SS-1Ag-1Nb-1Pd-1Ru & 6.7 \\
\hline ZR08SS04 & $\mathrm{Zr}-8 \mathrm{SS}$ & 6.6 \\
\hline Copper & Pure Copper & 8.9 \\
\hline $\mathrm{C}-22$ & C-22 & 8.7 \\
\hline AISI 1018 & Mild Steel & 7.9 \\
\hline
\end{tabular}

${ }^{\mathrm{a}}$ Bold Print Indicates Tests at 60 and $90^{\circ} \mathrm{C}$.

Corrosion rates of the alloys listed in Table I-5 determined at $20^{\circ} \mathrm{C}$ in $\mathrm{pH}=12$ solution, concentrated J-13 solution and the high chloride solutions $\left(1,000 \mathrm{ppm} \mathrm{Cl}^{-}\right.$and 10,000 ppm $\mathrm{Cl}^{-}$) using the polarization resistance method are shown in Figures I-1 through I-4 as a function of alloy. Three measurements were made on each alloy except for the $\mathrm{pH}=12$ solution. Results of each measurement, the average of three measurements, and the standard deviations (when appropriate) are given in Tables A-3 through A-6 of Appendix A. Although these data show considerable scatter, they are consistent with the previously reported observations. For $\mathrm{pH}=12$, corrosion rates for the metal waste form samples are 
above and below that of stainless steel and most are higher than the rate for Alloy C-22. In concentrated $\mathrm{J}-13$ solution, $\mathrm{pH} \sim 8.2$, the corrosion rates of the metal waste form alloys are comparable with the rate for 316 stainless steel and Alloy C22. In the high chloride tests $\left(1,000 \mathrm{ppm} \mathrm{Cl}^{-}\right.$and $\left.10,000 \mathrm{ppm} \mathrm{Cl}^{-}\right)$, the metal waste form alloys have better corrosion resistance than stainless steel and are comparable to Alloy C22.

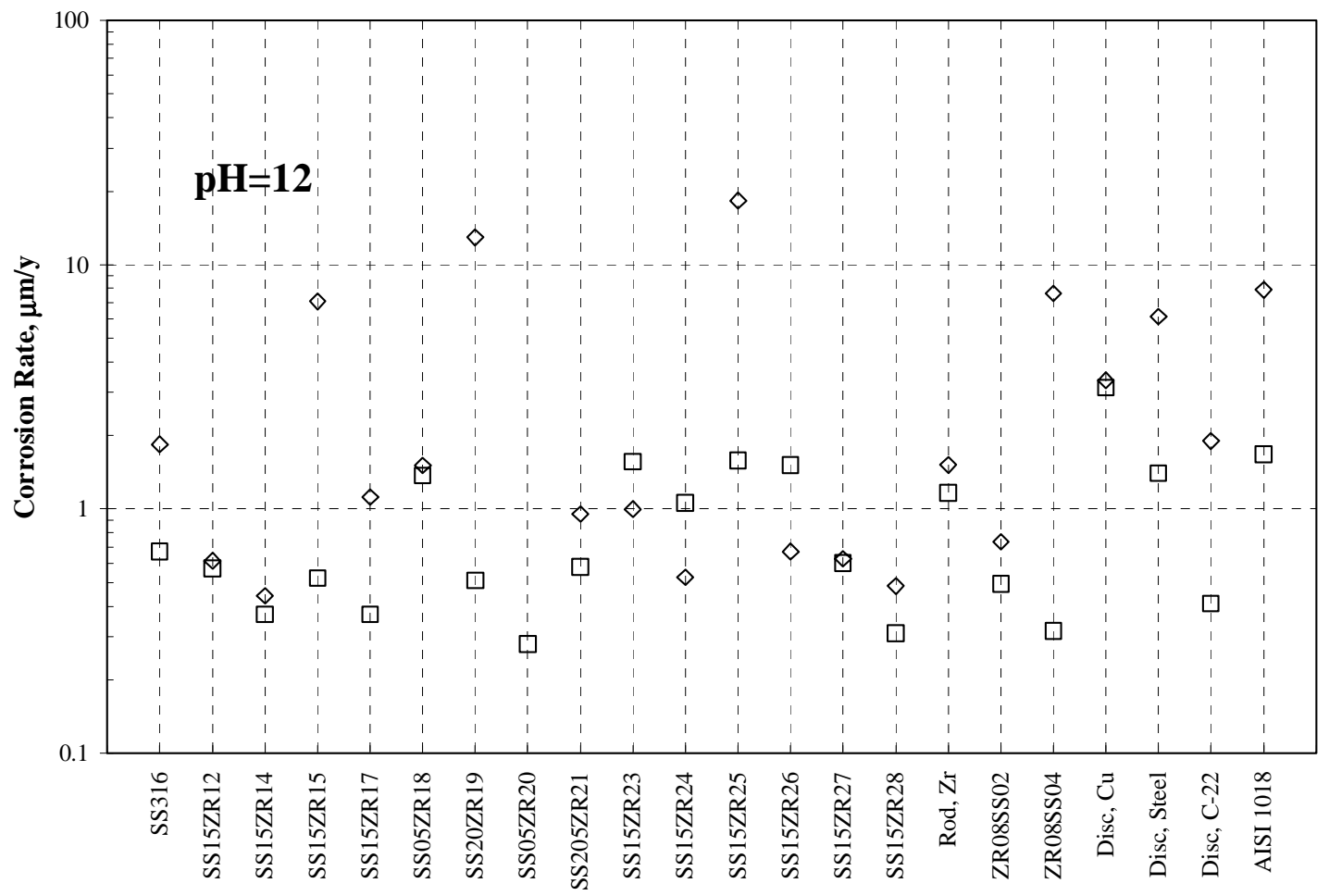

Figure I-1. Corrosion Rates Measured in $\mathrm{pH}=12$ Solution at $20^{\circ} \mathrm{C}$. 


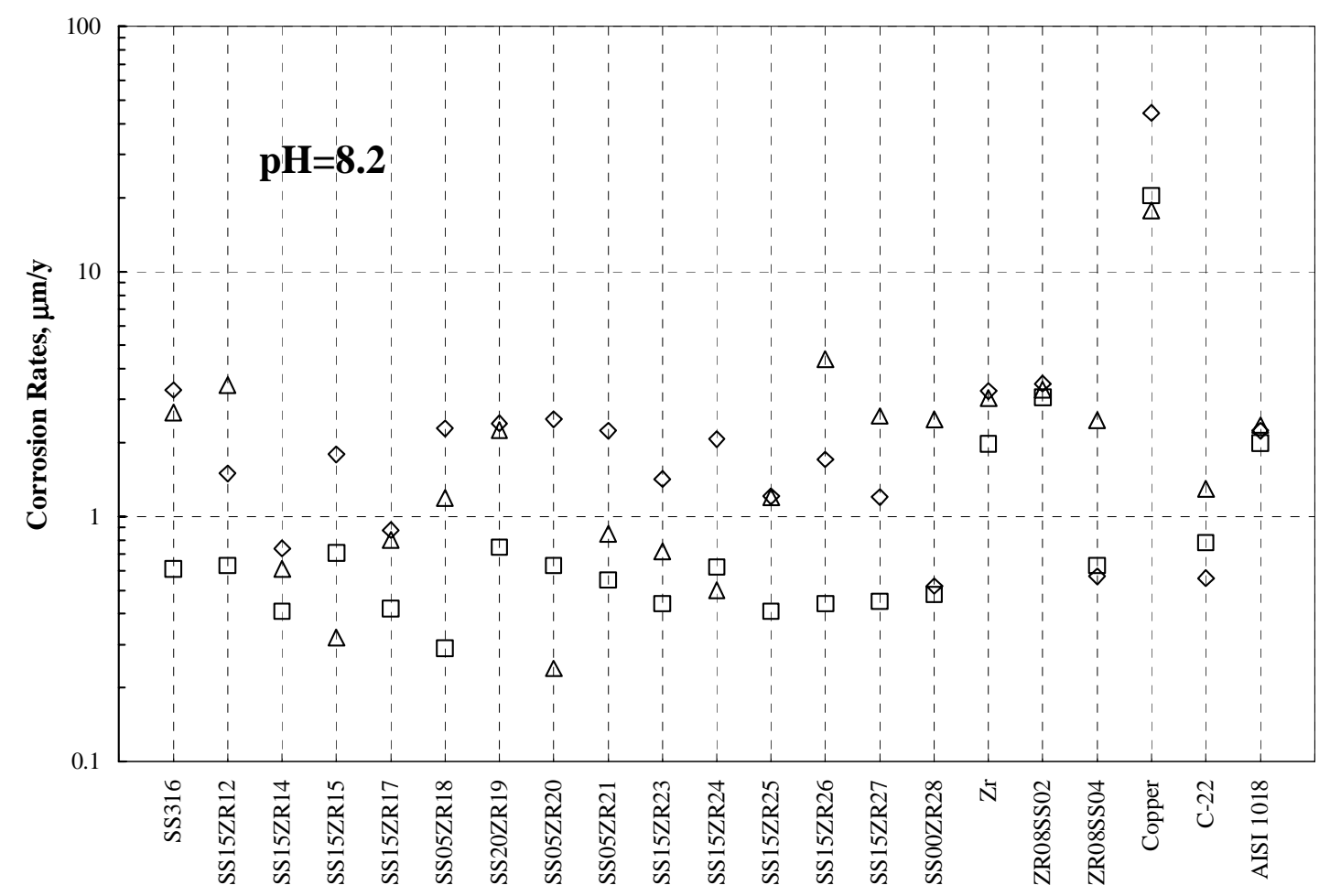

Figure I-2. Corrosion Rates Measured in Concentrated J-13 (pH=8.2) Solution at $20^{\circ} \mathrm{C}$.

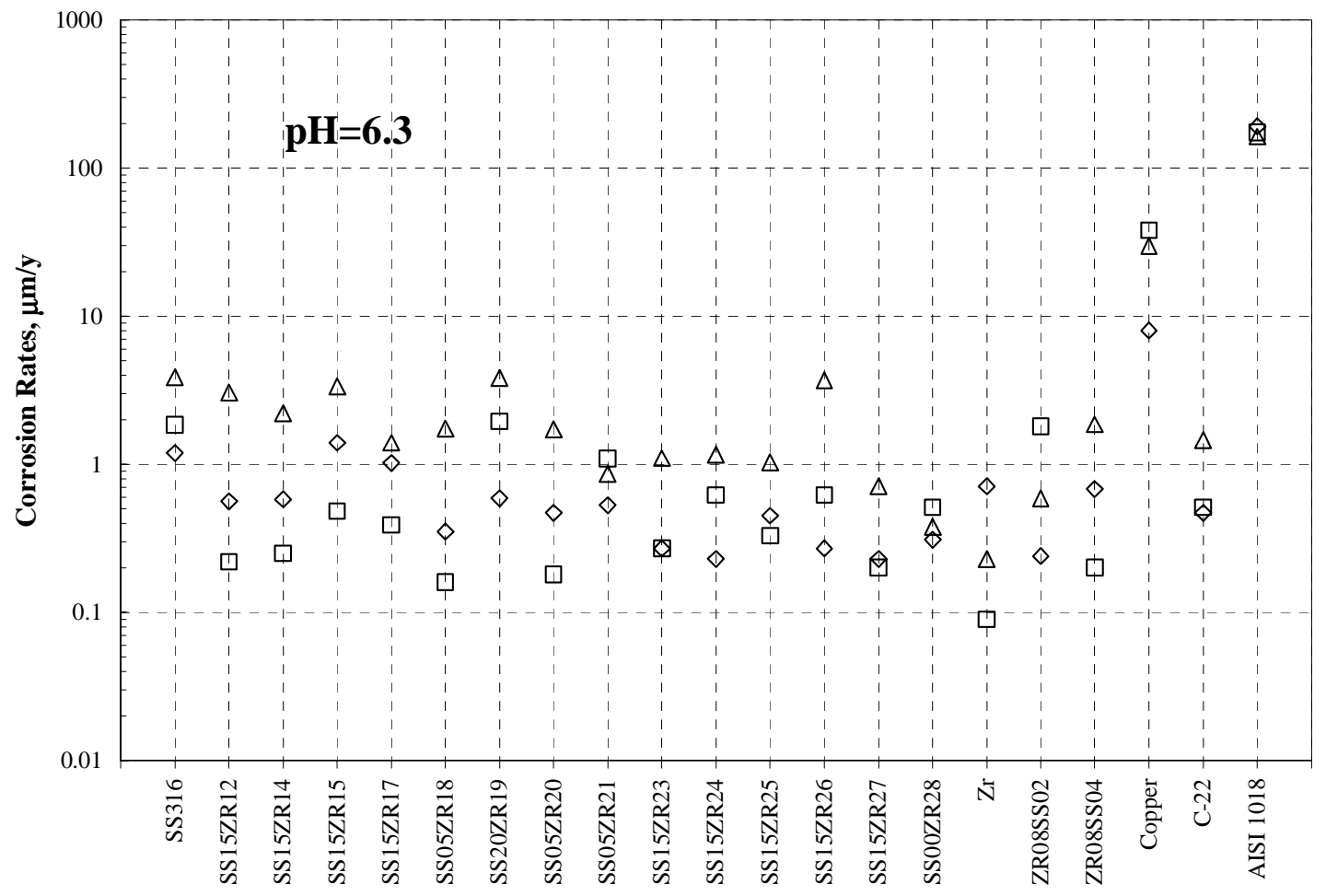

Figure I-3. Corrosion Rates Measured in 10,000 ppm Chloride (pH=6.3) Solution at $20^{\circ} \mathrm{C}$. 


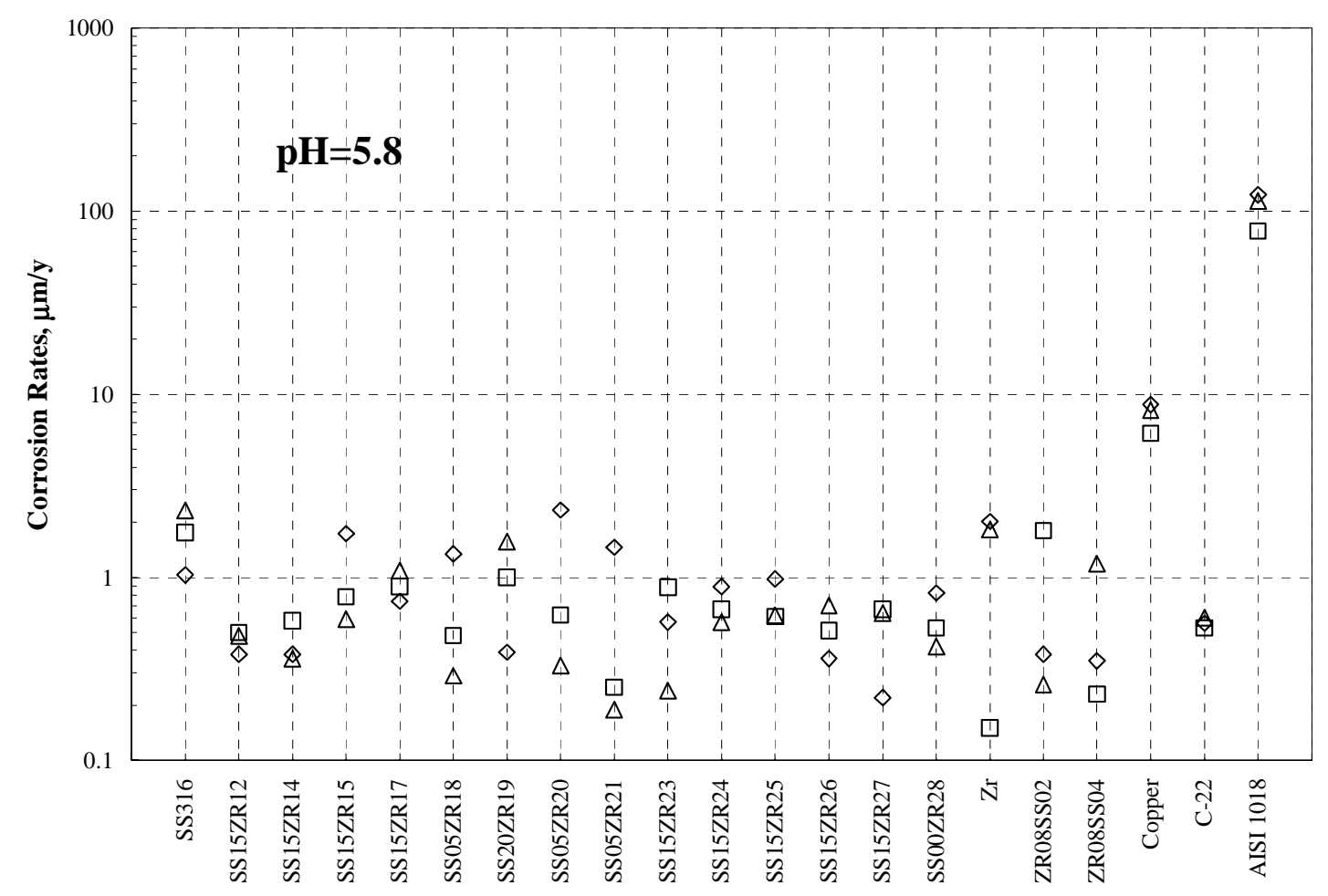

Figure I-4. Corrosion Rates Measured in 1,000 ppm Chloride $(\mathrm{pH}=5.8)$ Solution at $20^{\circ} \mathrm{C}$.

Results of polarization resistance measurements at $60^{\circ} \mathrm{C}$ and $90^{\circ} \mathrm{C}$ on 316 stainless steel and four metal waste form alloys are shown in Figures I-5 through I-15. The data graphed in these figures, the averages from three measurements, and the standard deviations are given in Appendix A: Tables A-7 through A-12 for $60^{\circ} \mathrm{C}$ tests and Tables A-13 through A-19 for $90^{\circ} \mathrm{C}$ tests. Corrosion results for metal waste form alloys at both $60^{\circ} \mathrm{C}$ and $90^{\circ} \mathrm{C}$ are similar to results for 316 stainless steel. In some cases, the metal waste form alloys give higher corrosion rates than those for 316 stainless steel. Corrosion rate data at 60 and $90^{\circ} \mathrm{C}$ are above those given from analysis of 304 and 316 stainless steel corrosion data [4]. The scatter in the data is sufficient that no obvious difference is discernable between the different compositions of the metal waste form alloys. 


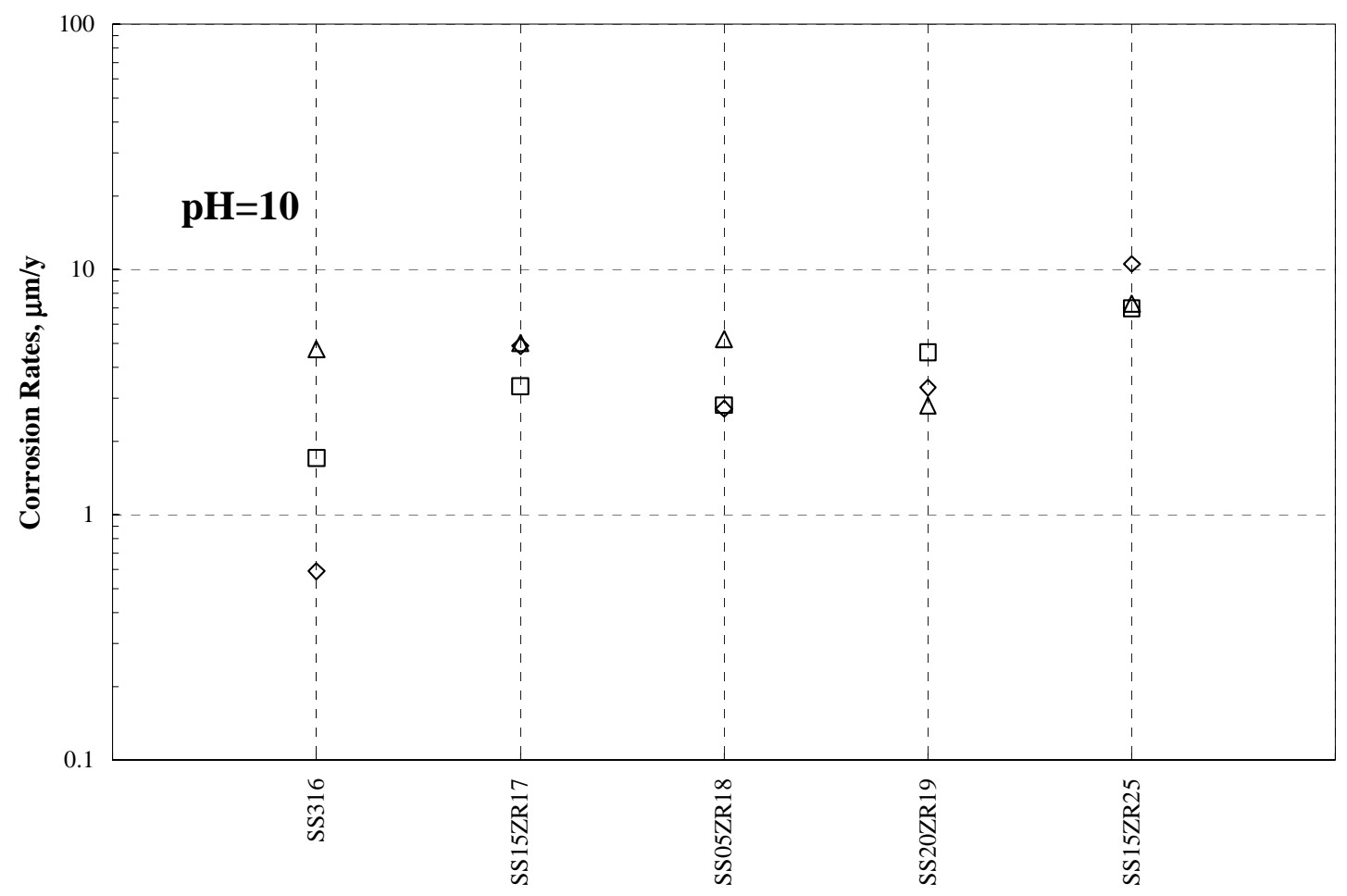

Figure I-5. Corrosion Rates Measured in $\mathrm{pH}=10$ Solution at $60^{\circ} \mathrm{C}$.

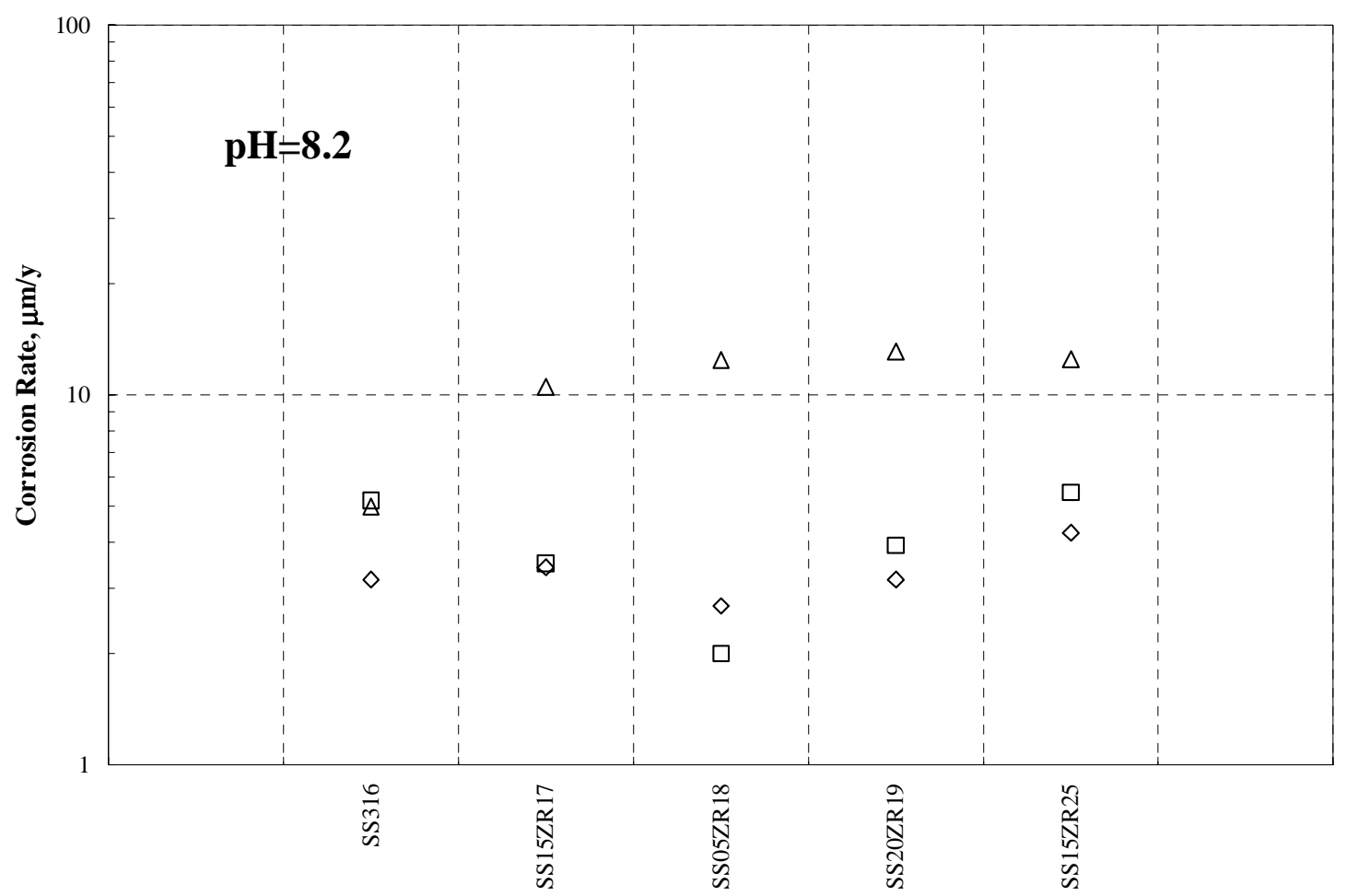

Figure I-6. Corrosion Rates Measured in Concentrated J-13 (pH=8.2) Solution at $60^{\circ} \mathrm{C}$. 


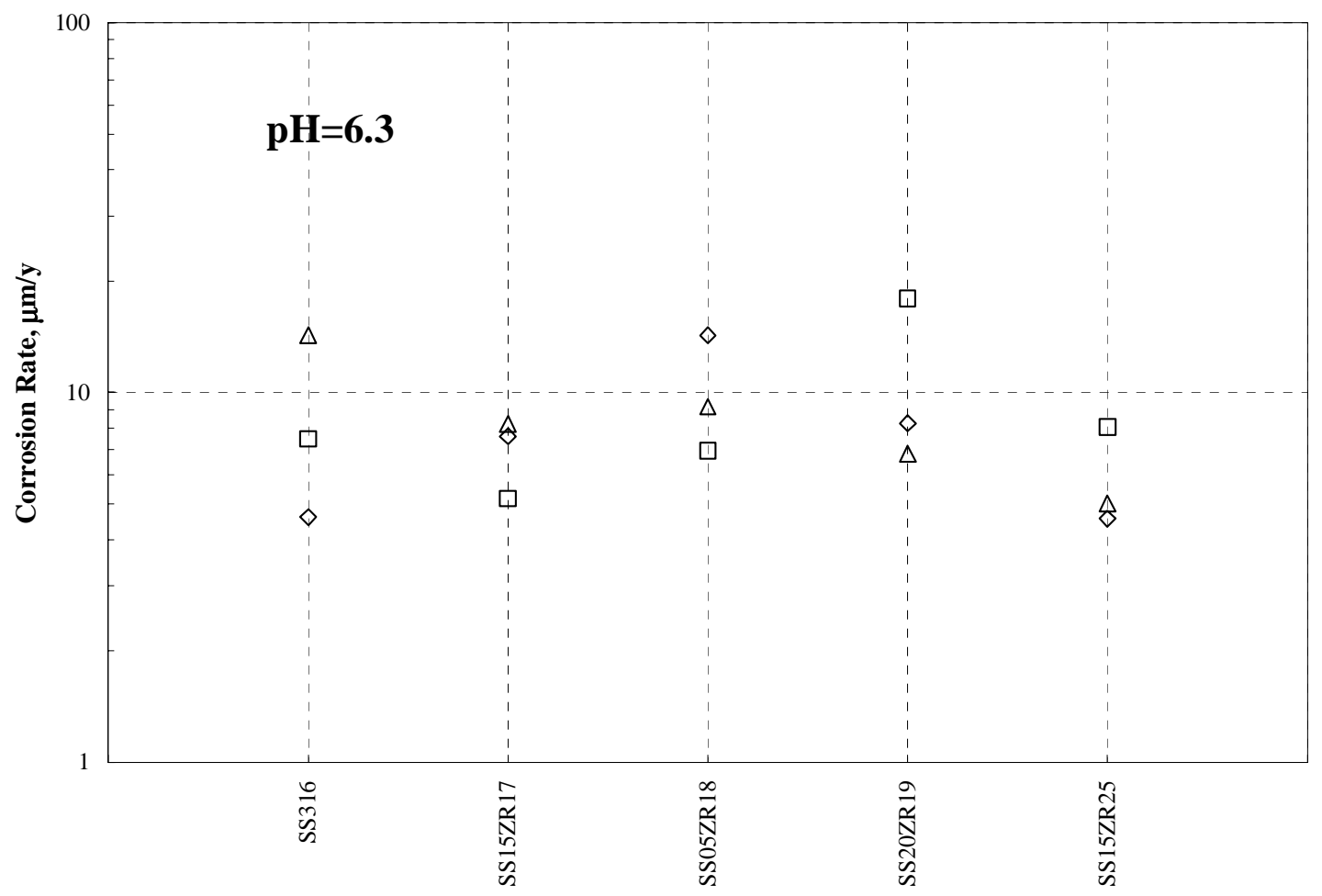

Figure I-7. Corrosion Rates Measured in 10,000 ppm Chloride (pH=6.3) Solution at $60^{\circ} \mathrm{C}$.

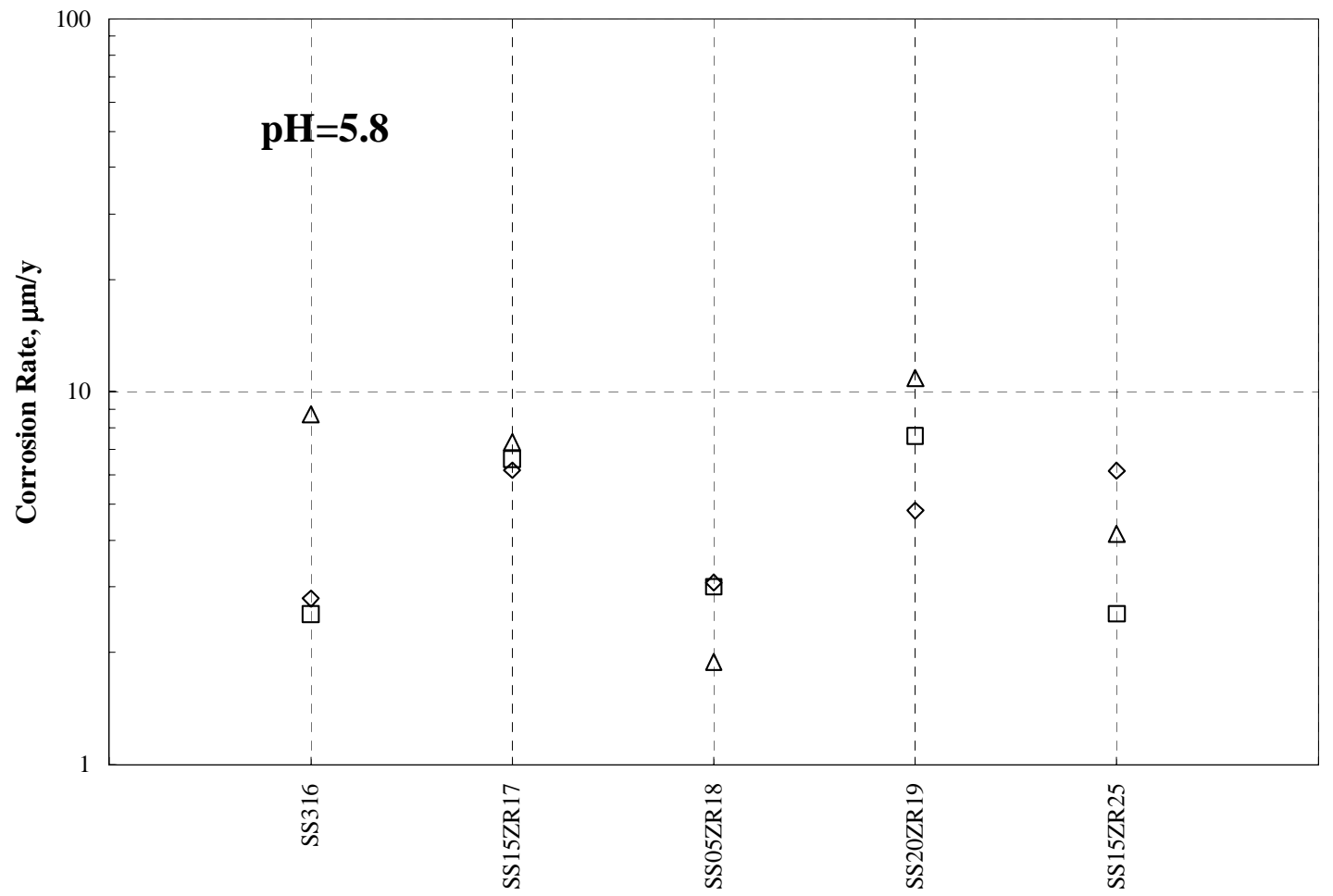

Figure I-8. Corrosion Rates Measured in 1,000 ppm Chloride (pH=5.8) Solution at $60^{\circ} \mathrm{C}$. 


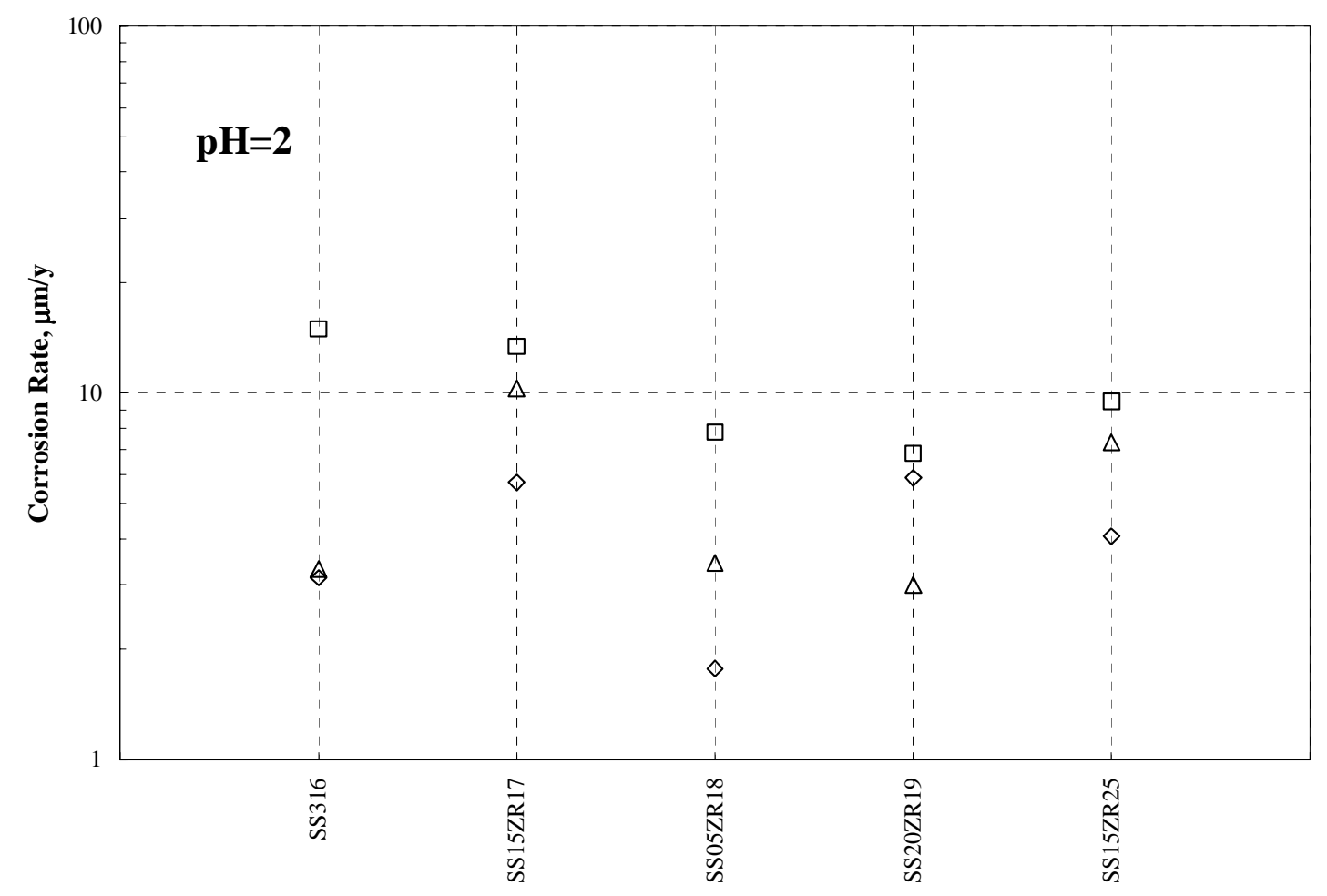

Figure I-9. Corrosion Rates Measured in $\mathrm{pH}=2$ Solution at $60^{\circ} \mathrm{C}$.

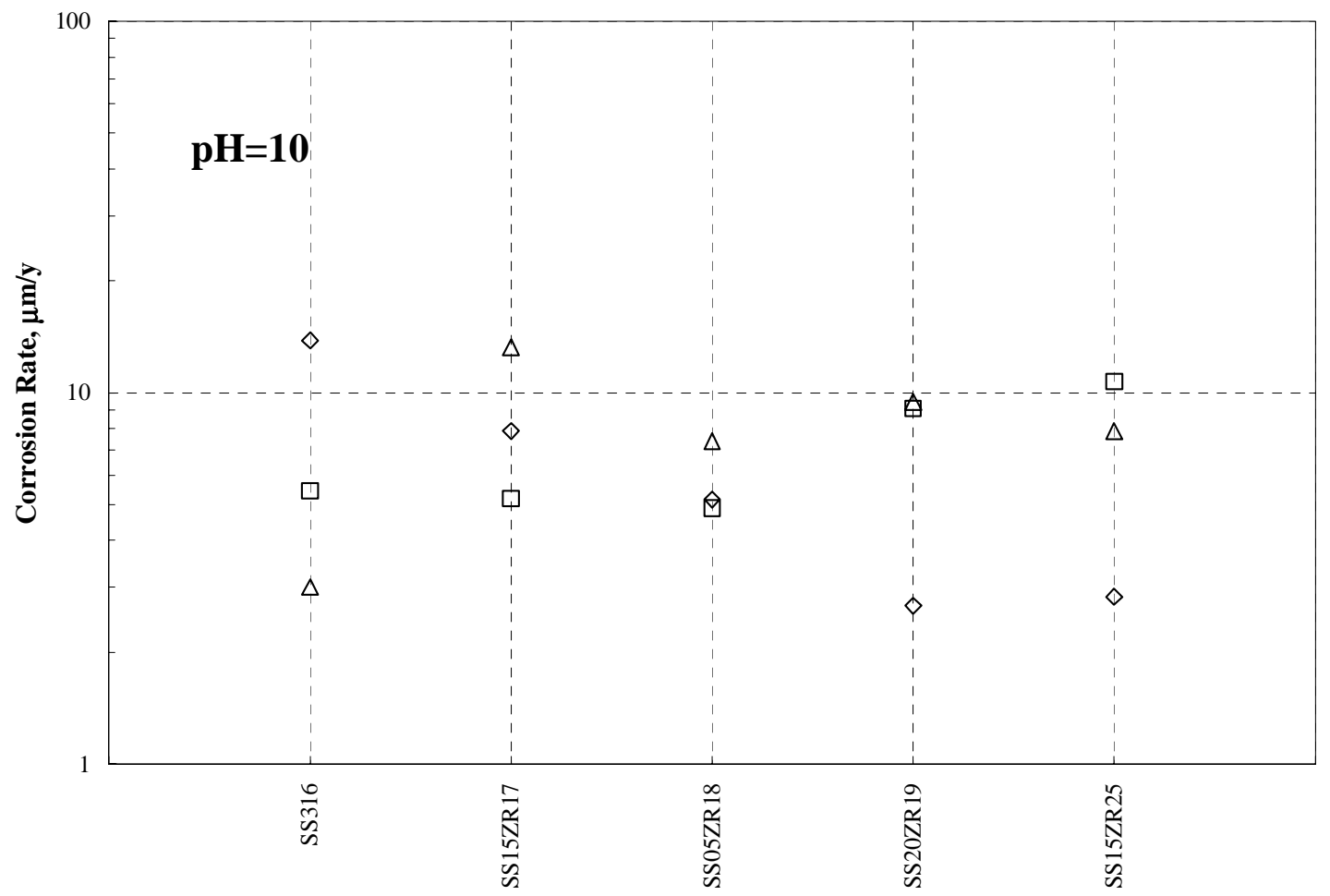

Figure I-10. Corrosion Rates Measured in $\mathrm{pH}=10$ Solution at $90^{\circ} \mathrm{C}$. 


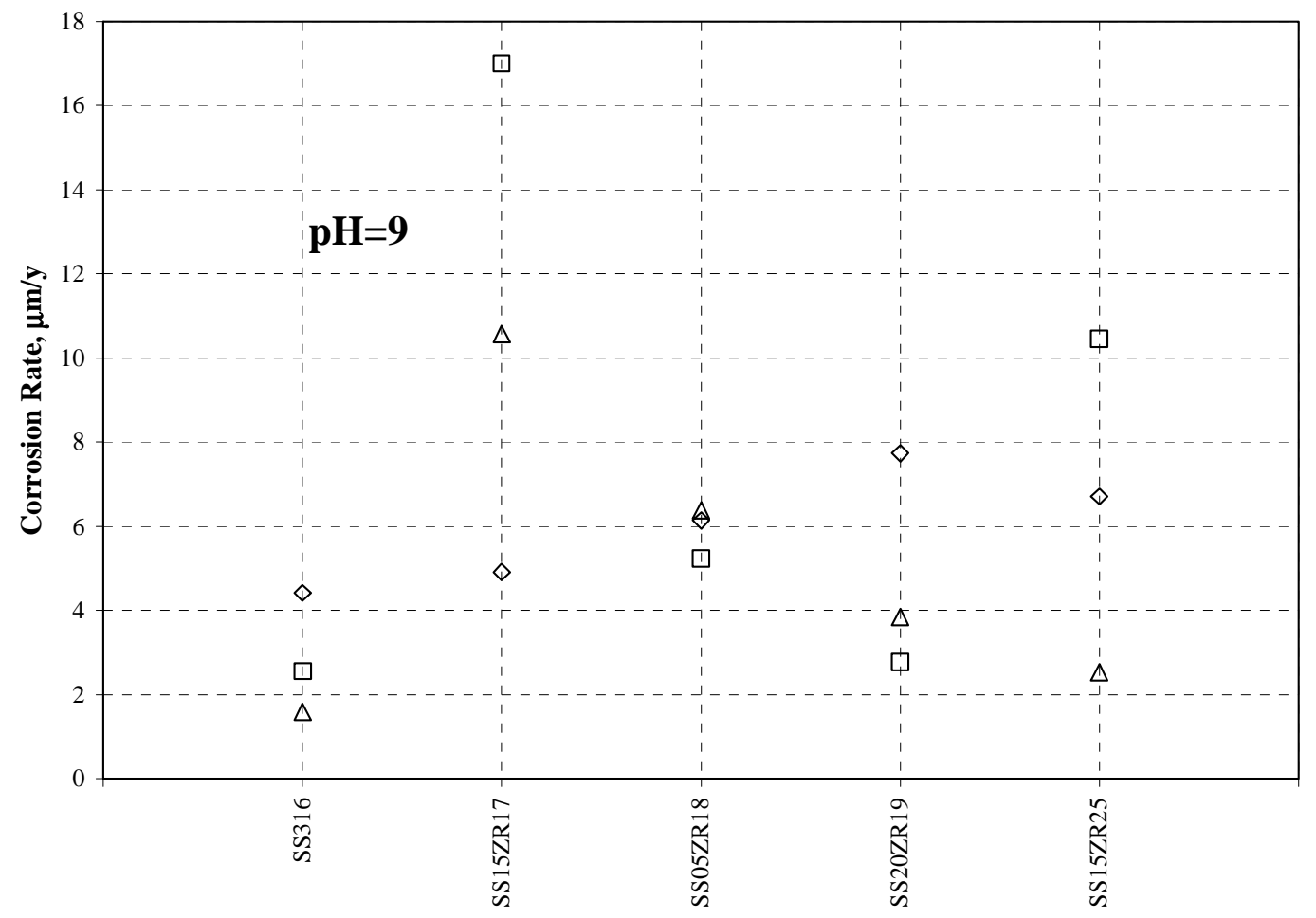

Figure I-11. Corrosion Rates Measured in $\mathrm{SJ13}(\mathrm{pH}=9)$ Solution at $90^{\circ} \mathrm{C}$.

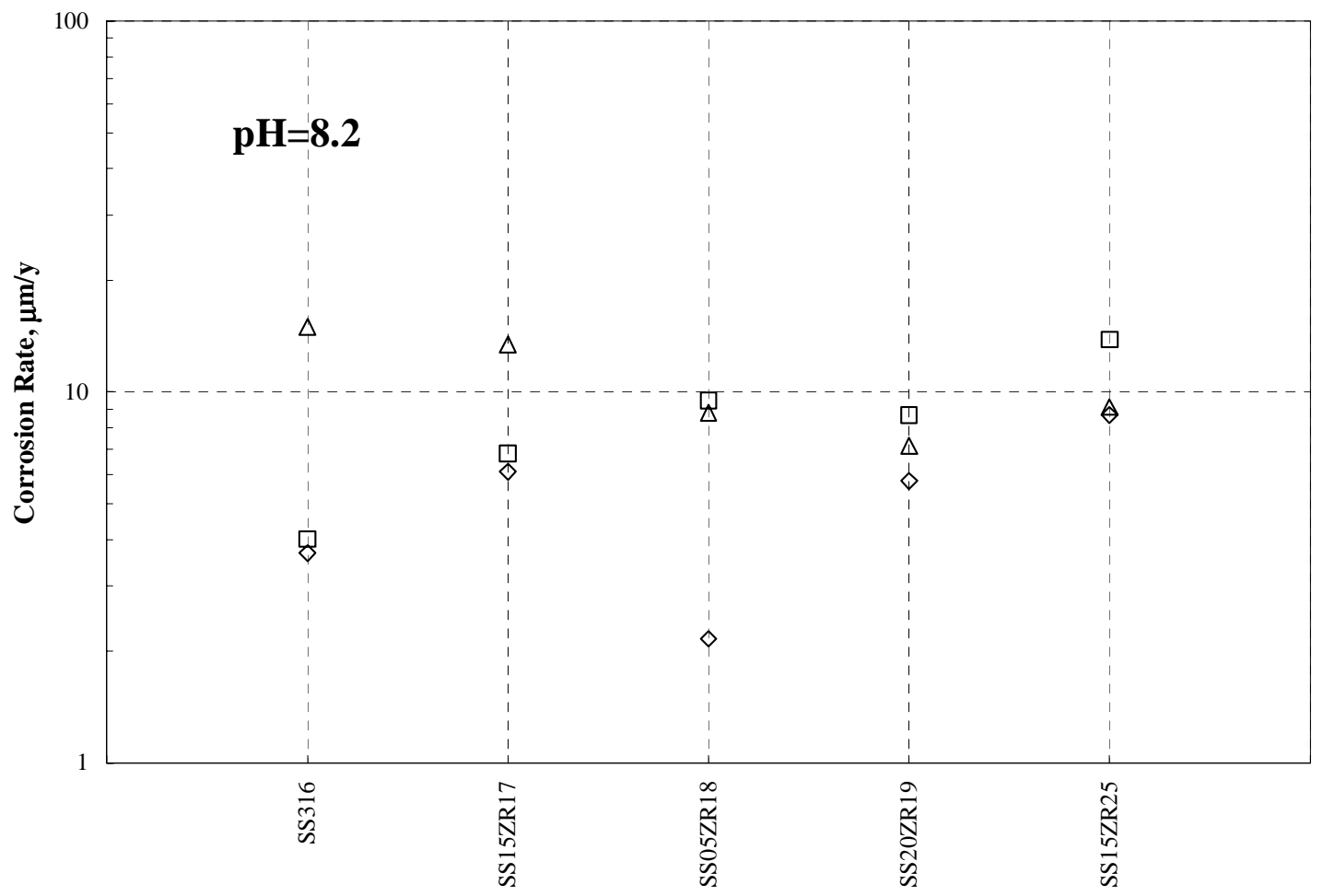

Figure I-12. Corrosion Rates Measured in $\mathrm{CJ13}(\mathrm{pH}=8.2)$ Solution at $90^{\circ} \mathrm{C}$. 


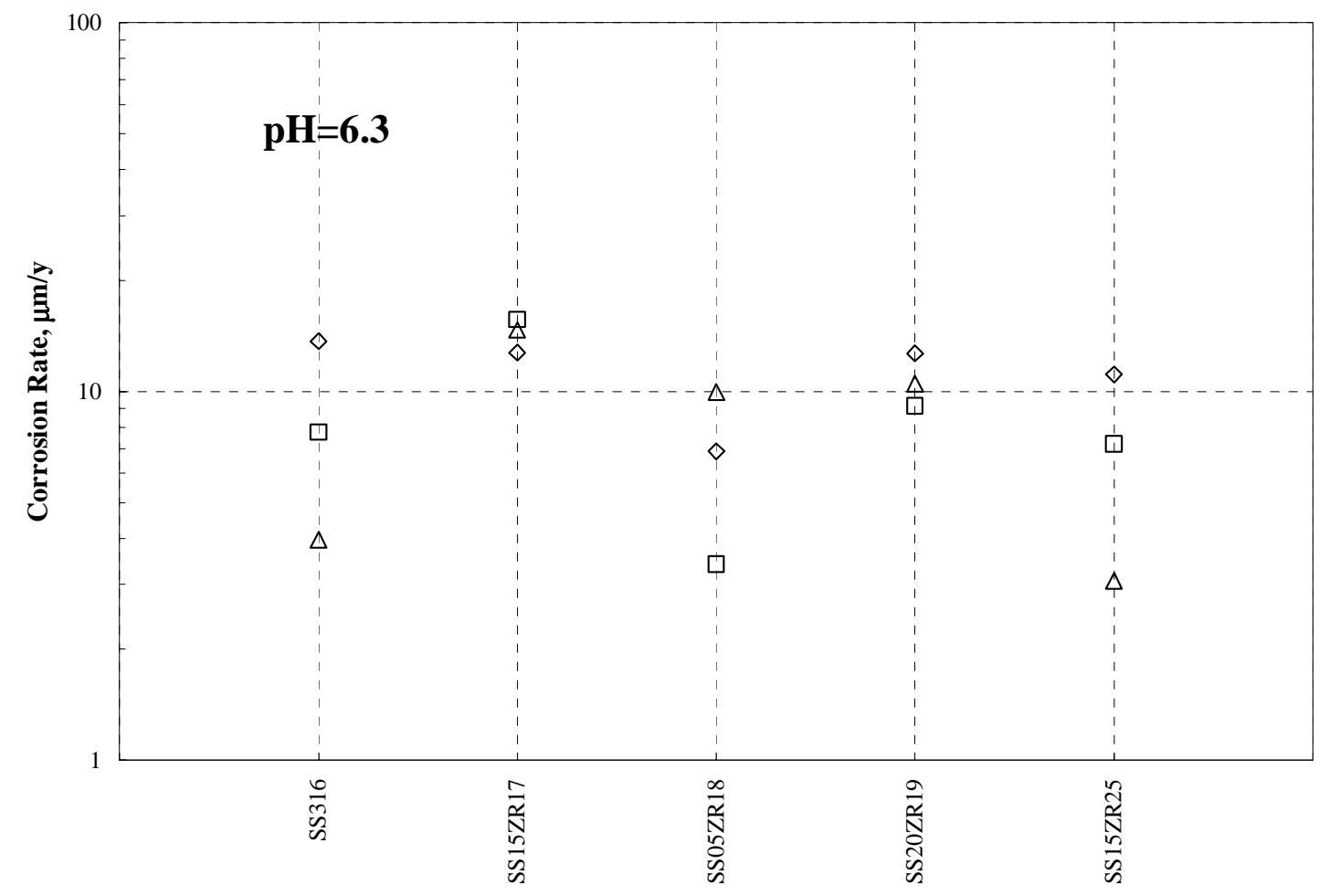

Figure I-13. Corrosion Rates Measured in 10,000 ppm Chloride (pH=6.3) Solution at $90^{\circ} \mathrm{C}$.

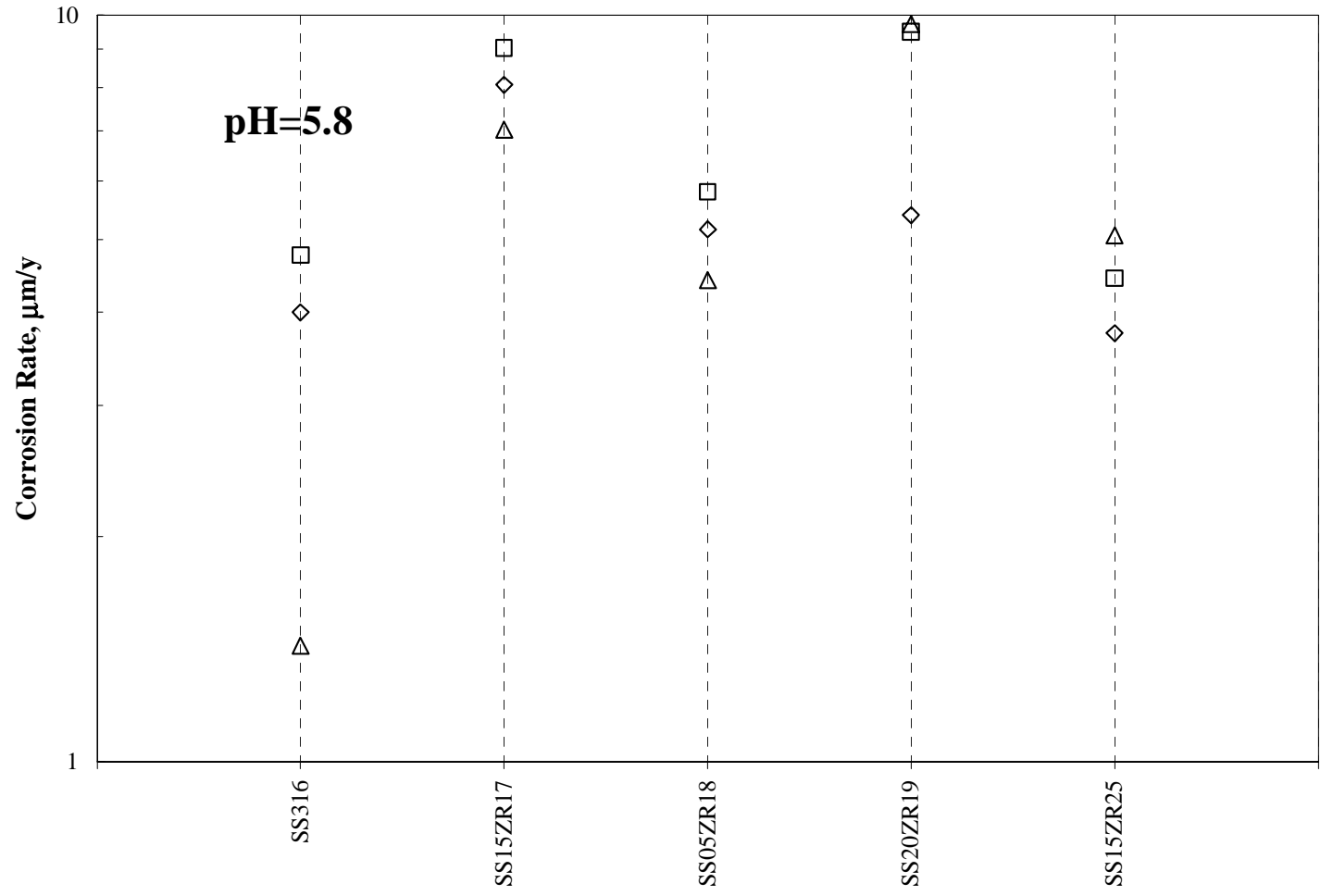

Figure I-14. Corrosion Rates Measured in $1,000 \mathrm{ppm}$ Chloride (pH=5.8) Solution at $90^{\circ} \mathrm{C}$. 


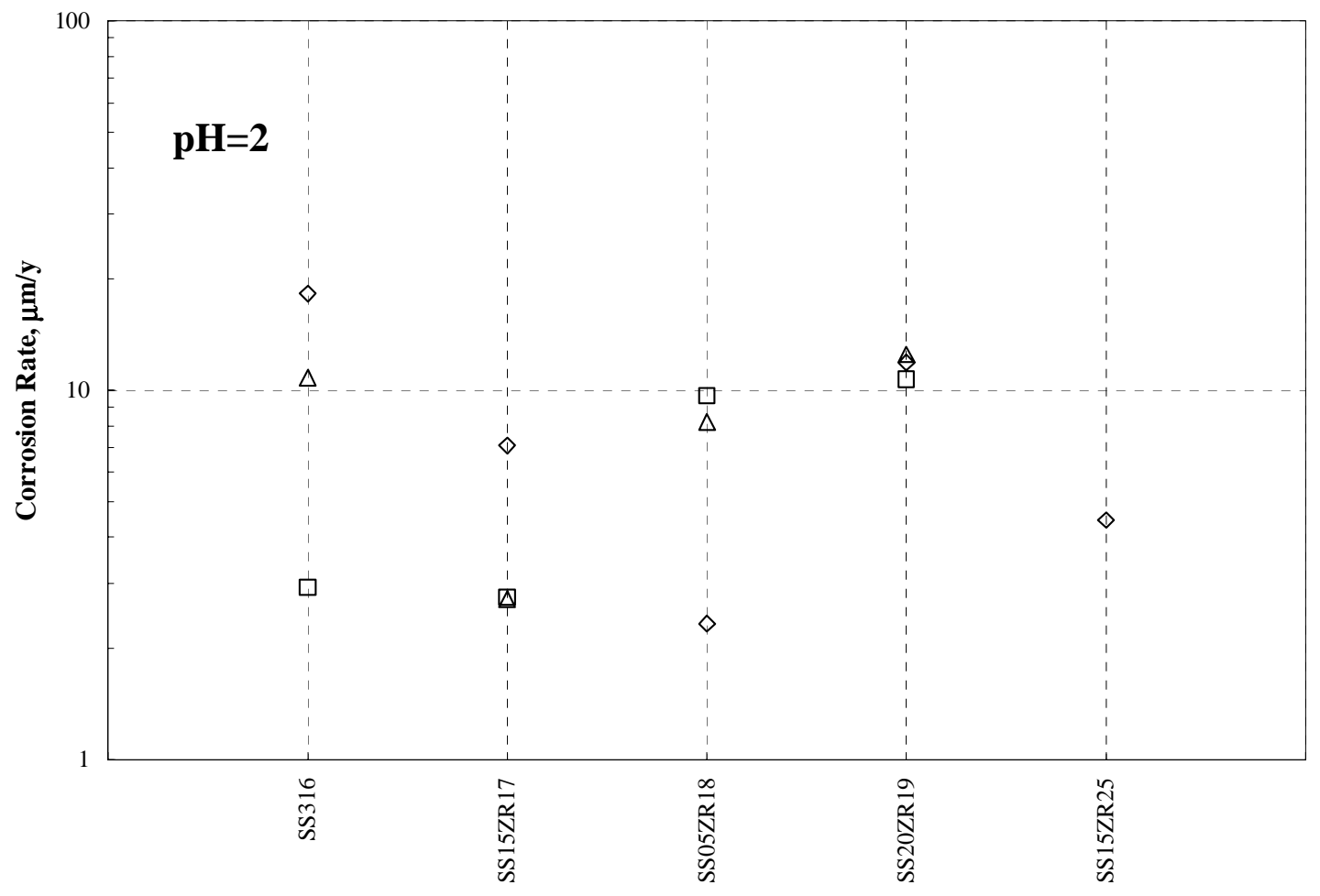

Figure I-15. Corrosion Rates Measured in $\mathrm{pH}=2$ Solution at $90^{\circ} \mathrm{C}$.

Comparisons of the average corrosion rates as a function of temperature for 20,60 , and $90^{\circ} \mathrm{C}$ are shown in Figures I-16 through I-20 for each solution. In these figures, the standard deviations $(1 \sigma)$ have been included for the $60^{\circ} \mathrm{C}$ data to indicate the extent of data scatter. Standard deviations for $20^{\circ} \mathrm{C}$ and $90^{\circ} \mathrm{C}$ have not been included in the figures because they are so large that these standard deviations intersect. The average values shown in these graphs with the standard deviations for each temperature are tabulated in Appendix A Tables A-20 through A-24. Although for most $\mathrm{pH}$ values and most metal waste form alloy samples, the average corrosion rate increases with temperature, this is not true for all cases. For example, Figure I-20 for $\mathrm{pH}=2$ shows this expected behavior only for the SS20ZR19 and 316 stainless steel. This departure for the average corrosion rate from the expected trend of increase in corrosion with temperature may arise from the large scatter in the data, which in some cases is as high as $50 \%$. The source of the large scatter in the data is not known. A factor of two uncertainty has been introduced by assuming the Tafel slopes to be 0.5 volts. The polarization current uncertainty arising from the Tafel slope uncertainty and data scatter is a factor of four. Other sources of error associated with using the polarization method to determine corrosion rate have been reported by Mansfeld [5]. 


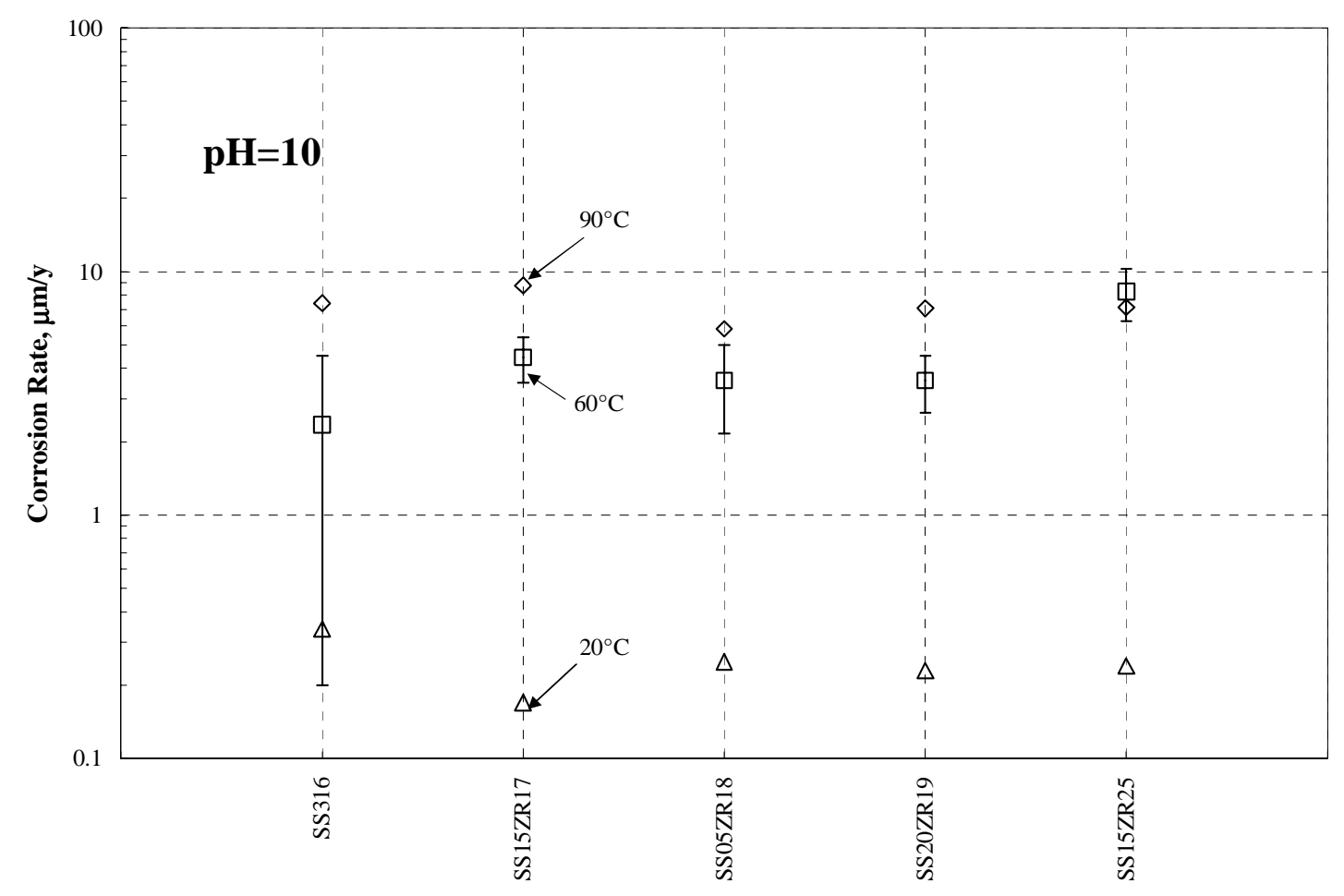

Figure I-16. Average Corrosion Rates Measured in pH=10 Solution.

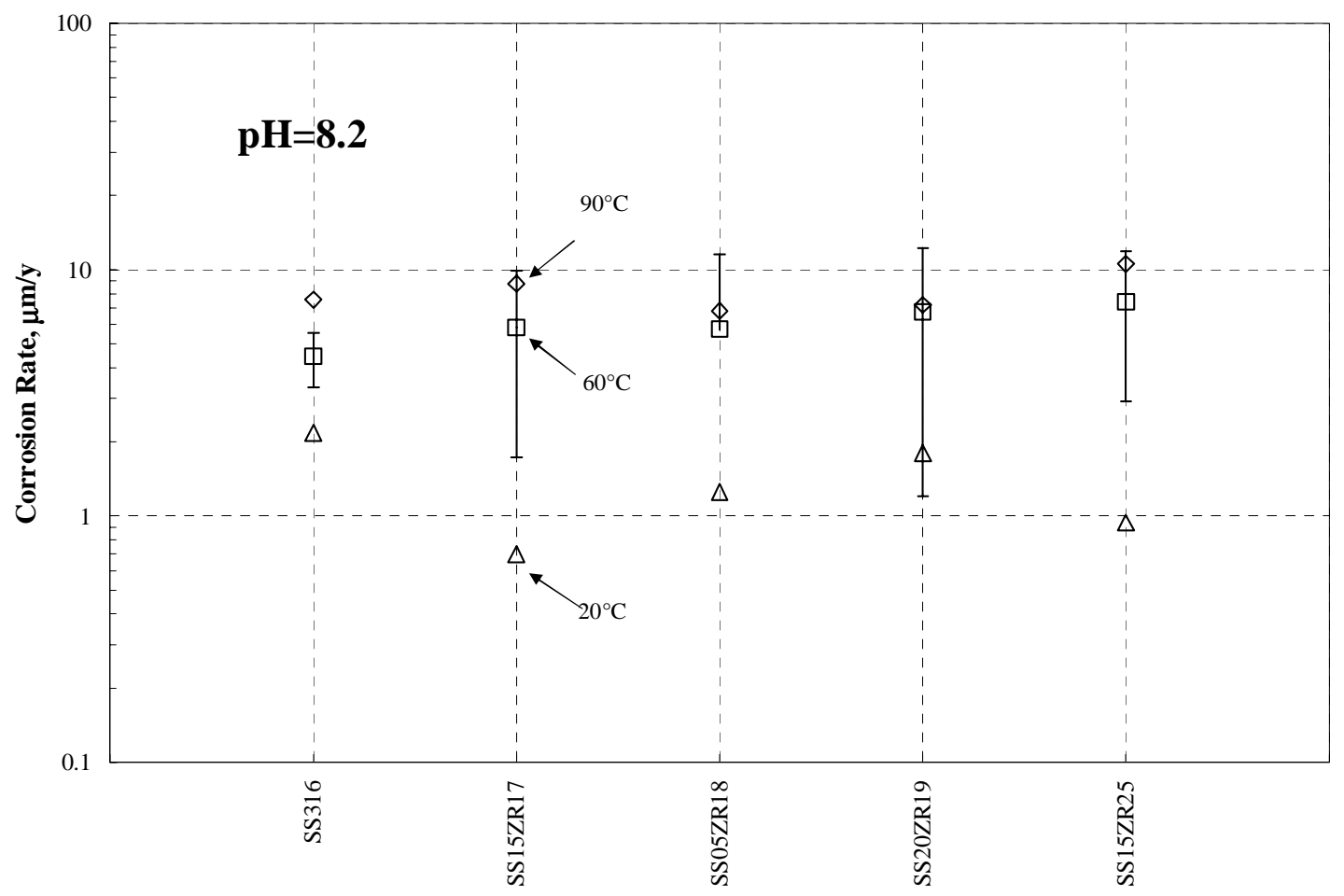

Figure I-17. Average Corrosion Rates Measured in Concentrated J-13 (pH=8.2) Solution. 


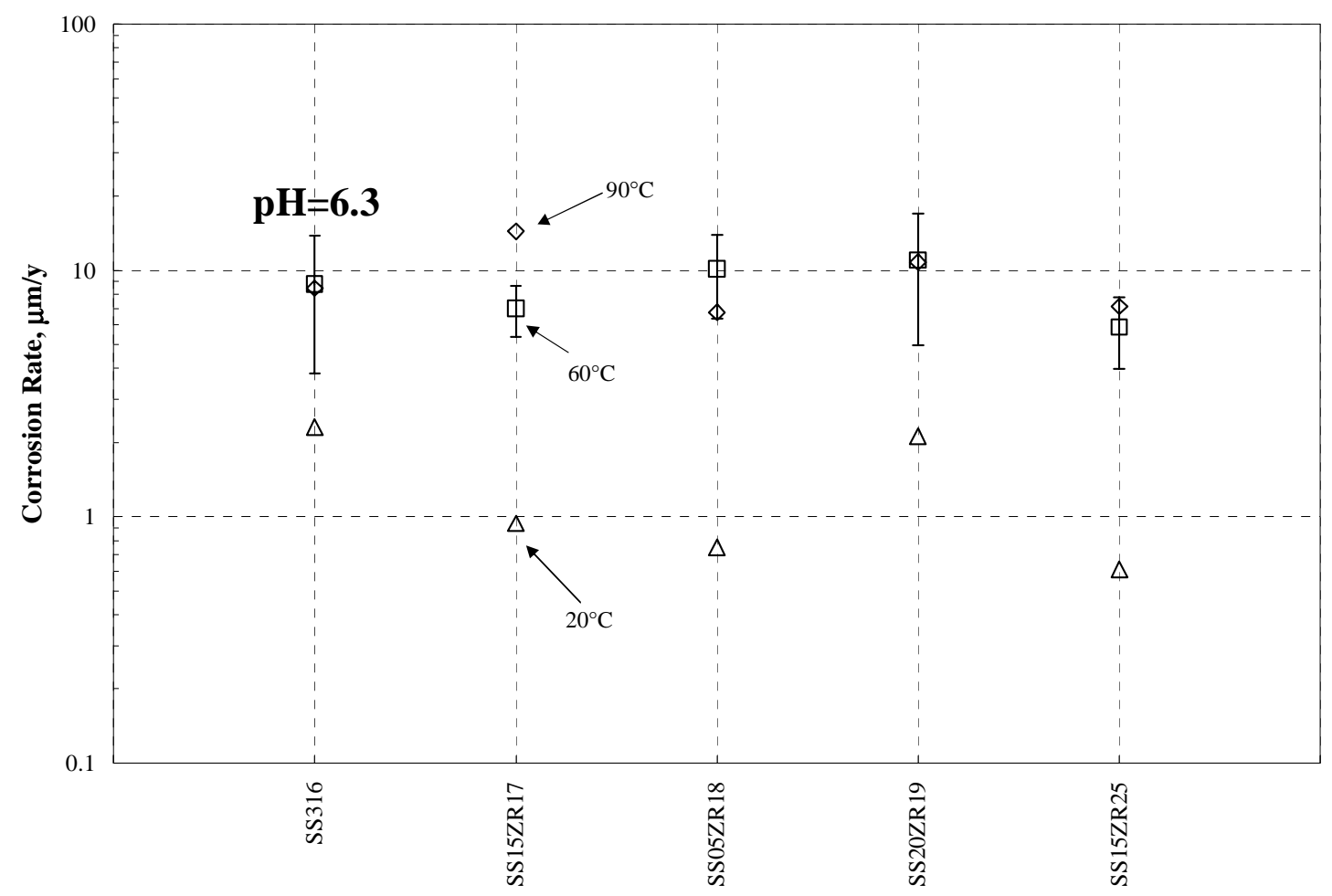

Figure I-18. Average Corrosion Rates Measured in 10,000 ppm Chloride (pH=6.3) Solution.

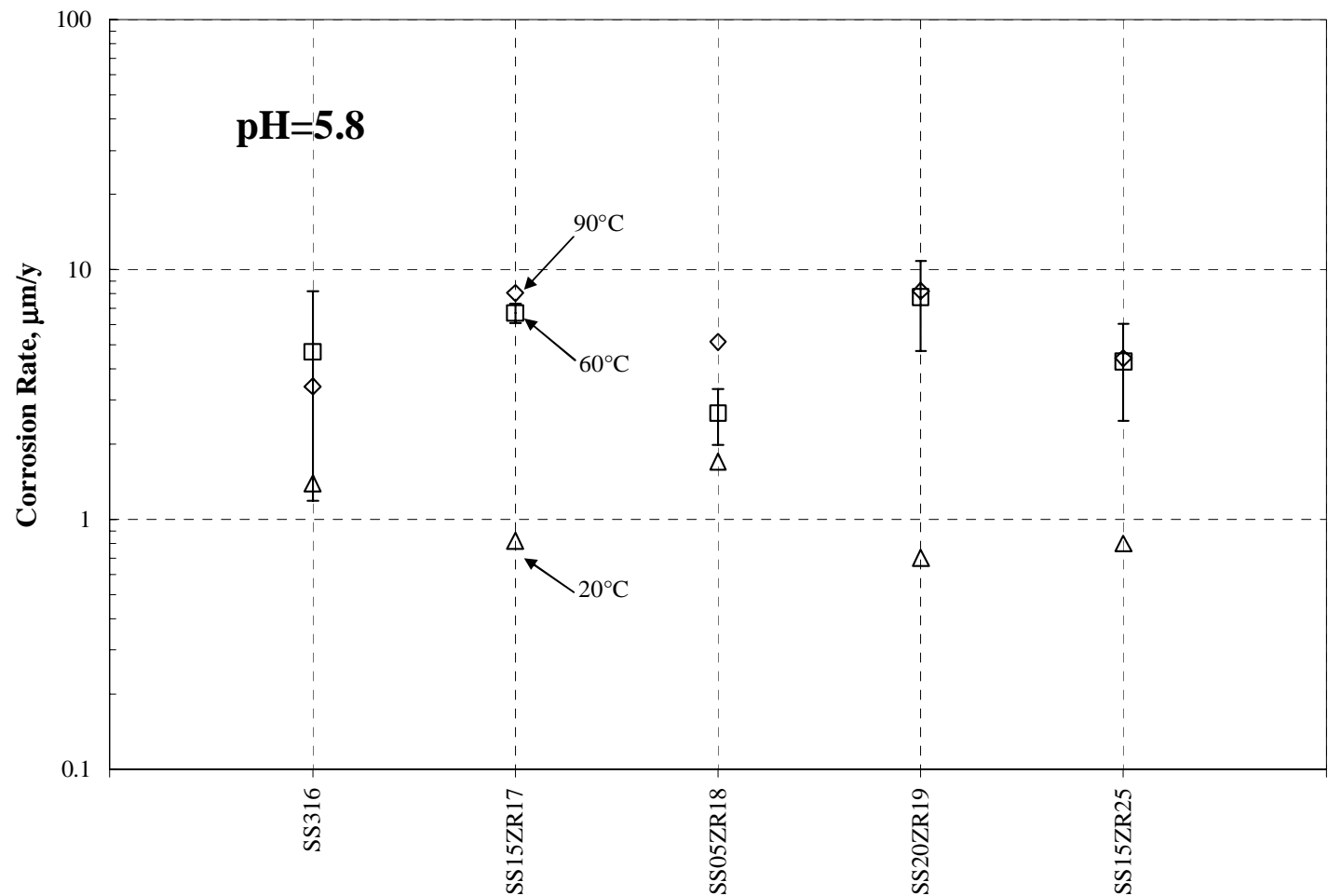

Figure I-19. Average Corrosion Rates Measured in 1,000 ppm Chloride (pH=5.8) Solution. 


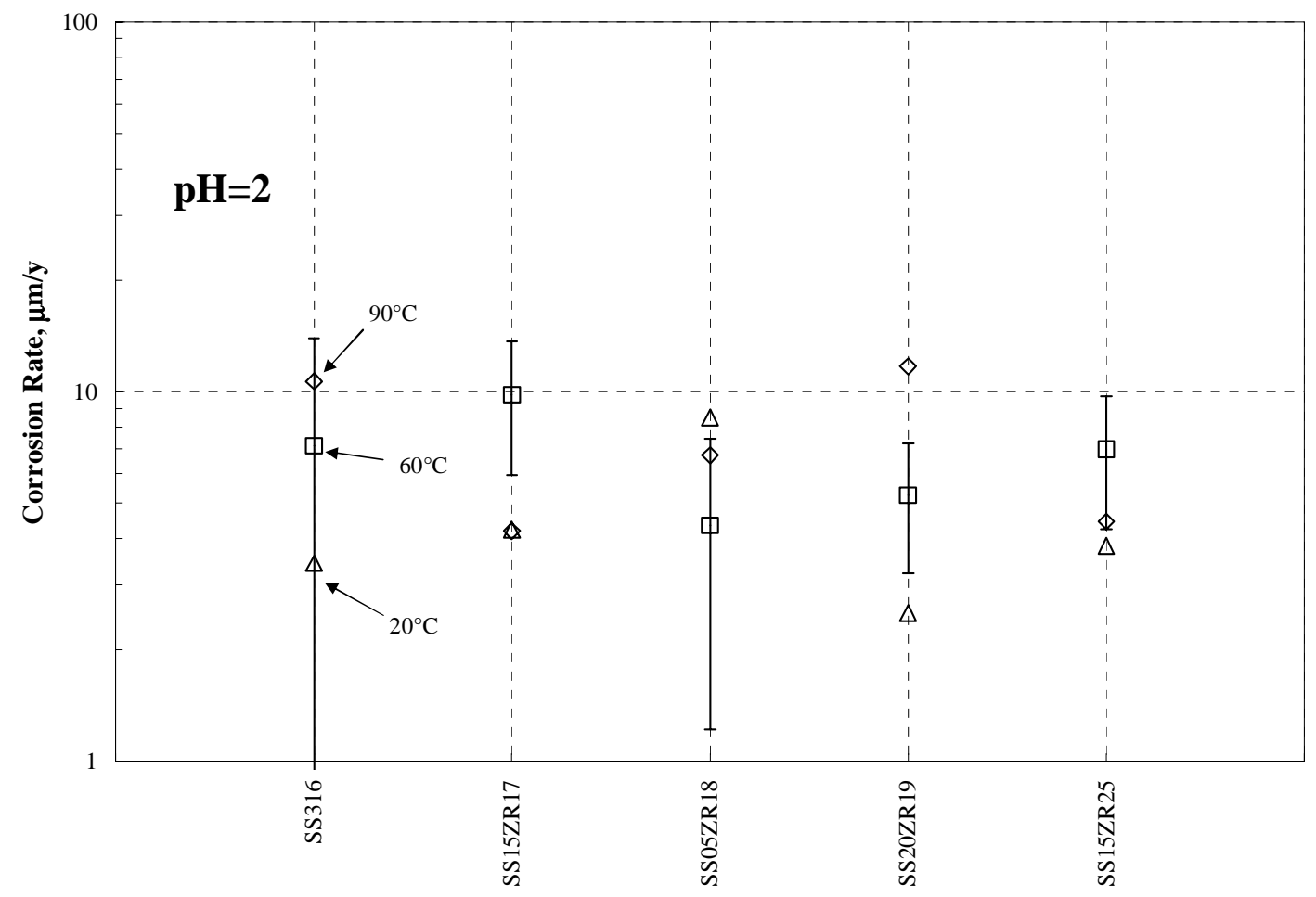

Figure I-20. Average Corrosion Rates Measured in $\mathbf{p H}=2$ Solution.

Fink et al. [4] examined the available metal waste form electrochemical corrosion rate data as a function of $\mathrm{Zr}$ content, composition, $\mathrm{pH}$, and temperature. The scatter in the data was sufficiently large that it was not possible to discern any dependence on addition of noble metal fission products, technetium, or uranium or on $\mathrm{Zr}$ content. Thus, all the data were analyzed together as a function of $\mathrm{pH}$, temperature, and chloride content. The corrosion rate data were converted from $(\mu \mathrm{m} / \mathrm{y})$ to $\mathrm{g} /\left(\mathrm{m}^{2} \mathrm{y}\right)$ by multiplying by the sample density, which given in Table I-5 for each alloy tested. The data were fit by a least squares minimization method to a number of functional forms consistent with metal corrosion. In calculation of the total variance, the contributions to the variance at each temperature were divided by the number of data at that temperature so that the fit was not biased by the temperature for which the most data were available. The best fit to the logarithm to the base 10 of the corrosion rate was obtained by the equation

$$
\log _{10} C R=1.52+2.07 \times 10^{-3} \mathrm{~T}+4.15 \times 10^{-2} \mathrm{pH}-3.35 \mathrm{pH} / \mathrm{T}+1.82 \times 10^{-7} \mathrm{Cl}^{-} \mathrm{T}
$$

where $\quad C R=$ electrochemical uniform corrosion rate in $\mathrm{g} /\left(\mathrm{m}^{2} \mathrm{y}\right)$

$$
\begin{aligned}
& \mathrm{T}=\text { temperature in }{ }^{\circ} \mathrm{C} \quad\left(20^{\circ} \mathrm{C} \leq \mathrm{T} \leq 90^{\circ} \mathrm{C}\right) \\
& \mathrm{pH}=\mathrm{pH} \text { of the bulk solution }(2 \leq \mathrm{pH} \leq 12) \\
& \mathrm{Cl}^{-}=\text {the halide or chloride ion concentration in ppm or } \mathrm{mg} / \mathrm{L} \text {. }
\end{aligned}
$$

The standard deviation for the fit of the $\log _{10} \mathrm{CR}$ is 0.36 . Corrosion rates as a function of $\mathrm{pH}$ determined from the above equation are shown in Figures I-21 through I-23 for temperatures 90,60 , and $20^{\circ} \mathrm{C}$. The data analyzed have been included in each figure. 
Note that this analysis gives an increase in corrosion rate with decreasing $\mathrm{pH}$ at $20^{\circ} \mathrm{C}$ but the $\mathrm{pH}$ dependence decreases with increasing temperature. At $90^{\circ} \mathrm{C}$, the scatter in the data is so large that this analysis provided almost no dependence on $\mathrm{pH}$. This lack of dependence on $\mathrm{pH}$ with increasing temperature is not expected for releases. Equations for releases from high level waste glass [6] show significant $\mathrm{pH}$ dependence at both room temperature and at higher temperatures, with minimums near neutral $\mathrm{pH}$ solutions.

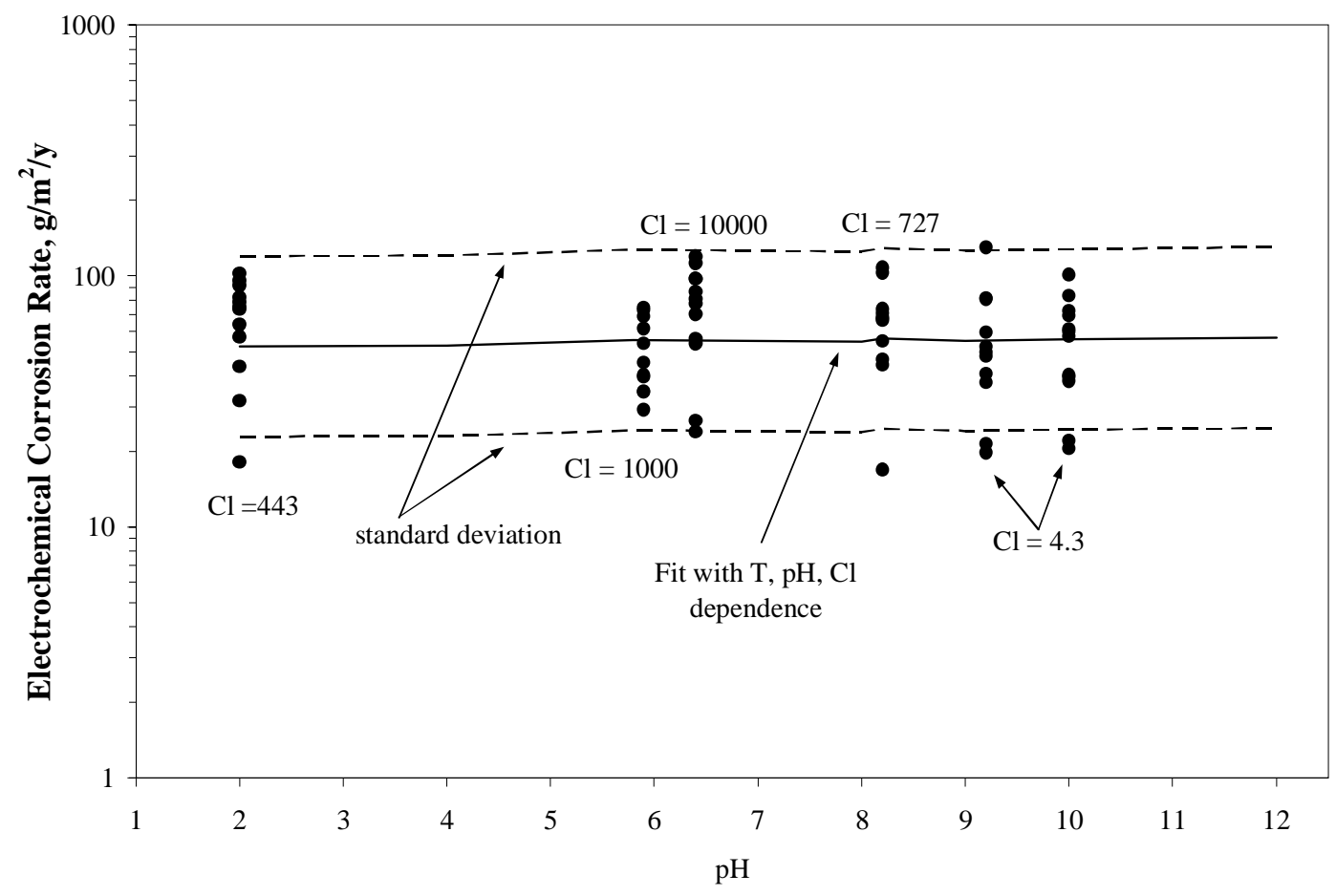

Figure I-21. Fit to Electrochemical Corrosion Data at $90^{\circ} \mathrm{C}$. 


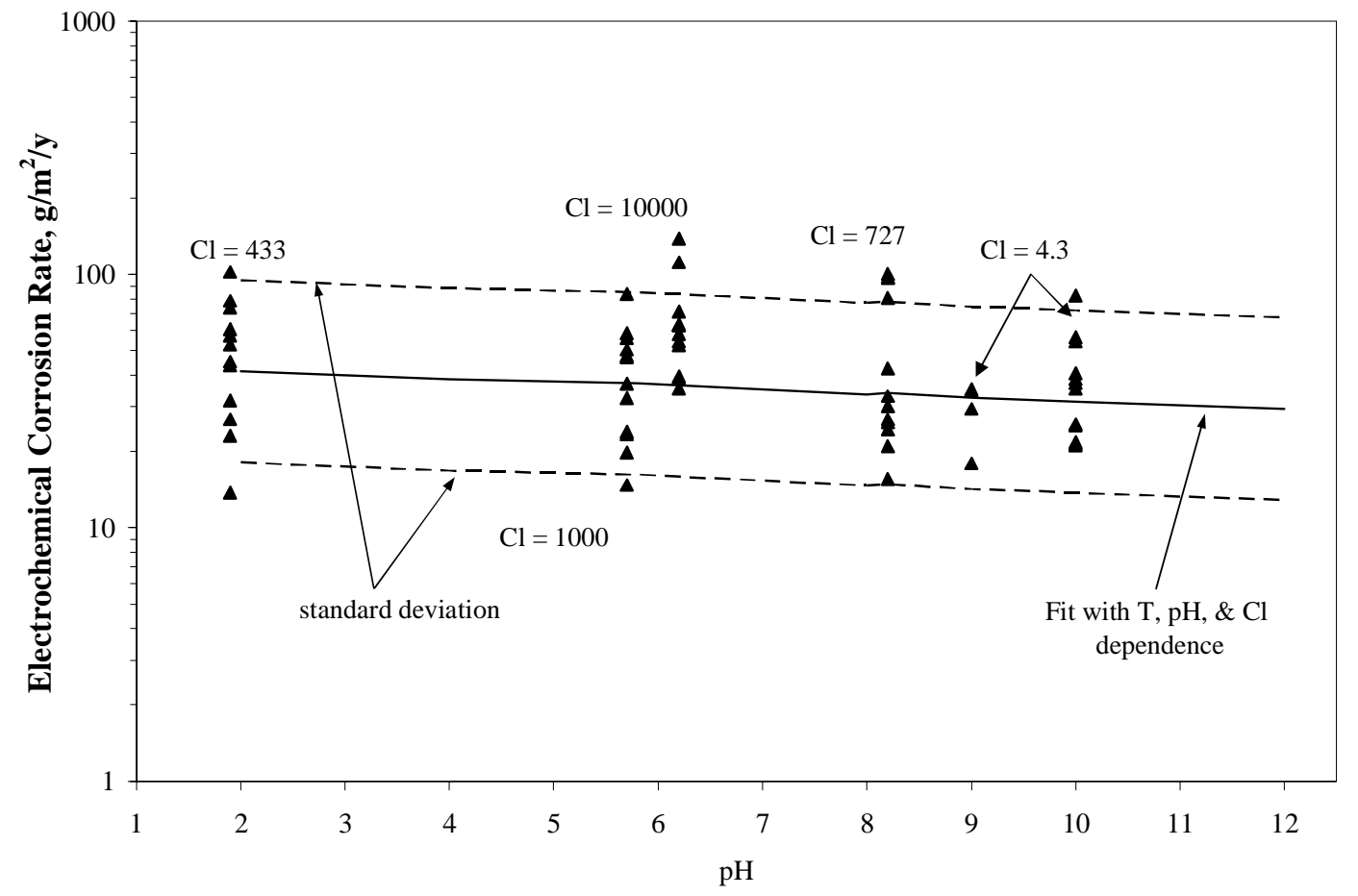

Figure I-22. Fit to Electrochemical Corrosion Data at $60^{\circ} \mathrm{C}$.

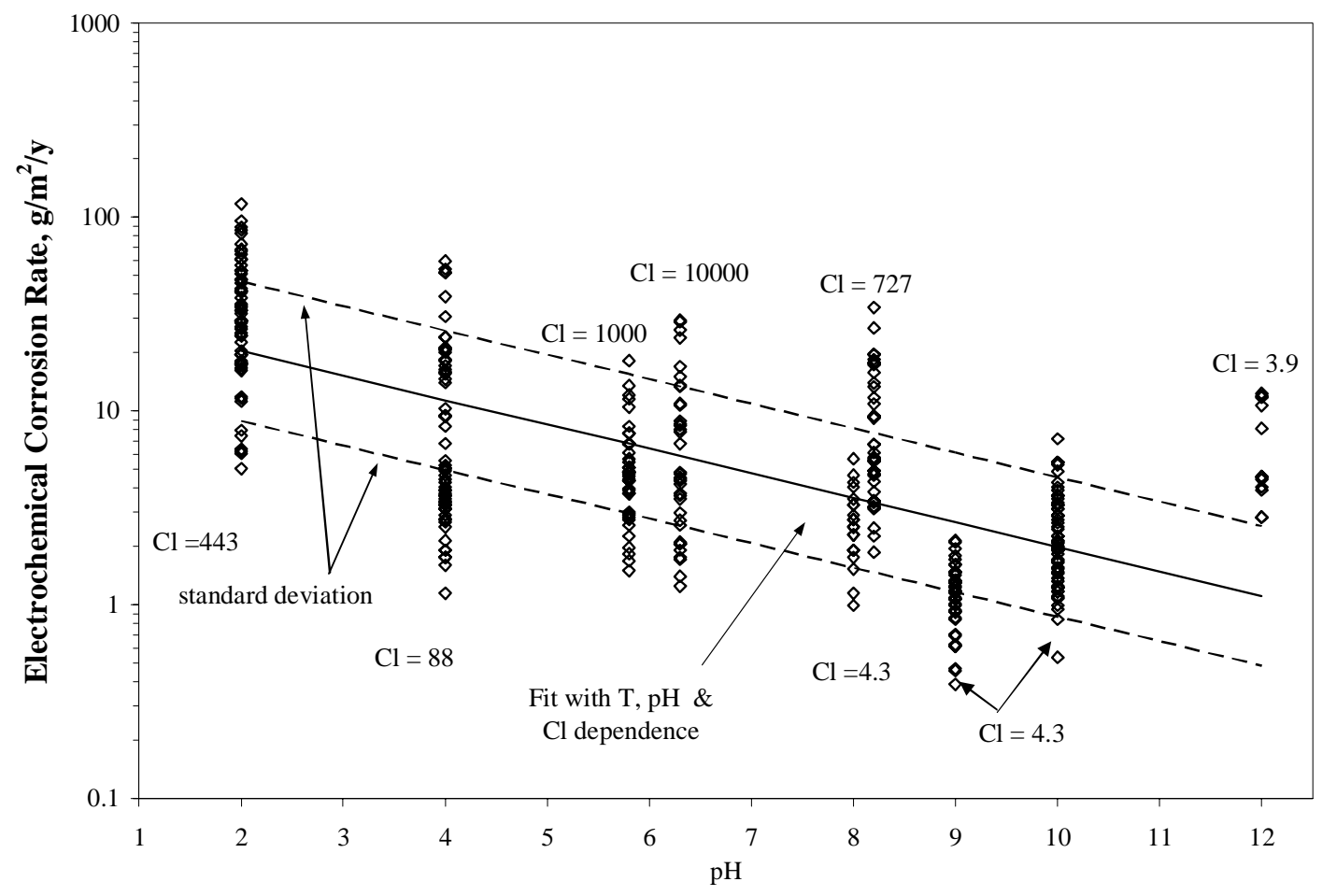

Figure I-23. Fit to Electrochemical Corrosion Data at $20^{\circ} \mathrm{C}$.

The electrochemical corrosion data for the metal waste form alloys are useful for ranking the corrosion of the metal waste form relative to the corrosion of other alloys. However, it is not clear if these data are appropriate for determination of a long-term corrosion rate 
or for modeling releases. From his literature review and analysis of stainless steel corrosion data, Petri [7] found that long term corrosion rates for stainless steel obtained from immersion data are consistently lower than rates obtained from electrochemical measurements. At room temperature, the rates differ by about a factor of five. Both stainless steel and the metal waste form develop a passive oxide film that protects these alloys from aqueous corrosion. Because the linear polarization measurements have been made on highly polished samples, they give the initial corrosion rate during the formation of the passive oxide film not the rate after the passive oxide layer has been established.

\section{Role of Passive Oxide Layer}

The metal waste form, like stainless steel, develops a passive oxide layer over the ironsolid solution and intermetallic phases that limits corrosion. The long-term goal of the corrosion studies is development of a mechanistic model of aqueous corrosion and releases that includes

1. development of a passive oxide layer from reaction of metal cations with oxide ions

2. diffusion through the passive layer

3. releases from dissolution of the outer passive layer in the aqueous solution.

The point-defect model of Macdonald [8], which models the growth and breakdown of the passive oxide film of a metal has been considered by Fink et al. [4] for development of a mechanistic model for the corrosion and releases from the metal waste form. The Macdonald point-defect model is appropriate because it relates the rate of formation of the passive oxide layer to the rate of dissolution to the barrier layer-outer layer interface. The status of model development has been reported in Section V of Reference 4. A large effort is required to develop this mechanistic model, which requires identification of the corrosion products in the passive oxide layer and understanding the processes for movement of alloy elements through the passive oxide layer to react with the aqueous phase. Information required for this model development include:

1. understanding the structure of the metal waste form and the oxide layers over each alloy phase to identify the compositions of the barrier and outer oxide layer;

2. release data as a function of time under a range of conditions.

The structure of the oxide layers must be understood so that the limiting process can be identified. At present, it is not known if the limiting process is (a) diffusion of the oxide to the metal interface or (b) diffusion of elements from the metal to the oxide layer. The metal waste form and the oxide layers have been characterized from examinations using Auger electron spectroscopy, transmission electron microscopy, and X-ray diffraction. The Metal Waste Form Handbook [1] provides information on the structure of the metal waste form and characterizes the two main phases (iron solid solution and intermetallic phase) and minor phases from examinations on a number of samples. Because most fission products and the actinides are located in the $\mathrm{ZrFe}_{2}$-type intermetallic phase, most examinations of the oxide layers have concentrated on the oxide over the intermetallic phase. Results of studies of the oxide layers formed on samples immersed for two years in deionized water and samples exposed to $200^{\circ} \mathrm{C}$ saturated steam are summarized by Fink et al. [4]. Additional details on the examinations have been reported in a number of papers. Appendix B contains a bibliography of relevant publications by D. Abraham on 
characterization of the oxide layers, microstructure and phase stability of the metal waste form, and model development.

Release data as a function of time under a range of conditions are required in order to formulate the dissolution term in the MacDonald model as a function of $\mathrm{pH}$, chloride and/or fluoride concentration, and temperature. Such a dissolution term may be needed for each element of interest in the metal waste form in order to develop a mechanistic model of corrosion and release.

\section{Review of Releases from Existing Immersion Tests}

Initial immersion tests in simulated J13 solution and deionized water for 90 and 365 days, which were reported in the Metal Waste Handbook [1], provided little data on releases because releases were so small that they were often below limits of detectability. In accord with the recommendations of the National Research Council [9], new immersion tests were done at $90^{\circ} \mathrm{C}$ for periods of 7 to 365 days using more aggressive solutions (a high-chloride solution and a concentrated J-13 solution (CJ13), which contained 100 to 150 times the chloride and bicarbonate concentrations of J13 well water). Separate polished SS-15wt\%Zr samples containing noble metal fission products were immersed in these solutions for 7, 14, 28, 60, 95, 182 and 365 days. The immersion tests were done in Teflon vessels. The composition of the SS-15 wt\% $\mathrm{Zr}$ samples is given in Table I-6. Compositions of the solutions are given in Table I-7.

Table I-6. Composition (wt \%) of SS15ZR25 Alloy Samples ${ }^{a}$

\begin{tabular}{|c|c|c|c|c|c|c|c|c|c|c|c|c|c|}
\hline \multicolumn{4}{|c|}{ Major Elements } & \multicolumn{4}{c|}{ Noble Metal Fission Products } & \multicolumn{5}{c|}{ Minor Elements } \\
\hline $\mathrm{Fe}$ & $\mathrm{Cr}$ & $\mathrm{Ni}$ & $\mathrm{Zr}$ & $\mathrm{Nb}$ & $\mathrm{Pd}$ & $\mathrm{Rh}$ & $\mathrm{Ru}$ & $\mathrm{Mo}$ & $\mathrm{Mn}$ & $\mathrm{Co}$ & $\mathrm{Cu}$ & $\mathrm{V}$ & $\mathrm{Si}$ \\
\hline 56.5 & 14.1 & 8.65 & 14.2 & 0.8 & 0.98 & 0.93 & 0.92 & 1.66 & 1.13 & 0.19 & 0.4 & 0.09 & 0.32 \\
\hline
\end{tabular}

${ }^{\mathrm{a}}$ Sample composition was determined by ACL-CMT using ICPMS and ICPAES.

Table I-7. Composition of Solutions used for Immersion Tests ${ }^{\mathrm{a}}$

\begin{tabular}{|c|c|c|c|c|c|c|c|c|c|c|}
\hline & & \multicolumn{7}{|c|}{ Solution Composition $(\mathrm{mg} / \mathrm{L}$ or ppm) } \\
\cline { 3 - 11 } Solution & $\mathrm{pH}$ & $\mathrm{Na}$ & $\mathrm{K}$ & $\mathrm{Ca}$ & $\mathrm{Mg}$ & $\mathrm{Si}$ & $\mathrm{SO}_{4}^{-2}$ & $\mathrm{Cl}^{-1}$ & $\mathrm{NO}_{3}^{-1}$ & $\mathrm{HCO}_{3}^{-1}$ \\
\hline $1000 \mathrm{ppm} \mathrm{Cl}$ & $\sim 58$ & 607 & - & - & - & - & - & 1000 & - & - \\
\hline Conc. J-13 & $\sim 8.2$ & 5300 & 510 & 6 & 1.9 & 30 & 22 & 727 & 11 & 12700 \\
\hline
\end{tabular}

${ }^{\mathrm{a}}$ Solutions were prepared and analyzed by ACL-CMT.

Following immersion of each sample for 7 to 365 days, the sample was examined visually for any changes and weighed. The leaching solution was analyzed. The vessel was filled with an acid wash to remove any material that had migrated to the vessel walls. Then this acid solution was analyzed. Data obtained from these examinations and analyses are summarized in tables in Appendix C. Tabulated data given in Appendix C include: mass changes and observations of the condition of the samples, concentrations of each element in the leachate and in the acid wash, the total mass released during each test, and normalized losses of each element in the leachate and acid wash. The equation used to calculate the normalized losses has been included in Appendix C. 
Figure I-24 shows the total mass released during each test in the $1,000 \mathrm{ppm} \mathrm{Cl}^{-}$at $90^{\circ} \mathrm{C}$. The detected masses in the solution and on the walls at the end of each test have also been included in the figure. Data from the tests lasting from 7 to 95 days show no consistency. Total releases from the 14 day test are the highest and releases from the 95 day test are the lowest. However, releases from the 365 day test are higher than those of the 182 day test, as expected. It is not known if the unusual results are from sample variability and lack of statistics or from other test variables. No conclusions regarding releases can be drawn from these data.

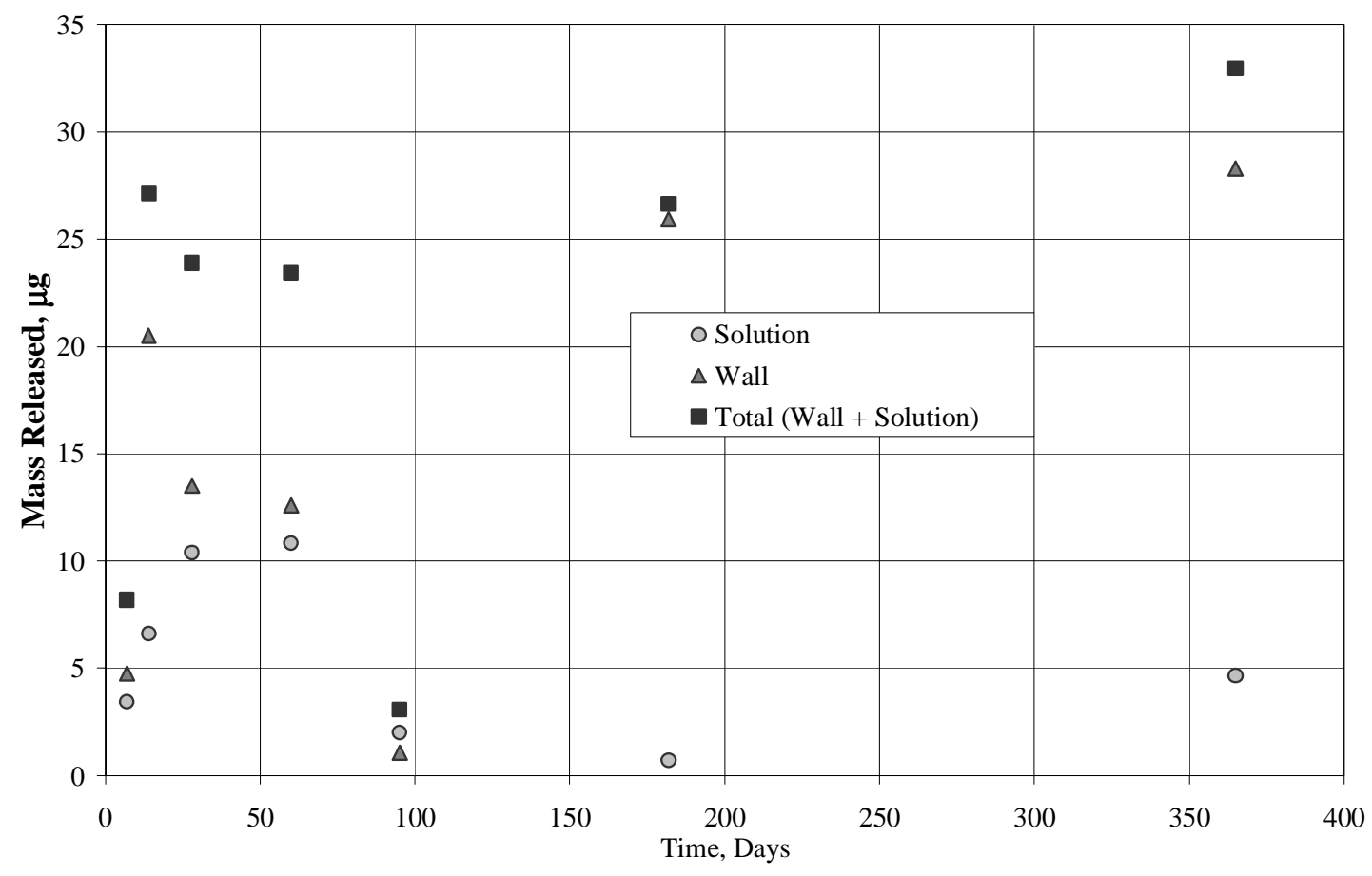

\section{Figure I-24. Mass Releases in $1 \mathrm{KCl}$ Solution Tests at $90^{\circ} \mathrm{C}$.}

The total mass released and masses in solution and on the walls for each of the tests in CJ13 solution at $90^{\circ} \mathrm{C}$ are shown in Figure I-25. The total mass released from these tests increases with test duration for tests less than 60 days. However, for longer tests, the mass in solution does not increase with test duration but appears to reach a constant level. The total mass of the wall deposit appears to increase with length of the immersion test. The comparison of the Fe releases and Fe wall deposits with total releases and wall deposits in Figure I-26 shows that the Fe behavior is similar to that of the total releases and that Fe makes up most of the mass released and the mass deposited on the walls. It is possible that after immersion for approximately 60 days, the test solution becomes saturated in Fe and that element is then deposited on the walls. 


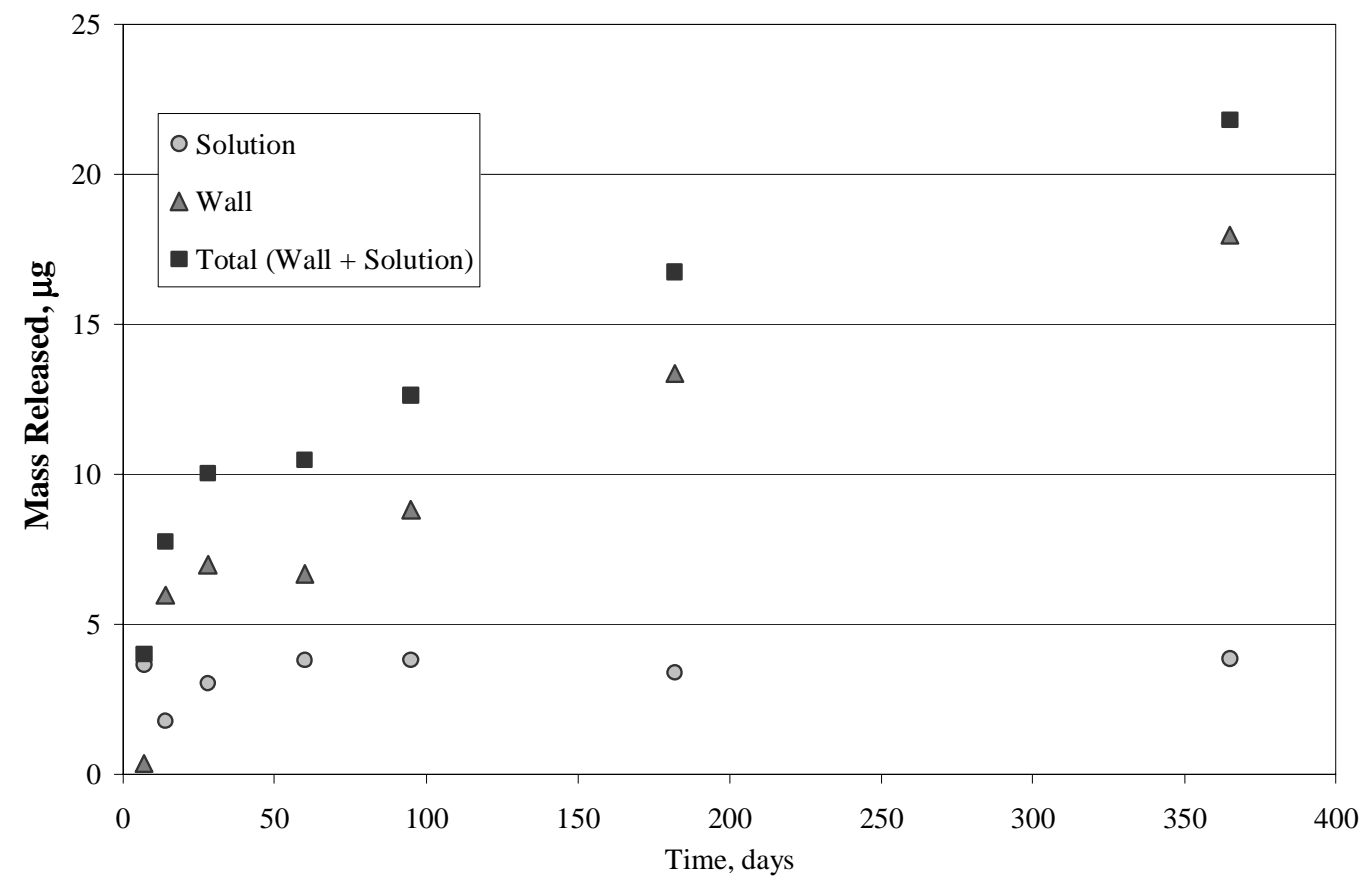

Figure I-25. Mass released in CJ13 Tests at $90^{\circ} \mathrm{C}$.

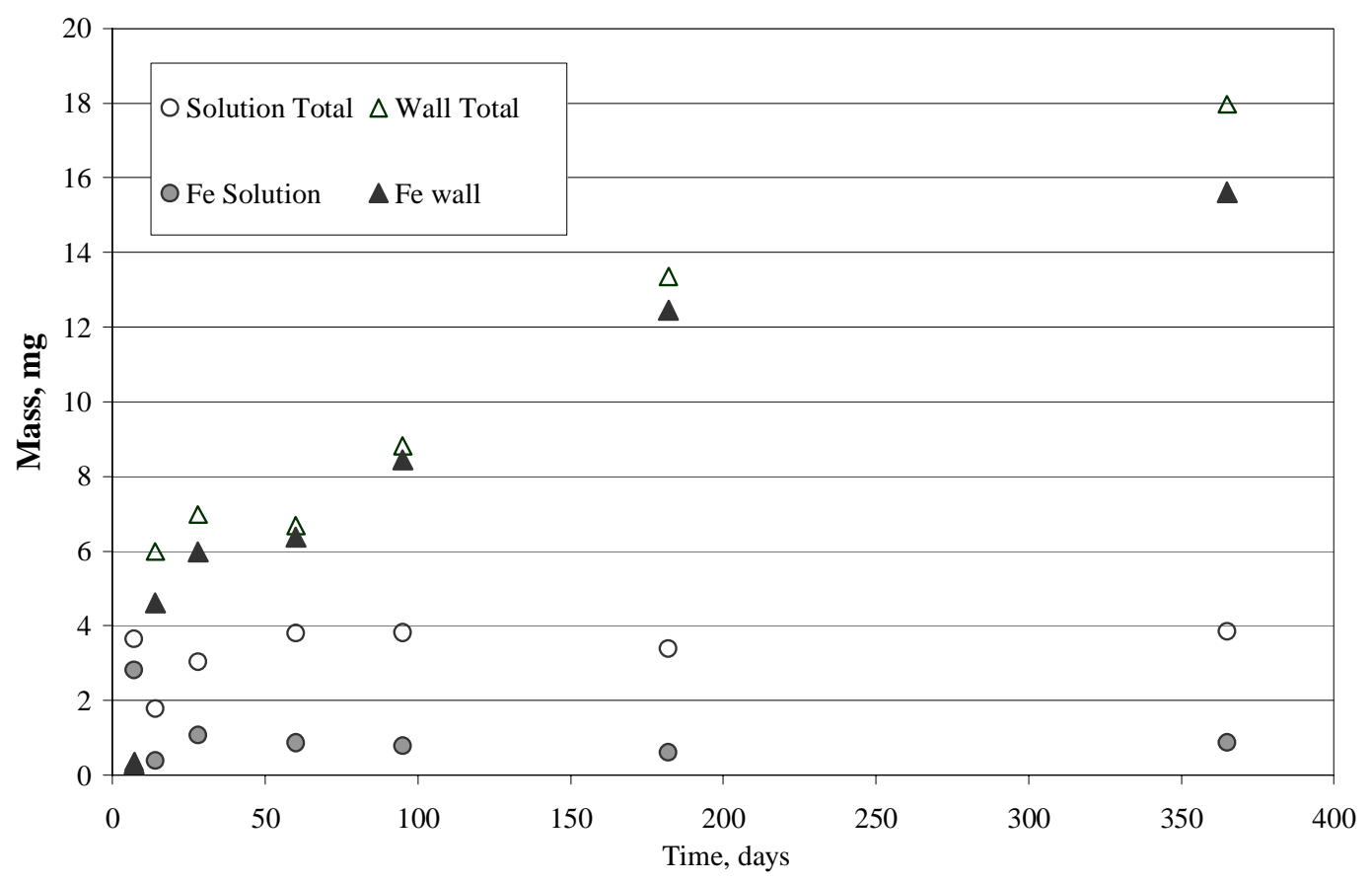

Figure I-26. Comparison of Fe Release with Total Release in $\mathrm{CJ} 13$ at $90^{\circ} \mathrm{C}$.

Although the release data from the tests in $\mathrm{CJ} 13$ solution at $90^{\circ} \mathrm{C}$ (Figure I-25), appear to show more consistency than the data from the high chloride tests (Figure I-24), both sets of data have large uncertainties because (1) each test was done on a different waste form sample, (2) only one sample was immersed for each time period so no statistics exist for 
each datum, and (3) except for Fe in the CJ13 tests, large scatter exists in releases of a given element as a function of time in both test series.

Rates of release as a function of time calculated from the total releases and $\mathrm{Fe}$ and $\mathrm{Mo}$ normalized losses for the tests in $\mathrm{CJ} 13$ at $90^{\circ} \mathrm{C}$ are compared in Figure I-27 with the corrosion rates from the three electrochemical corrosion tests in $\mathrm{CJ} 13$ at $90^{\circ} \mathrm{C}$. The corrosion rates are shown as constants because data are available only for measurements on polished samples. No data are available on how the corrosion rate changes as a function of time during which the passive oxide film is developed. Comparison of the 7 day immersion test with the electrochemical corrosion data shows that the release rates are two orders of magnitude below the electrochemical corrosion rates. For the 365 day test, the rates differ by three orders of magnitude.

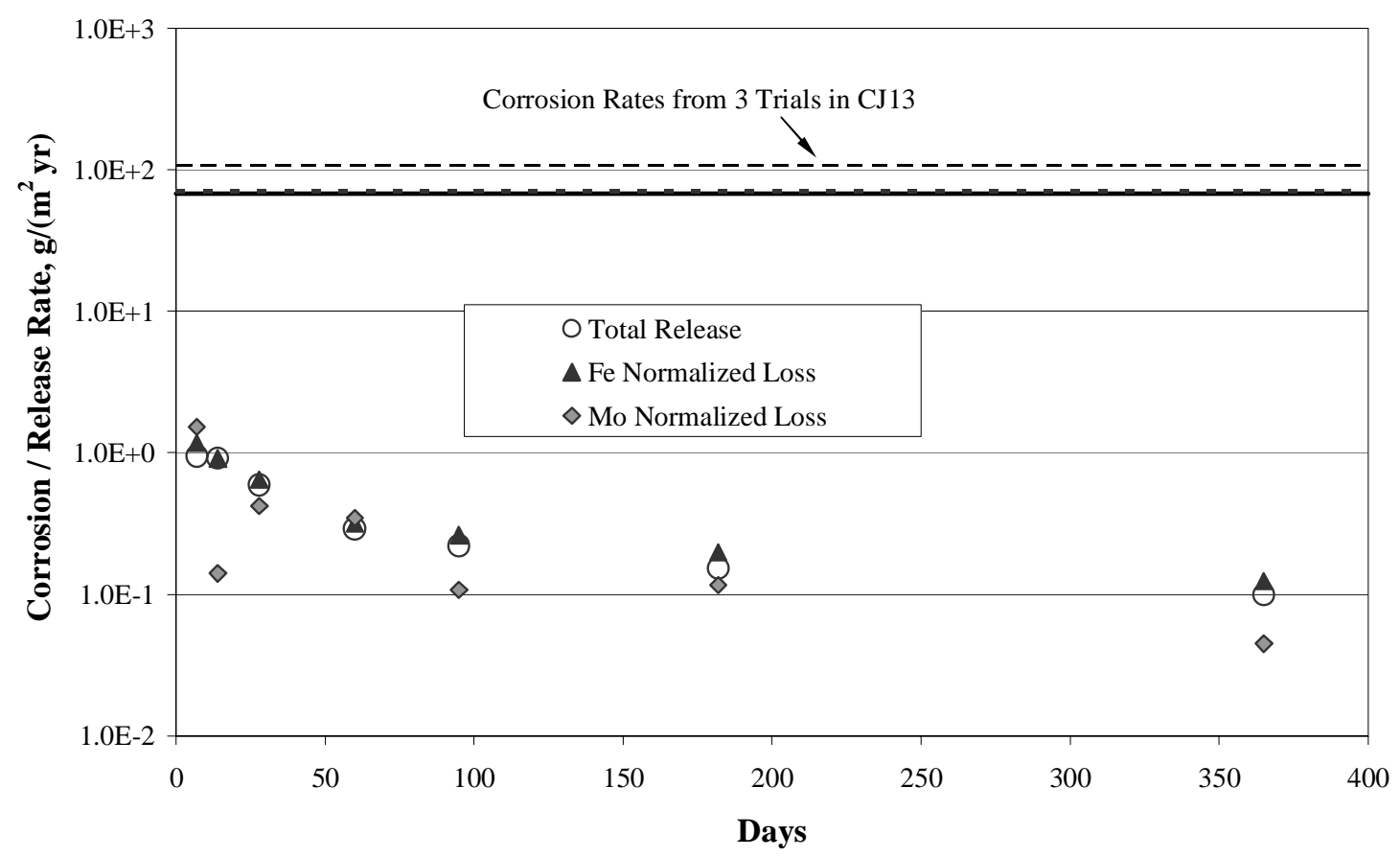

Figure I-27. Comparison of Corrosion and Release Rates from $90^{\circ} \mathrm{C} \mathrm{CJ13} \mathrm{Tests.}$

\section{B. Need for Additional Immersion Tests}

The available data discussed above are not adequate for development of a mechanistic corrosion and release model, such as the point defect model of Macdonald [8]. The initial immersion tests in simulated J13 solution and deionized water for 90 and 365 days [1] were done under such benign conditions that meaningful release rates could not be determined from the data. The total release data as a function of time on samples immersed for different times at $90^{\circ} \mathrm{C}$ in $\mathrm{CJ} 13$ solution and in $1000 \mathrm{ppm} \mathrm{Cl}^{-}$solution are inadequate for model development because these data do not provide release as a function of time for one sample, lack statistical information to estimate uncertainties, and raise some questions regarding the tests such as the possibility of Fe saturation of the solution for tests longer than 60 days. 
New immersion tests are needed to answer a number of questions, which are discussed below.

1. In the Yucca Mountain repository, the metal waste form would be oxidized by air for a number of years prior to any aqueous corrosion. During this time, a passive oxide layer would be formed on the sample. Immersion tests on both polished and oxidized samples under the same conditions are needed to determine if pre-oxidation prior to contact with water makes any difference on the releases.

2. Consideration has been given to co-packaging the metal waste form with the ceramic waste. This could result in water high in chloride contacting the metal waste form. Thus tests on multiple samples in high chloride solutions are needed to provide release data with good statistics to determine the effect of chloride on releases.

3. The effect of $\mathrm{pH}$ on releases is not known because all immersion tests have been done at $\mathrm{pH}$ levels very close to 8 (the $\mathrm{pH}$ of simulated $\mathrm{J} 13$ solution). Electrochemical tests showed little $\mathrm{pH}$ dependence at $90^{\circ} \mathrm{C}$ but significant $\mathrm{pH}$ dependence at room temperature. Electrochemical tests do not measure releases and the relation between electrochemical tests and releases (if any) is not known. Thus, tests at $90^{\circ} \mathrm{C}$ in an aggressive solution with a very low $\mathrm{pH}(\mathrm{pH}=2)$ where any effect on releases from the change in $\mathrm{pH}$ will be evident are needed. If these tests indicate $\mathrm{pH}$ dependence, then additional tests are required to determine the $\mathrm{pH}$ dependence of releases.

4. Comparison of Fe releases from tests of samples immersed in CJ13 at $90^{\circ} \mathrm{C}$ for different times showed that the Fe release increased with exposure time for short times of exposure but reached a maximum for longer exposures. It is not clear if this apparent leveling off, which was observed in the longer tests, is due to limitation of Fe release from Fe saturation of the water or if the reduction in the Fe release rate with time is from formation of protective passive oxide layers on the two phases. To determine if $\mathrm{Fe}$ saturation limited the Fe releases for longer exposure times, tests are needed in which the samples are put in new solutions after weekly terminations so that the solutions do not become saturated. Analysis of the solutions from these weekly terminations will determine if the Fe release rate decreases with immersion time. 


\section{EXPERIMENTAL}

Immersion corrosion tests were initiated on nonradioactive samples of the metal waste form in May and October, 2000. The tests were based on Materials Characterization Center Protocol \#1 (MCC-1) (ASTM C 1220) [10], a static leach test procedure initially developed to evaluate glass-based waste forms. It measures selective leaching of elements from the waste form into representative test solutions, and provides chemical durability and corrosion resistance information.

This procedure describes the steps needed for the time-dependent study of elemental releases into solution of the metal waste form, SS-15Zr-1Nb-1Ru-1Pd-1Rh. The results of this study will be incorporated into a database in order to develop a mechanistic model for the corrosion of metal waste form alloys. The corrosion model is being developed as part of the Yucca Mountain Performance Assessment Studies for SS-15Zr waste forms.

Immersion tests at $90^{\circ} \mathrm{C}$ in four solutions were initiated May 2, 2000. Additional tests were initiated October 17, 2000, consisting of $90^{\circ} \mathrm{C}$ and ambient room temperature. Solution identification and test vessel information can be found in Table D-1. The SJ13 solution is intended to replicate the groundwater in the J-13 well at the Yucca Mountain geologic repository. However, the J-13 solution prepared for these immersion tests did not contain fluoride, which has been reported at a level of $2.2 \mathrm{mg} / \mathrm{L}$ in samples of J-13 well-water [11] (see Table 1 in the Introduction). The other solutions represented stringent conditions that may be encountered by the waste form during the lifetime of the geologic repository [12]. The immersion tests started in May were conducted on 3 samples polished to $0.5 \mu \mathrm{m}$ and 2 samples polished to $0.5 \mu \mathrm{m}$ and pre-oxidized at $500^{\circ} \mathrm{C}$ for 2 hours. The immersion tests started in October were conducted on 1 sample polished to $1 \mu \mathrm{m}$. Each sample was machined by the CMT machine shop from ingots SS15Zr25 and SS15Zr26 cast with a nominal composition of SS15Zr1Nb1Pd1Rh. Each round coupon had a sample area of $219.9 \mathrm{~mm}^{2}$. When placed into the Teflon vessel, each sample rested on a Teflon support surrounded by the designated solution. The test vessels were contained in a secondary container filled with deionized water, and were placed into an oven set at $90^{\circ} \mathrm{C}$ or placed in a designated area of the countertop in laboratory H-126. At certain time intervals, each sample was removed from the Teflon vessel, examined visually, and placed into a cleaned Teflon vessel filled with fresh solution. The acidified test solution, any residue present, and an overnight "acid strip" solution from the terminated Teflon vessel was weighed and analyzed by the Analytical Chemistry Laboratory. The samples were analyzed by Inductively Coupled PlasmaMass Spectrometry (ICP-MS) and Inductively Coupled Plasma-Atomic Emission Spectrometry (ICP-AES). Each test termination yielded $2 \times 30-\mathrm{mL}$ high-density polyethylene sample bottles for each Teflon test vessel, and dried residue from any solutions in which one may be present. The first sample bottle contained the leachate from the vessel. This solution along with the dried residues measured the elemental constituents of the alloy that dissolved in the solution. The second bottle contained the acid-strip solution that measured the elemental constituents of the alloy that deposited on the walls of the vessels. The combined data from the three analyses provided a measure of the alloy dissolution during the experiment. The as-polished samples were expected to 
provide information on elemental release during the buildup of the passive layer, and the pre-oxidized samples are expected to yield information on the steady state release from the alloy samples.

Sample analysis data was received and incorporated into a database along with all sample parameters. All elemental release and control blank concentrations were converted to normalized loss $\left(\mathrm{NL}_{\mathrm{i}}\right)$ according to the following equation:

Normalized Loss Formula with No Correction for Blanks Used for Comparing Fe Normalized Loss with High Level Glass Waste

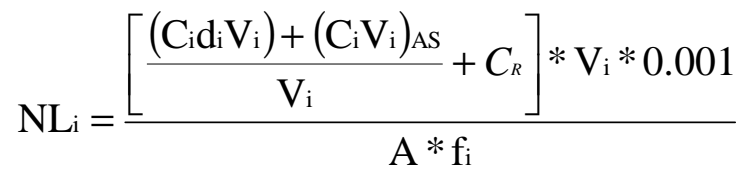

$\mathrm{NL}_{\mathrm{i}}=$ Normalized Loss $\left(\mathrm{g} / \mathrm{m}^{2}\right)$

$\mathrm{C}_{\mathrm{i}}=$ Concentration of $\mathrm{i}^{\text {th }}$ element in solution $(\mu \mathrm{g} / \mathrm{L})$

$\mathrm{d}_{\mathrm{i}}=$ dilution factor for test solution containing $\mathrm{i}^{\text {th }}$ element (because solution is acidified) $\mathrm{V}_{\mathrm{i}}=$ Volume of test solution containing $\mathrm{i}^{\text {th }}$ element $(\mathrm{mL})$

$\mathrm{AS}=$ Acid Strip (refers to elemental concentration and volume of acid strip solutions)

$\mathrm{A}=$ area of specimen $\left(\mathrm{mm}^{2}\right)$

$\mathrm{f}_{\mathrm{i}}=$ fraction of $\mathrm{i}^{\text {th }}$ element in specimen

$\mathrm{C}_{\mathrm{R}}=$ Concentration of $\mathrm{i}^{\text {th }}$ element in residue $(\mu \mathrm{g} / \mathrm{L})$

Notes:

1. The 1 st term in the equation gives the elemental content in the test and acid strip solutions.

2. The multiplication factor 0.001 is used to convert the normalized loss value to $\mathrm{g} / \mathrm{m}^{2}$.

Converting release concentration data to normalized loss provides an indication of the quantity of a given element released into solution based on the weight fraction of the element in the alloy, and the surface area of the sample coupon in contact with the immersion test solution. Comparison of the data with high level waste glass data is possible when in this form. 


\section{RESULTS}

\section{A. Initial Tests}

\section{Releases of Elements from Each Test}

After each sampling interval, the total release of each element was determined from the release to the solution, the release to the walls (obtained from the acid strip wash), and the detected residue. The releases detected in the test solution, in the acid strip from the walls, and the residues for each element are shown as bar graphs in Appendix E. Tabulated values are in Appendix F. Average detection limits for the leachate and acid strip have been included on the bar graphs. The detection limits of each element as a function of time are given in Appendix G. Detection limits varied from day to day, depending on the instrument calibration. This variation of detection limits led to spurious results when the element released was so low that it was not detected except on the days when the detection limit was lower than usual.

Appendix $\mathrm{H}$ contains graphs of the total releases of each element from the five metal waste form samples (3 polished, and 2 pre-oxidized) in the $90^{\circ} \mathrm{C}$ tests in four solutions (SJ13, CJ13, 10KCl, and AJ13) for each sampling interval, as a function of sampling interval. The amount of each element detected in the control vial solution has been included as a bar graph for comparison. The control data provide useful information regarding the uncertainties in the tests. These uncertainties are discussed below for the metal waste form major elements $(\mathrm{Fe}, \mathrm{Zr}, \mathrm{Cr}$, and $\mathrm{Ni})$, the fission product elements $(\mathrm{Nb}$, $\mathrm{Pd}, \mathrm{Ru}, \mathrm{Rh}$, and $\mathrm{Mo}$ ) and the minor elements ( $\mathrm{Mn}, \mathrm{Cu}, \mathrm{Co}$, and $\mathrm{V})$.

Appendices $\mathrm{J}-\mathrm{M}$ contains results from room temperature tests and from the $1 \mathrm{KCl}$ test at $90^{\circ} \mathrm{C}$.

\section{a) Effect of Reuse of Teflon Vials on Releases of Major Elements}

These tests showed that the Teflon vials should not be reused. The standard cleaning procedure for the first 22 weeks ( 154 days) of the $90^{\circ} \mathrm{C}$ tests was to thoroughly rinse the vessels and boil for 1 hour in deionized water, then clean the vessels according to the 1996 ASTM "Standard Test Method for Static Leaching of Monolithic Waste Forms for Disposal of Radioactive Waste" [10]. After the initial boiling step, the cleaning procedure consisted of filling each vial with $1 \mathrm{wt} \% \mathrm{HNO}_{3}$ and placing it into the oven at $110^{\circ} \mathrm{C}$ for 24 hours. After removal from the oven, the vials were emptied, rinsed, and boiled again for 1 hour in deionized water. The vessels were refilled with deionized water and placed back into the oven for 16 hours. Upon removal from the oven and cooling, the $\mathrm{pH}$ of every vessel was checked to ensure it was in the $\mathrm{pH}$ range of 5-7. The vials were dried in the oven overnight, allowed to cool, then reused immediately for immersion testing or placed in a sealed plastic bag for storage. Then the vials were reused.

Later tests of second acid washes on vials showed that the cleaning procedure did not always remove all the material that had migrated into the wall, particularly when the vial 
had been used for the high chloride solution or the $\mathrm{pH}=2, \mathrm{AJ} 13$ solution. Although the masses removed from the wall with the second acid wash are small relative to the releases in $\mathrm{AJ} 13$ and $10 \mathrm{KCl}$ and did not affect those test results, they are not always small compared to releases in SJ13 and CJ13. Reuse of vials from aggressive solutions (AJ13 and $10 \mathrm{KCl}$ ) for the less aggressive solutions (SJ13 and CJ13) could give a higher release from the acid wash of the wall, which removes elements that are in the wall. Figures III1 and III-2, which show the Fe release in SJ13 and CJ13, illustrate the problem of contamination from the Fe that remained in the Teflon wall. According to Appendix D, which gives the order of vial reuse, the vial for the SJ13 control sample analyzed on day 98 had been previously used for a metal waste form sample for the first week test in $10 \mathrm{KCl}$. The large Fe release in the blank is most likely Fe that was not removed from the Teflon walls in the acid wash. Samples P7, P8, and P9 in CJ13 for day 98 were also in Teflon vials that had been previously used for the first week $10 \mathrm{KCl}$ test. These samples had much higher releases than the day 98 CJ13 Samples O10 and O11, which were in Teflon vials that had previously been used for a blank and for an AJ13 test, respectively.

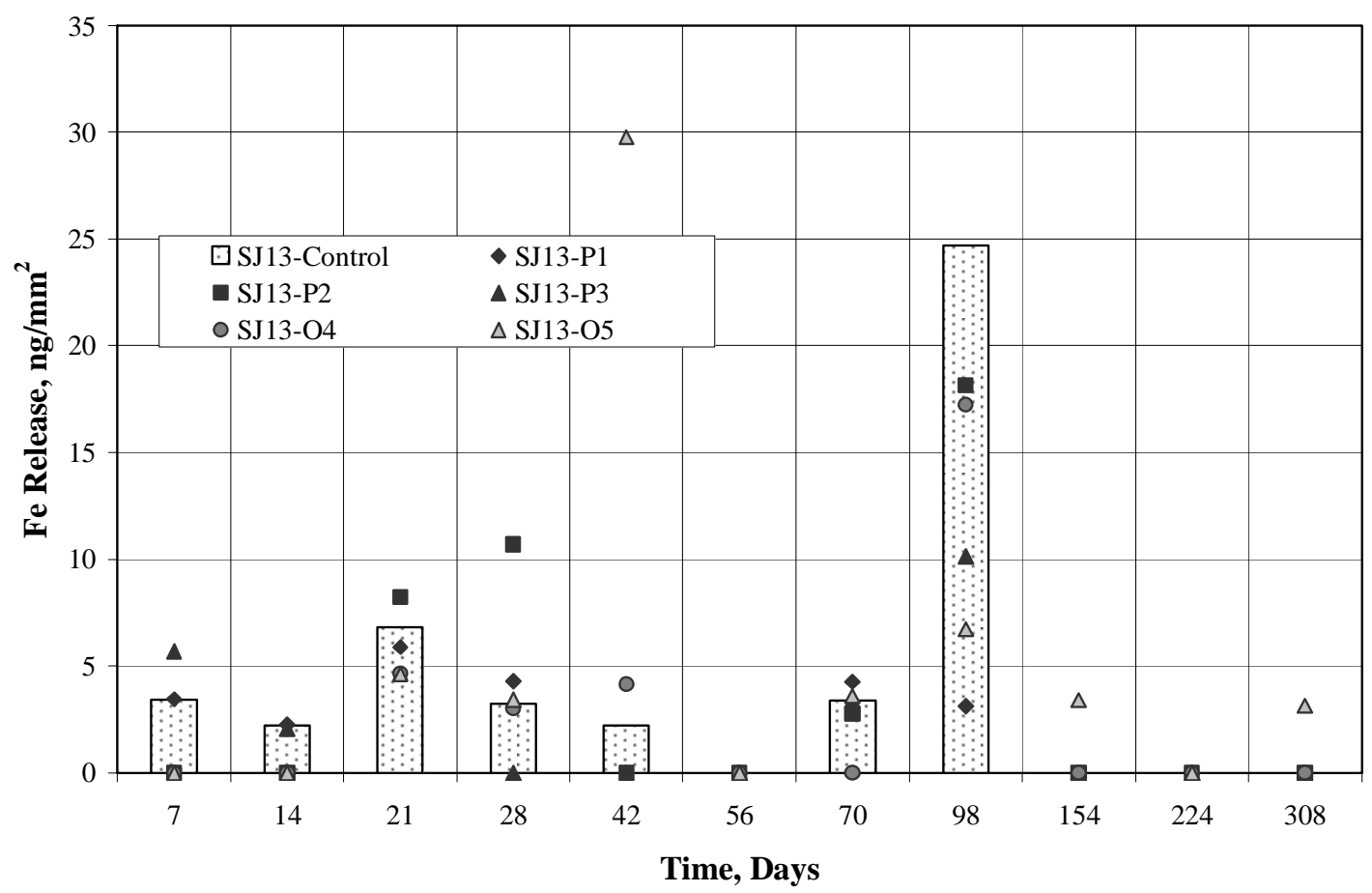

Figure III-1. Iron releases in $\mathrm{SJ} 13$ at $90^{\circ} \mathrm{C}$. 


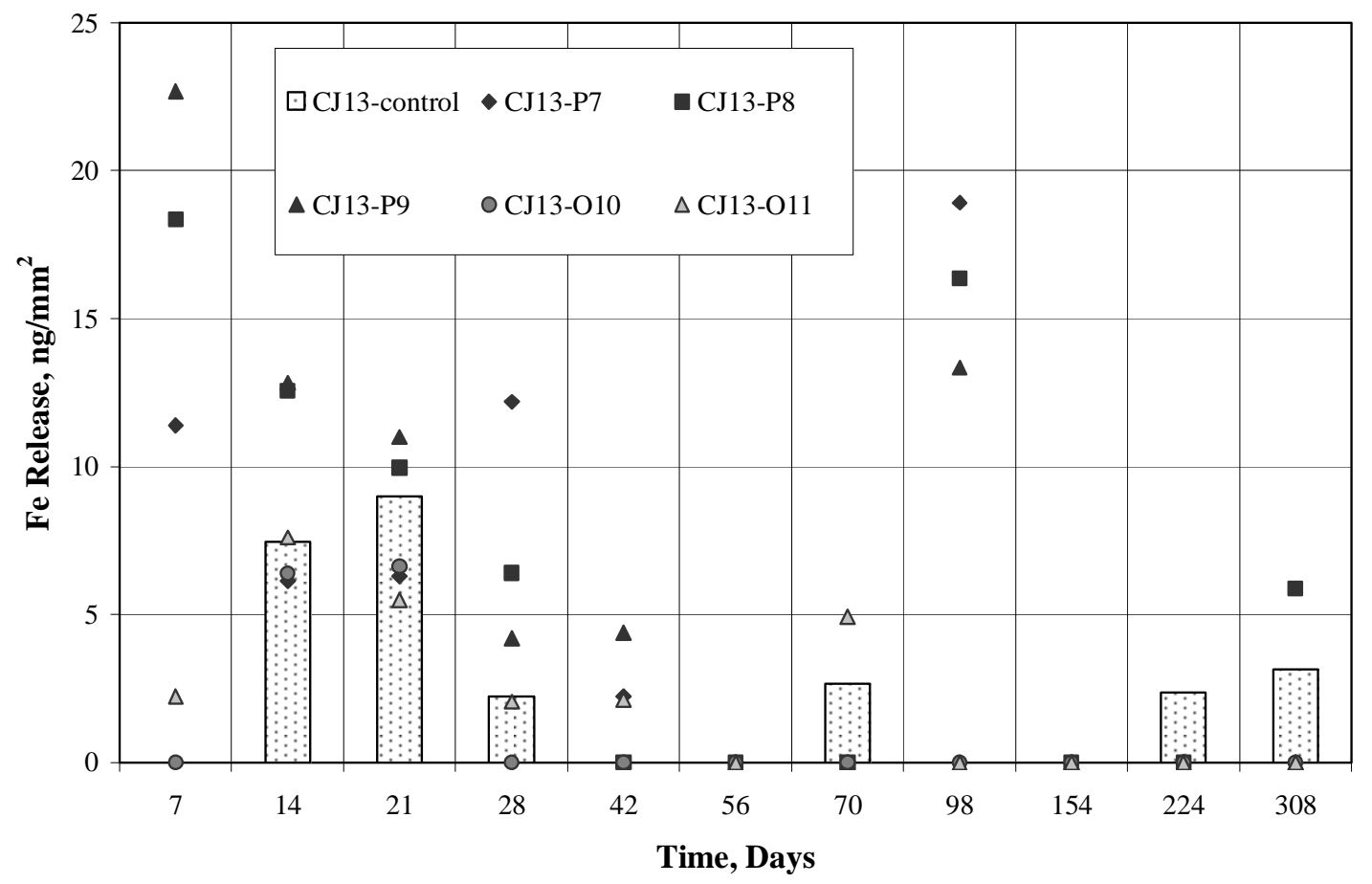

Figure III-2. Iron releases in $\mathrm{CJ} 13$ at $90^{\circ} \mathrm{C}$.

These figures also illustrate that the releases in SJ13 and CJ13 were so low even for the major elements released, that the detected releases were near the amount of element detected in the blank samples-even for the tests after week 22 (154 days) when new vials were used for each test.

\section{b) Effect of Variation of Detection Limits on Reported Releases}

Some fission-product elements and minor elements had releases that were near the detection limits—particularly in solutions SJ13 and CJ13. For elements released near the limit of detection, the variation in the detection limit determined whether or not any element was detected. An example of this is the release of Pd in SJ13, shown in Figure III-3. The solution detection limits for Pd in SJ13 ranged from a low of $0.0030 \mathrm{ng} / \mathrm{mm}^{2}$ on day 14 (week 2) to a high of $0.037 \mathrm{ng} / \mathrm{mm}^{2}$ on day 21 (week 3). The acid strip detection limits for Pd in SJ13 ranged from a low of $0.003 \mathrm{ng} / \mathrm{mm}^{2}$ on week 2 (day 14) to a high of $0.044 \mathrm{ng} / \mathrm{mm}^{2}$ on week 3 (day 21). Thus, if Pd was released during the time from week 2 (day 14) to week 3 (day 21) at the same rate as the previous week, it would not have been detected in either the solution or the acid strip from week 3 (day 21). Another example, shown in Figure III-4, is the detection of $0.069 \mathrm{ng} / \mathrm{mm}^{2}$ of Ru from sample 2 immersed in SJ13. Ru was detected in the acid strip of the walls on week 22 (day 154), which had a detection limit of $0.03 \mathrm{ng} / \mathrm{mm}^{2}$ for that day. The detection limit from the acid strip ranged from a low of $0.007 \mathrm{ng} / \mathrm{mm}^{2}$ to $0.27 \mathrm{ng} / \mathrm{mm}^{2}$. No other Ru was detected from any sample immersed in SJ13 for the entire test series. 


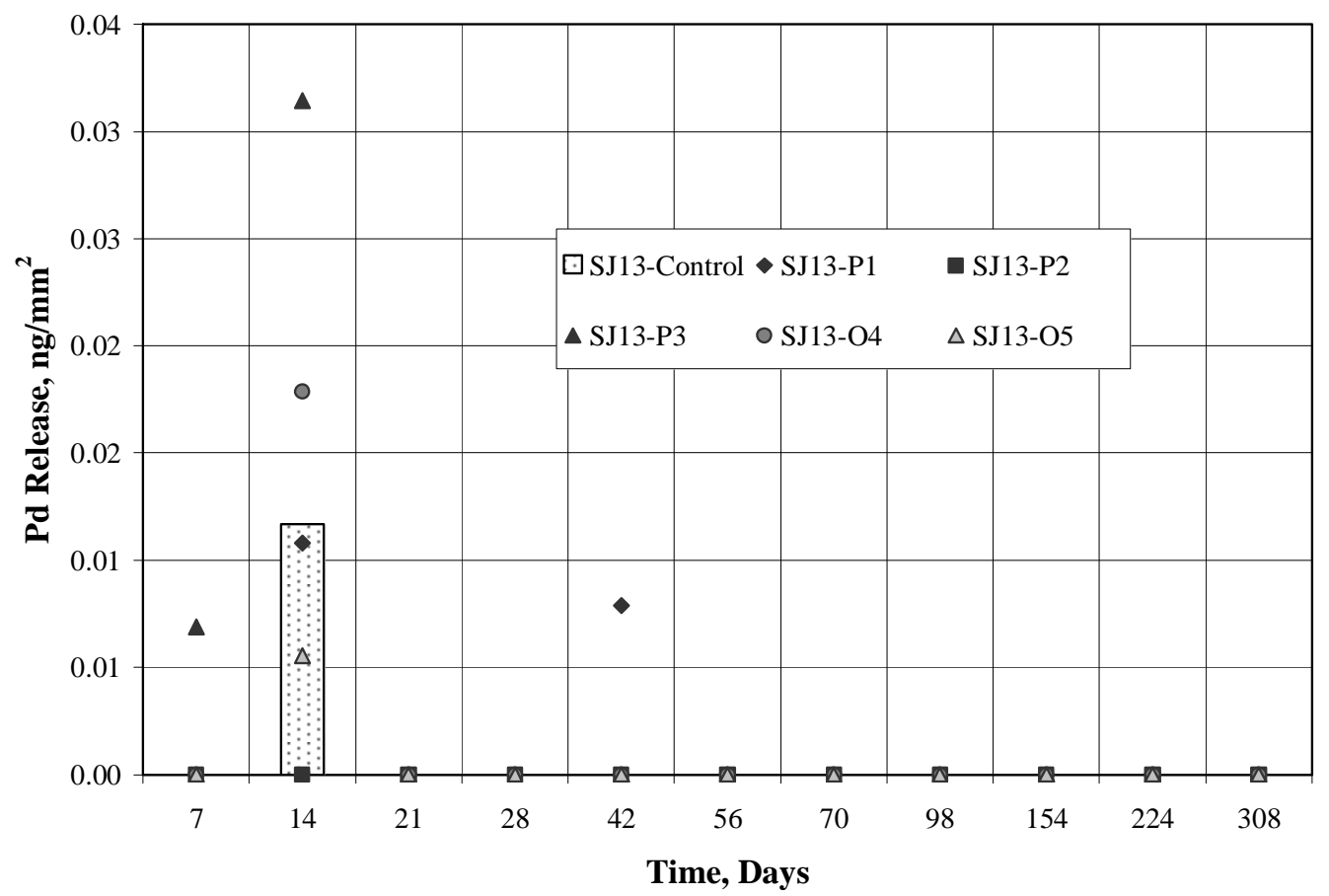

Figure III-3. Palladium releases in $\mathrm{SJ} 13$ at $90^{\circ} \mathrm{C}$.

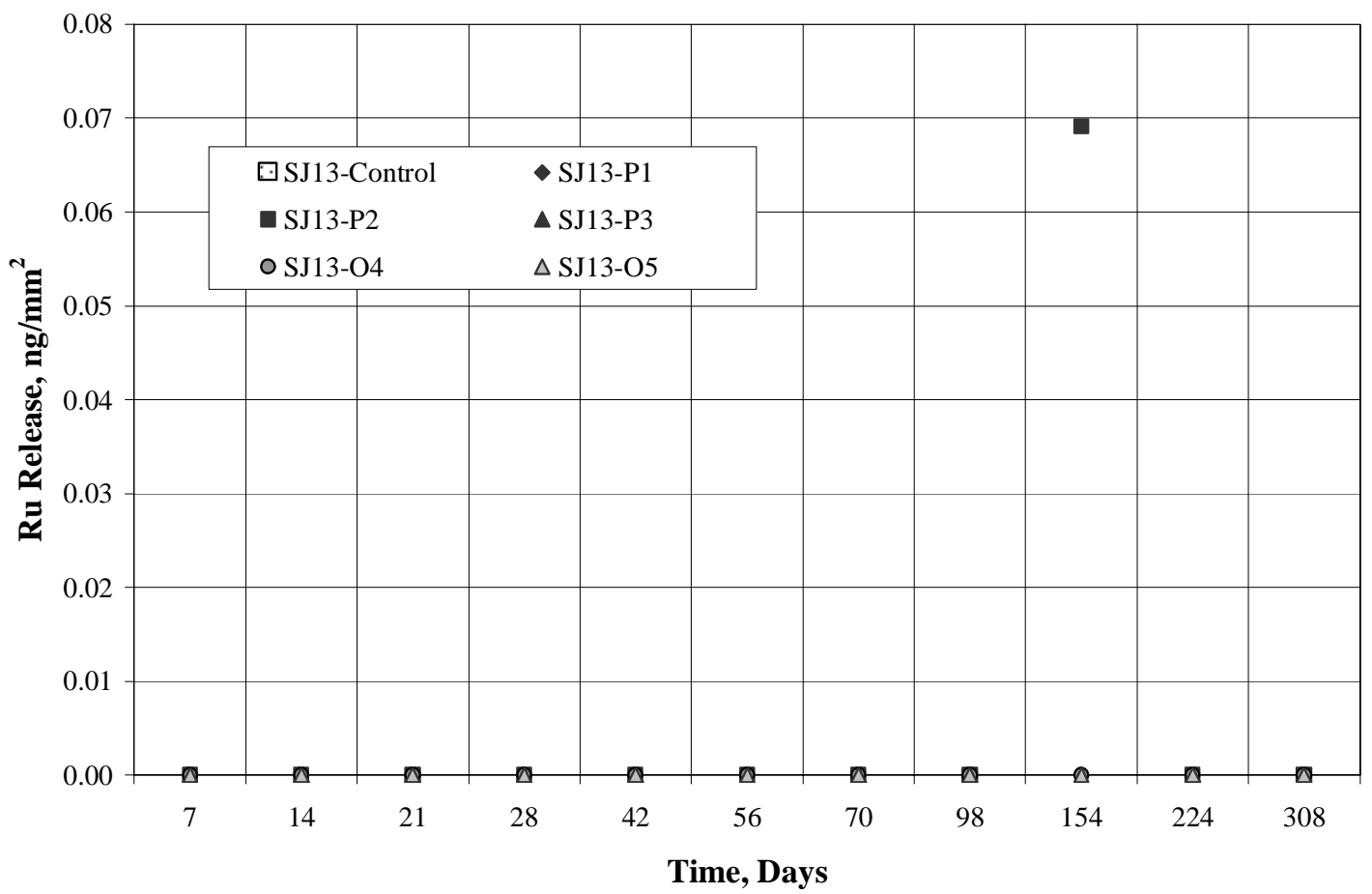

Figure III-4. Ruthenium releases in $\mathrm{SJ13}$ at $90^{\circ} \mathrm{C}$. 


\section{c) Sample Contamination of Minor Elements \& Mo}

Examination of releases of $\mathrm{Mo}, \mathrm{Cu}$, and $\mathrm{V}$ showed unusual fluctuations that could not be attributed to changes in detection limits or previous use of vials. Upon checking the history of laboratory use during the test time of high releases, it was found that experimenters not related to the Metal Waste Form Project were using the laboratory balance to measure powders containing $\mathrm{Mo}, \mathrm{Cu}$, and $\mathrm{V}$. It is believed that the test samples were contaminated from airborne powders of these elements. Thus, reported releases of these three elements are not reliable. Figure III-5 shows unusually high Mo from residue on week 4 (day 28) in the $10 \mathrm{KCl}$ test. Examination of the test data for the other samples shows similar high Mo from residue. It is believed this is from sample contamination.

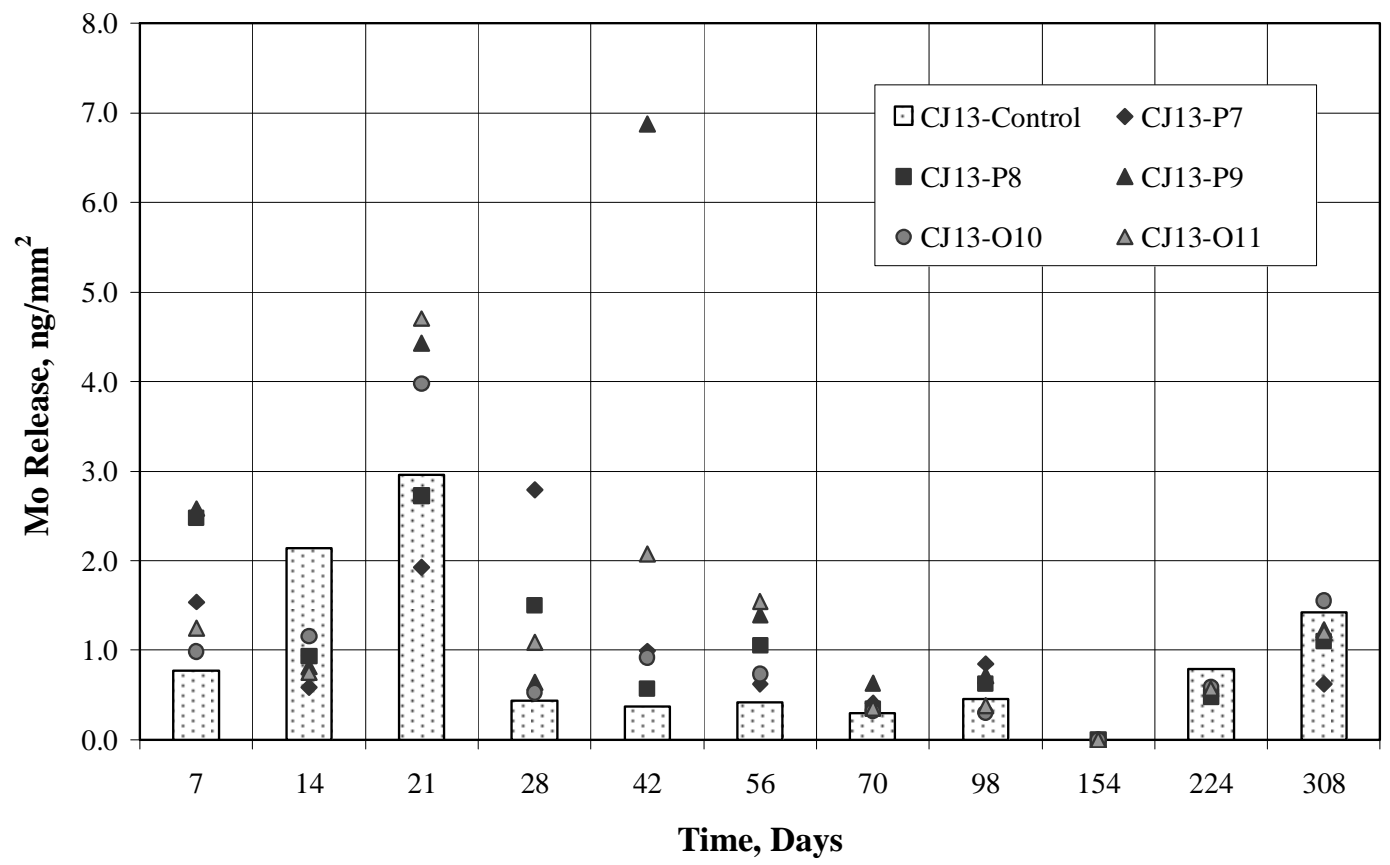

Figure III-5. Molybdenum releases in $\mathrm{CJ} 13$ at $90^{\circ} \mathrm{C}$.

The $\mathrm{Cu}$ and $\mathrm{V}$ release data in Appendix E show random high releases. Although some could be from changes in detection limits, others are most likely related to contamination from other work with powdered $\mathrm{Cu}$ and $\mathrm{V}$ in the laboratory.

\section{d) Mo and Minor Elements (Mn, Co, Cu, and V)}

Because of contamination problems for $\mathrm{Mo}, \mathrm{Cu}$, and $\mathrm{V}$ and the lack of interest in the low released minor elements, releases of these elements will not be discussed. These elements have not been included in the reported total release. Inclusion or not inclusion of the minor elements, $\mathrm{Mn}$ and $\mathrm{Co}$, make no difference in the total release. However, inclusion of the elements for which the solutions were sometimes contaminated $(\mathrm{Mo}, \mathrm{Cu}$, and $\mathrm{V}$ ) in the sum of the total release may produce occasional increases from the contamination in SJ13 tests when the releases of the major elements were small. Because 
the data for $\mathrm{Mo}, \mathrm{Cu}$, and $\mathrm{V}$ lack validity because of contamination, they have not been included in the total release.

\section{Cumulative Releases at $90^{\circ} \mathrm{C}$ for Each Solution}

\section{a) SJ13:}

Except for the releases of $\mathrm{Fe}$ and $\mathrm{Zr}$, few elements were detected from the immersion tests in SJ13. $\mathrm{Cr}$ and $\mathrm{Rh}$ were not detected in any of the examinations. The small amounts of $\mathrm{Ni}$ and fission-product elements detected were near the limits of detection. The total cumulative releases, which is defined as the sum of the major elements $(\mathrm{Fe}, \mathrm{Zr}$, $\mathrm{Cr}, \mathrm{Ni}$ ) and the fission product elements ( $\mathrm{Pd}, \mathrm{Nb}, \mathrm{Ru}, \mathrm{Rh}$ ), are shown in Figure III-6 from five samples in SJ13. The higher releases for sample SJ13-O5 relative to the other samples arises from the combined higher releases of $\mathrm{Zr}$ and $\mathrm{Fe}$ for that sample.

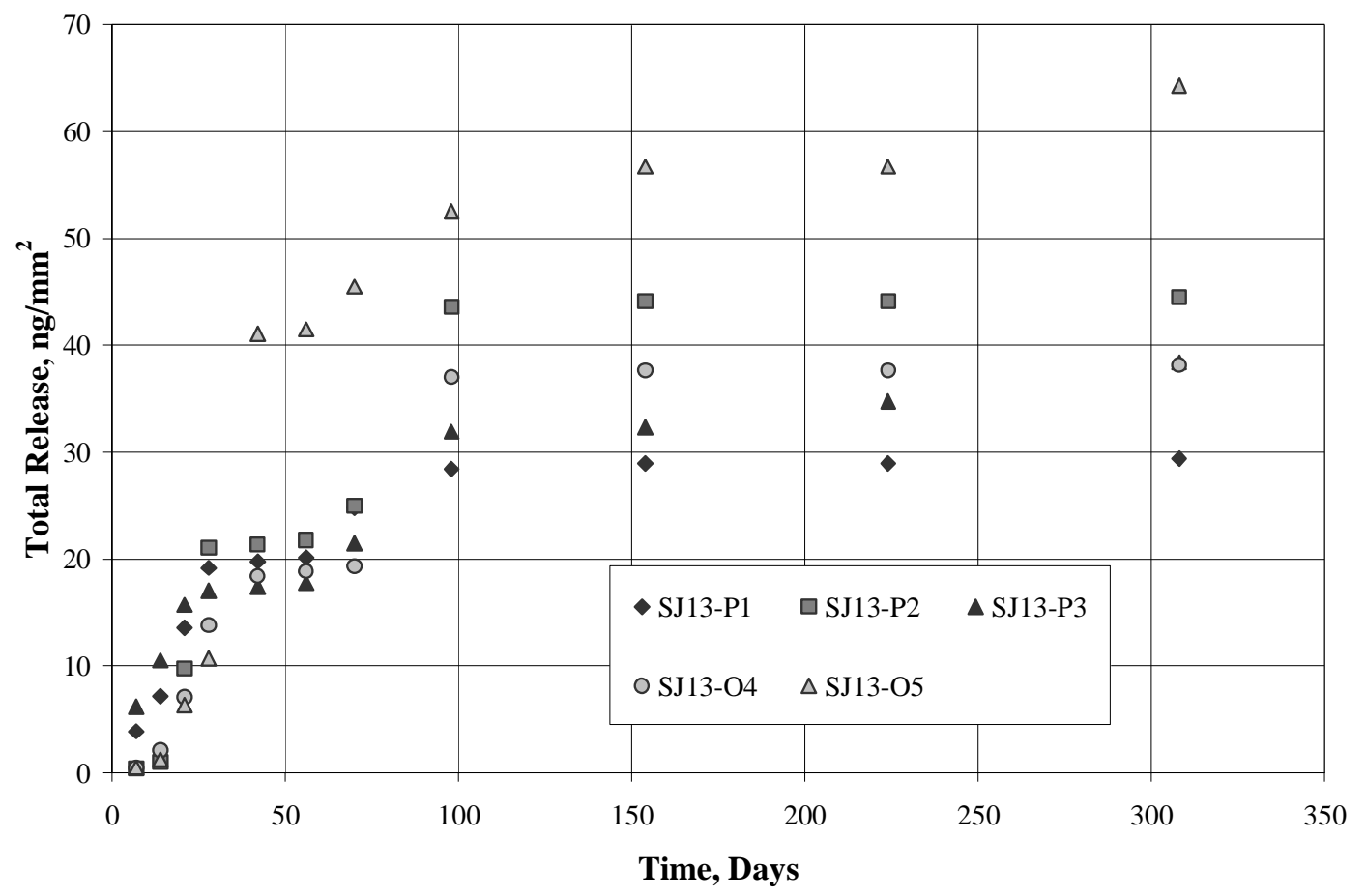

Figure III-6. Total cumulative releases in $\mathrm{SJ} 13$ at $90^{\circ} \mathrm{C}$.

\section{Release of Major Elements}

The amounts of Fe detected in SJ13 solutions were low compared to the Fe detected in the more aggressive solutions, $\mathrm{AJ} 13$ and $10 \mathrm{KCl}$. Thus, removal of Fe from walls of Teflon vials reused from the high chloride and $\mathrm{pH}=2, \mathrm{AJ} 13$ solutions adds uncertainty to the cumulative Fe release in SJ13, as discussed above. The cumulative release of Fe in $\mathrm{SJ} 13$ at $90^{\circ} \mathrm{C}$ is shown in Figure III-7. The large scatter and jumps in the data are related to vial reuse and indicate the uncertainty in the reported results. The cumulative release data for $\mathrm{Zr}$ in $\mathrm{SJ} 13$ at $90^{\circ} \mathrm{C}$ is shown in Figure III-8. The large scatter between the different immersion samples arises because the releases are so small. In fact, amounts of 
$\mathrm{Zr}$ detected in the control vials from SJ13 tests were almost as high as that from vials that contained Metal Waste Form samples. Figure III-9 indicates that Ni was only detected in two samples at two times. No Cr was detected in any samples immersed in $\mathrm{SJ} 13$ at $90^{\circ} \mathrm{C}$.

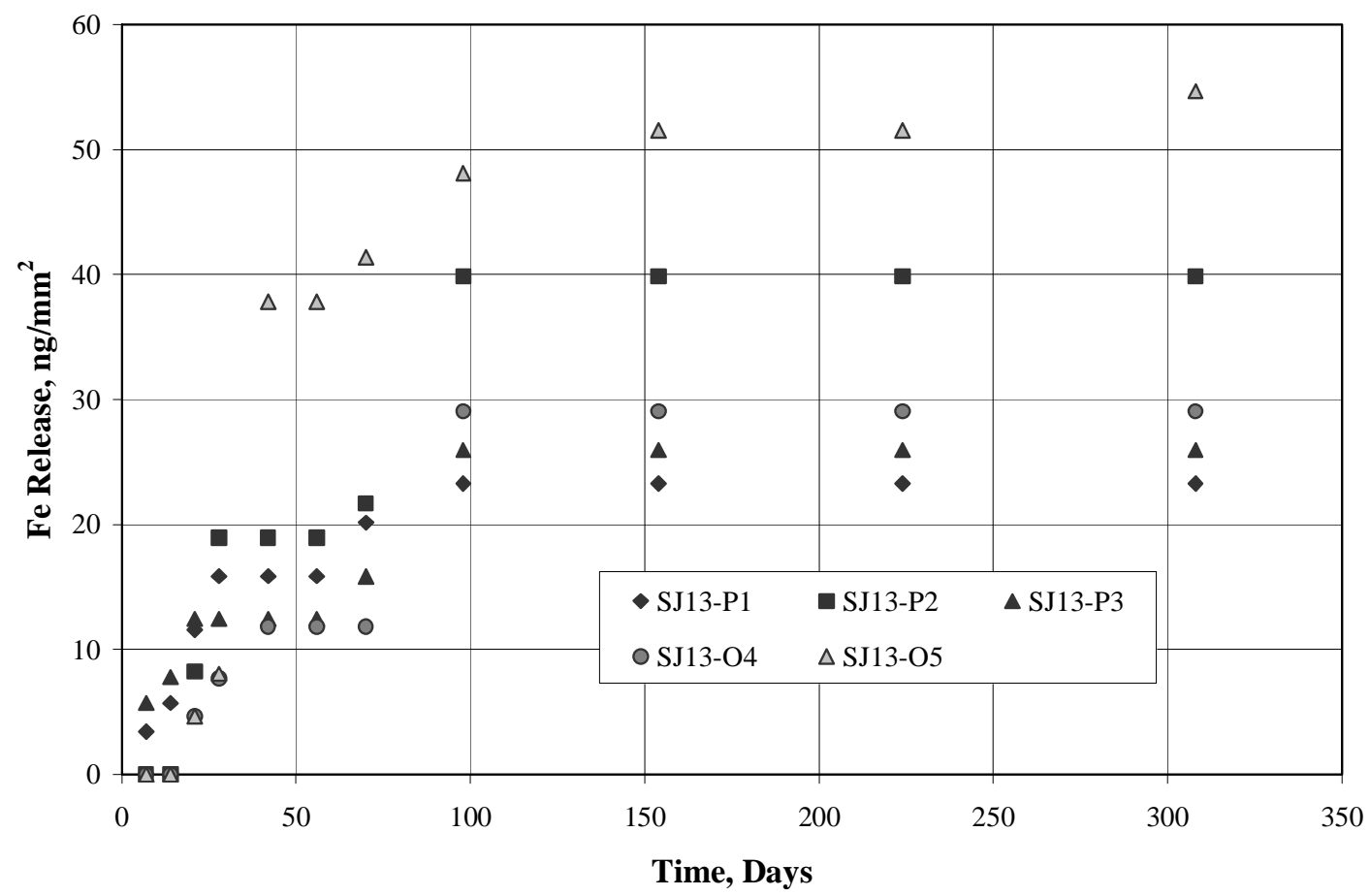

Figure III-7. Cumulative Iron releases in $\mathrm{SJ} 13$ at $90^{\circ} \mathrm{C}$.

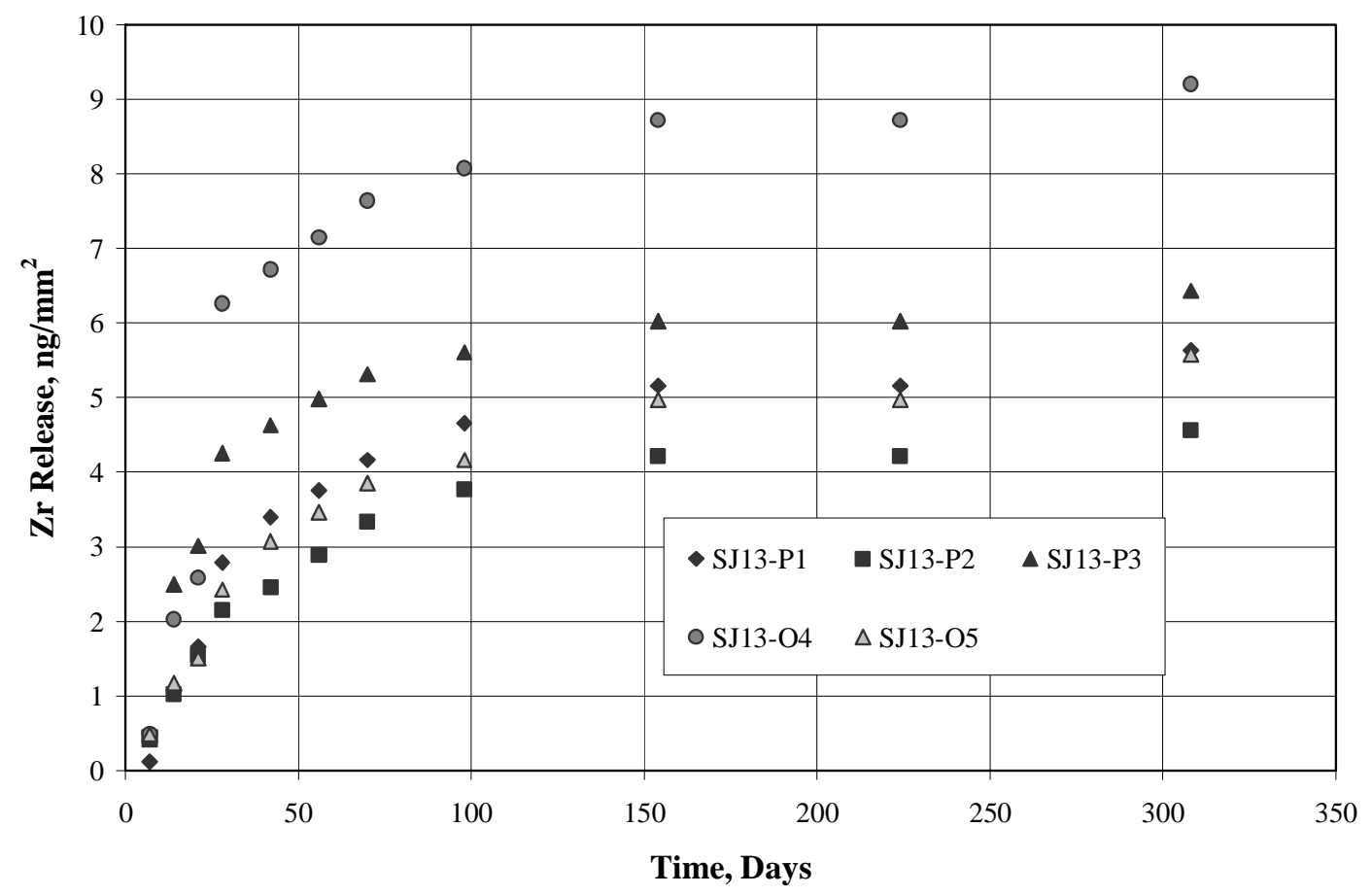

Figure III-8. Cumulative Zirconium releases in $\mathrm{SJ} 13$ at $90^{\circ} \mathrm{C}$. 


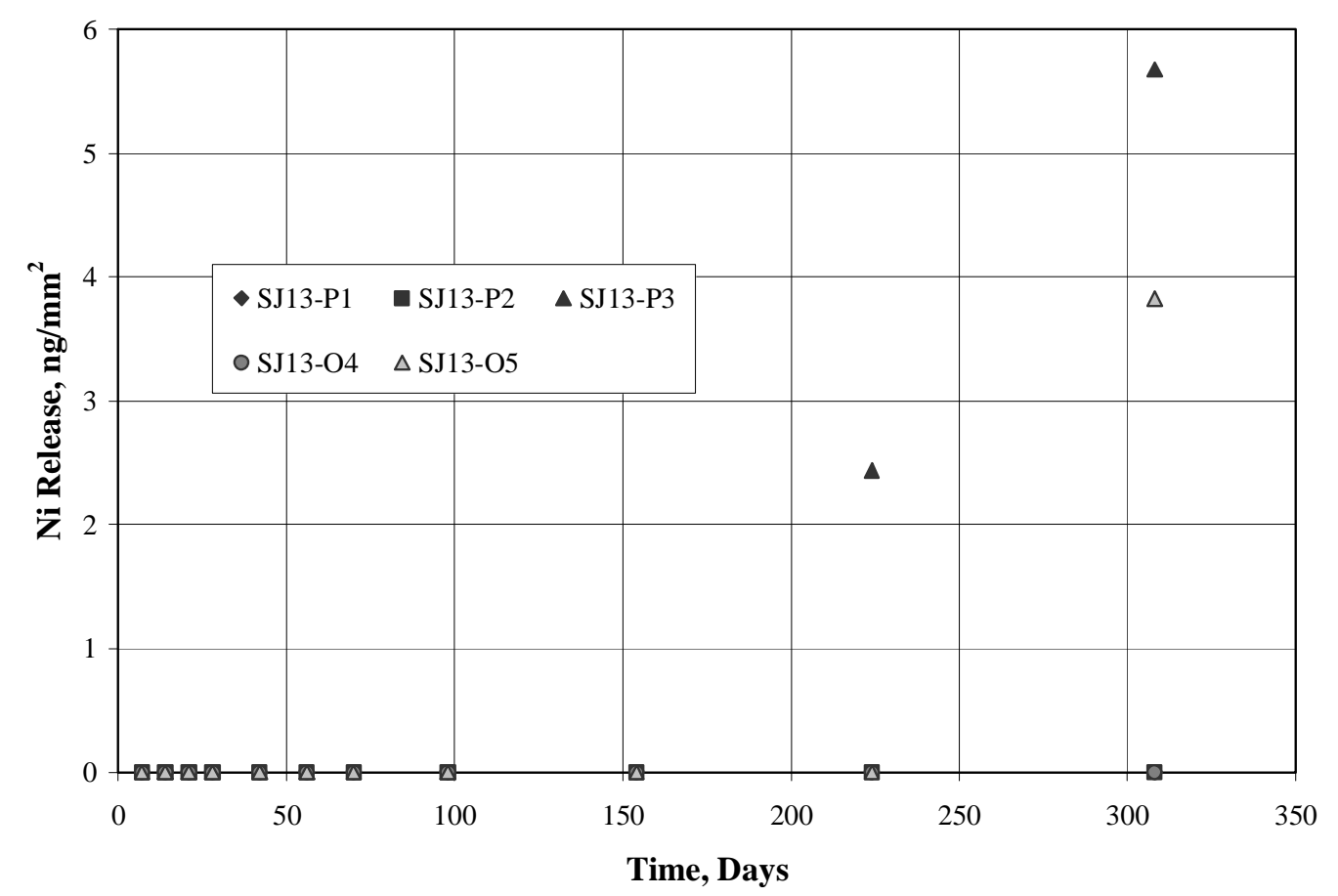

Figure III-9. Cumulative Nickel releases in $\mathrm{SJ} 13$ at $90^{\circ} \mathrm{C}$.

\section{Release of Fission-Product Elements}

The cumulative release of Ru, shown in Figure III-10, shows a jump at 154 days for one sample and then a constant value because Ru was detected in only one acid strip wash of sample P2 during week 22 analysis, as discussed above. The scatter in the cumulative Pd release, shown in Figure III-11, results from the Pd release being so close to the detection limit, that it is only detected on days when the detection limits were unusually low, as discussed above. The large scatter in the cumulative Nb release, shown in Figure III-12, indicates that these data have significant uncertainty because of the low $\mathrm{Nb}$ release. 


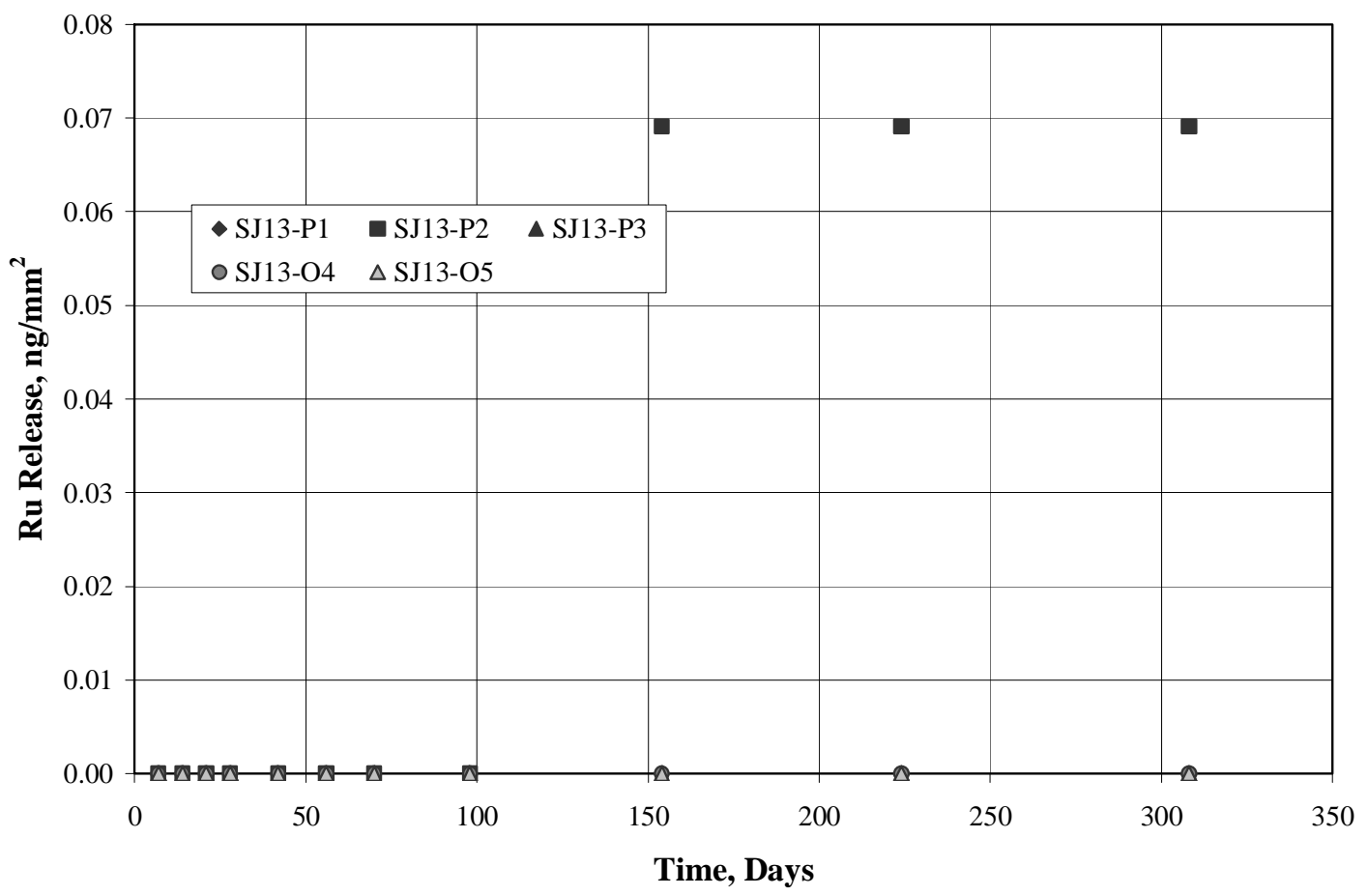

Figure III-10. Cumulative Ruthenium releases in $\mathrm{SJ} 13$ at $90^{\circ} \mathrm{C}$.

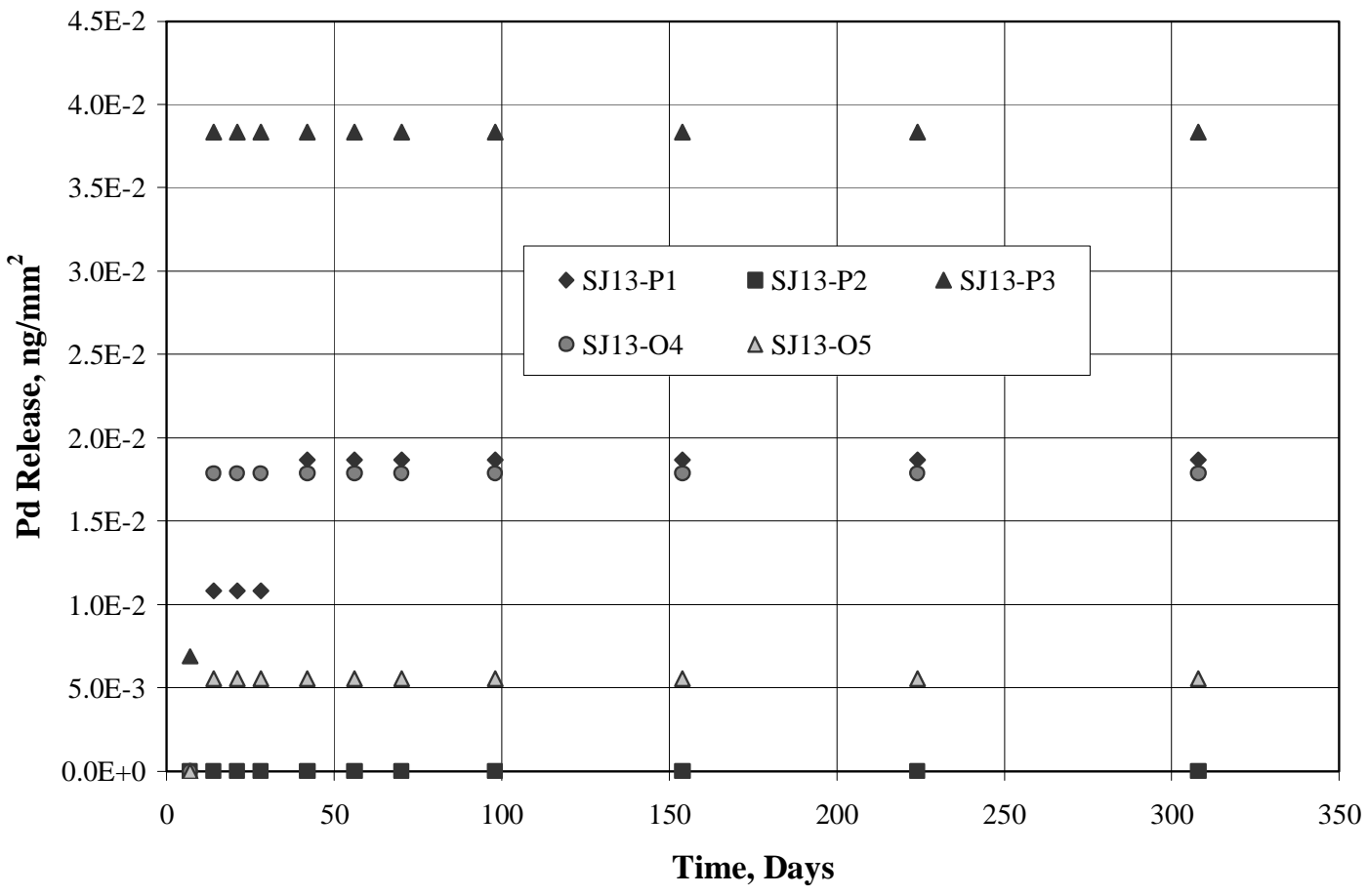

Figure III-11. Cumulative Palladium releases in $\mathrm{SJ}_{13}$ at $9^{\circ} \mathrm{C}$. 


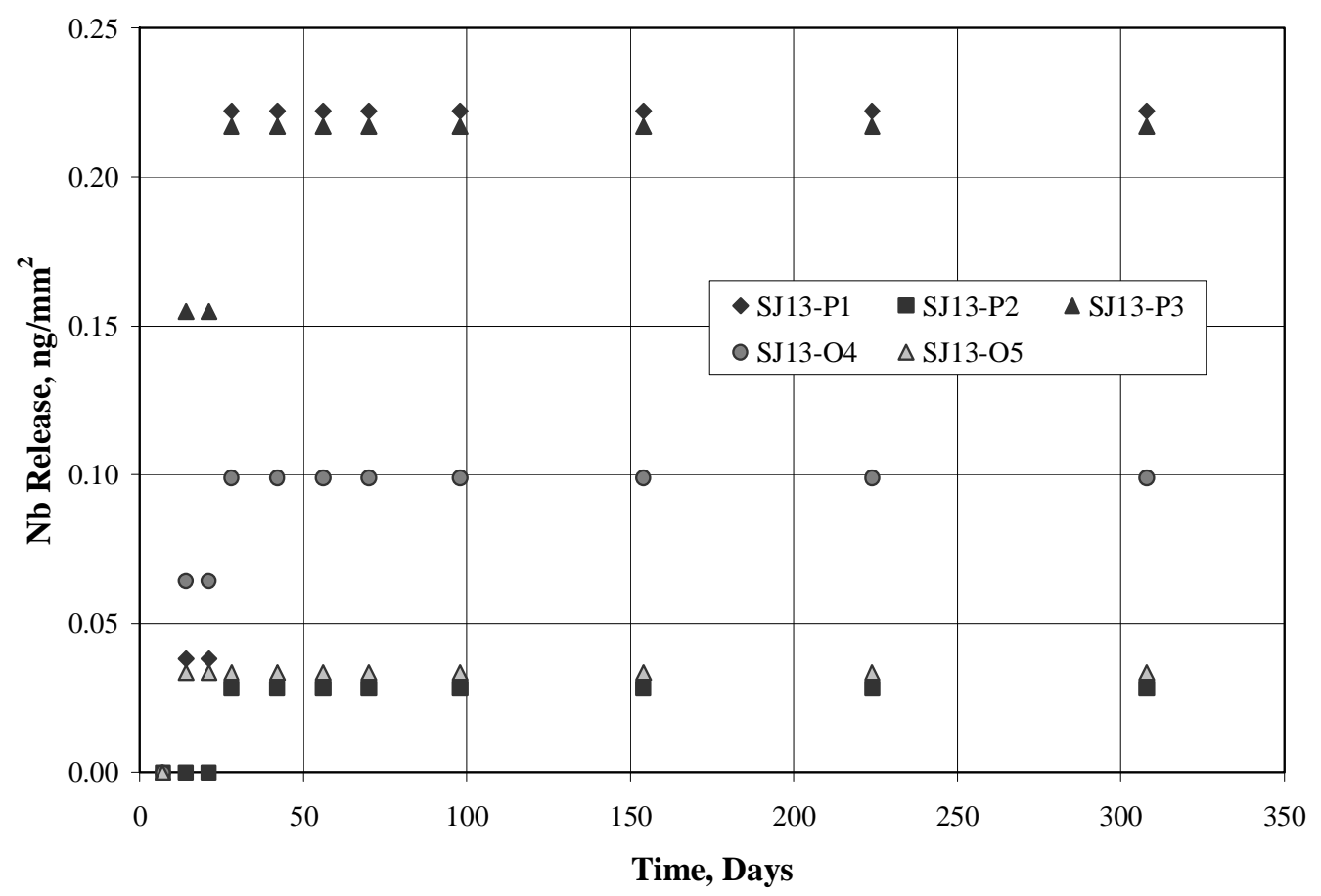

Figure III-12. Cumulative Niobium releases in $\mathrm{SJ13}$ at $90^{\circ} \mathrm{C}$.

\section{SJ13 Summary}

Figure III-13 compares the averages of the cumulative releases of Fe, $\mathrm{Zr}$, and the fissionproduct elements with the average total release in $\mathrm{SJ} 13$. The average release of $\mathrm{Ni}$, which was released at similar levels as the fission-product elements, has not been shown because inclusion of $\mathrm{Ni}$ in the figure would make it more difficult to discern differences of the fission-product elements. Figure III-13 shows that the main contribution to the total cumulative release is the release of $\mathrm{Fe}$. $\mathrm{Zr}$ release is about an order of magnitude lower. Fission-product element releases are even lower and are close to their detection limits. In some cases, an element was detected in only one test-a test that had a lower detection limit than other tests. This indicates that longer time intervals between analysis of the solutions are needed. Thus, normalized losses based on these data may not be reliable. 


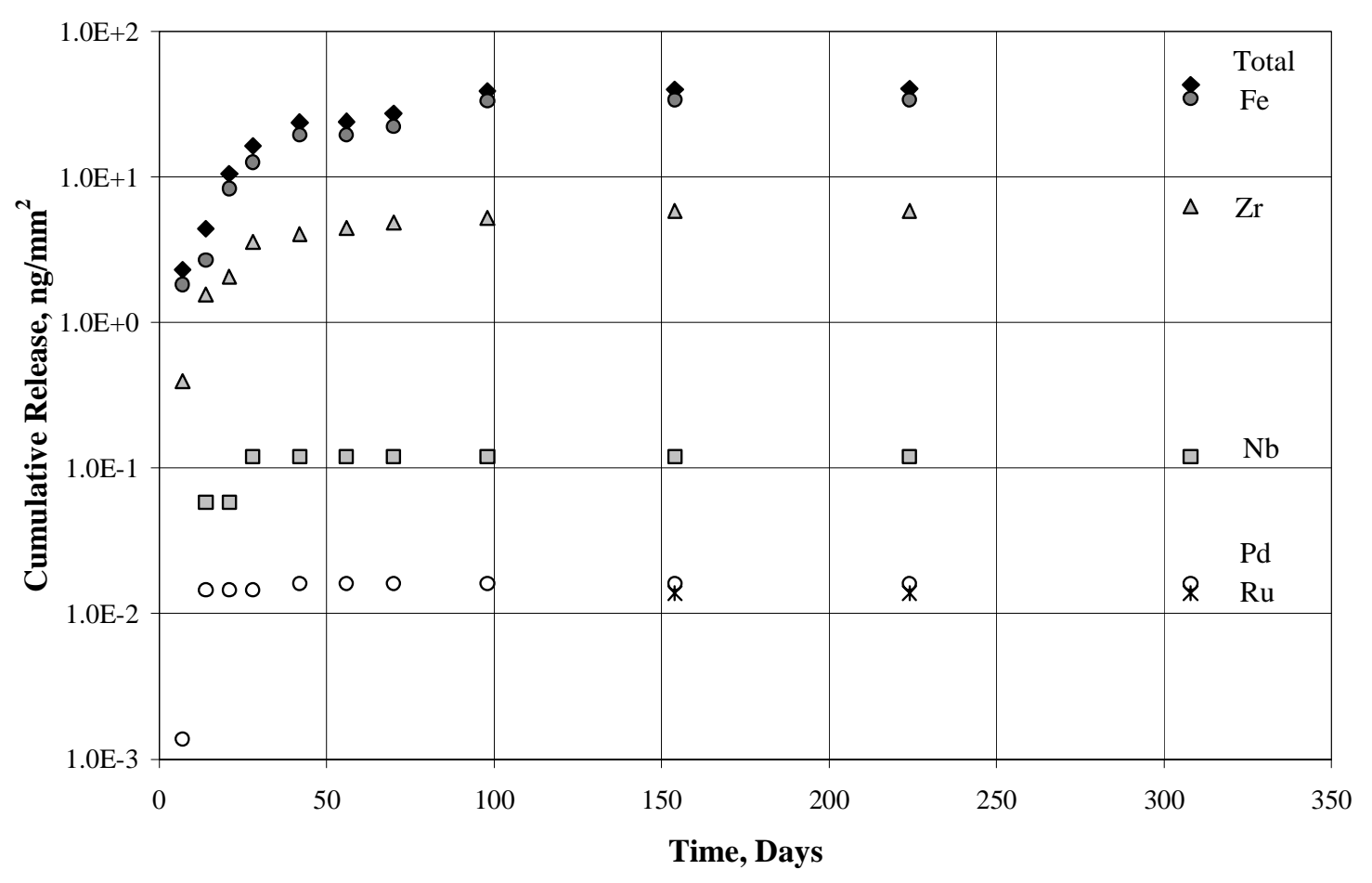

Figure III-13. Average cumulative release in $\mathrm{SJ} 13$ at $90^{\circ} \mathrm{C}$.

\section{b) CJ13:}

The CJ13 solution was selected to have a similar $\mathrm{pH}$ to that of SJ13 but to be a little more aggressive, yet not as aggressive as the high chloride and AJ13 solutions. Total releases of the major elements ( $\mathrm{Fe}, \mathrm{Zr}, \mathrm{Cr}$, and $\mathrm{Ni}$ ) and the fission-product elements $(\mathrm{Pd}, \mathrm{Nb}, \mathrm{Rh}$, $\mathrm{Ru})$ in $\mathrm{CJ} 13$ are shown in Figure III-14. These total releases are only slightly higher than the total releases in SJ13, Figure III-6. This solution appears to differ from SJ13, in that the total releases of the two pre-oxidized samples (O10 and O11) are consistently lower than the releases from the polished samples. 


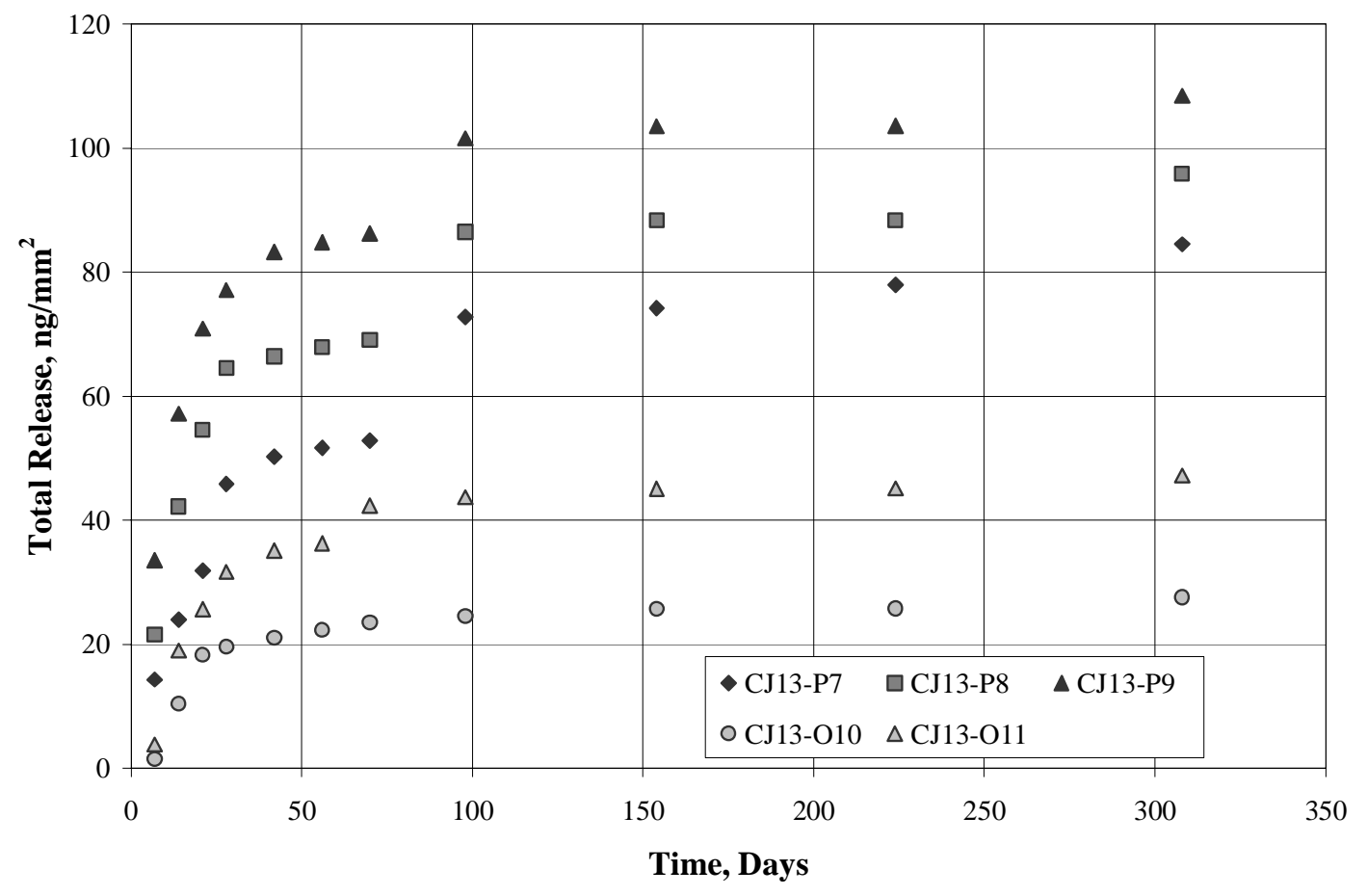

Figure III-14. Total cumulative releases in $\mathrm{CJ} 13$ at $90^{\circ} \mathrm{C}$.

\section{Release of Major Elements}

The cumulative releases of Fe from samples immersed in CJ13, shown in Figure III-15, show similar behavior to the total releases in CJ13. The differences between the Fe releases from polished and oxidized samples for the first few weeks are more pronounced than for the total releases in CJ13. The jump in the releases from the polished samples at day 98 may be from Fe leaching from the walls because the vials for these three samples were previously used for a test in $10 \mathrm{KCl}$, which aggressively attacks the Fe. The samples that do not show the jump had been previously used as a control and for an AJ13 test. Cumulative releases of $\mathrm{Zr}$ in CJ13 are shown in Figure III-16. The large scatter in the data for the first two weeks affected all subsequent cumulative releases. Like the $\mathrm{Fe}$ releases, $\mathrm{Zr}$ releases from sample $\mathrm{O} 10$ are the lowest, but the $\mathrm{Zr}$ releases from the polished sample P7 are lower than the releases from the oxidized sample O11, indicating that the oxidation may not affect the $\mathrm{Zr}$ releases as much as the Fe releases. Figures III17 and III-18 indicate that little $\mathrm{Ni}$ and $\mathrm{Cr}$ were detected in CJ13, just like SJ13 releases of these elements. 


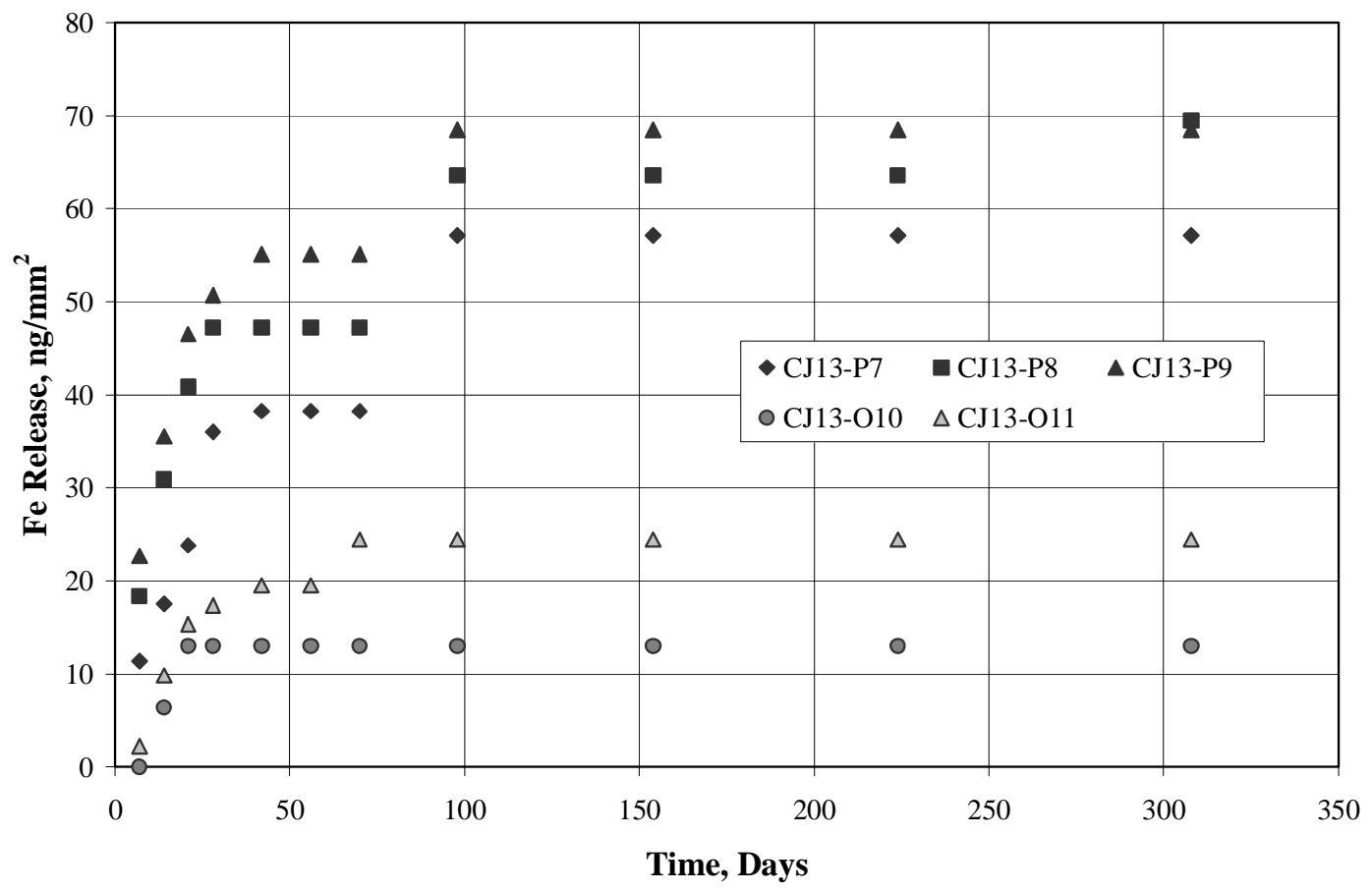

Figure III-15. Cumulative Iron releases in $\mathbf{C J} 13$ at $90^{\circ} \mathrm{C}$.

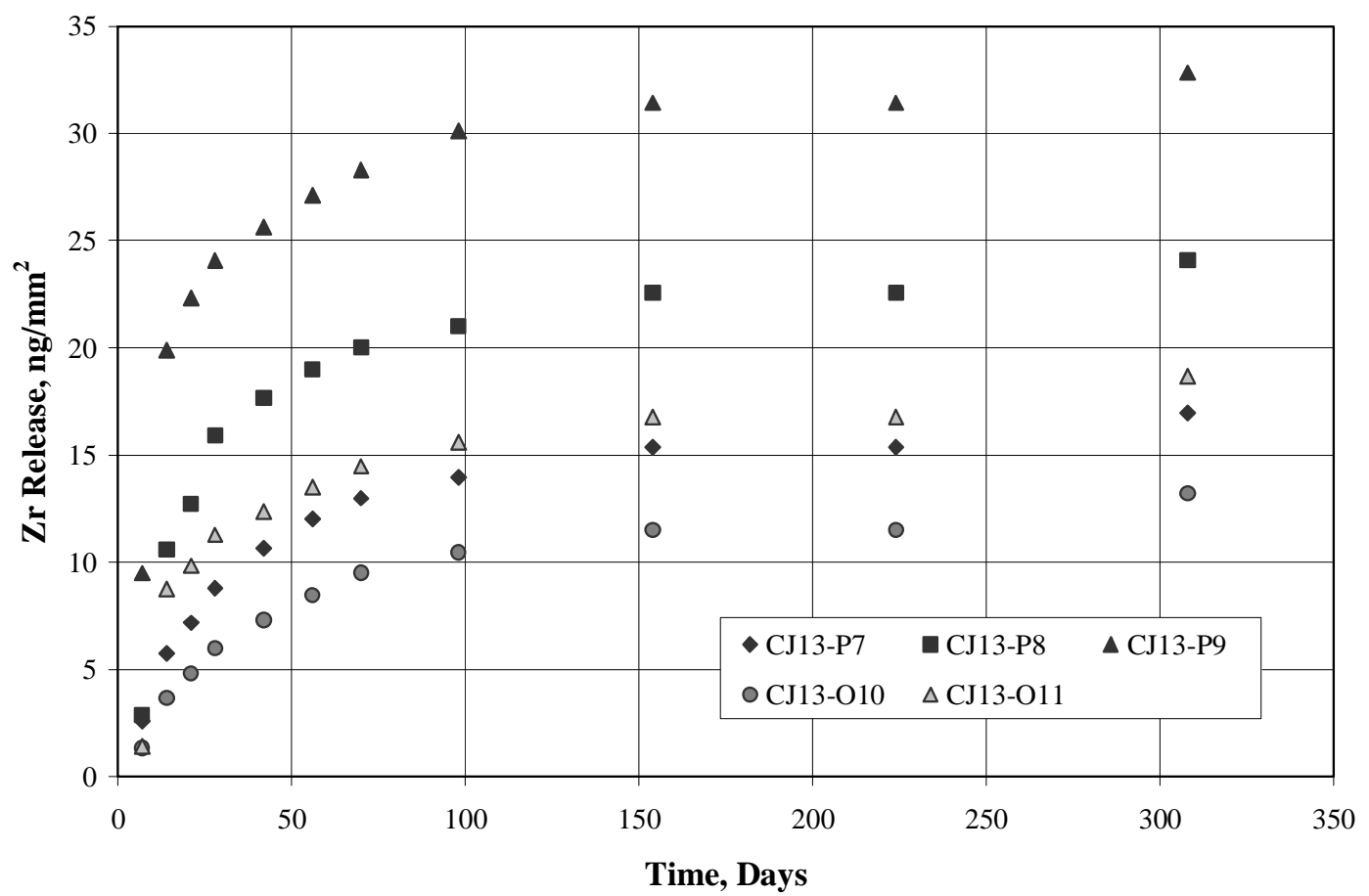

Figure III-16. Cumulative Zirconium releases in $\mathrm{CJ} 13$ at $90^{\circ} \mathrm{C}$. 


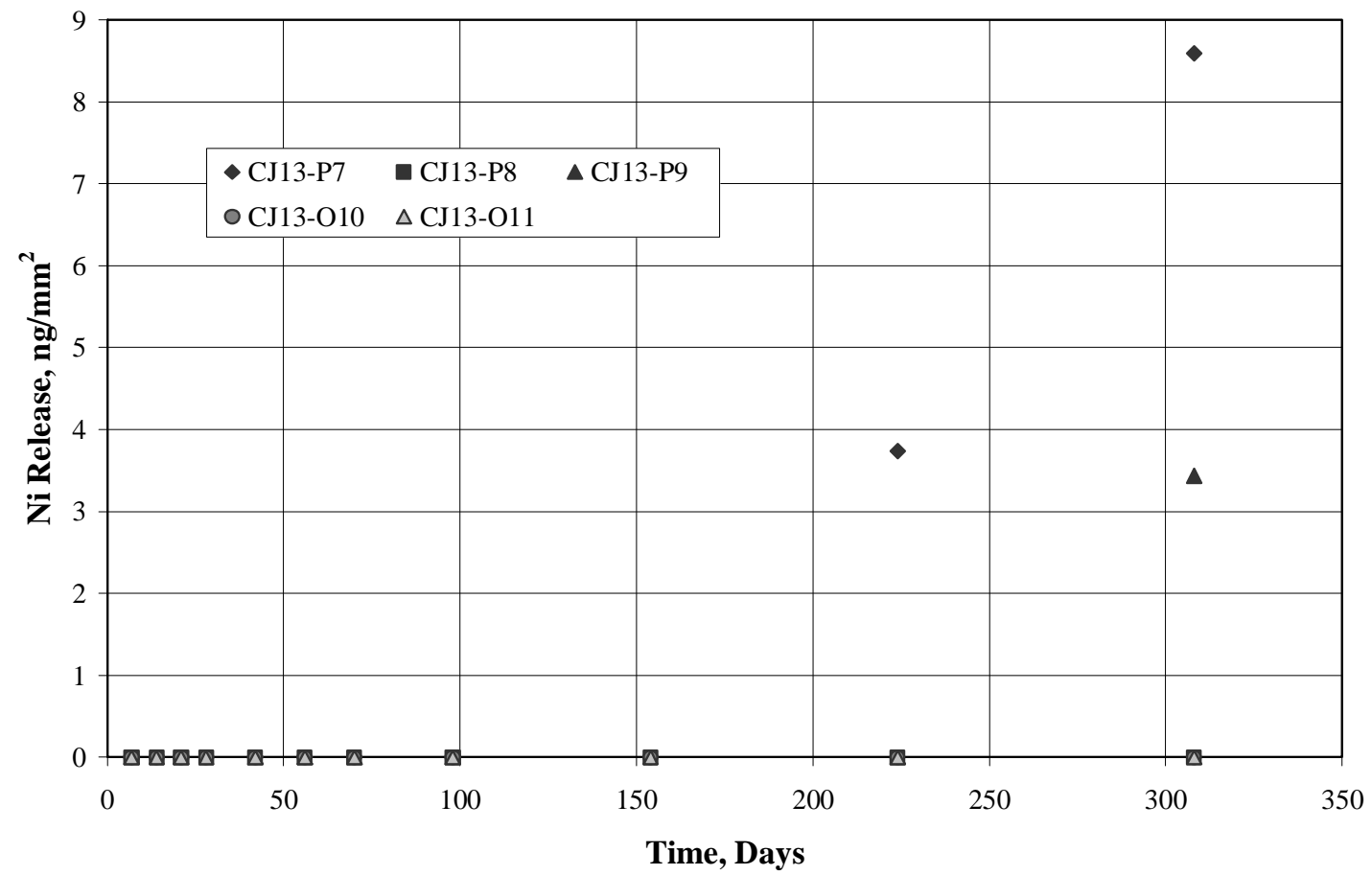

Figure III-17. Cumulative Nickel releases in $\mathrm{CJ}_{13}$ at $9^{\circ} \mathrm{C}$.

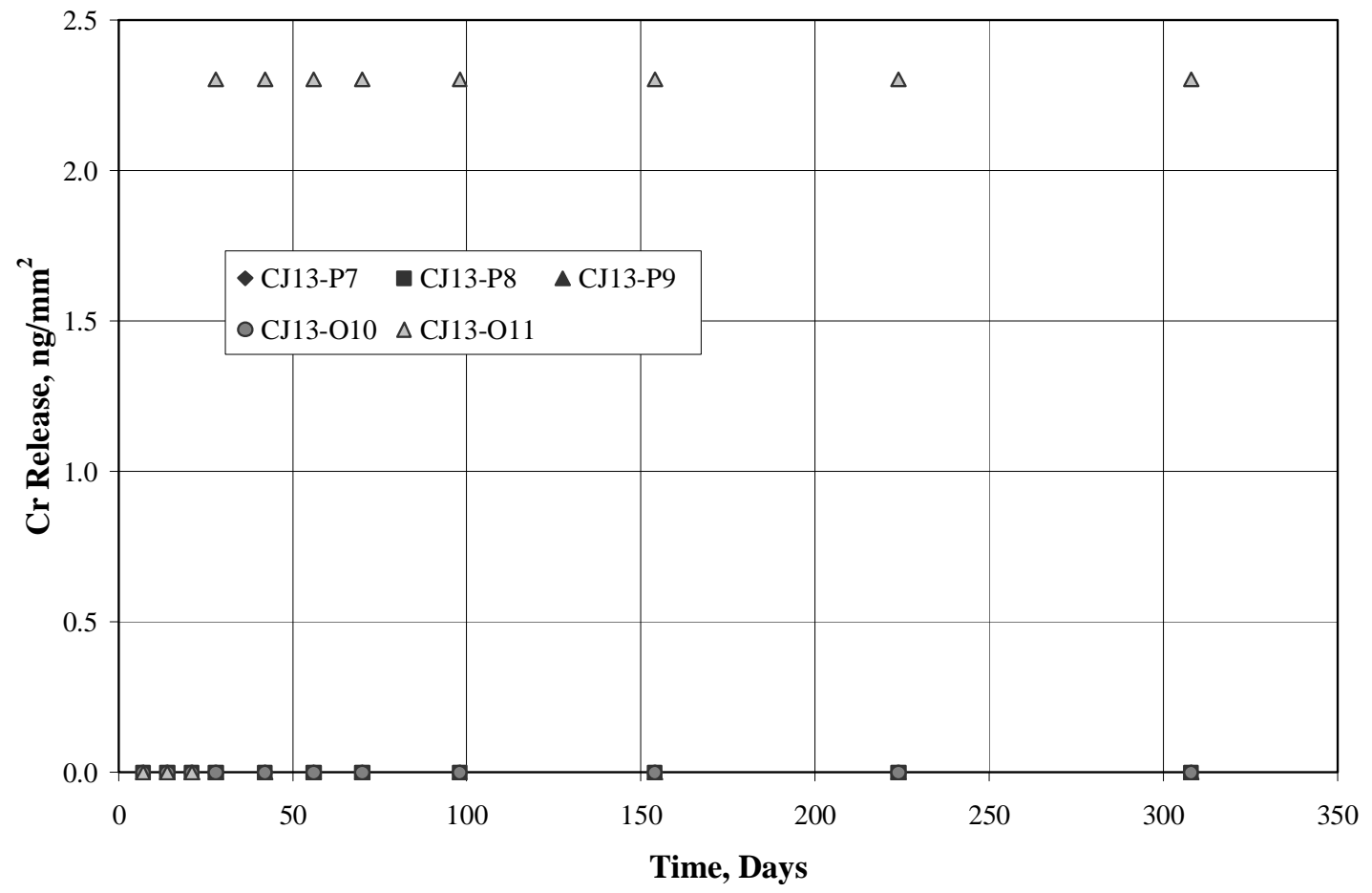

Figure III-18. Cumulative Chromium releases in $\mathrm{CJ} 13$ at $90^{\circ} \mathrm{C}$. 


\section{Release of Fission-Product Elements}

Cumulative releases of the fission products, $\mathrm{Nb}, \mathrm{Pd}, \mathrm{Ru}$, and $\mathrm{Rh}$ in $\mathrm{CJ} 13$ are shown in Figures III-19 through III-22. Releases of these fission products were detected in all samples for the first week of the tests. Figure III-19 shows that $\mathrm{Nb}$ releases from oxidized samples for the first four weeks were consistently lower than the $\mathrm{Nb}$ releases from polished samples, similar to the Fe release. Although the cumulative releases of Pd, shown in Figure III-20, are of similar magnitude to the $\mathrm{Nb}$ releases, the amounts of Pd detected in the control vials are often as large as the amount of Pd detected from Metal Waste Form samples (see Appendix F) indicating uncertainty in these data. Except for the first week of tests, releases of $\mathrm{Ru}$ and $\mathrm{Rh}$ were so small that they were often near detection limits or near the amounts detected from control vials.

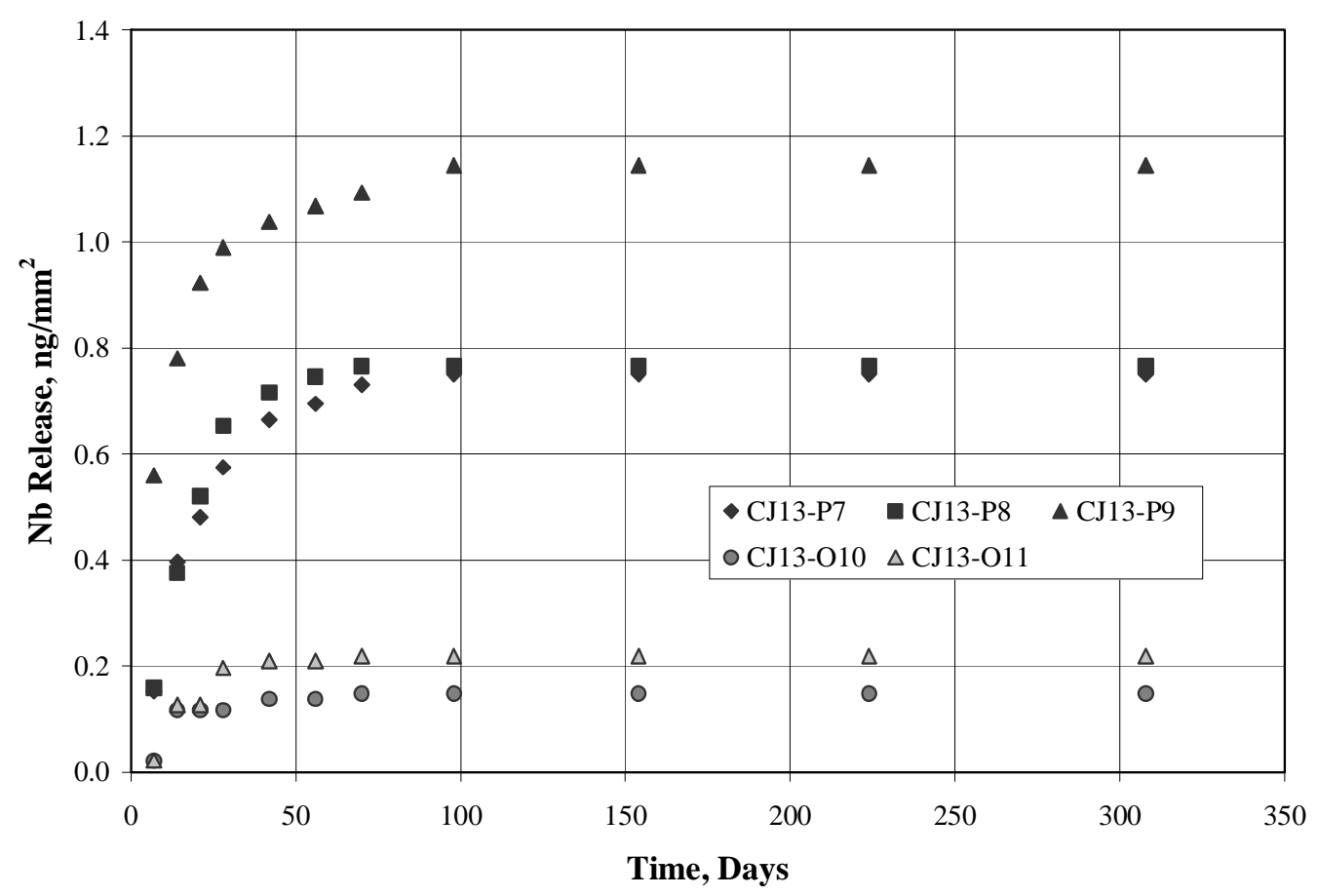

Figure III-19. Cumulative Niobium releases in $\mathrm{CJ} 13$ at $90^{\circ} \mathrm{C}$. 


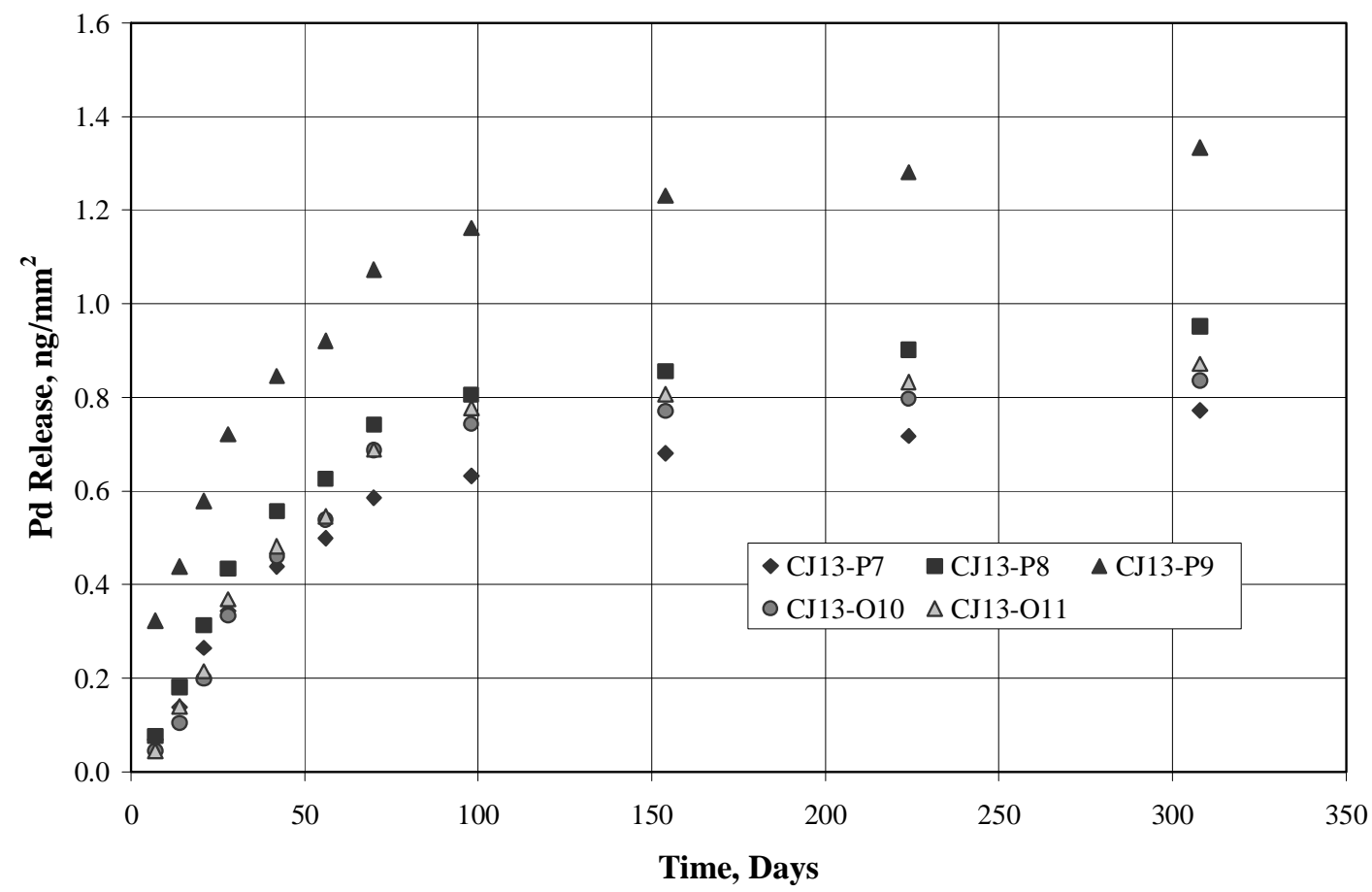

Figure III-20. Cumulative Palladium releases in $\mathrm{CJ} 13$ at $9^{\circ} \mathrm{C}$.

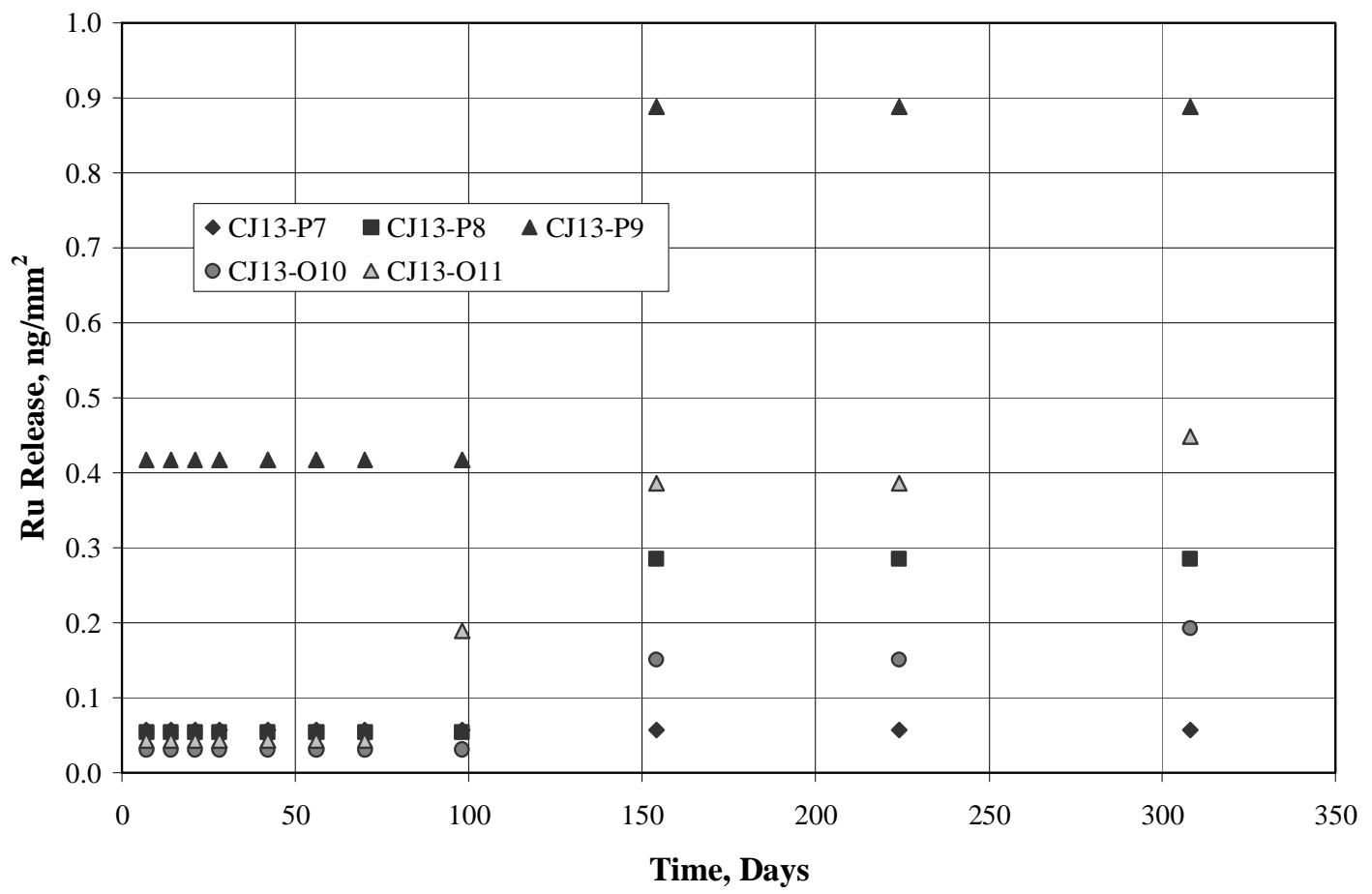

Figure III-21. Cumulative Ruthenium releases in $\mathrm{CJ13}$ at $90^{\circ} \mathrm{C}$. 


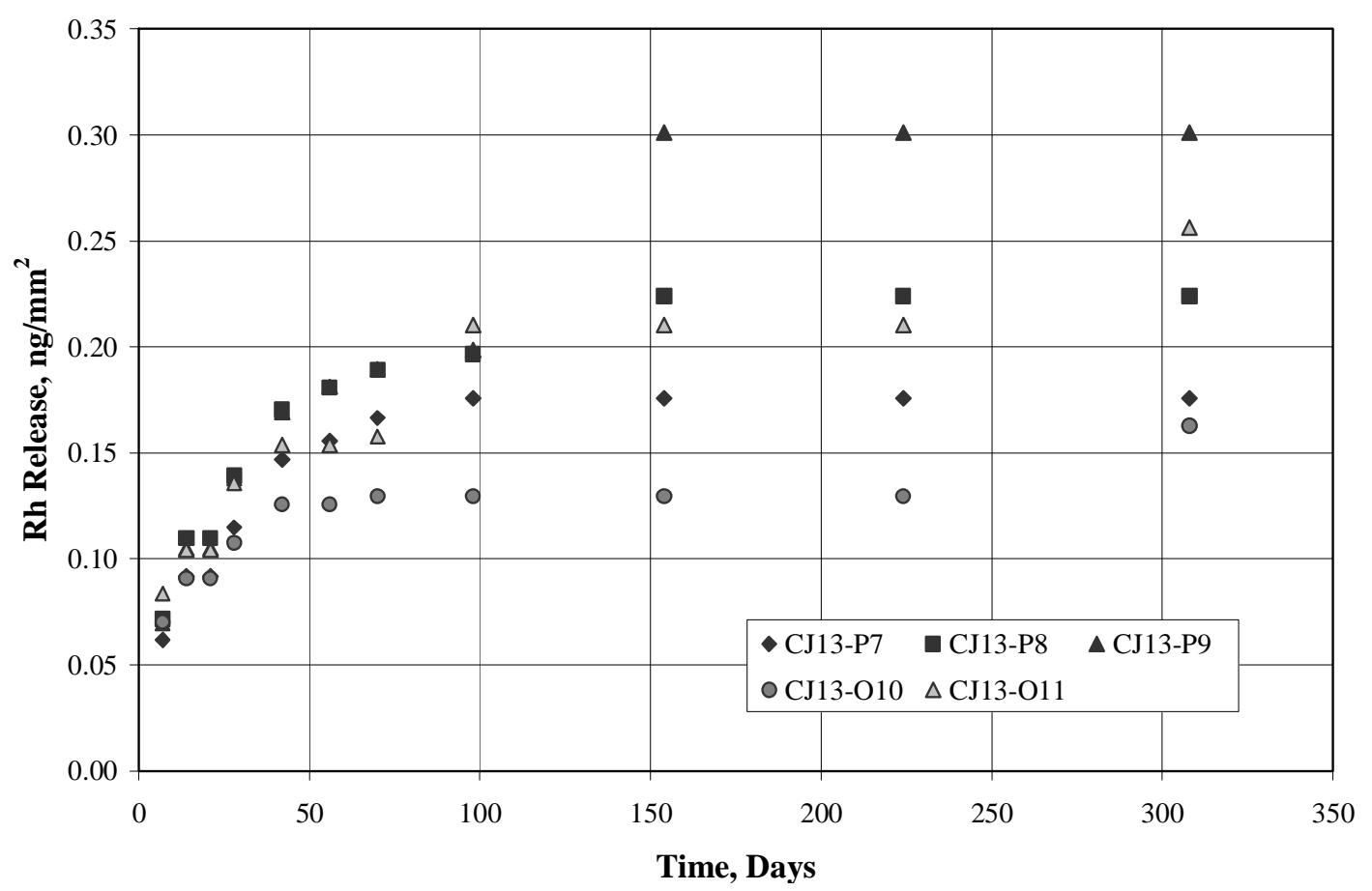

Figure III-22. Cumulative Rhodium releases in $\mathrm{CJ} 13$ at $90^{\circ} \mathrm{C}$.

\section{CJ13 Summary}

Because significant differences were observed in the releases of some elements from oxidized samples and polished samples, these data were not averaged. In Figure III-23 the average total release from polished samples is compared with the average releases of $\mathrm{Fe}, \mathrm{Zr}, \mathrm{Nb}, \mathrm{Pd}, \mathrm{Ru}$, and $\mathrm{Rh}$ from polished samples in $\mathrm{CJ} 13$. Average releases from oxidized samples are shown in Figure III-24. Comparison of these two figures shows some differences. For both polished and oxidized samples, the total release is dominated by the $\mathrm{Fe}$ release. However, the average cumulative $\mathrm{Zr}$ release is much closer to the average $\mathrm{Fe}$ release for oxide samples than for polished samples and thus makes a greater contribution to the total release for oxide samples than for polished samples. For both polished and oxidized samples, the fission-product elements are lower by an order of magnitude with releases close to the detection limits (as for SJ13). 


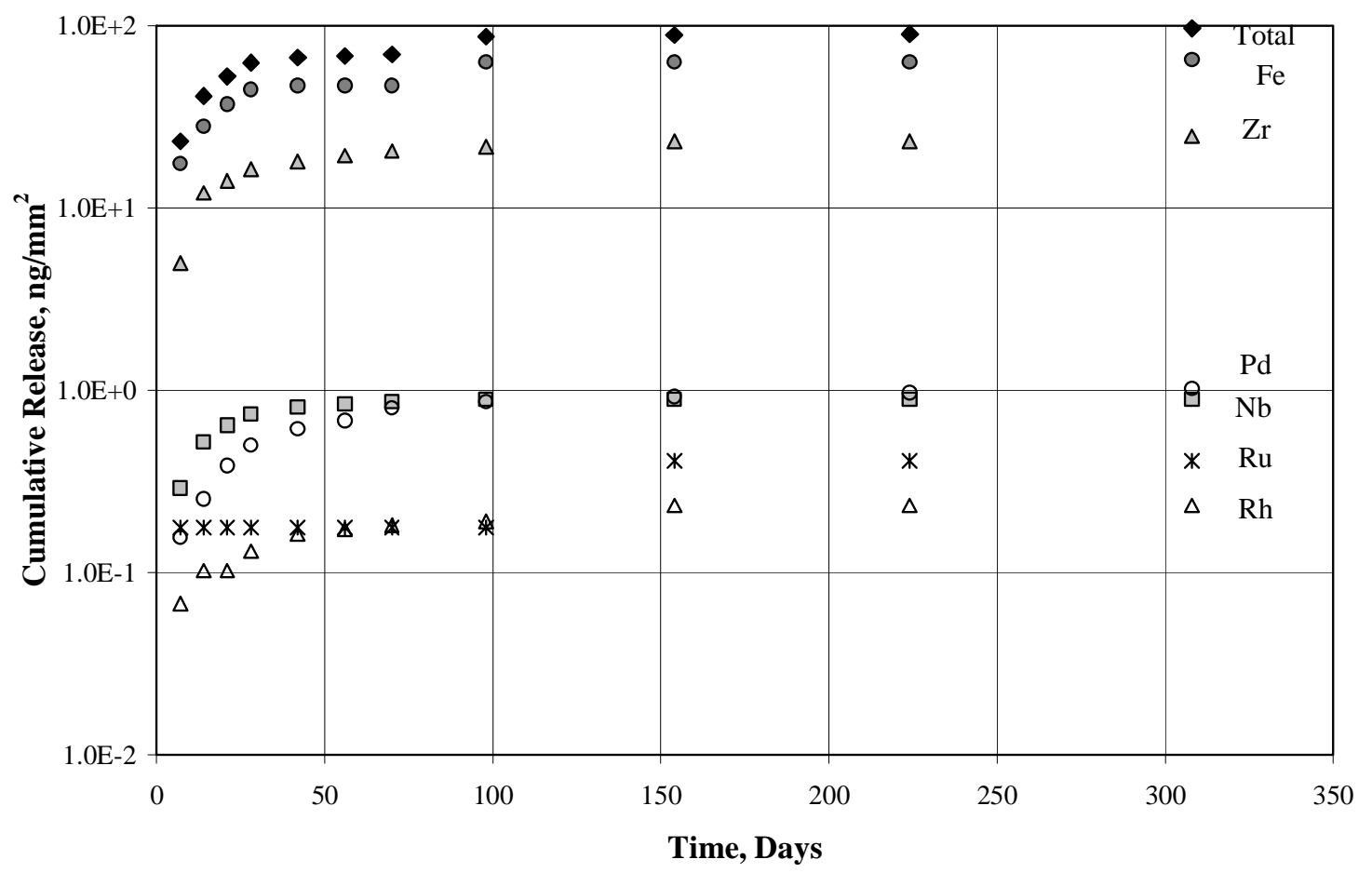

Figure III-23. Average cumulative release of polished samples in $\mathrm{CJ} 13$ at $90^{\circ} \mathrm{C}$.

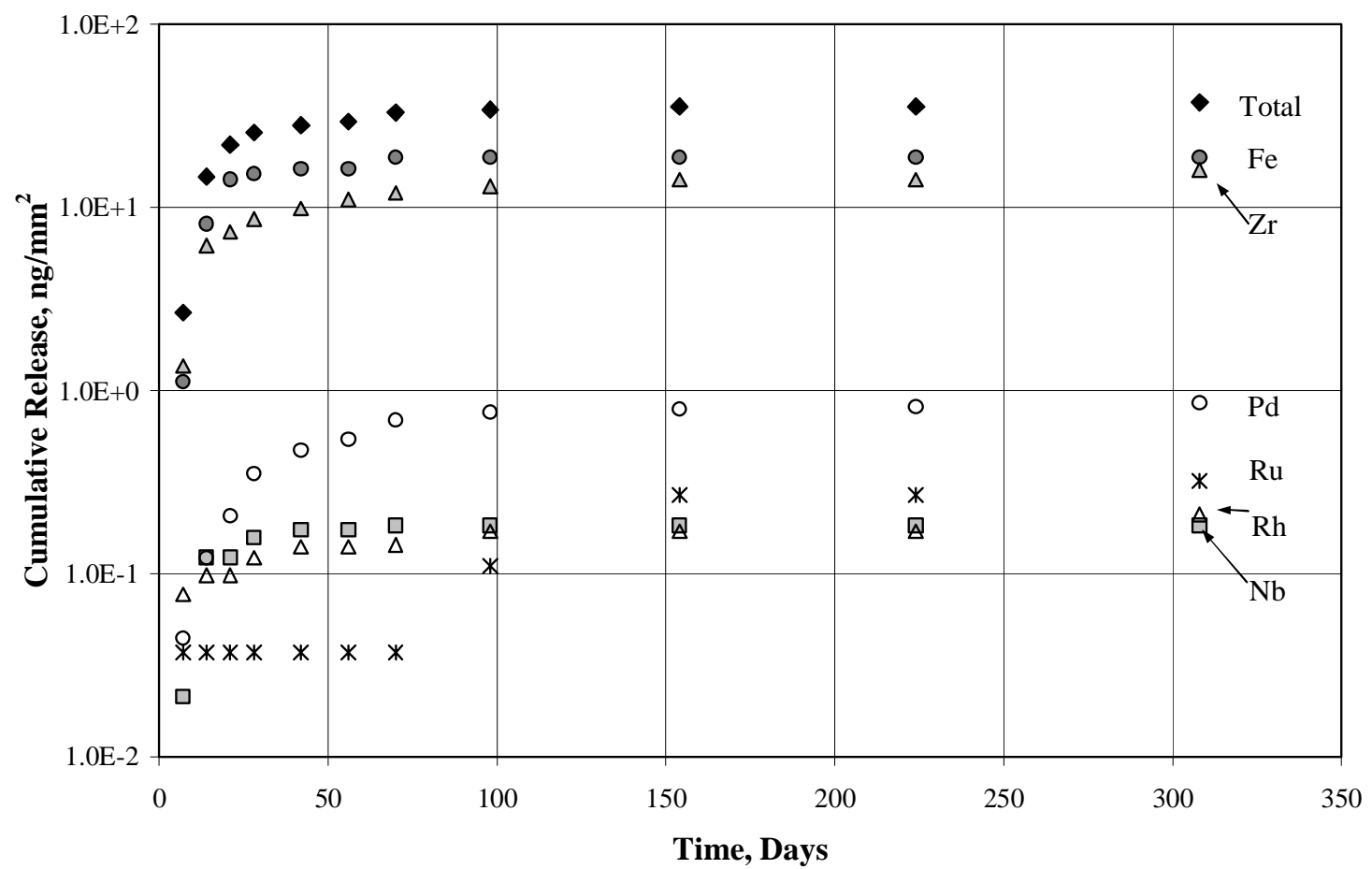

Figure III-24. Average cumulative release of oxidized samples in $\mathrm{CJ} 13$ at $90^{\circ} \mathrm{C}$. 


\section{c) 10KCl:}

Cumulative total releases in $10 \mathrm{KCl}$, shown in Figure III-25, are almost 2 orders of magnitude higher than the total releases in SJ13 and about 50 times higher than the total releases in CJ13. As with samples in SJ13, total releases are highest the first few weeks and decrease with time. However, unlike samples in SJ13, the cumulative release curves are still increasing slightly after 44 weeks (day 308). These high total releases are from the $\mathrm{Cl}^{-}$attack of the components of stainless steel in the Metal Waste Form, as discussed below.

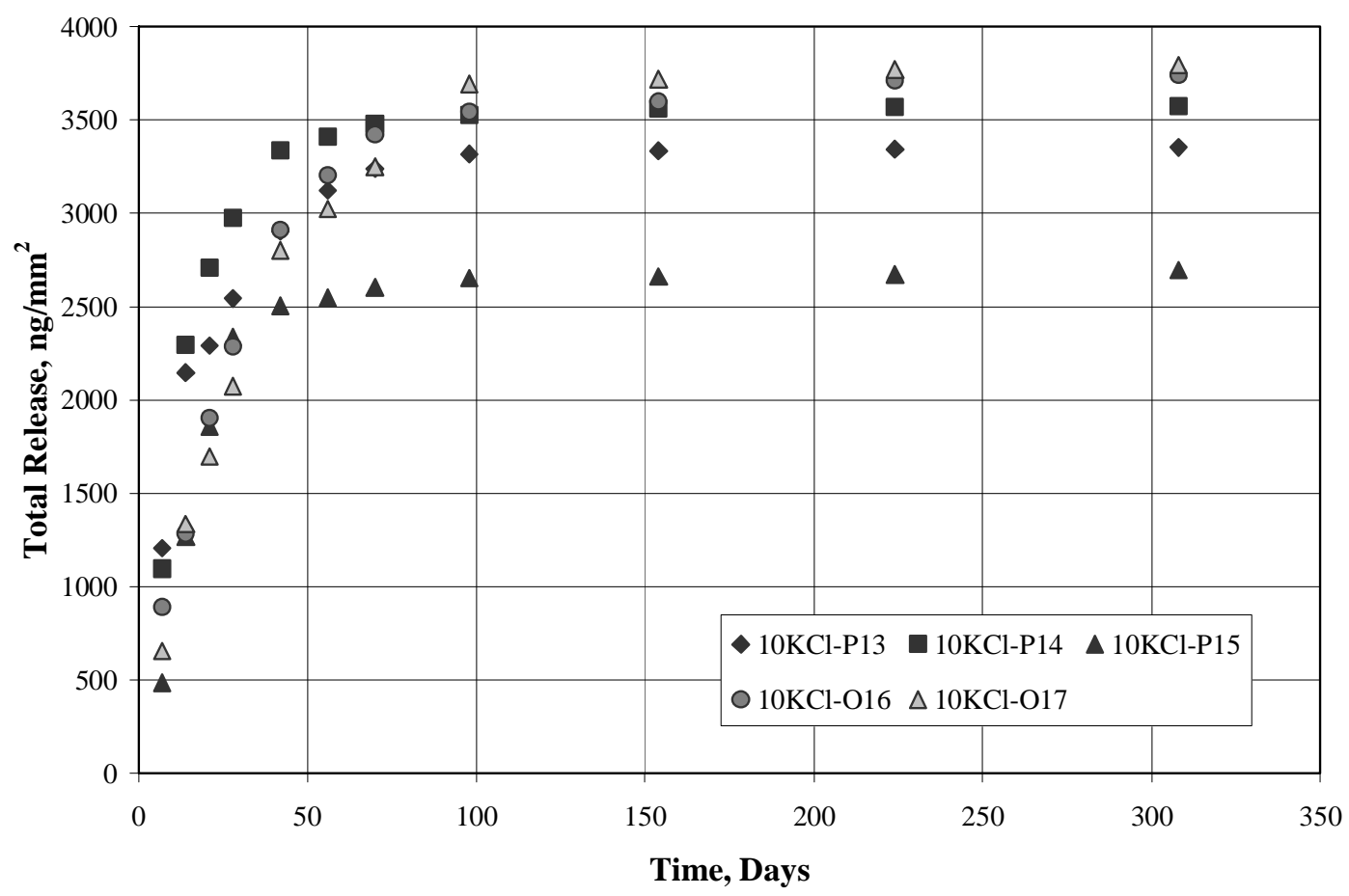

Figure III-25. Cumulative total release in $10 \mathrm{KCl}$ at $90^{\circ} \mathrm{C}$.

\section{Release of Major Elements}

Cumulative releases of $\mathrm{Fe}, \mathrm{Cr}$, and $\mathrm{Ni}$, the main components of stainless steel, are shown in Figures III-26 through III-28. The Fe releases are about a factor of 6 higher than the releases of $\mathrm{Cr}$ and $\mathrm{Ni}$, which are of similar magnitude. Starting with day 42, releases from sample P15 are consistently lower than releases from other samples, making the cumulative releases from this sample lower than that from other samples. This is particularly pronounced for Fe. The reason for this is not known. It may only reflect the variability of the small samples. Although these releases are considerably higher than releases in $\mathrm{SJ} 13$, there is still considerable scatter in the data. 


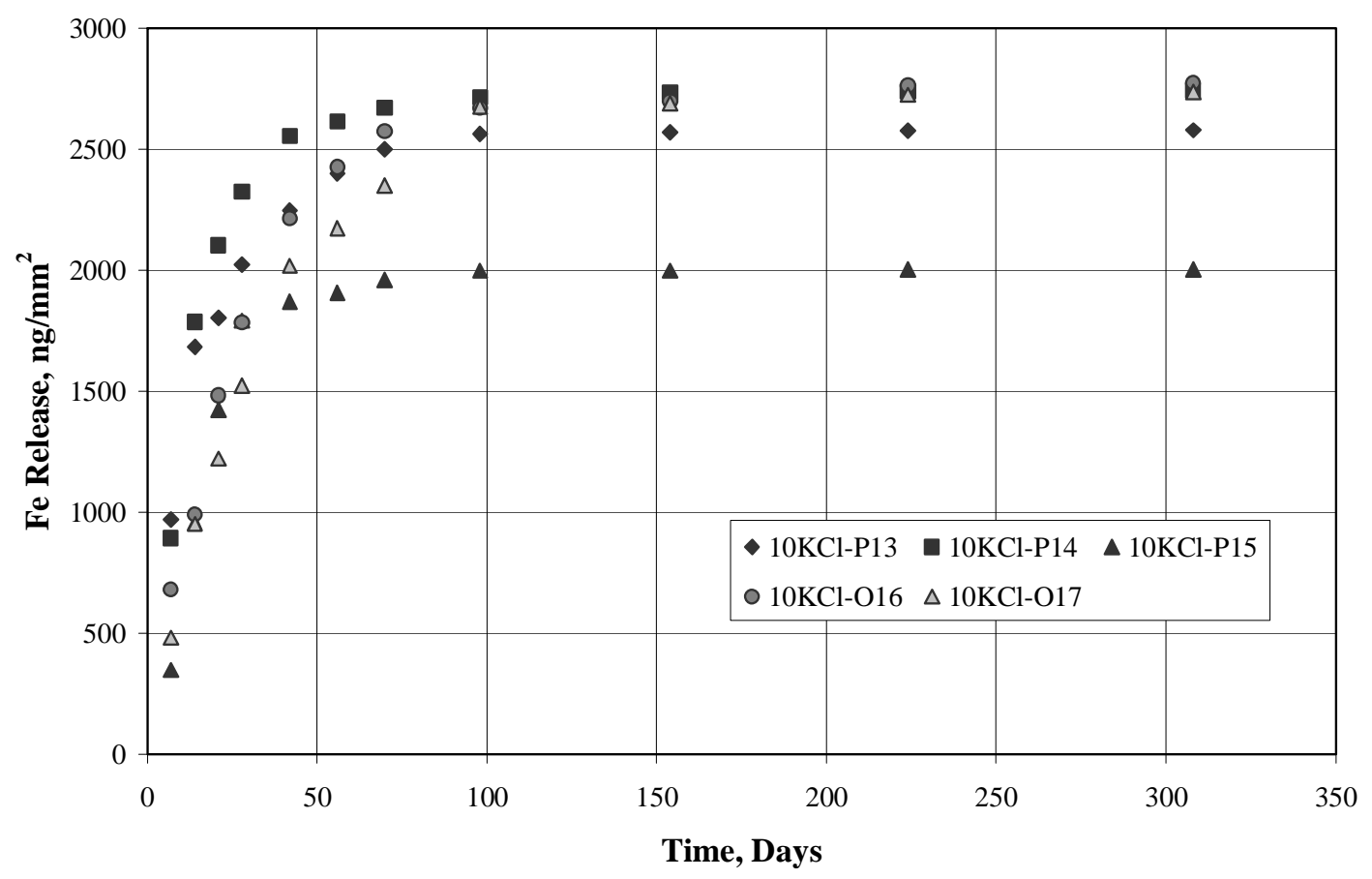

Figure III-26. Cumulative Iron release in $10 \mathrm{KCl}$ at $90^{\circ} \mathrm{C}$.

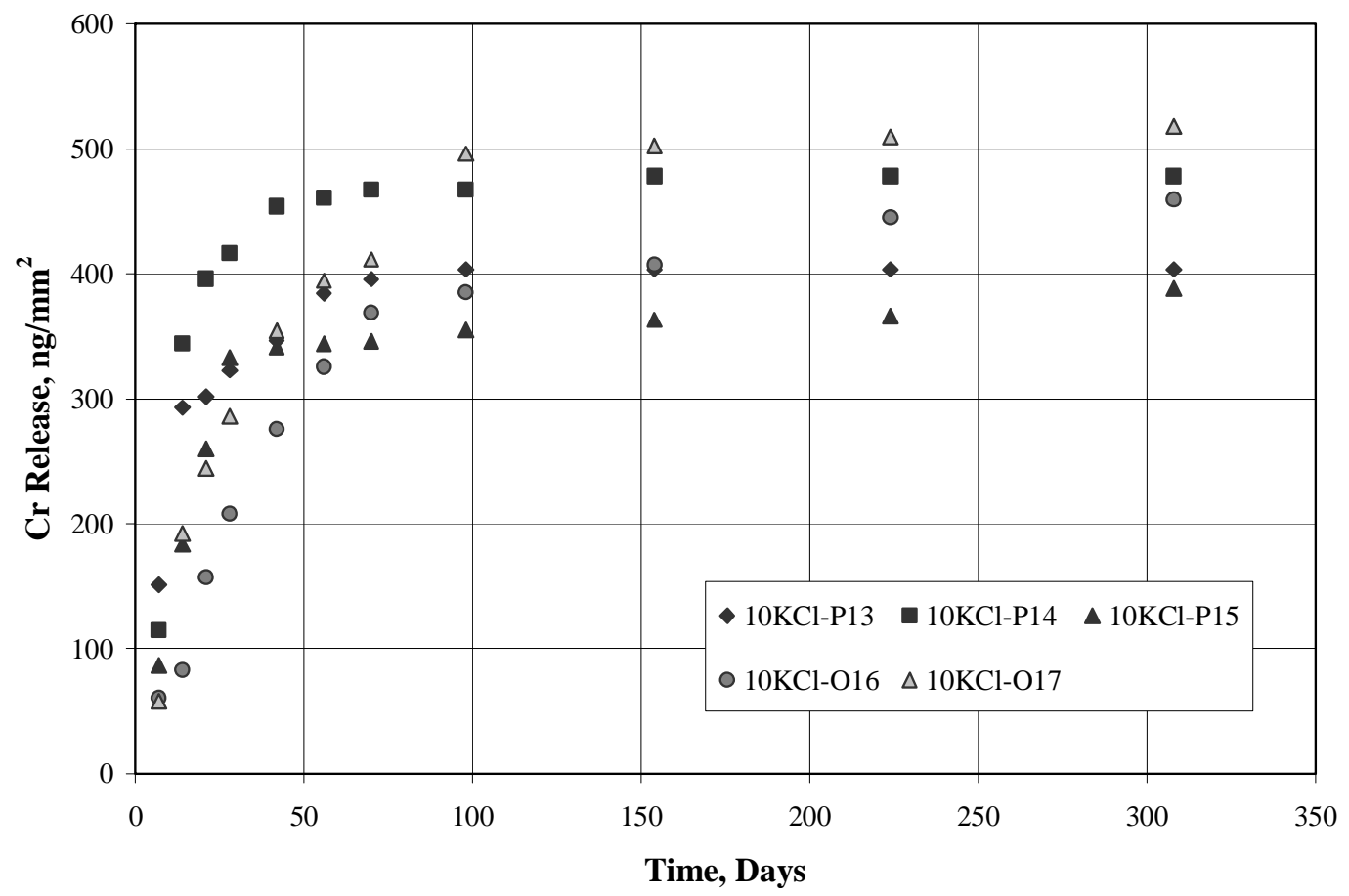

Figure III-27. Cumulative Chromium release in $10 \mathrm{KCl}$ at $90^{\circ} \mathrm{C}$. 


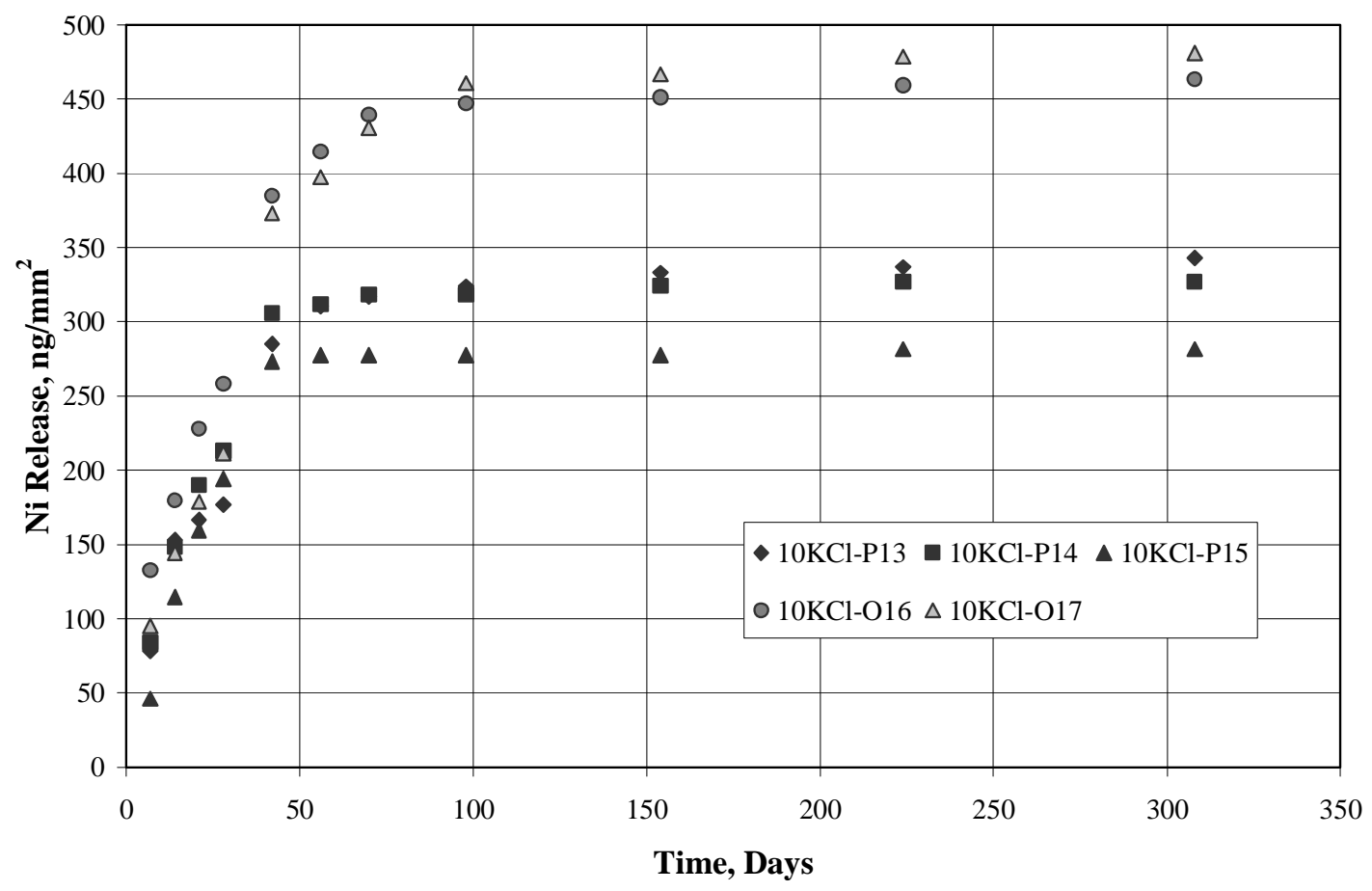

Figure III-28. Cumulative Nickel release in $10 \mathrm{KCl}$ at $90^{\circ} \mathrm{C}$.

Cumulative releases of $\mathrm{Zr}$, shown in Figure III-29, are about an order of magnitude lower than the releases of $\mathrm{Cr}$. Releases of $\mathrm{Zr}$ decrease with time, so that cumulative release curves turn over and flatten after about 98 days, 14 weeks.

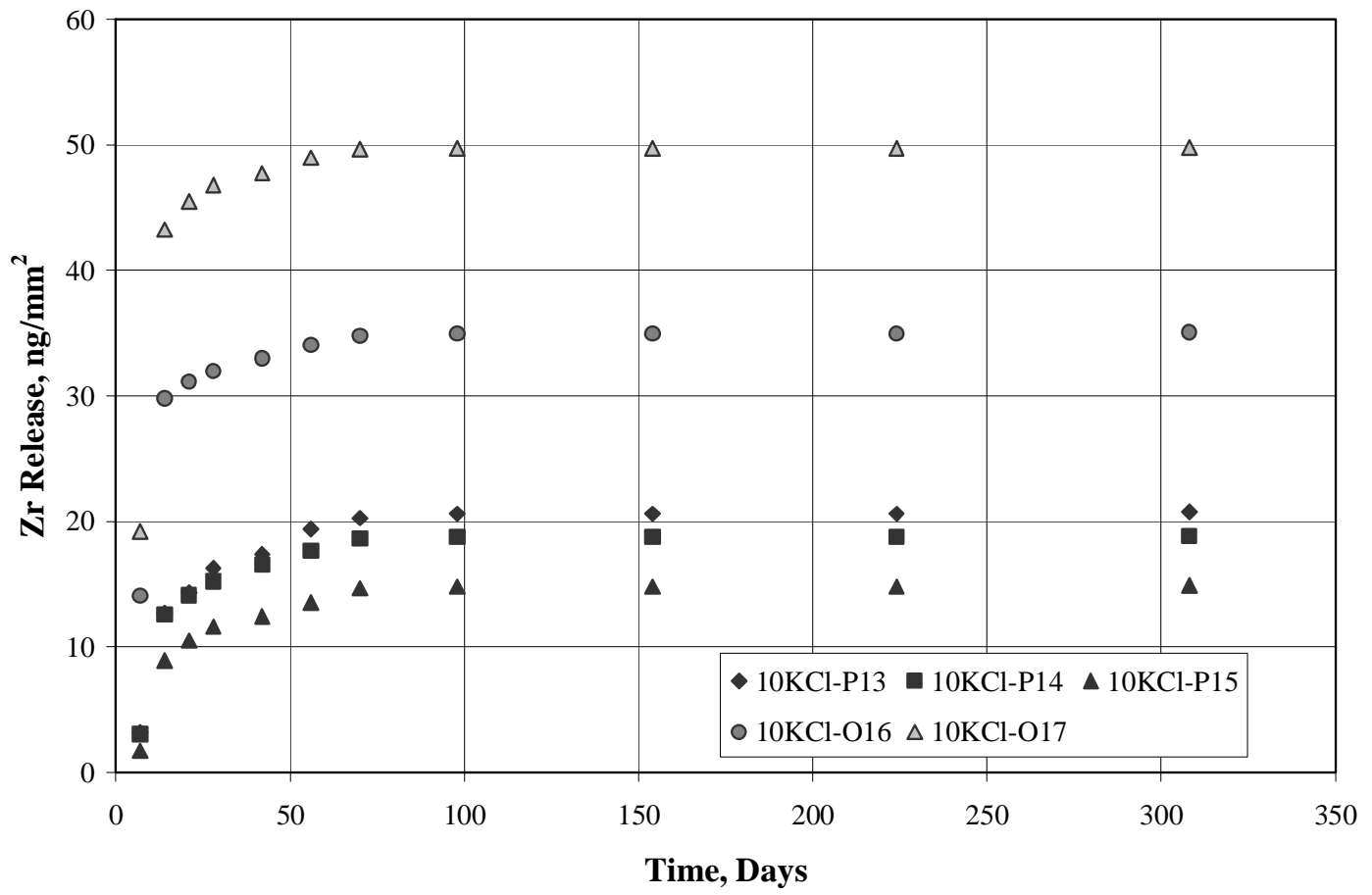

Figure III-29. Cumulative Zirconium release in $10 \mathrm{KCl}$ at $90^{\circ} \mathrm{C}$. 


\section{Release of Fission-Product Elements}

The high $\mathrm{Cl}^{-}$solution also gave higher releases of fission-product elements compared to the less aggressive solutions, SJ13, and CJ13. The cumulative releases of $\mathrm{Nb}$ as a function of time are shown in Figure III-30. The high Nb release from the oxidized sample $0-17$ from the second week of the test is reflected in the consistently higher cumulative releases from that sample throughout the rest of the test. From day 28 through day 98 , releases were close to the detection limits creating significant scatter. No $\mathrm{Nb}$ was detected on day 154 and $\mathrm{Nb}$ was only detected in one sample after that time. Cumulative Pd releases in $10 \mathrm{KCl}$ are shown in Figure III-31. The data are fairly consistent until week 32 (day 224) at which time releases were near the detection limits for Pd. Although cumulative releases of Ru, shown in Figure III-32, are of similar magnitude to those for Pd, the data lack the consistency of the Pd data because of higher detection limits for Ru compared to Pd. The scatter in the data arises from releases near the detection limits and the variation in the detection limits from week to week. Cumulative Rh releases in $10 \mathrm{KCl}$ are shown in Figure III-33. On day 14, a release of 1.7 $\mathrm{ng} / \mathrm{mm}^{2} \mathrm{Rh}$ was detected from sample O-17 compared to Rh releases on the order 0.2 $\mathrm{ng} / \mathrm{mm}^{2}$ from the other samples, causing the cumulative release from that sample to be higher after that time. Releases decreased with time. On day 224, Rh was detected in releases from only one sample. No Rh was detected on day 308.

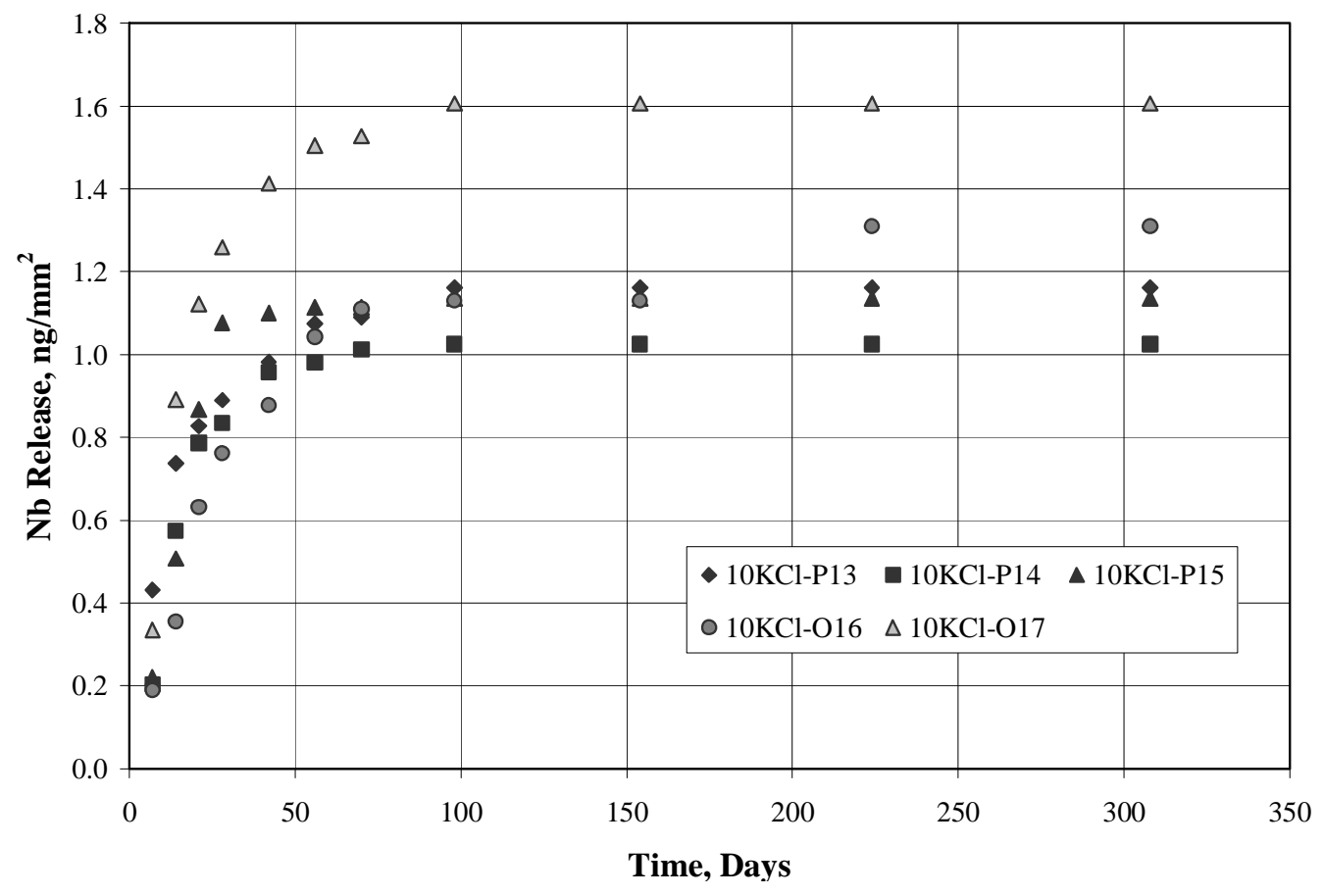

Figure III-30. Cumulative Niobium release in $10 \mathrm{KCl}$ at $90^{\circ} \mathrm{C}$. 


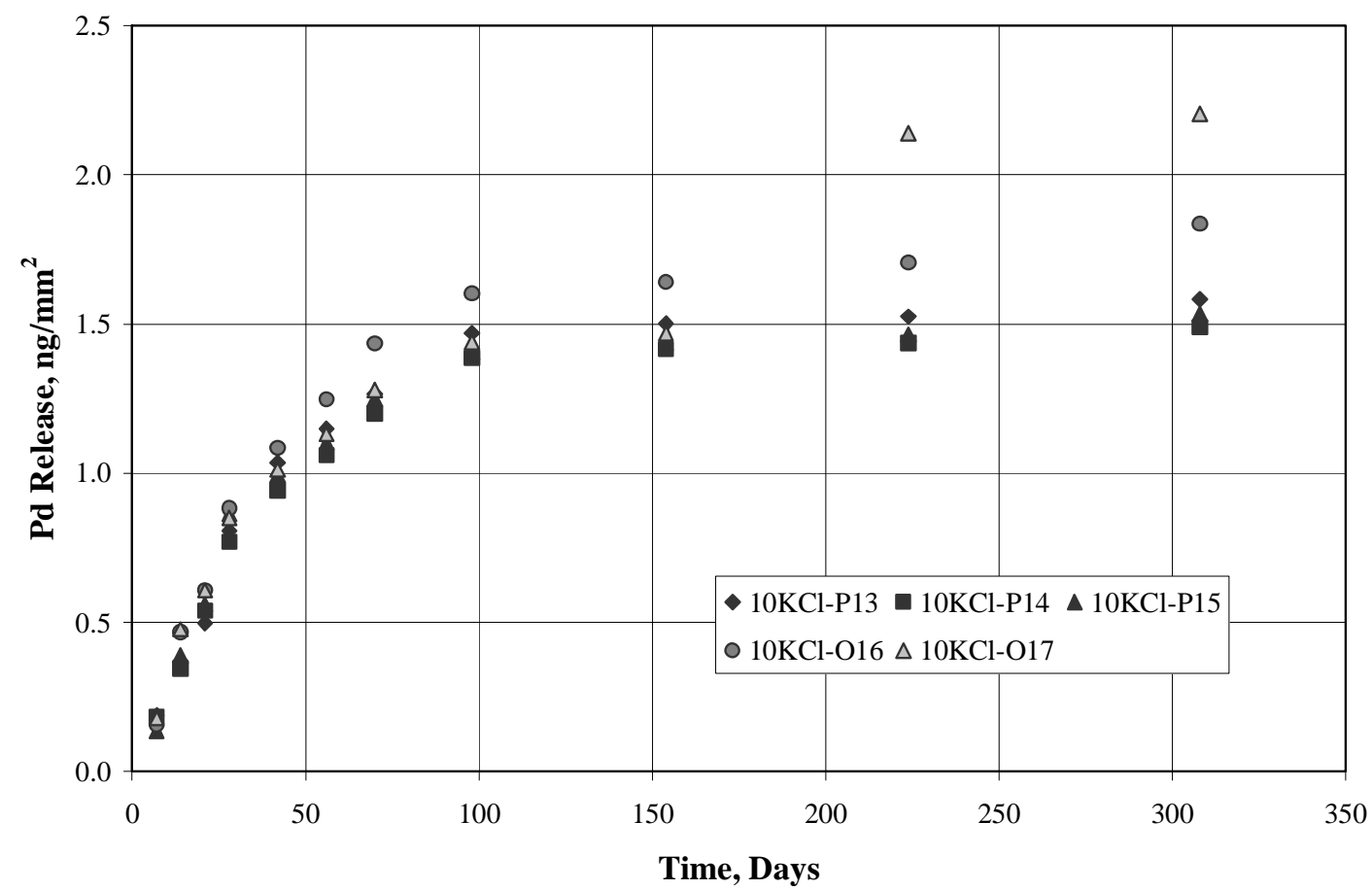

Figure III-31. Cumulative Palladium release in $10 \mathrm{KCl}$ at $90^{\circ} \mathrm{C}$.

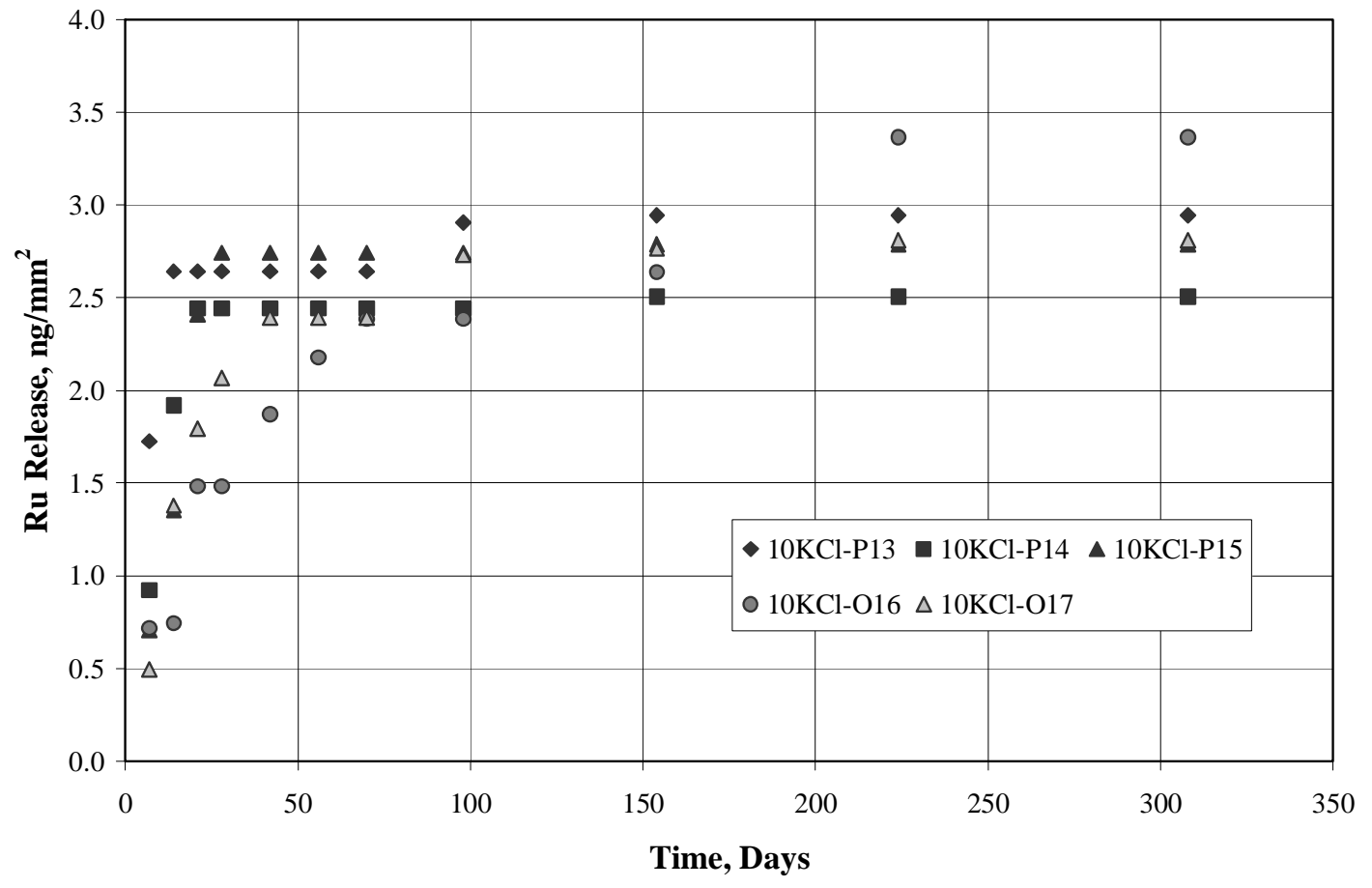

Figure III-32. Cumulative Ruthenium release in $10 \mathrm{KCl}$ at $90^{\circ} \mathrm{C}$. 


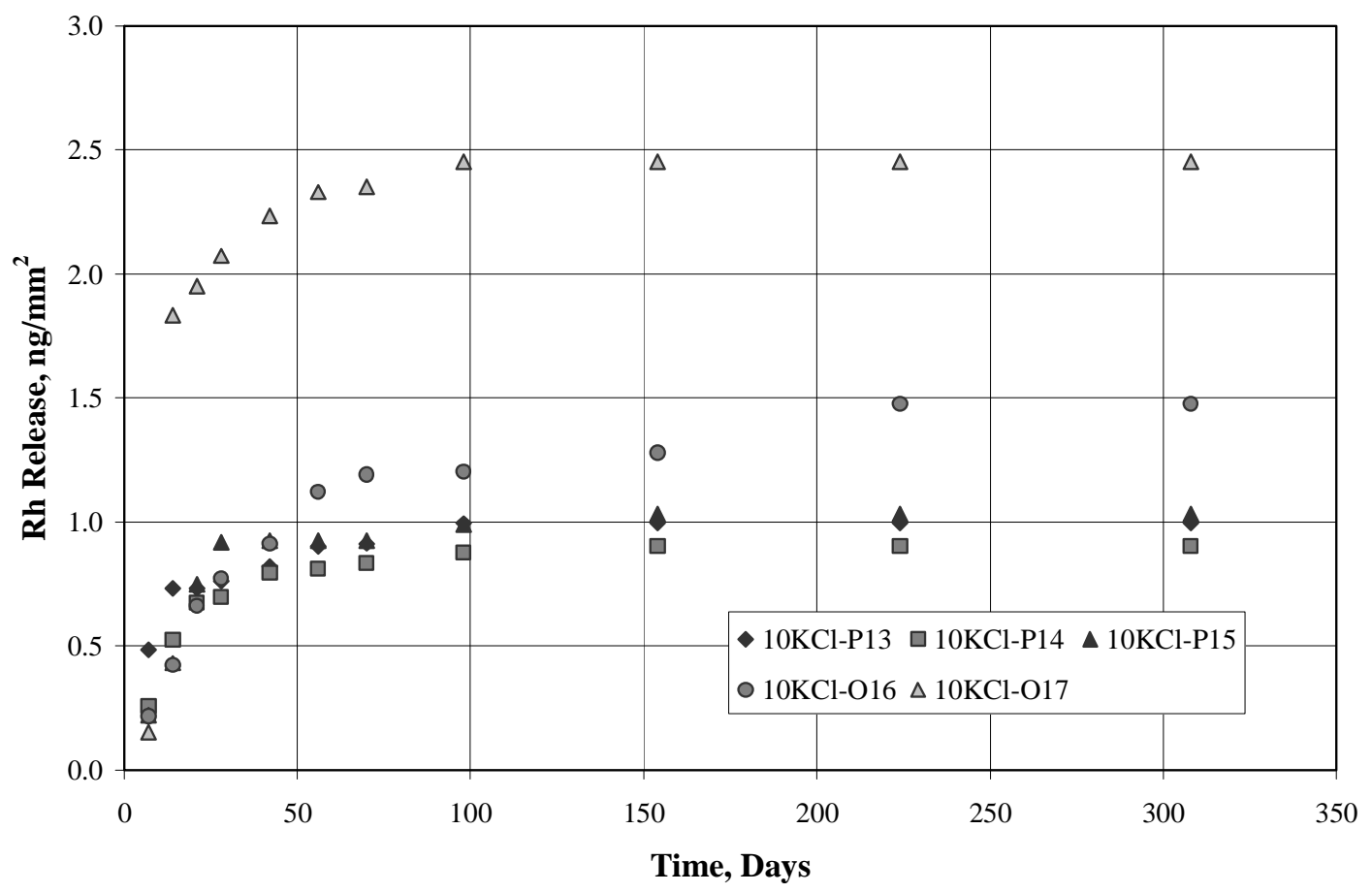

Figure III-33. Cumulative Rhodium release in $10 \mathrm{KCl}$ at $90^{\circ} \mathrm{C}$.

\section{$10 \mathrm{KCl}$ Summary}

In Figure III-34, average cumulative releases of $\mathrm{Fe}, \mathrm{Zr}, \mathrm{Nb}, \mathrm{Pd}, \mathrm{Ru}$, and $\mathrm{Rh}$ are compared with the average total release. As in the other solutions, the total release is dominated by the $\mathrm{Fe}$ release. However, releases of $\mathrm{Cr}$ and $\mathrm{Ni}$, which are about a factor of 6 lower than the Fe release, make some contribution to the total release. The average cumulative $\mathrm{Zr}$ release is more than an order of magnitude lower than the total release. Releases of fission-product elements are about 3 orders of magnitude lower than the total release. The average $\mathrm{Ru}$ release is consistently higher than that of the other fission-product elements. The average cumulative release of $\mathrm{Pd}$ is slightly higher than those of $\mathrm{Nb}$ and $\mathrm{Rh}$. 


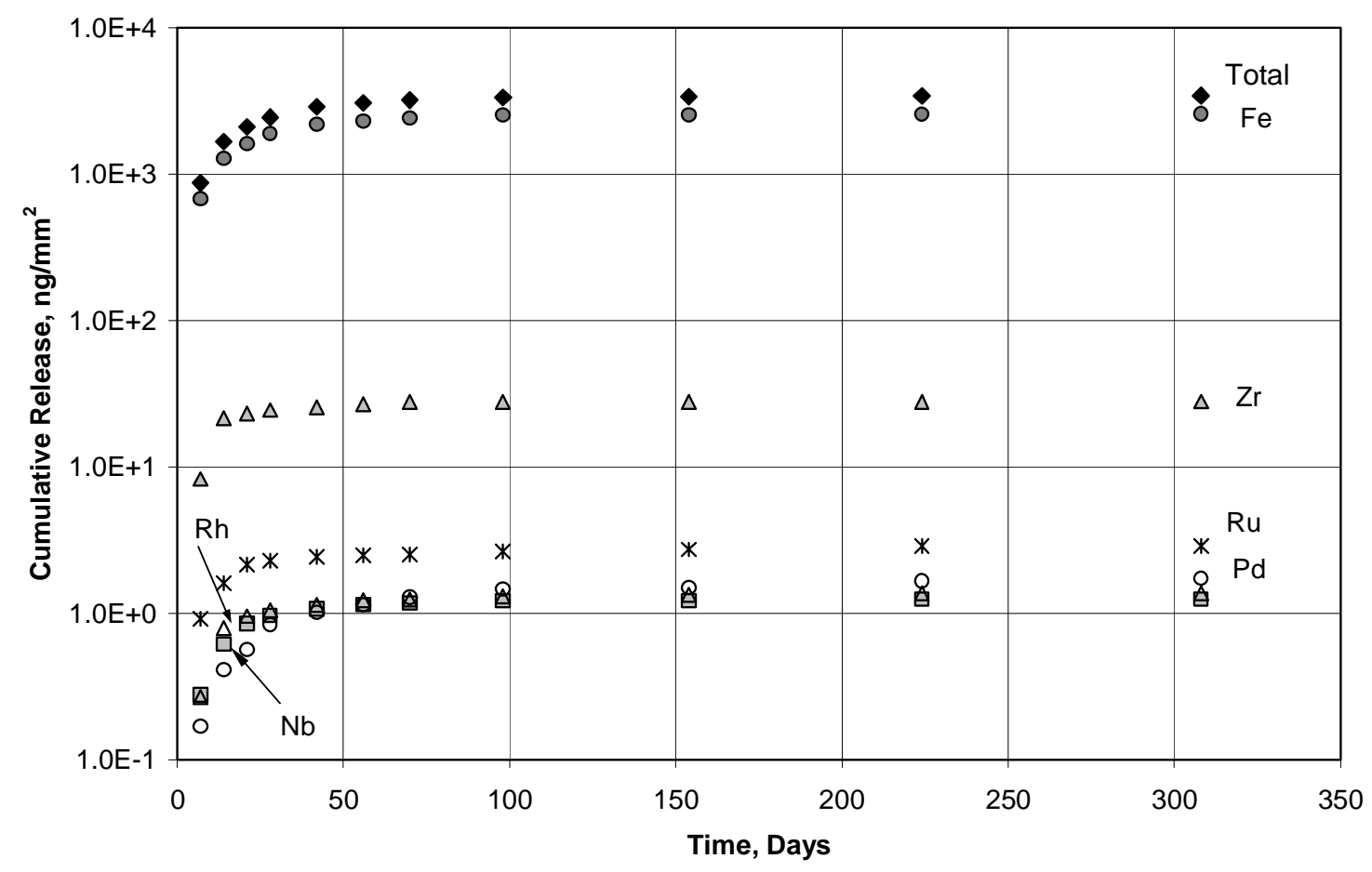

Figure III-34. Average cumulative release in $10 \mathrm{KCl}$ at $90^{\circ} \mathrm{C}$.

\section{d) AJ13:}

Cumulative total releases of the major elements and fission-product elements $\mathrm{Nb}, \mathrm{Pd}, \mathrm{Ru}$, and $\mathrm{Rh}$ in $\mathrm{AJ} 13$ solution at $90^{\circ} \mathrm{C}$ are shown in Figure III-35. Total releases in this $\mathrm{pH}=2$ solution differ significantly from the releases in SJ13, CJ13, and the $10 \mathrm{KCl}$ solutions. Cumulative total releases in AJ13 continue to increase with time with only a small change in the linear slope. The cumulative total releases in SJ13, CJ13, and the $10 \mathrm{KCl}$ solution turned over and became almost flat. After 308 days of tests, cumulative total releases in AJ13 are two order of magnitude higher than the cumulative total releases in the $10 \mathrm{KCl}$ solution and four orders of magnitude higher than the cumulative total releases in SJ13. 


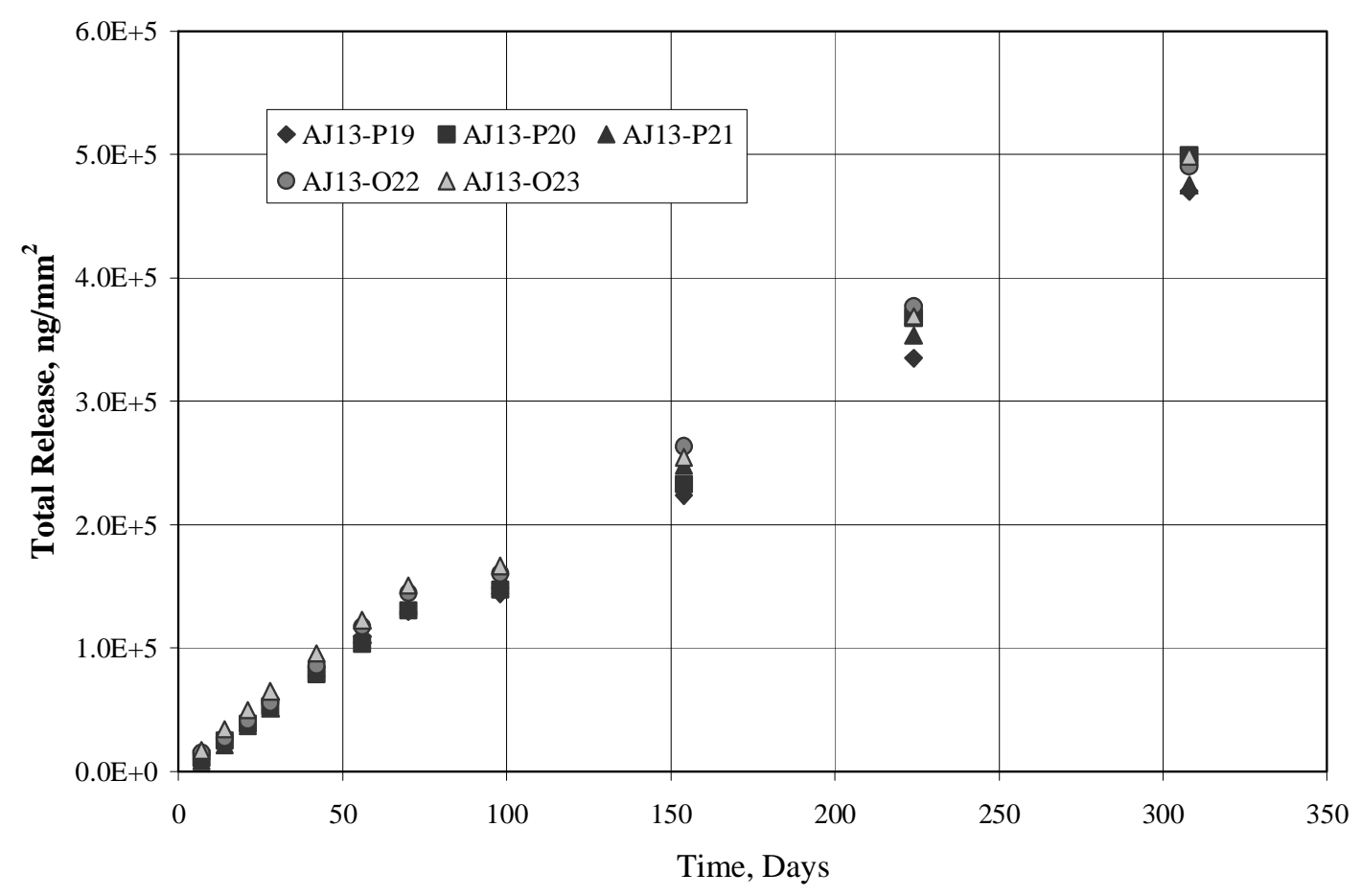

Figure III-35. Cumulative total release in $\mathrm{AJ} 13$ at $90^{\circ} \mathrm{C}$.

\section{Release of Major Elements}

The cumulative release of $\mathrm{Fe}$ in $\mathrm{AJ} 13$ solution at $90^{\circ} \mathrm{C}$, shown in Figure III-36, follows the same trend as the cumulative total release shown in Figure III-35. The initial slope is linear. The slope appears to change between 70 and 98 days but the trend from 98 through 308 days is also linear with a reduced slope. Unlike the tests in other solutions, there is little scatter in these Fe releases. The cumulative release of $\mathrm{Cr}$ in AJ13 solution at $90^{\circ} \mathrm{C}$, shown in Figure III-37, shows the same trends as the Fe release but is lower by about a factor of four and the data have more scatter. Cumulative releases of Ni in AJ13 solution at $90^{\circ} \mathrm{C}$, shown in Figure III-38, appear linear for the first 154 days with little scatter. There is then a jump after the analysis on day 224 and then the previous linear trend resumes with a similar slope. The reason for the discontinuity on day 224 is not known. The $\mathrm{Zr}$ cumulative releases in $\mathrm{AJ} 13$ at $90^{\circ} \mathrm{C}$, shown in Figure III-39, are much lower than the $\mathrm{Fe}, \mathrm{Cr}$, and $\mathrm{Ni}$ releases and show much scatter after 98 days. 


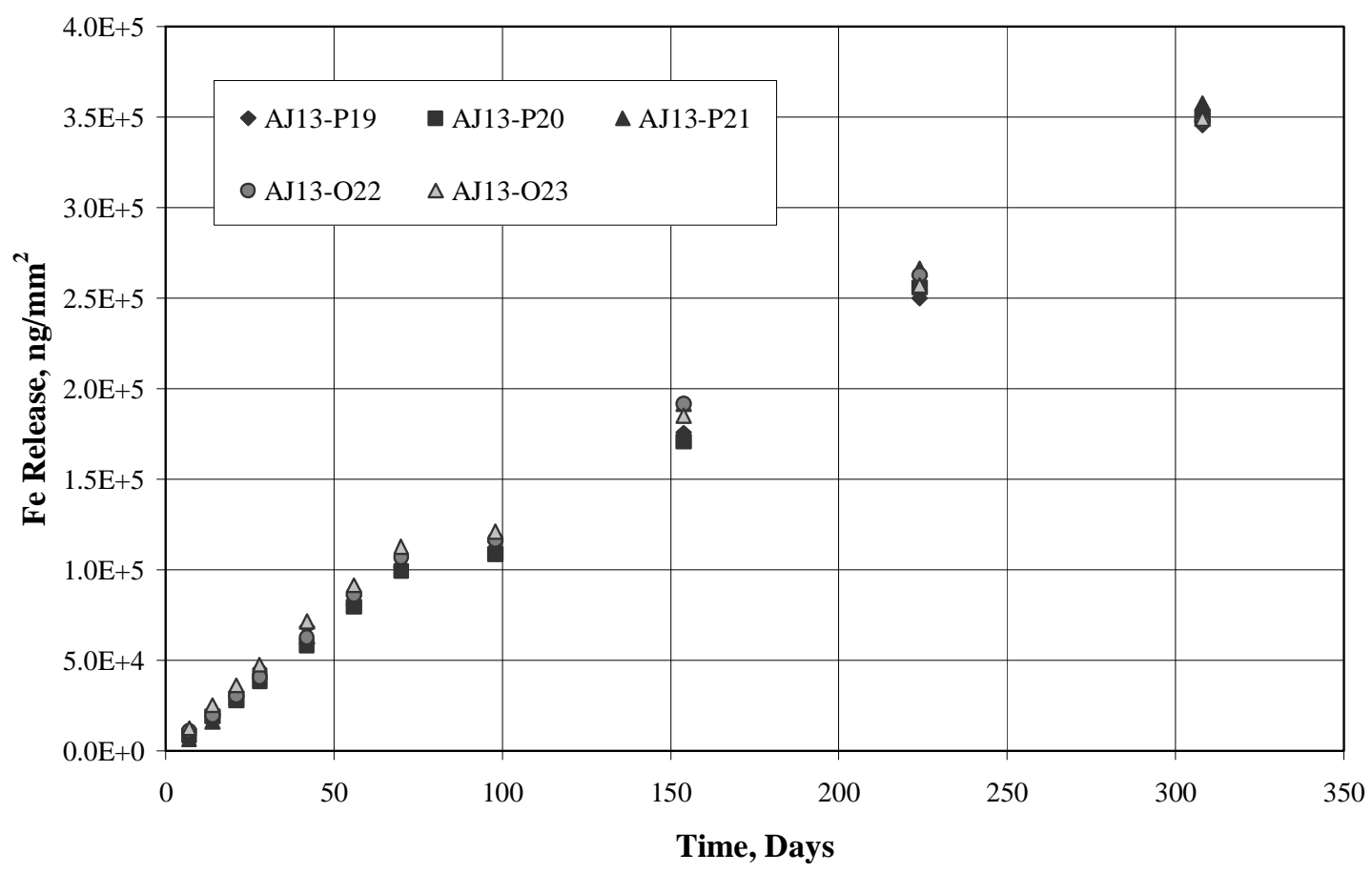

Figure III-36. Cumulative Iron release in $\mathrm{AJ} 13$ at $90^{\circ} \mathrm{C}$.

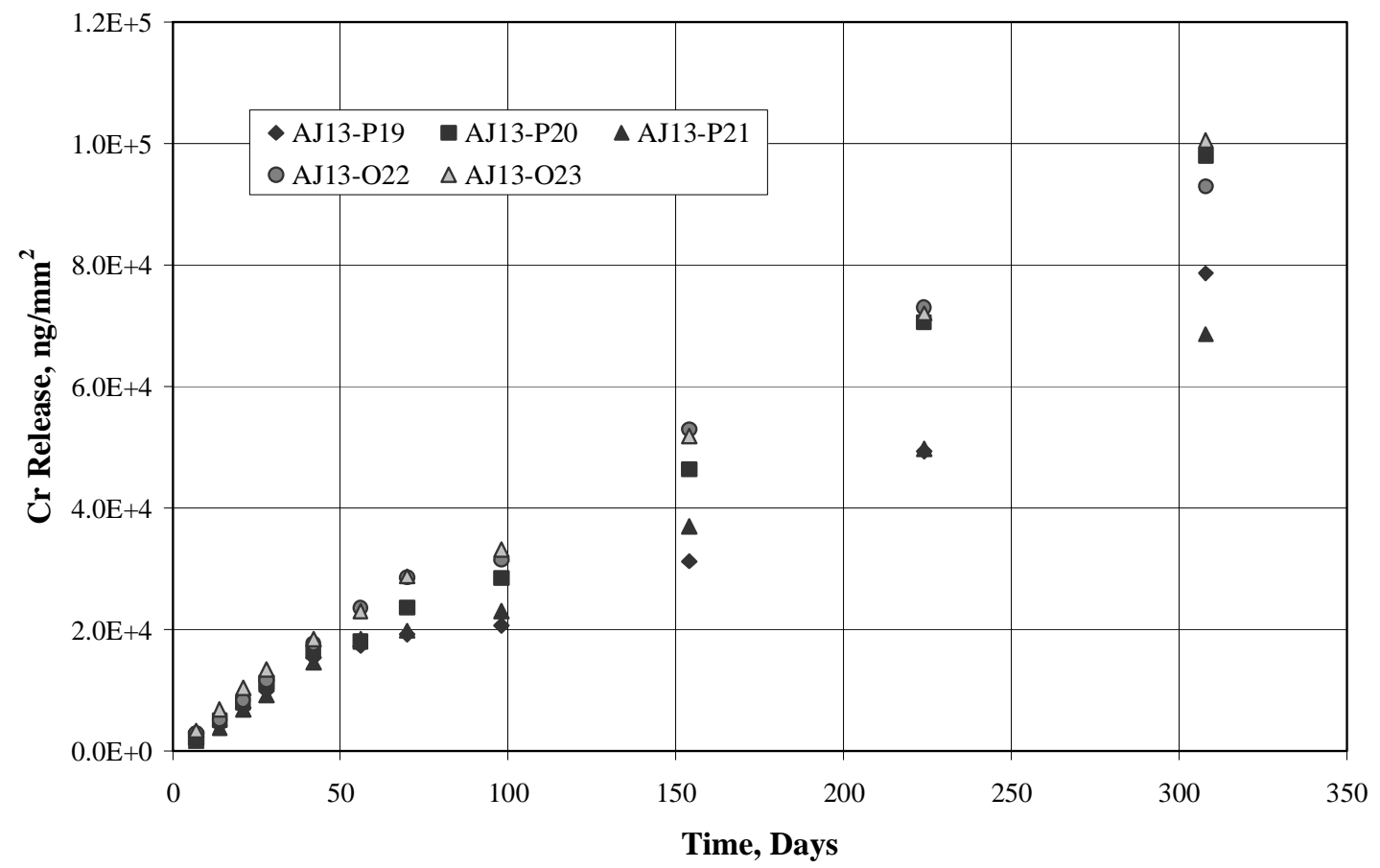

Figure III-37. Cumulative Chromium release in $\mathbf{A J 1 3}$ at $9^{\circ} \mathrm{C}$. 


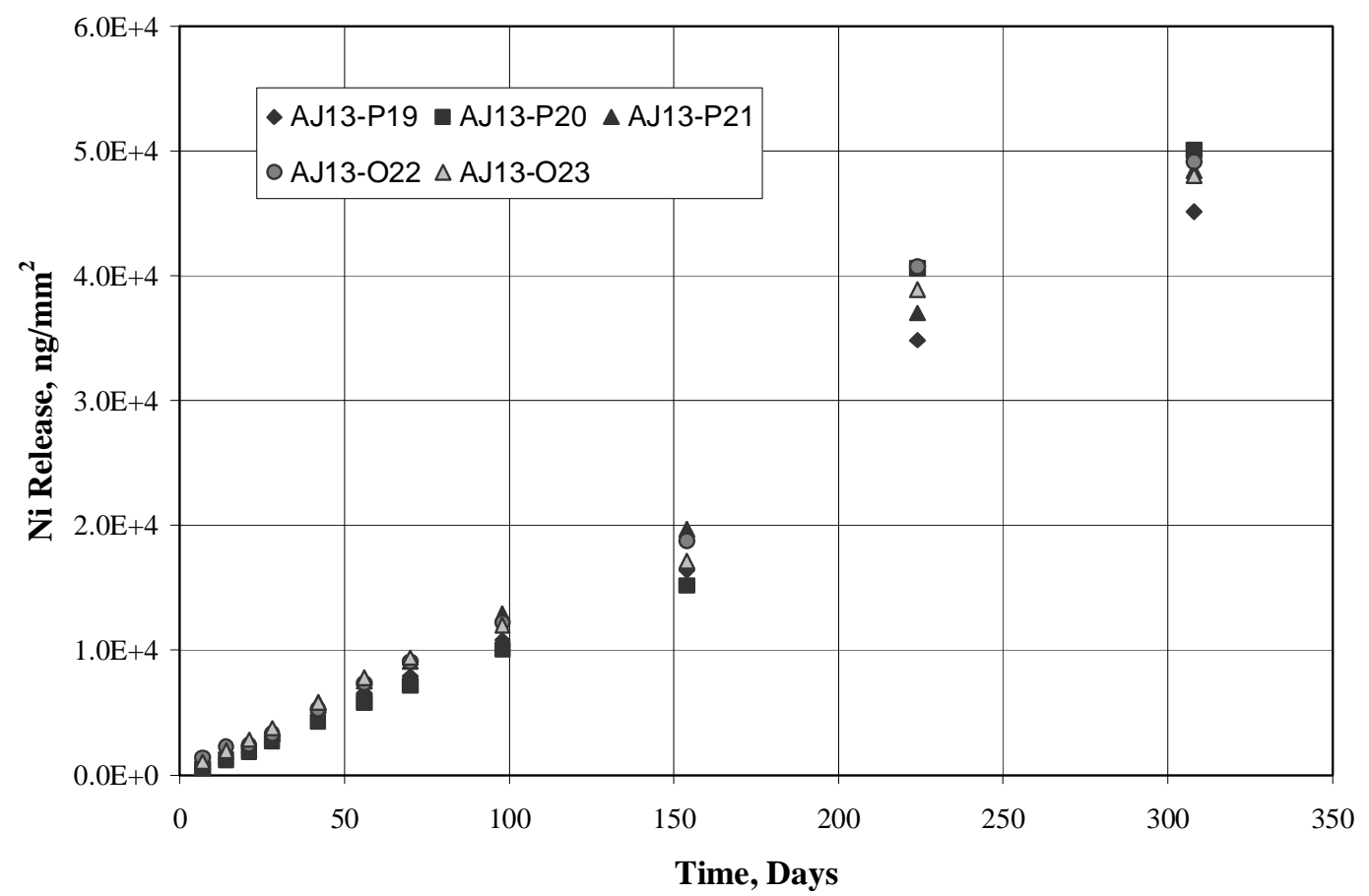

Figure III-38. Cumulative Nickel release in $\mathrm{AJ13}$ at $90^{\circ} \mathrm{C}$.

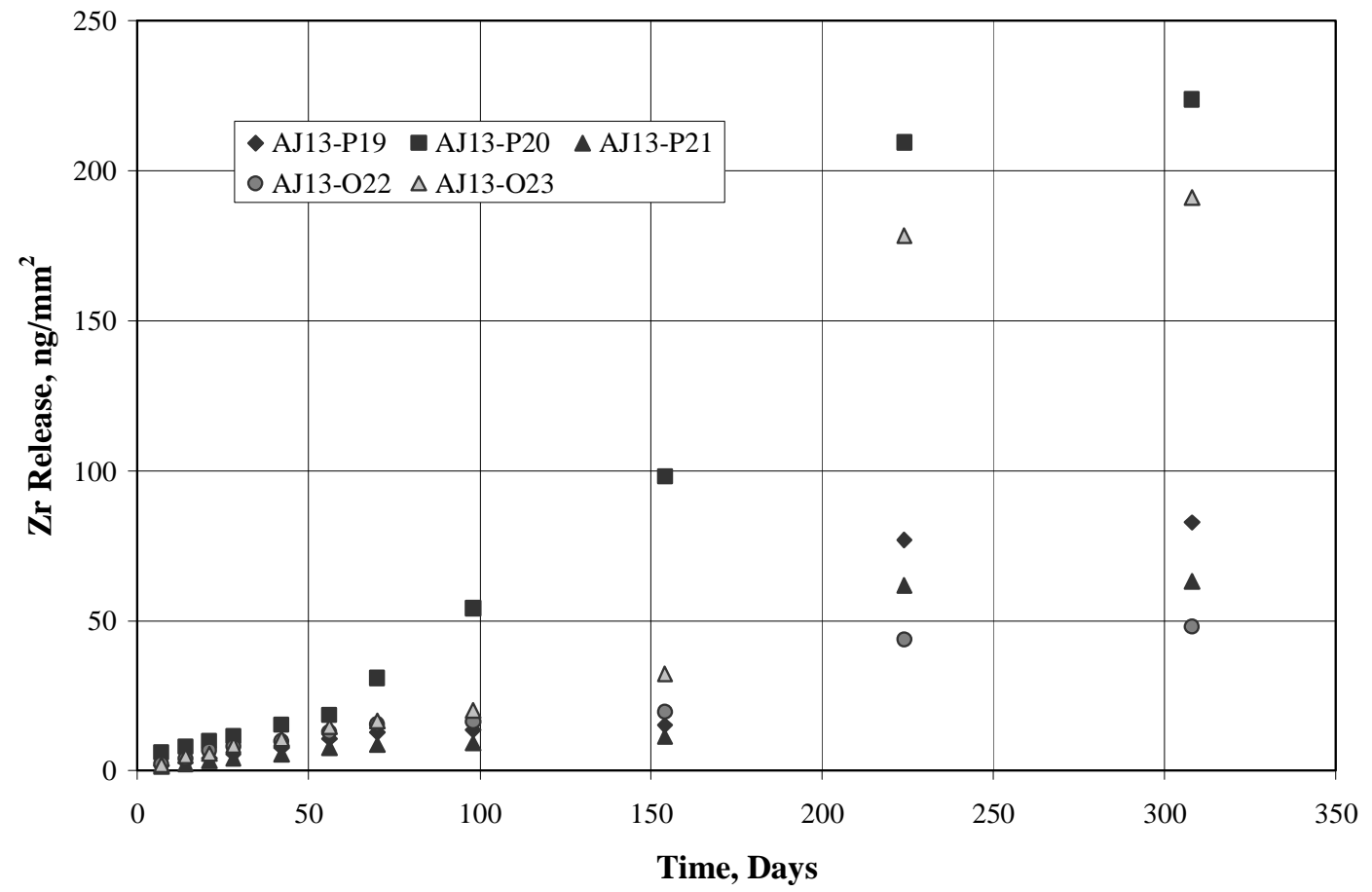

Figure III-39. Cumulative Zirconium release in $\mathrm{AJ} 13$ at $90^{\circ} \mathrm{C}$. 


\section{Release of Fission-Product Elements}

The cumulative releases of the fission-product elements $\mathrm{Nb}, \mathrm{Pd}, \mathrm{Ru}$ and $\mathrm{Rh}$, in $\mathrm{AJ} 13$ solution at $90^{\circ} \mathrm{C}$ are significantly higher than their cumulative releases at $90^{\circ} \mathrm{C}$ in the other test solutions. Cumulative releases of $\mathrm{Nb}$ and $\mathrm{Pd}$ in $\mathrm{AJ} 13$ at $90^{\circ} \mathrm{C}$, shown respectively, in Figures III-40 and III-41, do not show the linear trends observed for the cumulative release of $\mathrm{Fe}$ in AJ13. Both are about two orders of magnitude higher than their releases in SJ13. Cumulative releases of $\mathrm{Ru}$ and $\mathrm{Rh}$ in $\mathrm{AJ} 13$ at $90^{\circ} \mathrm{C}$, shown respectively, in Figures III-42 and III-43, have significant scatter but appear to be more linear then the cumulative releases of $\mathrm{Nb}$ and Pd. Scatter in the data increases with the duration of the tests.

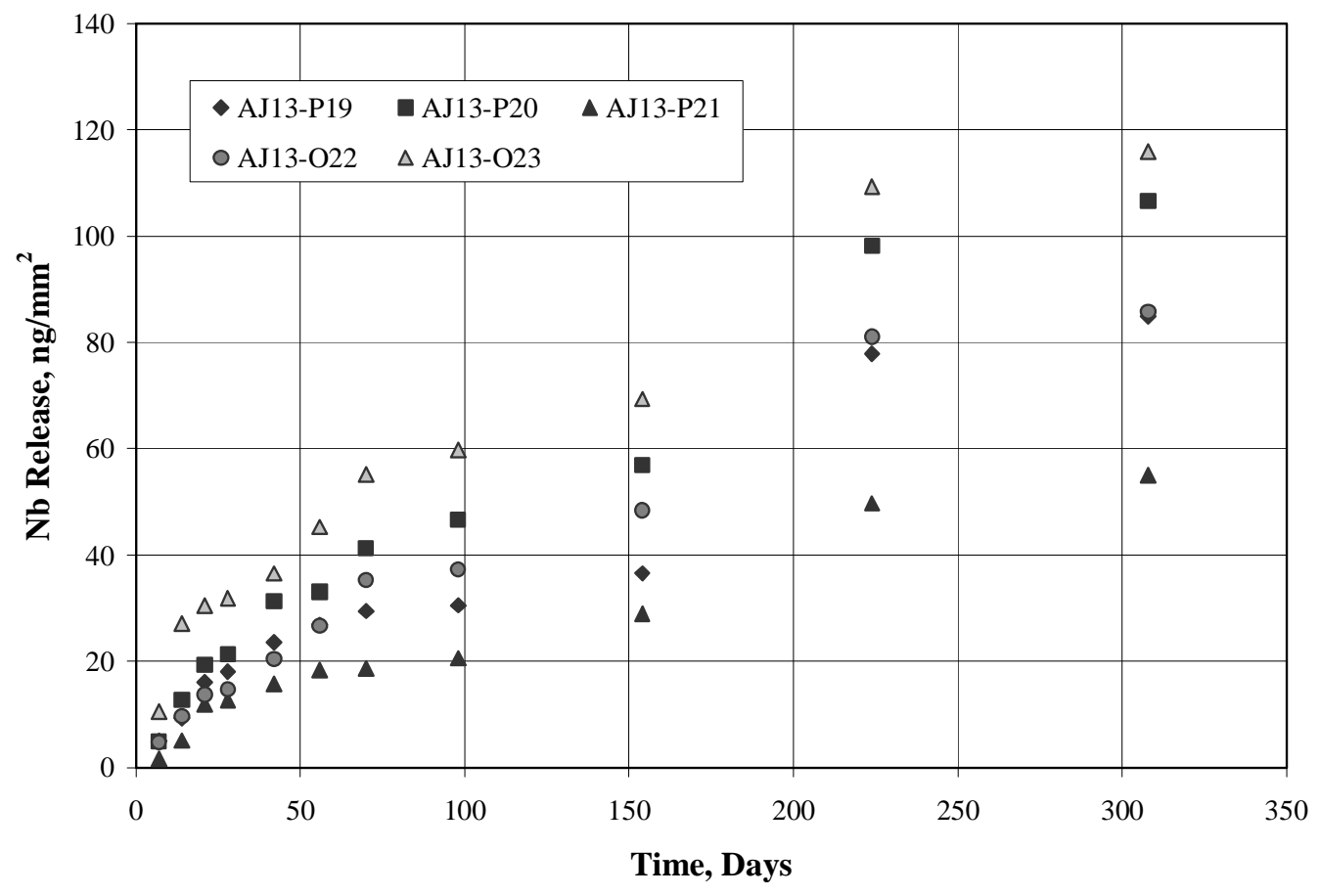

Figure III-40. Cumulative Niobium release in $\mathrm{AJ} 13$ at $90^{\circ} \mathrm{C}$. 


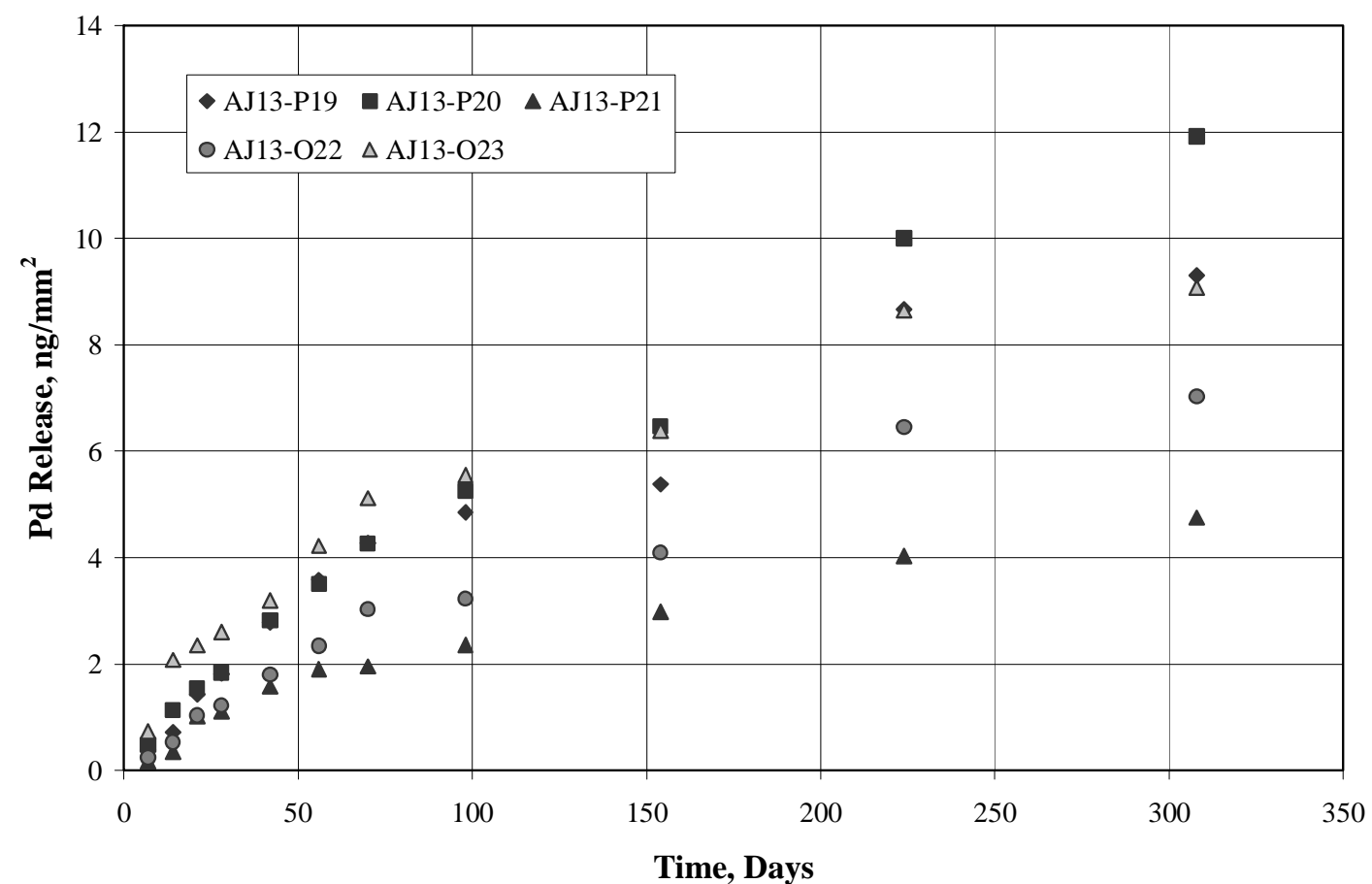

Figure III-41. Cumulative Palladium release in $\mathrm{AJ} 13$ at $9^{\circ} \mathrm{C}$.

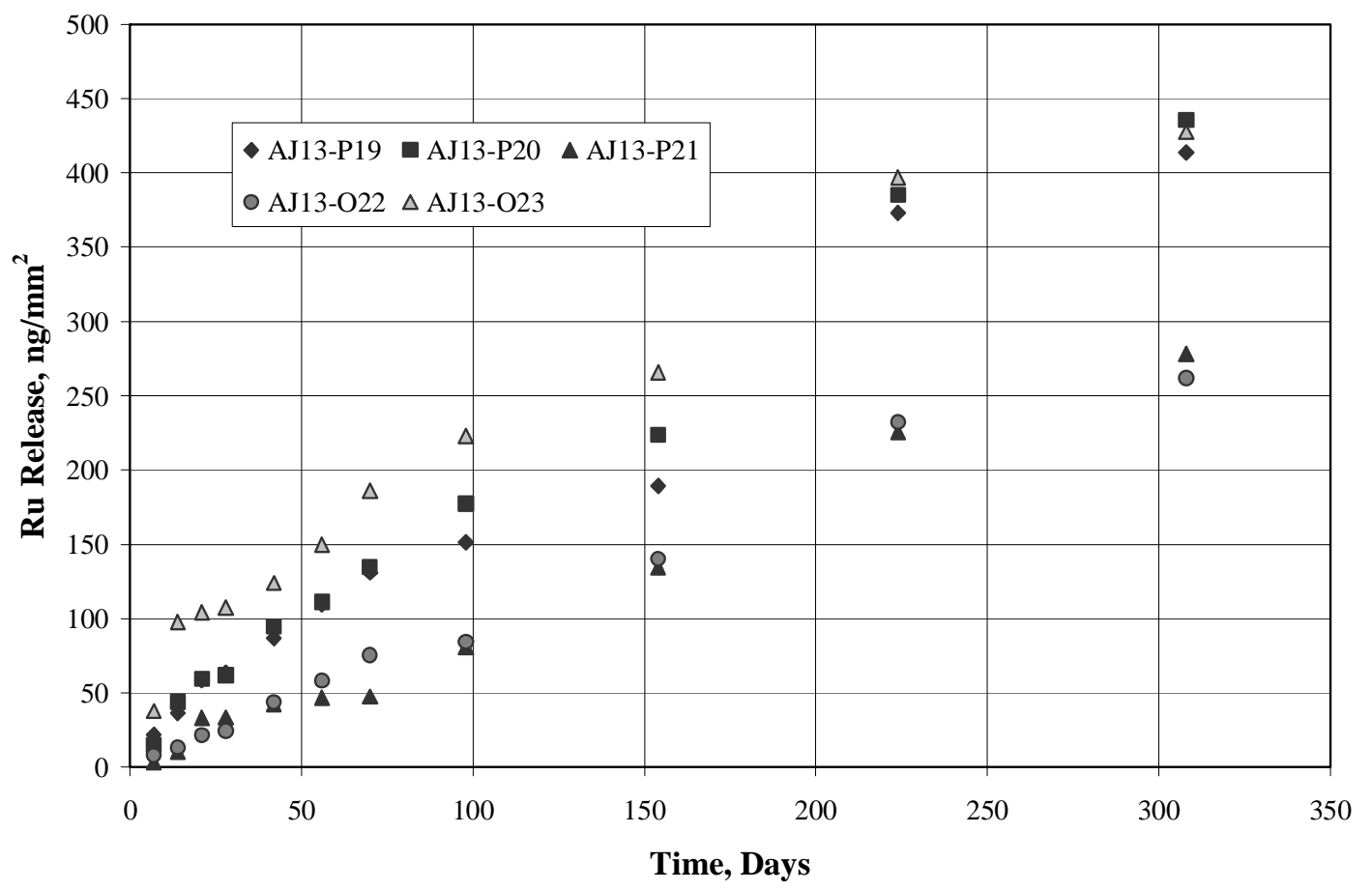

Figure III-42. Cumulative Ruthenium release in $\mathrm{AJ13}$ at $90^{\circ} \mathrm{C}$. 


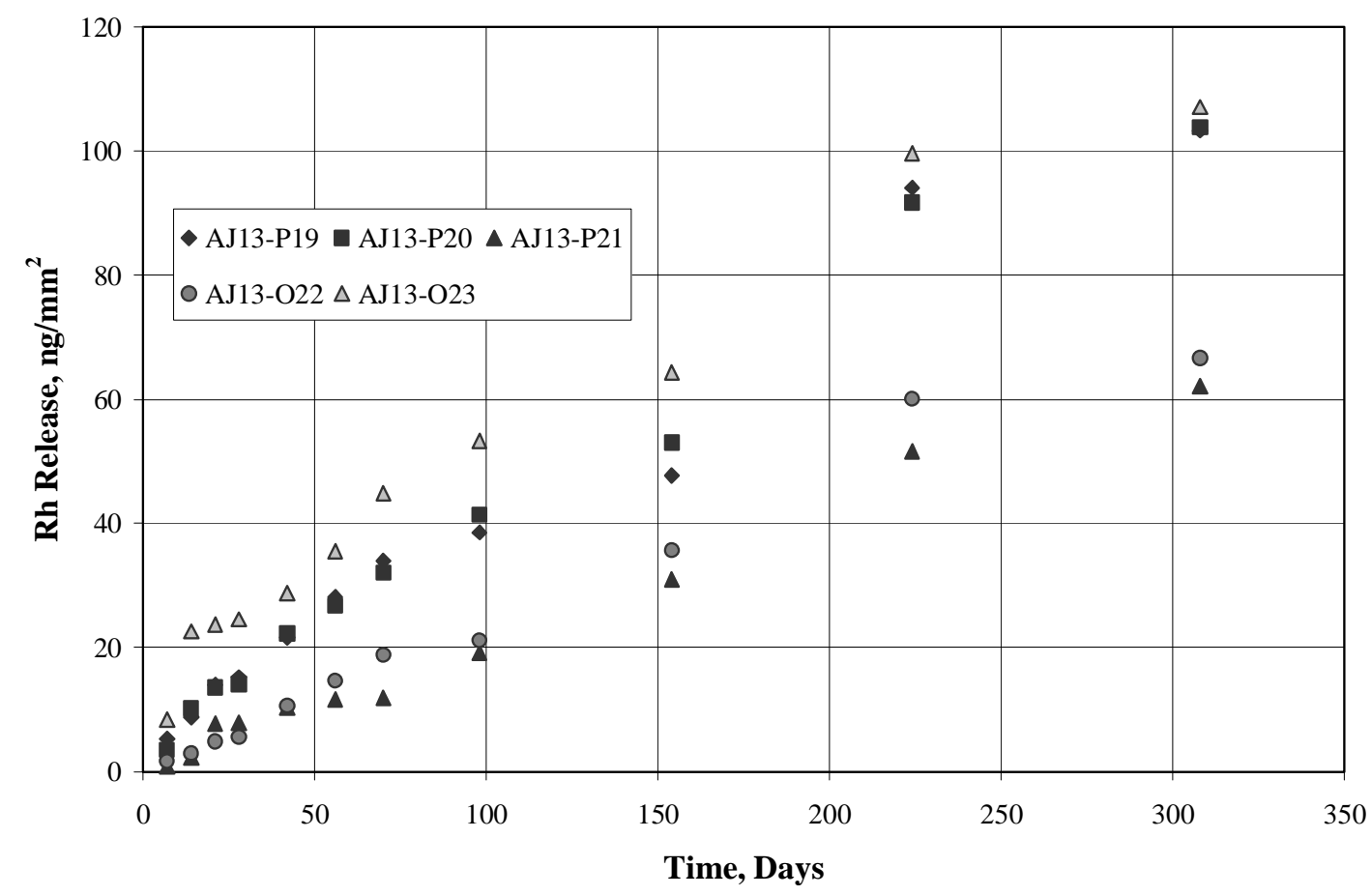

Figure III-43. Cumulative Rhodium release in $\mathrm{AJ} 13$ at $90^{\circ} \mathrm{C}$.

\section{AJ13 Summary}

The total release is dominated by the Fe release. Cr release is about a factor of four lower than the Fe release. Ni release is even lower (about a factor of seven). Releases of fission-product elements and $\mathrm{Zr}$ are more than two orders of magnitude lower than the $\mathrm{Fe}$ release. Average cumulative releases of $\mathrm{Fe}, \mathrm{Zr}, \mathrm{Nb}, \mathrm{Pd}, \mathrm{Ru}$, and $\mathrm{Rh}$ are compared with the average cumulative total release (sum of major elements and these four fissionproduct elements) in Figure III-44. Note that in this low $\mathrm{pH}$ solution, the initial cumulative $\mathrm{Zr}$ release is lower than the initial cumulative releases of $\mathrm{Ru}, \mathrm{Rh}$, and $\mathrm{Nb}$. At the end of the tests, the average cumulative $\mathrm{Ru}$ release is higher than the average cumulative $\mathrm{Zr}$ release. The average cumulative $\mathrm{Pd}$ release is the lowest. 


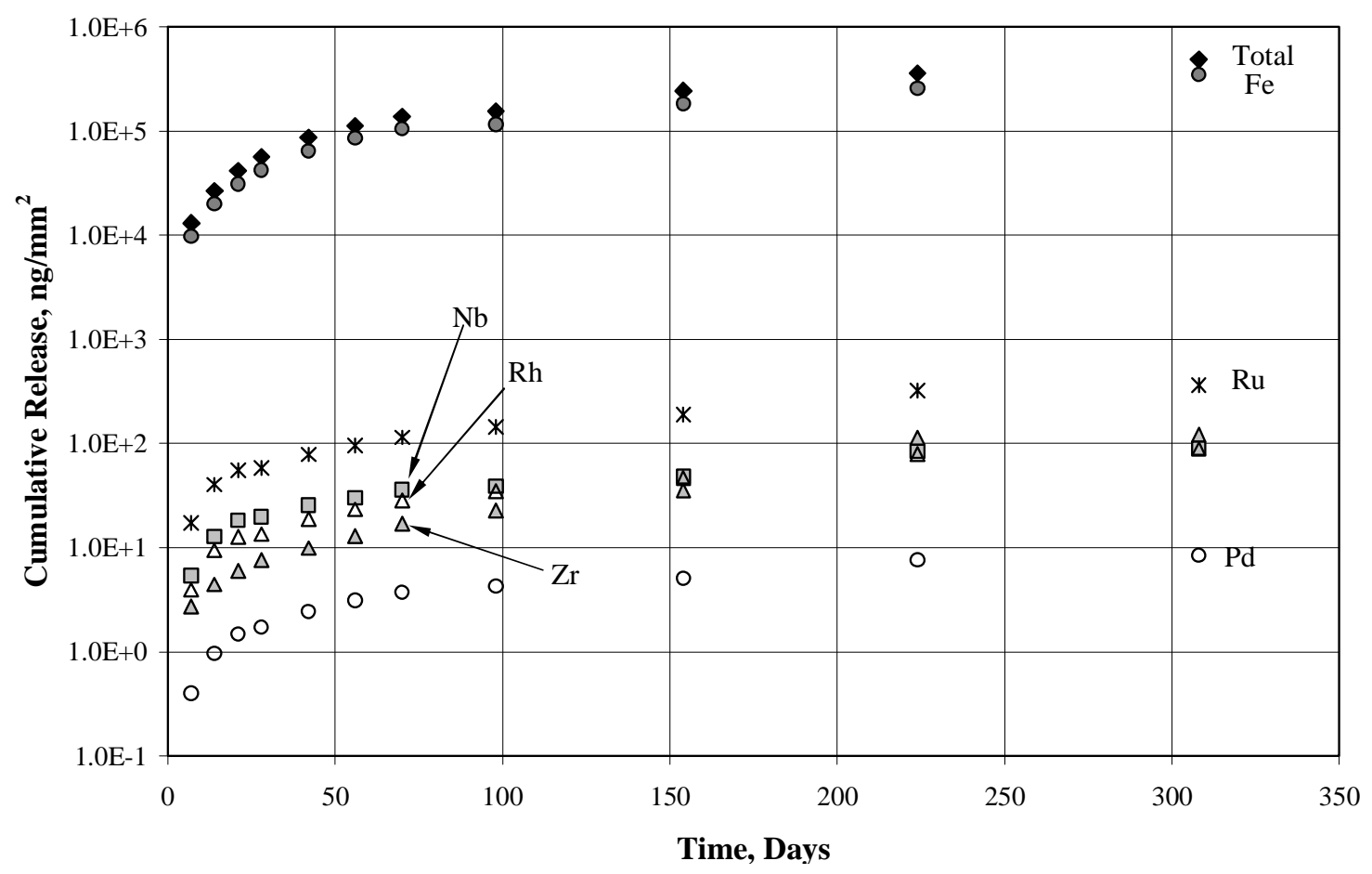

Figure III-44. Average cumulative release in $\mathrm{AJ} 13$ at $90^{\circ} \mathrm{C}$.

\section{Comparison of $90^{\circ} \mathrm{C}$ Cumulative Releases as a Function of Solution}

The average cumulative total releases in the four solutions at $90^{\circ} \mathrm{C}$ are compared in Figure III-45. Releases in the $\mathrm{pH}=2, \mathrm{AJ} 13$ solution were more than three orders of magnitude higher than releases in SJ13. Releases in the $10 \mathrm{KCl}$ solution were about two orders of magnitude higher than releases in SJ13. Releases in CJ13 were similar to those in SJ13 with the releases from polished samples higher and those from oxidized samples lower. Fe cumulative releases in the four solutions, shown in Figure III-46, are similar to the total release trends, as expected because the total releases are mainly $\mathrm{Fe}$. $\mathrm{Cr}$ and $\mathrm{Ni}$ releases have similar trends to Fe except for not being detected in some solutions. 


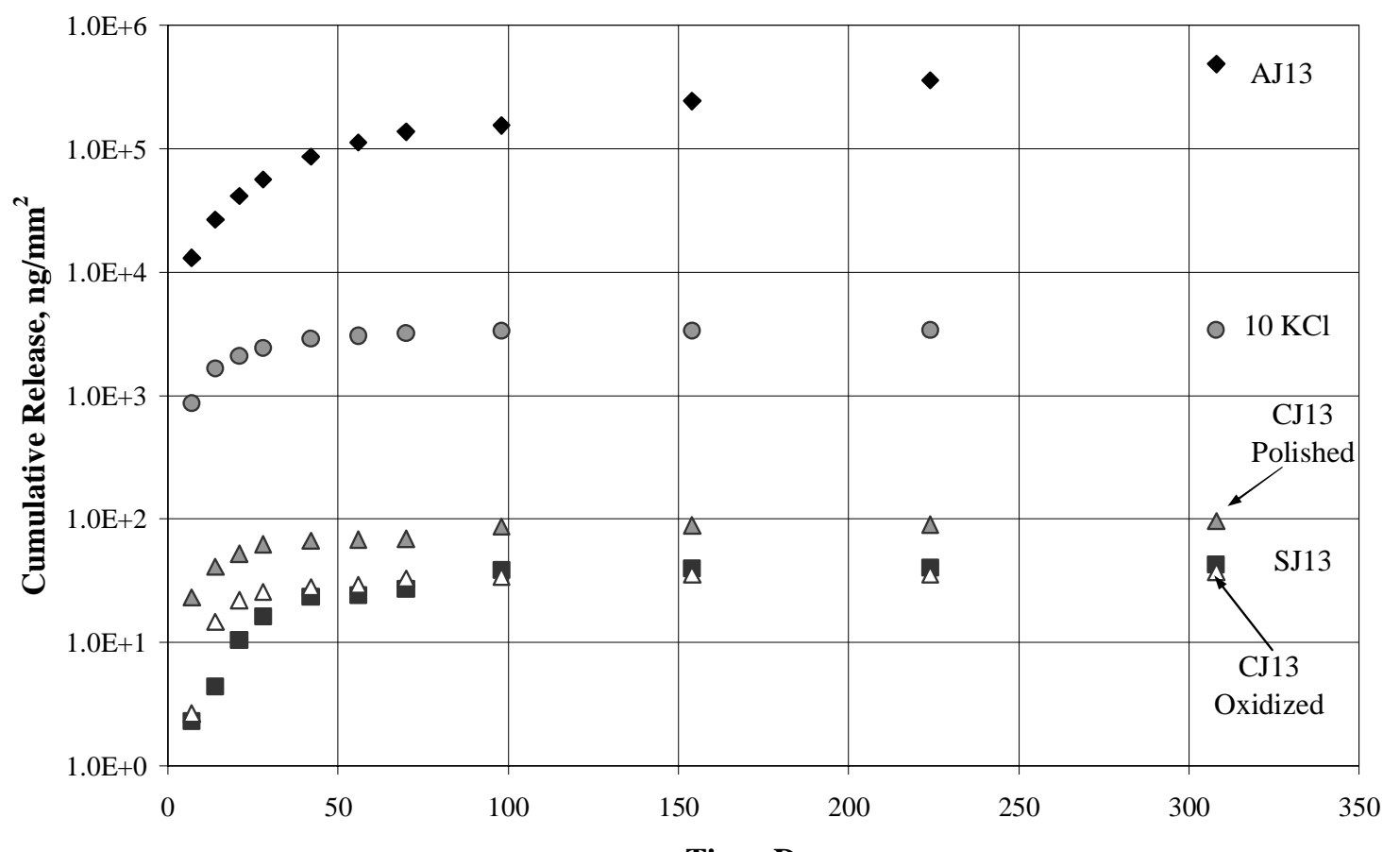

Time, Days

Figure III-45. Average cumulative total release at $90^{\circ} \mathrm{C}$ in four solutions.

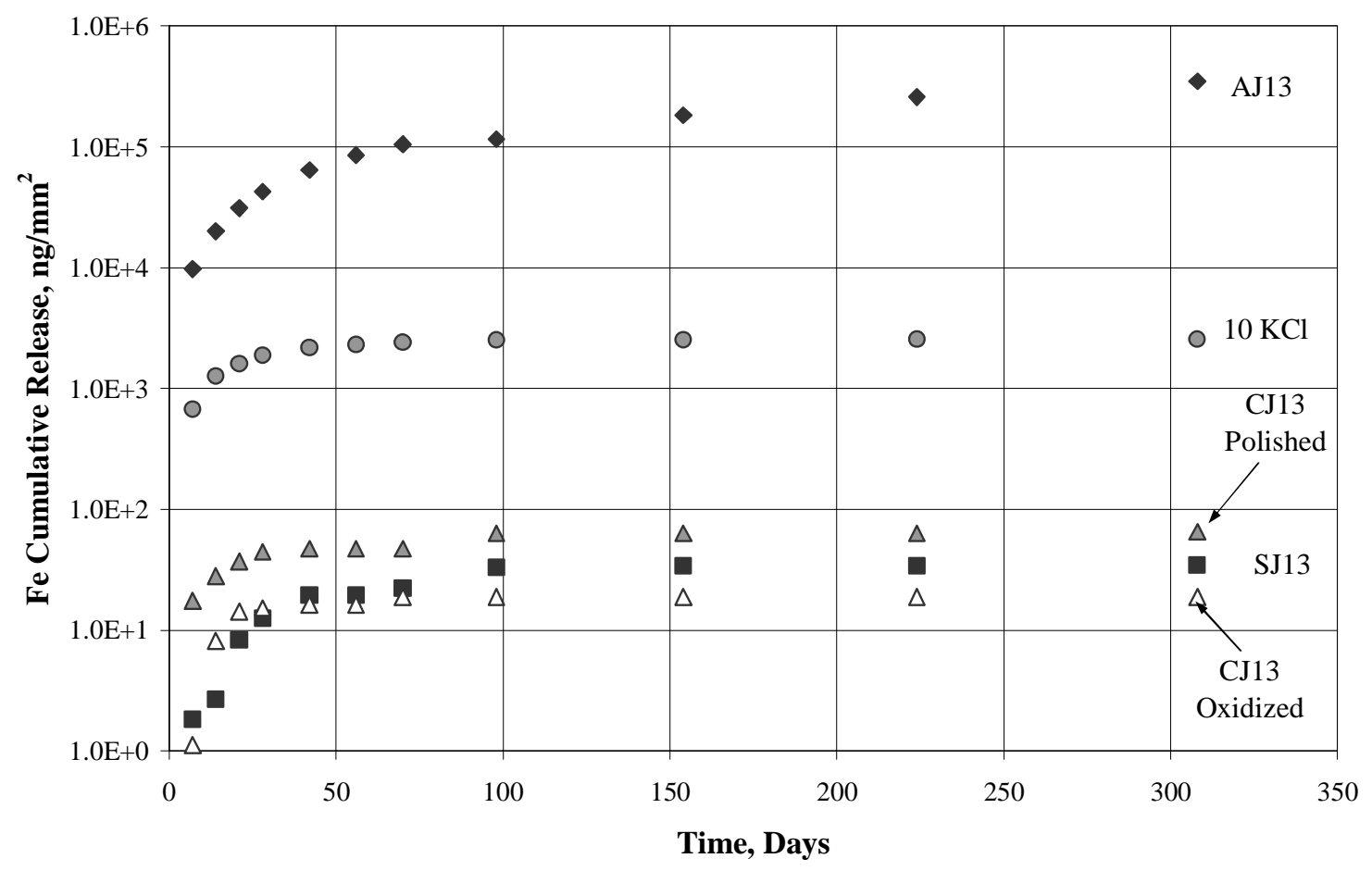

Figure III-46. Average cumulative Iron release at $90^{\circ} \mathrm{C}$ in four solutions.

Average cumulative $\mathrm{Zr}$ releases in the four solutions, shown in Figure III-47, do not have as large a difference between the different solutions as Fe. $\mathrm{Zr}$ releases are highest in AJ13 and lowest in SJ13. Releases of fission-product elements in the four solutions, 
Figures III-48 through III-51, show similar trends to $\mathrm{Zr}$ releases but with variations of about 3 orders of magnitude between SJ13 releases and AJ13 releases. These results indicate significant effect of $\mathrm{pH}$ on the releases of $\mathrm{Fe}, \mathrm{Cr}$, and $\mathrm{Ni}$ and the fission-product elements.

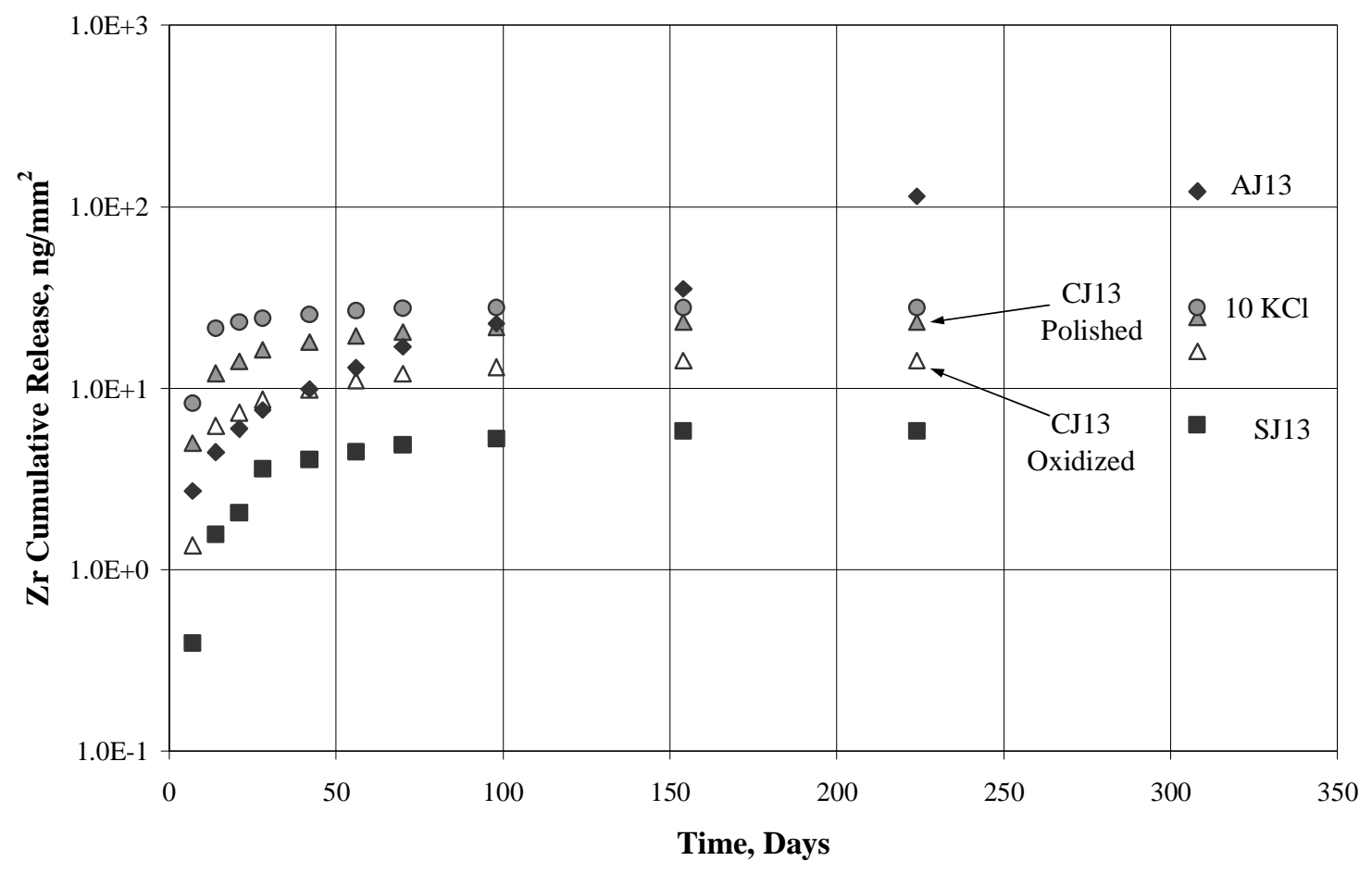

Figure III-47. Average cumulative Zirconium release at $90^{\circ} \mathrm{C}$ in four solutions. 


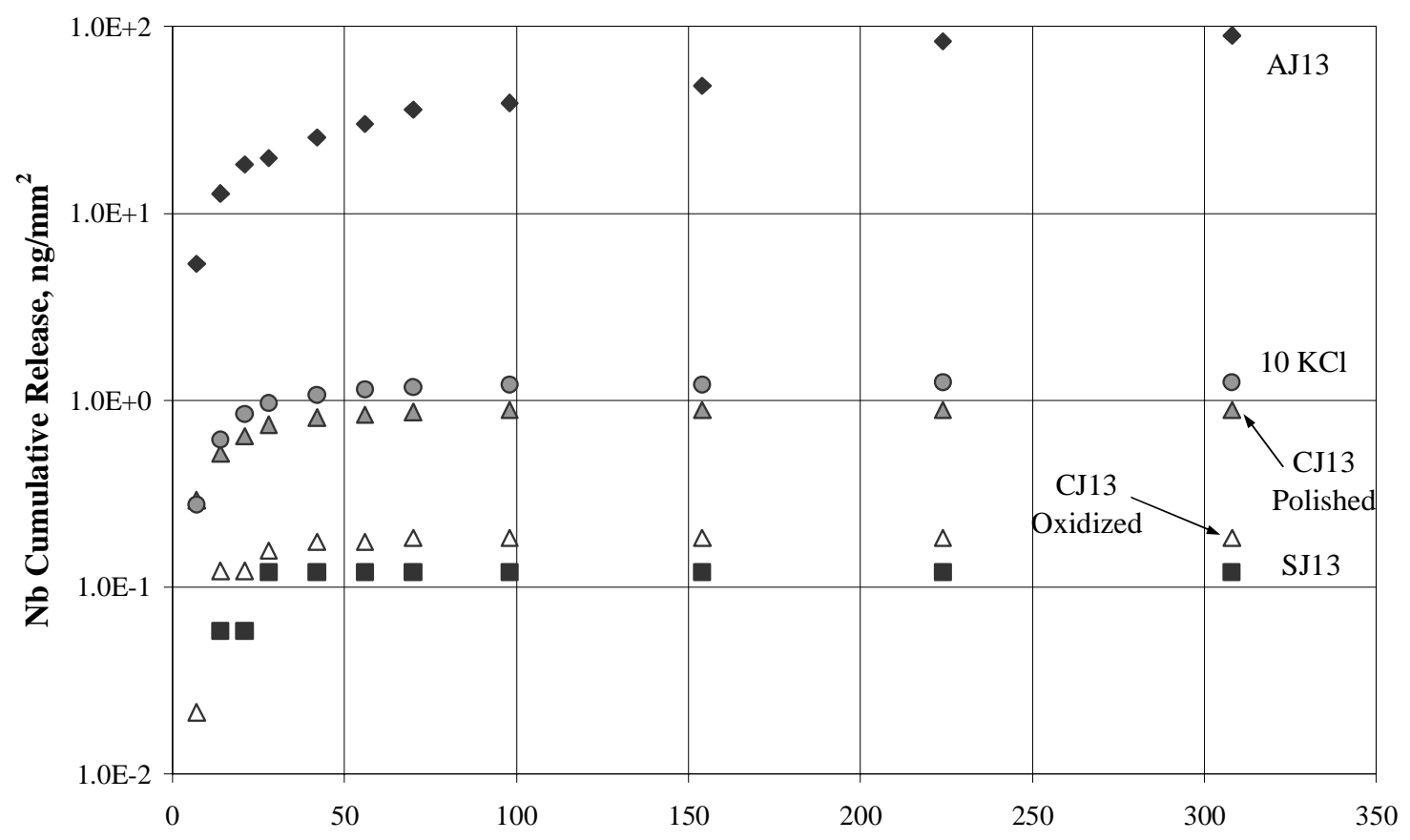

Time, Days

Figure III-48. Average cumulative Niobium release at $90^{\circ} \mathrm{C}$ in four solutions.

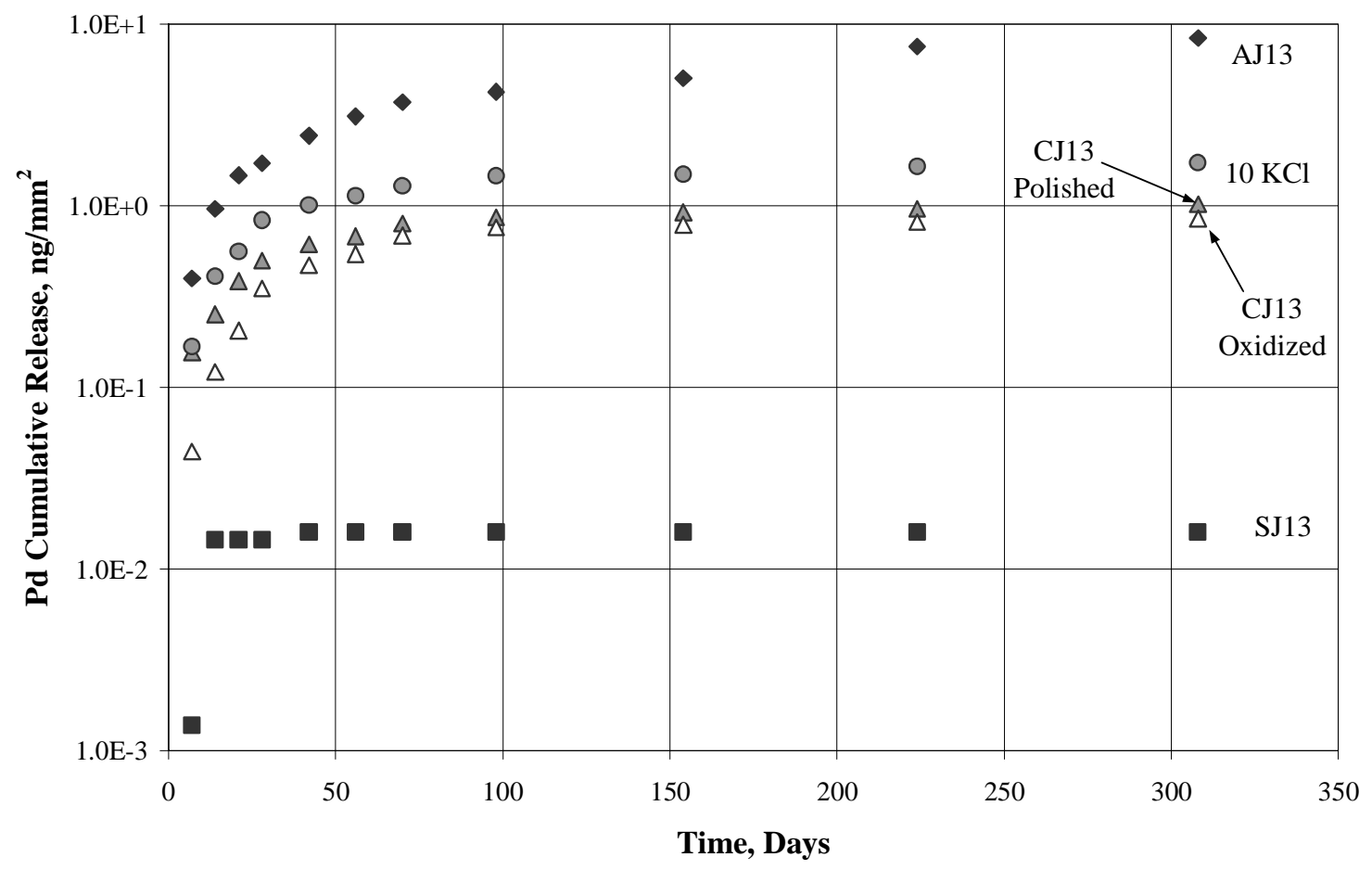

Figure III-49. Average cumulative Palladium release at $90^{\circ} \mathrm{C}$ in four solutions. 


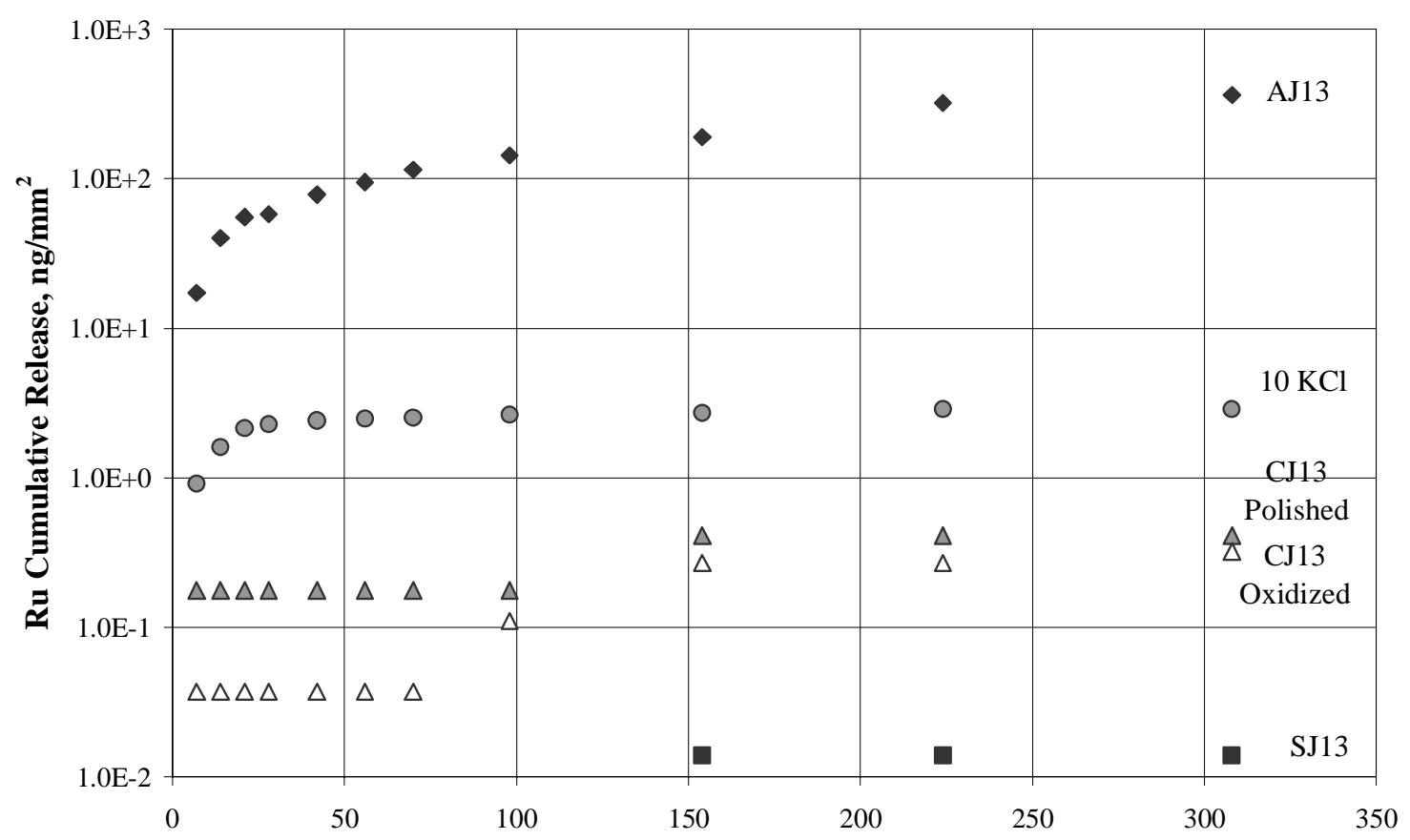

Time, Days

Figure III-50. Average cumulative Ruthenium release at $90^{\circ} \mathrm{C}$ in four solutions.

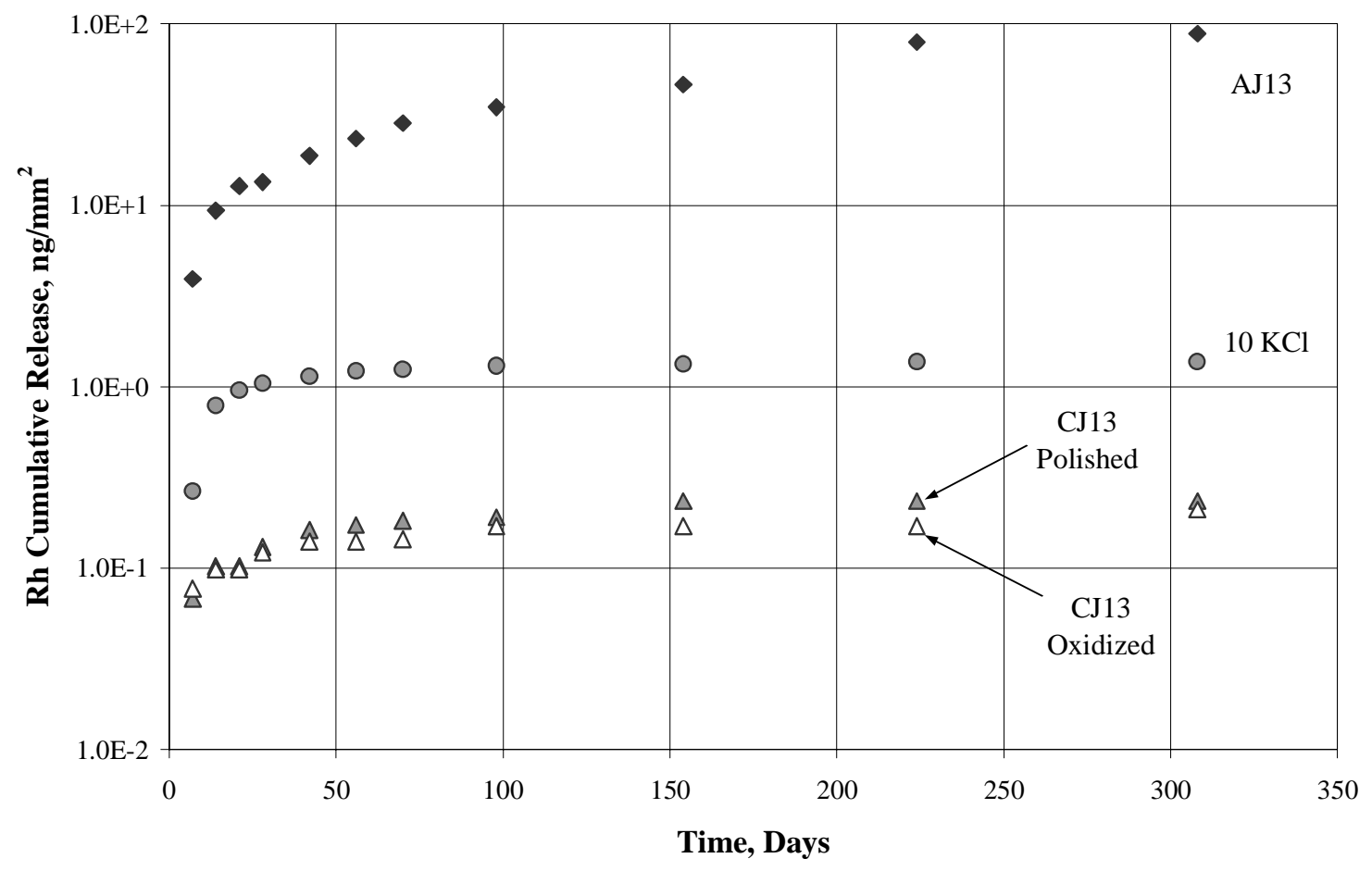

Figure III-51. Average cumulative Rhodium release at $90^{\circ} \mathrm{C}$ in three solutions. 


\section{B. Supplementary Test Samples}

\section{Releases of Elements from Each Test}

Supplementary test samples were terminated at intervals of 14, 28, 42, 84, and 140 days. There were 3 samples and blanks conducted at ambient (room) temperature and 1 sample conducted at $90^{\circ} \mathrm{C}$. A solution of $1 \mathrm{KCl}$ was added in addition to the $10 \mathrm{KCl}$ and $\mathrm{AJ} 13$ solutions. One of the ambient temperature samples and the $90^{\circ} \mathrm{C}$ sample consisted of the $1 \mathrm{KCl}$ solution. The remaining ambient temperature samples consisted of one $10 \mathrm{KCl}$ and one AJ13 solutions. After each sampling interval, the total release of each element was determined from the release to the solution, and the release to the walls obtained from the acid strip wash. There was no residue detected. The releases detected in the test solutions and the acid strip from the walls for each element are shown as bar graphs in Appendix J. Tabulated values are in Appendix K. Average detection limits for the leachate and acid strip have been included on the bar graphs. The detection limits of each as a function of time are given in Appendix L. Detection limits varied from day to day, depending on the instrument calibration. This variation of detection limits led to spurious results when the element released was so low that it was only detected on the days when the detection limit was lower than usual.

Appendix $\mathrm{M}$ contains graphs of the total releases of each element from the waste form samples in the $90^{\circ} \mathrm{C}$ test in $1 \mathrm{KCl}$ solution, and the 3 waste form samples in the $1 \mathrm{KCl}$, $10 \mathrm{KCl}$, and $\mathrm{AJ} 13$ solutions at ambient temperature for each sampling interval, as a function of sampling interval. The amount of each element detected in the control vial solution has been included in the graphs as a bar graph for comparison. The control data provide useful information regarding the uncertainties in the tests. New vials were used for each test, so the uncertainties pertain solely to the test solution releases and do not include carryover from previous vial use.

\section{a) Sample Contamination of Minor Elements and Mo}

Examination of releases of $\mathrm{Mo}, \mathrm{Cu}$, and $\mathrm{V}$ showed fluctuations that could not be attributed to changes in detection limits. Upon checking the history of laboratory use during the test time of high releases, it was found that experimenters not involved in the Metal Waste Form (MWF) Project were using the laboratory balance and laboratory area in close proximity to the MWF work to measure powders of $\mathrm{Mo}, \mathrm{Cu}$, and $\mathrm{V}$. It is believed that the test samples were contaminated from airborne powders of these elements. Thus, reported releases of these three elements are not reliable.

\section{b) Mo and Minor Elements (Mn, Co, Cu, and V)}

Due to the sample contamination with $\mathrm{Mo}, \mathrm{Cu}$, and $\mathrm{V}$, and the low levels of release in the minor elements, releases of these elements will not be discussed. These elements have not been included in the reported total release. 


\section{Cumulative Release at $90^{\circ} \mathrm{C}$}

\section{a) 1KCl:}

Few elements were detected from the immersion test in $1 \mathrm{KCl}$. The small amounts detected were near the limits of detection.

Release of Major Elements

The major elements consist of $\mathrm{Fe}, \mathrm{Zr}, \mathrm{Cr}$, and $\mathrm{Ni}$. Fe had the highest release at 4.83 $\mathrm{ng} / \mathrm{mm}^{2}$ at 14 days as shown in Figure III-52. Ni was only detected on day 14 at 3.63 $\mathrm{ng} / \mathrm{mm}^{2}$ as shown in Figure III-53, $1.64 \mathrm{ng} / \mathrm{mm}^{2}$ above the detection limit of $2.07 \mathrm{ng} / \mathrm{mm}^{2}$ $\mathrm{Zr}$ releases were below $0.5 \mathrm{ng} / \mathrm{mm}^{2}$ as shown in Figure III-54. Cr was not detected.

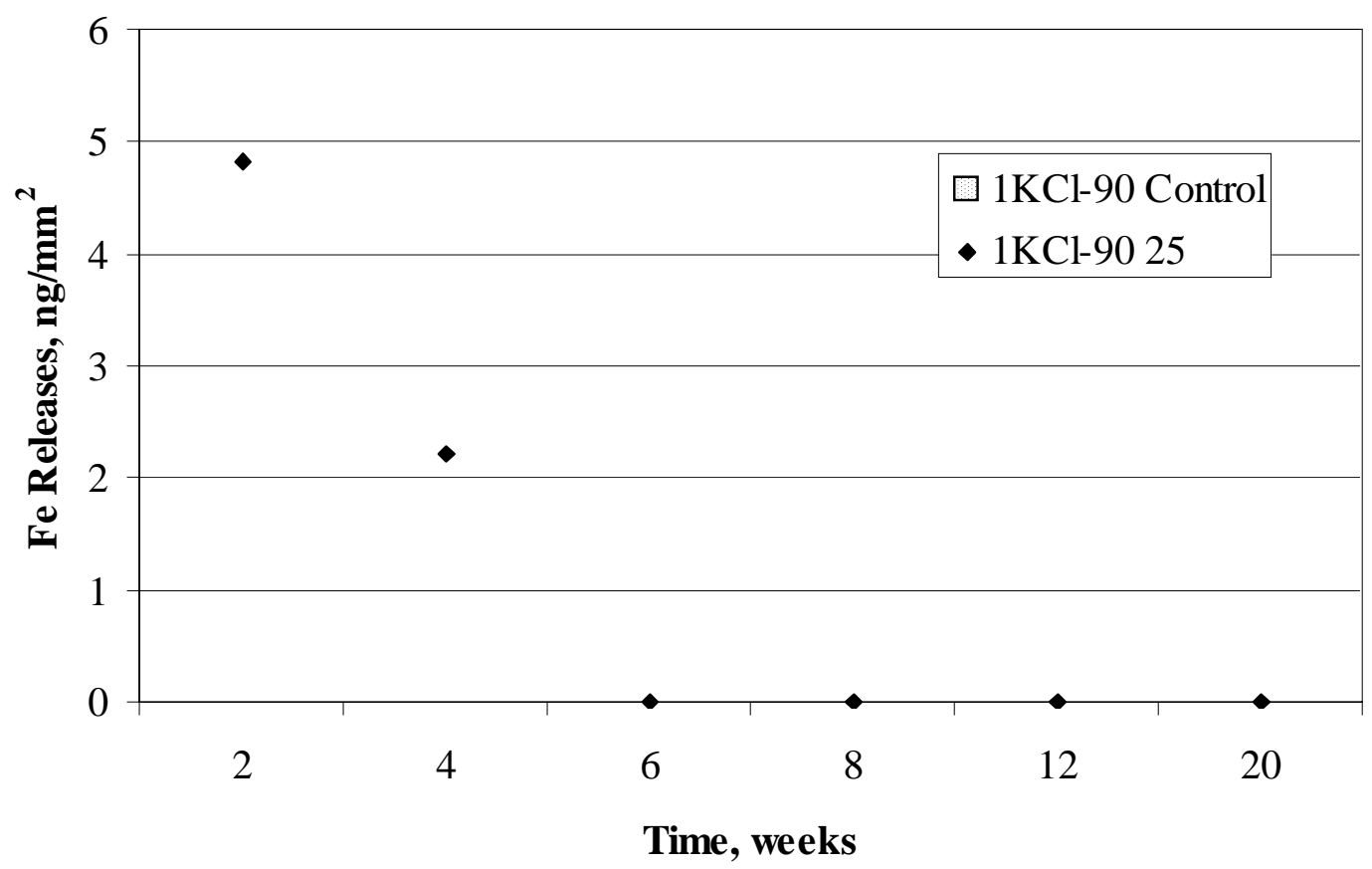

Figure III-52. Iron releases in $1 \mathrm{KCl}$ at $90^{\circ} \mathrm{C}$. 


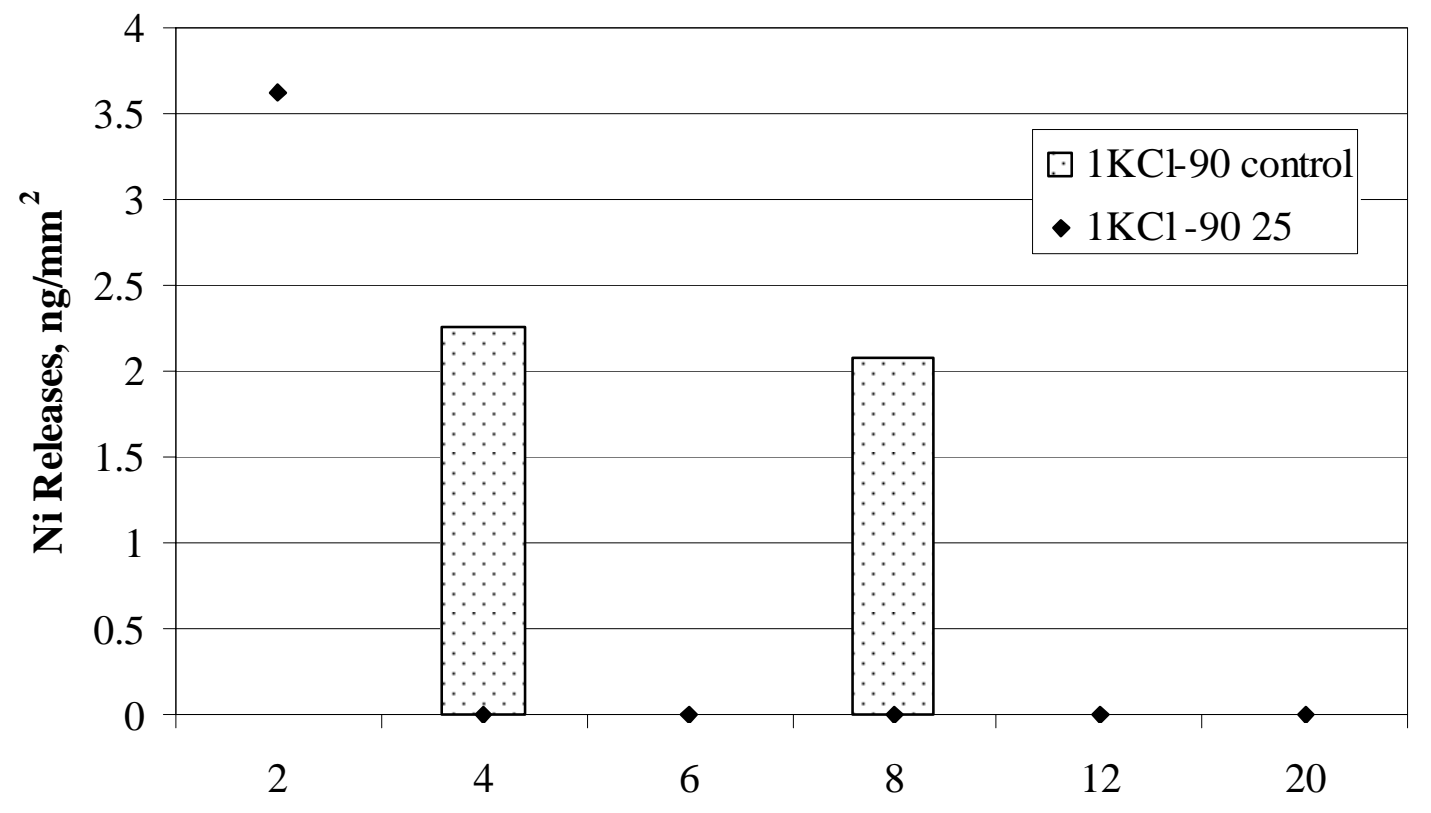

Time, weeks

Figure III-53. Nickel releases in $1 \mathrm{KCl}$ at $90^{\circ} \mathrm{C}$.

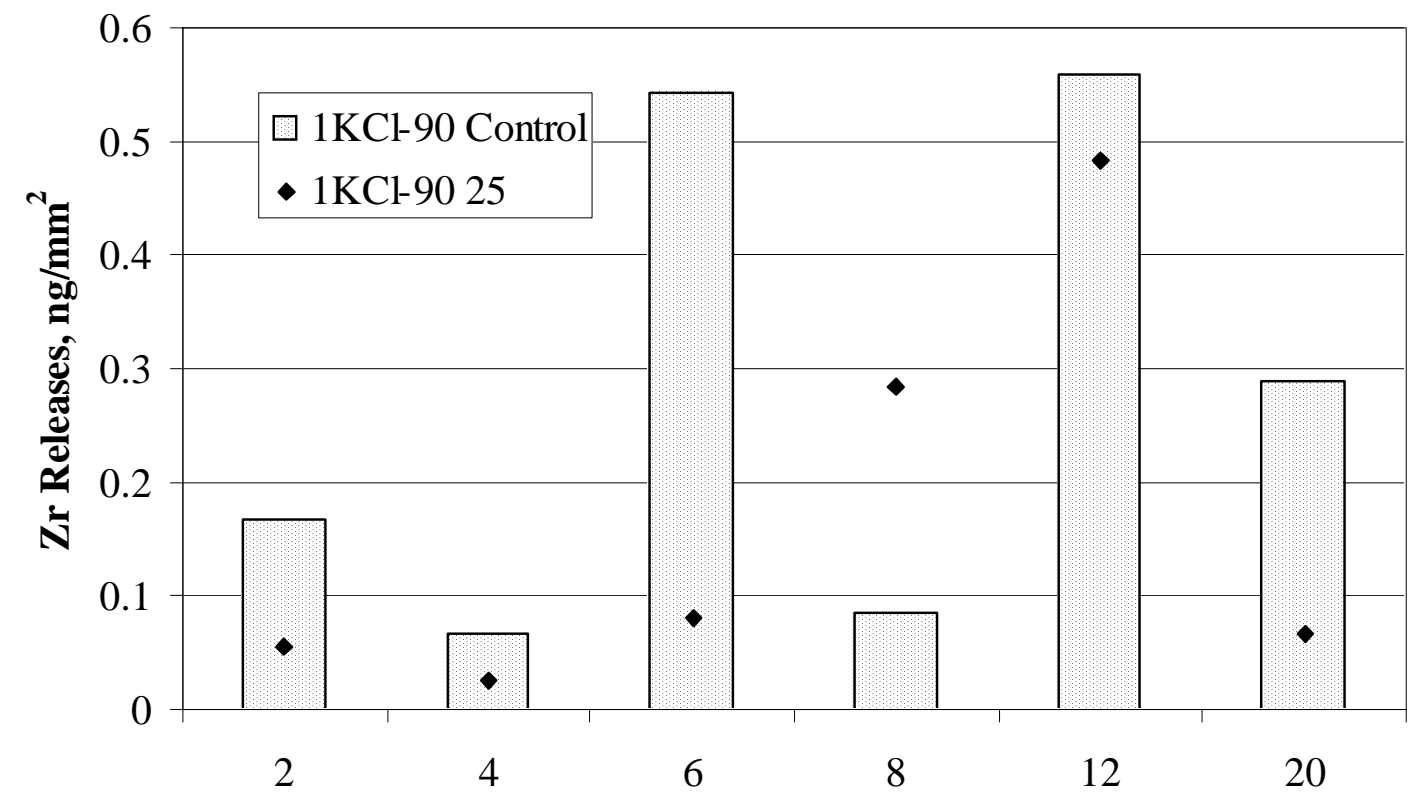

Time, weeks

Figure III-54. Zirconium releases in $1 \mathrm{KCl}$ at $90^{\circ} \mathrm{C}$.

\section{Release of Fission Product Elements}

Fission product elements consist of $\mathrm{Pd}, \mathrm{Nb}, \mathrm{Ru}$, and $\mathrm{Rh}$. Both $\mathrm{Rh}$ and $\mathrm{Ru}$ were only detected on day 42 at approximately $0.03 \mathrm{ng} / \mathrm{mm}^{2}$ as shown in Figures III-55 and III-56, $0.01 \mathrm{ng} / \mathrm{mm}^{2}$ above the detection limit of $0.02 \mathrm{ng} / \mathrm{mm}^{2}$. Nb and Pd were not detected. 


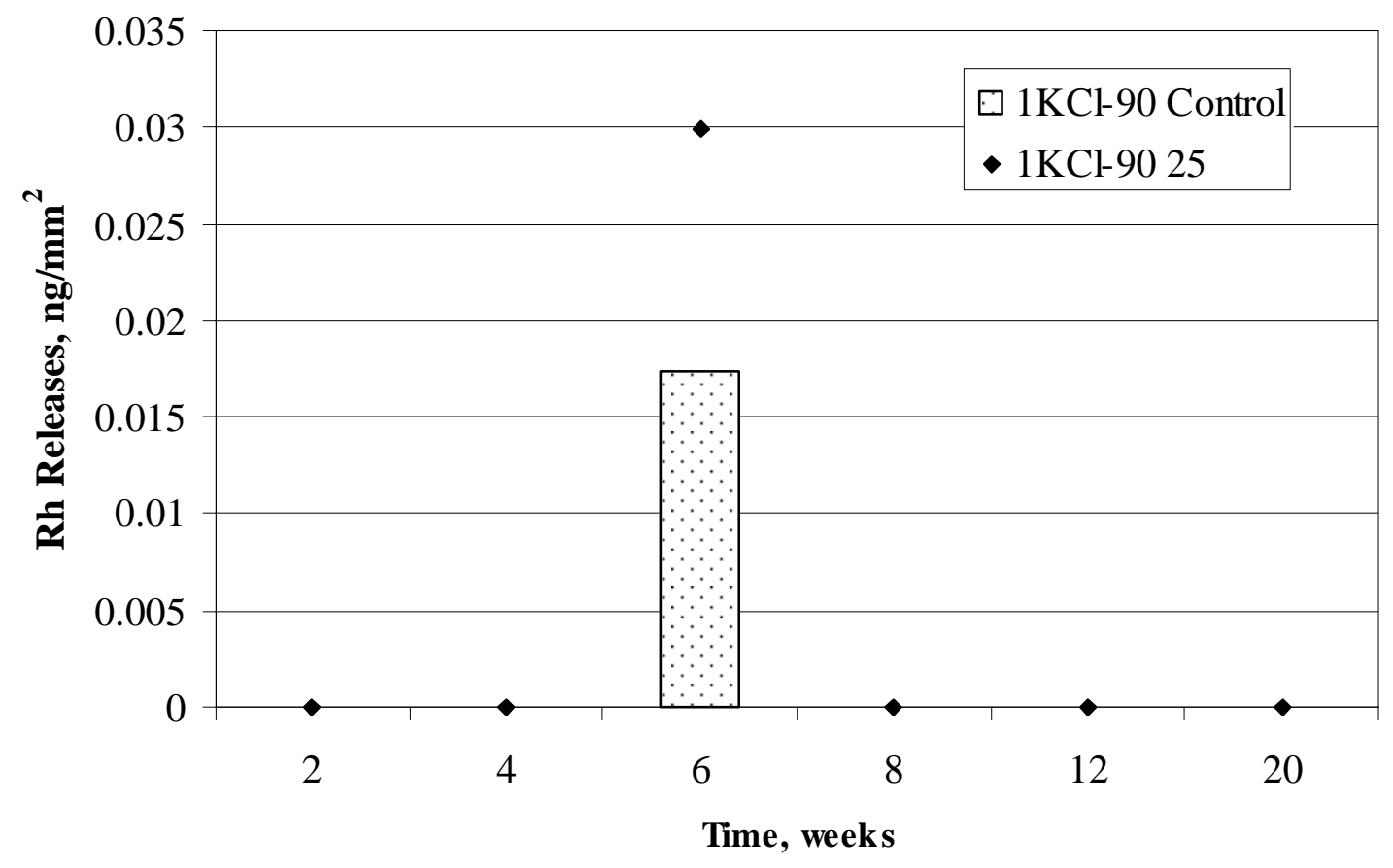

Figure III-55. Rhodium releases in $1 \mathrm{KCl}$ at $90^{\circ} \mathrm{C}$.

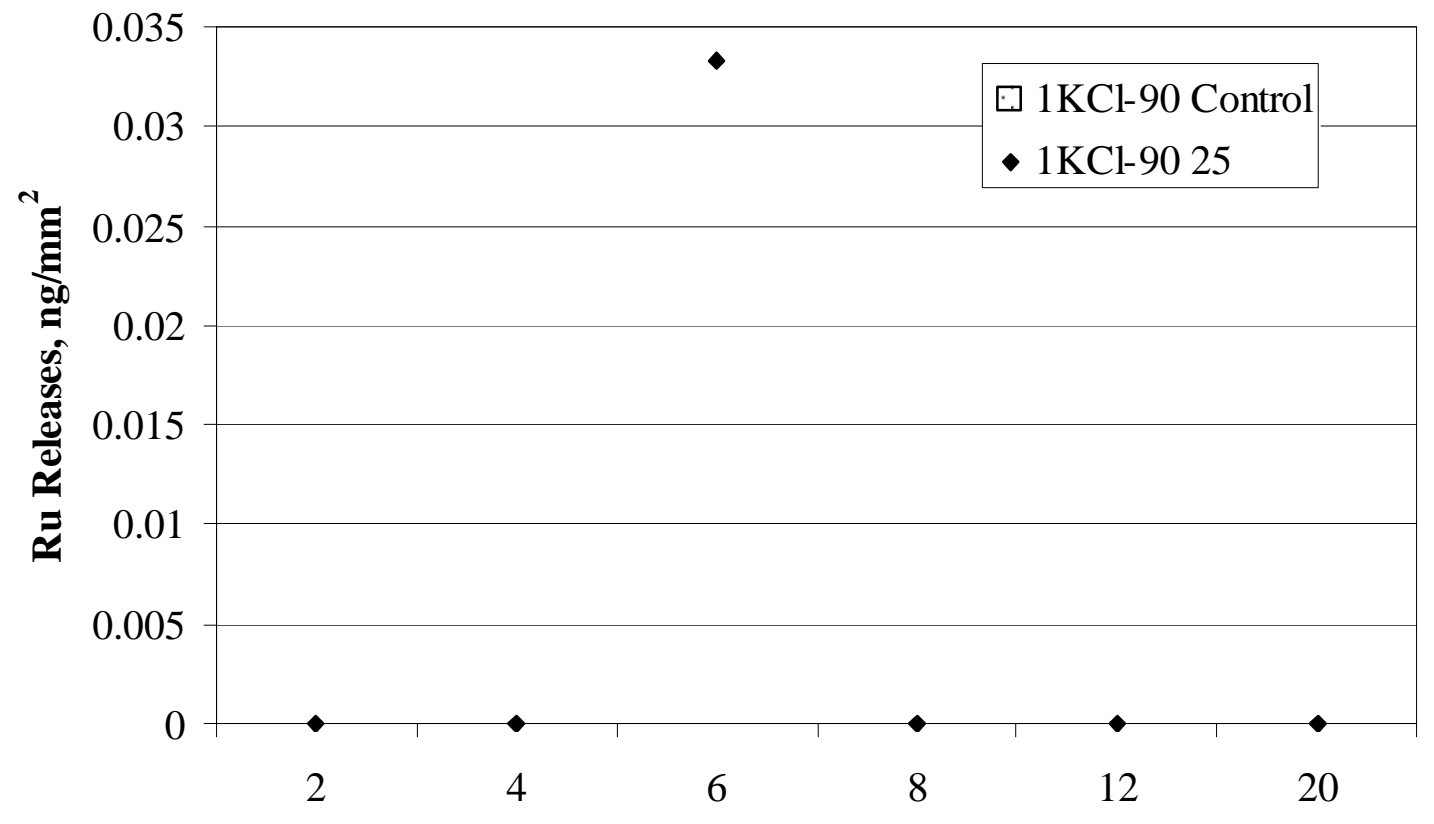

Time, weeks

Figure III-56. Ruthenium releases in $1 \mathrm{KCl}$ at $90^{\circ} \mathrm{C}$. 


\section{$1 \mathrm{KCl}$ chloride Summary}

Of the major elements $\mathrm{Fe}$ and $\mathrm{Ni}$ showed the highest releases at $90^{\circ} \mathrm{C}$, but even these values were just above the detection limits. Releases for $\mathrm{Zr}$ were below $0.5 \mathrm{ng} / \mathrm{mm}^{2}$. Both $\mathrm{Rh}$ and $\mathrm{Ru}$ were detected once at 42 days with the release again just above the detection limit.

\section{Cumulative Release at Ambient Temperature:}

\section{a) 1KCl:}

Cumulative releases were near the detection limit or not detected.

\section{Release of Major Elements}

Of the major elements (Fe, $\mathrm{Zr}, \mathrm{Cr}, \mathrm{Ni}) \mathrm{Fe}$ was detected at 14 days at $7.68 \mathrm{ng} / \mathrm{mm}^{2}$, lower than the corresponding control vessel, as shown in Figure III-57. Ni was detected at 28 days at $4.54 \mathrm{ng} / \mathrm{mm}^{2}$ as shown in Figure III-58. Zr was detected at $0.44 \mathrm{ng} / \mathrm{mm}^{2}$ just above the detection limit on day 84 as shown in Figure III-59. Cr was not detected.

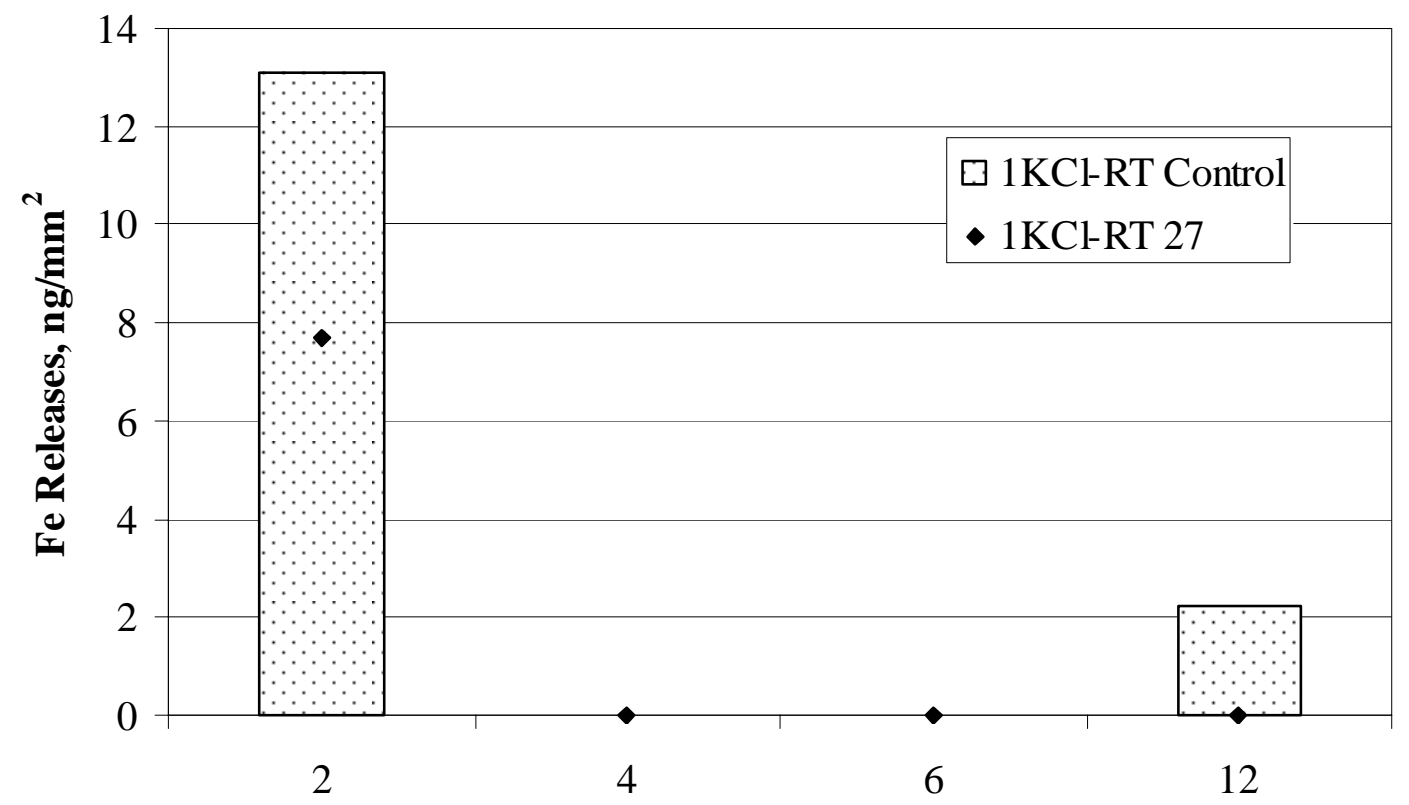

Time, weeks

Figure III-57. Iron releases in $1 \mathrm{KCl}$ at room temperature. 


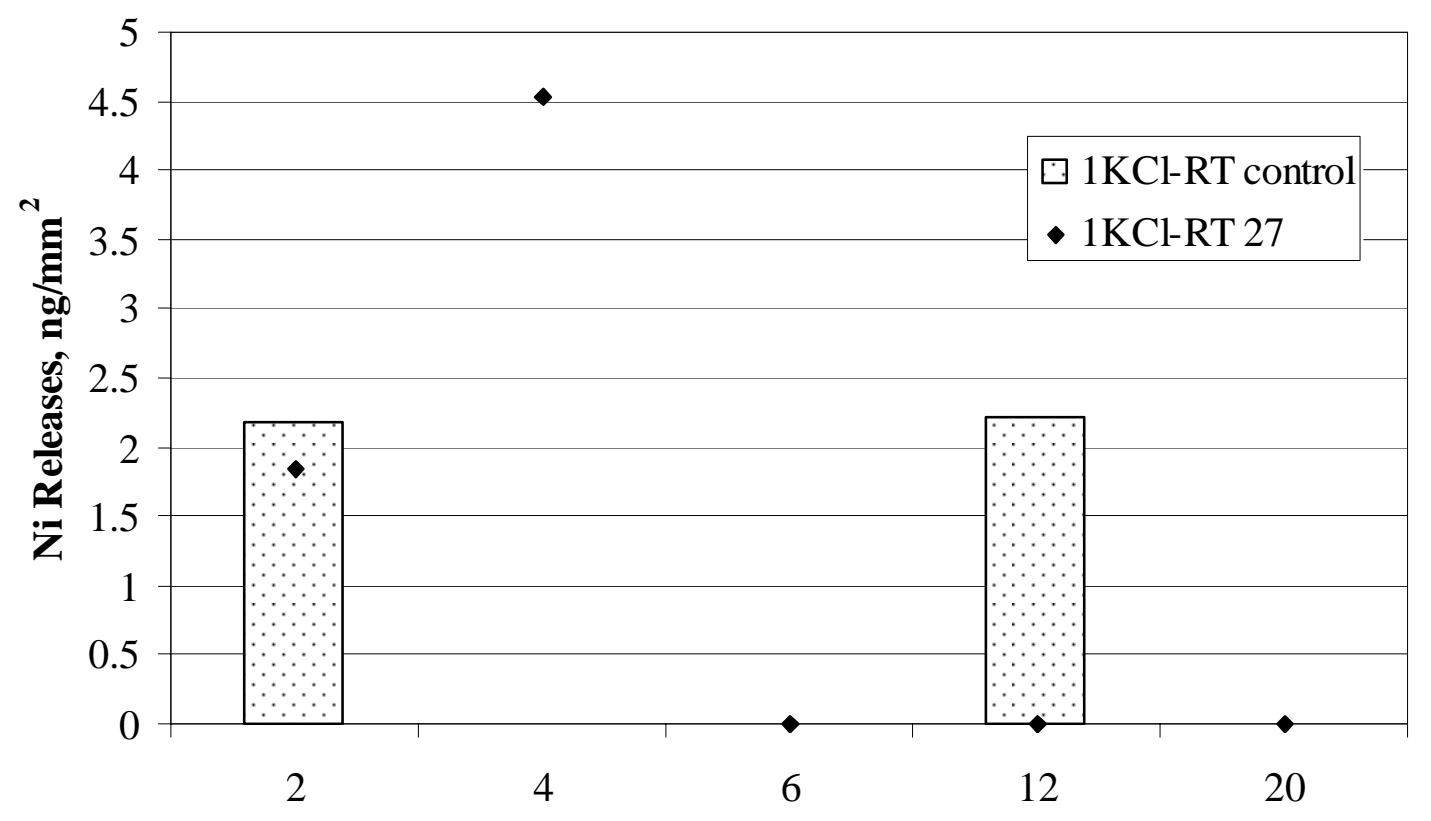

Time, weeks

Figure III-58. Nickel releases in $1 \mathrm{KCl}$ at room temperature.

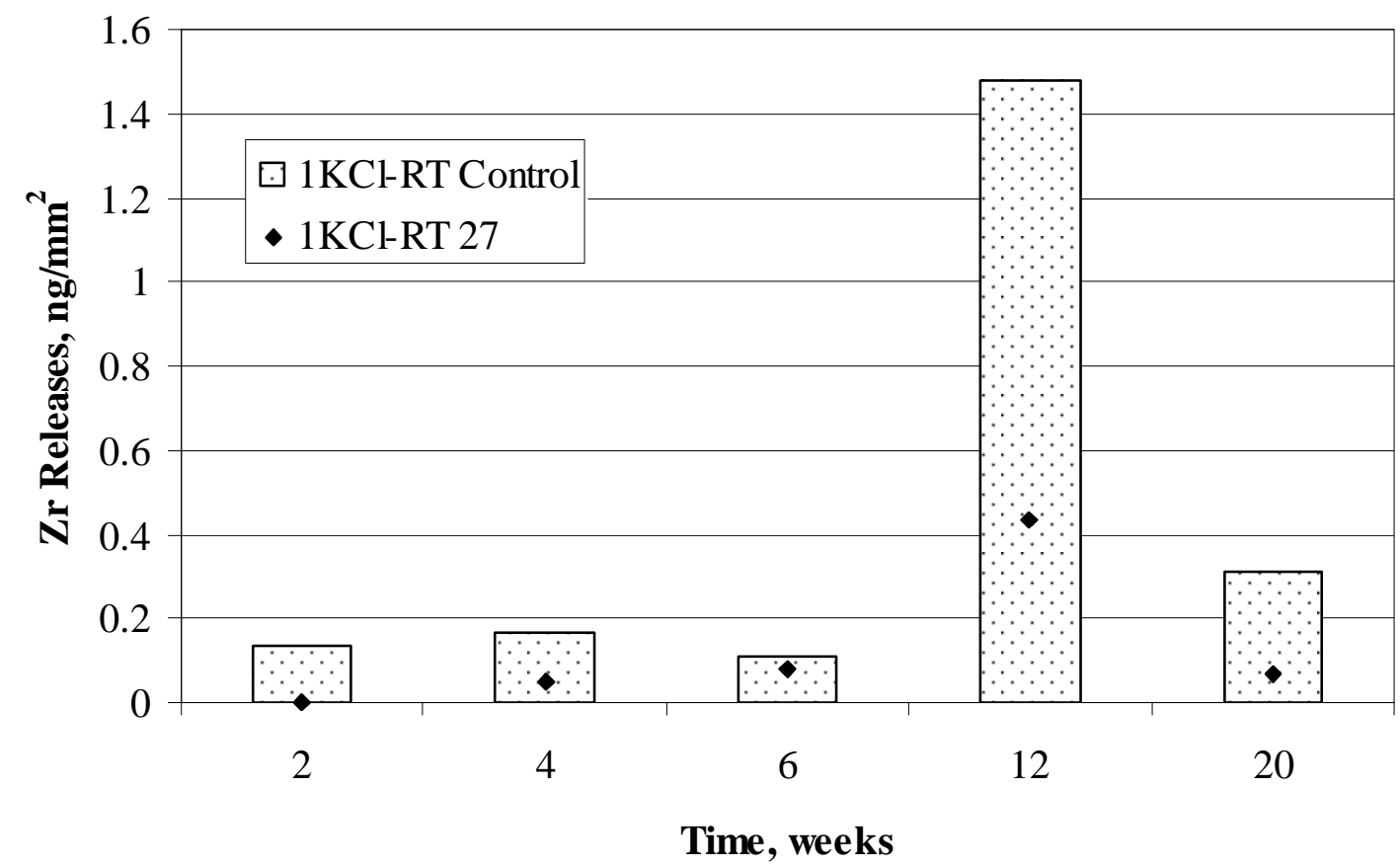

Figure III-59. Zirconium releases in $1 \mathrm{KCl}$ at room temperature.

Release of Fission Product Elements

None of the fission product elements $(\mathrm{Pd}, \mathrm{Nb}, \mathrm{Ru}, \mathrm{Rh})$ were detected. 


\section{IKCl Summary:}

Most of the cumulative releases were near the detection limit or not detected. The highest releases were for the major elements $\mathrm{Fe}\left(7.68 \mathrm{ng} / \mathrm{mm}^{2}\right)$ and $\mathrm{Ni}\left(4.54 \mathrm{ng} / \mathrm{mm}^{2}\right)$ during the 14-28 day period. $\mathrm{Zr}$ was detected at just above the detection limit at 84 days. No fission product elements were detected.

\section{b) 10KCl:}

The highest releases were the major elements $\mathrm{Fe}, \mathrm{Cr}$, and $\mathrm{Ni}$. The fission product elements and $\mathrm{Zr}$ were detected at just above the detection limit.

\section{Release of Major Elements:}

Of the major elements $(\mathrm{Fe}, \mathrm{Zr}, \mathrm{Cr}, \mathrm{Ni}) \mathrm{Fe}$ and $\mathrm{Cr}$ were detected at 84 days. $\mathrm{Fe}$ was detected at $262.25 \mathrm{ng} / \mathrm{mm}^{2}$ as shown in Figure III-60 and Cr was detected at 74.50 $\mathrm{ng} / \mathrm{mm}^{2}$ as shown in Figure III-61. Ni was detected at $23.80 \mathrm{ng} / \mathrm{mm}^{2}$ at 140 days as shown in Figure III-62. $\mathrm{Zr}$ was detected at 14 days at $1.19 \mathrm{ng} / \mathrm{mm}^{2}$ as shown in Figure III-63.

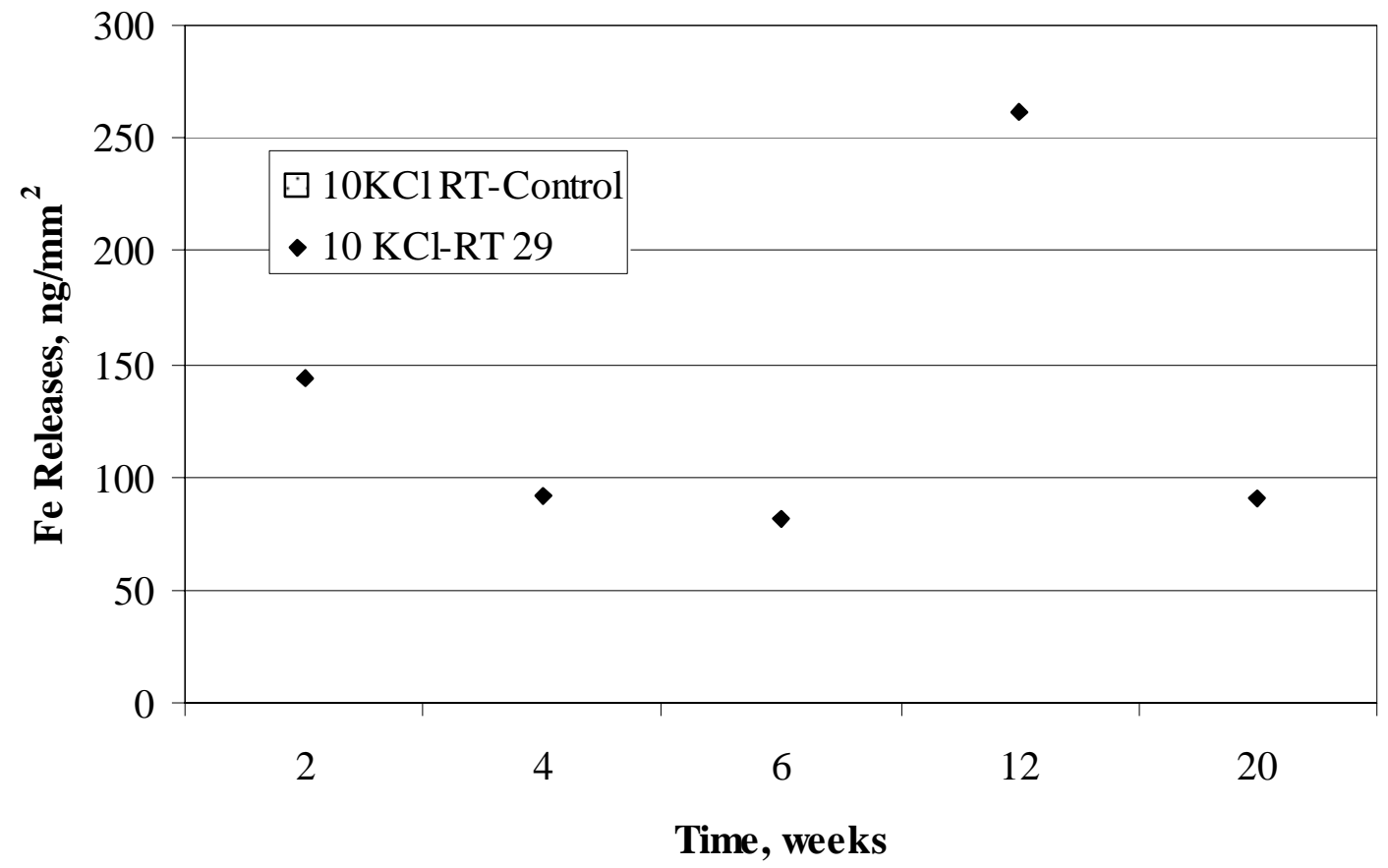

Figure III-60. Iron releases in $10 \mathrm{KCl}$ at room temperature. 


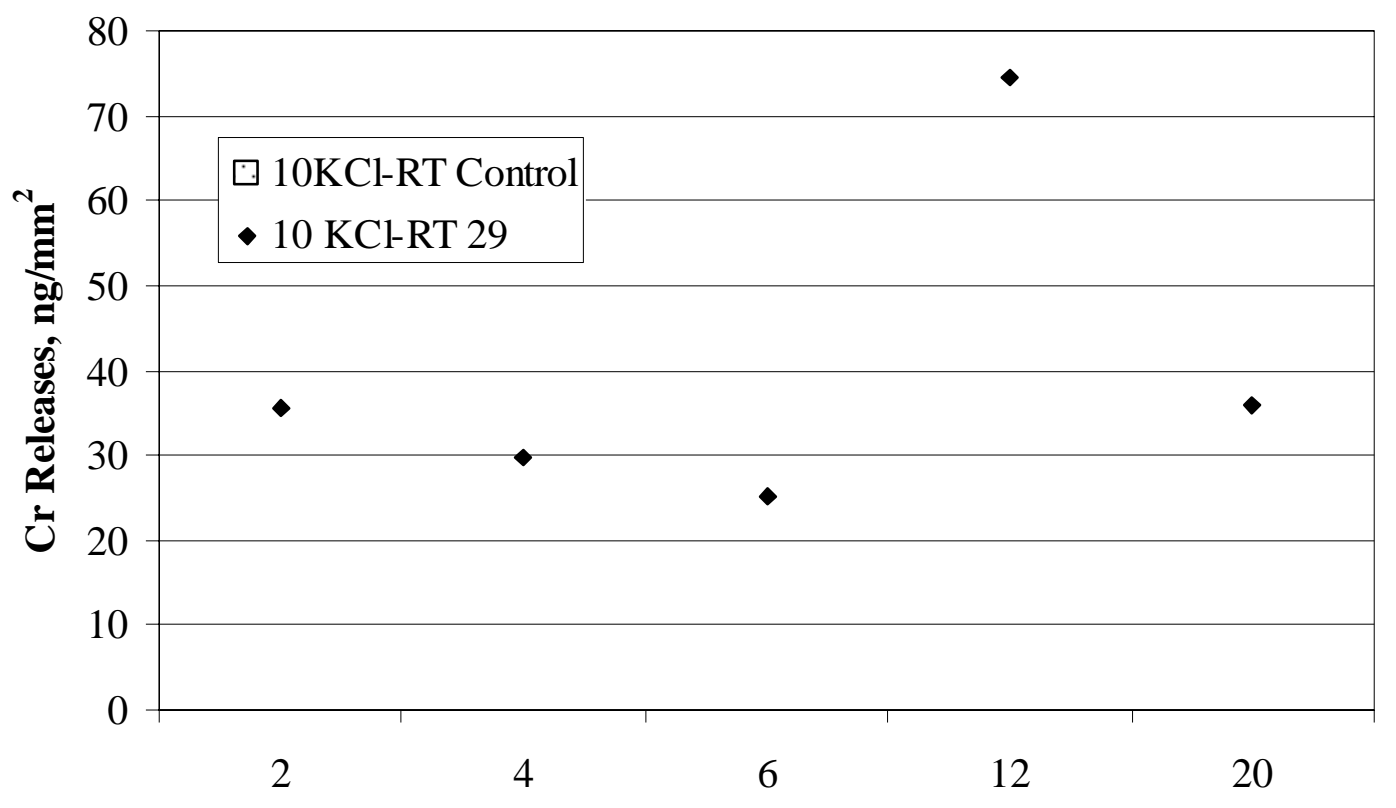

Time, weeks

Figure III-61. Chromium releases in $10 \mathrm{KCl}$ at room temperature.

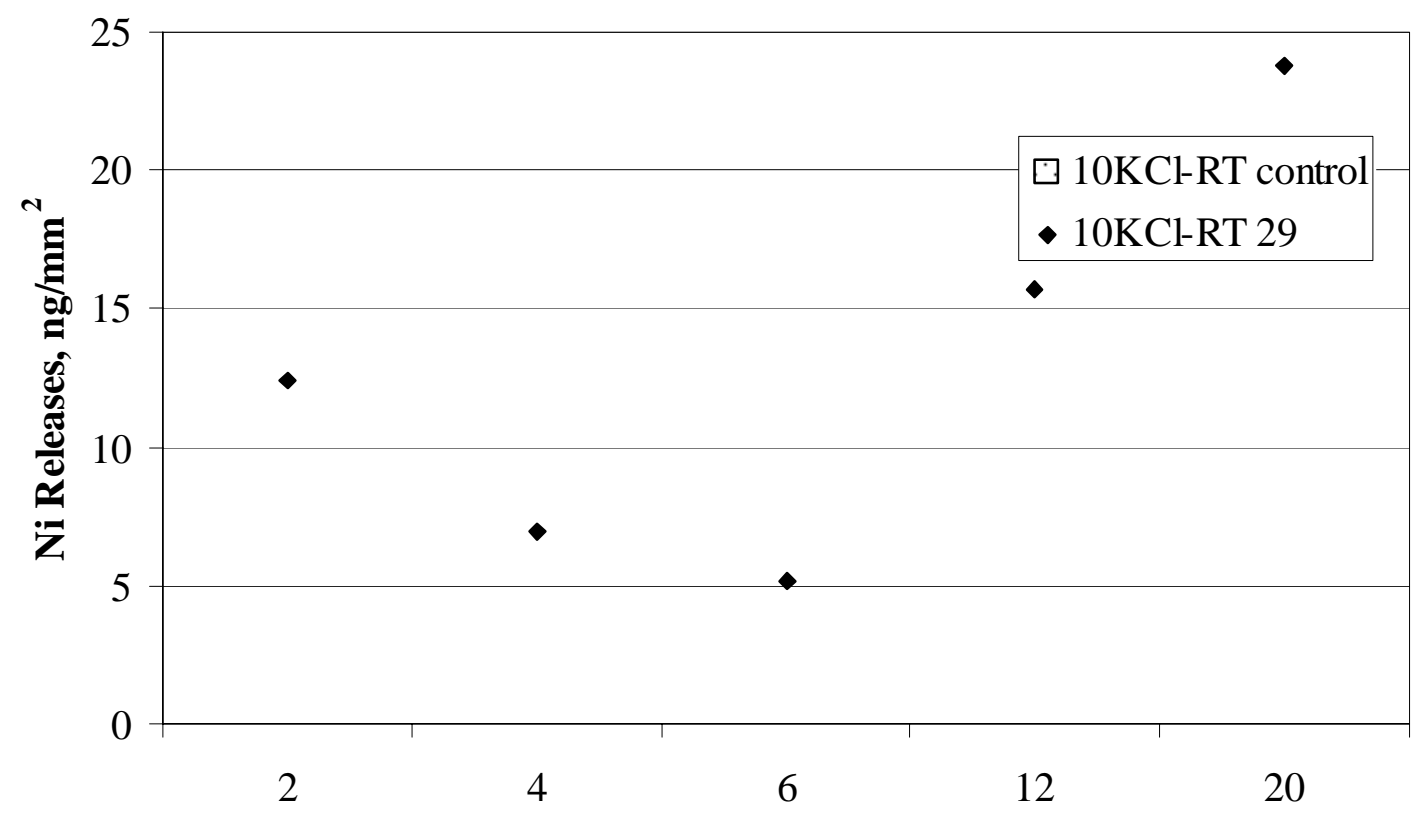

Time, weeks

Figure III-62. Nickel releases in $10 \mathrm{KCl}$ at room temperature. 


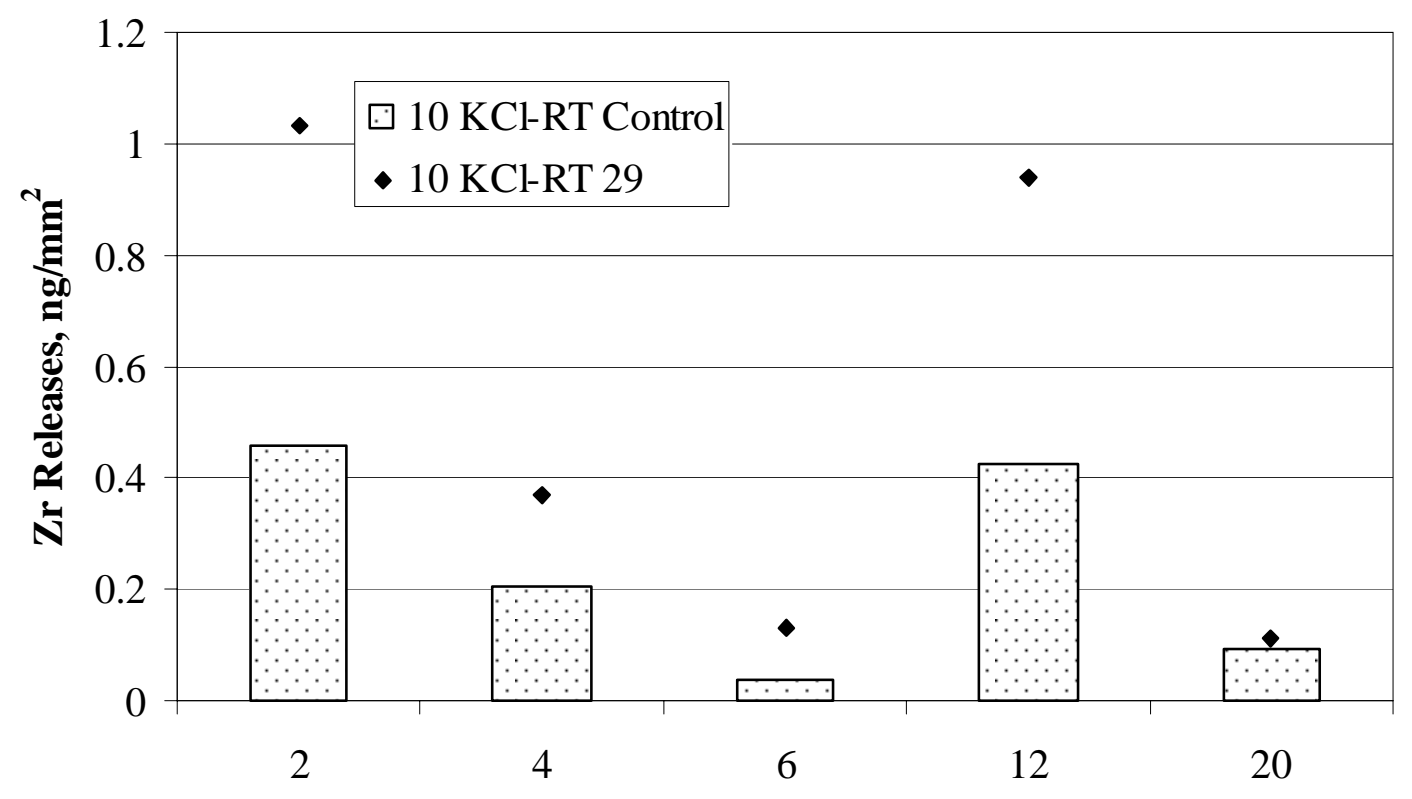

Time, weeks

Figure III-63. Zirconium releases in $10 \mathrm{KCl}$ at room temperature.

Release of Fission Product Elements:

The fission product elements $(\mathrm{Pd}, \mathrm{Nb}, \mathrm{Rh}, \mathrm{Ru})$ were all detected at 84 days at levels just above the detection limits represented by Figure III-64. Pd was detected at $0.09 \mathrm{ng} / \mathrm{mm}^{2}$, $\mathrm{Nb}$ at $0.16 \mathrm{ng} / \mathrm{mm}^{2}$, Rh at $0.61 \mathrm{ng} / \mathrm{mm}^{2}$ and $\mathrm{Ru}$ at $0.74 \mathrm{ng} / \mathrm{mm}^{2}$.

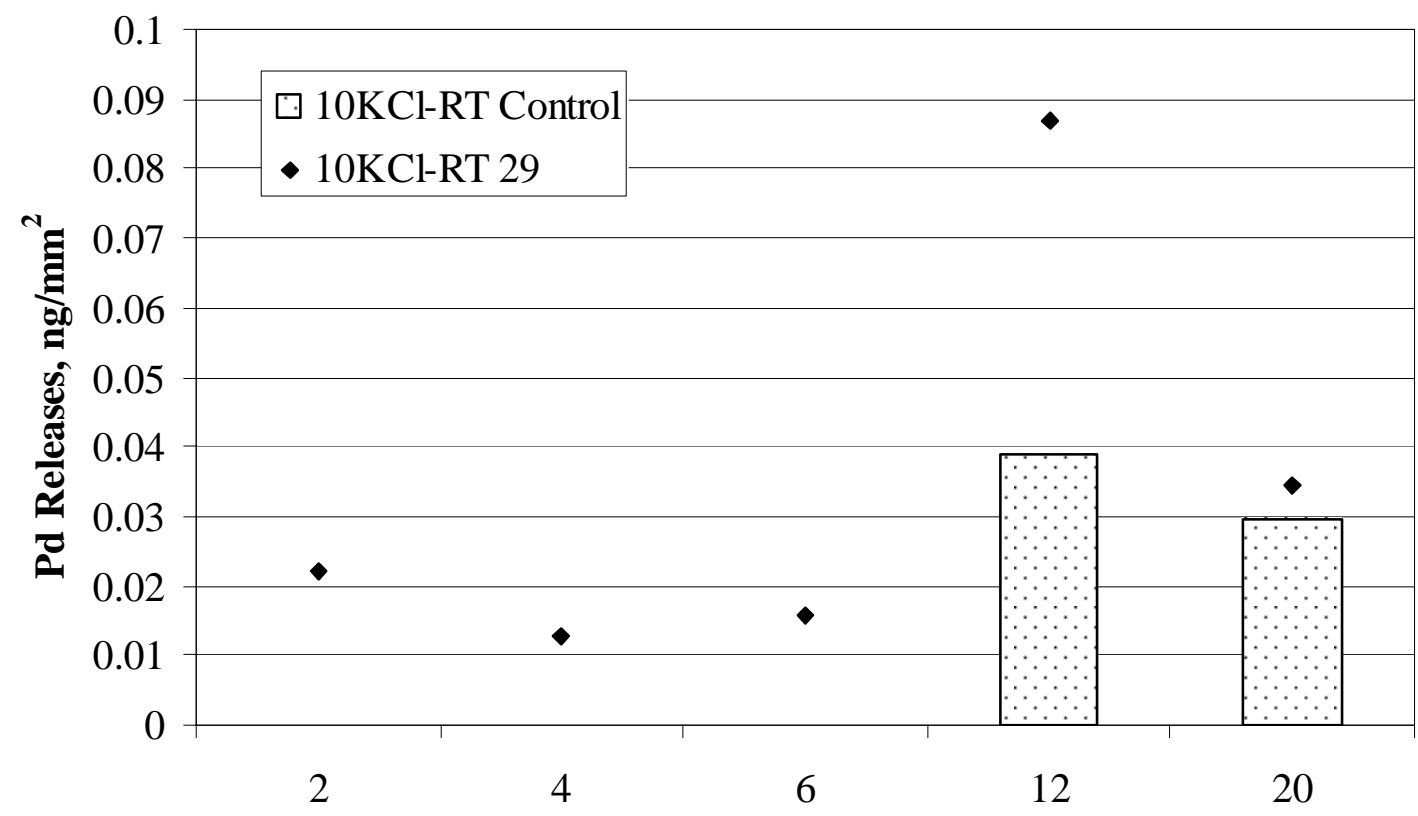

Time, weeks

Figure III-64. Palladium releases in $10 \mathrm{KCl}$ at room temperature. 


\section{KCl Summary}

The highest releases were the major elements $\mathrm{Fe}, \mathrm{Cr}$, and $\mathrm{Ni}$. Fe was the major contributor to the total cumulative release. Cr release was a factor of three lower than $\mathrm{Fe}$ release followed by $\mathrm{Ni}$ release at an order of magnitude lower. $\mathrm{Fe}$ and $\mathrm{Cr}$ were detected at 84 days and $\mathrm{Ni}$ was detected at 140 days. Zr was detected at 14 days. The fission product elements and $\mathrm{Zr}$ were detected at just above the detection limit.

\section{c) AJ13:}

The highest releases were for the major elements. Cumulative releases for the fission product elements were near the detection limit or not detected.

\section{Release of Major Elements:}

The highest releases of all the major elements (Fe, $\mathrm{Zr}, \mathrm{Cr}, \mathrm{Ni}$ ) occurred primarily at 140 days. Fe was detected at $797.00 \mathrm{ng} / \mathrm{mm}^{2}$ as shown in Figure III-65, Zr at $6.24 \mathrm{ng} / \mathrm{mm}^{2}$, $\mathrm{Cr}$ at $248.92 \mathrm{ng} / \mathrm{mm}^{2}$, and $\mathrm{Ni}$ at $57.20 \mathrm{ng} / \mathrm{mm}^{2}$. These values represented a change in the release rate as, prior to this time, release into solution was very low.

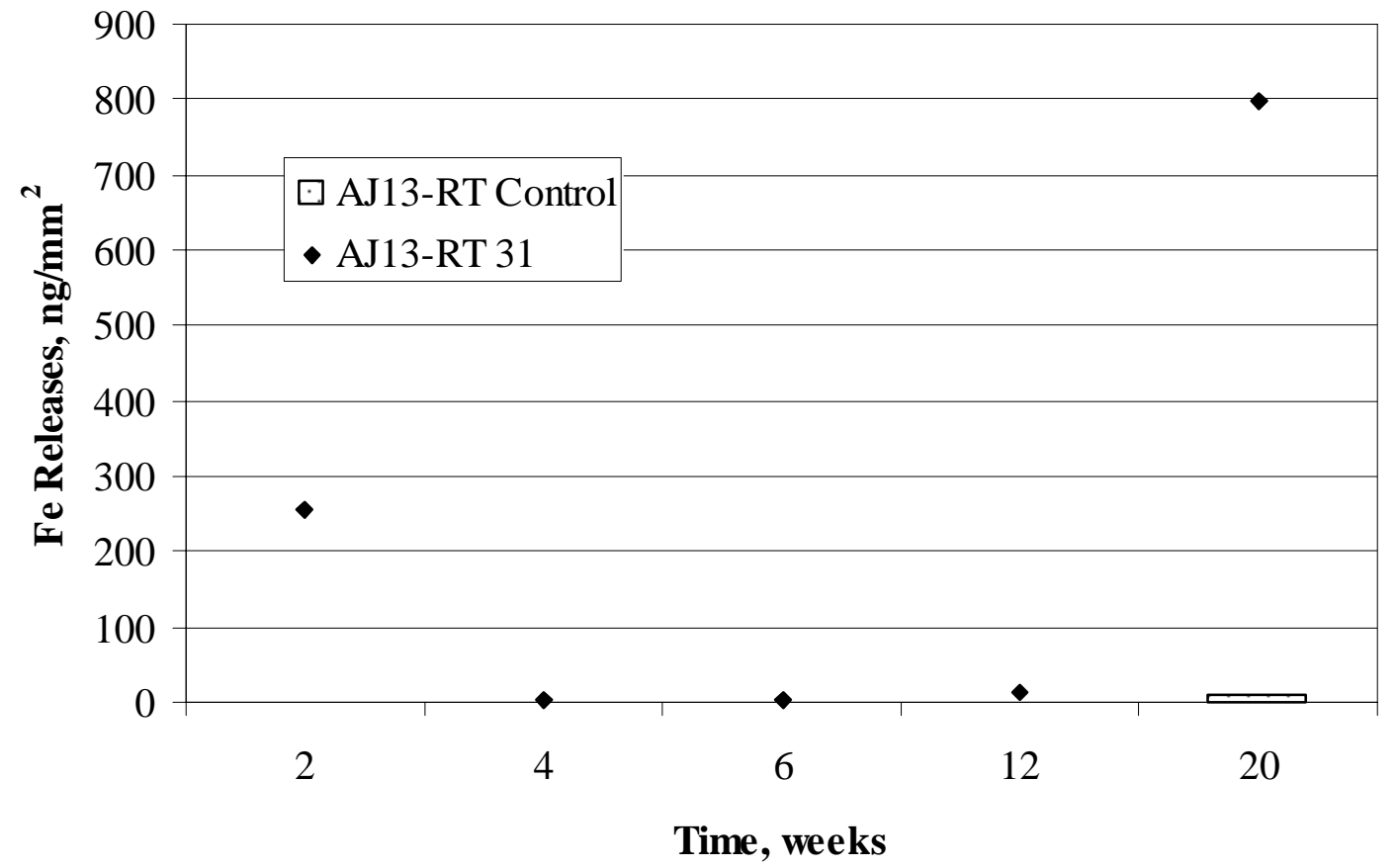

Figure III-65. Iron releases in AJ13 at room temperature.

\section{Release of Fission Product Elements:}

The highest release of fission product elements $(\mathrm{Pd}, \mathrm{Nb}, \mathrm{Ru}, \mathrm{Rh})$ was $\mathrm{Ru}$ at $2.48 \mathrm{ng} / \mathrm{mm}^{2}$ at 140 days. $\mathrm{Nb}$ at $0.16 \mathrm{ng} / \mathrm{mm}^{2}$ and $\mathrm{Pd}$ at $0.09 \mathrm{ng} / \mathrm{mm}^{2}$ were detected at 84 days. The values are just above the detection limit for both elements. Rh was not detected. 


\section{AJ13 Summary}

The highest releases were the major elements at 140 days. Fe was the major contributor to the total cumulative release. $\mathrm{Cr}$ release was a factor of three lower than Fe release followed by Ni release at just over one order of magnitude lower. Zr release was two orders of magnitude lower than Fe. Cumulative releases for the fission product elements $\mathrm{Ru}, \mathrm{Nb}$, and $\mathrm{Pd}$ occurred at 84 days and the values were near the detection limit. $\mathrm{Rh}$ was not detected.

\section{Comparison of $90^{\circ} \mathrm{C}$ and $25^{\circ} \mathrm{C}$ Results as a Function of Solution}

\section{a) $10 \mathrm{KCl}$}

The $10 \mathrm{KCl}$ solution results were compared for both temperatures. The $25^{\circ} \mathrm{C}$ results indicated that $\mathrm{Fe}$ was the major release element and contributed the most to the total value as shown in Figure III-66. This trend is consistent with the $90^{\circ} \mathrm{C}$ data results. However, the temperature effect is evident on the magnitude of the values of total cumulative release as shown in Figure III-67. The $90^{\circ} \mathrm{C}$ total is almost a factor of 5 greater than that of the $25^{\circ} \mathrm{C}$ total.

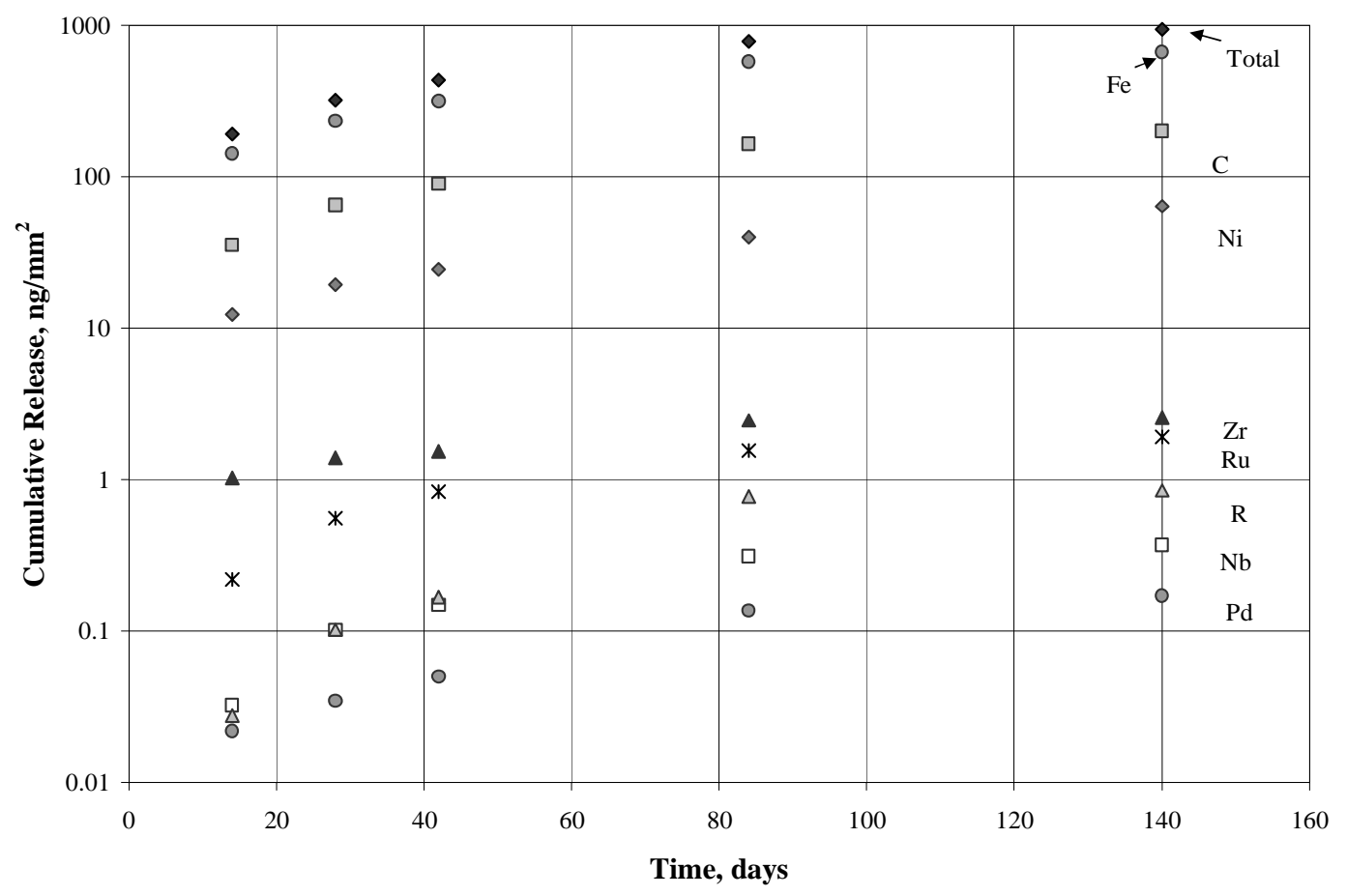

Figure III-66. Cumulative releases in $10 \mathrm{KCl}$ at room temperature. 


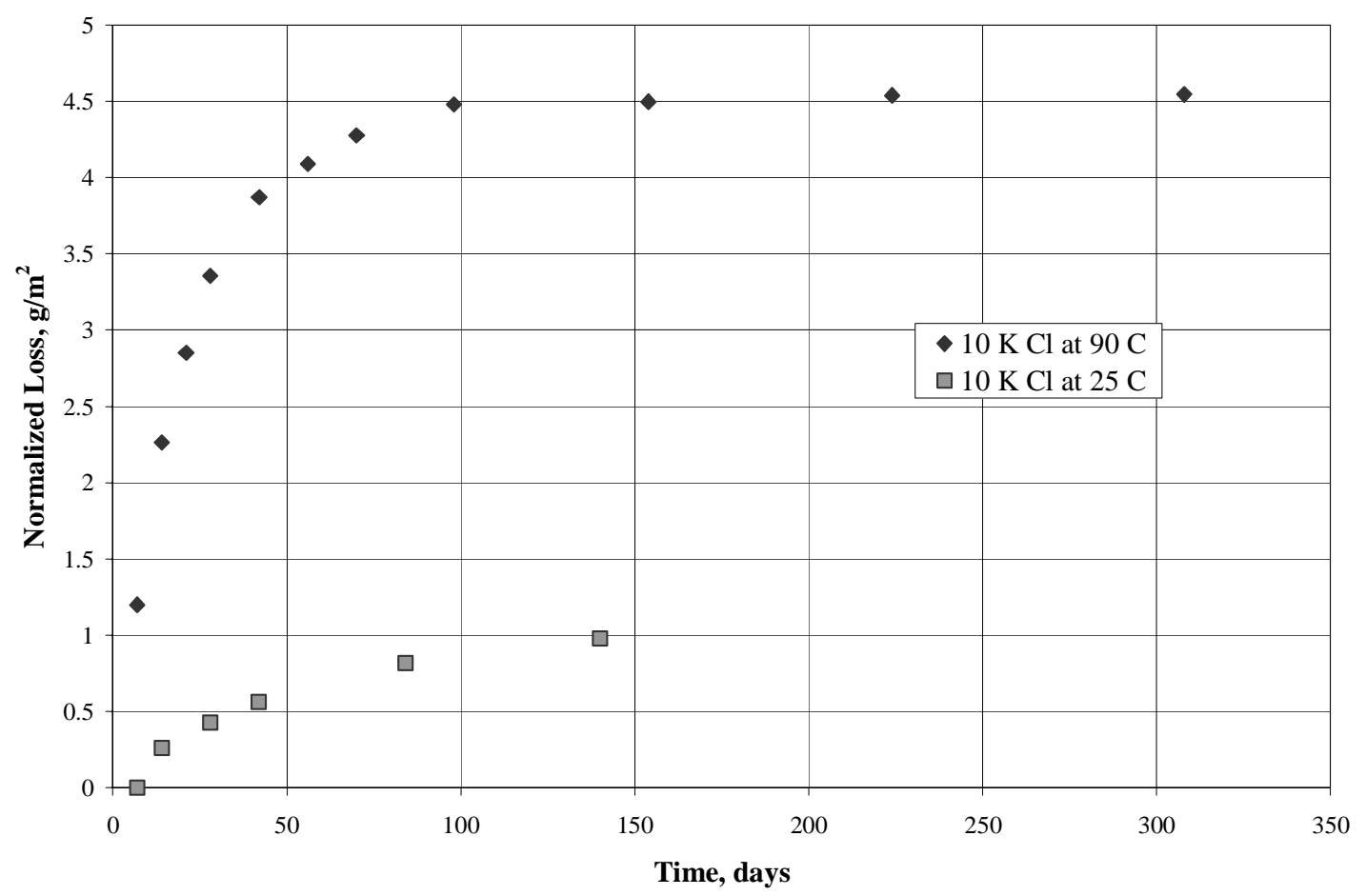

Figure III-67. Cumulative Loss of Iron in 10KCl.

\section{b) $\mathrm{AJ13}$}

The AJ13 solution results were compared for both temperatures. The $25^{\circ} \mathrm{C}$ results indicated that $\mathrm{Fe}$ was the major release element and contributed the most to the total value as shown in Figure III-68. This trend is consistent with the $90^{\circ} \mathrm{C}$ data results. However, the temperature effect is evident on the magnitude of the values of total cumulative release as shown in Figure III-69. The $90^{\circ} \mathrm{C}$ total is 3 orders of magnitude greater than that of the $25^{\circ} \mathrm{C}$ total. 


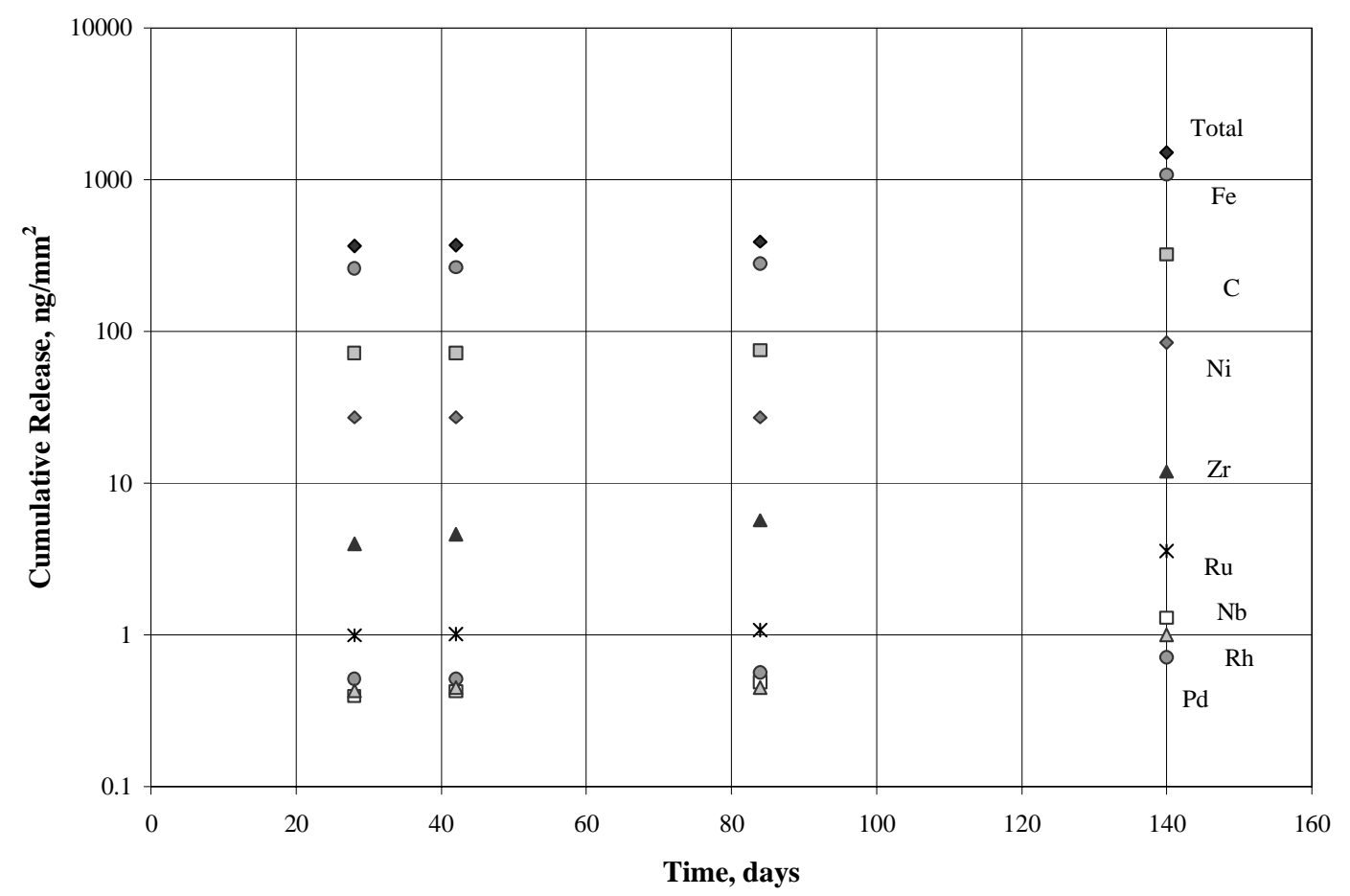

Figure III-68. Cumulative releases in AJ13 at room temperature.

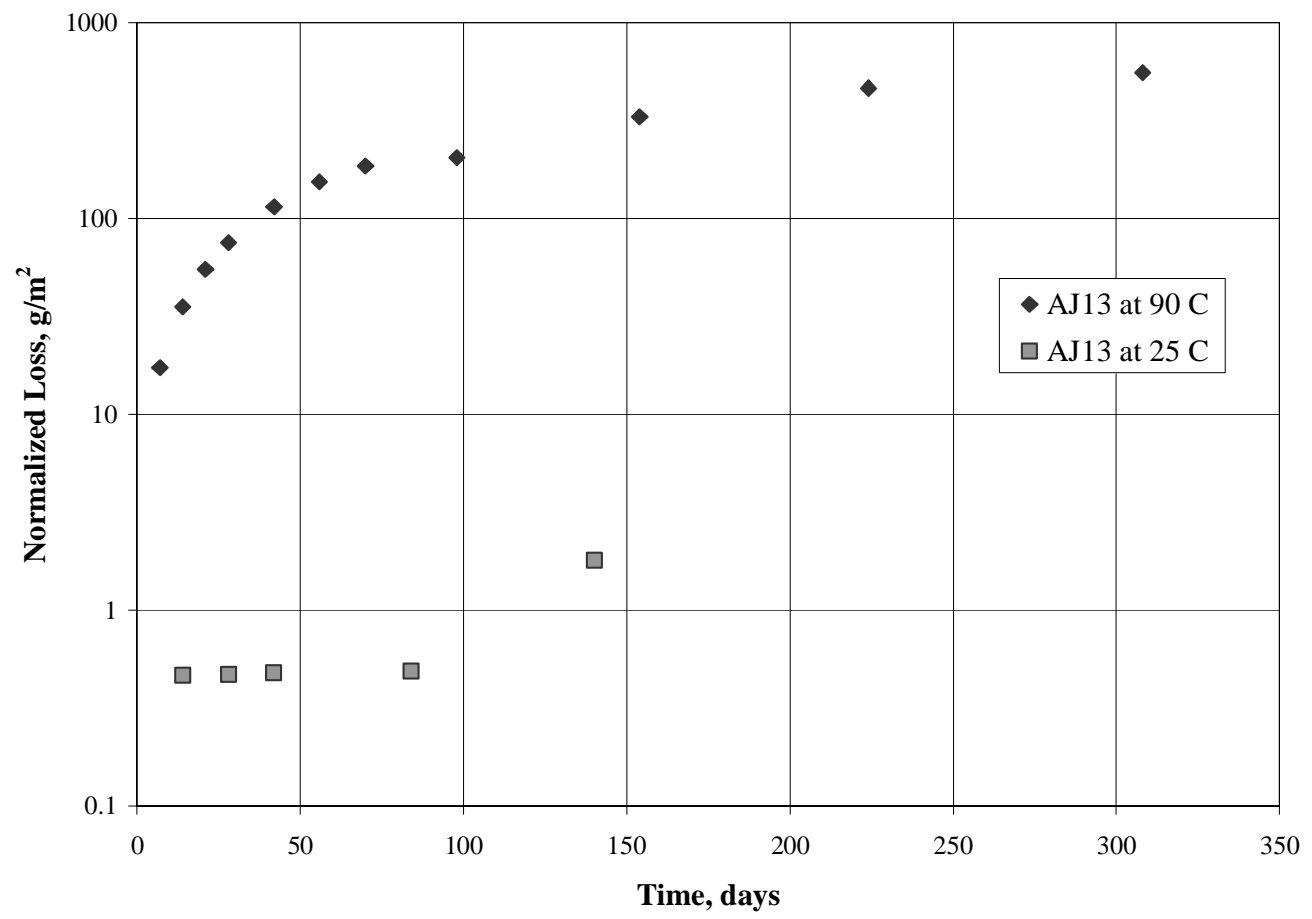

Figure III-69. Cumulative Loss of Iron in AJ13 solution. 


\section{Comparison at Ambient Temperature}

\section{a) $10 \mathrm{KCl}$ and $\mathrm{AJ13}$}

The $10 \mathrm{KCl}$ and $\mathrm{AJ} 13$ solutions represent the most aggressive groundwater seepage and/or vapor condensation environment the MWF may be subjected to in the repository. A comparison of total cumulative releases is shown in Figure III-20. The $10 \mathrm{KCl}$ solution showed a steady release over the entire 140 days. The AJ13 solution showed an initial release at 14 days and remained at this level until 140 days when the value increased by a factor of 4 .

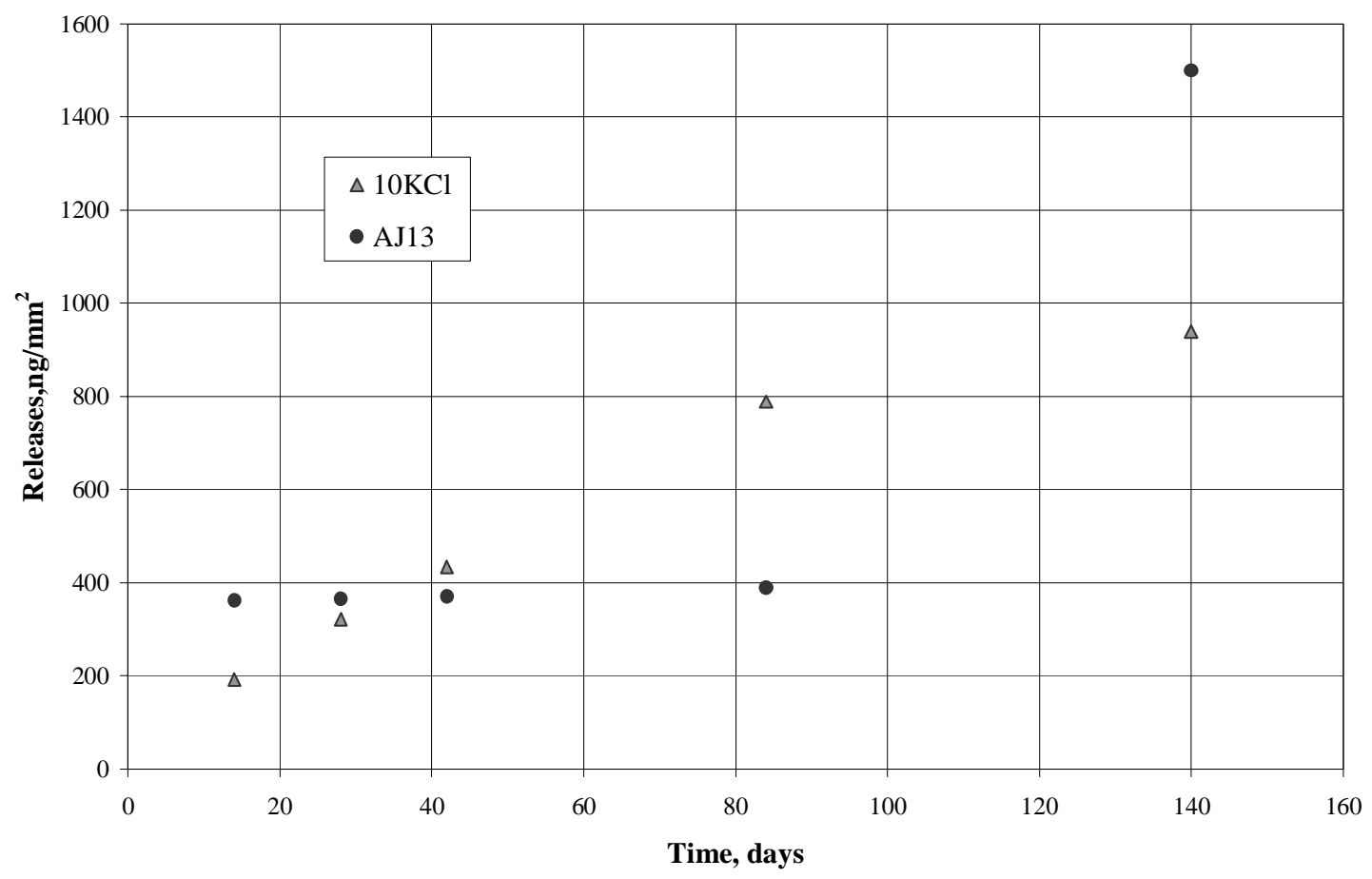

Figure III-70. Cumulative releases in $10 \mathrm{KCl}$ and $\mathrm{AJ} 13$ at Room Temperature.

The release curve trend for both solutions appears very similar. Curve fitting for cumulative loss of $\mathrm{Fe}$ in $10 \mathrm{KCl}$ and $1 \mathrm{KCl}$ is shown in Figures III-20 and III-21, respectively. 


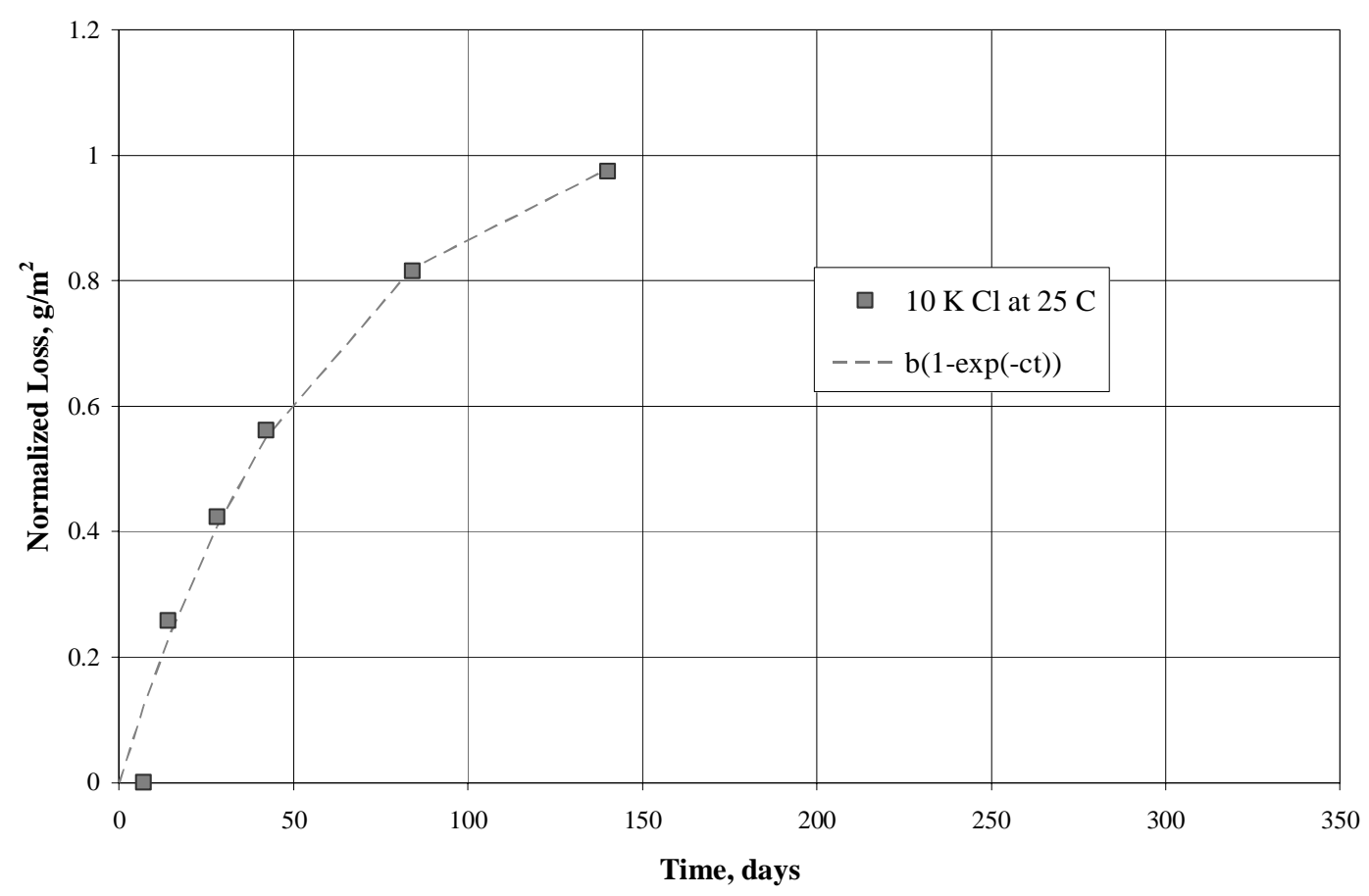

Figure III-71. Curve Fitting with Cumulative Loss of Iron in 10KCl solution at room temperature.

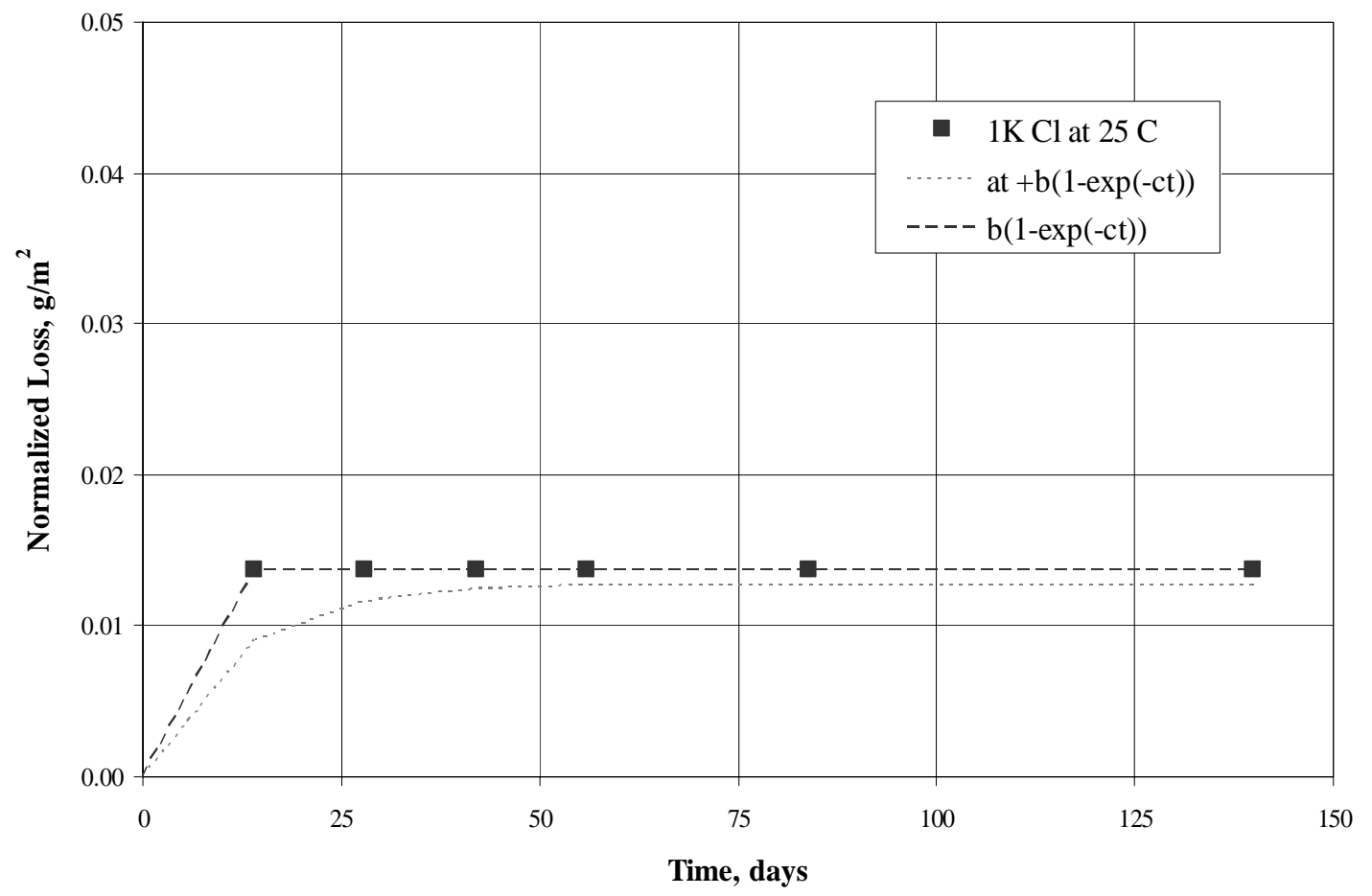

Figure III-72. Curve Fitting with Cumulative Loss of Iron in 1KCl solution at room temperature. 


\section{Comparison of $90^{\circ} \mathrm{C}$ Releases with Electrochemical Corrosion Data}

Because release data were not available, electrochemical corrosion data have been previously used to estimate releases from the metal waste form [4]. To determine the reliability of these estimates, the total releases at $90^{\circ} \mathrm{C}$ have been compared with the electrochemical data. These comparisons are shown for the four solutions SJ13, CJ13, $10 \mathrm{KCl}$, and AJ13 in Figures III-73 through III-76. The electrochemical corrosion rate data have been integrated to provide corrosion as a function of time from the corrosion rates. For completeness, the release rates for high level waste glass (HLWG) have been included in the figures.

Figures III-73 and III-74 show that in $\mathrm{SJ} 13$ and $\mathrm{CJ} 13$ (pH=9.2 and 8.2, respectively) the total releases from the metal waste form are one or more orders of magnitude lower than the electrochemical corrosion data and the releases from HLWG. However, in SJ13, the electrochemical corrosion data are of similar magnitude to releases from HLWG and in CJ13, the electrochemical corrosion data are higher than releases from HLWG.

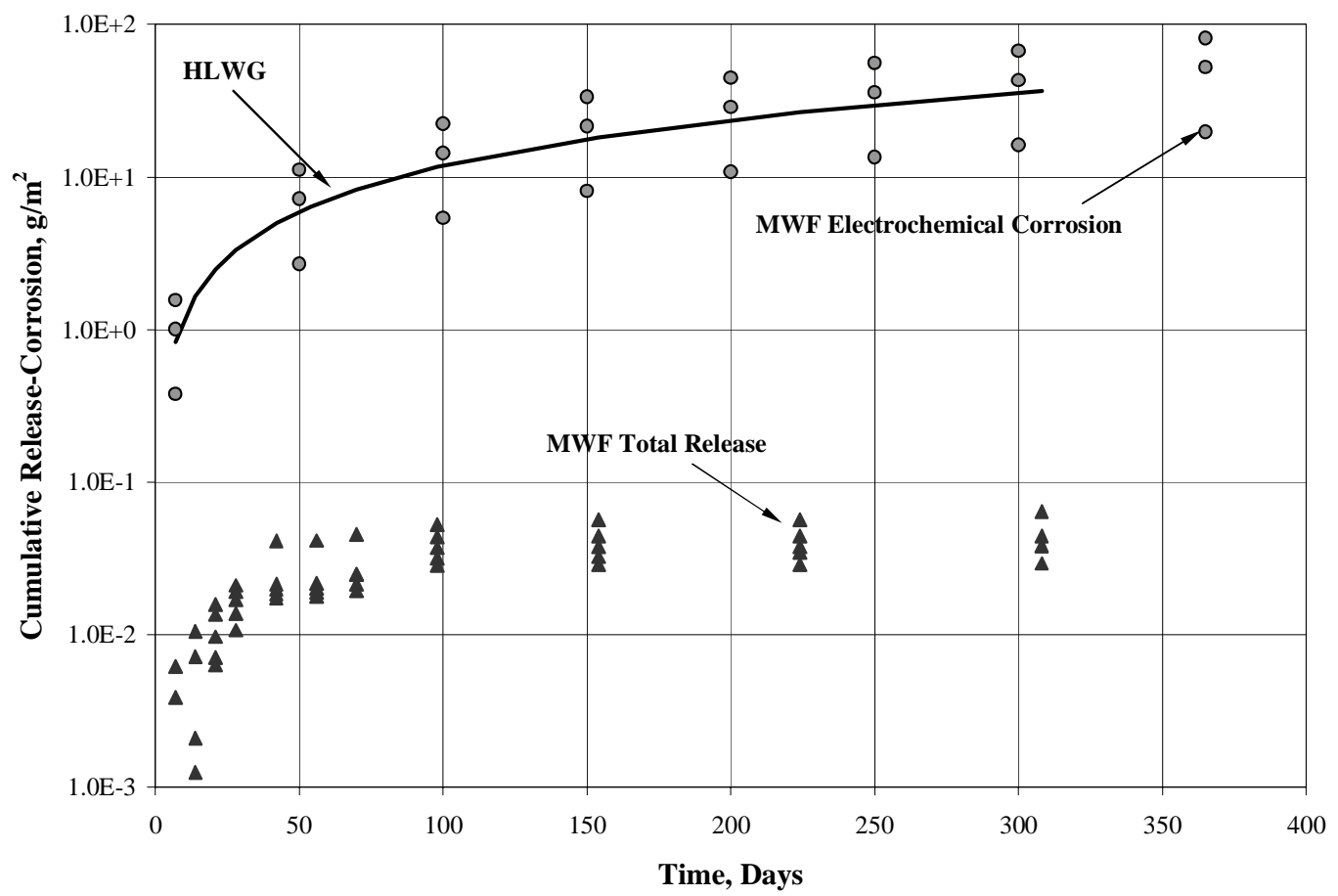

Figure III-73. Comparison of MWF Electrochemical Corrosion and Total releases in $\mathrm{SJ13}, \mathrm{pH}=9.2$, at $90^{\circ} \mathrm{C}$. 


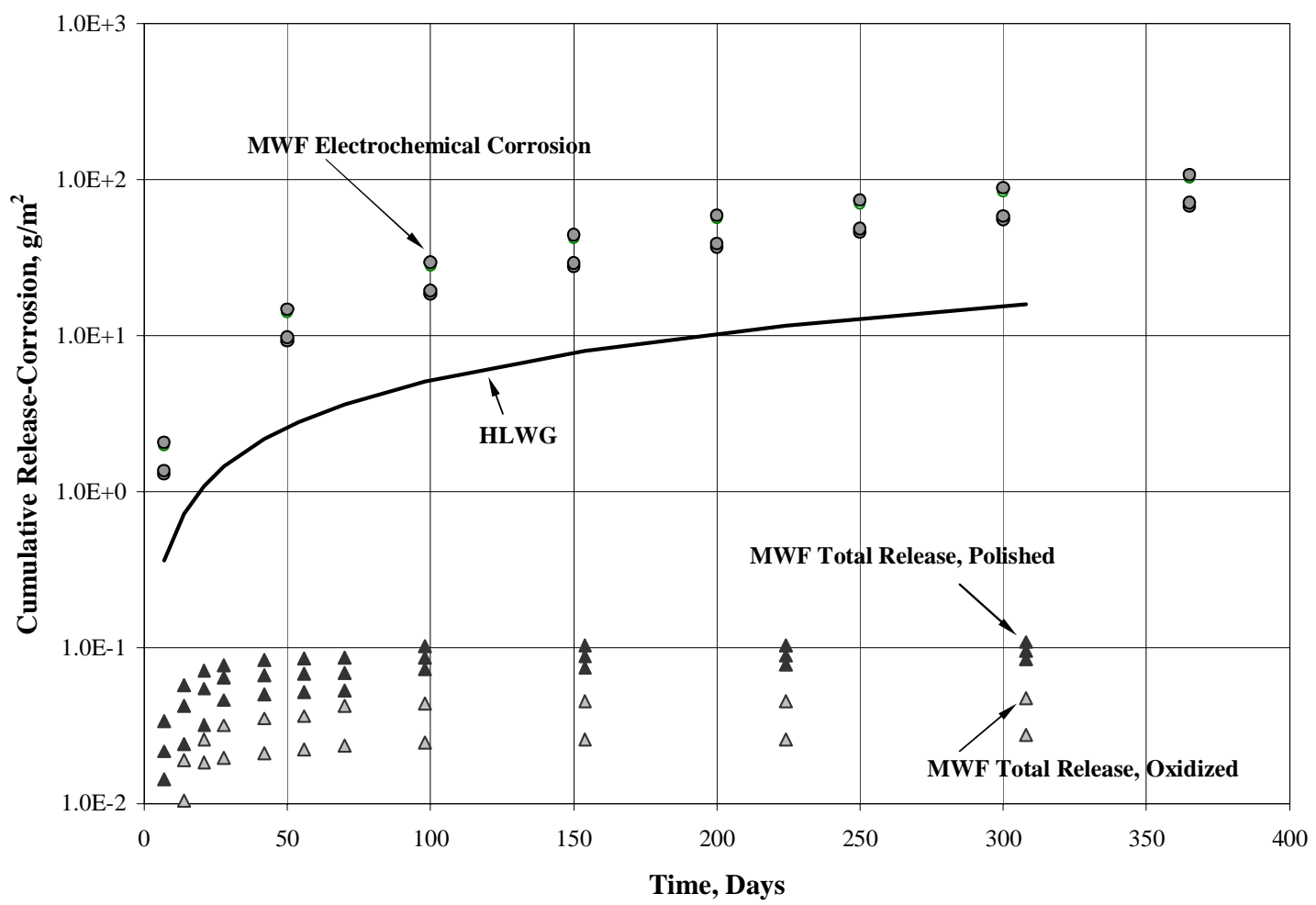

Figure III-74. Comparison of MWF Electrochemical Corrosion and Total releases in $\mathrm{CJ} 13, \mathrm{pH}=8.3$, at $90^{\circ} \mathrm{C}$.

In $10 \mathrm{KCl}$ solutions with $\mathrm{pH}=6.9$ (Figure III-75), the releases and corrosion of the MWF are similar at 7 days but the corrosion rate is higher giving higher corrosion at later time intervals. Releases from the MWF are initially higher than those from HLWG but after 98 days, the MWF releases level off so that at 224 days the total MWF releases are below those for HLWG. 


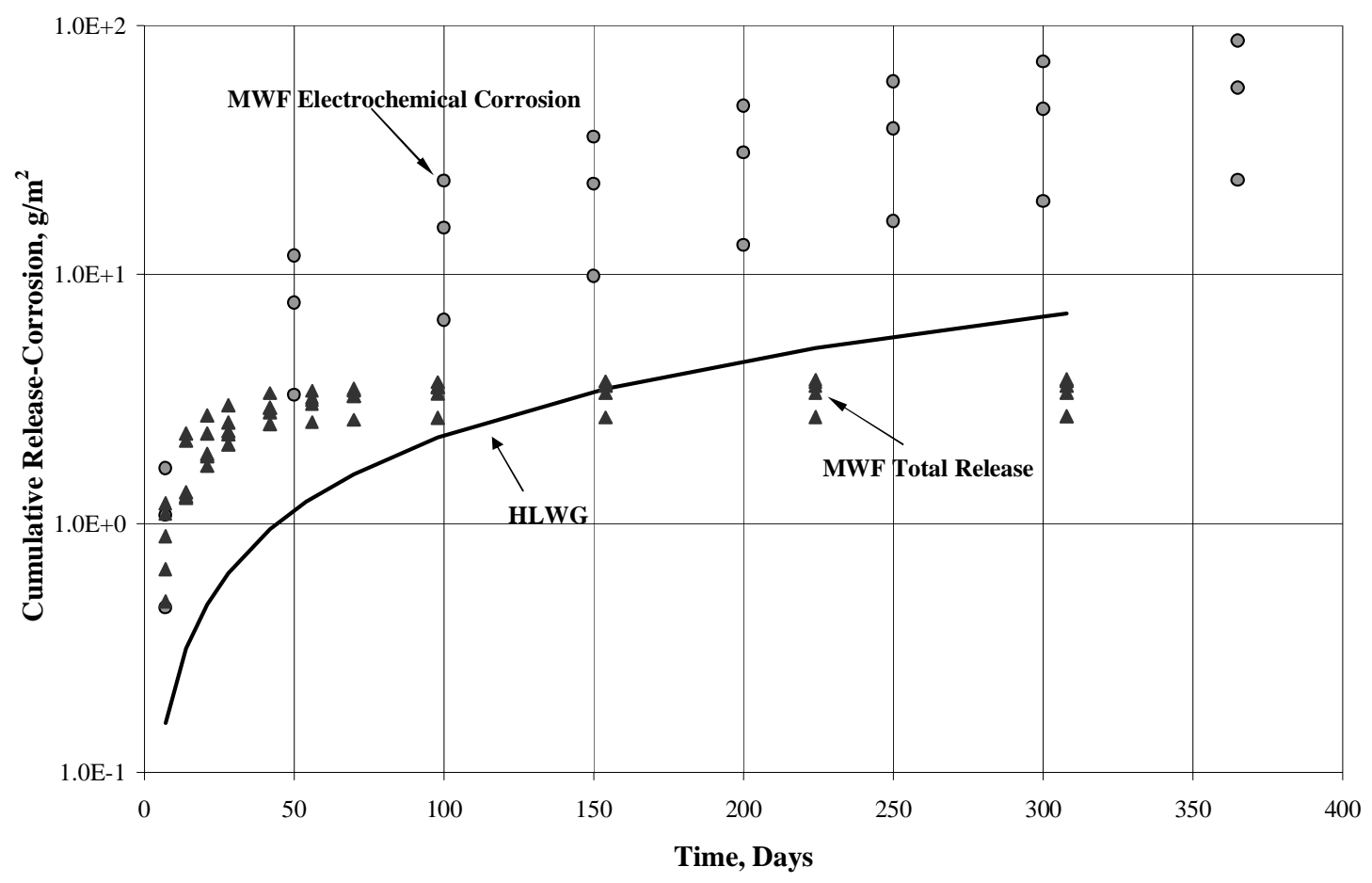

Figure III-75. Comparison of MWF Electrochemical Corrosion and Total releases in $10 \mathrm{KCl}, \mathrm{pH}=6.9$, at $90^{\circ} \mathrm{C}$.

Figure III-76 shows that at $\mathrm{pH}=2$ and $90^{\circ} \mathrm{C}$, the total releases from the $\mathrm{MWF}$ are higher than the MWF electrochemical corrosion. Releases from HLWG are higher than the total releases from the MWF samples. The fact that at the higher $\mathrm{pH}$ values $\mathrm{pH}=6.9,8.2$, and 9.2), the MWF releases are lower than the electrochemical corrosion but this trend is reversed for $\mathrm{pH}=2$, indicates that, at $90^{\circ} \mathrm{C}, \mathrm{MWF}$ corrosion data have a different $\mathrm{pH}$ dependence than the release data. Thus, the electrochemical corrosion data cannot be used to estimate the releases from the MWF as was done by Fink et al.[4]. 


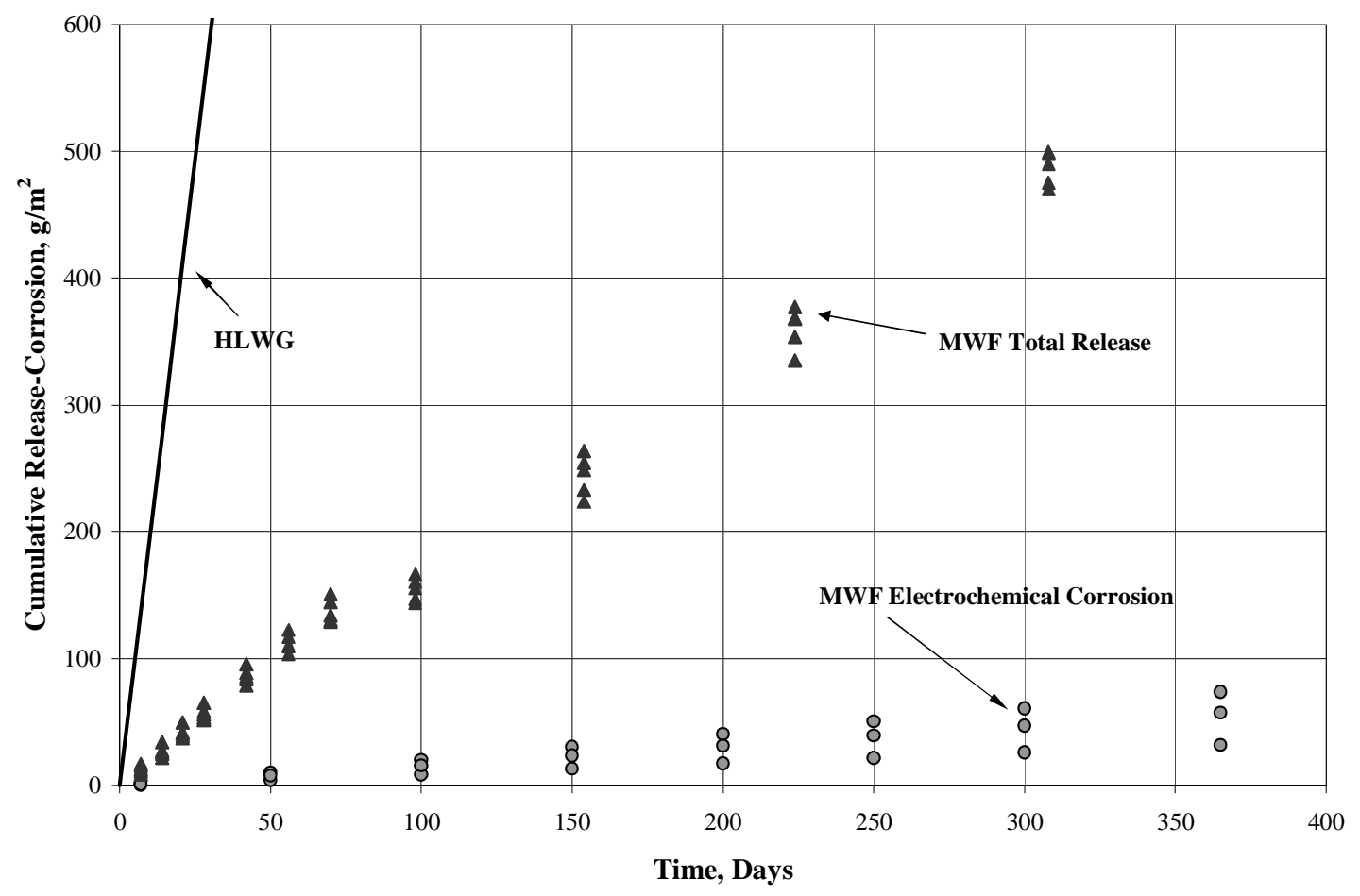

Figure III-76. Comparison of MWF Electrochemical Corrosion and Total releases in $\mathrm{AJ13}, \mathrm{pH}=2$, at $90^{\circ} \mathrm{C}$.

\section{Comparison of Releases from the MWF and High Level Waste Glass}

The release model for high level waste glass (HLWG) developed by Ebert et al. [6] is based on equations for the normalized loss of boron, the element released at the highest rate. Total releases from the metal waste form samples were comprised mainly of iron. Thus, for consistency with the HLWG release model, normalized losses of Fe have been determined as a function of $\mathrm{pH}$ and temperature from the $90^{\circ} \mathrm{C}$ and room temperature tests. The equation used to determine the normalized losses of $\mathrm{Fe}$ is given in Section 2. The normalized loss of Fe from the five samples for each test were averaged except for the $90^{\circ} \mathrm{C}$ test in CJ13 because for this tests the results for oxidized samples and polished samples belonged to different sets. For the CJ13 test, results from the three polished samples were averaged to obtain an averaged normalized loss of $\mathrm{Fe}$ from polished samples and the results from the two oxide samples were averaged to obtain the normalized loss from oxidized samples. In order to compare releases from the MWF with high level waste glass using Ebert's glass model, Fe normalized losses have been fit to an equation, suggested by Irving Johnson, which is:

$$
a t+b[1-\exp (-c t)]
$$


where the parameters $a, b$, and $c$ are defined in Table 2 .

The data were fit by a least squares minimization procedure in EXCEL using solver, which required reasonable first guesses of the coefficients. In order to easily obtain convergence, the data were first fit to the second term to obtain first guesses of $\mathrm{b}$ and $\mathrm{c}$. Then the data were refit to Eq.(1) with these first guesses of b and c. In some instances, the best fit was obtained with the parameter for the linear term effectively 0 . These cases indicate that the tests have not been run for long enough times to determine the linear term coefficient. The fits of the average cumulative normalized loss of $\mathrm{Fe}$ at $90^{\circ} \mathrm{C}$ are shown in Figure III-77. The fits of the $25^{\circ} \mathrm{C}$ Fe normalized losses are shown in Figure III-78. These figures show that reasonable fits were obtained for all the $90^{\circ} \mathrm{C}$ tests and for the $25^{\circ} \mathrm{C}$ test in $10 \mathrm{KCl}$. However, the fit to the $25^{\circ} \mathrm{C} \mathrm{AJ} 13$ test data is not as good because very little Fe was detected at 4, 6, and 12 weeks even though significant Fe was found following 20 weeks of immersion. Thus, the datum at 20 weeks is defining the fit. The parameters used in these fits are given in Table 1. Standard deviations of the fits are shown in the last column of Table III-1.

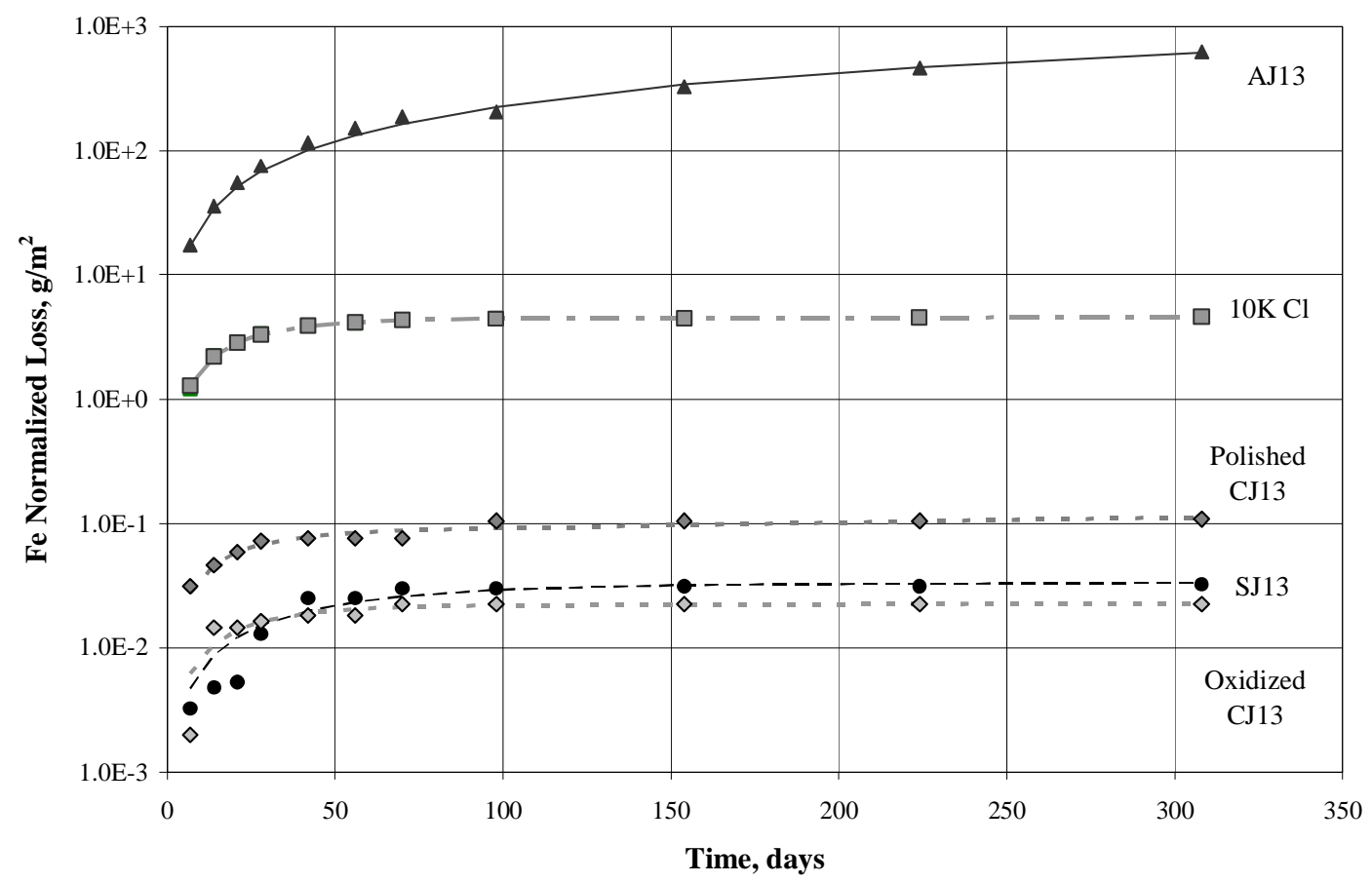

Figure III-77. Fits to the Average Cumulative Fe Normalized Losses at $90^{\circ} \mathrm{C}$. 


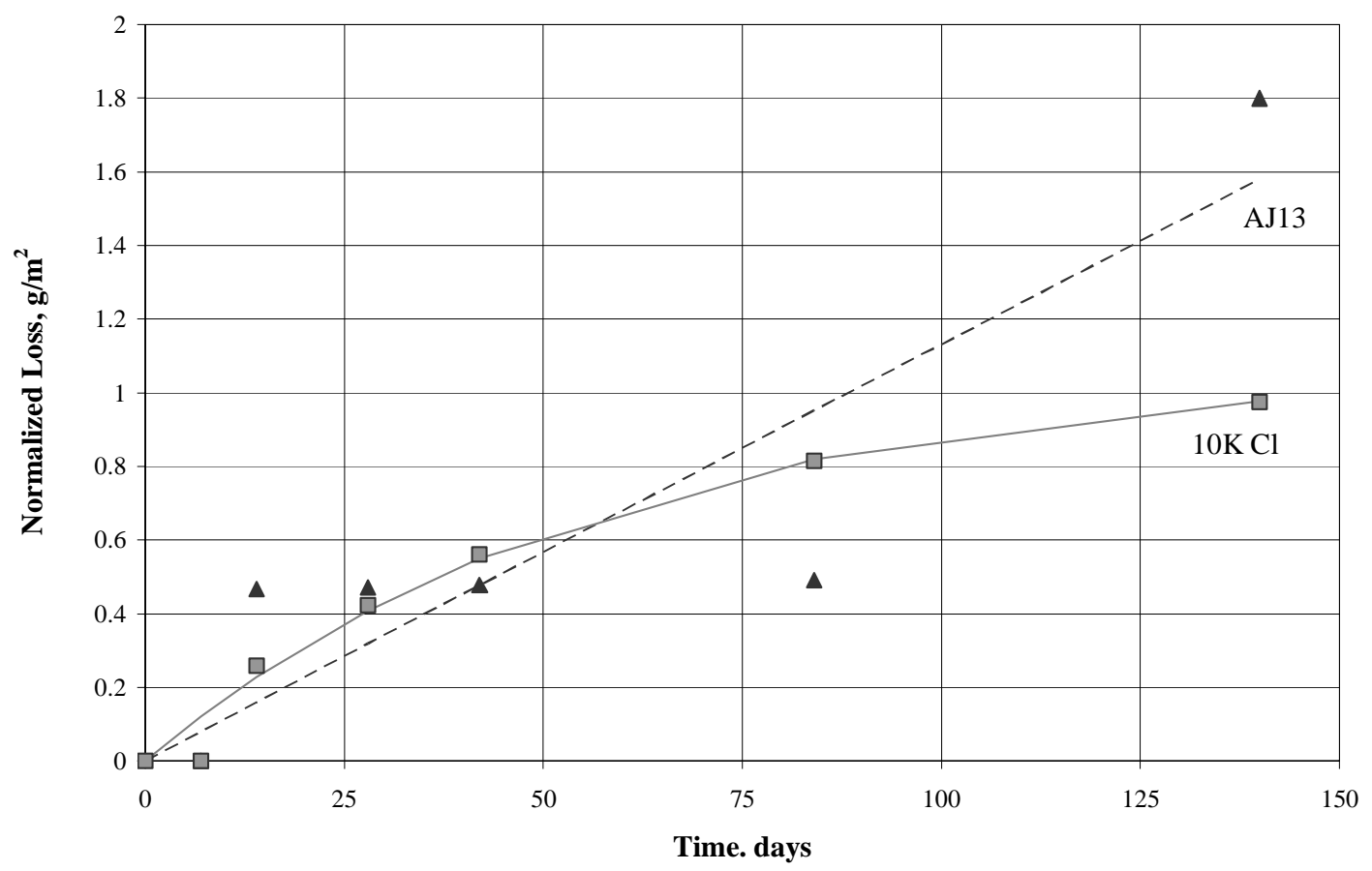

Figure III-78. Fits to Cumulative Fe Normalized Loss Data at $25^{\circ} \mathrm{C}$.

Table III-1. Parameters used in Equation (1) to Fit Fe Normalized Losses

\begin{tabular}{|l|c|c|c|c|c|c|}
\hline Solution & $\mathrm{T},{ }^{\circ} \mathrm{C}$ & $\mathrm{pH}$ & $\mathrm{a}$ & $\mathrm{b}$ & $\mathrm{c}$ & $\mathrm{Std}^{\mathrm{a}}$ \\
\hline SJ13 & 90 & 9.2 & $1.00 \times 10-7$ & $3.30 \times 10-2$ & $2.19 \times 10-2$ & 0.0036 \\
\hline CJ13 Polished & 90 & 8.3 & $9.93 \times 10-5$ & $8.20 \times 10-2$ & $5.62 \times 10-2$ & 0.0073 \\
\hline CJ13 Oxidized & 90 & 8.3 & $2.89 \times 10-6$ & $2.18 \times 10-2$ & $4.78 \times 10-2$ & 0.002 \\
\hline $10 \mathrm{KCl}$ & 90 & 6.9 & $5.23 \times 10-4$ & 4.42 & $4.91 \times 10-2$ & 0.05 \\
\hline $\mathrm{AJ} 13$ & 90 & 2 & $6.57 \times 10-5$ & $1.68 \times 103$ & $1.46 \times 10-3$ & 15.1 \\
\hline $10 \mathrm{KCl}$ & 25 & 6.1 & 0 & 1.08 & $1.72 \times 10-2$ & 0.063 \\
\hline $\mathrm{AJ} 13$ & 25 & 2 & $3.58 \times 10-4$ & 78.9 & $1.40 \times 10-4$ & 0.31 \\
\hline
\end{tabular}

${ }^{\text {a }}$ Std is the standard deviation of the fit, defined as

$$
S t d=\left[\sum(\text { Fit }- \text { Data })^{2} /(N-3)\right]
$$

where $N$ is the number of data.

For comparison with high level waste glass (HLWG), the derivative of Eq.(1) was taken at 7 days to determine the rate of release, $\mathrm{k}$. Comparison of release rates determined from Fe normalized losses from the MWF with the release rates from HLWG model of Ebert et al.[6] are shown in the Figure III-79. In all cases except $10 \mathrm{KCl}$ at $90^{\circ} \mathrm{C}$, the rates of release from the MWF are less than those from HLWG. Thus, except under high 
chloride conditions, releases of $\mathrm{Fe}$ and noble metal fission products are below those accepted for HLWG. Note that these tests did not measure releases of Tc and the actinide elements, $\mathrm{U}, \mathrm{Pu}$, and $\mathrm{Np}$, so this comparison does not compare release rates of $\mathrm{Tc}$ and actinides with release rates from HLWG.

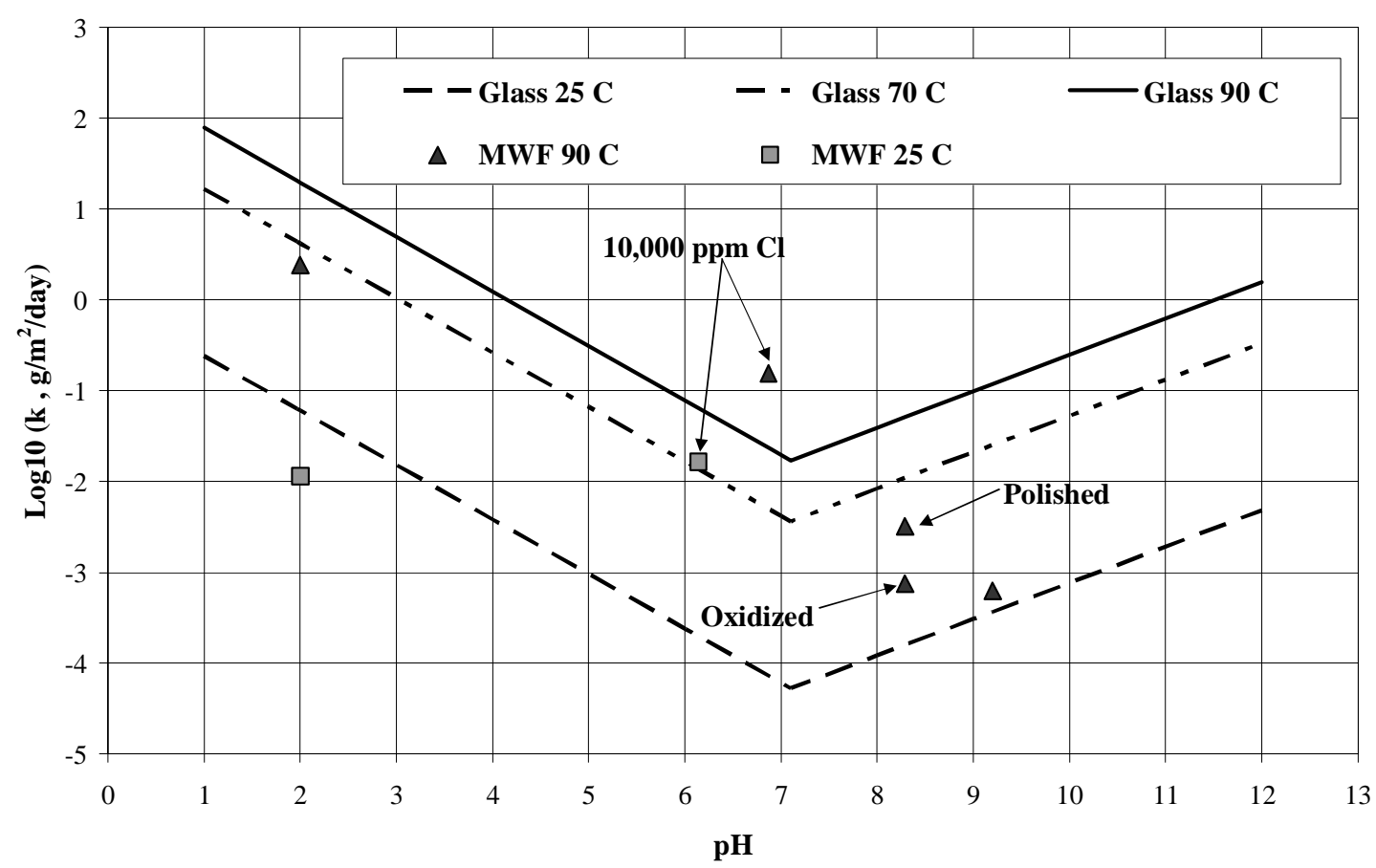

Figure III-79. Comparison of $\log _{10}$ of the release rates of the MWF and HLWG. 


\section{SUMMARY AND CONCLUSIONS}

\section{A. Summarv of Results}

\section{Results of Test Matrix Experiments}

A test matrix to immerse polished and oxidized SS-15Zr-1Nb-1Ru-1Pd-1Rh samples in four different solutions at $90^{\circ} \mathrm{C}$ was designed to address five issues. Four of these issues were to study the effects of (1) the solution aggressiveness, (2) high-chloride content of the solution, (3) solution $\mathrm{pH}$, and (4) the state of the metal surface-polished vs. oxidized on the releases. The fifth issue was to determine if the releases are limited by iron saturation of the solution. Results from the 308-day immersion tests in SJ13, CJ13, $10 \mathrm{KCl}$, and $\mathrm{AJ} 13$ are listed below relative to each of these issues.

1) The highest releases were detected in the most aggressive solution-AJ13 solution at $90^{\circ} \mathrm{C}$, which had a $\mathrm{pH}$ of 2 . At the end of the 308 day tests, total releases in this solution were a factor of $1 \times 10^{4}$ greater than releases from the test at $90^{\circ} \mathrm{C}$ in $\mathrm{SJ} 13$.

2) The high chloride solution $(10 \mathrm{KCl})$ mainly increased the releases of components from the steel- $\mathrm{Fe}, \mathrm{Cr}$, and $\mathrm{Ni}$. Total releases were dominated by the $\mathrm{Fe}$ releases with releases of $\mathrm{Cr}$ and $\mathrm{Ni}$ about a factor of 6 lower. Releases of fission-product elements and $\mathrm{Zr}$ were at least an order of magnitude lower.

3) Releases of all elements were significantly increased in the $\mathrm{pH}=2$ solution at $90^{\circ} \mathrm{C}$. Cumulative total releases continued to increase with time with only a small change in slope. This differed from the electrochemical data, which showed no significant change in corrosion rate with decreasing $\mathrm{pH}$ at $90^{\circ} \mathrm{C}$. In $\mathrm{AJ} 13$ solutions, total releases were dominated by $\mathrm{Fe}$ with $\mathrm{Cr}$ releases about a factor of 4 lower.

4) Except for a few cases, such as Fe and $\mathrm{Zr}$ releases in CJ13, differences between the releases from polished and oxidized samples were within expectations for statistical variation of multiple samples.

5) Saturation is not limiting the release of Fe. The significant reduction of releases with time in $\mathrm{SJ} 13, \mathrm{CJ} 13$, and $10 \mathrm{KCl}$ solutions appears to be from the formation of protective oxide films on the iron-solid-solution and intermetallic phases. Releases from the very aggressive $\mathrm{AJ} 13(\mathrm{pH}=2)$ solution have not leveled off as much as the releases from tests in the other solutions. Samples used in these tests did not contain any minor phases (such as a sulfur phase). So these tests provide no data on releases from these phases, which are not expected to have protective oxide films. 


\section{Results from Additional Tests}

Single samples immersed for 140 days in $10 \mathrm{KCl}$ at $25^{\circ} \mathrm{C}$, and $\mathrm{AJ} 13$ at $25^{\circ} \mathrm{C}$ provided data to compare room temperature and $90^{\circ} \mathrm{C}$ releases in aggressive solutions. As in the $90^{\circ} \mathrm{C}$ tests, total releases at room temperature were dominated by Fe. After 140 days, releases of $\mathrm{Ru}$ and other fission products were more than a factor of 300 lower than the $\mathrm{Fe}$ releases in both room temperature solutions. Comparison of releases from $25^{\circ} \mathrm{C}$ in $10 \mathrm{KCl}$ and AJ13 solutions with releases from samples immersed in these solutions at $90^{\circ} \mathrm{C}$ showed that the increased temperature had a bigger effect for the AJ13 solution than for the $10 \mathrm{KCl}$ solution. After 140 days of immersion testing, the normalized loss of Fe in $\mathrm{AJ} 13$ at $90^{\circ} \mathrm{C}$ was about a factor of 200 higher than the normalized loss of Fe in $\mathrm{AJ} 13$ at room temperature. After the same time, the normalized loss of $\mathrm{Fe}$ in $10 \mathrm{KCl}$ at $90^{\circ} \mathrm{C}$ was only a factor of 4 higher than the normalized loss of $\mathrm{Fe}$ in $10 \mathrm{KCl}$ at room temperature.

\section{B. Conclusions}

\section{MWF Release Conclusions}

Even though the MWF samples used in these tests contained no actinides and no Tc, conclusions can be made with respect to the releases of the noble metal fission products and the stainless steel constituents. MWF conclusions are listed below.

- Fe releases are an order of magnitude or higher than the releases of the noble metal fission-product elements in all solutions.

- Releases of noble metal fission products and Cr and Ni in SJ13 and CJ13 solutions at $90^{\circ} \mathrm{C}$ are close to the limits of detection.

- Solution concentration increased the $\mathrm{Zr}$ release. $\mathrm{Zr}$ releases from CJ13 were about a factor of 2 lower than the Fe release. In $\mathrm{CJ} 13, \mathrm{Zr}$ releases from oxidized samples were higher than from polished samples.

- Releases of all elements increased in the $\mathrm{AJ} 13, \mathrm{pH}=2$ solution. Total cumulative releases as a function of time continued to increase for the 308 days of tests unlike the behavior in other test solutions. Tests in solutions with $\mathrm{pH}$ between 2 and 8 are needed to understand the different behavior.

- Except for high chloride solutions $(10 \mathrm{KCl})$ release rates of stainless steel elements and noble metal fission products from the MWF samples are lower than release rates from HLWG.

\section{Other Conclusions}

In addition to conclusions relative to releases from the MWF, conclusions have been drawn from these tests, which may be useful in other immersion tests. These are listed below.

- Electrochemical corrosion tests cannot be used to predict releases. They are different processes with different $\mathrm{pH}$ dependence. 
- Teflon vials should not be reused. The cleaning procedure based on ASTM CFR C1220-92 was not sufficient to remove all the elements that had migrated to the walls. Additional elements were detected from second acid washes when the vials contained the aggressive solutions-AJ13 and $10 \mathrm{KCl}$.

- Blanks of each test solution should be run to detect problems in the test procedure such as sample contamination from the wall when vials were reused, contamination from other work being done in the laboratory where the tests were done, and uncertainties in chemical analysis.

- Caution must be taken in interpretation of low releases that are near the detection limit for a particular element. Because detection limits vary from day to day depending on calibrations, an element may be detected after one test interval and not for any other test intervals over the year. To aid in understanding these low releases, it may be useful to plot releases in ppb and detection limits in ppb for each element. Calculated normalized losses for elements released at the limits of detection are not reliable. 


\section{REFERENCES}

1. D. P. Abraham, Ed., Metal Waste Form Handbook, Argonne National Laboratory NT Technical Memorandum ANL-NT-121 (June 1999).

2. J. A. Beavers, N. G. Thompson, and C. L. Durr, "Potentiodynamic Polarization studies on Candidate Container Alloys for the Tuff Repository," Cortest Columbus Technologies, Inc., NUREG/CR-5708 (Jan. 1992).

3. ASTM G59-91, "Standard Practice for Conducting Potentiodynamic Polarization Resistance Measurements," Annual Book of ASTM Standards, Vol. 3.02 (1996), p. 216.

4. J. K. Fink, E. E. Morris, D. P. Abraham, Irving Johnson, S. G. Johnson, and R. A. Wigeland, Status of Metal Waste Form Corrosion and Release Rate Modeling, Argonne National Laboratory NT Technical Memorandum ANL-NT-154 (September 2000).

5. F. Mansfeld in Electrochemical Techniques for corrosion Engineering, R. Baboian, Editor, NACE, 1986, pp. 67-71.

6. W. L. Ebert, J. C. Cunnane, and T. A. Thornton, “An HLW Glass Degradation Model for TSPA-SR," paper presented at the International High-Level Radioactive Waste Management Conference (2001).

7. M. C. Petri, private communication to J. K. Fink [February 2000].

8. D. D. Macdonald, "Passivity - the Key to Our Metals-Based Civilization," Pure Appl. Chem. 71, 951-978 (1999).

9. National Research Council Committee on Electrometallurgical Techniques for DOE Spent Fuel Treatment, G. R. Choppin, Chair, "Electrometallurgical Techniques for DOE Spent Fuel Treatment, An Assessment of Waste Form Development and Characterization," National Academy Press, Washington, DC (1999).

10. American Society for Testing and Materials, Annual Book of ASTM Standards, 12.01, "Standard Test Method for Static Leaching of Monolithic Waste Forms for Disposal of Radioactive Waste", C 1220-92, pp. 709-723 (1996).

11. Argonne National Laboratory, unpublished information, July, 1998.

12. Metal Waste Form Handbook, D. Abraham, ed., ANL-NT-121, Chapter 6, pp.6-2. 



\section{APPENDICES}





\section{A. Data from Electrochemical Corrosion Tests}

\section{Using the Polarization Resistance Method}

Table A-1. Composition and Density of Alloys Tested.

\begin{tabular}{|c|c|c|}
\hline Ingot & Alloy Description & Density (g/mL) \\
\hline SS316 & SS316 & 8.0 \\
\hline SS15ZR12 & SS-15Zr-2Ru-1Pd-1Ag & 7.8 \\
\hline SS15ZR14 & SS-15Zr (annealed) & 7.65 \\
\hline SS15ZR15 & SS-15Zr-2Ru-1Nb-0.5Pd-0.5Ag & 7.8 \\
\hline SS15ZR17 & SS-15Zr (as-cast) & 7.65 \\
\hline SS05ZR18 & SS-5Zr-2Nb-1Ru-1Pd & 7.8 \\
\hline SS20ZR19 & SS-20Zr-2Nb-1Ru-1Pd & 7.7 \\
\hline SS05ZR20 & SS-5Zr-1Nb-0.5Ru-0.5Pd & 7.8 \\
\hline SS05ZR21 & SS-5Zr & 7.9 \\
\hline SS15ZR23 & SS-15Zr (cooled at $10^{\circ}$ C/min) & 7.65 \\
\hline SS15ZR24 & SS-15Zr (cooled at 5 $\left.{ }^{\circ} \mathrm{C} / \mathrm{min}\right)$ & 7.65 \\
\hline SS15ZR25 & SS-15Zr-1Nb-1Ru-1Pd-1Rh & 7.8 \\
\hline SS15ZR26 & SS-15Zr-1Nb-1Ru-1Pd-1Rh & 7.8 \\
\hline SS15ZR27 & SS-15Zr (cooled at $\left.1^{\circ} \mathrm{C} / \mathrm{min}\right)$ & 7.65 \\
\hline SS00ZR28 & SS-2Nb-1Ru-1Pd-1Ag & 8.0 \\
\hline Zr & Zr & 6.5 \\
\hline ZR08SS02 & Zr-8SS-1Ag-1Nb-1Pd-1Ru & 6.7 \\
\hline ZR08SS04 & Zr-8SS & 6.6 \\
\hline Copper & Pure Copper & 8.9 \\
\hline C-22 & C-22 & 8.7 \\
\hline AISI 1018 & Mild Steel & 7.9 \\
\hline
\end{tabular}


Table A-2. Typical Composition of Solutions Used for Electrochemical Testing at $20^{\circ} \mathrm{C}$.

\begin{tabular}{|c|c|c|c|c|c|c|c|c|c|c|}
\hline \multirow{2}{*}{ Solution } & & \multicolumn{7}{|c|}{ Solution Composition $(\mathrm{mg} / \mathrm{L}$ or $\mathrm{ppm})$} \\
\cline { 3 - 11 } & $\mathrm{Na}$ & $\mathrm{K}$ & $\mathrm{Ca}$ & $\mathrm{Mg}$ & $\mathrm{Si}$ & $\mathrm{SO}_{4}^{-2}$ & $\mathrm{Cl}^{-1}$ & $\mathrm{NO}_{3}^{-1}$ & $\mathrm{HCO}_{3}^{-1}$ \\
\hline $\mathrm{pH}=12$ & $\sim 12$ & 396 & 57 & 1.07 & 0.99 & 36.4 & 18.2 & 3.93 & 10.9 & 89 \\
\hline $\mathrm{pH}=10$ & $\sim 10$ & 65.2 & 5.32 & 10.4 & 2.18 & 37.9 & 18 & 4.33 & 9.5 & 88 \\
\hline Sim. J-13 & $\sim 9$ & 50.9 & 5.21 & 10.2 & 2.09 & 33.8 & 18 & 4.31 & 10.1 & 109 \\
\hline Conc. J-13 & $\sim 8.2$ & 5300 & 510 & 6 & 1.9 & 30 & 22 & 727 & 11 & 12700 \\
\hline $10000 \mathrm{ppm} \mathrm{Cl}$ & $\sim 6.3$ & 6270 & - & - & - & - & - & 10000 & - & - \\
\hline $1000 \mathrm{ppm} \mathrm{Cl}$ & $\sim 5.8$ & 607 & - & - & - & - & - & 1000 & - & - \\
\hline $\mathrm{pH}=2$ & $\sim 2$ & 49.1 & 5.1 & 10.9 & 2.12 & 35.1 & 17.8 & 443 & 10.5 & 4.4 \\
\hline
\end{tabular}

Table A-3. Corrosion Rates $(\mu \mathrm{m} / \mathrm{y})$ Measured in $\mathrm{pH}=12$ Solution at $20^{\circ} \mathrm{C}$.

\begin{tabular}{|c|c|c|}
\hline Ingot ID & Nominal Composition & $\begin{array}{c}\text { Corrosion } \\
\text { Rate }(\mu \mathrm{m} / \mathrm{y})\end{array}$ \\
\hline SS316 & SS316 & 0.67 \\
\hline SS15ZR12 & SS-15Zr-2Ru-1Pd-1Ag & 0.57 \\
\hline SS15ZR14 & SS-15Zr (annealed) & 0.037 \\
\hline SS15ZR15 & SS-15Zr-2Ru-1Nb-0.5Pd-0.5Ag & 0.052 \\
\hline SS15ZR17 & SS-15Zr (as-cast) & 0.37 \\
\hline SS05ZR18 & SS-5Zr-2Nb-1Ru-1Pd & 1.37 \\
\hline SS20ZR19 & SS-20Zr-2Nb-1Ru-1Pd & 0.51 \\
\hline SS05ZR20 & SS-5Zr-1Nb-0.5Ru-0.5Pd & 0.28 \\
\hline SS05ZR21 & SS-5Zr & 0.58 \\
\hline SS15ZR23 & SS-15Zr (cooled at 10 $\left.{ }^{\circ} \mathrm{C} / \mathrm{min}\right)$ & 1.56 \\
\hline SS15ZR24 & SS-15Zr (cooled at 5 $\left.{ }^{\circ} \mathrm{C} / \mathrm{min}\right)$ & 1.06 \\
\hline SS15ZR25 & SS-15Zr-1Nb-1Ru-1Pd-1Rh & 1.58 \\
\hline SS15ZR26 & SS-15Zr-1Nb-1Ru-1Pd-1Rh & 1.51 \\
\hline SS15ZR27 & SS-15Zr (cooled at $\left.1^{\circ} \mathrm{C} / \mathrm{min}\right)$ & 0.6 \\
\hline SS00ZR28 & SS-2Nb-1Ru-1Pd-1Ag & 0.31 \\
\hline Zr & Zr & 1.16 \\
\hline ZR08SS02 & Zr-8SS-1Ag-1Nb-1Pd-1Ru & 0.49 \\
\hline ZR08SS04 & Zr-8SS & 0.32 \\
\hline Copper & Pure Copper & 3.14 \\
\hline C-22 & C-22 & 0.41 \\
\hline AISI 1018 & Mild Steel & 1.67 \\
\hline
\end{tabular}


Table A-4. Corrosion Rates $(\mu \mathrm{m} / \mathrm{y})$ Measured in $\mathrm{pH}=12$ Solution at $20^{\circ} \mathrm{C}$.

\begin{tabular}{|c|c|c|c|c|c|}
\hline Ingot ID & Nominal Composition & \multicolumn{2}{|c|}{ Trial } & Mean & Std. \\
\cline { 3 - 4 } & & 2 & 3 & & Dev. $^{\text {a }}$ \\
\hline SS316 & SS316 & 1.84 & 0.67 & 1.25 & 0.83 \\
\hline SS15ZR12 & SS-15Zr-2Ru-1Pd-1Ag & 0.61 & 0.57 & 0.59 & 0.03 \\
\hline SS15ZR14 & SS-15Zr (annealed) & 0.44 & 0.37 & 0.41 & 0.05 \\
\hline SS15ZR15 & SS-15Zr-2Ru-1Nb-0.5Pd-0.5Ag & 7.07 & 0.52 & 3.79 & 4.63 \\
\hline SS15ZR17 & SS-15Zr (as-cast) & 1.12 & 0.37 & 0.74 & 0.53 \\
\hline SS05ZR18 & SS-5Zr-2Nb-1Ru-1Pd & 1.51 & 1.37 & 1.44 & 0.1 \\
\hline SS20ZR19 & SS-20Zr-2Nb-1Ru-1Pd & 12.94 & 0.51 & 6.72 & 8.79 \\
\hline SS05ZR20 & SS-5Zr-1Nb-0.5Ru-0.5Pd & 0.00 & 0.28 & 0.14 & 0.2 \\
\hline SS05ZR21 & SS-5Zr & 0.95 & 0.58 & 0.77 & 0.26 \\
\hline SS15ZR23 & SS-15Zr (cooled at10 ${ }^{\circ}$ C/min) & 1.00 & 1.56 & 1.28 & 0.4 \\
\hline SS15ZR24 & SS-15Zr (cooled at 5 ${ }^{\circ}$ C/min) & 0.52 & 1.06 & 0.79 & 0.38 \\
\hline SS15ZR25 & SS-15Zr-1Nb-1Ru-1Pd-1Rh & 18.34 & 1.58 & 9.96 & 11.85 \\
\hline SS15ZR26 & SS-15Zr-1Nb-1Ru-1Pd-1Rh & 0.67 & 1.51 & 1.09 & 0.59 \\
\hline SS15ZR27 & SS-15Zr (cooled at 1 $\left.{ }^{\circ} \mathrm{C} / \mathrm{min}\right)$ & 0.62 & 0.60 & 0.61 & 0.02 \\
\hline SS00ZR28 & SS-2Nb-1Ru-1Pd-1Ag & 0.48 & 0.31 & 0.40 & 0.12 \\
\hline Zr & Zr & 1.52 & 1.16 & 1.34 & 0.25 \\
\hline ZR08SS02 & Zr-8SS-1Ag-1Nb-1Pd-1Ru & 0.73 & 0.49 & 0.61 & 0.17 \\
\hline ZR08SS04 & Zr-8SS & 7.62 & 0.32 & 3.97 & 5.17 \\
\hline Copper & Pure Copper & 3.37 & 3.14 & 3.25 & 0.16 \\
\hline C-22 & C-22 & 1.89 & 0.41 & 1.15 & 1.05 \\
\hline AISI 1018 & Mild Steel & 7.90 & 1.67 & 4.79 & 4.41 \\
\hline
\end{tabular}

${ }^{\mathrm{a}} \mathrm{Std}$. Dev $=$ Standard Deviation $(1 \sigma)$ 
Table A-5. Corrosion Rates $(\mu \mathrm{m} / \mathrm{y})$ Measured in CJ13 Solution ${ }^{\mathrm{a}}$ at $\mathbf{2 0}^{\circ} \mathrm{C}$.

\begin{tabular}{|c|c|c|c|c|c|c|}
\hline Ingot ID & Nominal Composition & \multicolumn{3}{|c|}{ Trial } & Mean & $\begin{array}{c}\text { Std. } \\
\text { Dev. }\end{array}$ \\
\cline { 3 - 5 } & & 1 & 2 & 3 & & De. \\
\hline SS316 & SS316 & 3.28 & 0.61 & 2.66 & 2.18 & 1.40 \\
\hline SS15ZR12 & SS-15Zr-2Ru-1Pd-1Ag & 1.50 & 0.63 & 3.43 & 1.85 & 1.43 \\
\hline SS15ZR14 & SS-15Zr (annealed) & 0.74 & 0.41 & 0.61 & 0.59 & 0.17 \\
\hline SS15ZR15 & SS-15Zr-2Ru-1Nb-0.5Pd-0.5Ag & 1.79 & 0.71 & 0.32 & 0.94 & 0.76 \\
\hline SS15ZR17 & SS-15Zr (as-cast) & 0.88 & 0.42 & 0.80 & 0.70 & 0.25 \\
\hline SS05ZR18 & SS-5Zr-2Nb-1Ru-1Pd & 2.29 & 0.29 & 1.19 & 1.25 & 1.00 \\
\hline SS20ZR19 & SS-20Zr-2Nb-1Ru-1Pd & 2.40 & 0.75 & 2.25 & 1.80 & 0.91 \\
\hline SS05ZR20 & SS-5Zr-1Nb-0.5Ru-0.5Pd & 2.49 & 0.63 & 0.24 & 1.12 & 1.20 \\
\hline SS05ZR21 & SS-5Zr & 2.24 & 0.55 & 0.85 & 1.21 & 0.90 \\
\hline SS15ZR23 & SS-15Zr (cooled at10 C/min) & 1.42 & 0.44 & 0.72 & 0.86 & 0.51 \\
\hline SS15ZR24 & SS-15Zr (cooled at 5 C/min) & 2.07 & 0.62 & 0.50 & 1.06 & 0.87 \\
\hline SS15ZR25 & SS-15Zr-1Nb-1Ru-1Pd-1Rh & 1.21 & 0.41 & 1.20 & 0.94 & 0.46 \\
\hline SS15ZR26 & SS-15Zr-1Nb-1Ru-1Pd-1Rh & 1.71 & 0.44 & 4.39 & 2.18 & 2.02 \\
\hline SS15ZR27 & SS-15Zr (cooled at 1 $\left.{ }^{\circ} \mathrm{C} / \mathrm{min}\right)$ & 1.20 & 0.45 & 2.57 & 1.41 & 1.08 \\
\hline SS00ZR28 & SS-2Nb-1Ru-1Pd-1Ag & 0.52 & 0.48 & 2.49 & 1.16 & 1.15 \\
\hline Zr & Zr & 3.25 & 1.98 & 3.04 & 2.76 & 0.68 \\
\hline ZR08SS02 & Zr-8SS-1Ag-1Nb-1Pd-1Ru & 3.48 & 3.06 & 3.29 & 3.28 & 0.21 \\
\hline ZR08SS04 & Zr-8SS & 0.57 & 0.63 & 2.47 & 1.22 & 1.08 \\
\hline Copper & Pure Copper & 44.30 & 20.39 & 17.75 & 27.48 & 14.63 \\
\hline C-22 & C-22 & 0.56 & 0.78 & 1.30 & 0.88 & 0.38 \\
\hline AISI 1018 & Mild Steel & 2.24 & 1.99 & 2.36 & 2.20 & 0.19 \\
\hline pHe 8.2 & & & & & \\
\hline
\end{tabular}

${ }^{\mathrm{a}} \mathrm{pH}=8.2$

${ }^{\mathrm{b}}$ Std. Dev $=$ Standard Deviation $(1 \sigma)$ 
Table A-6. Corrosion Rates $(\mu \mathrm{m} / \mathrm{y})$ Measured in $10 \mathrm{KCl}$ Solution at $20^{\circ} \mathrm{C}$.

\begin{tabular}{|c|c|c|c|c|c|c|}
\hline \multirow[t]{2}{*}{ Ingot ID } & \multirow[t]{2}{*}{ Nominal Composition } & \multicolumn{3}{|c|}{ Trial } & \multirow[t]{2}{*}{ Mean } & \multirow{2}{*}{$\begin{array}{l}\text { Std. } \\
\text { Dev. }\end{array}$} \\
\hline & & 1 & 2 & 3 & & \\
\hline SS316 & SS316 & 1.19 & 1.85 & 3.89 & 2.31 & 1.41 \\
\hline SS15ZR12 & SS-15Zr-2Ru-1Pd-1Ag & 0.56 & 0.22 & 3.06 & 1.28 & 1.55 \\
\hline SS15ZR14 & SS-15Zr (annealed) & 0.58 & 0.25 & 2.22 & 1.02 & 1.06 \\
\hline SS15ZR15 & SS-15Zr-2Ru-1 Nb-0.5Pd-0.5Ag & 1.40 & 0.48 & 3.35 & 1.74 & 1.47 \\
\hline SS15ZR17 & SS-15Zr (as-cast) & 1.02 & 0.39 & 1.40 & 0.94 & 0.51 \\
\hline SS05ZR18 & $\mathrm{SS}-5 \mathrm{Zr}-2 \mathrm{Nb}-1 \mathrm{Ru}-1 \mathrm{Pd}$ & 0.35 & 0.16 & 1.74 & 0.75 & 0.86 \\
\hline SS20ZR19 & SS-20Zr-2Nb-1Ru-1Pd & 0.59 & 1.95 & 3.82 & 2.12 & 1.62 \\
\hline SS05ZR20 & $\mathrm{SS}-5 \mathrm{Zr}-1 \mathrm{Nb}-0.5 \mathrm{Ru}-0.5 \mathrm{Pd}$ & 0.47 & 0.18 & 1.72 & 0.79 & 0.82 \\
\hline SS05ZR21 & $\mathrm{SS}-5 \mathrm{Zr}$ & 0.53 & 1.09 & 0.86 & 0.83 & 0.28 \\
\hline SS15ZR23 & $\mathrm{SS}-15 \mathrm{Zr}\left(\right.$ cooled at $\left.10^{\circ} \mathrm{C} / \mathrm{min}\right)$ & 0.27 & 0.27 & 1.10 & 0.55 & 0.48 \\
\hline SS15ZR24 & $\mathrm{SS}-15 \mathrm{Zr}\left(\right.$ cooled at $\left.5^{\circ} \mathrm{C} / \mathrm{min}\right)$ & 0.23 & 0.62 & 1.16 & 0.67 & 0.47 \\
\hline SS15ZR25 & SS-15Zr-1Nb-1Ru-1Pd-1Rh & 0.45 & 0.33 & 1.03 & 0.61 & 0.38 \\
\hline SS15ZR26 & SS-15Zr-1Nb-1Ru-1Pd-1Rh & 0.27 & 0.62 & 3.70 & 1.53 & 1.89 \\
\hline SS15ZR27 & $\mathrm{SS}-15 \mathrm{Zr}$ (cooled at $\left.1^{\circ} \mathrm{C} / \mathrm{min}\right)$ & 0.23 & 0.20 & 0.71 & 0.38 & 0.29 \\
\hline SS00ZR28 & $\mathrm{SS}-2 \mathrm{Nb}-1 \mathrm{Ru}-1 \mathrm{Pd}-1 \mathrm{Ag}$ & 0.31 & 0.51 & 0.38 & 0.40 & 0.10 \\
\hline $\mathrm{Zr}$ & $\mathrm{Zr}$ & 0.71 & 0.09 & 0.23 & 0.34 & 0.32 \\
\hline ZR08SS02 & Zr-8SS-1Ag-1Nb-1Pd-1Ru & 0.24 & 1.80 & 0.59 & 0.87 & 0.82 \\
\hline ZR08SS04 & $\mathrm{Zr}-8 \mathrm{SS}$ & 0.68 & 0.20 & 1.86 & 0.91 & 0.86 \\
\hline Copper & Pure Copper & 7.99 & 38.00 & 29.69 & 25.23 & 15.50 \\
\hline $\mathrm{C}-22$ & $\mathrm{C}-22$ & 0.47 & 0.51 & 1.45 & 0.81 & 0.56 \\
\hline AISI 1018 & Mild Steel & 191.26 & 174.32 & 163.53 & 176.37 & 13.98 \\
\hline
\end{tabular}


Table A-7. Corrosion Rates $(\mu \mathrm{m} / \mathrm{y})$ Measured in $1 \mathrm{KCl}$ Solution at at $20^{\circ} \mathrm{C}$.

\begin{tabular}{|c|c|c|c|c|c|c|}
\hline Ingot ID & Nominal Composition & \multicolumn{3}{|c|}{ Trial } & Mean & Std. \\
\cline { 3 - 4 } & & 1 & 2 & 3 & & Dev. $^{\text {b }}$ \\
\hline SS316 & SS316 & 1.03 & 1.75 & 2.31 & 1.70 & 0.65 \\
\hline SS15ZR12 & SS-15Zr-2Ru-1Pd-1Ag & 0.38 & 0.50 & 0.48 & 0.46 & 0.06 \\
\hline SS15ZR14 & SS-15Zr (annealed) & 0.38 & 0.58 & 0.36 & 0.44 & 0.12 \\
\hline SS15ZR15 & SS-15Zr-2Ru-1Nb-0.5Pd-0.5Ag & 1.73 & 0.78 & 0.59 & 1.03 & 0.61 \\
\hline SS15ZR17 & SS-15Zr (as-cast) & 0.74 & 0.89 & 1.09 & 0.91 & 0.18 \\
\hline SS05ZR18 & SS-5Zr-2Nb-1Ru-1Pd & 1.34 & 0.48 & 0.29 & 0.70 & 0.56 \\
\hline SS20ZR19 & SS-20Zr-2Nb-1Ru-1Pd & 0.39 & 1.00 & 1.57 & 0.99 & 0.59 \\
\hline SS05ZR20 & SS-5Zr-1Nb-0.5Ru-0.5Pd & 2.33 & 0.62 & 0.33 & 1.10 & 1.08 \\
\hline SS05ZR21 & SS-5Zr & 1.46 & 0.25 & 0.19 & 0.63 & 0.72 \\
\hline SS15ZR23 & SS-15Zr (cooled at 10 ${ }^{\circ}$ C/min) & 0.57 & 0.88 & 0.24 & 0.56 & 0.32 \\
\hline SS15ZR24 & SS-15Zr (cooled at 5 $\left.{ }^{\circ} \mathrm{C} / \mathrm{min}\right)$ & 0.89 & 0.67 & 0.57 & 0.71 & 0.16 \\
\hline SS15ZR25 & SS-15Zr-1Nb-1Ru-1Pd-1Rh & 0.98 & 0.61 & 0.62 & 0.74 & 0.21 \\
\hline SS15ZR26 & SS-15Zr-1Nb-1Ru-1Pd-1Rh & 0.36 & 0.51 & 0.70 & 0.52 & 0.17 \\
\hline SS15ZR27 & SS-15Zr (cooled at $\left.1^{\circ} \mathrm{C} / \mathrm{min}\right)$ & 0.22 & 0.67 & 0.64 & 0.51 & 0.25 \\
\hline SS00ZR28 & SS-2Nb-1Ru-1Pd-1Ag & 0.82 & 0.53 & 0.42 & 0.59 & 0.21 \\
\hline Zr & Zr & 2.02 & 0.15 & 1.82 & 1.33 & 1.03 \\
\hline ZR08SS02 & Zr-8SS-1Ag-1Nb-1Pd-1Ru & 0.38 & 1.80 & 0.26 & 0.81 & 0.85 \\
\hline ZR08SS04 & Zr-8SS & 0.35 & 0.23 & 1.19 & 0.59 & 0.53 \\
\hline Copper & Pure Copper & 8.75 & 6.10 & 8.17 & 7.68 & 1.39 \\
\hline C-22 & C-22 & 0.56 & 0.53 & 0.60 & 0.56 & 0.04 \\
\hline AISI 1018 & Mild Steel & 122.96 & 77.85 & 114.15 & 104.99 & 23.91 \\
\hline
\end{tabular}

${ }^{\mathrm{a}} \mathrm{pH}=5.8$

${ }^{\mathrm{b}}$ Std. Dev $=$ Standard Deviation $(1 \sigma)$ 
Table A-8. Typical Composition of Solutions Used for Electrochemical Testing at $60^{\circ} \mathrm{C}$.

\begin{tabular}{|c|c|c|c|c|c|c|c|c|c|c|}
\hline & & \multicolumn{8}{|c|}{ Solution Composition $(\mathrm{mg} / \mathrm{L}$ or ppm) } \\
\cline { 3 - 11 } Solution & $\mathrm{pH}$ & $\mathrm{Na}$ & $\mathrm{K}$ & $\mathrm{Ca}$ & $\mathrm{Mg}$ & $\mathrm{Si}$ & $\mathrm{SO}_{4}^{-2}$ & $\mathrm{Cl}^{-1}$ & $\mathrm{NO}_{3}^{-1}$ & $\mathrm{HCO}_{3}^{-1}$ \\
\hline $\mathrm{pH}=10$ & $\sim 10$ & 65.2 & 5.32 & 10.4 & 2.18 & 37.9 & 18 & 4.33 & 9.5 & 88 \\
\hline Conc. J-13 & $\sim 8.2$ & 5300 & 510 & 6 & 1.9 & 30 & 22 & 727 & 11 & 12700 \\
\hline $10000 \mathrm{ppm} \mathrm{Cl}$ & $\sim 6.3$ & 6270 & - & - & - & - & - & 10000 & - & - \\
\hline $1000 \mathrm{ppm} \mathrm{Cl}$ & $\sim 5.8$ & 607 & - & - & - & - & - & 1000 & - & - \\
\hline $\mathrm{pH}=2$ & 2 & 49.1 & 5.1 & 10.9 & 2.12 & 35.1 & 17.8 & 443 & 10.5 & 4.4 \\
\hline
\end{tabular}

Table A-9. Corrosion Rates $(\mu \mathrm{m} / \mathrm{y})$ Measured in $\mathrm{pH}=10$ Solution at $60^{\circ} \mathrm{C}$.

\begin{tabular}{|c|c|c|c|c|c|c|}
\hline \multirow{2}{*}{$\begin{array}{c}\text { Ingot } \\
\text { ID }\end{array}$} & $\begin{array}{c}\text { Nominal } \\
\text { Composition }\end{array}$ & \multicolumn{3}{|c|}{ Trial } & Mean & Std. \\
\cline { 3 - 5 } & SS316 & 1 & 2 & 3 & & Dev. $^{\text {a }}$ \\
\hline SS316 & SS-15Zr (as-cast) & 4.89 & 3.35 & 5.04 & 4.43 & 0.93 \\
\hline SS15ZR17 & SS-5Zr-2Nb-1Ru-1Pd & 2.71 & 2.80 & 5.21 & 3.57 & 1.41 \\
\hline SS05ZR18 & SS-20Zr-2Nb-1Ru-1Pd & 3.30 & 4.60 & 2.79 & 3.56 & 0.94 \\
\hline SS20ZR19 & SS-15Zr-1Nb-1Ru-1Pd-1Rh & 10.56 & 6.95 & 7.25 & 8.26 & 2.00 \\
\hline SS15ZR25 & SS & & &
\end{tabular}

${ }^{\mathrm{a}}$ Std. Dev $=$ Standard Deviation $(1 \sigma)$

Table A-10. Corrosion Rates $(\mu \mathrm{m} / \mathrm{y})$ Measured in CJ13 Solution ${ }^{\mathrm{a}}$ at $60^{\circ} \mathrm{C}$.

\begin{tabular}{|c|c|c|c|c|c|c|}
\hline \multirow{2}{*}{$\begin{array}{c}\text { Ingot } \\
\text { ID }\end{array}$} & \multirow{2}{*}{$\begin{array}{c}\text { Nominal } \\
\text { Composition }\end{array}$} & \multicolumn{3}{|c|}{ Trial } & \multirow[t]{2}{*}{ Mean } & \multirow{2}{*}{$\begin{array}{c}\text { Std. } \\
\text { Dev. }\end{array}$} \\
\hline & & 1 & 2 & 3 & & \\
\hline SS316 & SS316 & 3.17 & 5.18 & 5.00 & 4.45 & 1.11 \\
\hline SS15ZR17 & SS-15Zr (as-cast) & 3.42 & 3.50 & 10.53 & 5.82 & 4.09 \\
\hline SS05ZR18 & SS-5Zr-2Nb-1Ru-1Pd & 2.69 & 2.00 & 12.46 & 5.72 & 5.85 \\
\hline SS20ZR19 & SS-20Zr-2Nb-1Ru-1Pd & 3.17 & 3.92 & 13.08 & 6.72 & 5.52 \\
\hline SS15ZR25 & SS-15Zr-1Nb-1Ru-1Pd-1Rh & 4.24 & 5.45 & 12.51 & 7.40 & 4.47 \\
\hline
\end{tabular}

${ }^{\mathrm{a}} \mathrm{pH}=8.2$

${ }^{\mathrm{b}} \mathrm{Std}$. Dev $=$ Standard Deviation $(1 \sigma)$ 
Table A-11. Corrosion Rates $(\mu \mathrm{m} / \mathrm{y})$ Measured in $10 \mathrm{KCl}$ Solution a at $60^{\circ} \mathrm{C}$

\begin{tabular}{|c|c|c|c|c|c|c|}
\hline \multirow{2}{*}{$\begin{array}{l}\text { Ingot } \\
\text { ID }\end{array}$} & \multirow{2}{*}{$\begin{array}{c}\text { Nominal } \\
\text { Composition }\end{array}$} & \multicolumn{3}{|c|}{ Trial } & \multirow[t]{2}{*}{ Mean } & \multirow{2}{*}{$\begin{array}{l}\text { Std. } \\
\text { Dev. }\end{array}$} \\
\hline & & 1 & 2 & 3 & & \\
\hline SS316 & SS316 & 4.60 & 7.49 & 14.30 & 8.80 & 4.98 \\
\hline SS15ZR17 & SS- $15 \mathrm{Zr}$ (as-cast) & 7.60 & 5.17 & 8.24 & 7.00 & 1.62 \\
\hline SS05ZR18 & SS-5Zr-2Nb-1Ru-1Pd & 14.29 & 6.95 & 9.15 & 10.13 & 3.77 \\
\hline SS20ZR19 & SS-20Zr-2Nb-1Ru-1Pd & 8.25 & 17.94 & 6.84 & 11.01 & 6.04 \\
\hline SS15ZR25 & SS-15Zr-1Nb-1Ru-1Pd-1Rh & 4.56 & 8.07 & 5.01 & 5.88 & 1.91 \\
\hline
\end{tabular}

${ }^{\mathrm{a}} \mathrm{pH}=6.3$

${ }^{\mathrm{b}}$ Std. Dev $=$ Standard Deviation $(1 \sigma)$

Table A-12. Corrosion Rates $(\mu \mathrm{m} / \mathrm{y})$ Measured in $1 \mathrm{KCl}$ Solution a at $60^{\circ} \mathrm{C}$.

\begin{tabular}{|c|c|c|c|c|c|c|}
\hline \multirow{2}{*}{$\begin{array}{l}\text { Ingot } \\
\text { ID }\end{array}$} & \multirow{2}{*}{$\begin{array}{c}\text { Nominal } \\
\text { Composition }\end{array}$} & \multicolumn{3}{|c|}{ Trial } & \multirow[t]{2}{*}{ Mean } & \multirow{2}{*}{$\begin{array}{l}\text { Std. } \\
\text { Dev. }\end{array}$} \\
\hline & & 1 & 2 & 3 & & \\
\hline SS316 & SS316 & 2.79 & 2.53 & 8.70 & 4.68 & 3.49 \\
\hline SS15ZR17 & SS-15Zr (as-cast) & 6.16 & 6.60 & 7.33 & 6.70 & 0.59 \\
\hline SS05ZR18 & 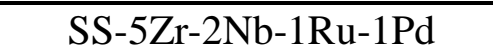 & 3.08 & 3.00 & 1.89 & 2.66 & 0.67 \\
\hline SS20ZR19 & SS-20Zr-2Nb-1Ru-1Pd & 4.81 & 7.60 & 10.89 & 7.77 & 3.05 \\
\hline SS15ZR25 & SS-15Zr-1Nb-1Ru-1Pd-1Rh & 6.14 & 2.54 & 4.17 & 4.28 & 1.80 \\
\hline
\end{tabular}

${ }^{\mathrm{a}} \mathrm{pH}=5.8$

${ }^{\mathrm{b}}$ Std. . Dev $=$ Standard Deviation $(1 \sigma)$

Table A-13. Corrosion Rates $(\mu \mathrm{m} / \mathrm{y})$ Measured in $\mathrm{pH}=2$ Solution at $60^{\circ} \mathrm{C}$.

\begin{tabular}{|c|c|c|c|c|c|c|}
\hline \multirow{2}{*}{$\begin{array}{c}\text { Ingot } \\
\text { ID }\end{array}$} & \multirow{2}{*}{$\begin{array}{c}\text { Nominal } \\
\text { Composition }\end{array}$} & \multicolumn{3}{|c|}{ Trial } & \multirow[t]{2}{*}{ Mean } & \multirow{2}{*}{$\begin{array}{l}\text { Std. } \\
\text { Dev. }{ }^{\text {a }}\end{array}$} \\
\hline & & 1 & 2 & 3 & & \\
\hline SS316 & SS316 & 3.13 & 14.94 & 3.31 & 7.13 & 6.77 \\
\hline SS15ZR17 & SS-15Zr (as-cast) & 5.70 & 13.38 & 10.28 & 9.79 & 3.86 \\
\hline SS05ZR18 & SS-5Zr-2Nb-1Ru-1Pd & 1.77 & 7.81 & 3.44 & 4.34 & 3.12 \\
\hline SS20ZR19 & SS-20Zr-2Nb-1Ru-1Pd & 5.87 & 6.85 & 2.99 & 5.24 & 2.01 \\
\hline SS15ZR25 & SS-15Zr-1Nb-1Ru-1Pd-1Rh & 4.07 & 9.47 & 7.35 & 6.96 & 2.72 \\
\hline
\end{tabular}

${ }^{\mathrm{a}}$ Std. Dev $=$ Standard Deviation $(1 \sigma)$ 
Table A-14. Typical Composition of Solutions Used for Electrochemical Testing at $90^{\circ} \mathrm{C}$.

\begin{tabular}{|c|c|c|c|c|c|c|c|c|c|c|}
\hline & & \multicolumn{7}{|c|}{ Solution Composition $(\mathrm{mg} / \mathrm{L}$ or ppm) } \\
\cline { 3 - 12 } Solution & $\mathrm{pH}$ & $\mathrm{Na}$ & $\mathrm{K}$ & $\mathrm{Ca}$ & $\mathrm{Mg}$ & $\mathrm{Si}$ & $\mathrm{SO}_{4}^{-2}$ & $\mathrm{Cl}^{-1}$ & $\mathrm{NO}_{3}^{-1}$ & $\mathrm{HCO}_{3}^{-1}$ \\
\hline $\mathrm{pH}=10$ & $\sim 10$ & 65.2 & 5.32 & 10.4 & 2.18 & 37.9 & 18 & 4.33 & 9.5 & 88 \\
\hline Sim. J-13 & $\sim 9$ & 50.9 & 5.21 & 10.2 & 2.09 & 33.8 & 18 & 4.31 & 10.1 & 109 \\
\hline Conc. J-13 & $\sim 8.2$ & 5300 & 510 & 6 & 1.9 & 30 & 22 & 727 & 11 & 12700 \\
\hline $10000 \mathrm{ppm} \mathrm{Cl}$ & $\sim 6.3$ & 6270 & - & - & - & - & - & 10000 & - & - \\
\hline $1000 \mathrm{ppm} \mathrm{Cl}$ & $\sim 5.8$ & 607 & - & - & - & - & - & 1000 & - & - \\
\hline $\mathrm{pH}=2$ & $\sim 2$ & 49.1 & 5.1 & 10.9 & 2.12 & 35.1 & 17.8 & 443 & 10.5 & 4.4 \\
\hline
\end{tabular}

Table A-15. Corrosion Rates $(\mu \mathrm{m} / \mathrm{y})$ Measured in $\mathrm{pH}=10$ Solution at $90^{\circ} \mathrm{C}$.

\begin{tabular}{|c|c|c|c|c|c|c|}
\hline \multirow{2}{*}{$\begin{array}{c}\text { Ingot } \\
\text { ID }\end{array}$} & \multirow{2}{*}{$\begin{array}{c}\text { Nominal } \\
\text { Composition }\end{array}$} & \multicolumn{3}{|c|}{ Trial } & \multirow[t]{2}{*}{ Mean } & \multirow{2}{*}{$\begin{array}{l}\text { Std. } \\
\text { Dev. }^{\text {a }}\end{array}$} \\
\hline & & 1 & 2 & 3 & & \\
\hline SS316 & SS316 & 13.82 & 5.44 & 3.00 & 7.42 & 5.67 \\
\hline SS15ZR17 & SS-15Zr (as-cast) & 7.89 & 5.18 & 13.25 & 8.77 & 4.11 \\
\hline SS05ZR18 & SS-5Zr-2Nb-1Ru-1Pd & 5.16 & 4.89 & 7.40 & 5.82 & 1.38 \\
\hline SS20ZR19 & SS-20Zr-2Nb-1Ru-1Pd & 2.67 & 9.06 & 9.46 & 7.06 & 3.81 \\
\hline SS15ZR25 & SS-15Zr-1Nb-1Ru-1Pd-1Rh & 2.82 & 10.71 & 7.87 & 7.13 & 3.99 \\
\hline
\end{tabular}

${ }^{\mathrm{a}}$ Std. Dev $=$ Standard Deviation $(1 \sigma)$

Table A-16. Corrosion Rates $(\mu \mathrm{m} / \mathrm{y})$ Measured in SJ13 Solution ${ }^{\mathrm{a}}$ at $\mathbf{9 0}^{\circ} \mathrm{C}$.

\begin{tabular}{|c|c|c|c|c|c|c|}
\hline \multirow{2}{*}{$\begin{array}{l}\text { Ingot } \\
\text { ID }\end{array}$} & \multirow{2}{*}{$\begin{array}{c}\text { Nominal } \\
\text { Composition }\end{array}$} & \multicolumn{3}{|c|}{ Trial } & \multirow[t]{2}{*}{ Mean } & \multirow{2}{*}{$\begin{array}{l}\text { Std. } \\
\text { Dev. }^{\text {b }}\end{array}$} \\
\hline & & 1 & 2 & 3 & & \\
\hline SS316 & SS316 & 4.42 & 2.56 & 1.59 & 2.86 & 1.44 \\
\hline SS15ZR17 & SS-15Zr (as-cast) & 4.91 & 17.00 & 10.57 & 10.83 & 6.05 \\
\hline SS05ZR18 & $\mathrm{SS}-5 \mathrm{Zr}-2 \mathrm{Nb}-1 \mathrm{Ru}-1 \mathrm{Pd}$ & 6.14 & 5.23 & 6.38 & 5.91 & 0.60 \\
\hline SS20ZR19 & SS-20Zr-2Nb-1Ru-1Pd & 7.74 & 2.78 & 3.85 & 4.79 & 2.61 \\
\hline SS15ZR25 & SS-15Zr-1Nb-1Ru-1Pd-1Rh & 6.71 & 10.45 & 2.53 & 6.57 & 3.97 \\
\hline
\end{tabular}

${ }^{\mathrm{a}} \mathrm{pH}=9$

${ }^{\mathrm{b}}$ Std. Dev $=$ Standard Deviation $(1 \sigma)$ 
Table A-17. Corrosion Rates $(\mu \mathrm{m} / \mathrm{y})$ Measured in CJ13 Solution ${ }^{\mathrm{a}}$ at $\mathbf{9 0}^{\circ} \mathrm{C}$.

\begin{tabular}{|c|c|c|c|c|c|c|}
\hline \multirow{2}{*}{$\begin{array}{l}\text { Ingot } \\
\text { ID }\end{array}$} & \multirow{2}{*}{$\begin{array}{c}\text { Nominal } \\
\text { Composition }\end{array}$} & \multicolumn{3}{|c|}{ Trial } & \multirow[t]{2}{*}{ Mean } & \multirow{2}{*}{$\begin{array}{c}\text { Std. } \\
\text { Dev. }{ }^{b}\end{array}$} \\
\hline & & 1 & 2 & 3 & & \\
\hline SS316 & SS316 & 3.68 & 4.01 & 15.00 & 7.56 & 6.44 \\
\hline SS15ZR17 & SS-15Zr (as-cast) & 6.10 & 6.81 & 13.44 & 8.78 & 4.05 \\
\hline SS05ZR18 & SS-5Zr-2Nb-1Ru-1Pd & 2.16 & 9.49 & 8.79 & 6.81 & 4.04 \\
\hline SS20ZR19 & SS-20Zr-2Nb-1Ru-1Pd & 5.76 & 8.66 & 7.16 & 7.19 & 1.45 \\
\hline SS15ZR25 & SS-15Zr-1Nb-1Ru-1Pd-1Rh & 8.67 & 13.84 & 9.11 & 10.54 & 2.87 \\
\hline
\end{tabular}

${ }^{\mathrm{a}} \mathrm{pH}=8.2$

${ }^{\mathrm{b}}$ Std. Dev $=$ Standard Deviation $(1 \sigma)$

Table A-18. Corrosion Rates $(\mu \mathrm{m} / \mathrm{y})$ in $10 \mathrm{KCl}$ Solution ${ }^{\mathrm{a}}$ at $90^{\circ} \mathrm{C}$.

\begin{tabular}{|c|c|c|c|c|c|c|}
\hline \multirow{2}{*}{$\begin{array}{c}\text { Ingot } \\
\text { ID }\end{array}$} & \multirow{2}{*}{$\begin{array}{c}\text { Nominal } \\
\text { Composition }\end{array}$} & \multicolumn{3}{|c|}{ Trial } & \multirow{2}{*}{ Mean } & Std. \\
\cline { 3 - 5 } & SS316 & 1 & 2 & 3 & & Dev. $^{\text {b }}$ \\
\hline SS316 & SS-15Zr (as-cast) & 12.75 & 7.76 & 3.96 & 8.47 & 4.91 \\
\hline SS15ZR17 & SS-5Zr-2Nb-1Ru-1Pd & 6.88 & 3.40 & 9.96 & 6.75 & 3.28 \\
\hline SS05ZR18 & SS-20Zr-2Nb-1Ru-1Pd & 12.69 & 9.14 & 10.51 & 10.78 & 1.79 \\
\hline SS20ZR19 & SS-15Zr-1Nb-1Ru-1Pd-1Rh & 11.14 & 7.21 & 3.07 & 7.14 & 4.03 \\
\hline SS15ZR25 & SS & & & & & \\
\hline
\end{tabular}

${ }^{\mathrm{a}} \mathrm{pH}=6.3$

${ }^{\mathrm{b}}$ Std. Dev $=$ Standard Deviation $(1 \sigma)$

Table A-19. Corrosion Rates $(\mu \mathrm{m} / \mathrm{y})$ Measured in $1 \mathrm{KCl}$ Solution ${ }^{\mathrm{a}}$ at $90^{\circ} \mathrm{C}$.

\begin{tabular}{|c|c|c|c|c|c|c|}
\hline $\begin{array}{c}\text { Ingot } \\
\text { ID }\end{array}$ & $\begin{array}{c}\text { Nominal } \\
\text { Composition }\end{array}$ & \multicolumn{3}{|c|}{ Trial } & Mean & $\begin{array}{c}\text { Std. } \\
\text { Dev. }\end{array}$ \\
\cline { 3 - 6 } & SS316 & 4.00 & 4.77 & 1.43 & 3.40 & 1.75 \\
\hline SS316 & SS-15Zr (as-cast) & 8.07 & 9.04 & 7.03 & 8.04 & 1.00 \\
\hline SS15ZR17 & SS-5Zr-2Nb-1Ru-1Pd & 5.17 & 5.80 & 4.42 & 5.13 & 0.69 \\
\hline SS05ZR18 & SS-20Zr-2Nb-1Ru-1Pd & 5.40 & 9.50 & 9.73 & 8.21 & 2.44 \\
\hline SS20ZR19 & SS-15Zr-1Nb-1Ru-1Pd-1Rh & 3.75 & 4.44 & 5.07 & 4.42 & 0.66 \\
\hline SS15ZR25 & SS & & & & &
\end{tabular}

${ }^{\mathrm{a}} \mathrm{pH}=5.8$

${ }^{\mathrm{b}}$ Std. Dev $=$ Standard Deviation $(1 \sigma)$ 
Table A-20. Corrosion Rates $(\mu \mathrm{m} / \mathrm{y})$ Measured in $\mathrm{pH}=2$ Solution at $90^{\circ} \mathrm{C}$.

\begin{tabular}{|c|c|c|c|c|c|c|}
\hline Ingot & Nominal & \multicolumn{3}{|c|}{ Trial } & Mean & Std. \\
\cline { 3 - 5 } & Composition & 1 & 2 & 3 & & Dev. $^{\text {b }}$ \\
\hline SS316 & SS316 & 18.27 & 2.92 & 10.80 & 10.66 & 7.68 \\
\hline SS15ZR17 & SS-15Zr (as-cast) & 7.08 & 2.75 & 2.72 & 4.19 & 2.51 \\
\hline SS05ZR18 & SS-5Zr-2Nb-1Ru-1Pd & 2.33 & 9.67 & 8.21 & 6.73 & 3.89 \\
\hline SS20ZR19 & SS-20Zr-2Nb-1Ru-1Pd & 11.88 & 10.70 & 12.50 & 11.69 & 0.91 \\
\hline SS15ZR25 & SS-15Zr-1Nb-1Ru-1Pd-1Rh & 4.45 & - & - & 4.45 & - \\
\hline
\end{tabular}

${ }^{\mathrm{a}}$ Std. Dev $=$ Standard Deviation $(1 \sigma)$

Table A-21. Comparison of Corrosion Rates $(\mu \mathrm{m} / \mathrm{y})$ Measured at $90^{\circ} \mathrm{C}, 60^{\circ} \mathrm{C}$, and $20^{\circ} \mathrm{C}$ in $\mathrm{pH}=10$ Solution.

\begin{tabular}{|c|c|c|c|c|c|c|c|}
\hline \multirow{2}{*}{$\begin{array}{c}\text { Ingot } \\
\text { ID }\end{array}$} & $\begin{array}{c}\text { Nominal } \\
\text { Composition }\end{array}$ & \multicolumn{2}{|c|}{$90^{\circ} \mathrm{C}$} & \multicolumn{2}{c|}{$60^{\circ} \mathrm{C}$} & \multicolumn{2}{c|}{$20^{\circ} \mathrm{C}$} \\
\cline { 3 - 8 } & Avg. & SD $^{\mathrm{b}}$ & Avg. $^{\mathrm{a}}$ & SD $^{\mathrm{b}}$ & Avg. $^{\mathrm{a}}$ & SD $^{\mathrm{b}}$ \\
\hline SS316 & SS316 & 7.42 & 5.67 & 2.35 & 2.15 & 0.34 & 0.12 \\
\hline SS15ZR17 & SS-15Zr & 8.77 & 4.11 & 4.43 & 0.93 & 0.17 & 0.06 \\
\hline SS05ZR18 & SS-5Zr-2Nb-1Pd-1Ru & 5.82 & 1.38 & 3.57 & 1.41 & 0.25 & 0.11 \\
\hline SS20ZR19 & SS-20Zr-2Nb-1Pd-1Ru & 7.06 & 3.81 & 3.56 & 0.94 & 0.23 & 0.07 \\
\hline SS15ZR25 & SS-15Zr-1Nb-1Pd-1Rh-1Ru & 7.13 & 3.99 & 8.26 & 2.00 & 0.24 & 0.05 \\
\hline
\end{tabular}

${ }^{a}$ Average from three specimens

${ }^{\mathrm{b}} \mathrm{SD}=$ Standard Deviation $(1 \sigma)$.

Table A-22. Comparison of Corrosion Rates $(\mu \mathrm{m} / \mathrm{y})$ Measured at $90^{\circ} \mathrm{C}, 60^{\circ} \mathrm{C}$, and $20^{\circ} \mathrm{C}$ in CJ13 Solution ( $\left.\mathrm{pH}=8.2\right)$.

\begin{tabular}{|c|c|c|c|c|c|c|c|}
\hline \multirow{2}{*}{$\begin{array}{c}\text { Ingot } \\
\text { ID }\end{array}$} & $\begin{array}{c}\text { Nominal } \\
\text { Composition }\end{array}$ & \multicolumn{2}{|c|}{$90^{\circ} \mathrm{C}$} & \multicolumn{2}{c|}{$60^{\circ} \mathrm{C}$} & \multicolumn{2}{c|}{$20^{\circ} \mathrm{C}$} \\
\cline { 3 - 8 } & Svg. & SD $^{\mathrm{b}}$ & Avg. $^{\mathrm{a}}$ & SD $^{\mathrm{b}}$ & Avg. $^{\mathrm{a}}$ & SD $^{\mathrm{b}}$ \\
\hline SS316 & SS-15Zr & 7.56 & 6.44 & 4.45 & 1.11 & 2.18 & 1.40 \\
\hline SS15ZR17 & & 8.78 & 4.05 & 5.82 & 4.09 & 0.70 & 0.25 \\
\hline SS05ZR18 & SS-5Zr-2Nb-1Pd-1Ru & 6.81 & 4.04 & 5.72 & 5.85 & 1.25 & 1.00 \\
\hline SS20ZR19 & SS-20Zr-2Nb-1Pd-1Ru & 7.19 & 1.45 & 6.72 & 5.52 & 1.80 & 0.91 \\
\hline SS15ZR25 & SS-15Zr-1Nb-1Pd-1Rh-1Ru & 10.54 & 2.87 & 7.40 & 4.47 & 0.94 & 0.46 \\
\hline
\end{tabular}

${ }^{a}$ Average from three specimens

${ }^{\mathrm{b}} \mathrm{SD}=$ Standard Deviation $(1 \sigma)$. 
Table A-23. Comparison of Corrosion Rates $(\mu \mathrm{m} / \mathrm{y})$ Measured at $90^{\circ} \mathrm{C}, 60^{\circ} \mathrm{C}$, and $20^{\circ} \mathrm{C}$ in $10 \mathrm{KCl}$ Solution (pH 6.2).

\begin{tabular}{|c|c|c|c|c|c|c|c|}
\hline \multirow{2}{*}{$\begin{array}{c}\text { Ingot } \\
\text { ID }\end{array}$} & \multirow{2}{*}{$\begin{array}{c}\text { Nominal } \\
\text { Composition }\end{array}$} & \multicolumn{2}{|c|}{$90^{\circ} \mathrm{C}$} & \multicolumn{2}{|c|}{$60^{\circ} \mathrm{C}$} & \multicolumn{2}{|c|}{$20^{\circ} \mathrm{C}$} \\
\hline & & Avg. ${ }^{a}$ & $\mathrm{SD}^{\mathrm{b}}$ & Avg. ${ }^{a}$ & $\mathrm{SD}^{\mathrm{b}}$ & Avg. ${ }^{a}$ & $\mathrm{SD}^{\mathrm{b}}$ \\
\hline Disc & SS316 & 8.47 & 4.91 & 8.80 & 4.98 & 2.31 & 1.41 \\
\hline SS15ZR17 & SS-15Zr & 14.37 & 1.49 & 7.00 & 1.62 & 0.94 & 0.51 \\
\hline SS05ZR18 & SS-5Zr-2Nb-1Pd-1Ru & 6.75 & 3.28 & 10.13 & 3.77 & 0.75 & 0.86 \\
\hline SS20ZR19 & SS-20Zr-2Nb-1Pd-1Ru & 10.78 & 1.79 & 11.01 & 6.04 & 2.12 & 1.62 \\
\hline SS15ZR25 & SS-15Zr-1Nb-1Pd-1Rh-1Ru & 7.14 & 4.03 & 5.88 & 1.91 & 0.61 & 0.38 \\
\hline
\end{tabular}

${ }^{a}$ Average from three specimens

${ }^{\mathrm{b}} \mathrm{SD}=$ Standard Deviation $(1 \sigma)$.

Table A-24. Comparison of Corrosion Rates $(\mu \mathrm{m} / \mathrm{y})$ Measured at $90^{\circ} \mathrm{C}, 60^{\circ} \mathrm{C}$, and $20^{\circ} \mathrm{C}$ in $1 \mathrm{KCl}$ Solution (pH 5.7).

\begin{tabular}{|c|c|c|c|c|c|c|c|}
\hline \multirow{2}{*}{$\begin{array}{c}\text { Ingot } \\
\text { ID }\end{array}$} & $\begin{array}{c}\text { Nominal } \\
\text { Composition }\end{array}$ & \multicolumn{2}{c|}{$90^{\circ} \mathrm{C}$} & \multicolumn{2}{c|}{$60^{\circ} \mathrm{C}$} & \multicolumn{2}{c|}{$20^{\circ} \mathrm{C}$} \\
\cline { 3 - 8 } & Avg. & SD $^{\mathrm{b}}$ & Avg. $^{\mathrm{a}}$ & SD $^{\mathrm{b}}$ & Avg. $^{\mathrm{a}}$ & SD $^{\mathrm{b}}$ \\
\hline SS316 & SS316 & 3.40 & 1.75 & 4.68 & 3.49 & 1.39 & 0.51 \\
\hline SS15ZR17 & SS-15Zr & 8.04 & 1.00 & 6.70 & 0.59 & 0.82 & 0.11 \\
\hline SS05ZR18 & SS-5Zr-2Nb-1Pd-1Ru & 5.13 & 0.69 & 2.66 & 0.67 & 1.70 & 1.72 \\
\hline SS20ZR19 & SS-20Zr-2Nb-1Pd-1Ru & 8.21 & 2.44 & 7.77 & 3.05 & 0.70 & 0.43 \\
\hline SS15ZR25 & SS-15Zr-1Nb-1Pd-1Rh-1Ru & 4.42 & 0.66 & 4.28 & 1.80 & 0.80 & 0.26 \\
\hline
\end{tabular}

${ }^{a}$ Average from three specimens

${ }^{\mathrm{b}} \mathrm{SD}=$ Standard Deviation $(1 \sigma)$.

Table A-25. Comparison of Corrosion Rates $(\mu \mathrm{m} / \mathrm{y})$ Measured at $90^{\circ} \mathrm{C}, 6^{\circ} \mathrm{C}$, and $20^{\circ} \mathrm{C}$ in $\mathbf{p H}=2$ Solution.

\begin{tabular}{|c|c|c|c|c|c|c|c|}
\hline \multirow{2}{*}{$\begin{array}{c}\text { Ingot } \\
\text { ID }\end{array}$} & $\begin{array}{c}\text { Nominal } \\
\text { Composition }\end{array}$ & \multicolumn{2}{|c|}{$90^{\circ} \mathrm{C}$} & \multicolumn{2}{c|}{$60^{\circ} \mathrm{C}$} & \multicolumn{2}{c|}{$20^{\circ} \mathrm{C}$} \\
\cline { 3 - 8 } & Avg. & SD $^{\mathrm{b}}$ & Avg. $^{\mathrm{a}}$ & SD $^{\mathrm{b}}$ & Avg. $^{\mathrm{a}}$ & SD $^{\mathrm{b}}$ \\
\hline Disc & SS316 & 10.66 & 7.68 & 7.13 & 6.77 & 3.43 & 3.1 \\
\hline SS15ZR17 & SS-15Zr & 4.19 & 2.51 & 9.79 & 3.86 & 4.24 & 2.22 \\
\hline SS05ZR18 & SS-5Zr-2Nb-1Pd-1Ru & 6.73 & 3.89 & 4.34 & 3.12 & 8.51 & 2.23 \\
\hline SS20ZR19 & SS-20Zr-2Nb-1Pd-1Ru & 11.69 & 0.91 & 5.24 & 2.01 & 2.51 & 0.96 \\
\hline SS15ZR25 & SS-15Zr-1Nb-1Pd-1Rh-1Ru & $4.45^{\mathrm{c}}$ & - & 6.96 & 2.72 & 3.82 & 0.73 \\
\hline
\end{tabular}

${ }^{a}$ Average from three specimens

${ }^{\mathrm{b}} \mathrm{SD}=$ Standard Deviation $(1 \sigma)$

${ }^{\mathrm{c}}$ One Measurement 


\section{B. Publications by D. P. Abraham on the Metal Waste Form Alloy and Protective Oxide Layers}

1. D.P. Abraham, N. Dietz, Accepted for publication in Mater. Sci. Eng. A., (2001), Title: Role of Laves Intermetallics in Nuclear Waste Disposal

2. D. P. Abraham, N. L. Dietz, and N. Finnegan, Proc. of the Corrosion 2001 Conf., Houston, TX, March 11-17, 2001, Title: Characterization of Oxidation Products on a $\mathrm{ZrFe}_{2}$-type Laves Intermetallic Exposed to $200^{\circ} \mathrm{C}$ Steam.

3. T.H. Bauer, D.P. Abraham, J. Fink, I. Johnson, S.G. Johnson, and R.A. Wigeland, Proc. of the 9th International High-Level Radioactive Waste Management Conference (IHLRWM), American Nuclear Society; April 29-May 3, 2001, Las Vegas NV; Title: Modeling Corrosion and Constituent Release from a Metal Waste Form.

4. D.D. Keiser, Jr., D.P. Abraham, W. Sinkler, J. W. Richardson, Jr., and S. M. McDeavitt, J. Nucl. Mater. 279 (2000) pp. 234-244; Title: Actinide Distribution in a Stainless Steel-15 wt\% Zirconium High-Level Nuclear Waste Form.

5. D.D. Keiser, Jr., D.P. Abraham, J. W. Richardson, Jr., J. Nucl. Mater. 277 (2000) 333; Title: Influence of Technetium on the Microstructure of a Stainless SteelZirconium alloy.

6. J. S. Luo and D. P. Abraham, Mat. Res. Soc. Symp. Proc. Vol. 608, 2000, pp. Materials Research Society, Pittsburgh, PA; (Scientific Basis for Nuclear Waste Management XXIII, R.W. Smith and D.W. Shoesmith, eds.); Title: TEM Characterization of Corrosion Products formed on a Stainless Steel-Zirconium alloy.

7. D. P. Abraham, J.J. Peterson, N.K. Katyal, D.D. Keiser, Jr., and B.A. Hilton, Proc. CORROSION 2000, Paper No. 205, NACE Publications, Houston, TX, (2000); Title: Electrochemical Testing of Metal Waste Forms

8. D.D. Keiser, Jr., W. Sinkler, D.P. Abraham, J. W. Richardson, Jr., and S. M. McDeavitt, Rare Earths and Actinides: Science, Technology and Applications IV, R.G. Bautista and B. Mishra, eds., The Minerals, Metals and Materials Society, Warrendale, PA, (2000), pp. 111-121. Title: The Effects of Actinides on the Microstructural Development in a Metallic High-Level Nuclear Waste Form.

9. D. P. Abraham, J. W. Richardson, Jr., in: Long Term Stability of High Temperature Materials, G.E. Fuchs, K.A. Dannemann and T.C. Deragon, eds., TMS, Warrendale, PA, 1999, 169-179; Title: Phase Stability of Laves Intermetallics in a Stainless Steel-Zirconium alloy. 
10. D. P. Abraham, L. J. Simpson, M. J. DeVries and D. E. Callahan, Proc. CORROSION 99, Paper No. 466, NACE Publications, Houston, TX, (1999); Title: Corrosion Behavior of Stainless Steel-Zirconium Alloy Waste Forms. 


\section{Data from 7, 14, 28, 60, 95, 182 and 365 day Immersion Tests at $90^{\circ} \mathrm{C}$ in $1 \mathrm{KCl}$ and $\mathrm{CJ} 13$}

Table C-1. Composition (wt\%) of SS15ZR25 Alloy Samples

\begin{tabular}{|c|c|c|c|c|c|c|c|c|c|c|c|c|c|}
\hline \multicolumn{4}{|c|}{ Major Elements } & \multicolumn{4}{|c|}{ Noble Metal Fission Products } & \multicolumn{5}{c|}{ Minor Elements } \\
\hline $\mathrm{Fe}$ & $\mathrm{Cr}$ & $\mathrm{Ni}$ & $\mathrm{Zr}$ & $\mathrm{Nb}$ & $\mathrm{Pd}$ & $\mathrm{Rh}$ & $\mathrm{Ru}$ & $\mathrm{Mo}$ & $\mathrm{Mn}$ & $\mathrm{Co}$ & $\mathrm{Cu}$ & $\mathrm{V}$ & $\mathrm{Si}$ \\
\hline 56.5 & 14.1 & 8.65 & 14.2 & 0.8 & 0.98 & 0.93 & 0.92 & 1.66 & 1.13 & 0.19 & 0.4 & 0.09 & 0.32 \\
\hline
\end{tabular}

${ }^{\mathrm{a}}$ Sample composition was determined by ACL-CMT using ICPMS and ICPAES

Table C-2. Composition of Solutions used for the Immersion Tests ${ }^{\mathrm{a}}$

\begin{tabular}{|c|c|c|c|c|c|c|c|c|c|c|}
\hline & & \multicolumn{8}{|c|}{ Solution Composition (mg/L or ppm) } \\
\cline { 3 - 12 } Solution & $\mathrm{pH}$ & $\mathrm{Na}$ & $\mathrm{K}$ & $\mathrm{Ca}$ & $\mathrm{Mg}$ & $\mathrm{Si}$ & $\mathrm{SO}_{4}^{-2}$ & $\mathrm{Cl}^{-1}$ & $\mathrm{NO}_{3}^{-1}$ & $\mathrm{HCO}_{3}^{-1}$ \\
\hline $1000 \mathrm{ppm} \mathrm{Cl}$ & $\sim 5.8$ & 607 & - & - & - & - & - & 1000 & - & - \\
\hline Conc. J-13 & $\sim 8.2$ & 5300 & 510 & 6 & 1.9 & 30 & 22 & 727 & 11 & 12700 \\
\hline
\end{tabular}

${ }^{\mathrm{a}}$ Solutions were prepared and analyzed by ACL-CMT. 
Table C-3. Weight Change Data and Surface Examination Results from Specimens Immersed in 1KCl solution (pH 5.7)

\begin{tabular}{|c|c|c|c|c|c|l|}
\hline Test & Duration & \multicolumn{3}{|c|}{ Sample Wt. (g) } & Final & \\
\cline { 3 - 5 } ID & days & Start & End & Gain & pH & \\
\hline $1 \mathrm{KCl}-1$ & 7 & 1.2022 & 1.2022 & 0 & 7.21 & Mainly unaffected; some rust observed. \\
\hline $1 \mathrm{KCl}-2^{\mathrm{a}}$ & 7 & & & & 6.47 & \\
\hline $1 \mathrm{KCl}-3$ & 14 & 1.229 & 1.2289 & -0.0001 & 6.93 & Mild tarnish; red-colored rust observed on one edge \\
\hline $1 \mathrm{KCl}-4^{\mathrm{a}}$ & 14 & & & & 6.48 & \\
\hline $1 \mathrm{KCl}-5$ & 28 & 1.2326 & 1.2324 & -0.0002 & 6.84 & Mild tarnish; red-colored rust observed on one edge \\
\hline $1 \mathrm{KCl}-6^{\mathrm{a}}$ & 28 & & & & 6.50 & \\
\hline $1 \mathrm{KCl}-7$ & 60 & 1.2106 & 1.2105 & -0.0001 & 7.03 & Mild tarnish; red-colored rust observed on one edge \\
\hline $1 \mathrm{KCl}-8^{\mathrm{a}}$ & 60 & & & & 6.20 & \\
\hline $1 \mathrm{KCl}-9$ & 95 & 1.218 & 1.2181 & 0.0001 & 5.87 & Faint red tinge \\
\hline $1 \mathrm{KCl}-10^{\mathrm{a}}$ & 95 & & & & 5.80 & \\
\hline $1 \mathrm{KCl}-11$ & 182 & 1.2193 & 1.2193 & 0 & 9.14 & Mild tarnish; red-colored rust observed on two edges \\
\hline $1 \mathrm{KCl}-12^{\mathrm{a}}$ & 182 & & & & 7.85 & \\
\hline $1 \mathrm{KCl}-13$ & 365 & 1.2135 & 1.2139 & 0.0004 & 7.48 & Mild tarnish; red-colored rust spots on one edge \\
\hline $1 \mathrm{KCl}-14^{\mathrm{a}}$ & 365 & & & & 7.41 & \\
\hline
\end{tabular}

${ }^{\mathrm{a}}$ Control Vessel 
Table C-4. Weight Change Data and Surface Examination Results from Specimens Immersed in CJ13 solution (pH 8.2)

\begin{tabular}{|c|c|c|c|c|c|c|}
\hline \multirow{2}{*}{$\begin{array}{c}\text { Test } \\
\text { ID }\end{array}$} & \multirow{2}{*}{$\begin{array}{c}\text { Duration, } \\
\text { days }\end{array}$} & \multicolumn{3}{|c|}{ Sample Wt. (g) } & \multirow{2}{*}{$\begin{array}{c}\text { Final } \\
\mathrm{pH}\end{array}$} & \multirow[t]{2}{*}{ Comments } \\
\hline & & Start & End & Gain & & \\
\hline MJ-1 & 7 & 1.2179 & 1.2181 & 0.0002 & 9.33 & Unaffected \\
\hline $\mathrm{MJ}-2^{\mathrm{a}}$ & 7 & & & & 9.27 & \\
\hline MJ-3 & 14 & 1.2194 & 1.2197 & 0.0003 & 9.57 & Mild tarnish \\
\hline $\mathrm{MJ}-4^{\mathrm{a}}$ & 14 & & & & 9.67 & \\
\hline MJ-5 & 28 & 1.2131 & 1.2134 & 0.0003 & 10.03 & Mild tarnish \\
\hline $\mathrm{MJ}-6^{\mathrm{a}}$ & 28 & & & & 10.03 & \\
\hline MJ-7 & 60 & 1.2273 & 1.228 & 0.0007 & 10.14 & Some pits at edges \\
\hline $\mathrm{MJ}-8^{\mathrm{a}}$ & 60 & & & & 10.13 & \\
\hline MJ-9 & 95 & 1.2305 & 1.2308 & 0.0003 & 10.20 & Mild tarnish \\
\hline $\mathrm{MJ}-10^{\mathrm{a}}$ & 95 & & & & 10.18 & \\
\hline MJ-11 & 182 & 1.2285 & 1.2287 & 0.0002 & 10.46 & Mild tarnish \\
\hline $\mathrm{MJ}-12^{\mathrm{a}}$ & 182 & & & & 10.43 & \\
\hline MJ-13 & 365 & 1.2168 & 1.2168 & 0 & 10.88 & Mild tarnish \\
\hline $\mathrm{MJ}-14^{\mathrm{a}}$ & 365 & & & & 10.61 & \\
\hline
\end{tabular}

${ }^{\mathrm{a}}$ Control Vessel 
Table C-5. Leachate Data $(\mu \mathrm{g} / \mathrm{L})$ for $90^{\circ} \mathrm{C}$ Immersion in $1 \mathrm{KCl}$ Solution

\begin{tabular}{|c|c|c|c|c|c|c|c|c|c|c|c|c|c|c|c|}
\hline \multirow{2}{*}{$\begin{array}{c}\text { Test } \\
\text { ID }\end{array}$} & \multirow{2}{*}{$\begin{array}{c}\text { Test } \\
\text { Duration }\end{array}$} & \multicolumn{4}{|c|}{ Major Elements } & \multicolumn{5}{|c|}{ NMFPs } & \multicolumn{5}{|c|}{ Minor Elements } \\
\hline & & $\mathrm{Fe}$ & $\mathrm{Cr}$ & $\mathrm{Ni}$ & $\mathrm{Zr}$ & $\mathrm{Nb}$ & $\mathrm{Pd}$ & $\mathrm{Rh}$ & $\mathrm{Ru}$ & Mo & $\mathrm{Mn}$ & $\mathrm{Co}$ & $\mathrm{Cu}$ & $\mathrm{V}$ & $\mathrm{Si}$ \\
\hline $1 \mathrm{KCl}-1$ & 7 & $\mathrm{a}$ & $\mathrm{a}$ & 130 & $\mathrm{a}$ & $\mathrm{a}$ & $\mathrm{a}$ & $\mathrm{a}$ & $\mathrm{a}$ & $\mathrm{a}$ & 36 & $\mathrm{a}$ & 2.22 & 1.5 & $\mathrm{a}$ \\
\hline $1 \mathrm{KCl}-2^{\mathrm{b}}$ & 7 & $\mathrm{a}$ & $\mathrm{a}$ & $\mathrm{a}$ & $\mathrm{a}$ & $\mathrm{a}$ & $\mathrm{a}$ & $\mathrm{a}$ & $\mathrm{a}$ & $\mathrm{a}$ & $\mathrm{a}$ & $\mathrm{a}$ & $\mathrm{a}$ & 1.4 & $\mathrm{a}$ \\
\hline $1 \mathrm{KCl}-3$ & 14 & $\mathrm{a}$ & 110 & 170 & $\mathrm{a}$ & $\mathrm{a}$ & $\mathrm{a}$ & 0.02 & $\mathrm{a}$ & 14 & 9.7 & $\mathrm{a}$ & 1.42 & 1.7 & 26.9 \\
\hline $1 \mathrm{KCl}-4^{\mathrm{b}}$ & 14 & $\mathrm{a}$ & $\mathrm{a}$ & $\mathrm{a}$ & $\mathrm{a}$ & $\mathrm{a}$ & $\mathrm{a}$ & $\mathrm{a}$ & $\mathrm{a}$ & $\mathrm{a}$ & $\mathrm{a}$ & 26.2 & 4.5 & 1.5 & 22.6 \\
\hline $1 \mathrm{KCl}-5$ & 28 & $\mathrm{a}$ & 19.2 & 290 & $\mathrm{a}$ & a & $\mathrm{a}$ & 0.06 & $\mathrm{a}$ & 8.2 & 96 & 13 & 3.06 & 1.38 & 41.7 \\
\hline $1 \mathrm{KCl}-6^{\mathrm{b}}$ & 28 & $\mathrm{a}$ & $\mathrm{a}$ & $\mathrm{a}$ & $\mathrm{a}$ & $\mathrm{a}$ & $\mathrm{a}$ & $\mathrm{a}$ & $\mathrm{a}$ & $\mathrm{a}$ & $\mathrm{a}$ & 0.04 & 3.99 & 1.4 & 34.6 \\
\hline $1 \mathrm{KCl}-7$ & 60 & $\mathrm{a}$ & 25.5 & 366 & 1.3 & 1.2 & $\mathrm{a}$ & $\mathrm{a}$ & $\mathrm{a}$ & 10 & 74.9 & 12.8 & 6.54 & 0.4 & 42.1 \\
\hline $1 \mathrm{KCl}-8^{\mathrm{b}}$ & 60 & $\mathrm{a}$ & $\mathrm{a}$ & $\mathrm{a}$ & $\mathrm{a}$ & $\mathrm{a}$ & $\mathrm{a}$ & $\mathrm{a}$ & $\mathrm{a}$ & $\mathrm{a}$ & $\mathrm{a}$ & $\mathrm{a}$ & 32 & 0.3 & 59.5 \\
\hline $1 \mathrm{KCl}-9$ & 95 & a & $\mathrm{a}$ & 17 & $\mathrm{a}$ & a & a & a & $\mathrm{a}$ & $\mathrm{a}$ & 6.6 & 1 & 23.5 & 0.3 & 45.2 \\
\hline $1 \mathrm{KCl}-10^{\mathrm{b}}$ & 95 & $\mathrm{a}$ & $\mathrm{a}$ & $\mathrm{a}$ & $\mathrm{a}$ & $\mathrm{a}$ & $\mathrm{a}$ & $\mathrm{a}$ & $\mathrm{a}$ & $\mathrm{a}$ & $\mathrm{a}$ & $\mathrm{a}$ & 15.3 & 0.4 & 37.2 \\
\hline $1 \mathrm{KCl}-11$ & 182 & $\mathrm{a}$ & 12.4 & 4.36 & $\mathrm{a}$ & $\mathrm{a}$ & $\mathrm{a}$ & 0.06 & 0.09 & 7.11 & $\mathrm{a}$ & 4.36 & 1.6 & 0.36 & $\mathrm{a}$ \\
\hline $1 \mathrm{KCl}-12^{\mathrm{b}}$ & 182 & $\mathrm{a}$ & $\mathrm{a}$ & $\mathrm{a}$ & $\mathrm{a}$ & $\mathrm{a}$ & $\mathrm{a}$ & $\mathrm{a}$ & 0.03 & 1.66 & $\mathrm{a}$ & $\mathrm{a}$ & 2.95 & 0.34 & $\mathrm{a}$ \\
\hline $1 \mathrm{KCl}-13$ & 365 & $\mathrm{a}$ & 9.1 & 14.3 & 0.08 & $\mathrm{a}$ & 0.07 & 0.08 & 0.12 & 50.9 & 1.57 & 0.55 & 1.04 & 5.04 & 100 \\
\hline $1 \mathrm{KCl}-14^{\mathrm{b}}$ & 365 & $\mathrm{a}$ & $\mathrm{a}$ & 0.92 & 0.06 & $\mathrm{a}$ & 0.03 & 0.08 & 0.09 & 2.52 & 0.31 & 0.06 & 4.09 & 6.79 & 111 \\
\hline
\end{tabular}

NMFPs $=$ Noble Metal Fission Products

${ }^{a}$ Element below detection limits of measuring instrument.

${ }^{\mathrm{b}}$ Control Vessel 
Table C-6. Acid Strip Data $(\mu \mathrm{g} / \mathrm{L})$ for $90^{\circ} \mathrm{C}$ Immersion in $1 \mathrm{KCl}$ Solution

\begin{tabular}{|c|c|c|c|c|c|c|c|c|c|c|c|c|c|c|c|}
\hline \multirow{2}{*}{$\begin{array}{c}\text { Test } \\
\text { ID }\end{array}$} & \multirow{2}{*}{$\begin{array}{c}\text { Test } \\
\text { Duration }\end{array}$} & \multicolumn{4}{|c|}{ Major Elements } & \multicolumn{5}{|c|}{ NMFPs } & \multicolumn{5}{|c|}{ Minor Elements } \\
\hline & & $\mathrm{Fe}$ & $\mathrm{Cr}$ & $\mathrm{Ni}$ & $\mathrm{Zr}$ & $\mathrm{Nb}$ & $\mathrm{Pd}$ & $\mathrm{Rh}$ & $\mathrm{Ru}$ & Mo & $\mathrm{Mn}$ & $\mathrm{Co}$ & $\mathrm{Cu}$ & $\mathrm{V}$ & $\mathrm{Si}$ \\
\hline $1 \mathrm{KCl}-1 \mathrm{AS}$ & 7 & 141 & 51.1 & $\mathrm{a}$ & $\mathrm{a}$ & $\mathrm{a}$ & $\mathrm{a}$ & 0.09 & $\mathrm{a}$ & $\mathrm{a}$ & $\mathrm{a}$ & $\mathrm{a}$ & 1.2 & $\mathrm{a}$ & $\mathrm{a}$ \\
\hline $1 \mathrm{KCl}-2 \mathrm{AS}^{\mathrm{b}}$ & 7 & $\mathrm{a}$ & $\mathrm{a}$ & $\mathrm{a}$ & $\mathrm{a}$ & $\mathrm{a}$ & $\mathrm{a}$ & $\mathrm{a}$ & $\mathrm{a}$ & $\mathrm{a}$ & $\mathrm{a}$ & 7.81 & $\mathrm{a}$ & $\mathrm{a}$ & $\mathrm{a}$ \\
\hline $1 \mathrm{KCl}-3 \mathrm{AS}$ & 14 & 491 & 193 & 100 & a & 0.4 & $\mathrm{a}$ & 0.99 & $\mathrm{a}$ & a & 40 & a & 6.16 & a & a \\
\hline $1 \mathrm{KCl}-4 \mathrm{AS}^{\mathrm{b}}$ & 14 & $\mathrm{a}$ & $\mathrm{a}$ & 0.8 & $\mathrm{a}$ & $\mathrm{a}$ & $\mathrm{a}$ & $\mathrm{a}$ & $\mathrm{a}$ & $\mathrm{a}$ & $\mathrm{a}$ & 22.5 & 1.42 & $\mathrm{a}$ & $\mathrm{a}$ \\
\hline $1 \mathrm{KCl}-5 \mathrm{AS}$ & 28 & 244 & 126 & 126 & 0.14 & 0.2 & 2.4 & 0.9 & 3.5 & 2 & 35 & 3.9 & 3.59 & 1.5 & a \\
\hline $1 \mathrm{KCl}-6 \mathrm{AS} \mathrm{S}^{\mathrm{b}}$ & 28 & $\mathrm{a}$ & $\mathrm{a}$ & $\mathrm{a}$ & 0.08 & $\mathrm{a}$ & $\mathrm{a}$ & $\mathrm{a}$ & $\mathrm{a}$ & 1.9 & $\mathrm{a}$ & $\mathrm{a}$ & 1.39 & $\mathrm{a}$ & $\mathrm{a}$ \\
\hline $1 \mathrm{KCl}-7 \mathrm{AS}$ & 60 & 286 & 123 & 45.6 & $\mathrm{a}$ & 0.2 & $\mathrm{a}$ & a & $\mathrm{a}$ & a & 29 & a & 10.7 & a & a \\
\hline $1 \mathrm{KCl}-8 \mathrm{AS}^{\mathrm{b}}$ & 60 & $\mathrm{a}$ & 2.36 & $\mathrm{a}$ & $\mathrm{a}$ & $\mathrm{a}$ & a & $\mathrm{a}$ & 3.6 & a & $\mathrm{a}$ & $\mathrm{a}$ & 4.79 & $\mathrm{a}$ & $\mathrm{a}$ \\
\hline $1 \mathrm{KCl}-9 \mathrm{AS}$ & 95 & 40.4 & $\mathrm{a}$ & $\mathrm{a}$ & $\mathrm{a}$ & $\mathrm{a}$ & $\mathrm{a}$ & $\mathrm{a}$ & $\mathrm{a}$ & $\mathrm{a}$ & $\mathrm{a}$ & $\mathrm{a}$ & 4.73 & $\mathrm{a}$ & $\mathrm{a}$ \\
\hline $1 \mathrm{KCl}-10 \mathrm{AS}$ & 95 & $\mathrm{a}$ & $\mathrm{a}$ & $\mathrm{a}$ & $\mathrm{a}$ & $\mathrm{a}$ & $\mathrm{a}$ & $\mathrm{a}$ & $\mathrm{a}$ & $\mathrm{a}$ & $\mathrm{a}$ & $\mathrm{a}$ & 4.08 & $\mathrm{a}$ & 5.22 \\
\hline $1 \mathrm{KCl}-11 \mathrm{AS}$ & 182 & 945 & 89.8 & 0.25 & $\mathrm{a}$ & 0.19 & $\mathrm{a}$ & 0.51 & 1.85 & 0.94 & 33.6 & 3.59 & 5.75 & 0.25 & $\mathrm{a}$ \\
\hline $1 \mathrm{KCl}-12 \mathrm{AS}^{\mathrm{b}}$ & 182 & $\mathrm{a}$ & $\mathrm{a}$ & $\mathrm{a}$ & $\mathrm{a}$ & $\mathrm{a}$ & $\mathrm{a}$ & $\mathrm{a}$ & 0.03 & $\mathrm{a}$ & $\mathrm{a}$ & $\mathrm{a}$ & 0.48 & 0.06 & $\mathrm{a}$ \\
\hline $1 \mathrm{KCl}-13 \mathrm{AS}$ & 365 & 859 & 48.1 & 125 & 0.48 & 0.17 & 0 & 0.64 & 2.18 & 0.41 & 93 & 4.14 & 4.8 & $\mathrm{a}$ & $\mathrm{a}$ \\
\hline $1 \mathrm{KCl}-14 \mathrm{AS}^{\mathrm{b}}$ & 365 & 6.8 & 4.7 & 0.86 & 0.42 & $\mathrm{a}$ & a & a & $\mathrm{a}$ & $\mathrm{a}$ & 0.59 & a & $\mathrm{a}$ & a & a \\
\hline
\end{tabular}

NMFPs $=$ Noble Metal Fission Products

${ }^{\mathrm{a}}$ Element below detection limits of measuring instrument.

${ }^{\mathrm{b}}$ Control Vessel 
Table C-7. Leachate Data $(\mu \mathrm{g} / \mathrm{L})$ for $90^{\circ} \mathrm{C}$ Immersion in CJ13 Solution

\begin{tabular}{|c|c|c|c|c|c|c|c|c|c|c|c|c|c|c|}
\hline \multirow{2}{*}{$\begin{array}{c}\text { Test } \\
\text { ID }\end{array}$} & \multirow{2}{*}{$\begin{array}{c}\text { Test } \\
\text { Duration }\end{array}$} & \multicolumn{4}{|c|}{ Major Elements } & \multicolumn{5}{|c|}{ NMFPs } & \multicolumn{4}{|c|}{ Minor Elements } \\
\hline & & $\mathrm{Fe}$ & $\mathrm{Cr}$ & $\mathrm{Ni}$ & $\mathrm{Zr}$ & $\mathrm{Nb}$ & $\mathrm{Pd}$ & $\mathrm{Rh}$ & $\mathrm{Ru}$ & Mo & $\mathrm{Mn}$ & $\mathrm{Co}$ & $\mathrm{Cu}$ & $\bar{V}$ \\
\hline MJ-1 & 7 & 146 & 2.2 & 7.4 & 20.1 & 1.0 & $\bar{a}$ & 0.12 & $\bar{a}$ & 5.5 & 0.9 & $\bar{a}$ & 4.62 & 0.7 \\
\hline $\mathrm{MJ}-2 *$ & 7 & 17.2 & $\mathrm{a}$ & $\mathrm{a}$ & 9.9 & 0.07 & $\mathrm{a}$ & 0.03 & $\mathrm{a}$ & $\mathrm{a}$ & $\mathrm{a}$ & $\mathrm{a}$ & 2.47 & $\mathrm{a}$ \\
\hline $\mathrm{MJ}-3$ & 14 & 20 & 5.85 & $\mathrm{a}$ & 40.6 & 1.4 & $\mathrm{a}$ & 0.13 & $\mathrm{a}$ & 13 & 0.4 & 8.25 & 1.2 & 0.7 \\
\hline $\mathrm{MJ}-4^{*}$ & 14 & $\mathrm{a}$ & $\mathrm{a}$ & $\mathrm{a}$ & 9.3 & 0.02 & $\mathrm{a}$ & 0.09 & $\mathrm{a}$ & 12 & $\mathrm{a}$ & 18.1 & $\mathrm{a}$ & 0.4 \\
\hline MJ-5 & 28 & 46 & 12.8 & $\bar{a}$ & 50.5 & 1.8 & $\bar{a}$ & 0.3 & $\bar{a}$ & 12 & 1.1 & 0.36 & 5.95 & 0.62 \\
\hline MJ-6* & 28 & 5.13 & $\mathrm{a}$ & $\mathrm{a}$ & 8.6 & 0.03 & $\mathrm{a}$ & 0.1 & $\mathrm{a}$ & 9.3 & 12 & 1.01 & 2.52 & 0.32 \\
\hline MJ-7 & 60 & 41.4 & 14.5 & $\mathrm{a}$ & 65.6 & 2.5 & 2.9 & $\mathrm{a}$ & $\mathrm{a}$ & 10 & $\mathrm{a}$ & $\mathrm{a}$ & 44.9 & 1.2 \\
\hline $\mathrm{MJ}-8^{*}$ & 60 & $\mathrm{a}$ & 2.28 & $\mathrm{a}$ & 8.3 & 0.04 & $\mathrm{a}$ & $\mathrm{a}$ & $\mathrm{a}$ & $\mathrm{a}$ & $\mathrm{a}$ & $\mathrm{a}$ & 28.5 & $\mathrm{a}$ \\
\hline MJ-9 & 95 & 36.2 & 22.4 & $\mathrm{a}$ & 76.3 & 2.3 & 2.7 & $\mathrm{a}$ & $\mathrm{a}$ & 12 & $\mathrm{a}$ & $\mathrm{a}$ & 23.3 & $\mathrm{a}$ \\
\hline MJ-10* & 95 & $\mathrm{a}$ & 2.8 & $\mathrm{a}$ & 6.9 & 0.03 & $\mathrm{a}$ & $\mathrm{a}$ & $\mathrm{a}$ & 7.3 & $\mathrm{a}$ & $\mathrm{a}$ & 18.9 & $\mathrm{a}$ \\
\hline MJ-11 & 182 & 24.6 & 35.4 & $\mathrm{a}$ & 56 & 1.87 & 2.54 & 0.08 & 0.62 & 12.4 & $\mathrm{a}$ & $\mathrm{a}$ & 3.07 & 0.27 \\
\hline $\mathrm{MJ}-12 *$ & 182 & $\mathrm{a}$ & $\mathrm{a}$ & 3.12 & 4.4 & 0.06 & $\mathrm{a}$ & 0.02 & 0.03 & 4.1 & 7.5 & 0.08 & 0.31 & 0.22 \\
\hline MJ-13 & 365 & 33.3 & 50.1 & 0.41 & 39.7 & 1.29 & 2.68 & 0.08 & 0.27 & 15.4 & 0.81 & 0.06 & 1.63 & 1.47 \\
\hline MJ-14* & 365 & $\bar{a}$ & $\mathrm{a}$ & 0.41 & 2.29 & 0.07 & 0.48 & 0.22 & 0.12 & 9.14 & 0.33 & 0.06 & 2.22 & 1.66 \\
\hline
\end{tabular}

NMFPs $=$ Noble Metal Fission Products

${ }^{\mathrm{a}}$ Element below detection limits of measuring instrument.

${ }^{\mathrm{b}}$ Control Vessel 
Table C-8. Acid Strip Data $(\mu \mathrm{g} / \mathrm{L})$ for $90^{\circ} \mathrm{C}$ Immersion in Modified J-13 Solution

\begin{tabular}{|c|c|c|c|c|c|c|c|c|c|c|c|c|c|c|}
\hline \multirow{2}{*}{$\begin{array}{l}\text { Test } \\
\text { ID }\end{array}$} & \multirow{2}{*}{$\begin{array}{c}\text { Test } \\
\text { Duration }\end{array}$} & \multicolumn{4}{|c|}{ Major Elements } & \multicolumn{5}{|c|}{ NMFPs } & \multicolumn{4}{|c|}{ Minor Elements } \\
\hline & & $\mathrm{Fe}$ & $\mathrm{Cr}$ & $\mathrm{Ni}$ & $\mathrm{Zr}$ & $\mathrm{Nb}$ & $\mathrm{Pd}$ & $\mathrm{Rh}$ & $\mathrm{Ru}$ & Mo & $\mathrm{Mn}$ & $\mathrm{Co}$ & $\mathrm{Cu}$ & $\mathrm{V}$ \\
\hline MJ-1AS & 7 & 12 & $\mathrm{a}$ & 1.0 & $\mathrm{a}$ & 0.01 & $\mathrm{a}$ & 0.19 & $\mathrm{a}$ & $\mathrm{a}$ & 0.9 & $\mathrm{a}$ & $\mathrm{a}$ & $\mathrm{a}$ \\
\hline $\mathrm{MJ}-2 \mathrm{AS} \mathrm{S}^{\mathrm{b}}$ & 7 & $\mathrm{a}$ & $\mathrm{a}$ & $\mathrm{a}$ & $\mathrm{a}$ & $\mathrm{a}$ & $\mathrm{a}$ & 0.01 & $\mathrm{a}$ & $\mathrm{a}$ & $\mathrm{a}$ & 6.35 & $\mathrm{a}$ & $\mathrm{a}$ \\
\hline MJ-3AS & 14 & 177 & 2.72 & 9.6 & $\mathrm{a}$ & 0.7 & $\mathrm{a}$ & 0.05 & $\mathrm{a}$ & $\mathrm{a}$ & 2.6 & 31.3 & 3.65 & $\mathrm{a}$ \\
\hline $\mathrm{MJ}-4 \mathrm{AS} \mathrm{S}^{\mathrm{b}}$ & 14 & 27.4 & $\mathrm{a}$ & 2 & $\mathrm{a}$ & 0.02 & $\mathrm{a}$ & $\mathrm{a}$ & $\mathrm{a}$ & $\mathrm{a}$ & 0.7 & $\mathrm{a}$ & 6.26 & $\mathrm{a}$ \\
\hline MJ-5AS & 28 & 237 & $\mathrm{a}$ & 24 & 1.8 & 0.88 & $\mathrm{a}$ & 0.3 & $\mathrm{a}$ & 2.2 & 6.5 & 1.1 & 3.53 & $\mathrm{a}$ \\
\hline MJ-6AS & 28 & 29.9 & $\mathrm{a}$ & $\mathrm{a}$ & 1.4 & $\mathrm{a}$ & $\mathrm{a}$ & $\mathrm{a}$ & $\mathrm{a}$ & $\mathrm{a}$ & 1.6 & 0.04 & 3.15 & $\mathrm{a}$ \\
\hline MJ-7AS & 60 & 255 & 2.84 & $\mathrm{a}$ & 1.8 & 0.8 & $\mathrm{a}$ & $\mathrm{a}$ & $\mathrm{a}$ & $\mathrm{a}$ & $\mathrm{a}$ & $\mathrm{a}$ & 6.97 & $\mathrm{a}$ \\
\hline MJ-8AS & 60 & 29.5 & $\mathrm{a}$ & $\mathrm{a}$ & 0.9 & $\mathrm{a}$ & $\mathrm{a}$ & $\mathrm{a}$ & $\mathrm{a}$ & $\mathrm{a}$ & $\mathrm{a}$ & $\mathrm{a}$ & 6.42 & $\mathrm{a}$ \\
\hline MJ-9AS & 95 & 345 & 4.98 & $\mathrm{a}$ & 3.55 & 0.8 & $\mathrm{a}$ & $\mathrm{a}$ & $\mathrm{a}$ & $\mathrm{a}$ & $\mathrm{a}$ & $\mathrm{a}$ & 6.3 & $\mathrm{a}$ \\
\hline MJ-10AS ${ }^{b}$ & 95 & 29.9 & $\mathrm{a}$ & $\mathrm{a}$ & 1.1 & $\mathrm{a}$ & $\mathrm{a}$ & $\mathrm{a}$ & $\mathrm{a}$ & $\mathrm{a}$ & $\mathrm{a}$ & $\mathrm{a}$ & 8.74 & $\mathrm{a}$ \\
\hline MJ-11AS & 182 & 517 & $\mathrm{a}$ & 15.4 & 12.6 & 1.23 & $\mathrm{a}$ & 0.87 & 0.13 & 0.25 & $\mathrm{a}$ & 1.07 & 5.35 & 0.25 \\
\hline $\mathrm{MJ}-12 \mathrm{AS} \mathrm{s}^{\mathrm{b}}$ & 182 & 32.3 & $\mathrm{a}$ & $\mathrm{a}$ & 5.03 & 0.09 & $\mathrm{a}$ & $\mathrm{a}$ & 0.03 & $\mathrm{a}$ & $\mathrm{a}$ & 0.06 & 6.01 & 0.06 \\
\hline MJ-13AS & 365 & 632 & 7.9 & 37.8 & 29.9 & 1.68 & 0.17 & 1.09 & 0.25 & $\mathrm{a}$ & 8.24 & 1.34 & 6.94 & $\mathrm{a}$ \\
\hline MJ-14AS ${ }^{b}$ & 365 & 42.3 & 4.9 & 1.94 & 6 & 0.14 & 0.03 & $\mathrm{a}$ & $\mathrm{a}$ & $\mathrm{a}$ & 1.34 & 0.07 & 6.19 & $\mathrm{a}$ \\
\hline
\end{tabular}

NMFPs = Noble Metal Fission Products

${ }^{\mathrm{a}}$ Element below detection limits of measuring instrument.

${ }^{\mathrm{b}}$ Control Vessel 
Table C-9. Total Concentrations and Mass Releases in Leachate and Acid Wash in $1 \mathrm{KCl}$ Solution at $90^{\circ} \mathrm{C}$

\begin{tabular}{|c|c|c|c|c|c|c|c|c|}
\hline \multirow{2}{*}{$\begin{array}{c}\text { Test } \\
\text { ID }\end{array}$} & \multirow{2}{*}{$\begin{array}{c}\text { Test } \\
\text { Duration } \\
\text { (days) }\end{array}$} & \multicolumn{3}{|c|}{ Leachate } & \multicolumn{3}{|c|}{ Acid Wash } & \multirow{2}{*}{$\begin{array}{l}\text { Total } \\
\text { Mass } \\
(\mu \mathrm{g})\end{array}$} \\
\hline & & $\begin{array}{c}\text { Concentration } \\
(\mu \mathrm{g} / \mathrm{L})\end{array}$ & $\begin{array}{c}\text { Volume } \\
\text { (mL) }\end{array}$ & $\begin{array}{c}\text { Mass } \\
(\mu g)\end{array}$ & $\begin{array}{c}\text { Concentration } \\
(\mu \mathrm{g} / \mathrm{L})\end{array}$ & $\begin{array}{c}\text { Volume } \\
(\mathrm{mL})\end{array}$ & $\begin{array}{l}\text { Mass } \\
(\mu \mathrm{g})\end{array}$ & \\
\hline $1 \mathrm{KCl}-1$ & 7 & 174 & 19.8 & 3.4 & 193 & 24.6 & 4.8 & 8.2 \\
\hline $1 \mathrm{KCl}-3$ & 14 & 335 & 19.8 & 6.6 & 832 & 24.6 & 20.5 & 27.1 \\
\hline $1 \mathrm{KCl}-5$ & 28 & 473 & 22.0 & 10.4 & 549 & 24.6 & 13.5 & 23.9 \\
\hline $1 \mathrm{KCl}-7$ & 60 & 541 & 20.0 & 10.8 & 494 & 25.4 & 12.6 & 23.4 \\
\hline $1 \mathrm{KCl}-9$ & 95 & 94 & 21.4 & 2.0 & 45 & 23.7 & 1.1 & 3.1 \\
\hline $1 \mathrm{KCl}-11$ & 182 & 30 & 23.6 & 0.7 & 1082 & 24.0 & 25.9 & 26.6 \\
\hline $1 \mathrm{KCl}-13$ & 365 & 183 & 25.5 & 4.7 & 1138 & 24.9 & 28.3 & 33.0 \\
\hline
\end{tabular}

Table C-10. Total Concentrations and Mass Releases in Leachate and Acid Wash in CJ13 at $90^{\circ} \mathrm{C}$

\begin{tabular}{|c|c|c|c|c|c|c|c|c|}
\hline Test & \multirow{2}{*}{$\begin{array}{c}\text { Test } \\
\text { ID }\end{array}$} & \multicolumn{3}{|c|}{ Leachate } & \multicolumn{3}{c|}{ Acid Wash } & Total \\
& Duration & $\begin{array}{c}\text { Concentration } \\
(\mu \mathrm{g} / \mathrm{L})\end{array}$ & $\begin{array}{c}\text { Volume } \\
(\mathrm{mL})\end{array}$ & $\begin{array}{c}\text { Mass } \\
(\mu \mathrm{g})\end{array}$ & $\begin{array}{c}\text { Concentration } \\
(\mu \mathrm{g} / \mathrm{L})\end{array}$ & $\begin{array}{c}\text { Volume } \\
(\mathrm{mL})\end{array}$ & $\begin{array}{c}\text { Mass } \\
(\mu \mathrm{g})\end{array}$ & $\begin{array}{c}\text { Mass } \\
(\mu \mathrm{g})\end{array}$ \\
\hline MJ-1 & 7 & 189 & 19.3 & 3.6 & 14 & 25 & 0.4 & 4 \\
\hline MJ-3 & 14 & 92 & 19.4 & 1.8 & 230 & 26 & 6 & 7.8 \\
\hline MJ-5 & 28 & 131 & 23.1 & 3 & 277 & 25.2 & 7 & 10 \\
\hline MJ-7 & 60 & 183 & 20.7 & 3.8 & 267 & 25 & 6.7 & 10.5 \\
\hline MJ-9 & 95 & 175 & 21.8 & 3.8 & 361 & 24.4 & 8.8 & 12.6 \\
\hline MJ-11 & 182 & 137 & 24.7 & 3.4 & 554 & 24.1 & 13.4 & 16.7 \\
\hline MJ-13 & 365 & 147 & 26.2 & 3.9 & 727 & 24.7 & 18 & 21.8 \\
\hline
\end{tabular}


Table C-11. Normalized Loss $\left(\mathrm{g} / \mathrm{m}^{2}\right)$ for Specimens Immersed in $1 \mathrm{KCl}$ Solution at $90^{\circ} \mathrm{C}$

\begin{tabular}{|c|c|c|c|c|c|c|c|c|c|c|c|c|c|c|c|}
\hline \multirow{2}{*}{$\begin{array}{l}\text { Test } \\
\text { ID }\end{array}$} & \multirow{2}{*}{$\begin{array}{c}\text { Duration } \\
\text { Days }\end{array}$} & \multicolumn{4}{|c|}{ Major Elements } & \multicolumn{5}{|c|}{ Noble Metal Fission Products } & \multicolumn{5}{|c|}{ Minor Elements } \\
\hline & & $\mathrm{Fe}$ & $\mathrm{Cr}$ & $\mathrm{Ni}$ & $\mathrm{Zr}$ & $\mathrm{Nb}$ & $\mathrm{Pd}$ & $\mathrm{Rh}$ & $\mathrm{Ru}$ & Mo & $\mathrm{Mn}$ & Co & $\mathrm{Cu}$ & $\mathrm{V}$ & $\mathrm{Si}$ \\
\hline $1 \mathrm{KCl}-1$ & 7 & 0.028 & 0.041 & 0.136 & $\mathrm{a}$ & $\mathrm{a}$ & $\mathrm{a}$ & 0.001 & $\mathrm{a}$ & $\mathrm{a}$ & 0.288 & $\mathrm{a}$ & 0.084 & 0.01 & $\mathrm{a}$ \\
\hline $1 \mathrm{KCl}-3$ & 14 & 0.097 & 0.224 & 0.306 & $\mathrm{a}$ & 0.006 & $\mathrm{a}$ & 0.012 & $\mathrm{a}$ & 0.076 & 0.474 & $\mathrm{a}$ & 0.063 & 0.02 & 0.121 \\
\hline $1 \mathrm{KCl}-5$ & 28 & 0.048 & 0.114 & 0.499 & $5.6 \mathrm{E}-5$ & 0.003 & 0.027 & 0.011 & 0.043 & 0.052 & 1.198 & 0.913 & 0.044 & 0.184 & 0.223 \\
\hline $1 \mathrm{KCl}-7$ & 60 & 0.059 & 0.116 & 0.447 & 0.001 & 0.017 & $\mathrm{a}$ & $\mathrm{a}$ & $\mathrm{a}$ & 0.055 & 0.902 & 0.615 & $\mathrm{a}$ & 0.01 & $\mathrm{a}$ \\
\hline $1 \mathrm{KCl}-9$ & 95 & 0.008 & $\mathrm{a}$ & 0.019 & $\mathrm{a}$ & $\mathrm{a}$ & $\mathrm{a}$ & $\mathrm{a}$ & $\mathrm{a}$ & $\mathrm{a}$ & 0.057 & 0.051 & 0.215 & $\mathrm{a}$ & 0.064 \\
\hline $1 \mathrm{KCl}-11$ & 182 & 0.182 & 0.079 & 0.006 & $\mathrm{a}$ & 0.003 & $\mathrm{a}$ & 0.007 & 0.022 & 0.041 & 0.324 & 0.452 & 0.108 & 0.026 & $\mathrm{a}$ \\
\hline $1 \mathrm{KCl}-13$ & 365 & 0.171 & 0.043 & 0.18 & $\mathrm{a}$ & 0.002 & $\mathrm{a}$ & 0.008 & 0.027 & 0.341 & 0.937 & 0.277 & 0.047 & $\mathrm{a}$ & $\mathrm{a}$ \\
\hline
\end{tabular}

${ }^{\mathrm{a}}$ Element below detection limits of measuring instrument.

Table C-12. Normalized Loss $\left(\mathrm{g} / \mathrm{m}^{2}\right)$ for Specimens Immersed in CJ13 Solution at $90^{\circ} \mathrm{C}$

\begin{tabular}{|c|c|c|c|c|c|c|c|c|c|c|c|c|c|c|}
\hline \multirow{2}{*}{$\begin{array}{l}\text { Test } \\
\text { ID }\end{array}$} & \multirow{2}{*}{$\begin{array}{c}\text { Duration } \\
\text { Days }\end{array}$} & \multicolumn{4}{|c|}{ Major Elements } & \multicolumn{5}{|c|}{ Noble Metal Fission Products } & \multicolumn{4}{|c|}{ Minor Elements } \\
\hline & & $\mathrm{Fe}$ & $\mathrm{Cr}$ & $\mathrm{Ni}$ & $\mathrm{Zr}$ & $\mathrm{Nb}$ & $\mathrm{Pd}$ & $\mathrm{Rh}$ & $\mathrm{Ru}$ & Mo & $\mathrm{Mn}$ & $\mathrm{Co}$ & $\mathrm{Cu}$ & $\mathrm{V}$ \\
\hline MJ-1 & 7 & 0.023 & 0.001 & 0.009 & 0.006 & 0.01 & $\bar{a}$ & 0.003 & $\bar{a}$ & 0.029 & 0.016 & $\bar{a}$ & 0.047 & 0.069 \\
\hline MJ-3 & 14 & 0.035 & 0.006 & 0.011 & 0.02 & 0.025 & $\bar{a}$ & 0.001 & $\bar{a}$ & 0.005 & 0.024 & 1.491 & $\bar{a}$ & 0.03 \\
\hline $\mathrm{MJ}-5$ & 28 & 0.049 & 0.01 & 0.032 & 0.031 & 0.036 & $\bar{a}$ & 0.006 & $\bar{a}$ & 0.032 & $\bar{a}$ & 0.028 & 0.098 & 0.035 \\
\hline MJ-7 & 60 & 0.052 & 0.01 & $\bar{a}$ & 0.039 & 0.04 & 0.028 & $\mathrm{a}$ & $\bar{a}$ & 0.057 & $\mathrm{a}$ & $\mathrm{a}$ & 0.4 & 0.126 \\
\hline MJ-9 & 95 & 0.068 & 0.018 & $\mathrm{a}$ & 0.05 & 0.039 & 0.027 & $\mathrm{a}$ & $\mathrm{a}$ & 0.028 & $\mathrm{a}$ & $\mathrm{a}$ & 0.026 & $\mathrm{a}$ \\
\hline MJ-11 & 182 & 0.099 & 0.028 & 0.015 & 0.047 & 0.041 & 0.029 & 0.011 & 0.008 & 0.058 & $\mathrm{a}$ & 0.053 & 0.056 & 0.029 \\
\hline MJ-13 & 365 & 0.124 & 0.045 & 0.047 & 0.05 & 0.04 & 0.028 & 0.011 & 0.005 & 0.045 & 0.074 & 0.075 & 0.004 & $\mathrm{a}$ \\
\hline
\end{tabular}

${ }^{\mathrm{a}}$ Element below detection limits of measuring instrument. 


\section{Vial Use}

For the first 22 weeks of the immersion tests, the Teflon vials were reused following acid washes. Then it became apparent that the acid washes did not always remove all the elements that had migrated to the Teflon walls. Elements, such as iron, were detected in analysis of solutions of vials that contained no samples. The probability for this to occur was greatest for vials that were used for the $\mathrm{pH} 2$ solution, AJ13, and the solution containing 10,000 ppm chloride. Thus, following week 22 new Teflon vials were used for each immersion test. Information on which vials had been used for each test had been recorded in the laboratory notebooks. These data are summarized in the table in this appendix. For ease of relation of these data to the test results, which are reported according to days, the relation between test week and days of the test are summarized below.

\section{Week/Day Relationships}

\begin{tabular}{|l|c|c|c|c|c|c|c|c|c|c|c|}
\hline Week & 1 & 2 & 3 & 4 & 6 & 8 & 10 & 14 & 22 & 32 & 44 \\
\hline Days & 7 & 14 & 21 & 28 & 42 & 56 & 70 & 98 & 154 & 224 & 308 \\
\hline
\end{tabular}


Table D-1. Table of Vial Use

\begin{tabular}{|c|c|c|c|c|c|c|}
\hline Vial & Solution & Ingot ID & Week & Solution/sample & Week & Solution/sample \\
\hline 1 & $365-$ SJ13 & Blank & 1 & SJ13-P1 & 8 & AJ13-P21 \\
\hline 2 & & SS316 & 1 & SJ13-P2 & 8 & $\mathrm{AJ} 13-\mathrm{O} 22$ \\
\hline 3 & & SS316 & 1 & SJ13-P3 & 8 & $\mathrm{AJ} 13-\mathrm{O} 23$ \\
\hline 4 & & SS316 & 1 & SJ13-O4 & 8 & AJ13 blank \\
\hline 5 & & SS-15Zr & 1 & SJ13-O5 & 10 & AJ13-P21 \\
\hline 6 & & SS-15Zr & 1 & SJ13 blank & 10 & $\mathrm{AJ} 13-\mathrm{O} 22$ \\
\hline 7 & & SS-15Zr & 1 & $\overline{\mathrm{CJ} 13-\mathrm{P} 7}$ & 10 & $\mathrm{AJ} 13-\mathrm{O} 23$ \\
\hline 8 & & SS-5Zr-2Nb-1Ru-1Pd & 1 & CJ13-P8 & 10 & AJ13 blank \\
\hline 9 & & SS-5Zr-2Nb-1Ru-1Pd & 1 & CJ13-P9 & 14 & SJ13-P1 \\
\hline 10 & & SS-5Zr-2Nb-1Ru-1Pd & 1 & CJ13-O10 & 14 & SJ13-P2 \\
\hline 11 & & SS-20Zr-2Nb-1Ru-1Pd & 1 & CJ13-O11 & 14 & SJ13-P3 \\
\hline 12 & & SS-20Zr-2Nb-1Ru-1Pd & 1 & CJ13 blank & 14 & SJ13-O4 \\
\hline 13 & & SS-20Zr-2Nb-1Ru-1Pd & 1 & $10 \mathrm{KCl}-\mathrm{P} 13$ & 14 & SJ13-O5 \\
\hline 14 & & SS-5Zr-2Nb-0.5Ru-0.5Pd & 1 & $10 \mathrm{KCl}-\mathrm{P} 14$ & 14 & SJ13-blank \\
\hline 15 & & SS-5Zr-2Nb-0.5Ru- $0.5 \mathrm{Pd}$ & 1 & $10 \mathrm{KCl}-\mathrm{P} 15$ & 14 & CJ13-P1 \\
\hline 16 & & SS-5Zr-2Nb-0.5Ru-0.5Pd & 1 & $10 \mathrm{KCl}-\mathrm{O} 16$ & 14 & CJ13-P2 \\
\hline 17 & & SS-5Zr & 1 & $10 \mathrm{KCl}-\mathrm{O} 17$ & 14 & CJ13-P3 \\
\hline 18 & & SS-5Zr & 1 & $10 \mathrm{KCl}$ blank & 14 & $\mathrm{CJ} 13-\mathrm{O} 4$ \\
\hline 19 & & SS-5Zr & 1 & AJ13-P19 & 14 & CJ13-O5 \\
\hline 20 & & slag-SS-15Zr-2Nb-1Ru-1Pd & 1 & AJ13-P20 & 14 & CJ13 blank \\
\hline 21 & & slag-SS-15Zr-2Nb-1Ru-1Pd & 1 & AJ13-P21 & 14 & $10 \mathrm{KCl}-\mathrm{P} 13$ \\
\hline 22 & & slag-SS-15Zr-2Nb-1Ru-1Pd & 1 & AJ13-O22 & 14 & 10KCl-P14 \\
\hline 23 & & SS-15Zr 10C/min & 1 & AJ13-O23 & 14 & 10KCl-P15 \\
\hline 24 & & SS-15Zr 10C/min & 1 & AJ13 blank & 14 & $10 \mathrm{KCl}-\mathrm{O} 16$ \\
\hline 25 & & SS-15Zr 10C/min & 2 & SJ13-P1 & 14 & $10 \mathrm{KCl}-\mathrm{O} 17$ \\
\hline 26 & & SS-15Zr 5C/min & 2 & SJ13-P2 & 14 & $10 \mathrm{KCl}$ blank \\
\hline 27 & & SS-15Zr 5C/min & 2 & SJ13-P3 & $\overline{14}$ & AJ13-P19 \\
\hline 28 & & SS-15Zr 5C/min & 2 & SJ13-O4 & 14 & AJ13-P20 \\
\hline 29 & & SS-15Zr-1Nb-1Ru-1Pd-1Rh & 2 & SJ13-O5 & 14 & AJ13-P21 \\
\hline 30 & & SS-15Zr-1Nb-1Ru-1Pd-1Rh & 2 & SJ13 blank & 14 & $\mathrm{AJ} 13-\mathrm{O} 22$ \\
\hline 31 & & SS-15Zr-1Nb-1Ru-1Pd-1Rh & 2 & $\overline{\mathrm{CJ} 13-\mathrm{P} 7}$ & 14 & $\mathrm{AJ} 13-\mathrm{O} 23$ \\
\hline 32 & & SS-15Zr 1C/min & 2 & CJ13-P8 & 14 & AJ13 blank \\
\hline 33 & & SS-15Zr 1C/min & 2 & CJ13-P9 & 22 & $\overline{S J 13-P 1}$ \\
\hline 34 & & SS-15Zr 1C/min & 2 & CJ13-O10 & 22 & SJ13-P2 \\
\hline 35 & & slag & 2 & CJ13-O11 & 22 & SJ13-P3 \\
\hline 36 & & slag & 2 & CJ13 blank & 22 & SJ13-O4 \\
\hline
\end{tabular}


Table D-1b. Table of Vial Use (Cont'd)

\begin{tabular}{|c|c|c|c|c|c|c|}
\hline Vial & Solution & Ingot ID & Week & Solution/sample & Week & Solution/sample \\
\hline 37 & & slag & 2 & $10 \mathrm{KCl}-\mathrm{P} 13$ & & \\
\hline 38 & & SS-2Nb-1Ru-1Pd-1Ag & 2 & $10 \mathrm{KCl}-\mathrm{P} 14$ & & \\
\hline 39 & & SS-2Nb-1Ru-1Pd-1Ag & 2 & $10 \mathrm{KCl}-\mathrm{P} 15$ & & \\
\hline 40 & & SS-2Nb-1Ru-1Pd-1Ag & 2 & $10 \mathrm{KCl}-\mathrm{O} 16$ & 22 & SJ13-O5 \\
\hline 41 & \multirow[t]{32}{*}{$365-\mathrm{H}_{2} \mathrm{O}$} & Blank & 2 & $10 \mathrm{KCl}-\mathrm{O} 17$ & 22 & SJ13-blank \\
\hline 42 & & SS316 & 2 & $10 \mathrm{KCl}$ blank & 22 & CJ13-P7 \\
\hline 43 & & SS316 & 2 & AJ13-P19 & 22 & CJ13-P8 \\
\hline 44 & & SS316 & 2 & AJ13-P20 & 22 & CJ13-P9 \\
\hline 45 & & SS-15Zr & 2 & AJ13-P21 & 22 & CJ13-O10 \\
\hline 46 & & SS-15Zr & 2 & AJ13-O22 & 22 & CJ13-O11 \\
\hline 47 & & SS-15Zr & 2 & AJ13-O23 & 22 & CJ13-blank \\
\hline 48 & & SS-5Zr-2Nb-1Ru-1Pd & 2 & AJ13 blank & 22 & $10 \mathrm{KCl}-\mathrm{P} 13$ \\
\hline 49 & & SS-5Zr-2Nb-1Ru-1Pd & 3 & SJ13-P1 & 22 & $10 \mathrm{KCl}-\mathrm{P} 14$ \\
\hline 50 & & SS-5Zr-2Nb-1Ru-1Pd & 3 & SJ13-P2 & 22 & $10 \mathrm{KCl}-\mathrm{P} 15$ \\
\hline 51 & & SS-20Zr-2Nb-1Ru-1Pd & 3 & SJ13-P3 & & \\
\hline 52 & & SS-20Zr-2Nb-1Ru-1Pd & 3 & SJ13-O4 & 22 & $10 \mathrm{KCl}-\mathrm{O} 16$ \\
\hline 53 & & SS-20Zr-2Nb-1Ru-1Pd & 3 & SJ13-O5 & 22 & $10 \mathrm{KCl}-\mathrm{O} 17$ \\
\hline 54 & & SS-5Zr-2Nb-0.5Ru-0.5Pd & 3 & SJ13 blank & 22 & $10 \mathrm{KCl}$ blank \\
\hline 55 & & SS-5Zr-2Nb-0.5Ru-0.5Pd & 3 & CJ13-P7 & 22 & AJ13-P19 \\
\hline 56 & & SS-5Zr-2Nb-0.5Ru-0.5Pd & 3 & CJ13-P8 & 22 & AJ13-P20 \\
\hline 57 & & SS-5Zr & 3 & CJ13-P9 & 22 & AJ13-P21 \\
\hline 58 & & SS-5Zr & 3 & $\mathrm{CJ} 13-\mathrm{O} 10$ & 22 & $\mathrm{AJ} 13-\mathrm{O} 22$ \\
\hline 59 & & SS- $5 \mathrm{Zr}$ & 3 & CJ13-O11 & 22 & AJ13-O23 \\
\hline 60 & & slag-SS-15Zr-2Nb-1Ru-1Pd & 3 & CJ13 blank & 22 & AJ13 blank2 \\
\hline 61 & & slag-SS-15Zr-2Nb-1Ru-1Pd & 3 & $10 \mathrm{KCl}-\mathrm{P} 13$ & & \\
\hline 62 & & slag-SS-15Zr-2Nb-1Ru-1Pd & 3 & $10 \mathrm{KCl}-\mathrm{P} 14$ & & \\
\hline 63 & & SS-15Zr 10C/min & 3 & $10 \mathrm{KCl}-\mathrm{P} 15$ & & \\
\hline 64 & & SS-15Zr 10C/min & 3 & $10 \mathrm{KCl}-\mathrm{O} 16$ & & \\
\hline 65 & & SS-15Zr 10C/min & 3 & $10 \mathrm{KCl}-\mathrm{O} 17$ & & \\
\hline 66 & & SS-15Zr 5C/min & 3 & $10 \mathrm{KCl}$ blank & & \\
\hline 67 & & SS-15Zr 5C/min & 3 & AJ13-P19 & & \\
\hline 68 & & SS-15Zr 5C/min & 3 & AJ13-P20 & & \\
\hline 69 & & SS-15Zr-1Nb-1Ru-1Pd-1Rh & 3 & AJ13-P21 & & \\
\hline 70 & & SS-15Zr-1Nb-1Ru-1Pd-1Rh & 3 & $\mathrm{AJ} 13-\mathrm{O} 22$ & & \\
\hline 71 & & SS-15Zr-1Nb-1Ru-1Pd-1Rh & 3 & AJ13-O23 & & \\
\hline 72 & & SS-15Zr 1C/min & 3 & AJ13 blank & & \\
\hline
\end{tabular}


Table D-1c. Table of Vial Use (Cont'd)

\begin{tabular}{|c|c|c|c|c|c|c|}
\hline Vial & Solution & Ingot ID & Week & Solution/sample & Week & Solution/sample \\
\hline 73 & & SS-15Zr 1C/min & 4 & SJ13-P1 & & \\
\hline 74 & & SS-15Zr 1C/min & 4 & SJ13-P2 & & \\
\hline 75 & & slag & 4 & SJ13-P3 & & \\
\hline 76 & & slag & 4 & SJ13-O4 & & \\
\hline 77 & & slag & 4 & SJ13-O5 & & \\
\hline 78 & & SS-2Nb-1Ru-1Pd-1Ag & 4 & SJ13 blank & & \\
\hline 79 & & SS-2Nb-1Ru-1Pd-1Ag & 4 & CJ13-P7 & & \\
\hline 80 & & SS-2Nb-1Ru-1Pd-1Ag & 4 & CJ13-P8 & & \\
\hline 81 & $90-$ SJ13 & Blank & 4 & CJ13-P9 & & \\
\hline 82 & & SS316 & 4 & CJ13-O10 & & \\
\hline 83 & & SS316 & 4 & CJ13-O11 & & \\
\hline 84 & & SS316 & 4 & CJ13 blank & & \\
\hline 85 & & SS- $15 Z \mathrm{Zr}$ & 4 & $10 \mathrm{KCl}-\mathrm{P} 13$ & & \\
\hline 86 & & SS-15Zr & 4 & $10 \mathrm{KCl}-\mathrm{P} 14$ & & \\
\hline 87 & & SS-15Zr & 4 & $10 \mathrm{KCl}-\mathrm{P} 15$ & & \\
\hline 88 & & SS-5Zr-2Nb-1Ru-1Pd & 4 & $10 \mathrm{KCl}-\mathrm{O} 16$ & & \\
\hline 89 & & SS-5Zr-2Nb-1Ru-1Pd & 4 & $10 \mathrm{KCl}-\mathrm{O} 17$ & & \\
\hline 90 & & SS-5Zr-2Nb-1Ru-1Pd & 4 & $10 \mathrm{KCl}$ blank & & \\
\hline 91 & & SS-20Zr-2Nb-1Ru-1Pd & 4 & AJ13-P19 & & \\
\hline 92 & & SS-20Zr-2Nb-1Ru-1Pd & 4 & AJ13-P20 & & \\
\hline 93 & & SS-20Zr-2Nb-1Ru-1Pd & 4 & AJ13-P21 & & \\
\hline 94 & & SS-5Zr-2Nb-0.5Ru-0.5Pd & 4 & AJ13-O22 & & \\
\hline 95 & & SS-5Zr-2Nb-0.5Ru-0.5Pd & 4 & $\mathrm{AJ} 13-\mathrm{O} 23$ & & \\
\hline 96 & & SS-5Zr-2Nb-0.5Ru-0.5Pd & 4 & AJ13 blank & & \\
\hline 97 & & SS-5Zr & 6 & SJ13-P1 & & \\
\hline 98 & & SS-5Zr & 6 & SJ13-P2 & & \\
\hline 99 & & SS-5Zr & 6 & SJ13-P3 & & \\
\hline 100 & & slag-SS-15Zr-2Nb-1Ru-1Pd & 6 & SJ13-O4 & & \\
\hline 101 & & slag-SS-15Zr-2Nb-1Ru-1Pd & 6 & SJ13-O5 & & \\
\hline 102 & & slag-SS-15Zr-2Nb-1Ru-1Pd & 6 & SJ13 blank & & \\
\hline 103 & & SS-15Zr 10C/min & 6 & CJ13-P7 & & \\
\hline 104 & & SS-15Zr 10C/min & 6 & CJ13-P8 & & \\
\hline 105 & & SS-15Zr 10C/min & 6 & CJ13-P9 & & \\
\hline 106 & & SS-15Zr 5C/min & 6 & CJ13-O10 & & \\
\hline 107 & & SS-15Zr 5C/min & 6 & CJ13-O11 & & \\
\hline 108 & & $\mathrm{SS}-15 \mathrm{Zr} 5 \mathrm{C} / \mathrm{min}$ & 6 & CJ13 blank & & \\
\hline
\end{tabular}


Table D-1d. Table of Vial Use (Cont'd)

\begin{tabular}{|c|c|c|c|c|c|c|}
\hline Vial & Solution & Ingot ID & Week & Solution/sample & Week & Solution/sample \\
\hline 109 & & SS-15Zr-1Nb-1Ru-1Pd-1Rh & 6 & $10 \mathrm{KCl}-\mathrm{P} 13$ & & \\
\hline 110 & & SS-15Zr-1Nb-1Ru-1Pd-1Rh & 6 & $10 \mathrm{KCl}-\mathrm{P} 14$ & & \\
\hline 111 & & SS-15Zr-1Nb-1Ru-1Pd-1Rh & 6 & $10 \mathrm{KCl}-\mathrm{P} 15$ & & \\
\hline 112 & & SS-15Zr 1C/min & 6 & $10 \mathrm{KCl}-\mathrm{O} 16$ & & \\
\hline 113 & & SS-15Zr 1C/min & 6 & $10 \mathrm{KCl}-\mathrm{O} 17$ & & \\
\hline 114 & & SS-15Zr 1C/min & 6 & $10 \mathrm{KCl}$ blank & & \\
\hline 115 & & slag & 6 & AJ13-P19 & & \\
\hline 116 & & slag & 6 & AJ13-P20 & & \\
\hline 117 & & slag & 6 & AJ13-P21 & & \\
\hline 118 & & SS-2Nb-1Ru-1Pd-1Ag & 6 & AJ13-O22 & & \\
\hline 119 & & SS-2Nb-1Ru-1Pd-1Ag & 6 & AJ13-O23 & & \\
\hline 120 & & SS-2Nb-1Ru-1Pd-1Ag & 6 & AJ13 blank & & \\
\hline 121 & $90-\mathrm{H}_{2} \mathrm{O}$ & blank & 8 & SJ13-P1 & & \\
\hline 122 & & SS316 & 8 & SJ13-P2 & & \\
\hline 123 & & SS316 & 8 & SJ13-P3 & & \\
\hline 124 & & SS316 & 8 & SJ13-O4 & & \\
\hline 125 & & SS-15Zr & 8 & SJ13-O5 & & \\
\hline 126 & & SS-15Zr & 8 & SJ13 blank & & \\
\hline 127 & & SS-15Zr & 8 & CJ13-P7 & & \\
\hline 128 & & SS-5Zr-2Nb-1Ru-1Pd & 8 & CJ13-P8 & & \\
\hline 129 & & SS-5Zr-2Nb-1Ru-1Pd & 8 & CJ13-P9 & & \\
\hline 130 & & SS-5Zr-2Nb-1Ru-1Pd & 8 & CJ13-O10 & & \\
\hline 131 & & SS-20Zr-2Nb-1Ru-1Pd & 8 & CJ13-O11 & & \\
\hline 132 & & SS-20Zr-2Nb-1Ru-1Pd & 8 & CJ13 blank & & \\
\hline 133 & & SS-20Zr-2Nb-1Ru-1Pd & 8 & $10 \mathrm{KCl}-\mathrm{P} 13$ & & \\
\hline 134 & & SS-5Zr-2Nb-0.5Ru-0.5Pd & 8 & $10 \mathrm{KCl}-\mathrm{P} 14$ & & \\
\hline 135 & & SS-5Zr-2Nb-0.5Ru-0.5Pd & 8 & $10 \mathrm{KCl}-\mathrm{P} 15$ & & \\
\hline 136 & & SS-5Zr-2Nb-0.5Ru-0.5Pd & 8 & $10 \mathrm{KCl}-\mathrm{O} 16$ & & \\
\hline 137 & & SS-5Zr & 8 & $10 \mathrm{KCl}-\mathrm{O} 17$ & & \\
\hline 138 & & SS-5Zr & 8 & $10 \mathrm{KCl}$ blank & & \\
\hline 139 & & SS-5Zr & 8 & AJ13-P1 & & \\
\hline 140 & & slag-SS-15Zr-2Nb-1Ru-1Pd & 8 & AJ13-P2 & & \\
\hline 141 & & slag-SS-15Zr-2Nb-1Ru-1Pd & 10 & SJ13-P1 & & \\
\hline 142 & & slag-SS-15Zr-2Nb-1Ru-1Pd & 10 & SJ13-P2 & & \\
\hline 143 & & SS-15Zr 10C/min & 10 & SJ13-P3 & & \\
\hline 144 & & SS-15Zr 10C/min & 10 & SJ13-O4 & & \\
\hline 145 & & SS-15Zr 10C/min & 10 & SJ13-O5 & & \\
\hline 146 & & SS-15Zr 5C/min & 10 & SJ13 blank & & \\
\hline
\end{tabular}


Table D-1e. Table of Vial Use (Cont'd)

\begin{tabular}{|c|c|c|c|c|c|c|}
\hline Vial & Solution & Ingot ID & Week & Solution/sample & Week & Solution/sample \\
\hline 147 & & SS-15Zr 5C/min & 10 & CJ13-P7 & & \\
\hline 148 & & SS-15Zr 5C/min & 10 & CJ13-P8 & & \\
\hline 149 & & SS-15Zr-1Nb-1Ru-1Pd-1Rh & 10 & CJ13-P9 & & \\
\hline 150 & & SS-15Zr-1Nb-1Ru-1Pd-1Rh & 10 & CJ13-O10 & & \\
\hline 151 & & SS-15Zr-1Nb-1Ru-1Pd-1Rh & 10 & CJ13-O11 & & \\
\hline 152 & & SS-15Zr 1C/min & 10 & CJ13 blank & & \\
\hline 153 & & SS-15Zr 1C/min & 10 & $10 \mathrm{KCl}-\mathrm{P} 13$ & & \\
\hline 154 & & SS-15Zr 1C/min & 10 & $10 \mathrm{KCl}-\mathrm{P} 14$ & & \\
\hline 155 & & slag & 10 & $10 \mathrm{KCl}-\mathrm{P} 15$ & & \\
\hline 156 & & slag & 10 & $10 \mathrm{KCl}-\mathrm{O} 16$ & & \\
\hline 157 & & slag & 10 & $10 \mathrm{KCl}-\mathrm{O} 17$ & & \\
\hline 158 & & SS-2Nb-1Ru-1Pd-1Ag & 10 & $10 \mathrm{KCl}$ blank & & \\
\hline 159 & & SS-2Nb-1Ru-1Pd-1Ag & 10 & AJ13-P19 & & \\
\hline 160 & & SS-2Nb-1Ru-1Pd-1Ag & 10 & AJ13-P20 & & \\
\hline
\end{tabular}


E. Releases and Detection Limits

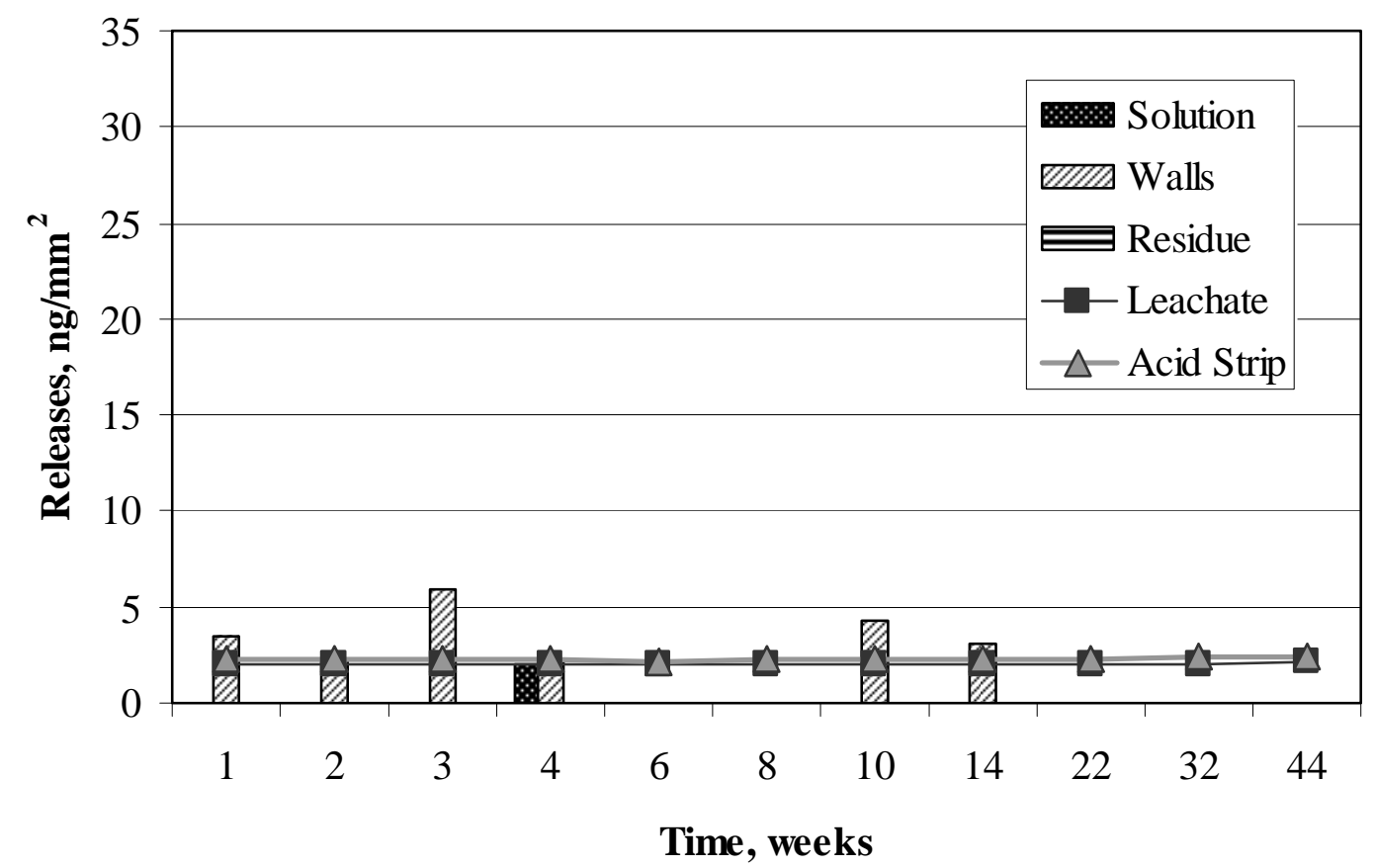

Figure E-1. Iron Releases in Solution, on Walls, and in Residue from Polished Sample 1 in SJ13 and Average Detection Limits for Leachate and Acid Strip.

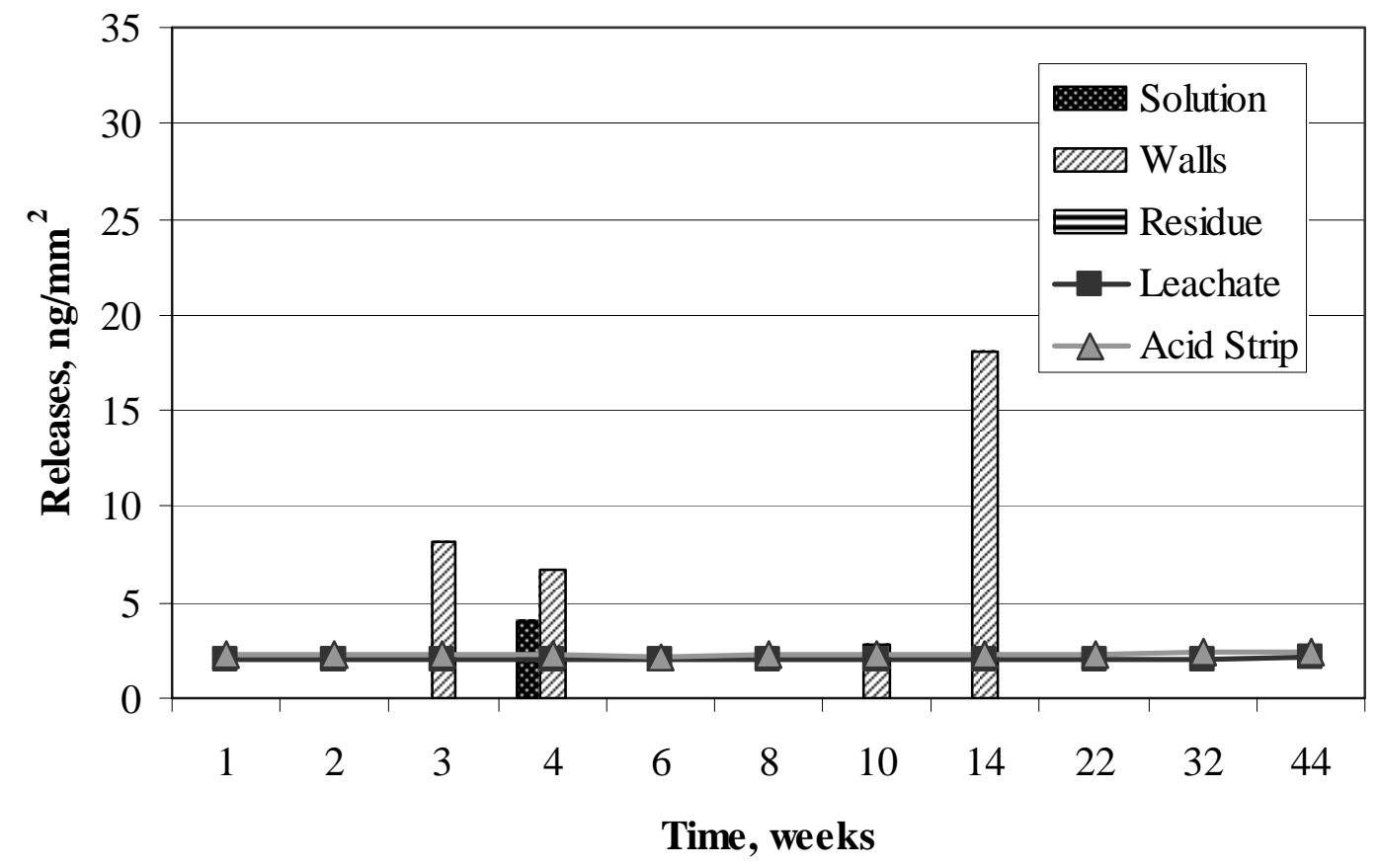

Figure E-2. Iron Releases in Solution, on Walls, and in Residue from Polished Sample 2 in SJ13 and Average Detection Limits for Leachate and Acid Strip. 


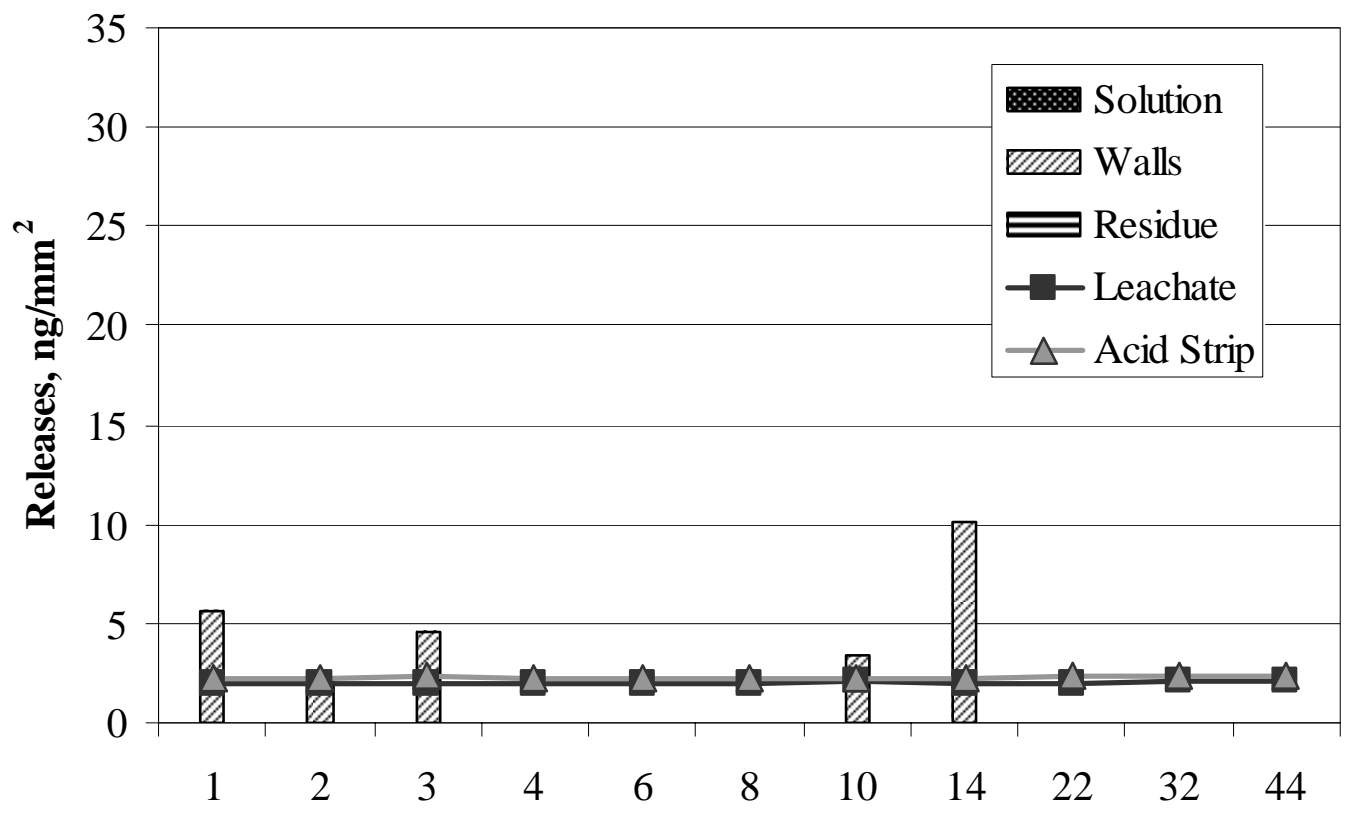

Time, weeks

Figure E-3. Iron Releases in Solution, on Walls, and in Residue from Polished Sample 3 in SJ13 and Average Detection Limits for Leachate and Acid Strip.

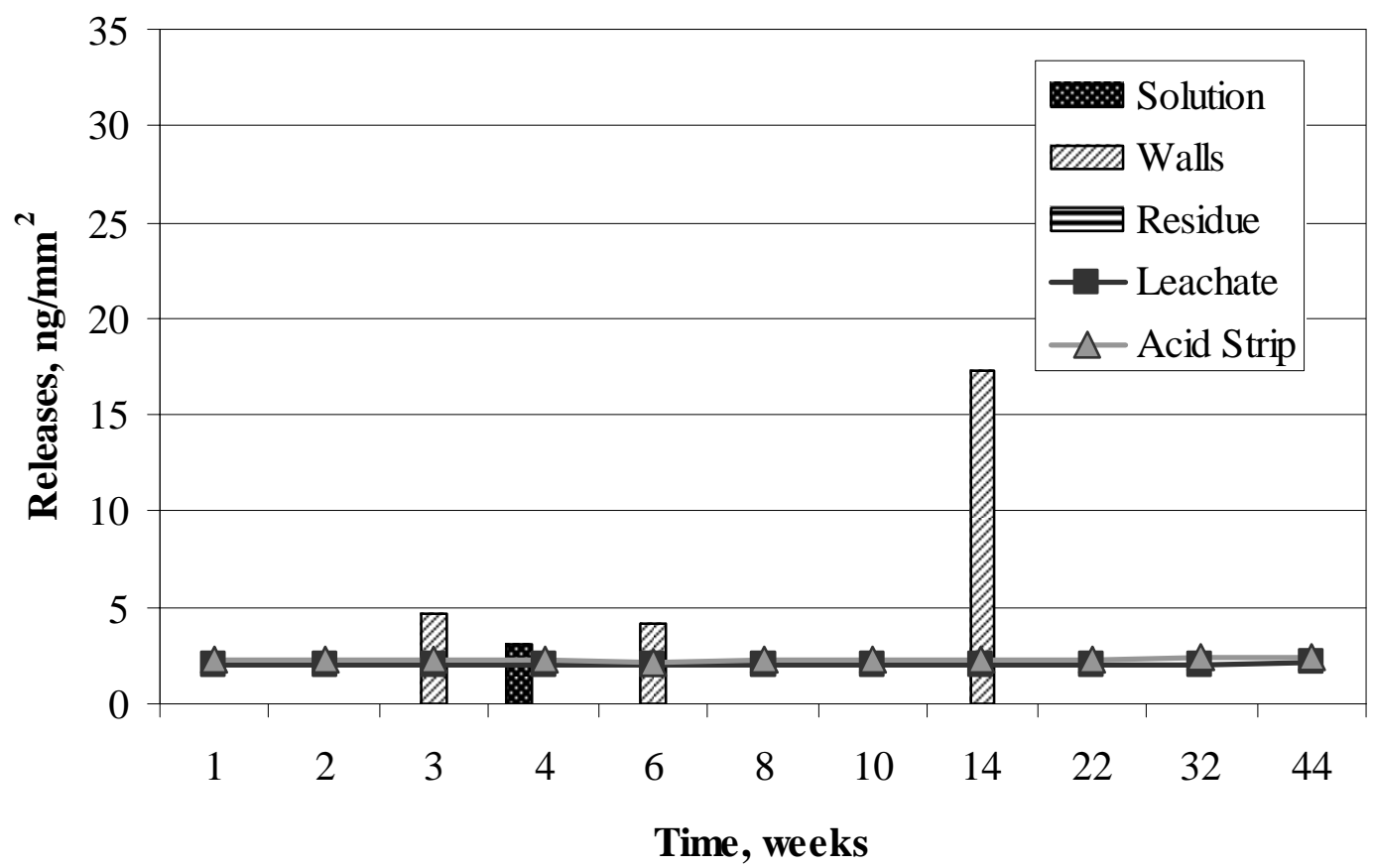

Figure E-4. Iron Releases in Solution, on Walls, and in Residue from Oxidized Sample 4 in SJ13 and Average Detection Limits for Leachate and Acid Strip. 


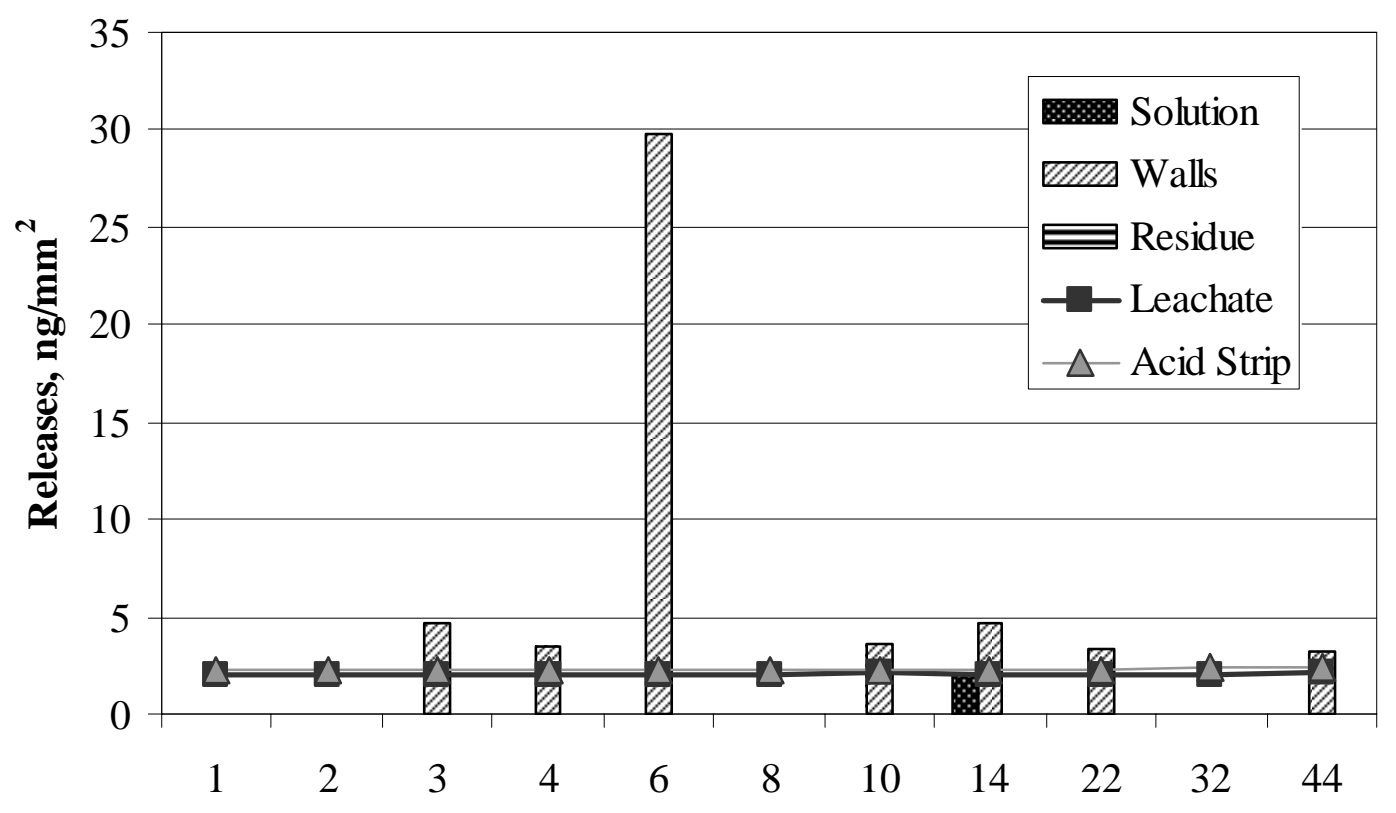

Time, weeks

Figure E-5. Iron Releases in Solution, on Walls, and in Residue from Oxidized Sample 5 in SJ13 and Average Detection Limits for Leachate and Acid Strip.

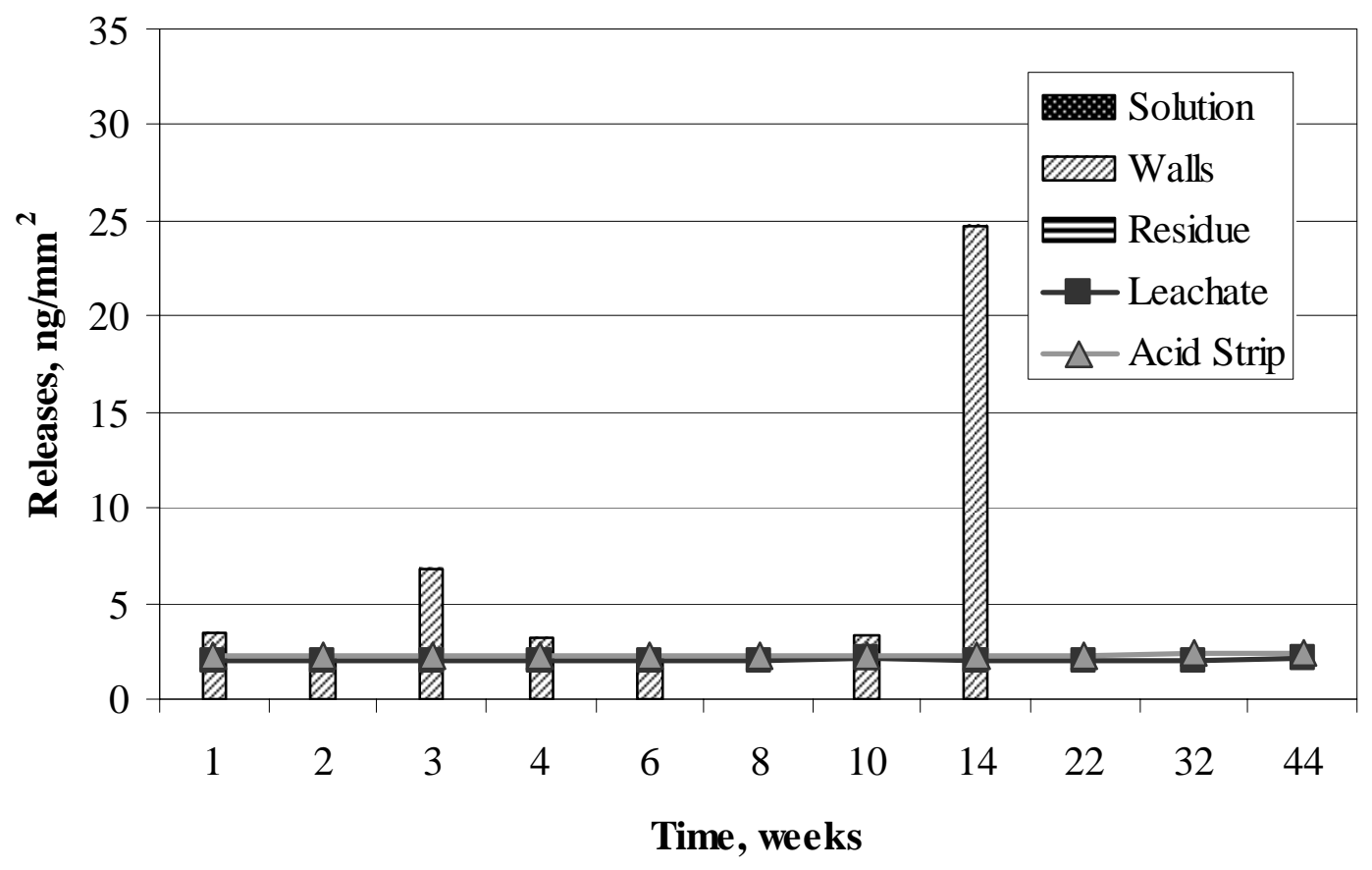

Figure E-6. Iron Present in Solution, on Walls, and in Residue from SJ13 Control and Average Detection Limits for Leachate and Acid Strip. 


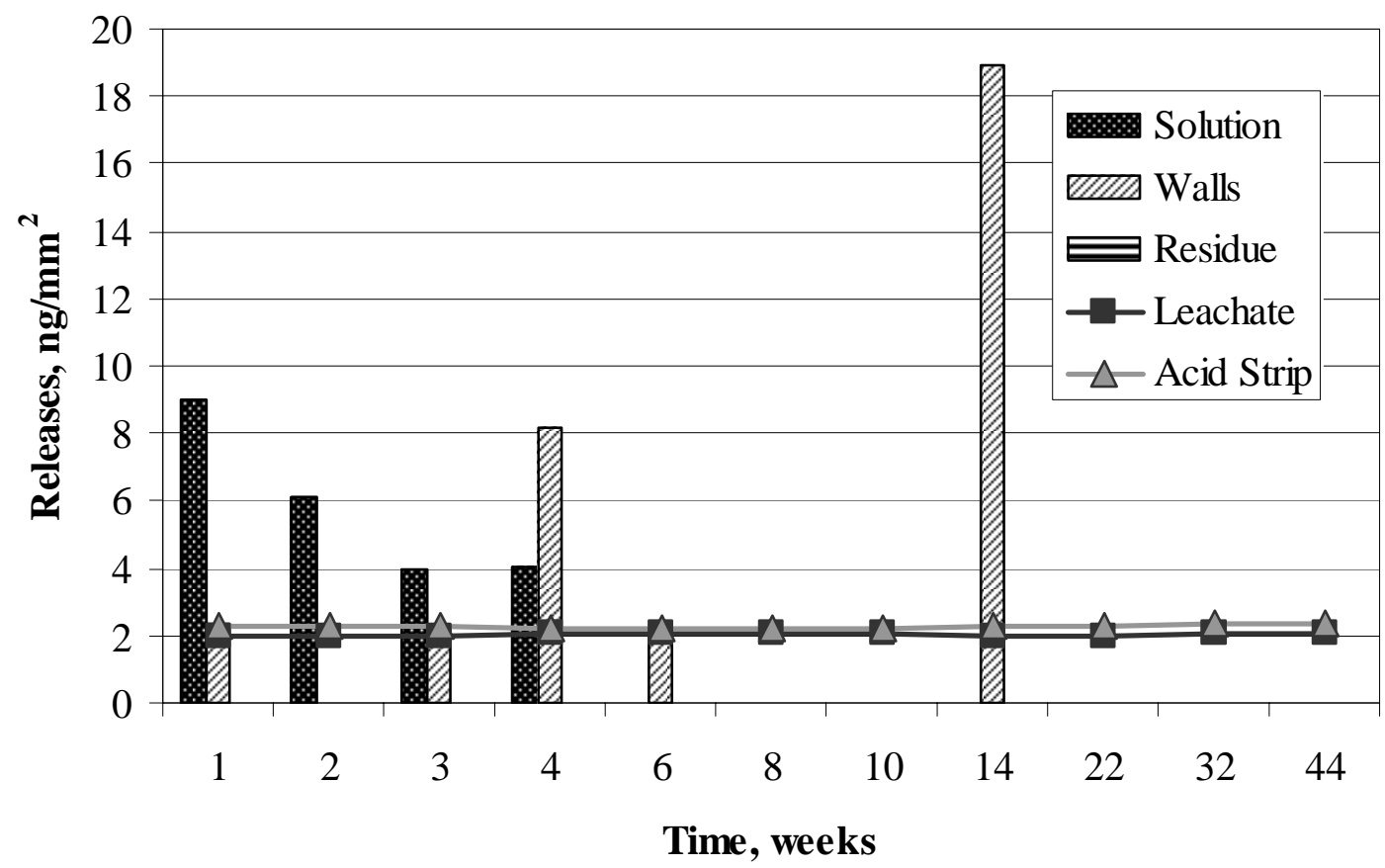

Figure E-7. Iron Releases in Solution, on Walls, and in Residue from Polished Sample 1 in CJ13 and Average Detection Limits for Leachate and Acid Strip.

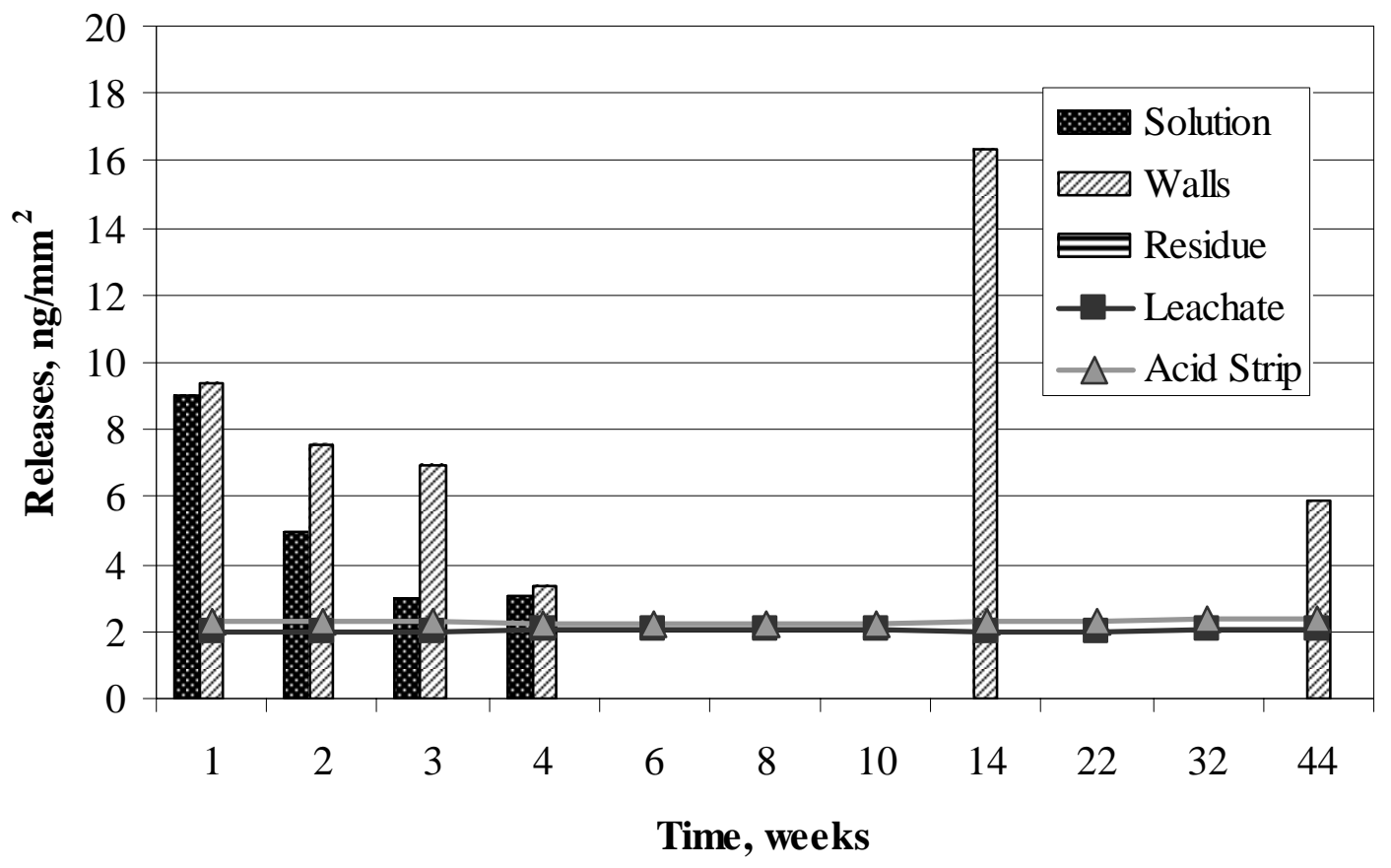

Figure E-8. Iron Releases in Solution, on Walls, and in Residue from Polished Sample 2 in CJ13 and Average Detection Limits for Leachate and Acid Strip. 


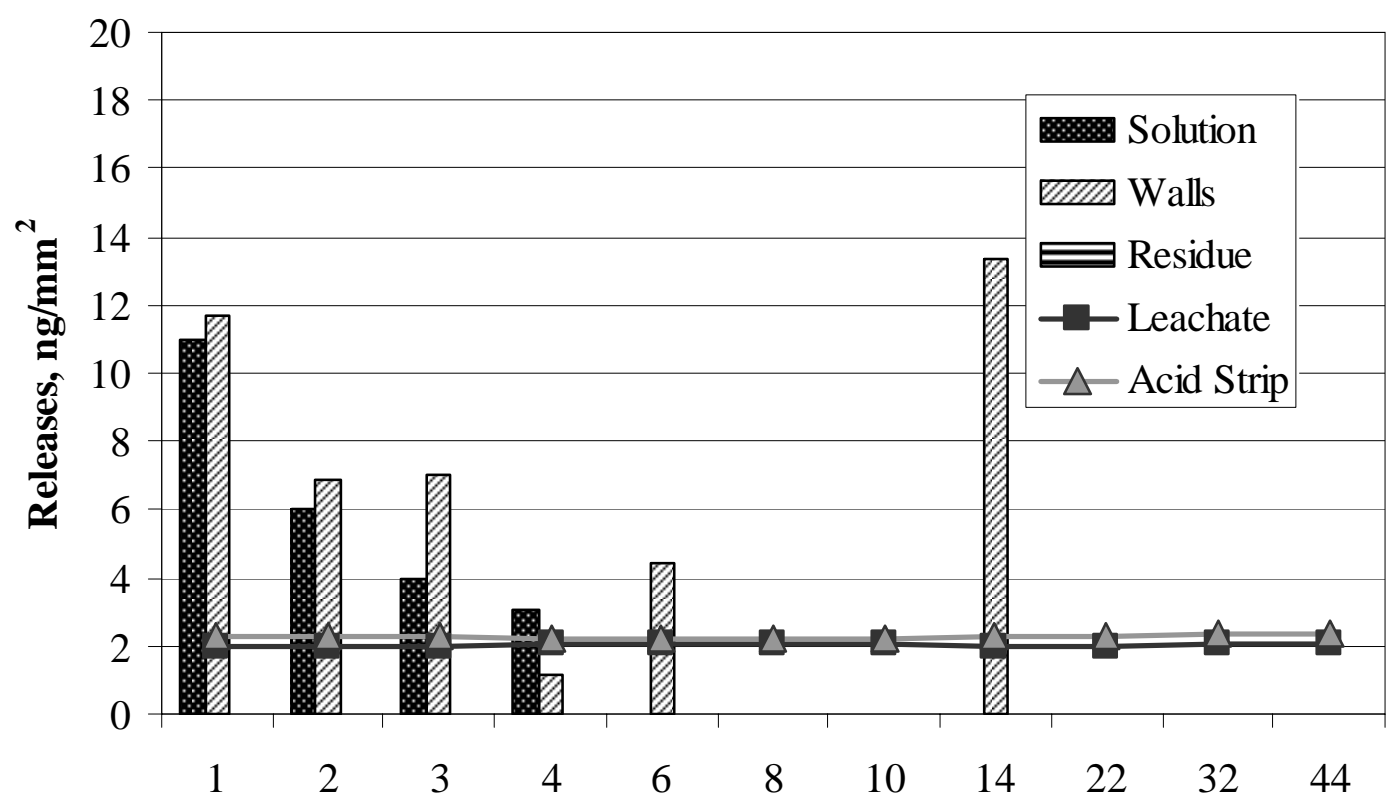

Time, weeks

Figure E-9. Iron Releases in Solution, on Walls, and in Residue from Polished Sample 3 in CJ13 and Average Detection Limits for Leachate and Acid Strip.

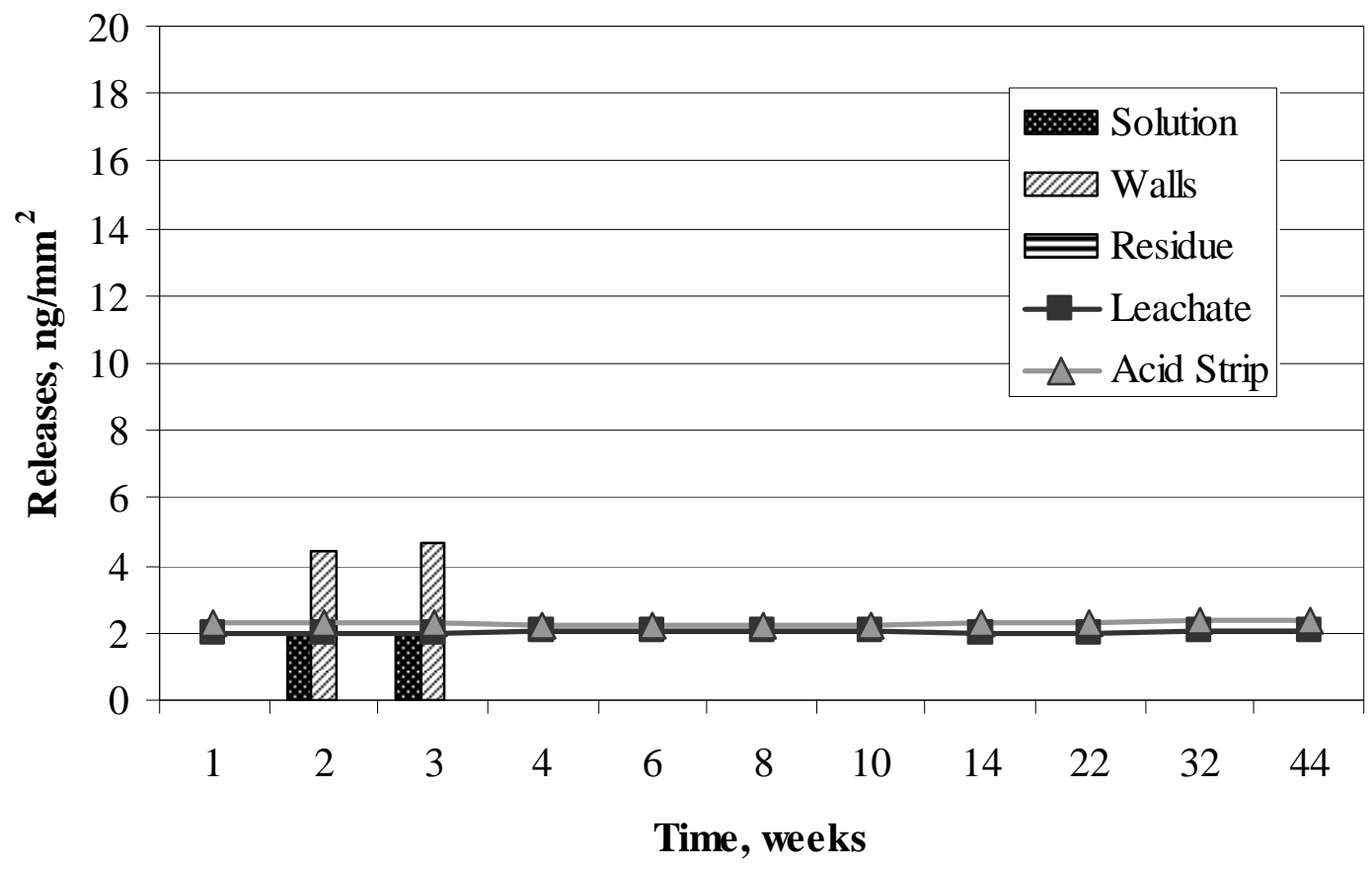

Figure E-10. Iron Releases in Solution, on Walls, and in Residue from Oxidized Sample 4 in CJ13 and Average Detection Limits for Leachate and Acid Strip. 


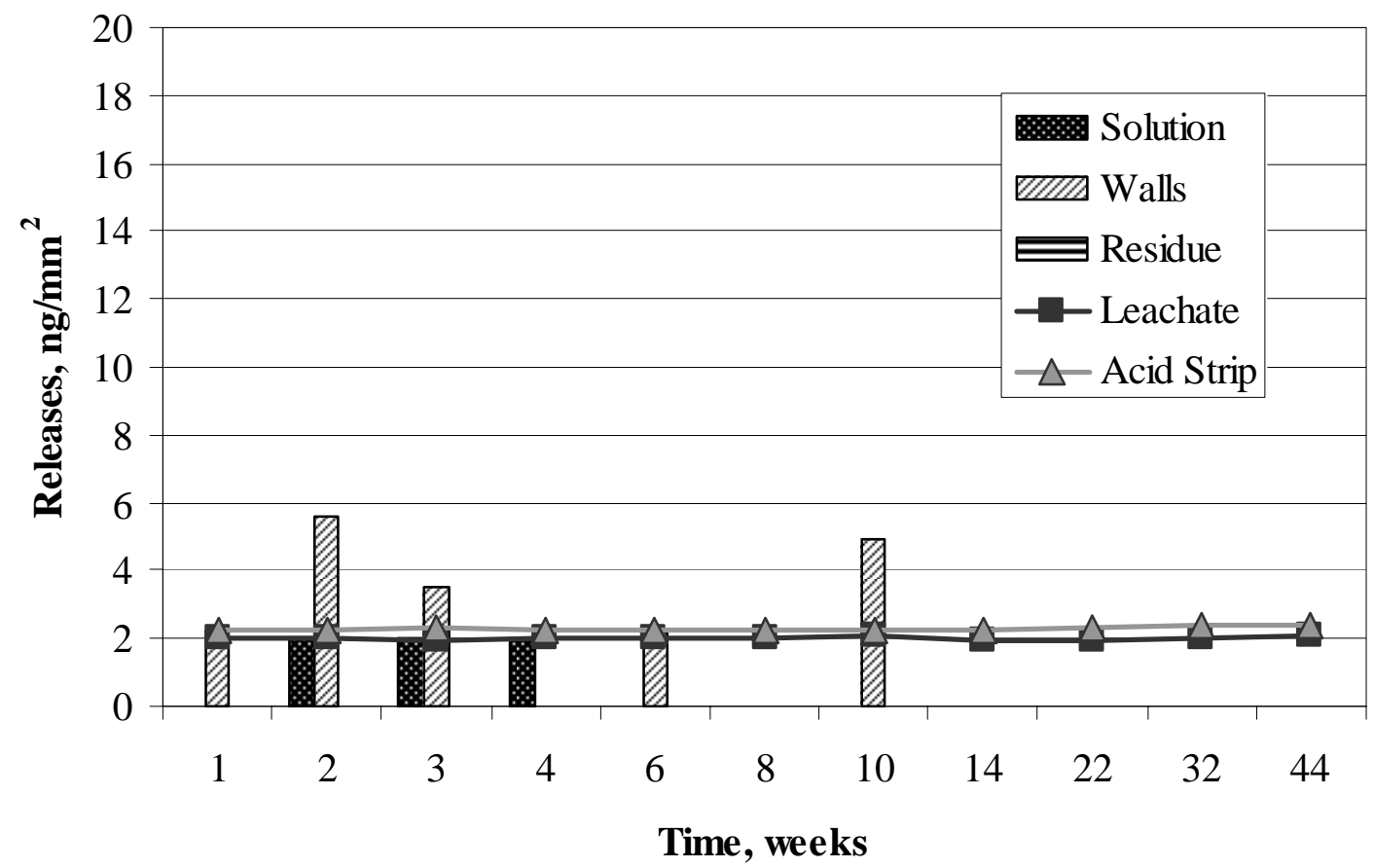

Figure E-11. Iron Releases in Solution, on Walls, and in Residue from Oxidized Sample 5 in CJ13 and Average Detection Limits for Leachate and Acid Strip.

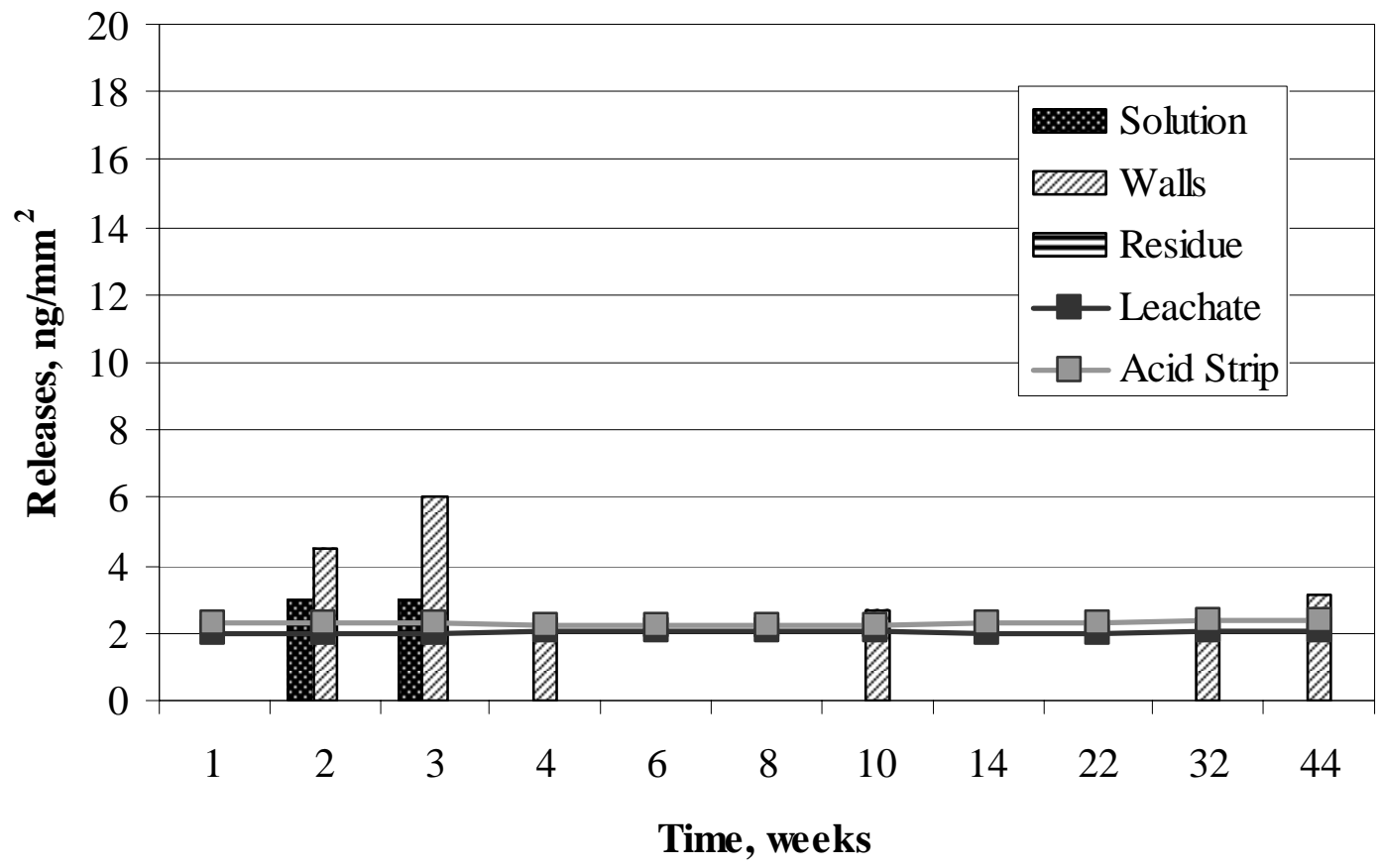

Figure E-12. Iron Present in Solution, on Walls, and in Residue from CJ13 Control and Average Detection Limits for Leachate and Acid Strip. 


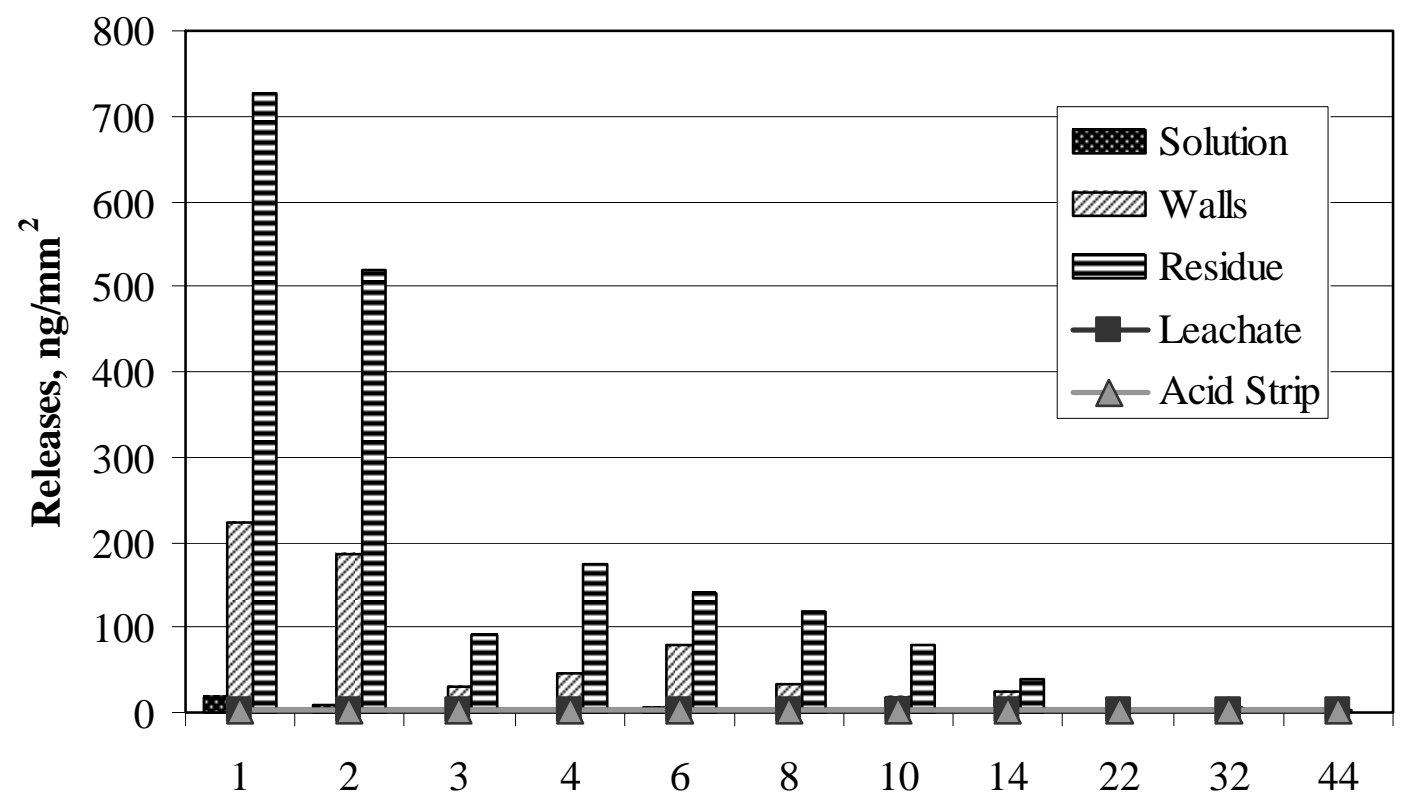

Time, weeks

Figure E-13. Iron Releases in Solution, on Walls, and in Residue from Polished Sample 1 in $10 \mathrm{KCl}$ and Average Detection Limits for Leachate and Acid Strip.

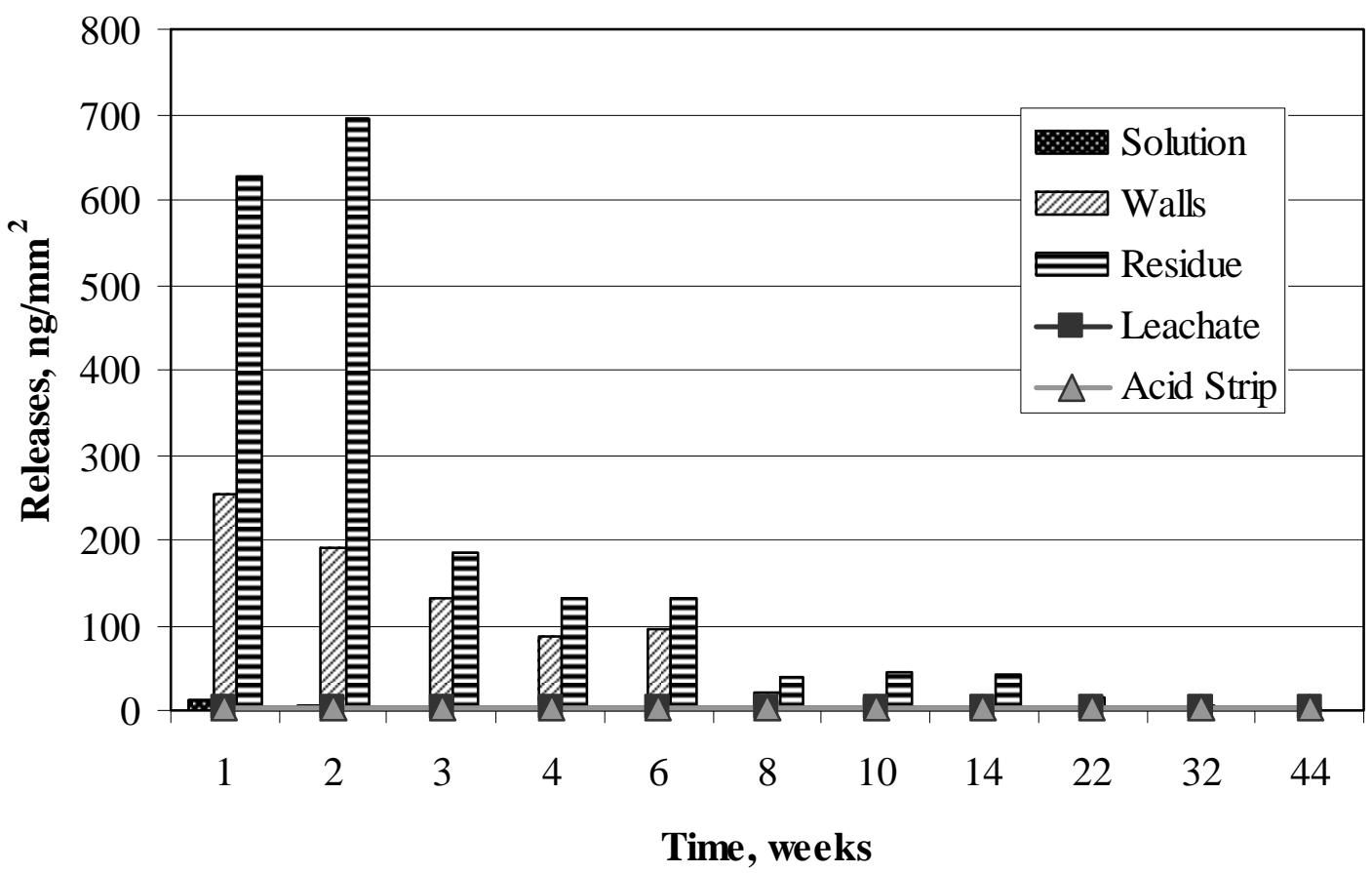

Figure E-14. Iron Releases in Solution, on Walls, and in Residue from Polished Sample 2 in 10KCl and Average Detection Limits for Leachate and Acid Strip. 


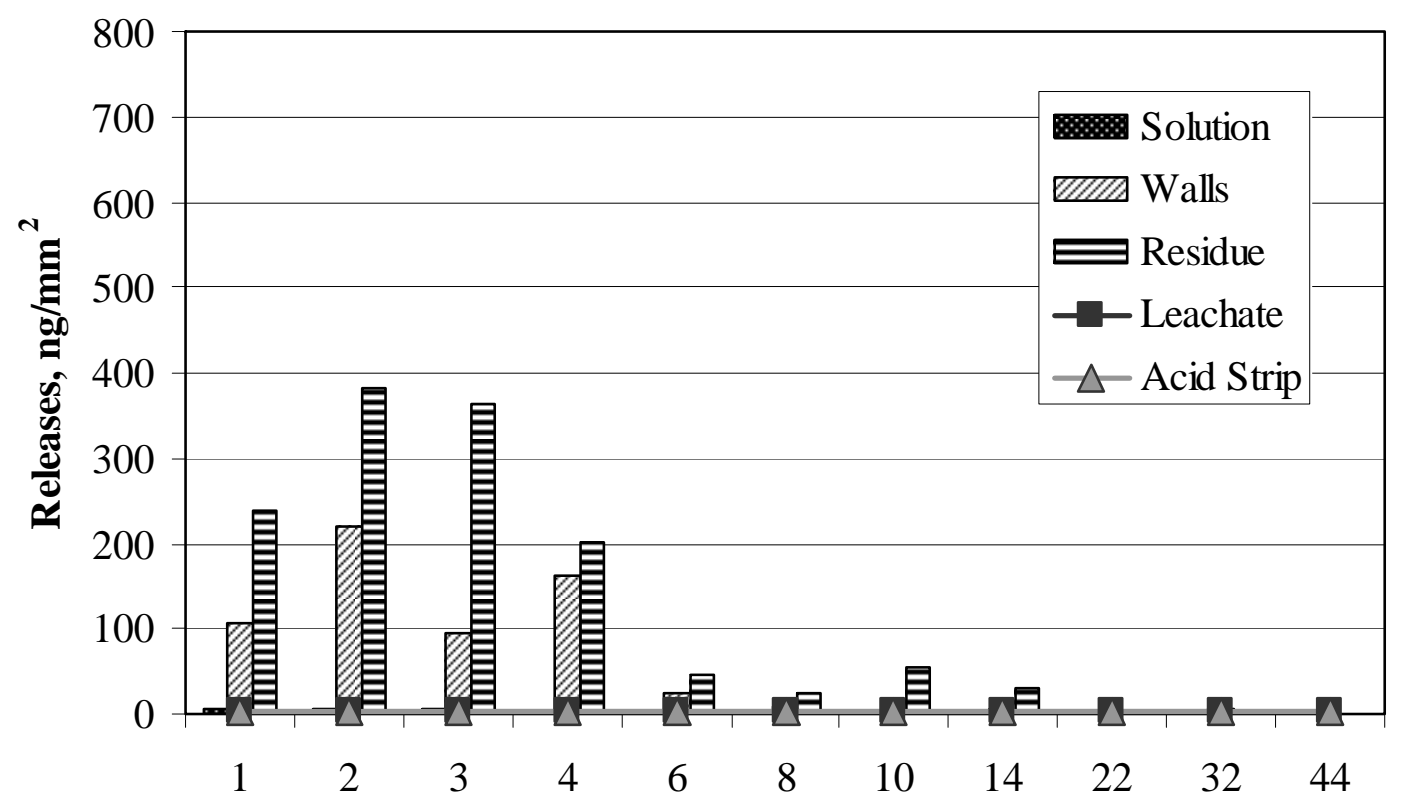

Time, weeks

Figure E-15. Iron Releases in Solution, on Walls, and in Residue from Polished Sample 3 in $10 \mathrm{KCl}$ and Average Detection Limits for Leachate and Acid Strip.

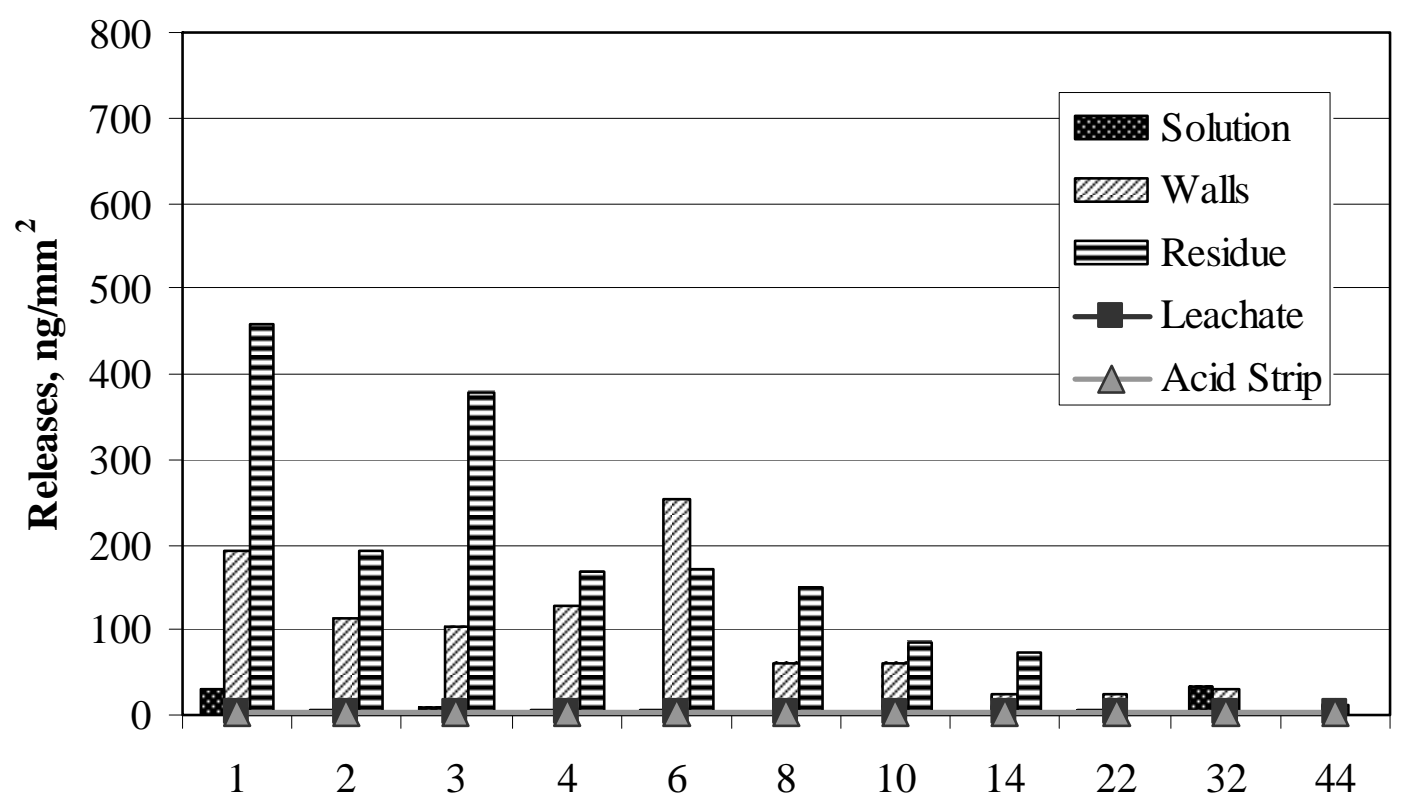

Time, weeks

Figure E-16. Iron Releases in Solution, on Walls, and in Residue from Oxidized Sample 4 in 10KCl and Average Detection Limits for Leachate and Acid Strip. 


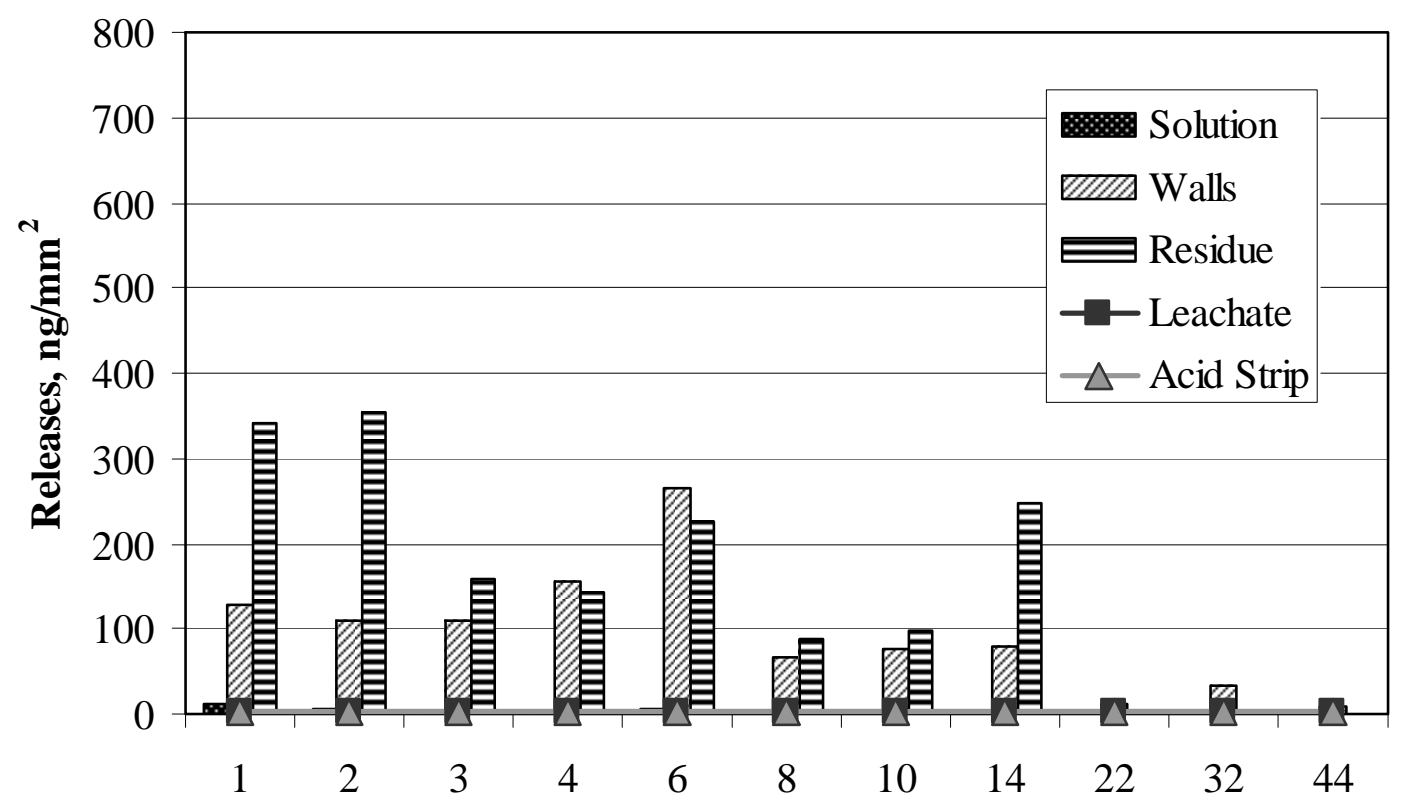

Time, weeks

Figure E-17. Iron Releases in Solution, on Walls, and in Residue from Oxidized Sample 5 in 10KCl and Average Detection Limits for Leachate and Acid Strip.

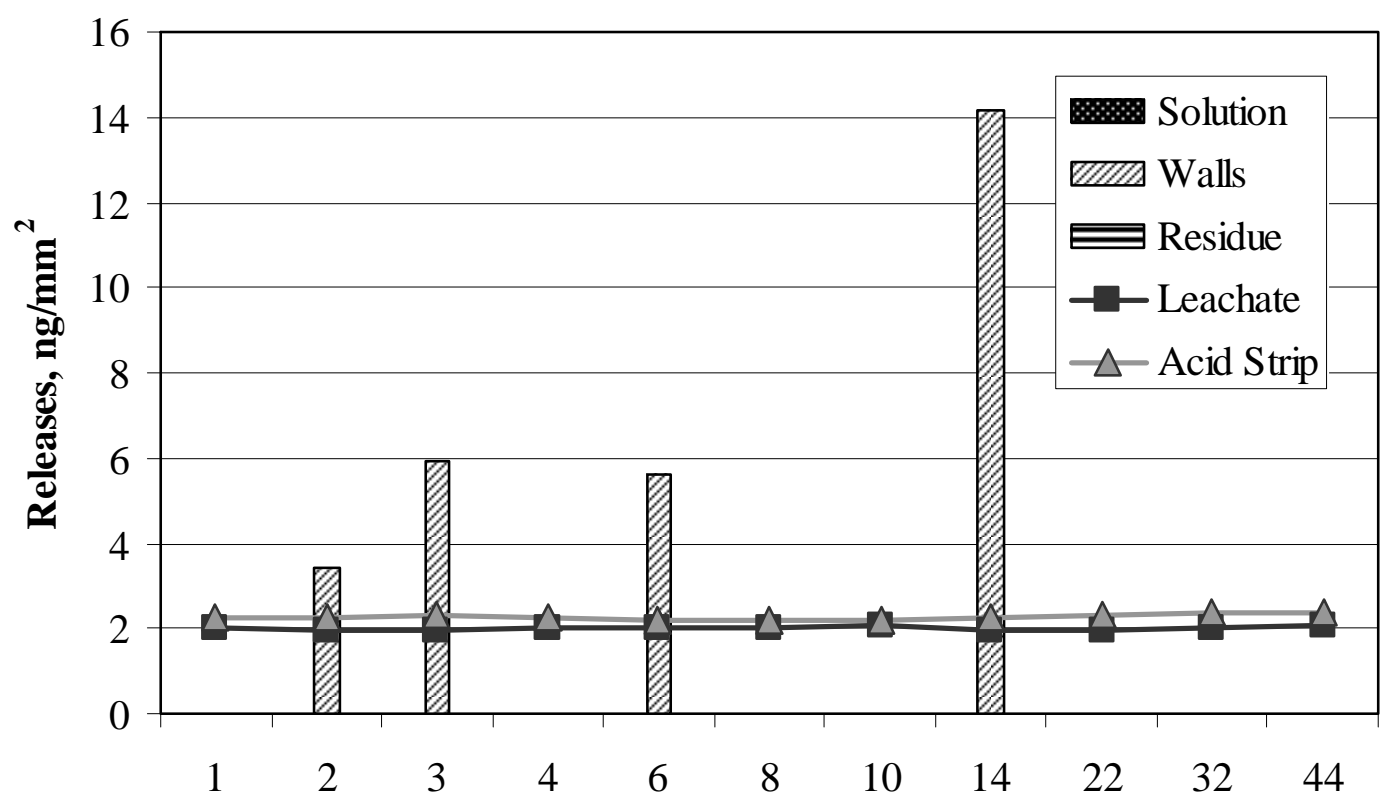

Time, weeks

Figure E-18. Iron Present in Solution, on Walls, and in Residue from $10 \mathrm{KCl}$ Control and Average Detection Limits for Leachate and Acid Strip. 


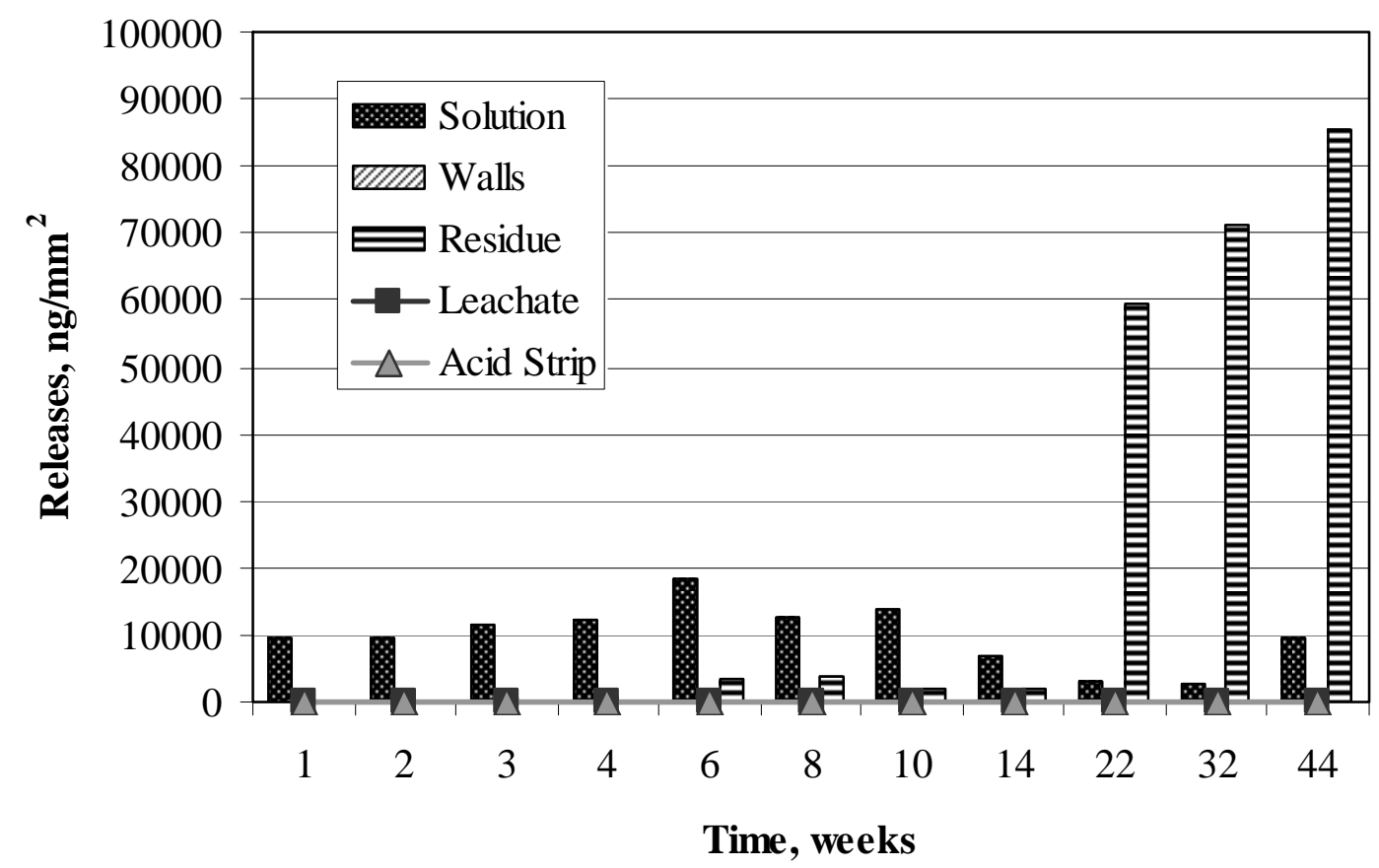

Figure E-19. Iron Releases in Solution, on Walls, and in Residue from Polished Sample 1 in AJ13 and Average Detection Limits for Leachate and Acid Strip.

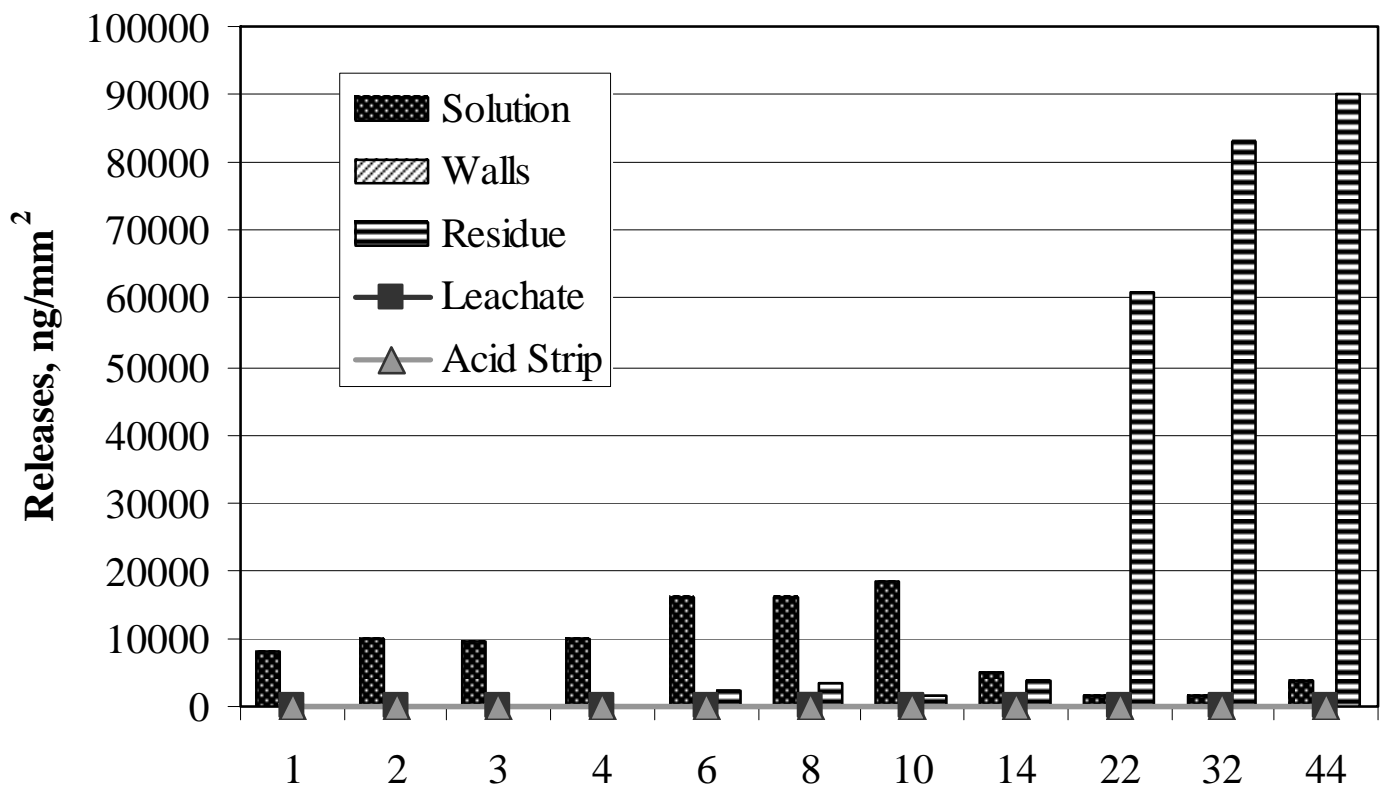

Time, weeks

Figure E-20. Iron Releases in Solution on Walls and in Residue from Polished Sample 2 in AJ13 and Average Detection Limits for Leachate and Acid Strip. 


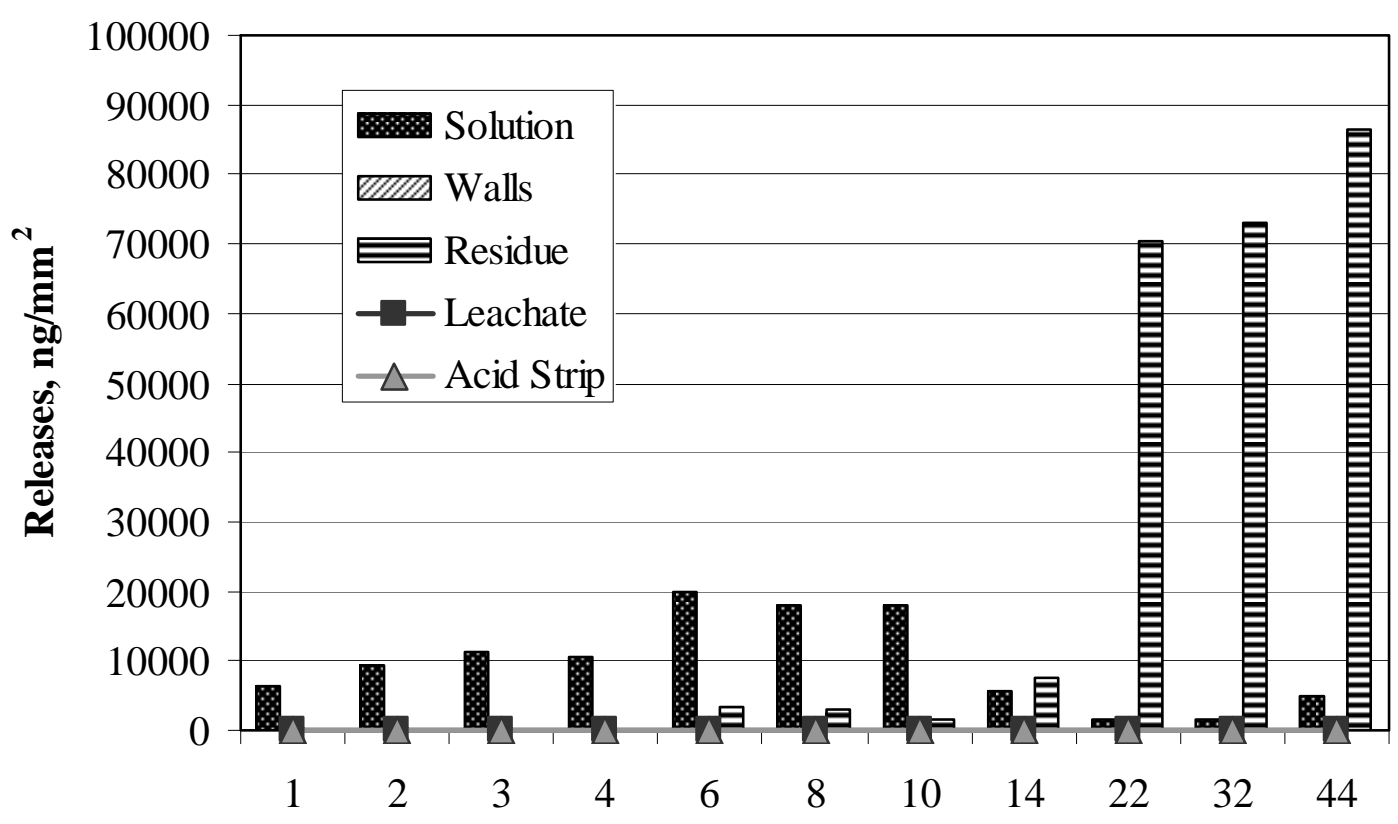

Time, weeks

Figure E-21. Iron Releases in Solution, on Walls, and in Residue from Polished Sample 3 in AJ13 and Average Detection Limits for Leachate and Acid Strip.

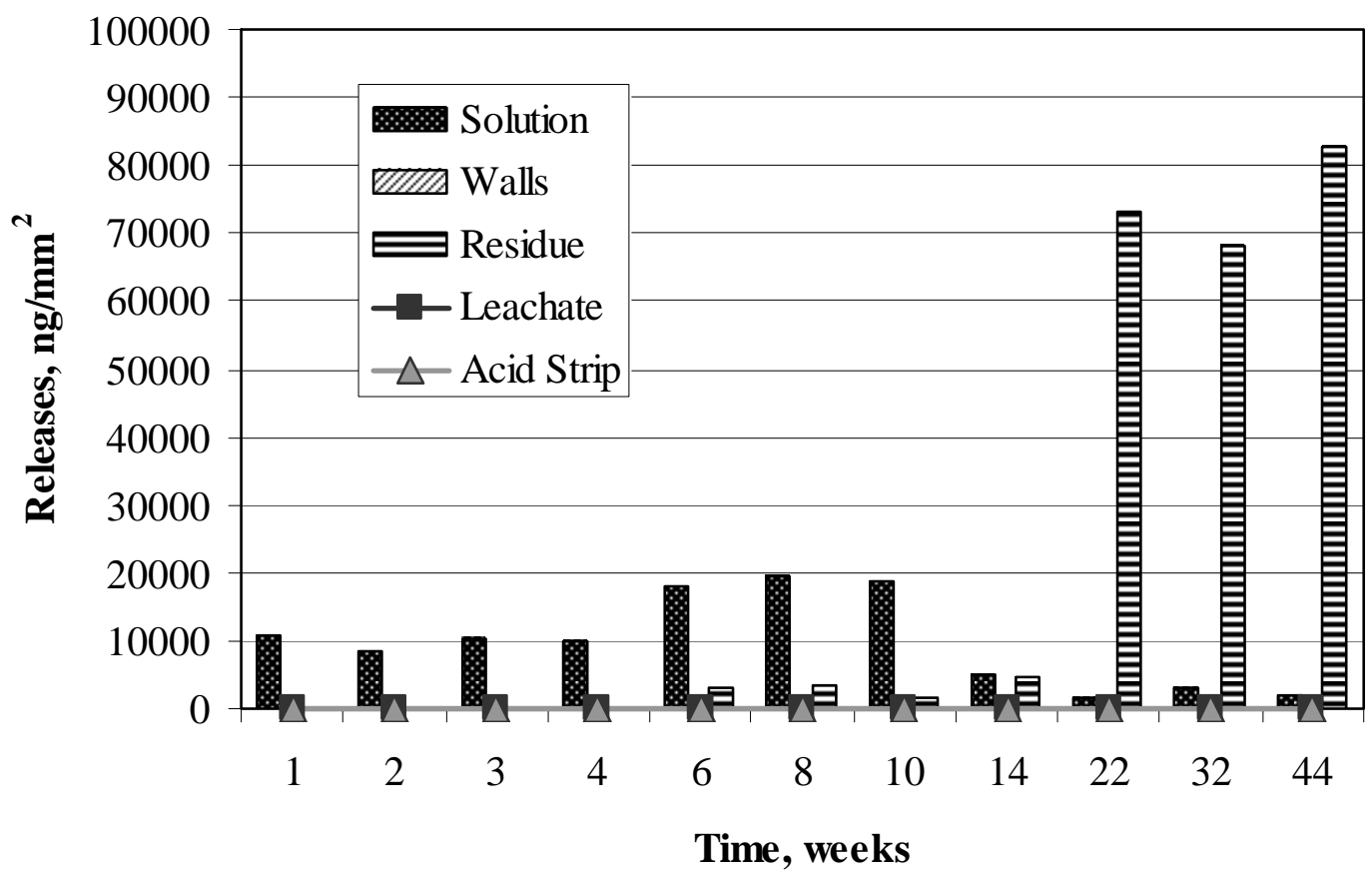

Figure E-22. Iron Releases in Solution, on Walls, and in Residue from Oxidized Sample 4 in AJ13 and Average Detection Limits for Leachate and Acid Strip. 


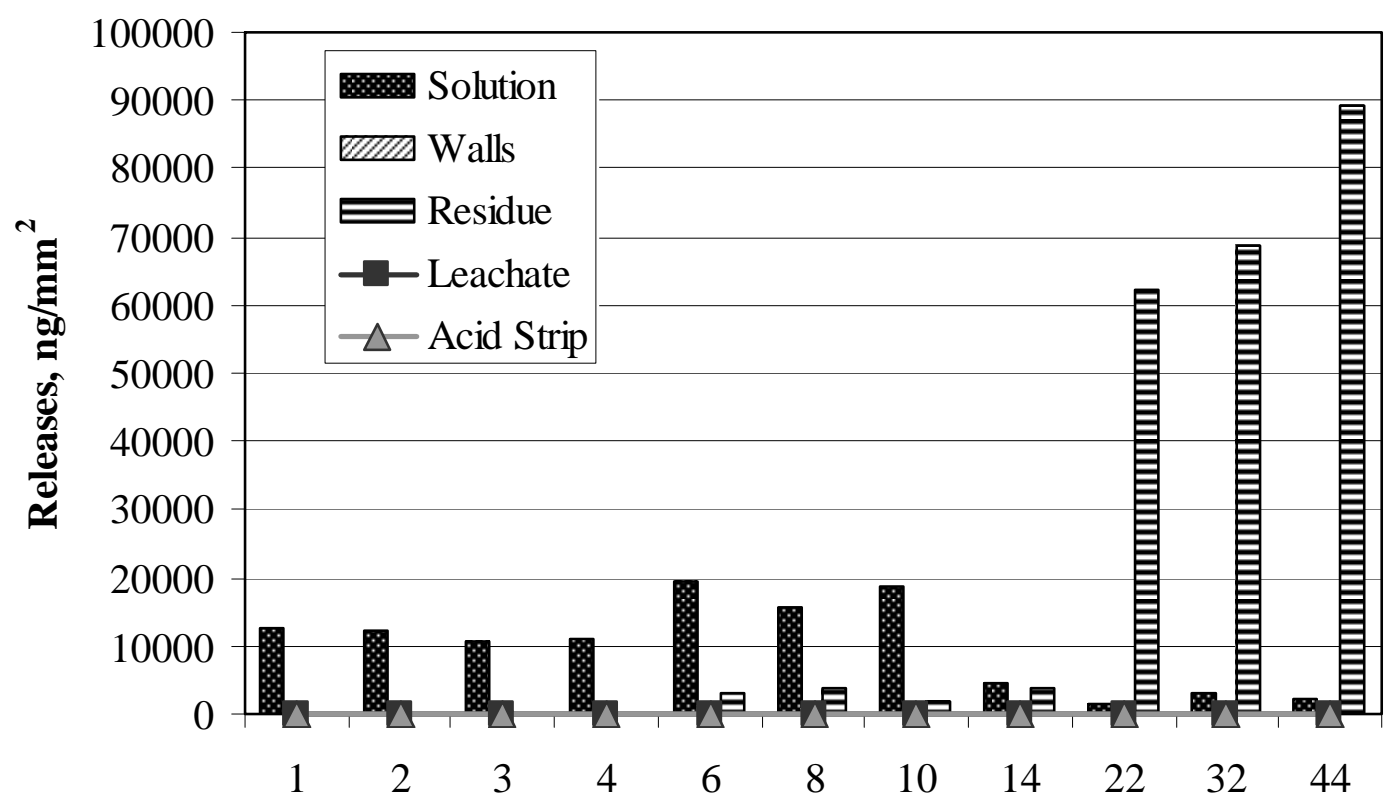

Time, weeks

Figure E-23. Iron Releases in Solution, on Walls, and in Residue from Oxidized Sample 5 in AJ13 and Average Detection Limits for Leachate and Acid Strip.

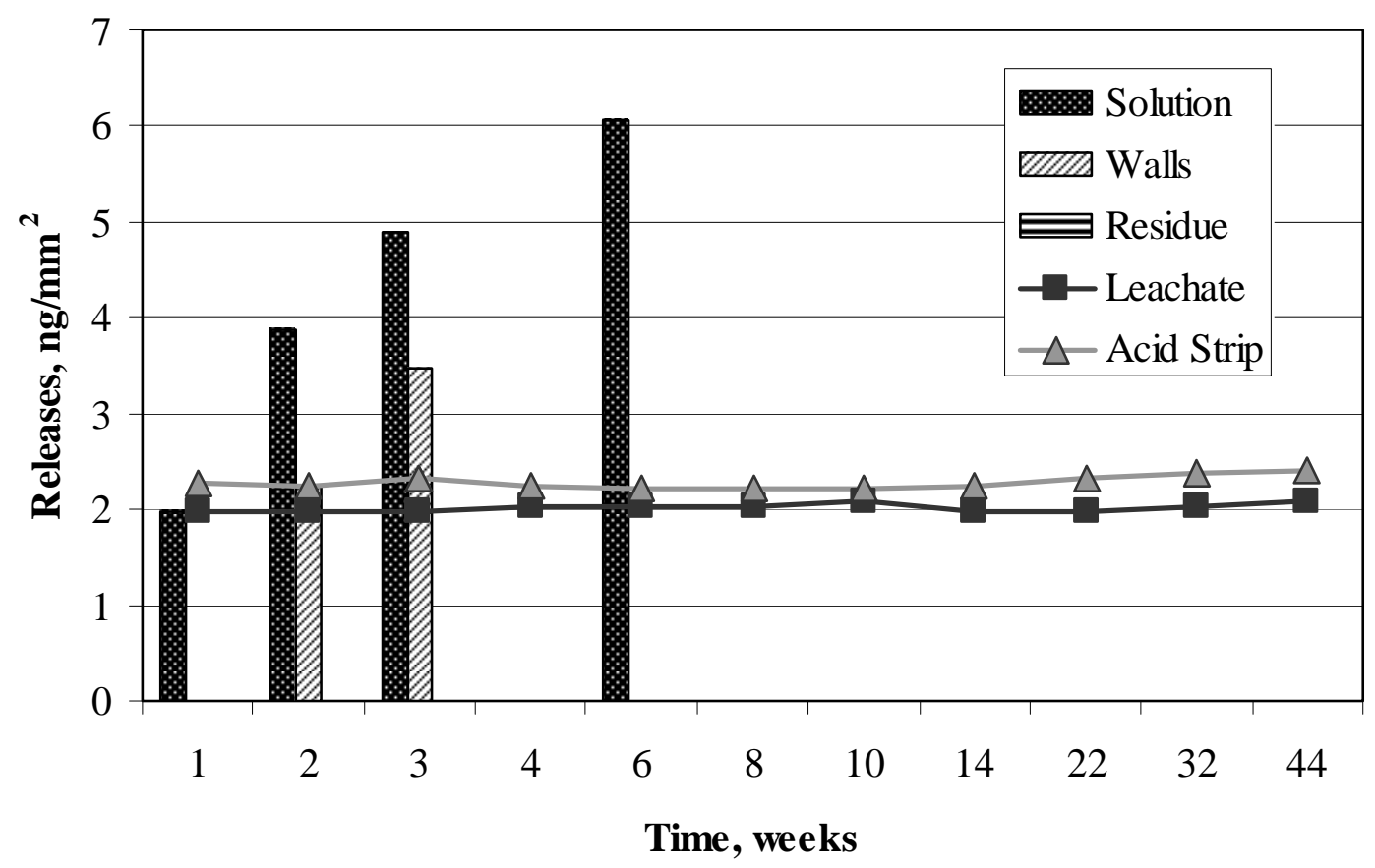

Figure E-24. Iron Present in Solution, on Walls, and in Residue from AJ13 Control and Average Detection Limits for Leachate and Acid Strip. 


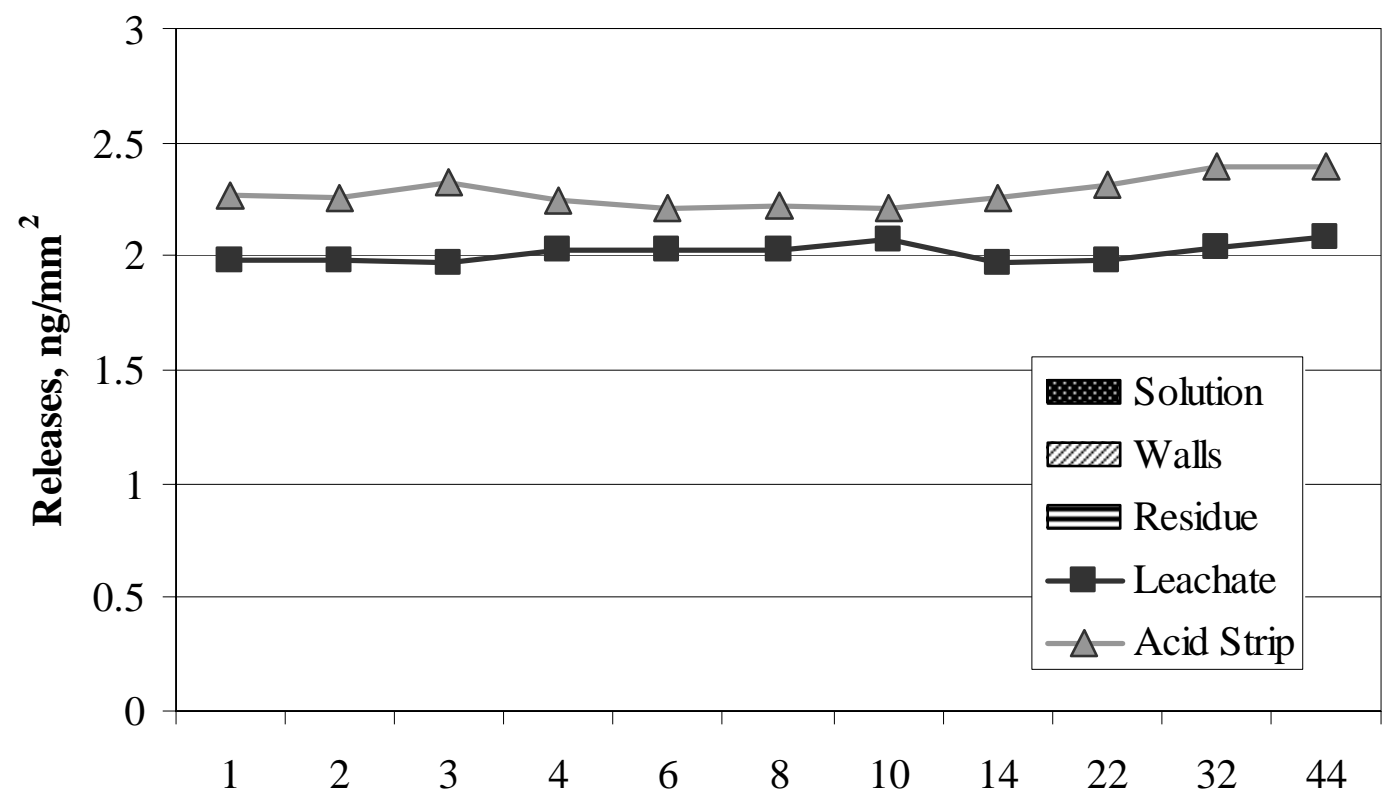

Time, weeks

Figure E-25. Chromium Releases in Solution, on Walls, and in Residue from Polished Sample 1 in SJ13 and Average Detection Limits for Leachate and Acid Strip.

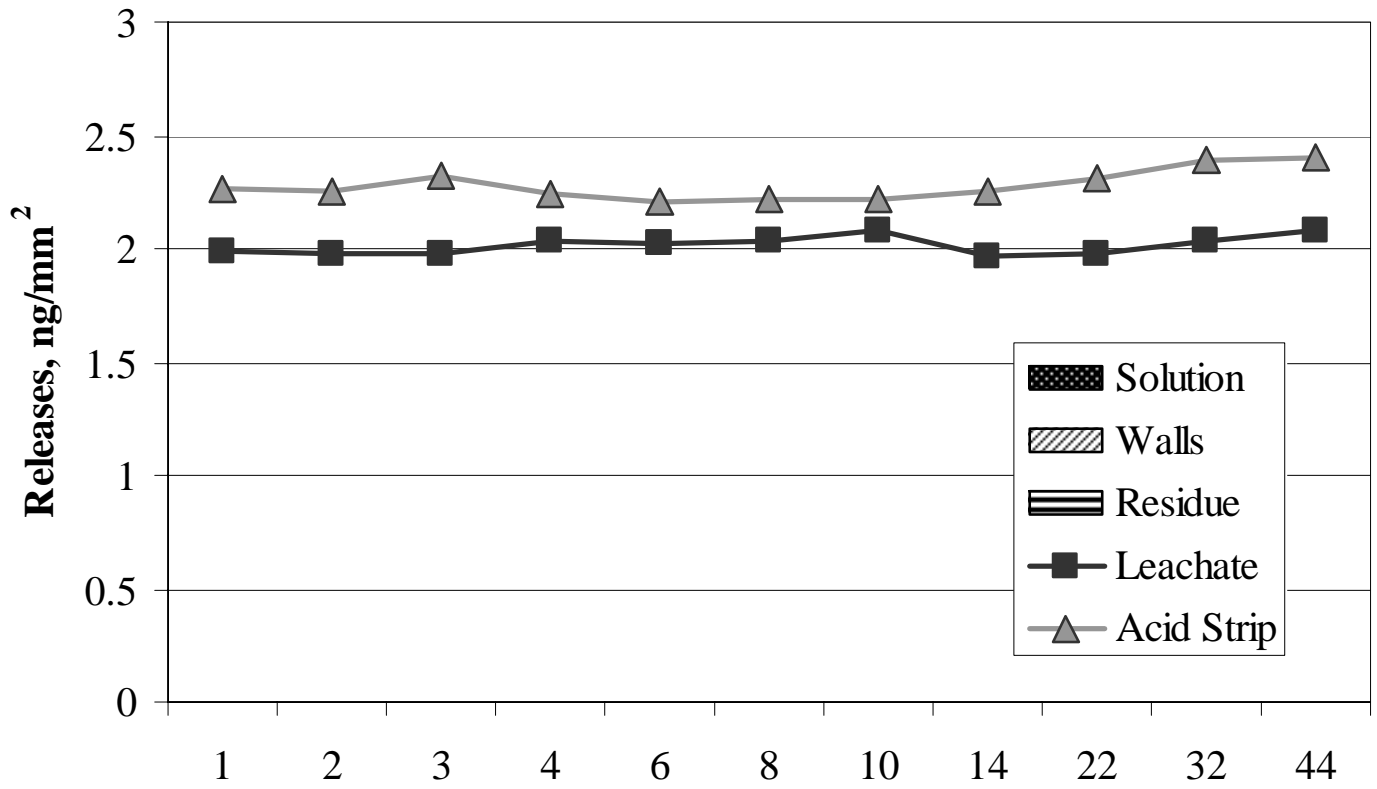

Time, weeks

Figure E-26. Chromium Releases in Solution, on Walls, and in Residue from Polished Sample in SJ13 and Average Detection Limits for Leachate and Acid Strip. 


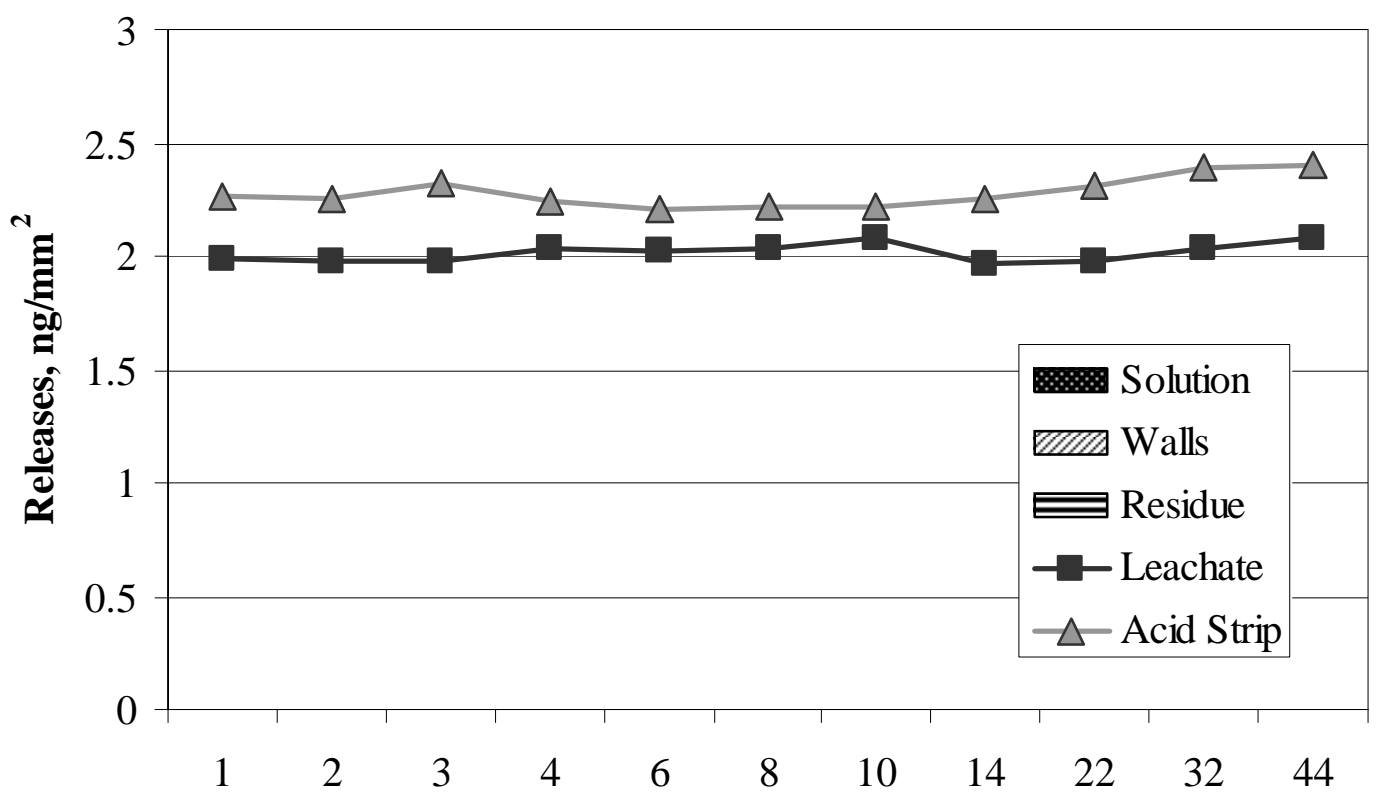

Time, weeks

Figure E-27. Chromium Releases in Solution, on Walls, and in Residue from Polished Sample 3 in SJ13 and Average Detection Limits for Leachate and Acid Strip.

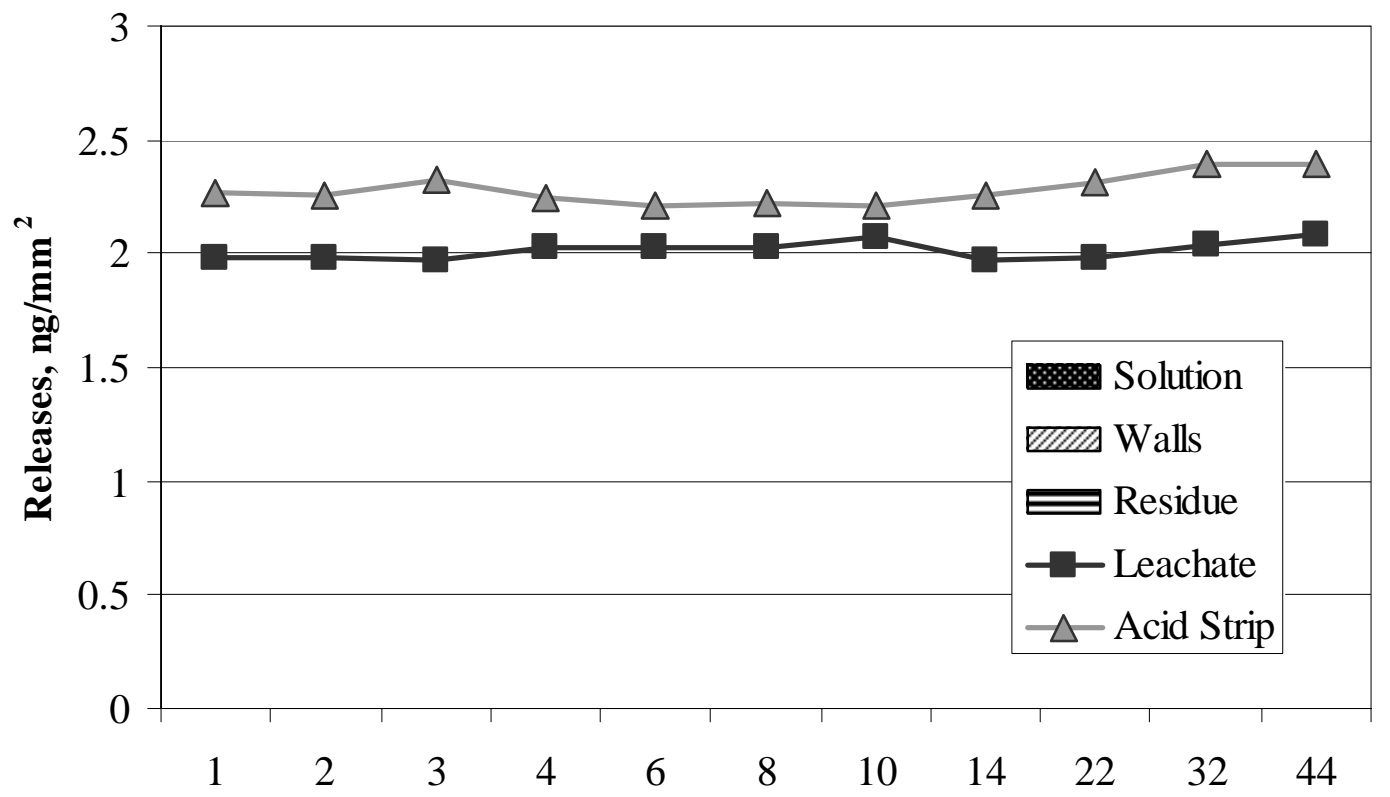

Time, weeks

Figure E-28. Chromium Releases in Solution, on Walls, and in Residue from Oxidized Sample 4 in SJ13 and Average Detection Limits for Leachate and Acid Strip. 


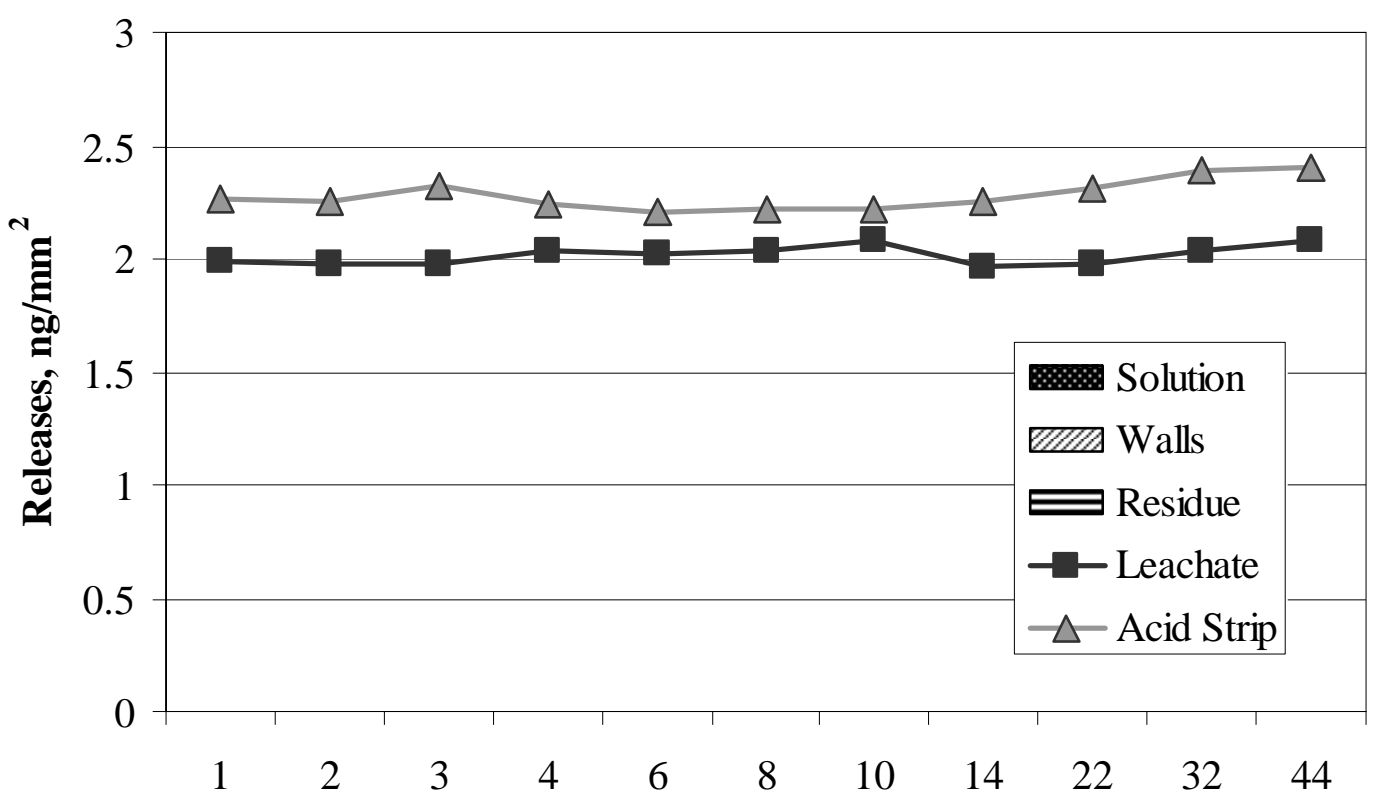

Time, weeks

Figure E-29. Chromium Releases in Solution, on Walls, and in Residue from Oxidized Sample 5 in SJ13 and Average Detection Limits for Leachate and Acid Strip.

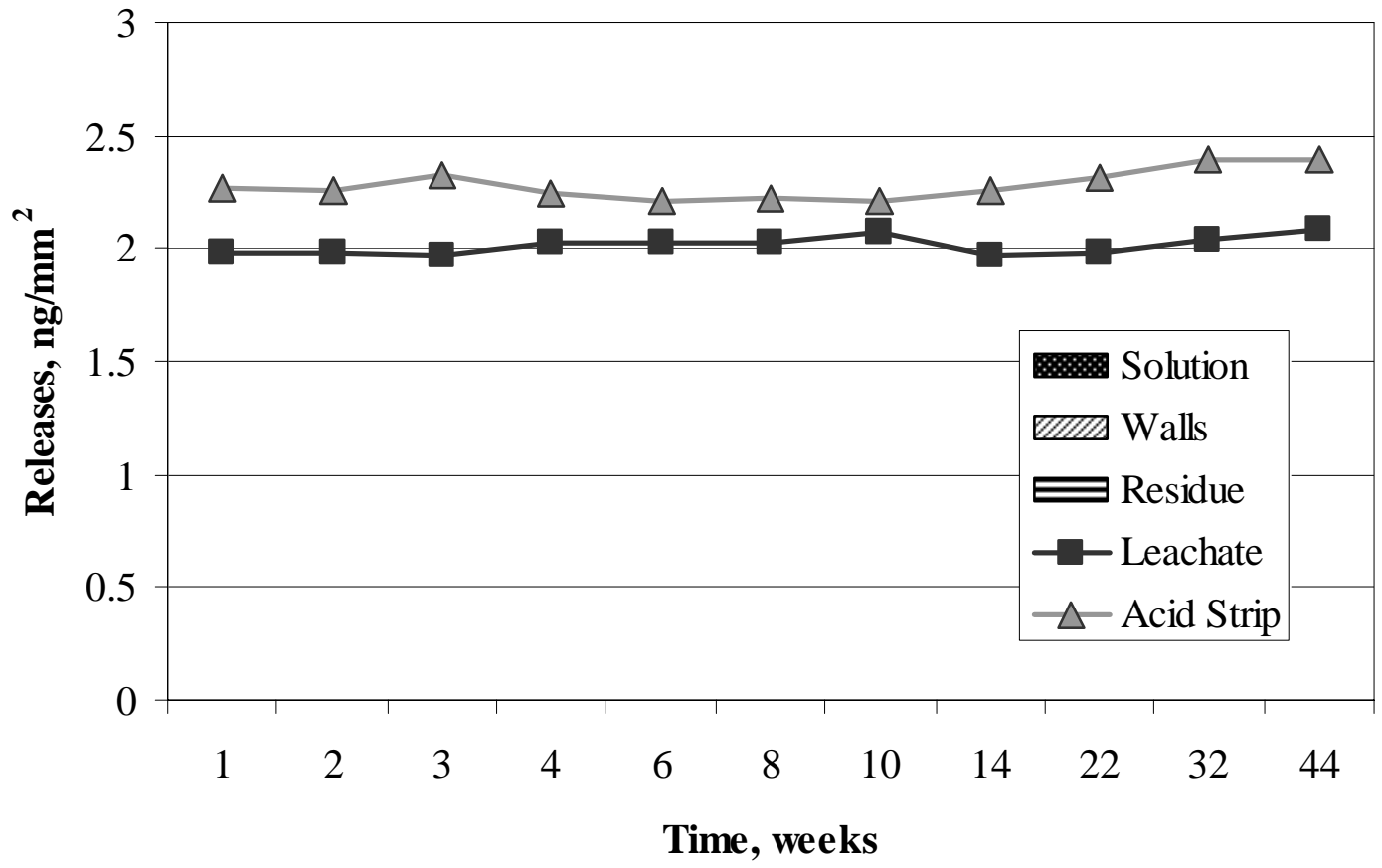

Figure E-30. Chromium Present in Solution, on Walls, and in Residue from SJ13 Control and Average Detection Limits for Leachate and Acid Strip. 


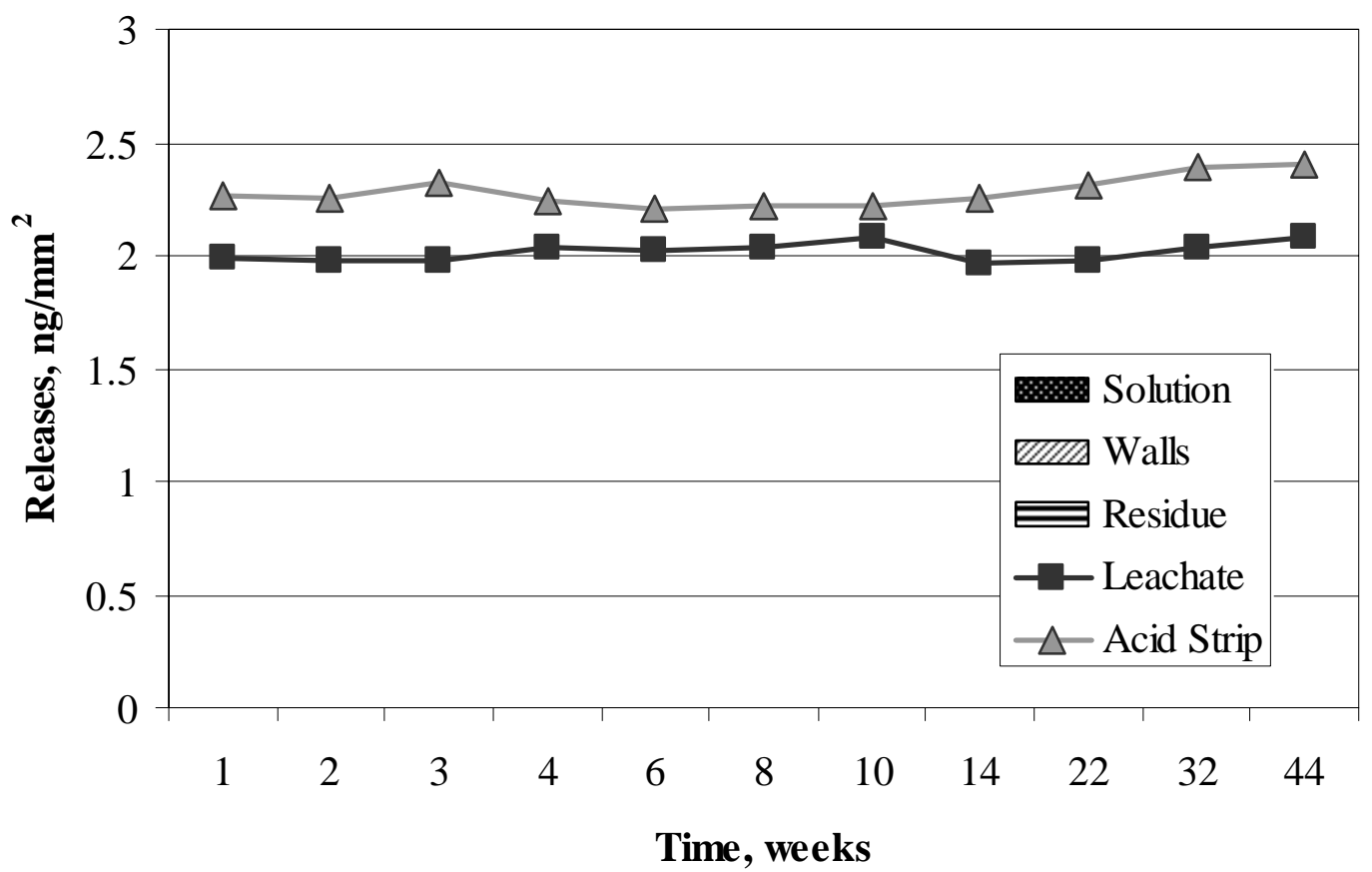

Figure E-31. Chromium Releases in Solution, on Walls, and in Residue from Polished Sample 1 in CJ13 and Average Detection Limits for Leachate and Acid Strip.

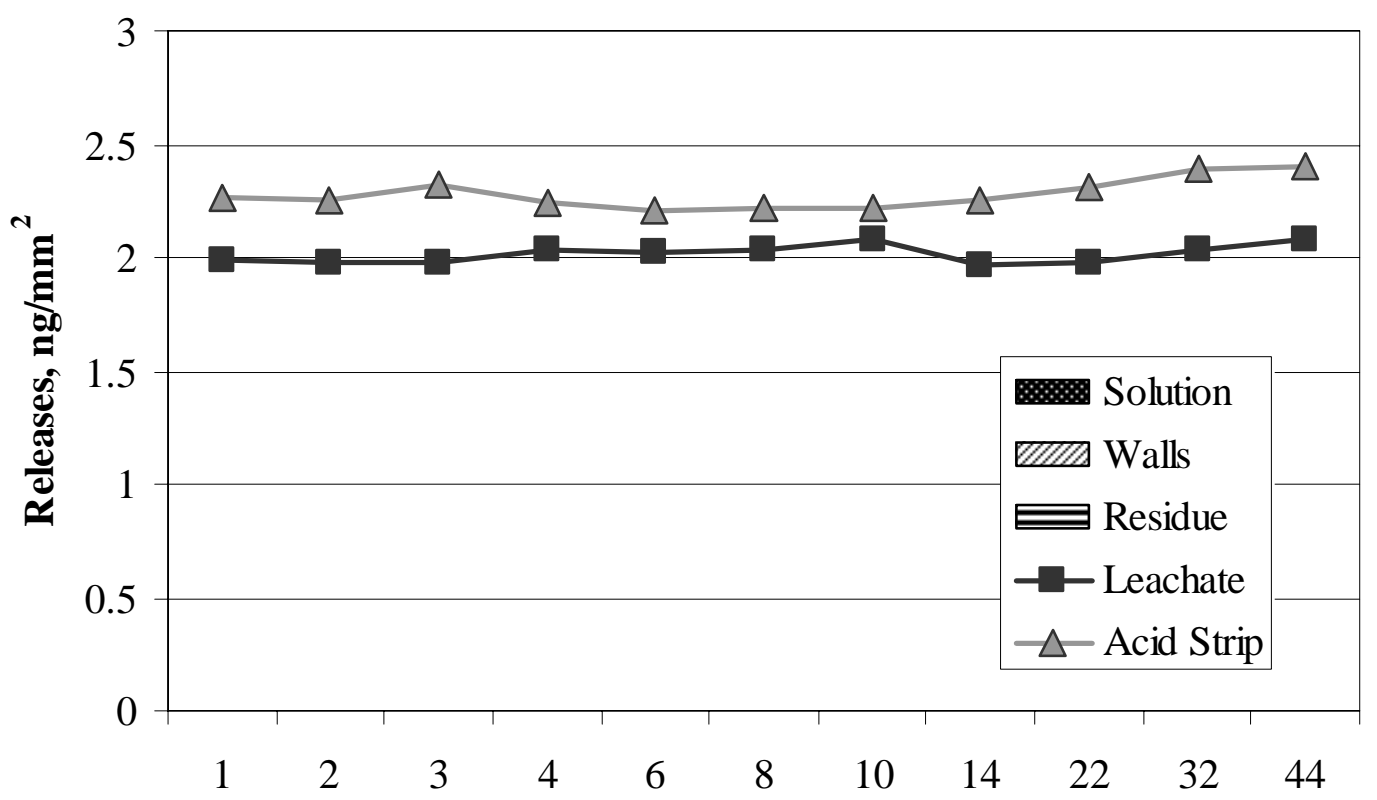

Time, weeks

Figure E-32. Chromium Releases in Solution, on Walls, and in Residue from Polished Sample 2 in CJ13 and Average Detection Limits for Leachate and Acid Strip. 


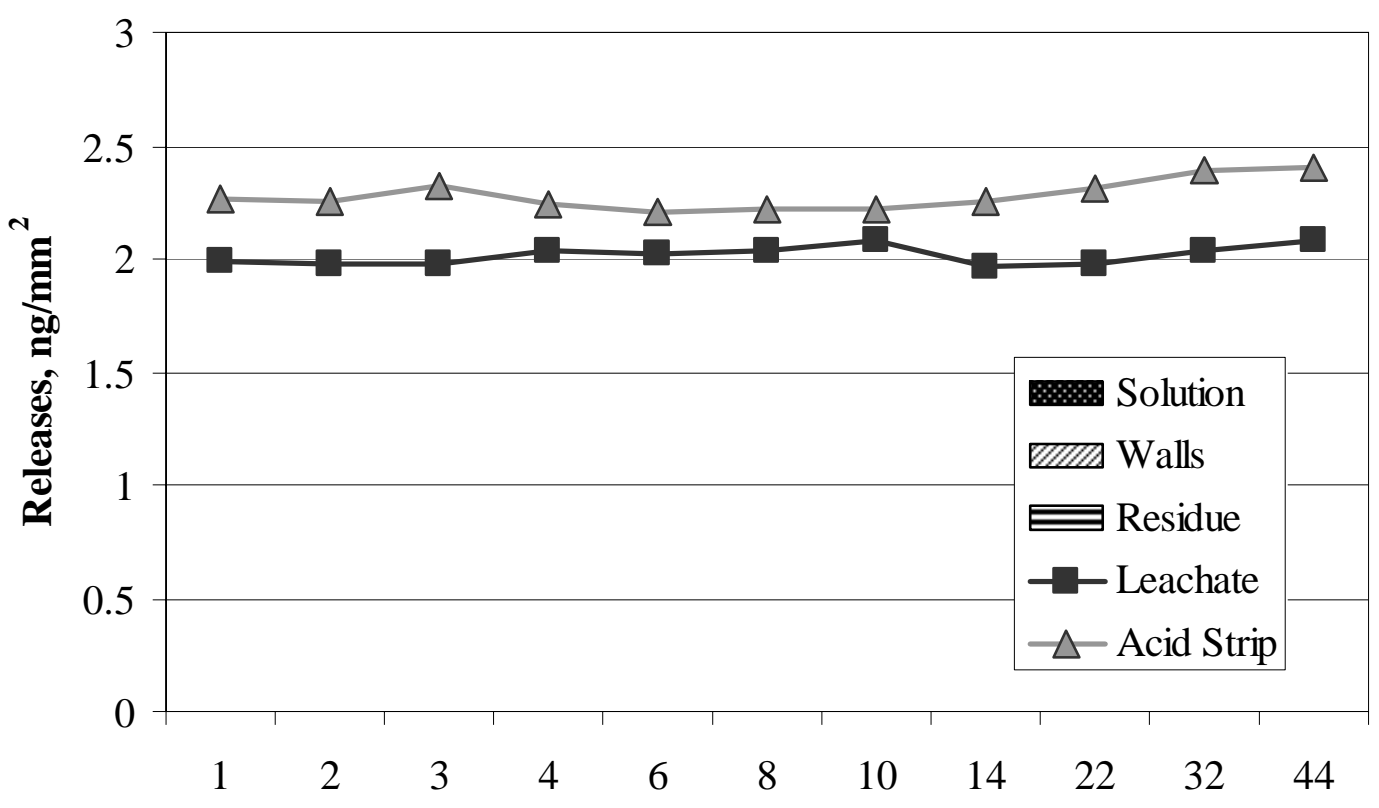

Time, weeks

Figure E-33. Chromium Releases in Solution, on Walls, and in Residue from Polished Sample 3 in CJ13 and Average Detection Limits for Leachate and Acid Strip.

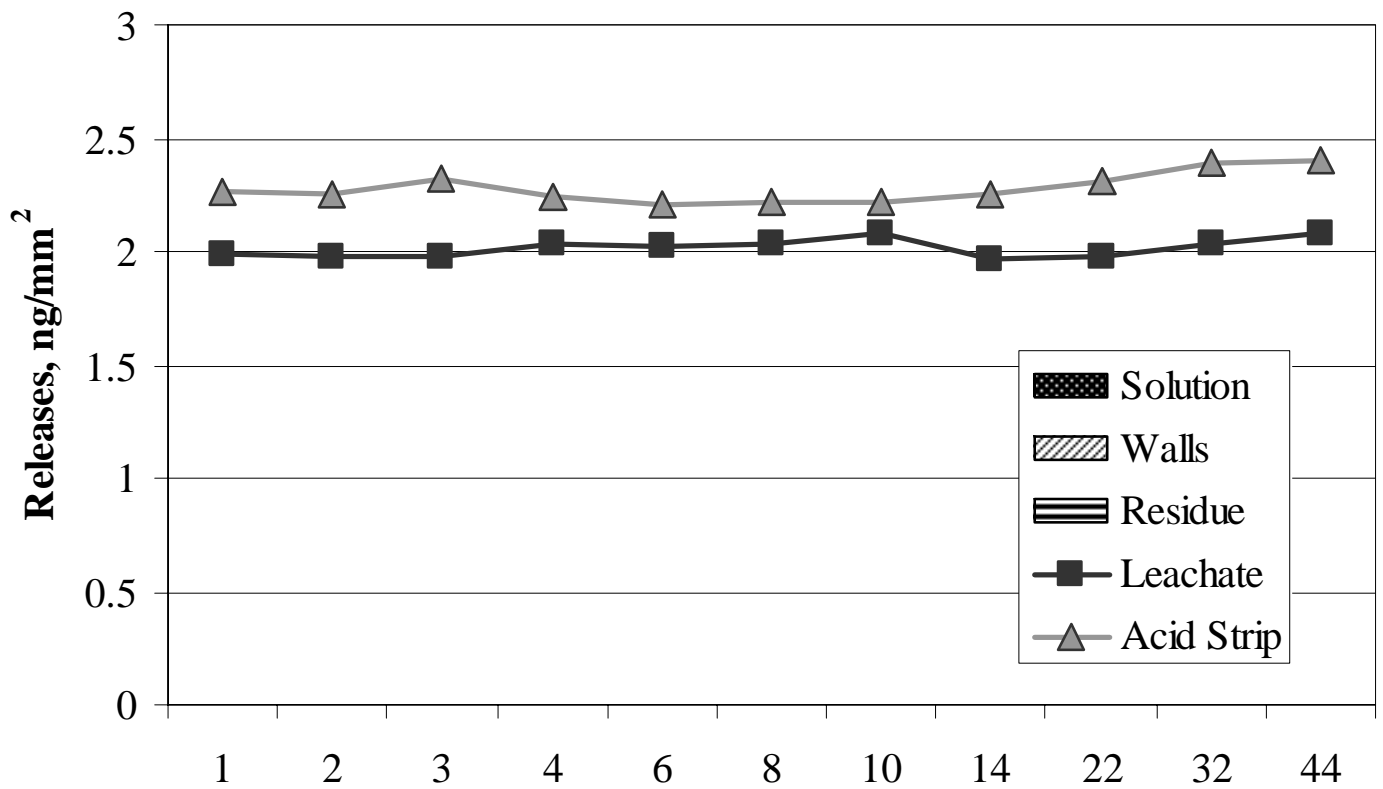

Time, weeks

Figure E-34. Chromium Releases in Solution, on Walls, and in Residue from Oxidized Sample 4 in CJ13 and Average Detection Limits for Leachate and Acid Strip. 


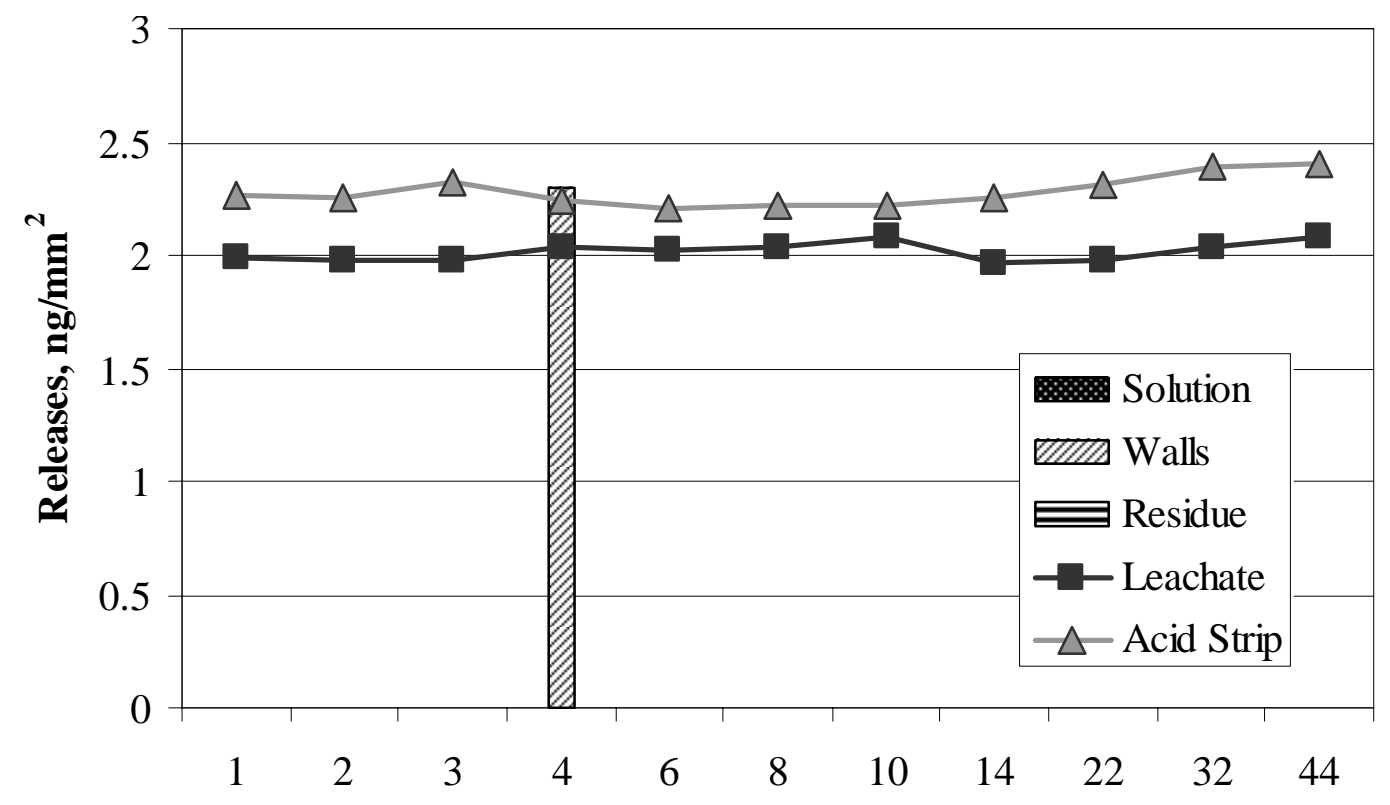

Time, weeks

Figure E-35. Chromium Releases in Solution, on Walls, and in Residue from Oxidized Sample 5 in CJ13 and Average Detection Limits for Leachate and Acid Strip.

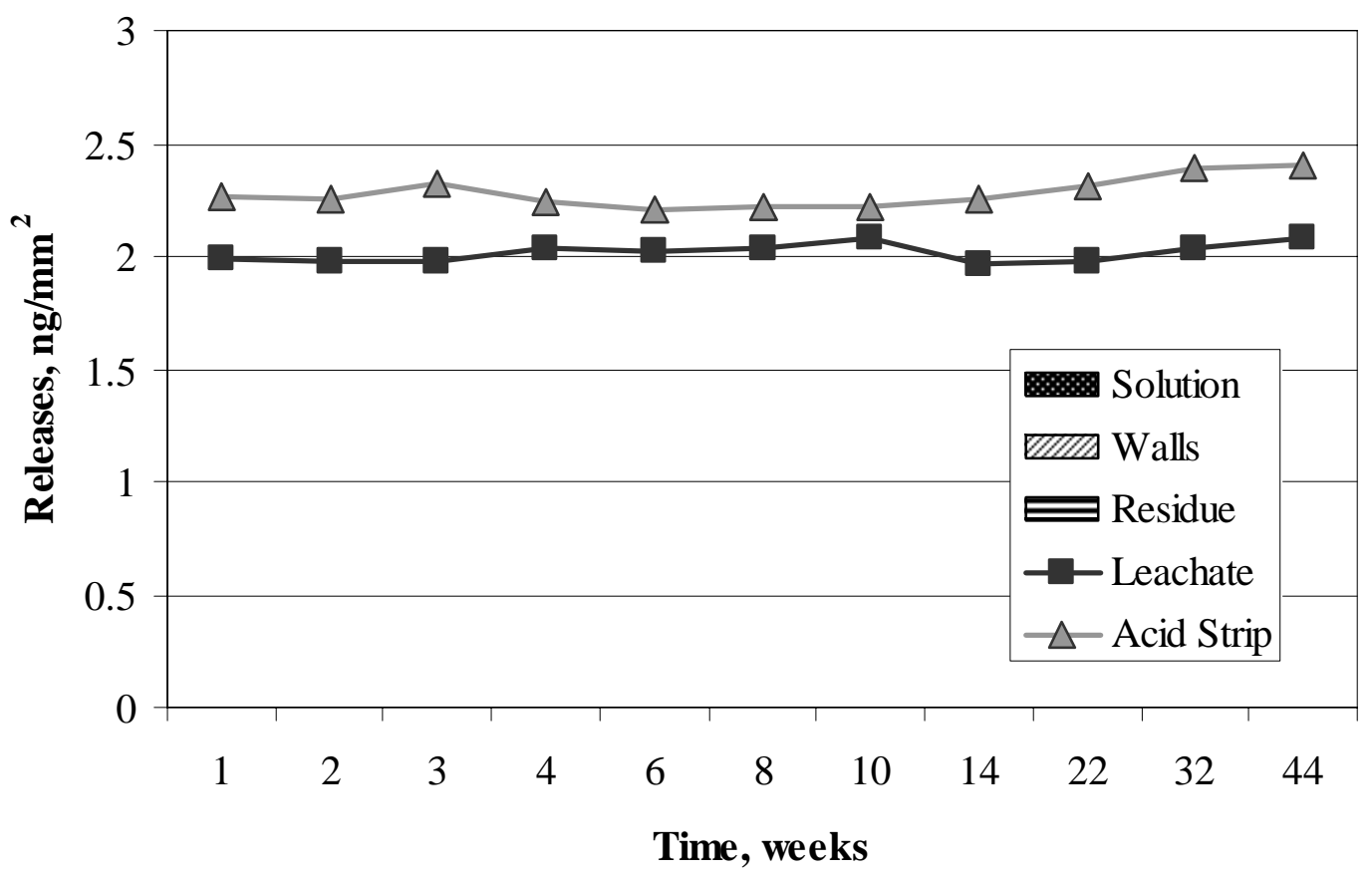

Figure E-36. Chromium Present in Solution, on Walls, and in Residue from CJ13 Control and Average Detection Limits for Leachate and Acid Strip. 


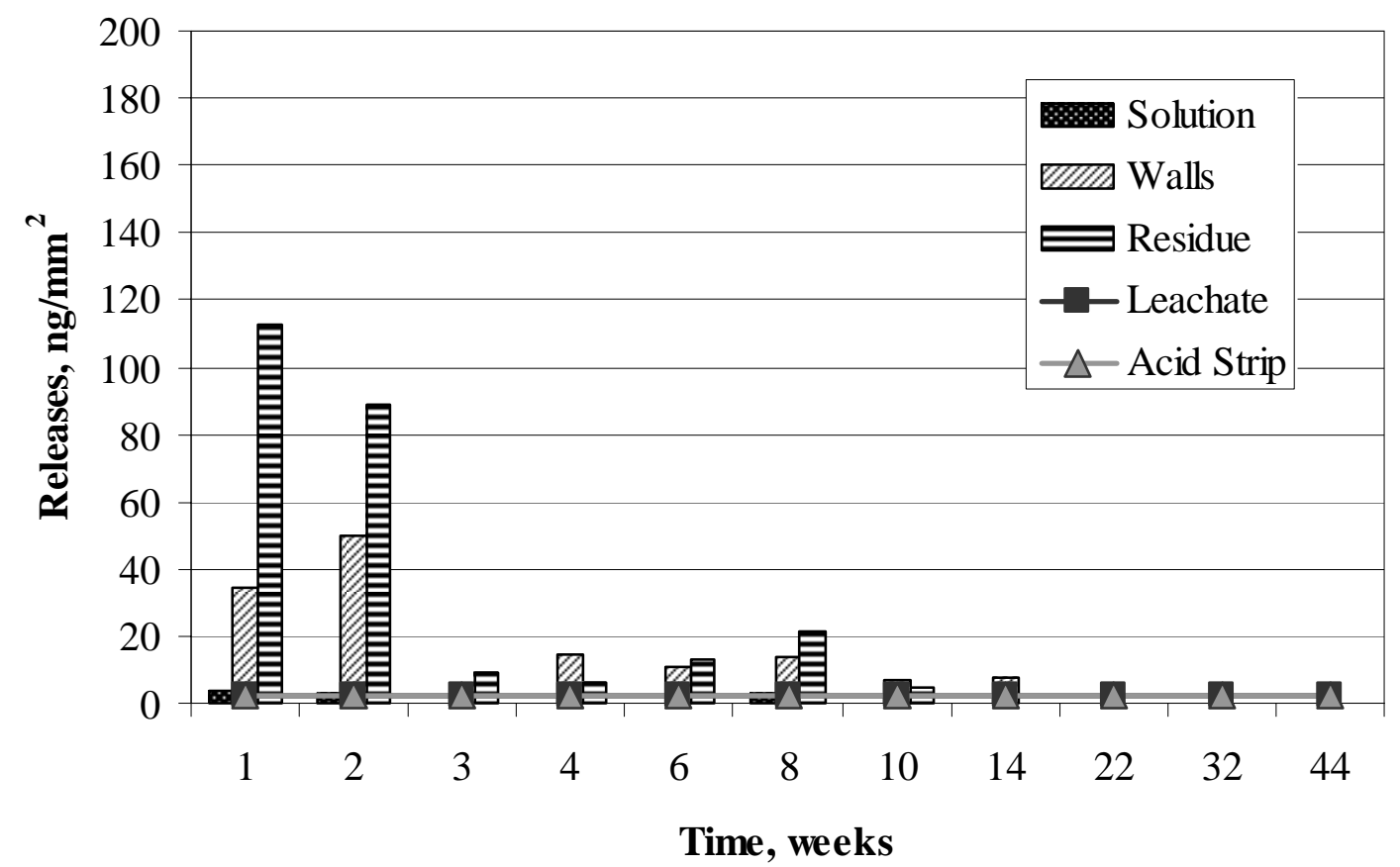

Figure E-37. Chromium Releases in Solution, on Walls, and in Residue from Polished Sample 1 in $10 \mathrm{KCl}$ and Average Detection Limits for Leachate and Acid Strip.

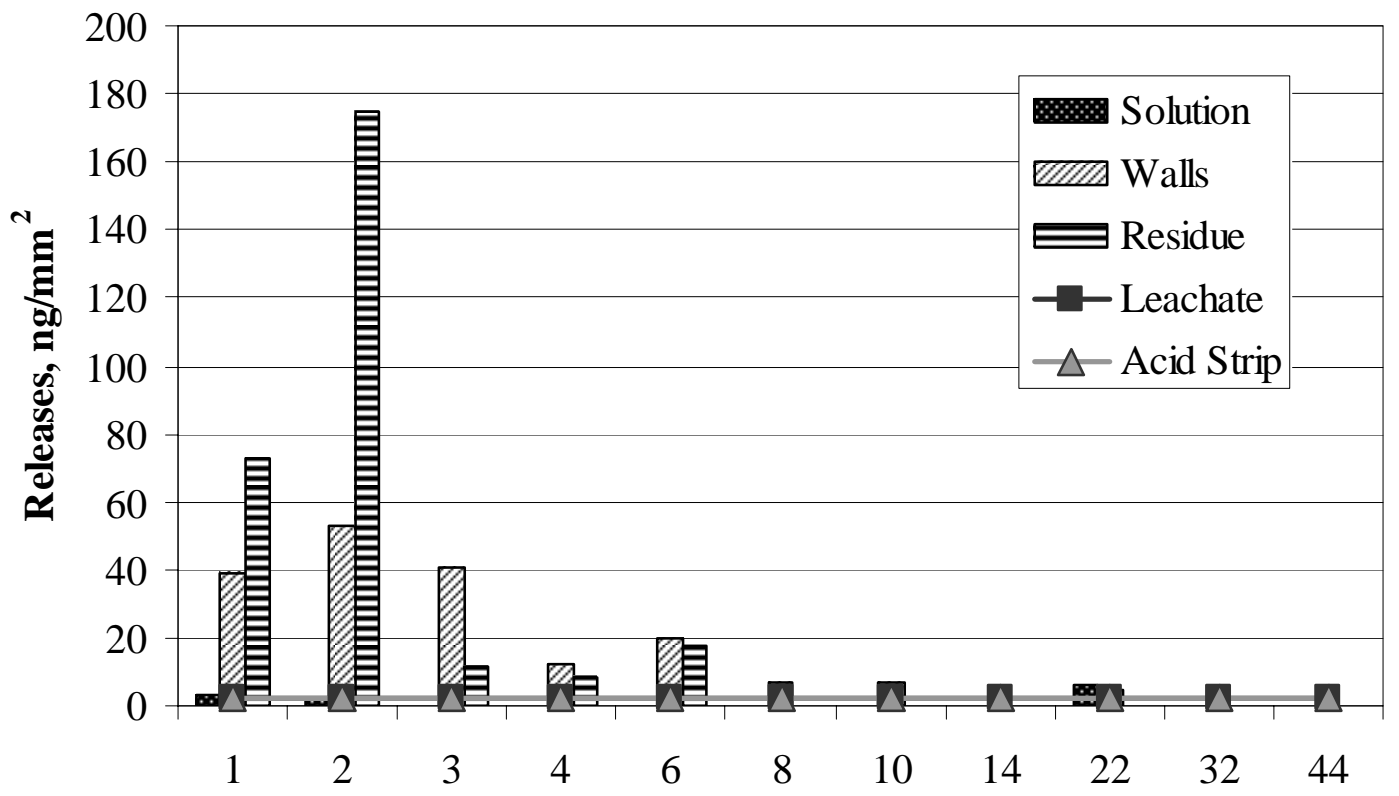

Time, weeks

Figure E-38. Chromium Releases in Solution, on Walls, and in Residue from Polished Sample 2 in $10 \mathrm{KCl}$ and Average Detection Limits for Leachate and Acid Strip. 


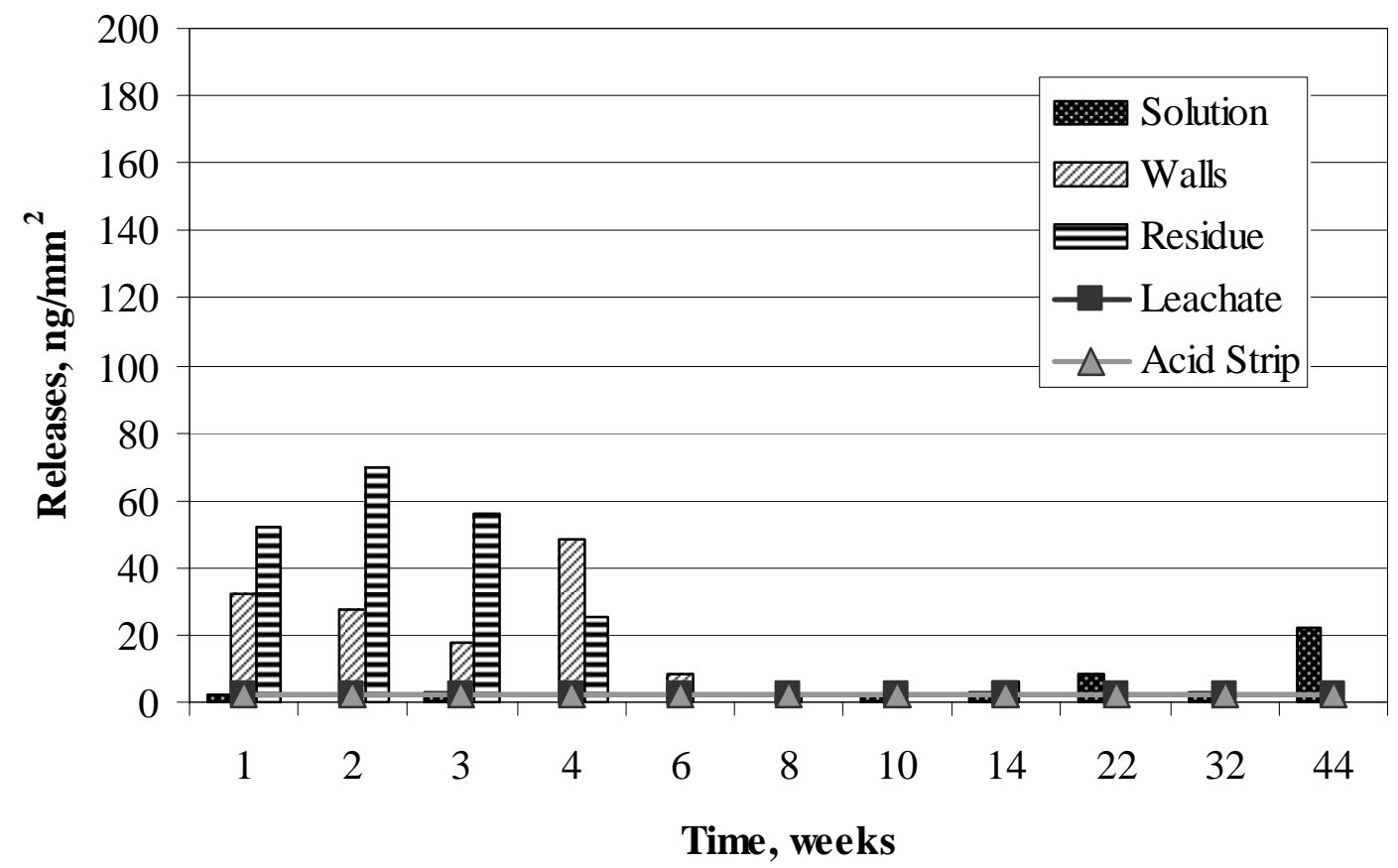

Figure E-39. Chromium Releases in Solution, on Walls, and in Residue from Polished Sample 3 in $10 \mathrm{KCl}$ and Average Detection Limits for Leachate and Acid Strip.

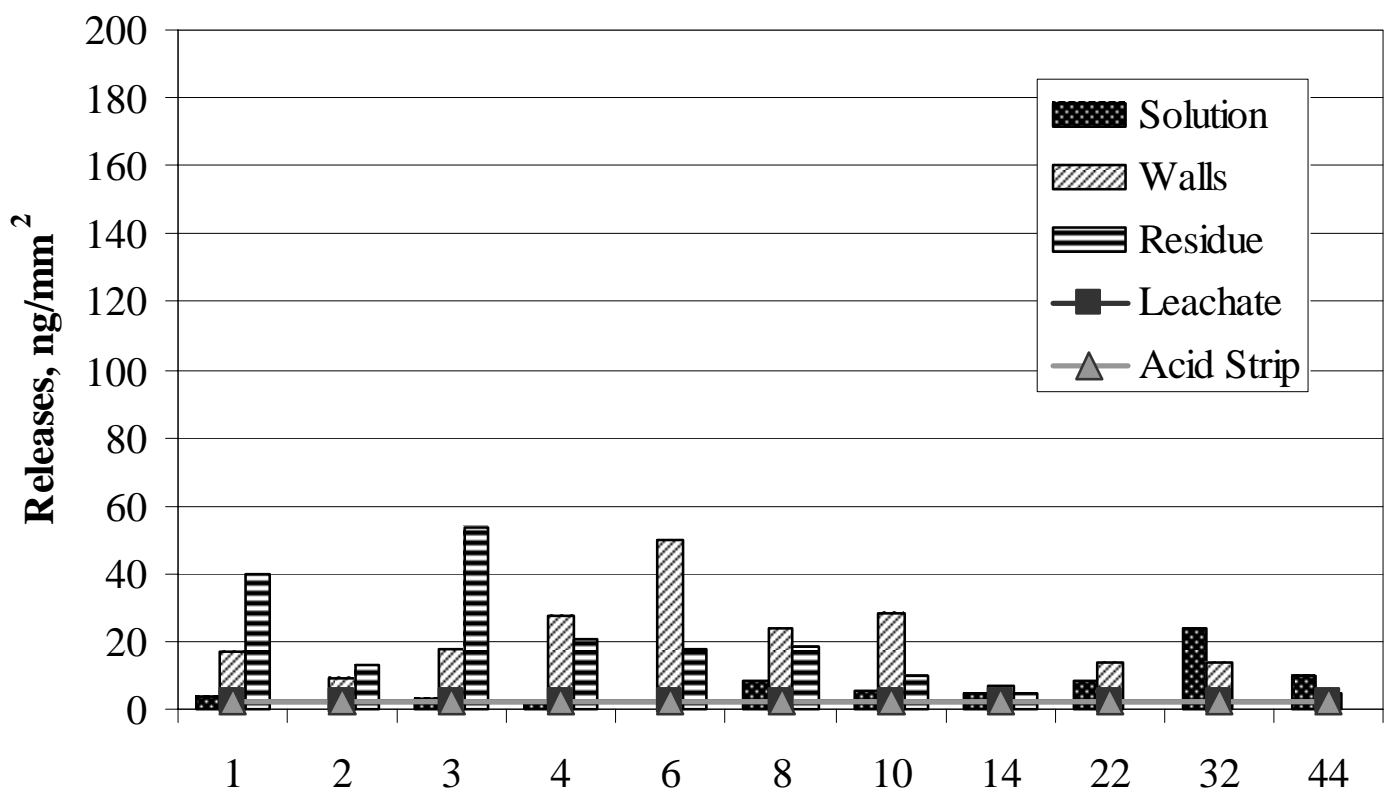

Time, weeks

Figure E-40. Chromium Releases in Solution, on Walls, and in Residue from Oxidized Sample 4 in $10 \mathrm{KCl}$ and Average Detection Limits for Leachate and Acid Strip. 


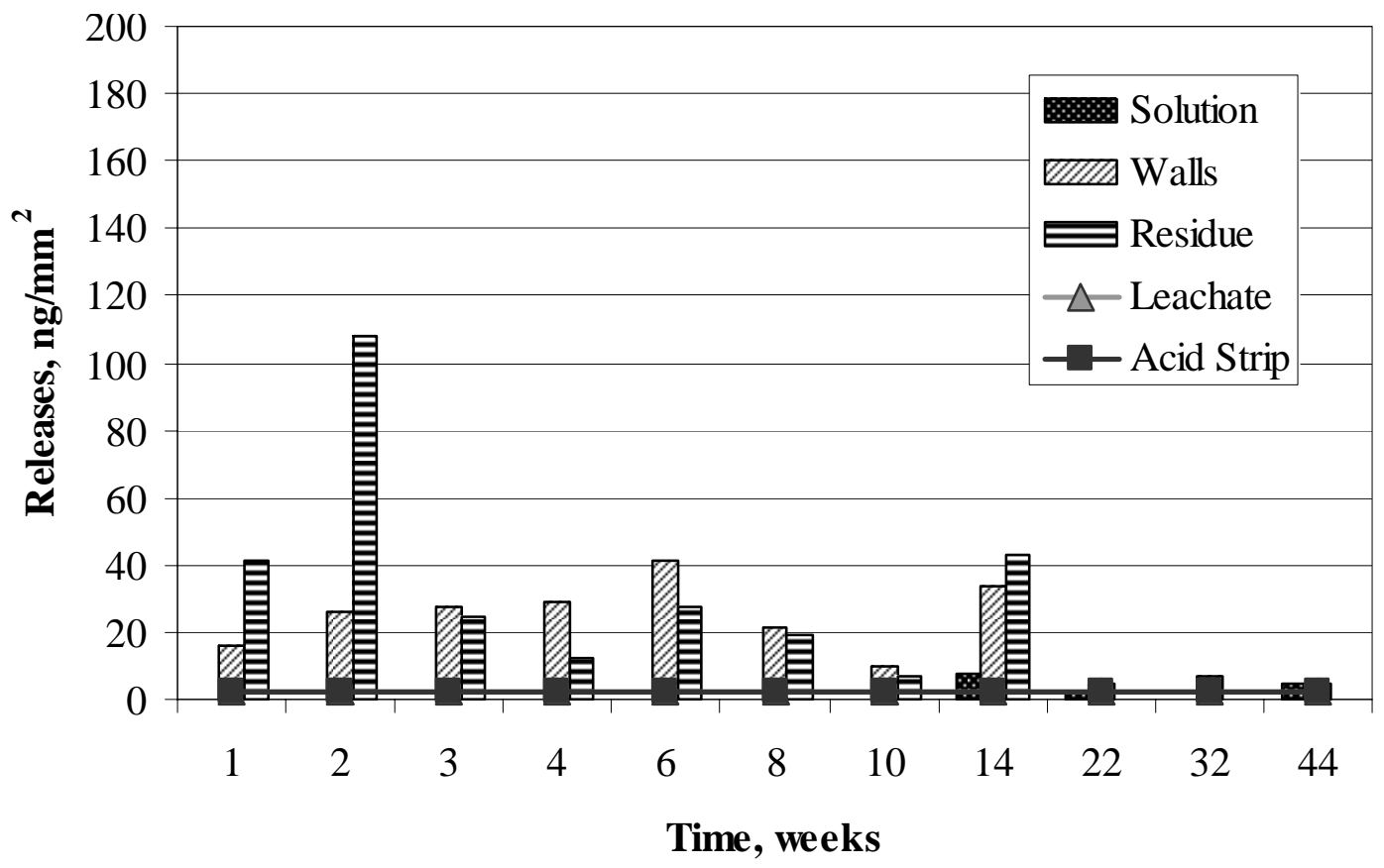

Figure E-41. Chromium Releases in Solution, on Walls, and in Residue from Oxidized Sample 5 in $10 \mathrm{KCl}$ and Average Detection Limits for Leachate and Acid Strip.

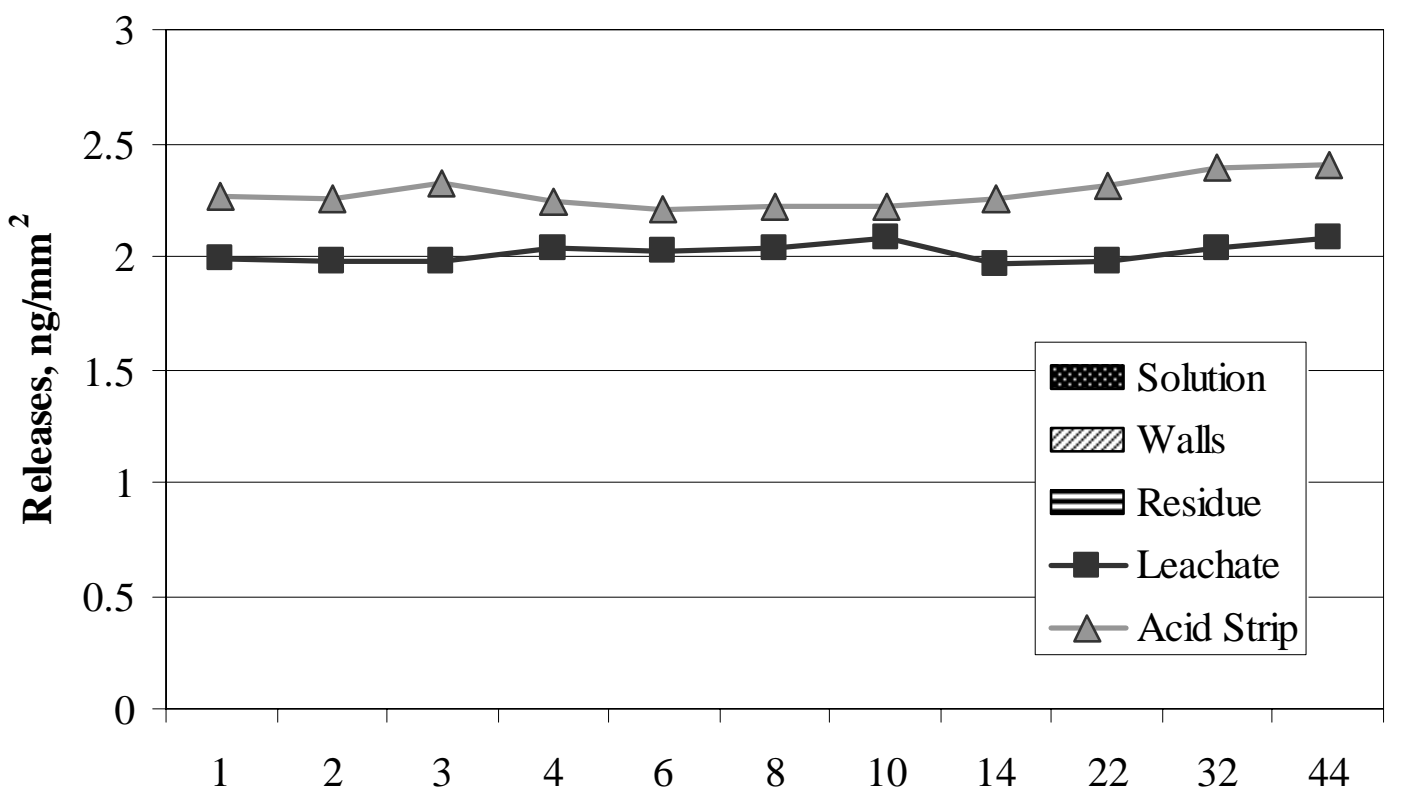

Time, weeks

Figure E-42. Chromium Present in Solution, on Walls, and in Residue from $10 \mathrm{KCl}$ Control and Average Detection Limits for Leachate and Acid Strip. 


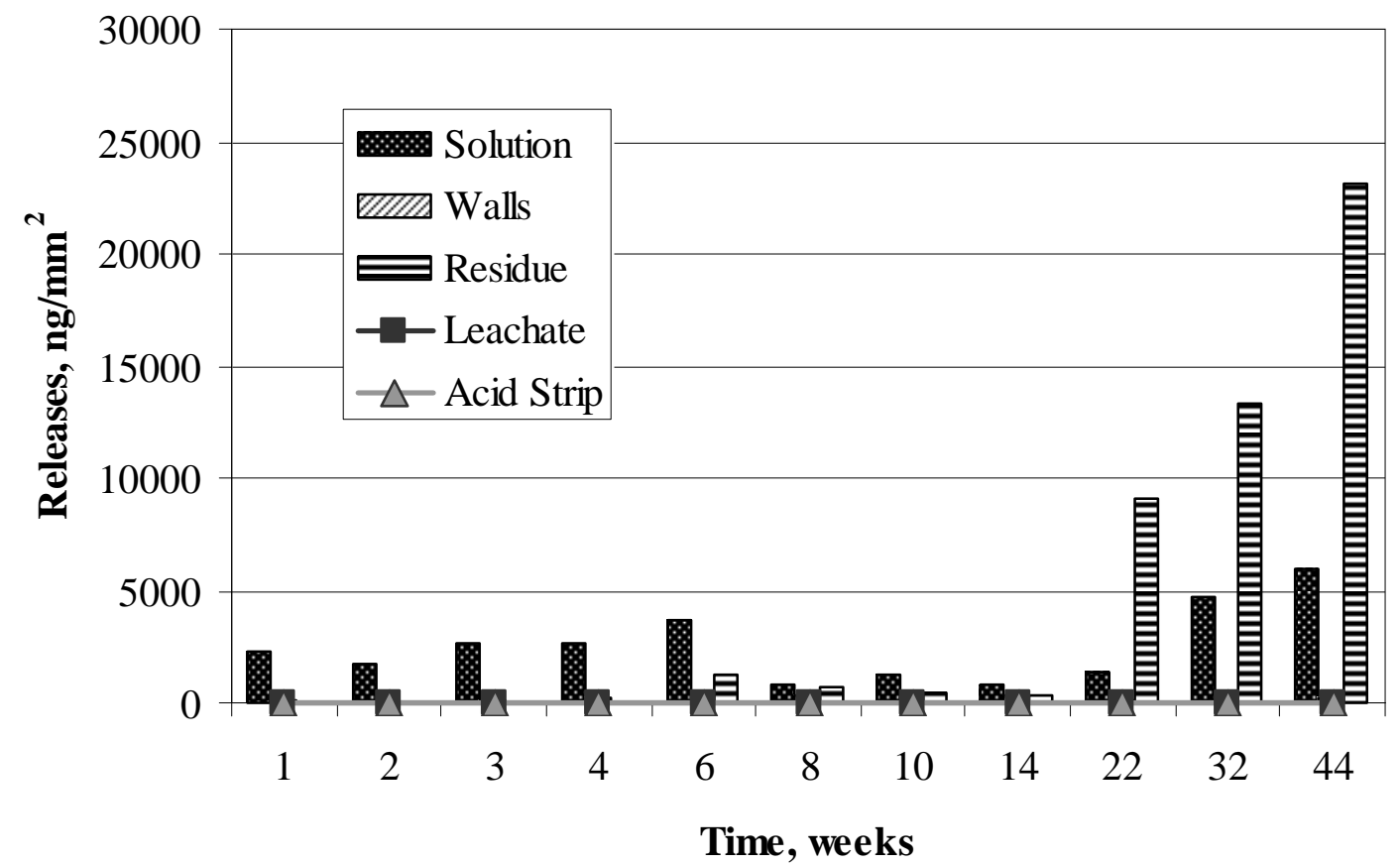

Figure E-43. Chromium Releases in Solution, on Walls, and in Residue from Polished Sample 1 in AJ13 and Average Detection Limits for Leachate and Acid Strip.

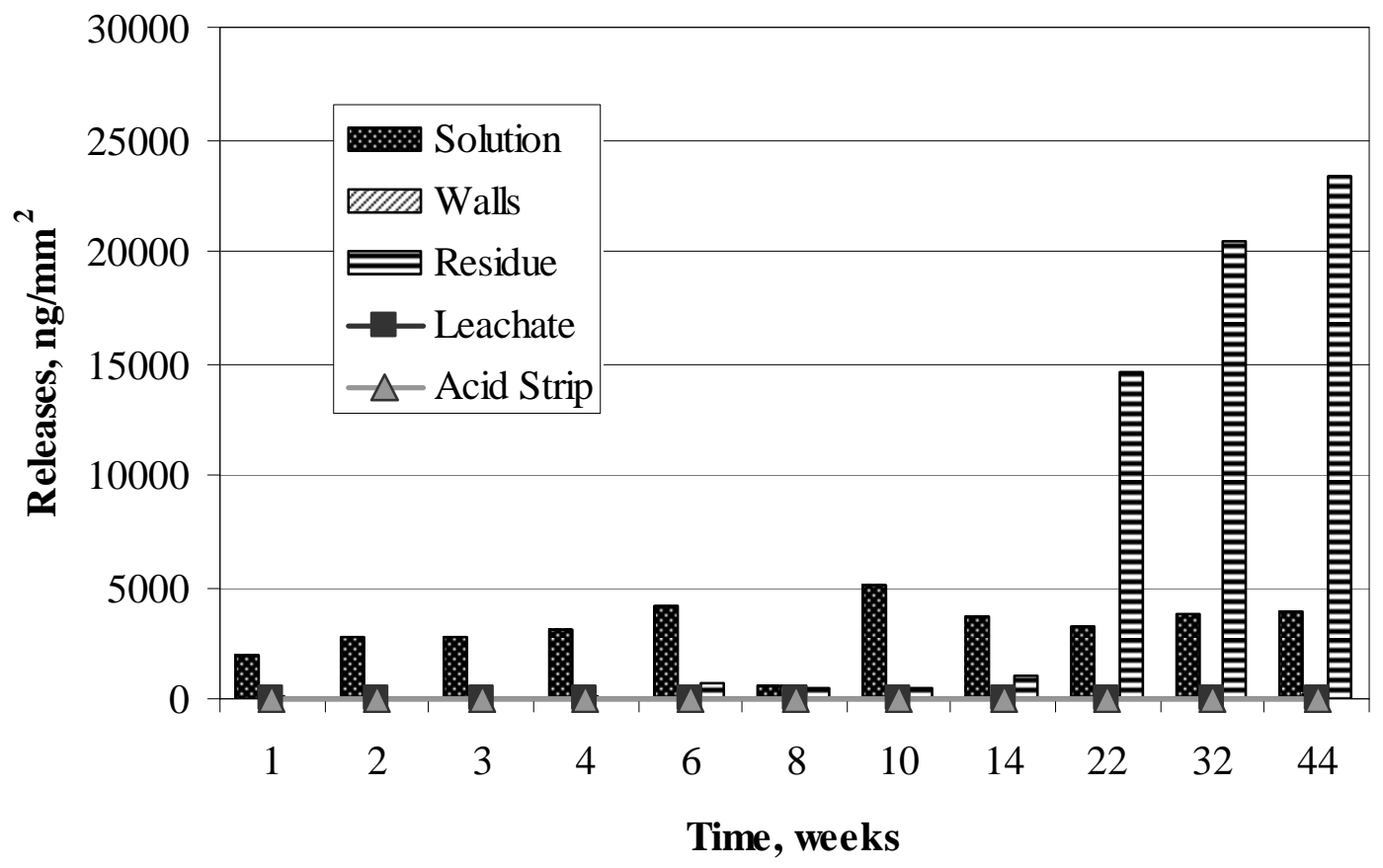

Figure E-44. Chromium Releases in Solution, on Walls, and in Residue from Polished Sample 2 in AJ13 and Average Detection Limits for Leachate and Acid Strip. 


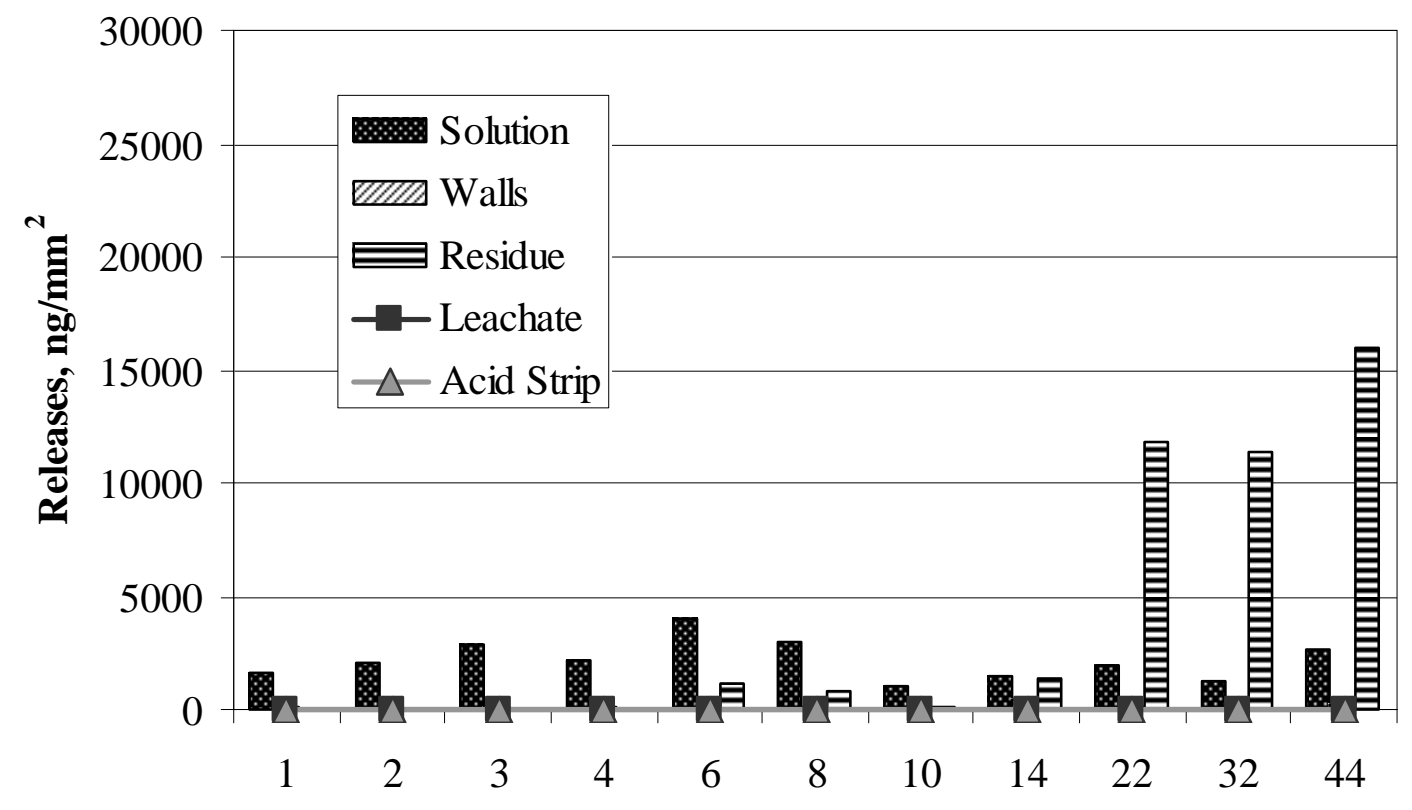

Time, weeks

Figure E-45. Chromium Releases in Solution, on Walls, and in Residue from Polished Sample 3 in AJ13 and Average Detection Limits for Leachate and Acid Strip.

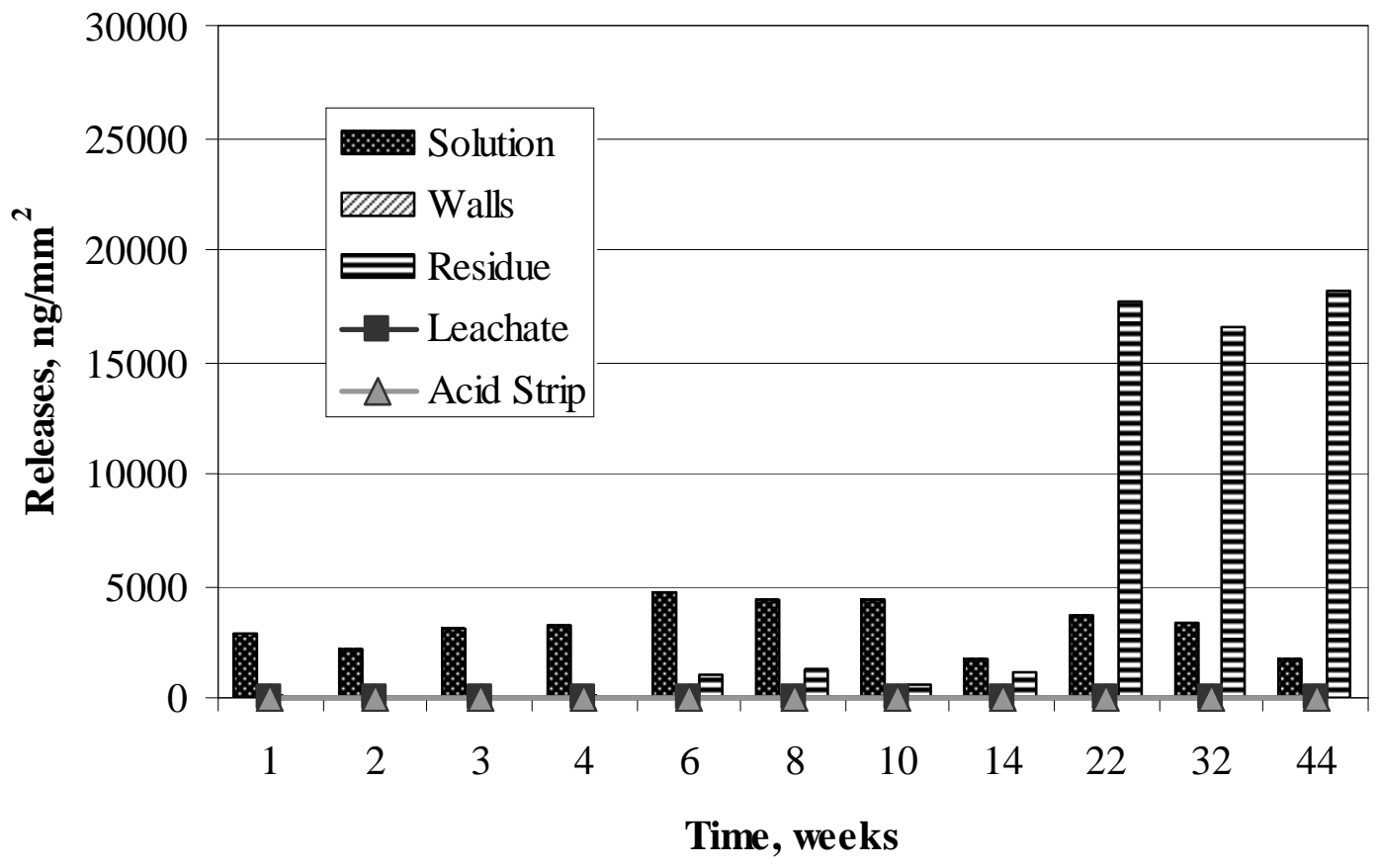

Figure E-46. Chromium Releases in Solution, on Walls, and in Residue from Oxidized Sample 4 in AJ13 and Average Detection Limits for Leachate and Acid Strip. 


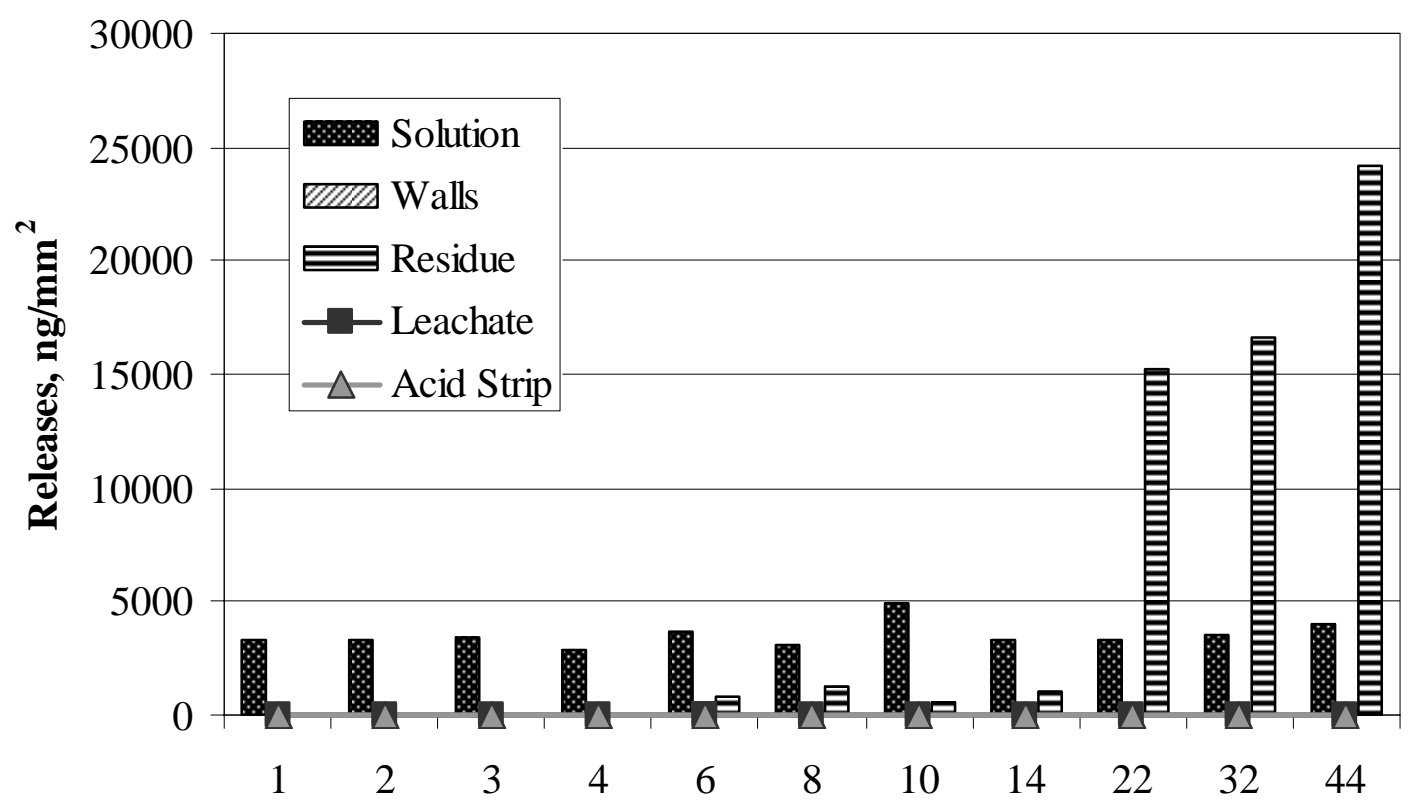

Time, weeks

Figure E-47. Chromium Releases in Solution, on Walls, and in Residue from Oxidized Sample 5 in AJ13 and Average Detection Limits for Leachate and Acid Strip.

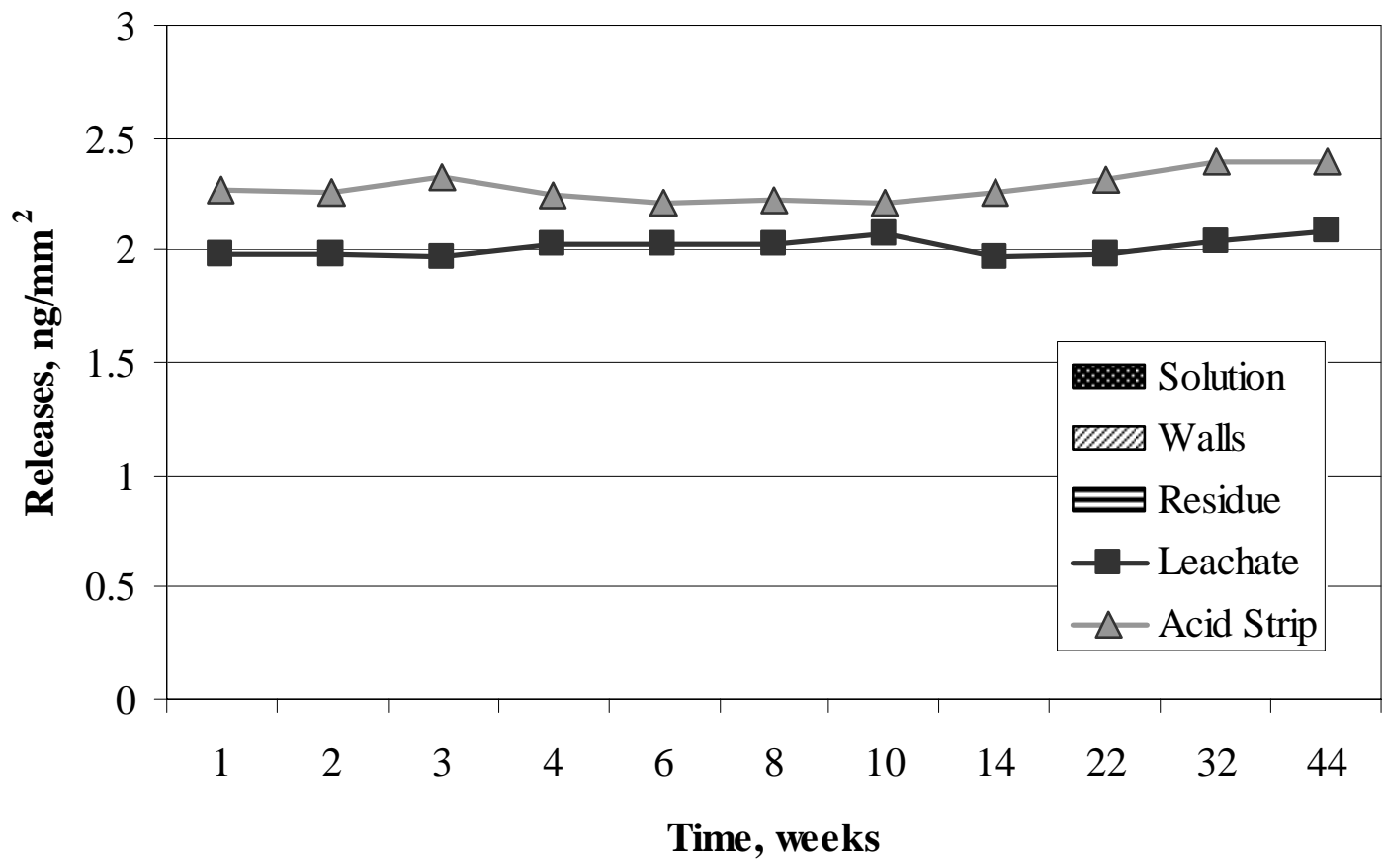

Figure E-48. Chromium Present in Solution, on Walls, and in Residue from AJ13 Control and Average Detection Limits for Leachate and Acid Strip. 


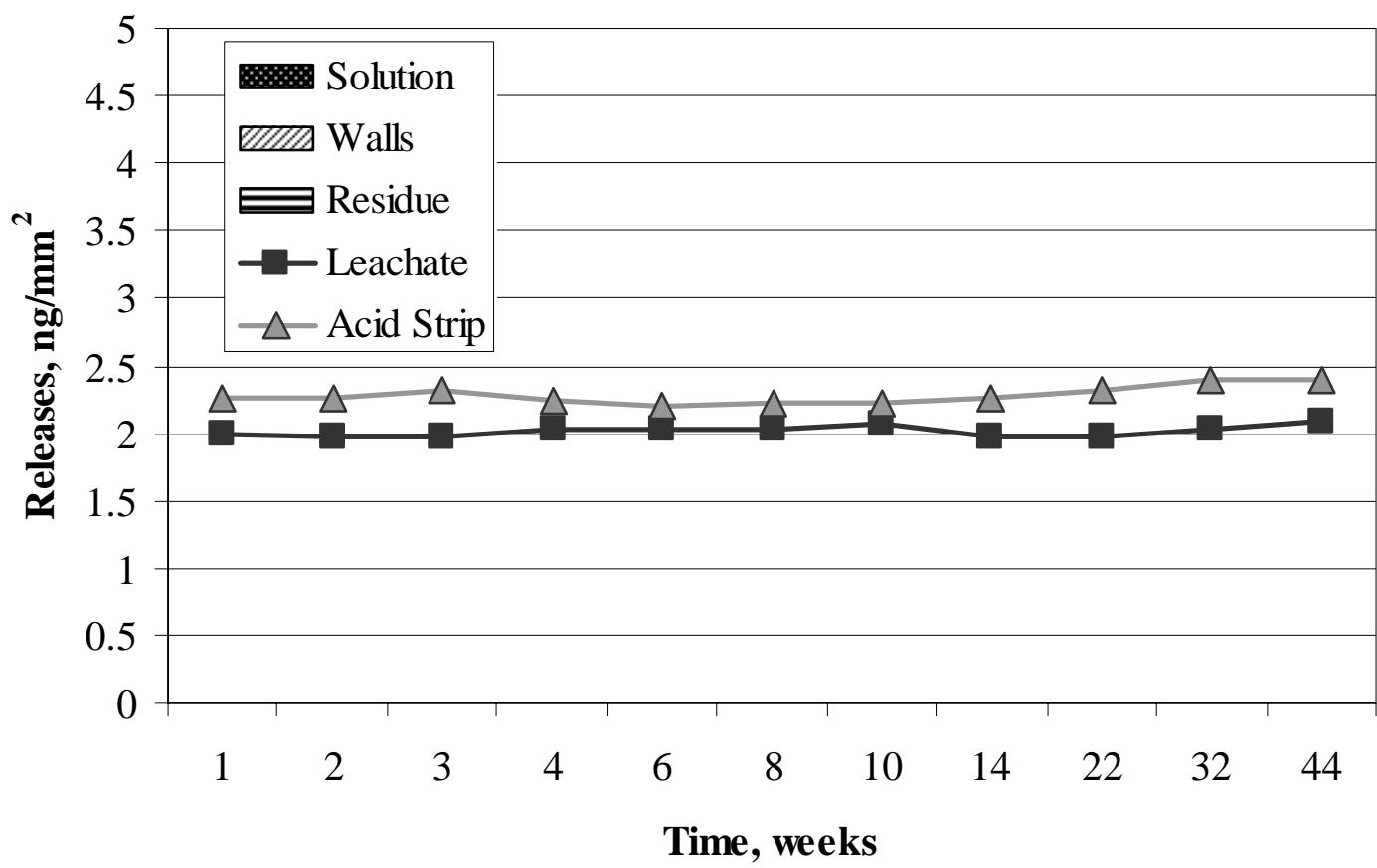

Figure E-49. Nickel Releases in Solution, on Walls, and in Residue from Polished Sample 1 in SJ13 and Average Detection Limits for Leachate and Acid Strip.

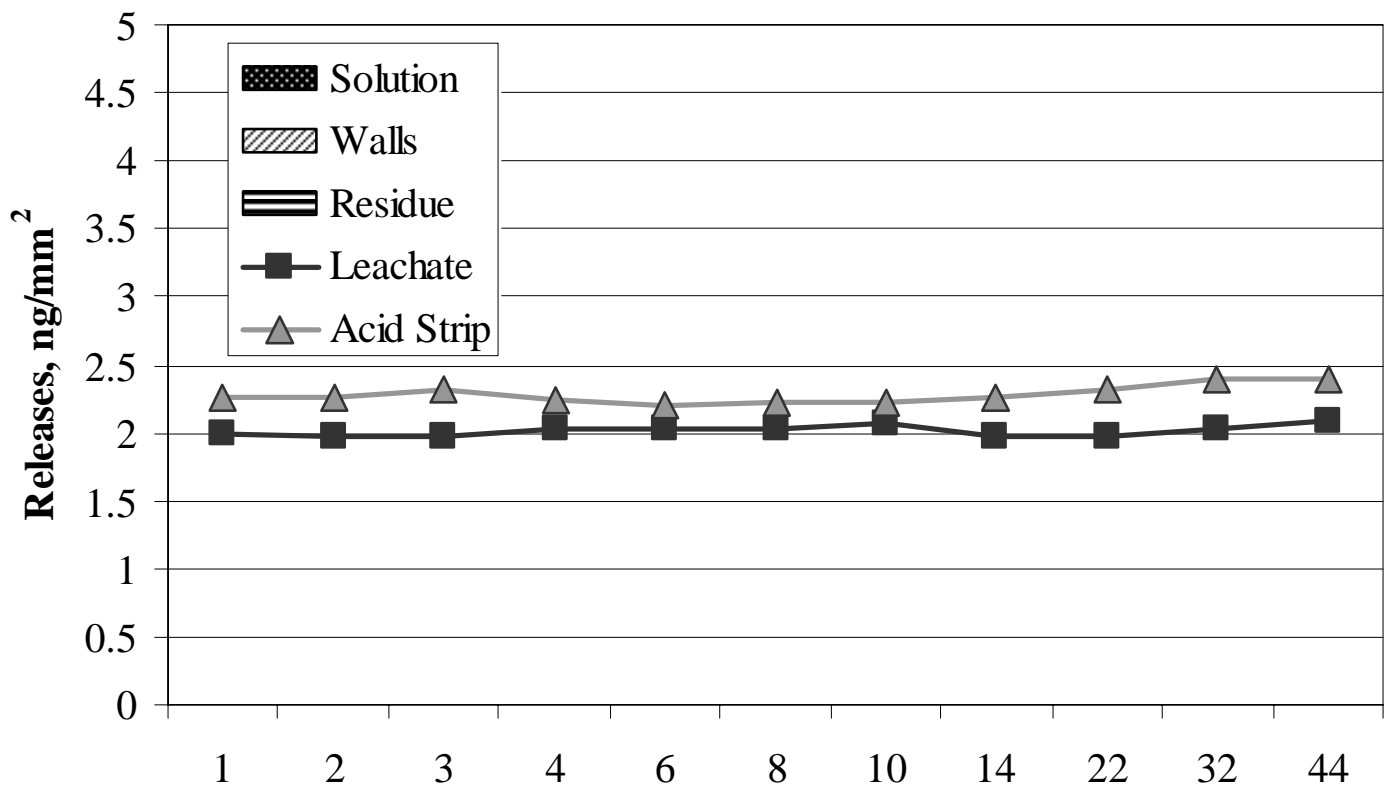

Time, weeks

Figure E-50. Nickel Releases in Solution, on Walls, and in Residue from Polished Sample 2 in SJ13 and Average Detection Limits for Leachate and Acid Strip. 


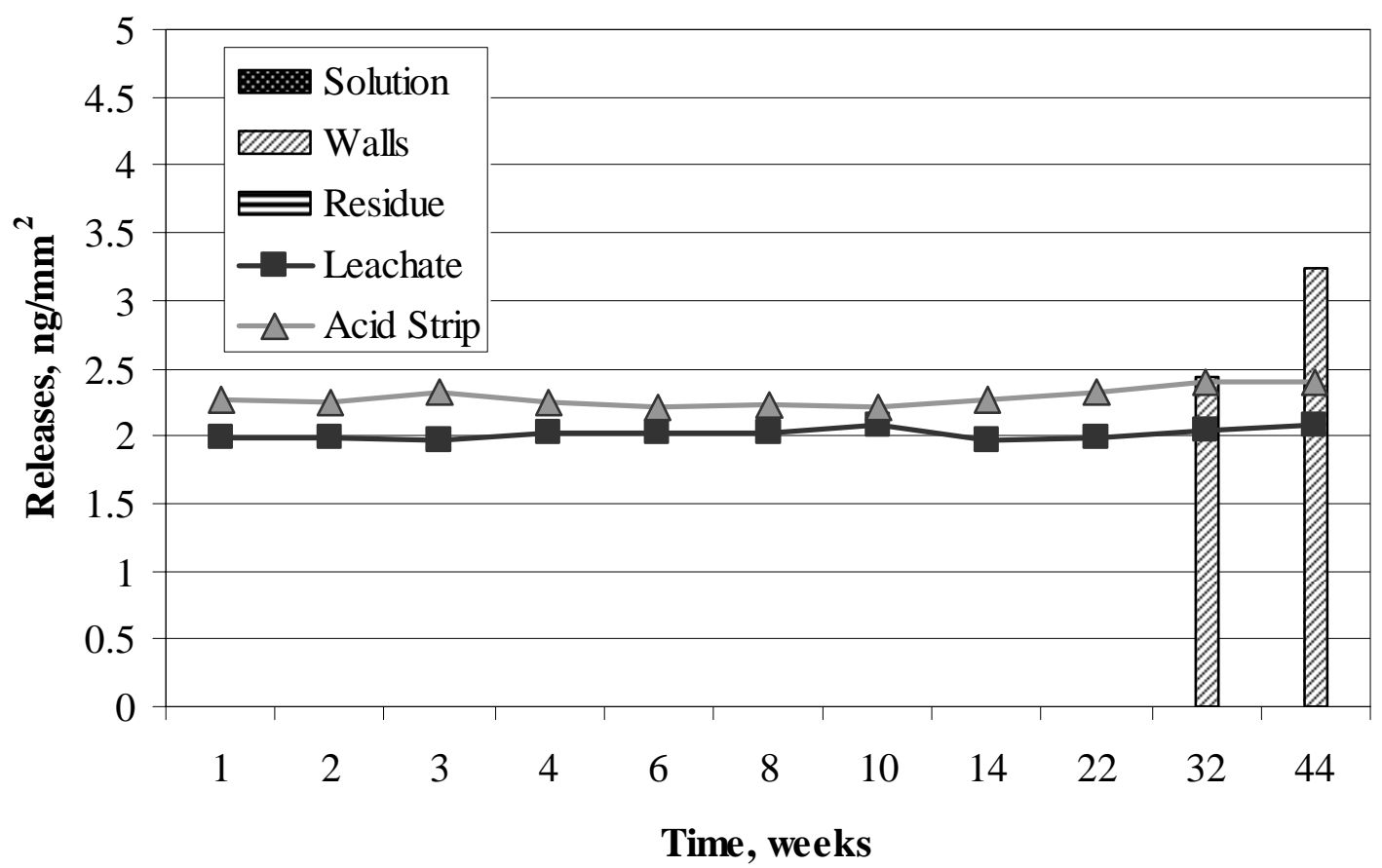

Figure E-51. Nickel Releases in Solution, on Walls, and in Residue from Polished Sample 3 in SJ13 and Average Detection Limits for Leachate and Acid Strip.

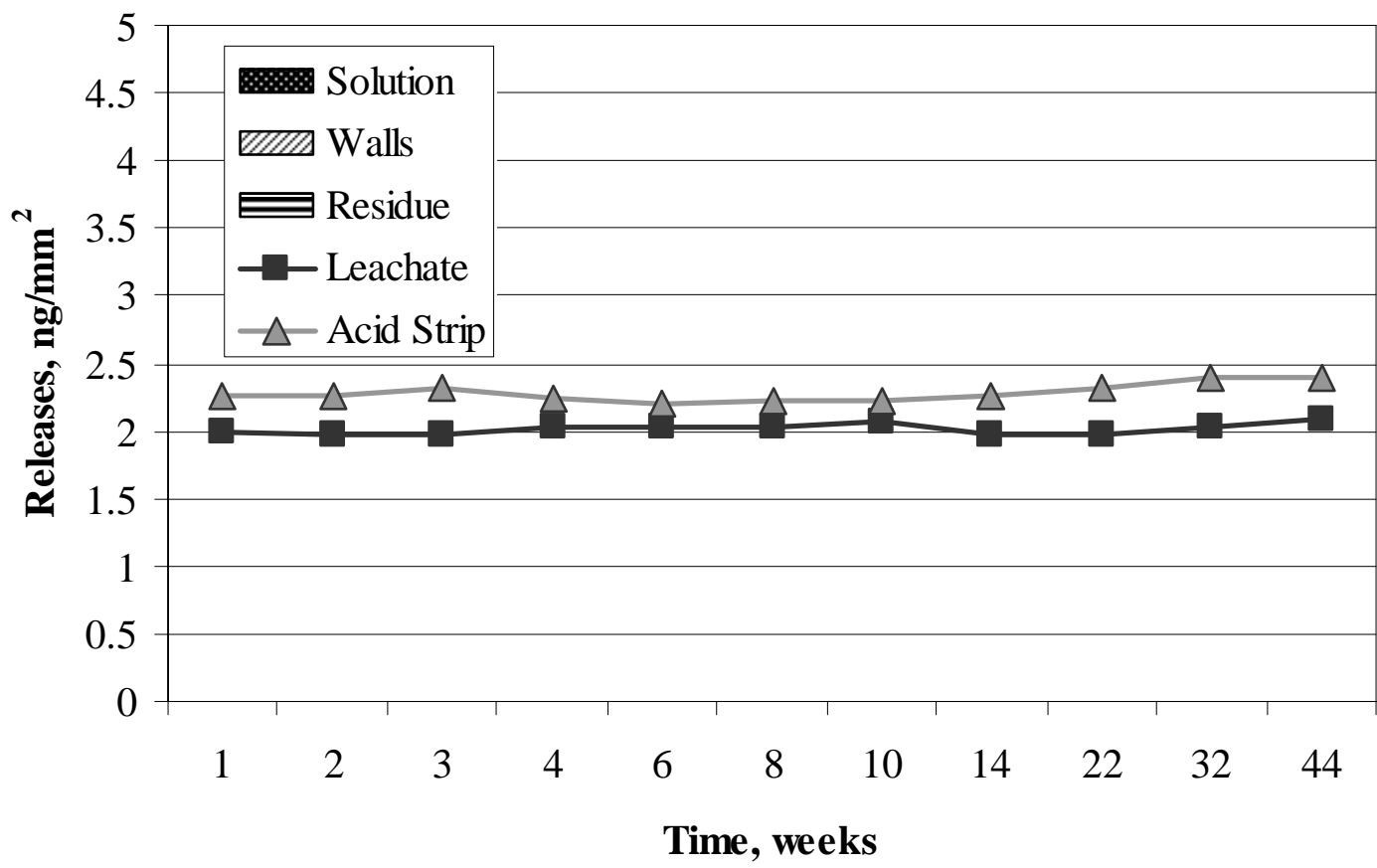

Figure E-52. Nickel Releases in Solution, on Walls, and in Residue from Oxidized Sample 4 in SJ13 and Average Detection Limits for Leachate and Acid Strip. 


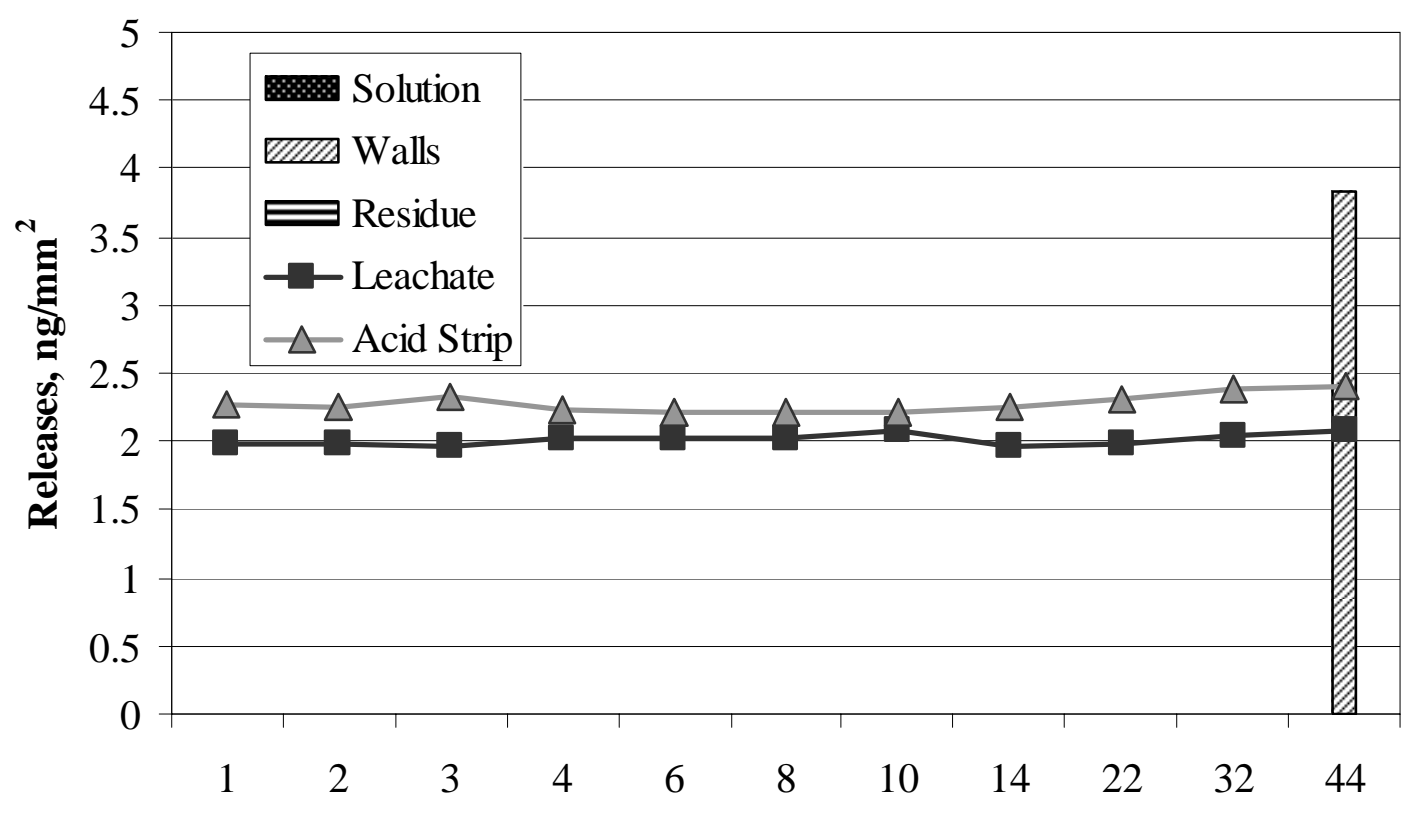

Time, weeks

Figure E-53. Nickel Releases in Solution, on Walls, and in Residue from Oxidized Sample 5 in SJ13 and Average Detection Limits for Leachate and Acid Strip.

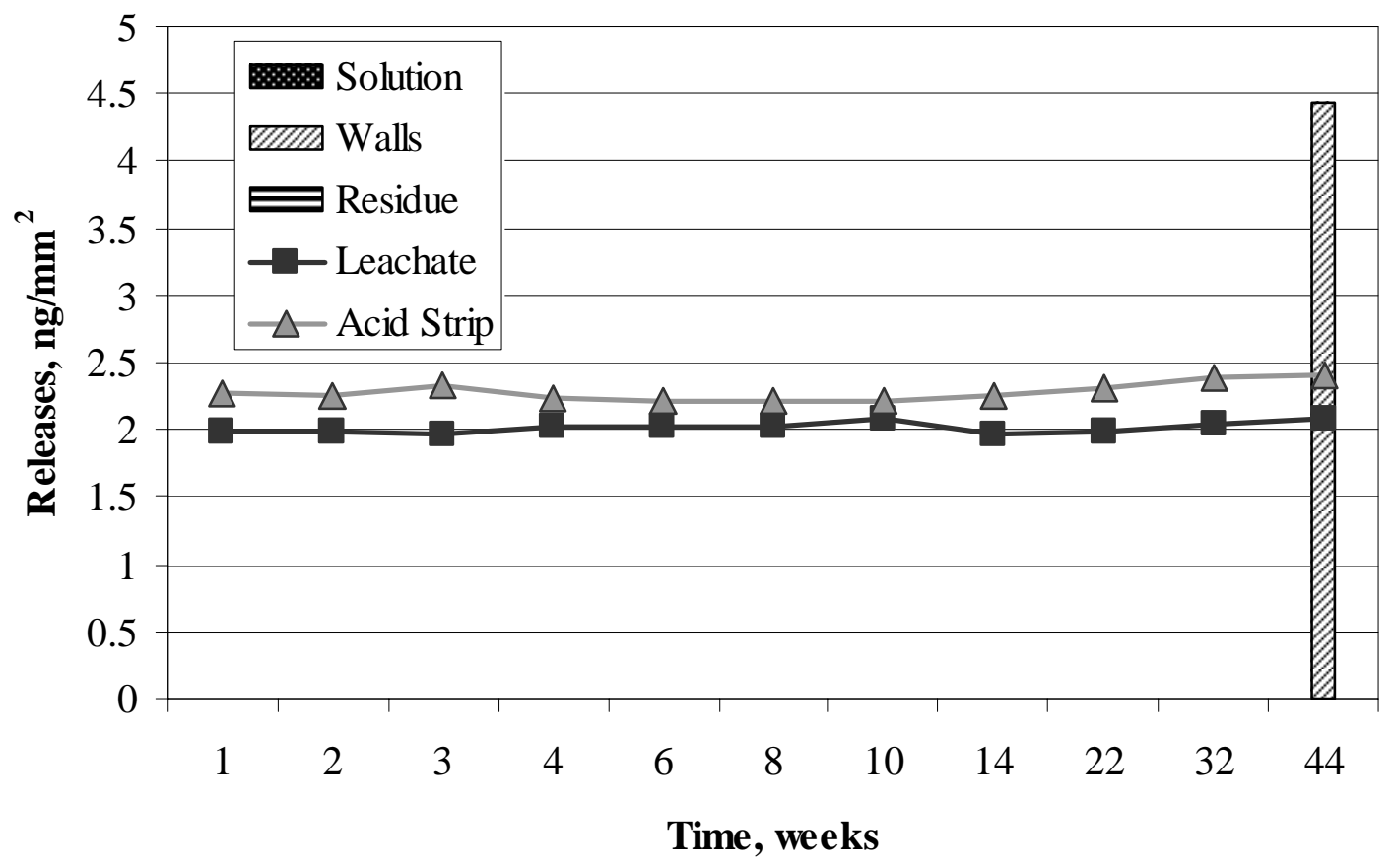

Figure E-54. Nickel Present in Solution, on Walls, and in Residue from SJ13 Control and Average Detection Limits for Leachate and Acid Strip. 


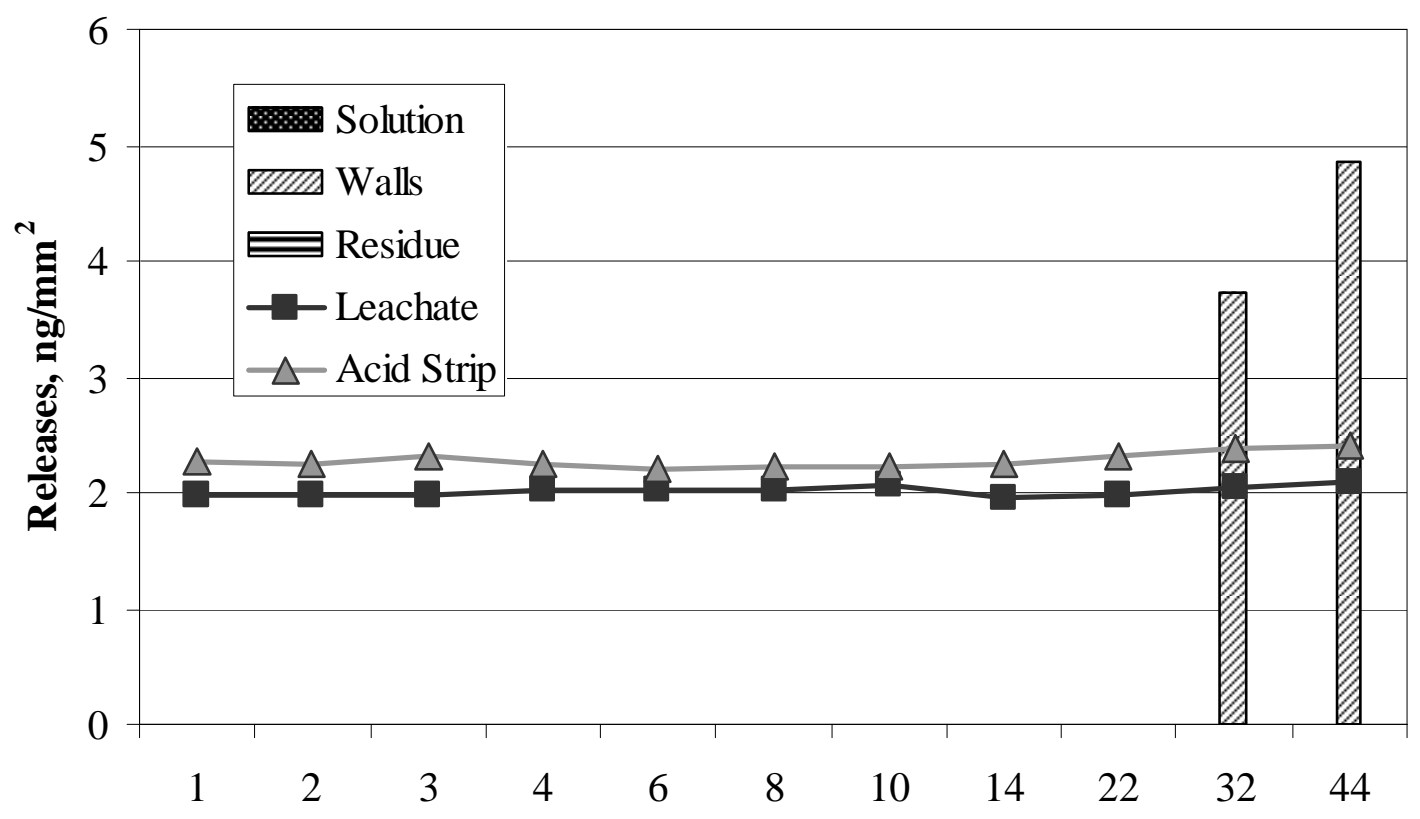

Time, weeks

Figure E-55. Nickel Releases in Solution, on Walls, and in Residue from Polished Sample 1 in CJ13 and Average Detection Limits for Leachate and Acid Strip.

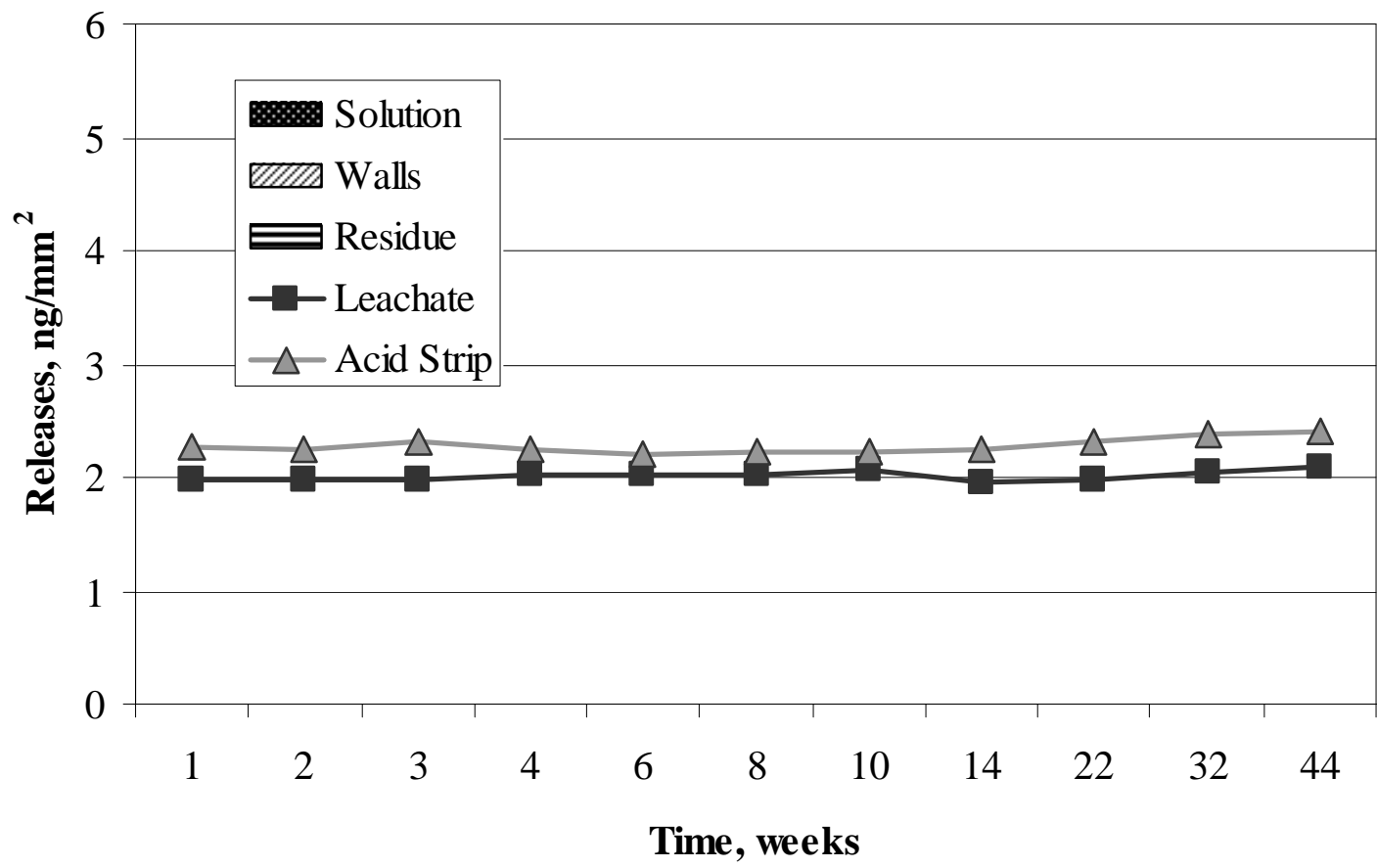

Figure E-56. Nickel Releases in Solution, on Walls, and in Residue from Polished Sample 2 in CJ13 and Average Detection Limits for Leachate and Acid Strip. 


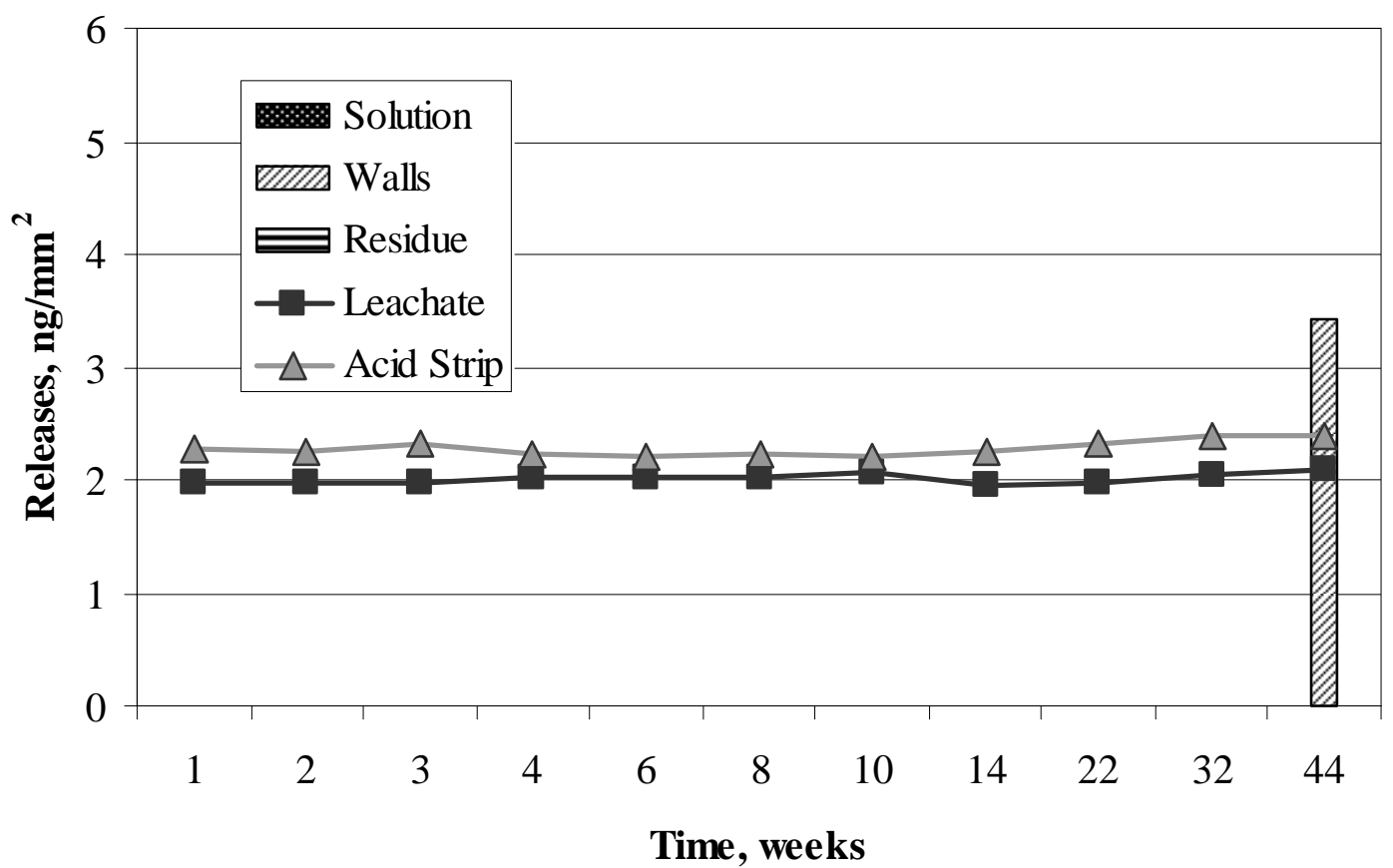

Figure E-57. Nickel Releases in Solution, on Walls, and in Residue from Polished Sample 3 in CJ13 and Average Detection Limits for Leachate and Acid Strip.

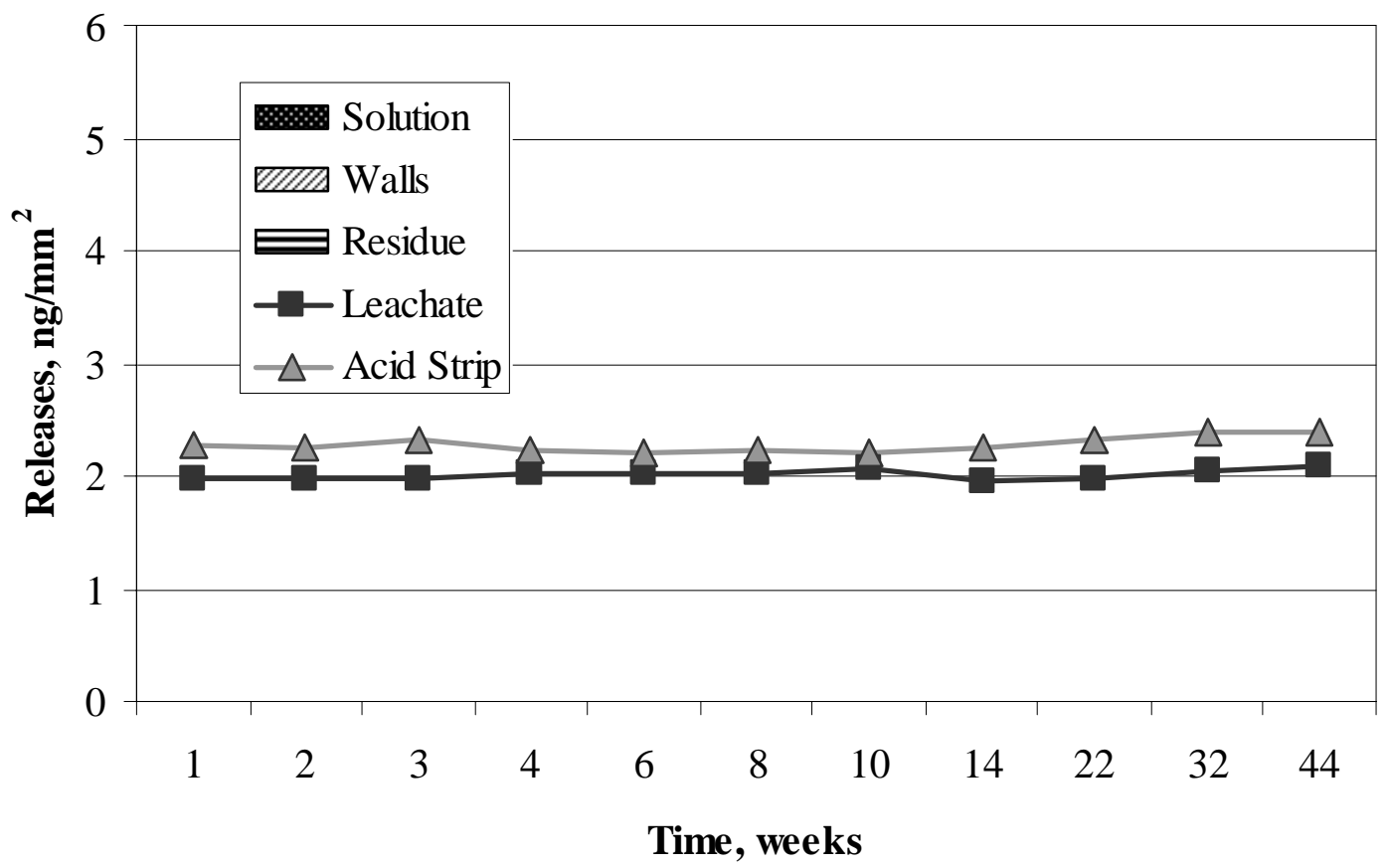

Figure E-58. Nickel Releases in Solution, on Walls, and in Residue from Oxidized Sample 4 in CJ13 and Average Detection Limits for Leachate and Acid Strip. 


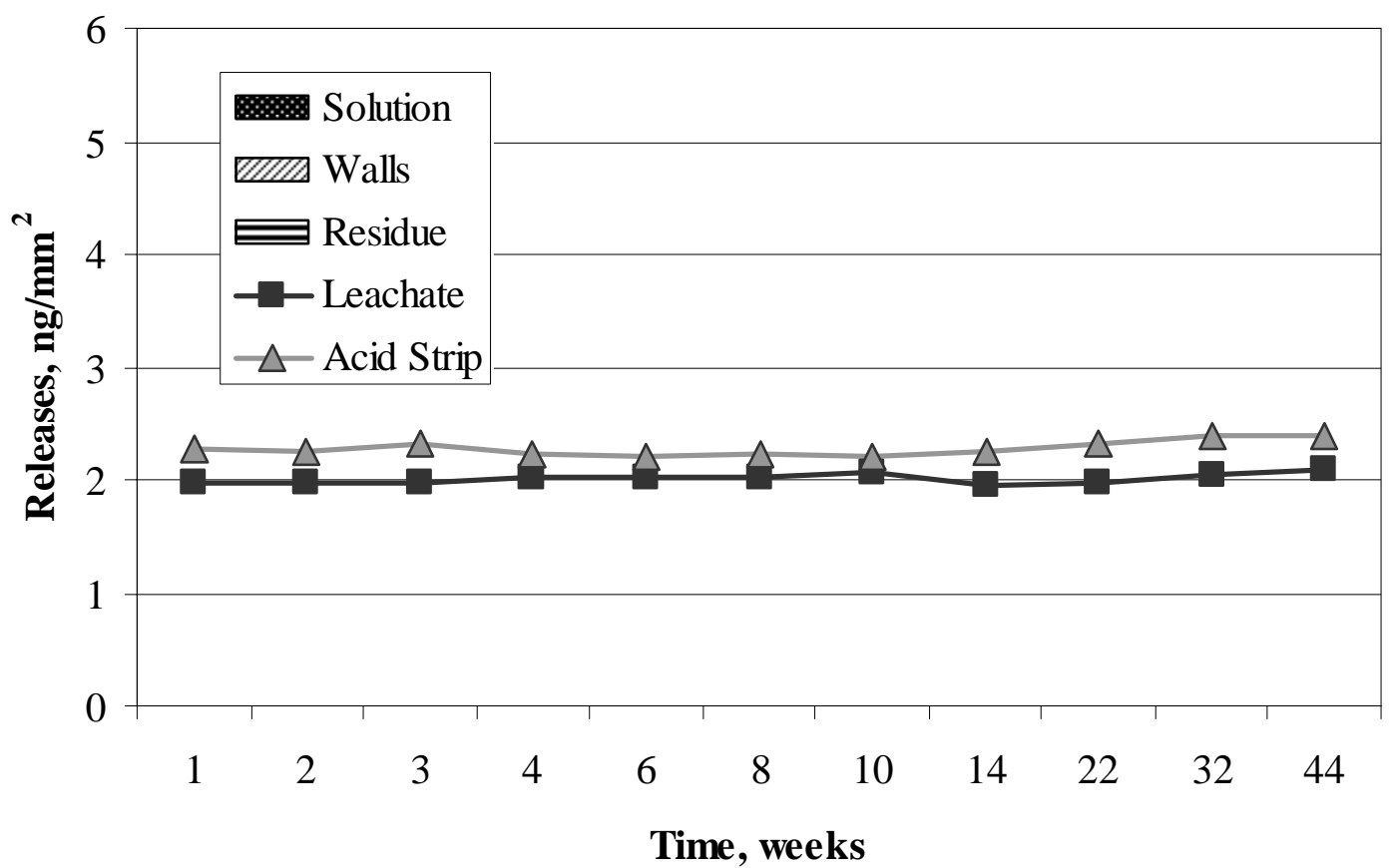

Figure E-59. Nickel Releases in Solution, on Walls, and in Acid Strip from Oxidized Sample 5 in CJ13 and Average Detection Limits for Leachate and Acid Strip.

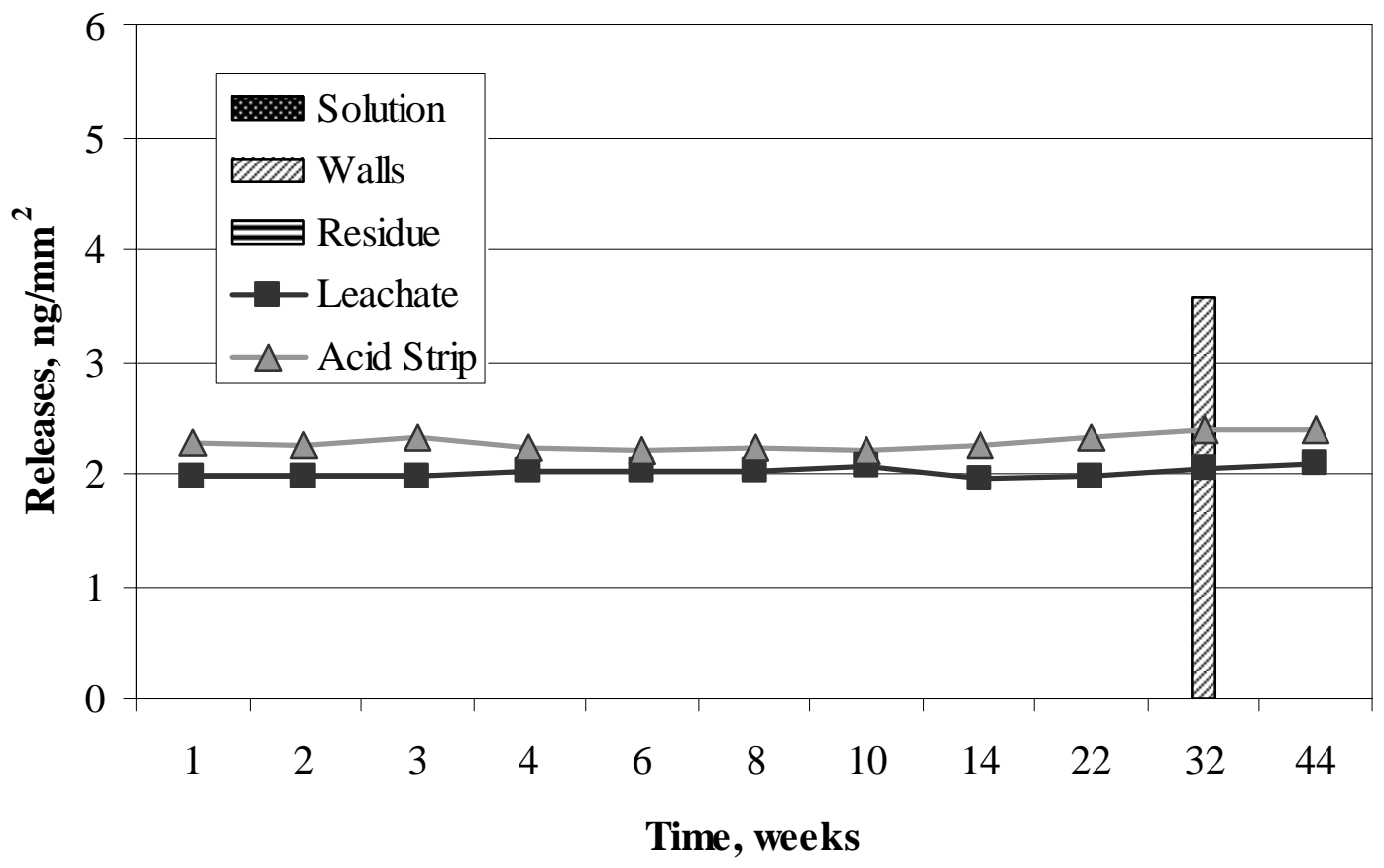

Figure E-60. Nickel Present in Solution, on Walls, and in Acid Strip from CJ13 Control and Average Detection Limits for Leachate and Acid Strip. 


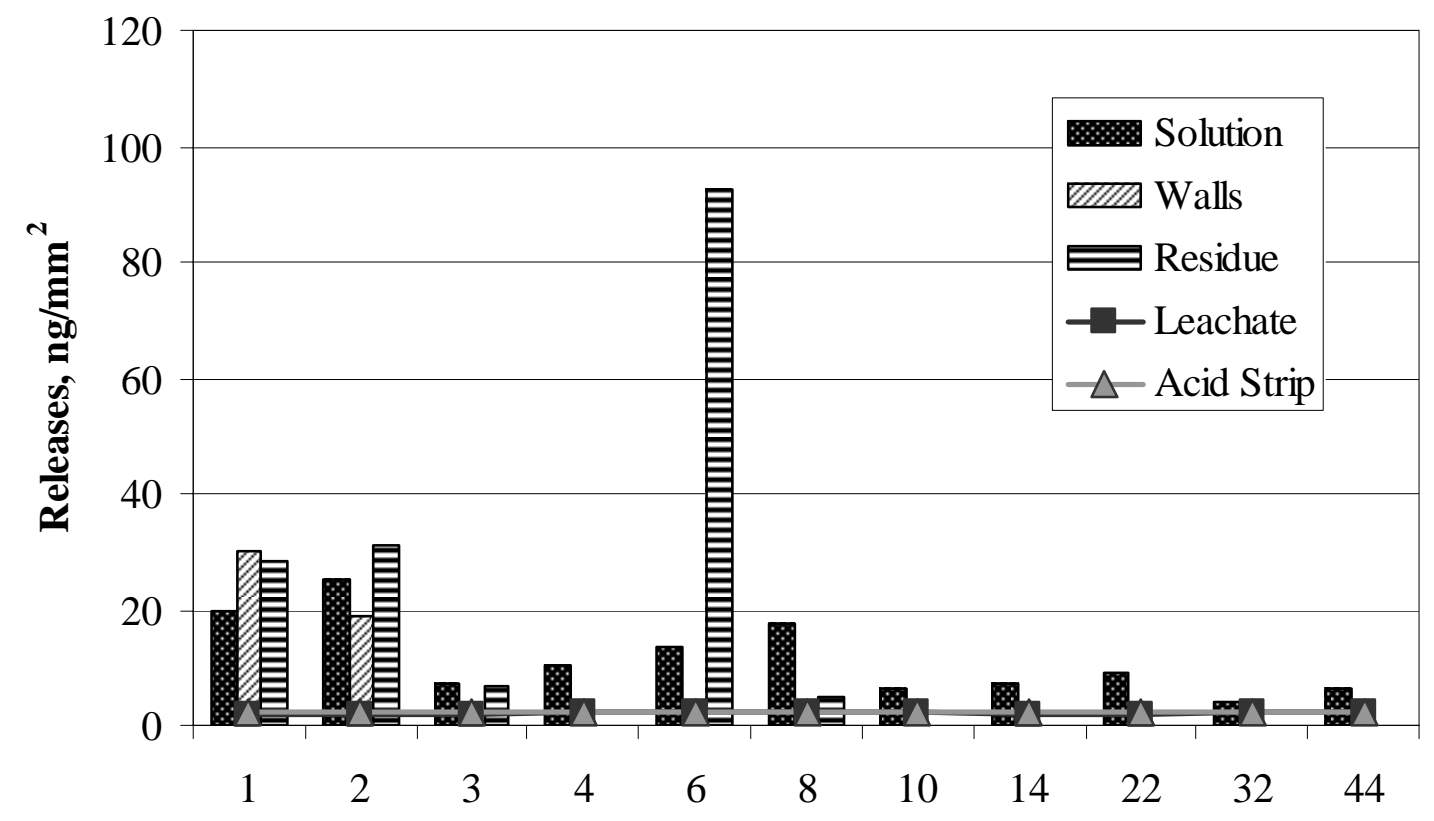

Time, weeks

Figure E-61. Nickel Releases in Solution, on Walls, and in Residue from Polished Sample 1 in 10KCl an Average Detection Limits for Leachate and Acid Strip.

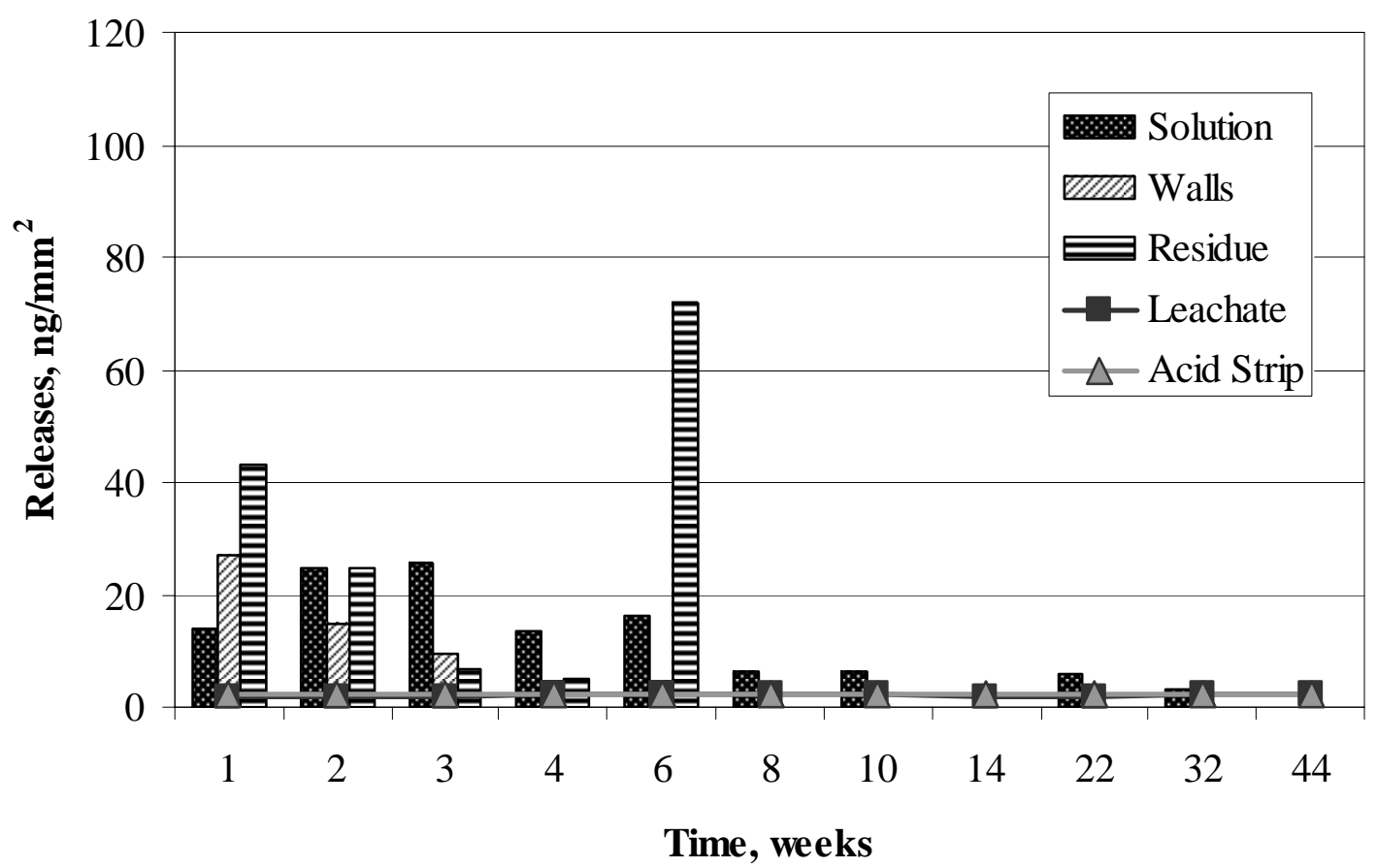

Figure E-62. Nickel Releases in Solution, on Walls, and in Residue from Polished Sample 2 in $10 \mathrm{KCl}$ and Average Detection Limits for Leachate and Acid Strip. 


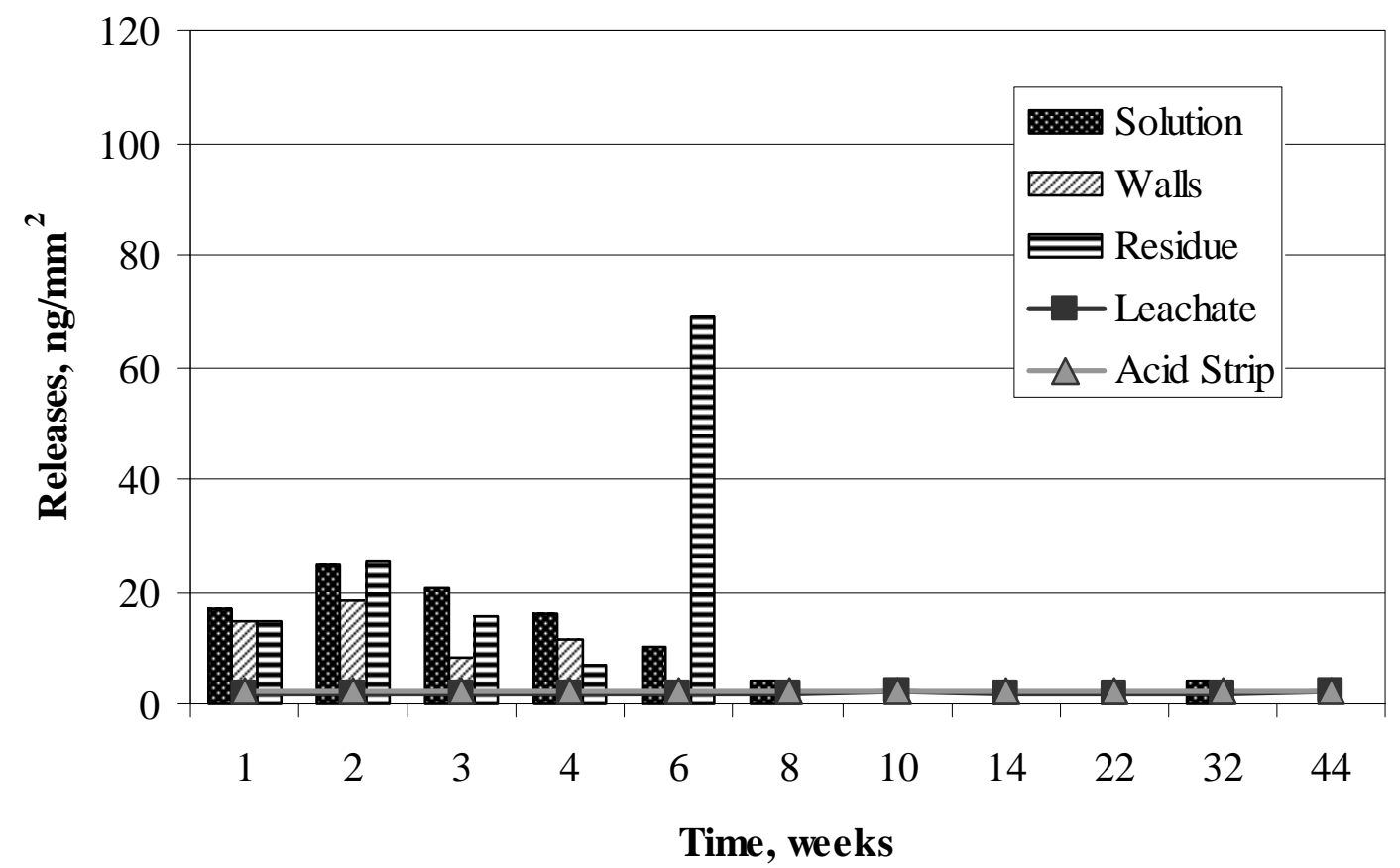

Figure E-63. Nickel Releases in Solution, on Walls, and in Residue from Polished Sample 3 in $10 \mathrm{KCl}$ and Average Detection Limits for Leachate and Acid Strip.

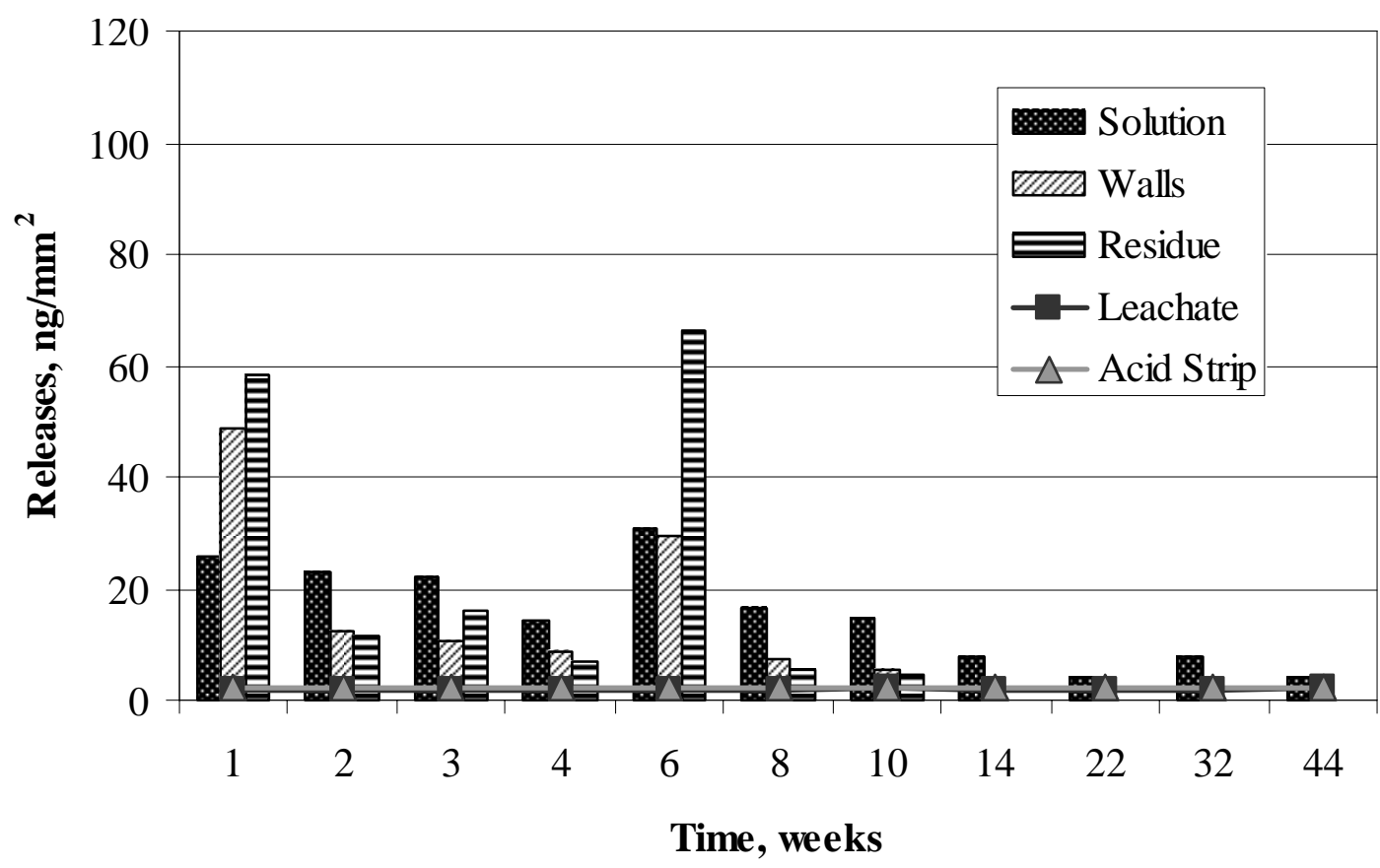

Figure E-64. Nickel Releases in Solution, on Walls, and in Residue from Oxidized Sample in $10 \mathrm{KCl}$ and Average Detection Limits for Leachate and Acid Strip. 


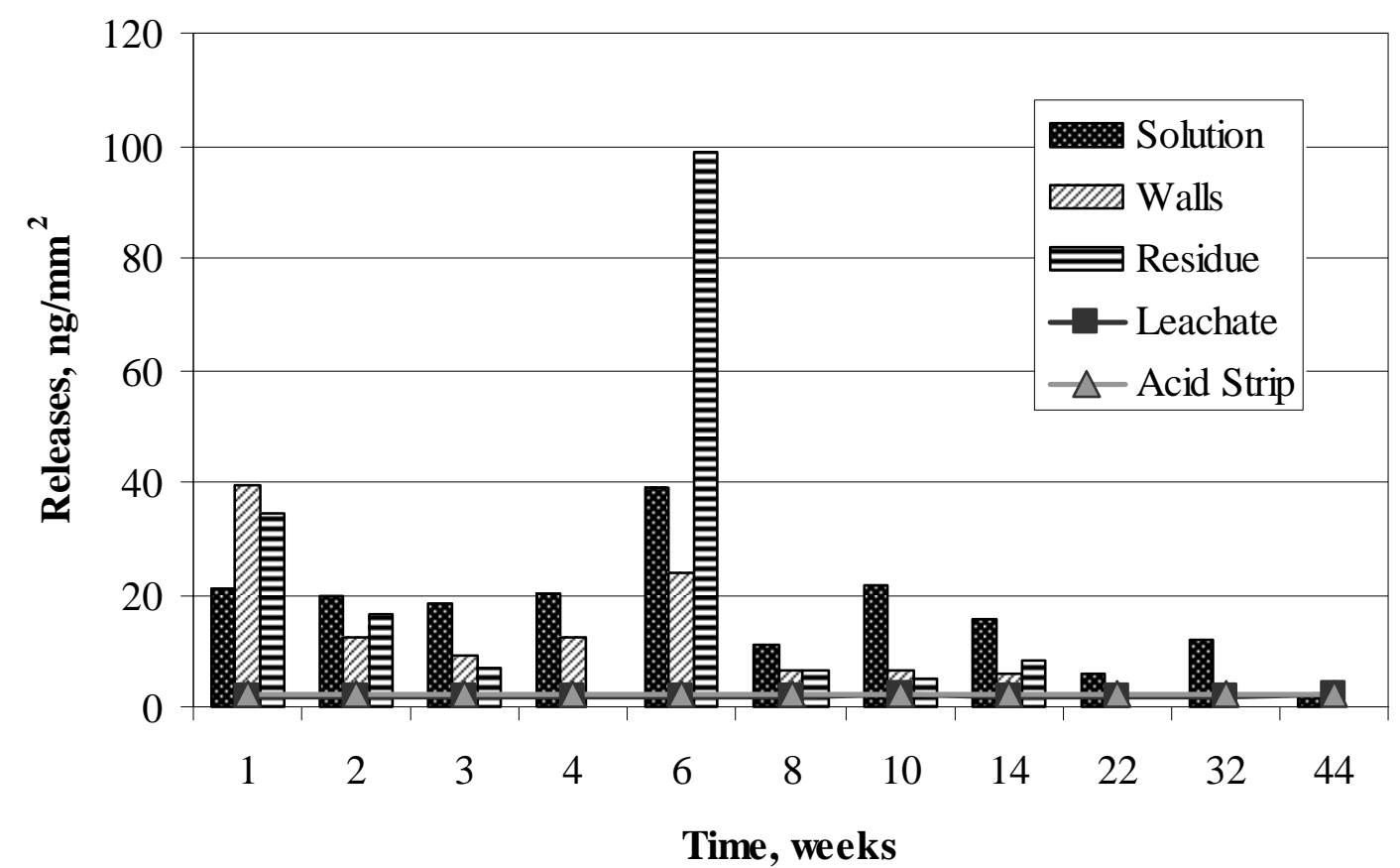

Figure E-65. Nickel Releases in Solution, on Walls, and in Residue from Oxidized Sample 5 in $10 \mathrm{KCl}$ and Average Detection Limits for Leachate and Acid Strip.

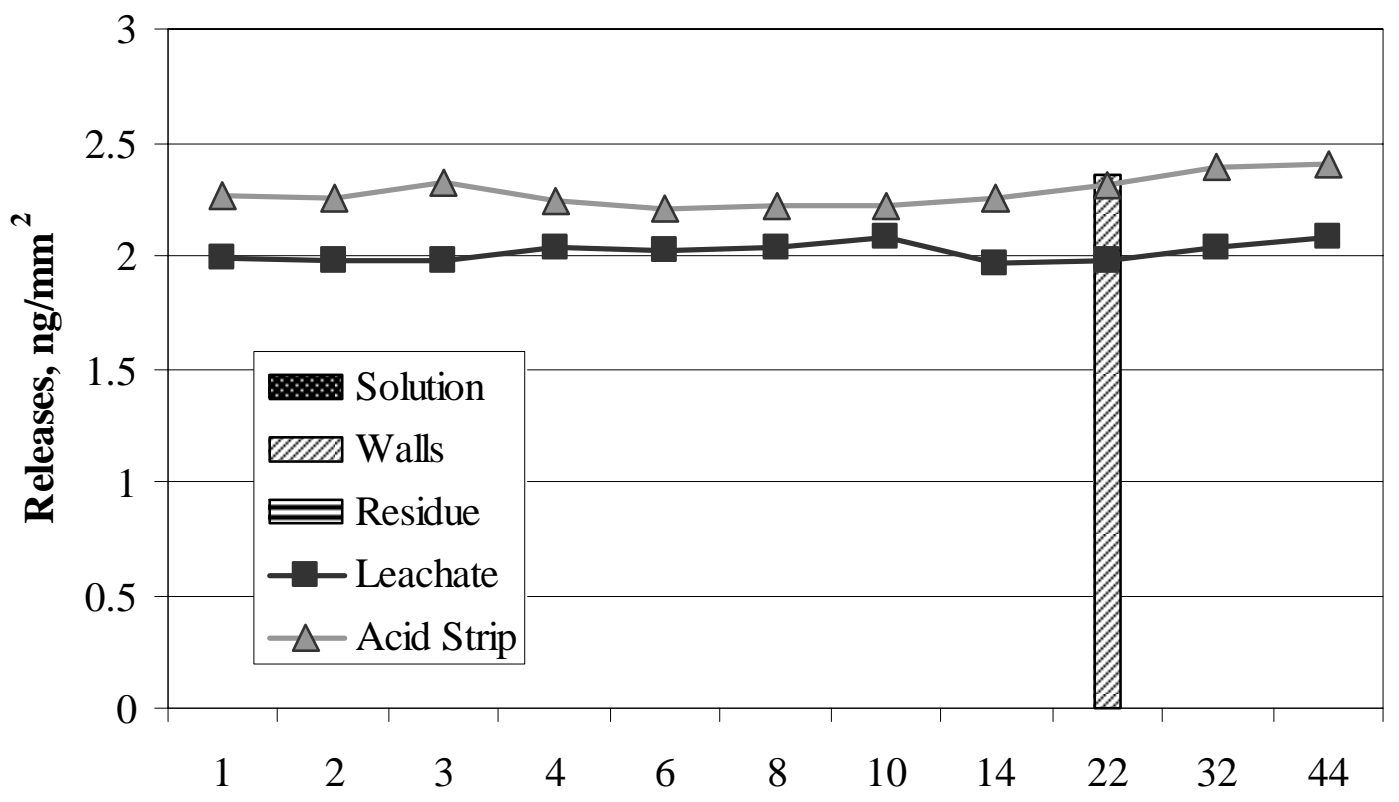

Time, weeks

Figure E-66. Nickel Present in Solution, on Walls, and in Residue from 10KCl Control and Average Detection Limits for Leachate and Acid Strip. 


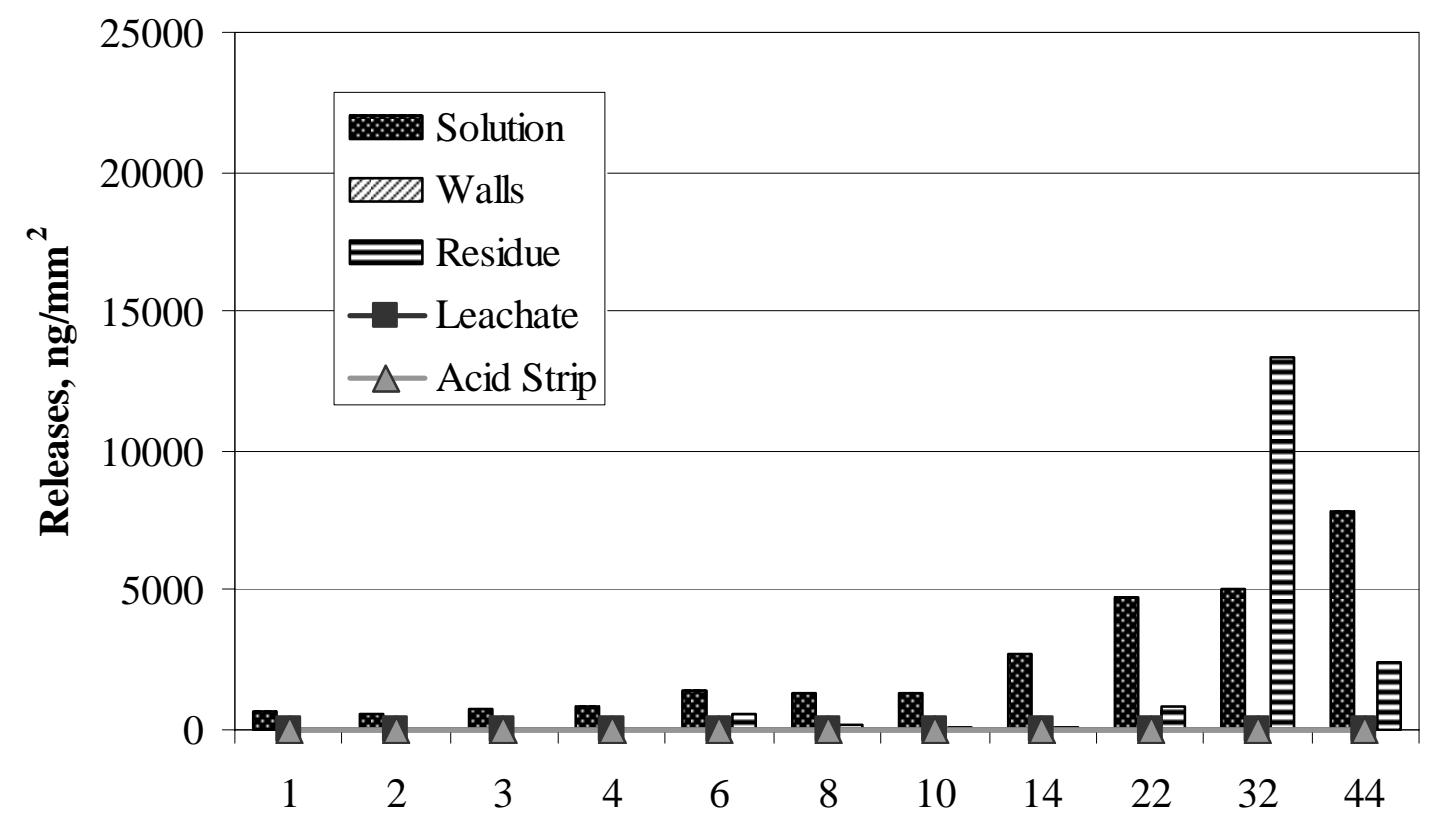

Time, weeks

Figure E-67. Nickel Releases in Solution, on Walls, and in Residue from Polished Sample 1 in AJ13 and Average Detection Limits for Leachate and Acid Strip.

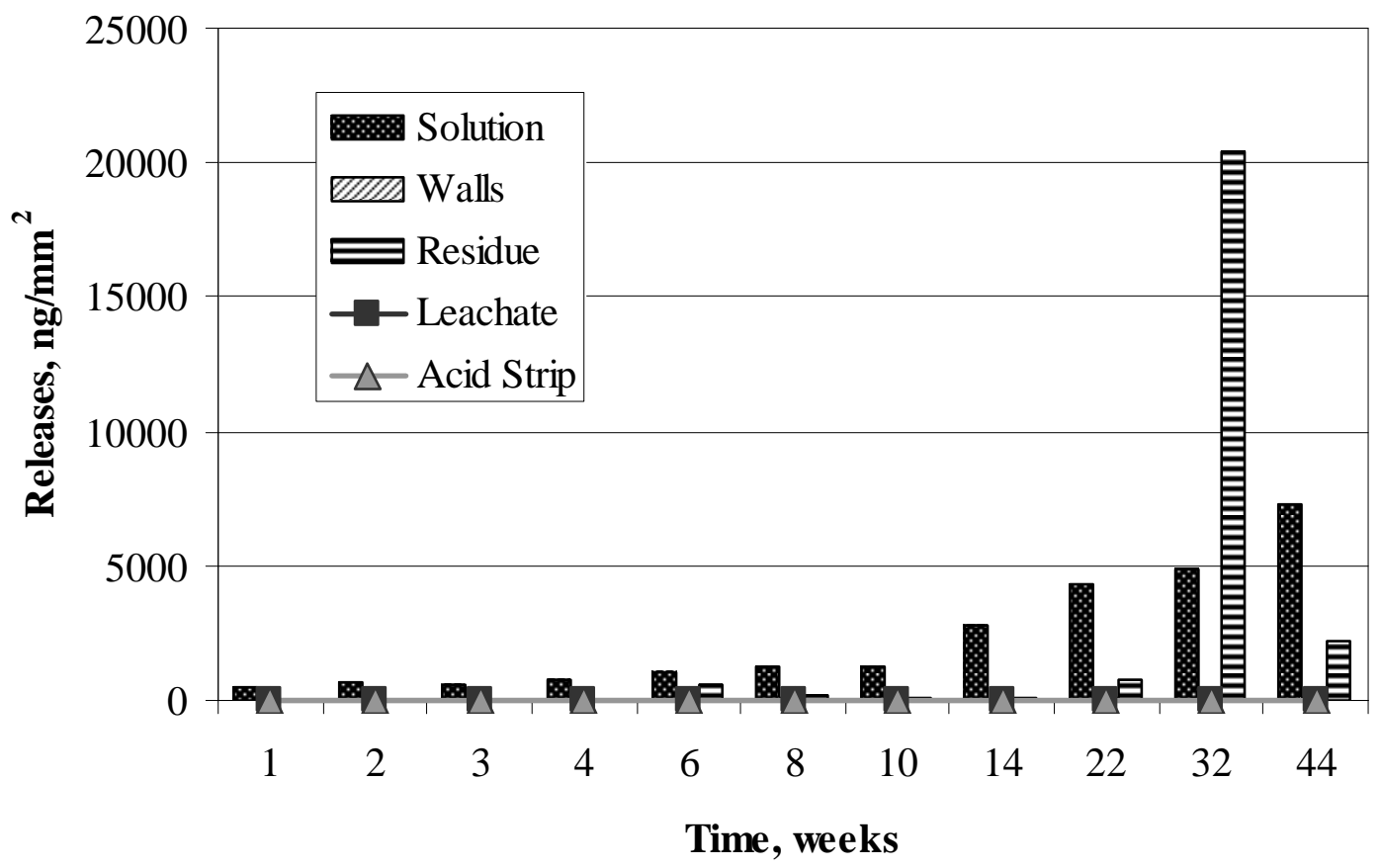

Figure E-68. Nickel Releases in Solution, on Walls, and in Residue from Polished Sample 2 in AJ13 and Average Detection Limits for Leachate and Acid Strip. 


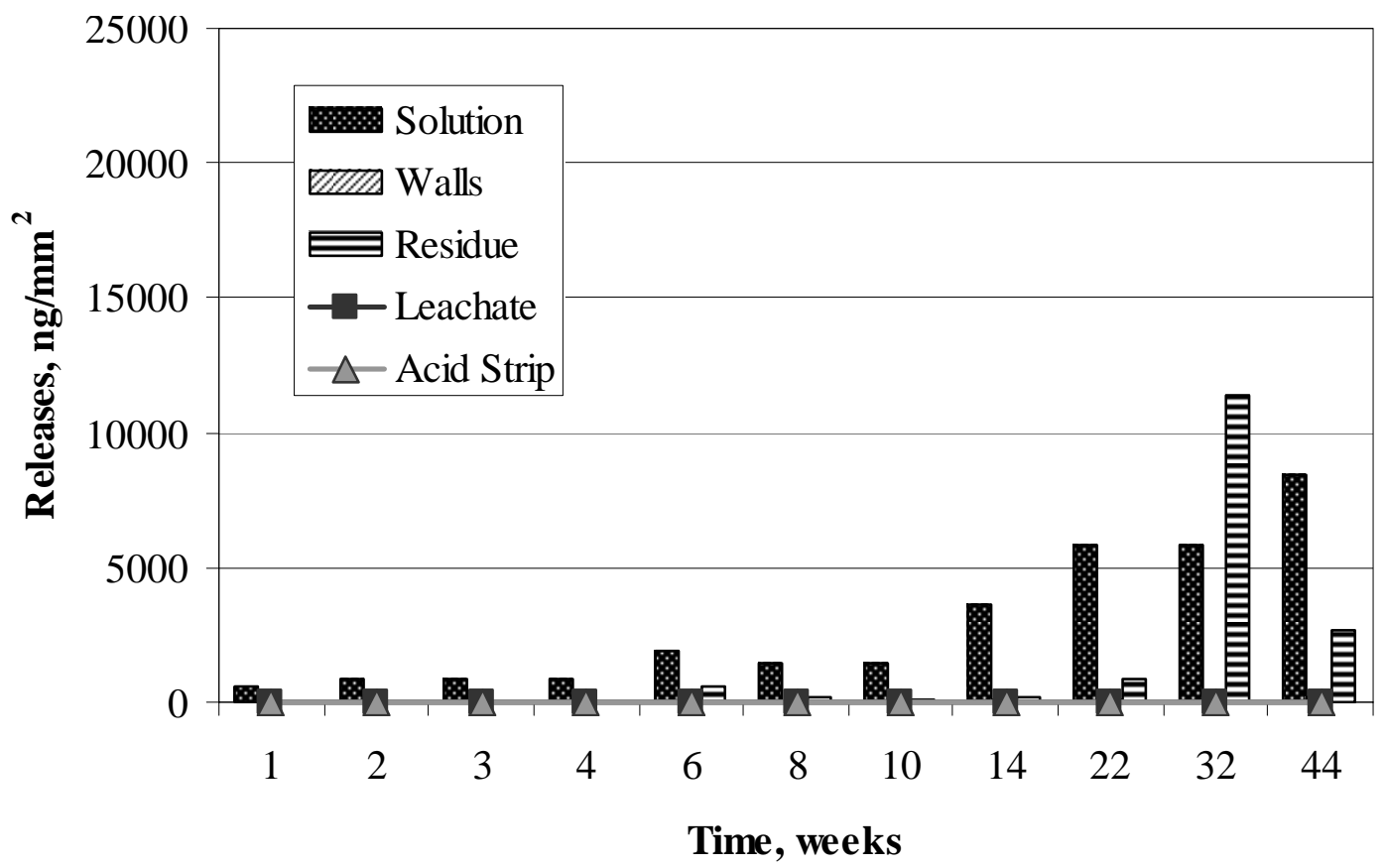

Figure E-69. Nickel Releases in Solution, on Walls, and in Residue from Polished Sample 3 in AJ13 and Average Detection Limits for Leachate and Acid Strip.

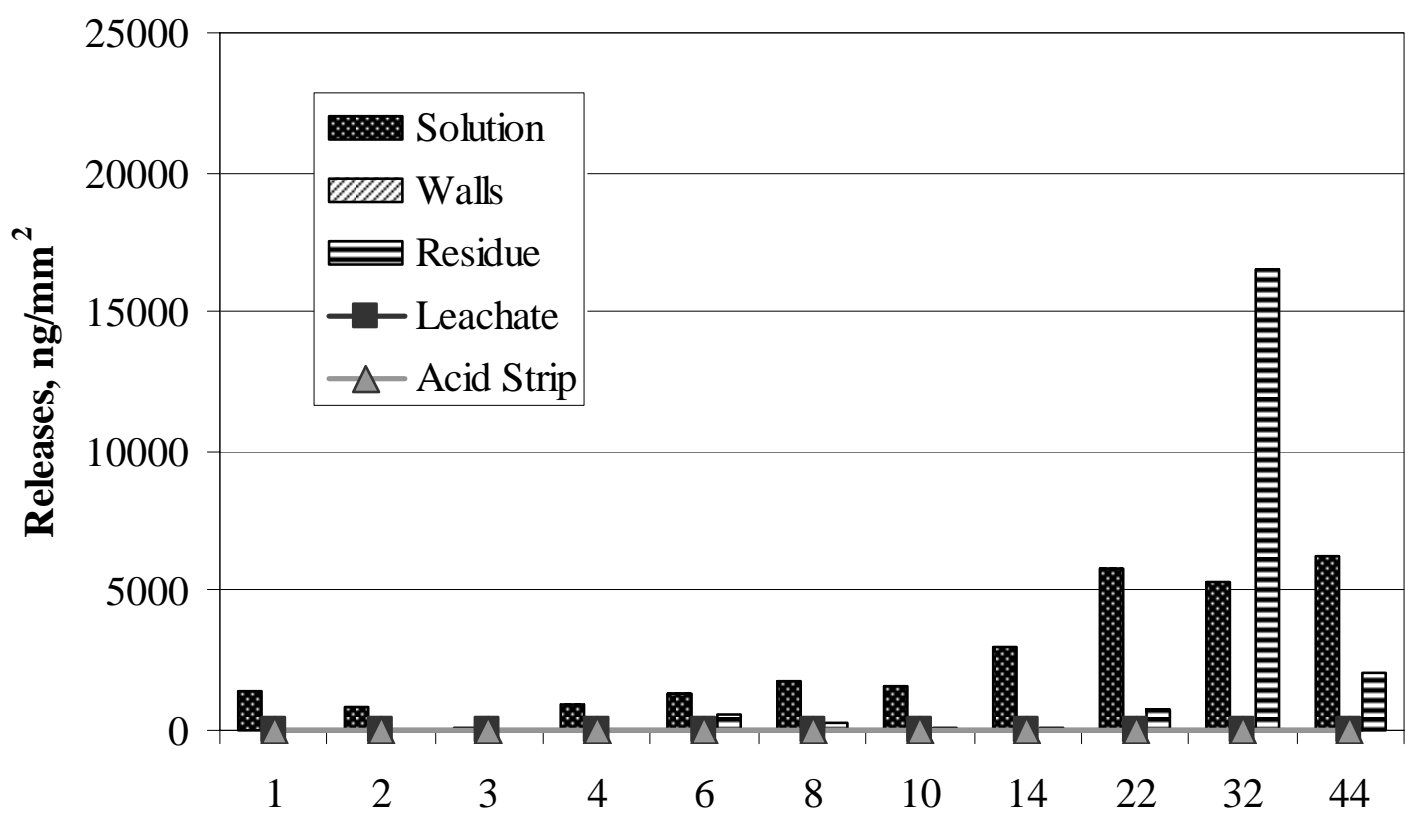

Time, weeks

Figure E-70. Nickel Releases in Solution, on Walls, and in Residue from Oxidized Sample 4 in AJ13 and Average Detection Limits for Leachate and Acid Strip. 


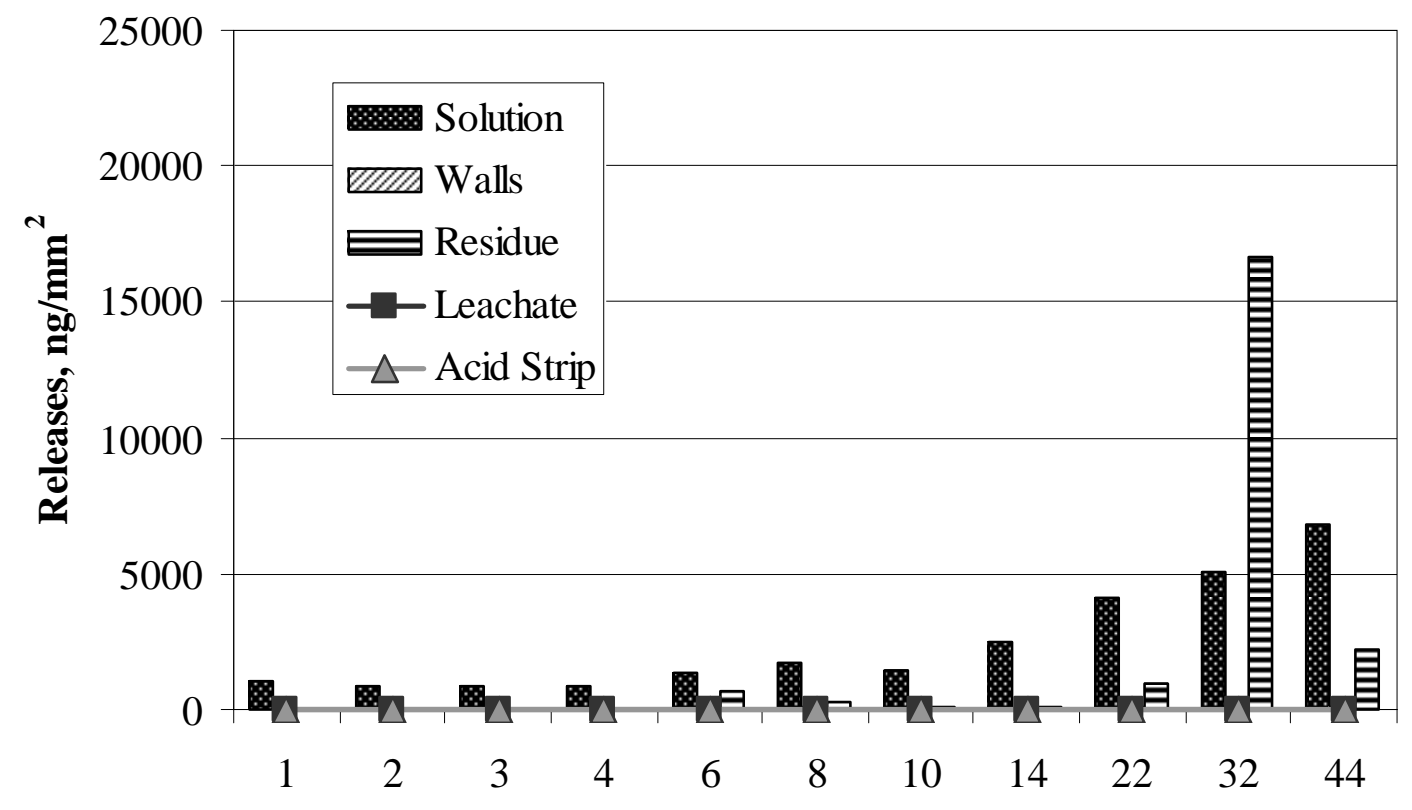

Time, weeks

Figure E-71. Nickel Releases in Solution, on Walls, and in Residue from Oxidized Sample 5 in AJ13 and Average Detection Limits for Leachate and Acid Strip.

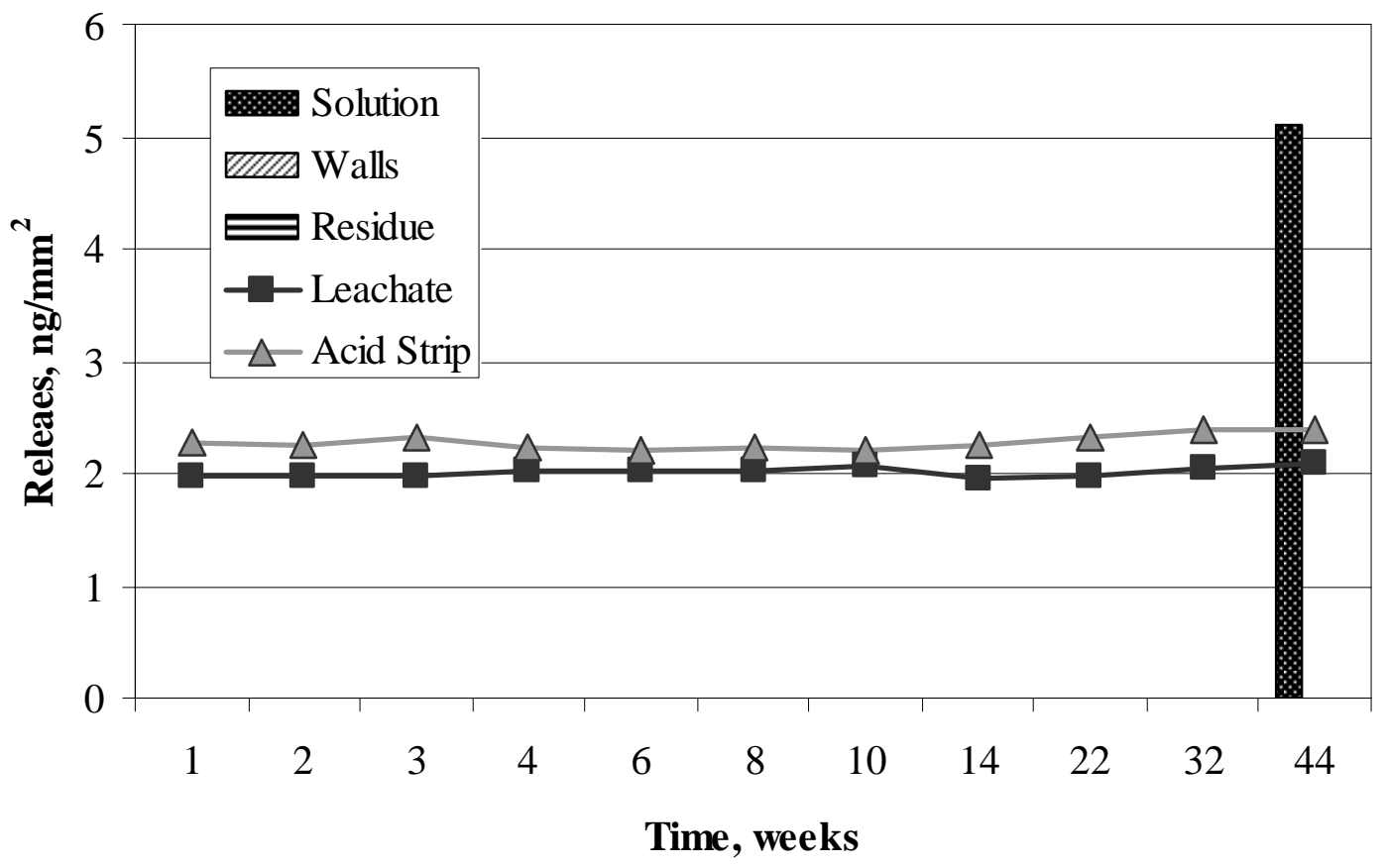

Figure E-72. Nickel Present in Solution, on Walls, and in Residue from AJ13 Control and Average Detection Limits for Leachate and Acid Strip. 


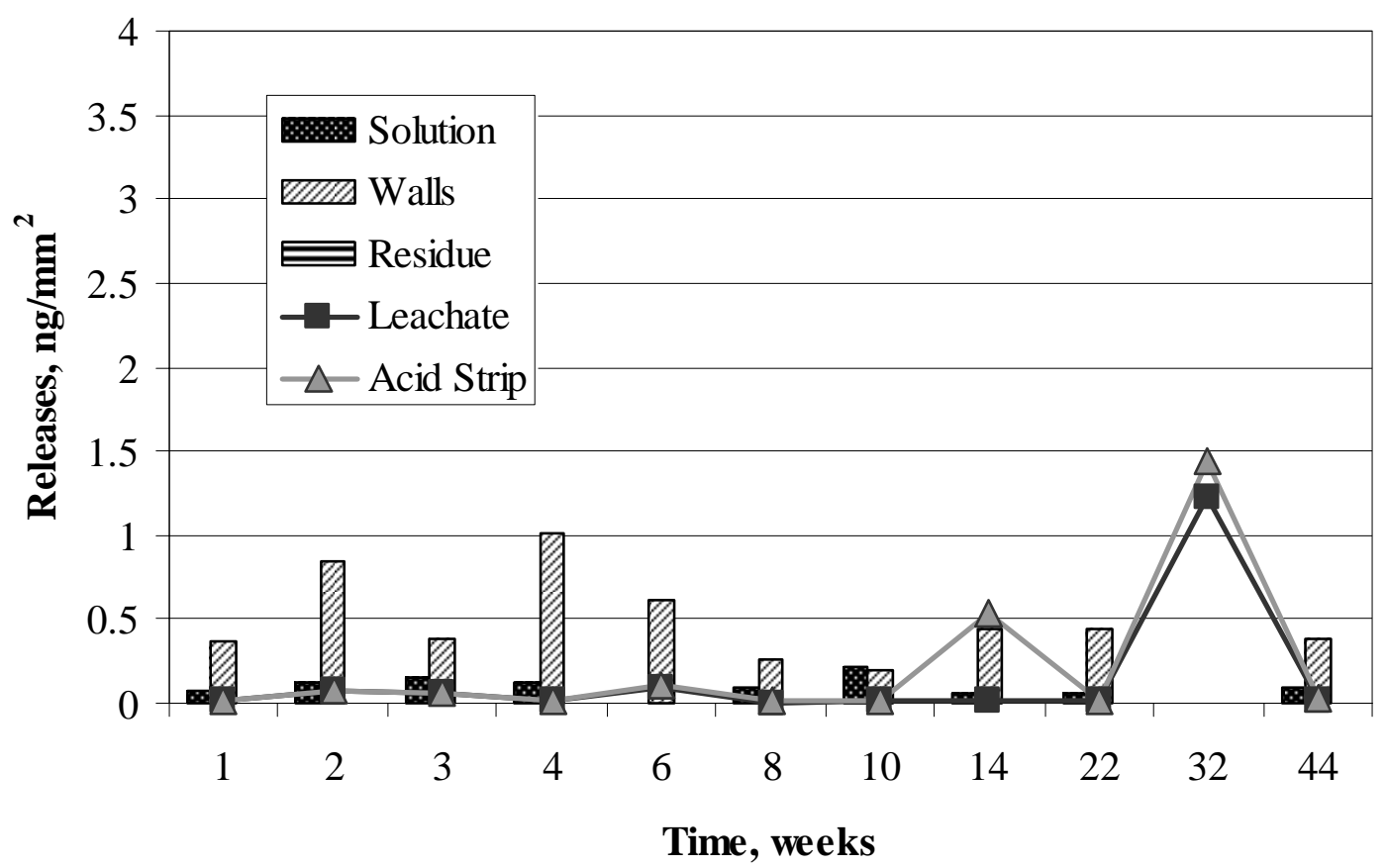

Figure E-73. Zirconium Releases in Solution, on Walls, and in Residue from Polished Sample 1 in SJ13 and Average Detection Limits for Leachate and Acid Strip.

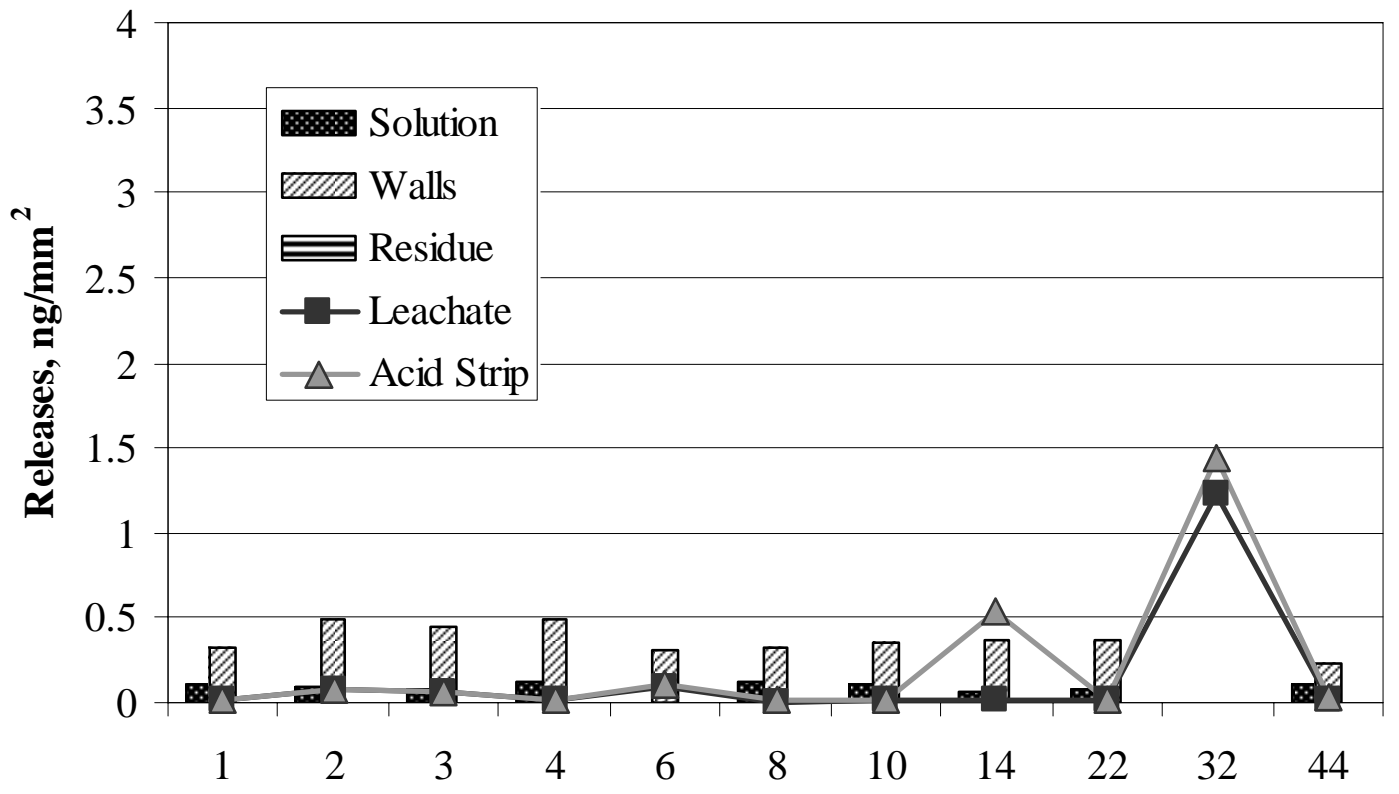

Time, weeks

Figure E-74. Zirconium Releases in Solution, on Walls, and in Residue from Polished Sample 2 in SJ13 and Average Detection Limits for Leachate and Acid Strip. 


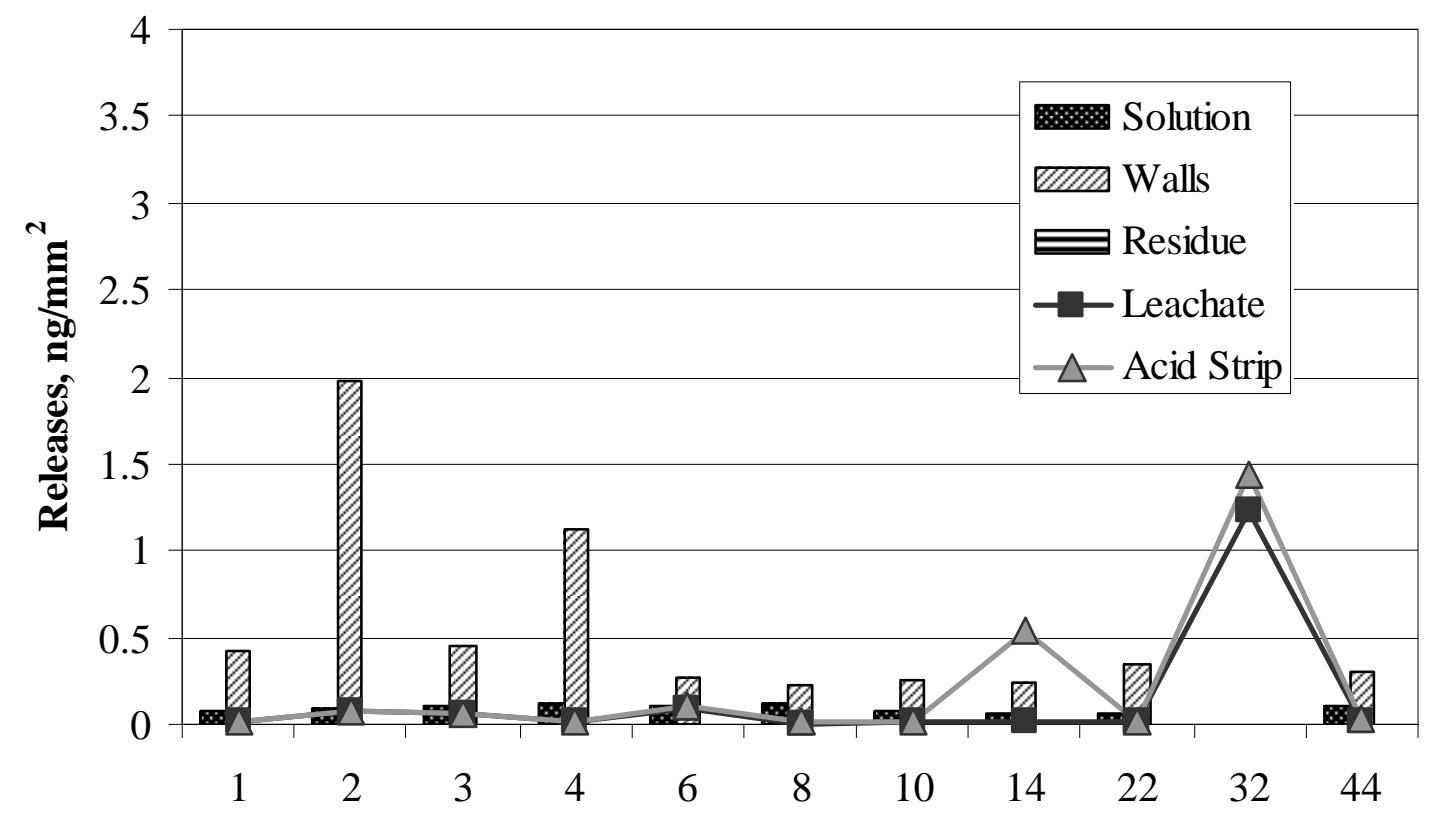

Time, weeks

Figure E-75. Zirconium Releases in Solution, on Walls, and in Residue from Polished Sample 3 in SJ13 and Average Detection Limits for Leachate and Acid Strip.

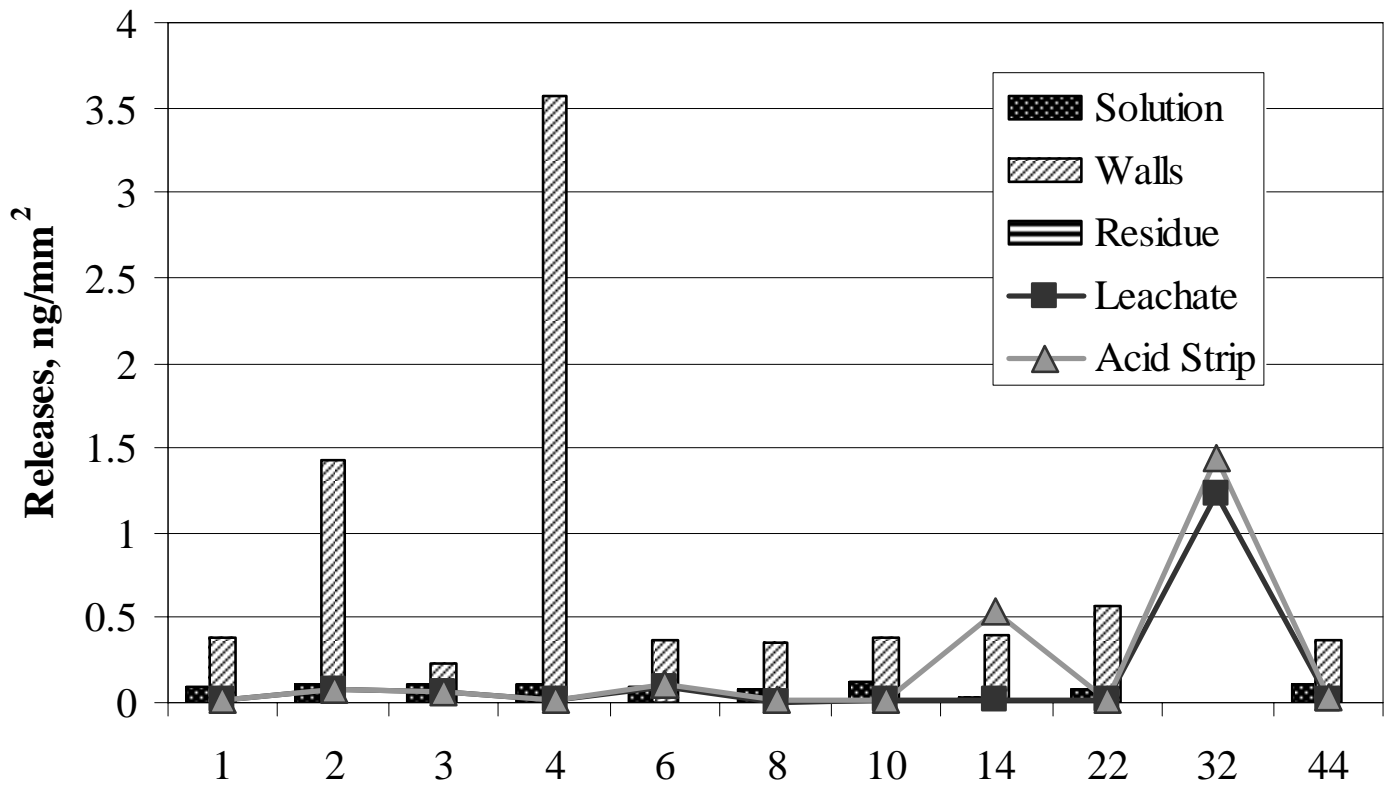

Time, weeks

Figure E-76. Zirconium Releases in Solution, on Walls, and in Residue from Oxidized Sample 4 in SJ13 and Average Detection Limits for Leachate and Acid Strip. 


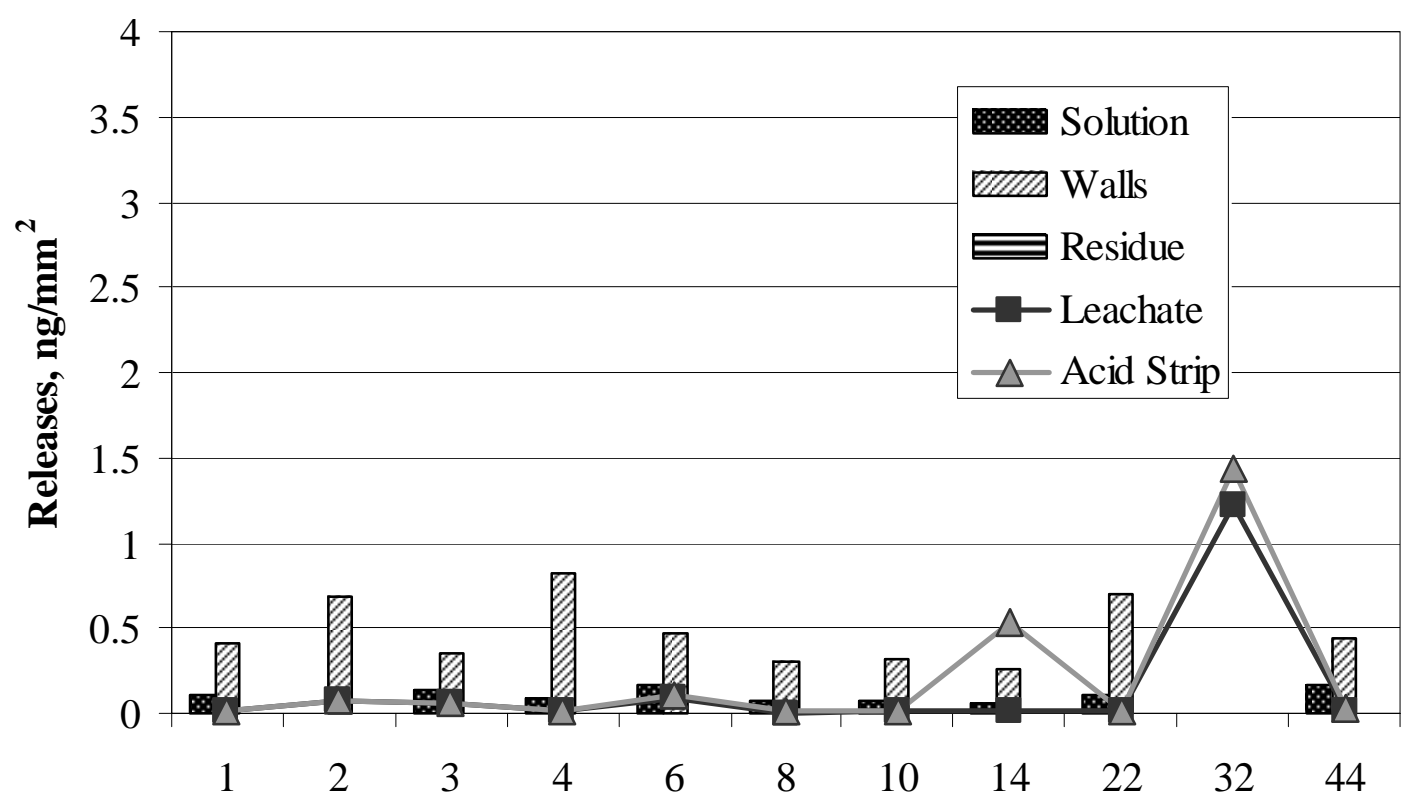

Time, weeks

Figure E-77. Zirconium Releases in Solution, on Walls, and in Residue from Oxidized Sample 5 in SJ13 and Average Detection Limits for Leachate and Acid Strip.

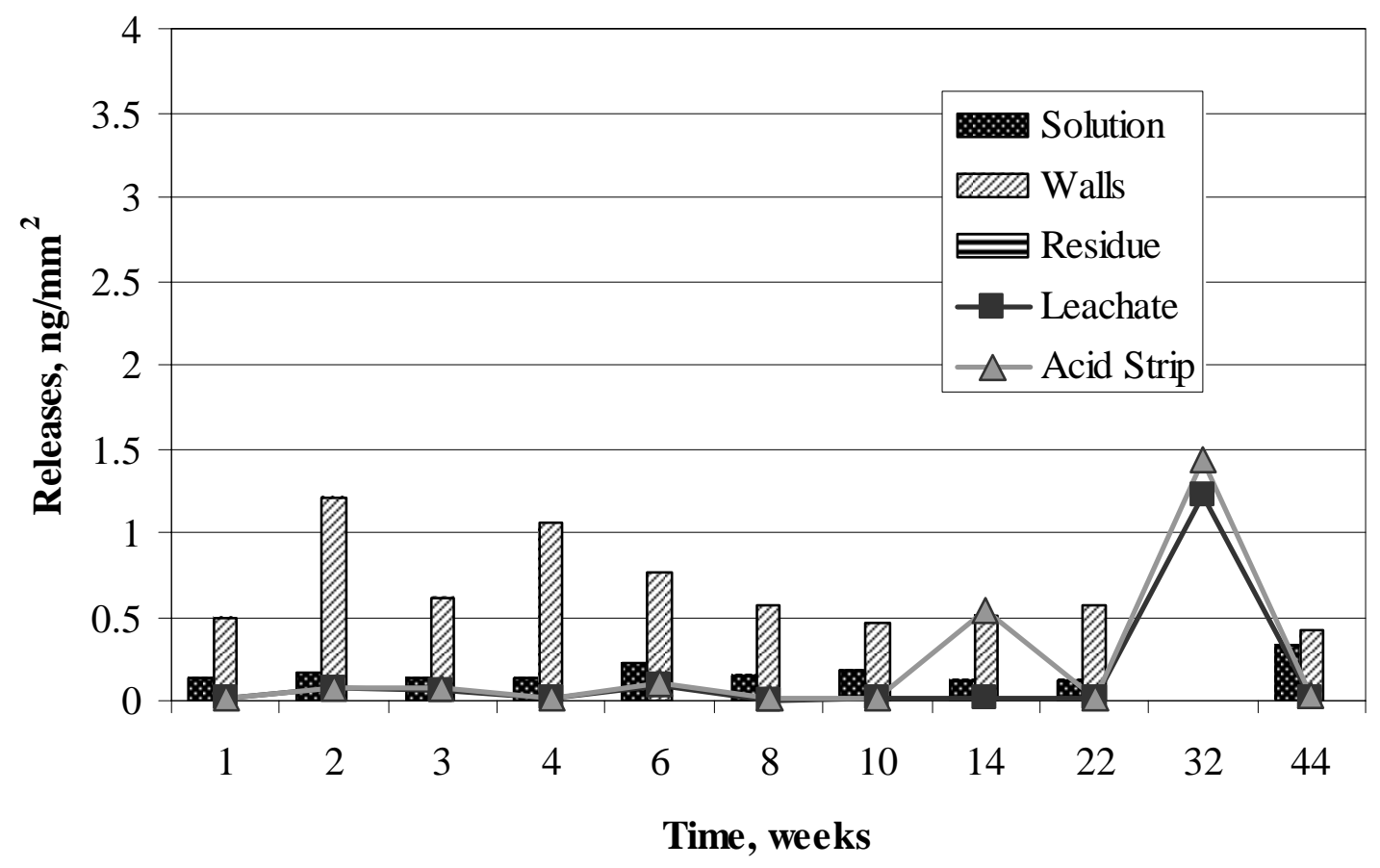

Figure E-78. Zirconium Present in Solution, on Walls, and in Residue from SJ13 Control and Average Detection Limits for Leachate and Acid Strip. 


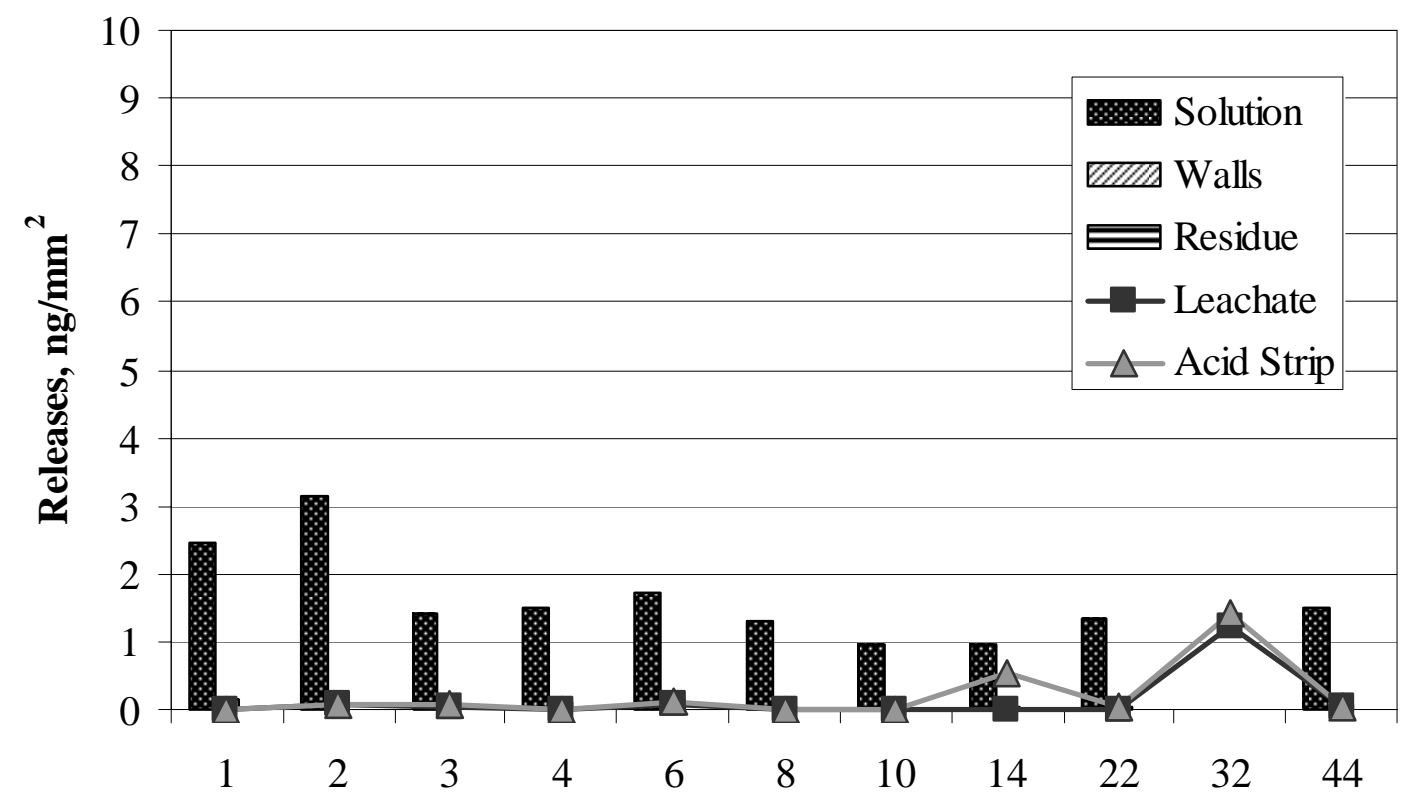

Time, weeks

Figure E-79. Zirconium Releases in Solution, on Walls, and in Residue from Polished Sample 1 in CJ13 and Average Detection Limits for Leachate and Acid Strip.

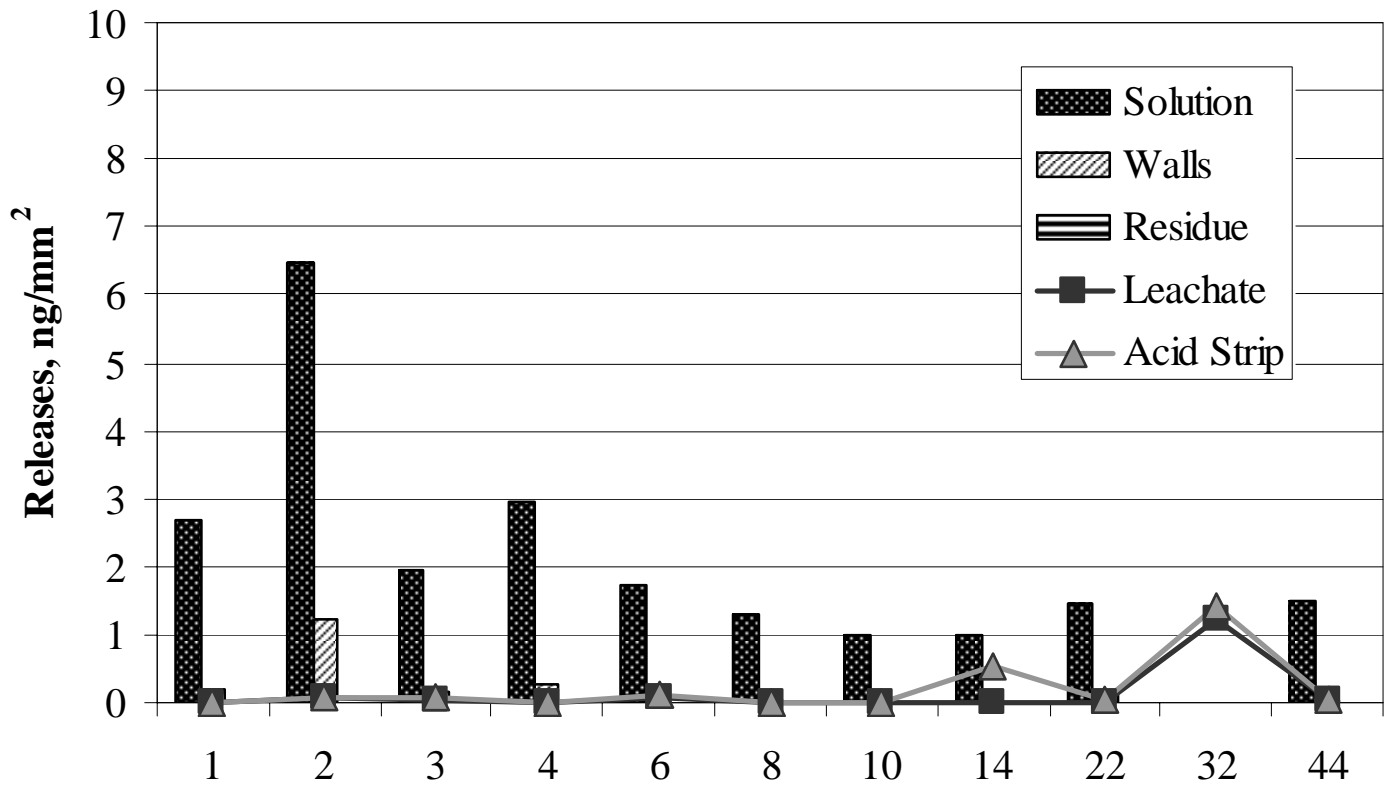

Time, weeks

Figure E-80. Zirconium Releases in Solution, on Walls, and in Residue from Polished Sample 2 in CJ13 and Average Detection Limits for Leachate and Acid Strip. 


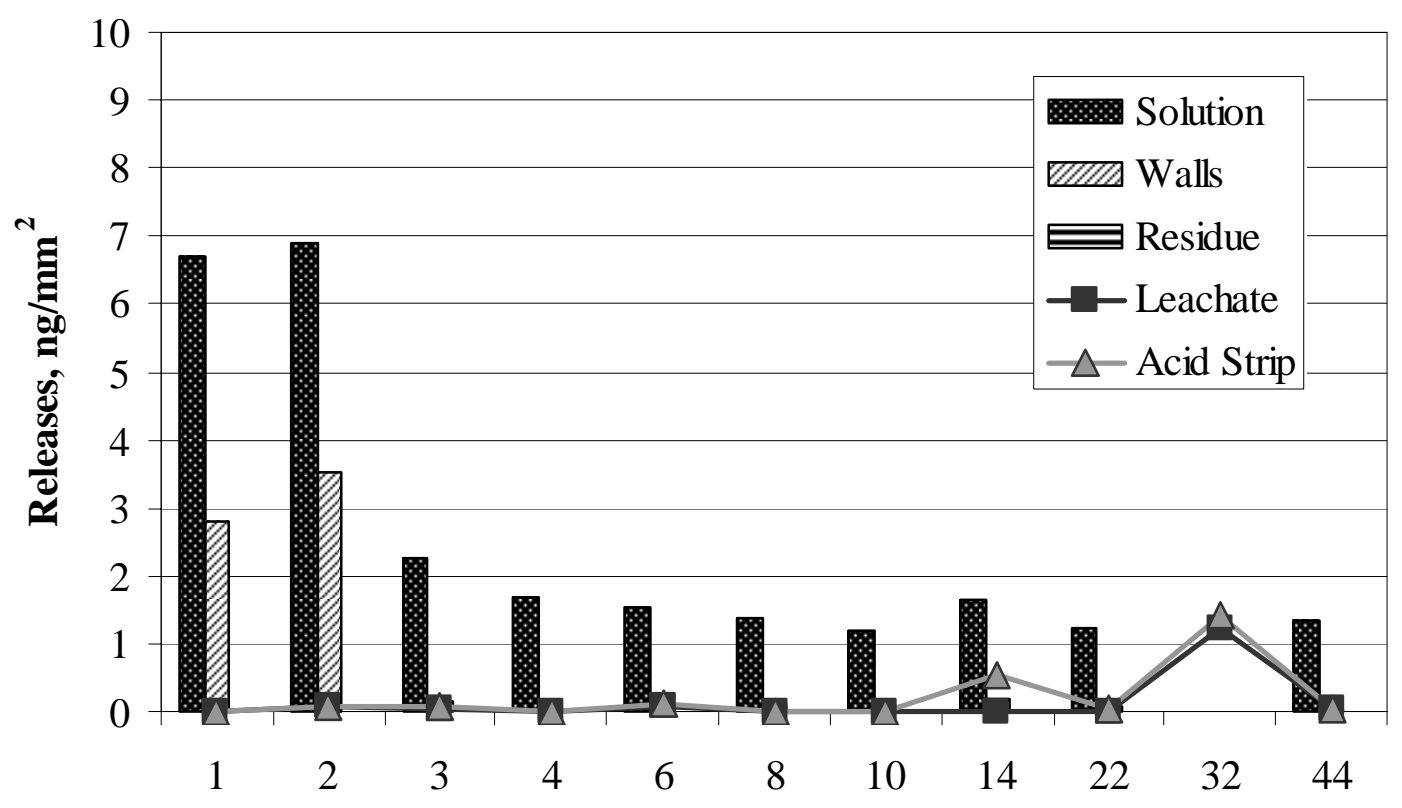

Time, weeks

Figure E-81. Zirconium Releases in Solution, on Walls, and in Acid Strip from Polished Sample 3 in CJ13 and Average Detection Limits for Leachate and Acid Strip.

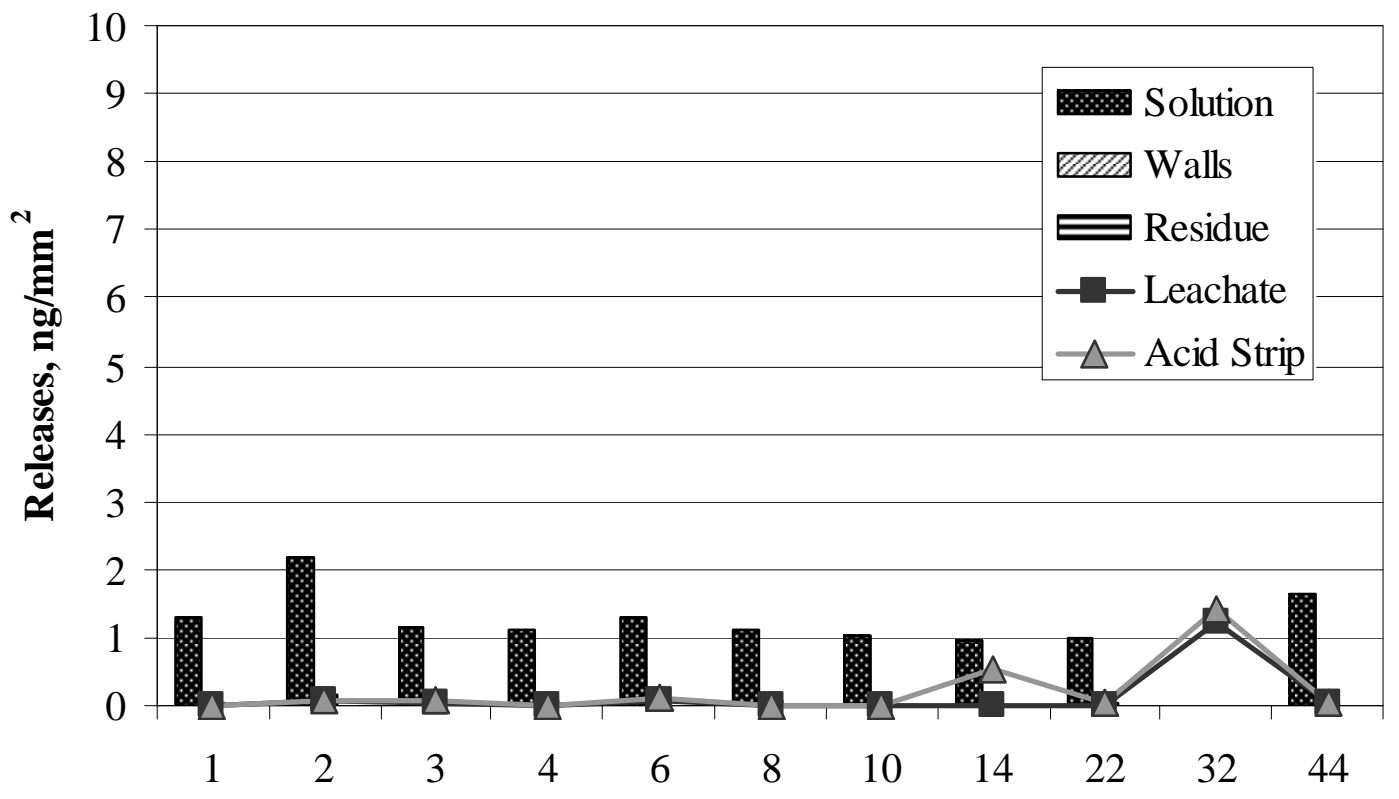

Time, weeks

Figure E-82. Zirconium Releases in Solution, on Walls, and in Acid Strip from Oxidized Sample 4 in CJ13 and Average Detection Limits for Leachate and Acid Strip. 


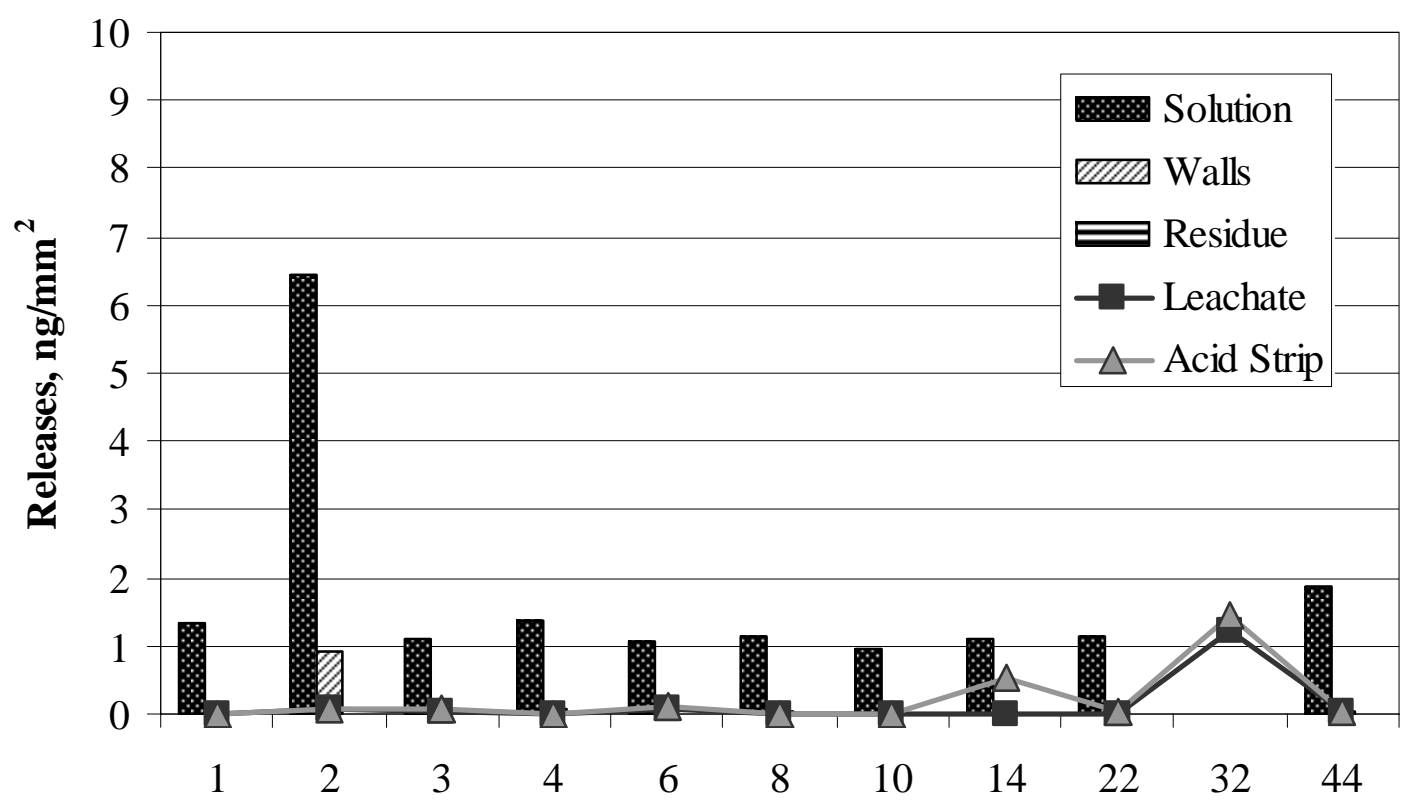

Time, weeks

Figure E-83. Zirconium Releases in Solution, on Walls, and in Residue from Oxidized Sample 5 in CJ13 and Average Detection Limits for Leachate and Acid Strip.

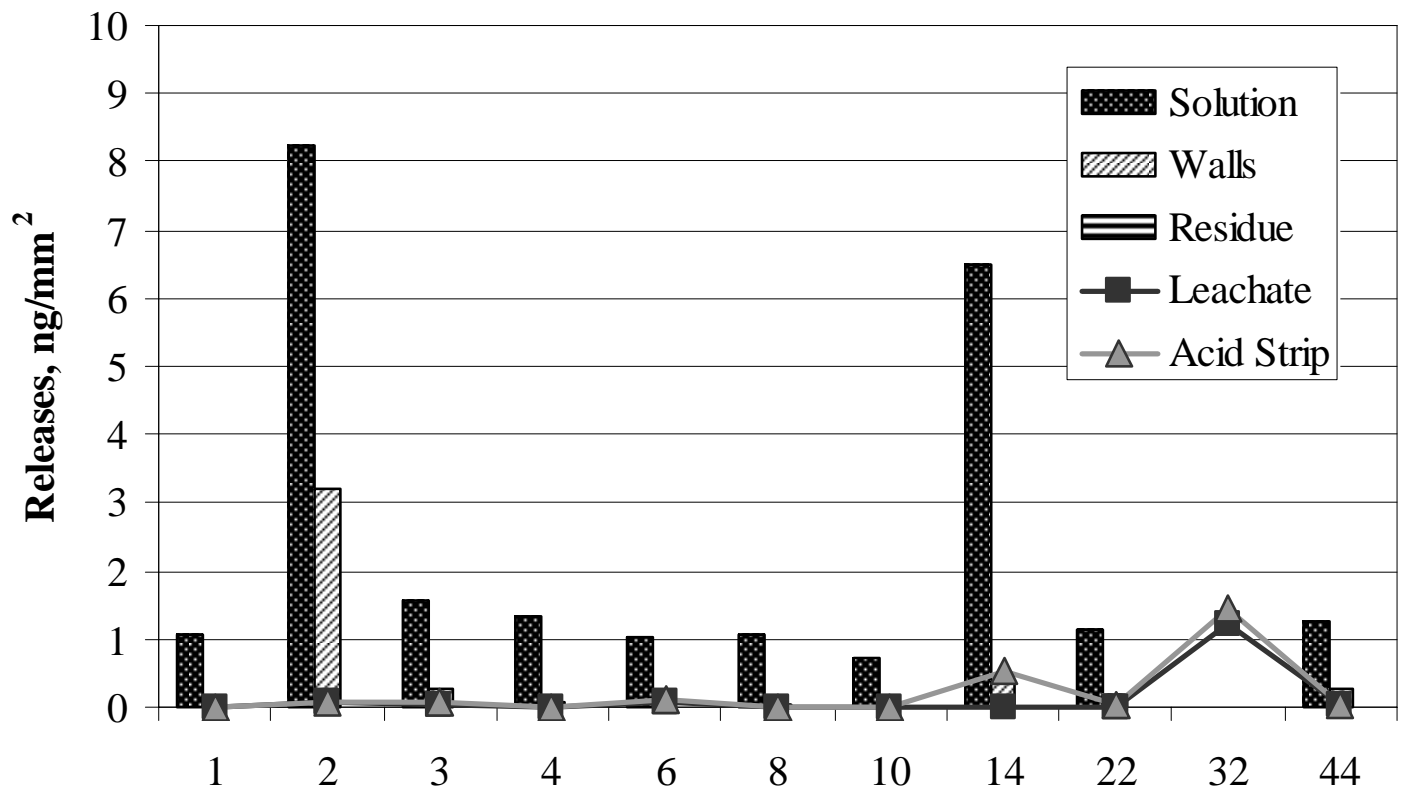

Time, weeks

Figure E-84. Zirconium Present in Solution, on Walls, and in Residue from CJ13 Control and Average Detection Limits for Leachate and Acid Strip. 


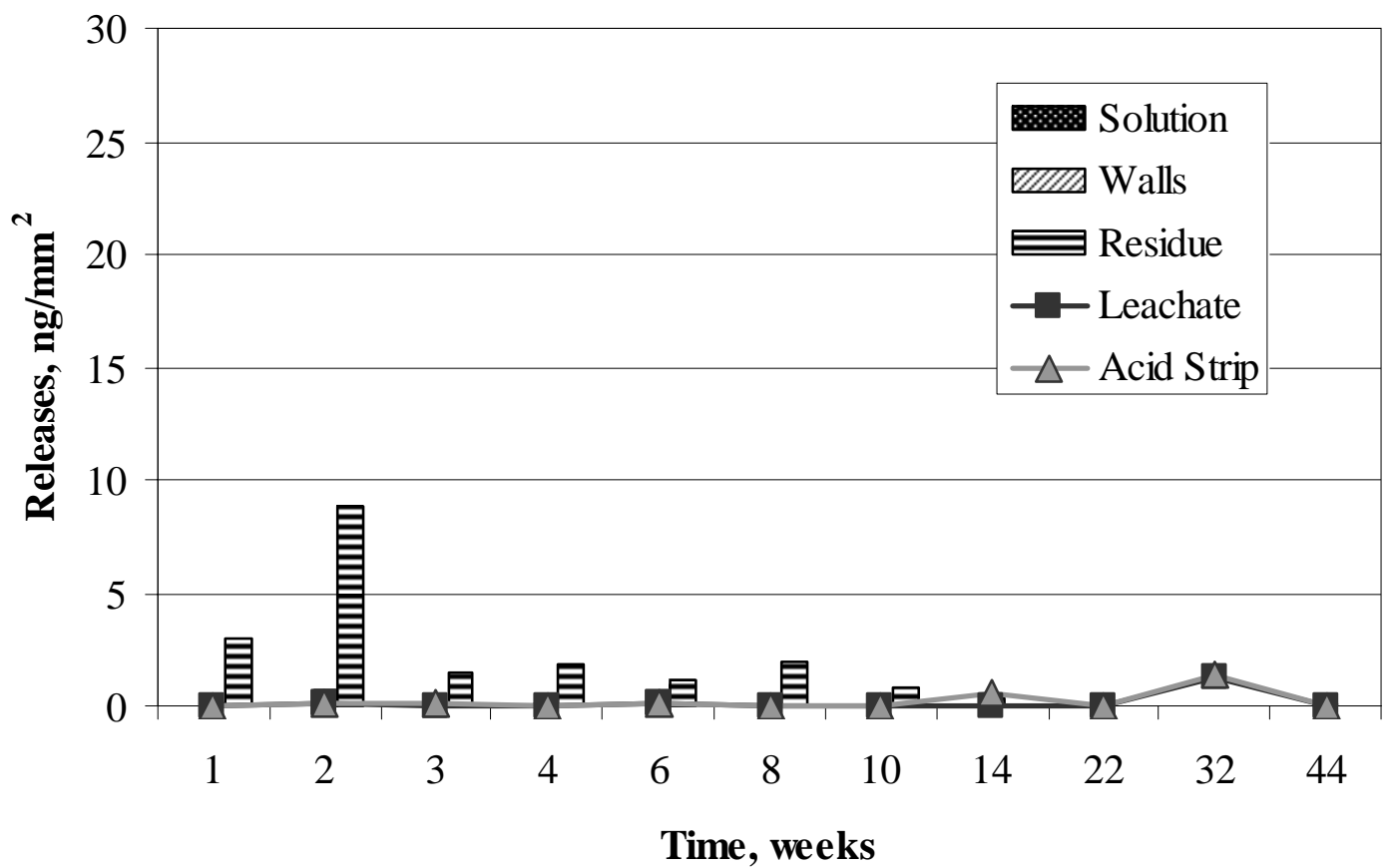

Figure E-85. Zirconium Releases in Solution, on Walls, and in Residue from Polished Sample 1 in $10 \mathrm{KCl}$ and Average Detection Limits for Leachate and Acid Strip.

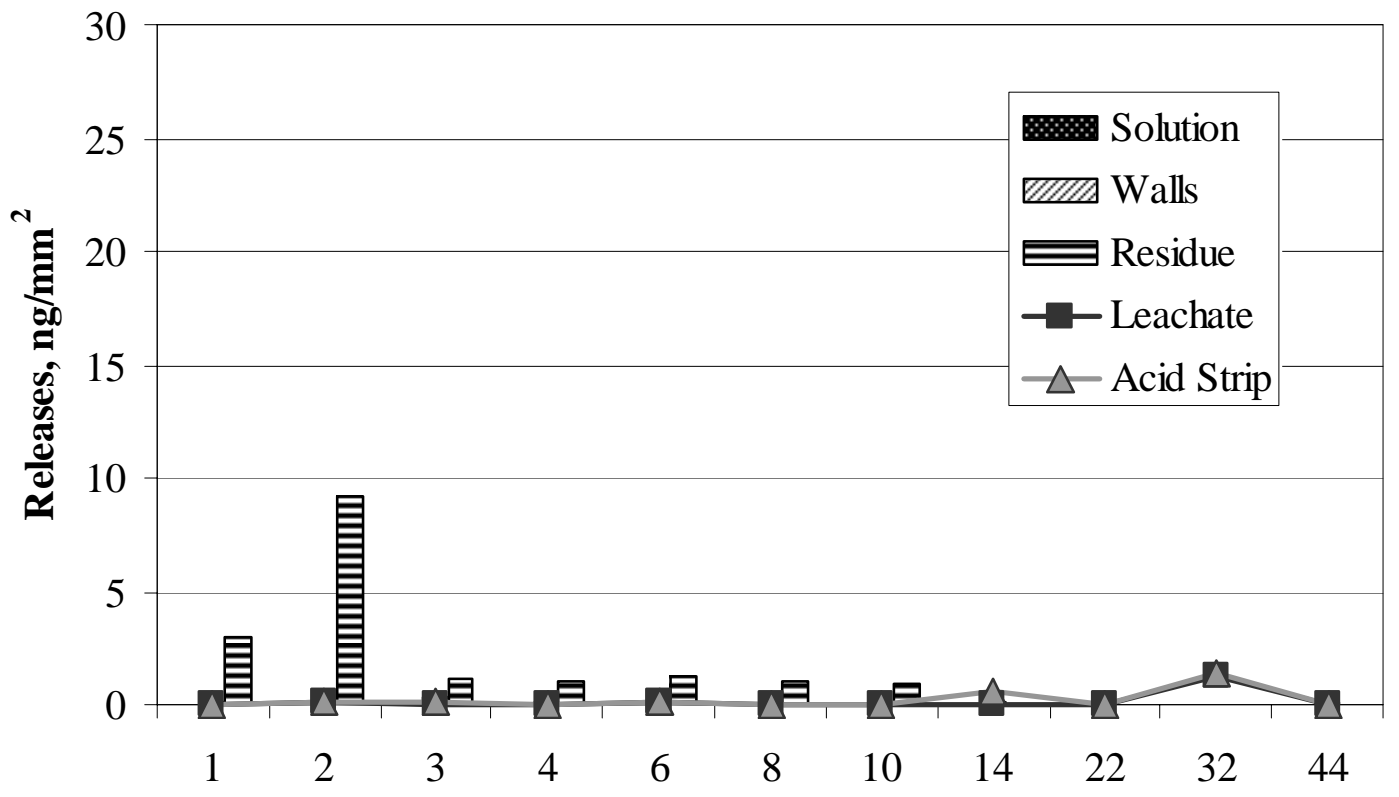

Time, weeks

Figure E-86. Zirconium Releases in Solution, on Walls, and in Residue from Polished Sample 2 in $10 \mathrm{KCl}$ and Average Detection Limits for Leachate and Acid Strip. 


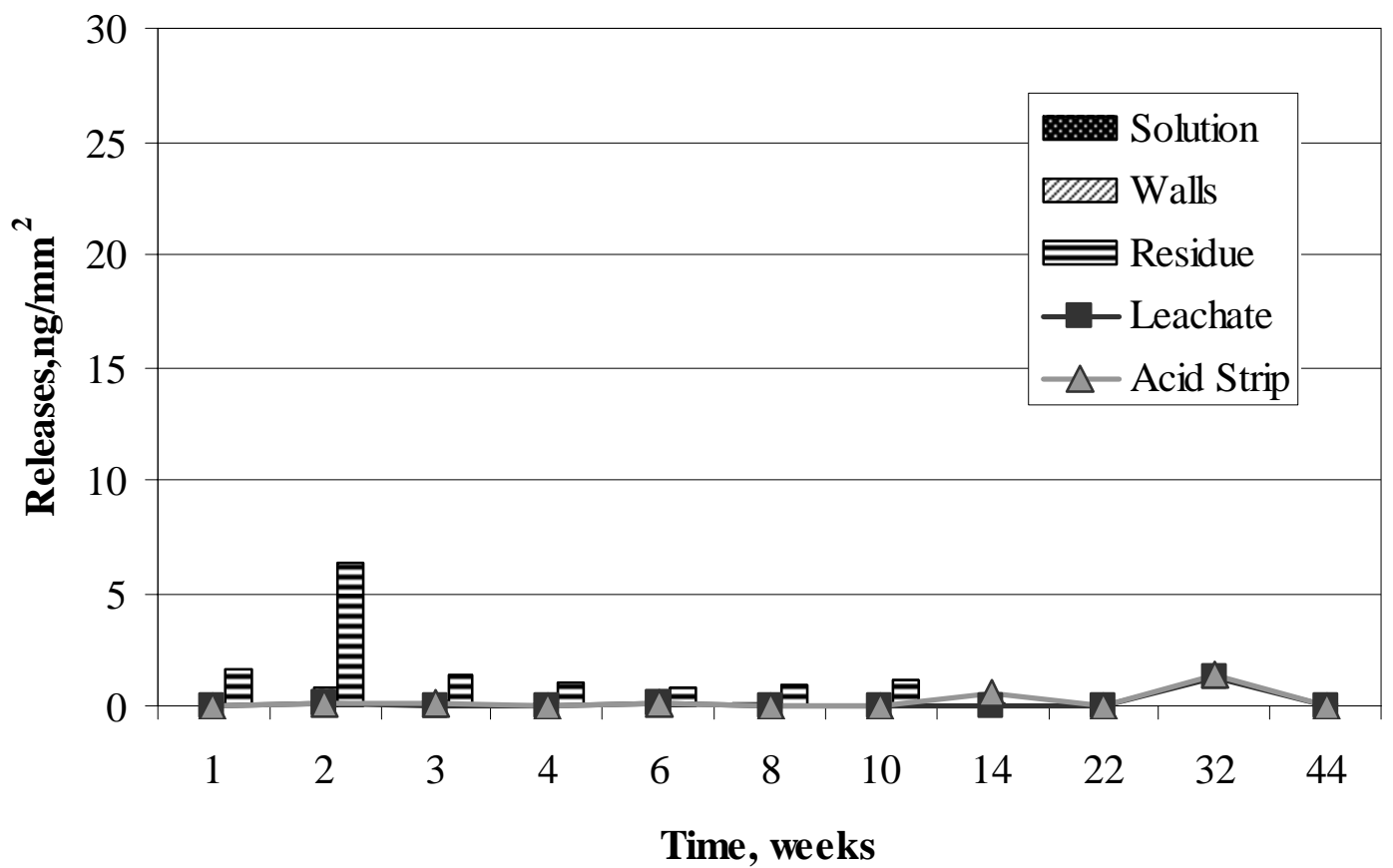

Figure E-87. Zirconium Releases in Solution, on Walls, and in Residue from Polished Sample 3 in $10 \mathrm{KCl}$ and Average Detection Limits for Leachate and Acid Strip.

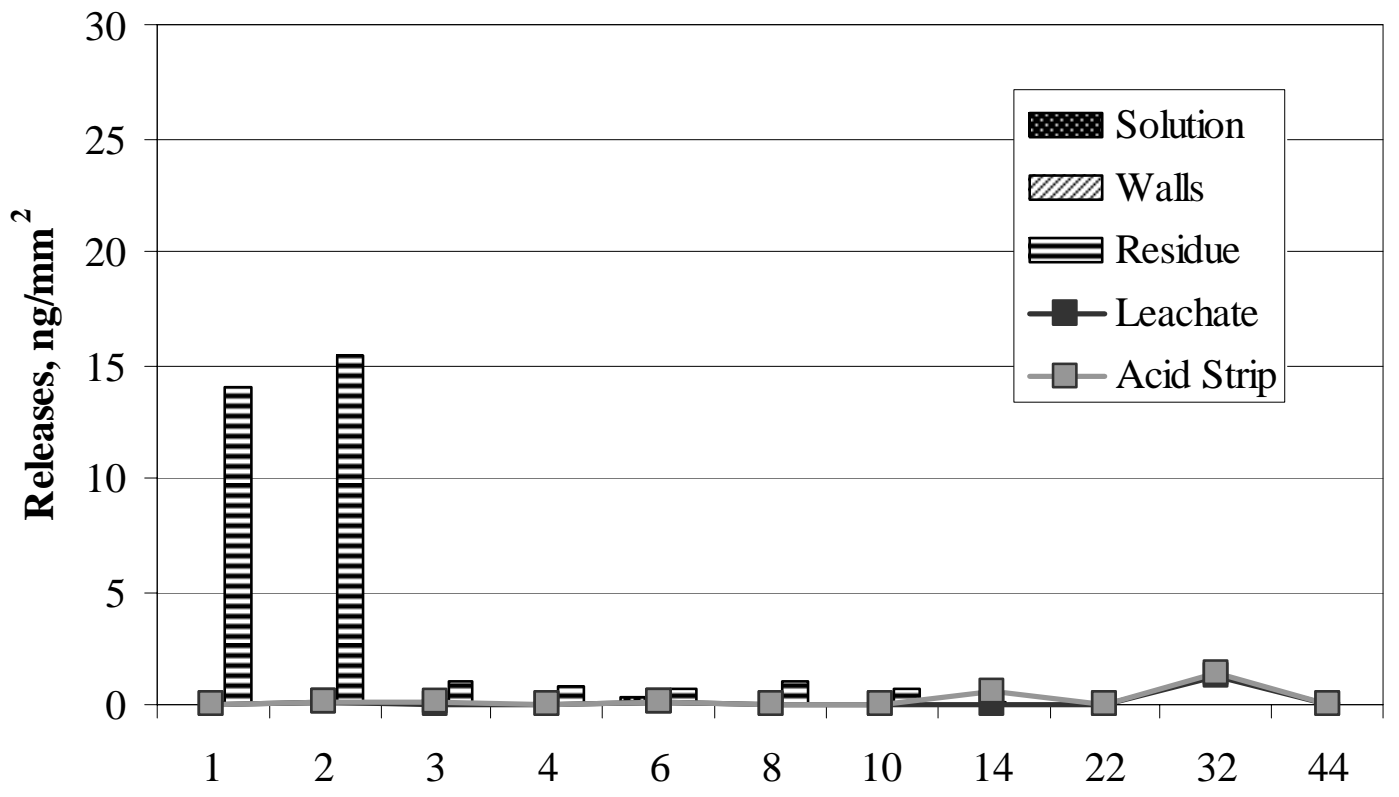

Time, weeks

Figure E-88. Zirconium Releases in Solution, on Walls, and in Residue from Oxidized Sample 4 in $10 \mathrm{KCl}$ and Average Detection Limits for Leachate and Acid Strip. 


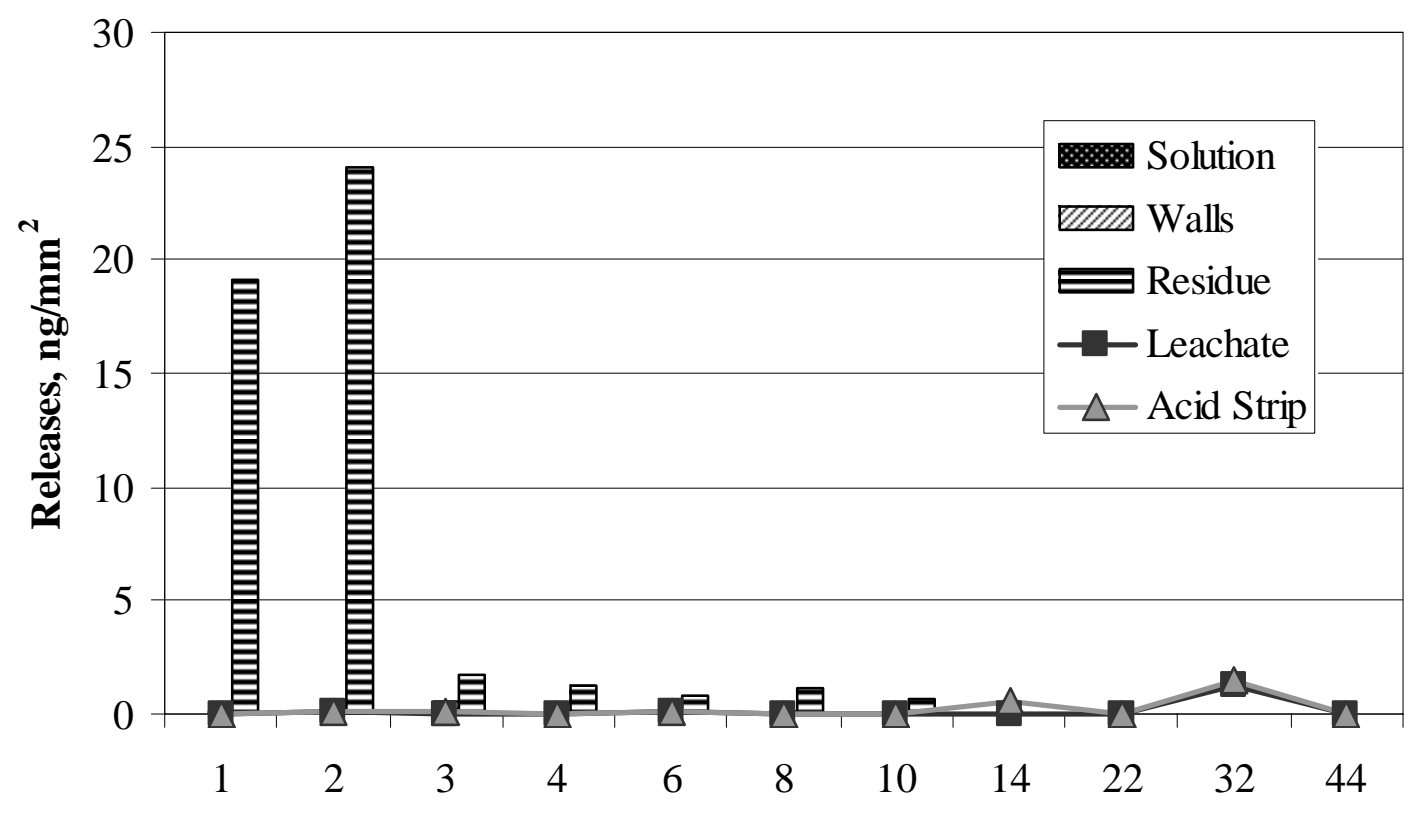

Time, weeks

Figure E-89. Zirconium Releases in Solution, on Walls, and in Residue from Oxidized Sample 5 in $10 \mathrm{KCl}$ and Average Detection Limits for Leachate and Acid Strip.

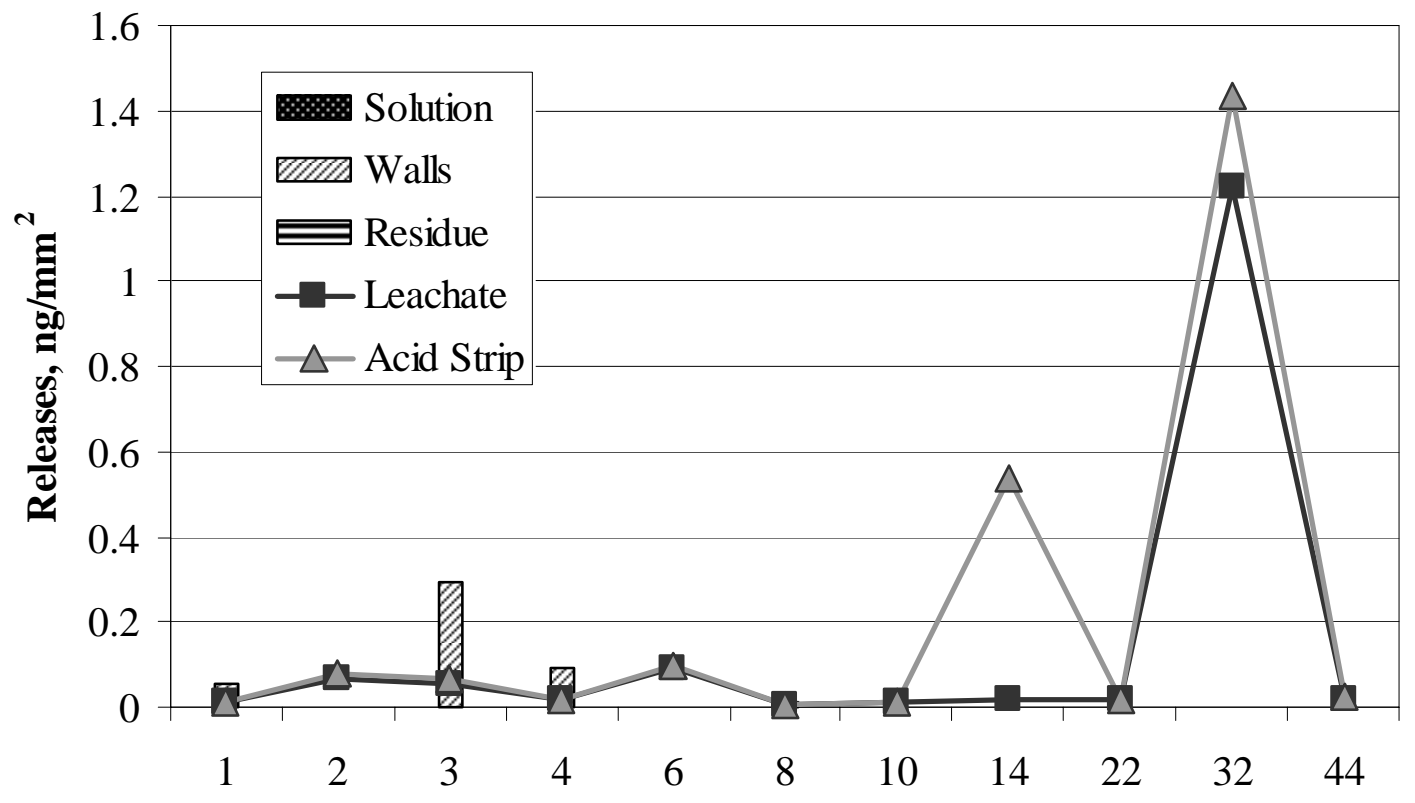

Time, weeks

Figure E-90. Zirconium Present in Solution, on Walls, and in Residue in 10KCl Control and Average Detection Limits for Leachate and Acid Strip. 


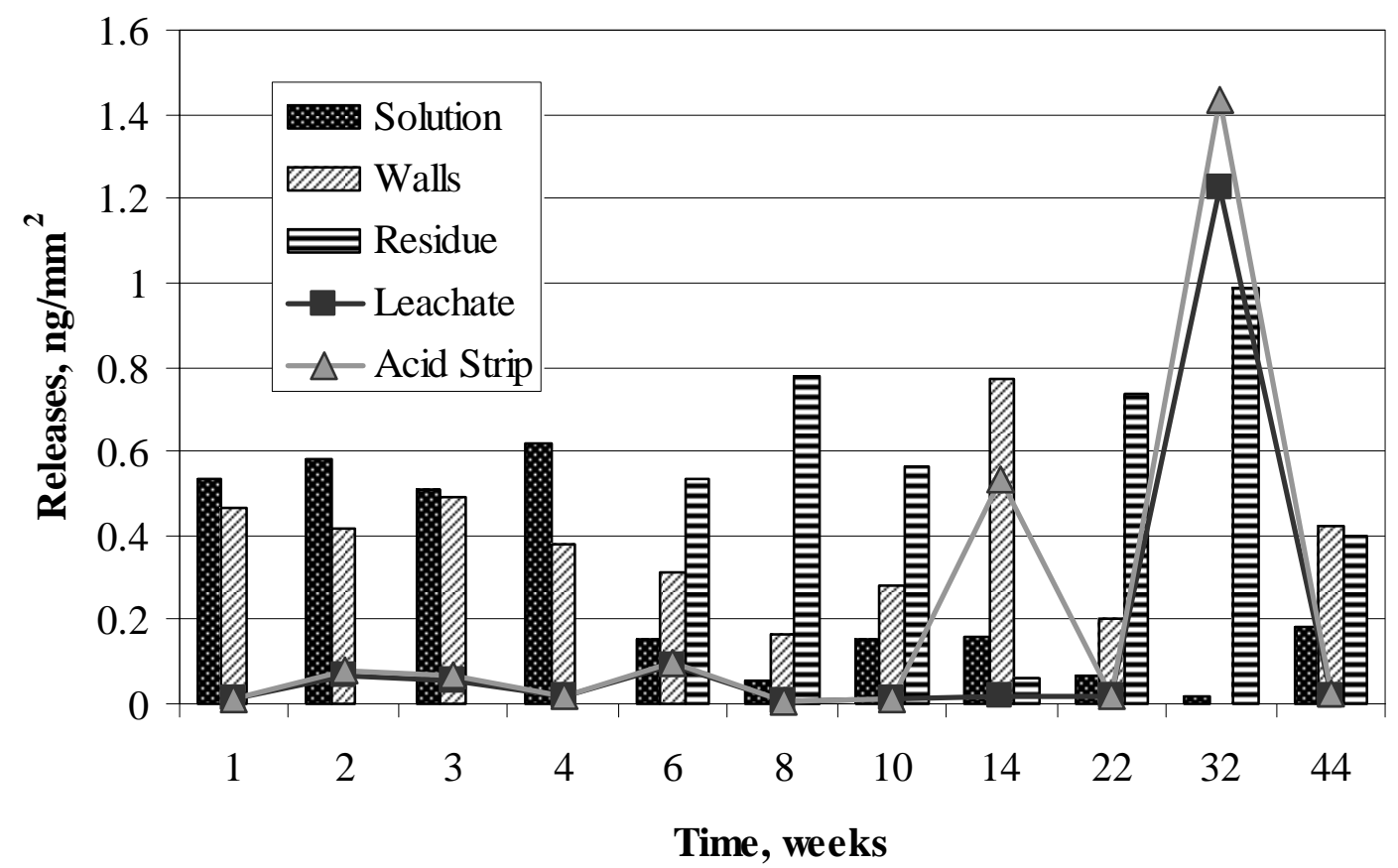

Figure E-91. Zirconium Releases in Solution, on Walls, and in Residue from Polished Sample 1 in AJ13 and Average Detection Limits for Leachate and Acid Strip.

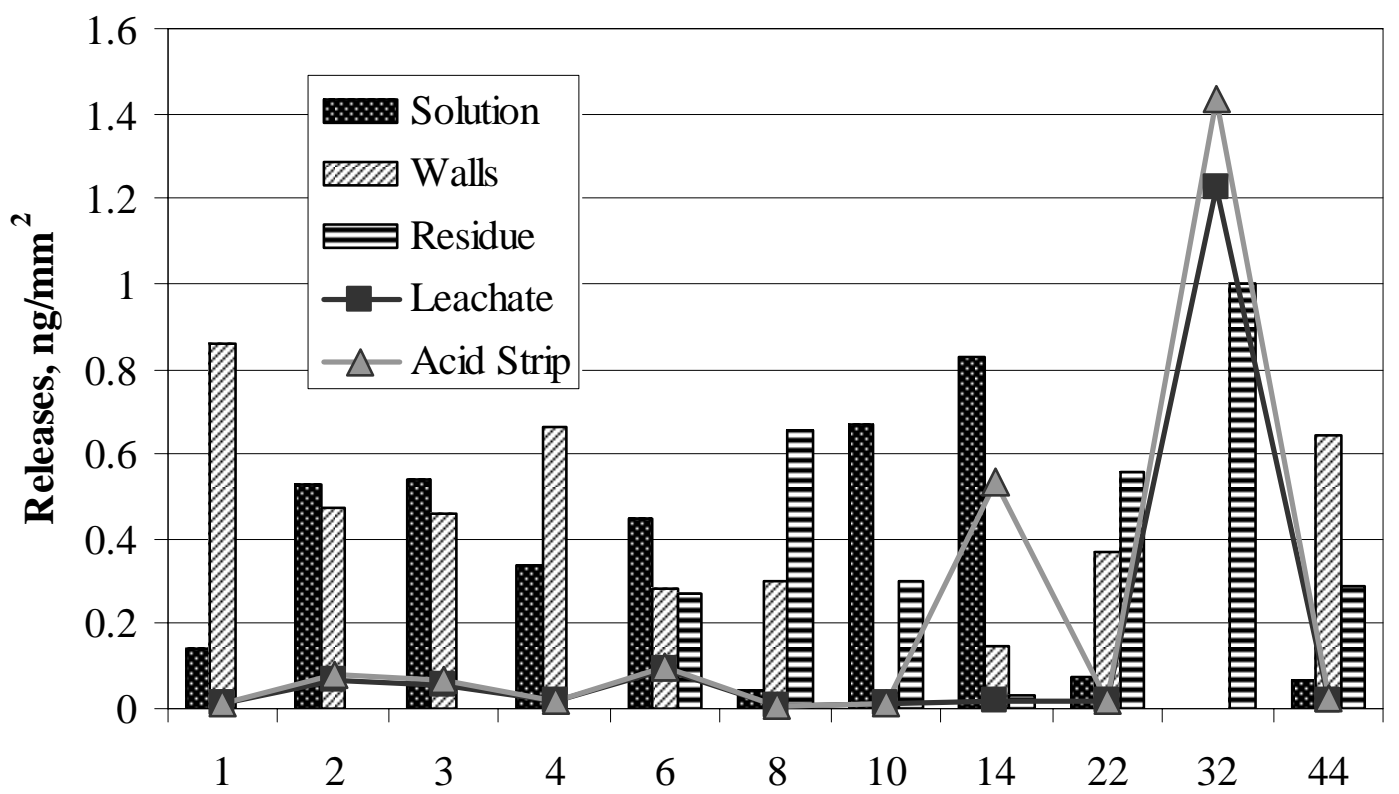

Time, weeks

Figure E-92. Zirconium Releases in Solution, on Walls, and in Residue from Polished Sample 2 in AJ13 and Average Detection Limits for Leachate and Acid Strip. 


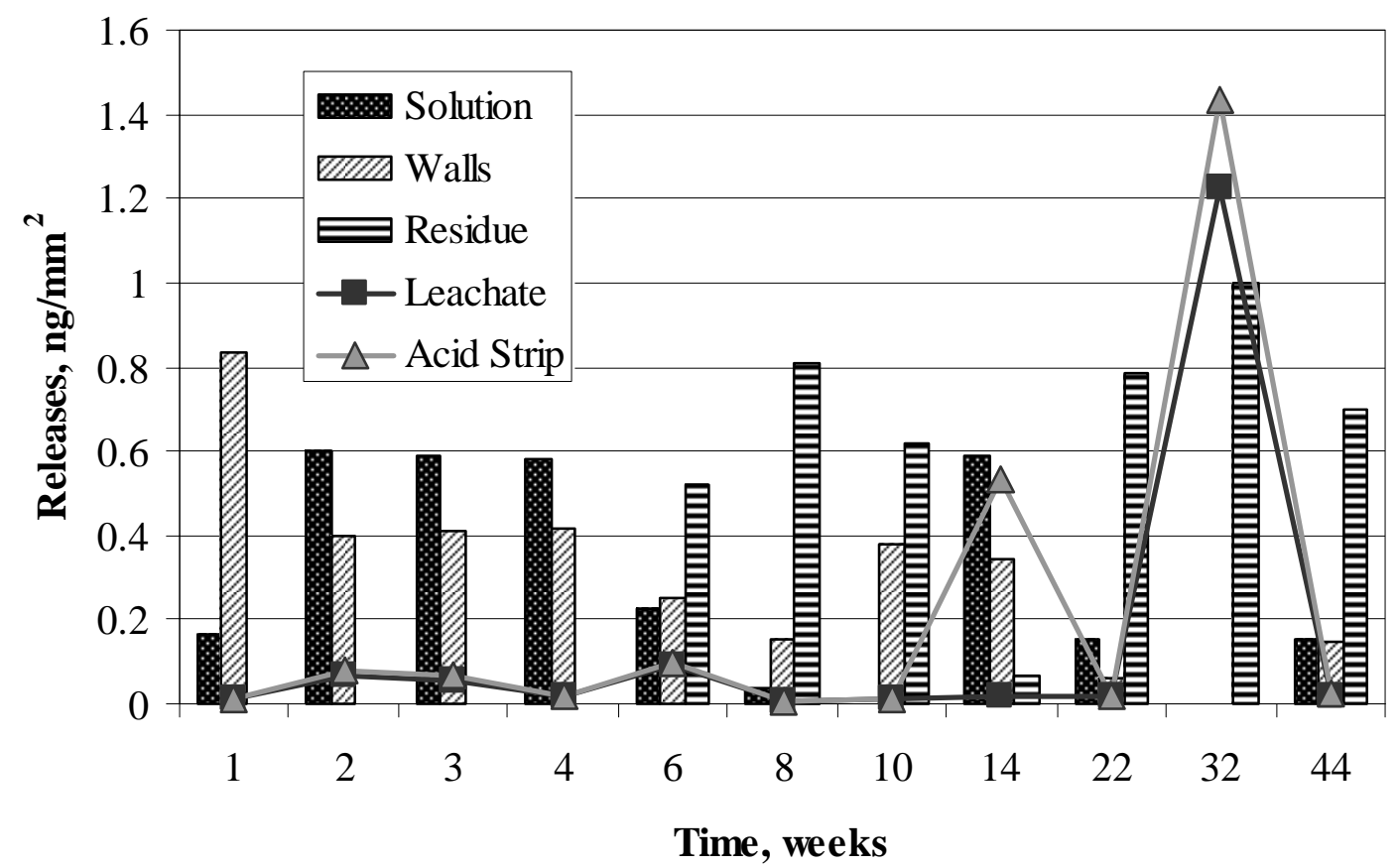

Figure E-93. Zirconium Releases in Solution, on Walls, and in Residue from Polished Sample 3 in AJ13 and Average Detection Limits for Leachate and Acid Strip.

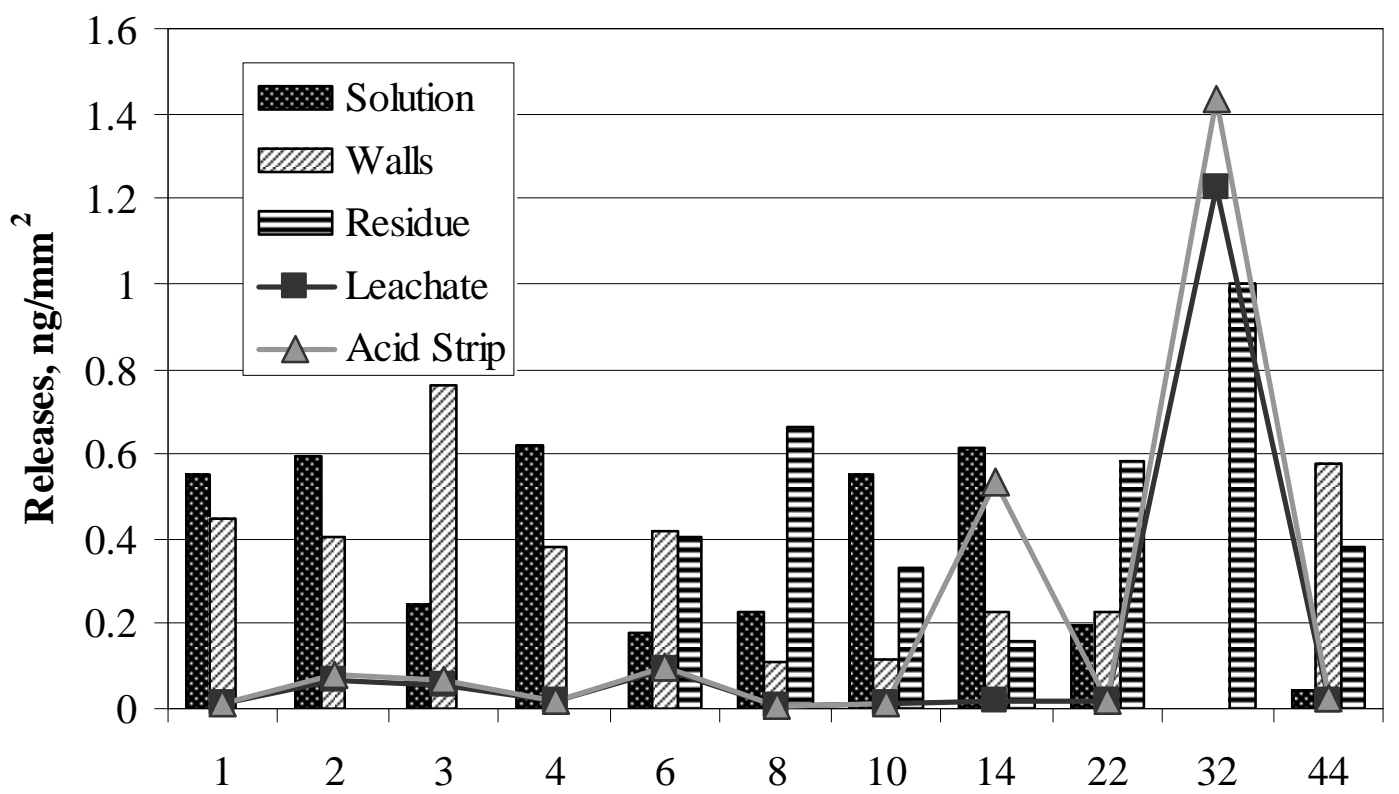

Time, weeks

Figure E-94. Zirconium Releases in Solution, on Walls, and in Residue from Oxidized Sample 4 in AJ13 and Average Detection Limits for Leachate and Acid Strip. 


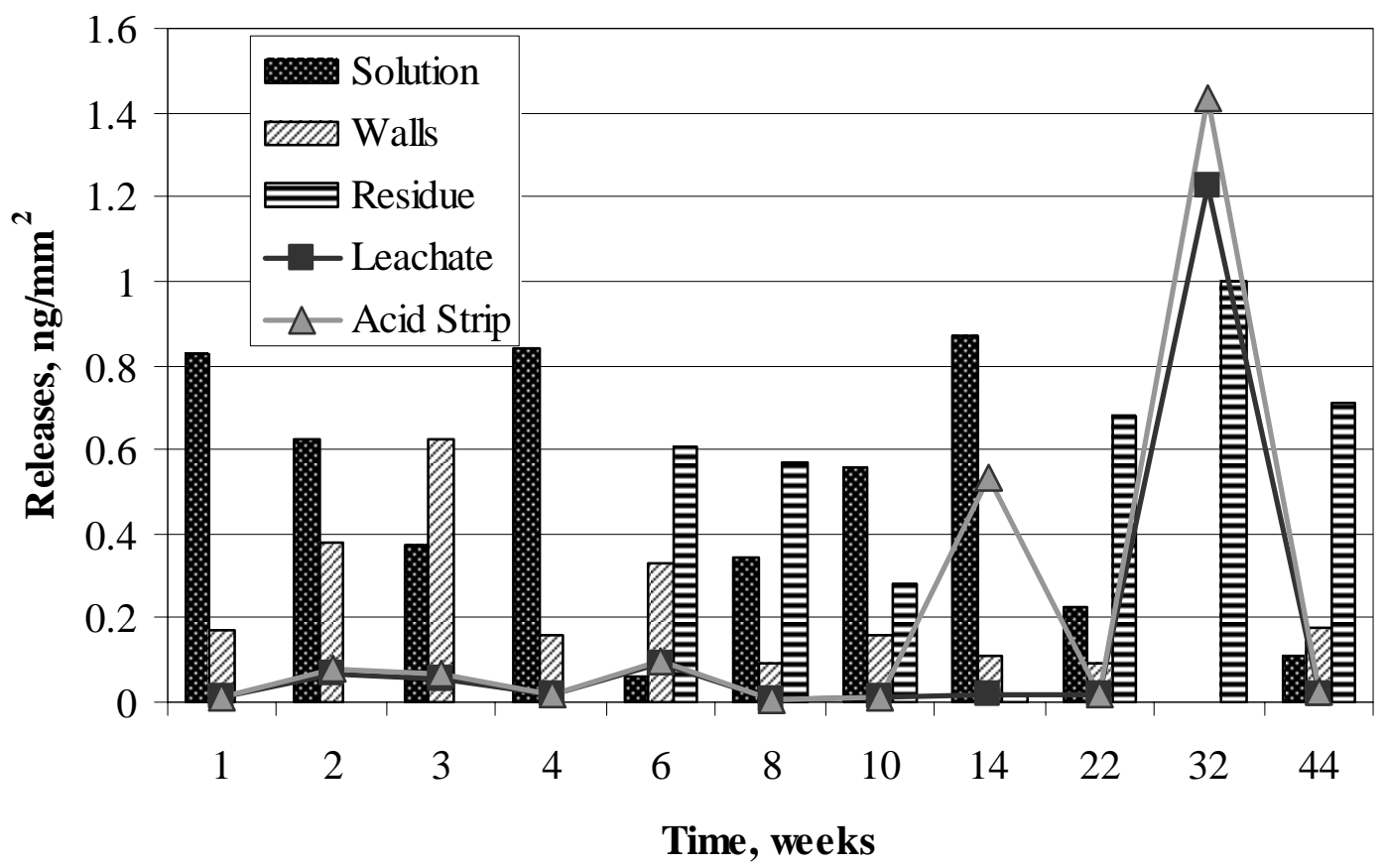

Figure E-95. Zirconium Releases in Solution, on Walls, and in Residue from Oxidized Sample 5 in AJ13 and Average Detection Limits for Leachate and Acid Strip.

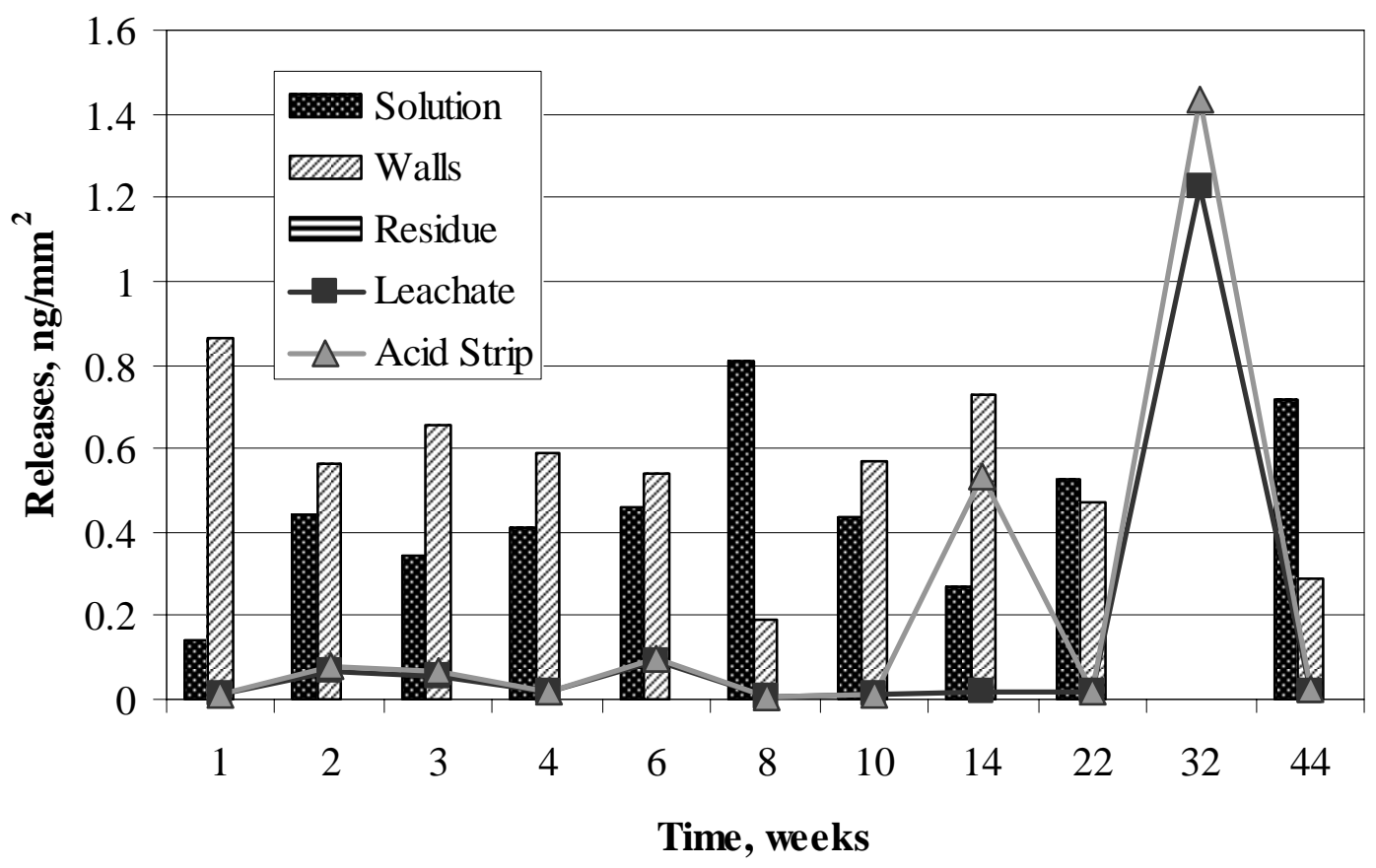

Figure E-96. Zirconium Present in Solution, on Walls, and in Residue from AJ13 Control and Average Detection Limits for Leachate and Acid Strip. 


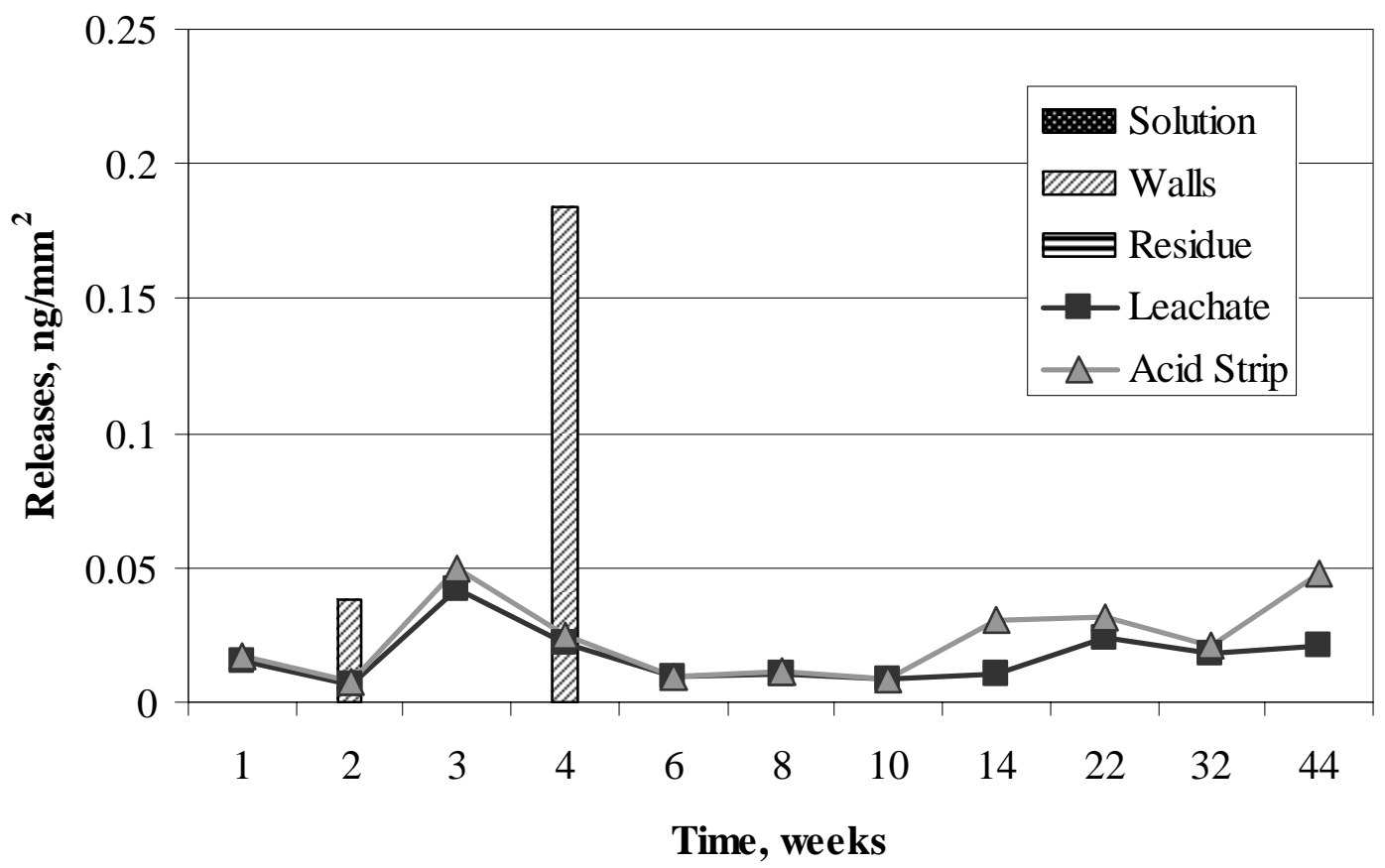

Figure E-97. Niobium Releases in Solution, on Walls, and in Residue from Polished Sample 1 in SJ13 and Average Detection Limits for Leachate and Acid Strip.

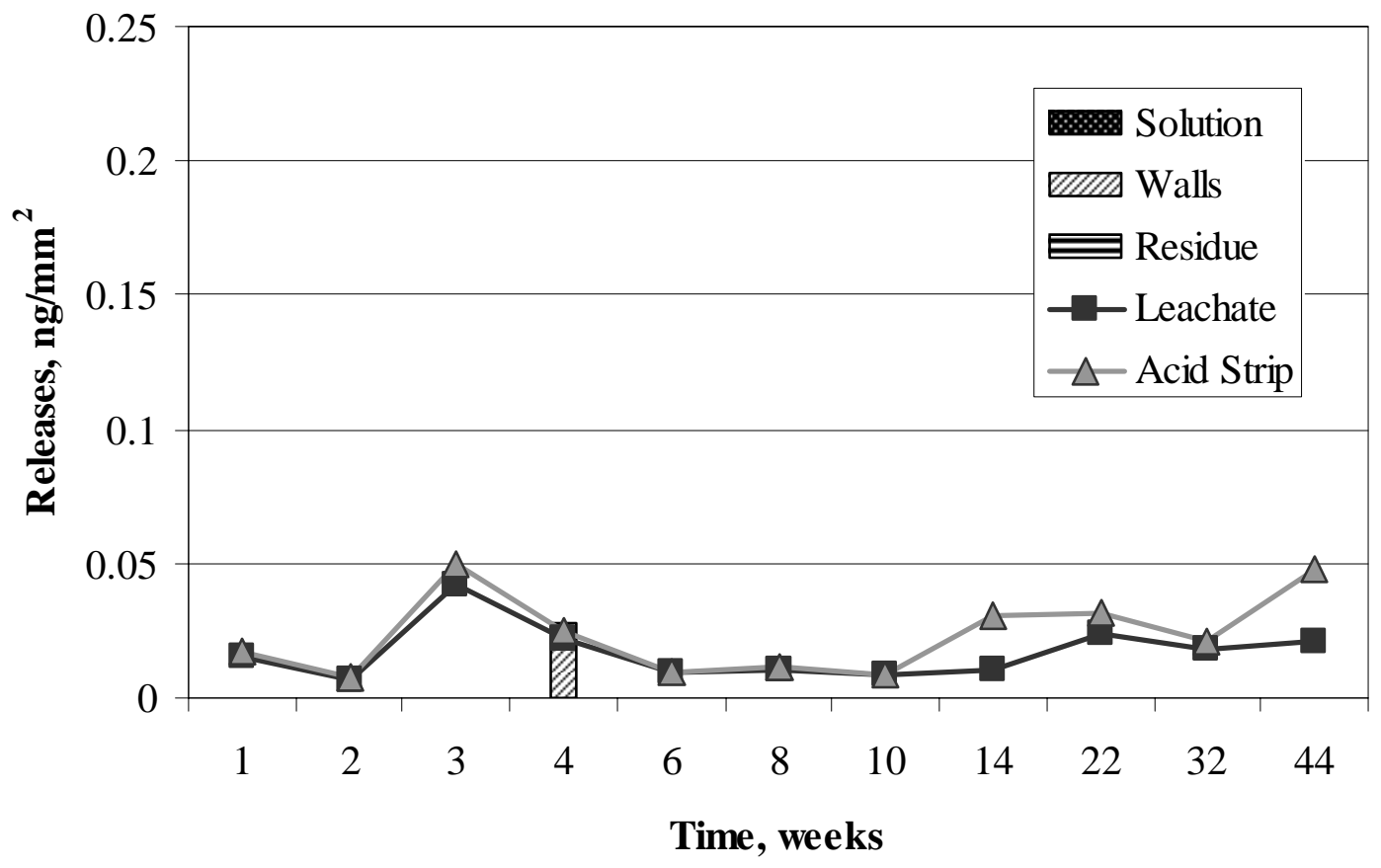

Figure E-98. Niobium Releases in Solution, on Walls, and in Residue from Polished Sample 2 in SJ13 and Average Detection Limits for Leachate and Acid Strip. 


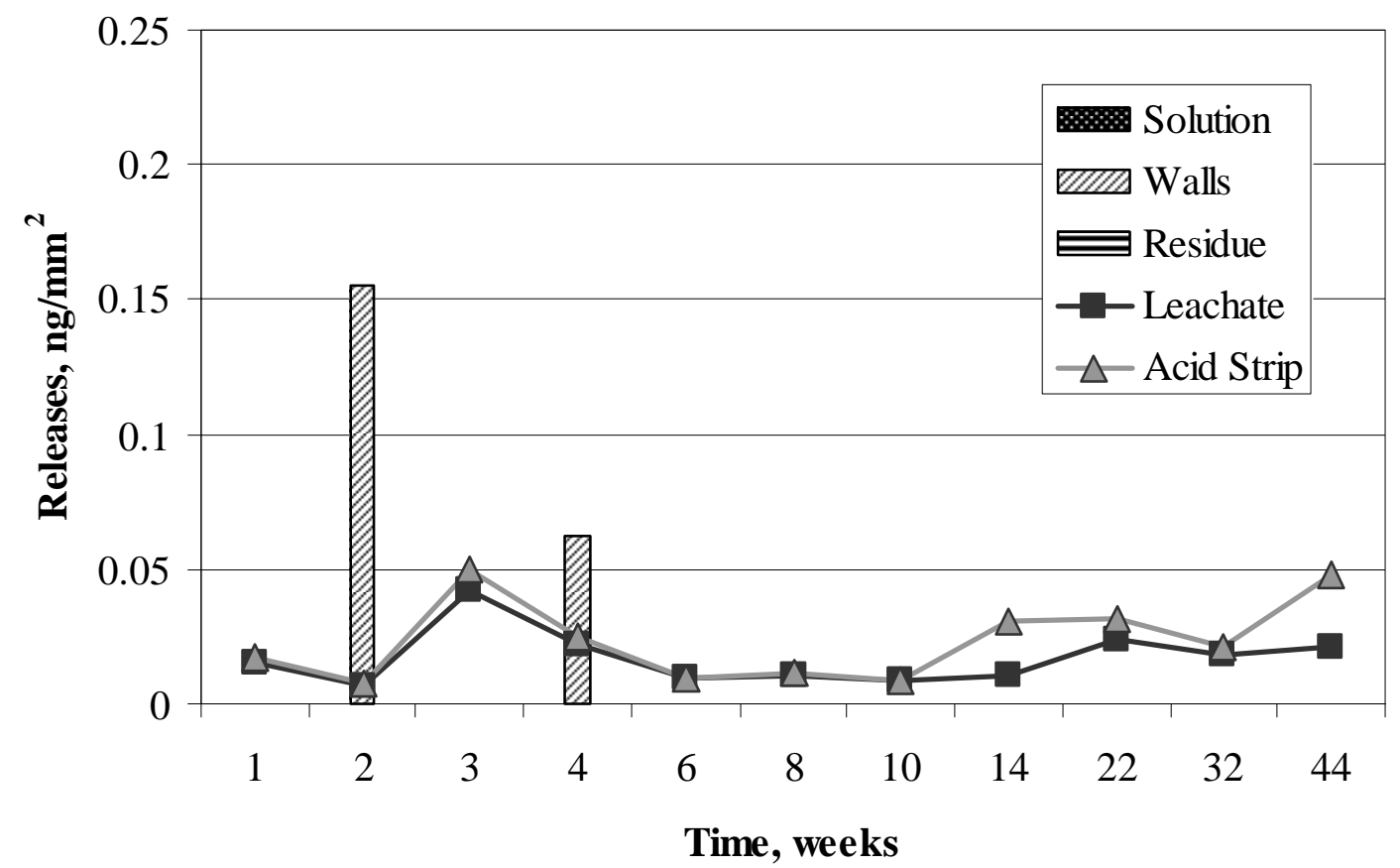

Figure E-99. Niobium Releases in Solution, on Walls, and in Residue from Polished Sample 3 in SJ13 and Average Detection Limits for Leachate and Acid Strip.

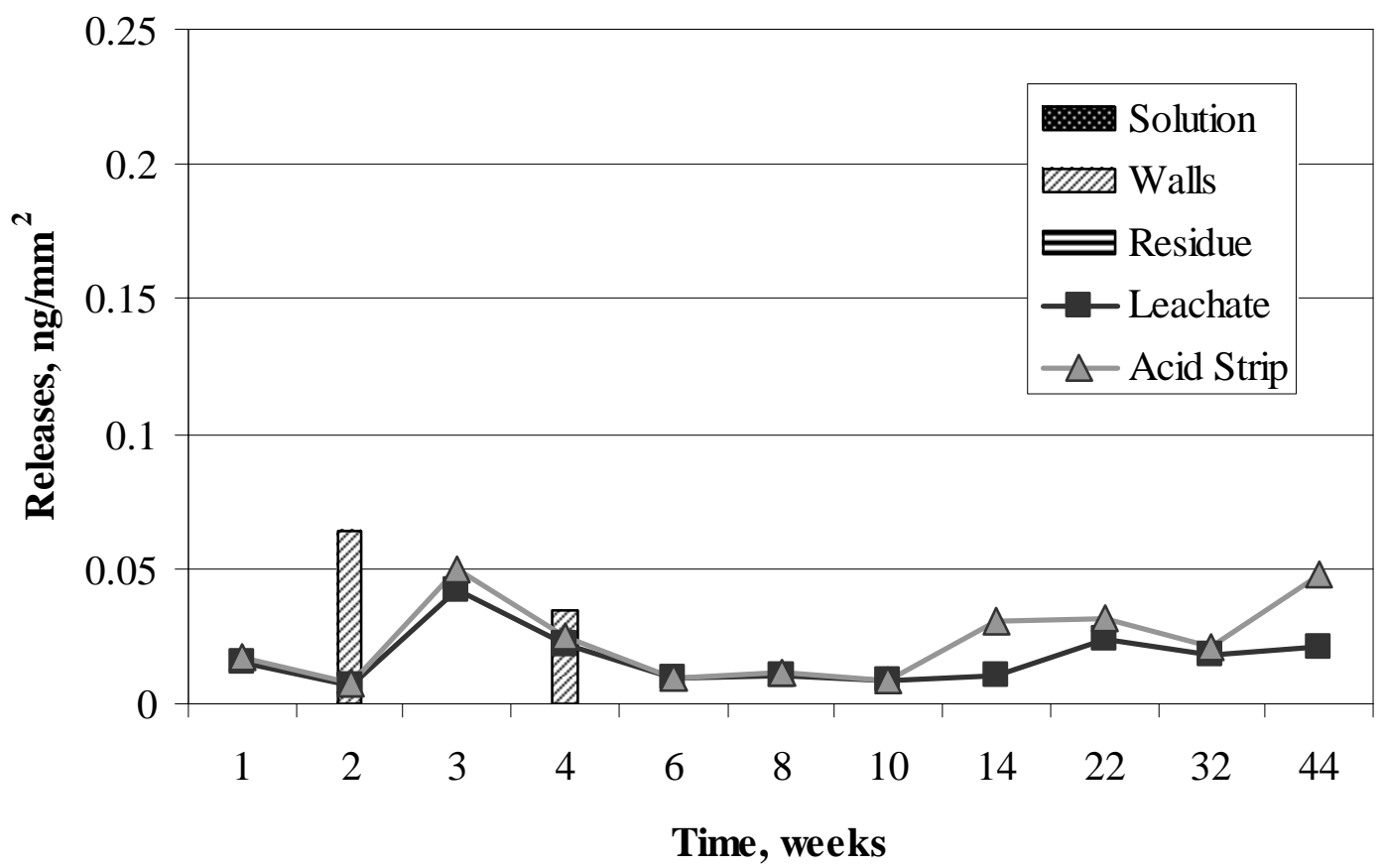

Figure E-100. Niobium Releases in Solution, on Walls, and in Residue from Oxidized Sample 4 in SJ13 and Average Detection Limits for Leachate and Acid Strip. 


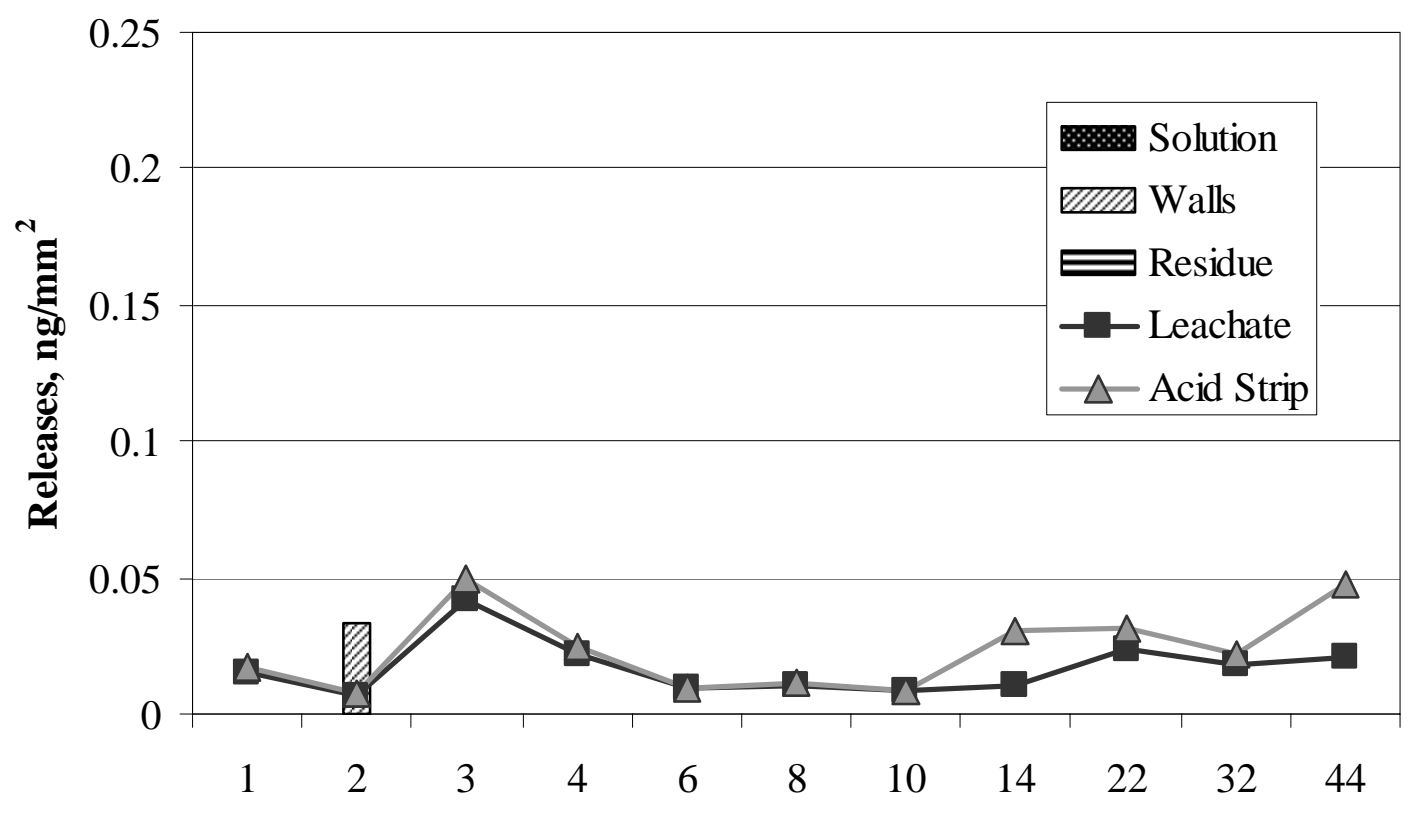

Time, weeks

Figure E-101. Niobium Releases in Solution, on Walls, and in Residue from Oxidized Sample 5 in SJ13 and Average Detection Limits for Leachate and Acid Strip.

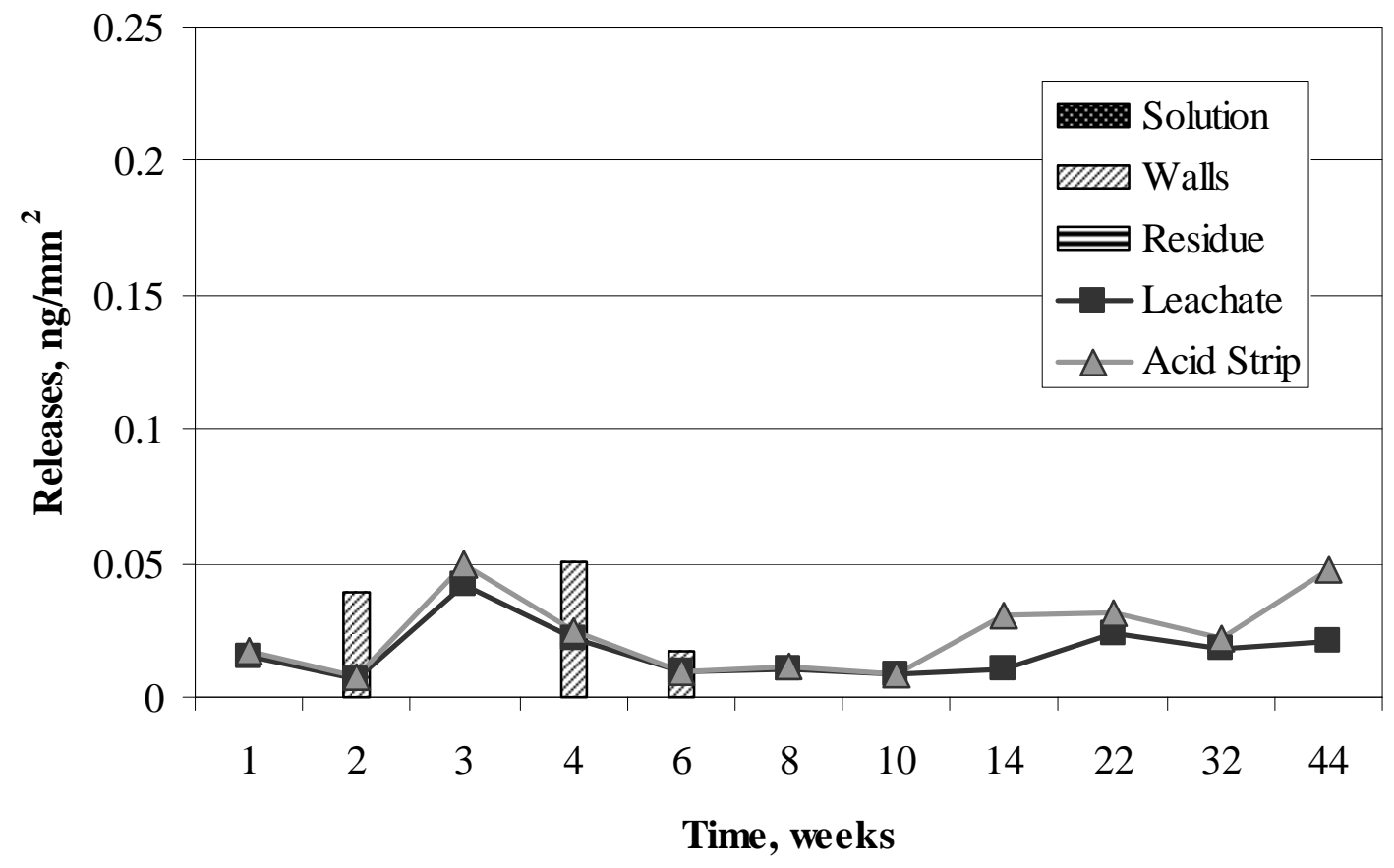

Figure E-102. Niobium Present in Solution, on Walls, and in Residue from SJ13 Control and Average Detection Limits for Leachate and Acid Strip. 


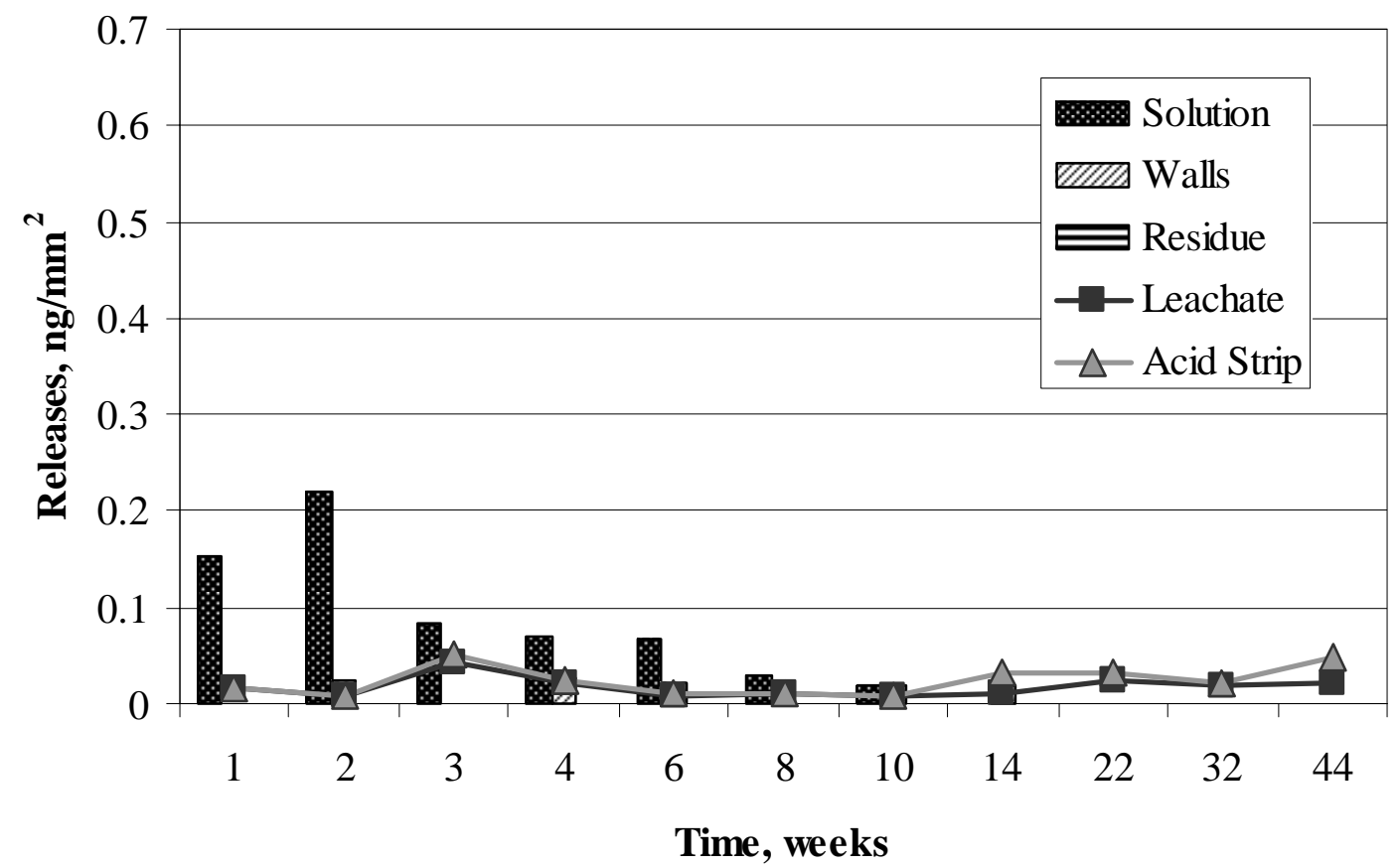

Figure E-103. Niobium Releases in Solution, on Walls, and in Residue from Polished Sample 1 in CJ13 and Average Detection Limits for Leachate and Acid Strip.

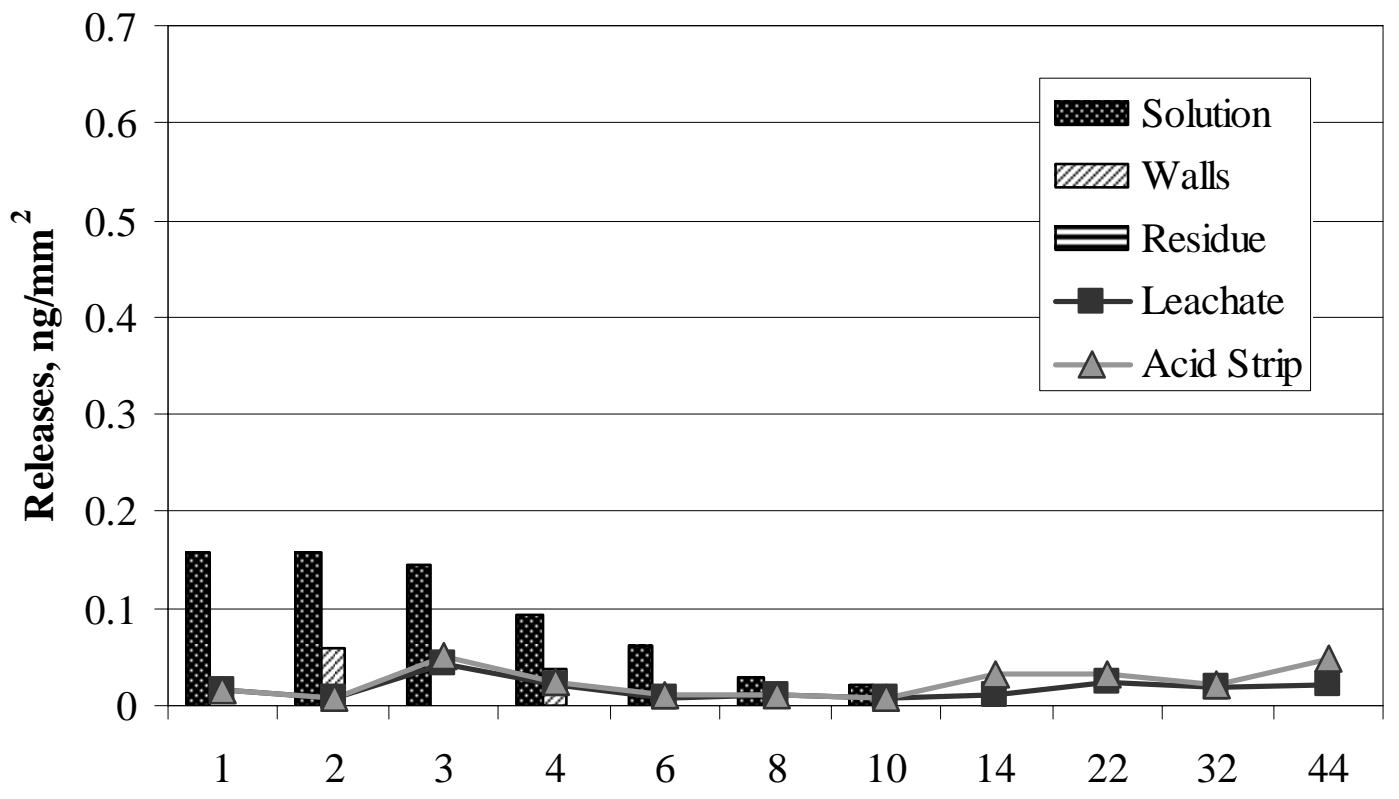

Time, weeks

Figure E-104. Niobium Releases in Solution, on Walls, and in Residue from Polished Sample 2 in CJ13 and Average Detection Limits for Leachate and Acid Strip. 


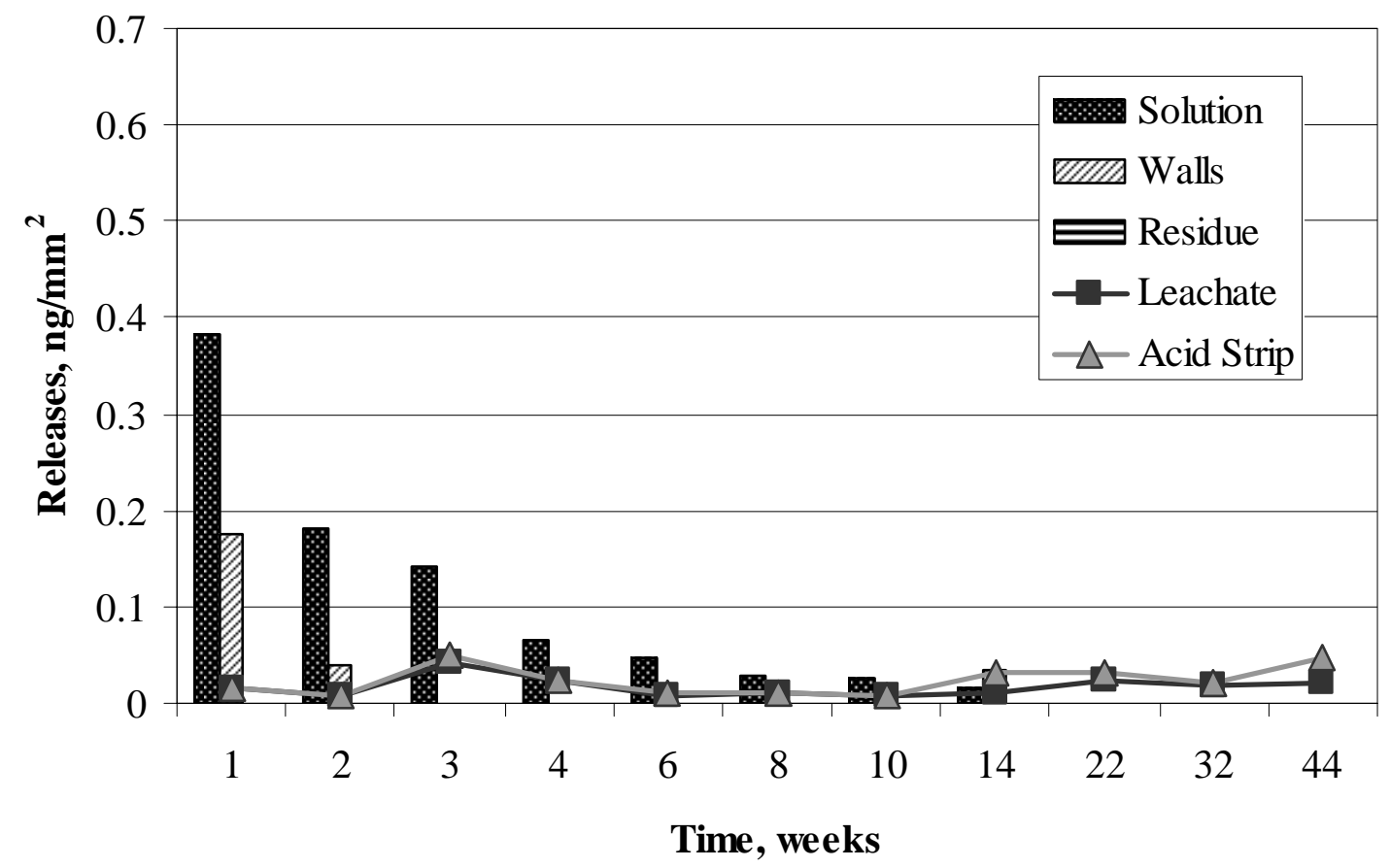

Figure E-105. Niobium Releases in Solution, on Walls, and in Residue from Polished Sample 3 in CJ13 and Average Detection Limits for Leachate and Acid Strip.

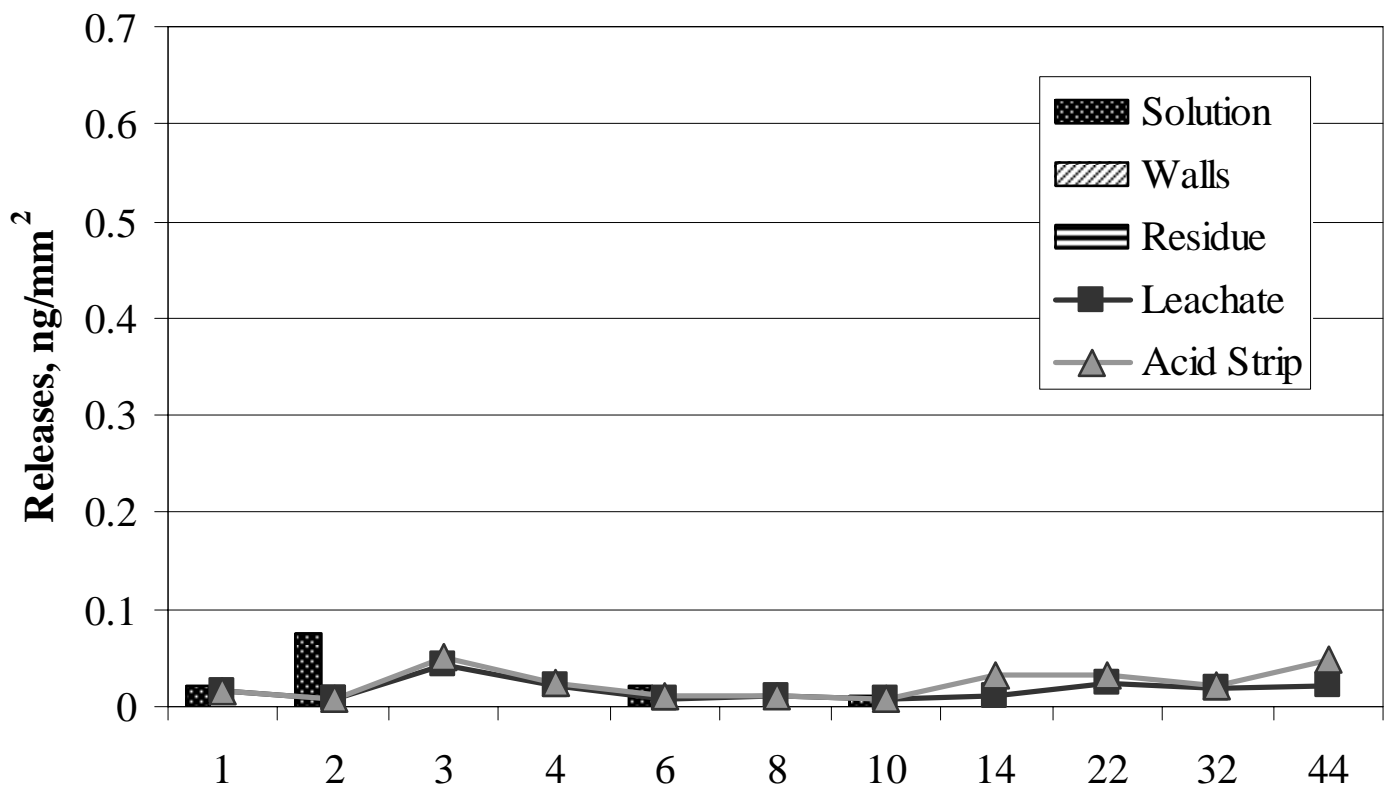

Time, weeks

Figure E-106. Niobium Releases in Solution, on Walls, and in Residue from Oxidized Sample 4 in CJ13 and Average Detection Limits for Leachate and Acid Strip. 


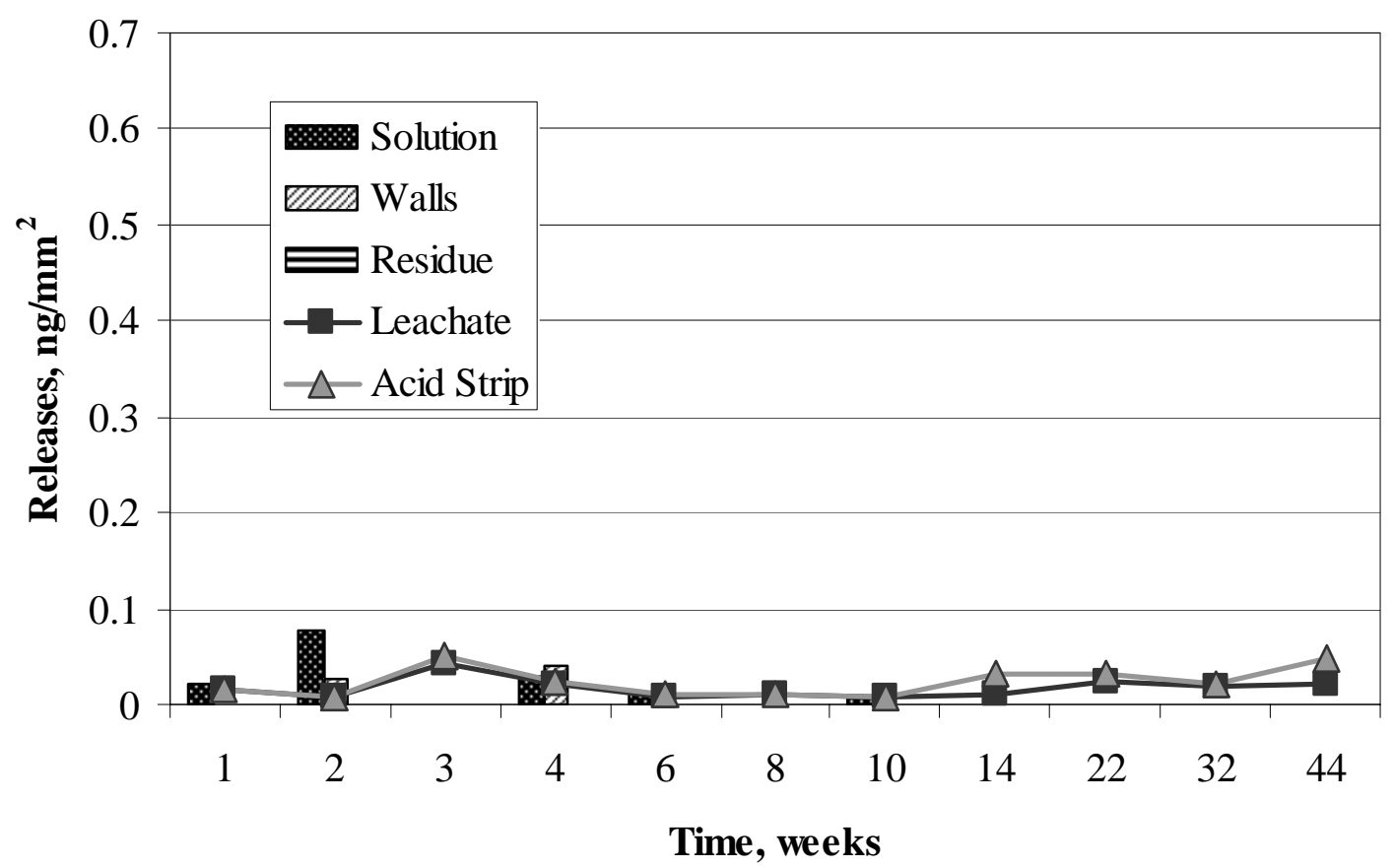

Figure E-107. Niobium Releases in Solution, on Walls, and in Residue from Oxidized Sample 5 in CJ13 and Average Detection Limits for Leachate and Acid Strip.

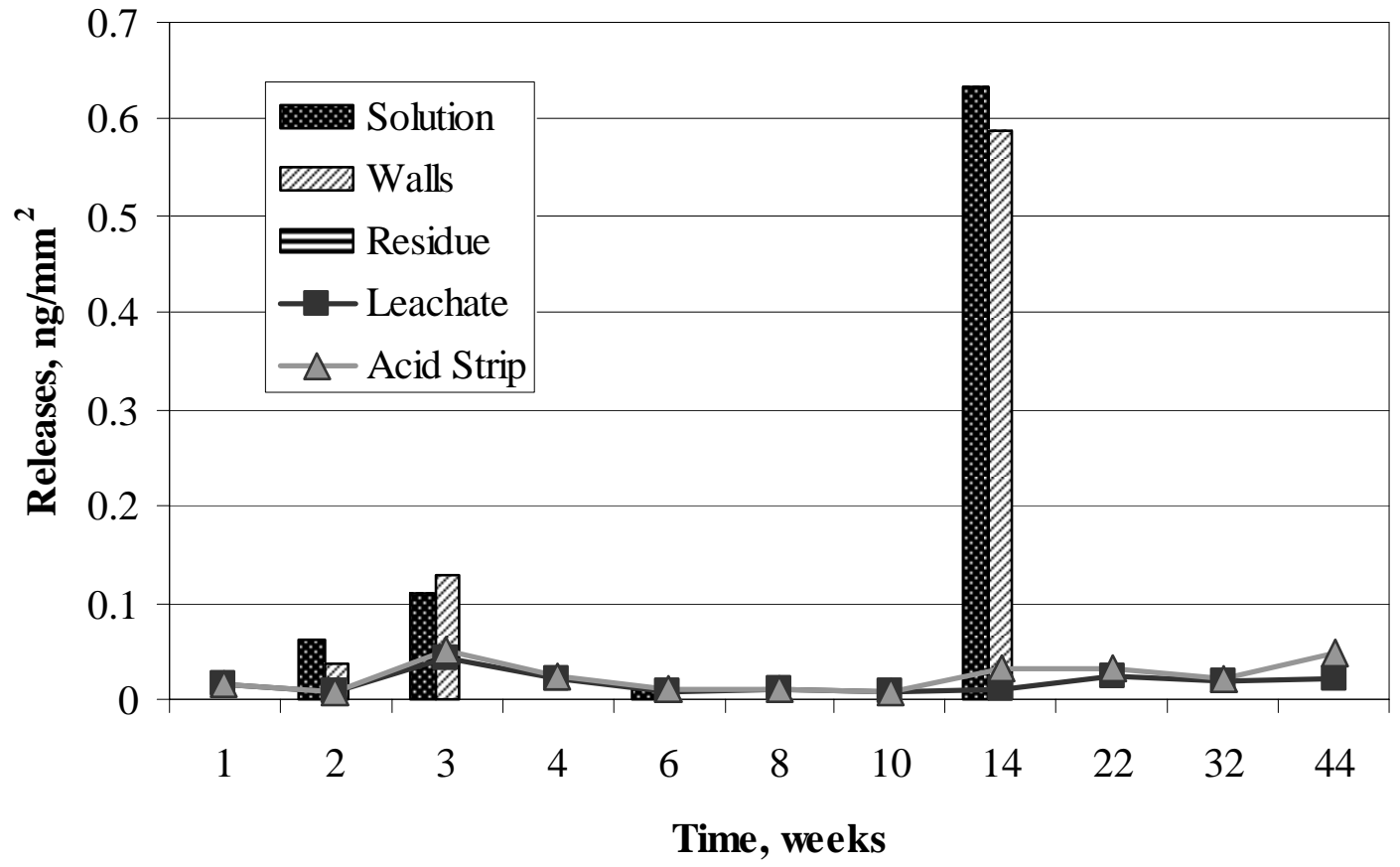

Figure E-108. Niobium Present in Solution, on Walls, and in Residue from CJ13 Control and Average Detection Limits for Leachate and Acid Strip. 


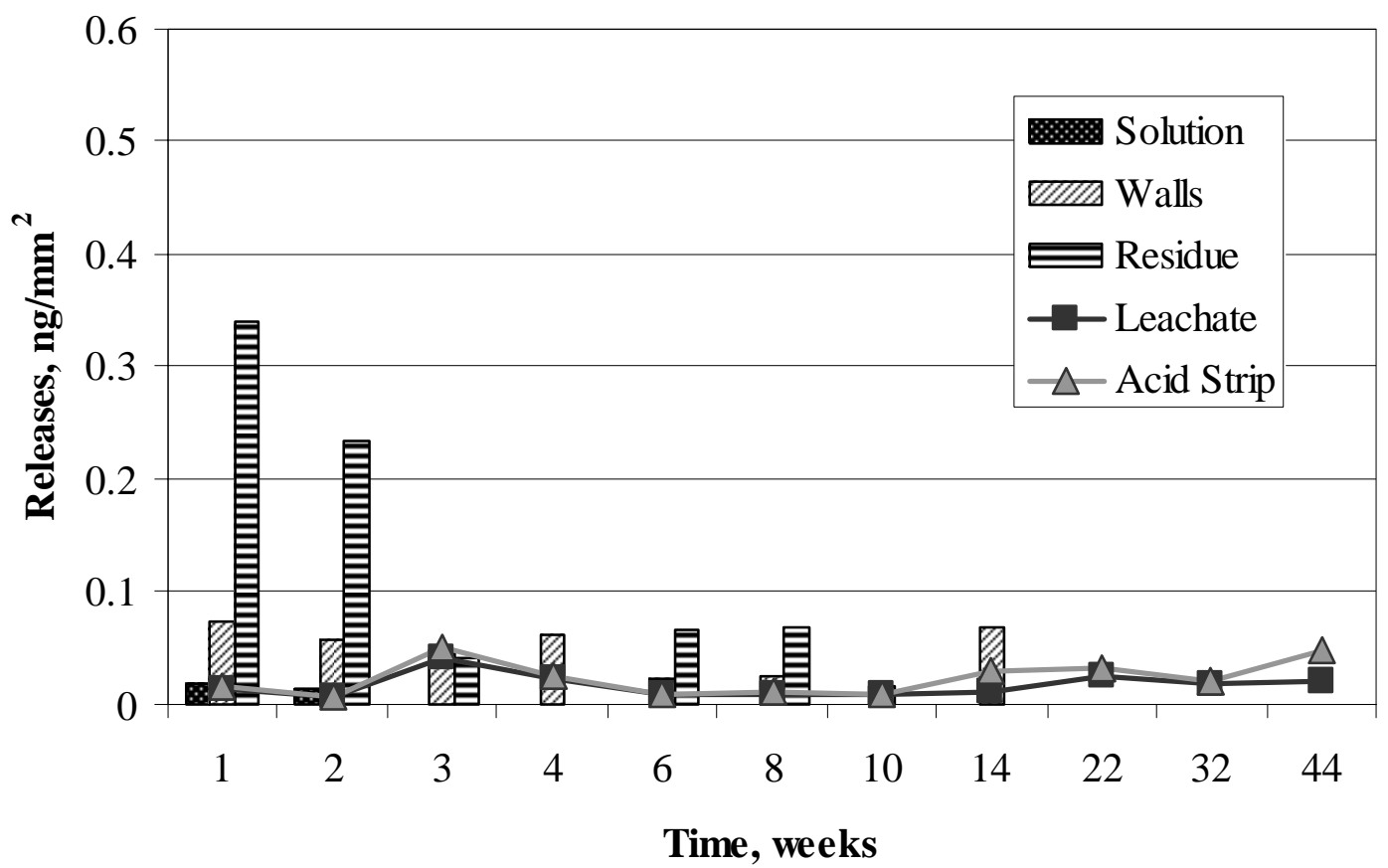

Figure E-109. Niobium Releases in Solution, on Walls, and in Residue from Polished Sample 1 in $10 \mathrm{KCl}$ and Average Detection Limits for Leachate and Acid Strip.

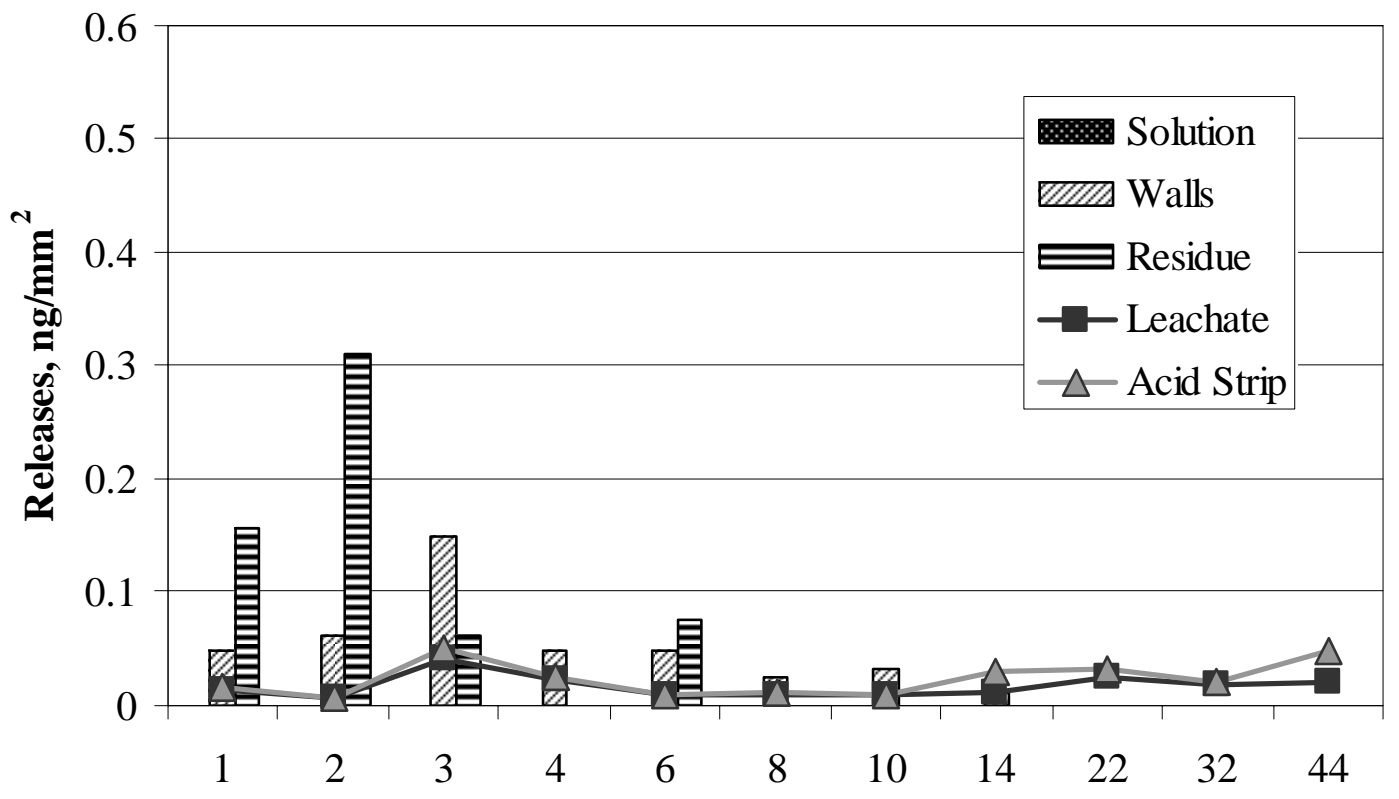

Time, weeks

Figure E-110. Niobium Releases in Solution, on Walls, and in Residue from Polished Sample 2 in $10 \mathrm{KCl}$ and Average Detection Limits for Leachate and Acid Strip. 


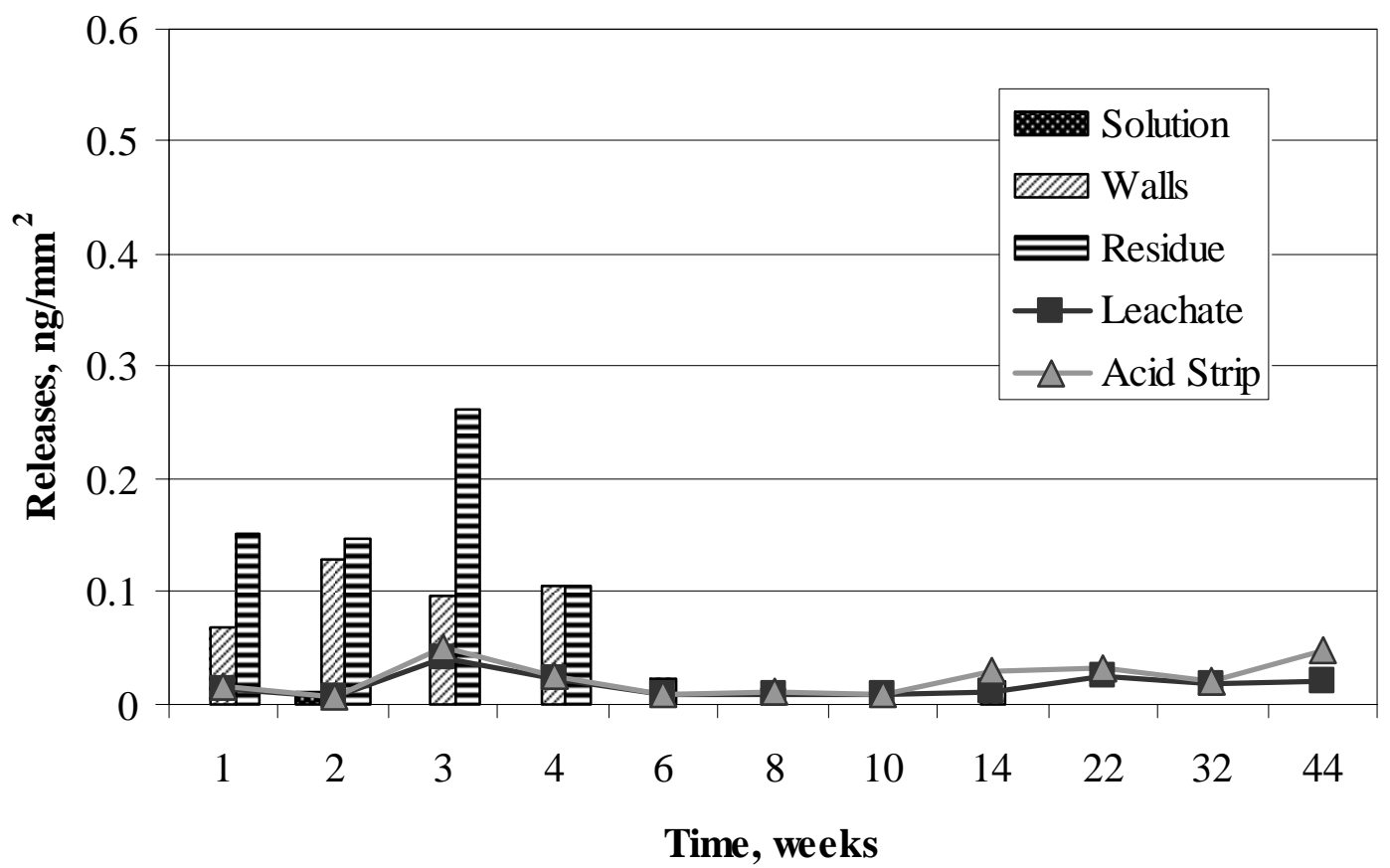

Figure E-111. Niobium Releases in Solution, on Walls, and in Residue from Polished Sample 3 in $10 \mathrm{KCl}$ and Average Detection Limits for Leachate and Acid Strip.

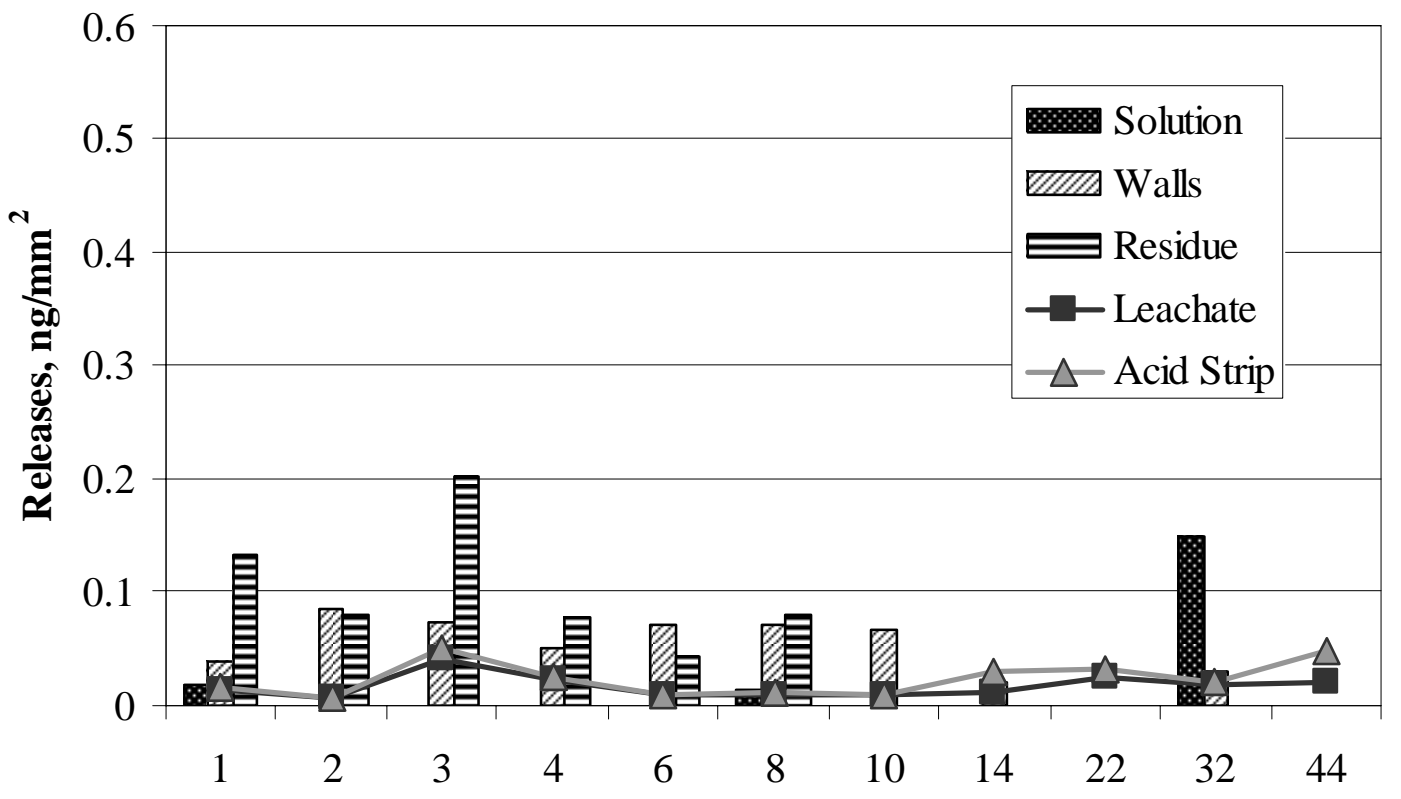

Time, weeks

Figure E-112. Niobium Releases in Solution, on Walls, and in Residue from Oxidized Sample 4 in $10 \mathrm{KCl}$ and Average Detection Limits for Leachate and Acid Strip. 


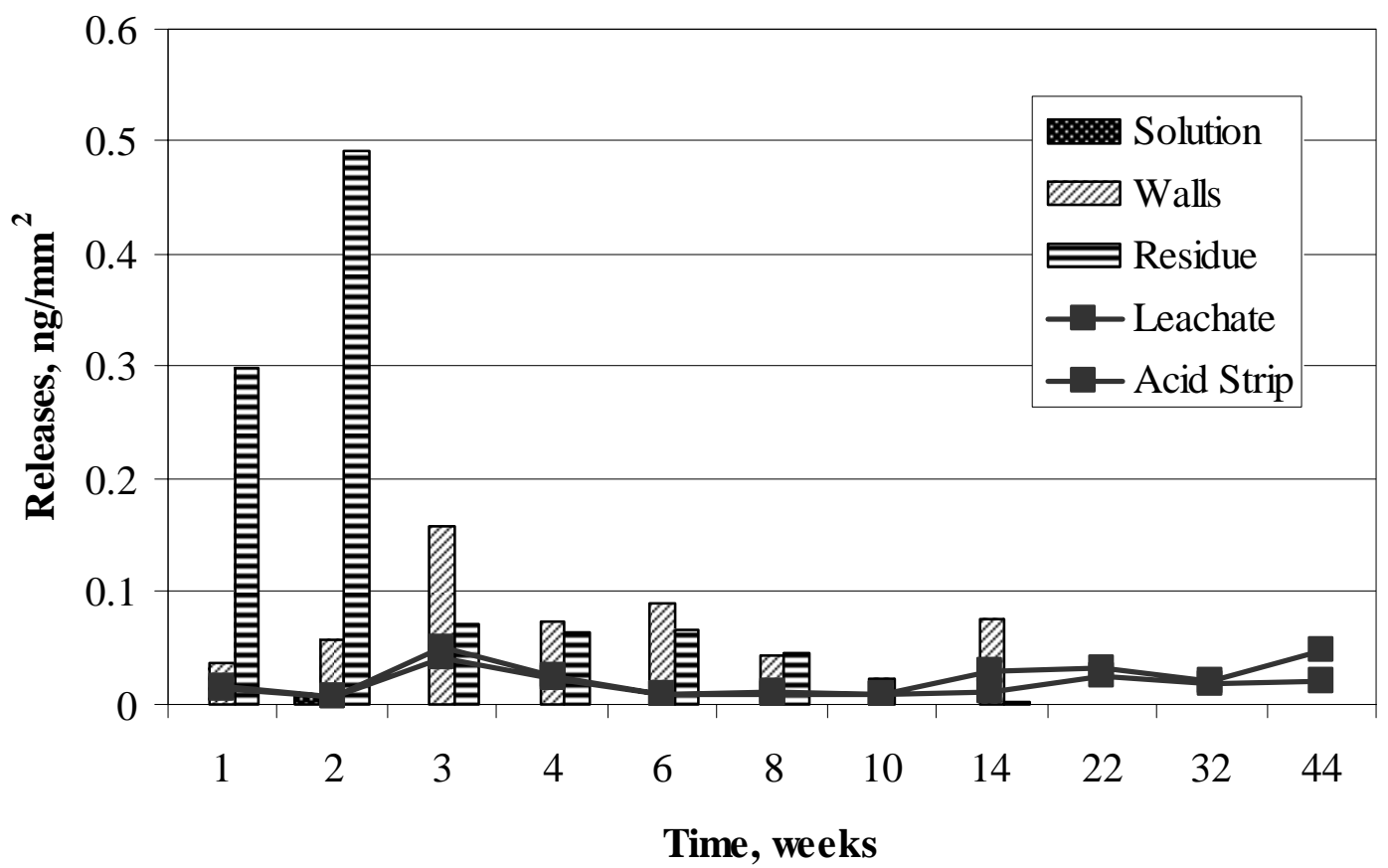

Figure E-113. Niobium Releases in Solution, on Walls, and in Residue from Oxidized Sample 5 in 10KCl and Average Detection Limits for Leachate and Acid Strip.

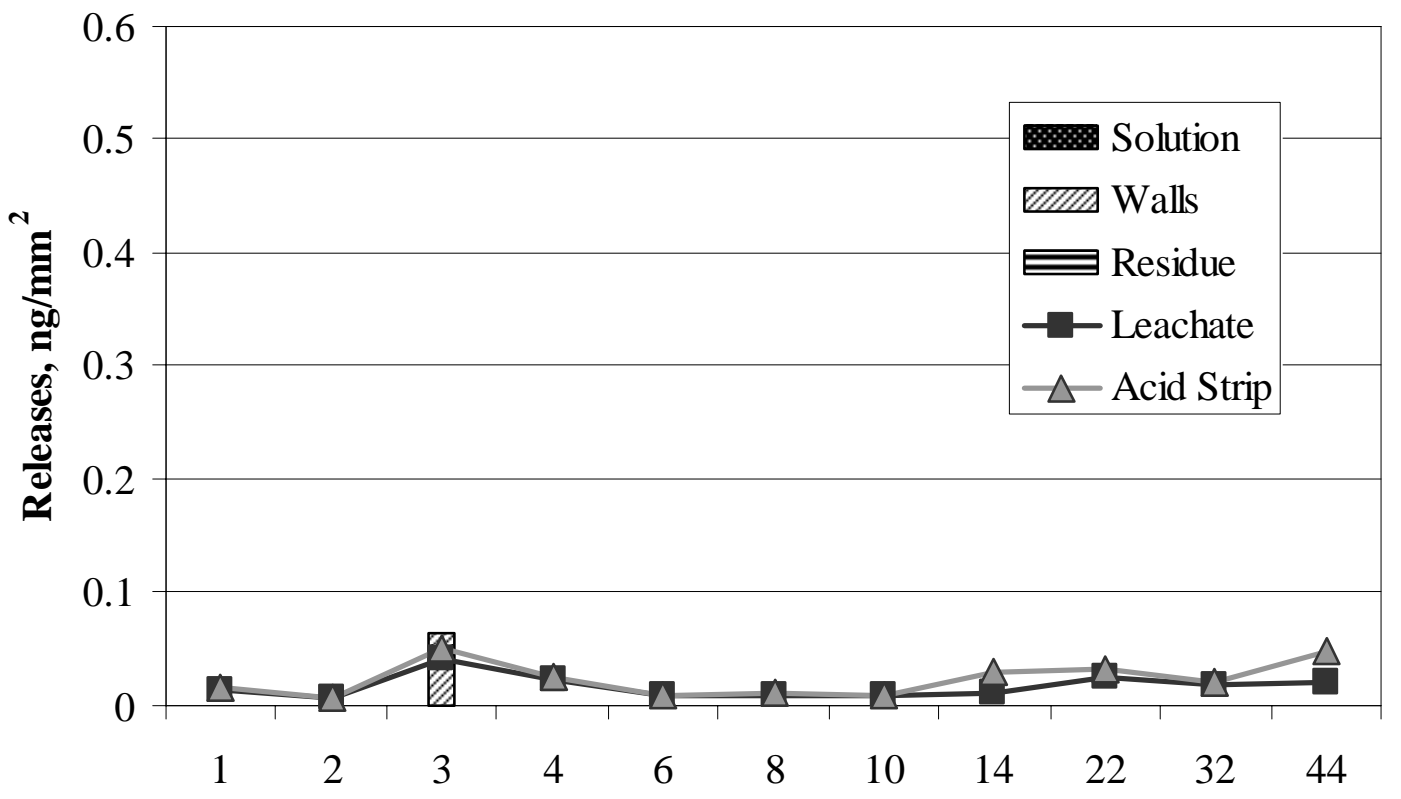

Time, weeks

Figure E-114. Niobium Present in Solution, on Walls, and in Residue from $10 \mathrm{KCl}$ Control and Average Detection Limits for Leachate and Acid Strip. 


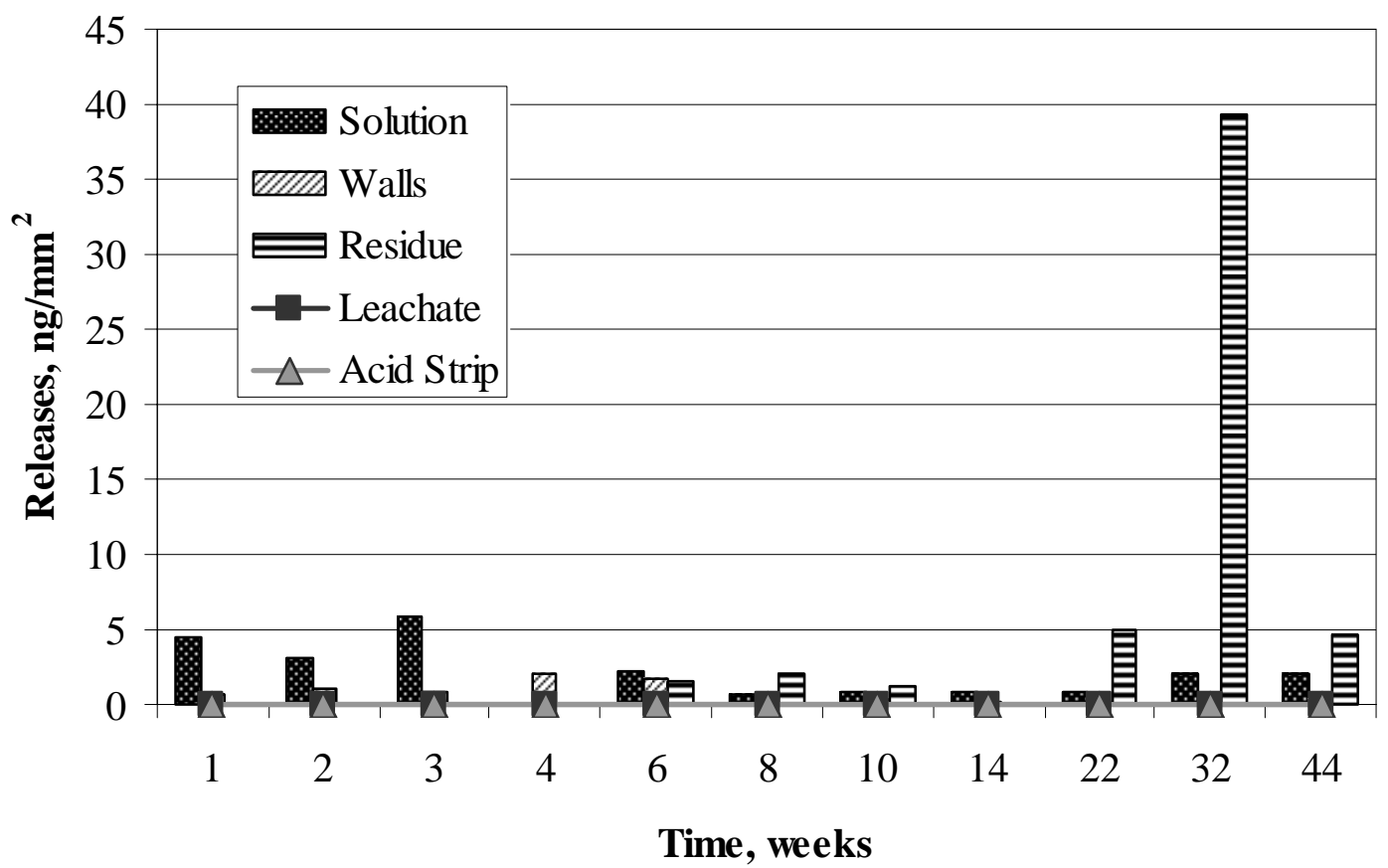

Figure E-115. Niobium Releases in Solution, on Walls, and in Residue from Polished Sample 1 in AJ13 and Average Detection Limits for Leachate and Acid Strip.

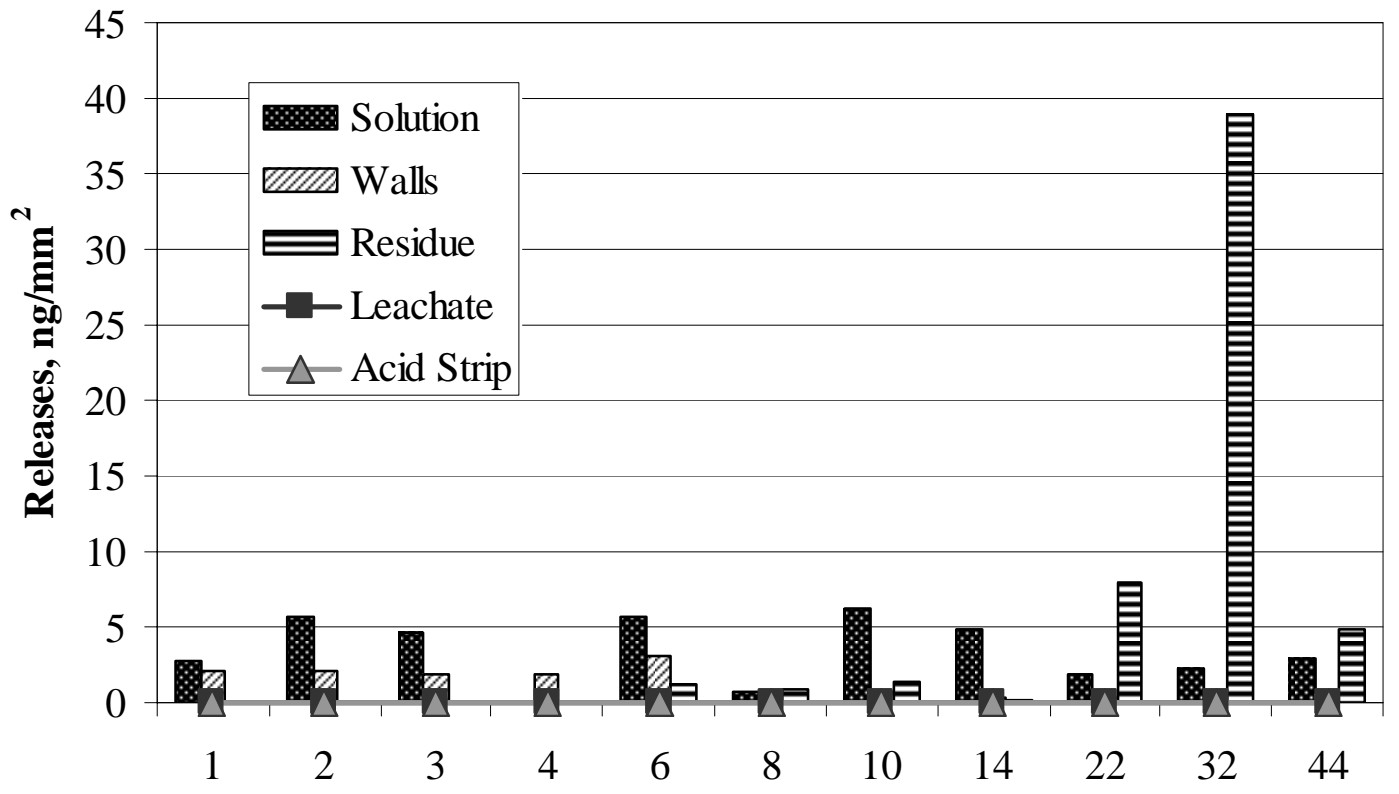

Time, weeks

Figure E-116. Niobium Releases in Solution, on Walls, and in Residue from Polished Sample 2 in AJ13 and Average Detection Limits for Leachate and Acid Strip. 


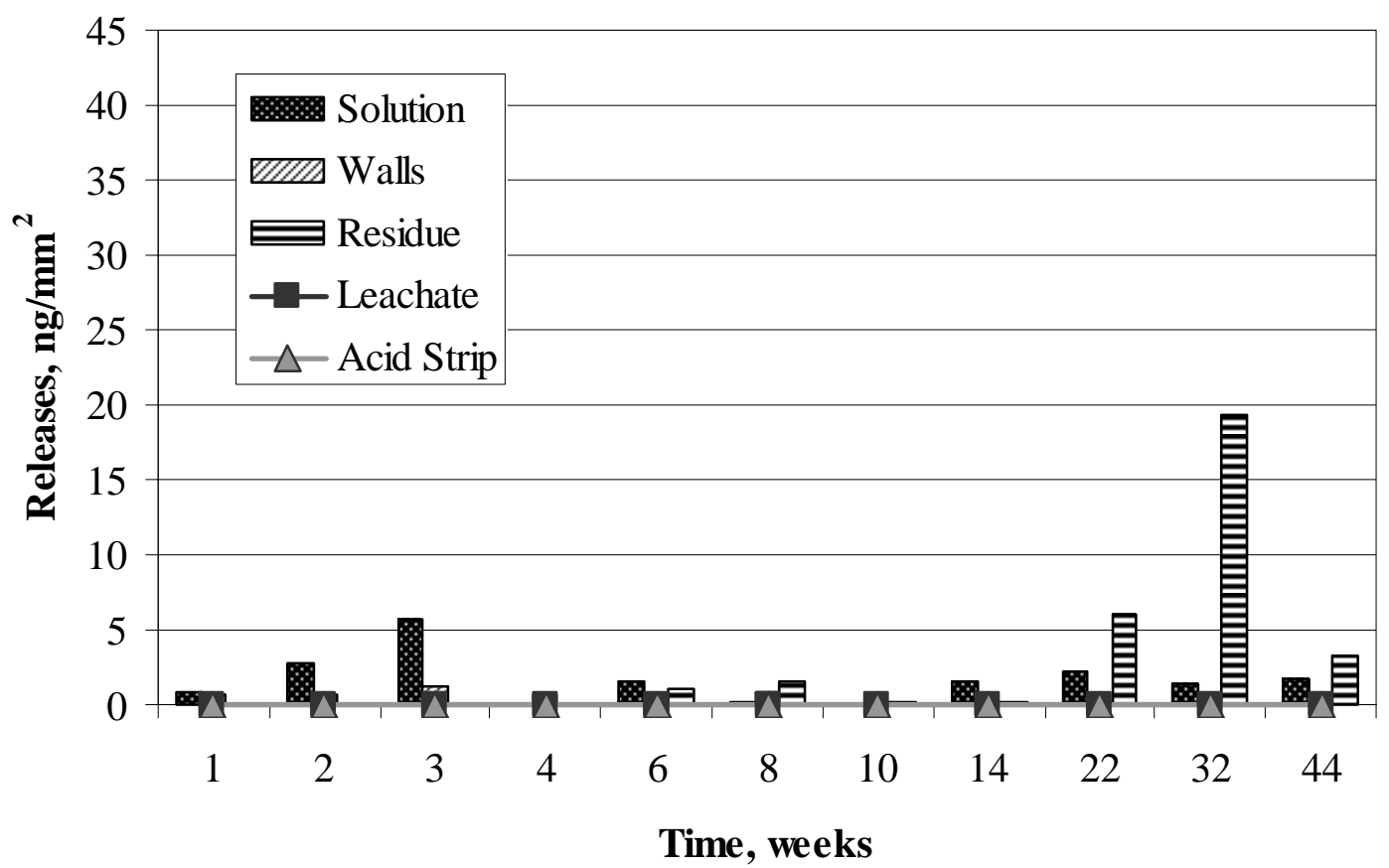

Figure E-117. Niobium Releases in Solution, on Walls, and in Residue from Polished Sample 3 in AJ13 and Average Detection Limits for Leachate and Acid Strip.

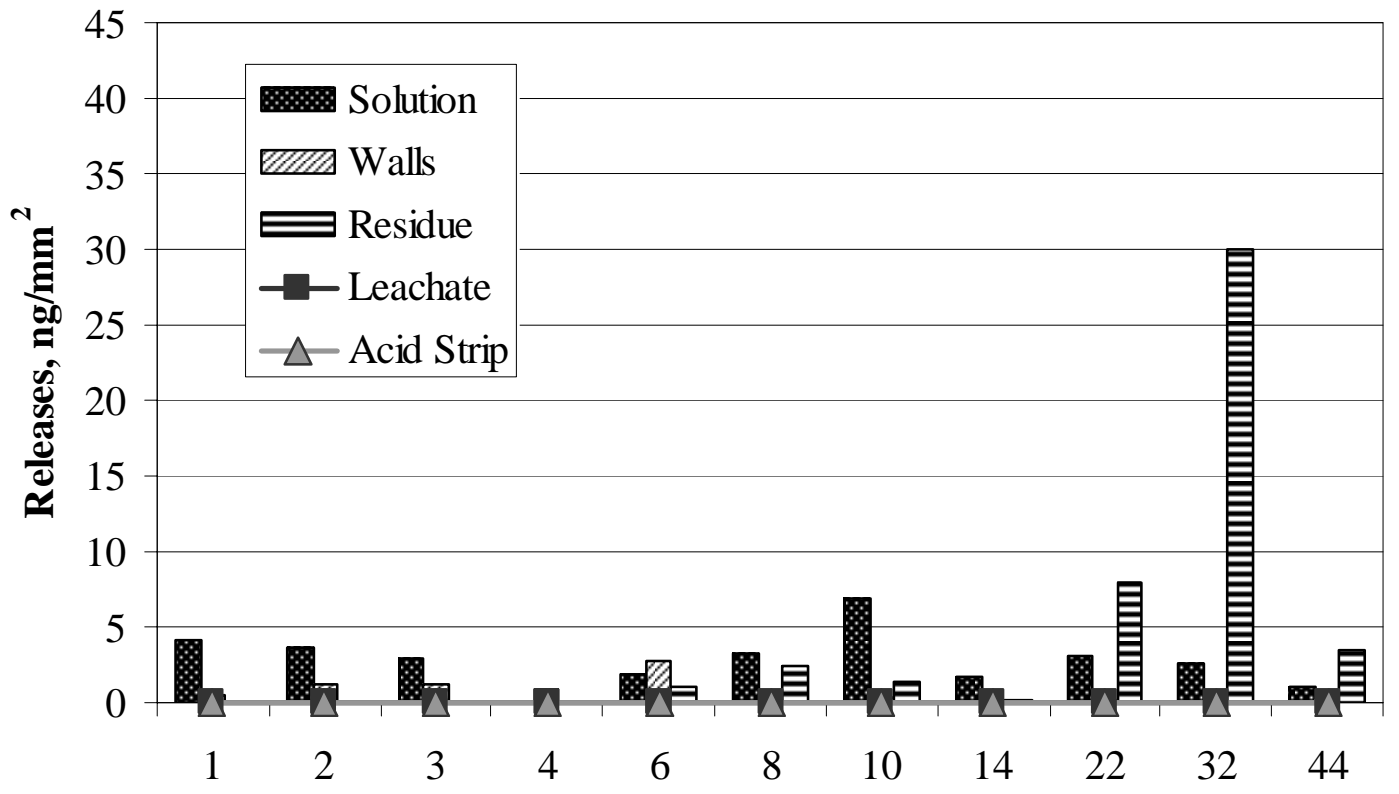

Time, weeks

Figure E-118. Niobium Releases in Solution, on Walls, and in Residue from Oxidized Sample 4 in AJ13 and Average Detection Limits for Leachate and Acid Strip. 


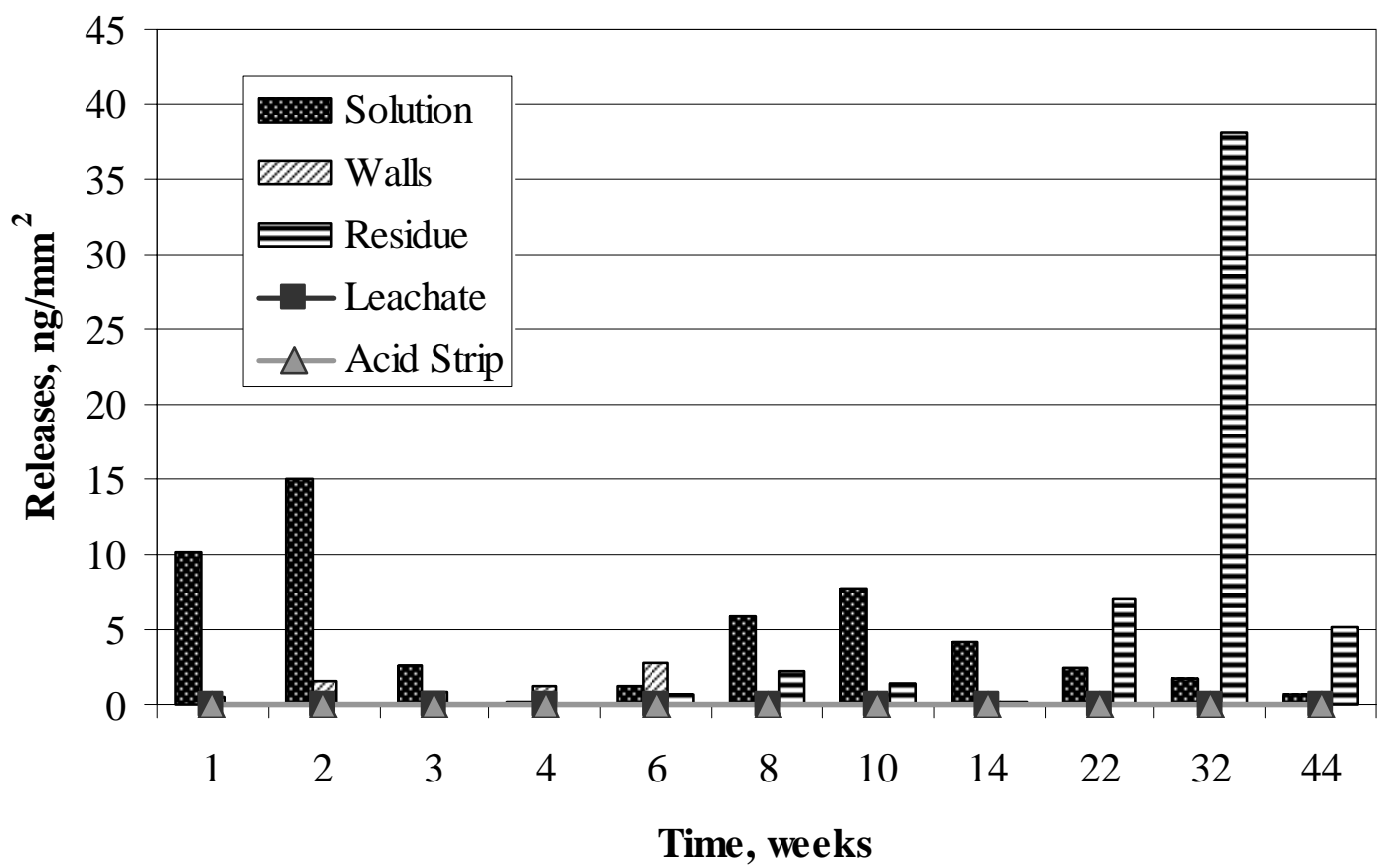

Figure E-119. Niobium Releases in Solution, on Walls, and in Residue from Oxidized Sample 5 in AJ13 and Average Detection Limits for Leachate and Acid Strip.

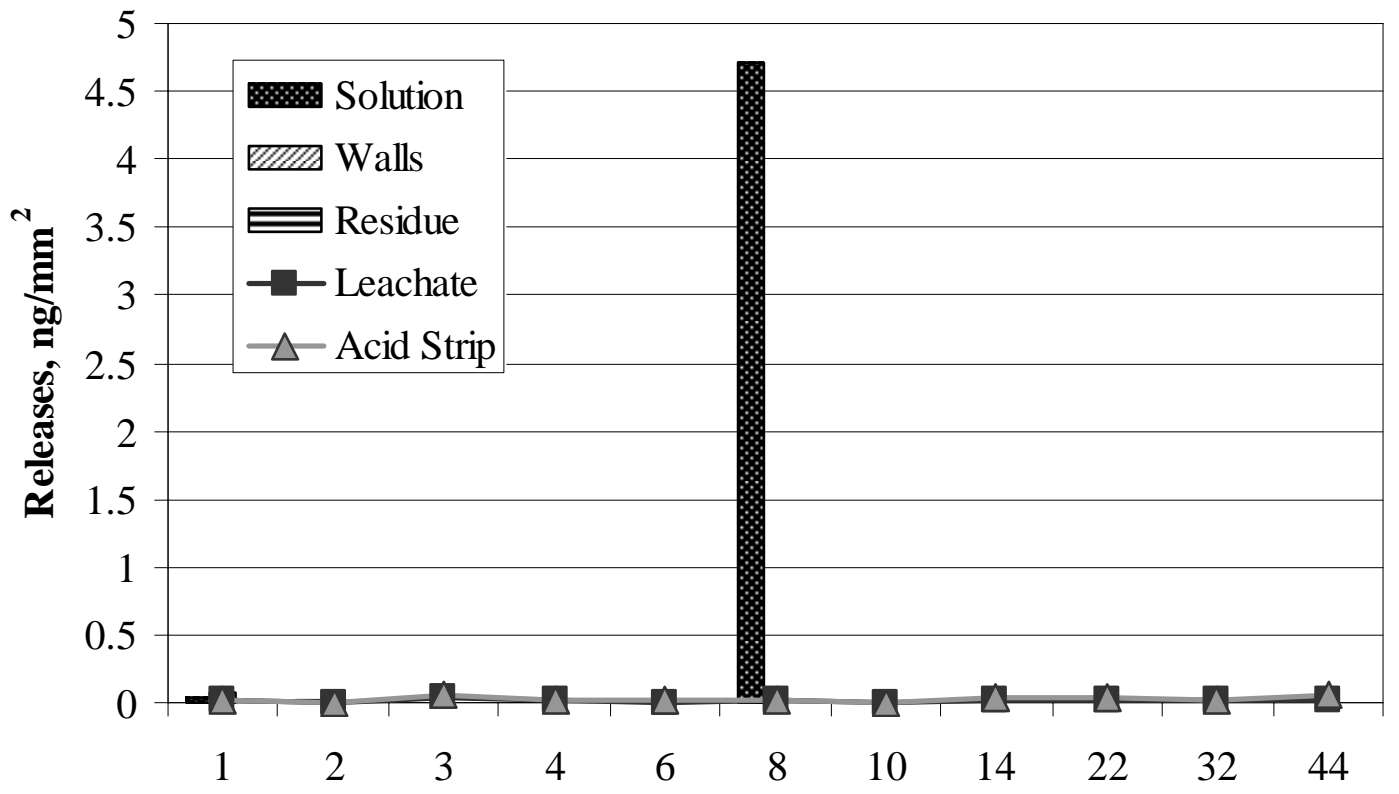

Time, weeks

Figure E-120. Niobium Present in Solution, on Walls, and in Residue from AJ13 Control and Average Detection Limits for Leachate and Acid Strip. 


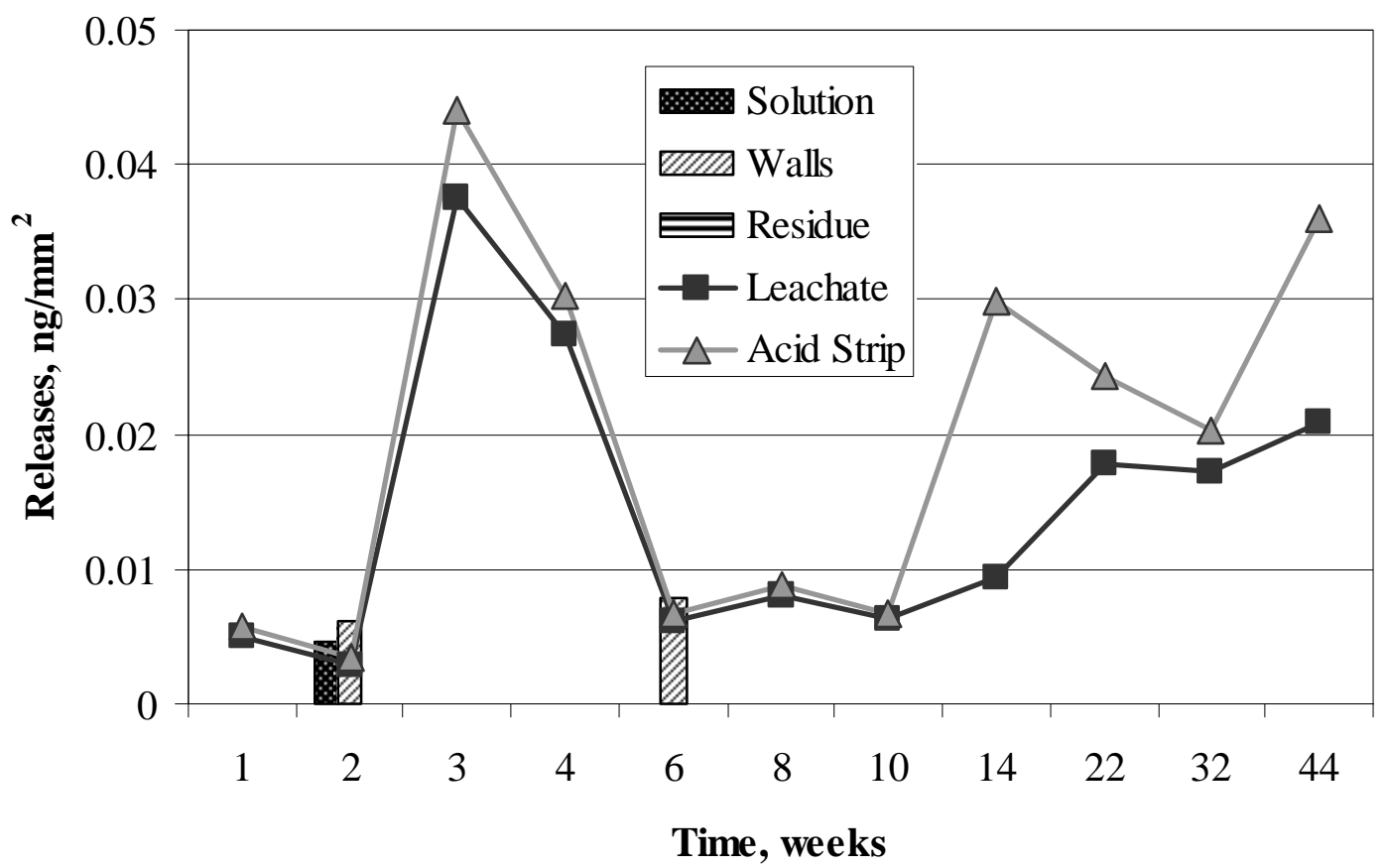

Figure E-121. Paladium Releases in Solution, on Walls, and in Residue from Polished Sample 1 in SJ13 and Average Detection Limits for Leachate and Acid Strip.

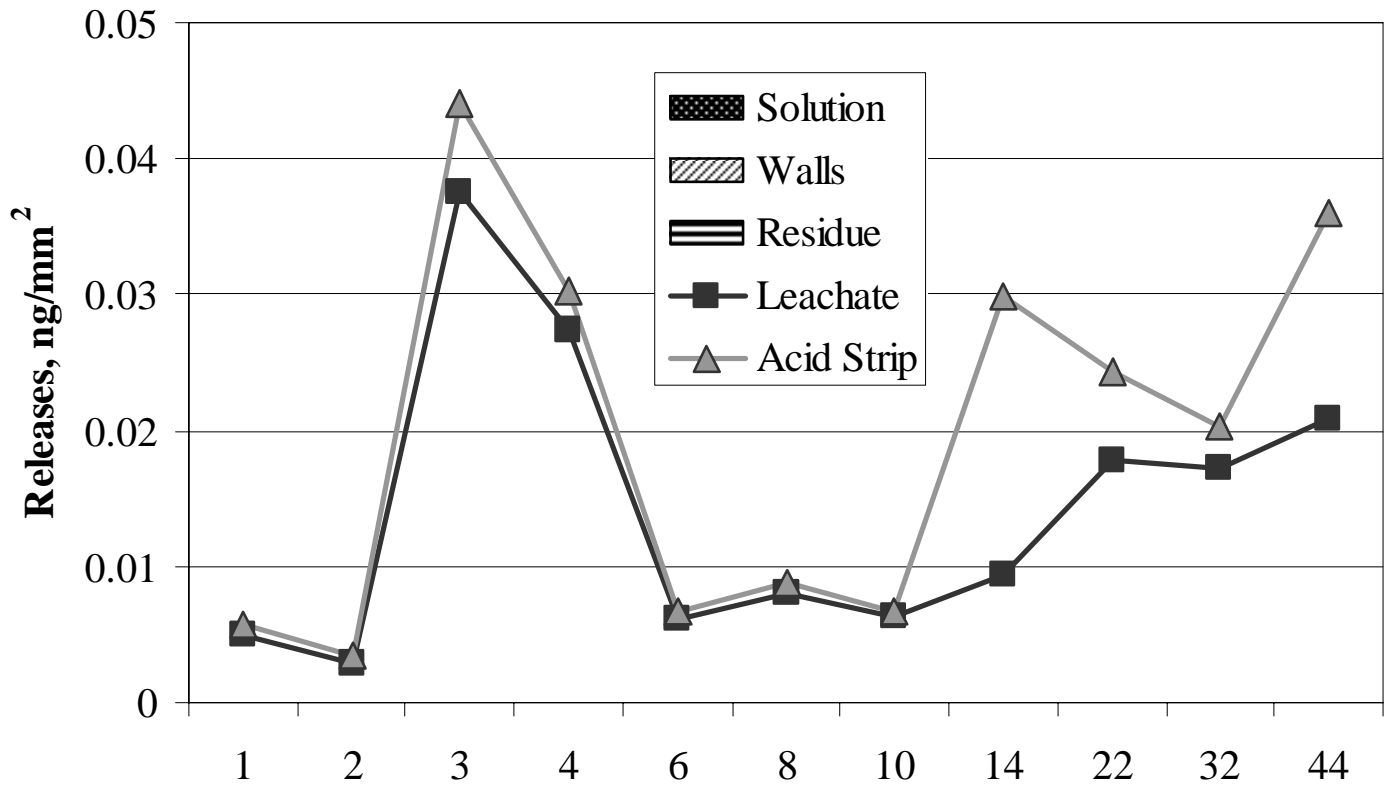

Time, weeks

Figure E-122. Paladium Releases in Solution, on Walls, and in Residue from Polished Sample 2 in SJ13 and Average Detection Limits for Leachate and Acid Strip. 


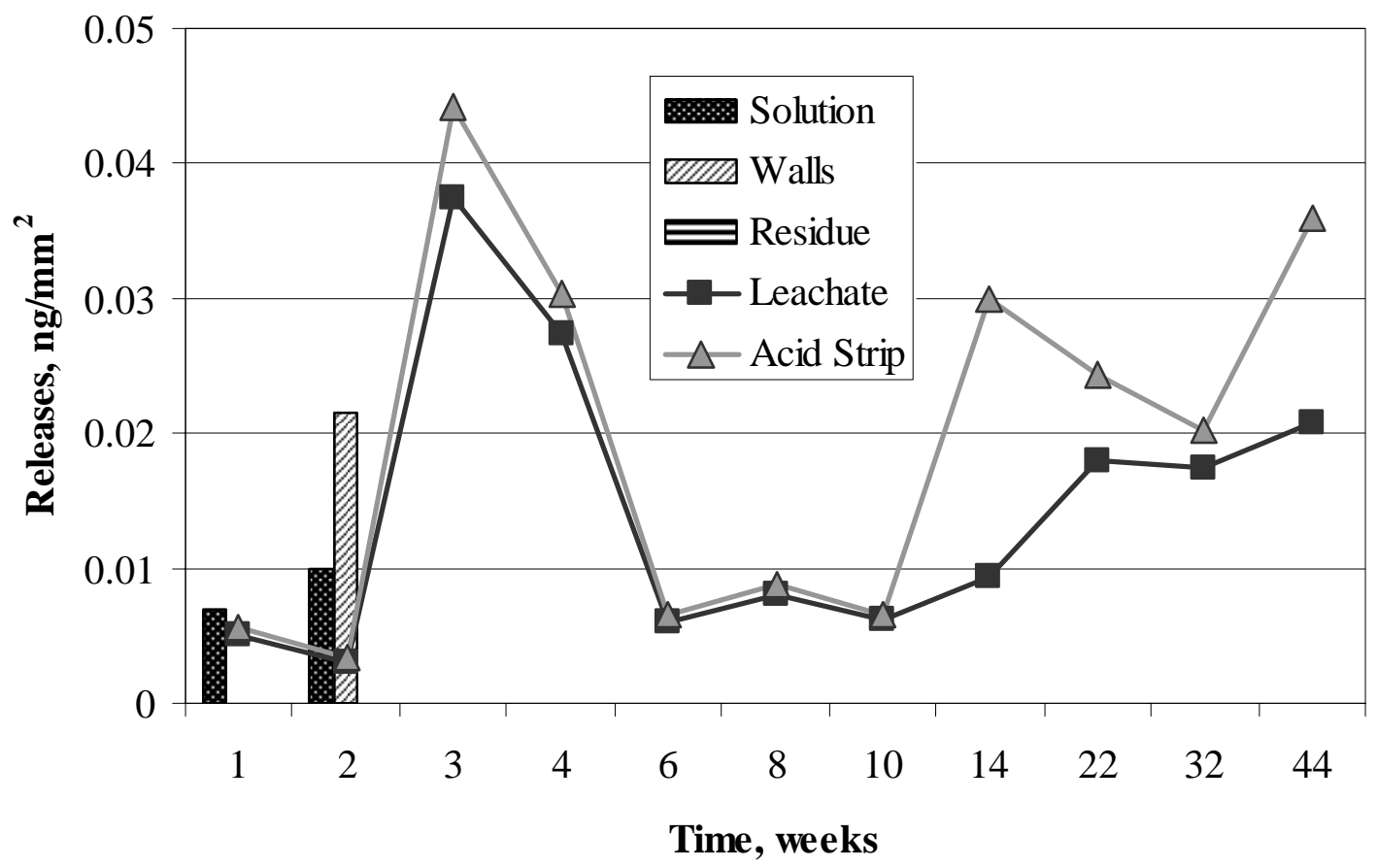

Figure E-123. Paladium Releases in Solution, on Walls, and in Residue from Polished Sample 3 in SJ13 and Average Detection Limits for Leachate and Acid Strip.

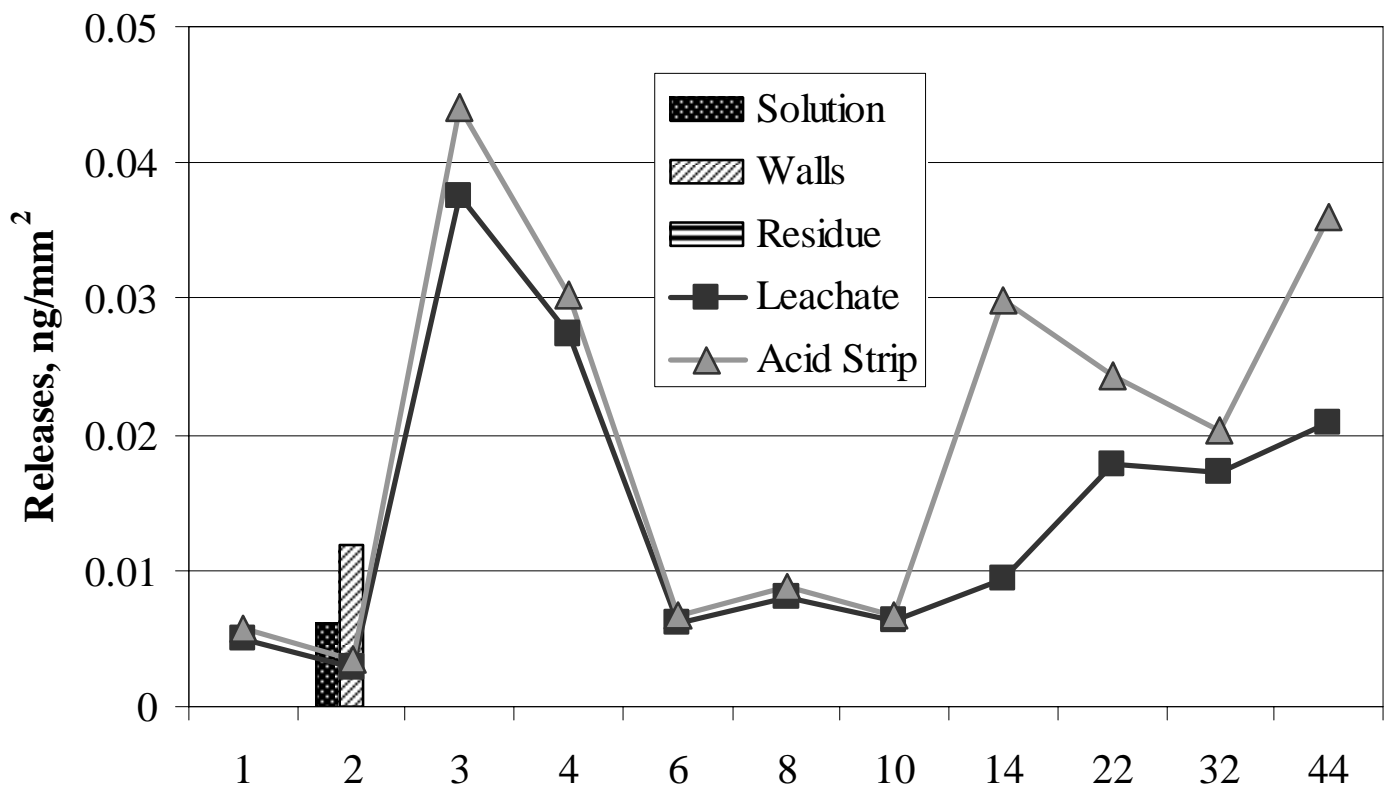

Time, weeks

Figure E-124. Paladium Releases in Solution, on Walls, and in Residue from Oxidized Sample 4 in SJ13 and Average Detection Limits for Leachate and Acid Strip. 


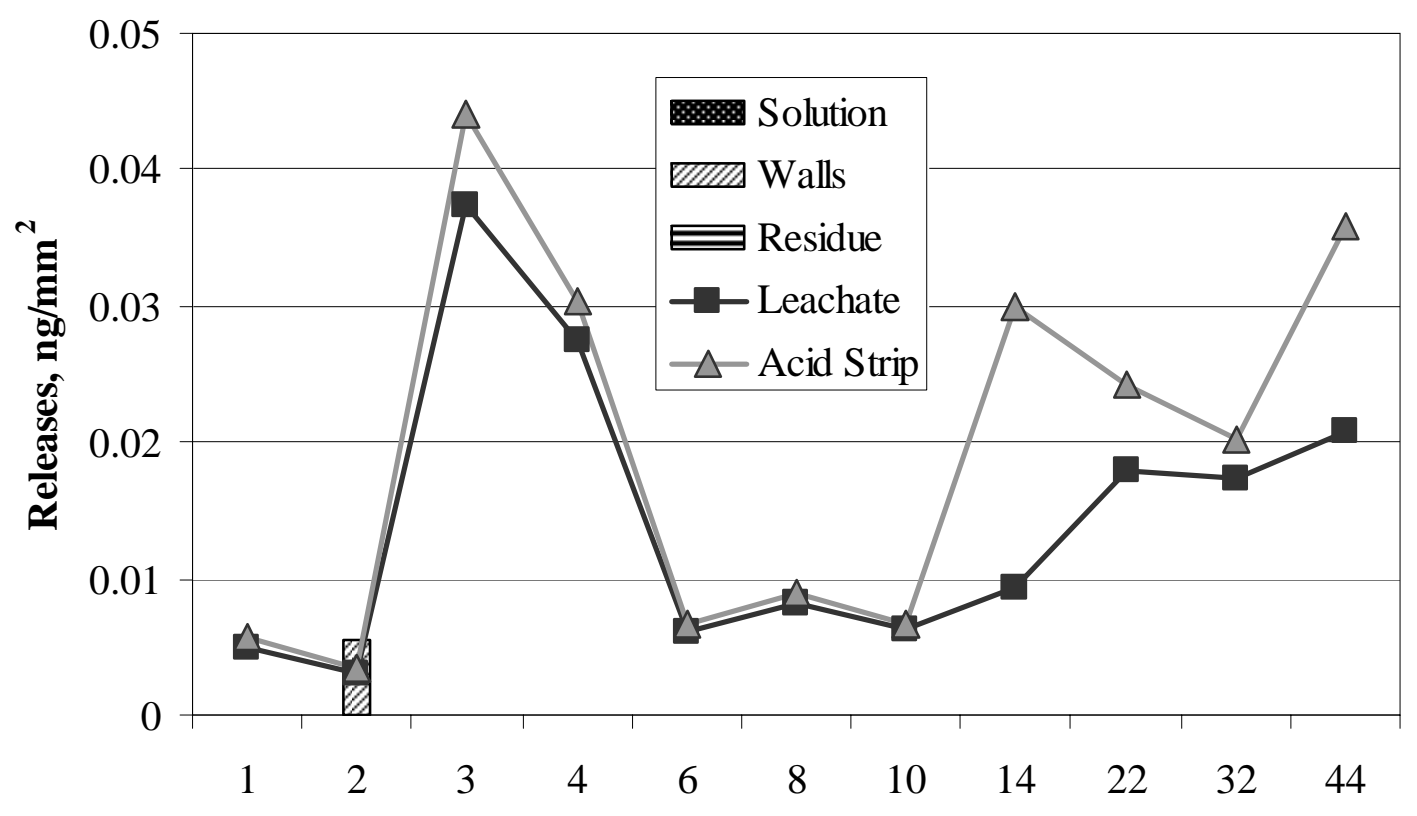

Time, weeks

Figure E-125. Paladium Releases in Solution, on Walls, and in Residue from Oxidized Sample 5 in SJ13 and Average Detection Limits for Leachate and Acid Strip.

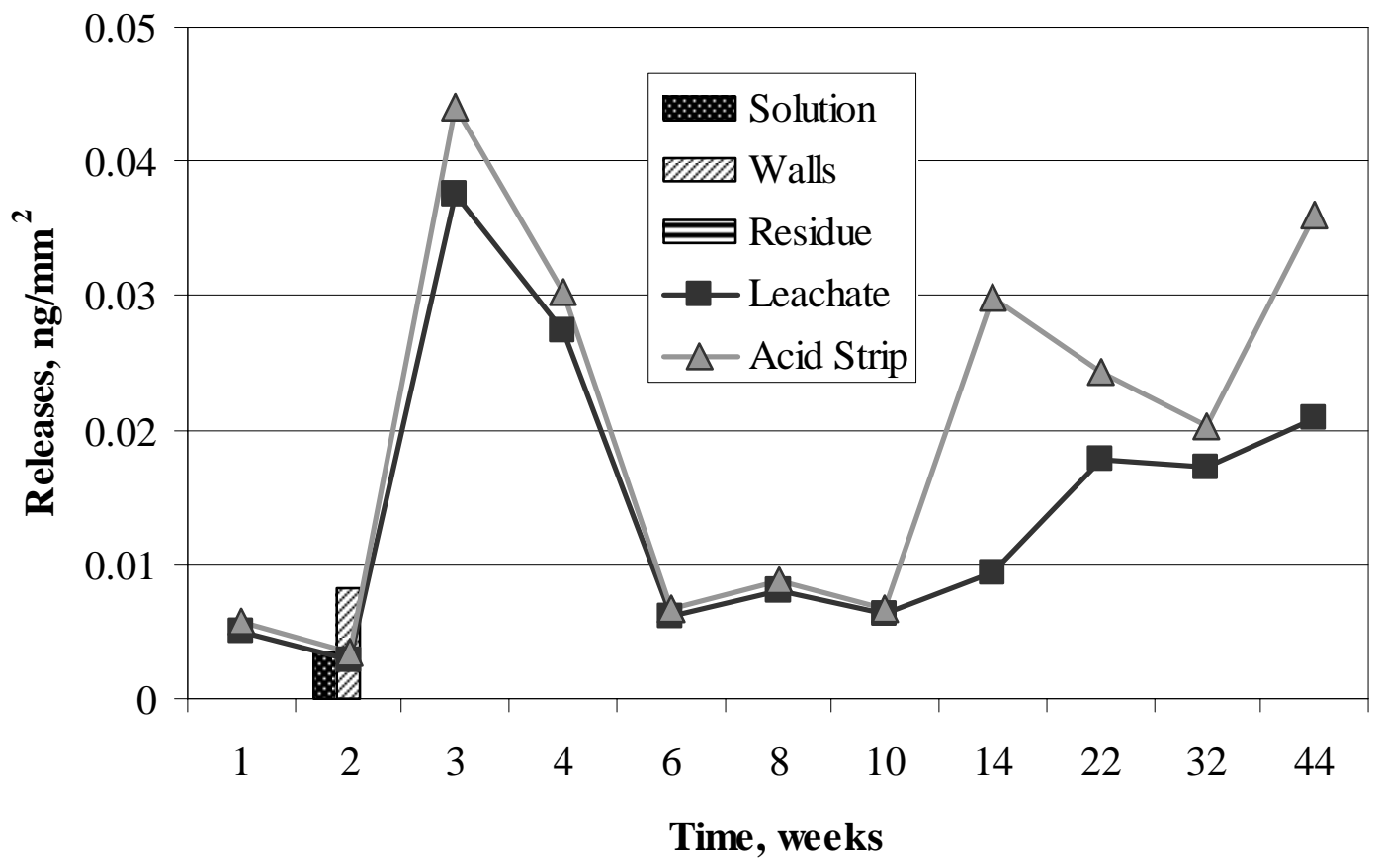

Figure E-126. Paladium Present in Solution, on Walls, and in Residue from SJ13 Control and Average Detection Limits for Leachate and Acid Strip. 


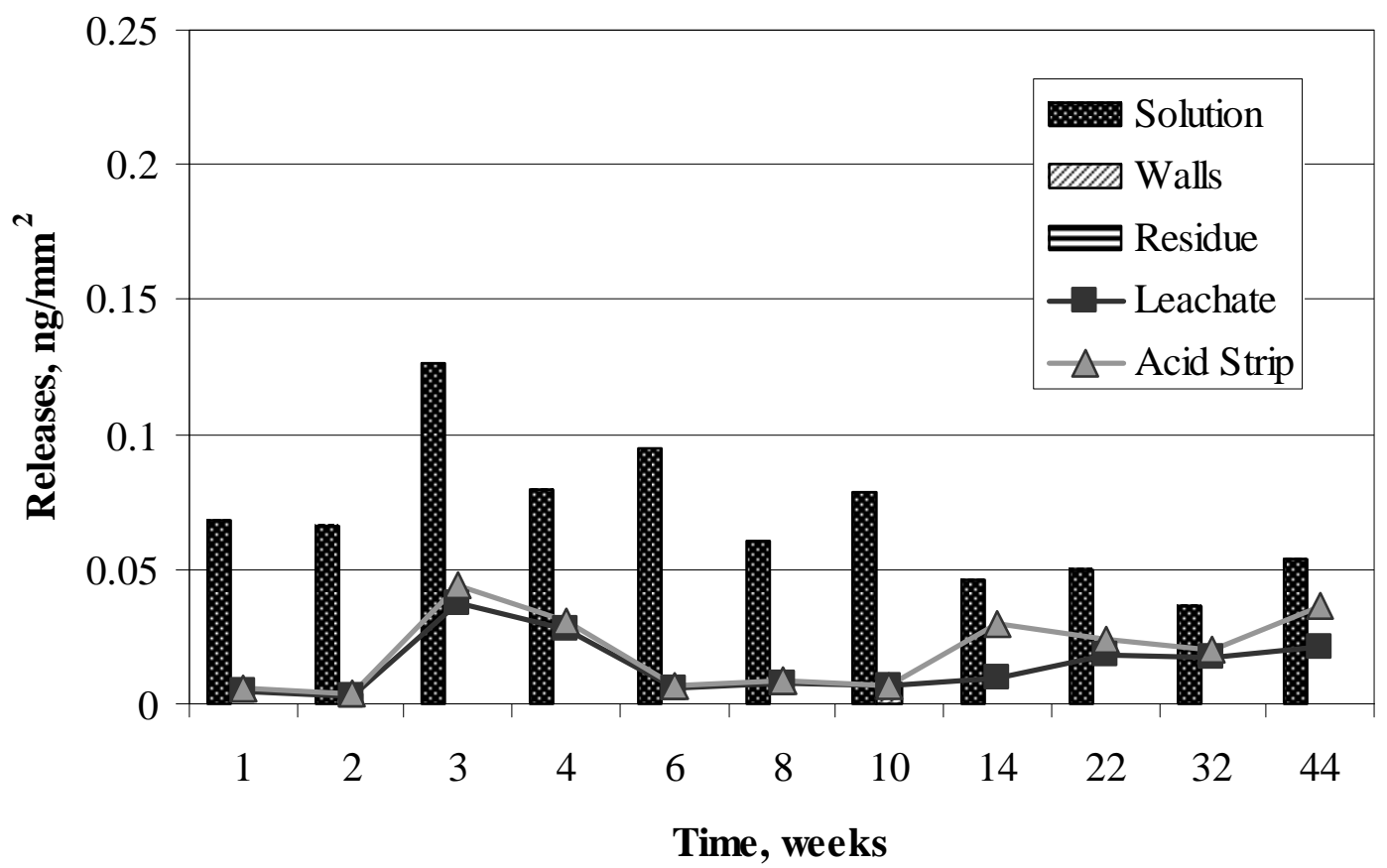

Figure E-127. Paladium Releases in Solution, on Walls, and in Residue from Polished Sample 1 in CJ13 and Average Detection Limits for Leachate and Acid Strip.

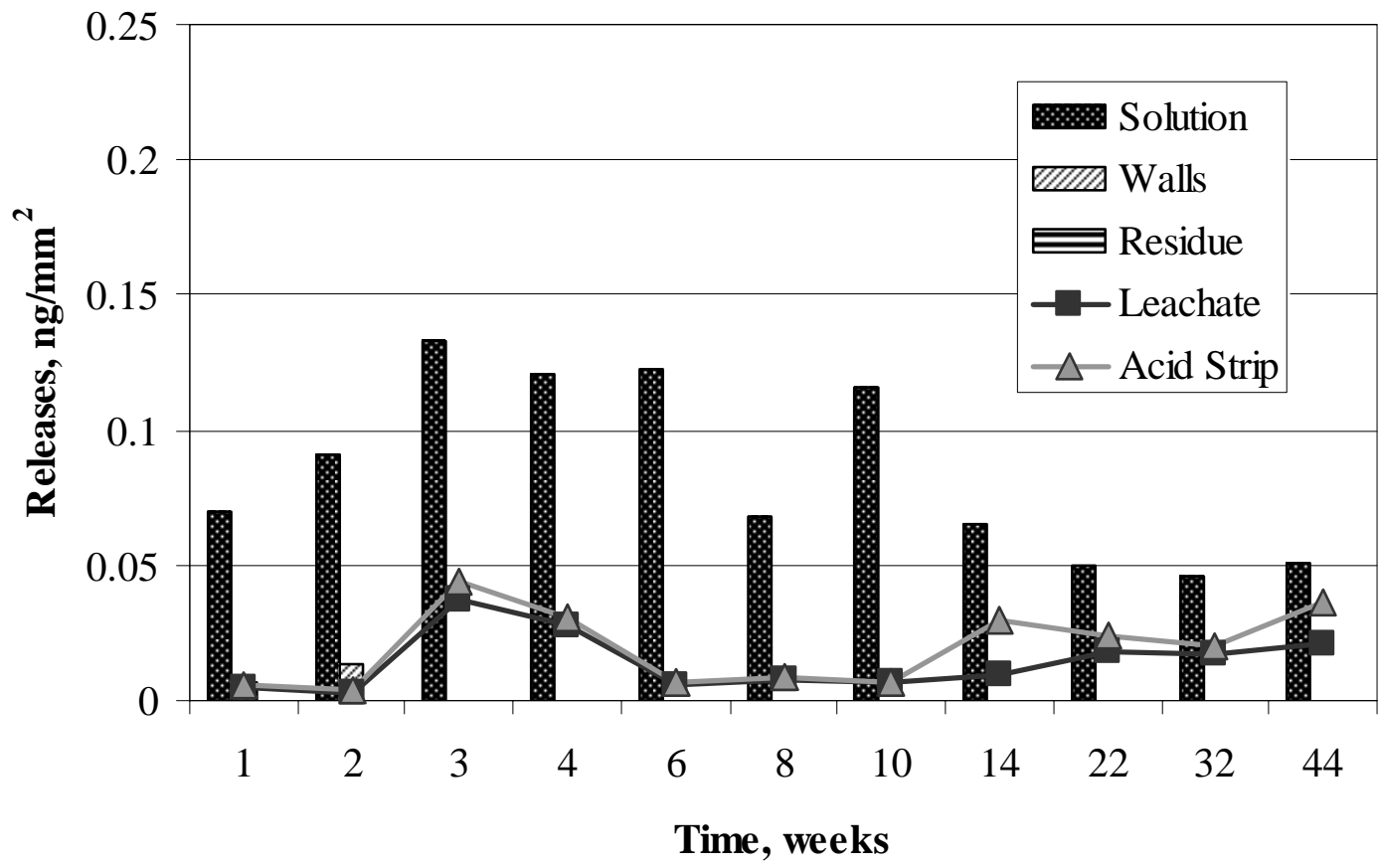

Figure E-128. Paladium Releases in Solution, on Walls, and in Residue from Polished Sample 2 in CJ13 and Average Detection Limits for Leachate and Acid Strip. 


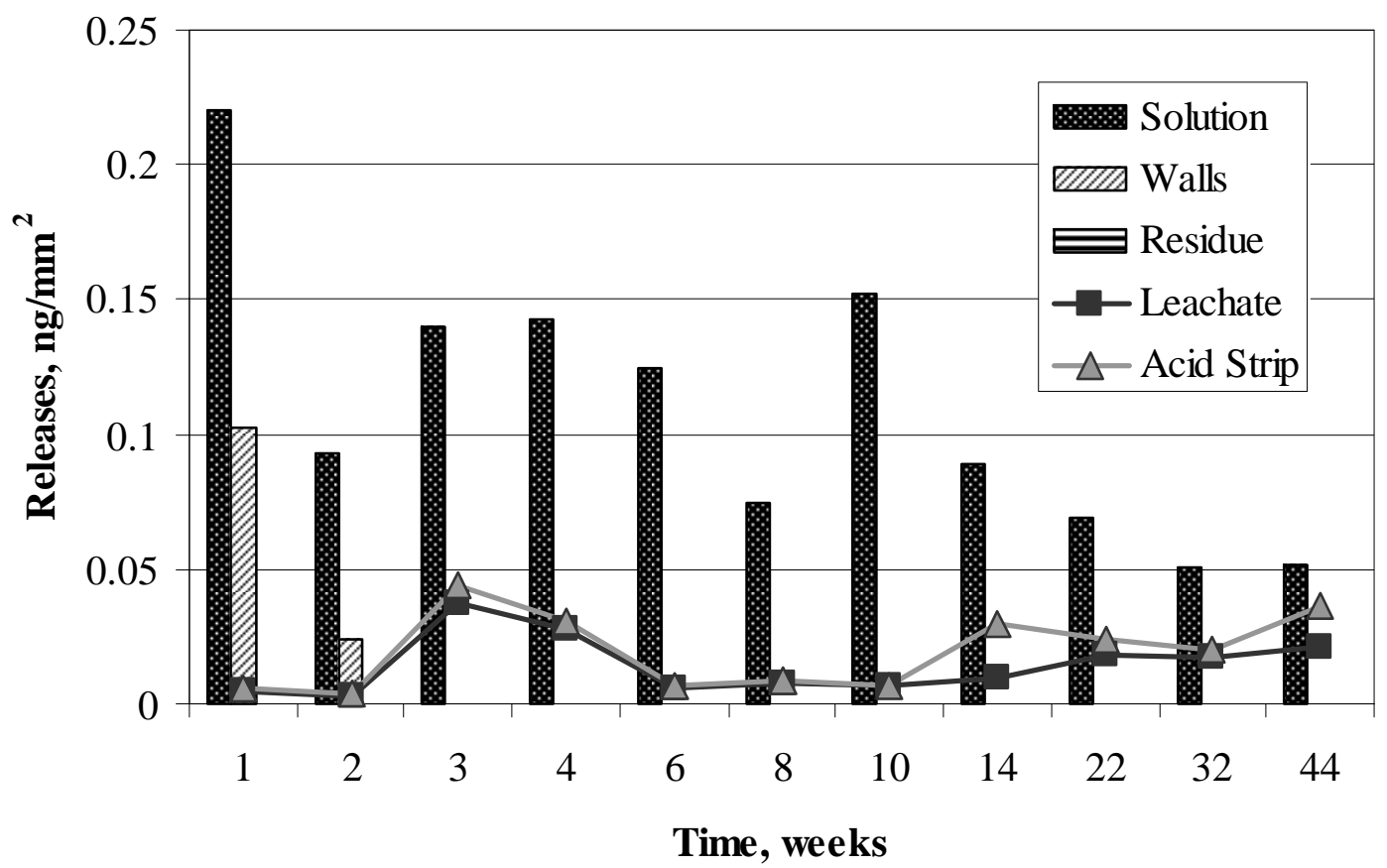

Figure E-129. Paladium Releases in Solution, on Walls, and in Residue from Polished Sample 3 in CJ13 and Average Detection Limits for Leachate and Acid Strip.

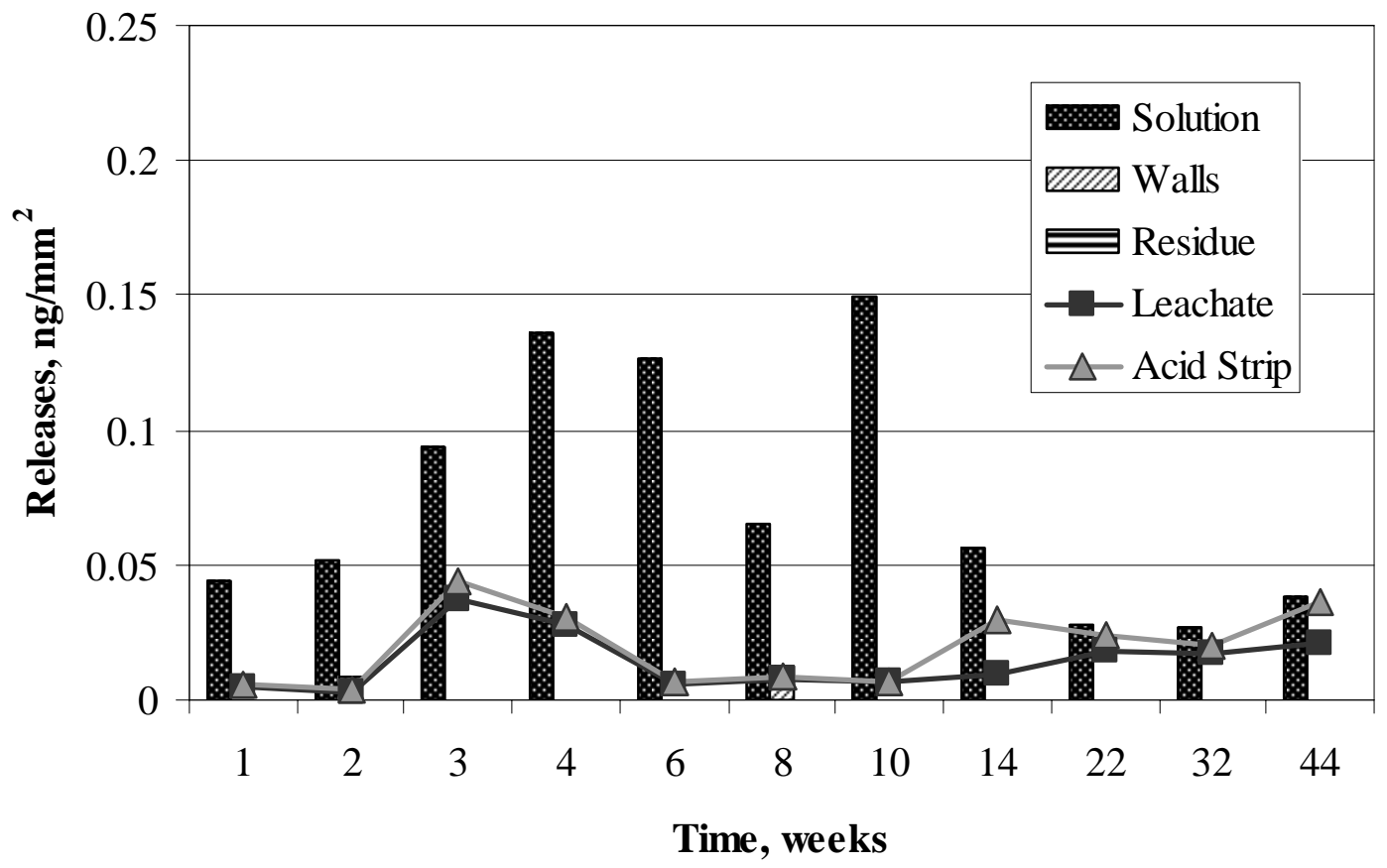

Figure E-130. Paladium Releases in Solution, on Walls, and in Residue from Oxidized Sample 4 in CJ13 and Average Detection Limits for Leachate and Acid Strip. 


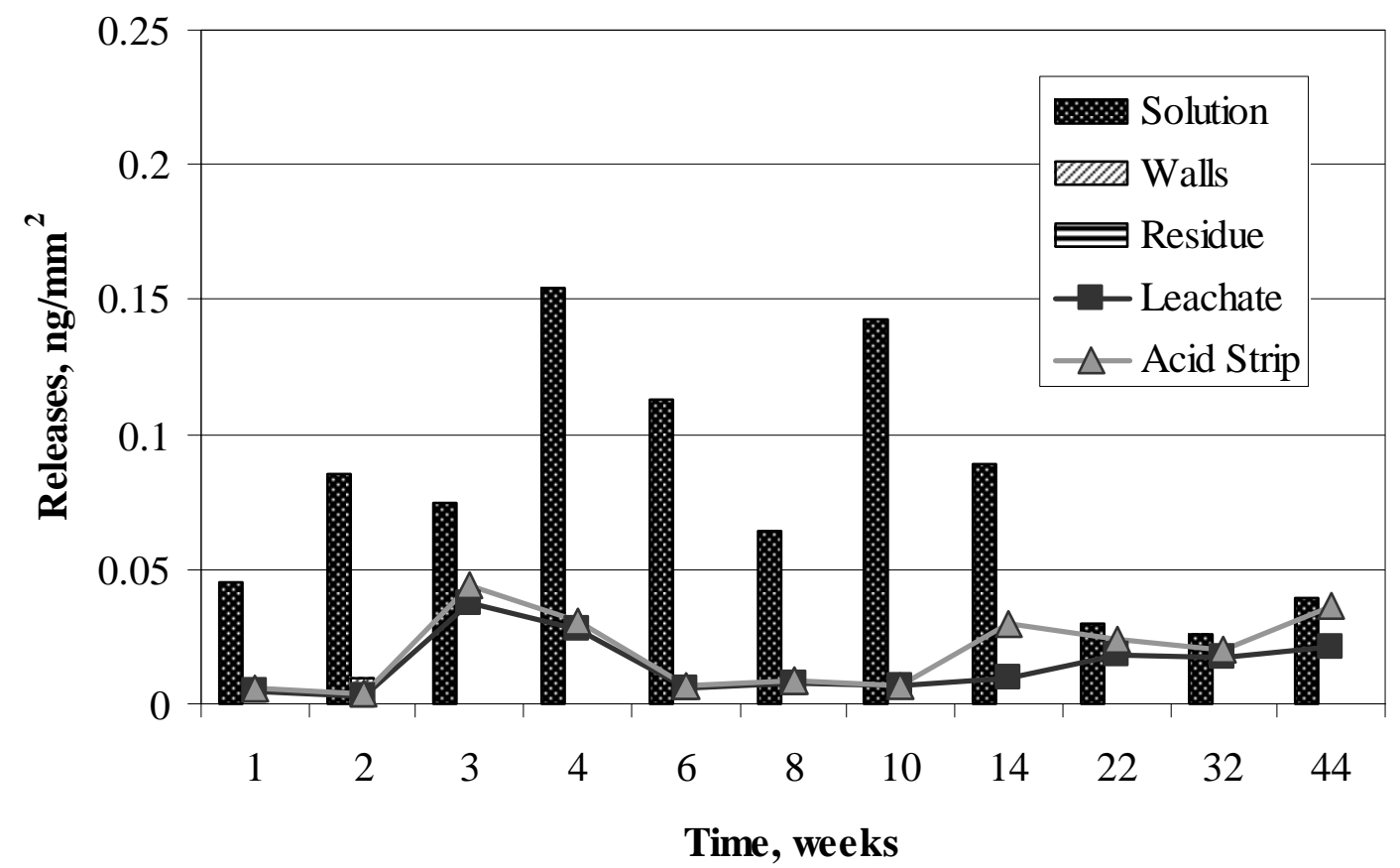

Figure E-131. Paladium Releases in Solution, on Walls, and in Residue from Oxidized Sample 5 in CJ13 and Average Detection Limits for Leachate and Acid Strip.

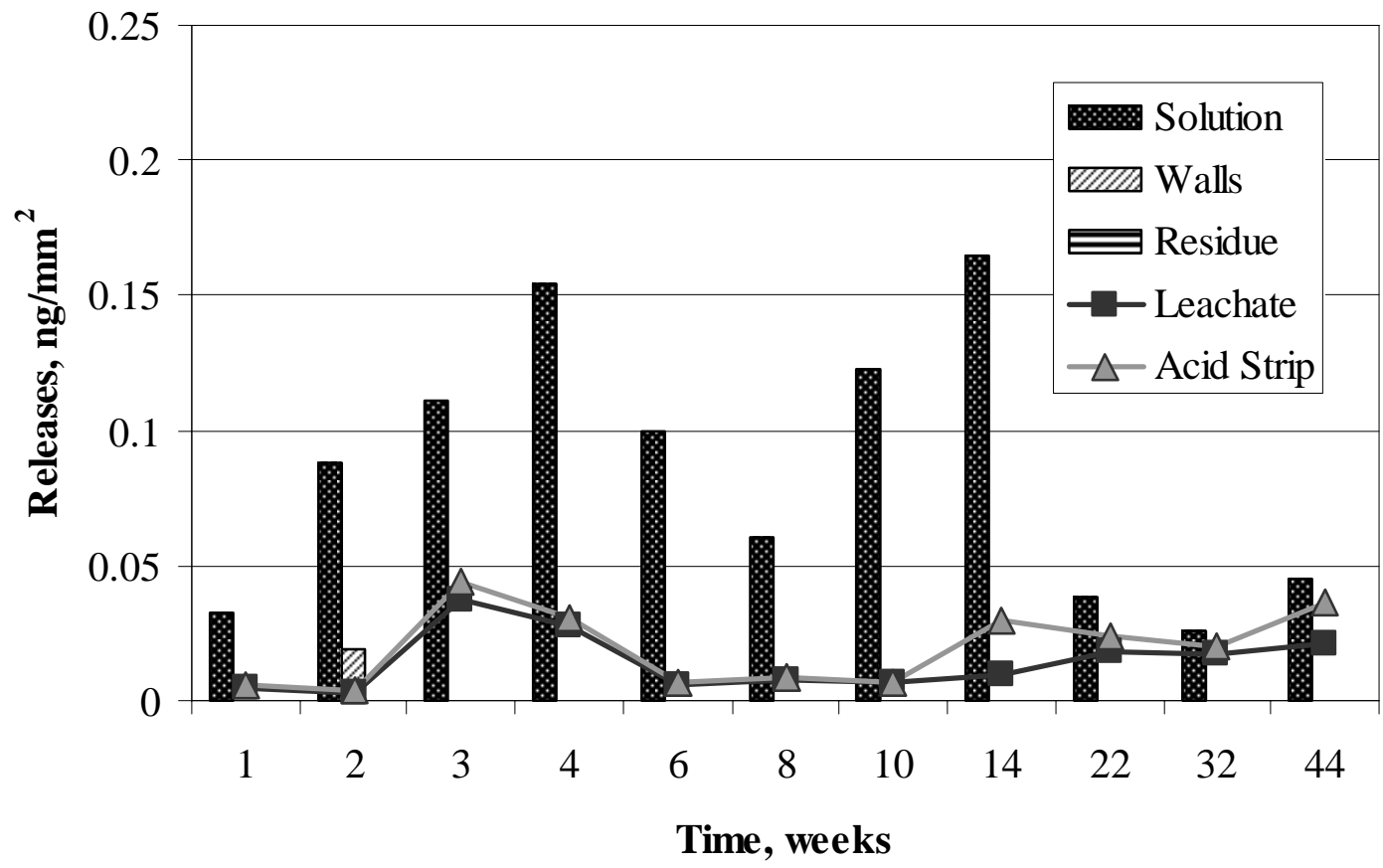

Figure E-132. Paladium Present in Solution, on Walls, and in Residue from CJ13 Control and Average Detection Limits for Leachate and Acid Strip. 


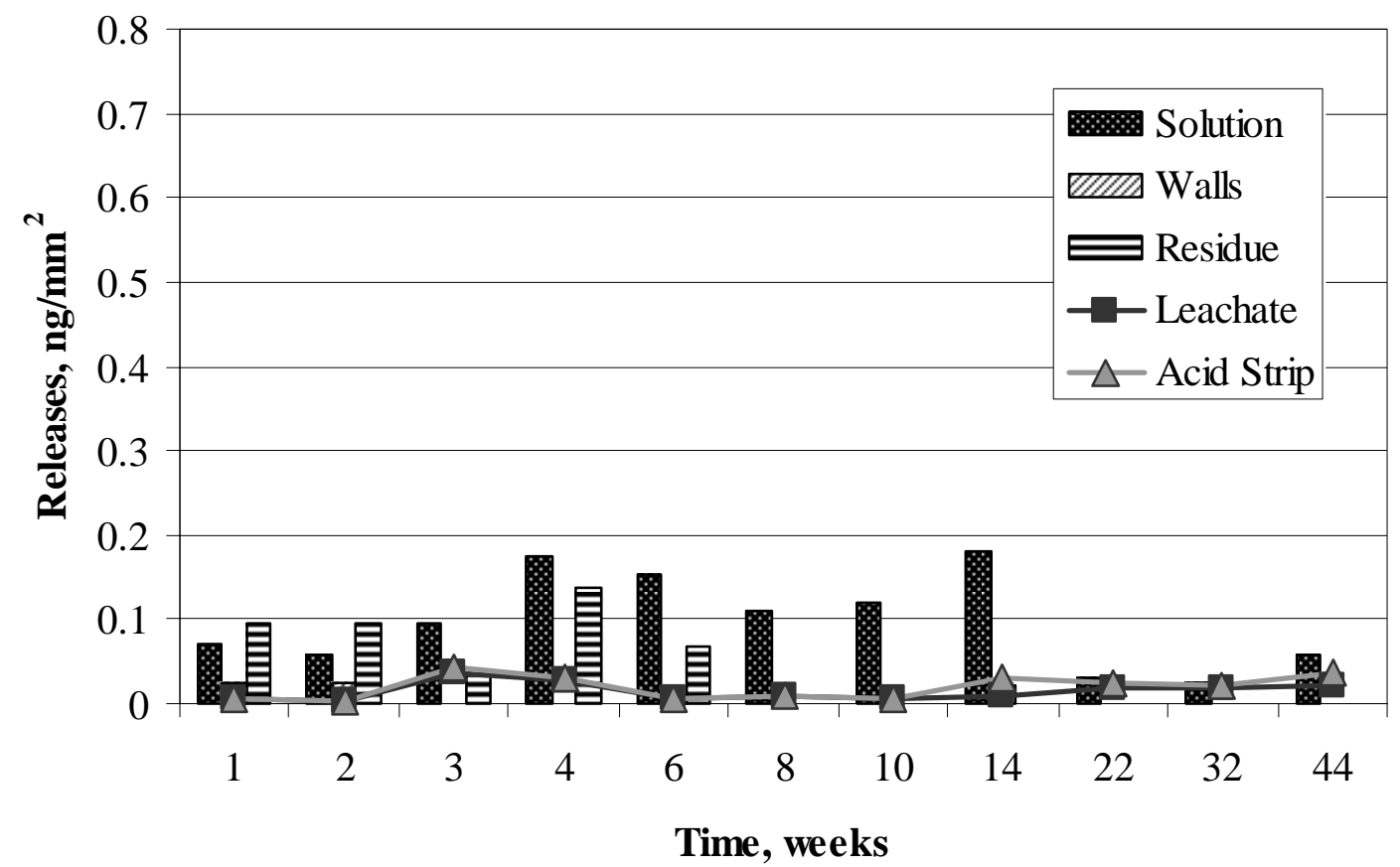

Figure E-133. Paladium Releases in Solution, on Walls, and in Residue from Polished Sample 1 in $10 \mathrm{KCl}$ and Average Detection Limits for Leachate and Acid Strip.

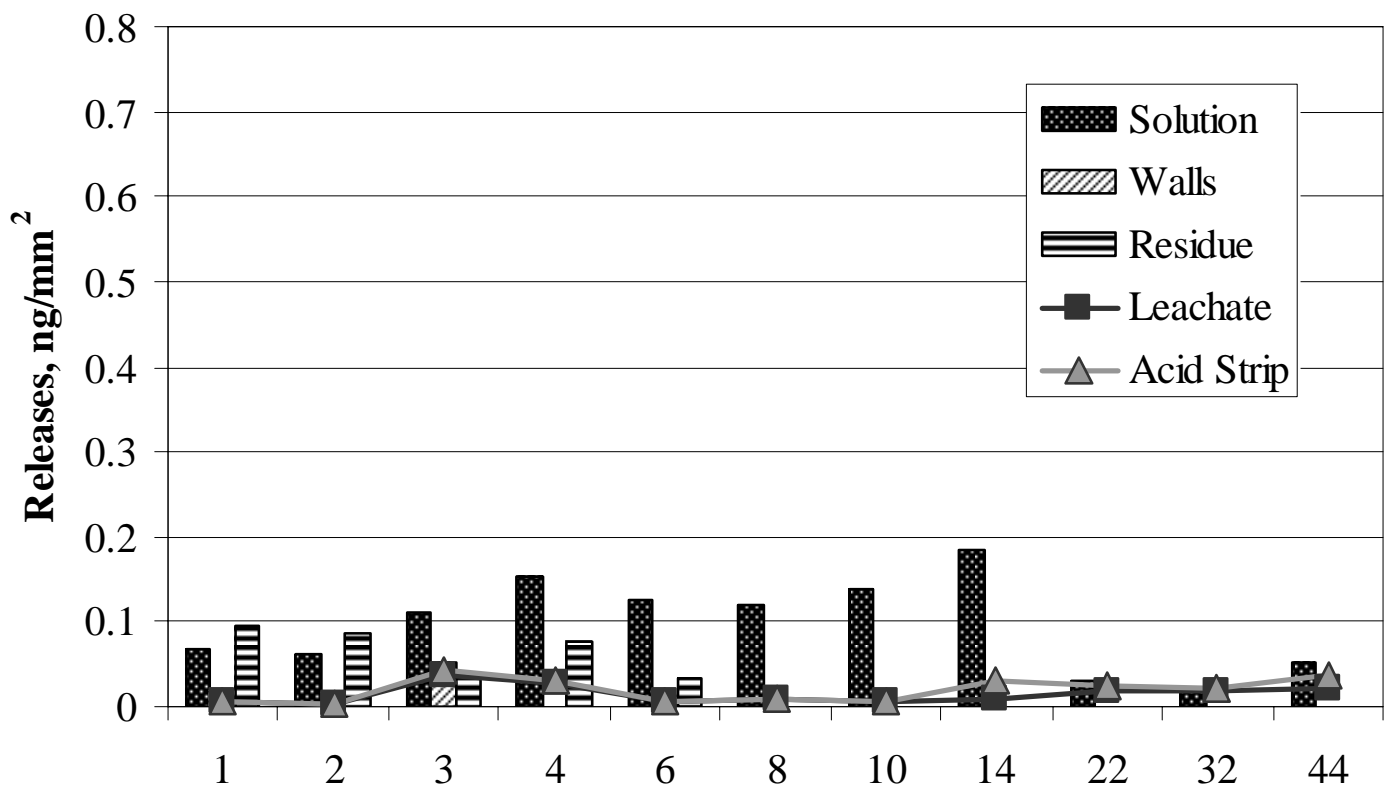

Time, weeks

Figure E-134. Paladium Releases in Solution, on Walls, and in Residue from Polished Sample 2 in $10 \mathrm{KCl}$ and Average Detection Limits for Leachate and Acid Strip. 


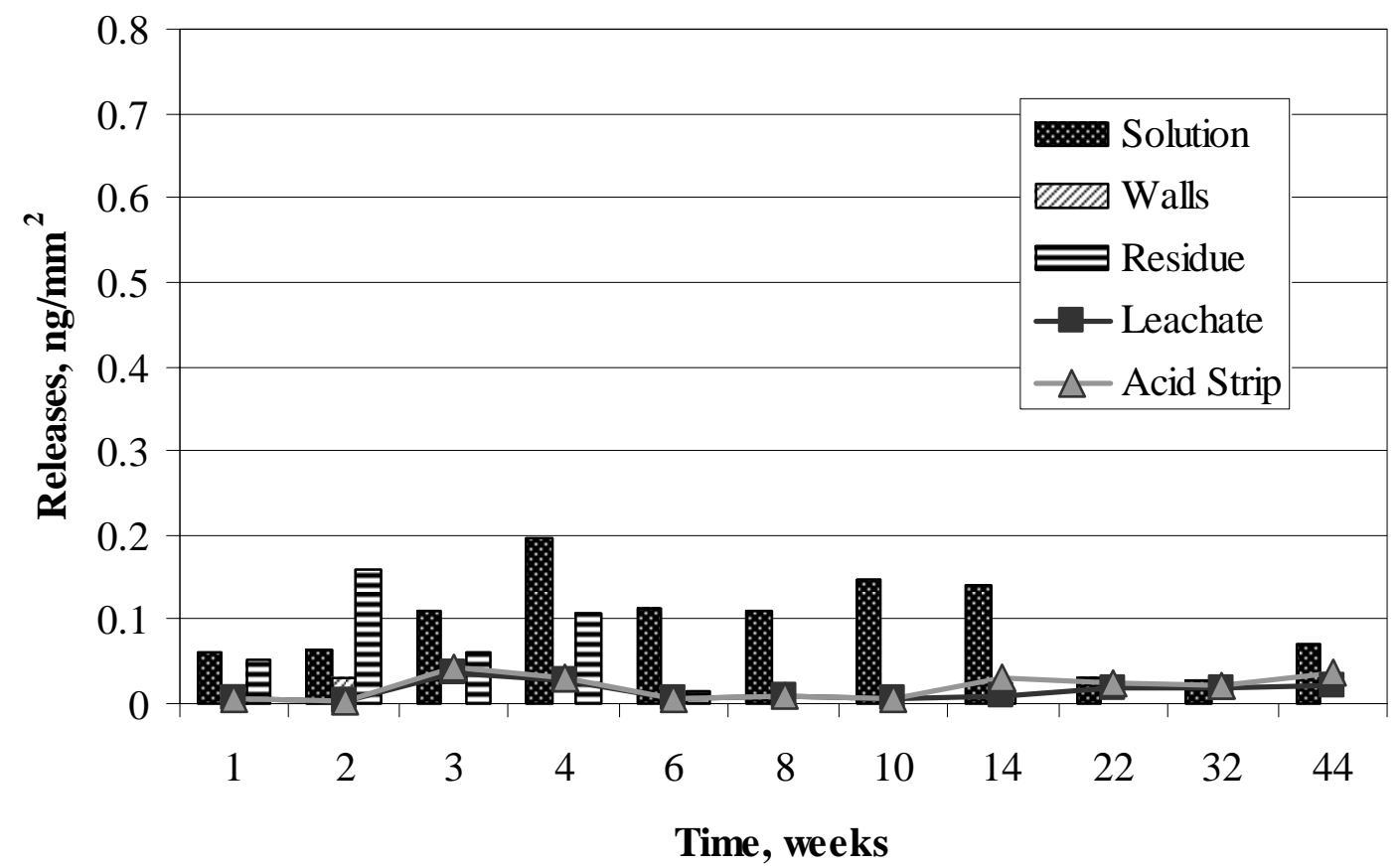

Figure E-135. Paladium Releases in Solution, on Walls, and in Residue from Polished Sample 3 in $10 \mathrm{KCl}$ and Average Detection Limits for Leachate and Acid Strip.

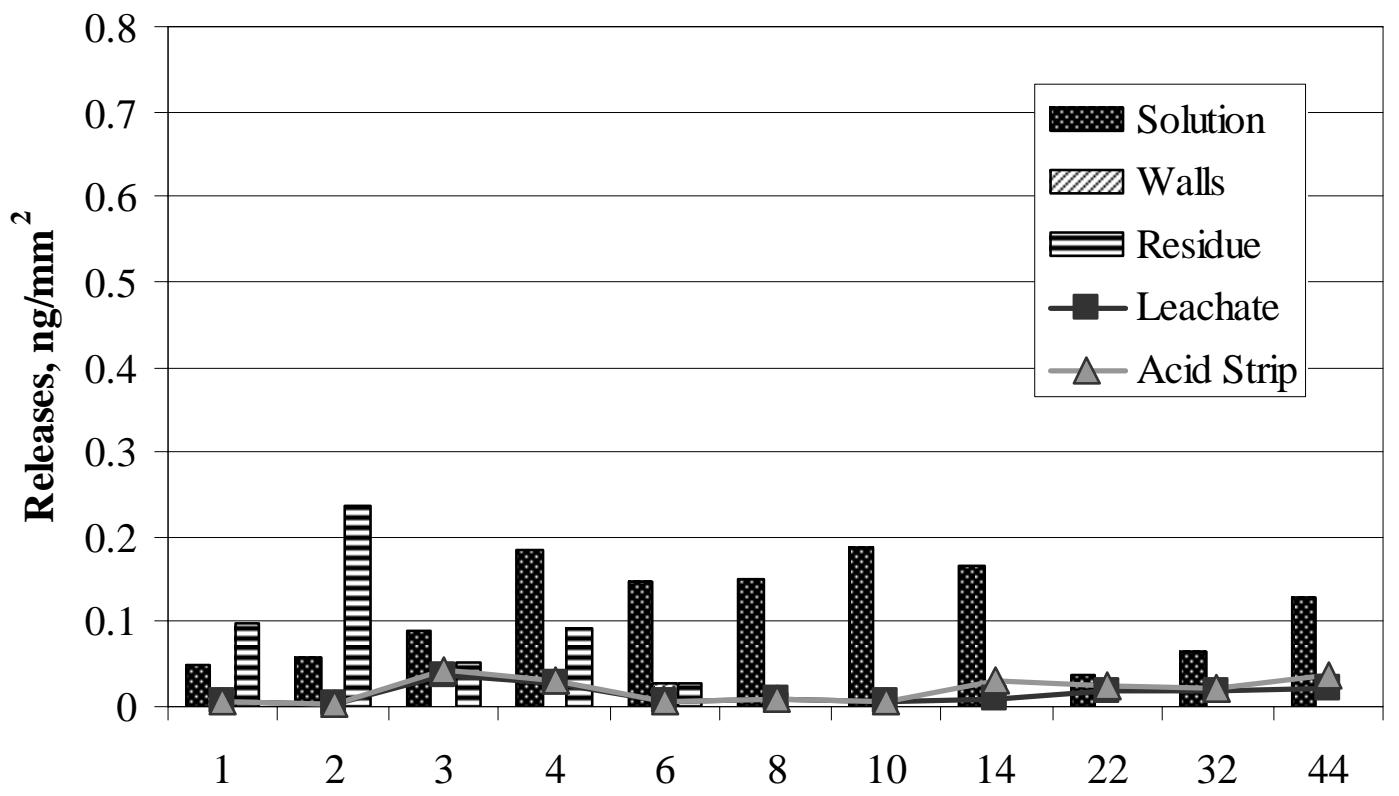

Time, weeks

Figure E-136. Paladium Releases in Solution, on Walls, and in Residue from Oxidized Sample 4 in $10 \mathrm{KCl}$ and Average Detection Limits for Leachate and Acid Strip. 


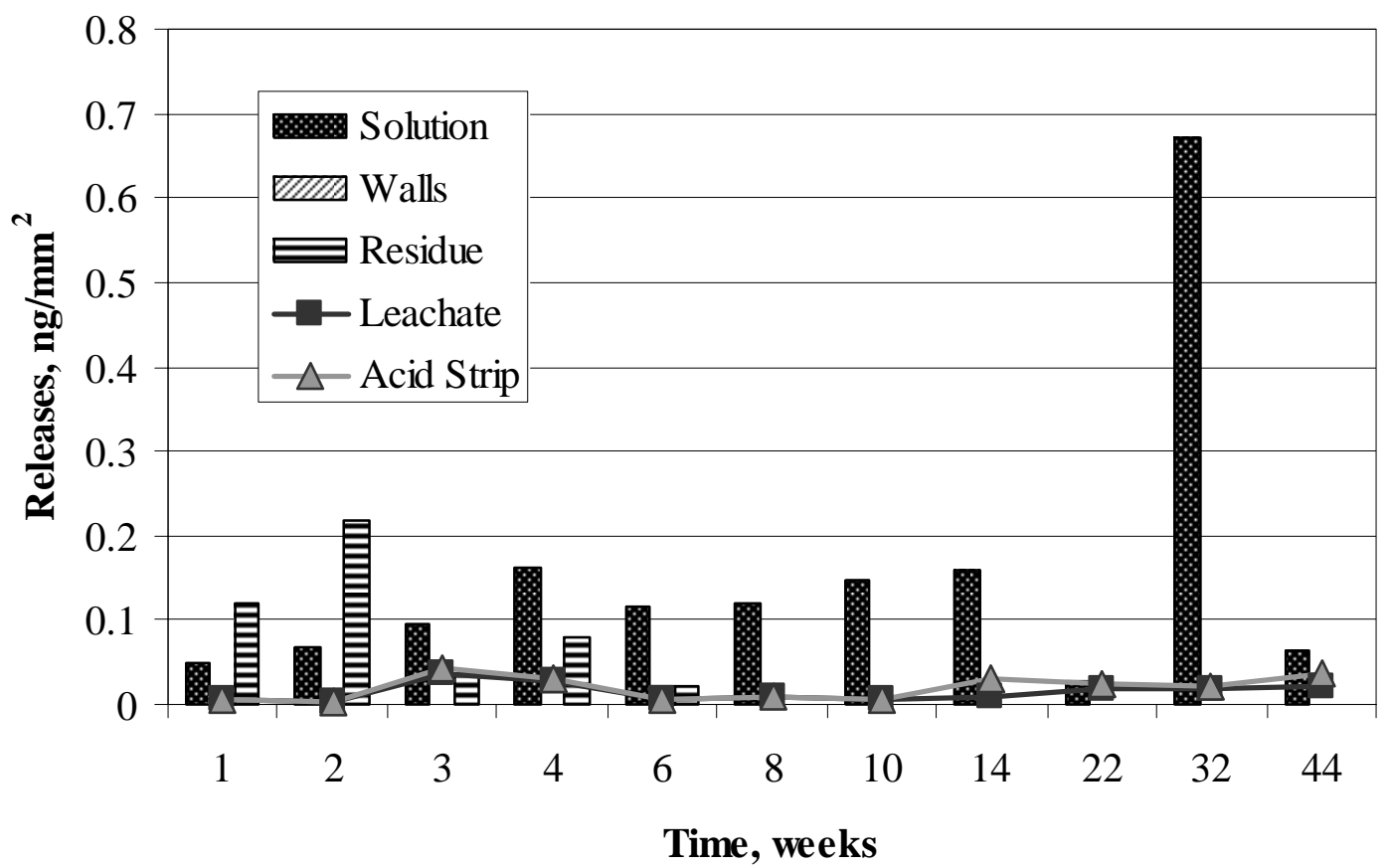

Figure E-137. Paladium Releases in Solution, on Walls, and in Residue from Oxidized Sample 5 in 10KCl and Average Detection Limits for Leachate and Acid Strip.

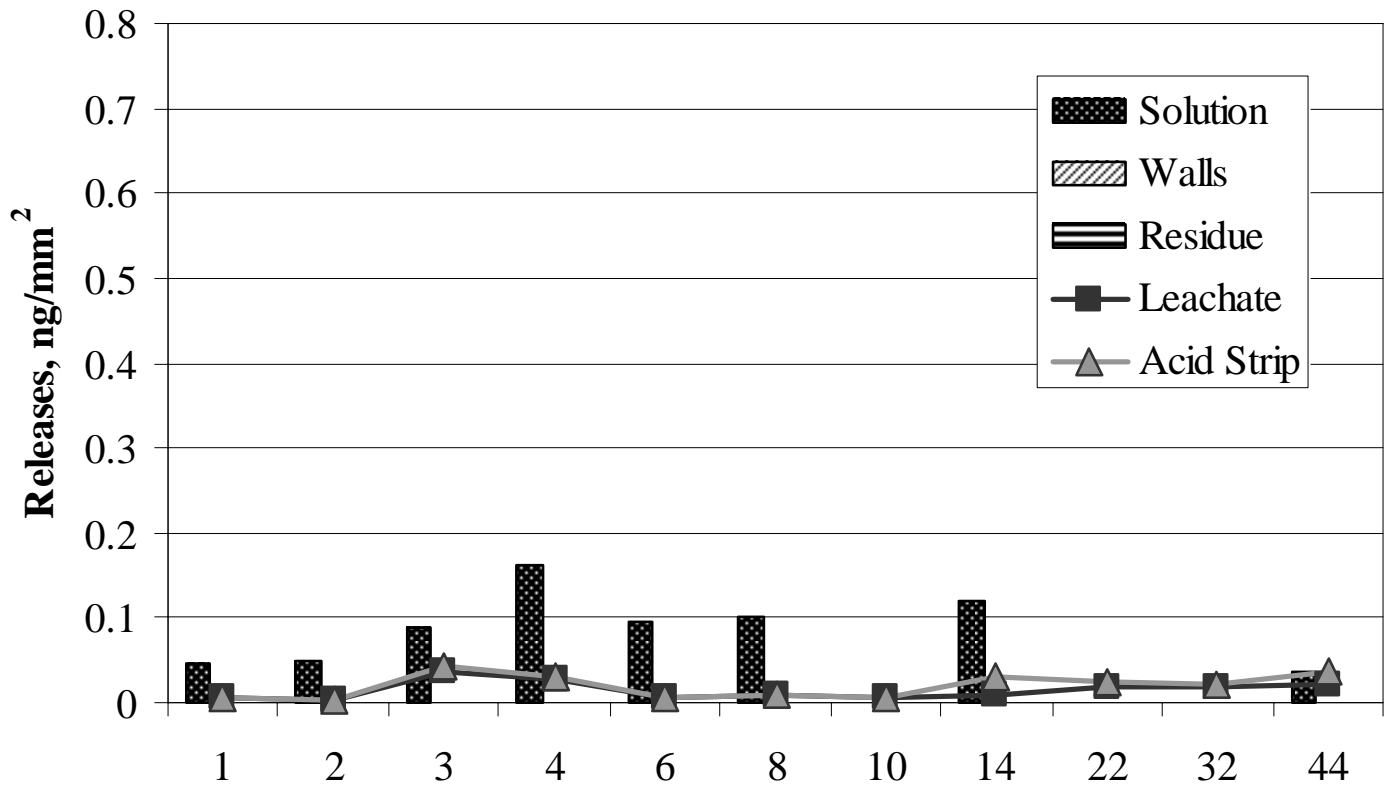

Time, weeks

Figure E-138. Paladium Present in Solution, on Walls, and in Residue from 10KCl Control and Average Detection Limits for Leachate and Acid Strip. 


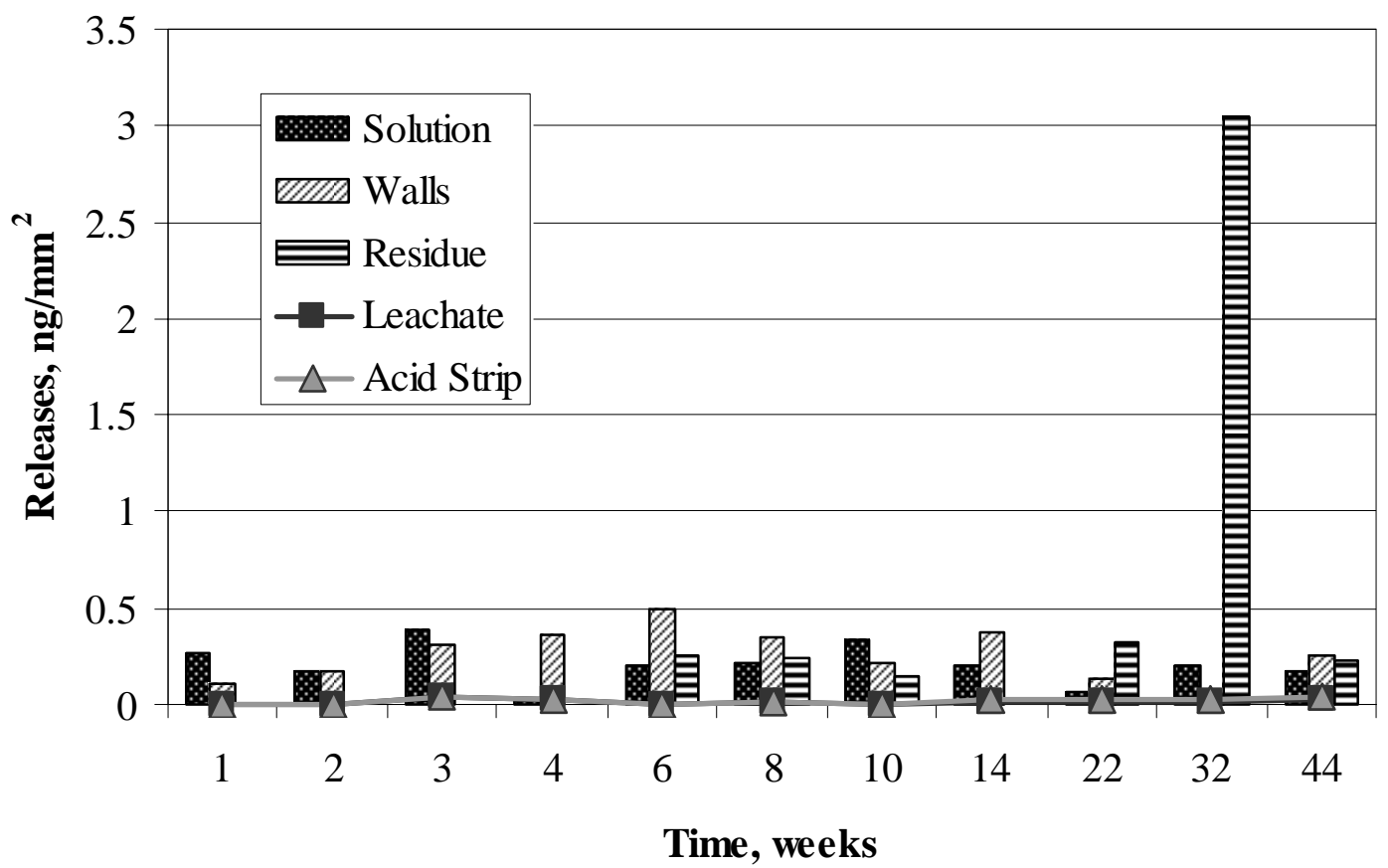

Figure E-139. Paladium Releases in Solution, on Walls, and in Residue from Polished Sample 1 in AJ13 and Average Detection Limits for Leachate and Acid Strip.

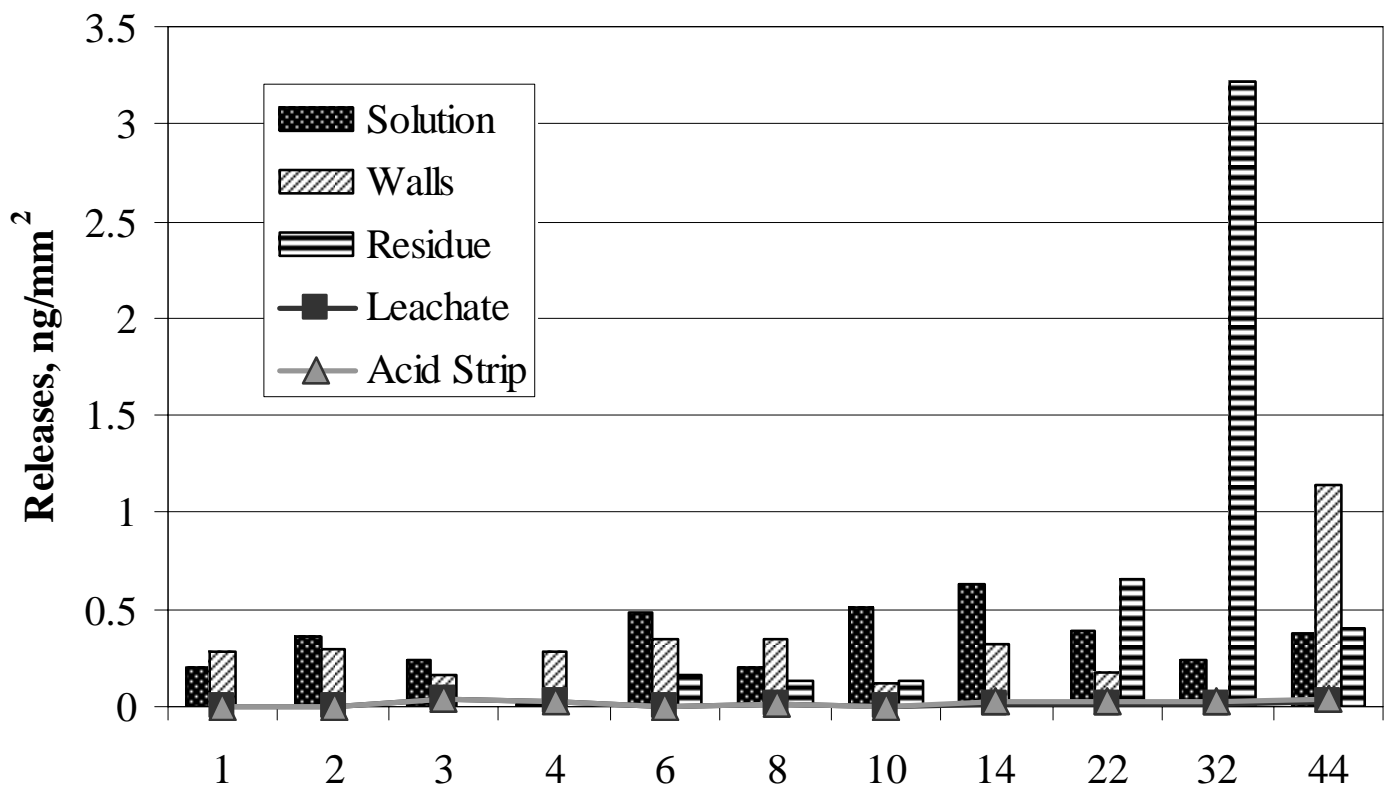

Time, weeks

Figure E-140. Paladium Releases in Solution, on Walls, and in Residue from Polished Sample 2 in AJ13 and Average Detection Limits for Leachate and Acid Strip. 


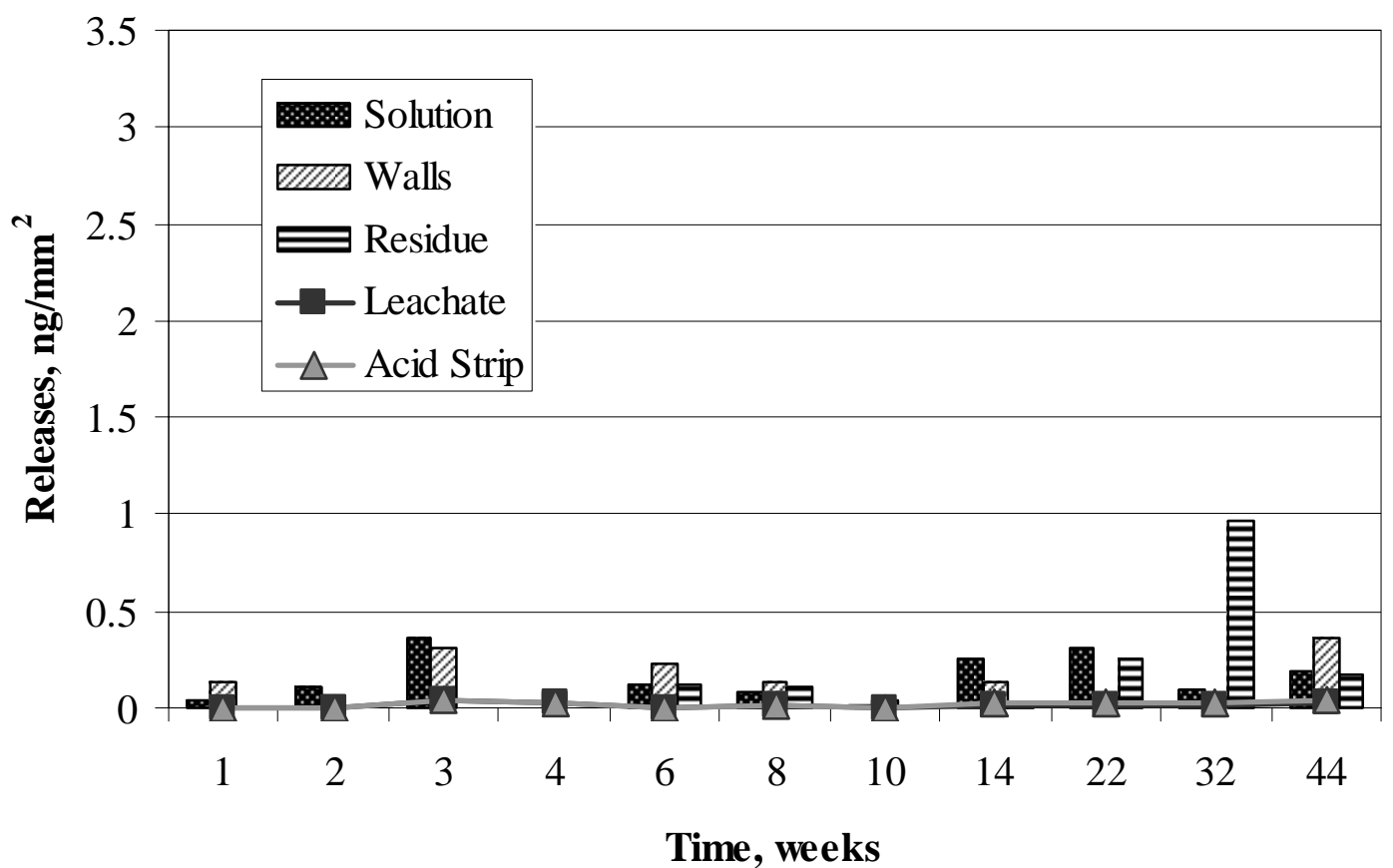

Figure E-141. . Paladium Releases in Solution, on Walls, and in Residue from Polished Sample 3 in AJ13 and Average Detection Limits for Leachate and Acid Strip.

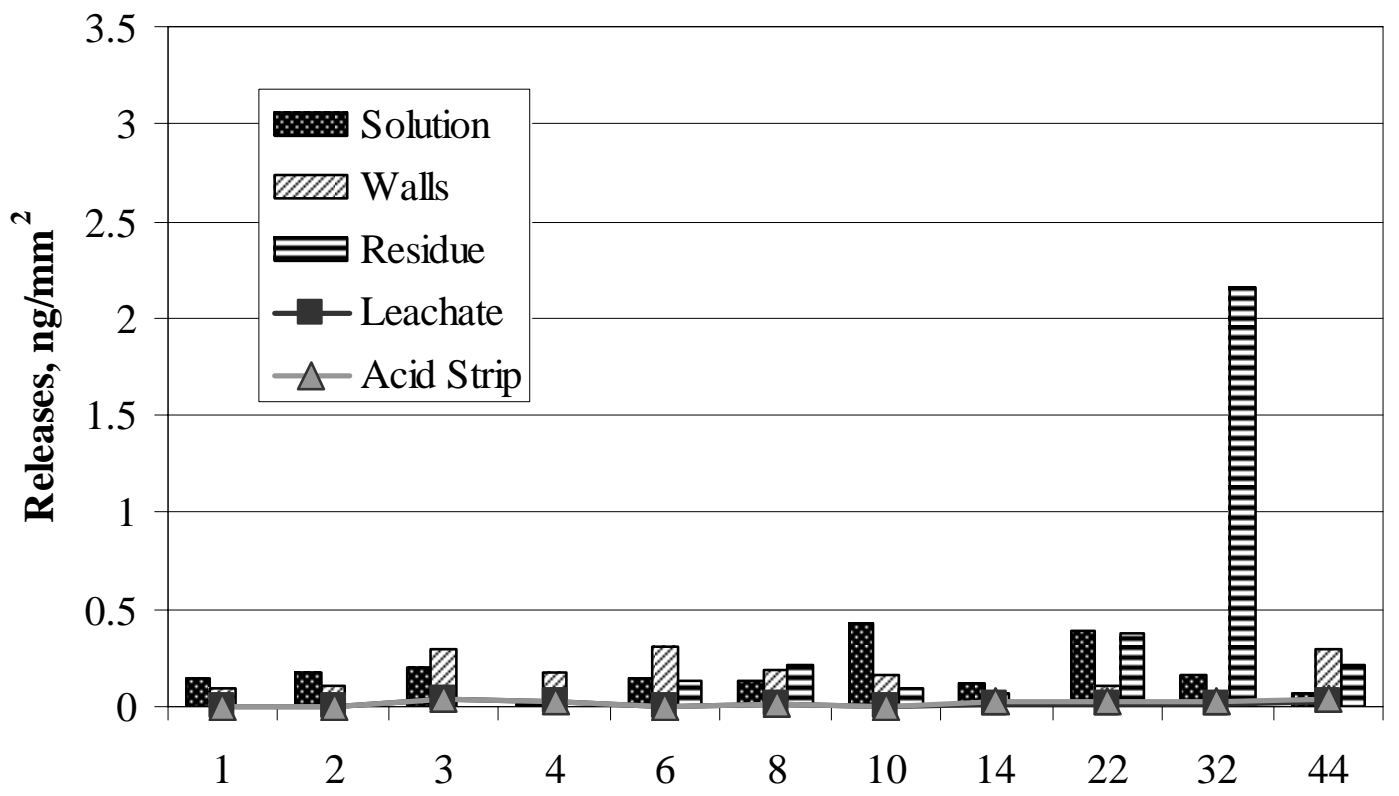

Time, weeks

Figure E-142. Paladium Releases in Solution, on Walls, and in Residue from Oxidized Sample 4 in AJ13 and Average Detection Limits for Leachate and Acid Strip. 


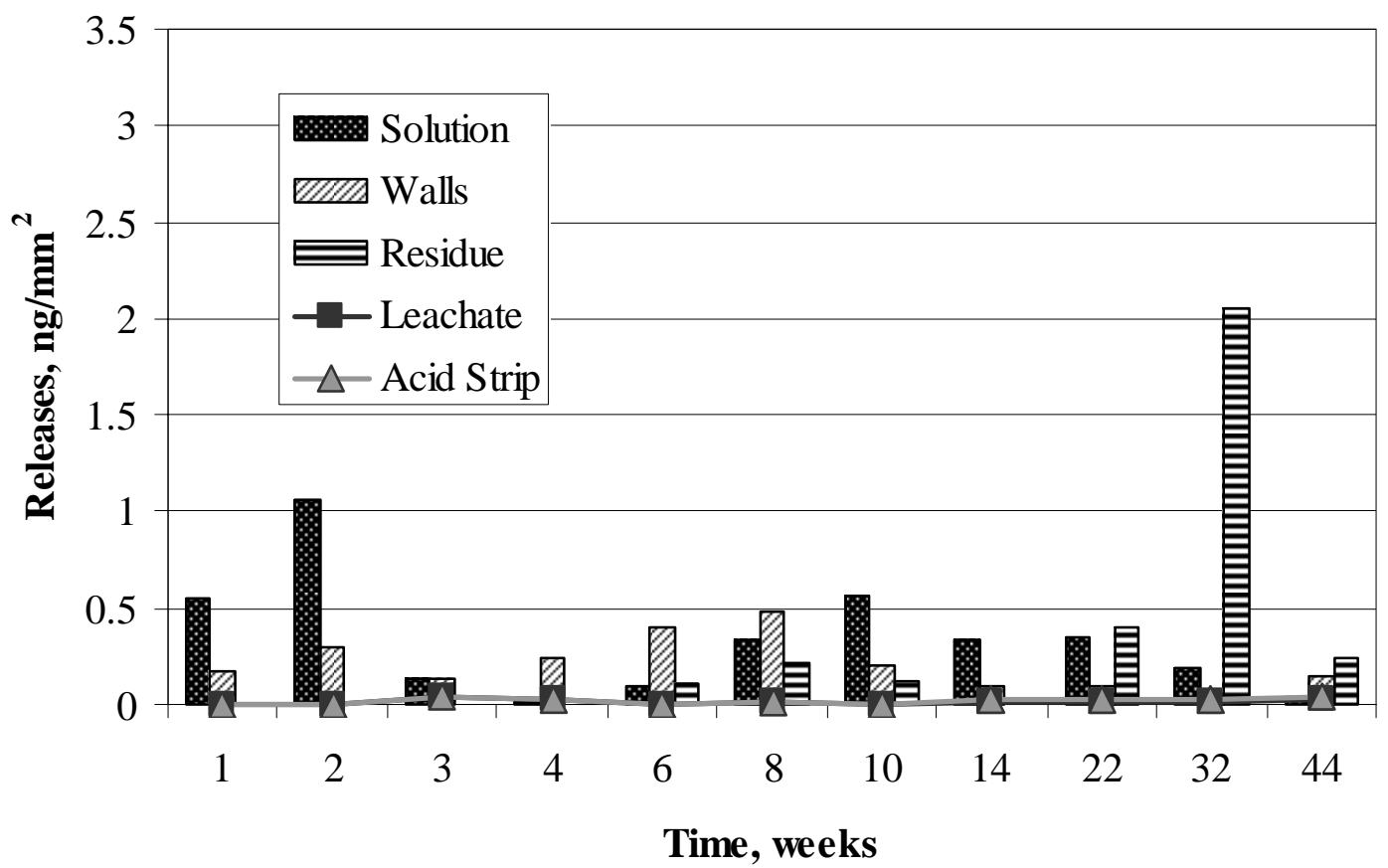

Figure E-143. Paladium Releases in Solution, on Walls, and in Residue from Oxidized Sample 5 in AJ13 and Average Detection Limits for Leachate and Acid Strip.

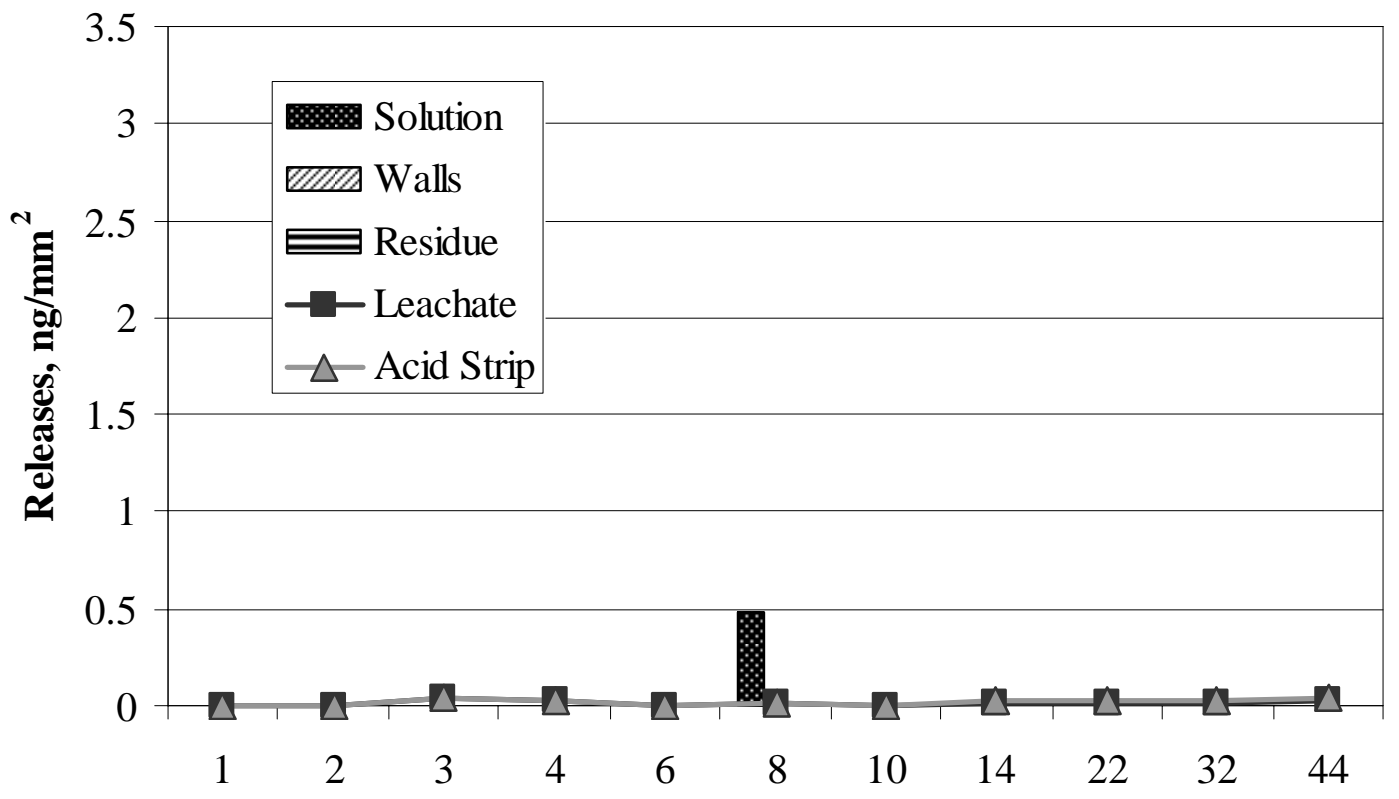

Time, weeks

Figure E-144. Paladium Present in Solution, on Walls, and in Residue from AJ13 Control and Average Detection Limits for Leachate and Acid Strip. 


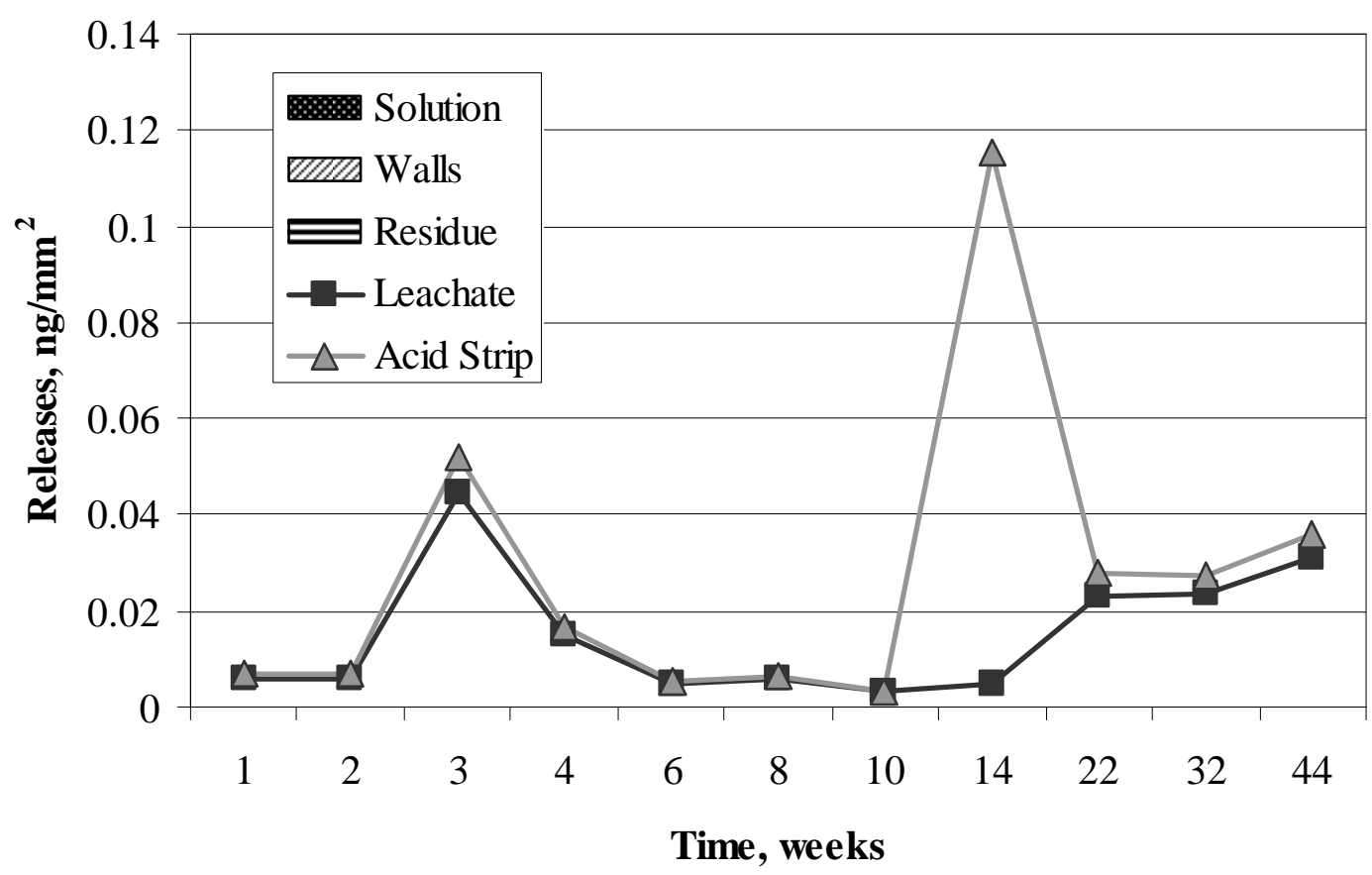

Figure E-145. Rhodium Releases in Solution, on Walls, and in Residue from Polished Sample 1 in SJ13 and Average Detection Limits for Leachate and Acid Strip.

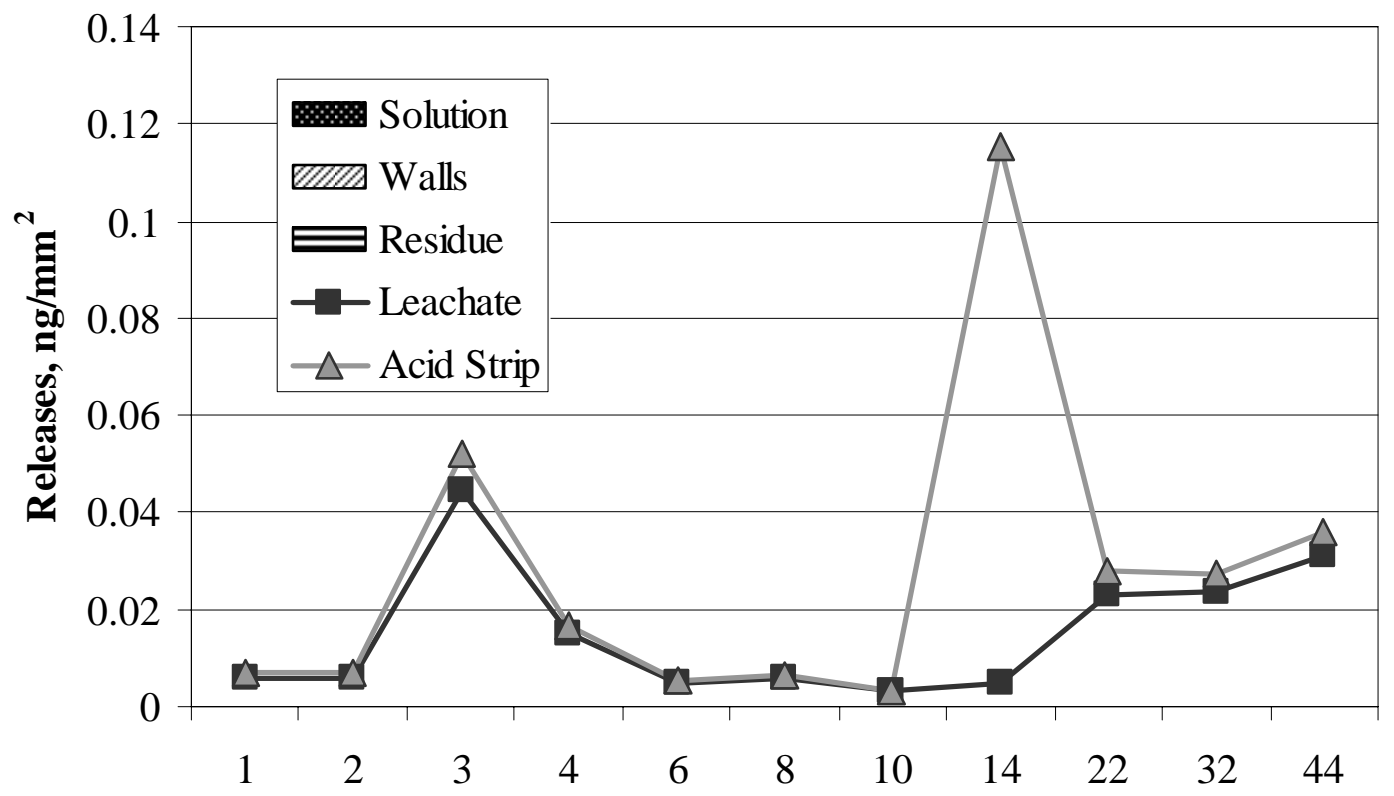

Time, weeks

Figure E-146. Rhodium Releases in Solution, on Walls, and in Residue from Polished Sample 2 in SJ13 and Average Detection Limits for Leachate and Acid Strip. 


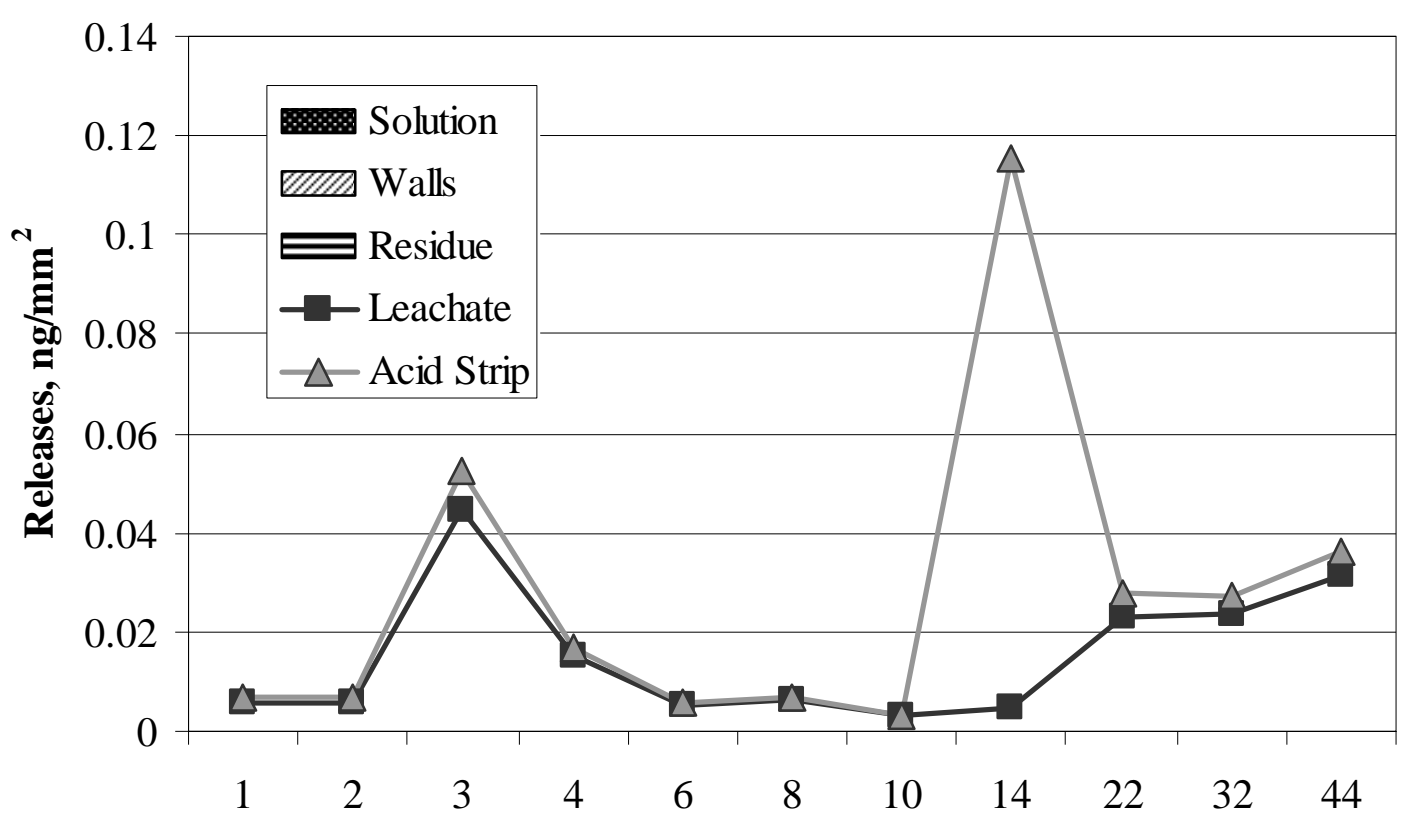

Time, weeks

Figure E-147. Rhodium Releases in Solution, on Walls, and in Residue from Polished Sample 3 in SJ13 and Average Detection Limits for Leachate and Acid Strip.

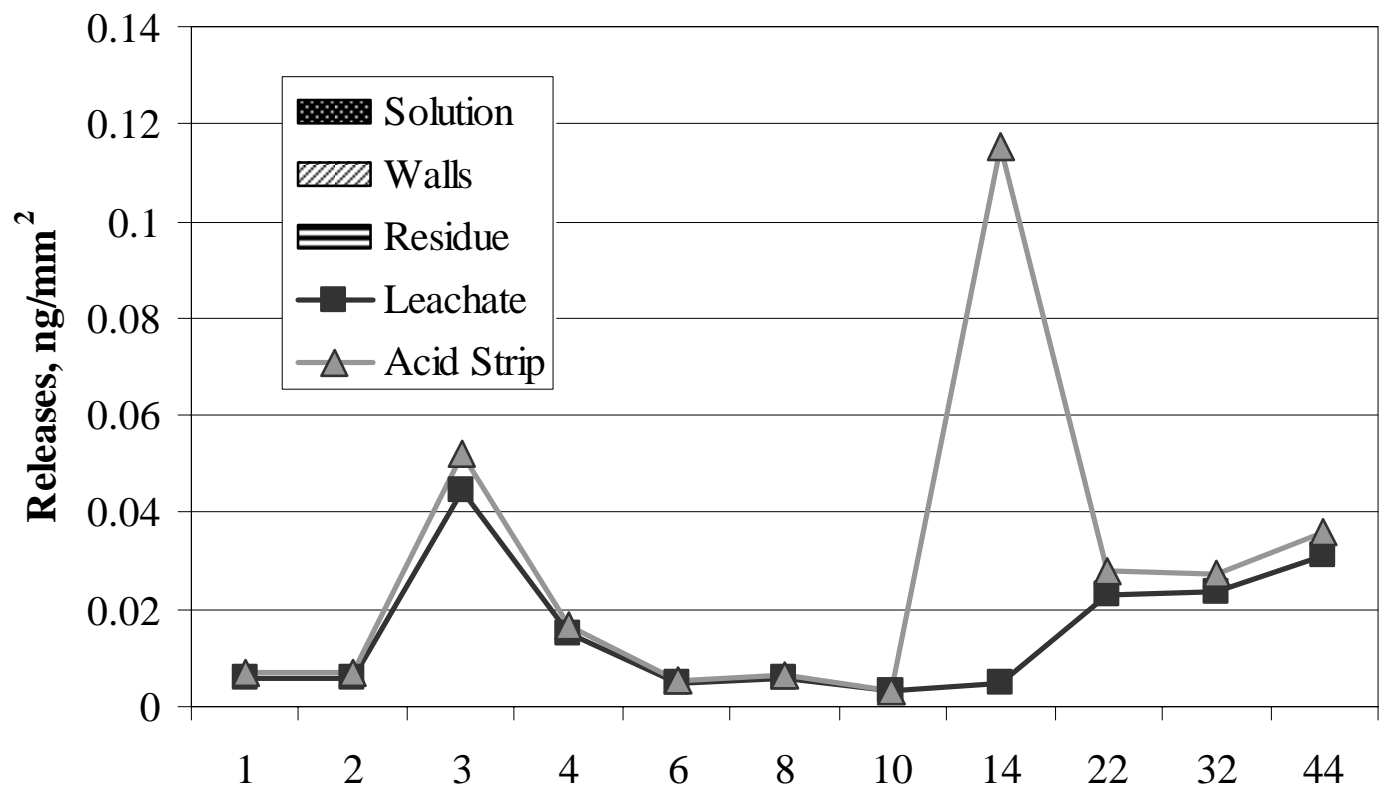

Time, weeks

Figure E-148. Rhodium Releases in Solution, on Walls, and in Residue from Oxidized Sample 4 in SJ13 and Average Detection Limits for Leachate and Acid Strip. 


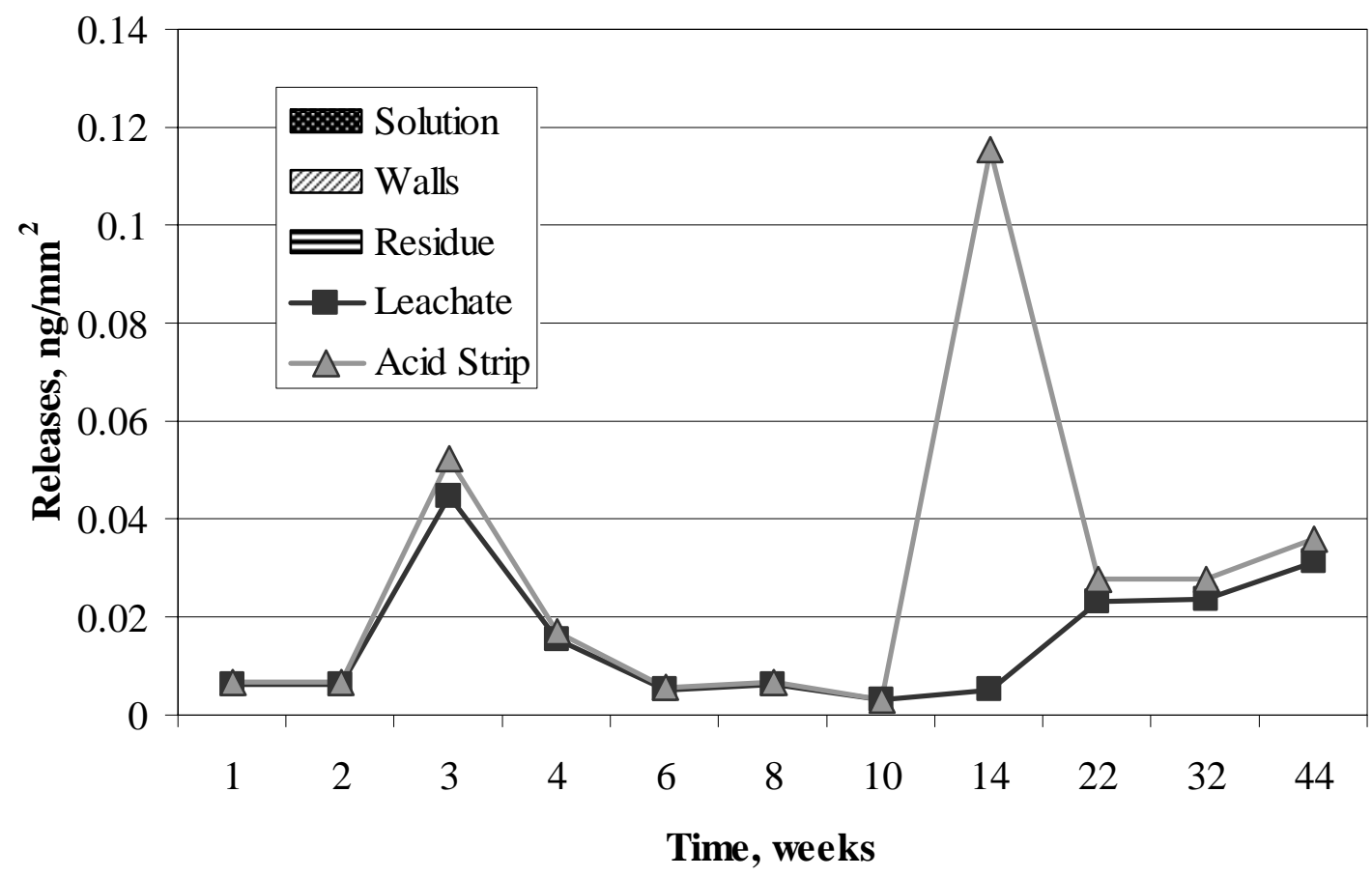

Figure E-149. Rhodium Releases in Solution, on Walls, and in Residue from Oxidized Sample 5 in SJ13 and Average Detection Limits for Leachate and Acid Strip.

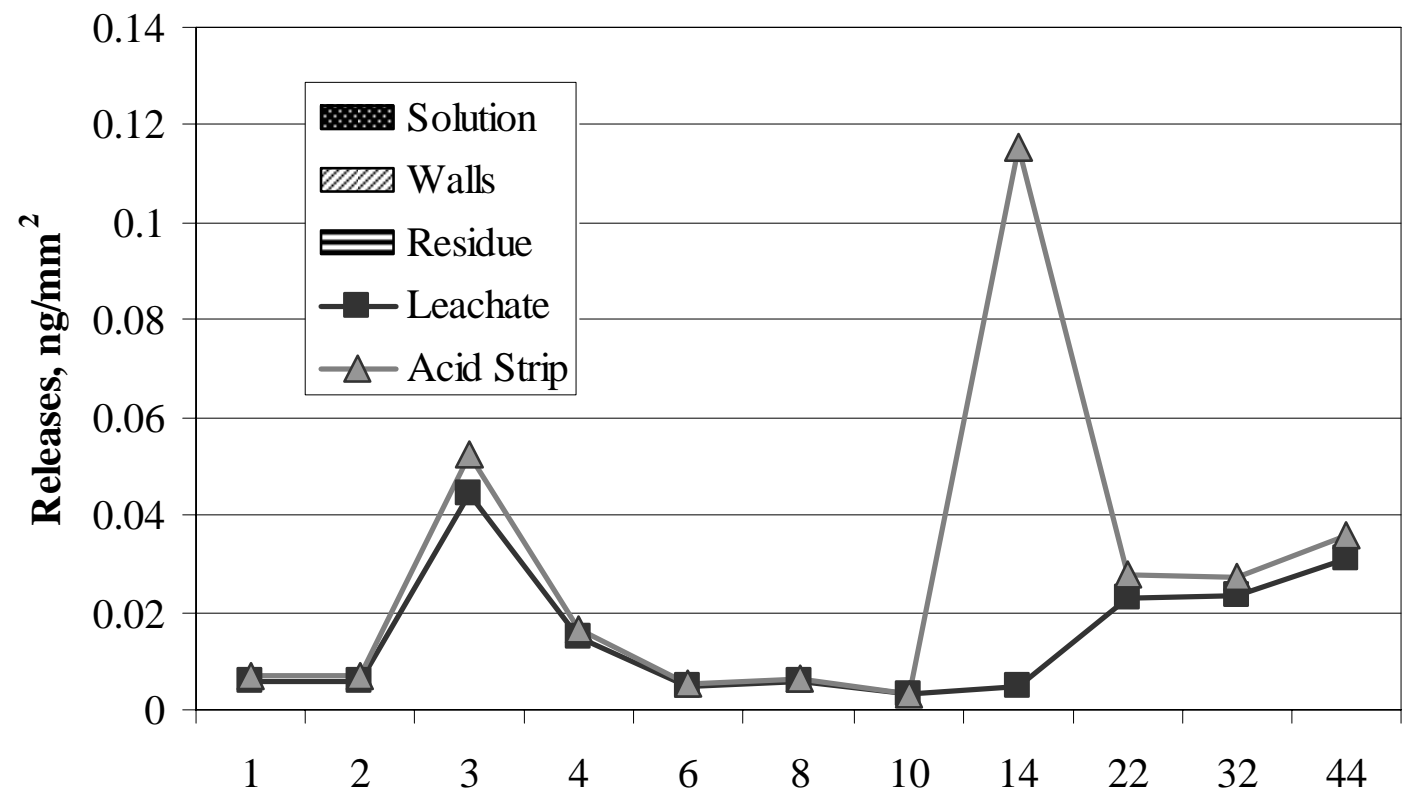

Time, weeks

Figure E-150. Rhodium Present in Solution, on Walls, and in Residue from SJ13 Control and Average Detection Limits for Leachate and Acid Strip. 


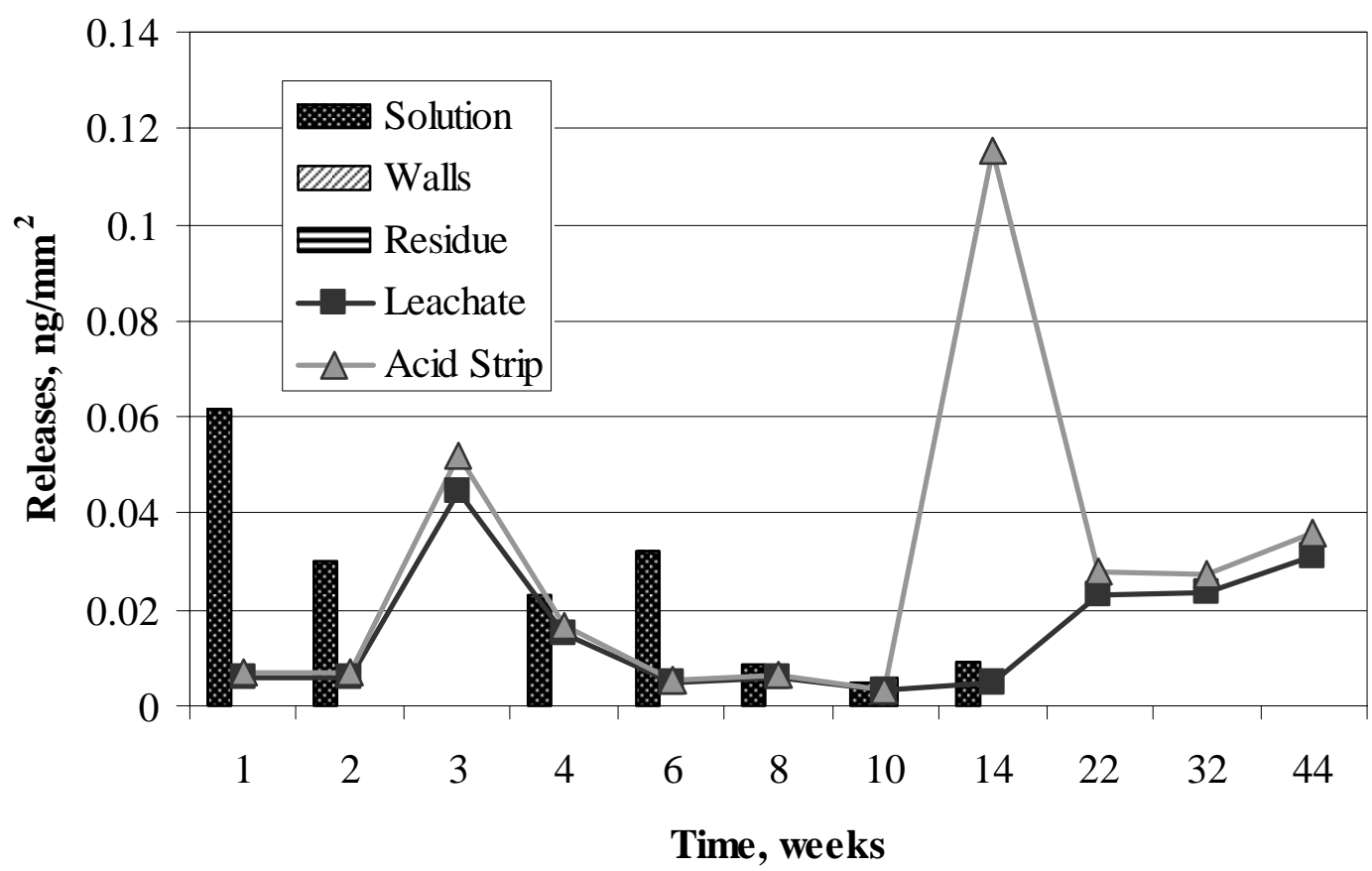

Figure E-151. Rhodium Releases in Solution, on Walls, and in Residue from Polished Sample 1 in CJ13 and Average Detection Limits for Leachate and Acid Strip.

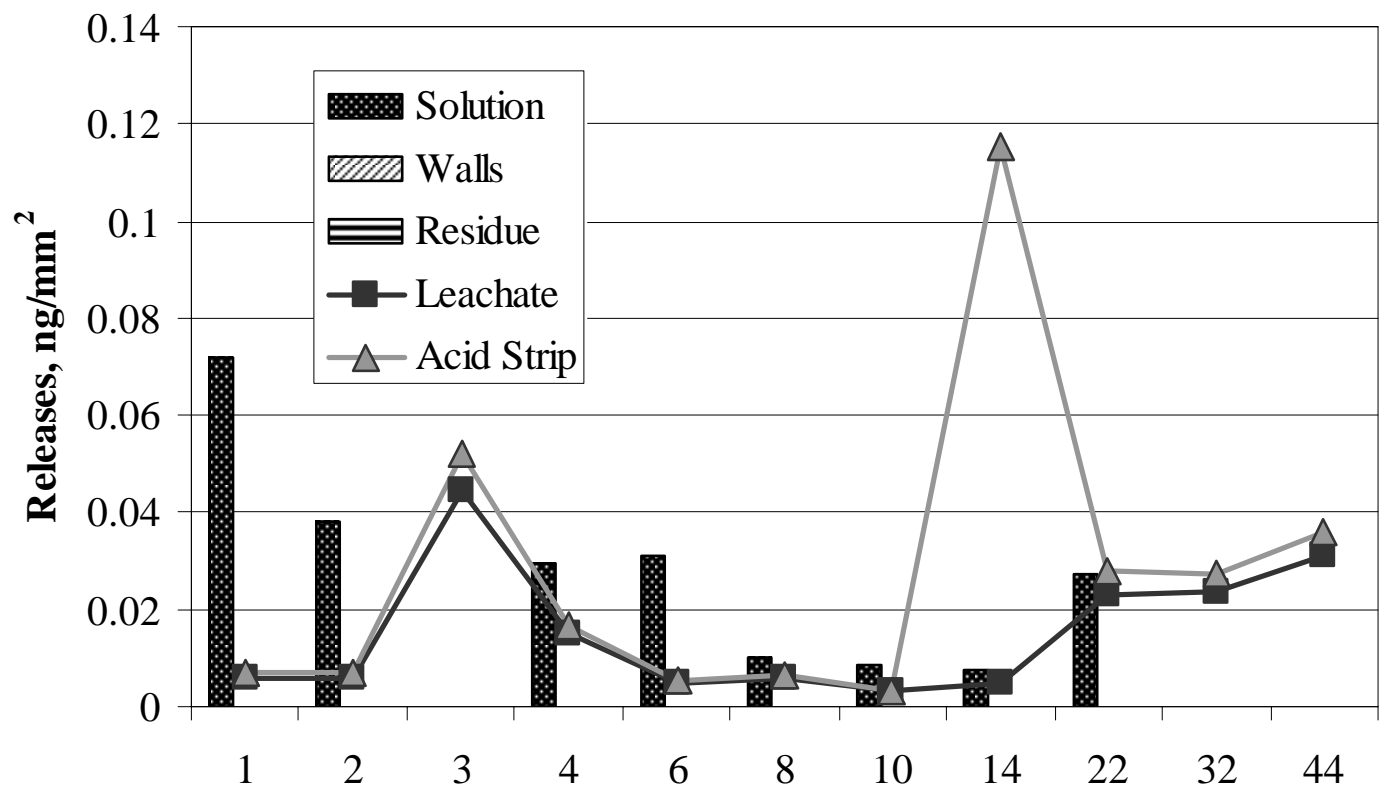

Time, weeks

Figure E-152. Rhodium Releases in Solution, on Walls, and in Residue from Polished Sample 2 in CJ13 and Average Detection Limits for Leachate and Acid Strip. 


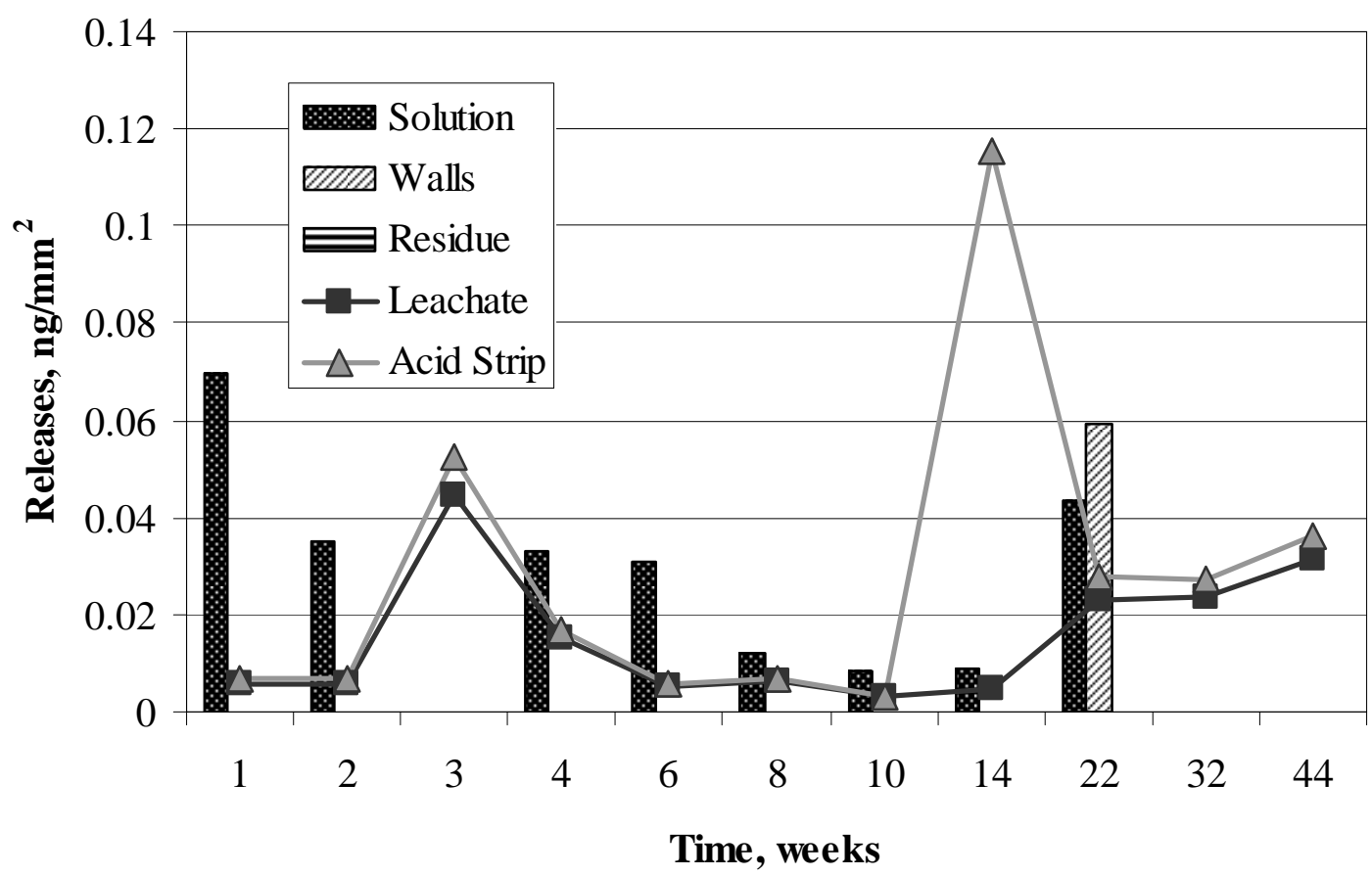

Figure E-153. Rhodium Releases in Solution, on Walls, and in Residue from Polished Sample 3 in CJ13 and Average Detection Limits for Leachate and Acid Strip.

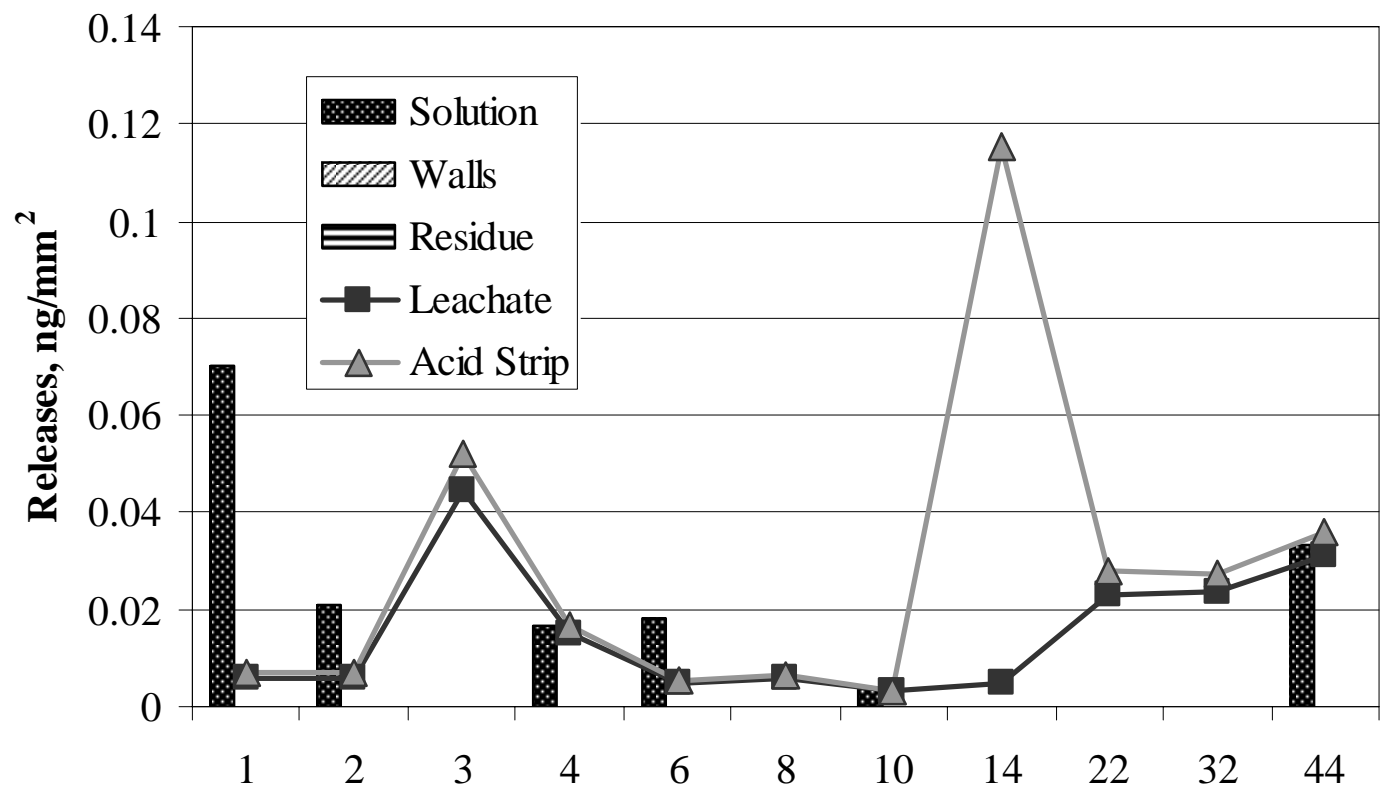

Time, weeks

Figure E-154. Rhodium Releases in Solution, on Walls, and in Residue from Oxidized Sample 4 in CJ13 and Average Detection Limits for Leachate and Acid Strip. 


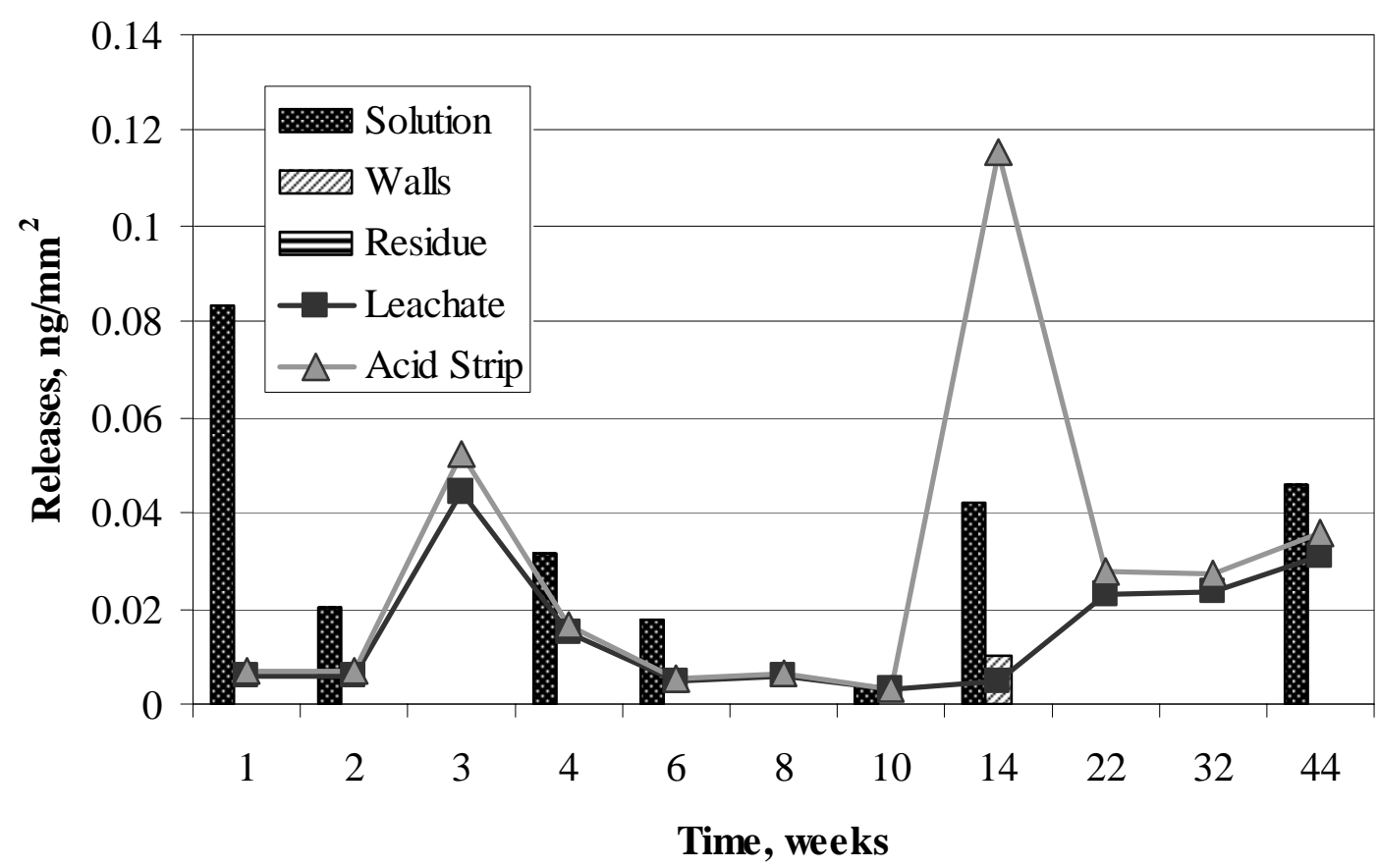

Figure E-155. Rhodium Releases in Solution, on Walls, and in Residue from Oxidized Sample 5 in CJ13 and Average Detection Limits for Leachate and Acid Strip.

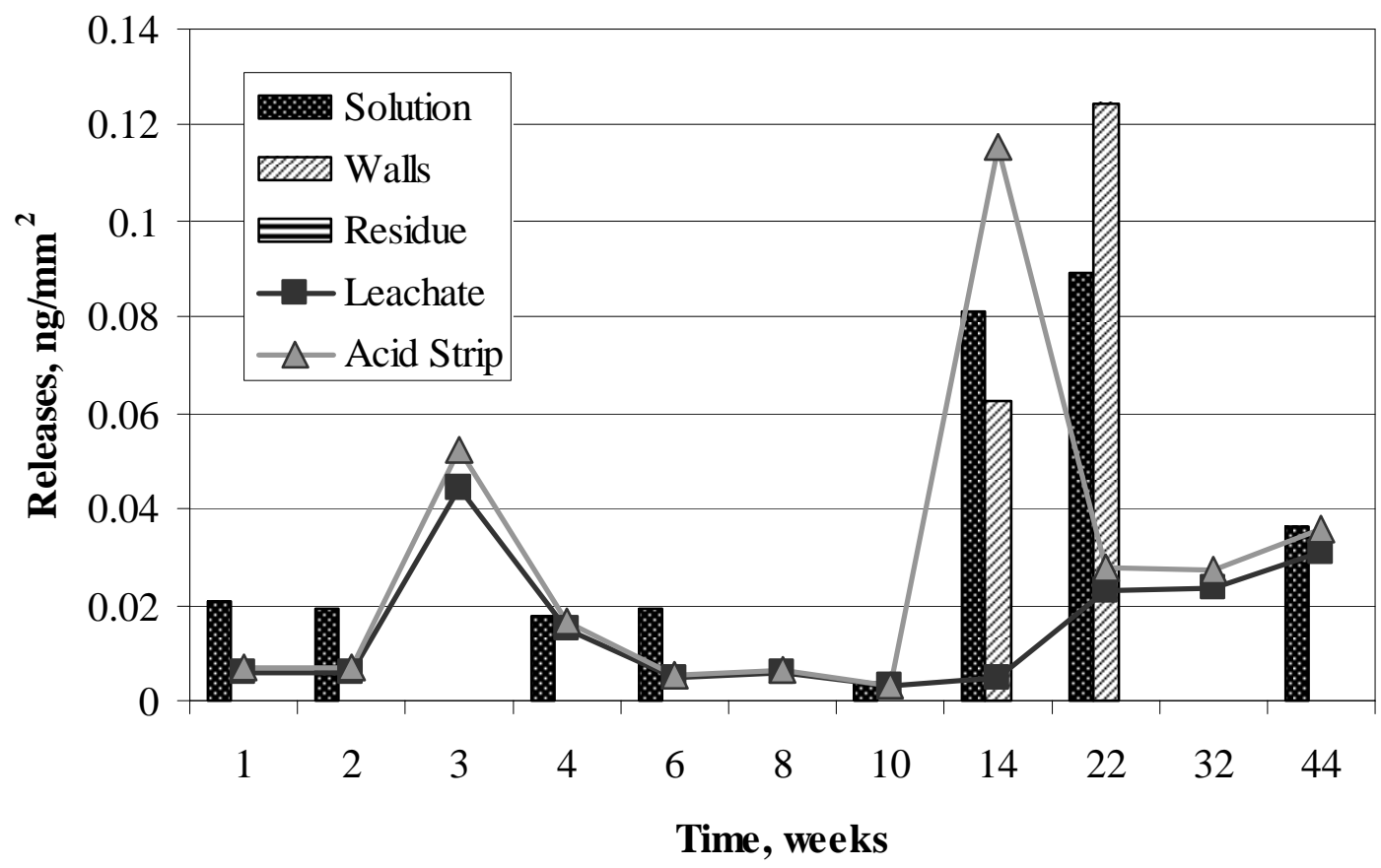

Figure E-156. Rhodium Present in Solution, on Walls, and in Residue from CJ13 Control and Average Detection Limits for Leachate and Acid Strip. 


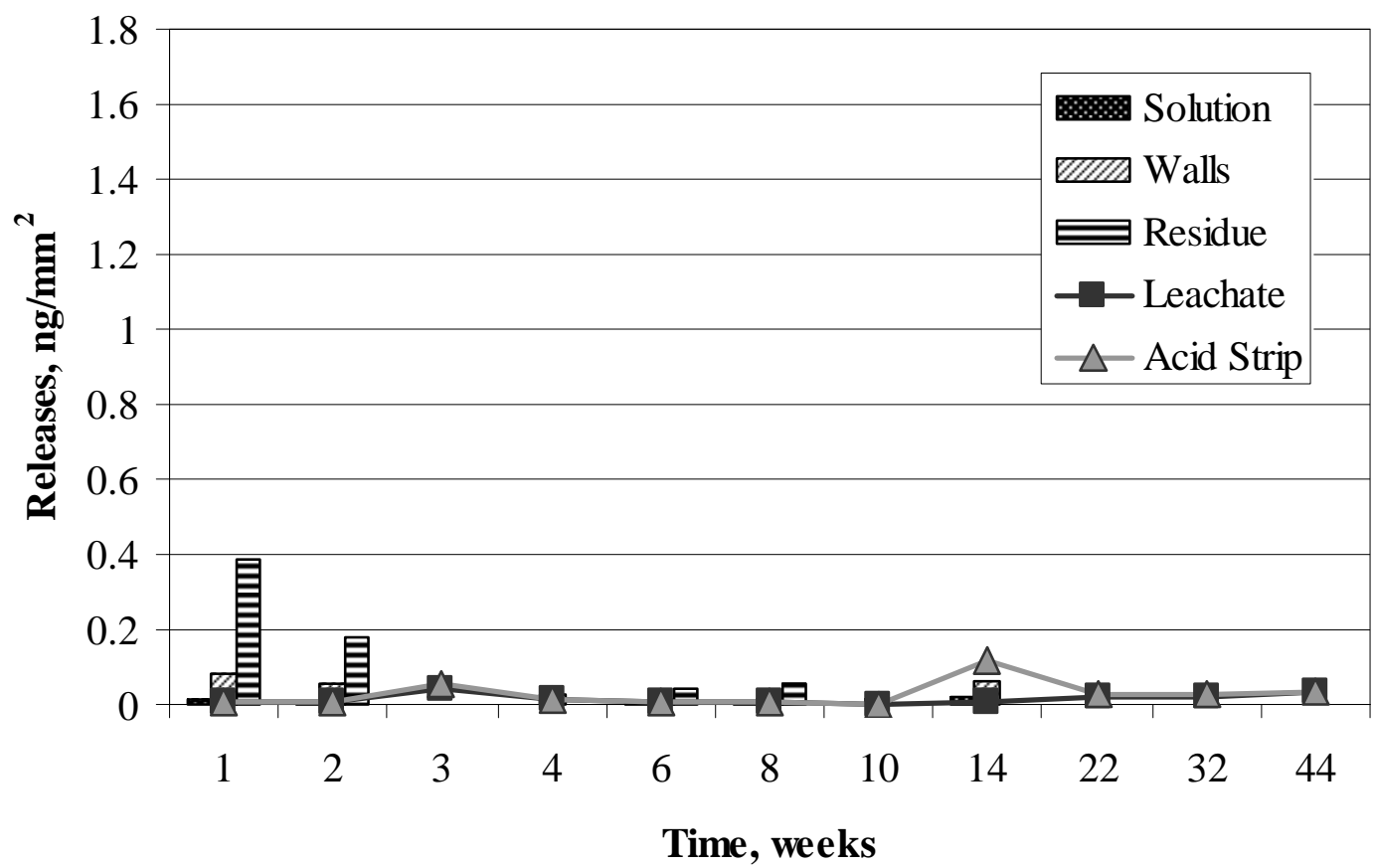

Figure E-157. Rhodium Releases in Solution, on Walls, and in Residue from Polished Sample 1 in $10 \mathrm{KCl}$ and Average Detection Limits for Leachate and Acid Strip.

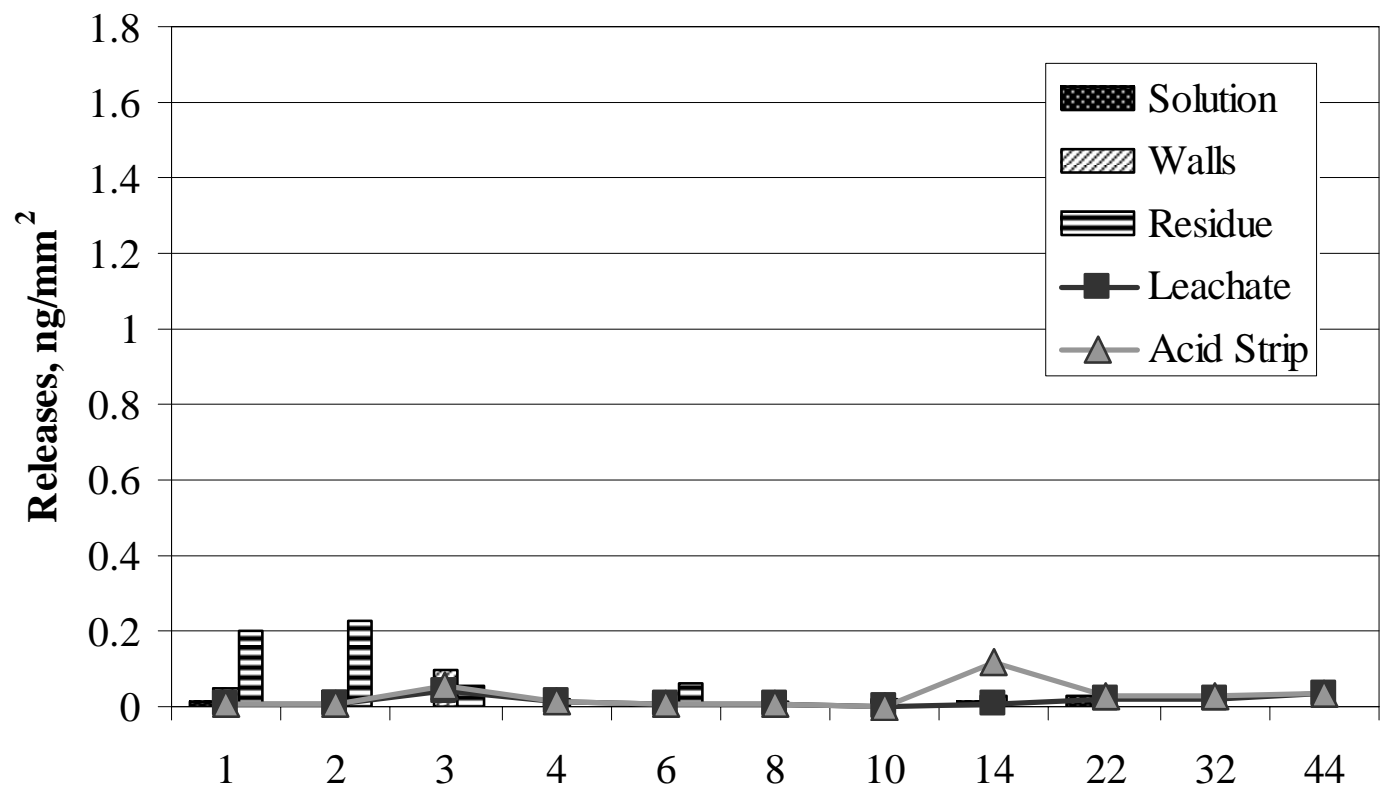

Time, weeks

Figure E-158. Rhodium Releases in Solution, on Walls, and in Residue from Polished Sample 2 in $10 \mathrm{KCl}$ and Average Detection Limits for Leachate and Acid Strip. 


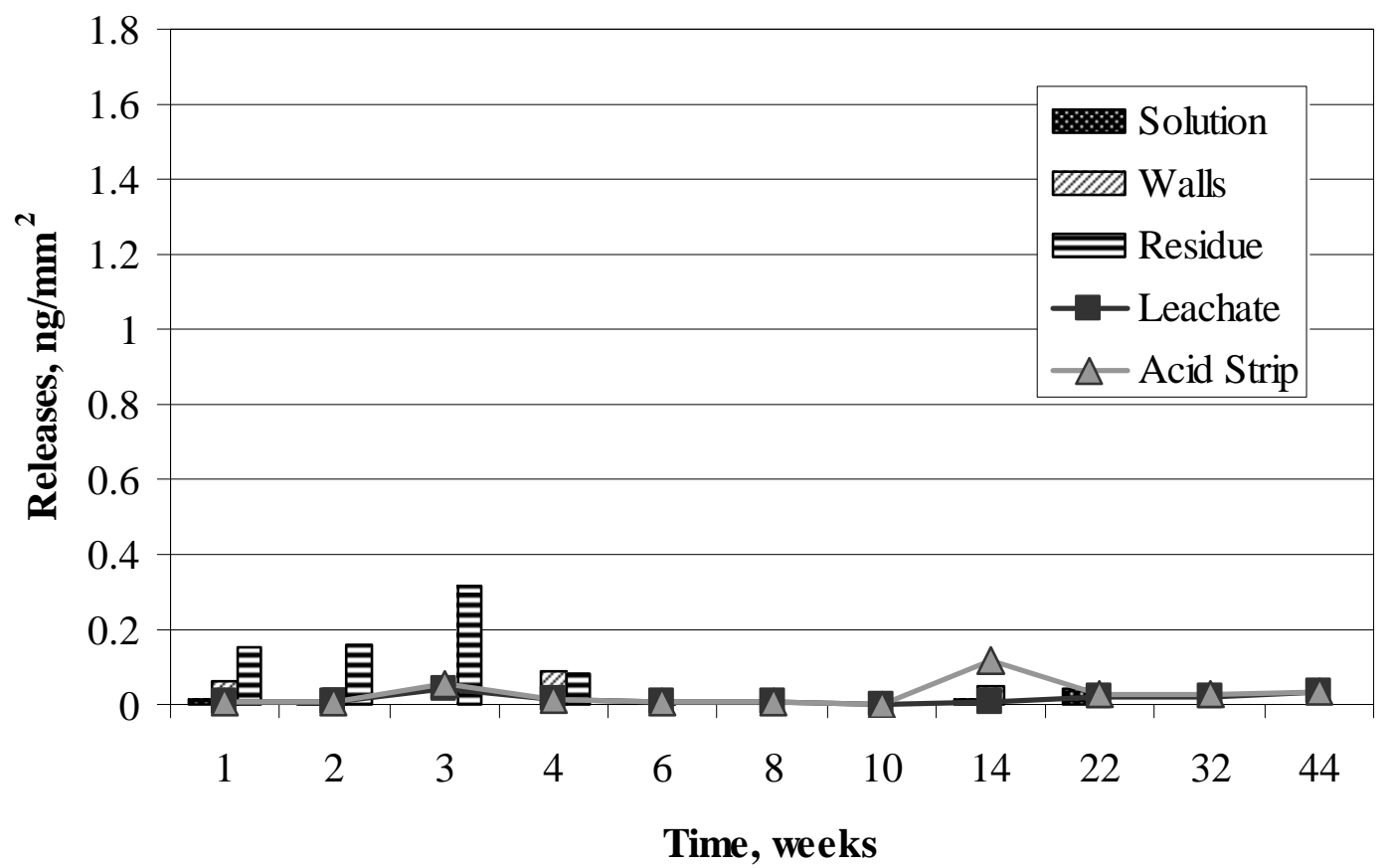

Figure E-159. Rhodium Releases in Solution, on Walls, and in Residue from Polished Sample 3 in $10 \mathrm{KCl}$ and Average Detection Limits for Leachate and Acid Strip.

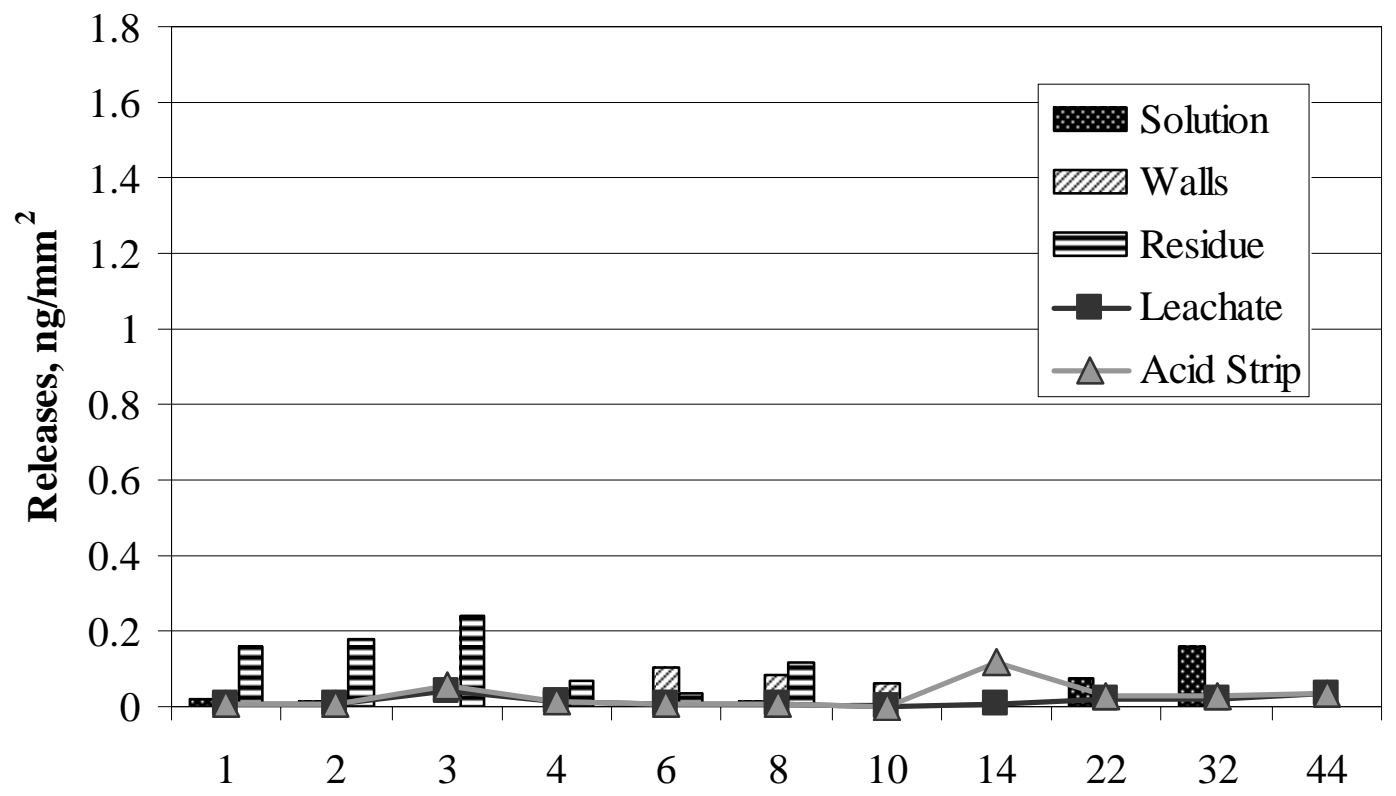

Time, weeks

Figure E-160. Rhodium Releases in Solution, on Walls, and in Residue from Oxidized Sample 4 in $10 \mathrm{KCl}$ and Average Detection Limits for Leachate and Acid Strip. 


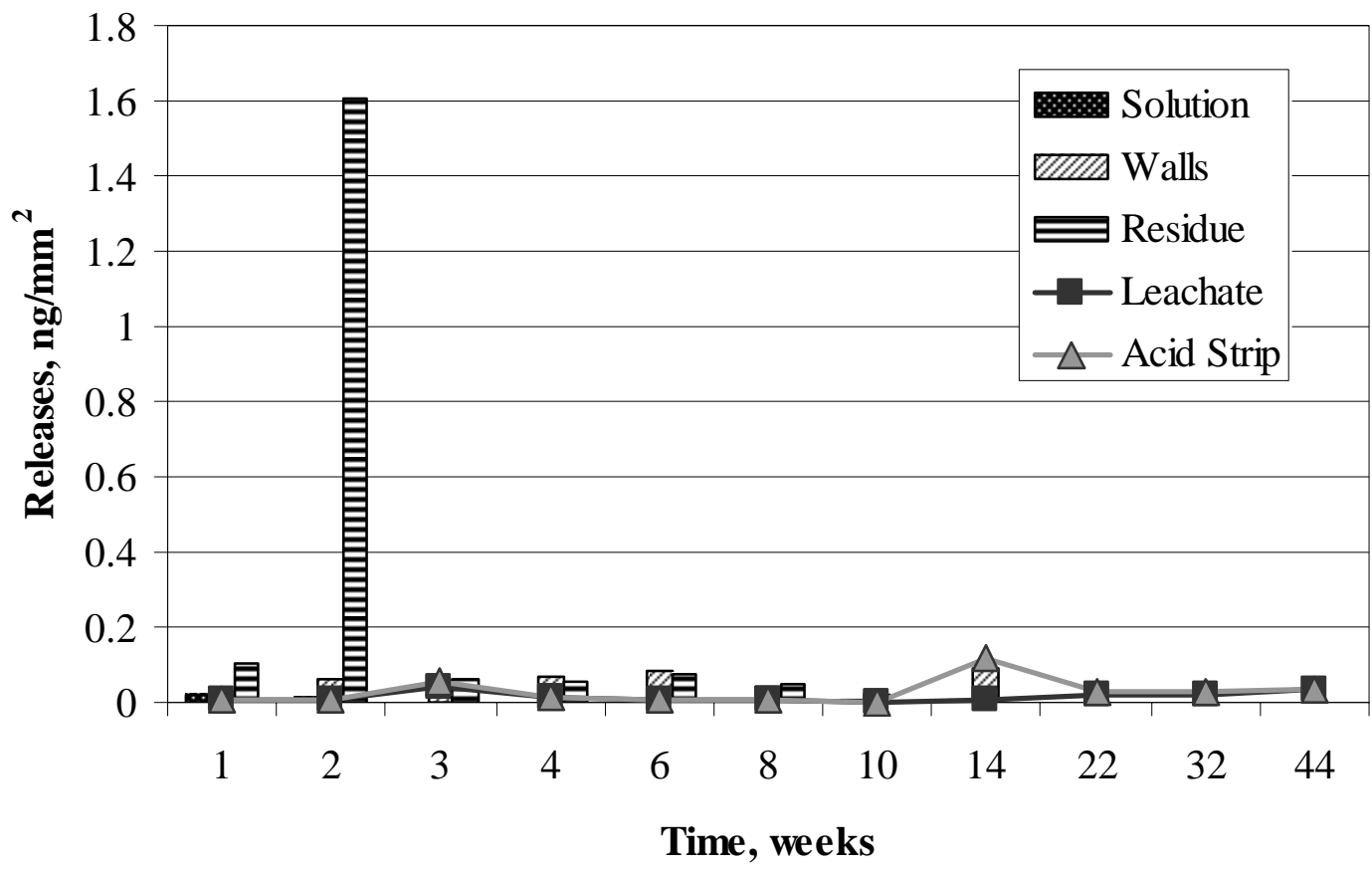

Figure E-161. Rhodium Releases in Solution, on Walls, and in Residue from Oxidized Sample 5 in $10 \mathrm{KCl}$ and Average Detection Limits for Leachate and Acid Strip.

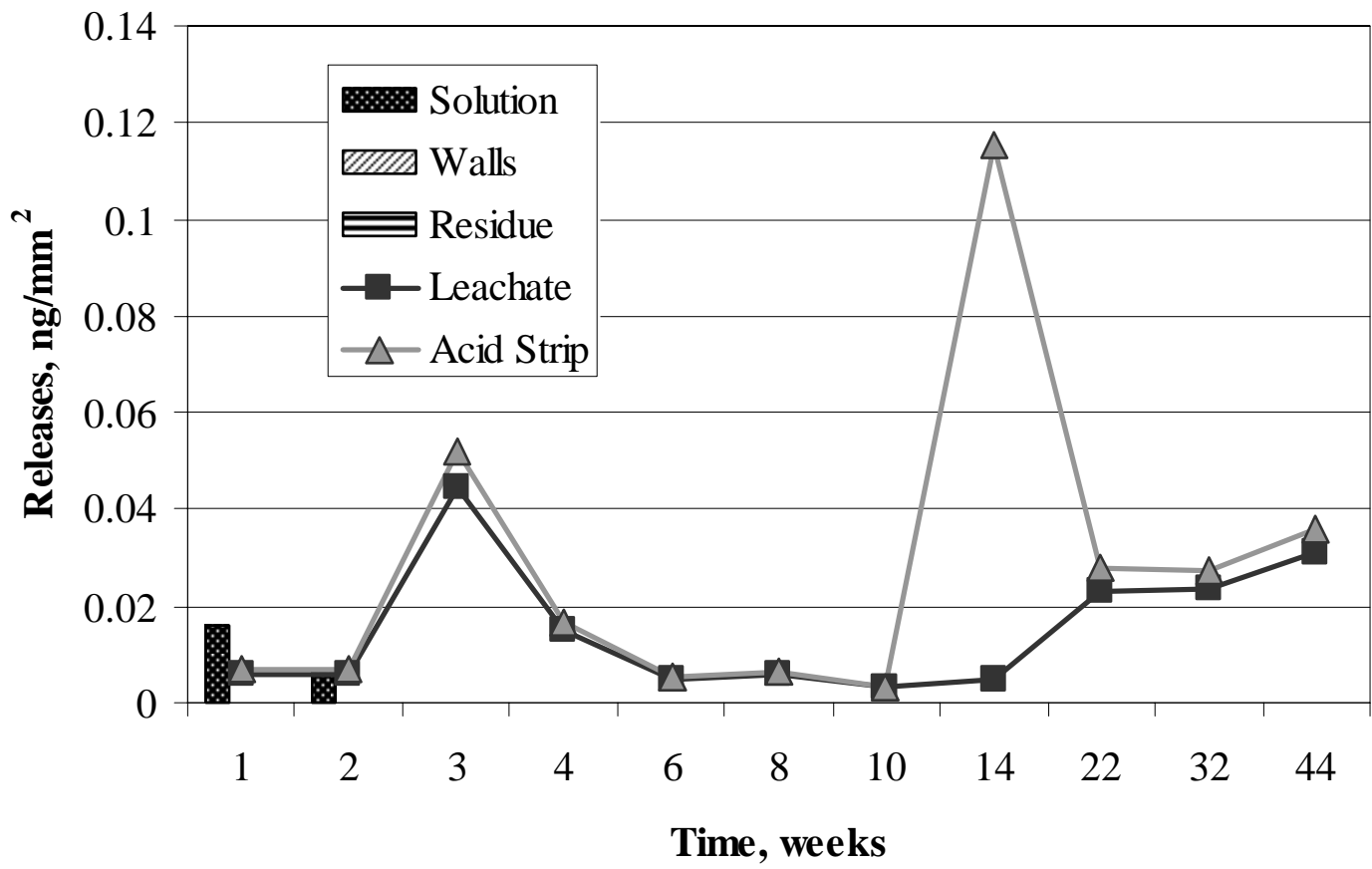

Figure E-162. Rhodium Present in Solution, on Walls, and in Residue from 10KCl Control and Average Detection Limits for Leachate and Acid Strip. 


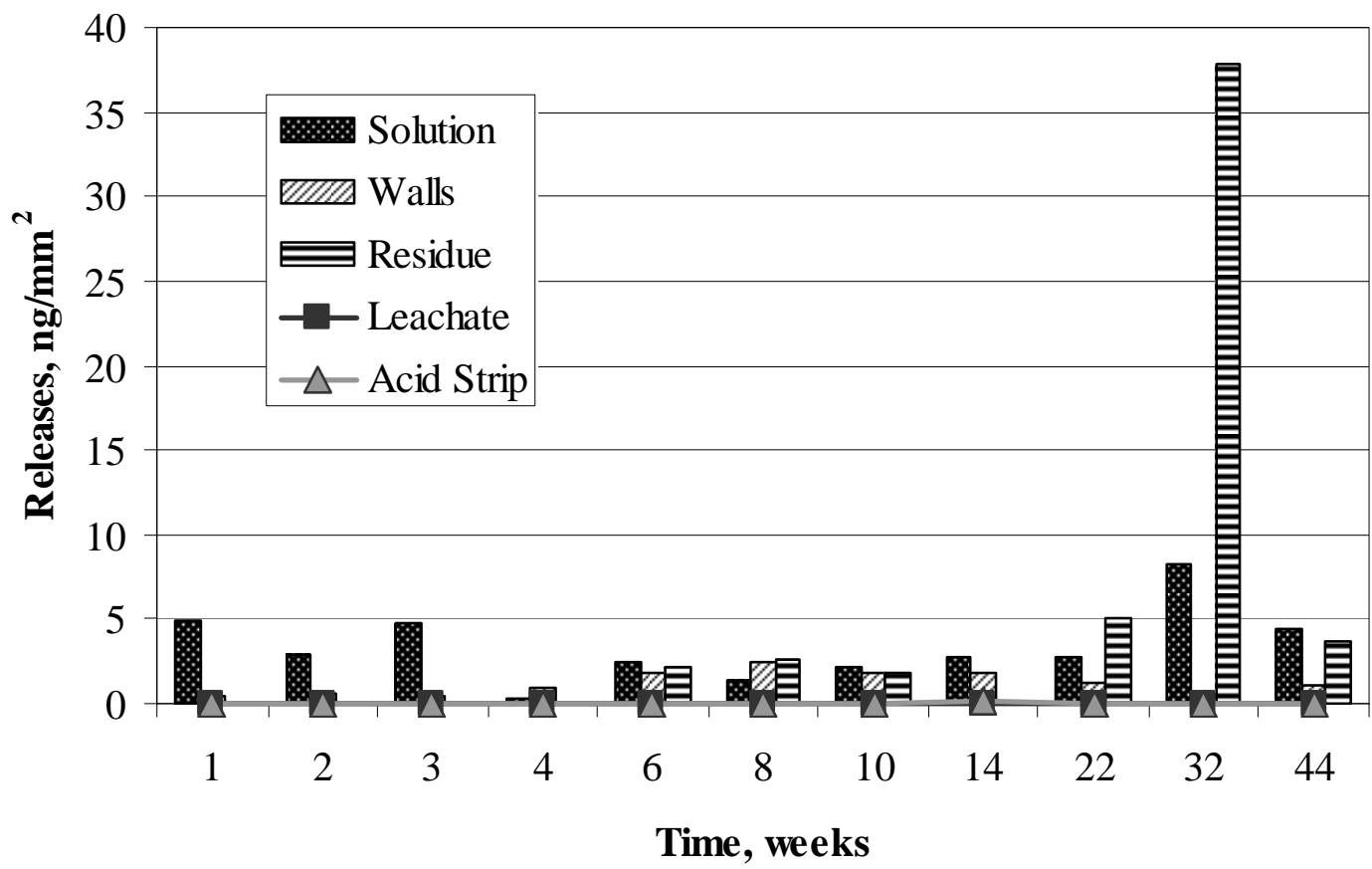

Figure E-163. Rhodium Releases in Solution, on Walls, and in Residue from Polished Sample 1 in AJ13 and Average Detection Limits for Leachate and Acid Strip.

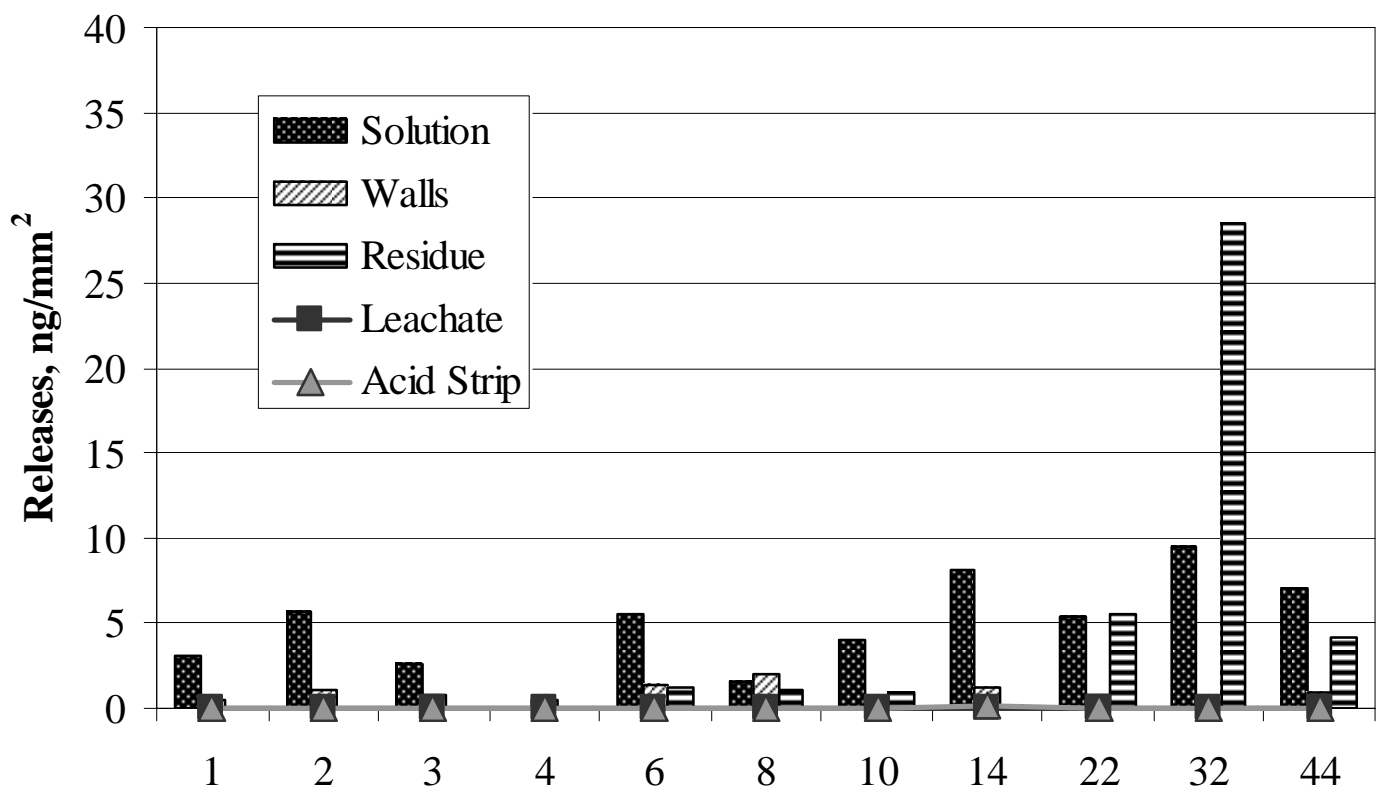

Time, weeks

Figure E-164. Rhodium Releases in Solution, on Walls, and in Residue from Polished Sample 2 in AJ13 and Average Detection Limits for Leachate and Acid Strip. 


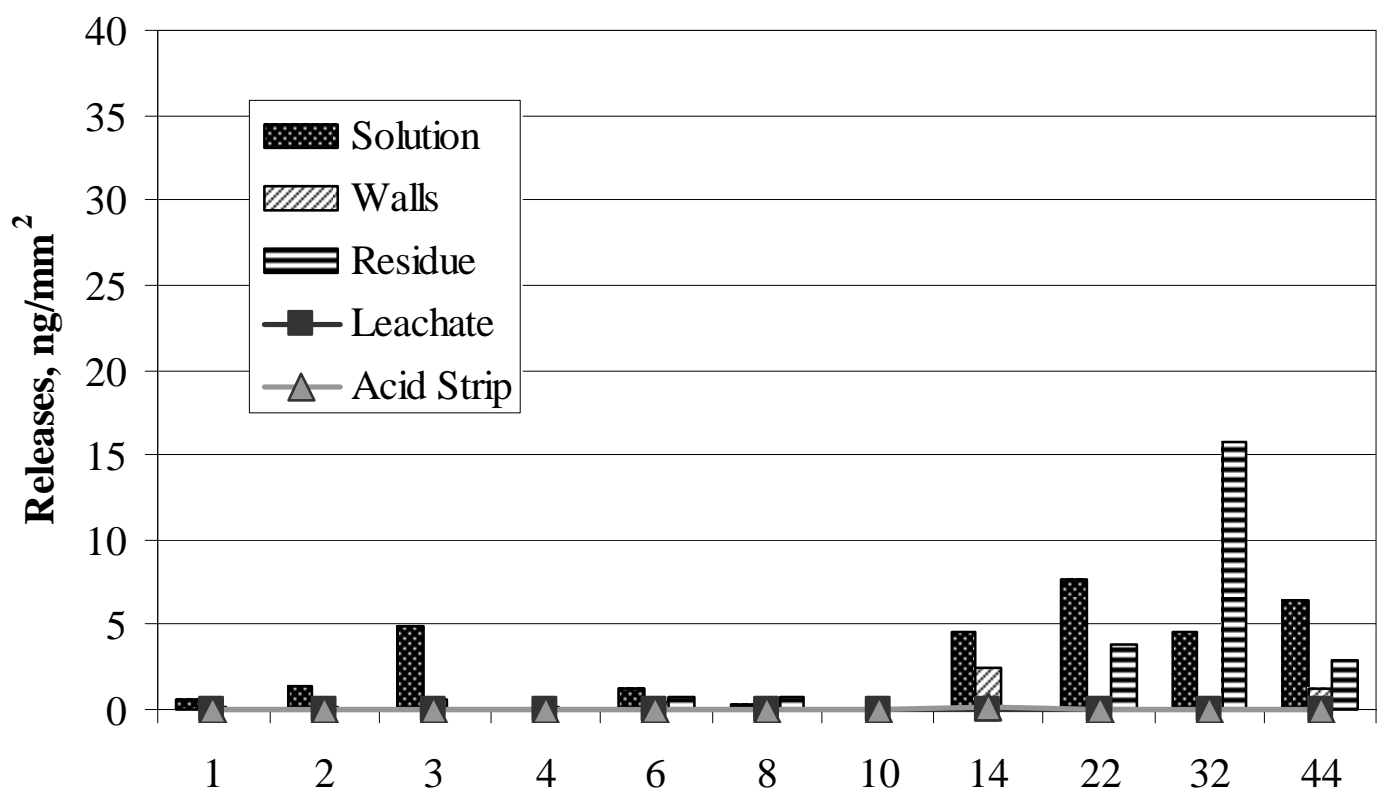

Time, weeks

Figure E-165. Rhodium Releases in Solution, on Walls, and in Residue from Polished Sample 3 in AJ13 and Average Detection Limits for Leachate and Acid Strip.

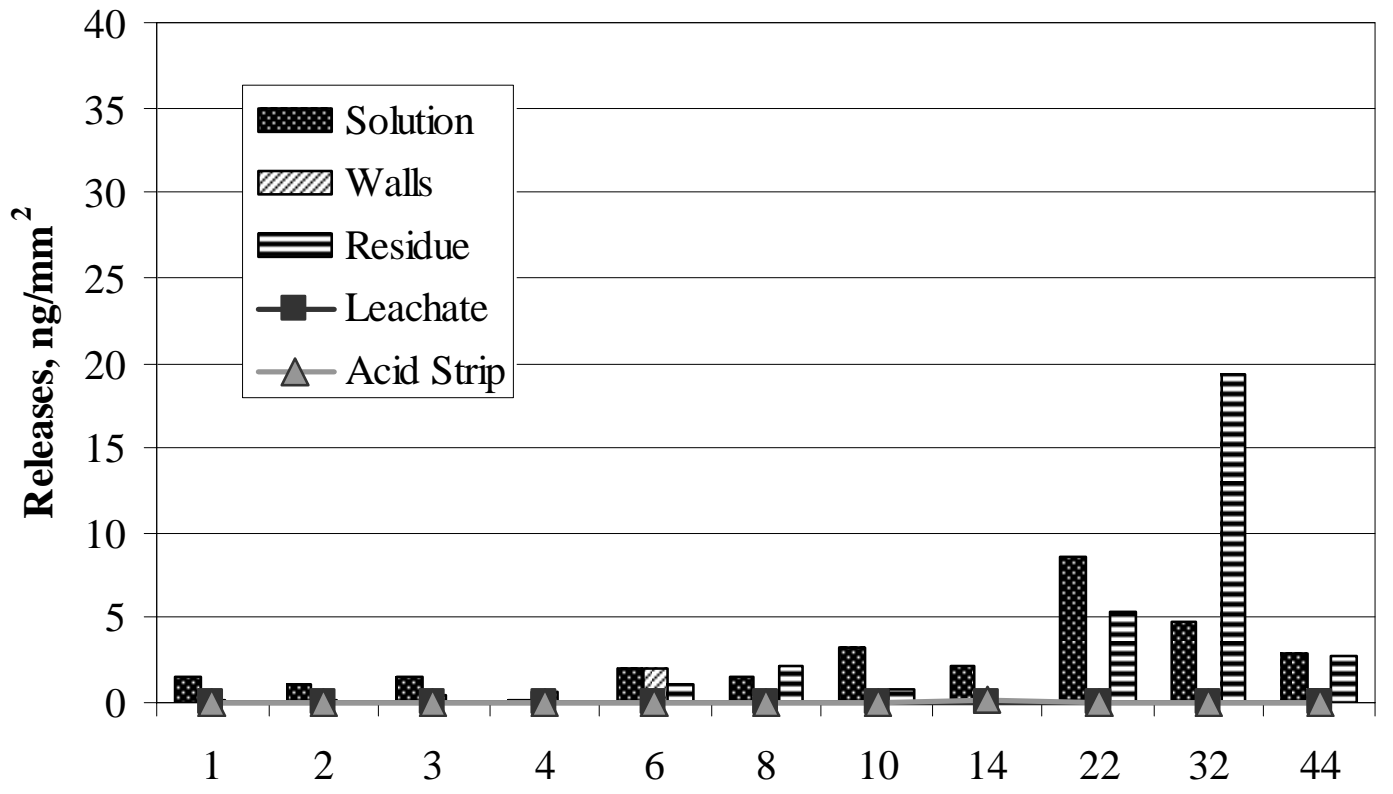

Time, weeks

Figure E-166. Rhodium Releases in Solution, on Walls, and in Residue from Oxidized Sample 4 in AJ13 and Average Detection Limits for Leachate and Acid Strip. 


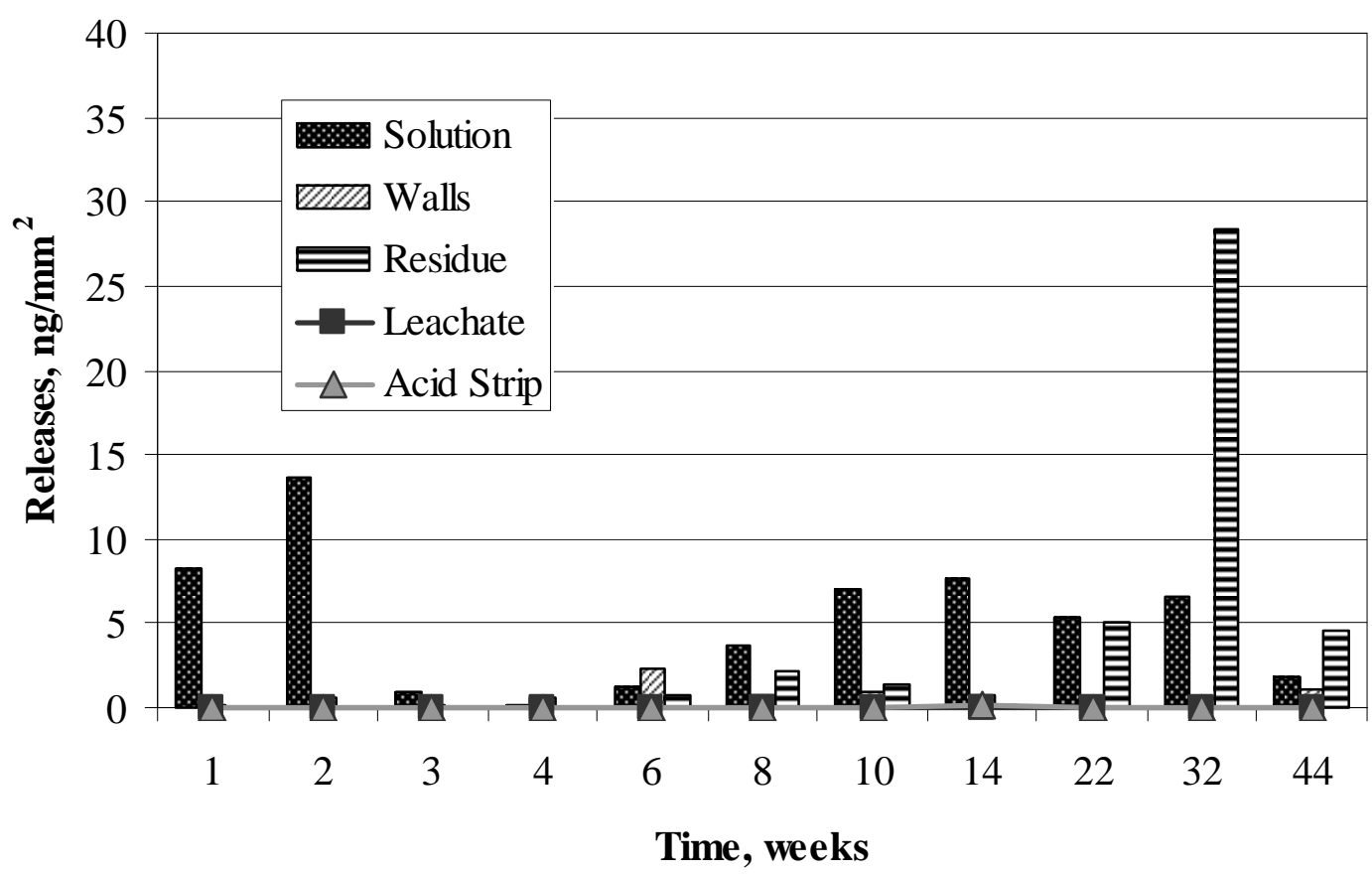

Figure E-167. Rhodium Releases in Solution, on Walls, and in Residue from Oxidized Sample 5 in AJ13 and Average Detection Limits for Leachate and Acid Strip.

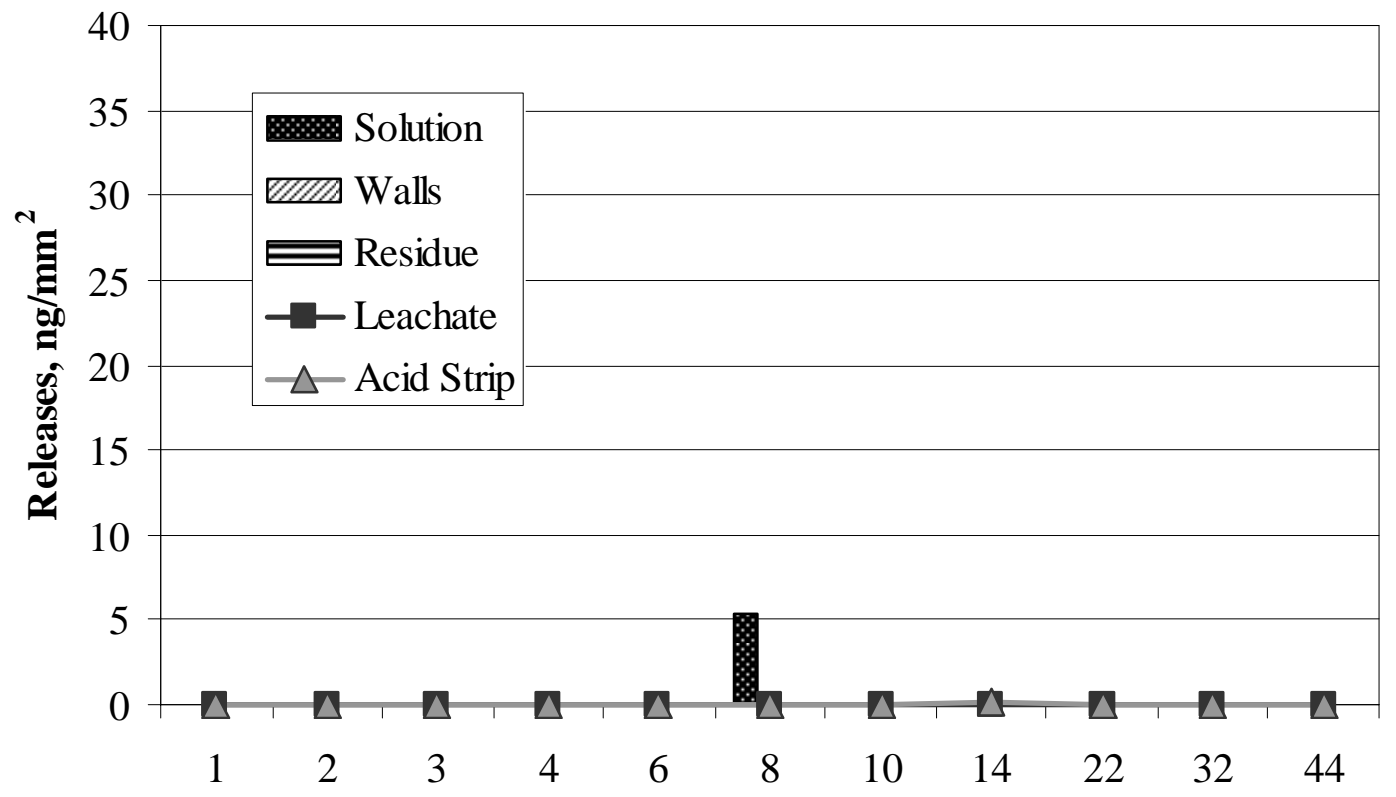

Time, weeks

Figure E-168. Rhodium Present in Solution, on Walls, and in Residue from AJ13 Control and Average Detection Limits for Leachate and Acid Strip. 


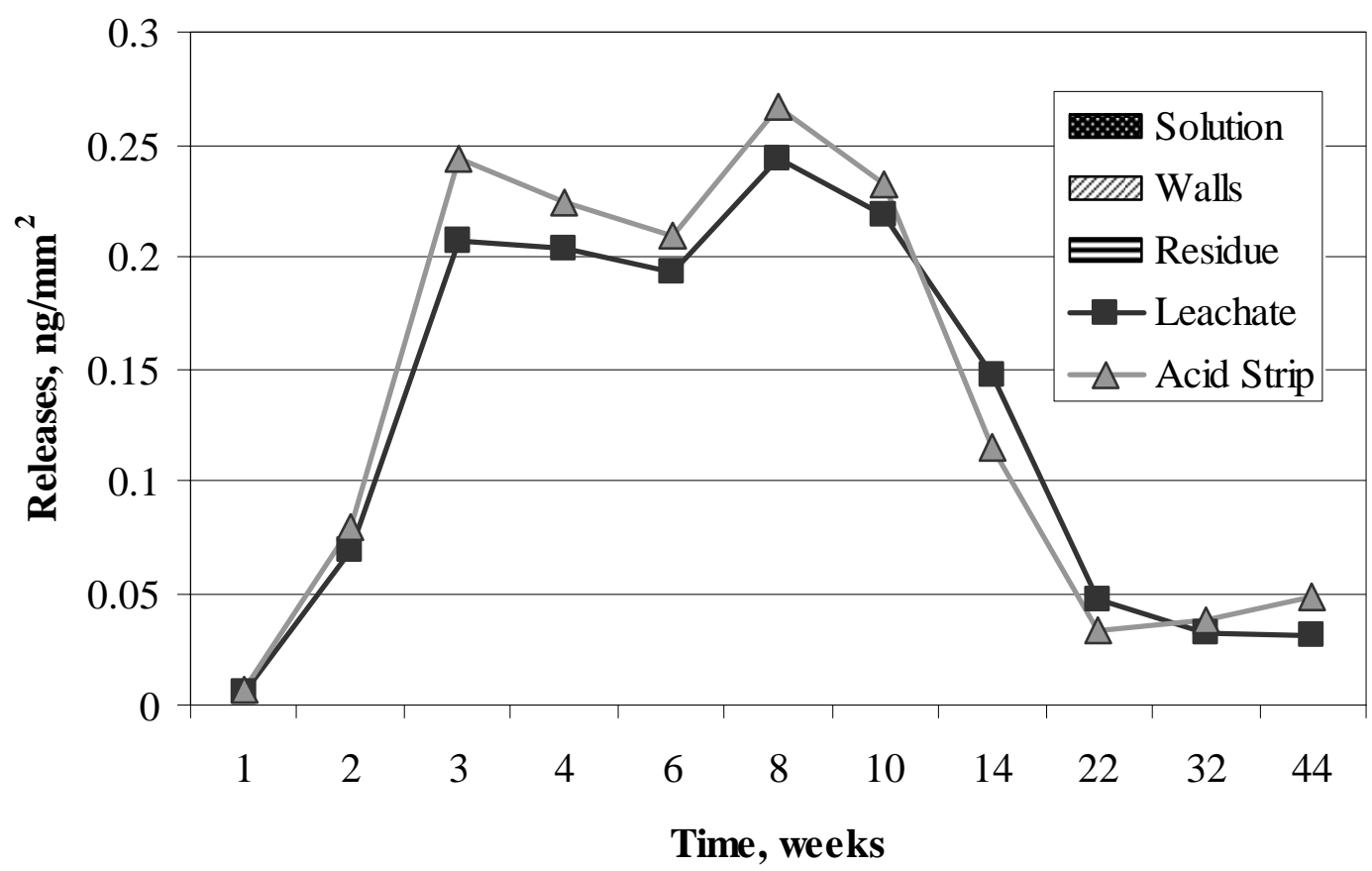

Figure E-169. Ruthenium Releases in Solution, on Walls, and in Residue from Polished Sample 1 in SJ13 and Average Detection Limits for Leachate and Acid Strip.

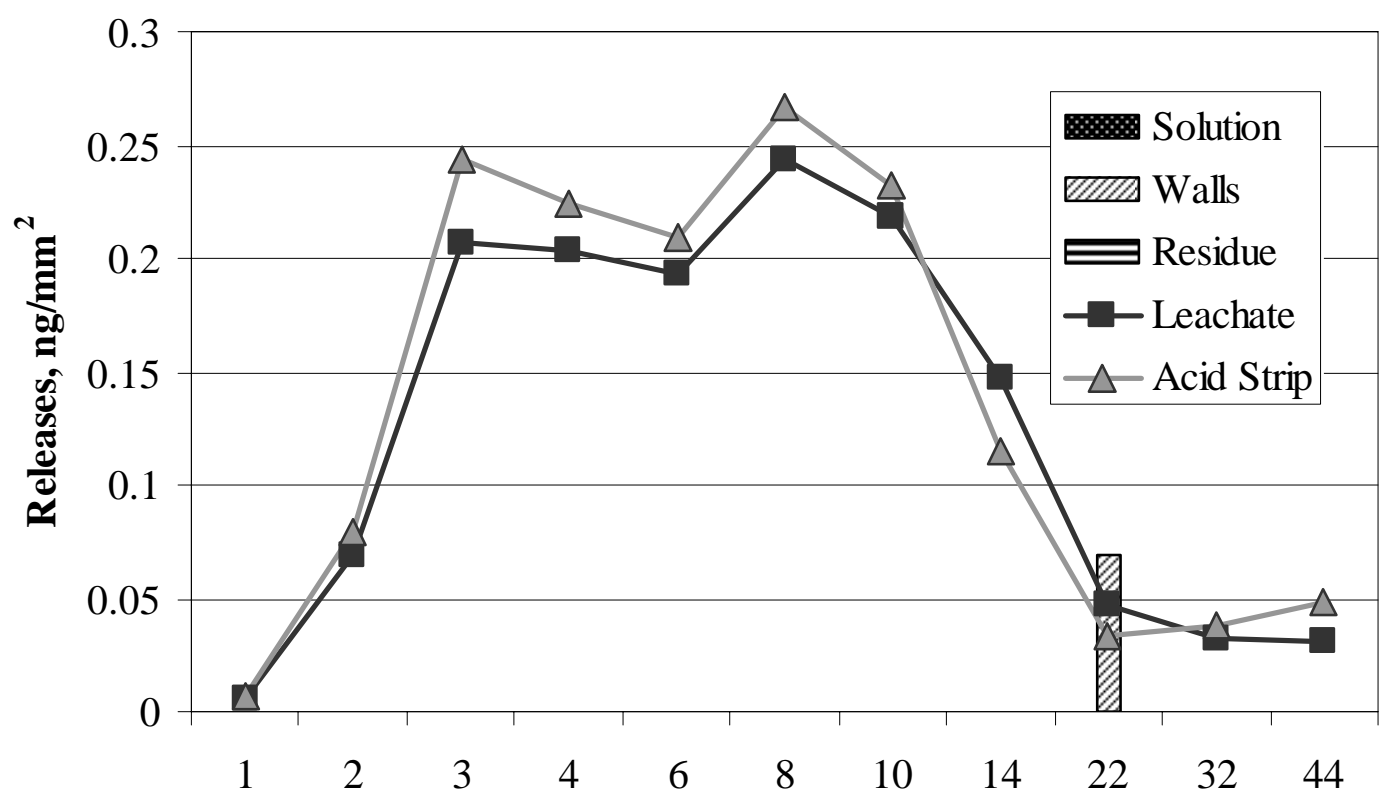

Time, weeks

Figure E-170. Ruthenium Releases in Solution, on Walls, and in Residue from Polished Sample 2 in SJ13 and Average Detection Limits for Leachate and Acid Strip. 


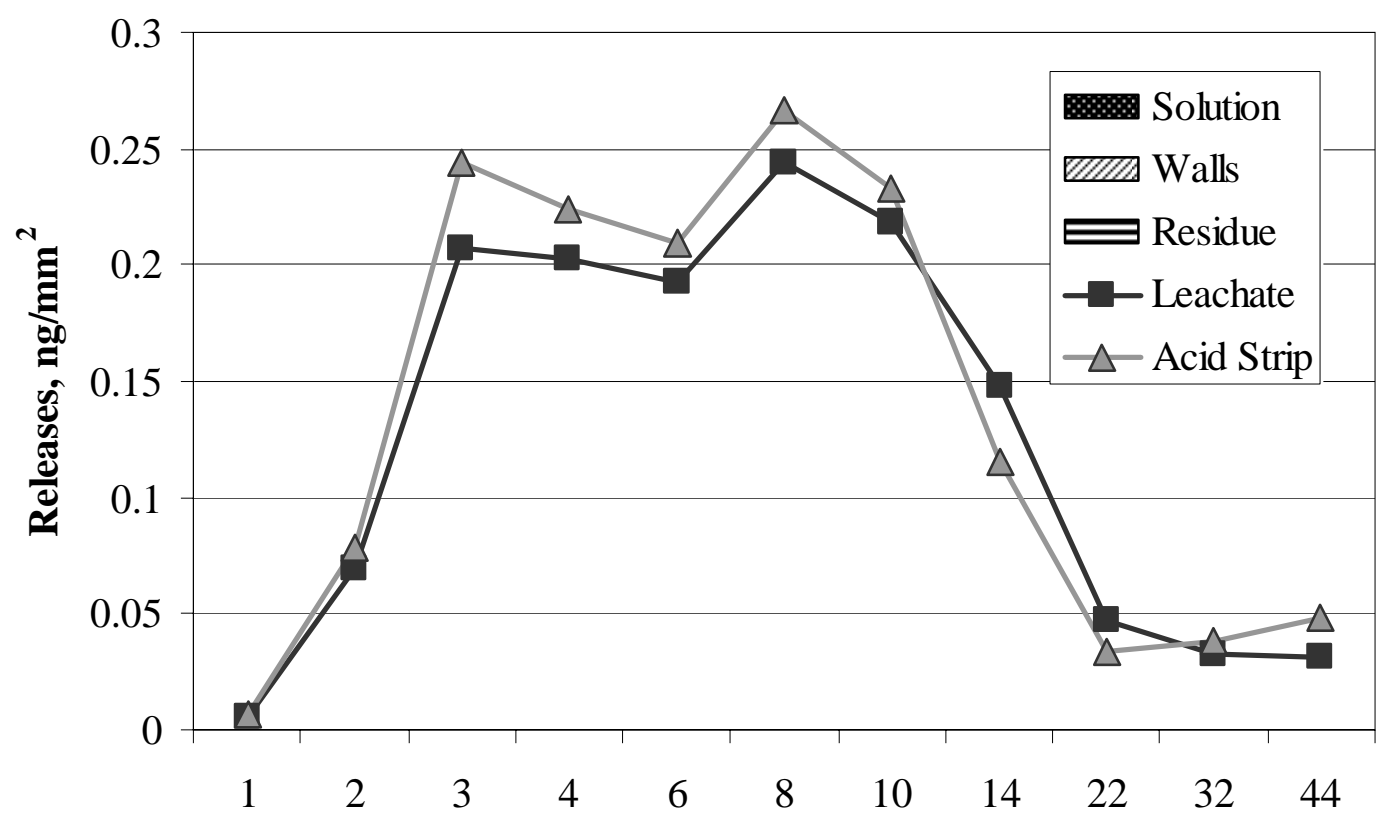

Time, weeks

Figure E-171. Ruthenium Releases in Solution, on Walls, and in Residue from Polished Sample 3 in SJ13 and Average Detection Limits for Leachate and Acid Strip.

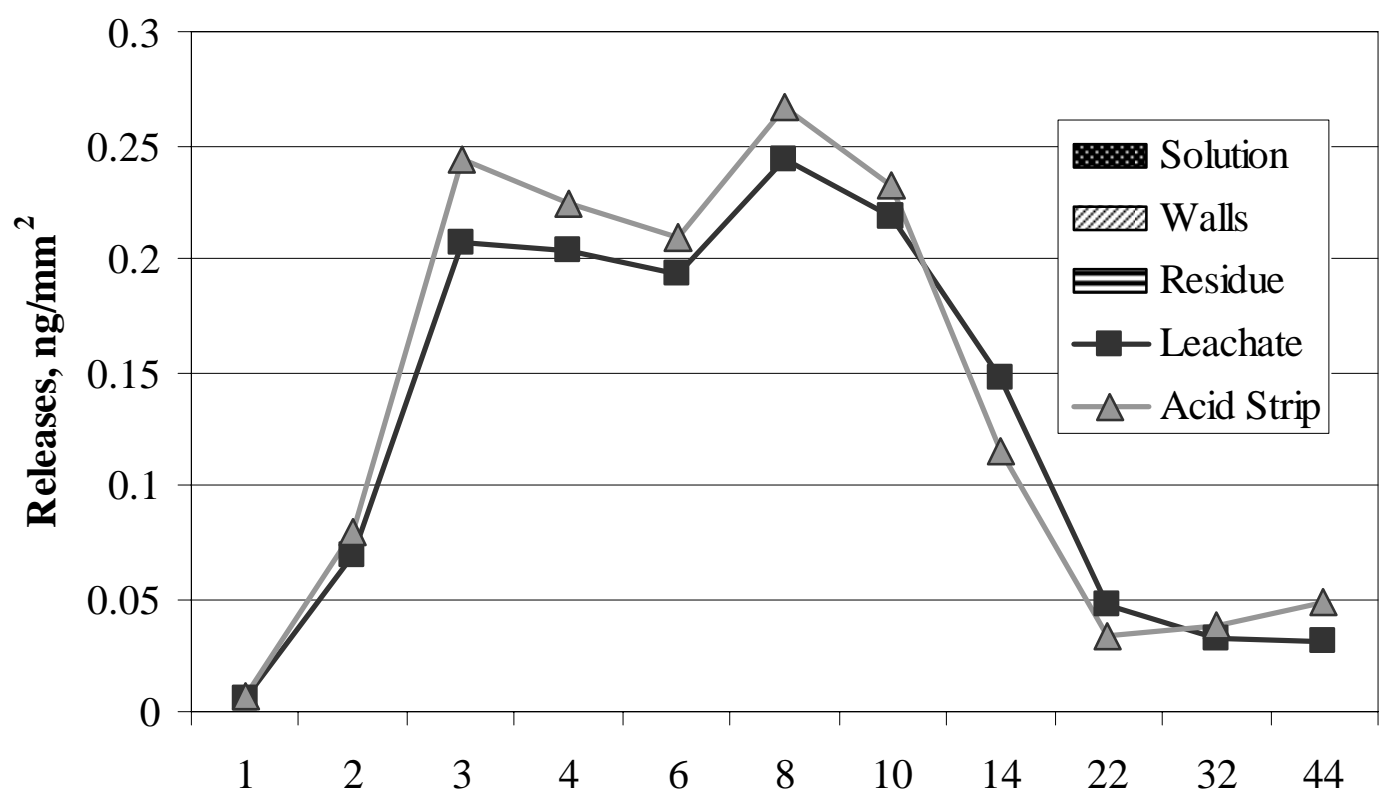

Time, weeks

Figure E-172. Ruthenium Releases in Solution, on Walls, and in Residue from Oxidized Sample 4 in SJ13 and Average Detection Limits for Leachate and Acid Strip. 


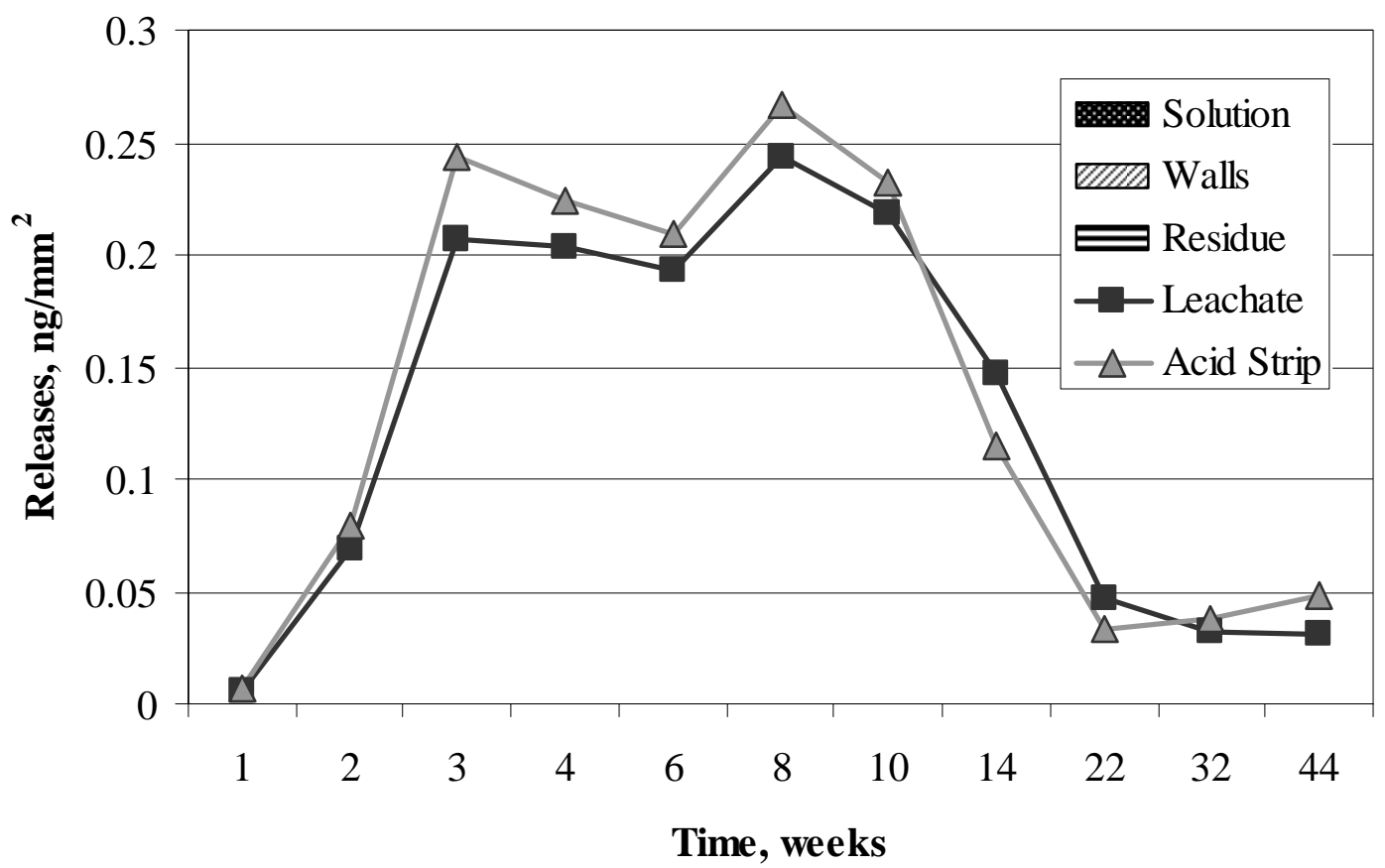

Figure E-173. Ruthenium Releases in Solution, on Walls, and in Residue from Oxidized Sample 5 in SJ13 and Average Detection Limits for Leachate and Acid Strip.

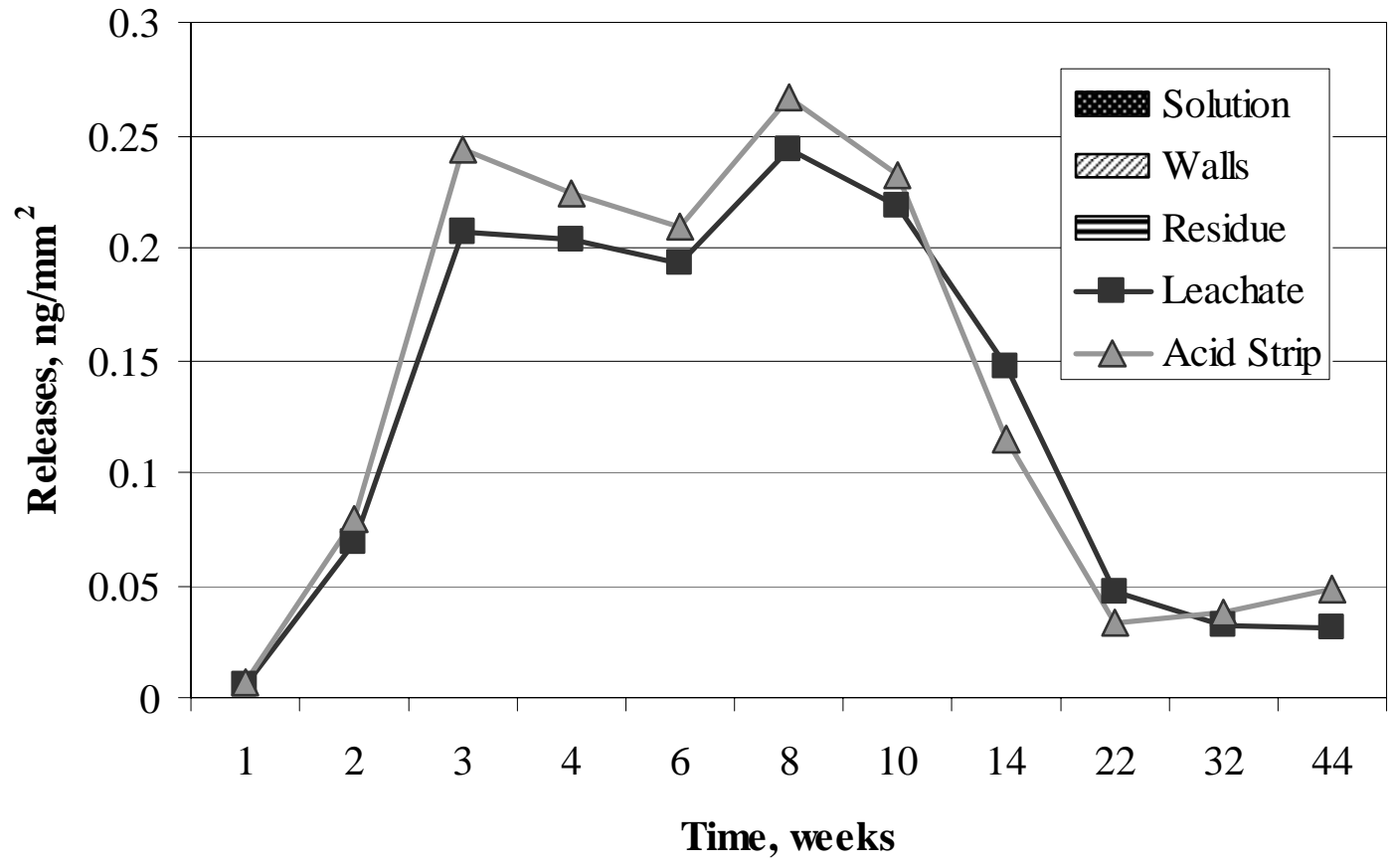

Figure E-174. Ruthenium Present in Solution, on Walls, and in Residue from SJ13 Control and Average Detection Limits for Leachate and Acid Strip. 


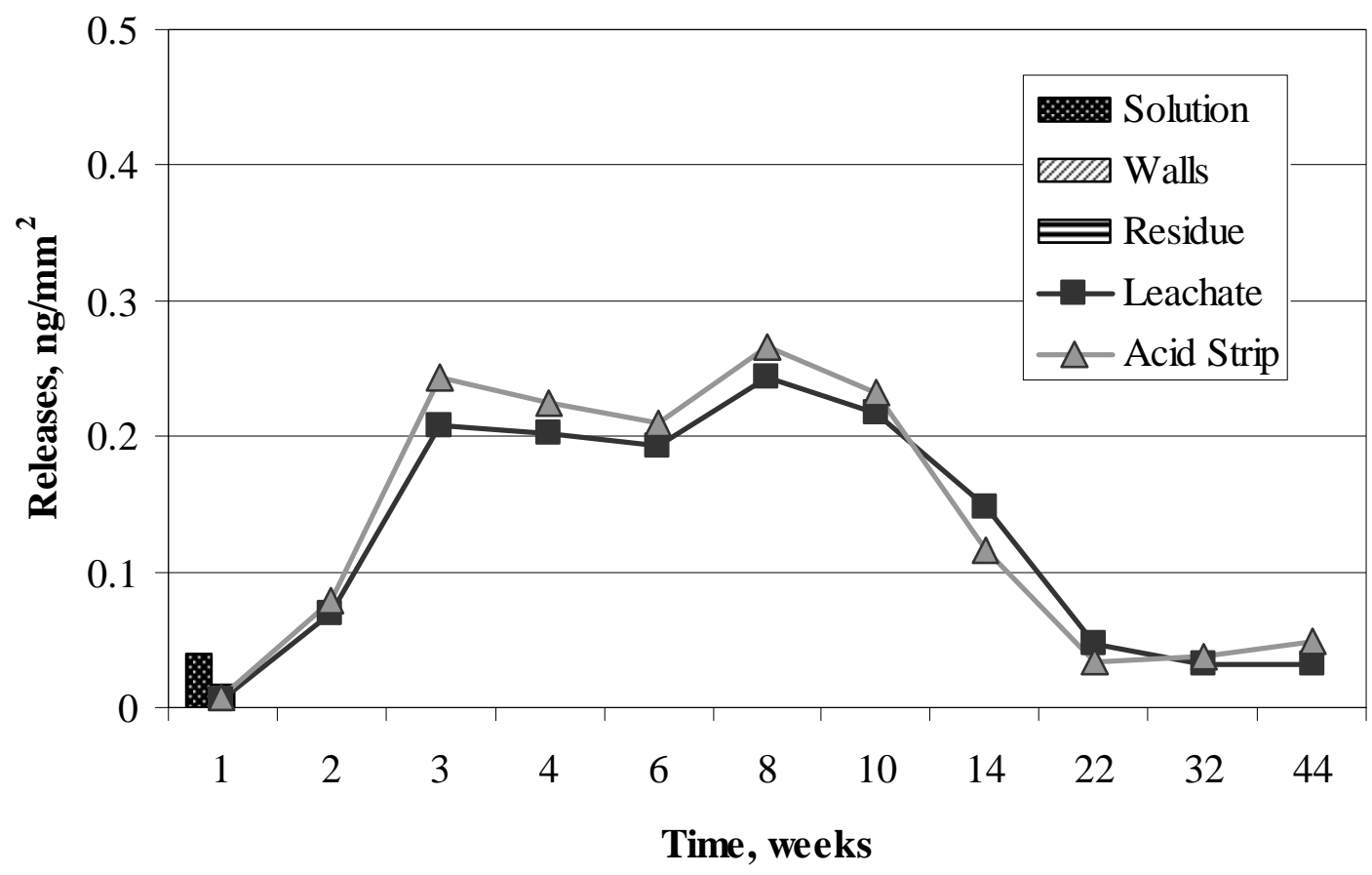

Figure E-175. Ruthenium Releases in Solution, on Walls, and in Residue from Polished Sample 1 in CJ13 and Average Detection Limits for Leachate and Acid Strip.

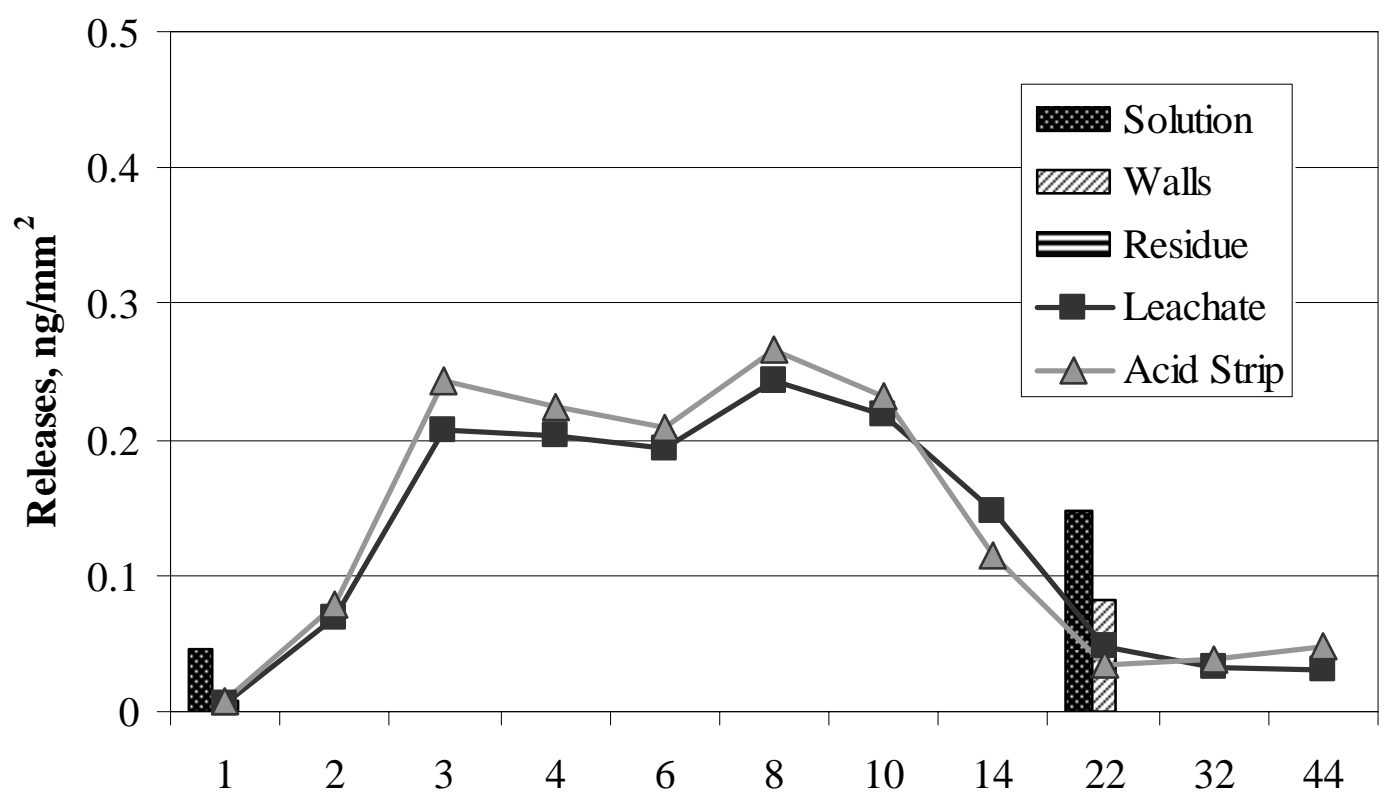

Time, weeks

Figure E-176. Ruthenium Releases in Solution, on Walls, and in Residue from Polished Sample 2 in CJ13 and Average Detection Limits for Leachate and Acid Strip. 


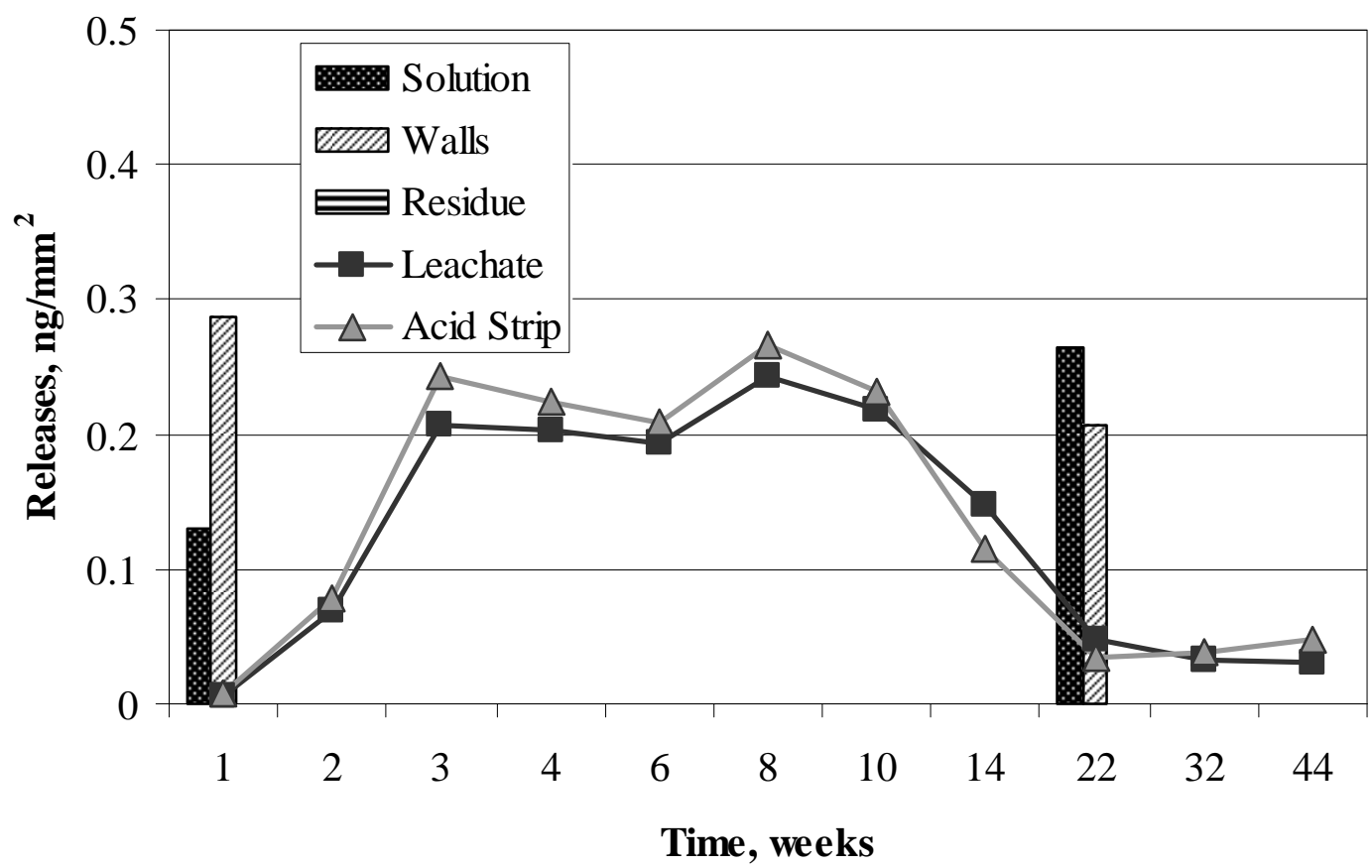

Figure E-177. Ruthenium Releases in Solution, on Walls, and in Residue from Polished Sample 3 in CJ13 and Average Detection Limits for Leachate and Acid Strip.

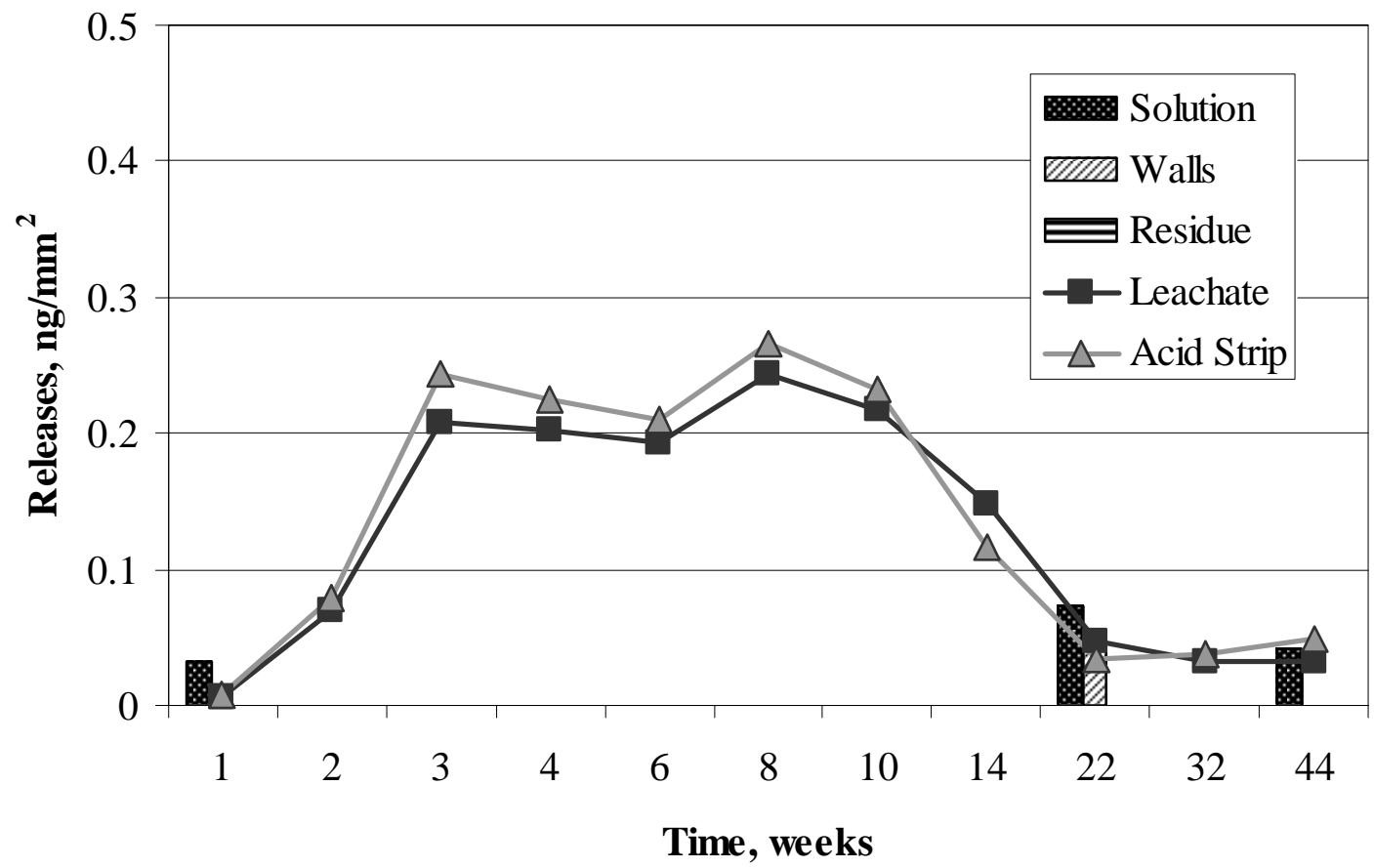

Figure E-178. Ruthenium Releases in Solution, on Walls, and in Residue from Oxidized Sample 4 in CJ13 and Average Detection Limits for Leachate and Acid Strip. 


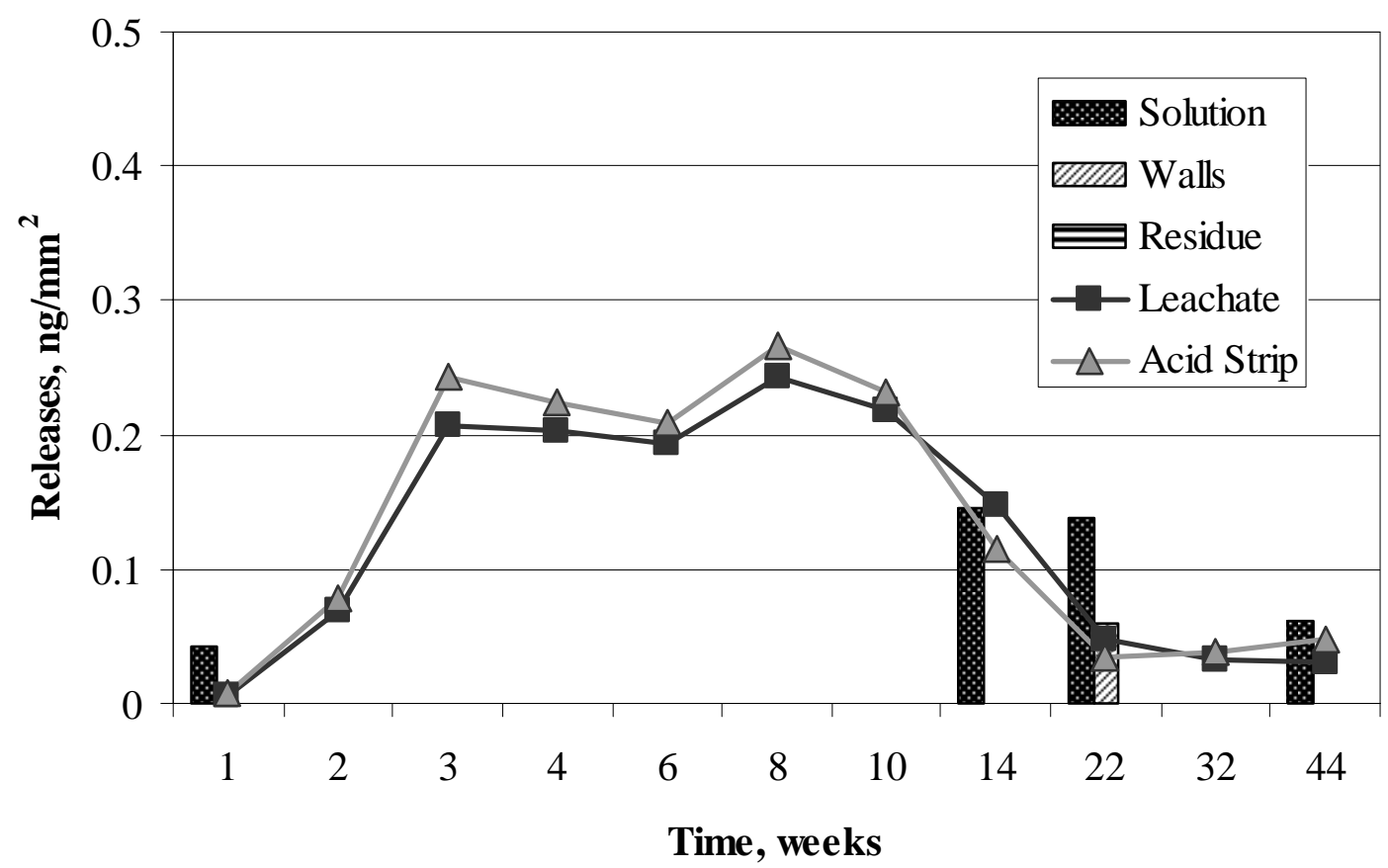

Figure E-179. Ruthenium Releases in Solution, on Walls, and in Residue from Oxidized Sample 5 in CJ13 and Average Detection Limits for Leachate and Acid Strip.

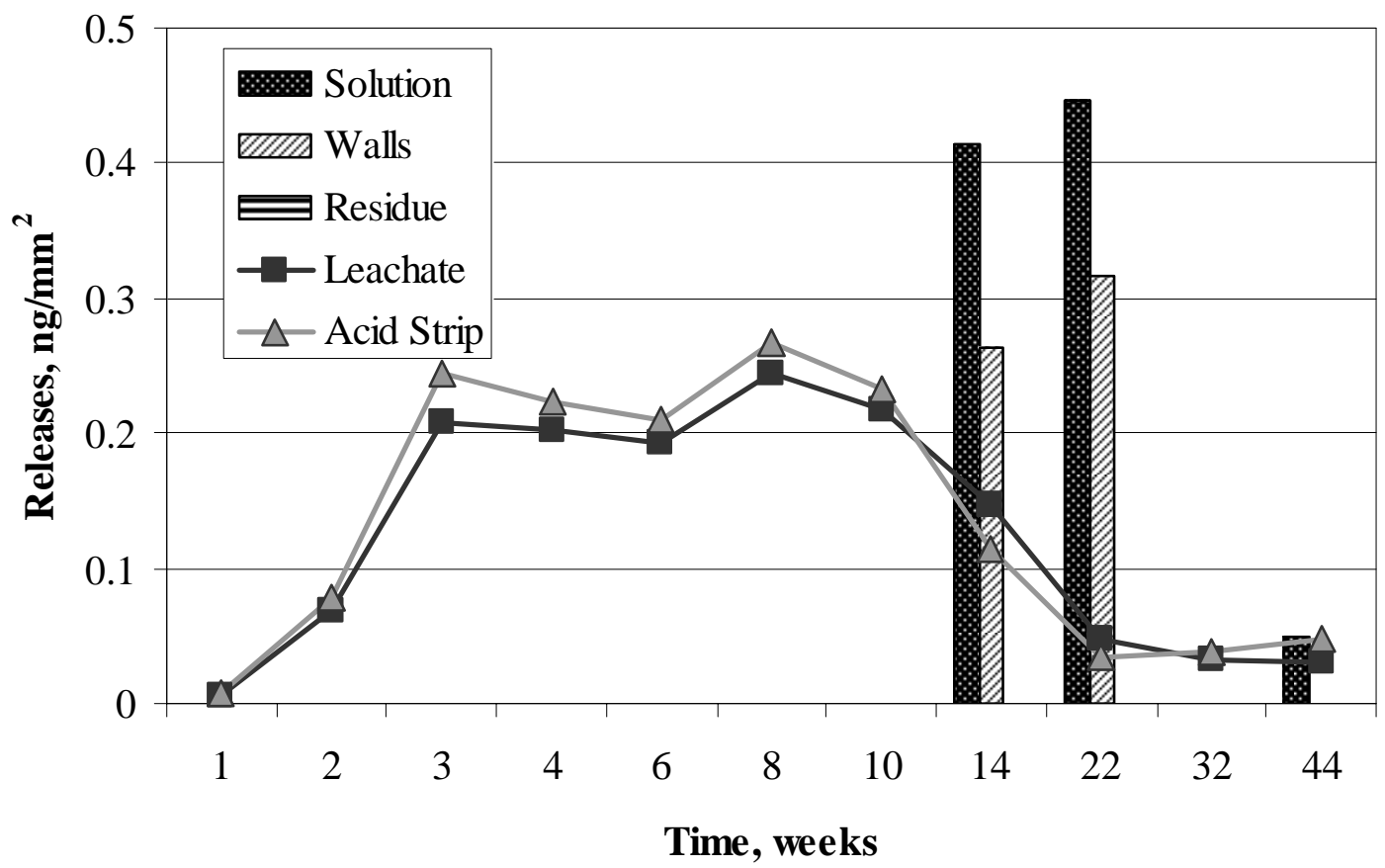

Figure E-180. Ruthenium Present in Solution, on Walls, and in Residue from CJ13 Control and Average Detection Limits for Leachate and Acid Strip. 


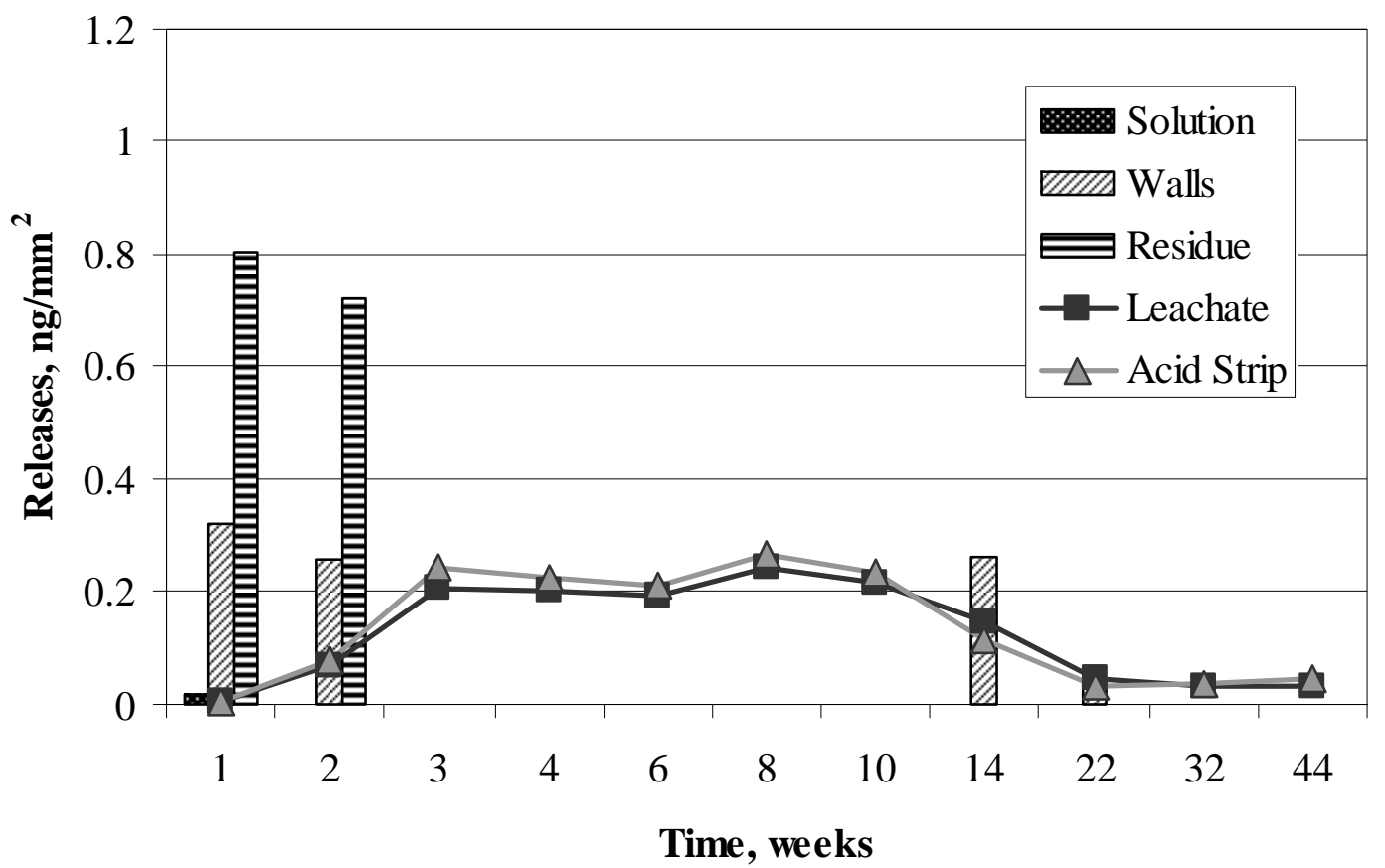

Figure E-181. Ruthenium Releases in Solution, on Walls, and in Residue from Polished Sample 1 in $10 \mathrm{KCl}$ and Average Detection Limits for Leachate and Acid Strip.

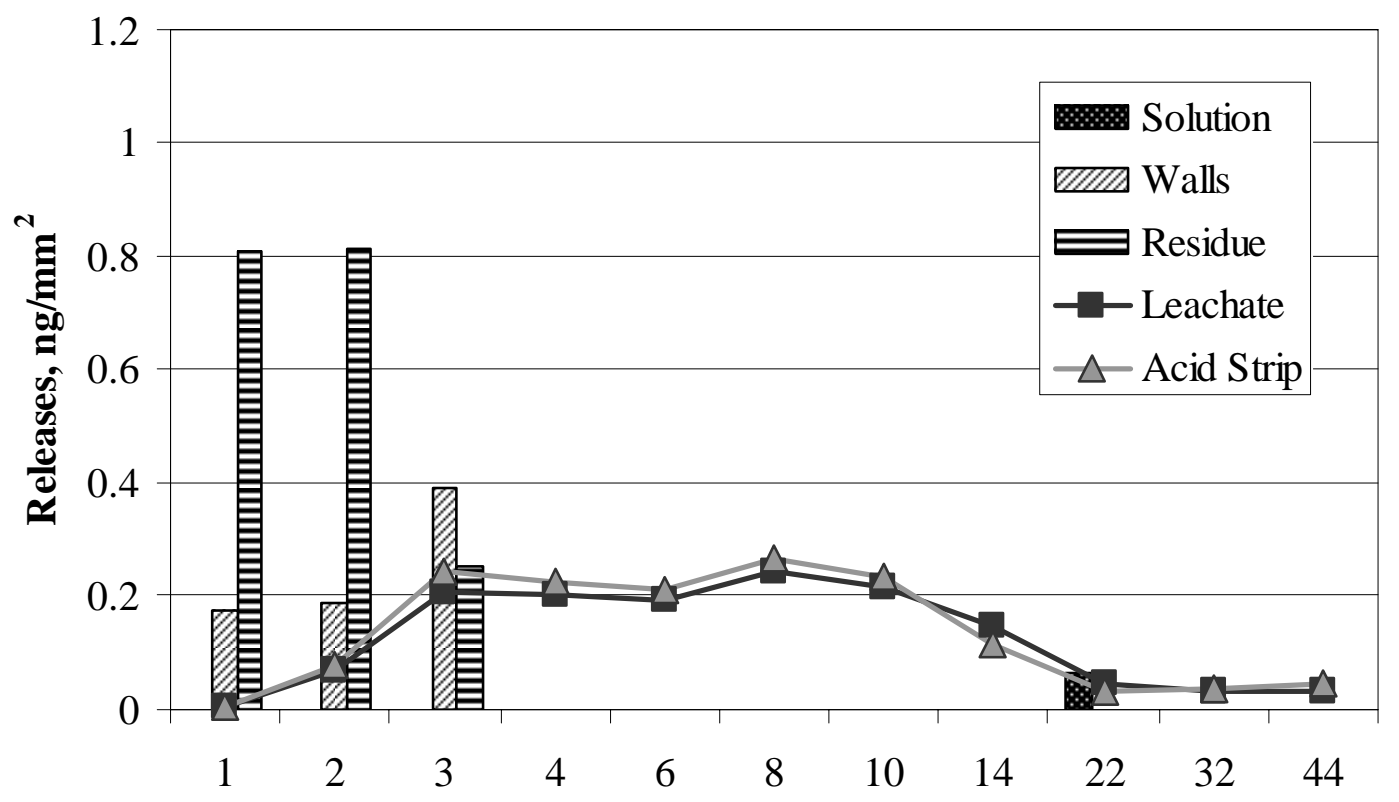

Time, weeks

Figure E-182. Ruthenium Releases in Solution, on Walls, and in Residue from Polished Sample 2 in $10 \mathrm{KCl}$ and Average Detection Limits for Leachate and Acid Strip. 


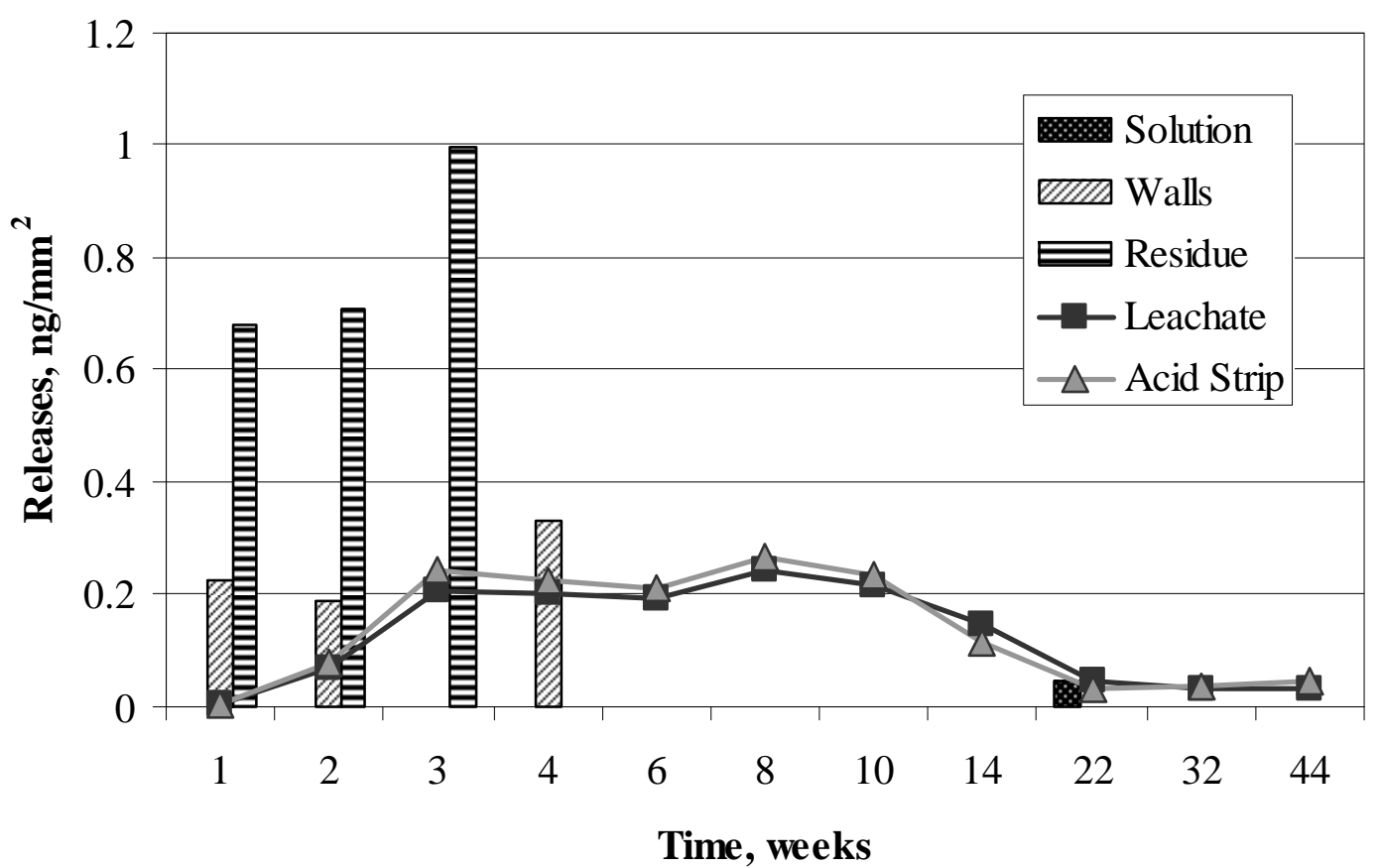

Figure E-183. Ruthenium Releases in Solution, on Walls, and in Residue from Polished Sample 3 in $10 \mathrm{KCl}$ and Average Detection Limits for Leachate and Acid Strip.

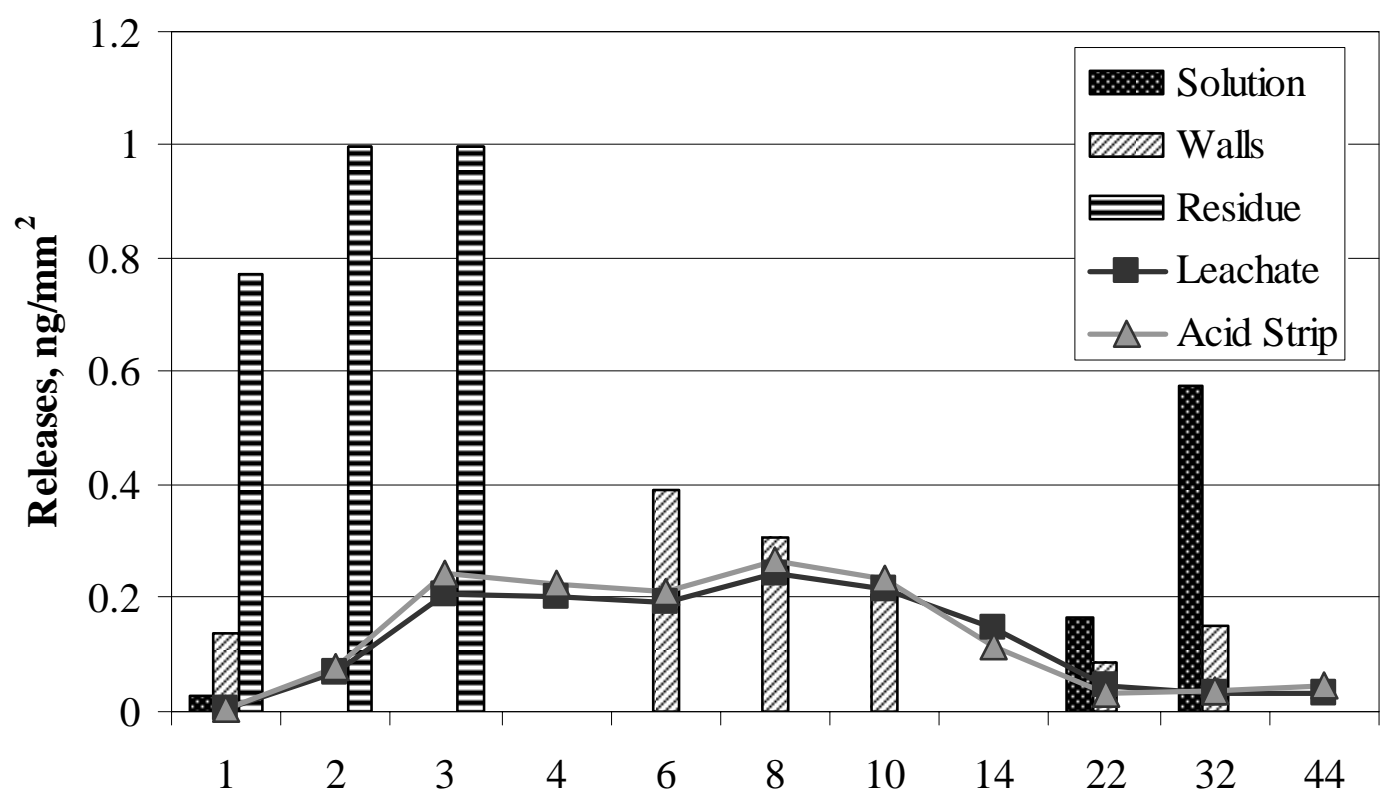

Time, weeks

Figure E-184. Ruthenium Releases in Solution, on Walls, and in Residue from Oxidized Sample 4 in $10 \mathrm{KCl}$ and Average Detection Limits for Leachate and Acid Strip. 


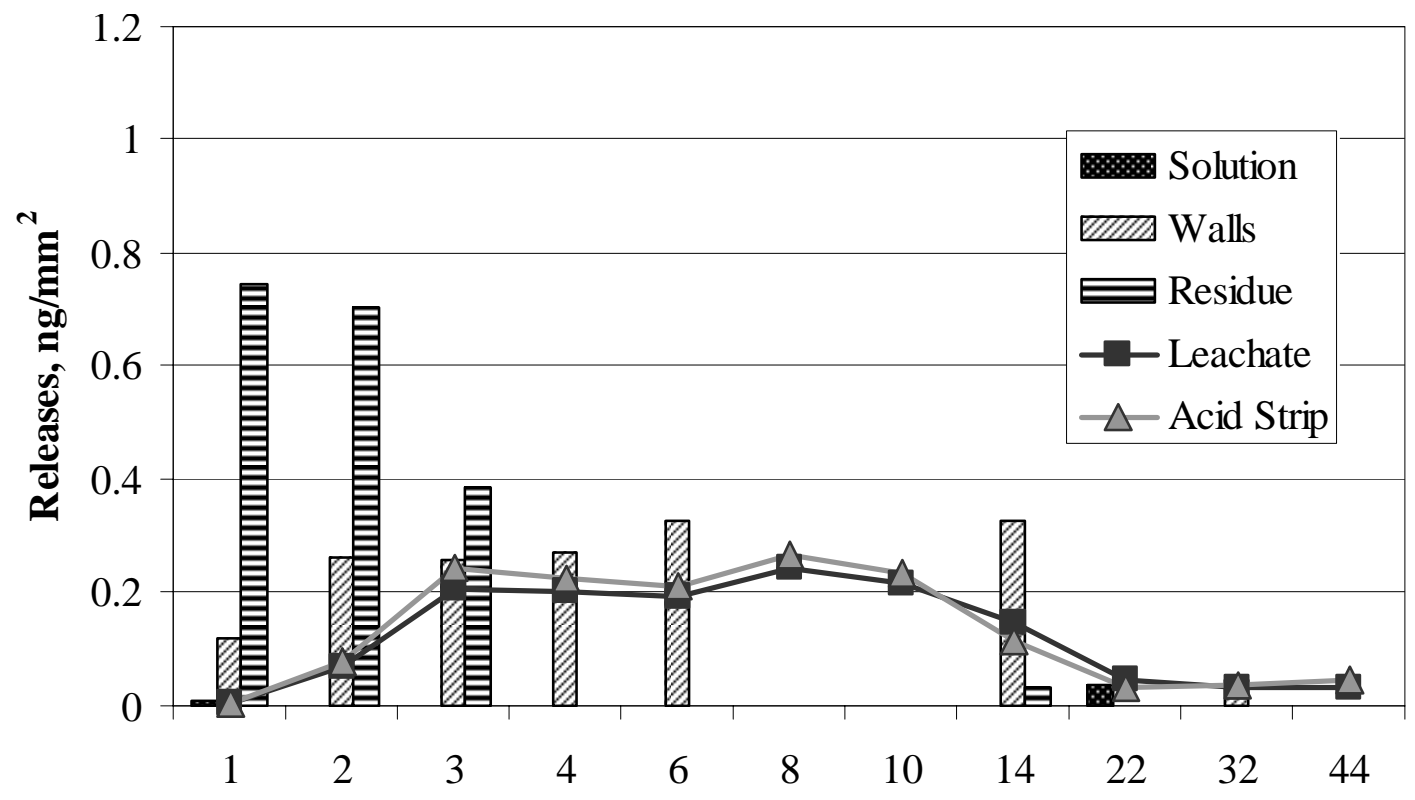

Time, weeks

Figure E-185. Ruthenium Releases in Solution, on Walls, and in Residue from Oxidized Sample 5 in $10 \mathrm{KCl}$ and Average Detection Limits for Leachate and Acid Strip.

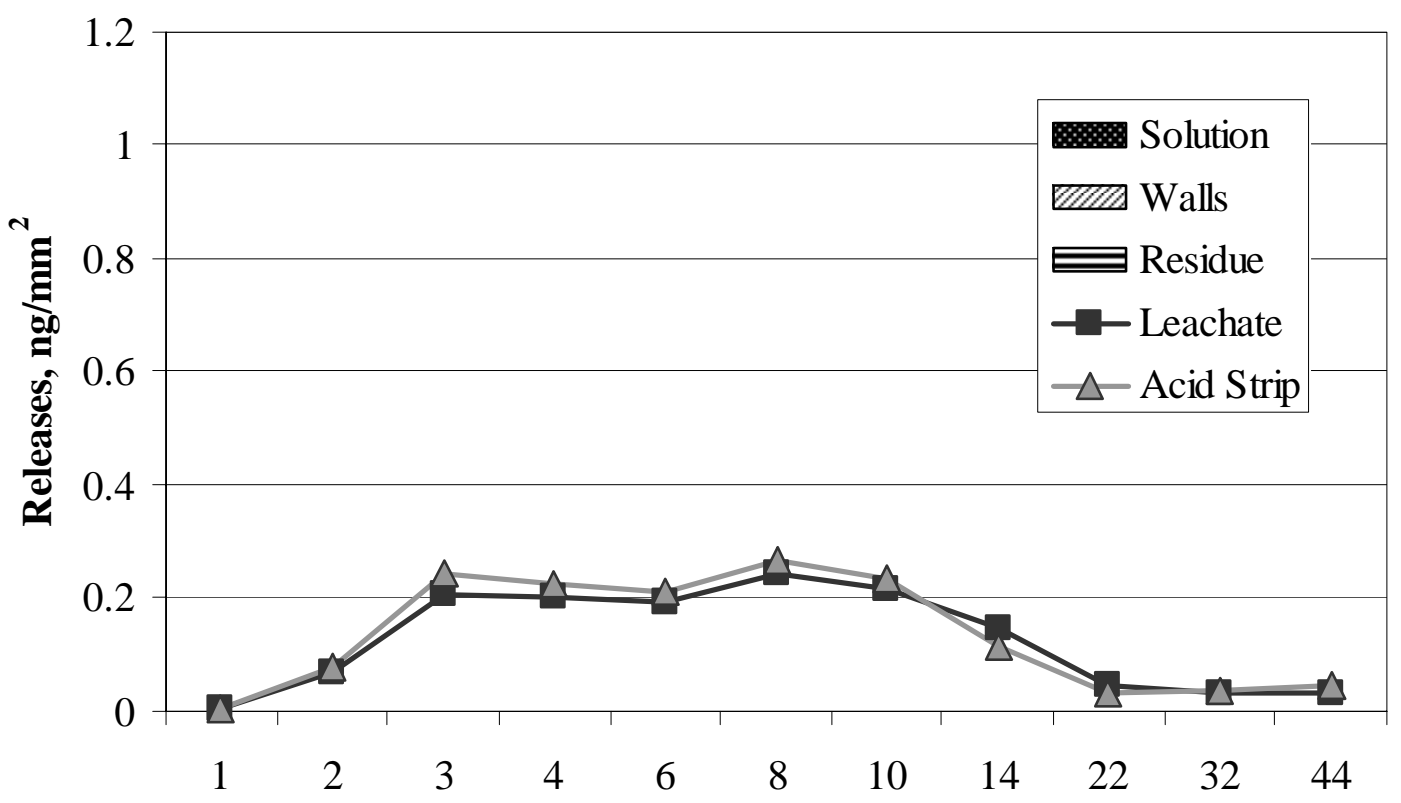

Time, weeks

Figure E-186. Ruthenium Present in Solution, on Walls, and in Residue from $10 \mathrm{KCl}$ Control and Average Detection Limits for Leachate and Acid Strip. 


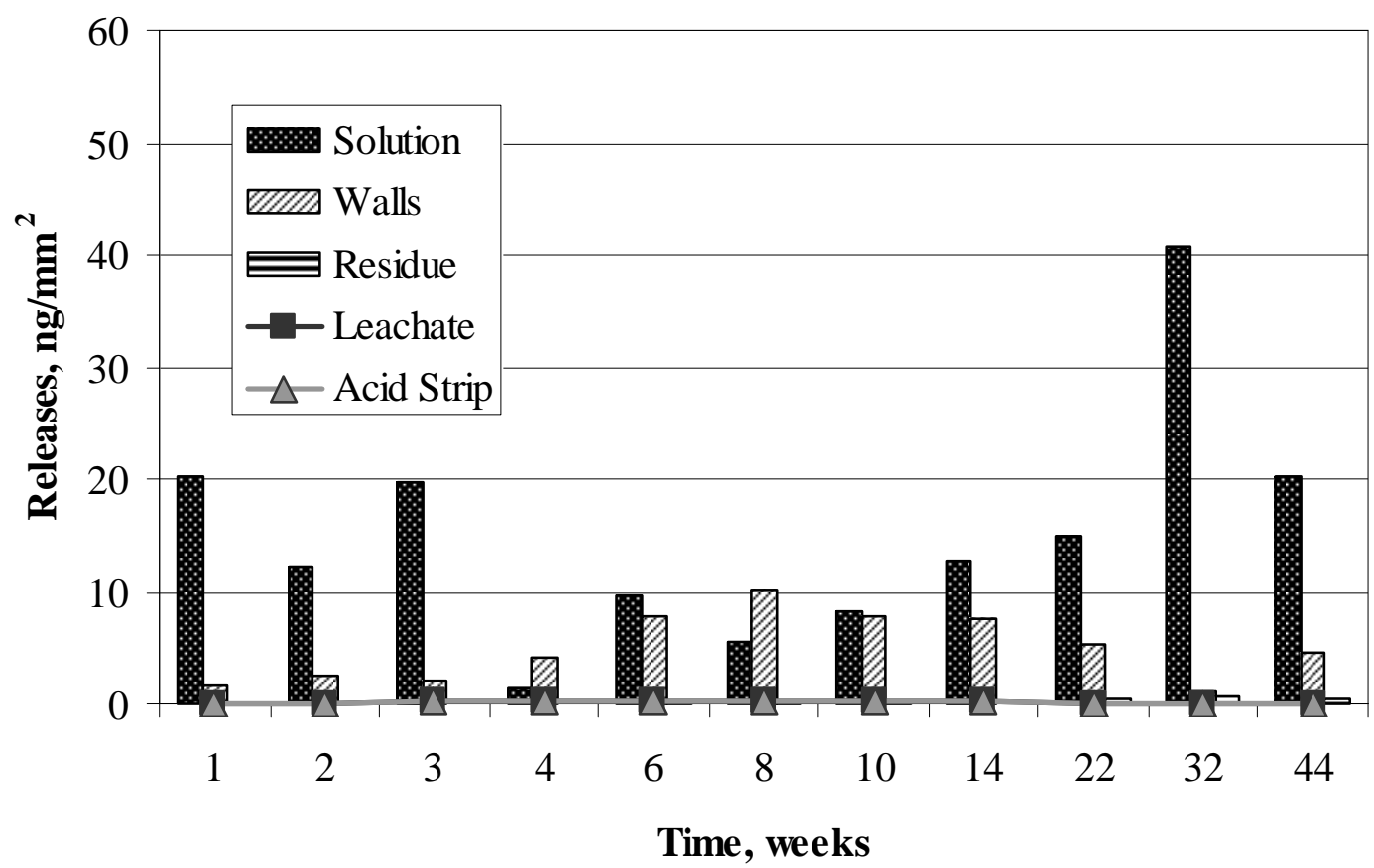

Figure E-187. Ruthenium Releases in Solution, on Walls, and in Residue from Polished Sample 1 in AJ13 and Average Detection Limits for Leachate and Acid Strip.

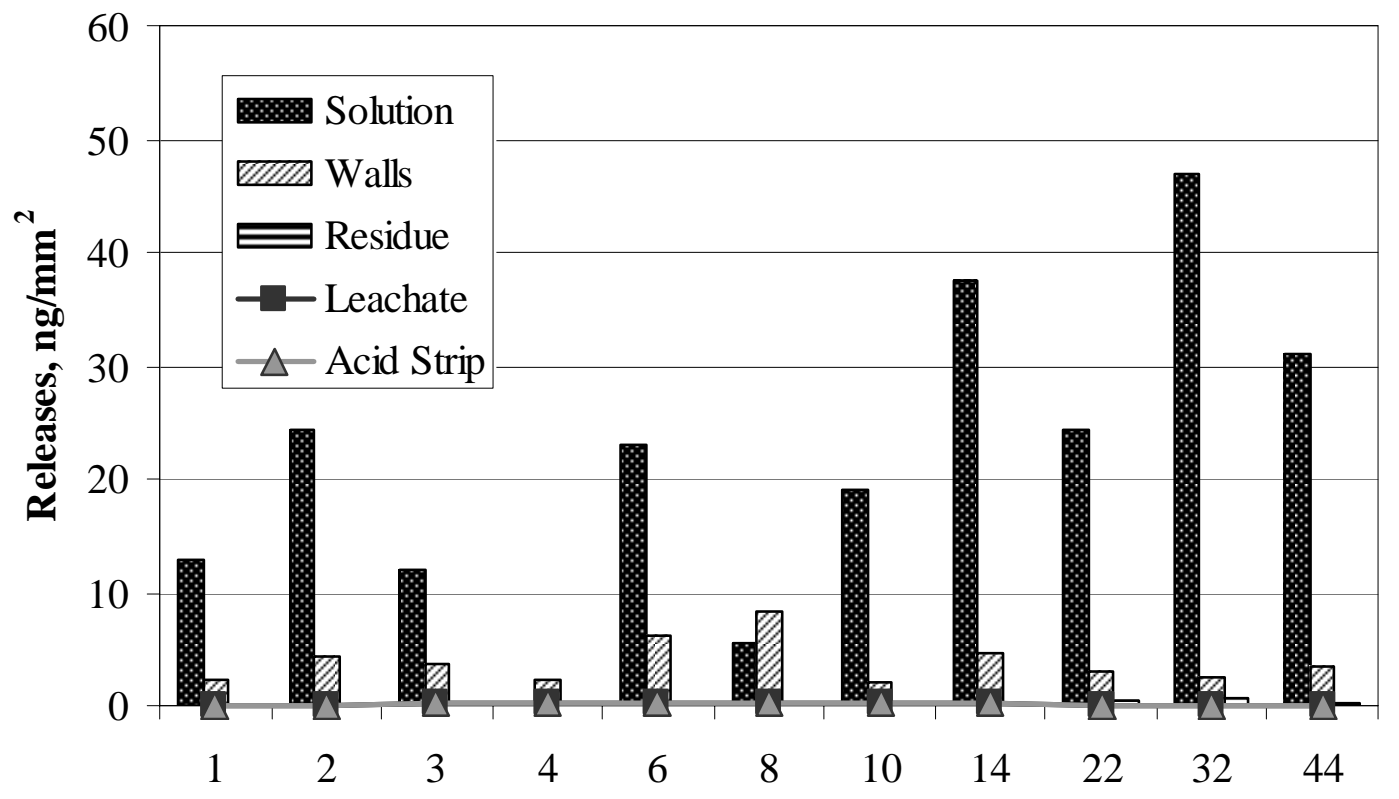

Time, weeks

Figure E-188. Ruthenium Releases in Solution, on Walls, and in Residue from Polished Sample 2 in AJ13 and Average Detection Limits for Leachate and Acid Strip. 


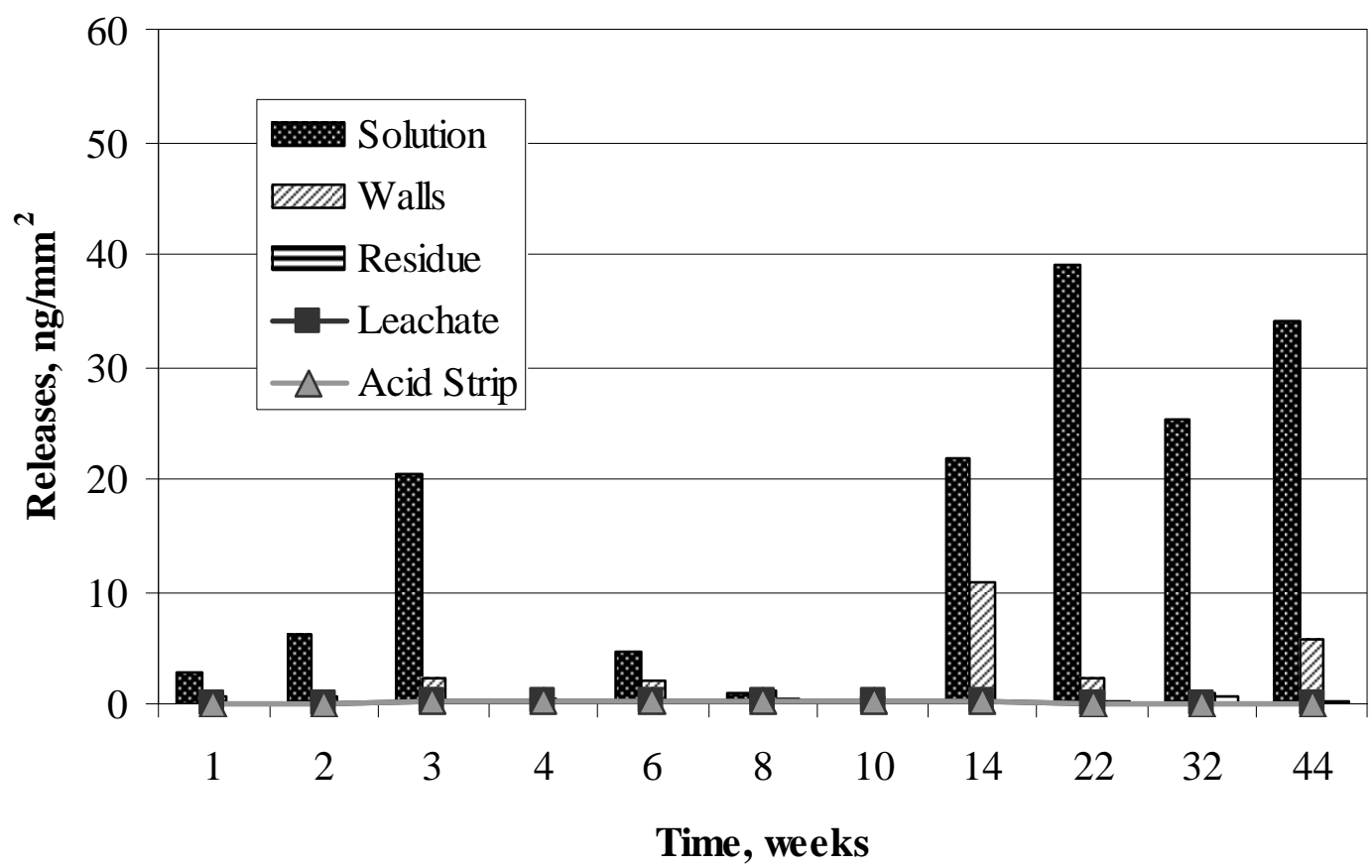

Figure E-189. Ruthenium Releases in Solution, on Walls, and in Residue from Polished Sample 3 in AJ13 and Average Detection Limits for Leachate and Acid Strip.

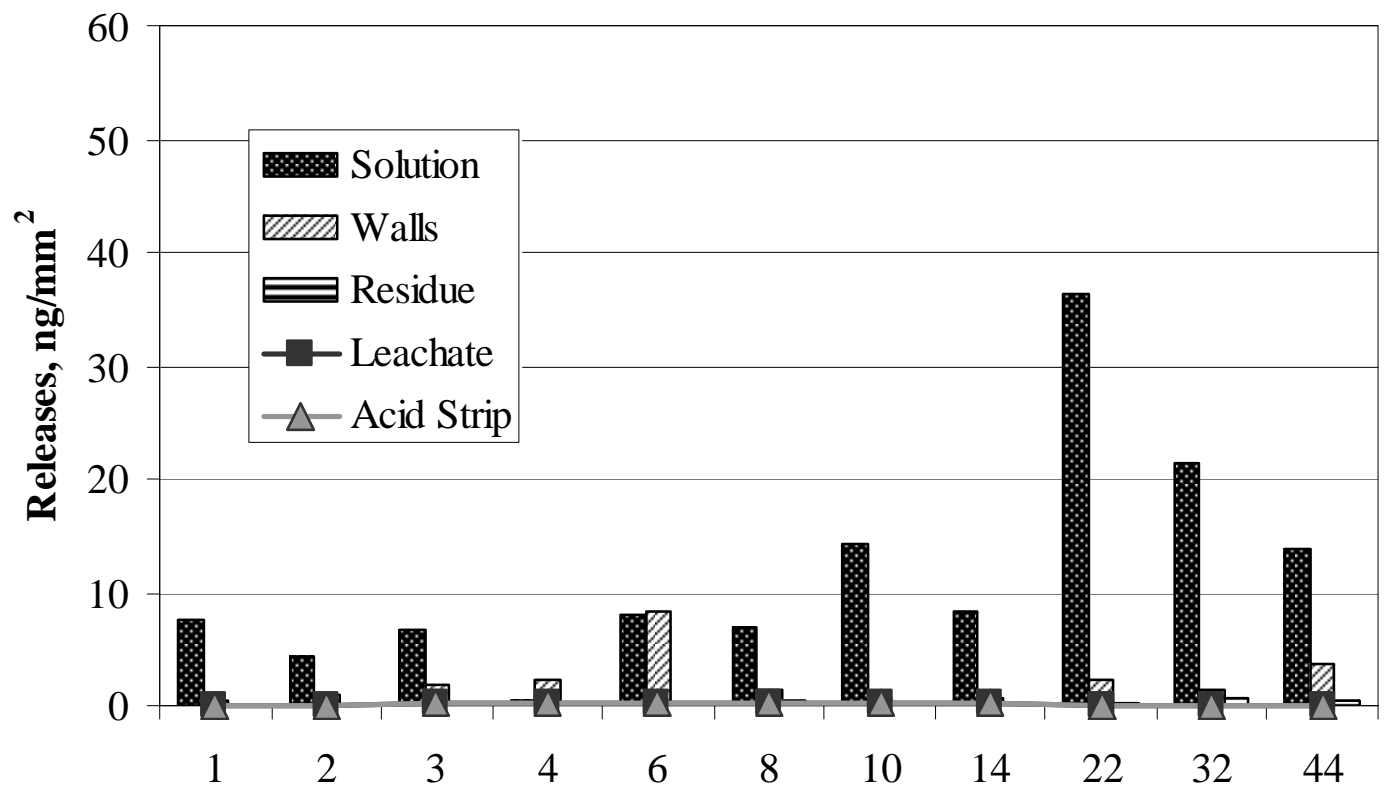

Time, weeks

Figure E-190. Ruthenium Releases in Solution, on Walls, and in Residue from Oxidized Sample 4 in AJ13 and Average Detection Limits for Leachate and Acid Strip. 


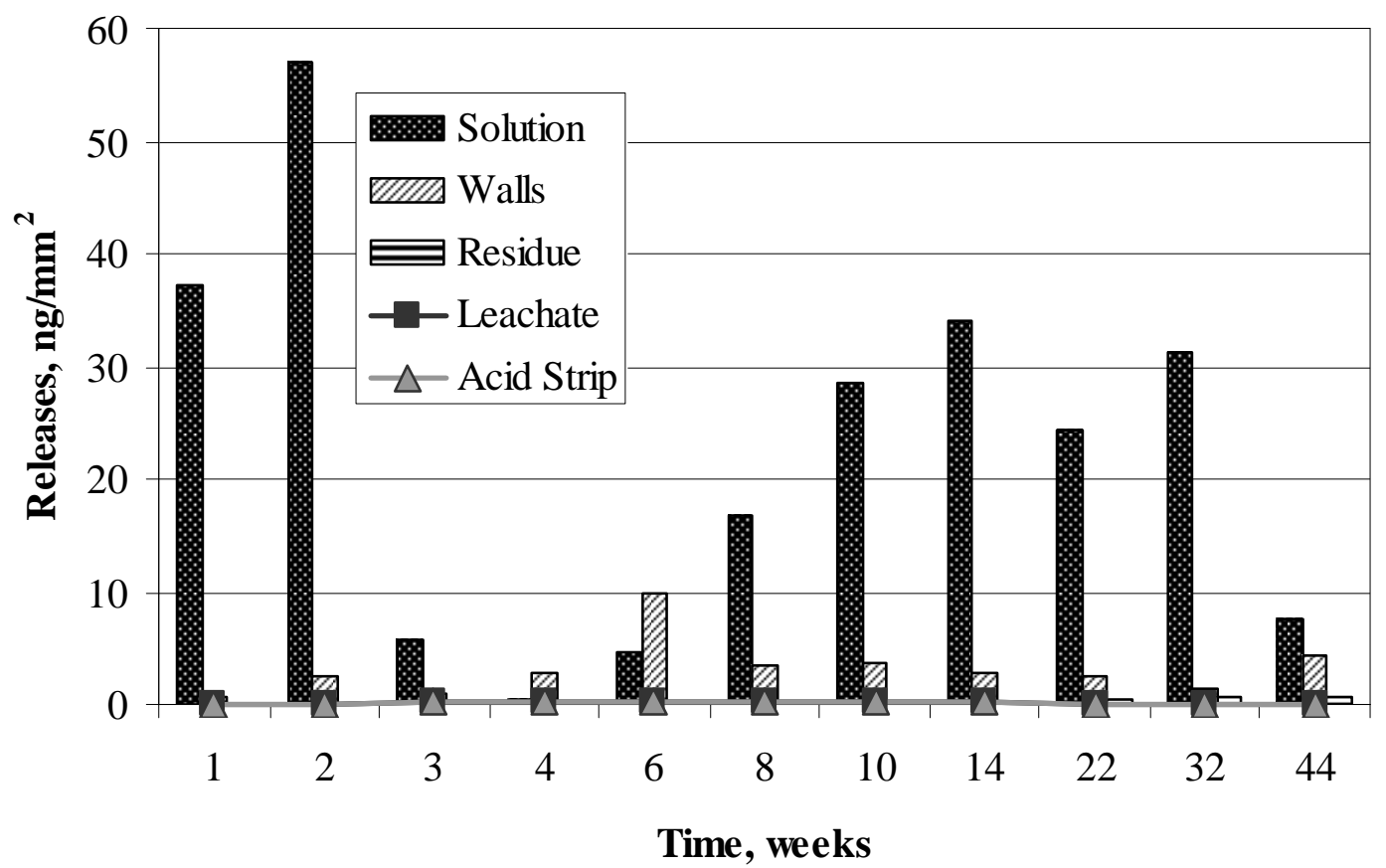

Figure E-191. Ruthenium Releases in Solution, on Walls, and in Residue from Oxidized Sample 5 in AJ13 and Average Detection Limits for Leachate and Acid Strip.

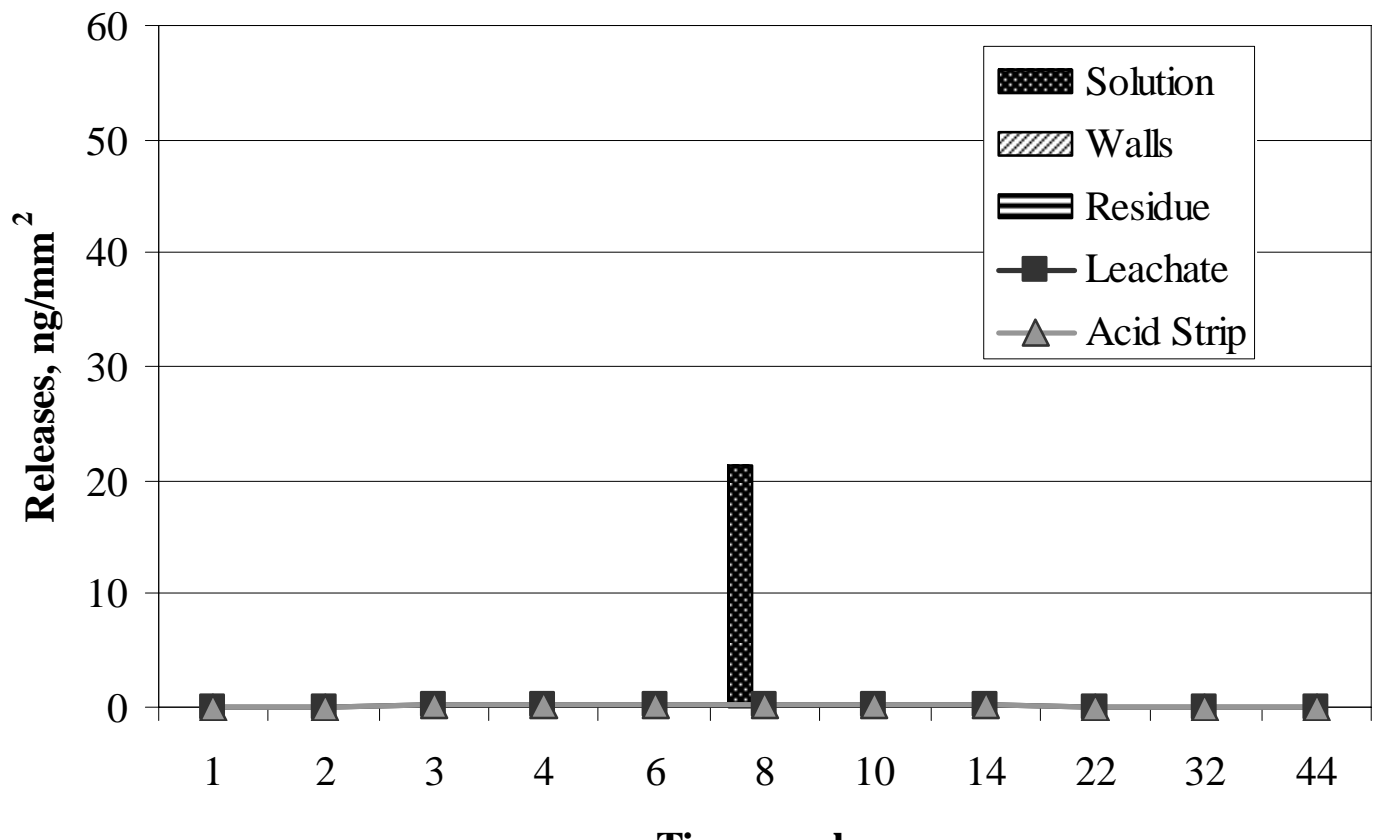

Time, weeks

Figure E-192. Ruthenium Present in Solution, on Walls, and in Residue from AJ13 Control and Average Detection Limits for Leachate and Acid Strip. 


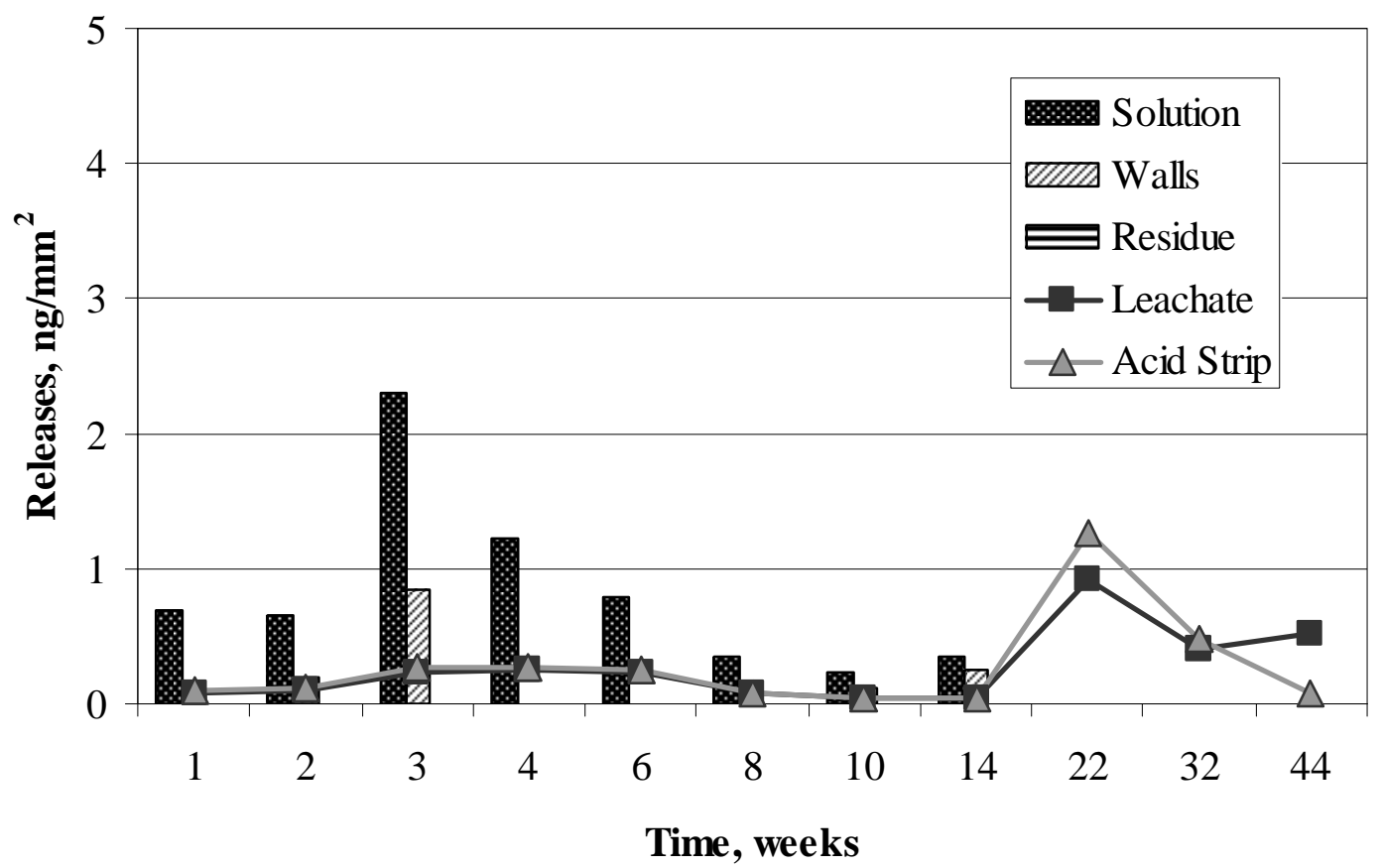

Figure E-193. Molybdenum Releases in Solution, on Walls, and in Residue from Polished Sample 1 in SJ13 and Average Detection Limits for Leachate and Acid Strip.

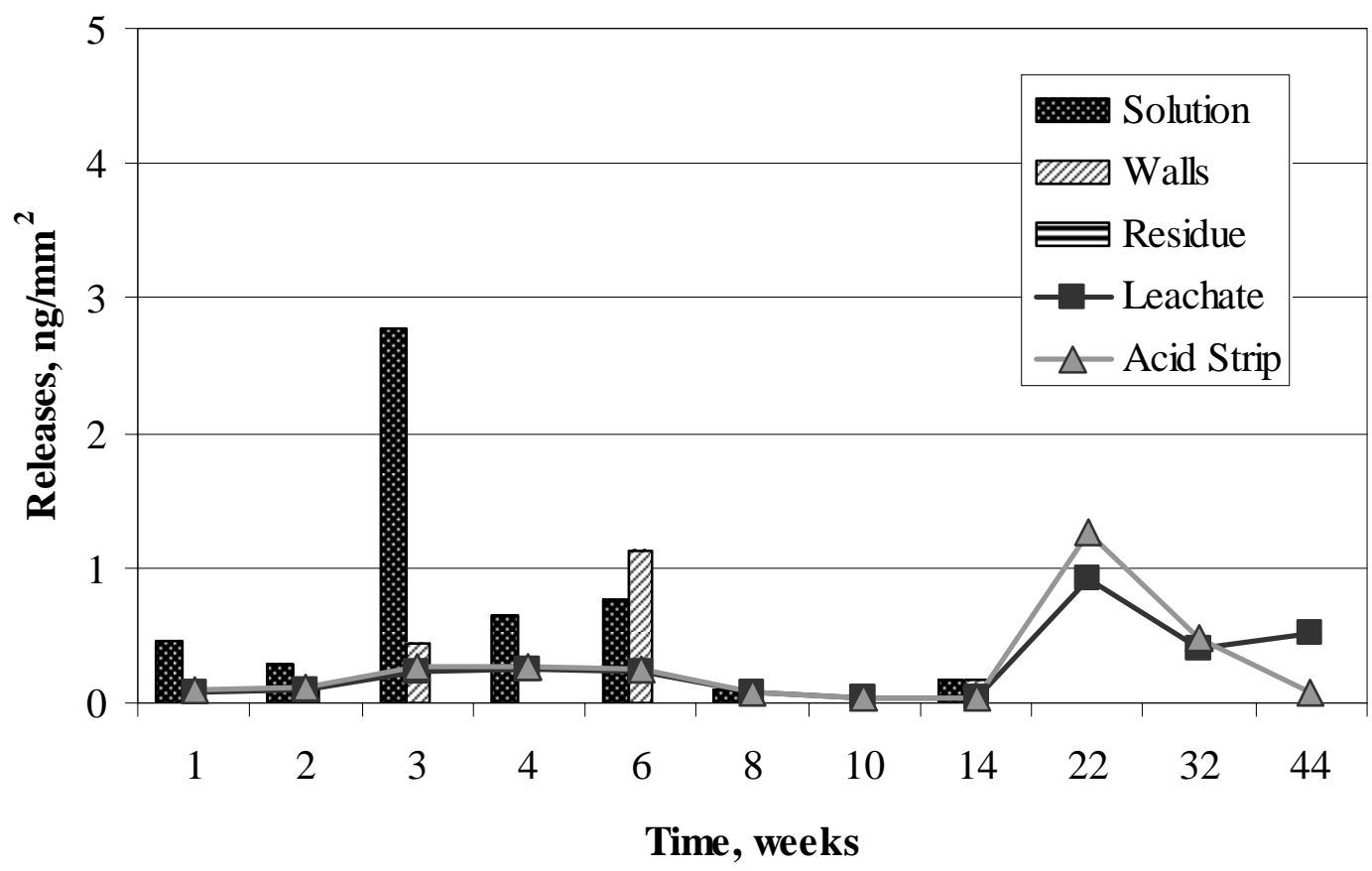

Figure E-194. Molybdenum Releases in Solution, on Walls, and in Residue from Polished Sample 2 in SJ13 and Average Detection Limits for Leachate and Acid Strip. 


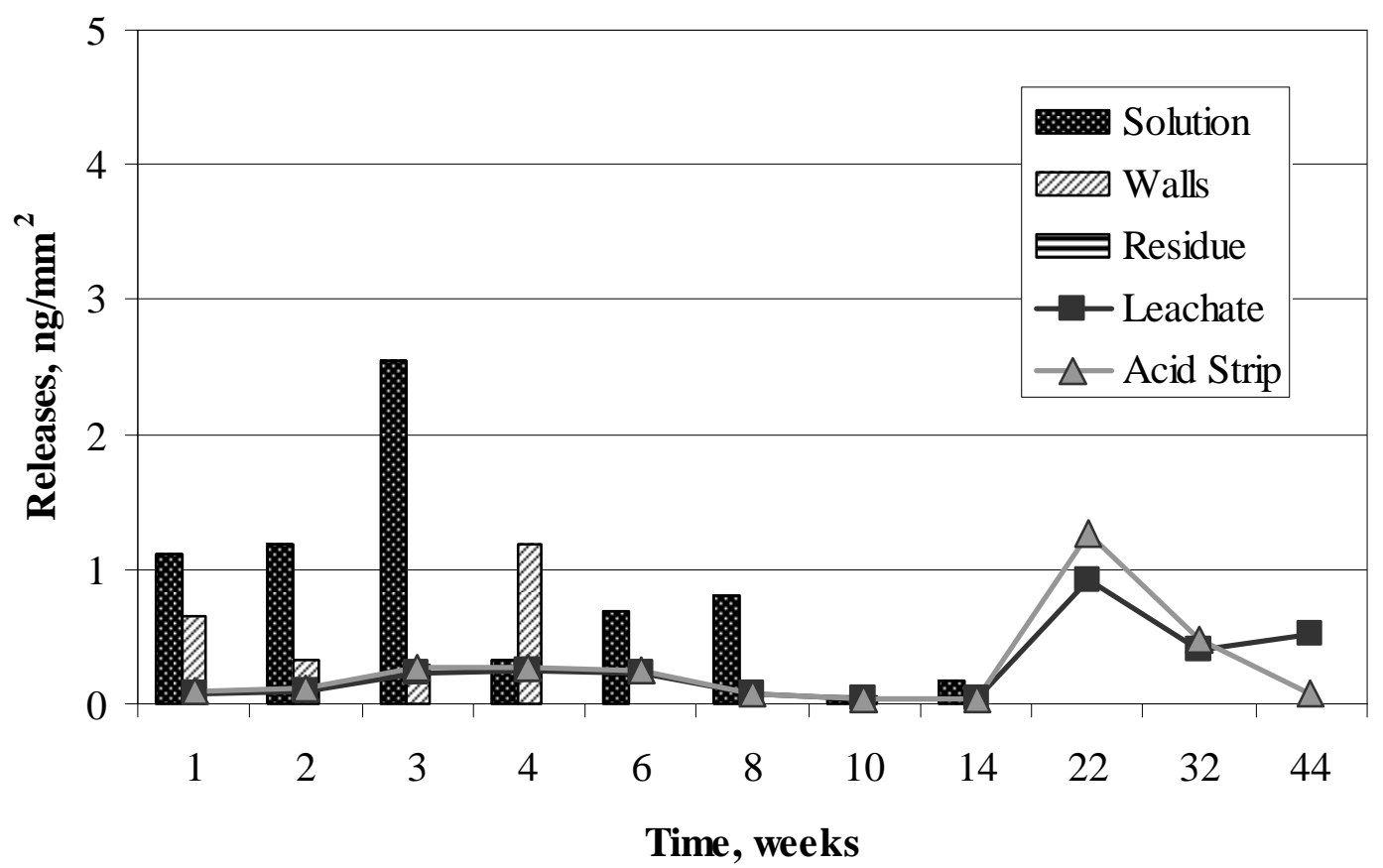

Figure E-195. Molybdenum Releases in Solution, on Walls, and in Residue from Polished Sample 3 in SJ13 and Average Detection Limits for Leachate and Acid Strip.

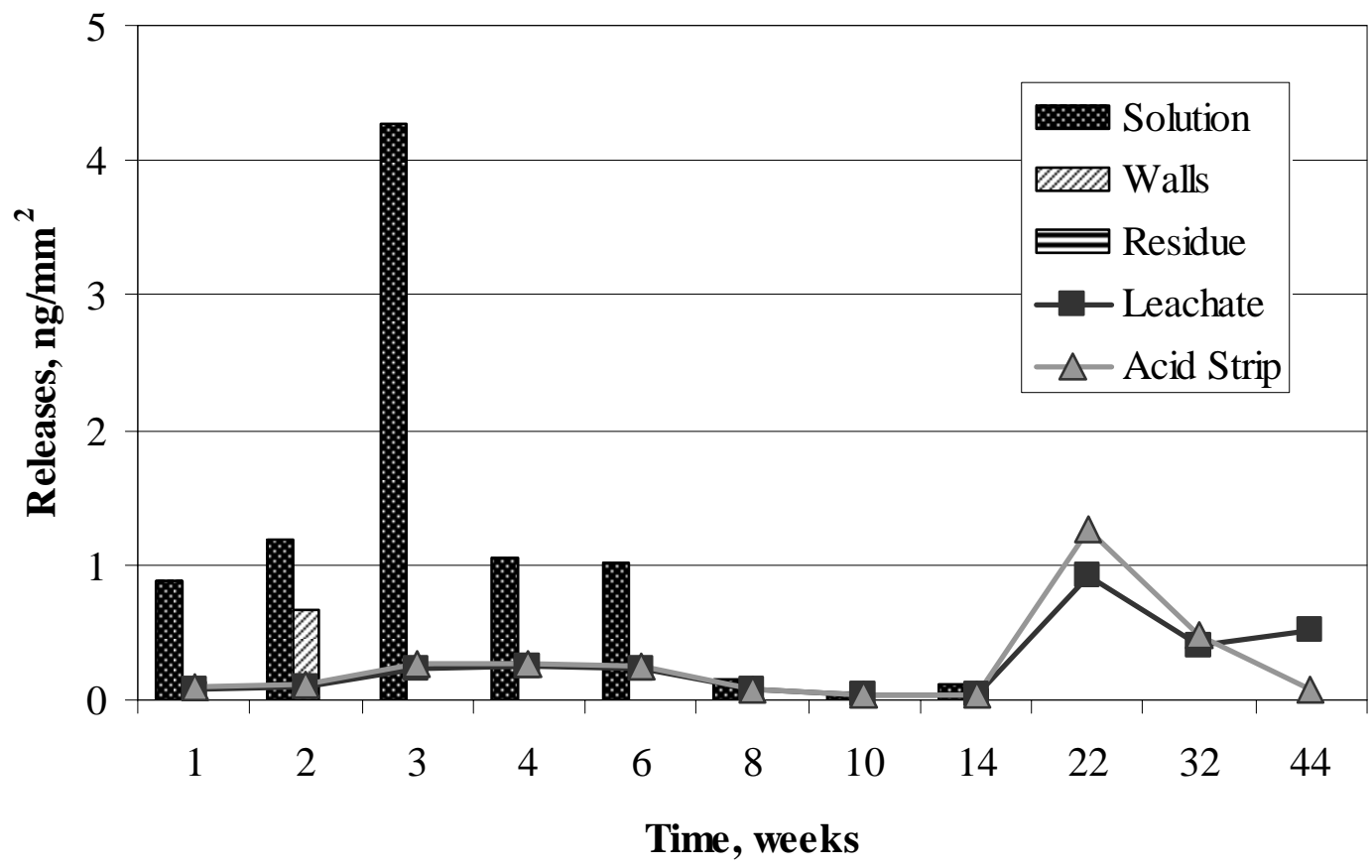

Figure E-196. Molybdenum Releases in Solution, on Walls, and in Residue from Oxidized Sample 4 in SJ13 and Average Detection Limits for Leachate and Acid Strip. 


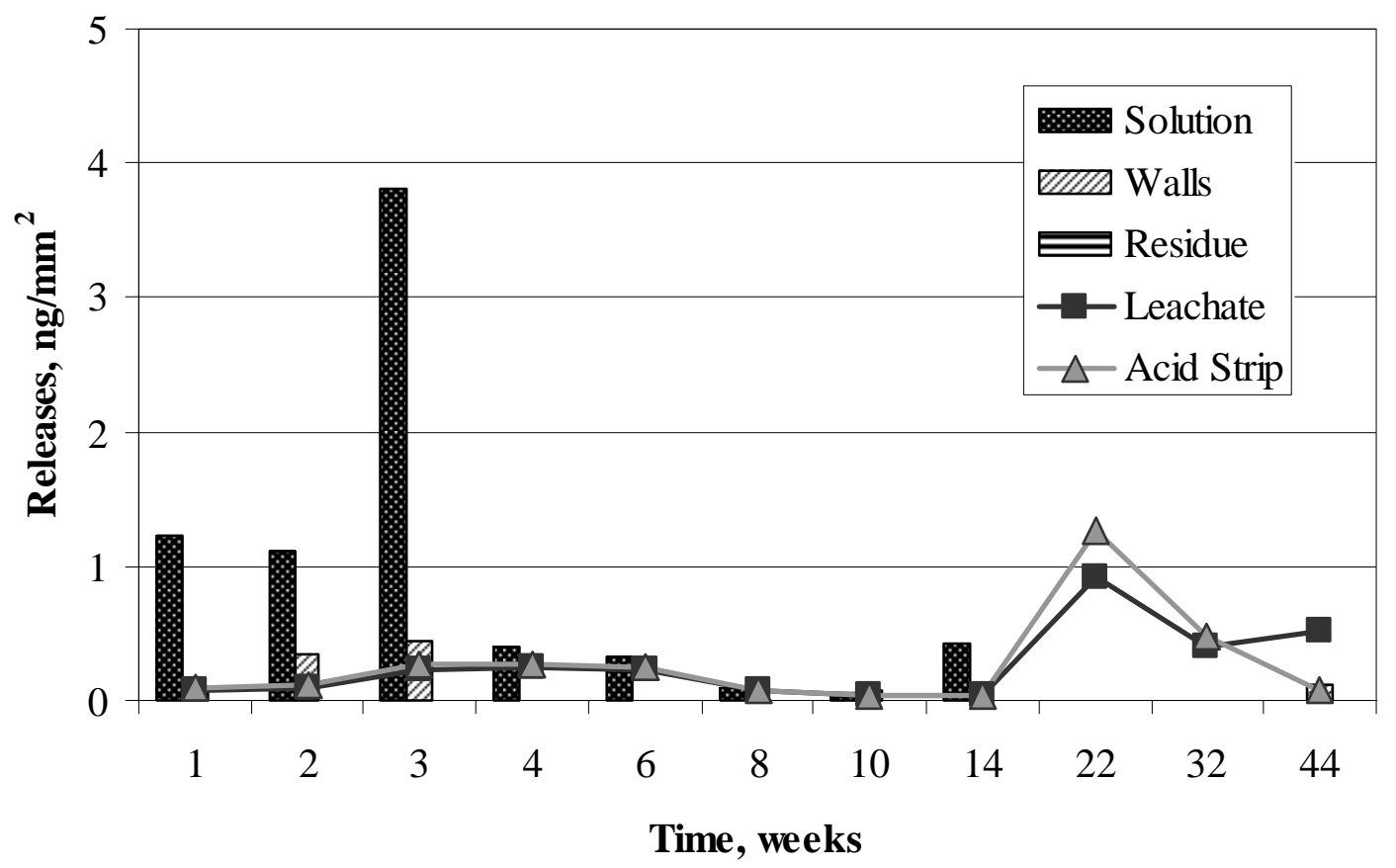

Figure E-197. Molybdenum Releases in Solution, on Walls, and in Residue from Oxidized Sample 5 in SJ13 and Average Detection Limits for Leachate and Acid Strip.

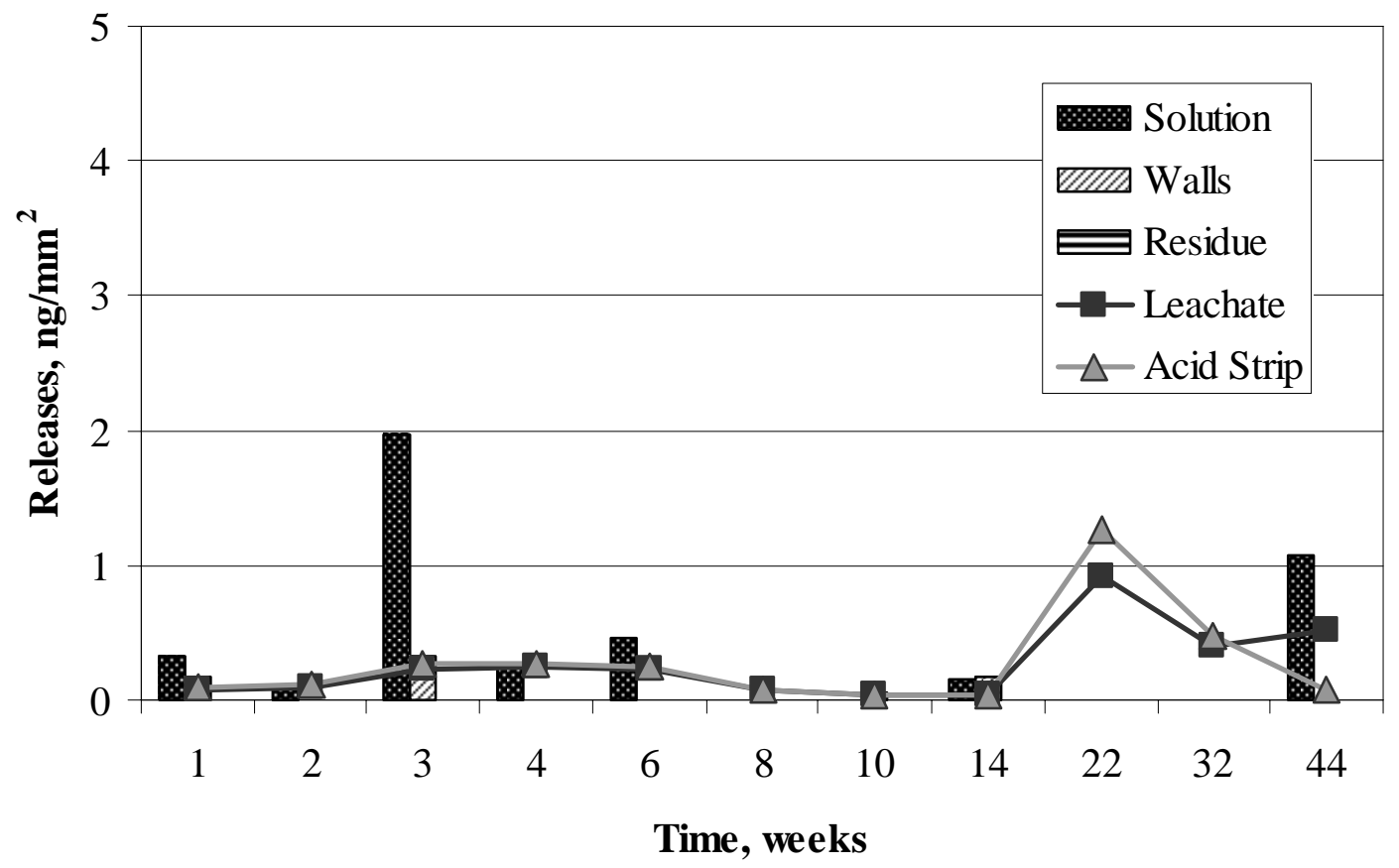

Figure E-198. Molybdenum Present in Solution, on Walls, and in Residue from SJ13 Control and Average Detection Limits for Leachate and Acid Strip. 


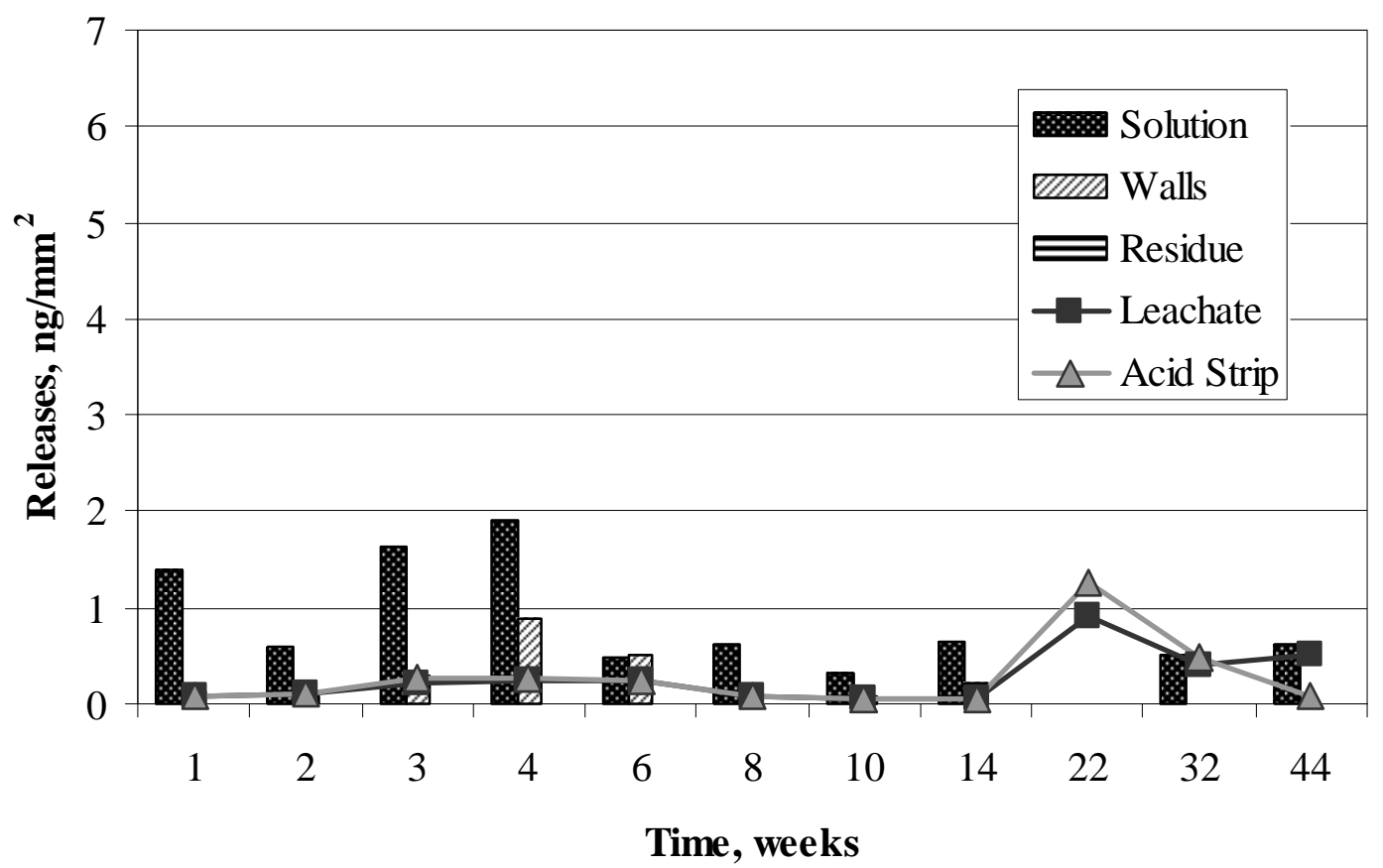

Figure E-199. Molybdenum Releases in Solution, on Walls, and in Residue from Polished Sample 1 in CJ13 and Average Detection Limits for Leachate and Acid Strip.

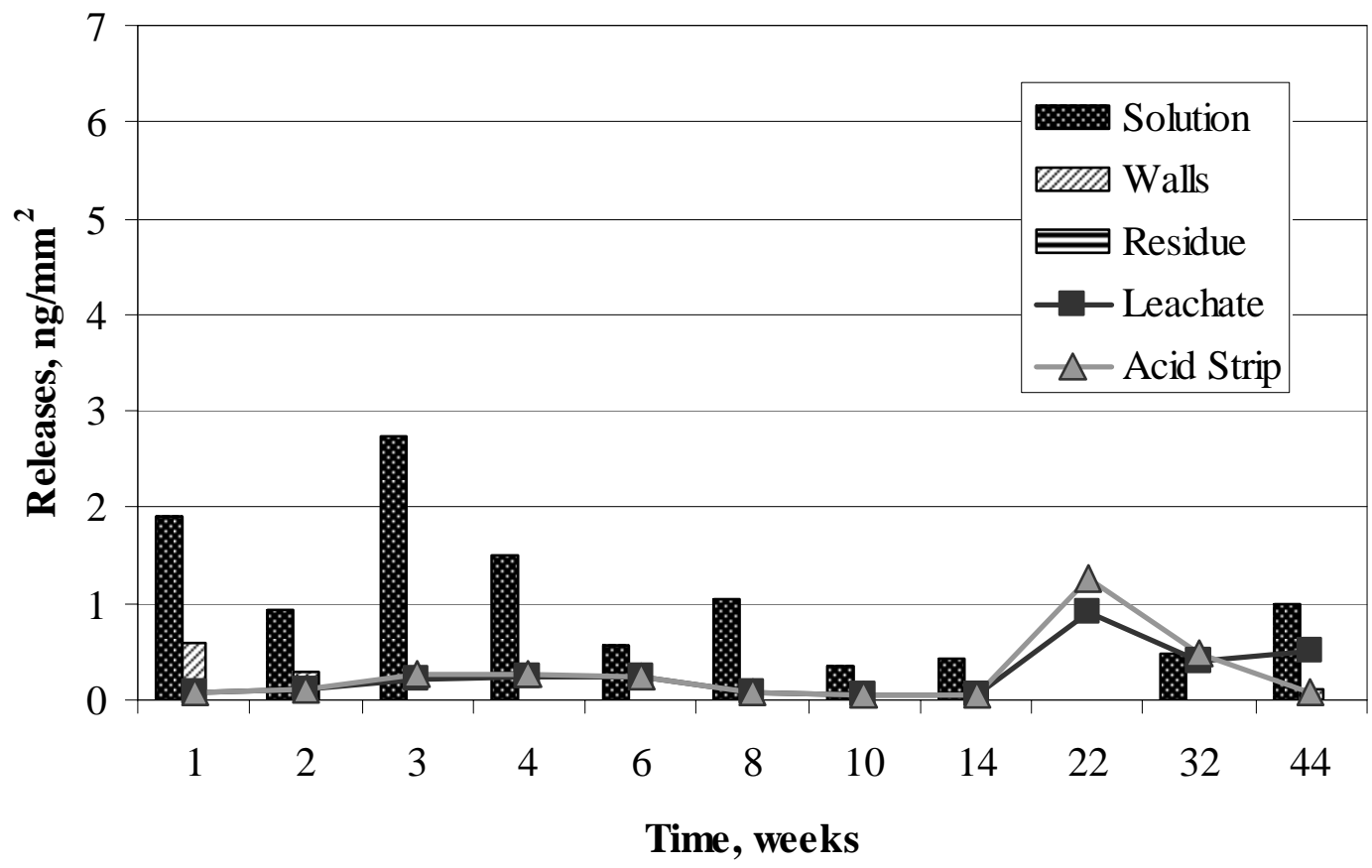

Figure E-200. Molybdenum Releases in Solution, on Walls, and in Residue from Polished Sample 2 in CJ13 and Average Detection Limits for Leachate and Acid Strip. 


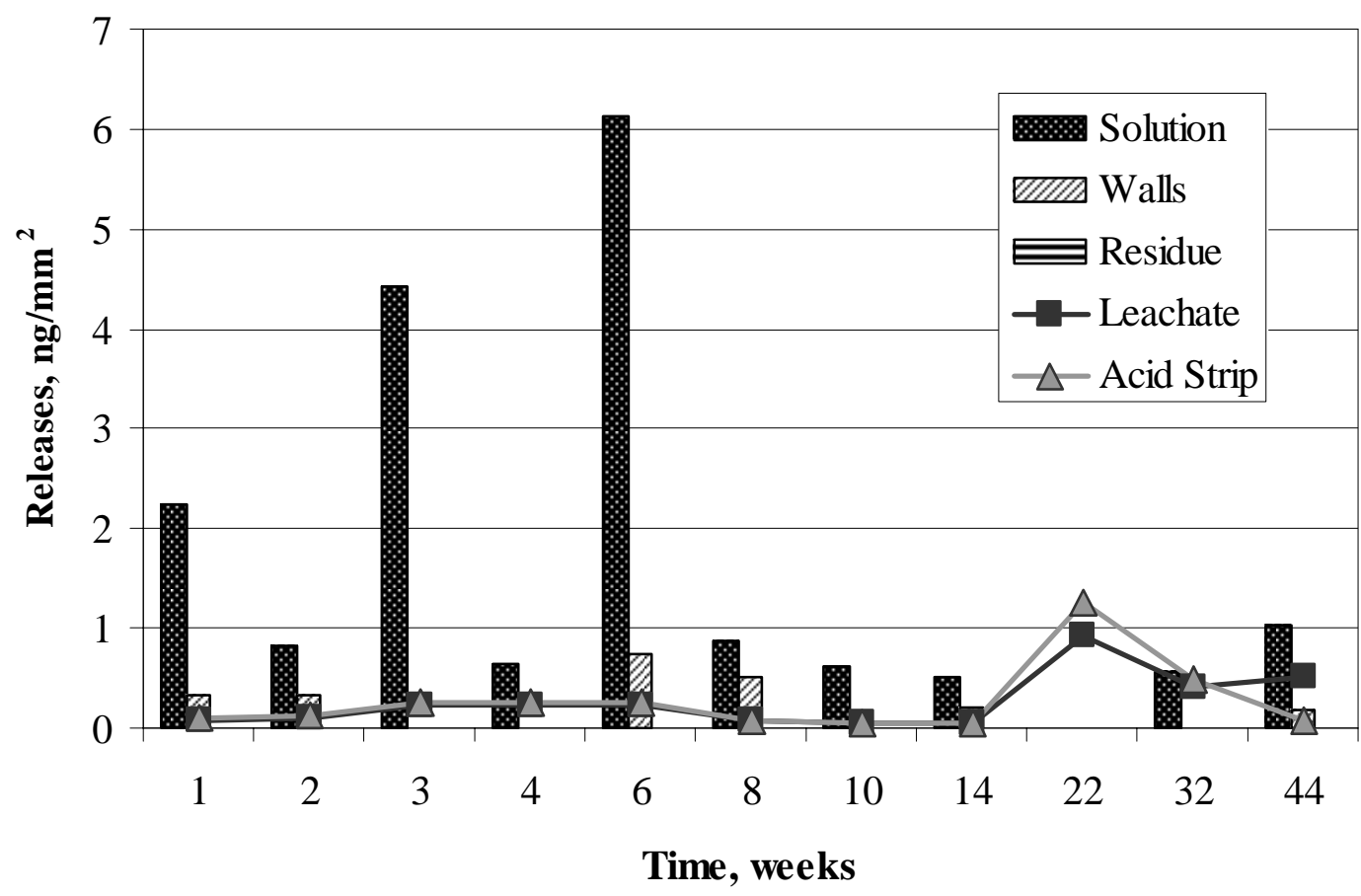

Figure E-201. Molybdenum Releases in Solution, on Walls, and in Residue from Polished Sample 3 in CJ13 and Average Detection Limits for Leachate and Acid Strip.

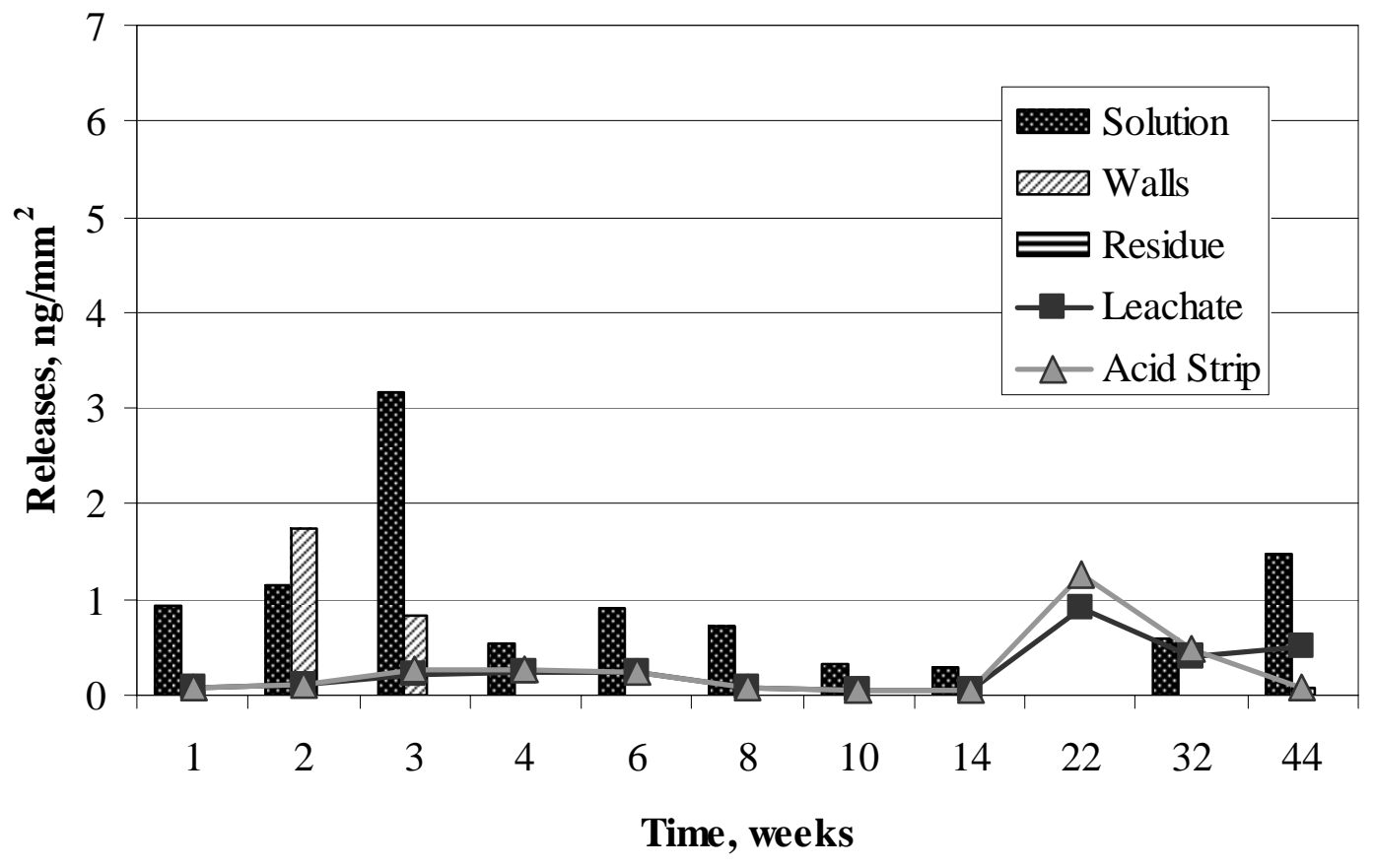

Figure E-202. Molybdenum Releases in Solution, on Walls, and in Residue from Oxidized Sample 4 in CJ13 and Average Detection Limits for Leachate and Acid Strip. 


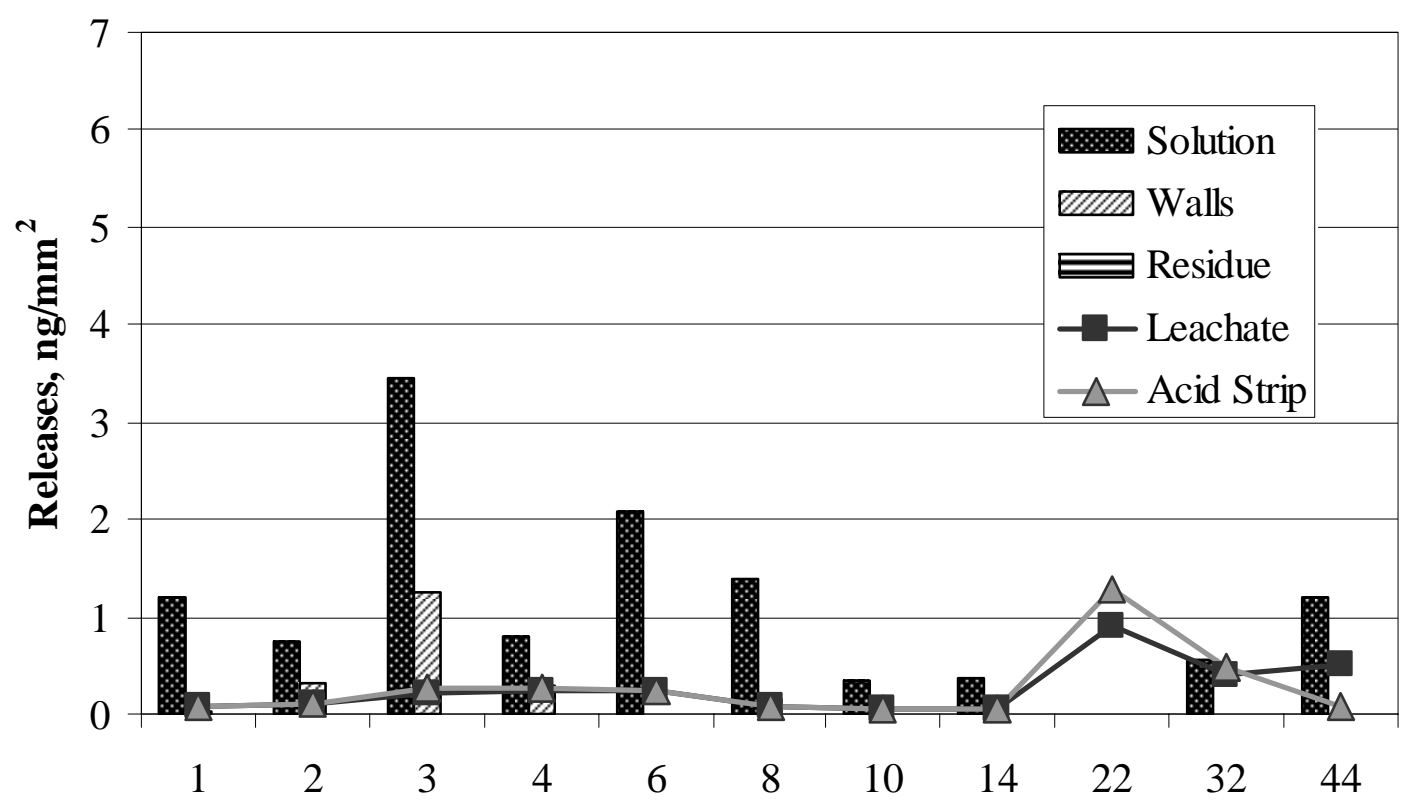

Time, weeks

Figure E-203. Molybdenum Releases in Solution, on Walls, and in Residue from Oxidized Sample 5 in CJ13 and Average Detection Limits for Leachate and Acid Strip.

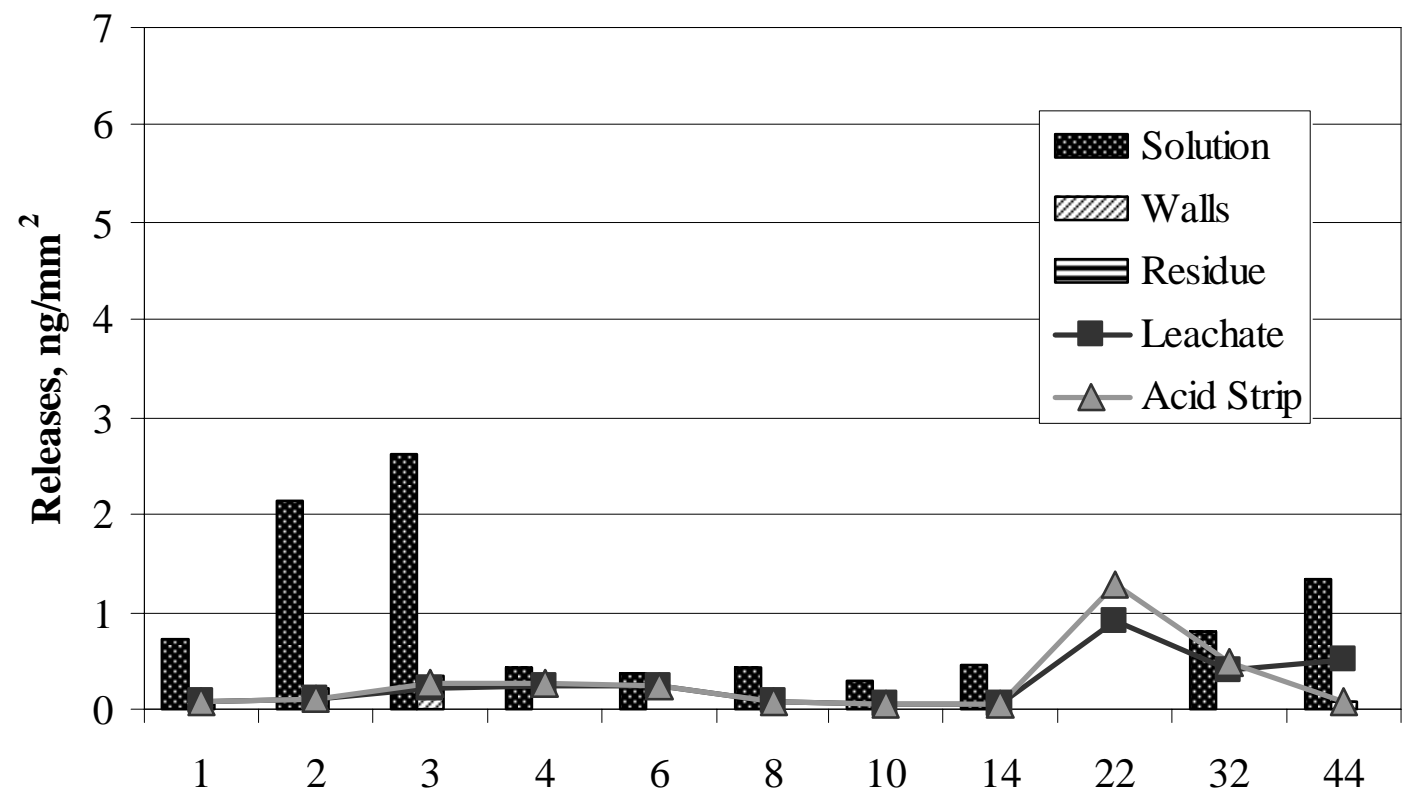

Time, weeks

Figure E-204. Molybdenum Present in Solution, on Walls, and in Residue from CJ13 Control and Average Detection Limits for Leachate and Acid Strip. 


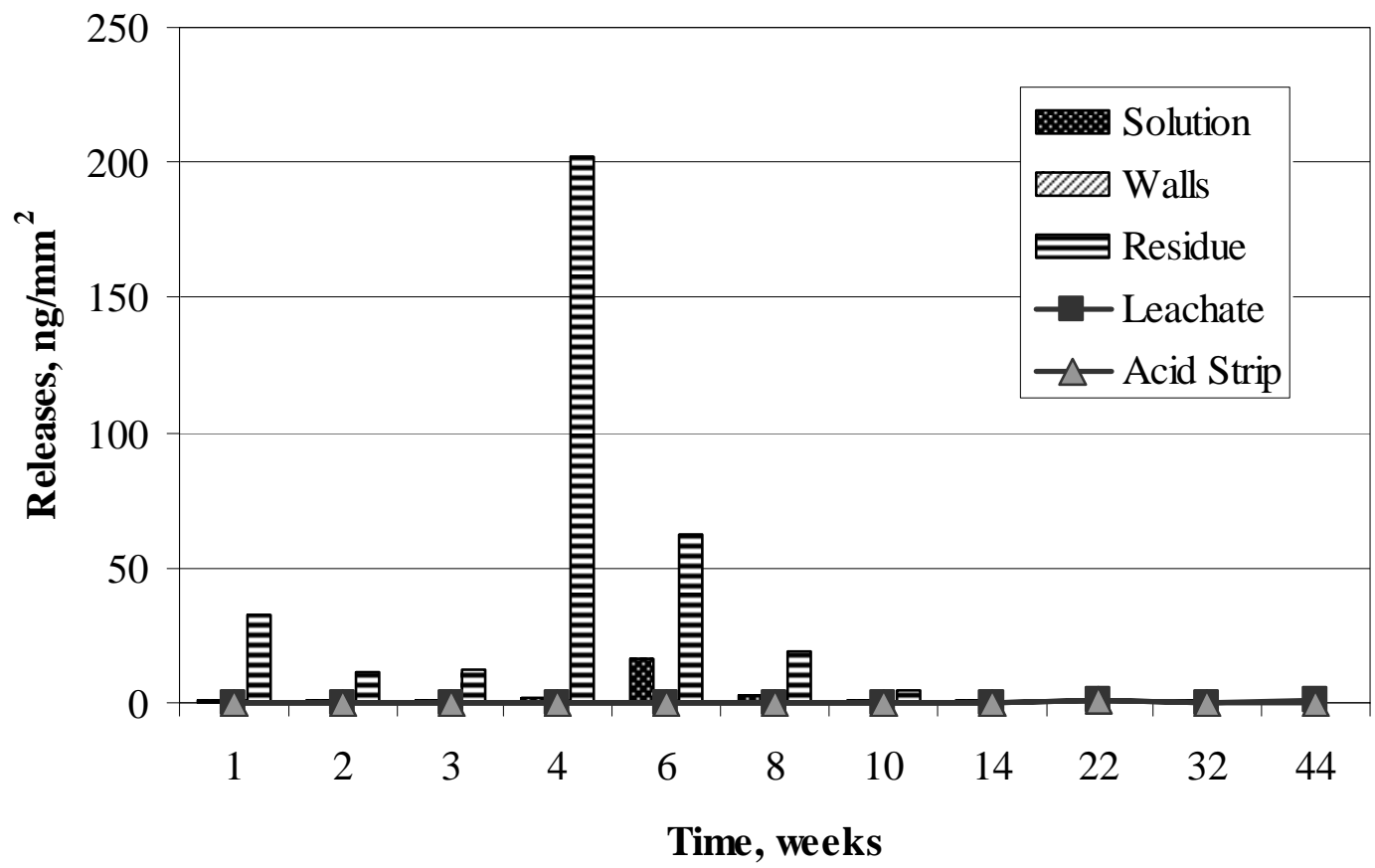

Figure E-205. Molybdenum Releases in Solution, on Walls, and in Residue from Polished Sample 1 in $10 \mathrm{KCl}$ and Average Detection Limits for Leachate and Acid Strip.

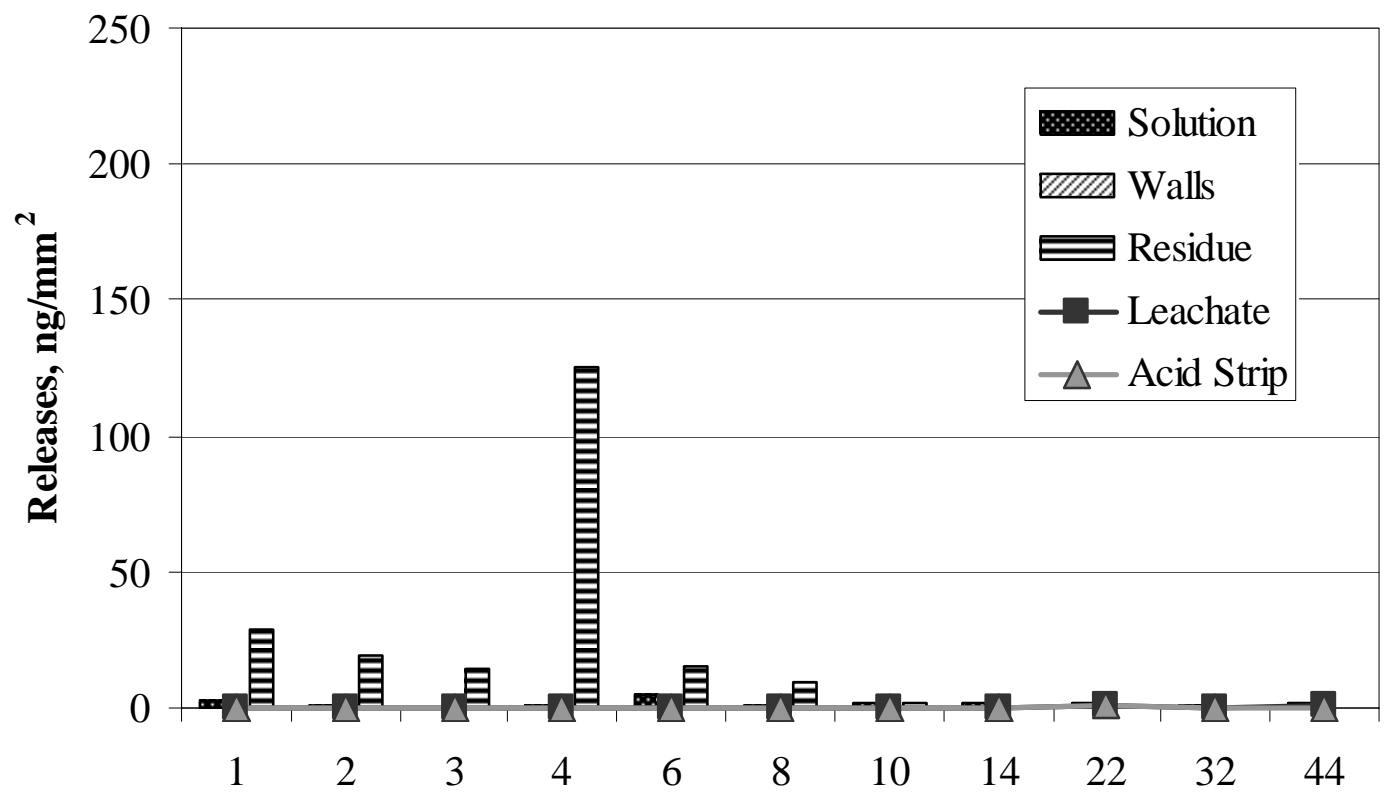

Time, weeks

Figure E-206. Molybdenum Releases in Solution, on Walls, and in Residue from Polished Sample 2 in $10 \mathrm{KCl}$ and Average Detection Limits for Leachate and Acid Strip. 


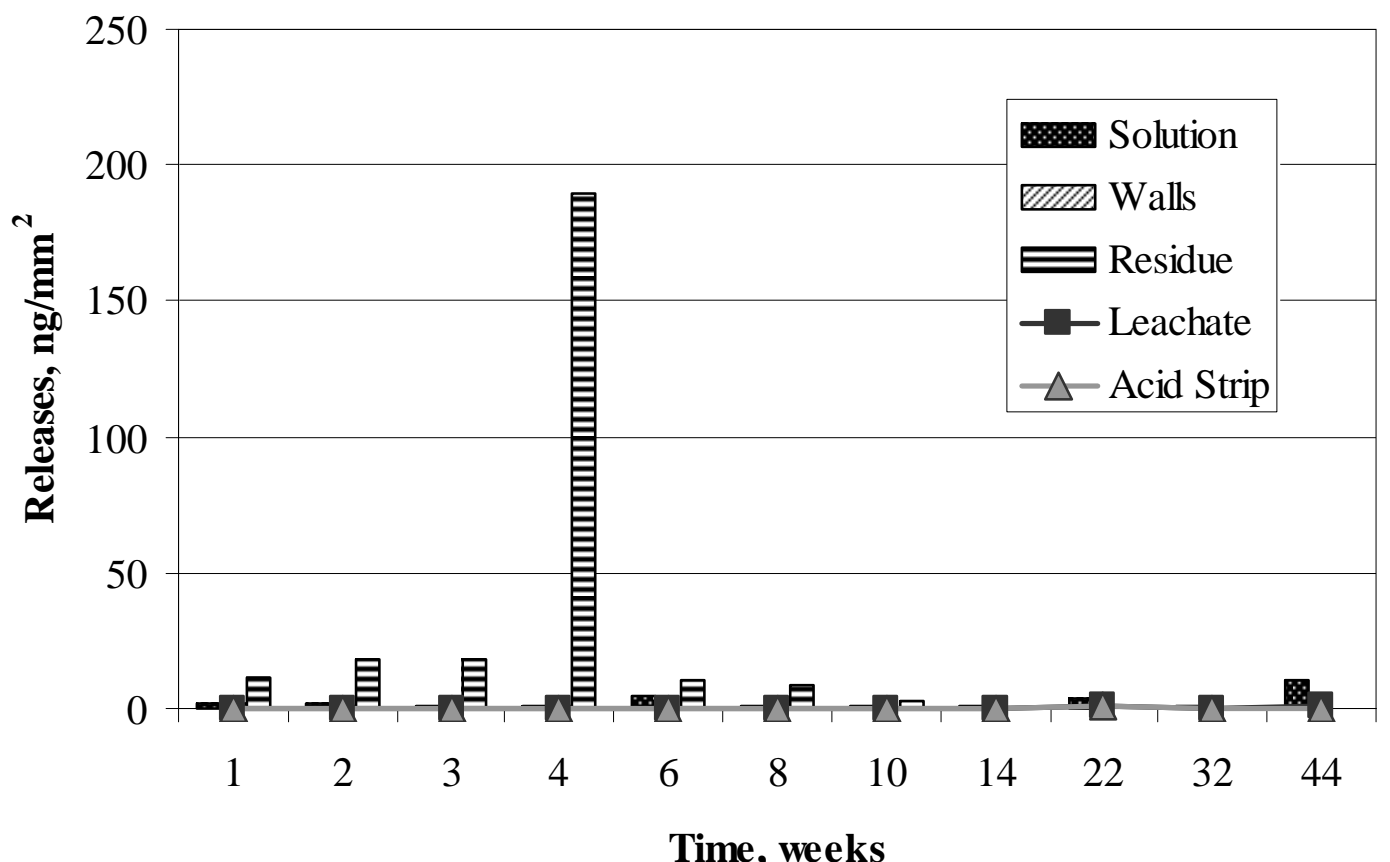

Figure E-207. Molybdenum Releases in Solution, on Walls, and in Residue from Polished Sample 3 in $10 \mathrm{KCl}$ and Average Detection Limits for Leachate and Acid Strip.

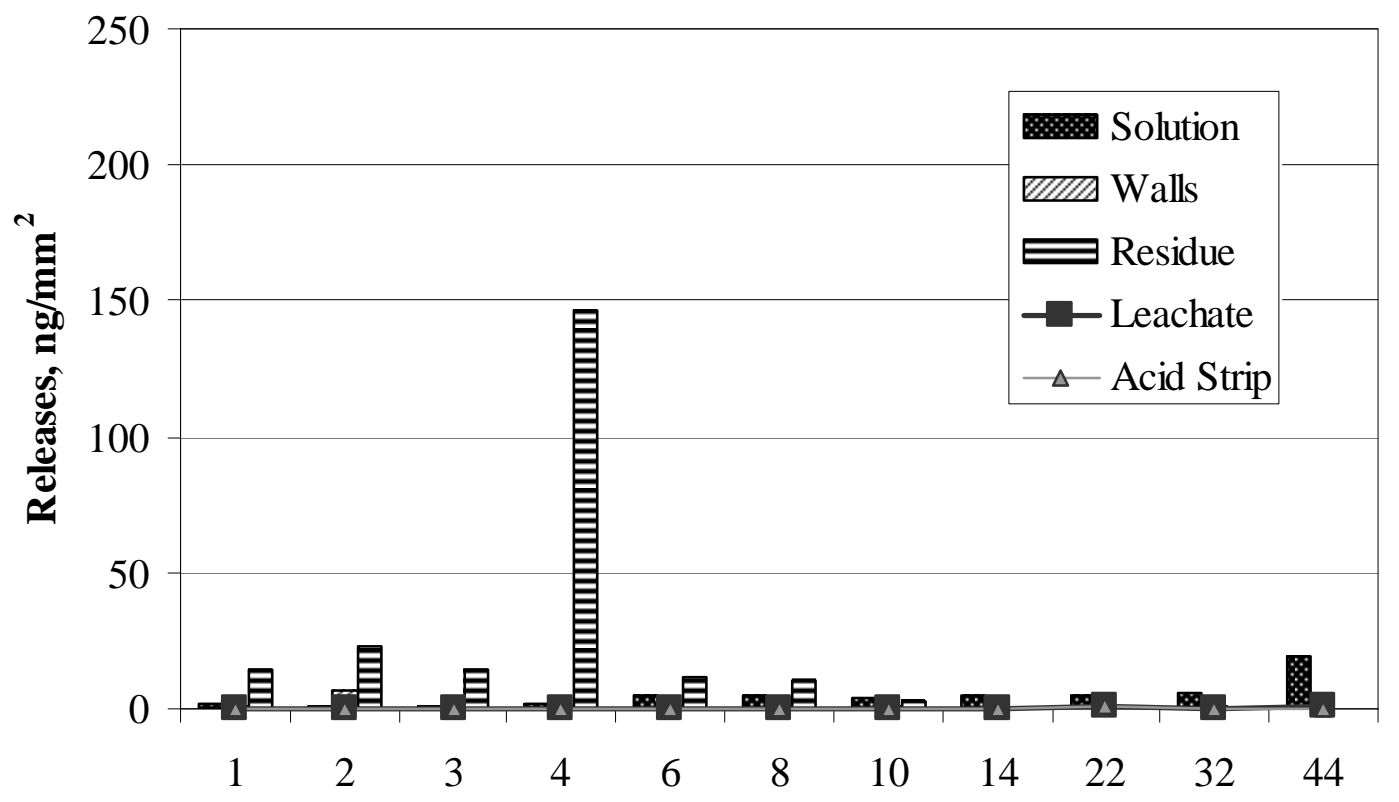

Time, weeks

Figure E-208. Molybdenum Releases in Solution, on Walls, and in Residue from Oxidized Sample 4 in $10 \mathrm{KCl}$ and Average Detection Limits for Leachate and Acid Strip. 


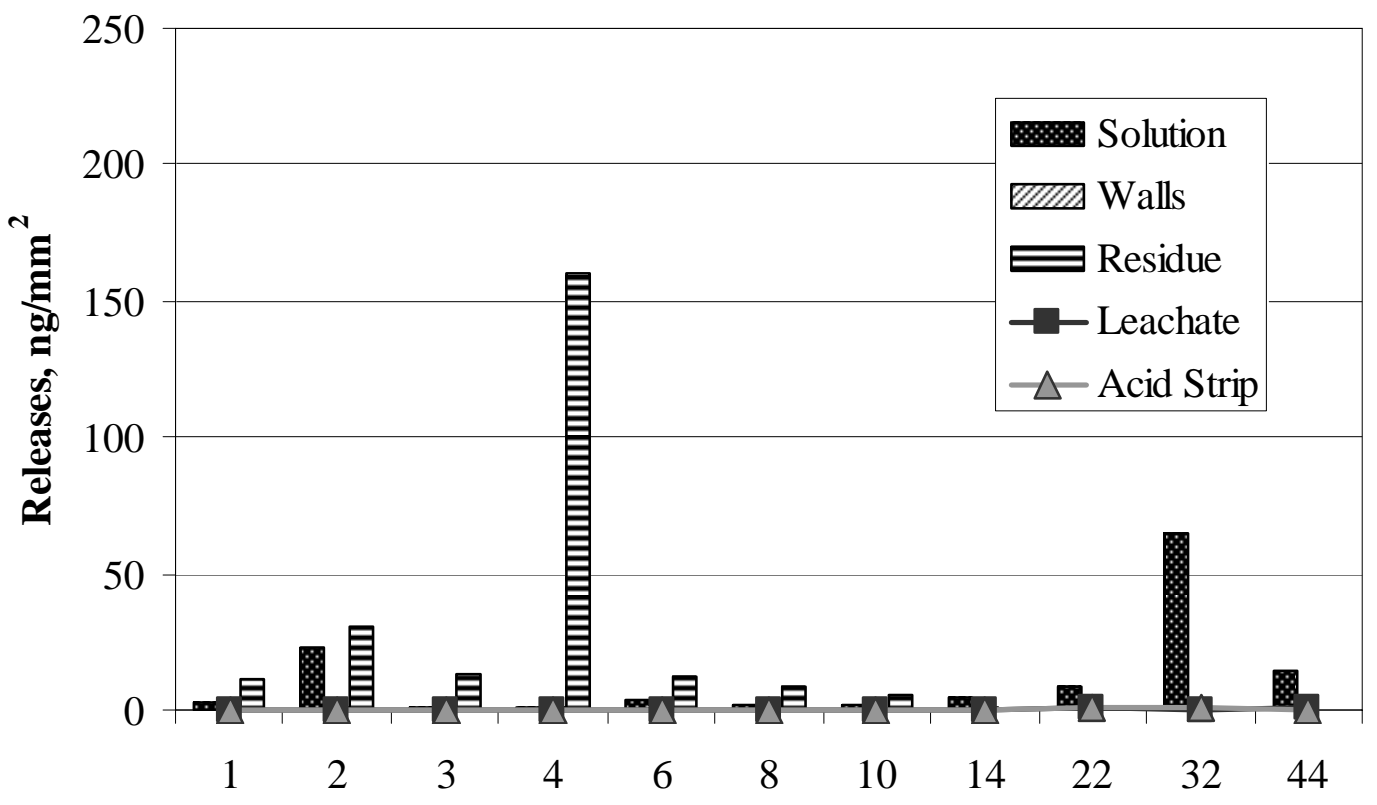

Time, weeks

Figure E-209. Molybdenum Releases in Solution, on Walls, and in Residue from Oxidized Sample 5 in $10 \mathrm{KCl}$ and Average Detection Limits for Leachate and Acid Strip.

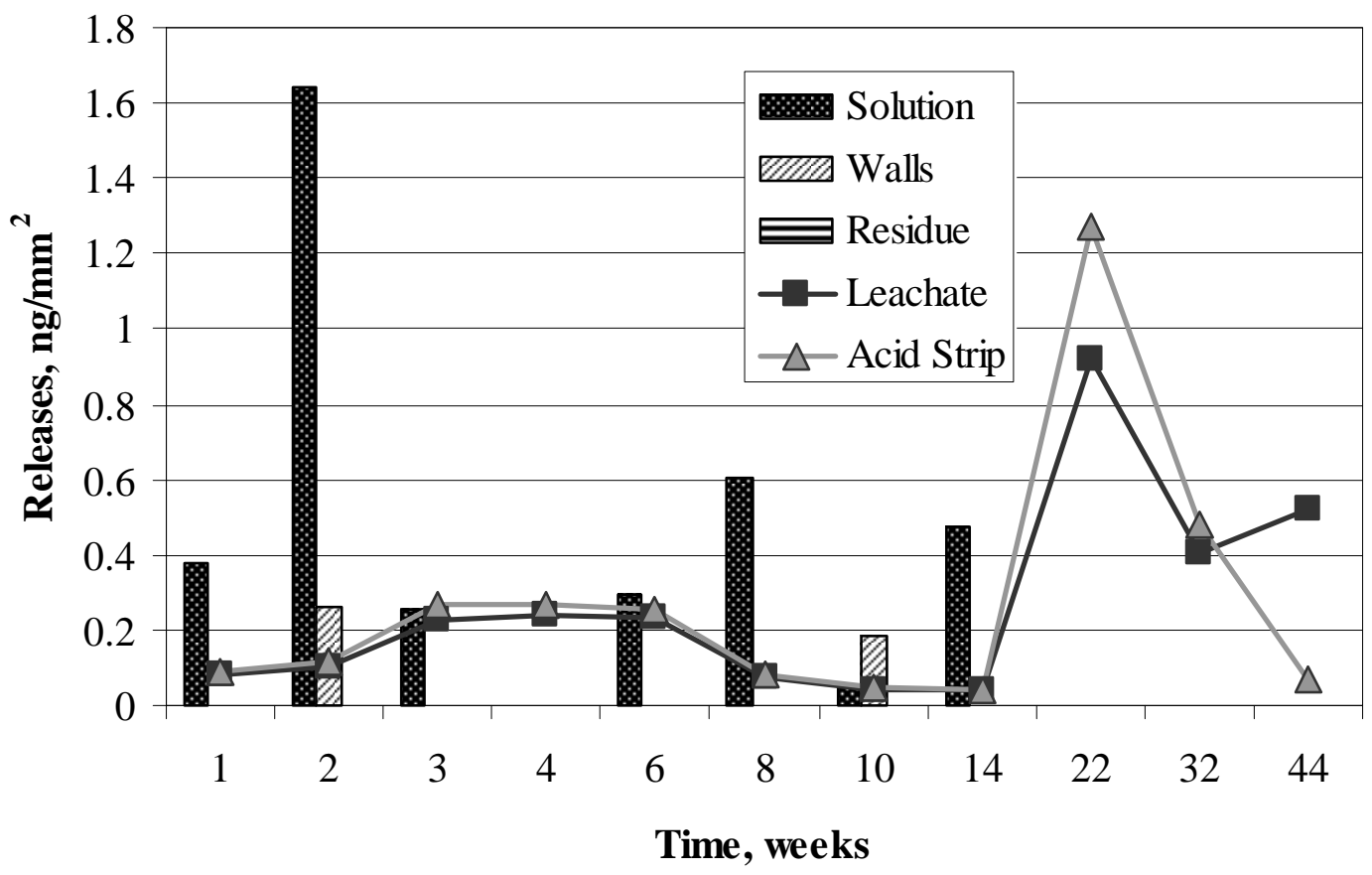

Figure E-210. Molybdenum Present in Solution, on Walls, and in Residue from $10 \mathrm{KCl}$ Control and Average Detection Limits for Leachate and Acid Strip. 


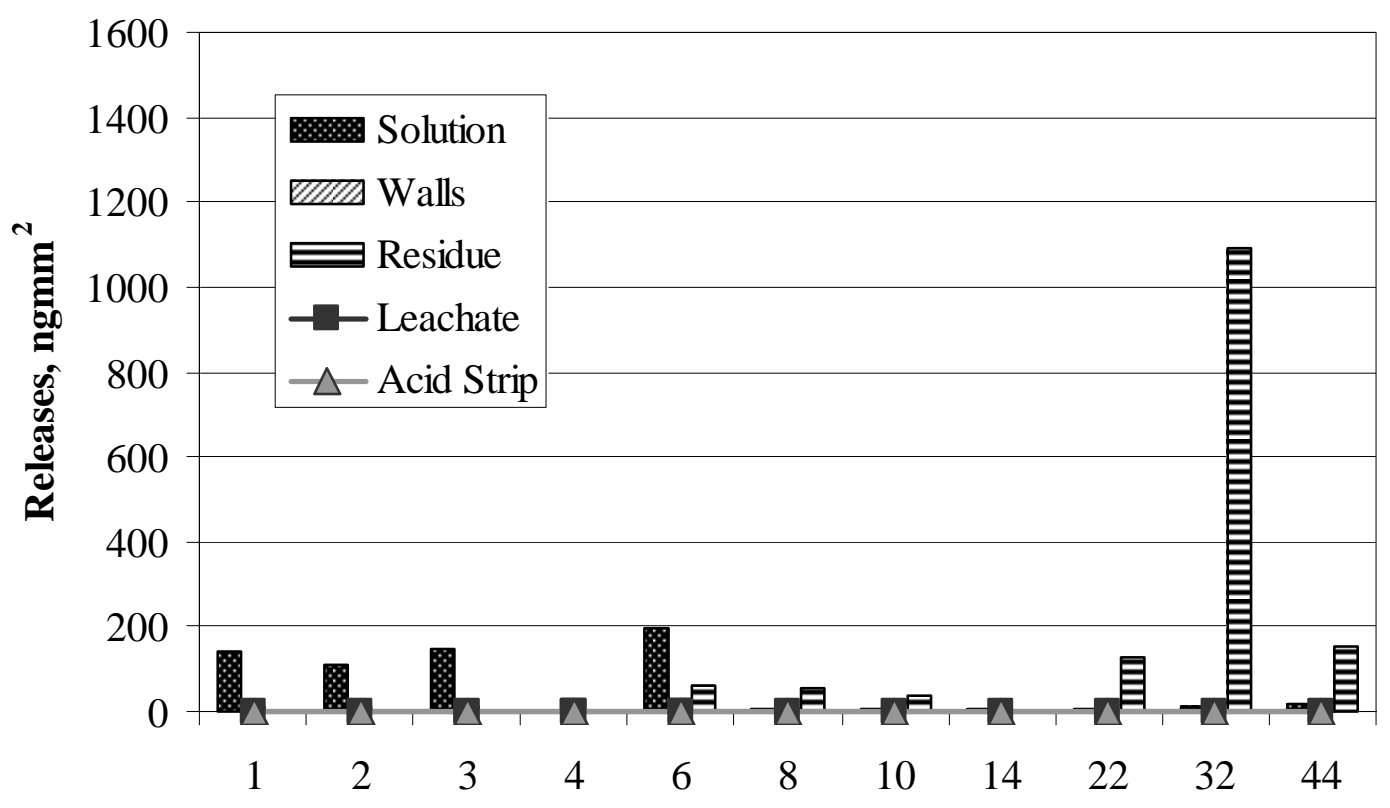

Time, weeks

Figure E-211. Molybdenum Releases in Solution, on Walls, and in Residue from Polished Sample 1 in AJ13 and Average Detection Limits for Leachate and Acid Strip.

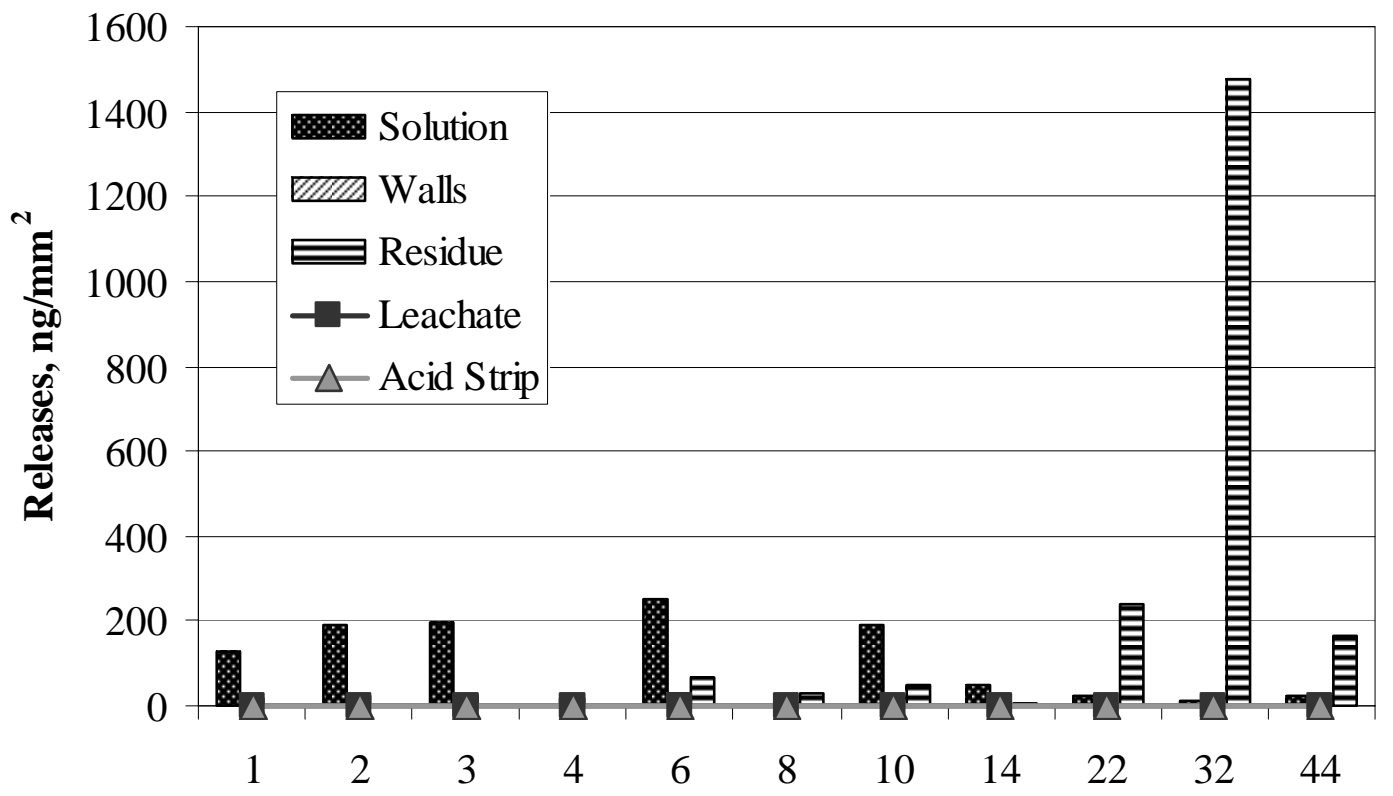

Time, weeks

Figure E-212. Molybdenum Releases in Solution, on Walls, and in Residue from Polished Sample 2 in AJ13 and Average Detection Limits for Leachate and Acid Strip. 


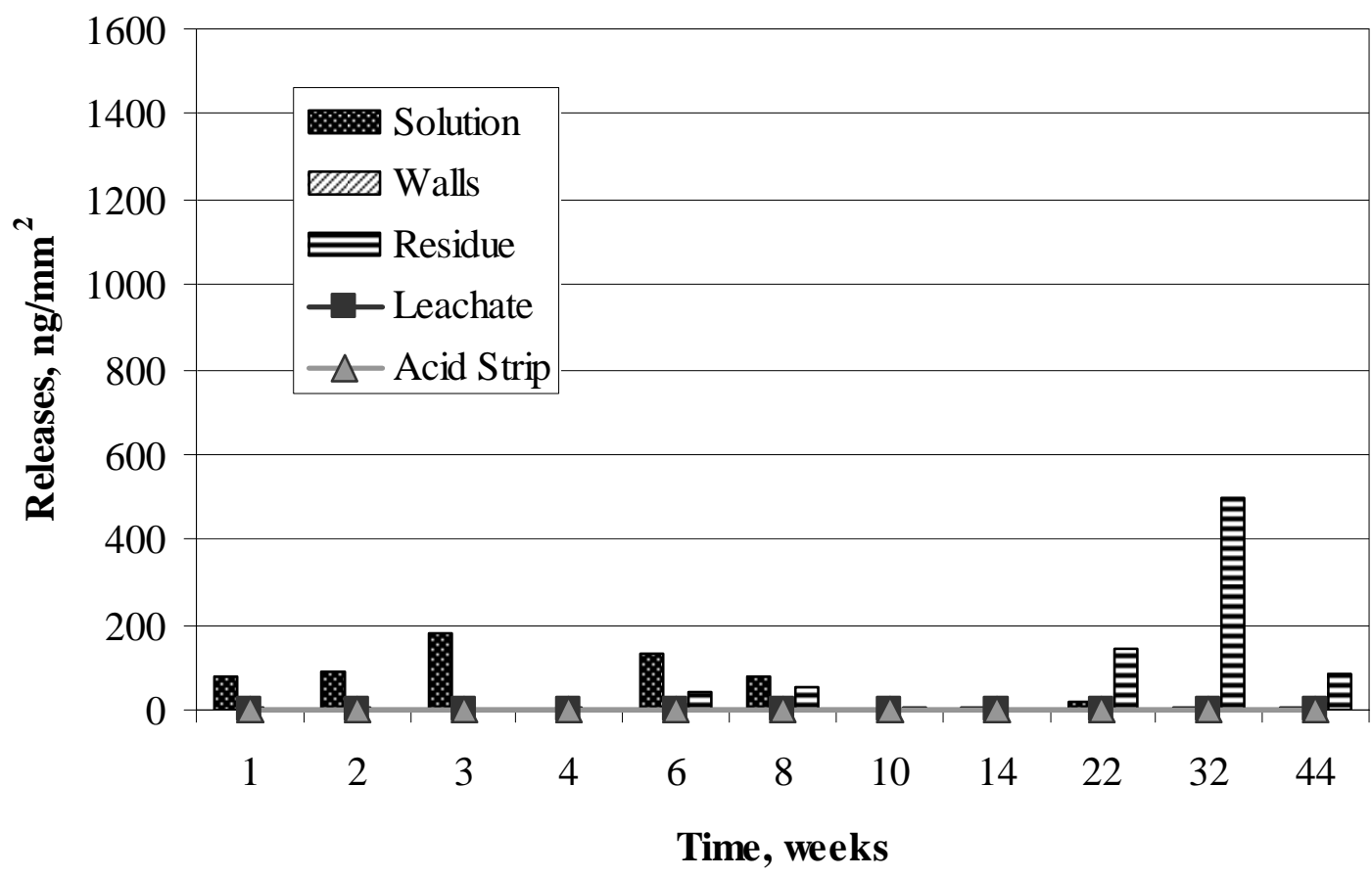

Figure E-213. Molybdenum Releases in Solution, on Walls, and in Residue from Polished Sample 3 in AJ13 and Average Detection Limits for Leachate and Acid Strip.

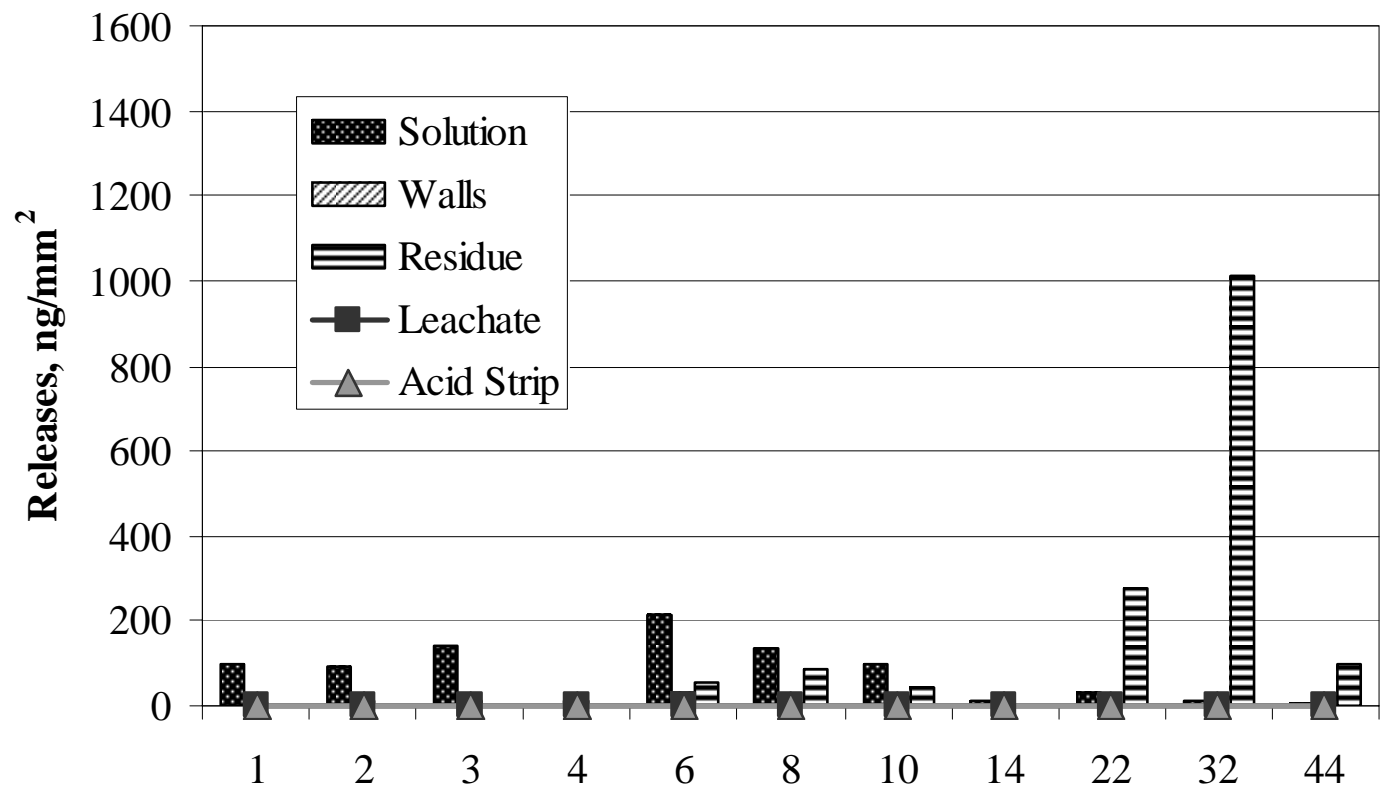

Time, weeks

Figure E-214. Molybdenum Releases in Solution, on Walls, and in Residue from Oxidized Sample 4 in AJ13 and Average Detection Limits for Leachate and Acid Strip. 


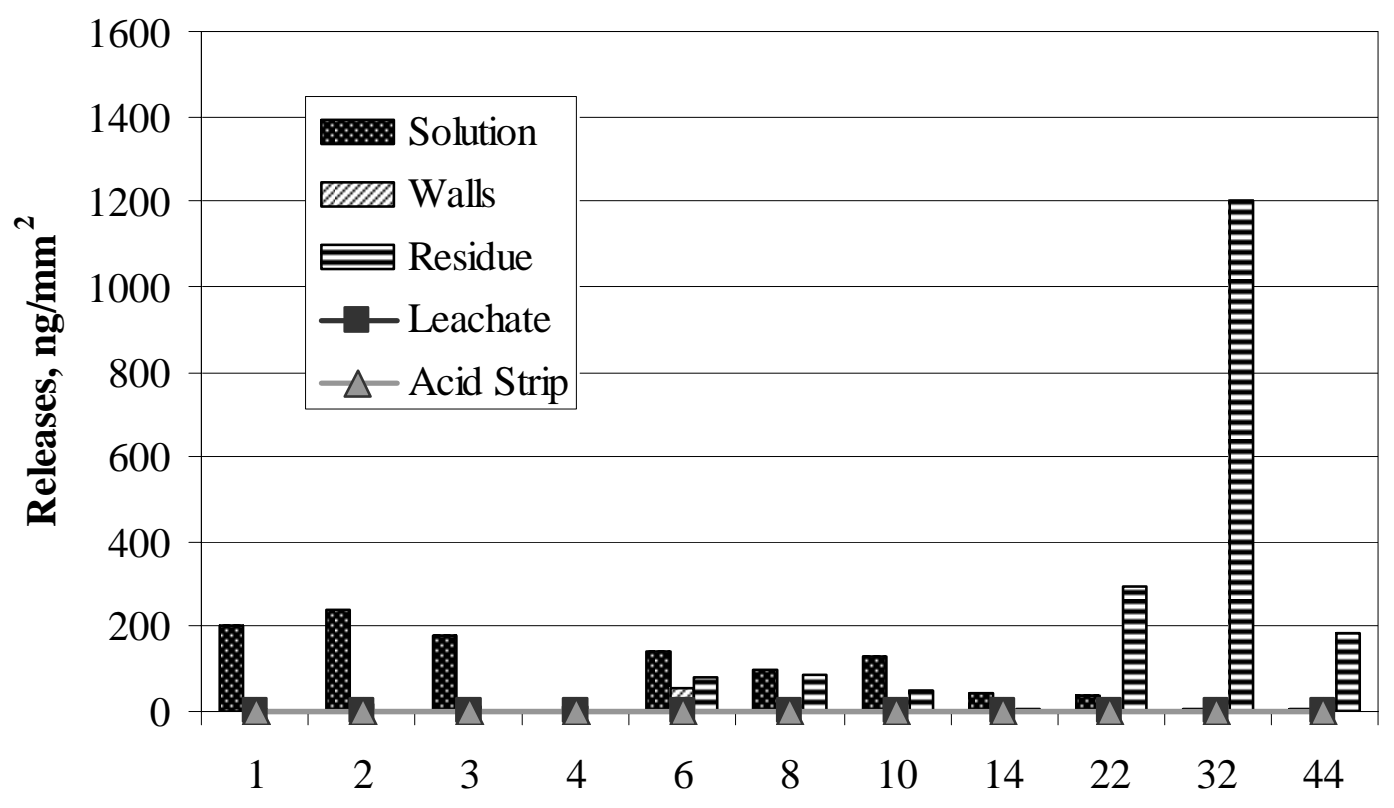

Time, weeks

Figure E-215. Molybdenum Releases in Solution, on Walls, and in Residue from Oxidized Sample 5 in AJ13 and Average Detection Limits for Leachate and Acid Strip.

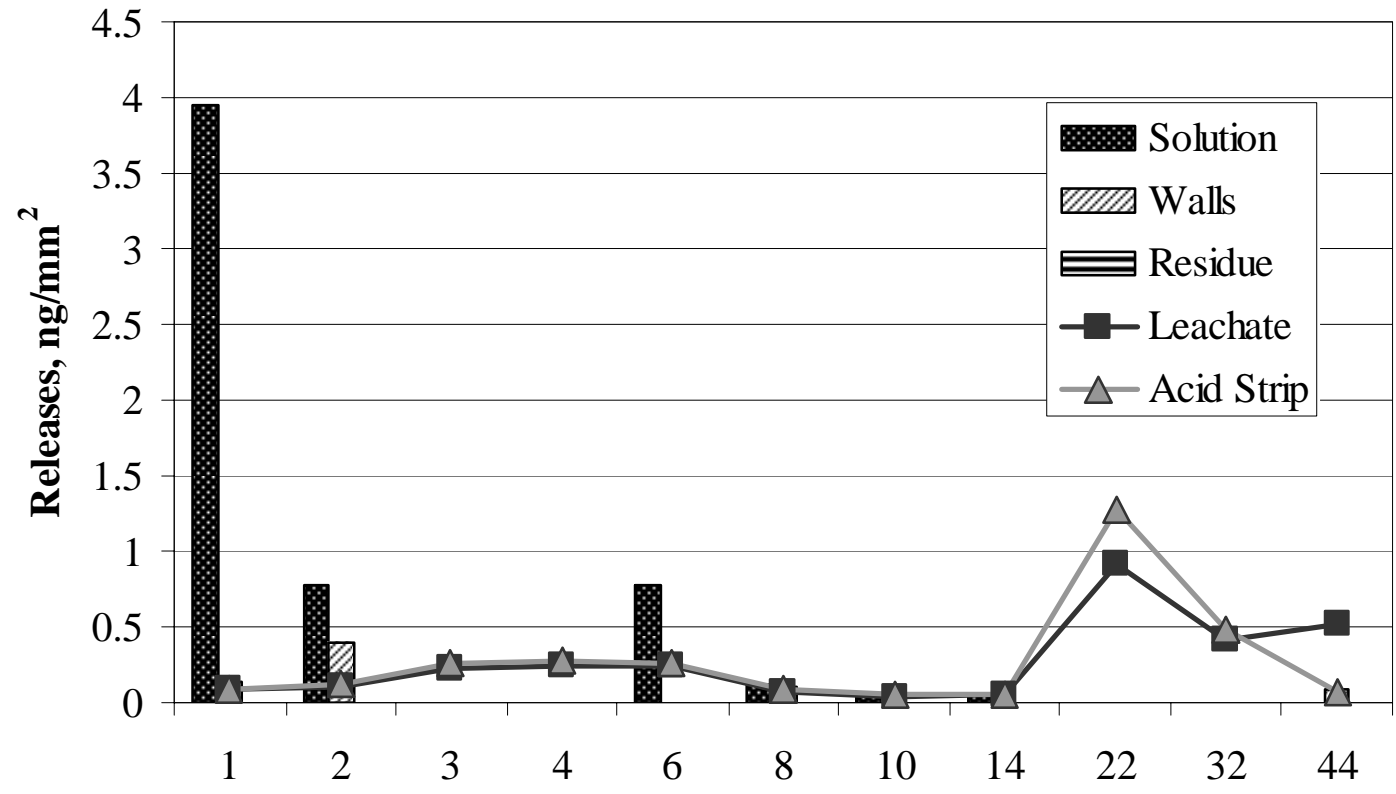

Time, weeks

Figure E-216. Molybdenum Present in Solution, on Walls, and in Residue from AJ13 Control and Average Detection Limits for Leachate and Acid Strip. 


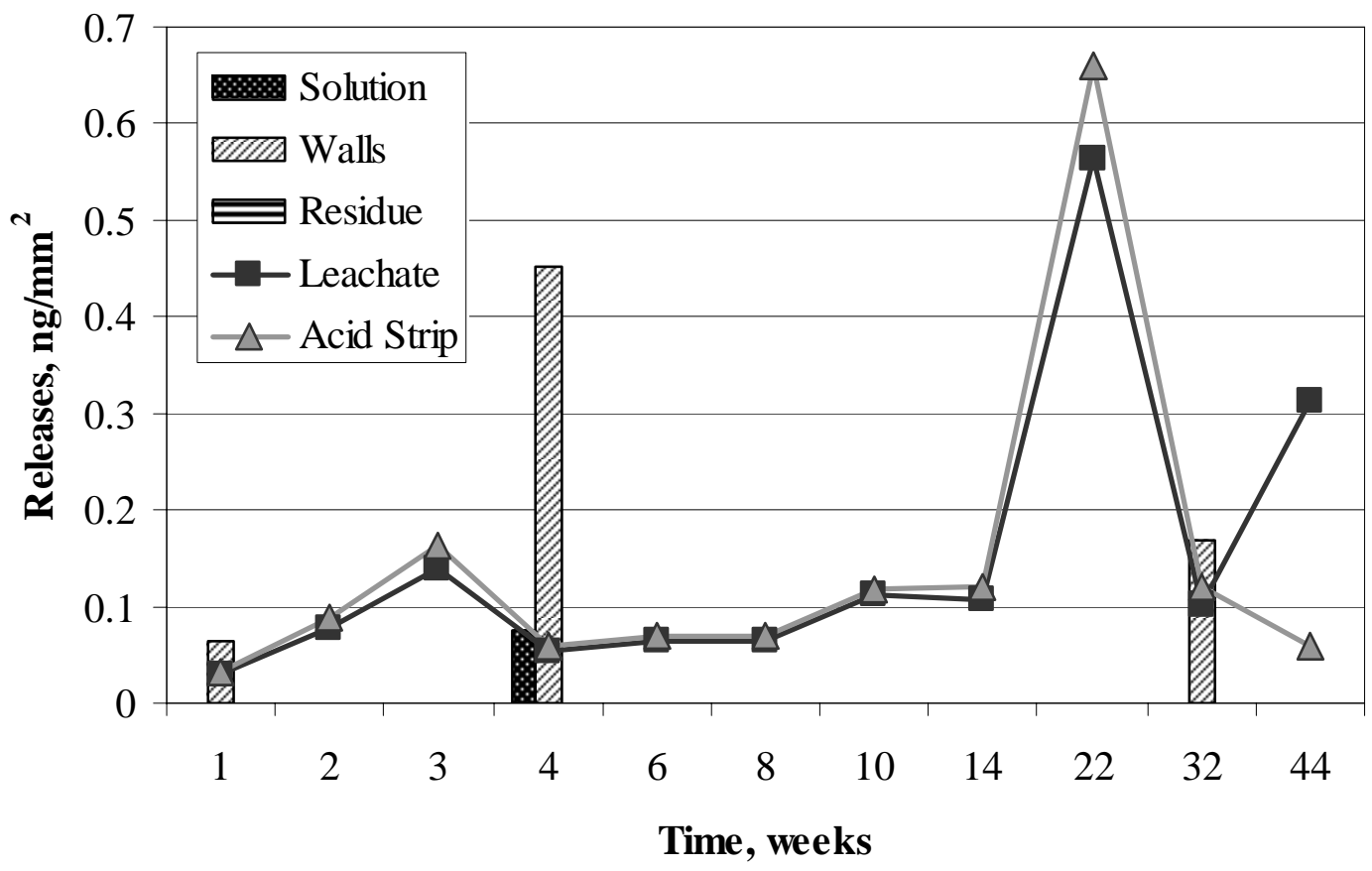

Figure E-217. Manganese Releases in Solution, on Walls, and in Residue from Polished Sample 1 in SJ13 and Average Detection Limits for Leachate and Acid Strip.

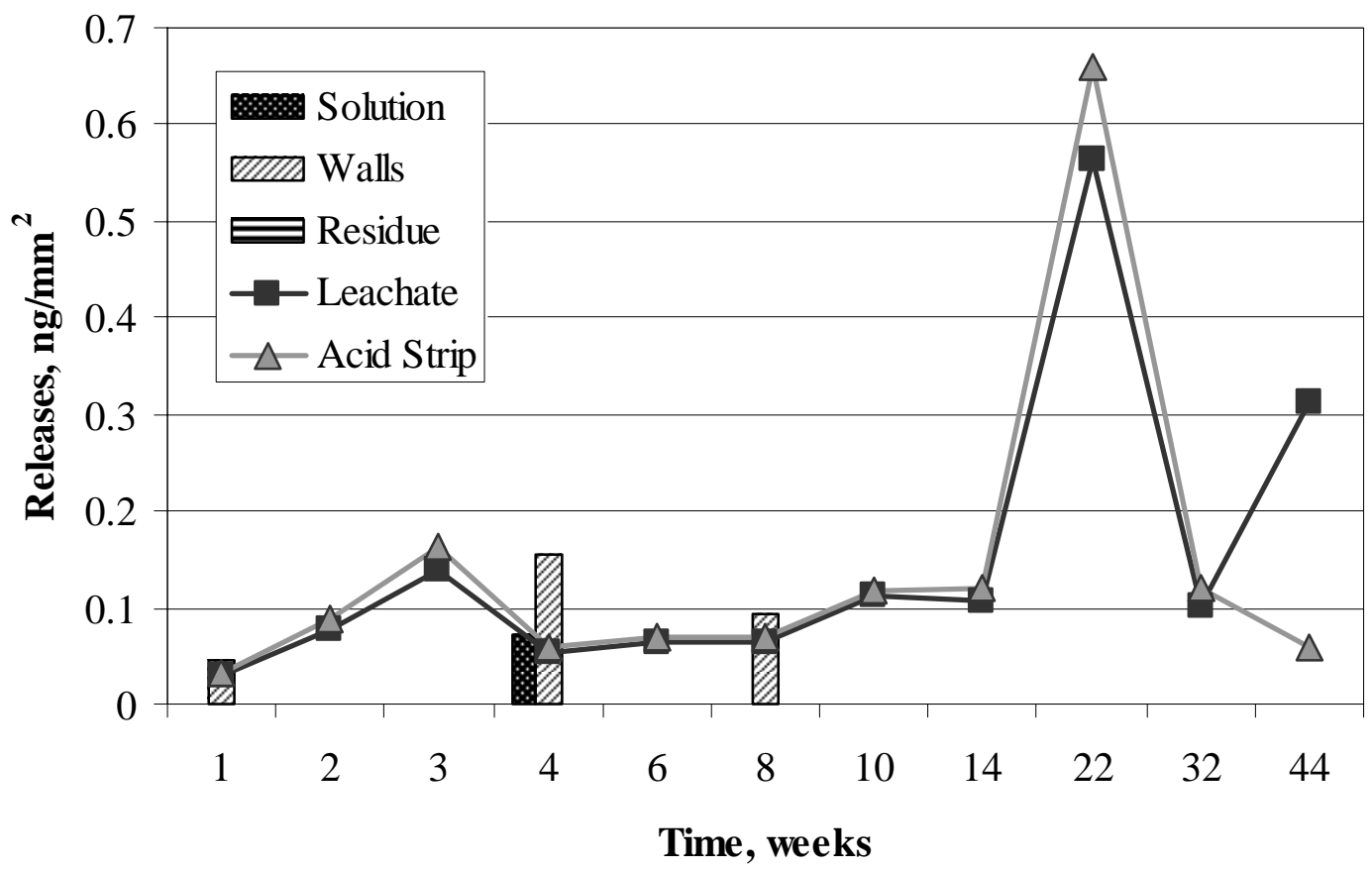

Figure E-218. Manganese Releases in Solution, on Walls, and in Residue from Polished Sample 2 in SJ13 and Average Detection Limits for Leachate and Acid Strip. 


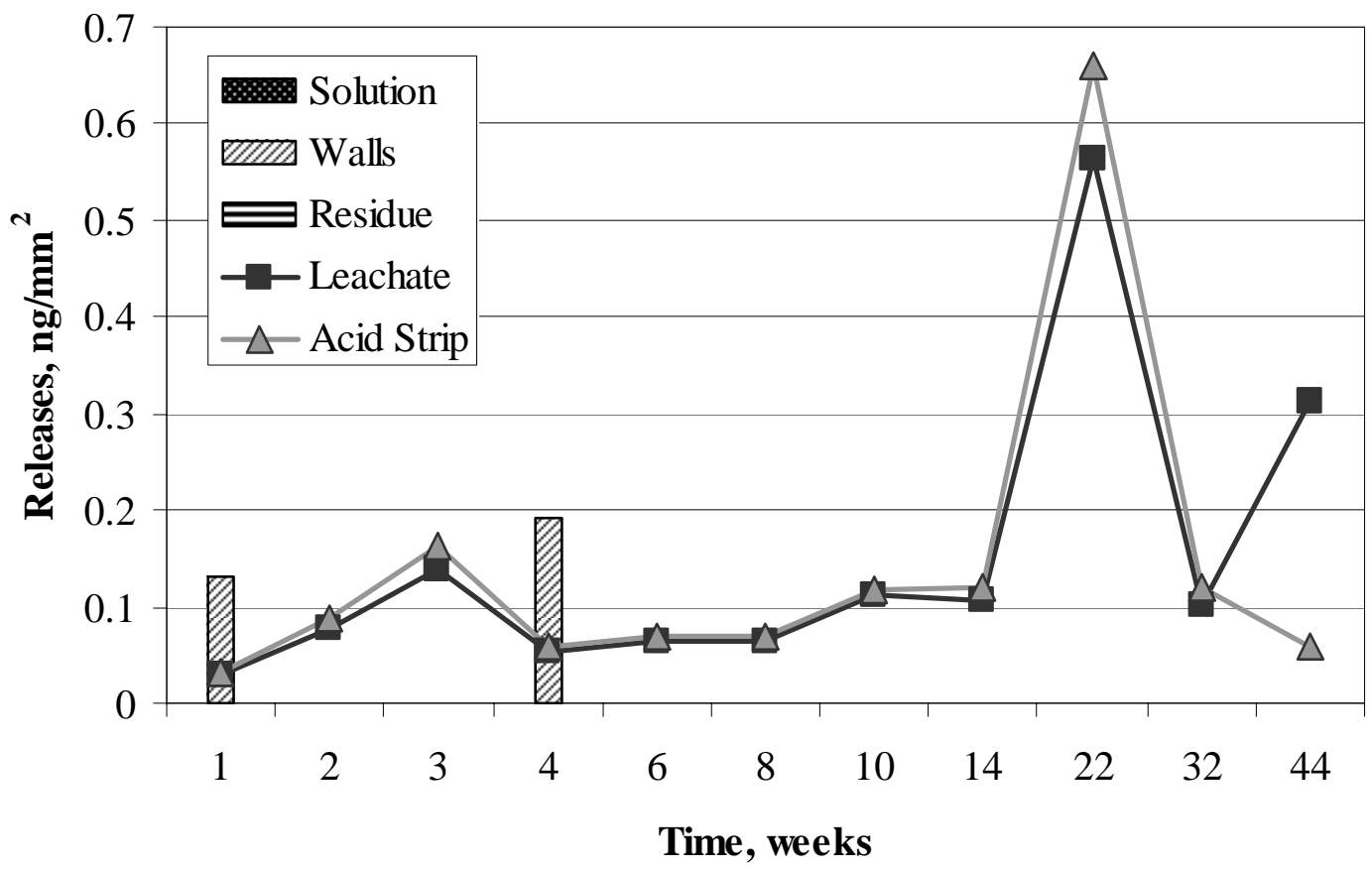

Figure E-219. Manganese Releases in Solution, on Walls, and in Residue from Polished Sample 3 in SJ13 and Average Detection Limits for Leachate and Acid Strip.

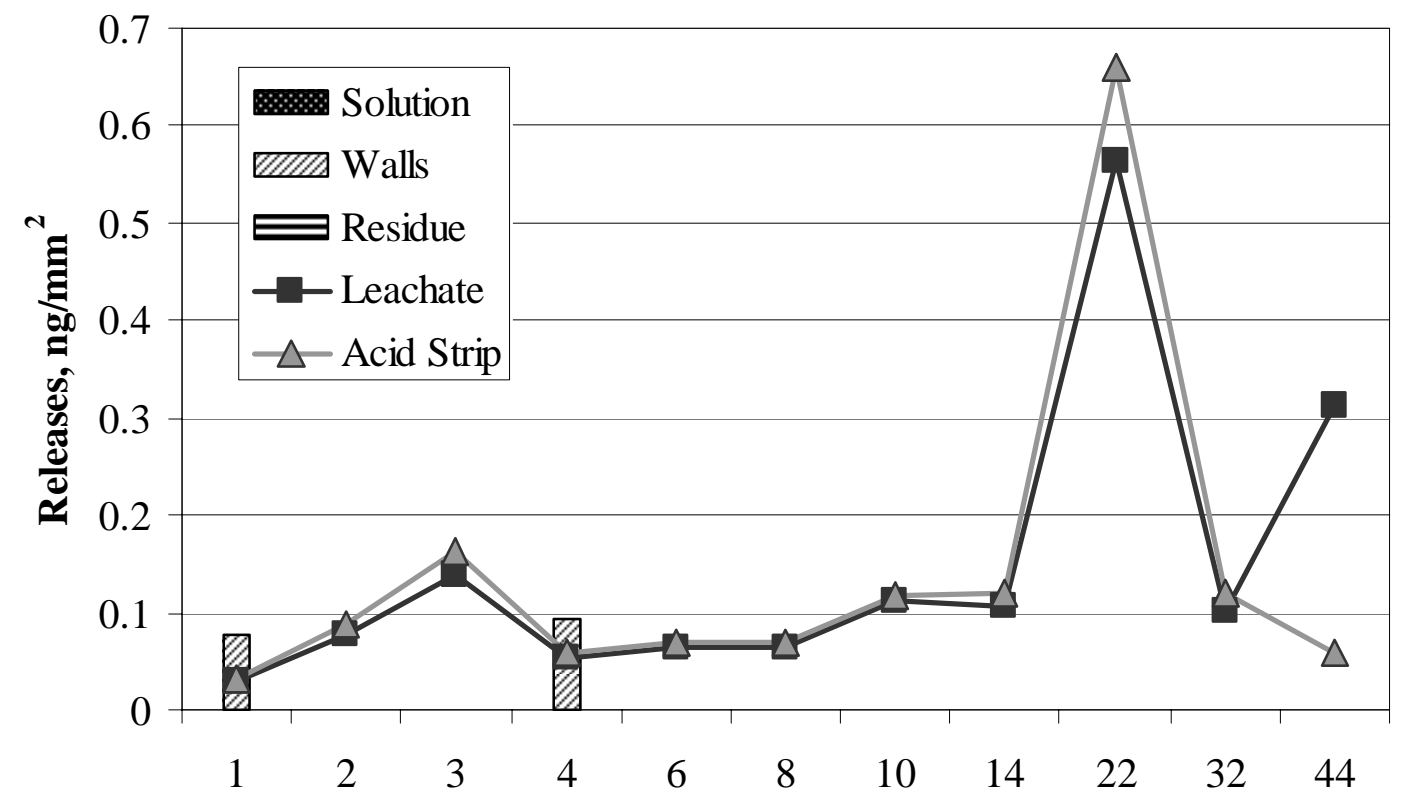

Time, weeks

Figure E-220. Manganese Releases in Solution, on Walls, and in Residue from Oxidized Sample 4 in SJ13 and Average Detection Limits for Leachate and Acid Strip. 


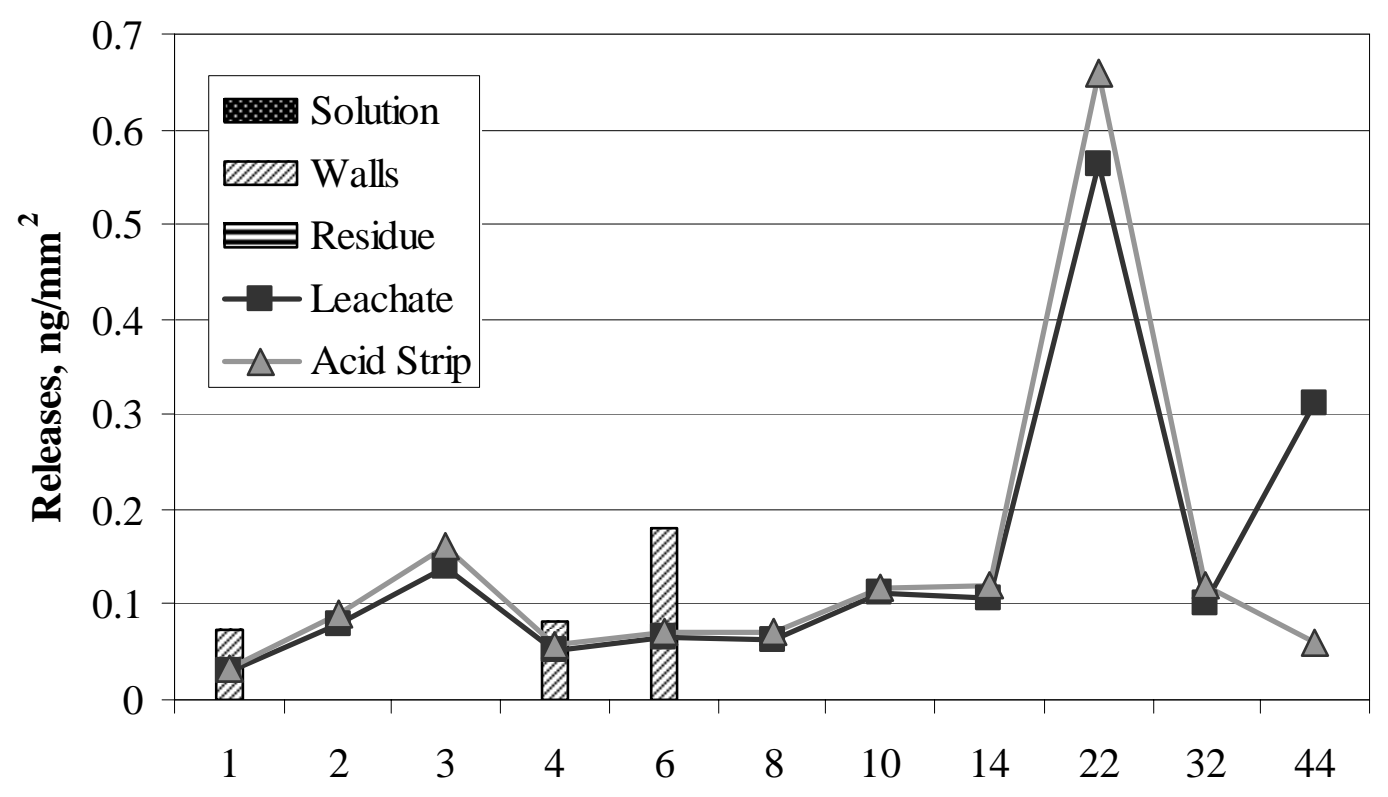

Time, weeks

Figure E-221. Manganese Releases in Solution, on Walls, and in Residue from Oxidized Sample 5 in SJ13 and Average Detection Limits for Leachate and Acid Strip.

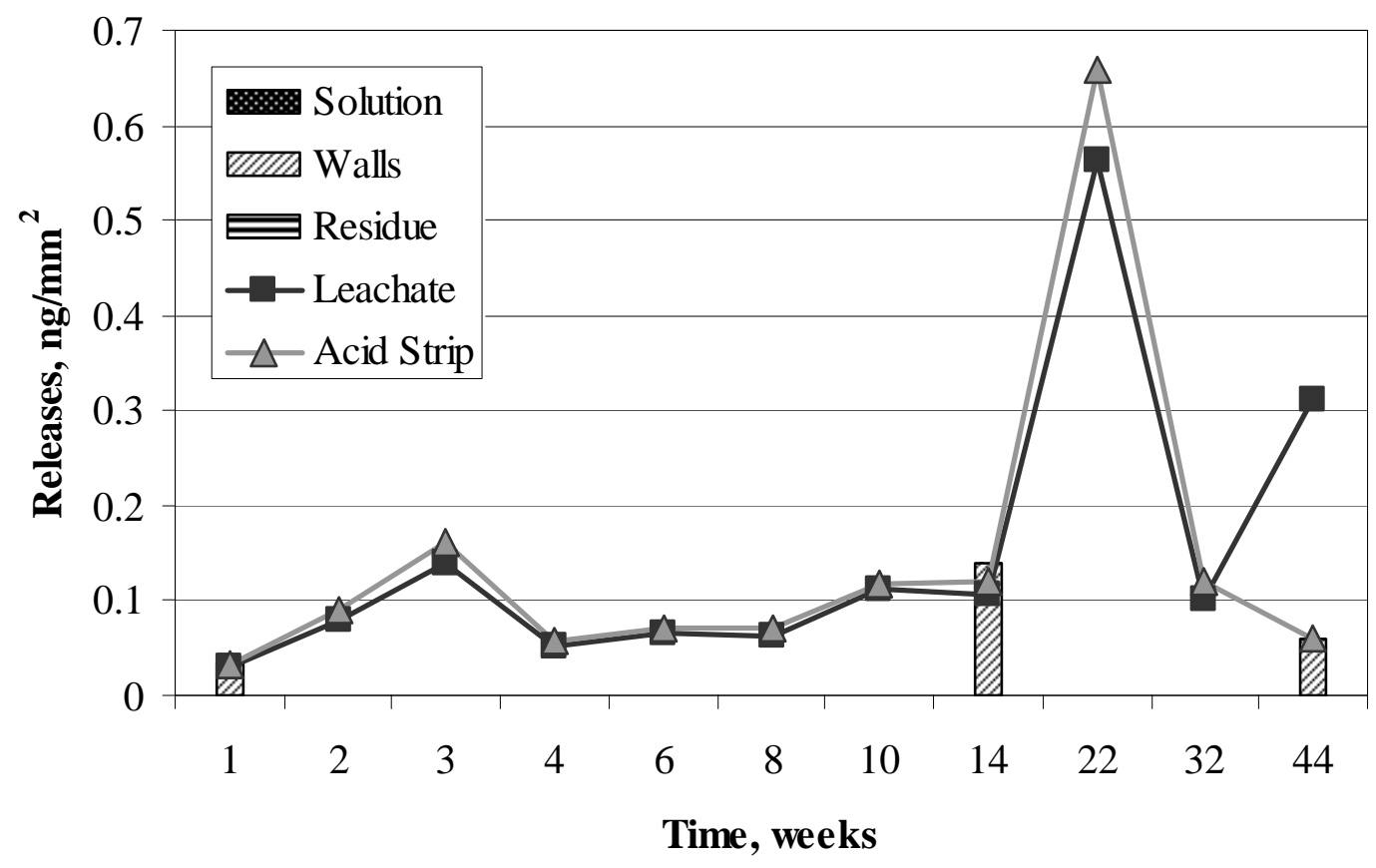

Figure E-222. Manganese Present in Solution, on Walls, and in Residue from SJ13 Control and Average Detection Limits for Leachate and Acid Strip. 


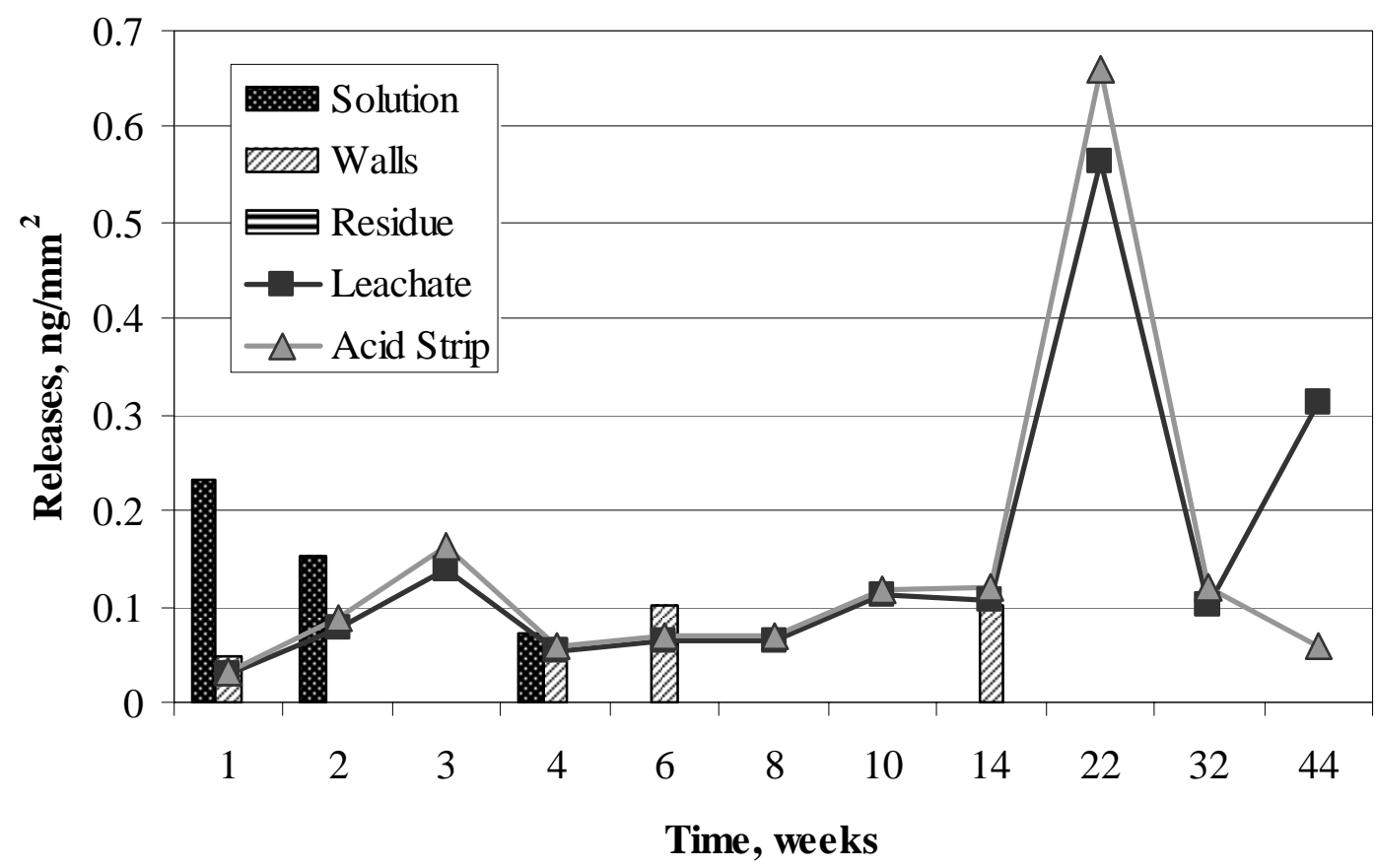

Figure E-223. Manganese Releases in Solution, on Walls, and in Residue from Polished Sample 1 in CJ13 and Average Detection Limits for Leachate and Acid Strip.

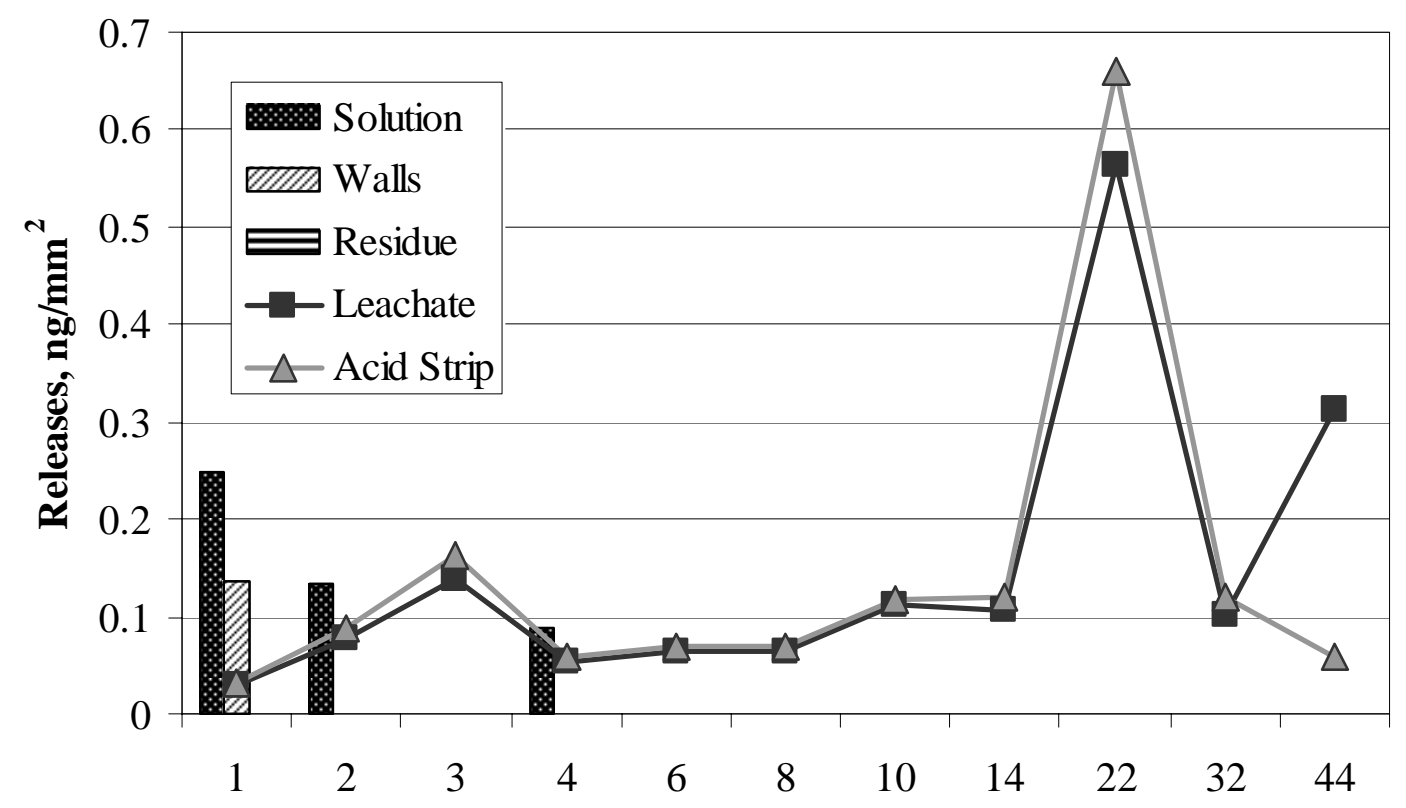

Time, weeks

Figure E-224. Manganese Releases in Solution, on Walls, and in Residue from Polished Sample 2 in CJ13 and Average Detection Limits for Leachate and Acid Strip. 


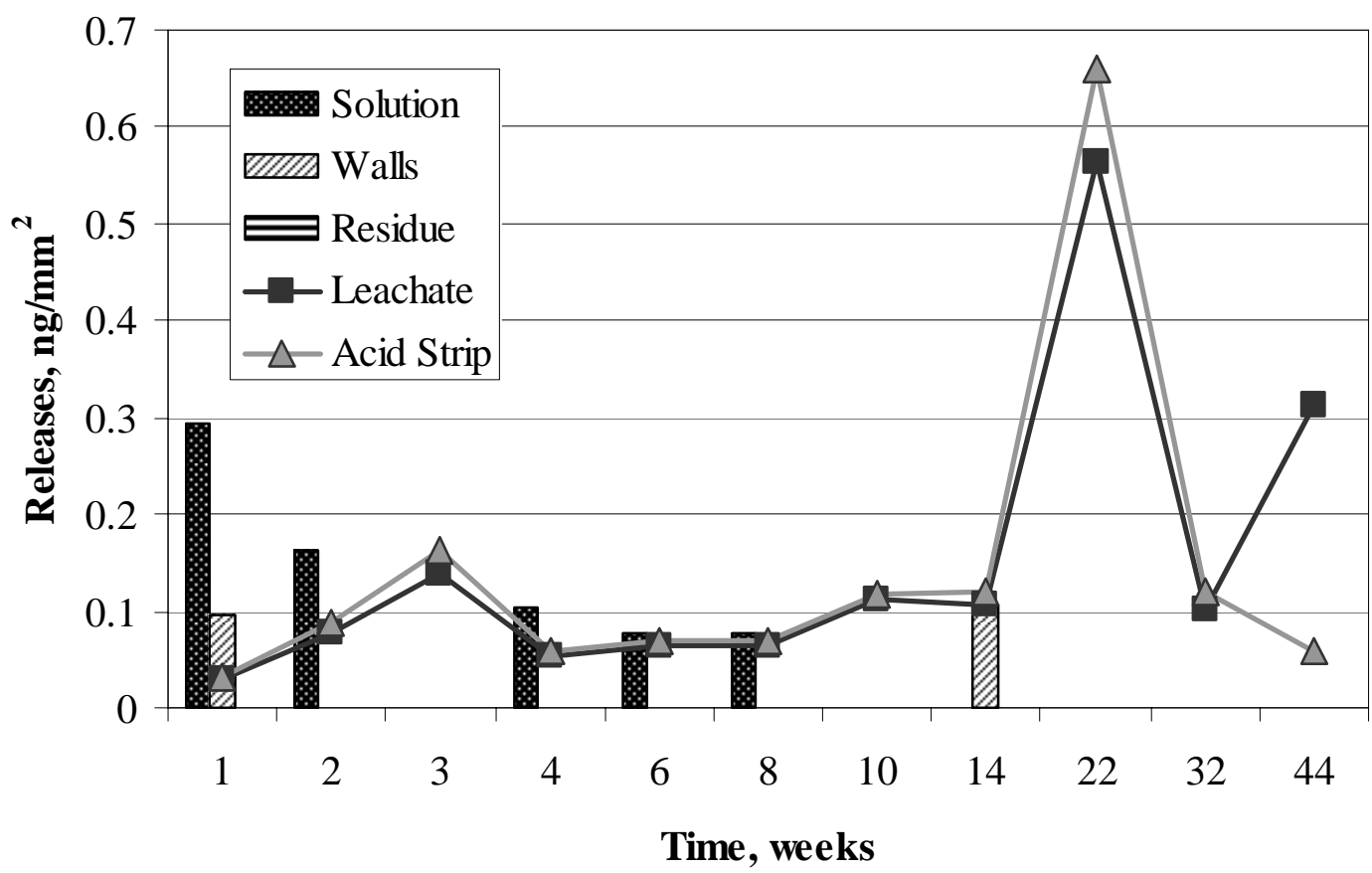

Figure E-225. Manganese Releases in Solution, on Walls, and in Residue from Polished Sample 3 in CJ13 and Average Detection Limits for Leachate and Acid Strip.

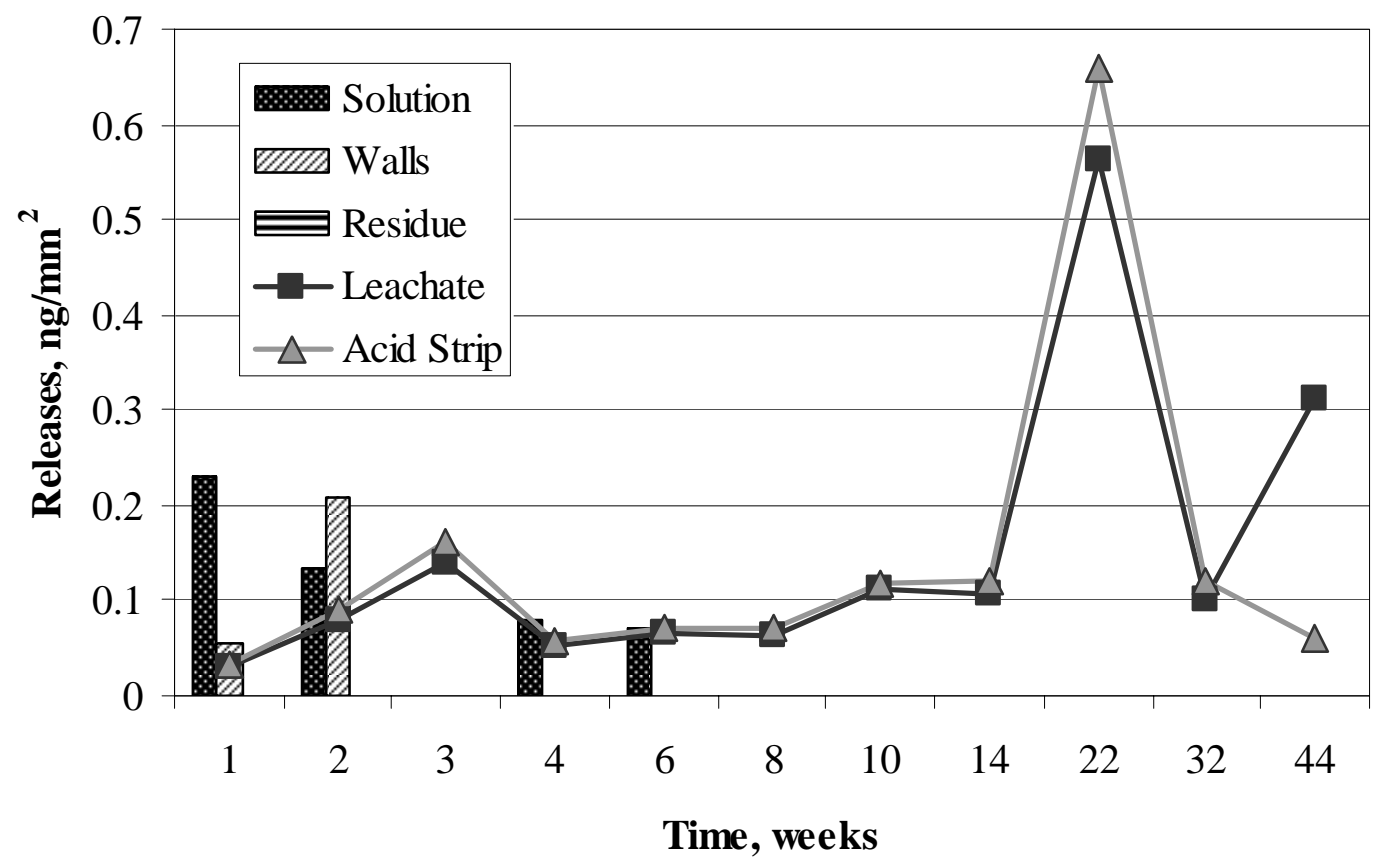

Figure E-226. Manganese Releases in Solution, on Walls, and in Residue from Oxidized Sample 4 in CJ13 and Average Detection Limits for Leachate and Acid Strip. 


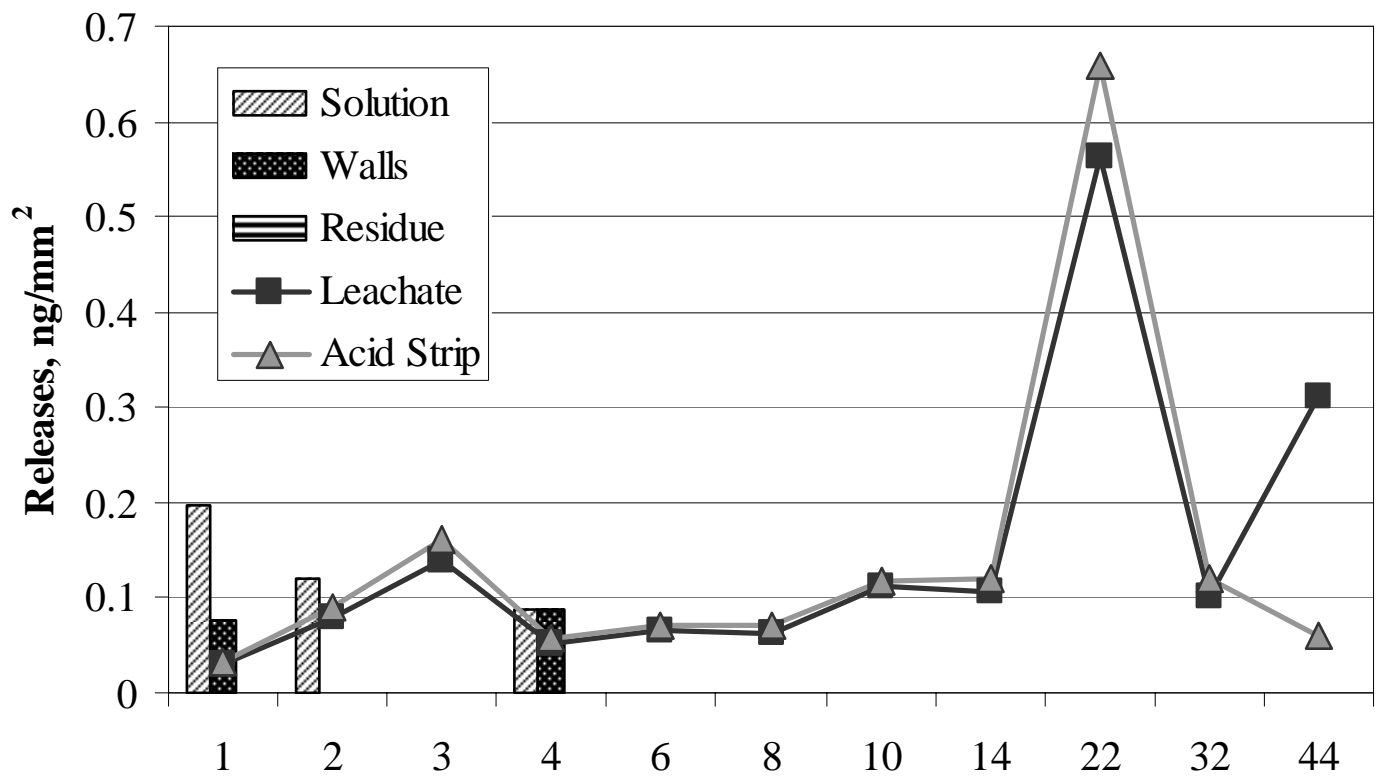

Time, weeks

Figure E-227. Manganese Releases in Solution, on Walls, and in Residue from Oxidized Sample 5 in CJ13 and Average Detection Limits for Leachate and Acid Strip.

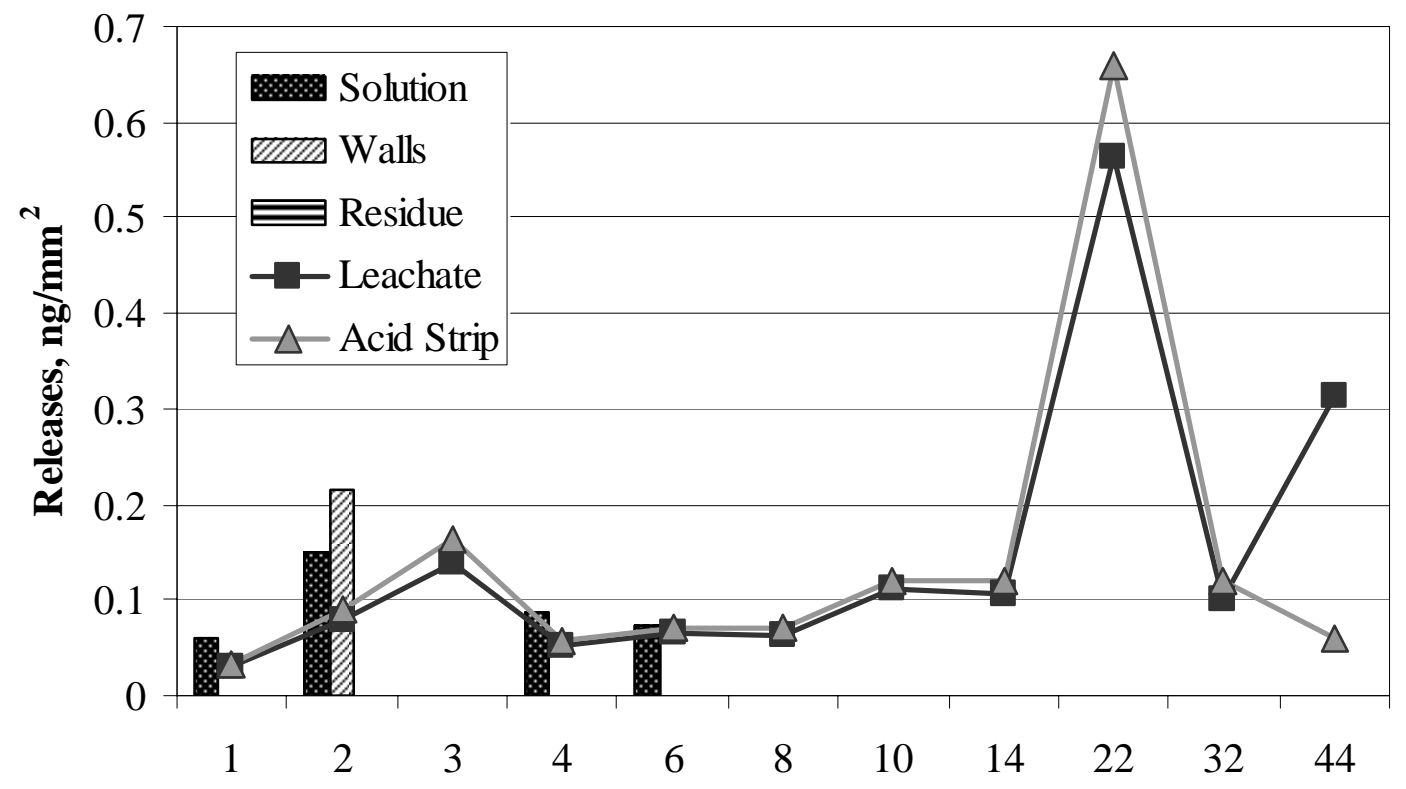

Time, weeks

Figure E-228. Manganese Present in Solution, on Walls, and in Residue from CJ13 Control and Average Detection Limits for Leachate and Acid Strip. 


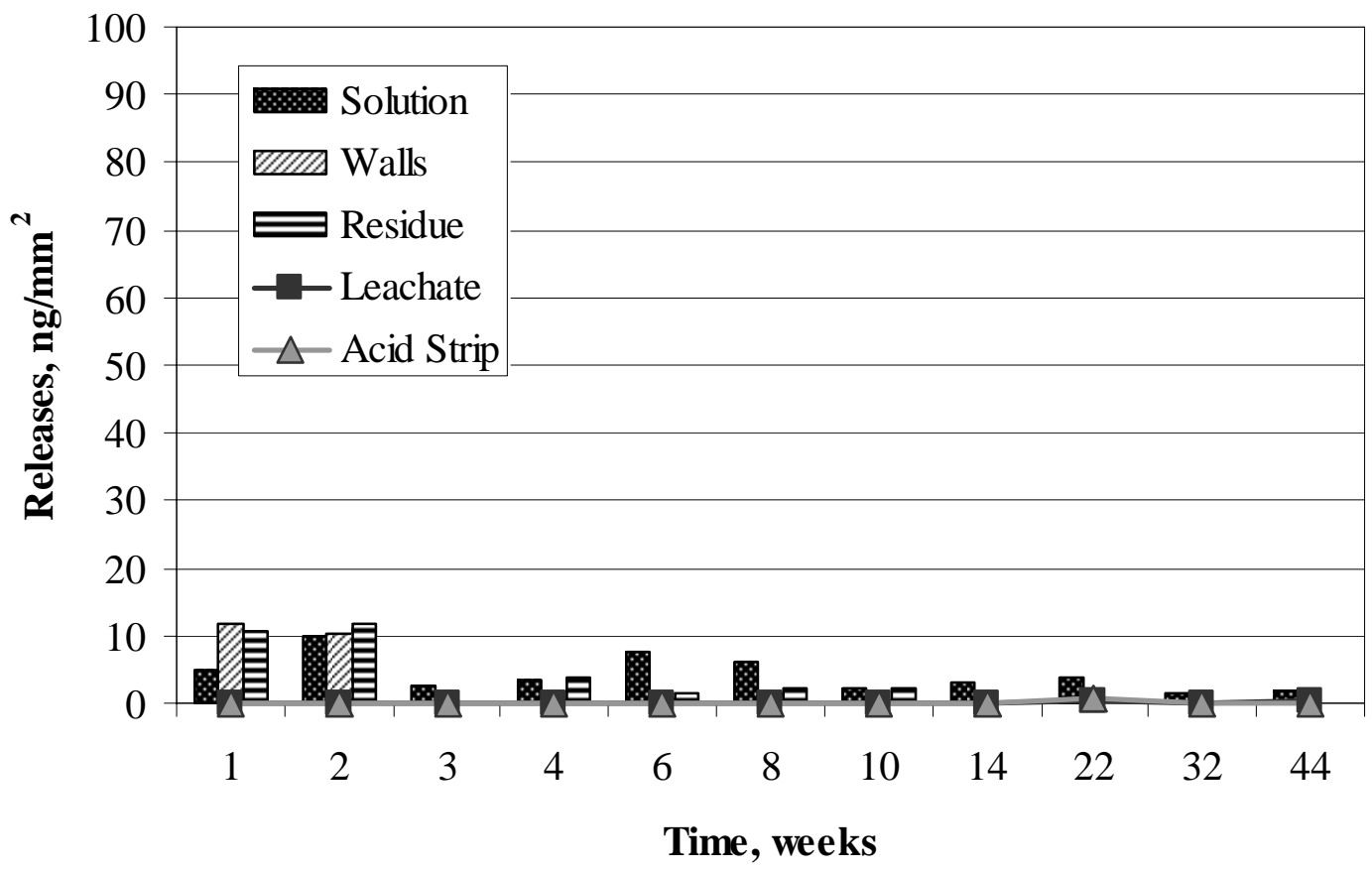

Figure E-229. Manganese Releases in Solution, on Walls, and in Residue from Polished Sample 1 in $10 \mathrm{KCl}$ and Average Detection Limits for Leachate and Acid Strip.

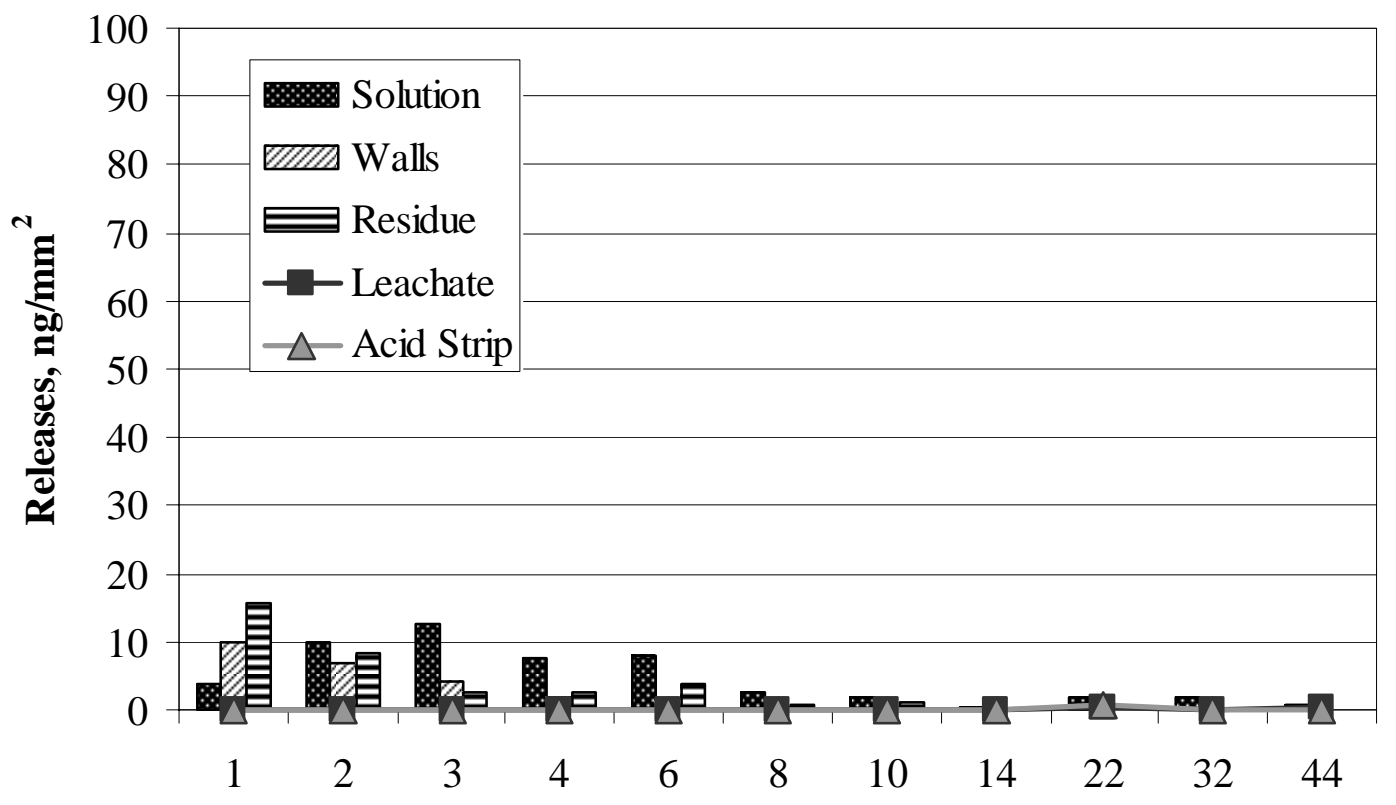

Time, weeks

Figure E-230. Manganese Releases in Solution, on Walls, and in Residue from Polished Sample 2 in $10 \mathrm{KCl}$ and Average Detection Limits for Leachate and Acid Strip. 


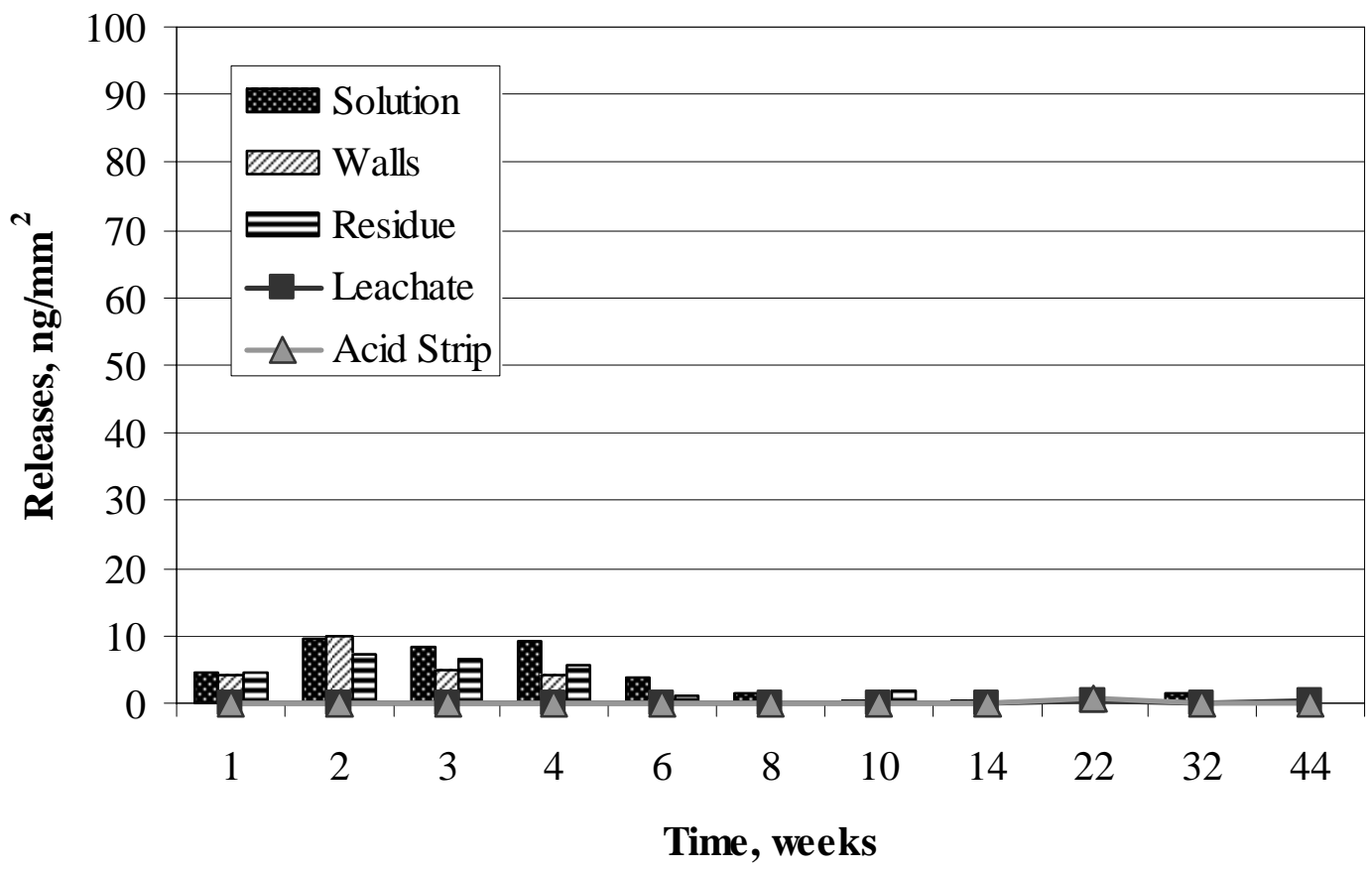

Figure E-231. Manganese Releases in Solution, on Walls, and in Residue from Polished Sample 3 in $10 \mathrm{KCl}$ and Average Detection Limits for Leachate and Acid Strip.

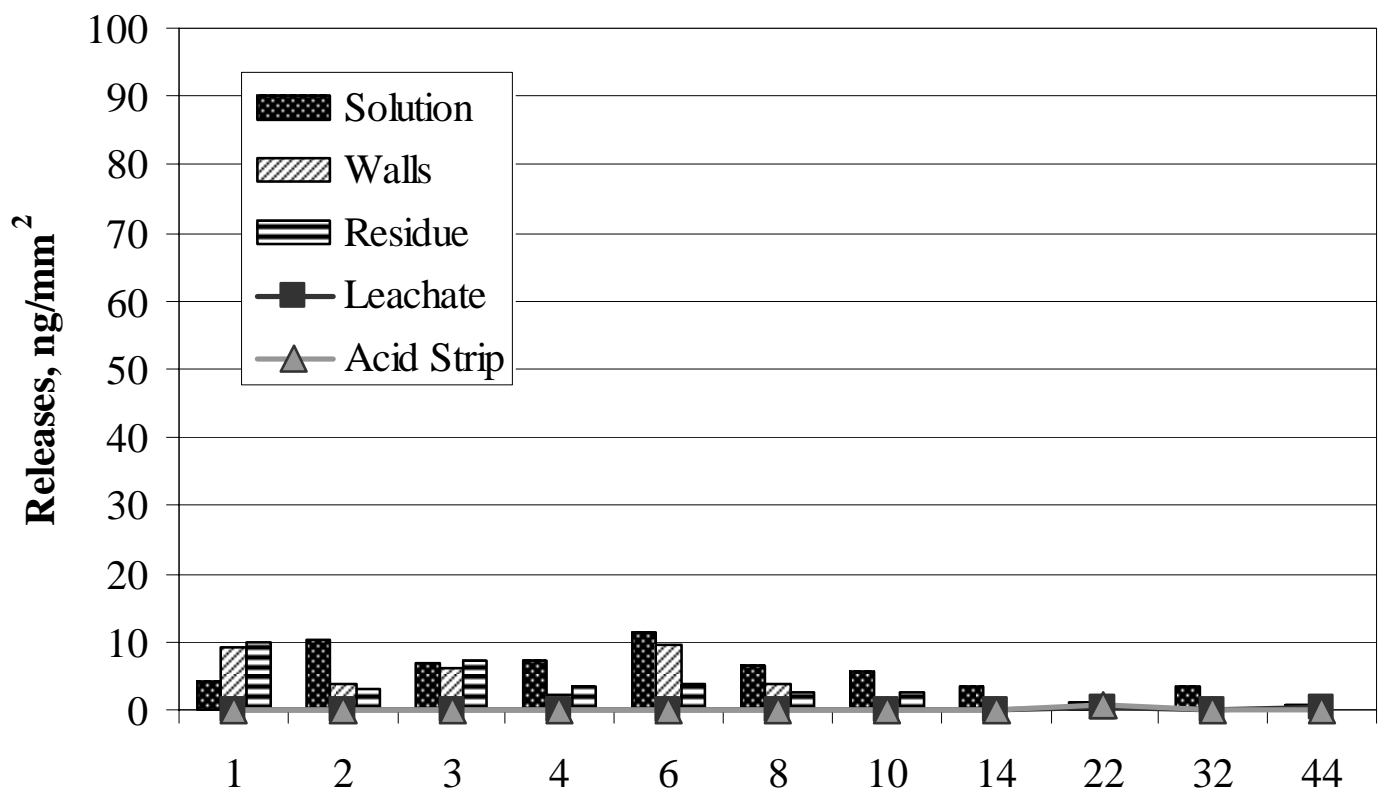

Time, weeks

Figure E-232. Manganese Releases in Solution, on Walls, and in Residue from Oxidized Sample 4 in 10KCl and Average Detection Limits for Leachate and Acid Strip. 


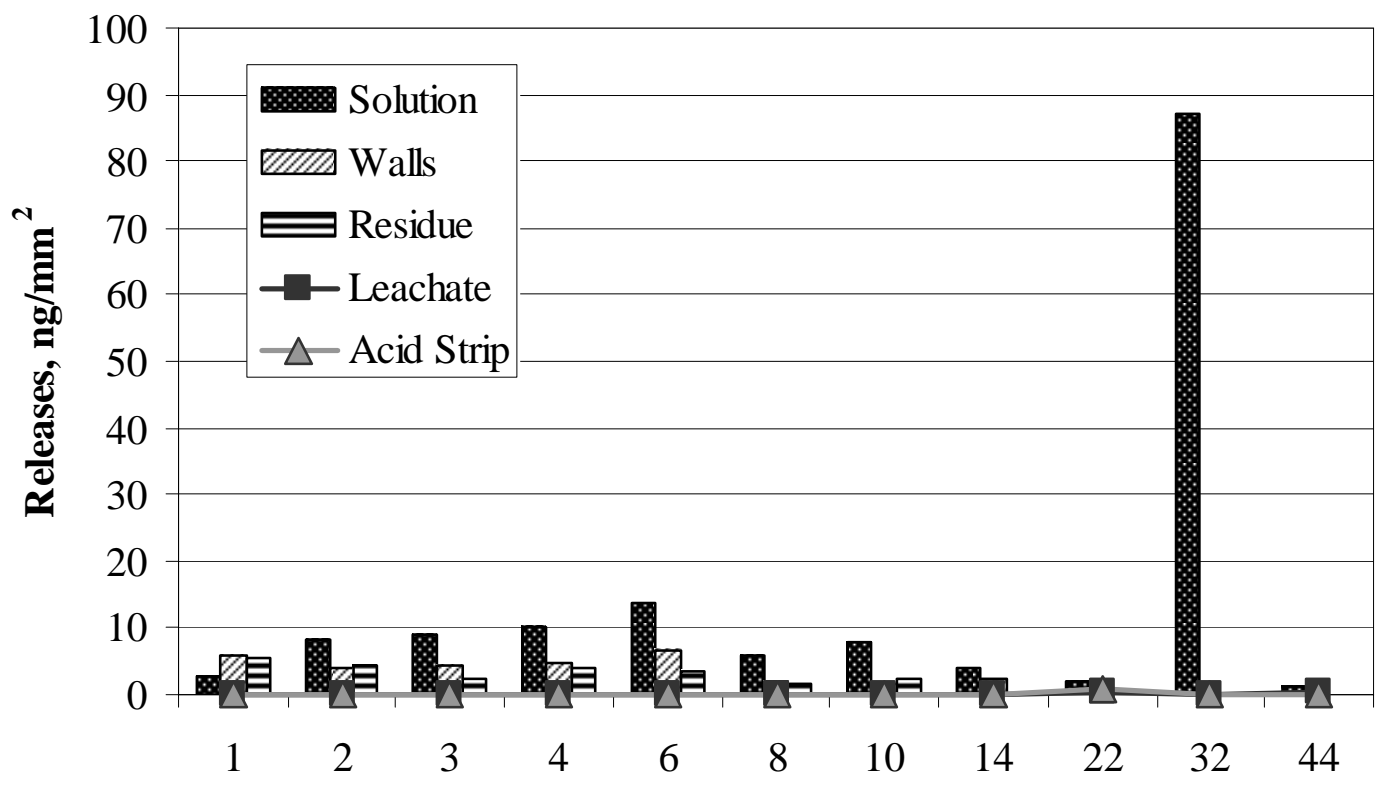

Time, weeks

Figure E-233. Manganese Releases in Solution, on Walls, and in Residue from Oxidized Sample 5 in 10KCl and Average Detection Limits for Leachate and Acid Strip.

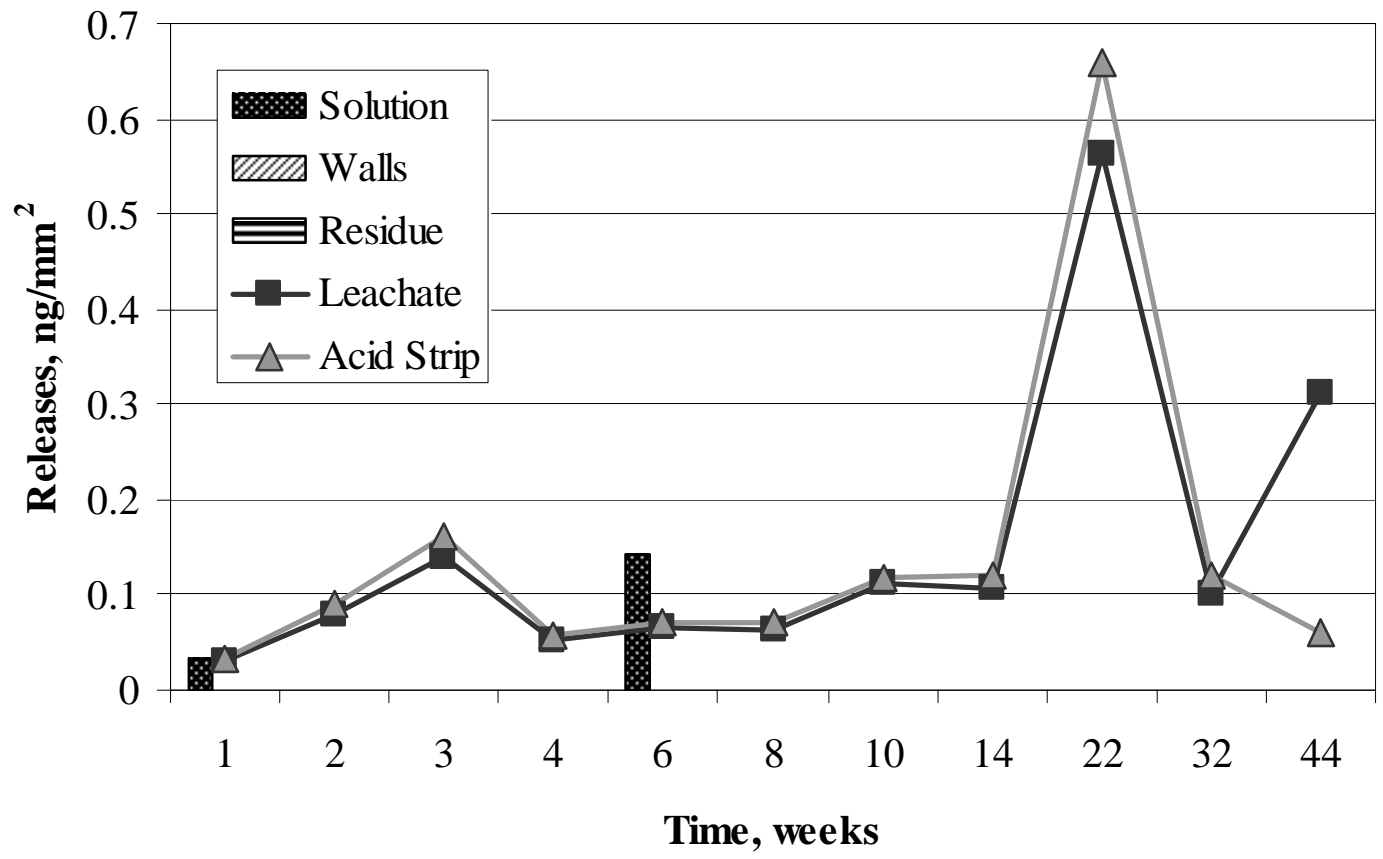

Figure E-234. Manganese Present in Solution, on Walls, and in Residue from $10 \mathrm{KCl}$ Control and Average Detection Limits for Leachate and Acid Strip. 


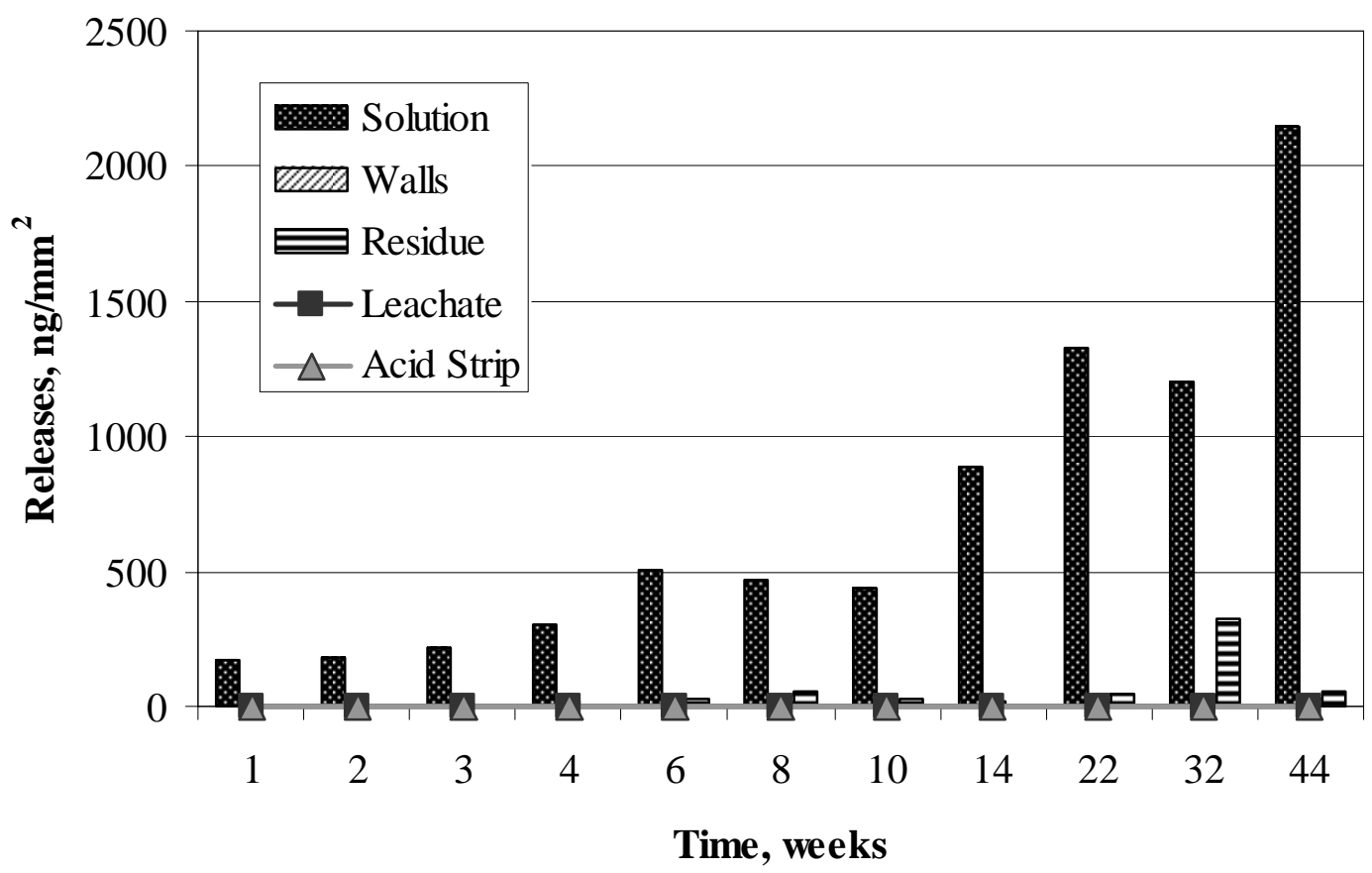

Figure E-235. Manganese Releases in Solution, on Walls, and in Residue from Polished Sample 1 in AJ13 and Average Detection Limits for Leachate and Acid Strip.

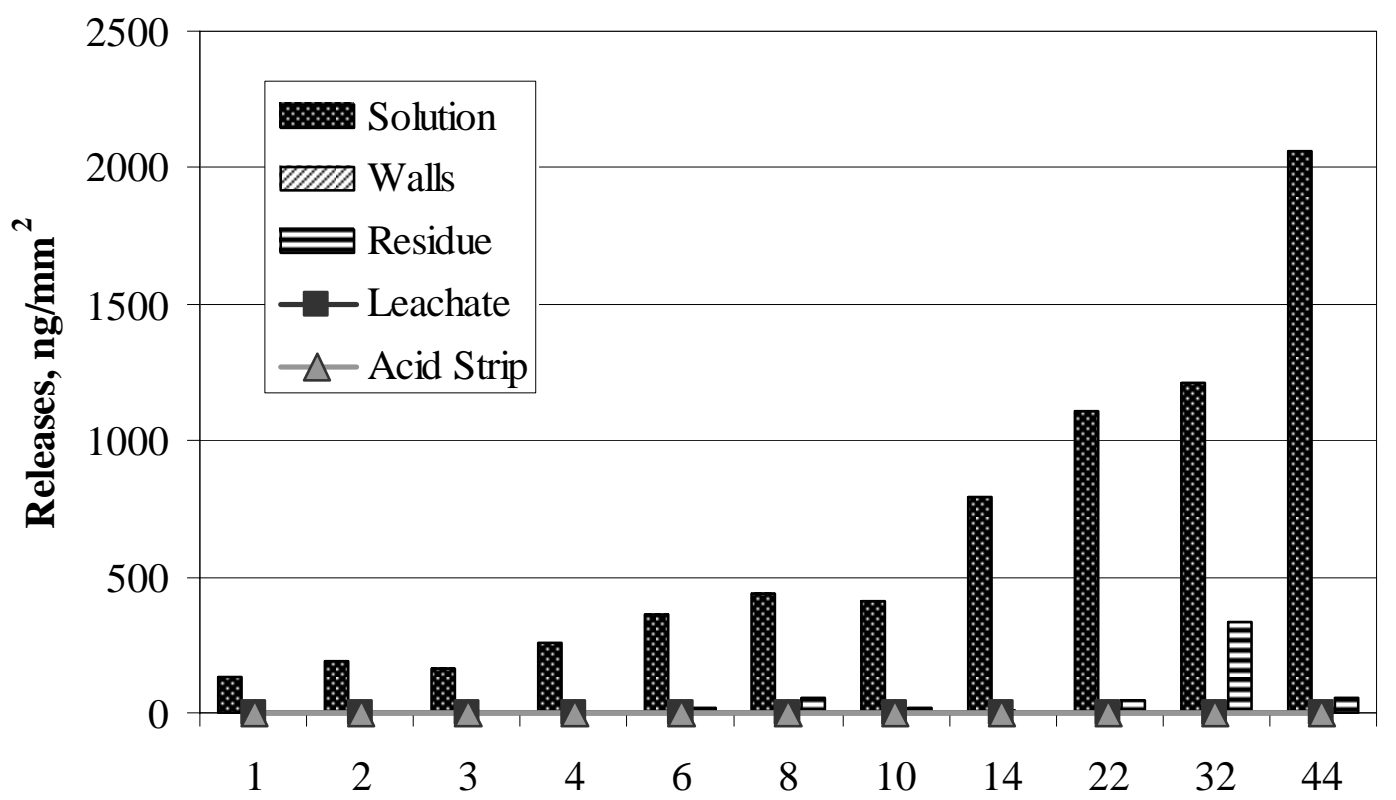

Time, weeks

Figure E-236. Manganese Releases in Solution, on Walls, and in Residue from Polished Sample 2 in AJ13 and Average Detection Limits for Leachate and Acid Strip. 


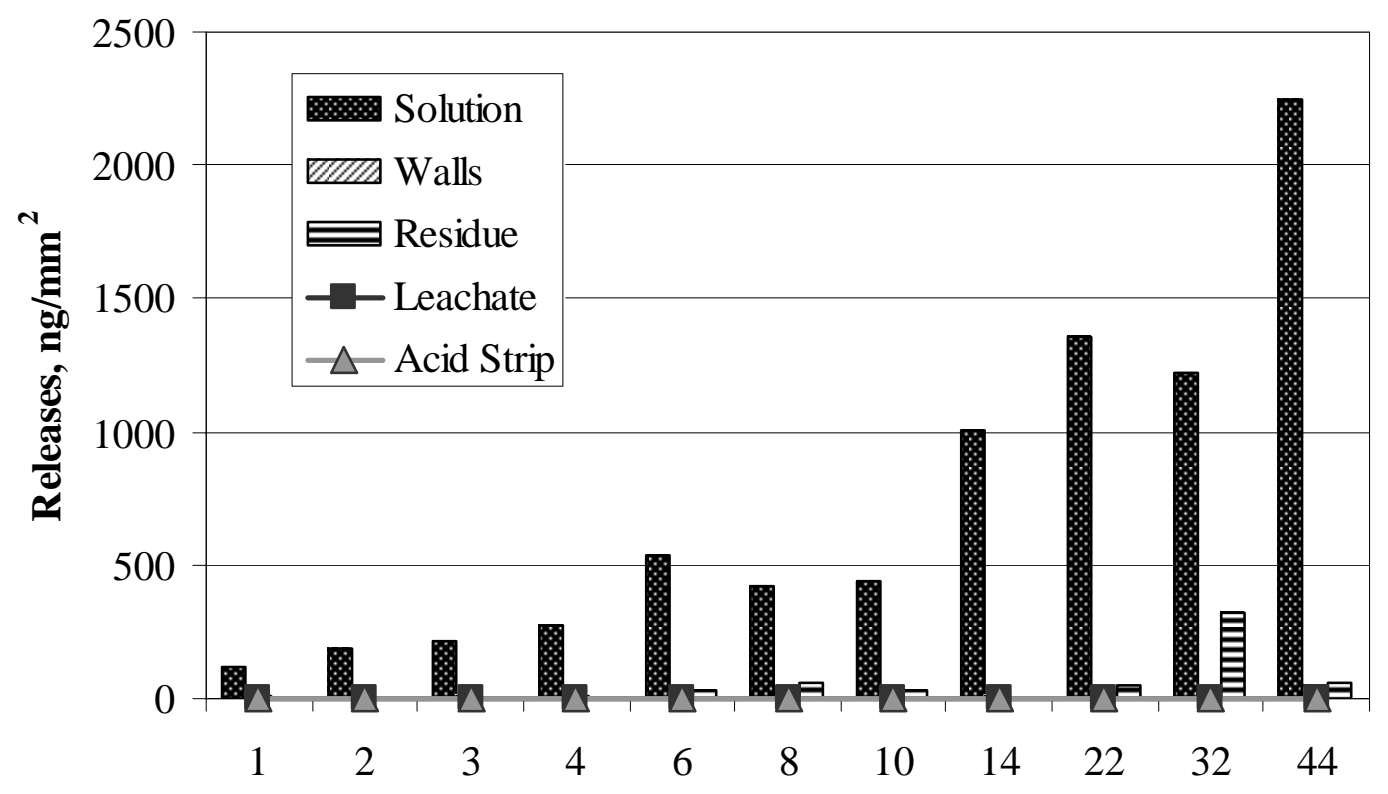

Time, weeks

Figure E-237. Manganese Releases in Solution, on Walls, and in Residue from Polished Sample 3 in AJ13 and Average Detection Limits for Leachate and Acid Strip.

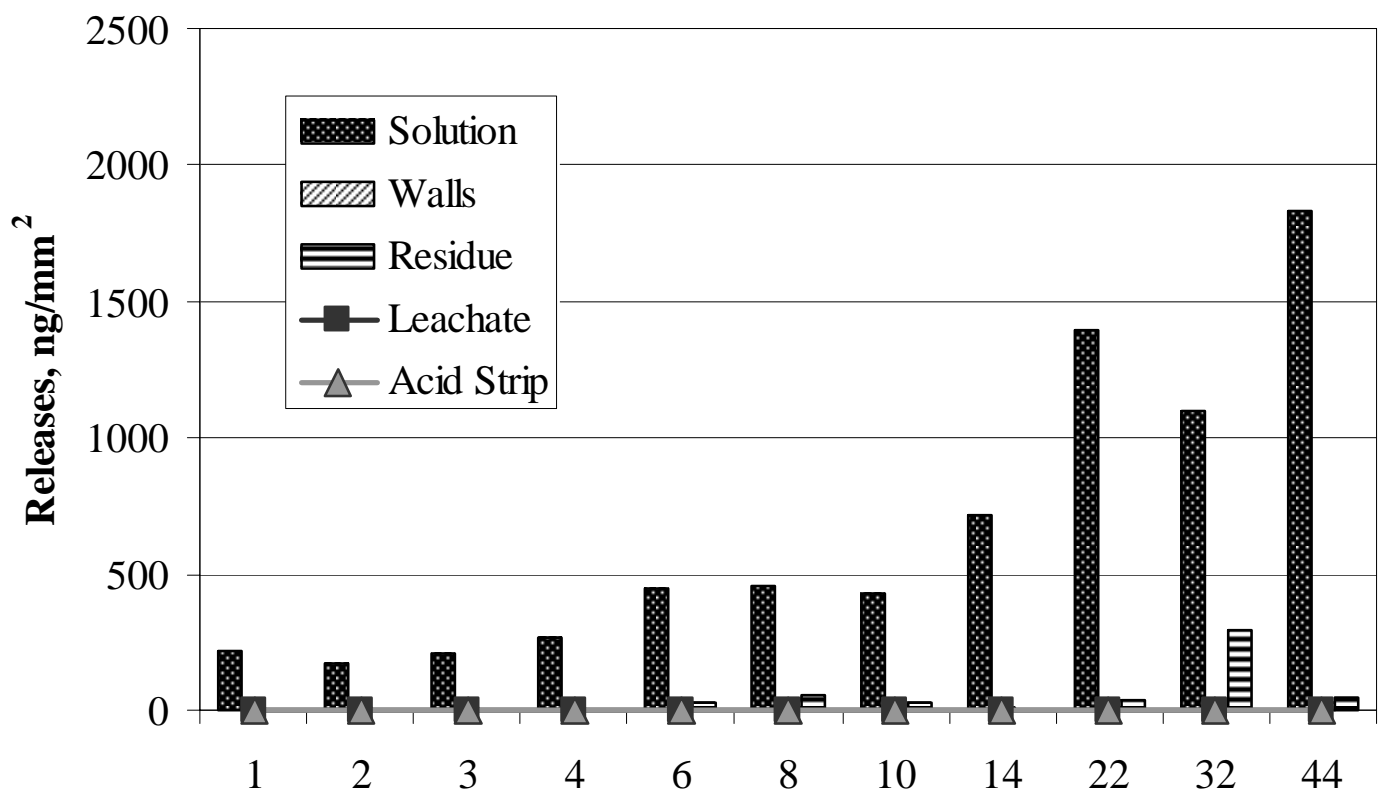

Time, weeks

Figure E-238. Manganese Releases in Solution, on Walls, and in Residue from Oxidized Sample 4 in AJ13 and Average Detection Limits for Leachate and Acid Strip. 


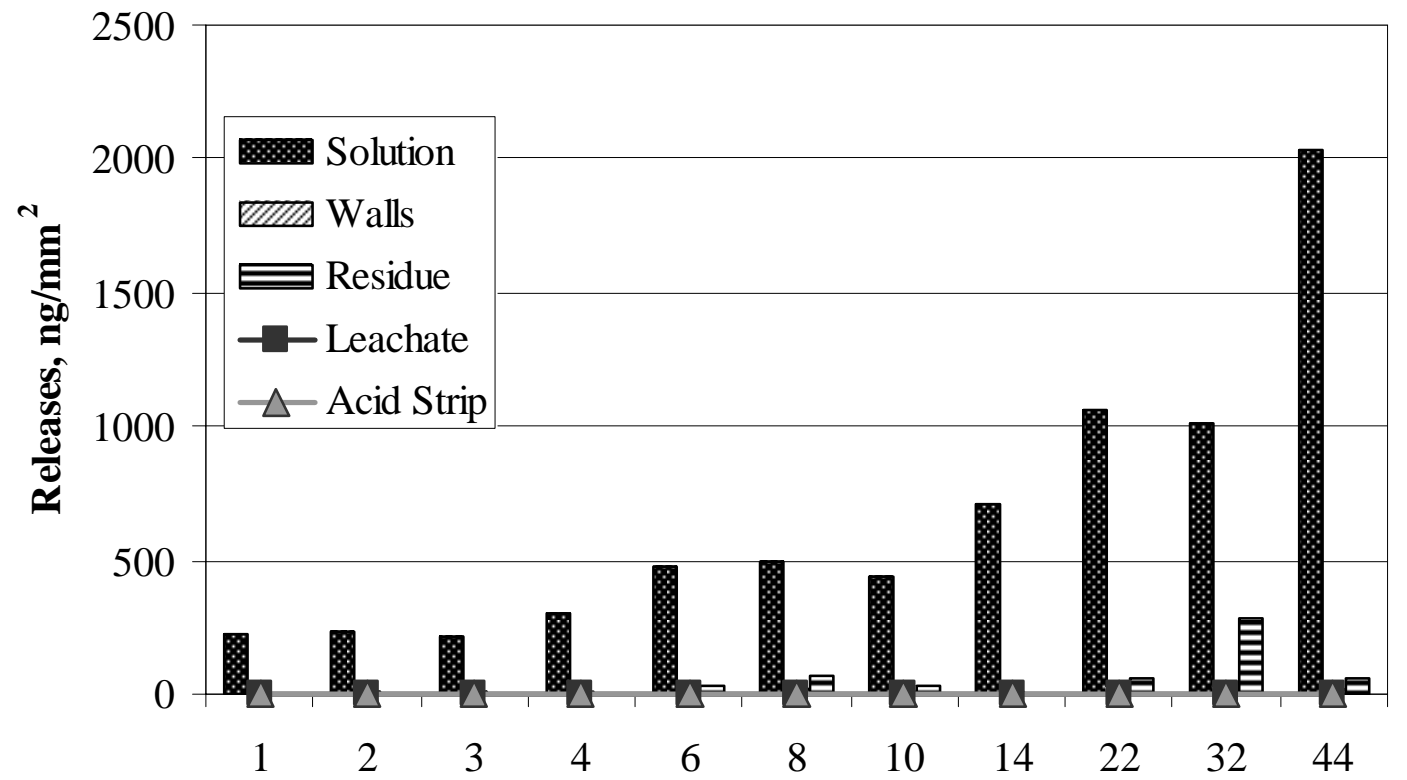

Time, weeks

Figure E-239. Manganese Releases in Solution, on Walls, and in Residue from Oxidized Sample 5 in AJ13 and Average Detection Limits for Leachate and Acid Strip.

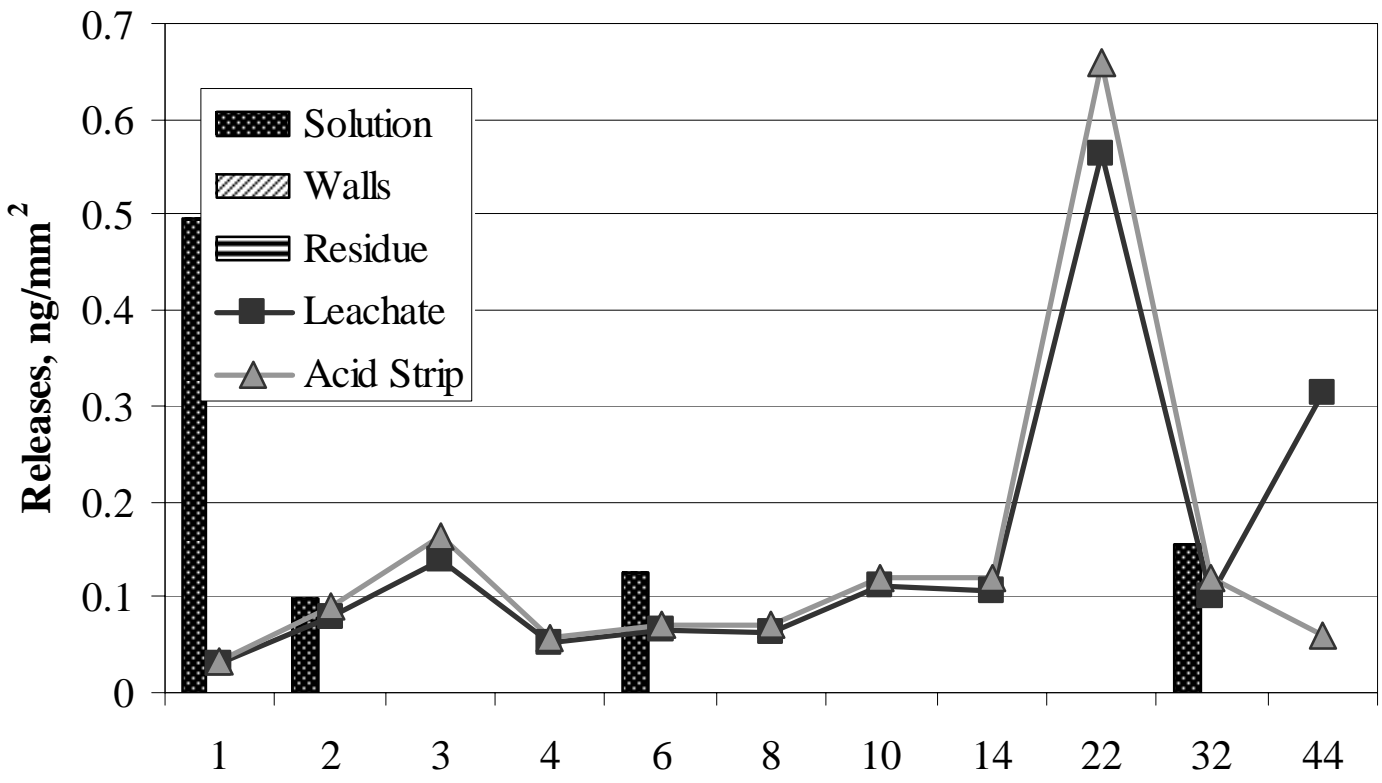

Time, weeks

Figure E-240. Manganese Present in Solution, on Walls, and in Residue from AJ13 Control and Average Detection Limits for Leachate and Acid Strip. 


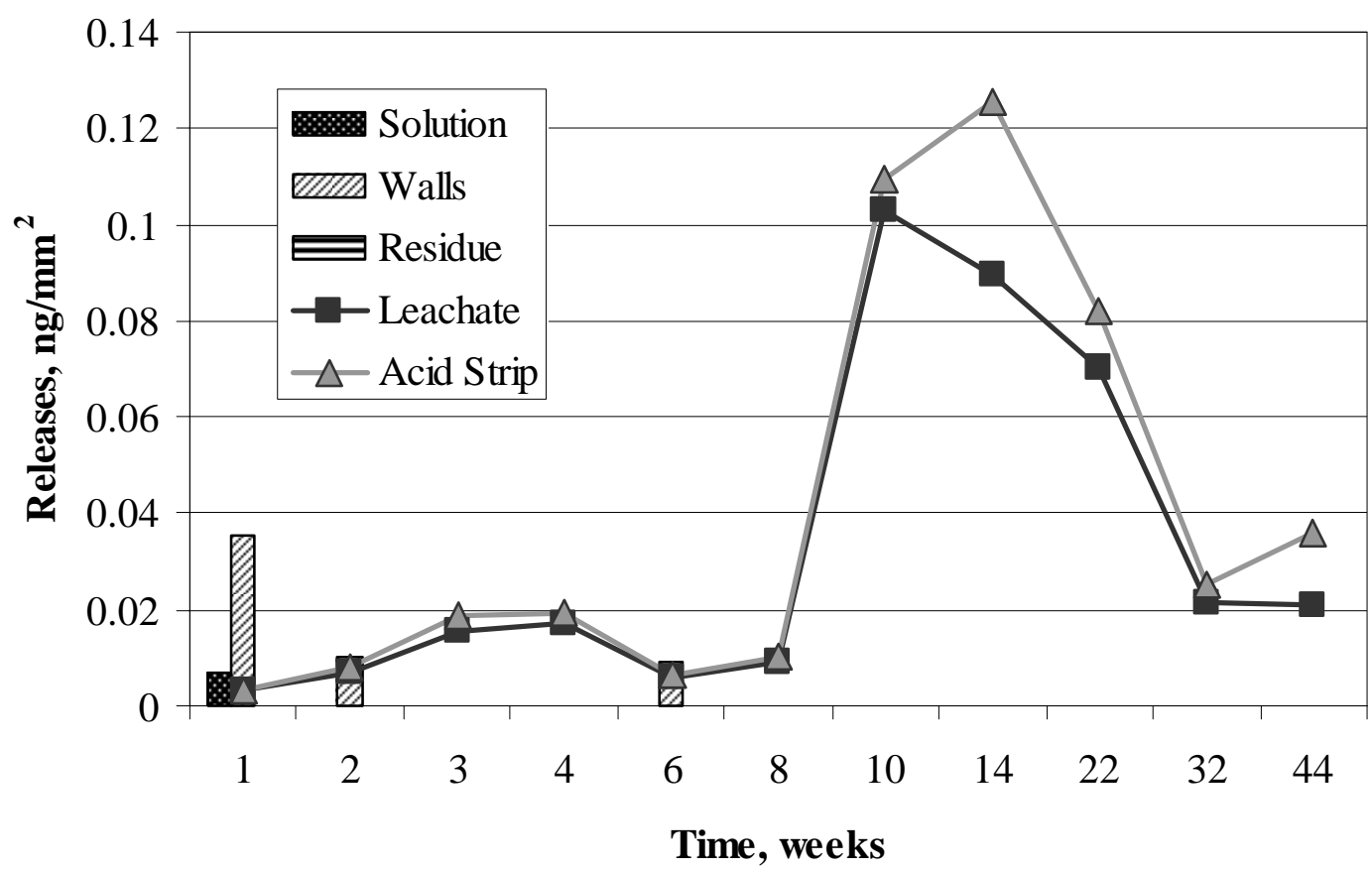

Figure E-241. Cobalt Releases in Solution, on Walls, and in Residue from Polished Sample 1 in SJ13 and Average Detection Limits for Leachate and Acid Strip.

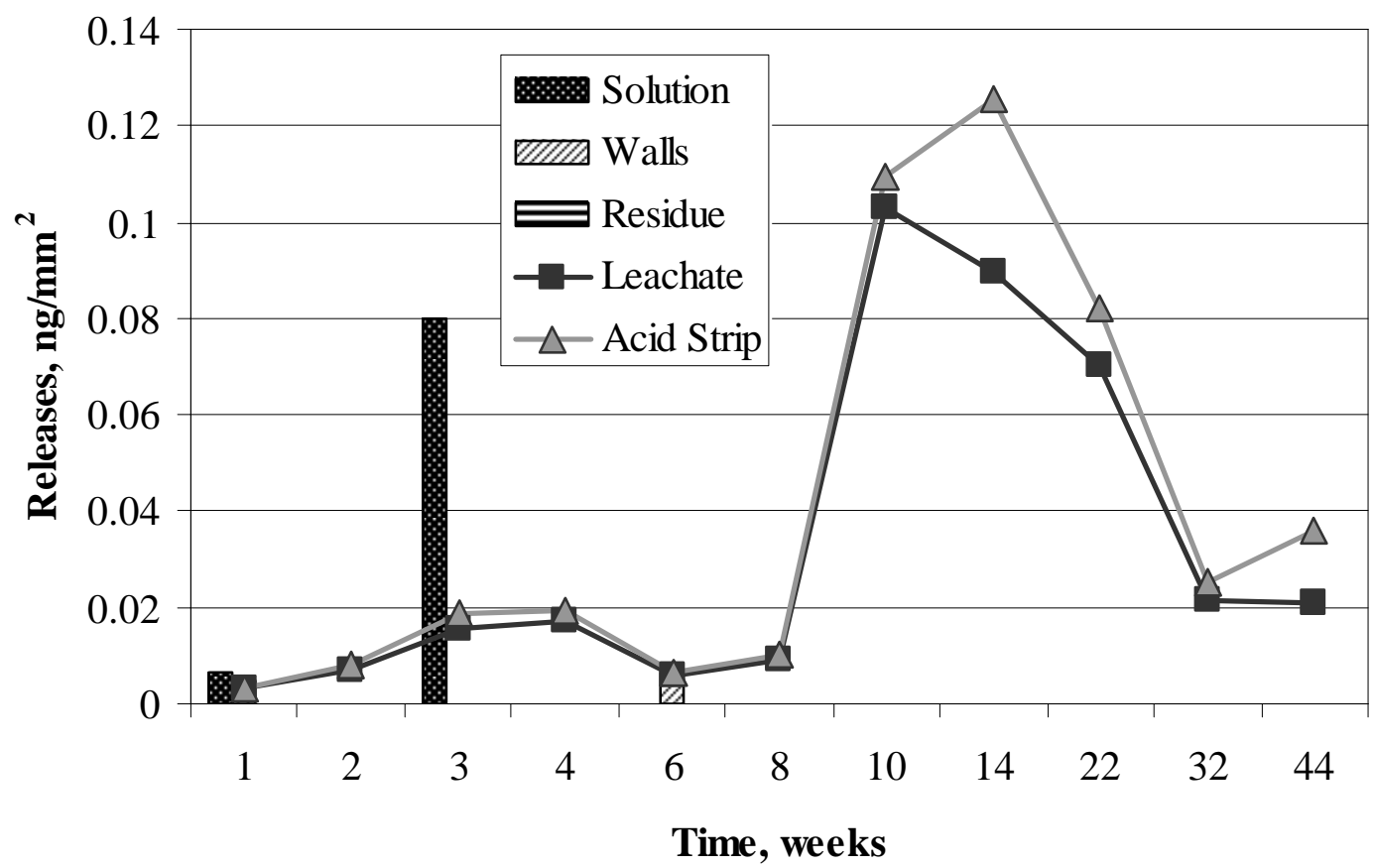

Figure E-242. Cobalt Releases in Solution, on Walls, and in Residue from Polished Sample 2 in SJ13 and Average Detection Limits for Leachate and Acid Strip. 


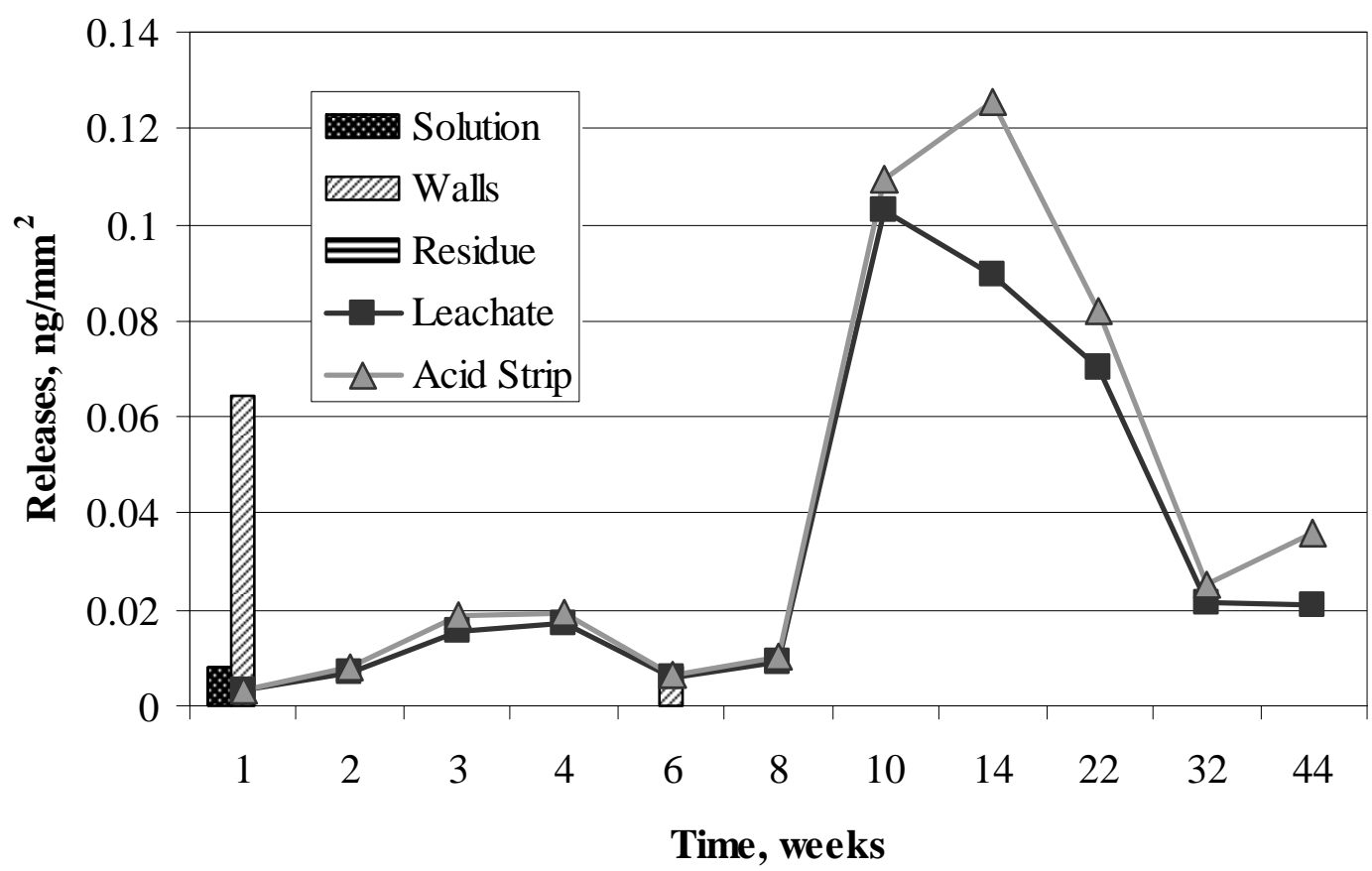

Figure E-243. Cobalt Releases in Solution, on Walls, and in Residue from Polished Sample 3 in SJ13 and Average Detection Limits for Leachate and Acid Strip.

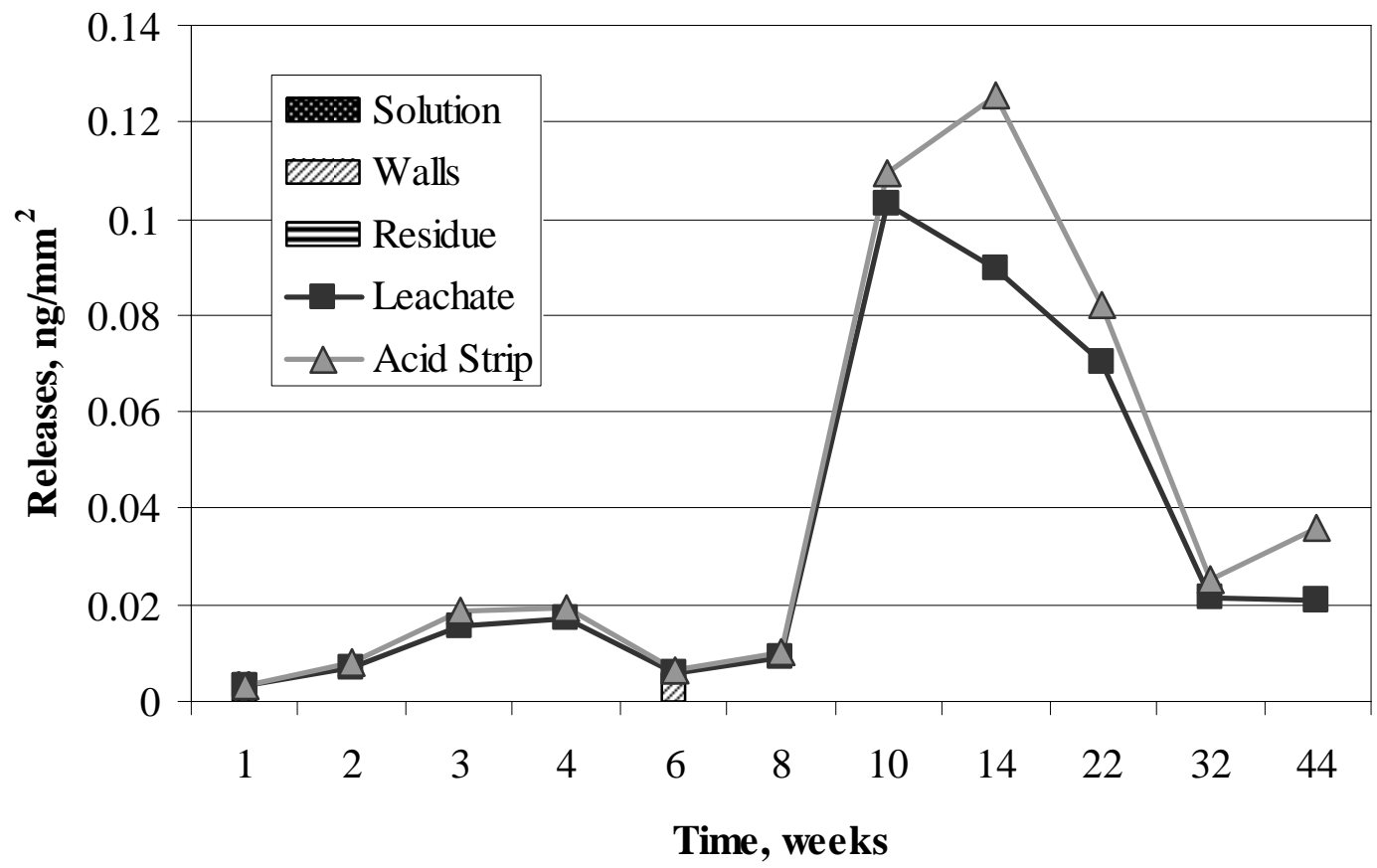

Figure E-244. Cobalt Releases in Solution, on Walls, and in Residue from Oxidized Sample 4 in SJ13 and Average Detection Limits for Leachate and Acid Strip. 


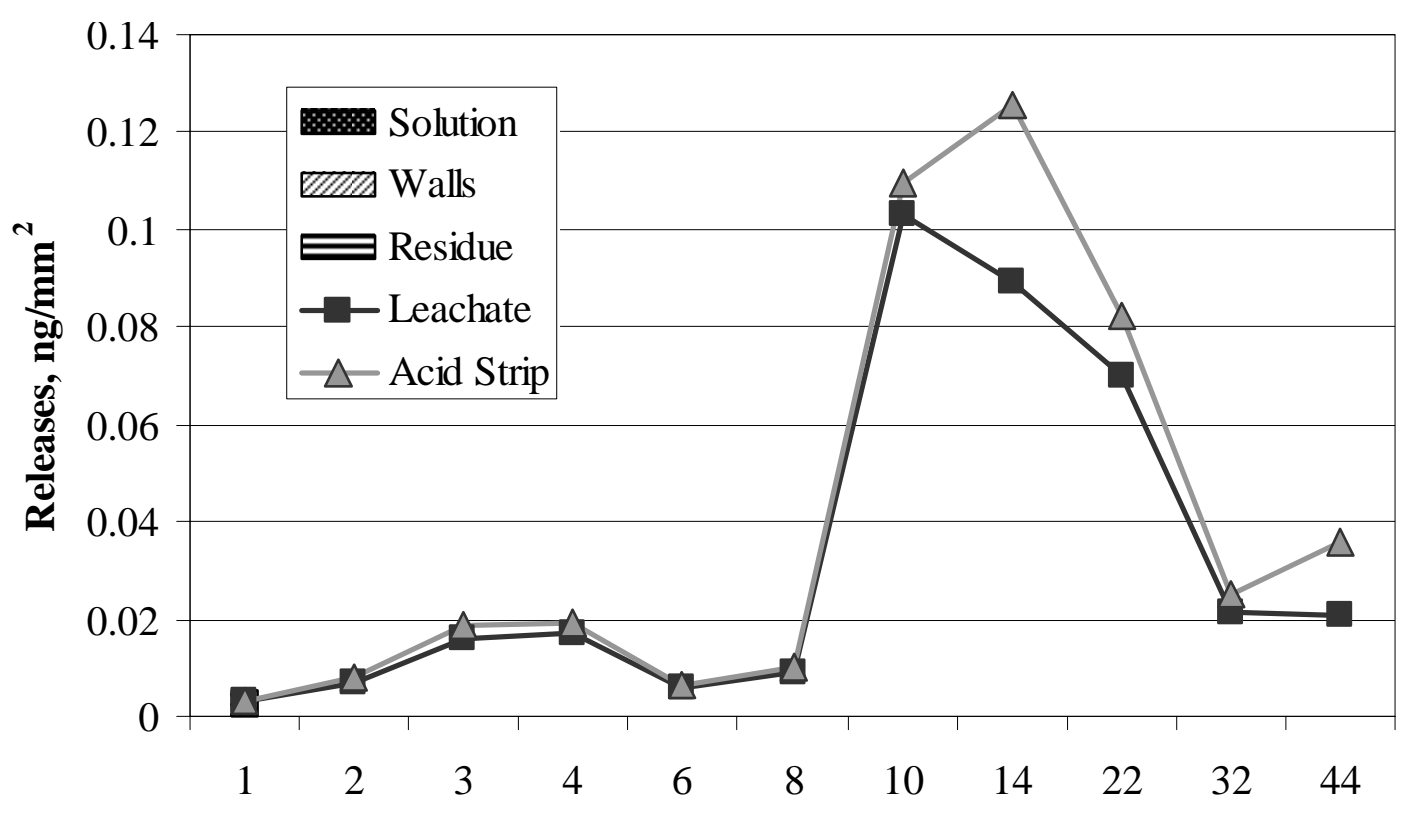

Time, weeks

Figure E-245. Cobalt Releases in Solution, on Walls, and in Residue from Oxidized Sample 5 in SJ13 and Average Detection Limits for Leachate and Acid Strip.

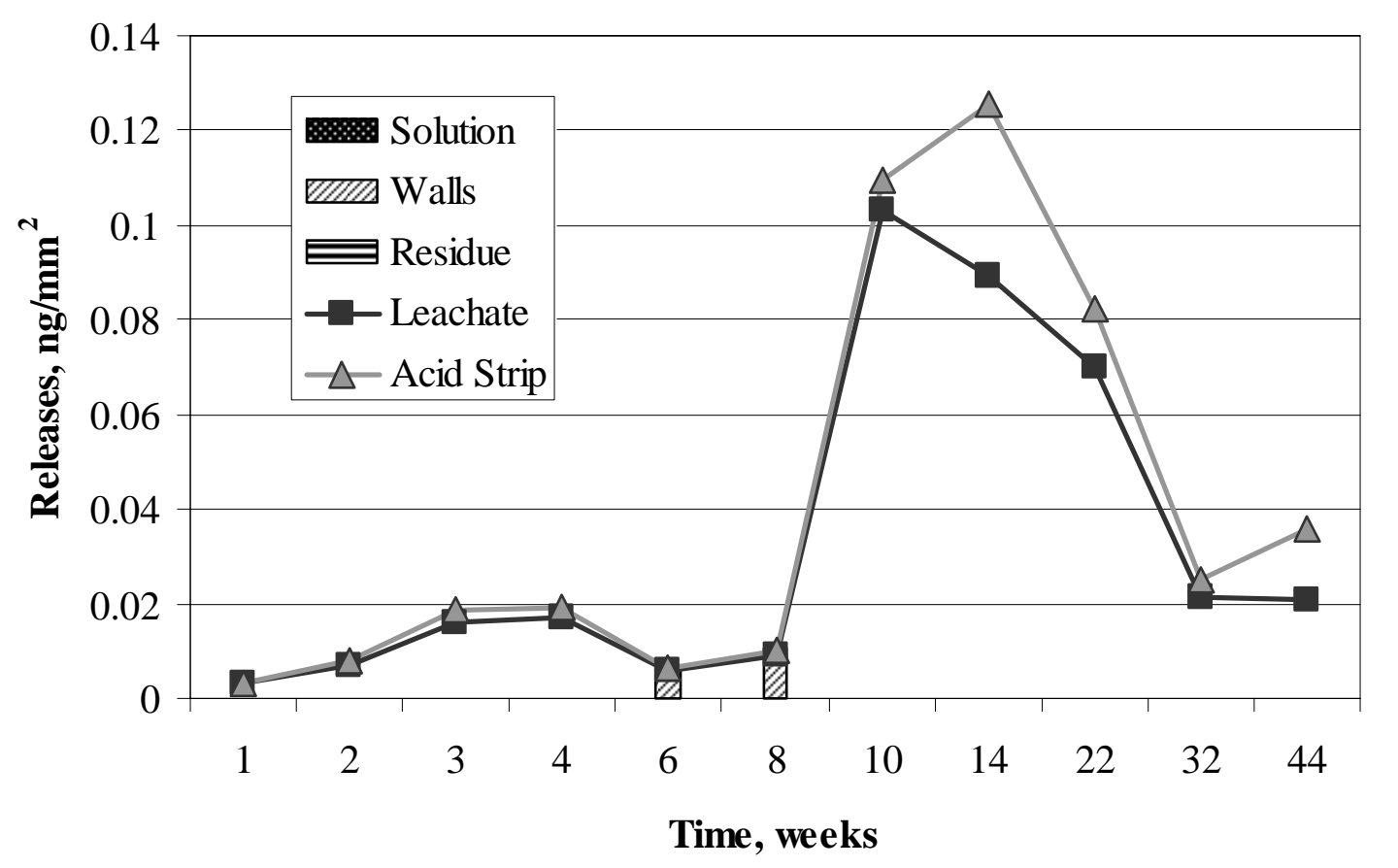

Figure E-246. Cobalt Present in Solution, on Walls, and in Residue from SJ13 Control and Average Detection Limits for Leachate and Acid Strip. 


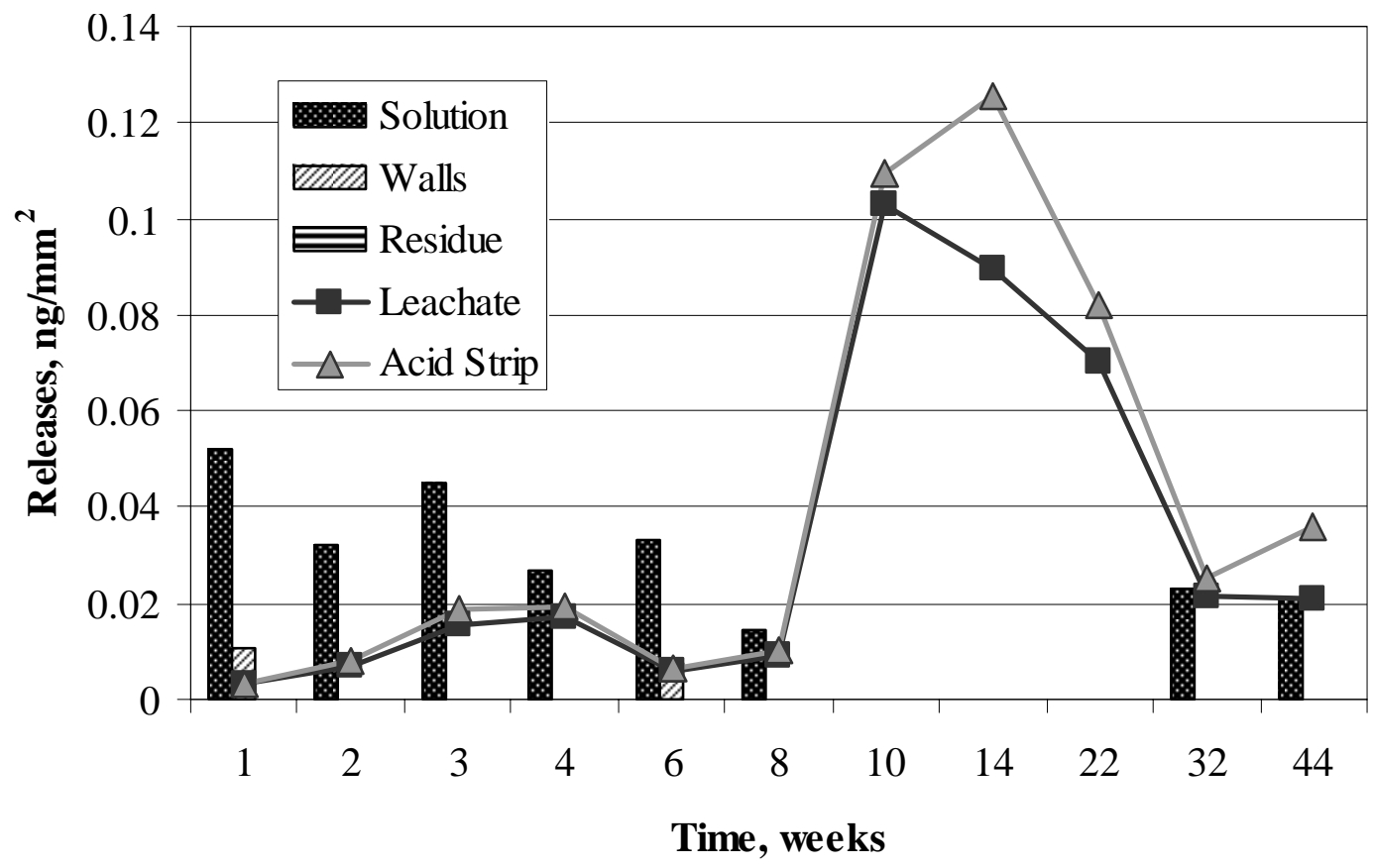

Figure E-247. Cobalt Releases in Solution, on Walls, and in Residue from Polished Sample 1 in CJ13 and Average Detection Limits for Leachate and Acid Strip.

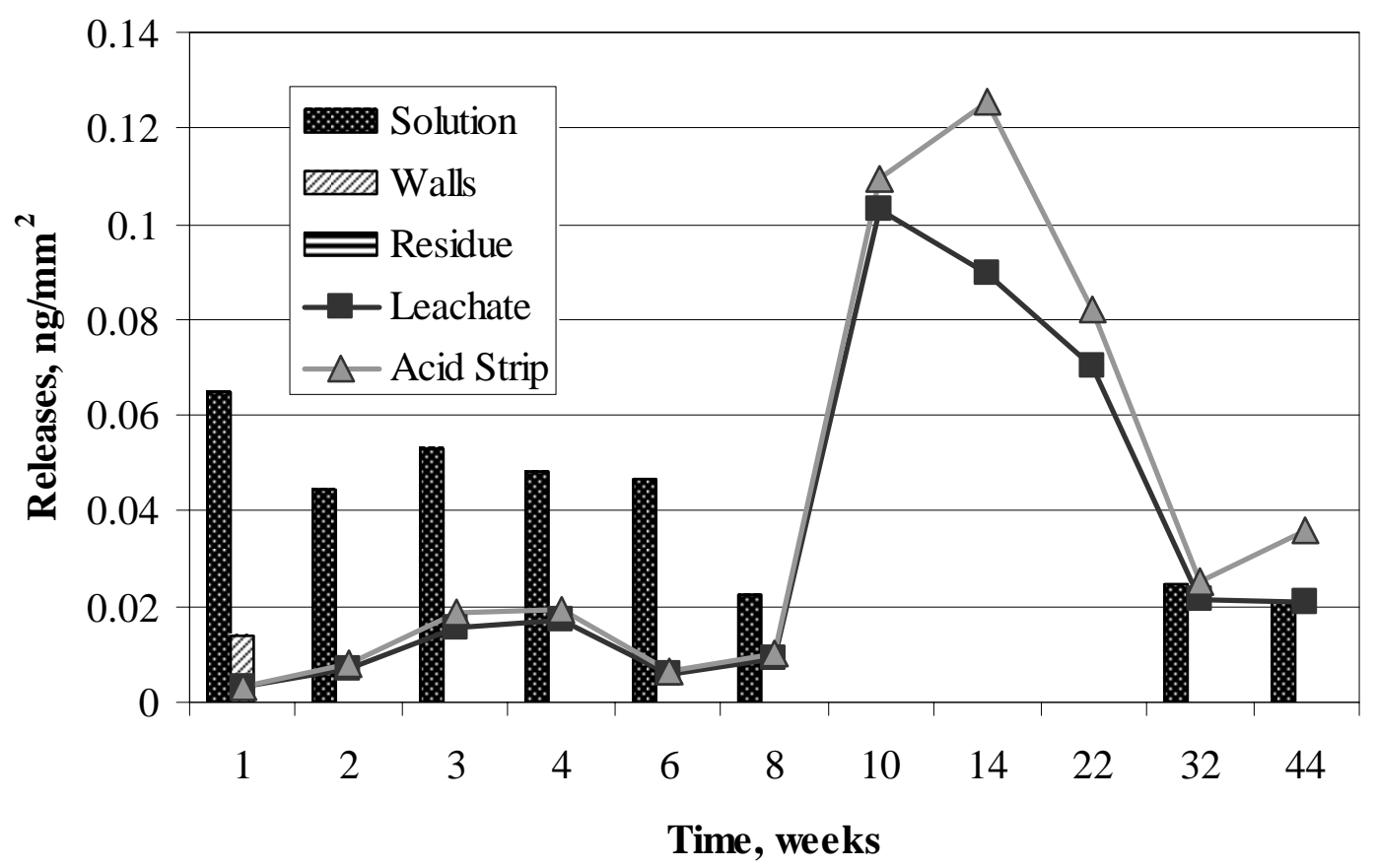

Figure E-248. Cobalt Releases in Solution, on Walls, and in Residue from Polished Sample 2 in CJ13 and Average Detection Limits for Leachate and Acid Strip. 


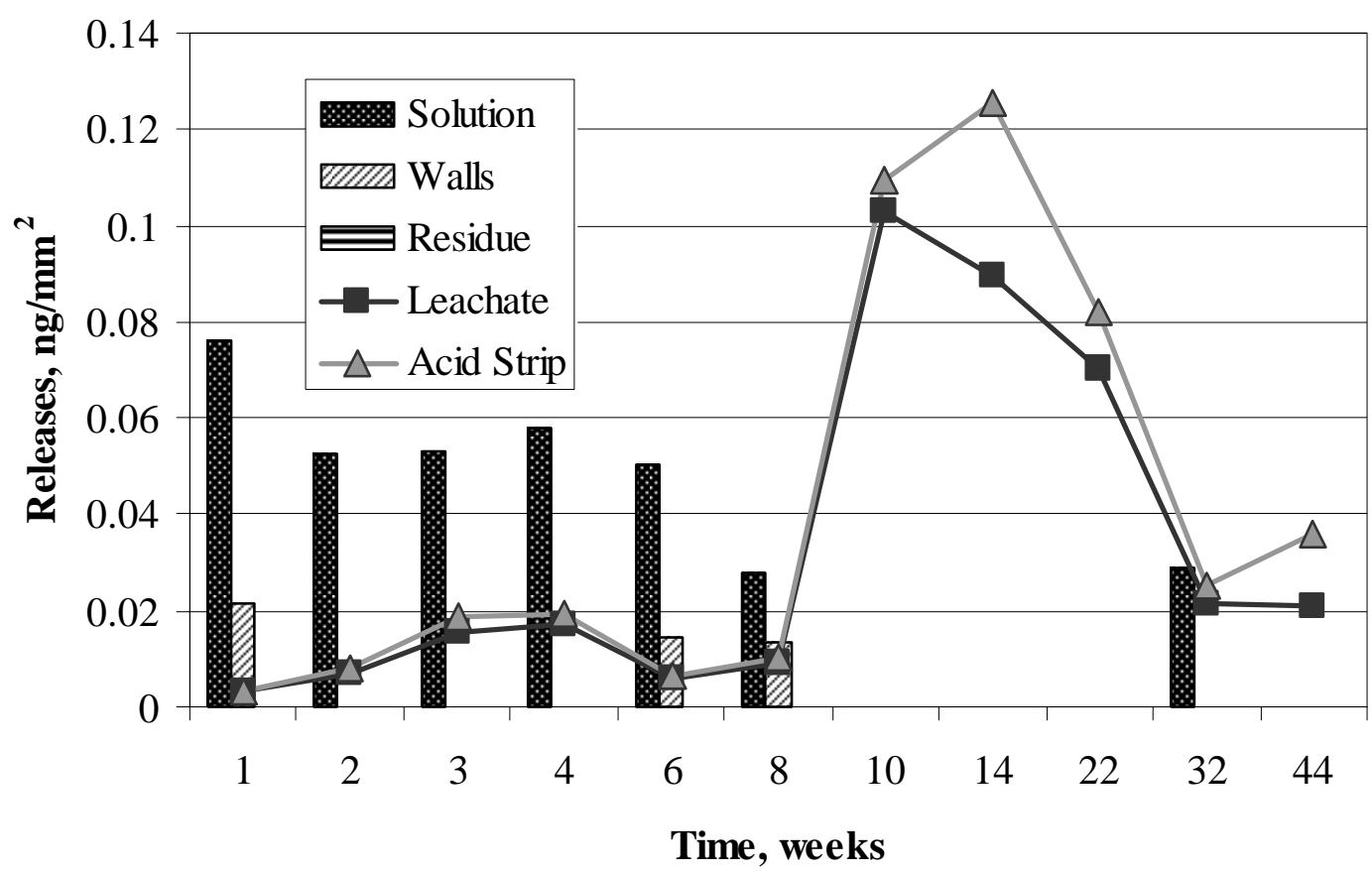

Figure E-249. Cobalt Releases in Solution, on Walls, and in Residue from Polished Sample 3 in CJ13 and Average Detection Limits for Leachate and Acid Strip.

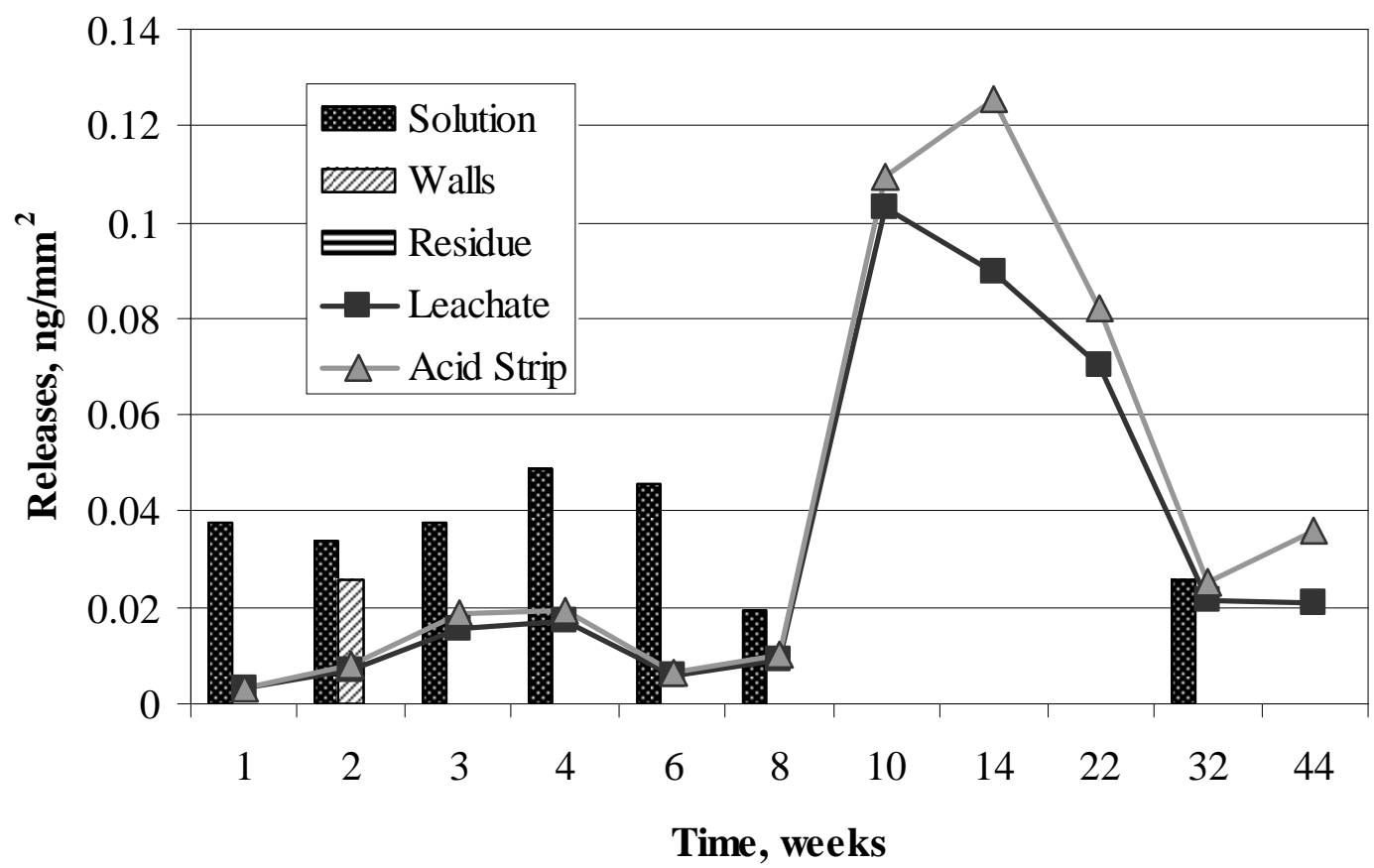

Figure E-250. Cobalt Releases in Solution, on Walls, and in Residue from Oxidized Sample 4 in CJ13 and Average Detection Limits for Leachate and Acid Strip. 


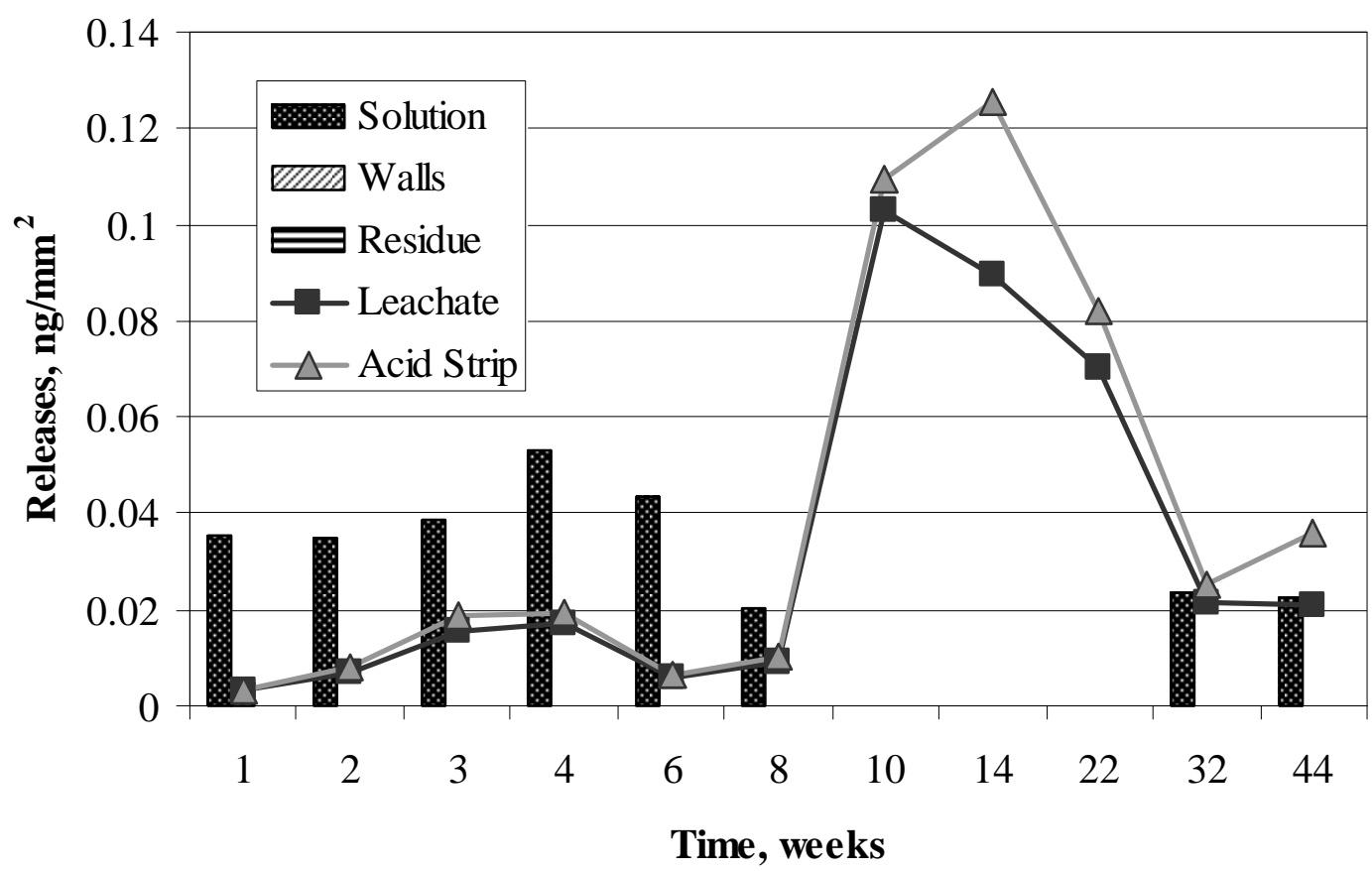

Figure E-251. Cobalt Releases in Solution, on Walls, and in Residue from Oxidized Sample 5 in CJ13 and Average Detection Limits for Leachate and Acid Strip.

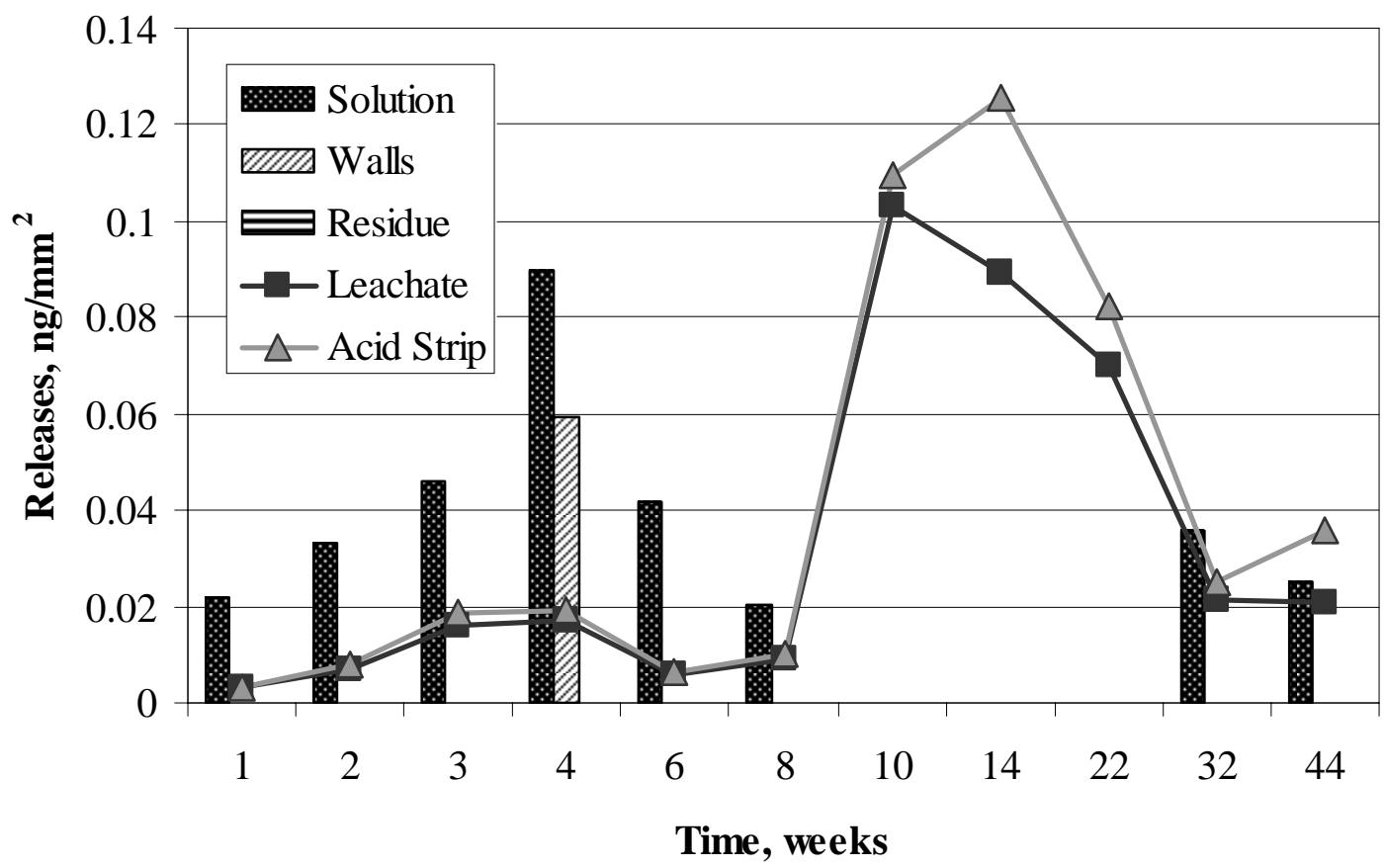

Figure E-252. Cobalt Present in Solution, on Walls, and in Residue from CJ13 Control and Average Detection Limits for Leachate and Acid Strip. 


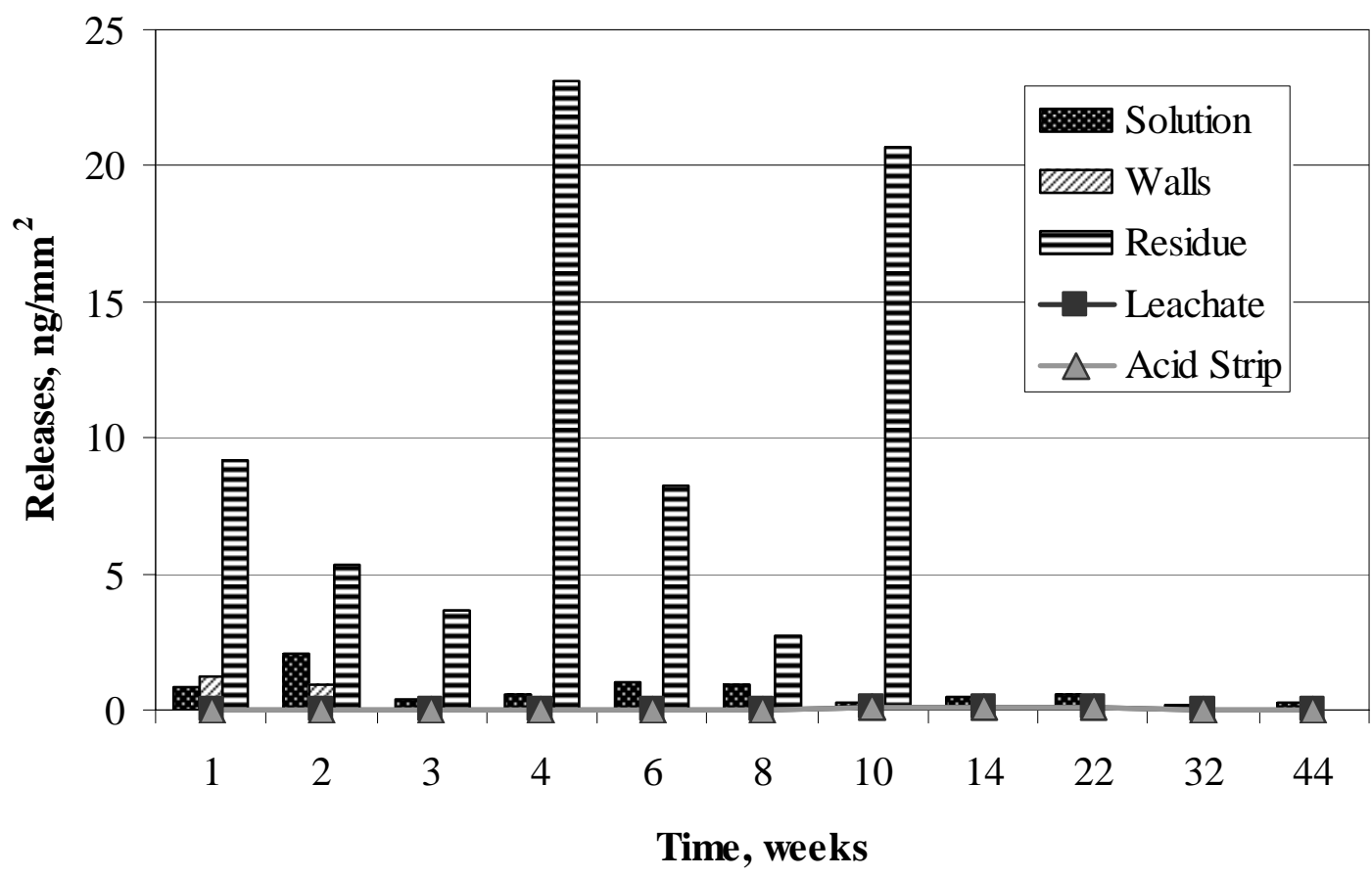

Figure E-253. Cobalt Releases in Solution, on Walls, and in Residue from Polished Sample 1 in $10 \mathrm{KCl}$ and Average Detection Limits for Leachate and Acid Strip.

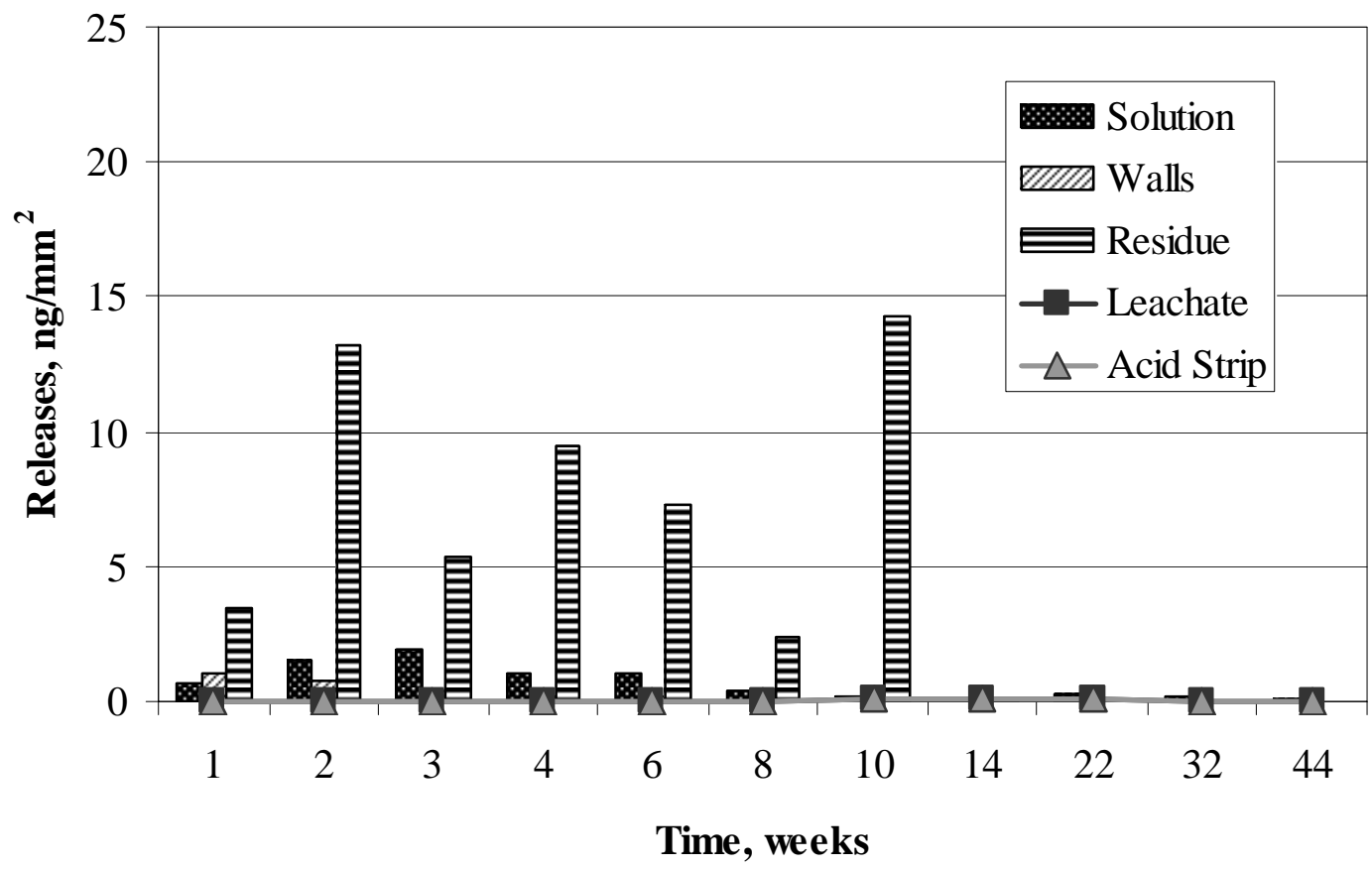

Figure E-254. Cobalt Releases in Solution, on Walls, and in Residue from Polished Sample 2 in 10KCl and Average Detection Limits for Leachate and Acid Strip. 


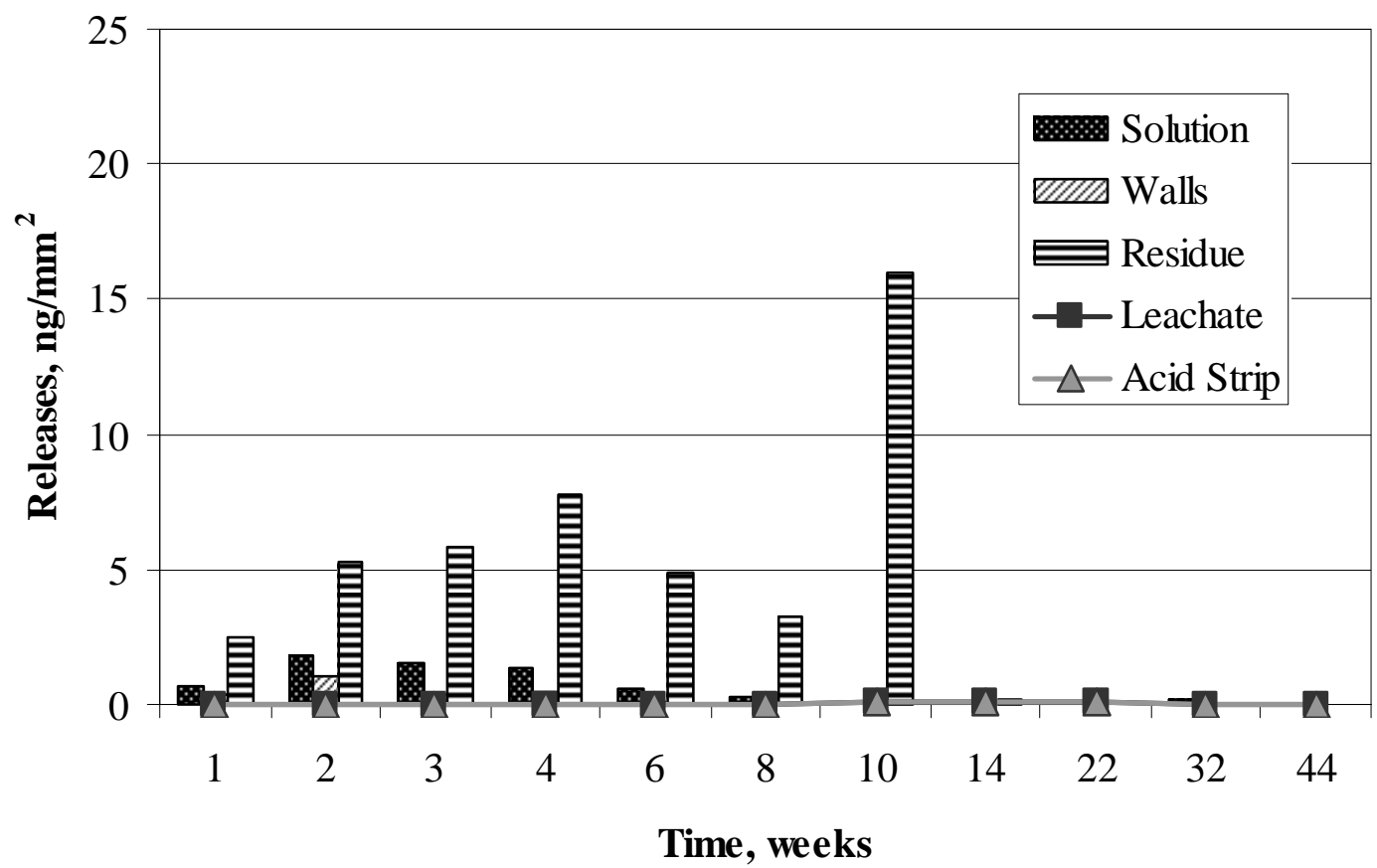

Figure E-255. Cobalt Releases in Solution, on Walls, and in Residue from Polished Sample 3 in 10KCl and Average Detection Limits for Leachate and Acid Strip.

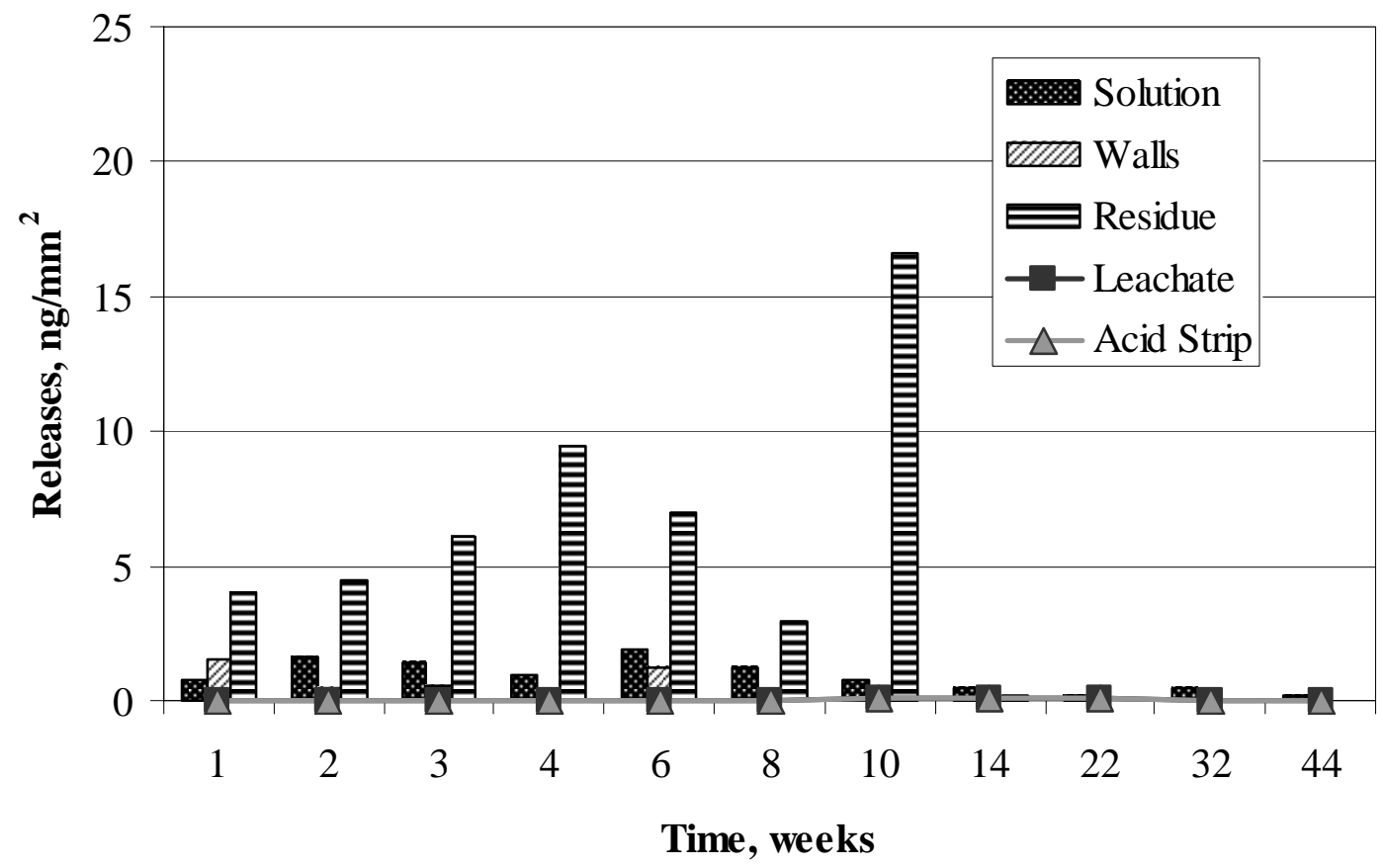

Figure E-256. Cobalt Releases in Solution, on Walls, and in Residue from Oxidized Sample 4 in 10KCl and Average Detection Limits for Leachate and Acid Strip. 


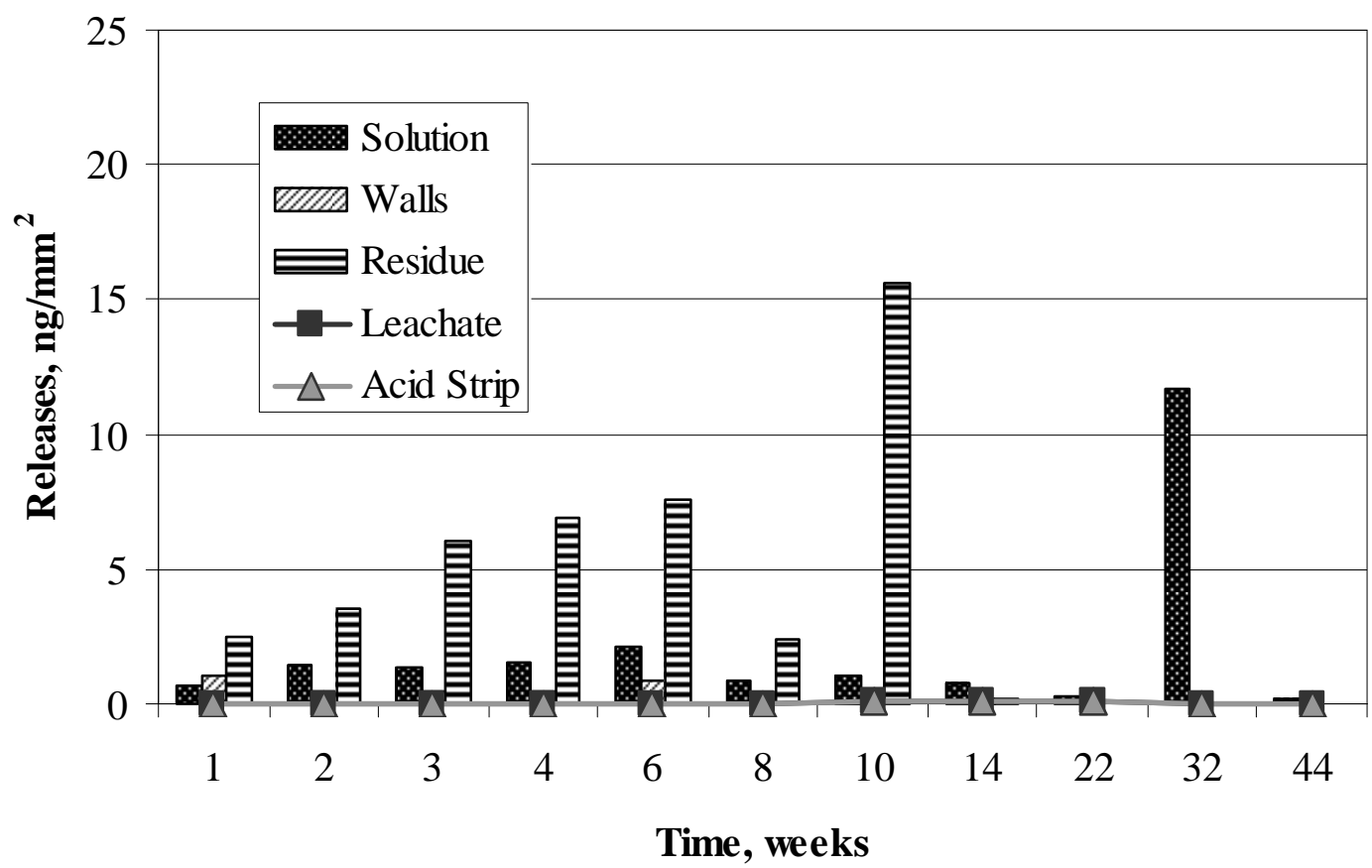

Figure E-257. Cobalt Releases in Solution, on Walls, and in Residue from Oxidized Sample 5 in 10KCl and Average Detection Limits for Leachate and Acid Strip.

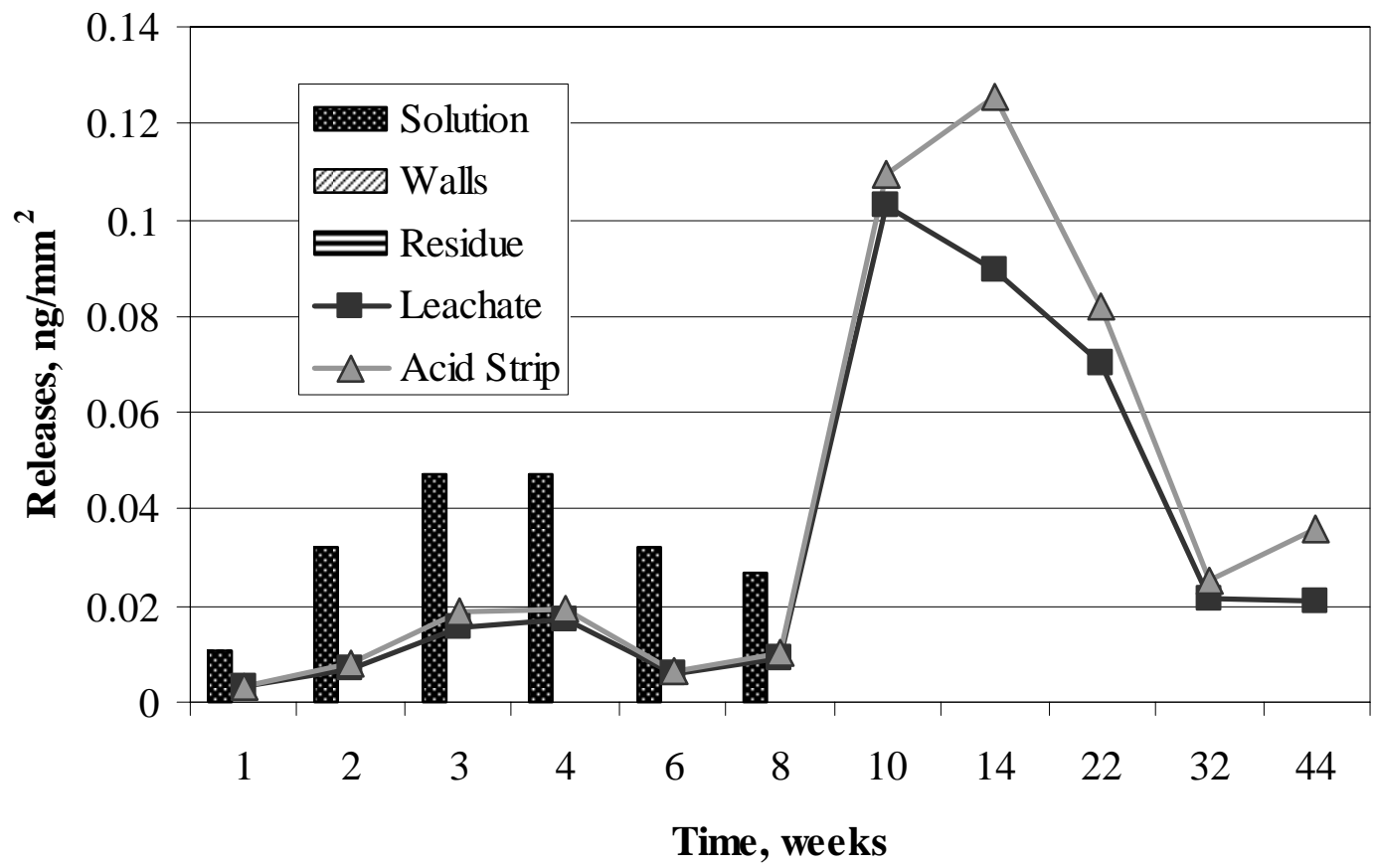

Figure E-258. Cobalt Present in Solution, on Walls, and in Residue from 10KCl Control and Average Detection Limits for Leachate and Acid Strip. 


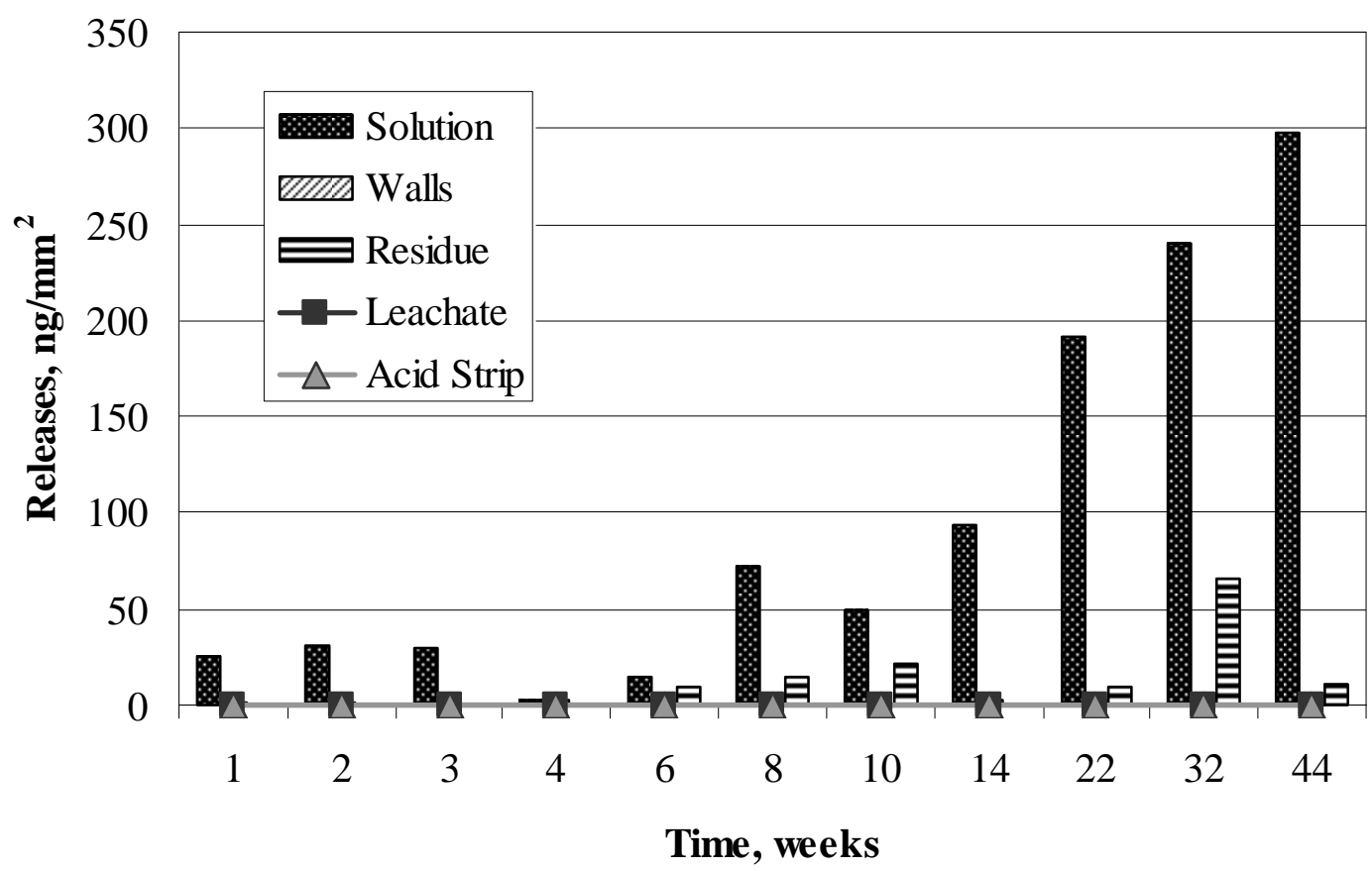

Figure E-259. Cobalt Releases in Solution, on Walls, and in Residue from Polished Sample 1 in AJ13 and Average Detection Limits for Leachate and Acid Strip.

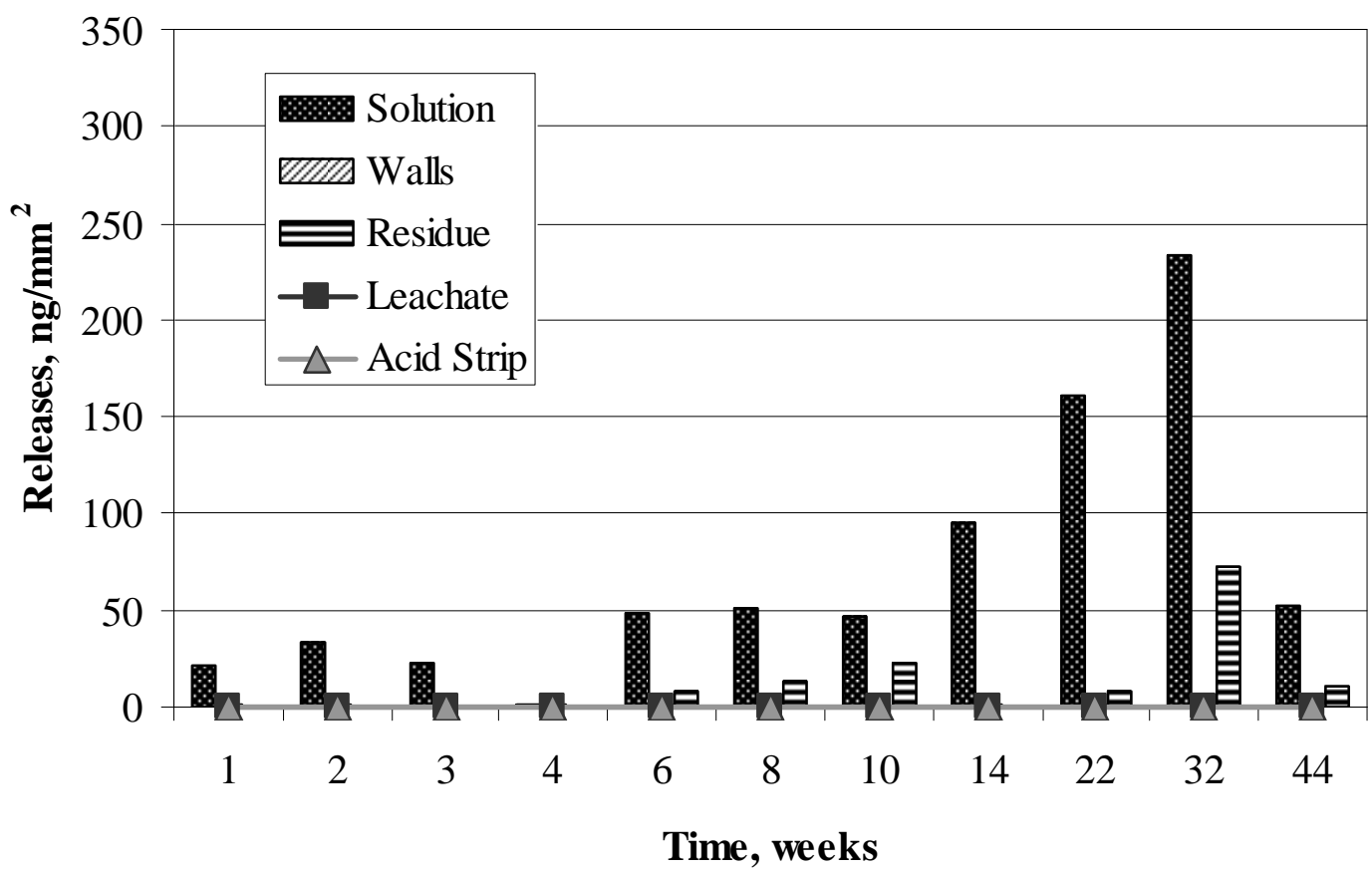

Figure E-260. Cobalt Releases in Solution, on Walls, and in Residue from Polished Sample 2 in AJ13 and Average Detection Limits for Leachate and Acid Strip. 


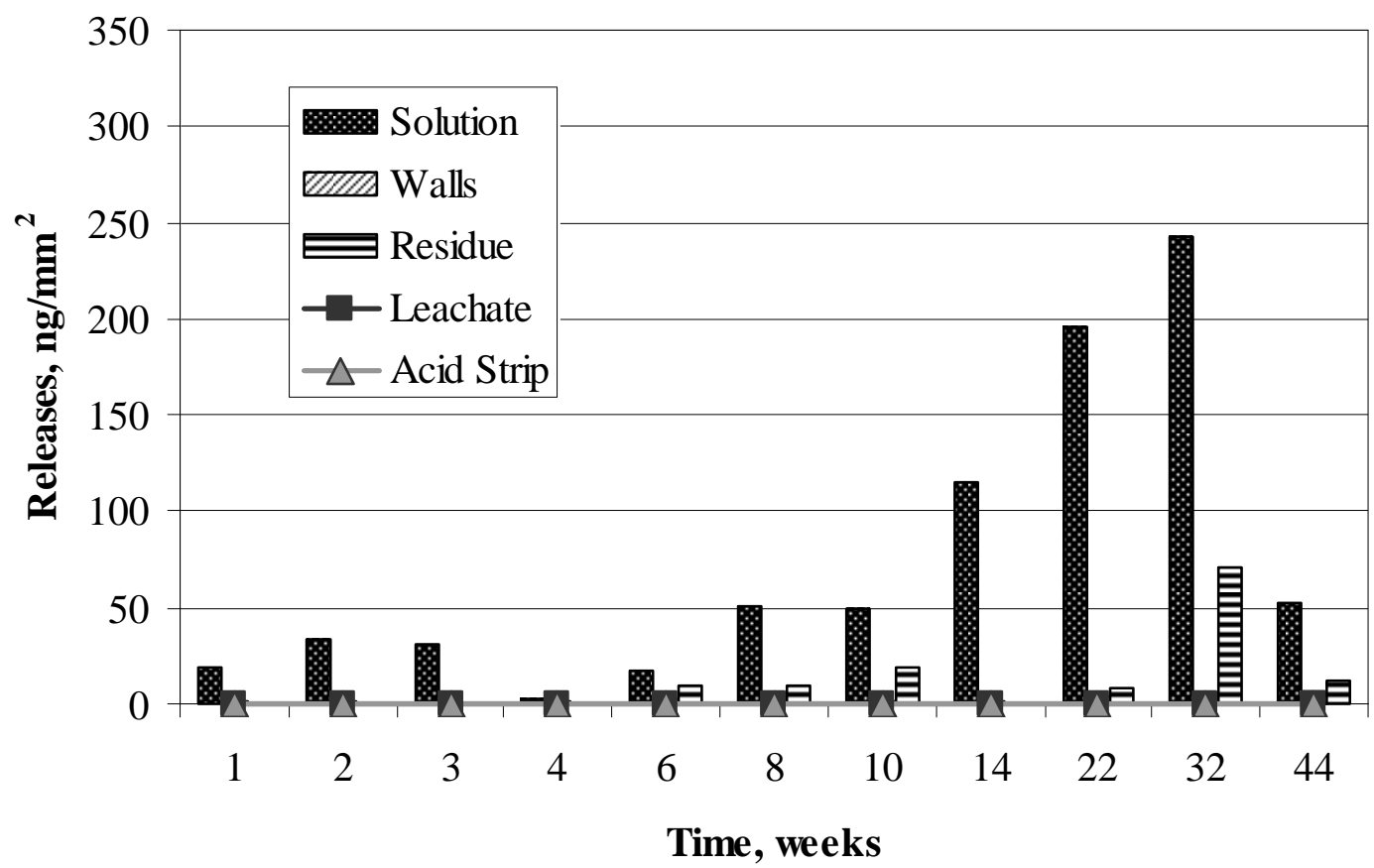

Figure E-261. Cobalt Releases in Solution, on Walls, and in Residue from Polished Sample 3 in AJ13 and Average Detection Limits for Leachate and Acid Strip.

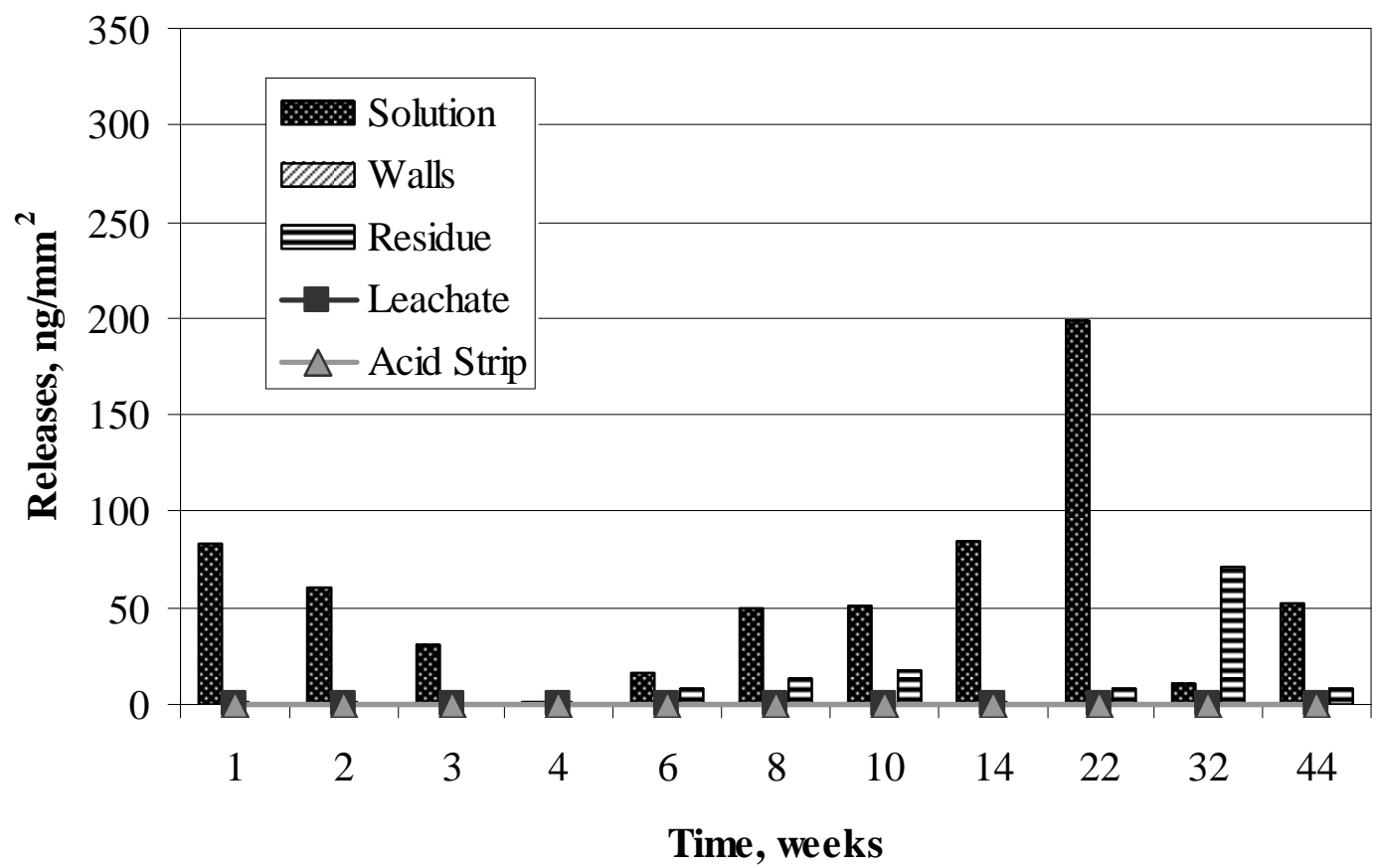

Figure E-262. Cobalt Releases in Solution, on Walls, and in Residue from Oxidized Sample 4 in AJ13 and Average Detection Limits for Leachate and Acid Strip. 


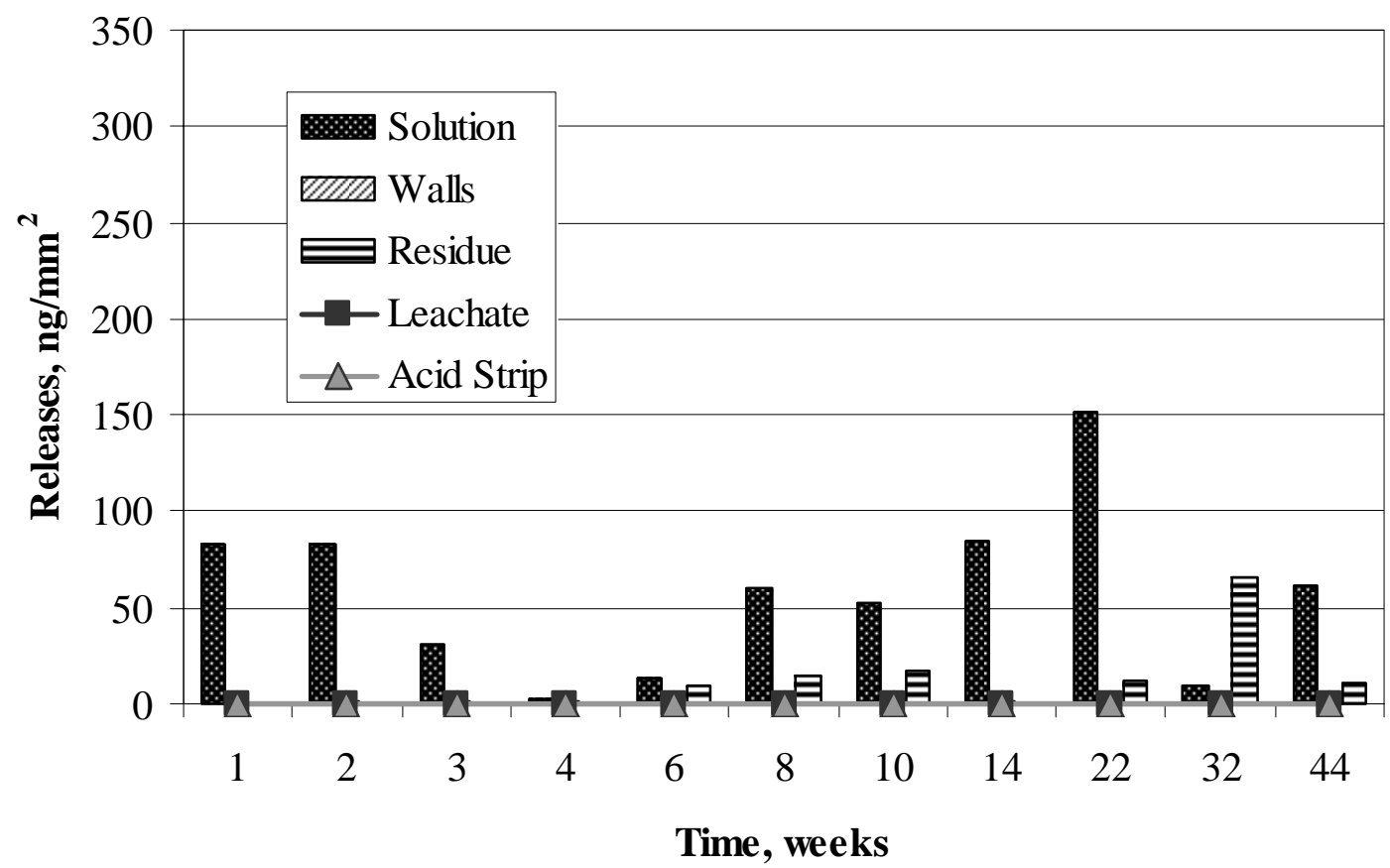

Figure E-263. Cobalt Releases in Solution, on Walls, and in Residue from Oxidized Sample 5 in AJ13 and Average Detection Limits for Leachate and Acid Strip.

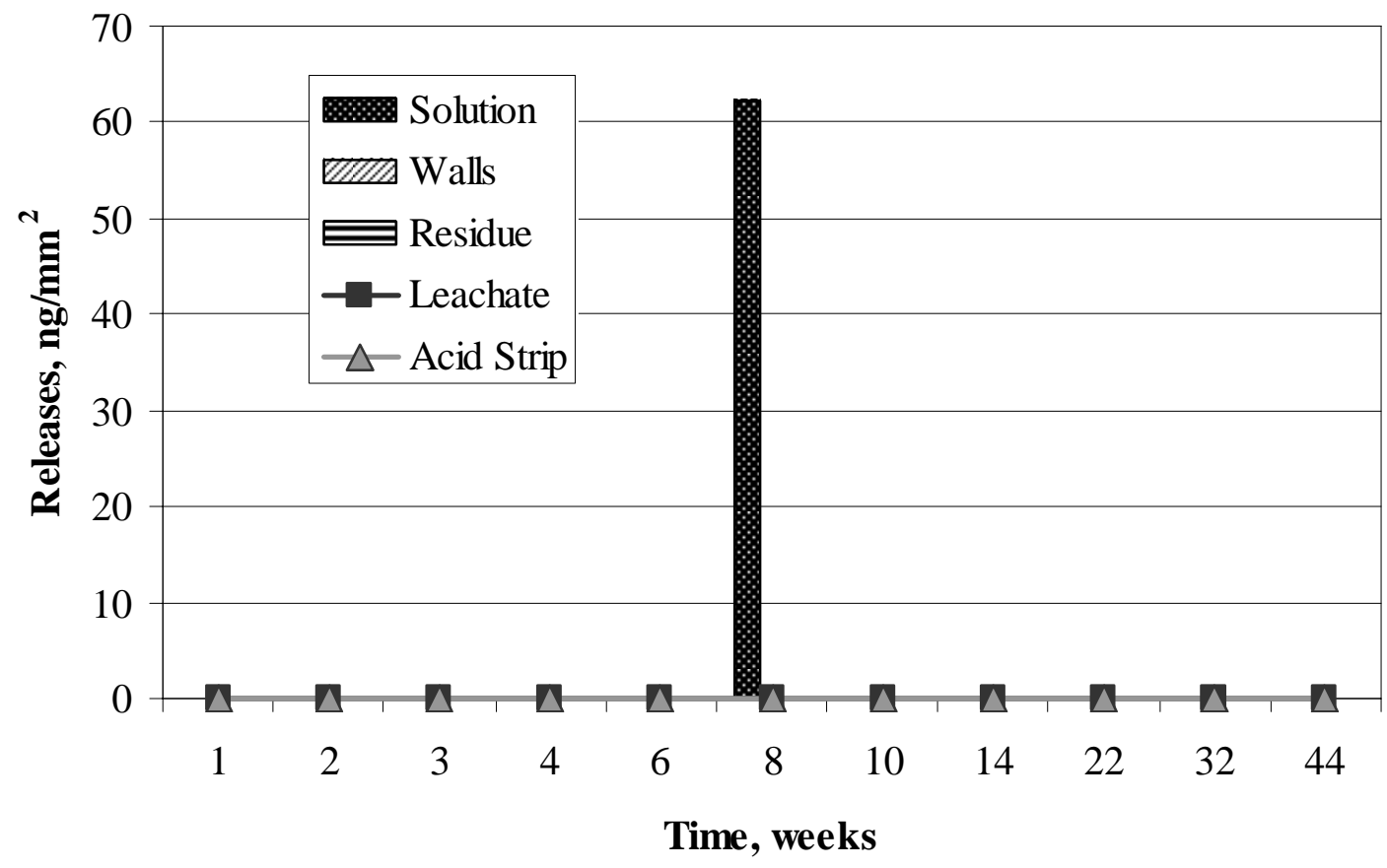

Figure E-264. Cobalt Present in Solution, on Walls, and in Residue from AJ13 Control and Average Detection Limits for Leachate and Acid Strip. 


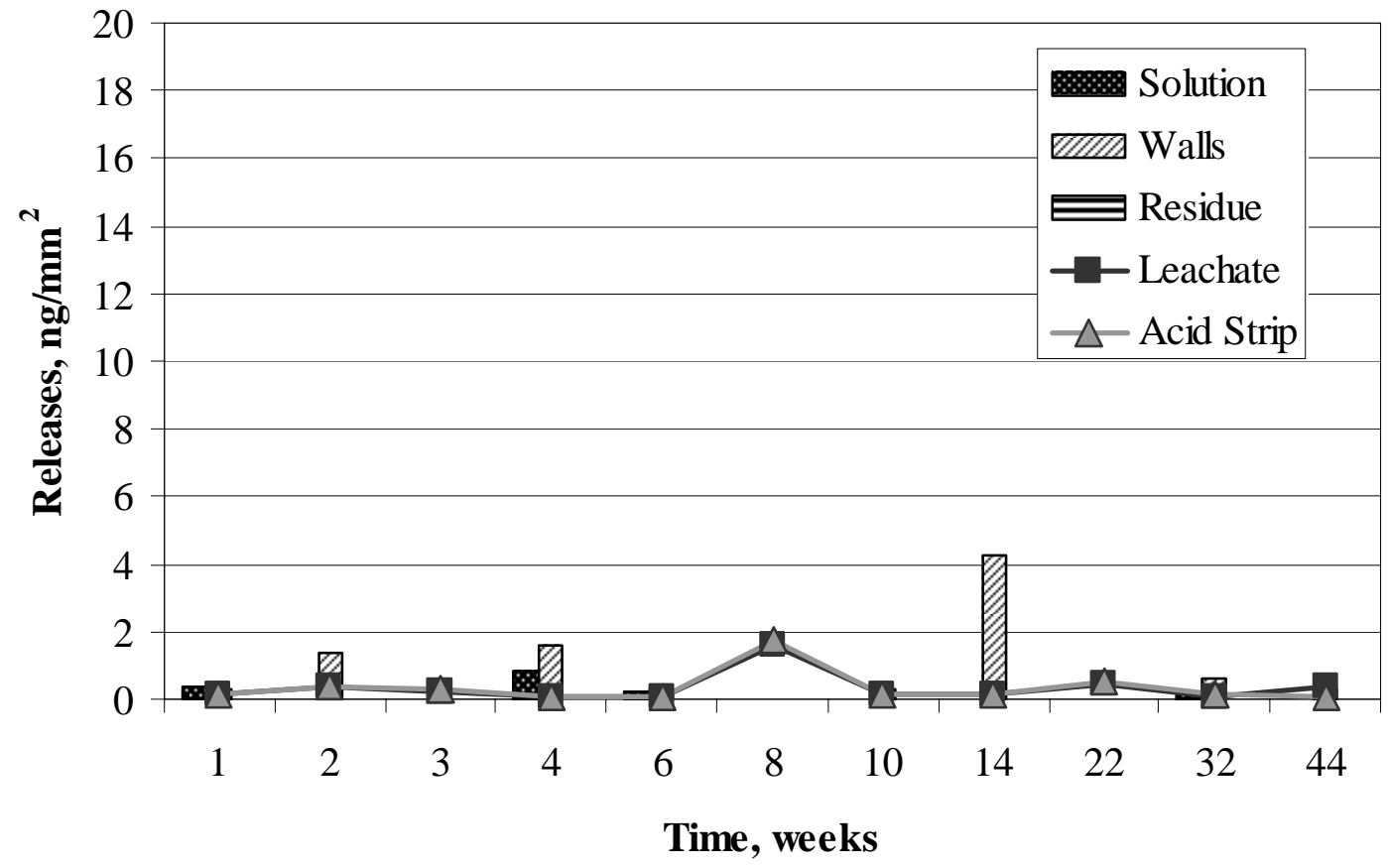

Figure E-265. Copper Releases in Solution, on Walls, and in Residue from Polished Sample 1 in SJ13 and Average Detection Limits for Leachate and Acid Strip.

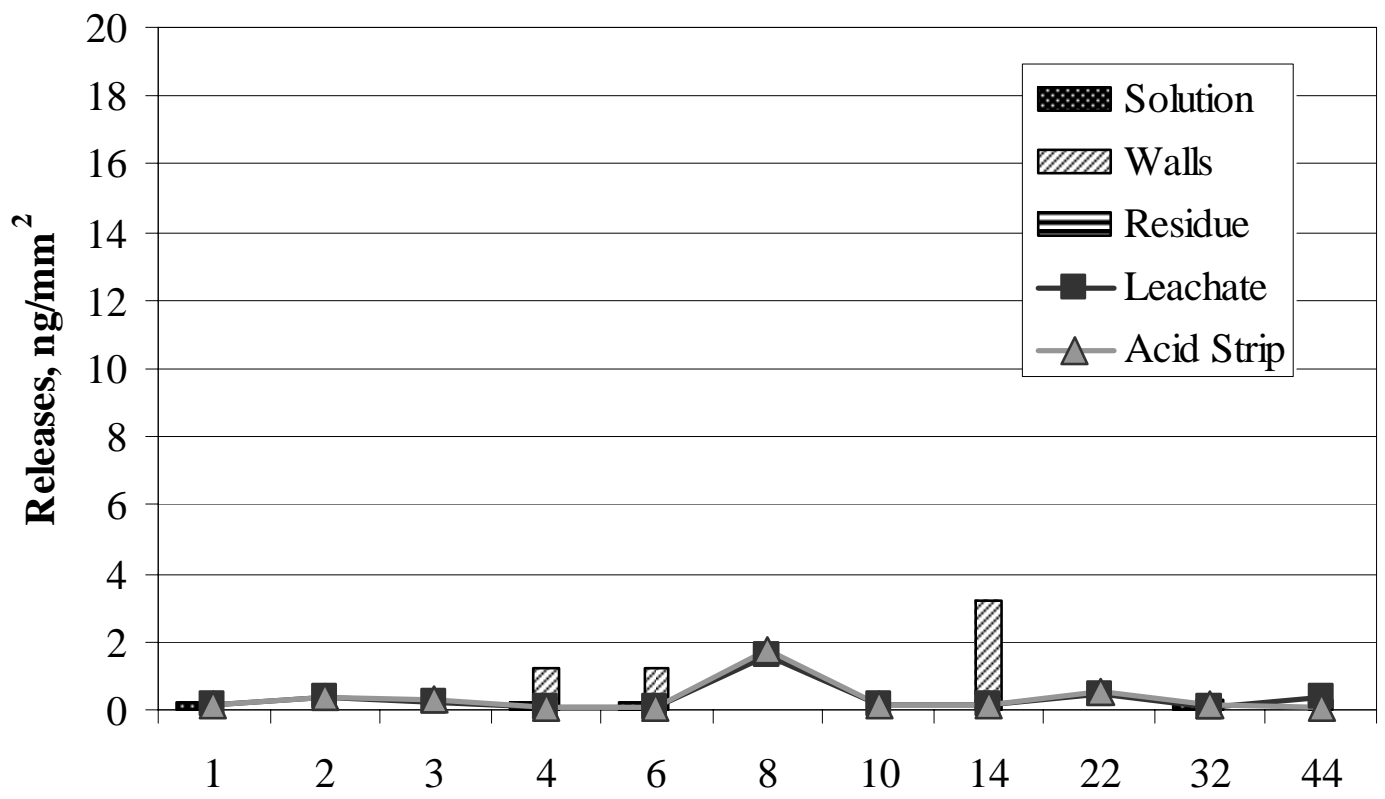

Time, weeks

Figure E-266. Copper Releases in Solution, on Walls, and in Residue from Polished Sample 2 in SJ13 and Average Detection Limits for Leachate and Acid Strip. 


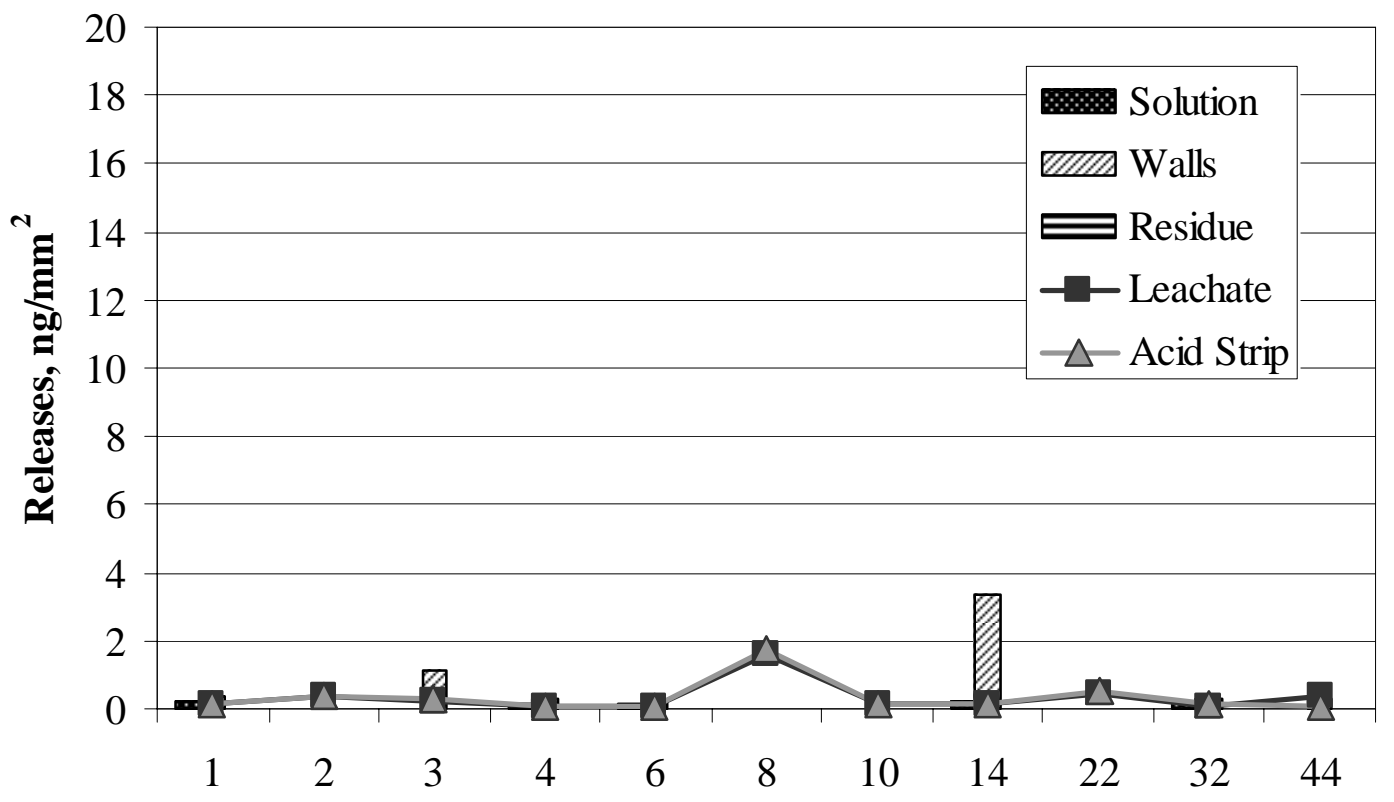

Time, weeks

Figure E-267. Copper Releases in Solution, on Walls, and in Residue from Polished Sample 3 in SJ13 and Average Detection Limits for Leachate and Acid Strip.

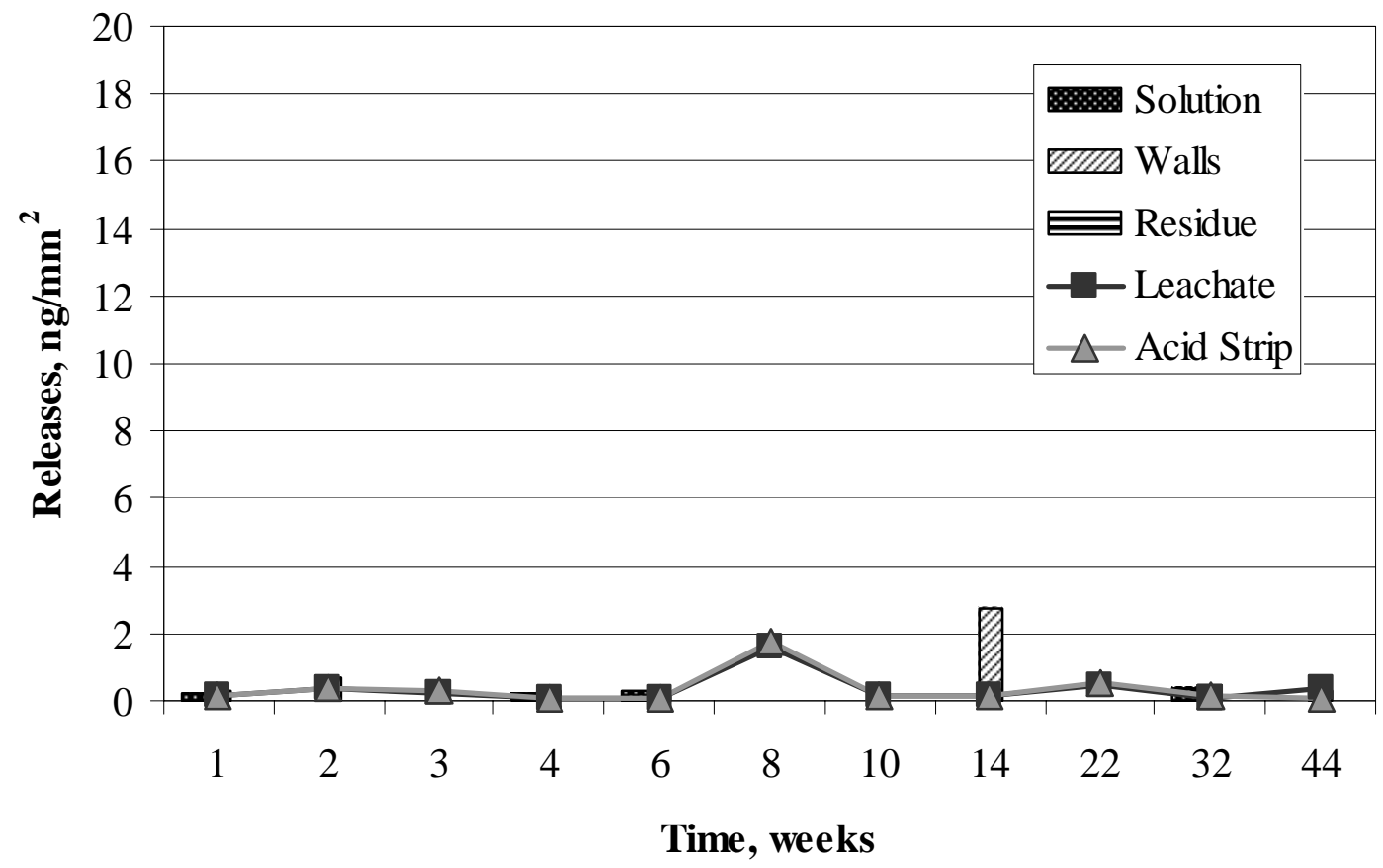

Figure E-268. Copper Releases in Solution, on Walls, and in Residue from Oxidized Sample 4 in SJ13 and Average Detection Limits for Leachate and Acid Strip. 


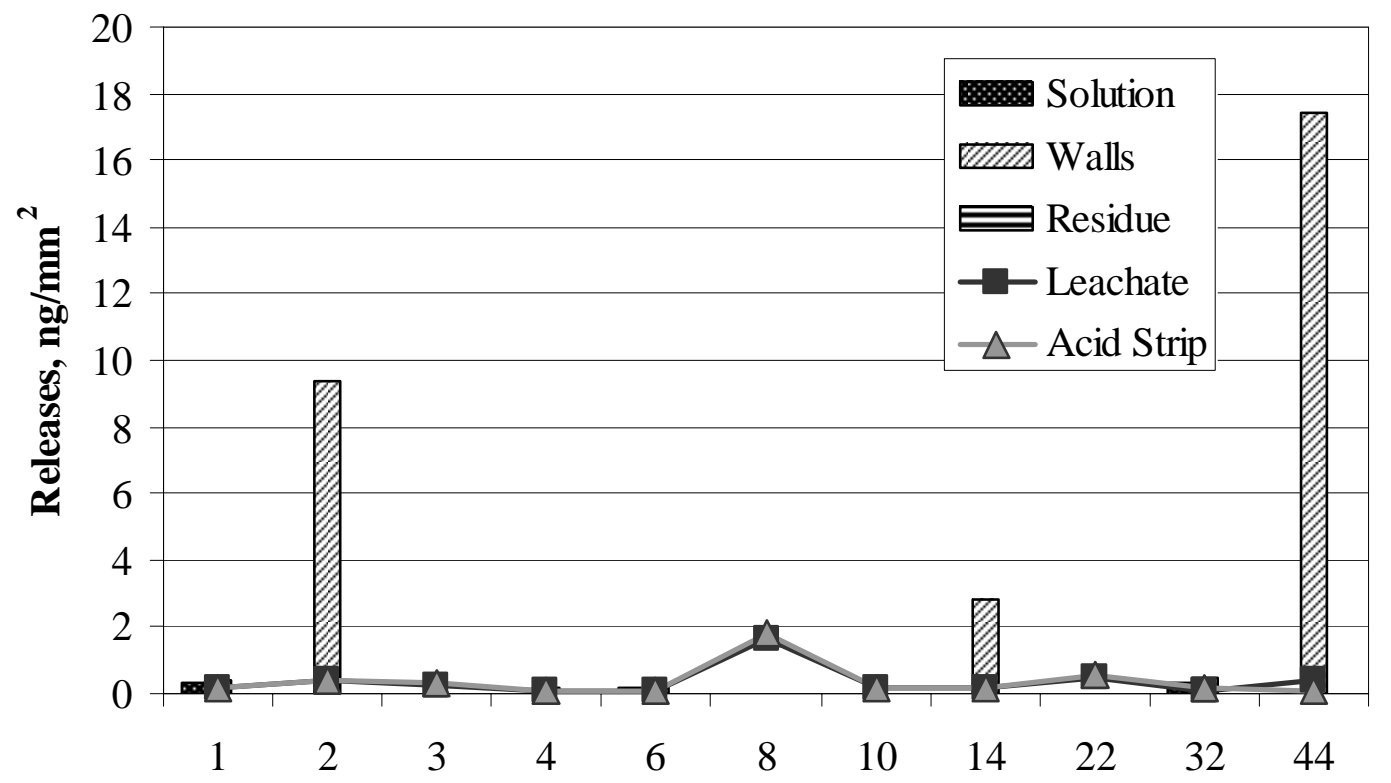

Time, weeks

Figure E-269. Copper Releases in Solution, on Walls, and in Residue from Oxidized Sample 5 in SJ13 and Average Detection Limits for Leachate and Acid Strip.

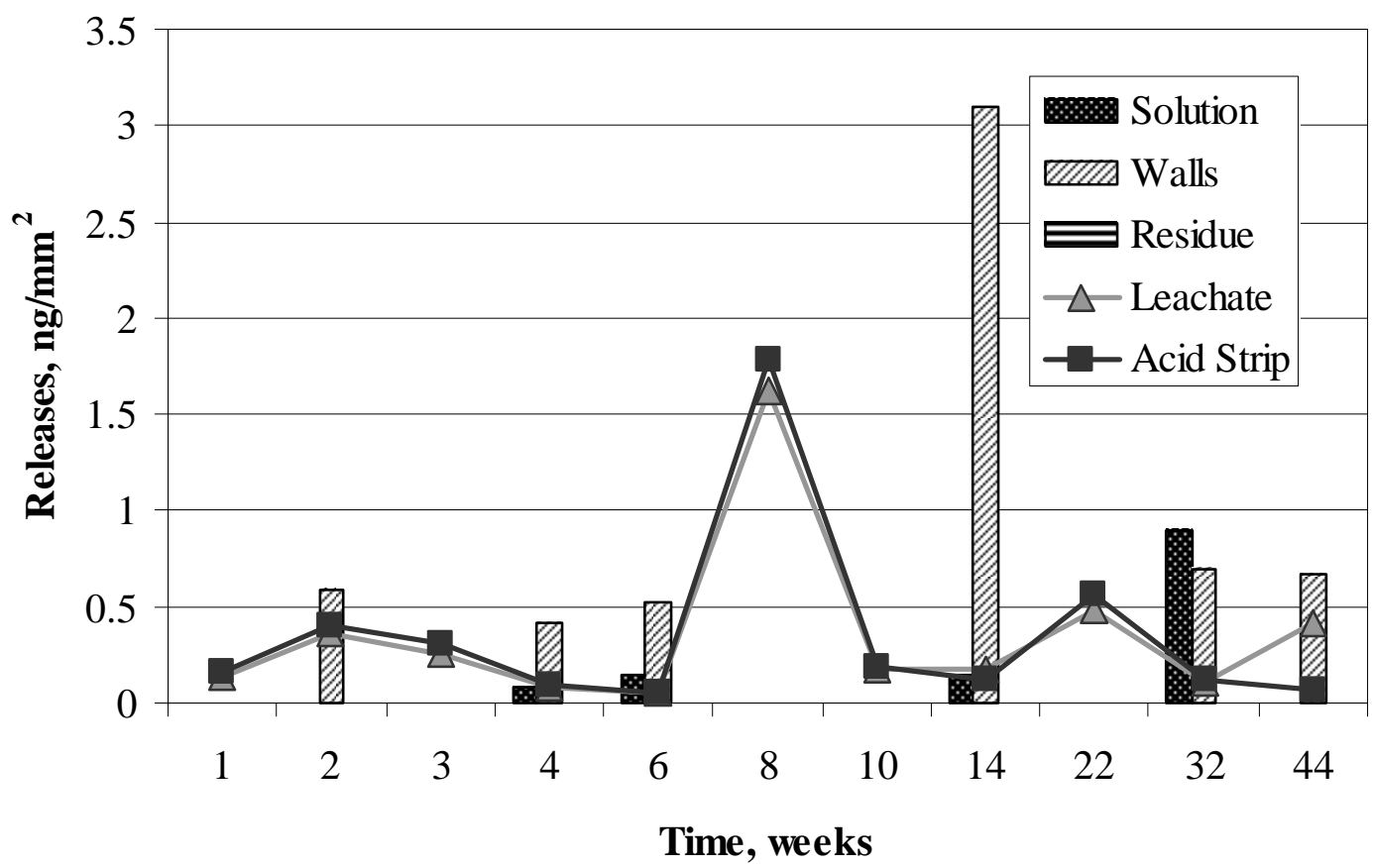

Figure E-270. Copper Present in Solution, on Walls, and in Residue from SJ13 Control and Average Detection Limits for Leachate and Acid Strip. 


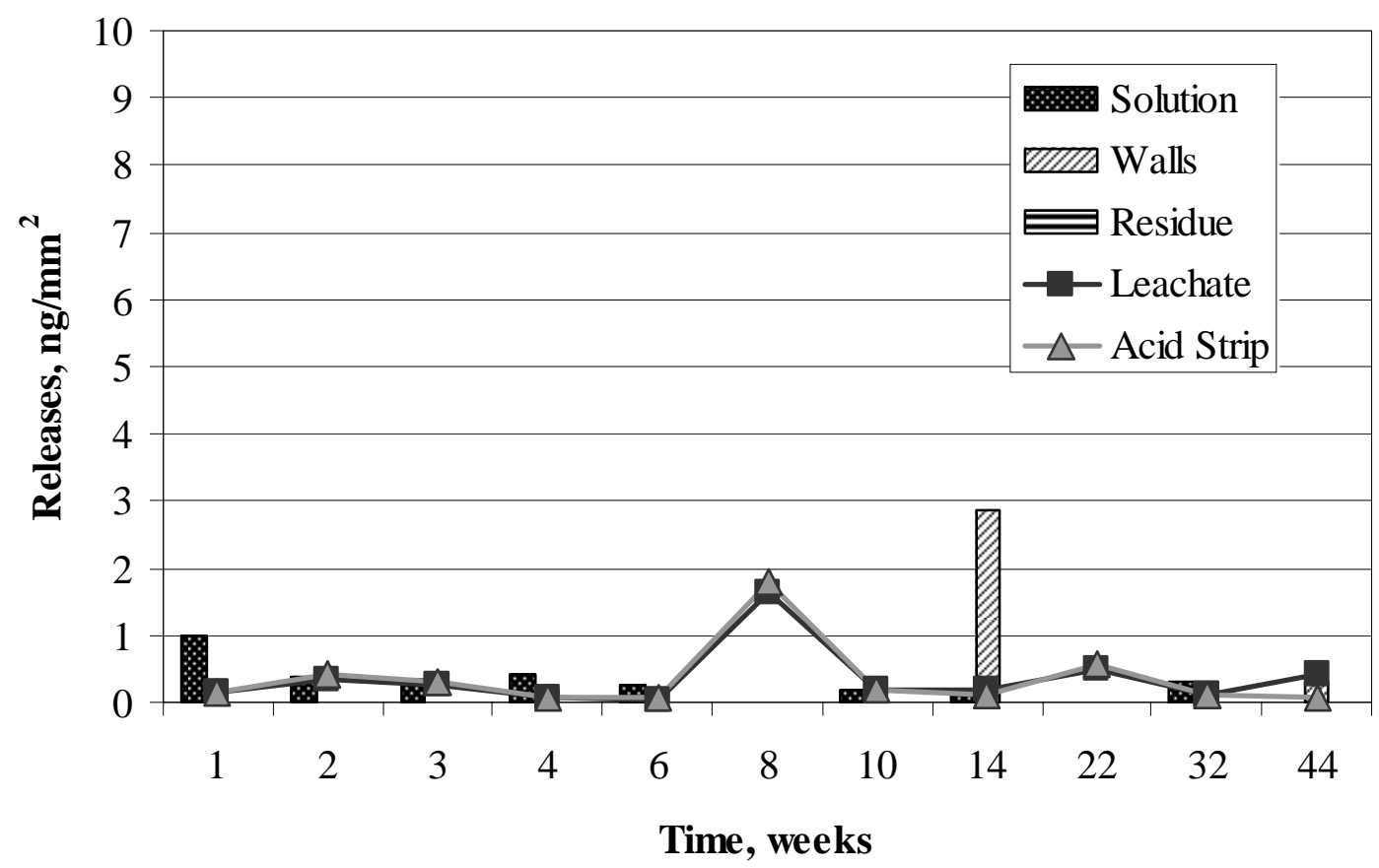

Figure E-271. Copper Releases in Solution, on Walls, and in Residue from Polished Sample 1 in CJ13 and Average Detection Limits for Leachate and Acid Strip.

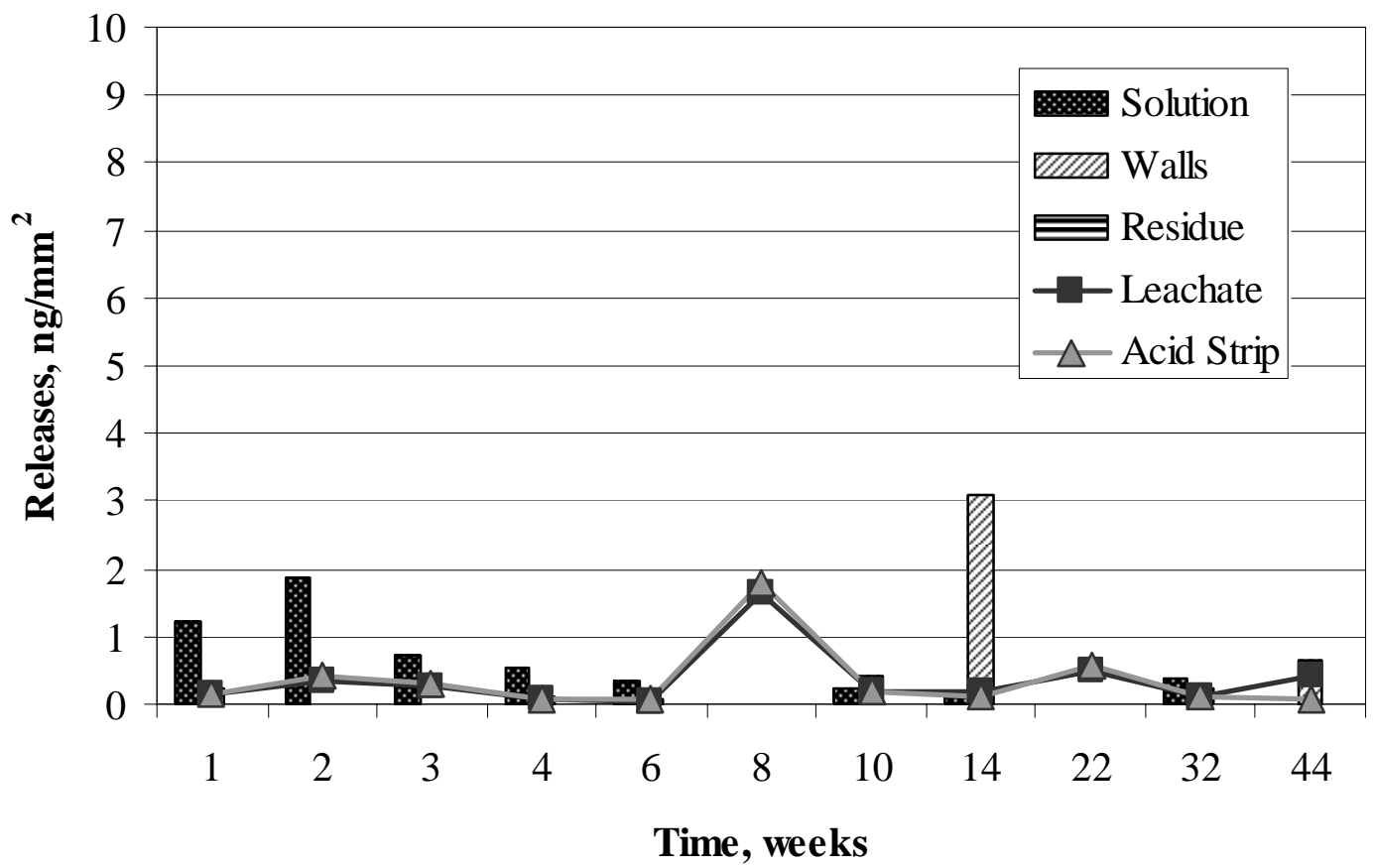

Figure E-272. Copper Releases in Solution, on Walls, and in Residue from Polished Sample 2 in CJ13 and Average Detection Limits for Leachate and Acid Strip. 


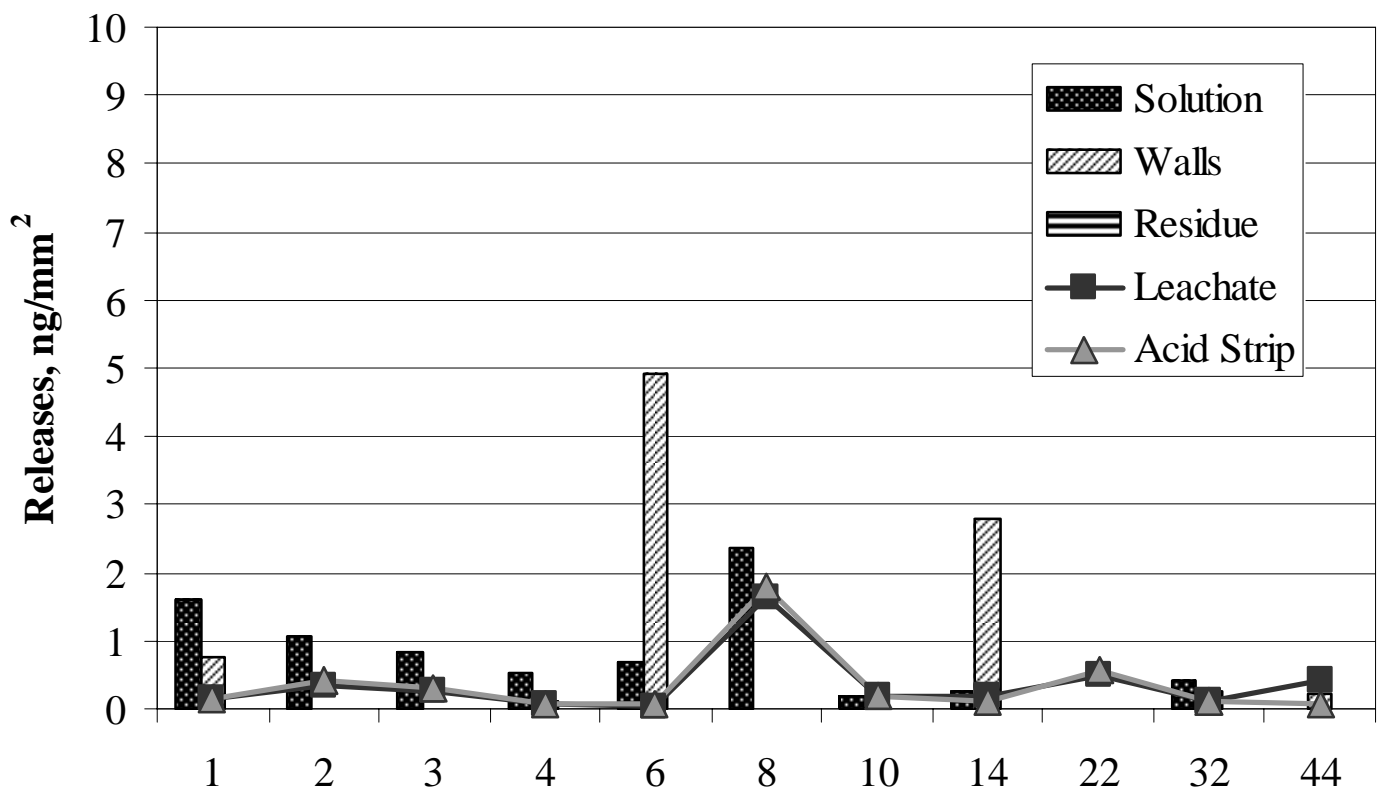

Time, weeks

Figure E-273. Copper Releases in Solution, on Walls, and in Residue from Polished Sample 3 in CJ13 and Average Detection Limits for Leachate and Acid Strip.

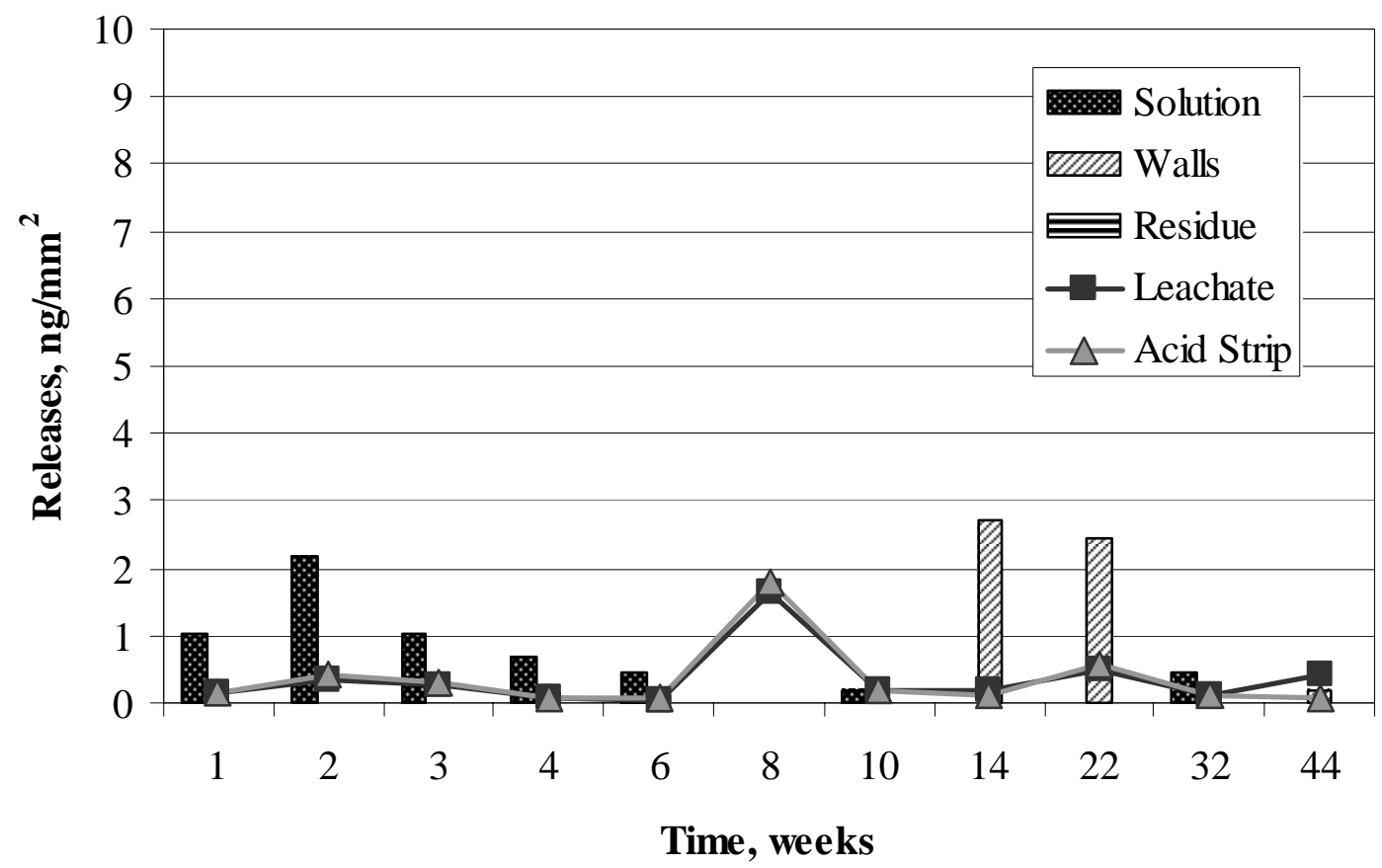

Figure E-274. Copper Releases in Solution, on Walls, and in Residue from Oxidized Sample 4 in CJ13 and Average Detection Limits for Leachate and Acid Strip. 


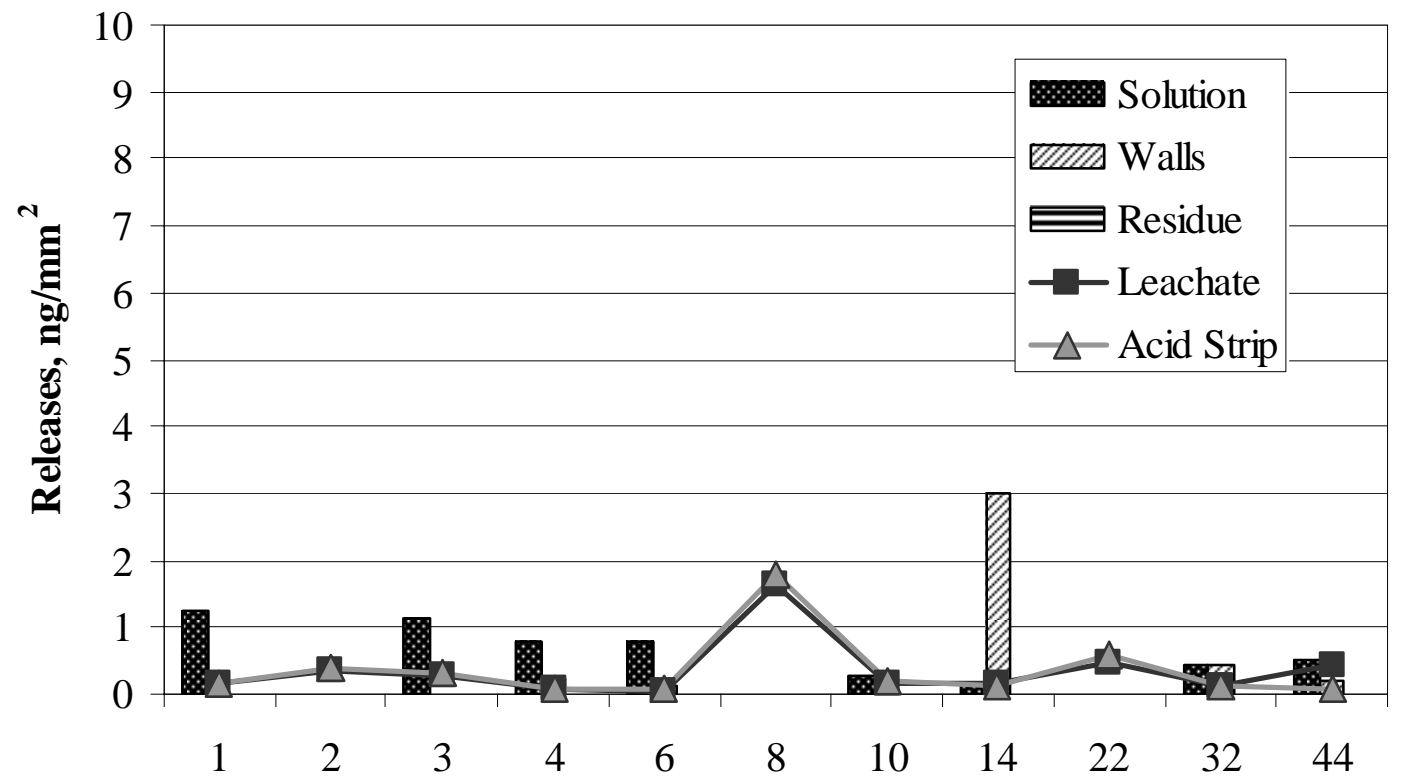

Time, weeks

Figure E-275. Copper Releases in Solution, on Walls, and in Residue from Oxidized Sample 5 in CJ13 and Average Detection Limits for Leachate and Acid Strip.

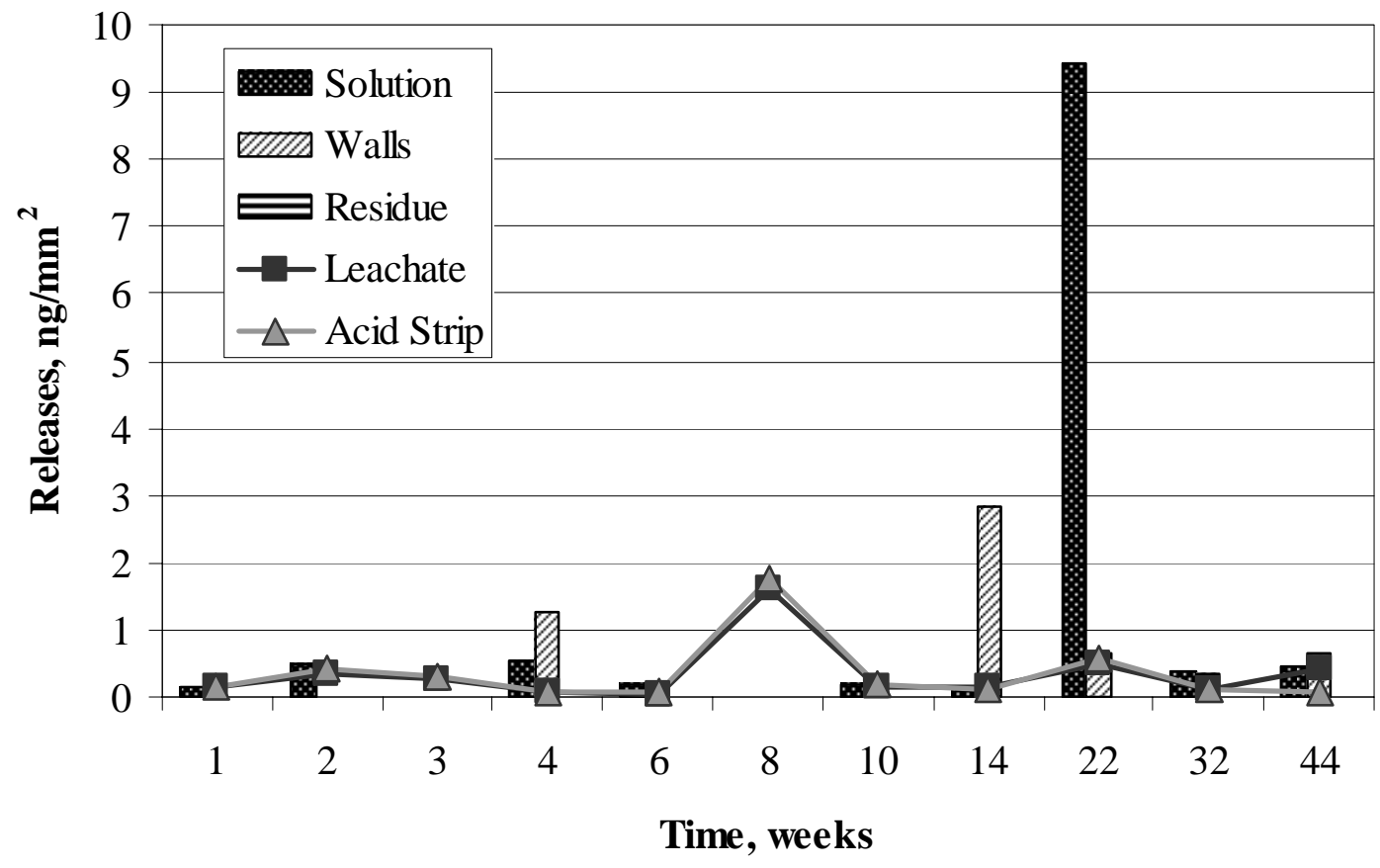

Figure E-276. Copper Present in Solution, on Walls, and in Residue from CJ13 Control and Average Detection Limits for Leachate and Acid Strip. 


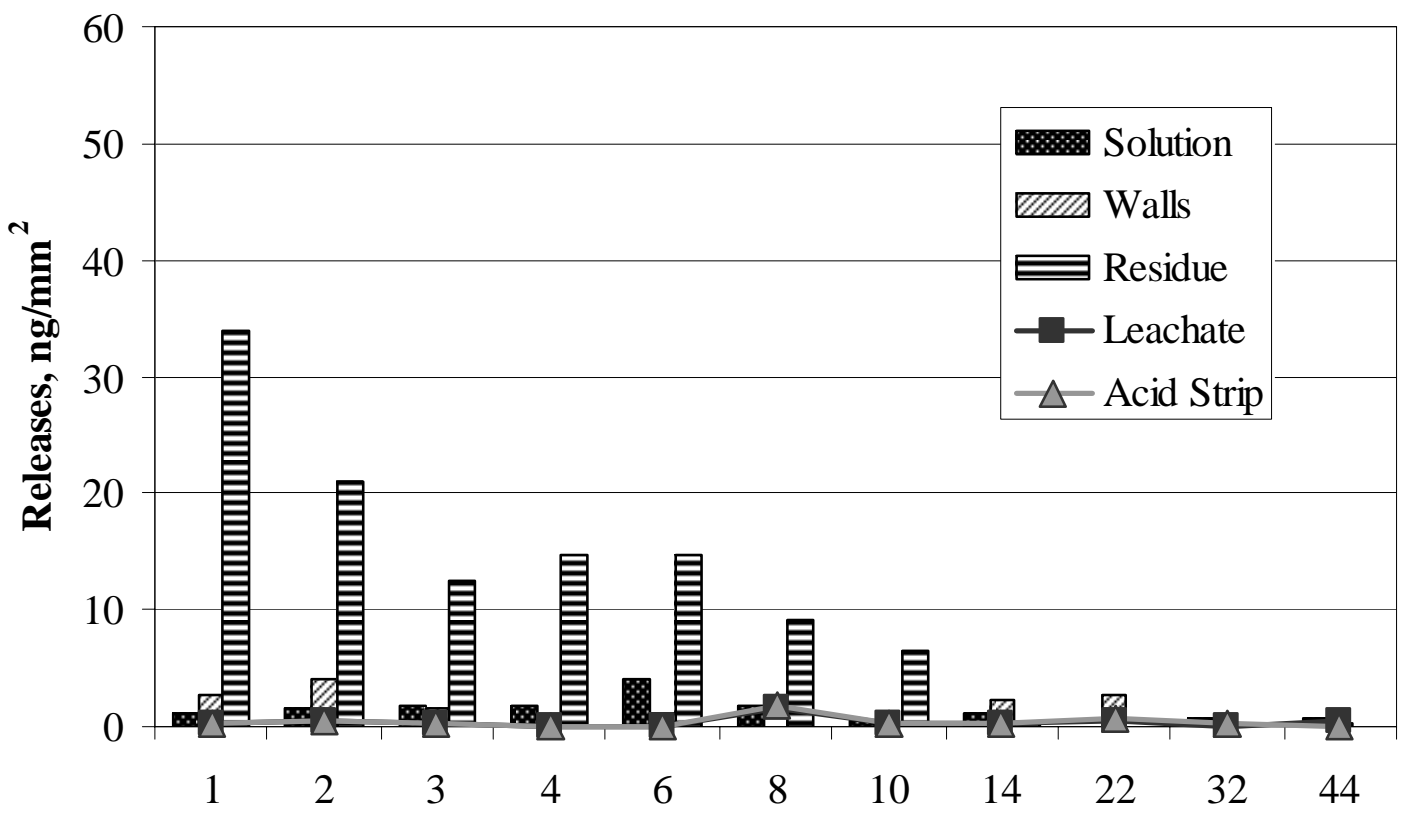

Time, weeks

Figure E-277. Copper Releases in Solution, on Walls, and in Residue from Polished Sample 1 in 10KCl and Average Detection Limits for Leachate and Acid Strip.

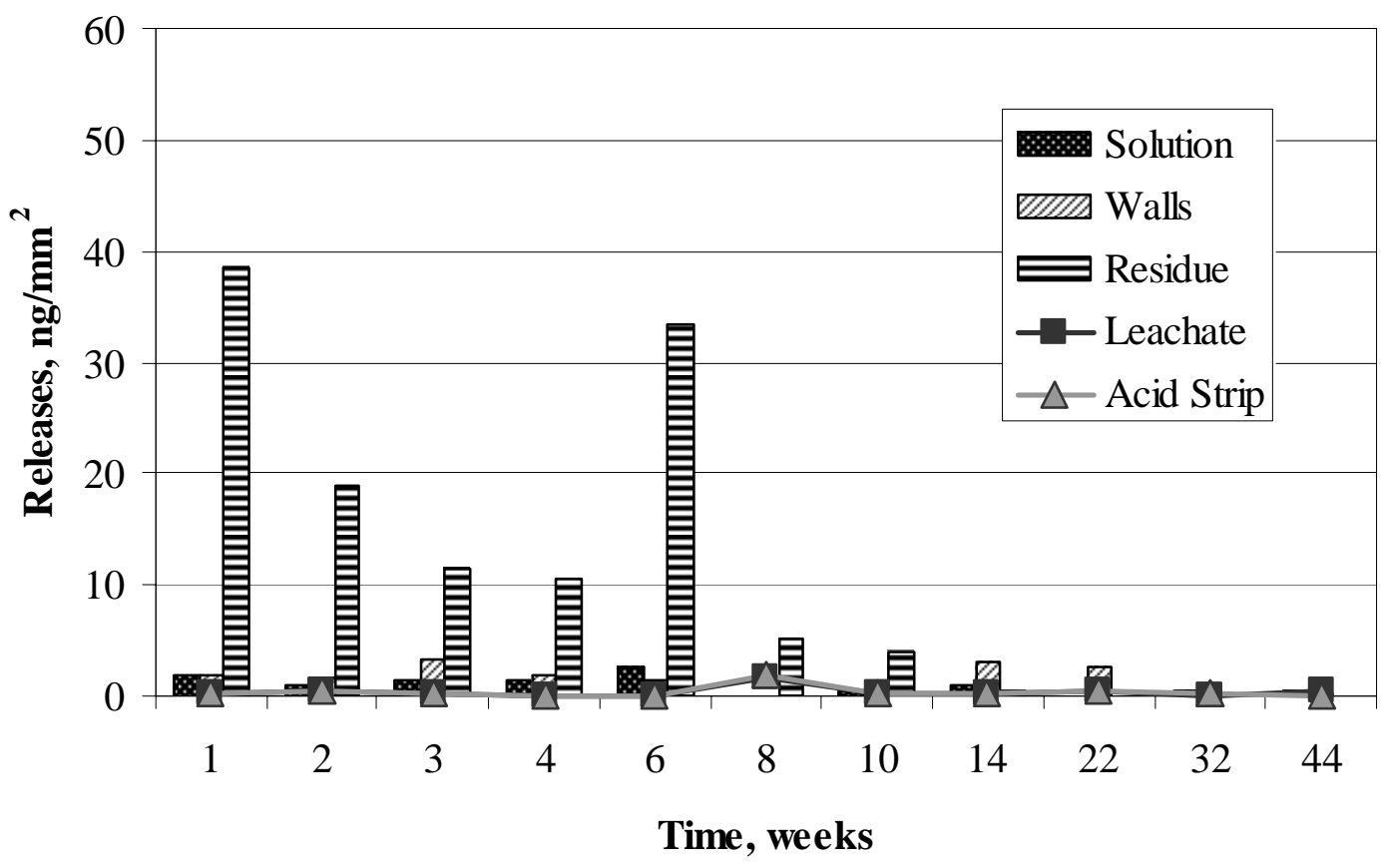

Figure E-278. Copper Releases in Solution, on Walls, and in Residue from Polished Sample 2 in $10 \mathrm{KCl}$ and Average Detection Limits for Leachate and Acid Strip. 


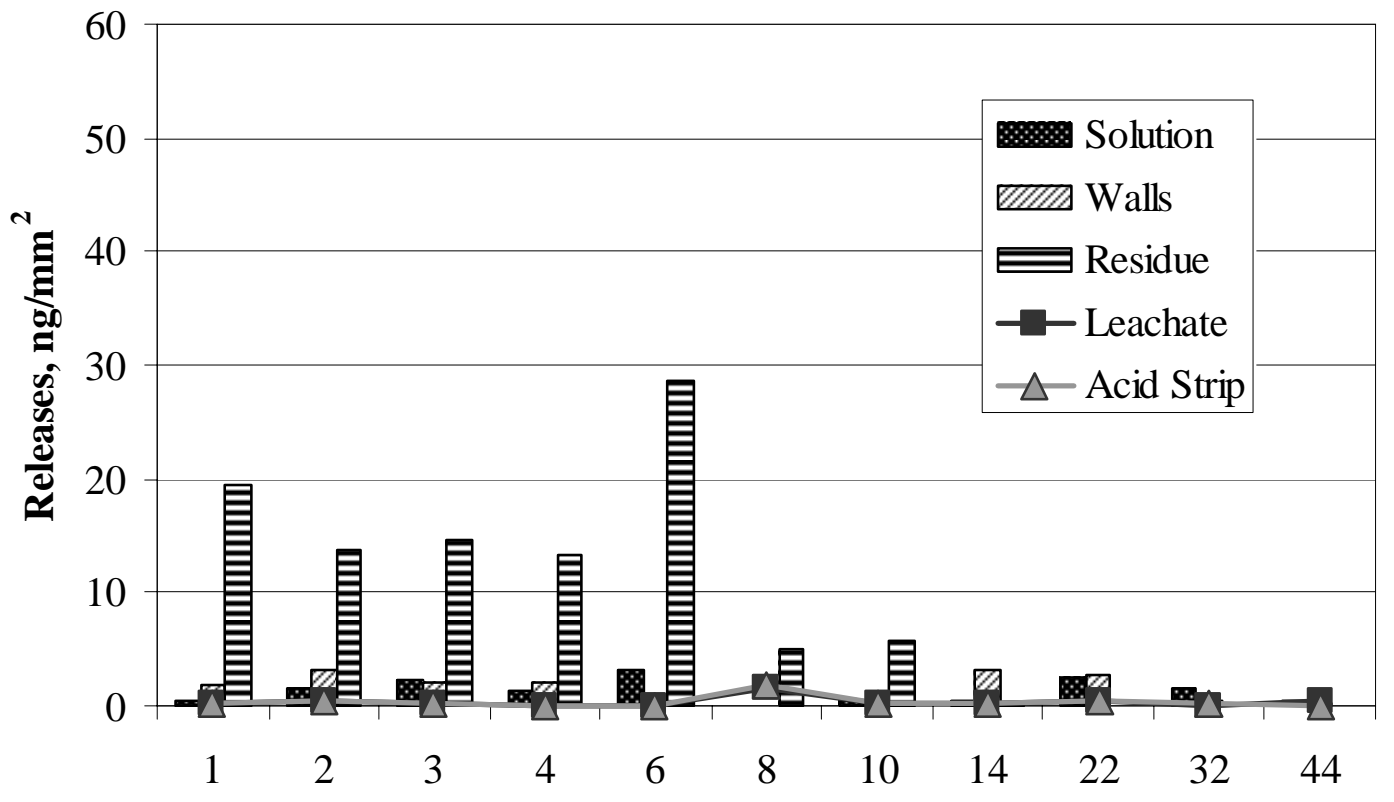

Time, weeks

Figure E-279. Copper Releases in Solution, on Walls, and in Residue from Polished Sample 3 in 10KCl and Average Detection Limits for Leachate and Acid Strip.

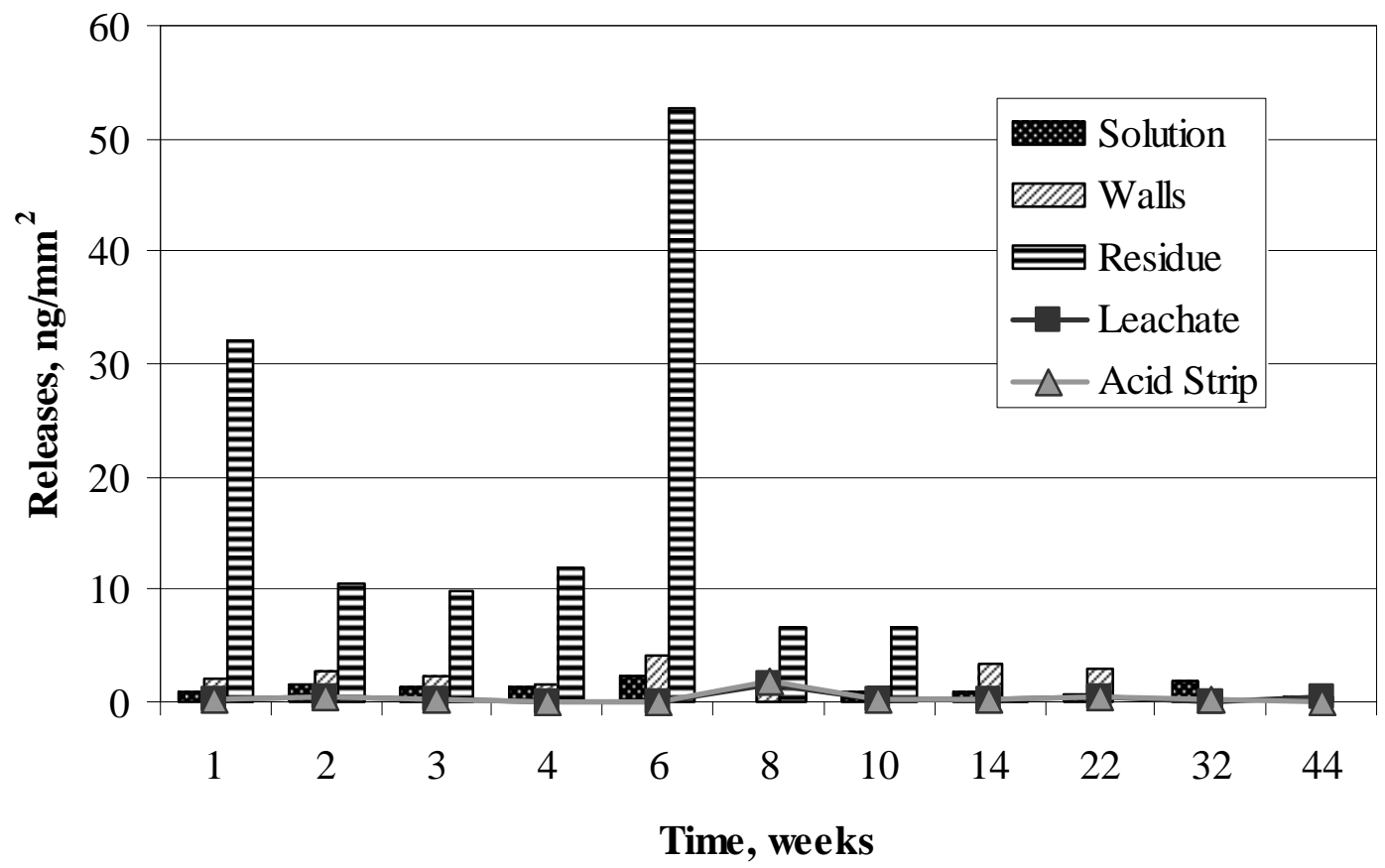

Figure E-280. Copper Releases in Solution, on Walls, and in Residue from Oxidized Sample 4 in 10KCl and Average Detection Limits for Leachate and Acid Strip. 


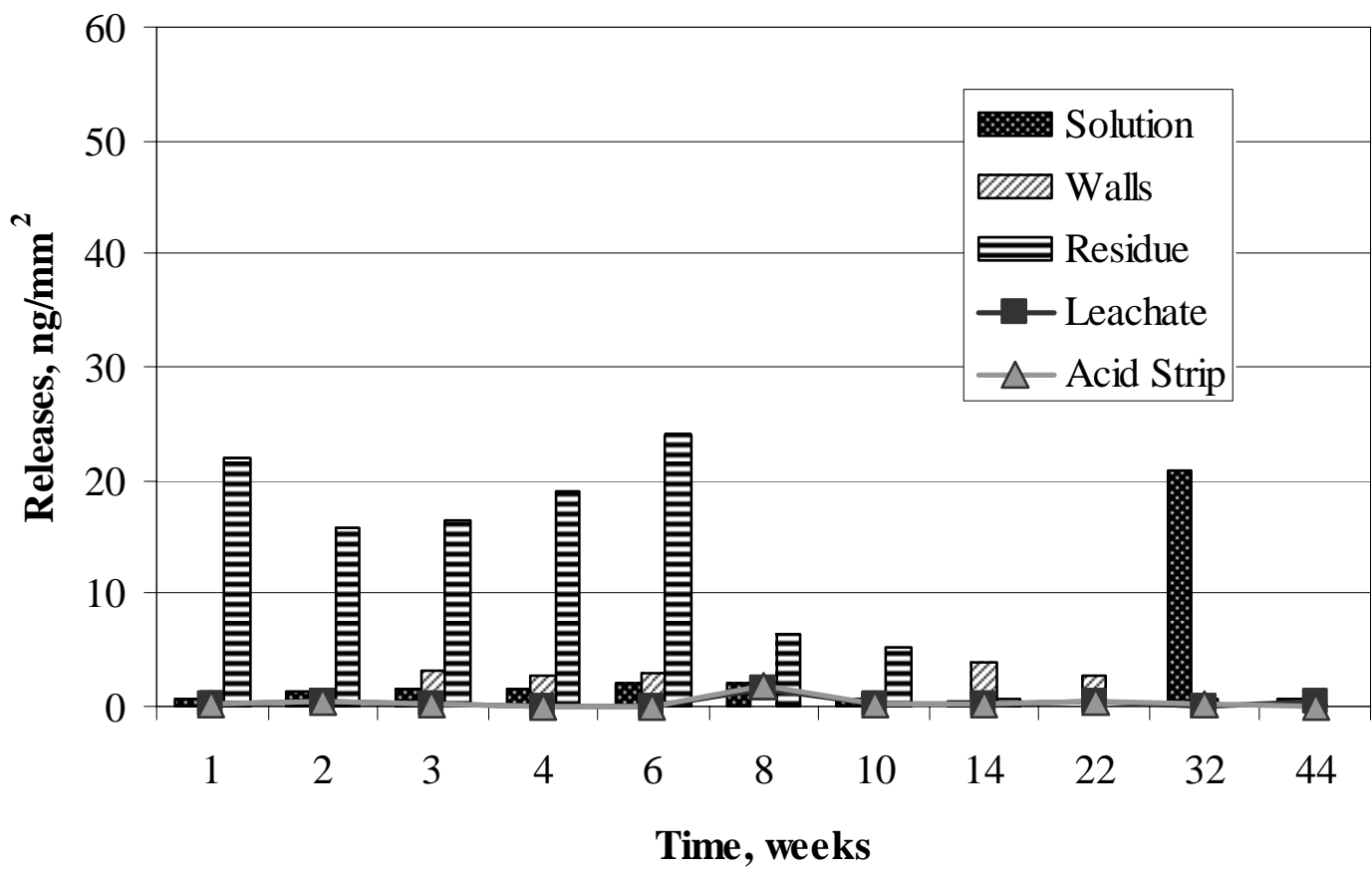

Figure E-281. Copper Releases in Solution, on Walls, and in Residue from Oxidized Sample 5 in 10KCl and Average Detection Limits for Leachate and Acid Strip.

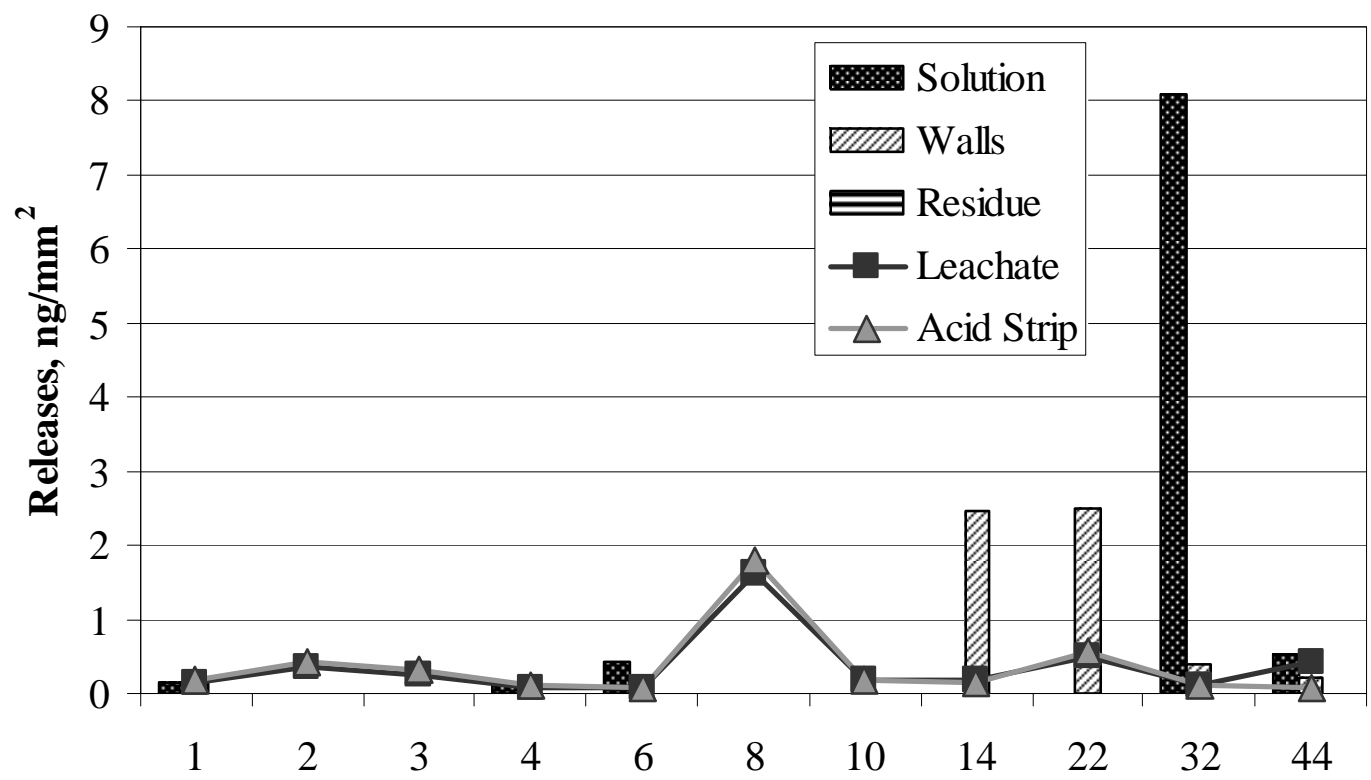

Time, weeks

Figure E-282. Copper Present in Solution, on Walls, and in Residue from 10KCl Control and Average Detection Limits for Leachate and Acid Strip. 


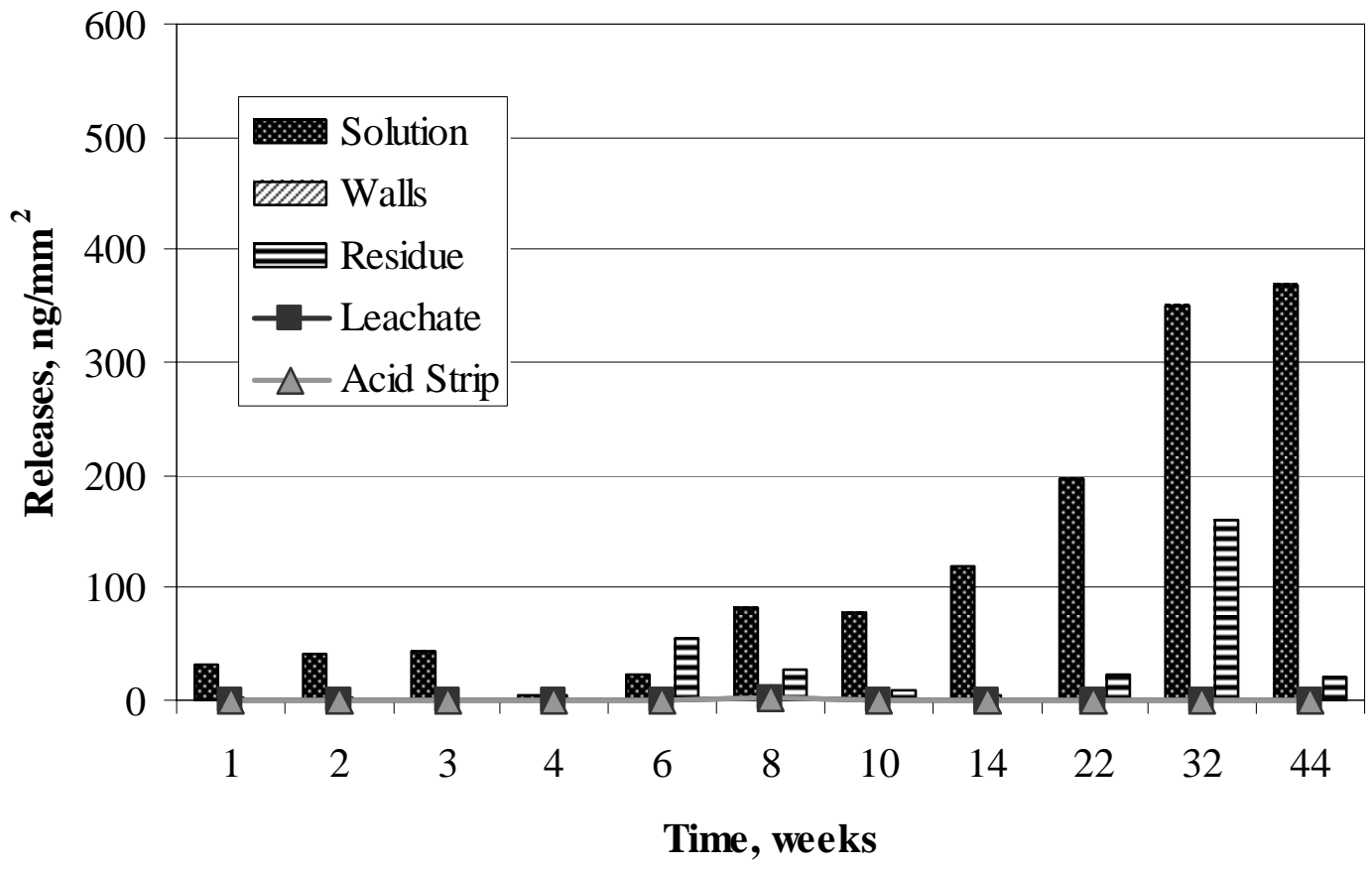

Figure E-283. Copper Releases in Solution, on Walls, and in Residue from Polished Sample 1 in AJ13 and Average Detection Limits for Leachate and Acid Strip.

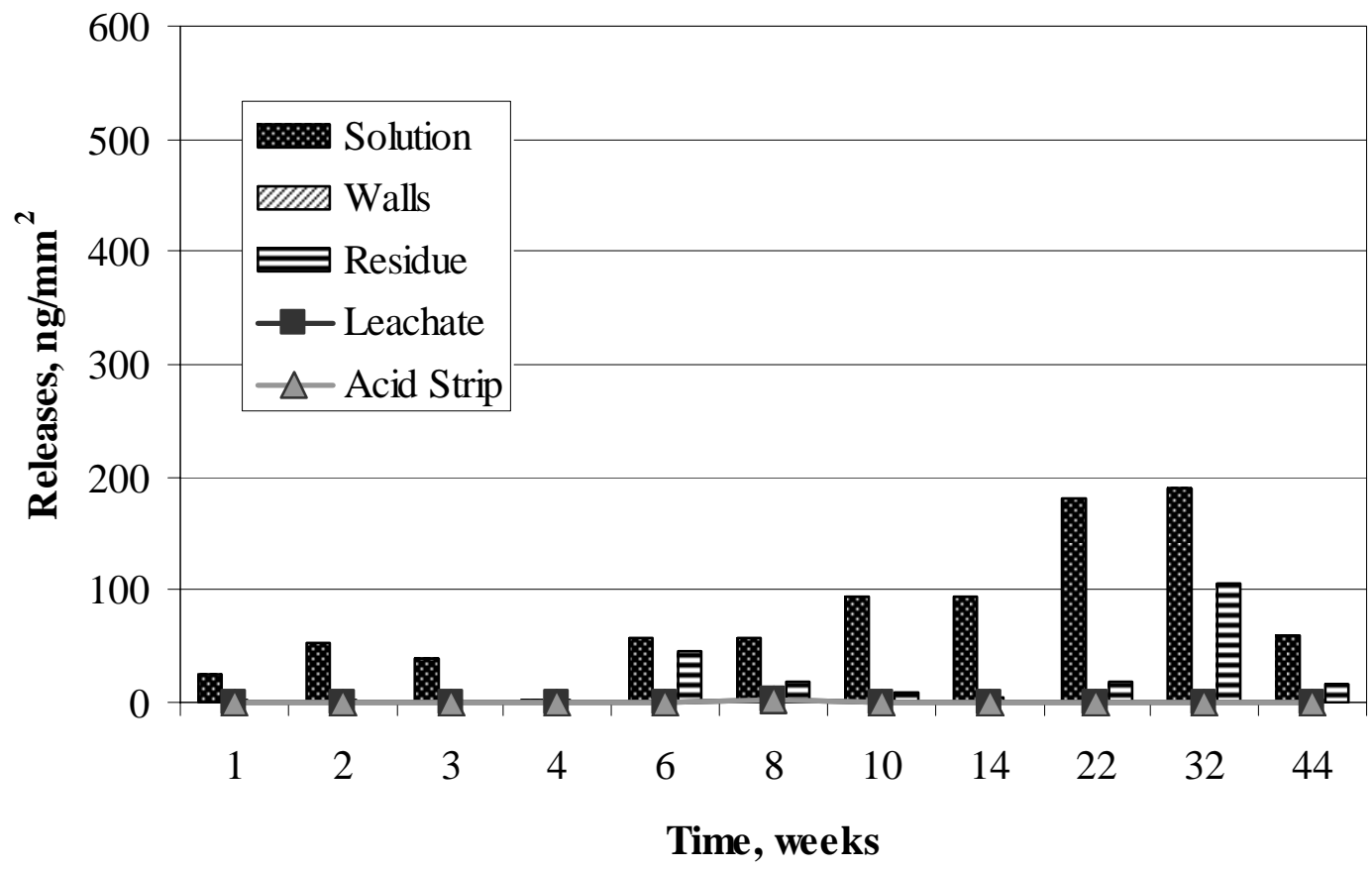

Figure E-284. Copper Releases in Solution, on Walls, and in Residue from Polished Sample 2 in AJ13 and Average Detection Limits for Leachate and Acid Strip. 


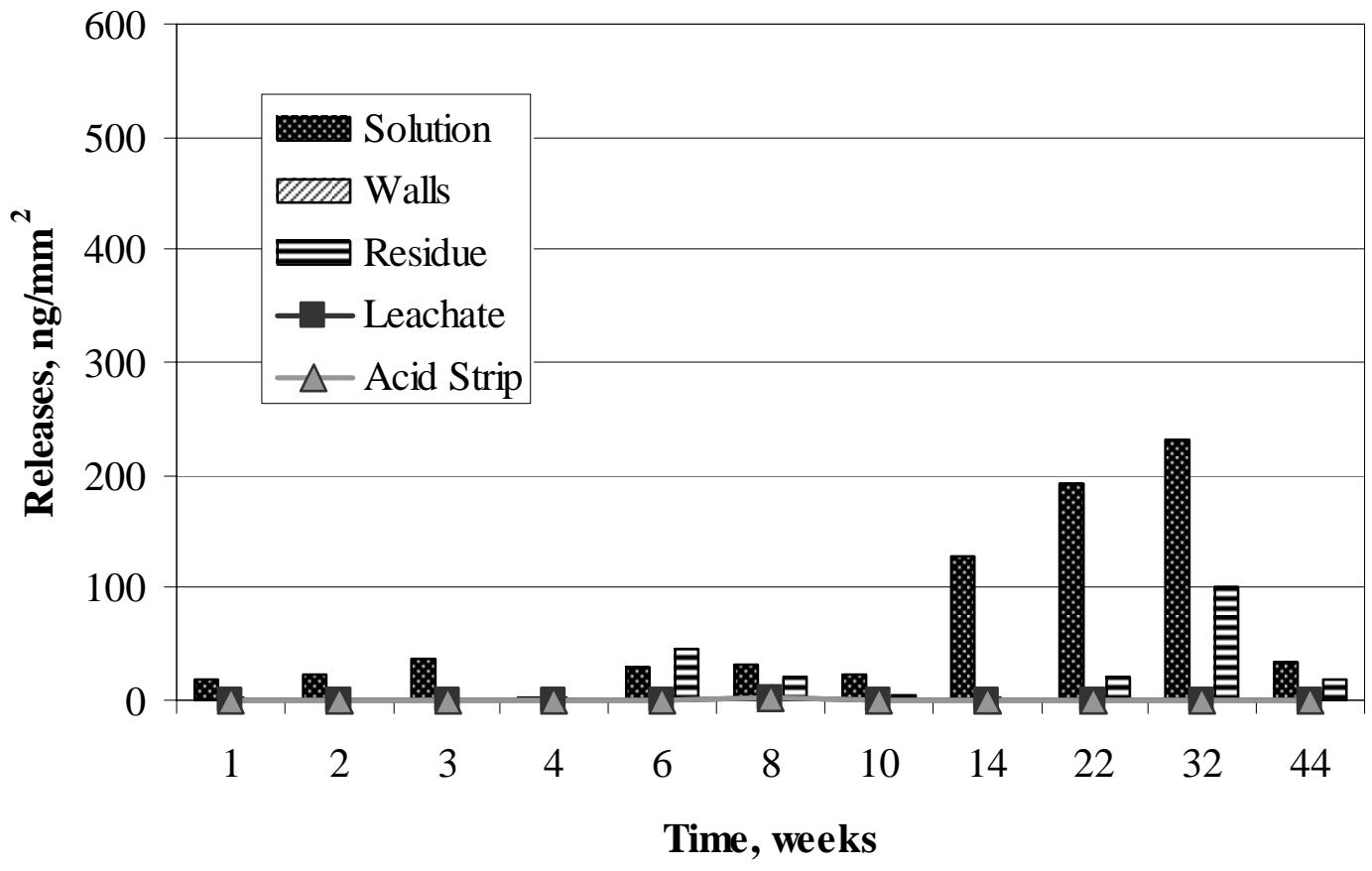

Figure E-285. Copper Releases in Solution, on Walls, and in Residue from Polished Sample 3 in AJ13 and Average Detection Limits for Leachate and Acid Strip.

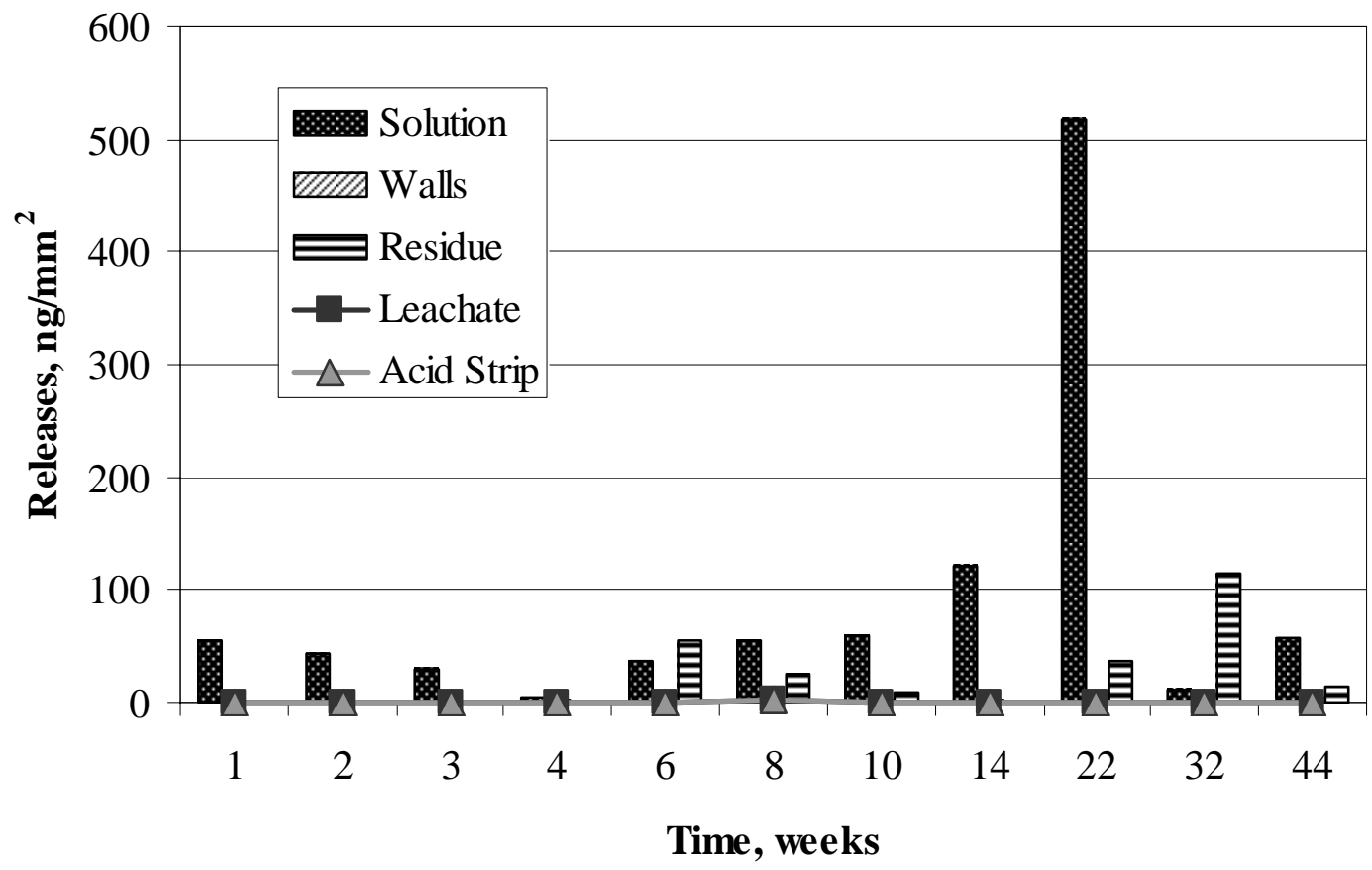

Figure E-286. Copper Releases in Solution, on Walls, and in Residue from Oxidized Sample 4 in AJ13 and Average Detection Limits for Leachate and Acid Strip. 


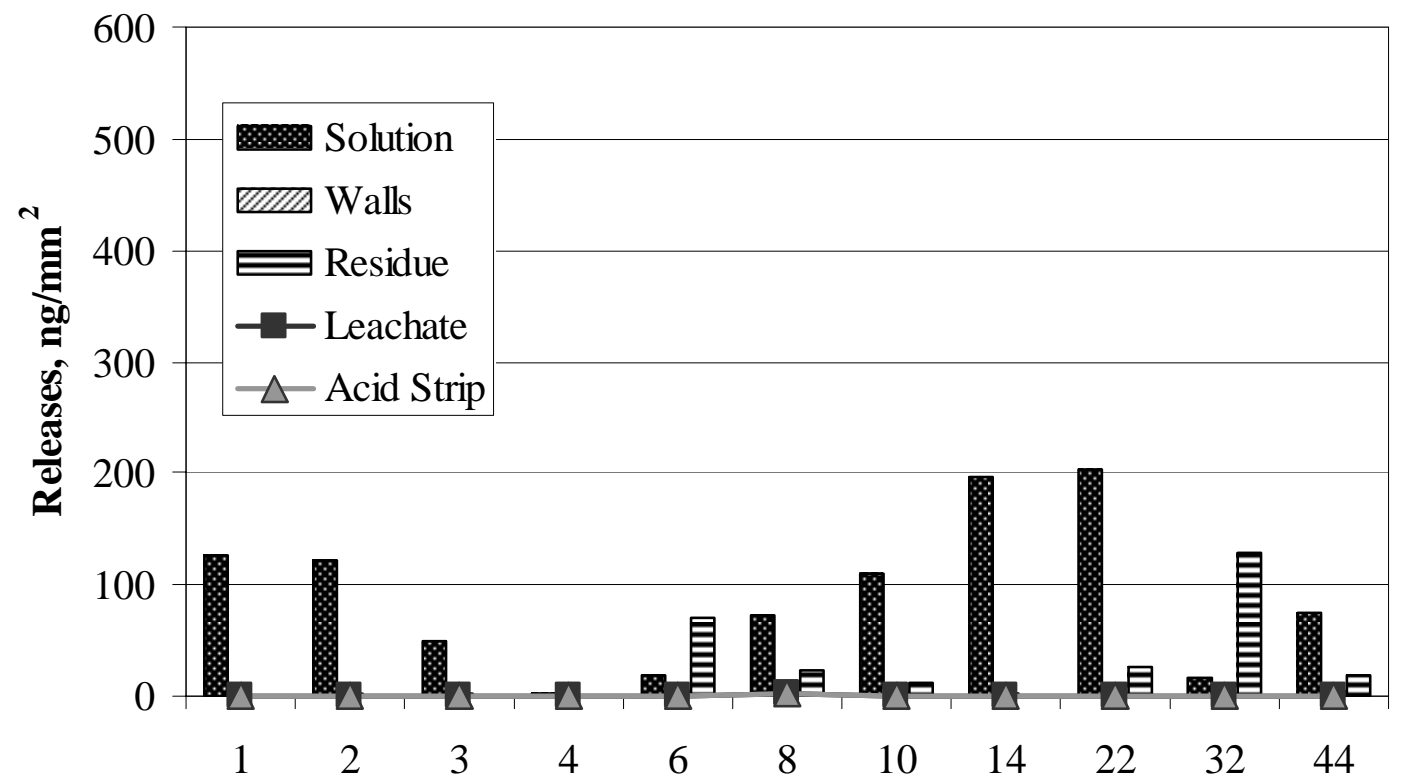

Time, weeks

Figure E-287. Copper Releases in Solution, on Walls, and in Residue from Oxidized Sample 5 in AJ13 and Average Detection Limits for Leachate and Acid Strip.

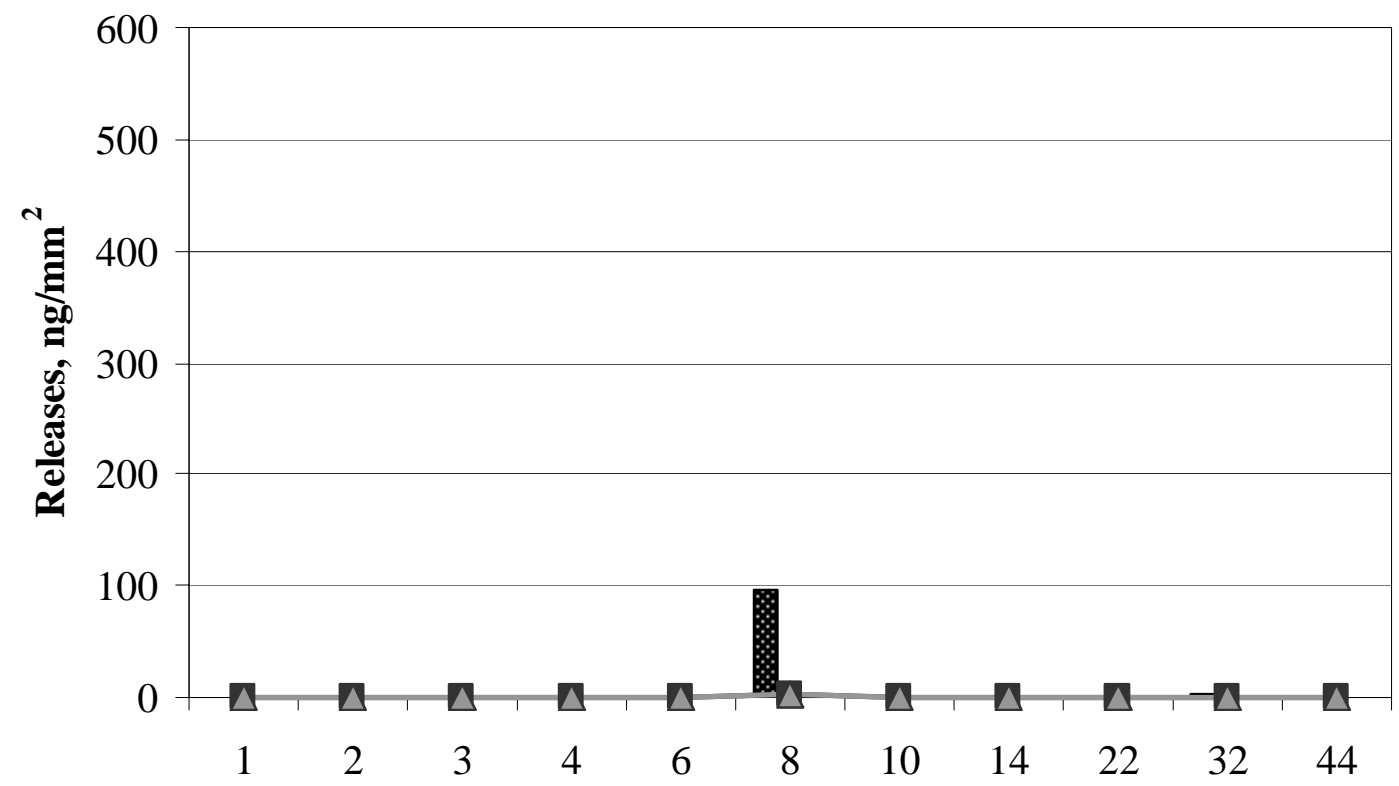

Time, weeks

Figure E-288. Copper Present in Solution, on Walls, and in Residue from AJ13 Control and Average Detection Limits for Leachate and Acid Strip. 


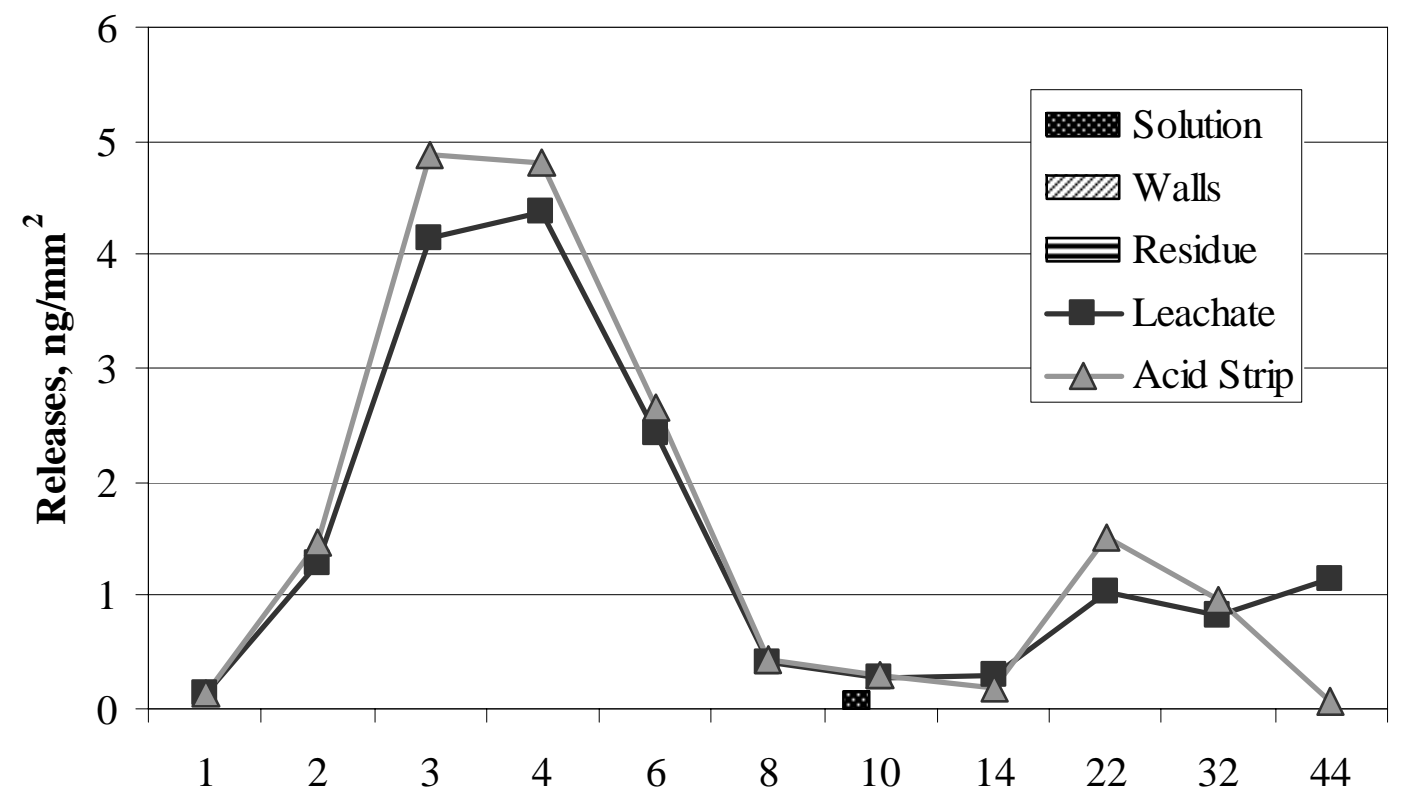

Time, weeks

Figure E-289. Vanadium Releases in Solution, on Walls, and in Residue from Polished Sample 1 in SJ13 and Average Detection Limits for Leachate and Acid Strip.

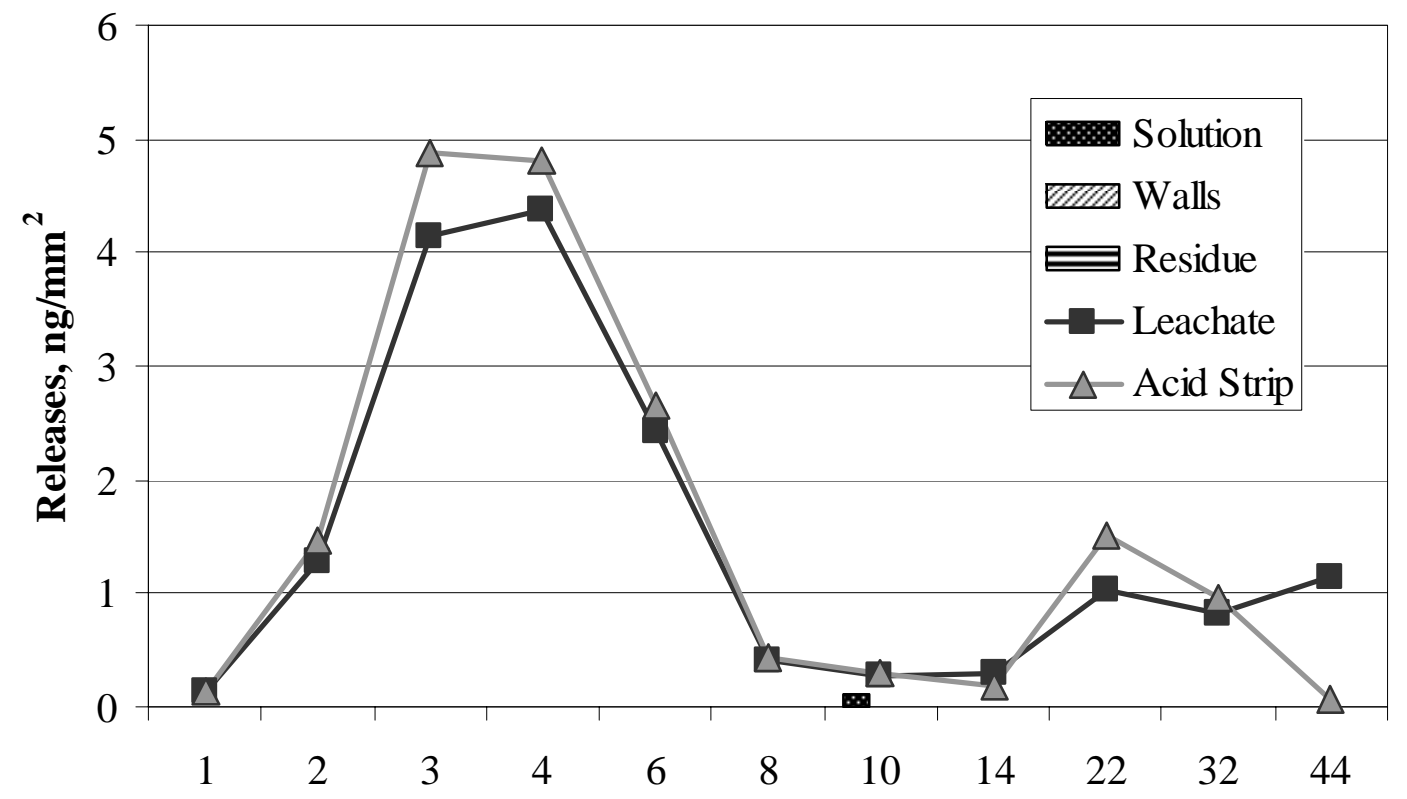

Time, weeks

Figure E-290. Vanadium Releases in Solution, on Walls, and in Residue from Polished Sample 2 in SJ13 and Average Detection Limits for Leachate and Acid Strip. 


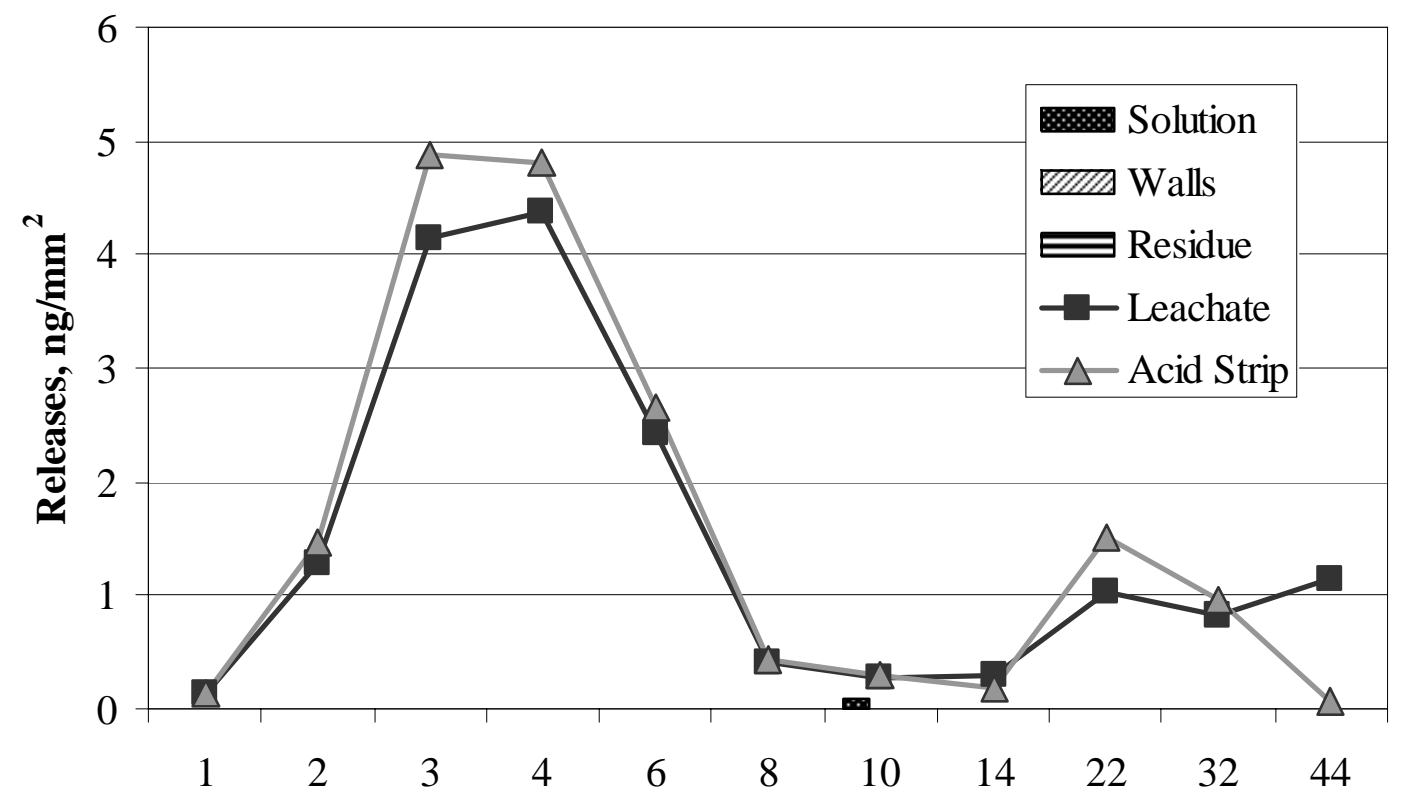

Time, weeks

Figure E-291. Vanadium Releases in Solution, on Walls, and in Residue from Polished Sample 3 in SJ13 and Average Detection Limits for Leachate and Acid Strip.

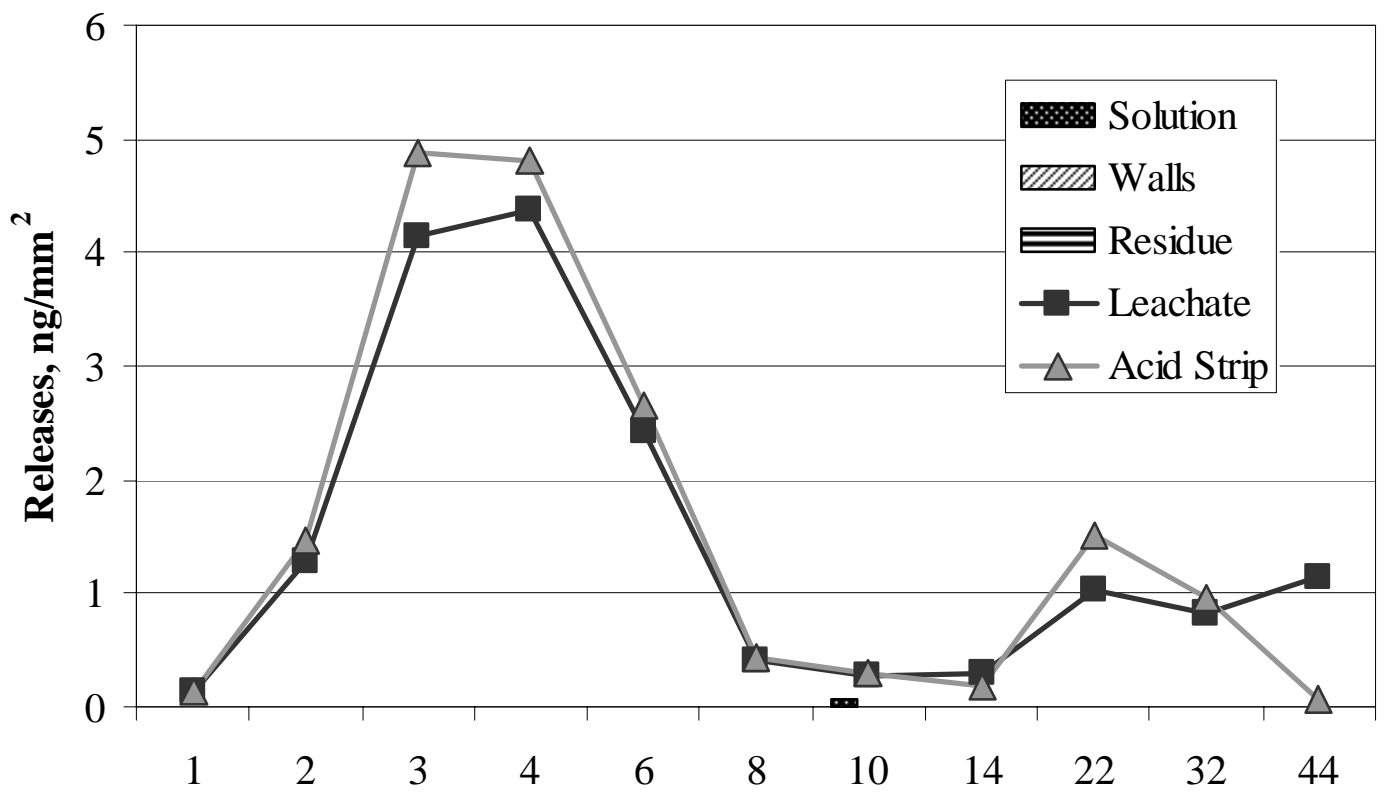

Time, weeks

Figure E-292. Vanadium Releases in Solution, on Walls, and in Residue from Oxidized Sample 4 in SJ13 and Average Detection Limits for Leachate and Acid Strip. 


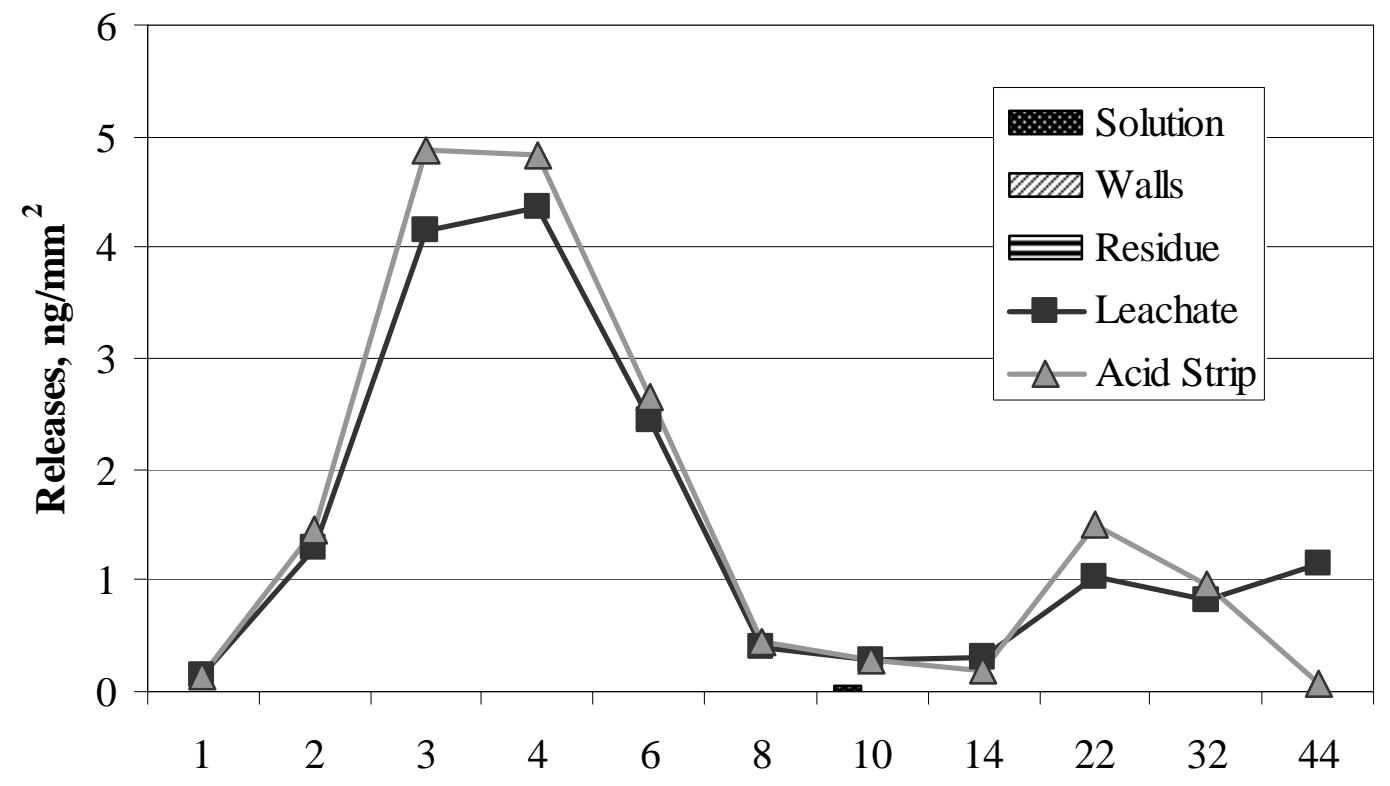

Time, weeks

Figure E-293. Vanadium Releases in Solution, on Walls, and in Residue from Oxidized Sample 5 in SJ13 and Average Detection Limits for Leachate and Acid Strip.

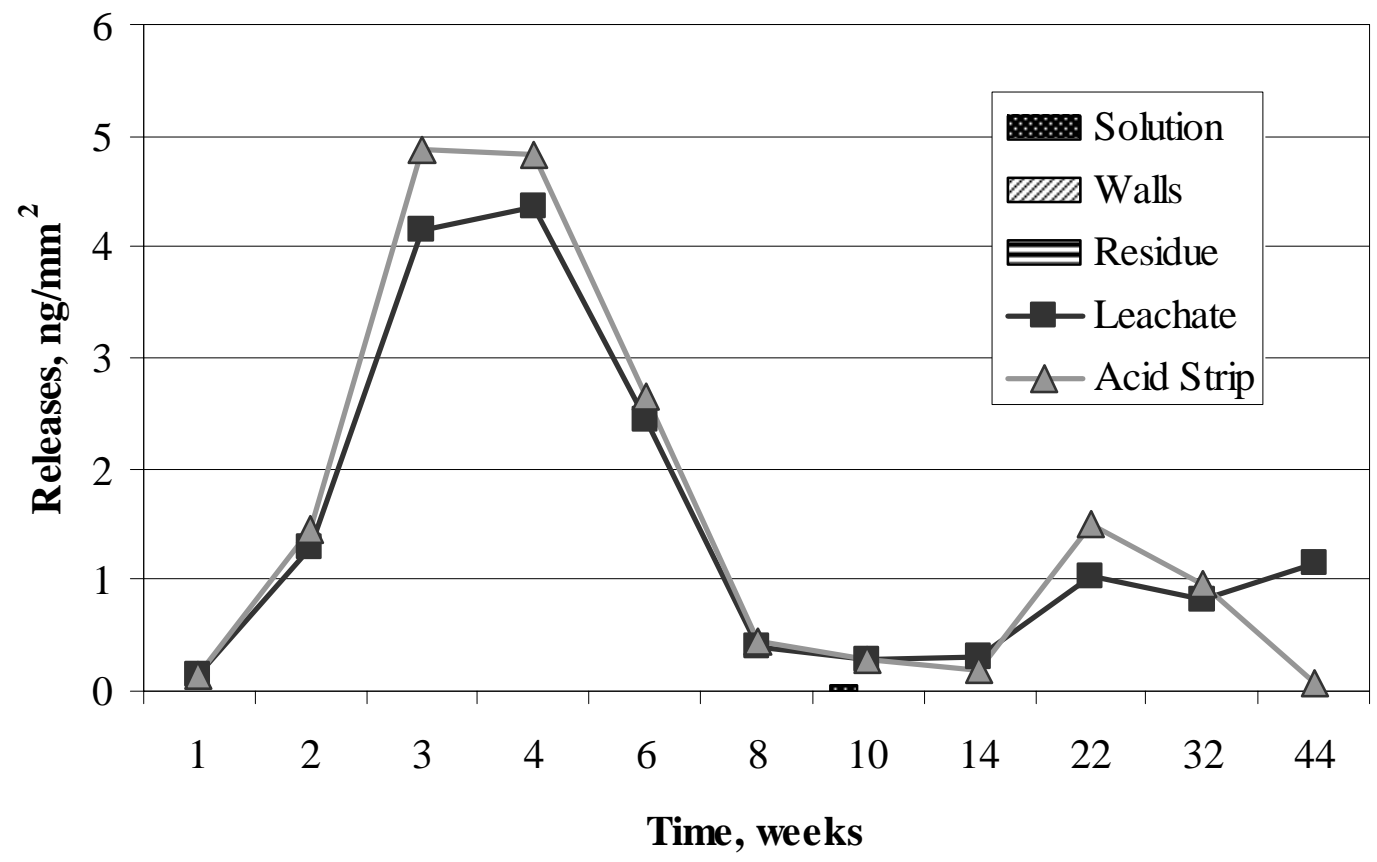

Figure E-294. Vanadium Present in Solution, on Walls, and in Residue from SJ13 Control and Average Detection Limits for Leachate and Acid Strip. 


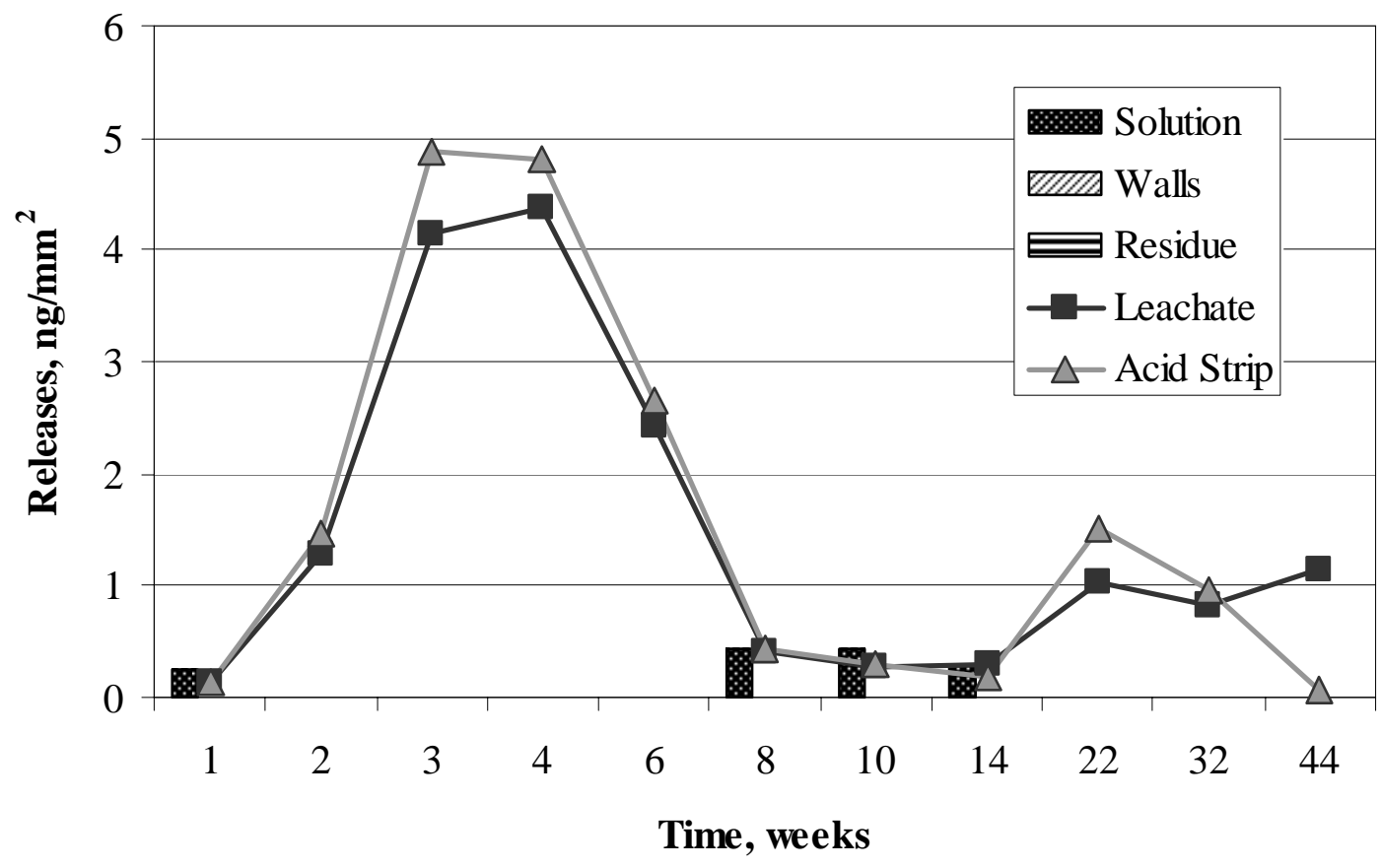

Figure E-295. Vanadium Releases in Solution, on Walls, and in Residue from Polished Sample 1 in CJ13 and Average Detection Limits for Leachate and Acid Strip.

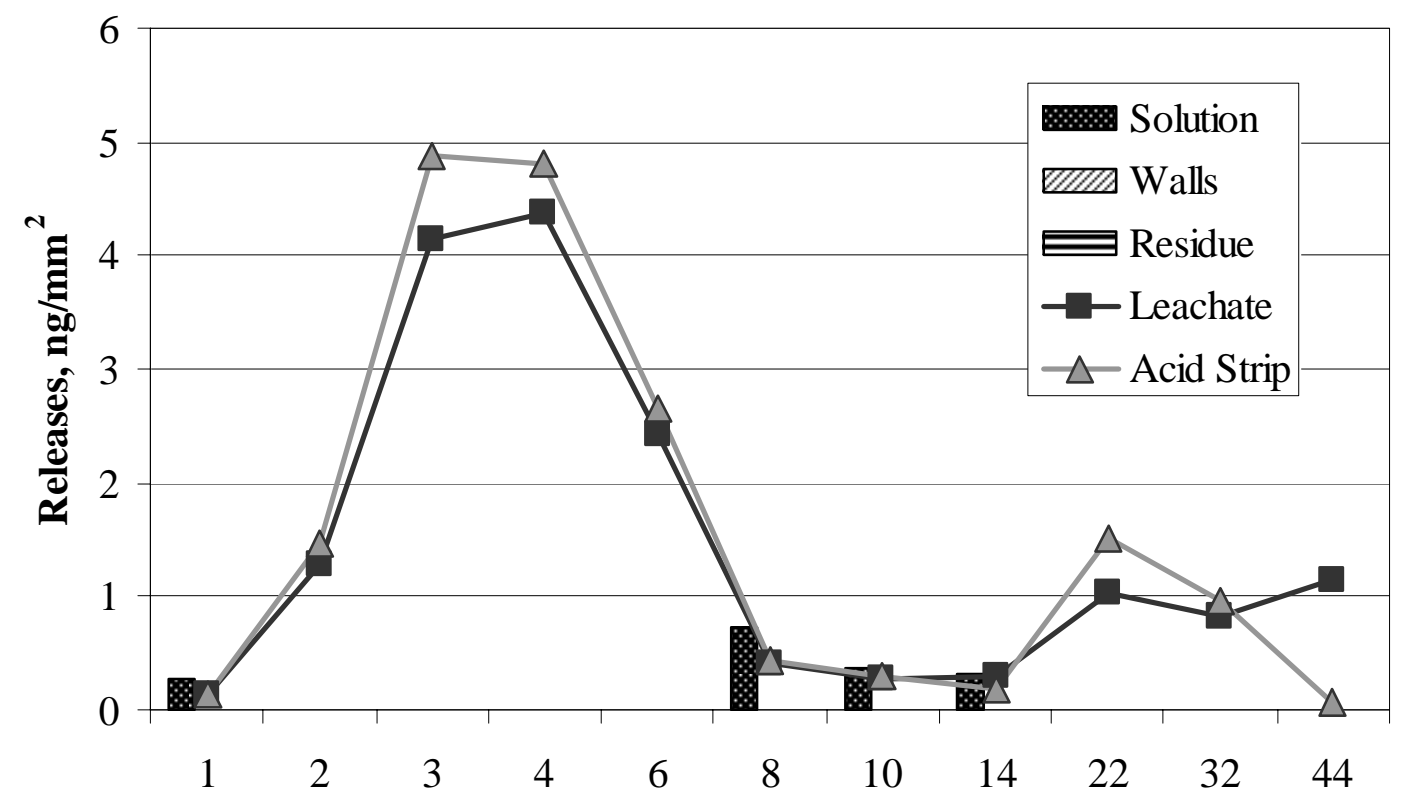

Time, weeks

Figure E-296. Vanadium Releases in Solution, on Walls, and in Residue from Polished Sample 2 in CJ13 and Average Detection Limits for Leachate and Acid Strip. 


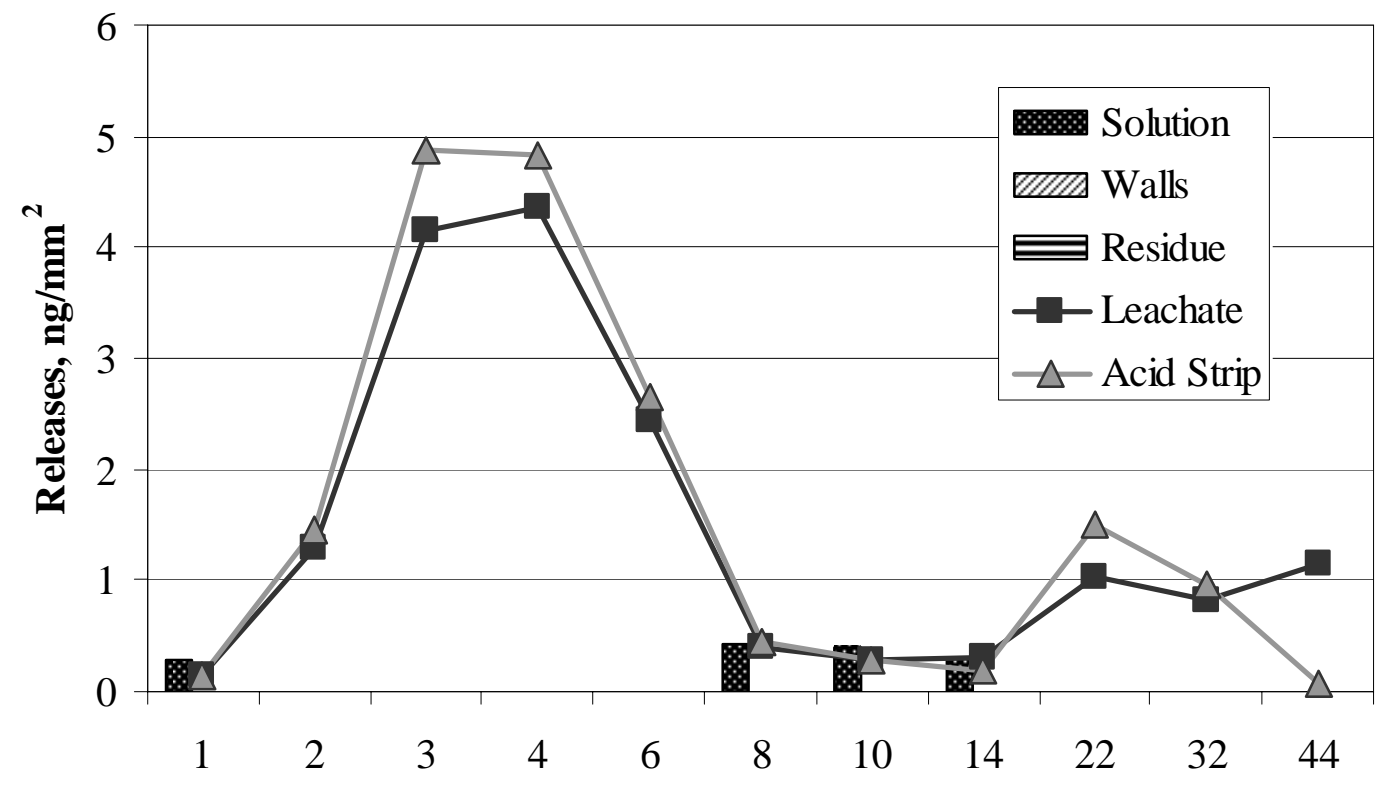

Time, weeks

Figure E-297. Vanadium Releases in Solution, on Walls, and in Residue from Polished Sample 3 in CJ13 and Average Detection Limits for Leachate and Acid Strip.

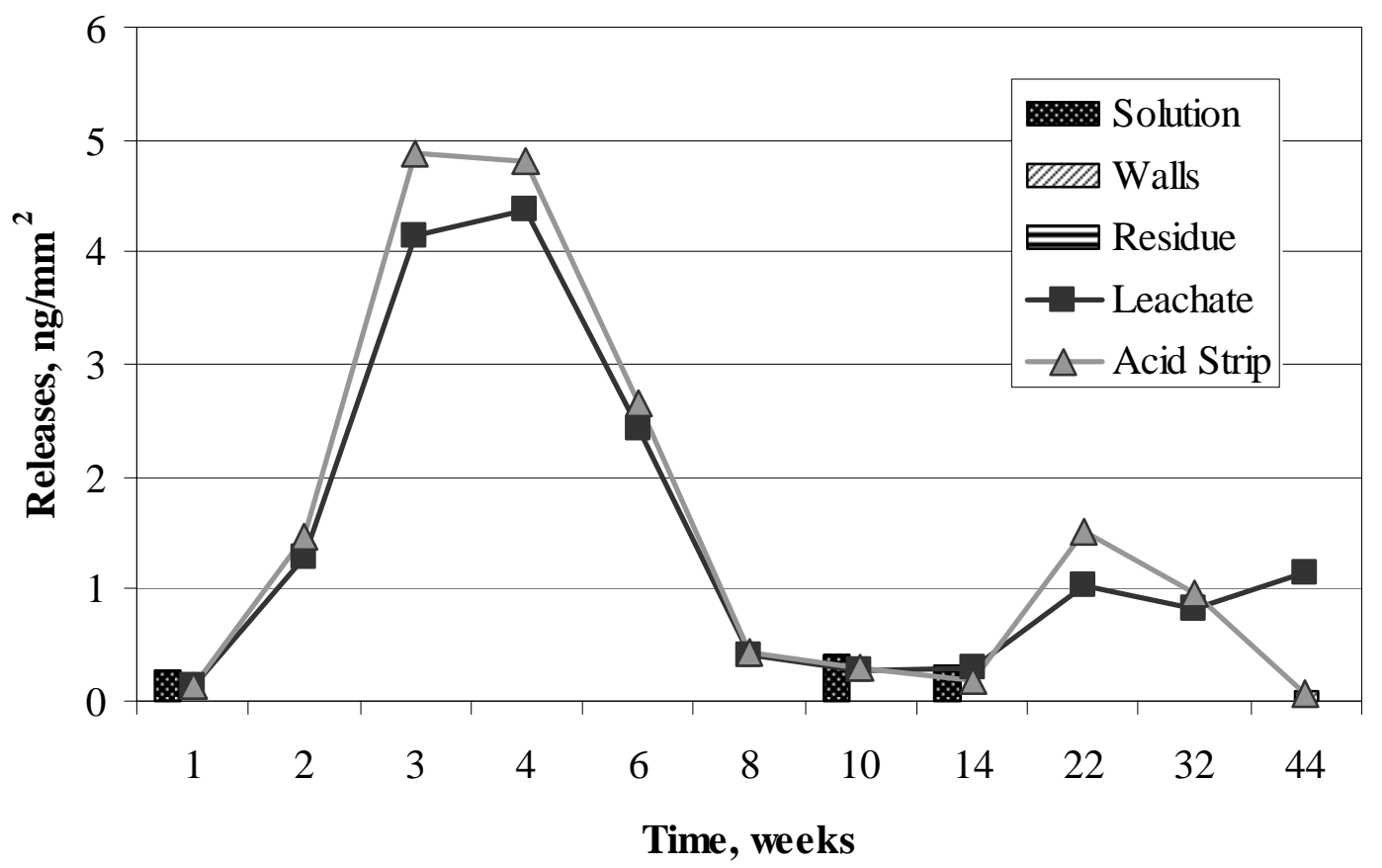

Figure E-298. Vanadium Releases in Solution, on Walls, and in Residue from Oxidized Sample 4 in CJ13 and Average Detection Limits for Leachate and Acid Strip. 


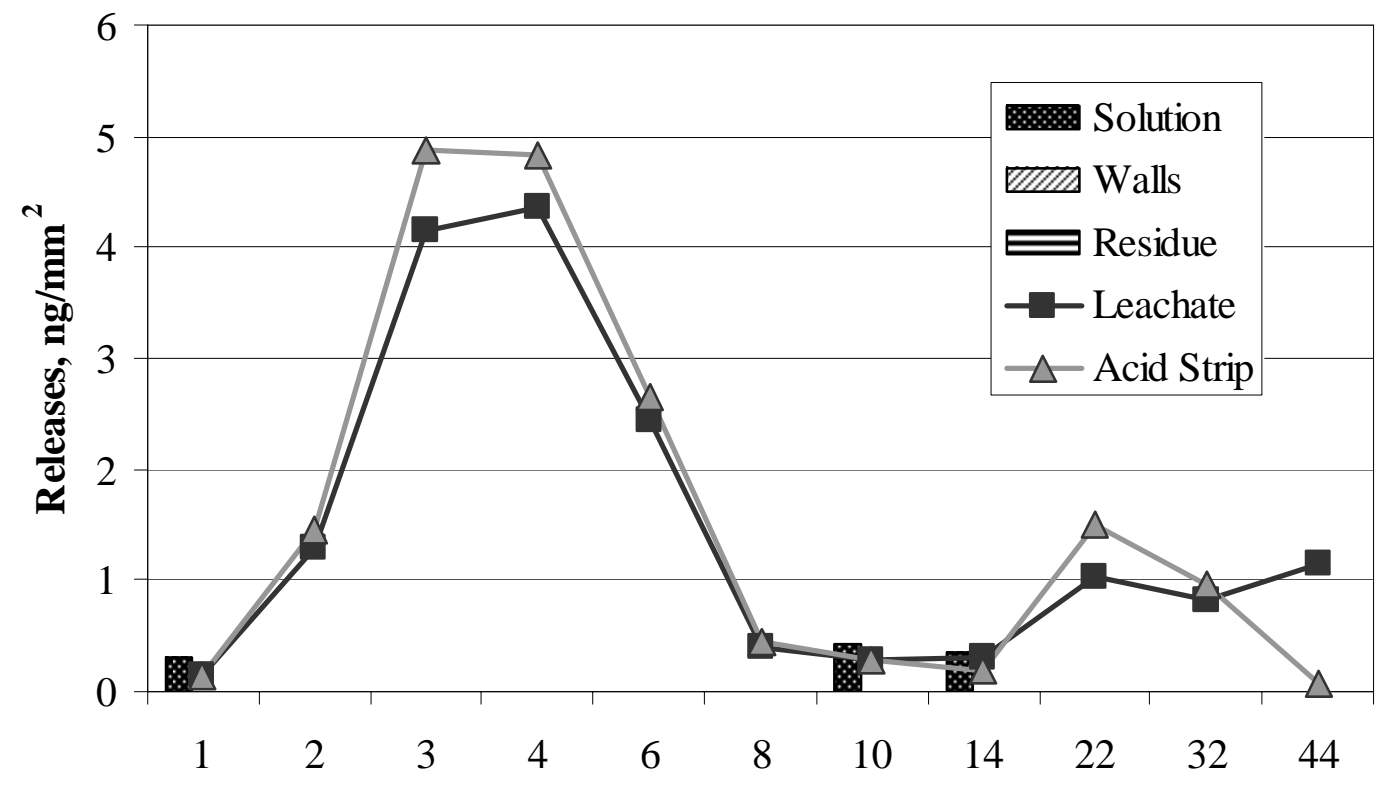

Time, weeks

Figure E-299. Vanadium Releases in Solution, on Walls, and in Residue from Oxidized Sample 5 in CJ13 and Average Detection Limits for Leachate and Acid Strip.

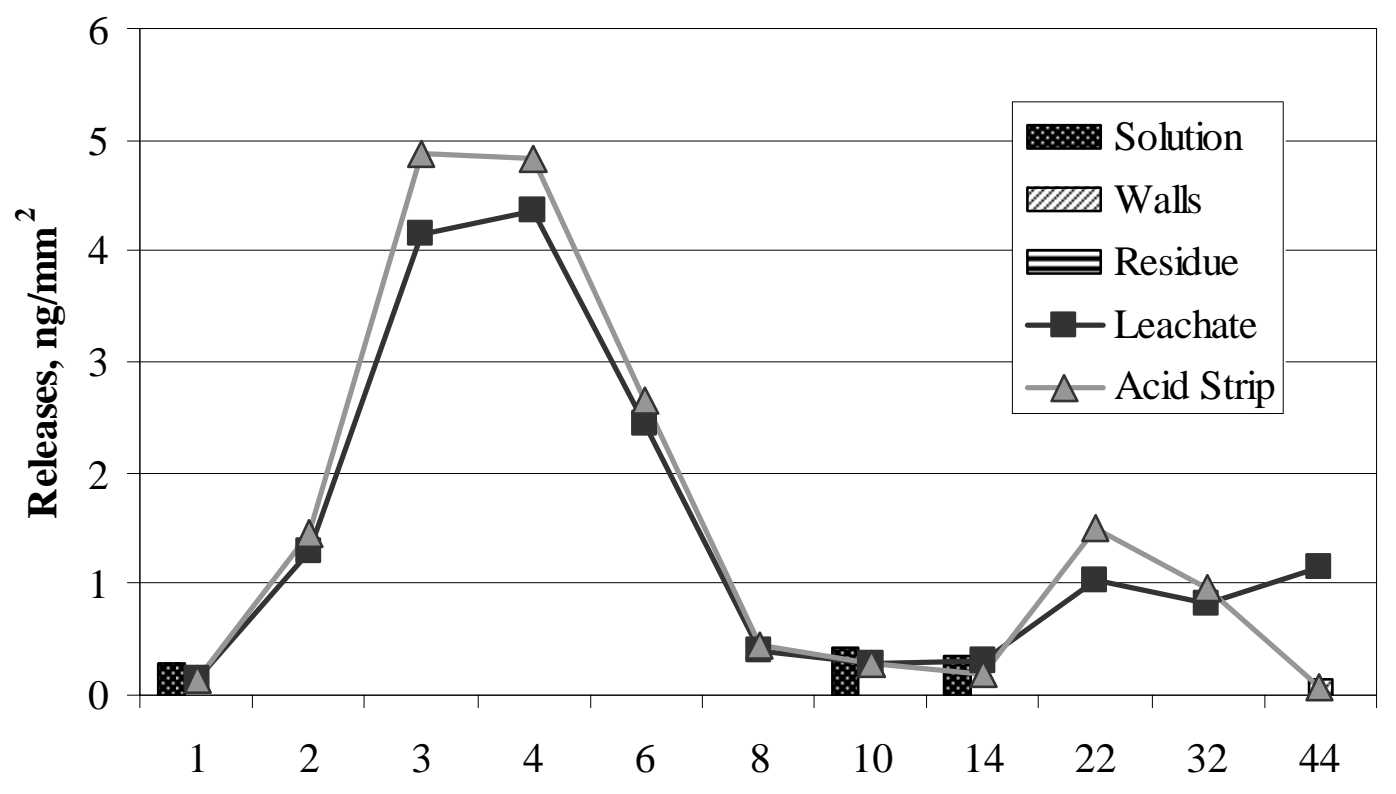

Time, weeks

Figure E-300. Vanadium Present in Solution, on Walls, and in Residue from CJ13 Control and Average Detection Limits for Leachate and Acid Strip. 


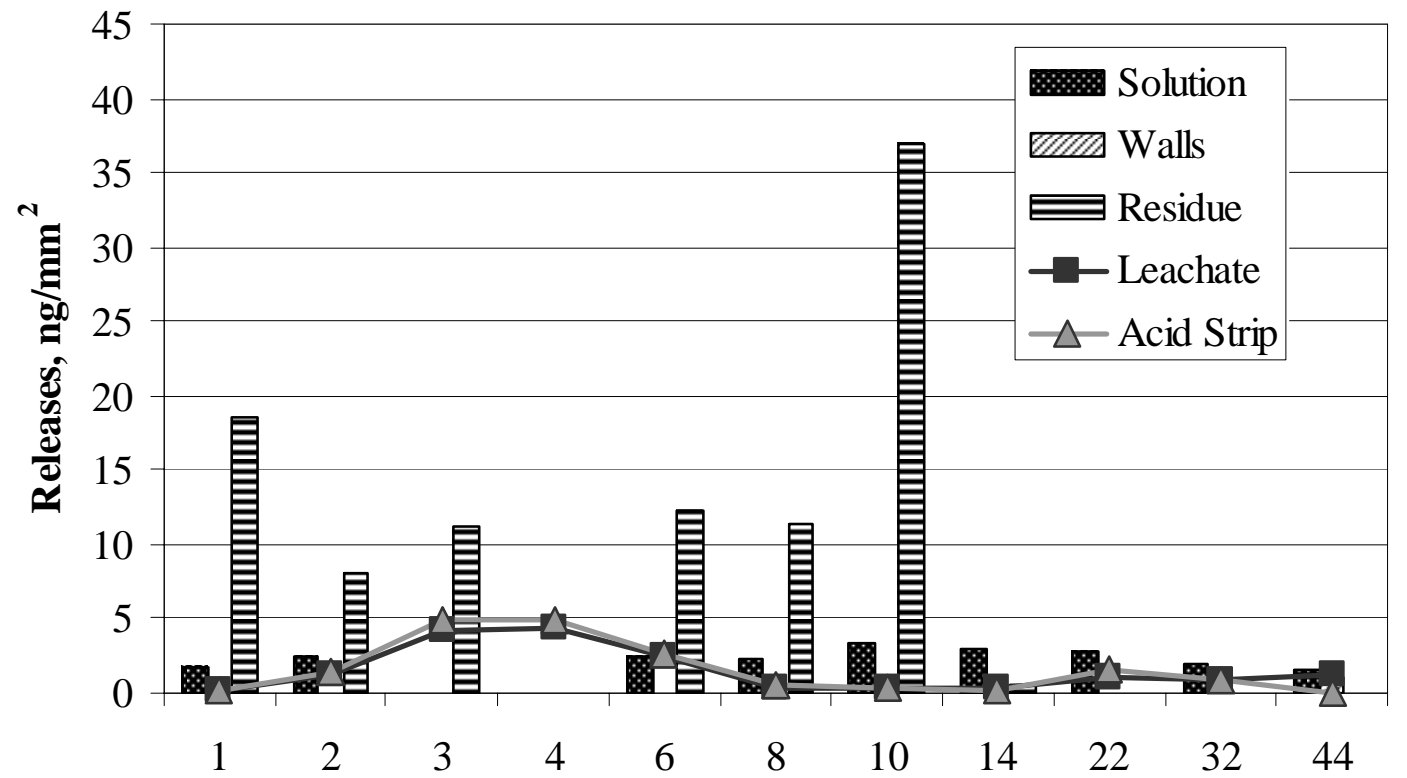

Time, weeks

Figure E-301. Vanadium Releases in Solution, on Walls, and in Residue from Polished Sample 1 in $10 \mathrm{KCl}$ and Average Detection Limits for Leachate and Acid Strip.

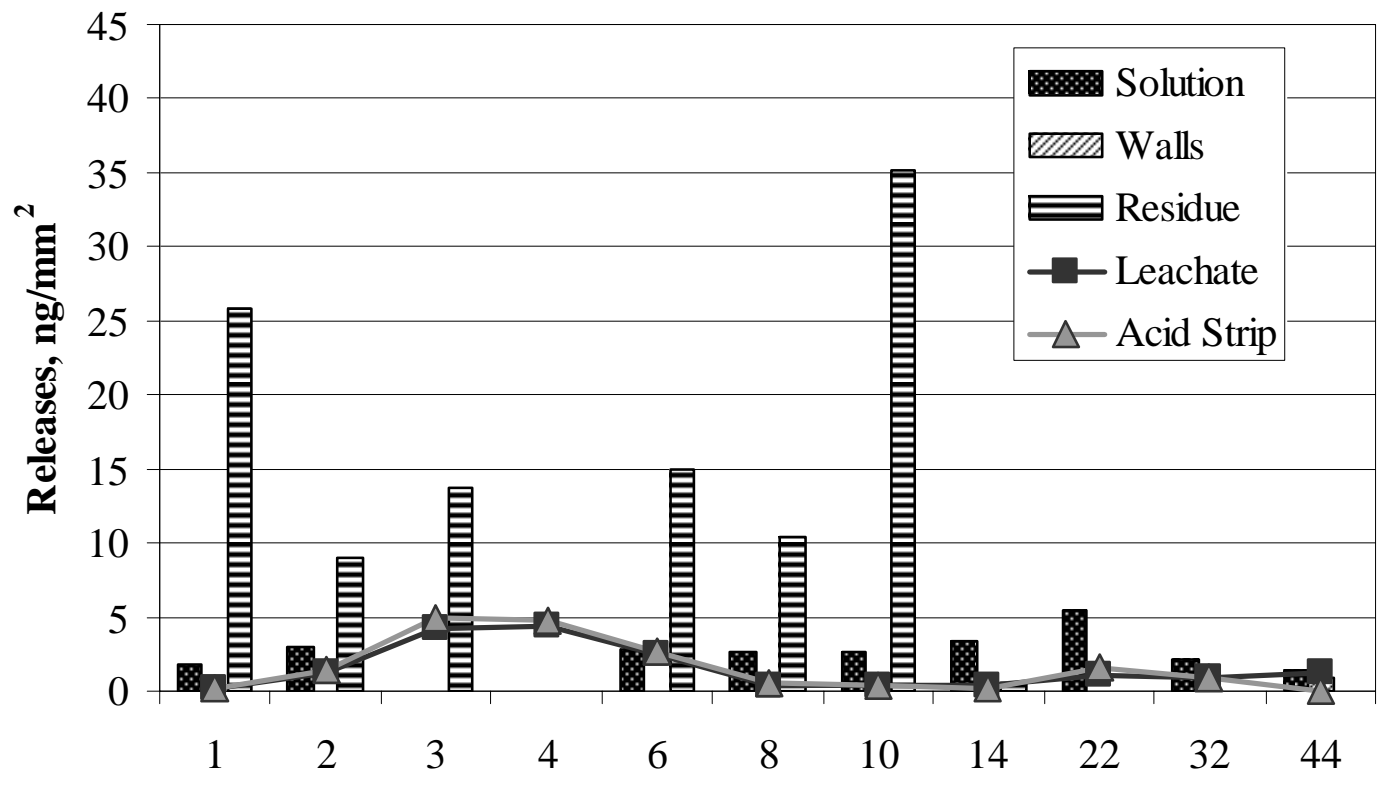

Time, weeks

Figure E-302. Vanadium Releases in Solution, on Walls, and in Residue from Polished Sample 2 in $10 \mathrm{KCl}$ and Average Detection Limits for Leachate and Acid Strip. 


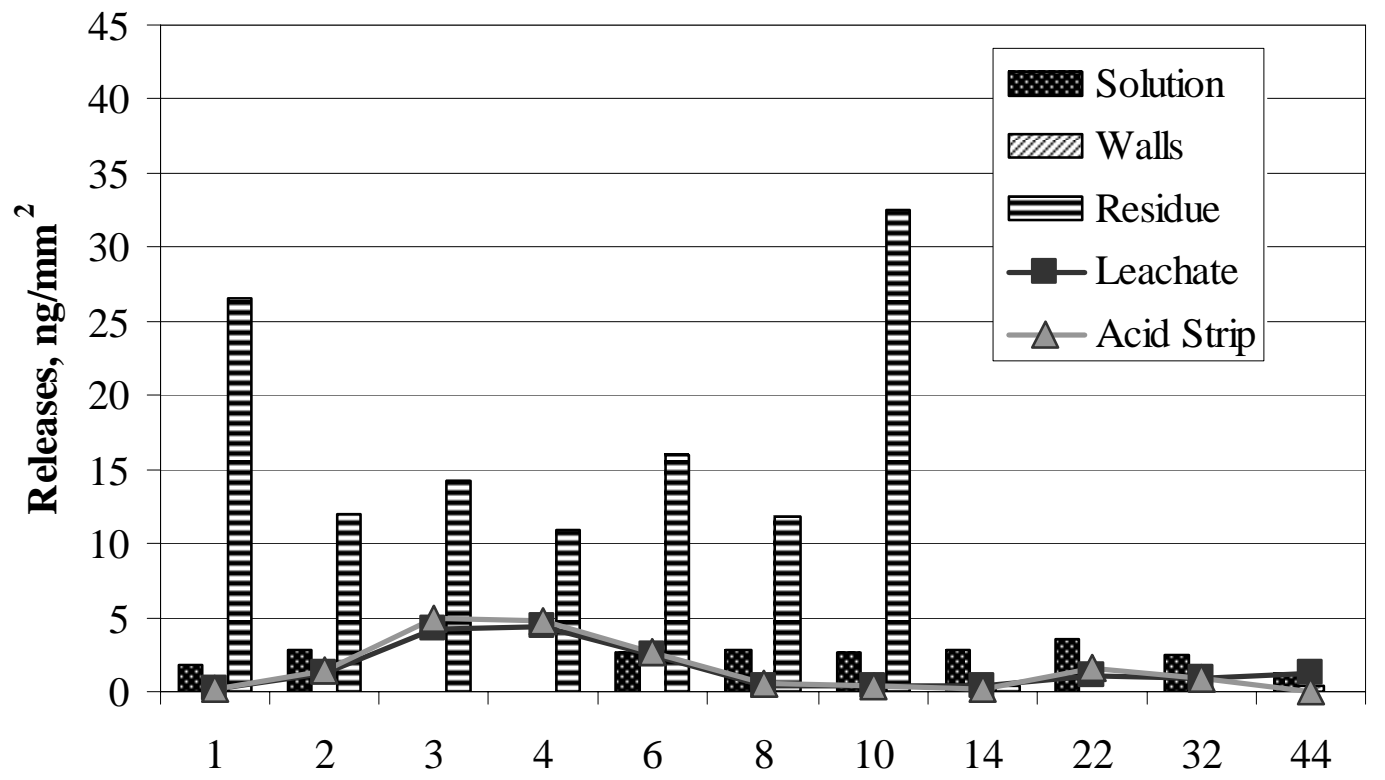

Time, weeks

Figure E-303. Vanadium Releases in Solution, on Walls, and in Residue from Polished Sample 3 in $10 \mathrm{KCl}$ and Average Detection Limits for Leachate and Acid Strip.

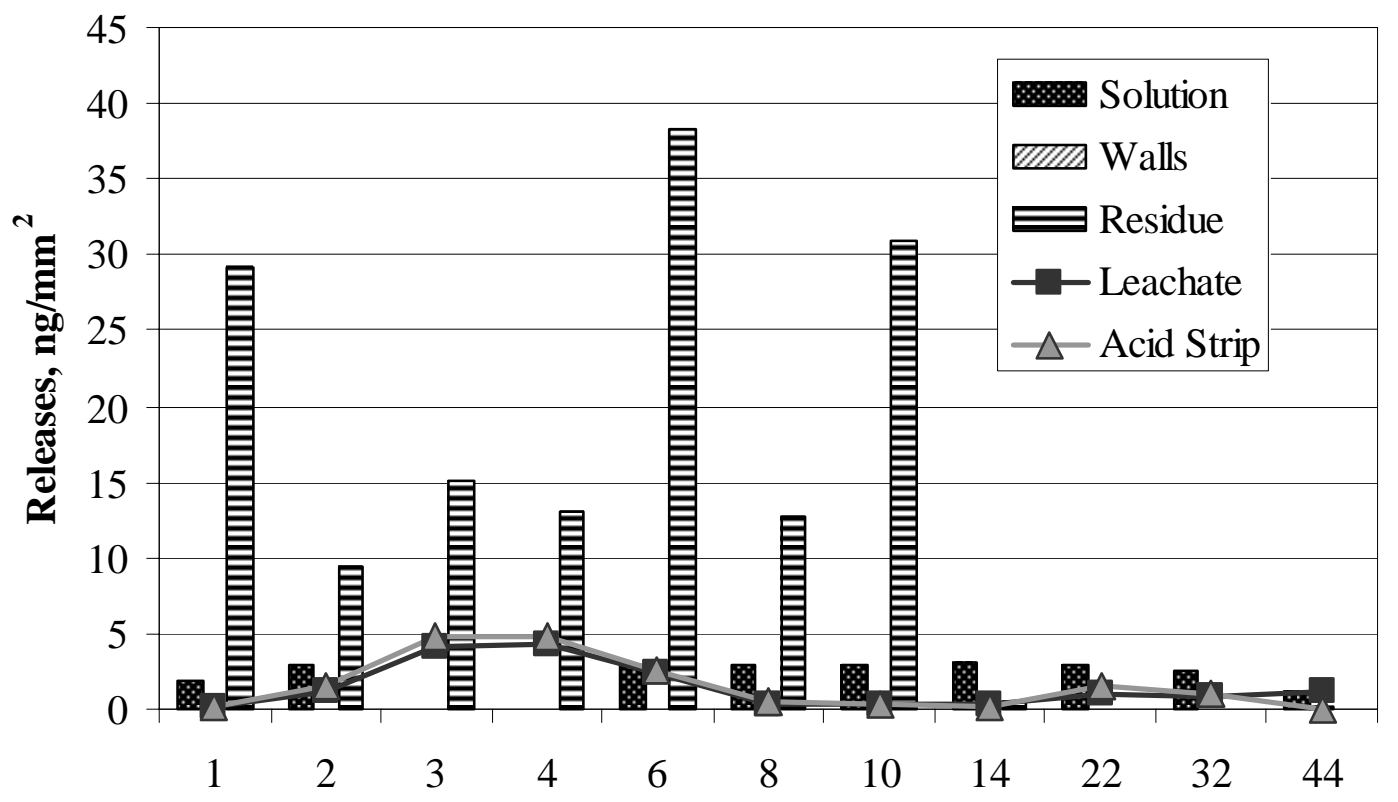

Time, weeks

Figure E-304. Vanadium Releases in Solution, on Walls, and in Residue from Oxidized Sample 4 in $10 \mathrm{KCl}$ and Average Detection Limits for Leachate and Acid Strip. 


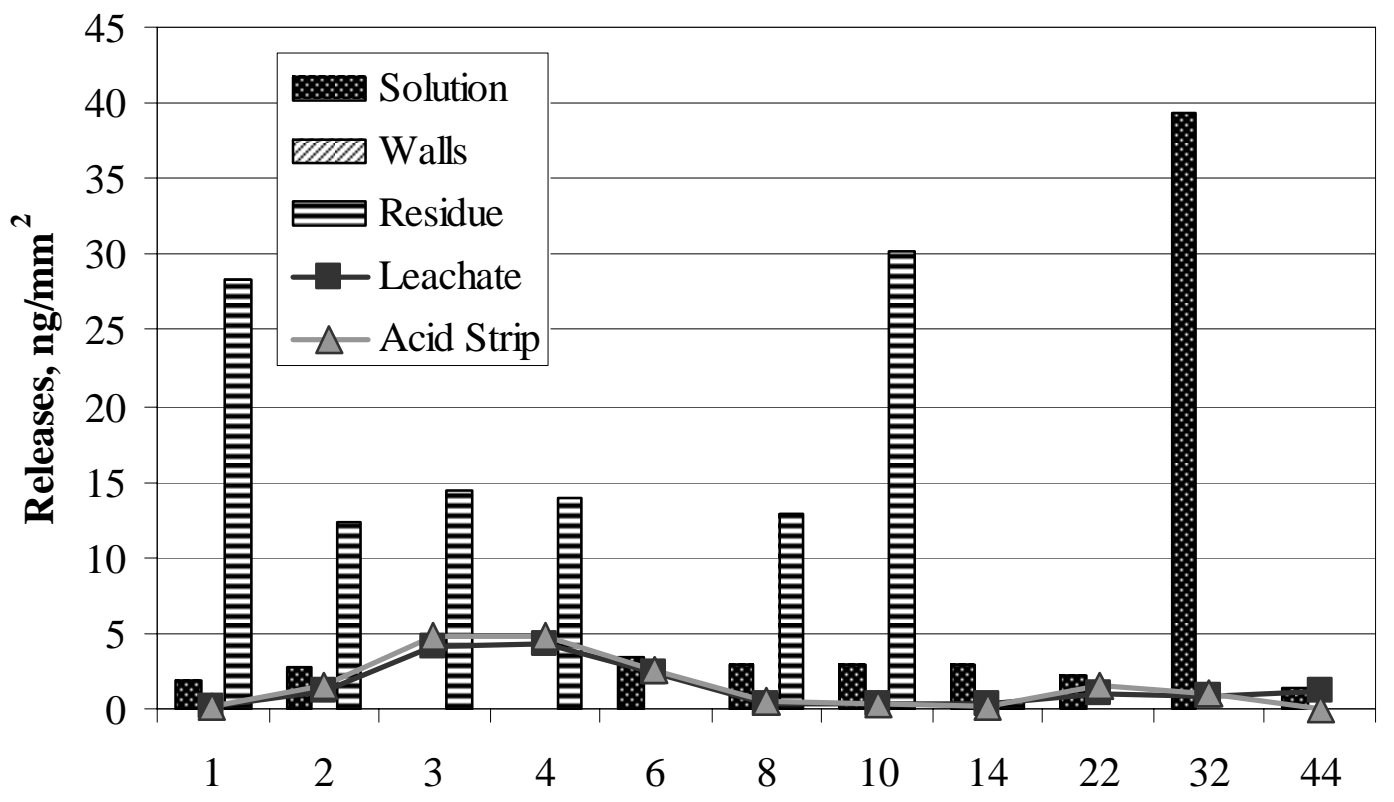

Time, weeks

Figure E-305. Vanadium Releases in Solution, on Walls, and in Residue from Oxidized Sample 5 in $10 \mathrm{KCl}$ and Average Detection Limits for Leachate and Acid Strip.

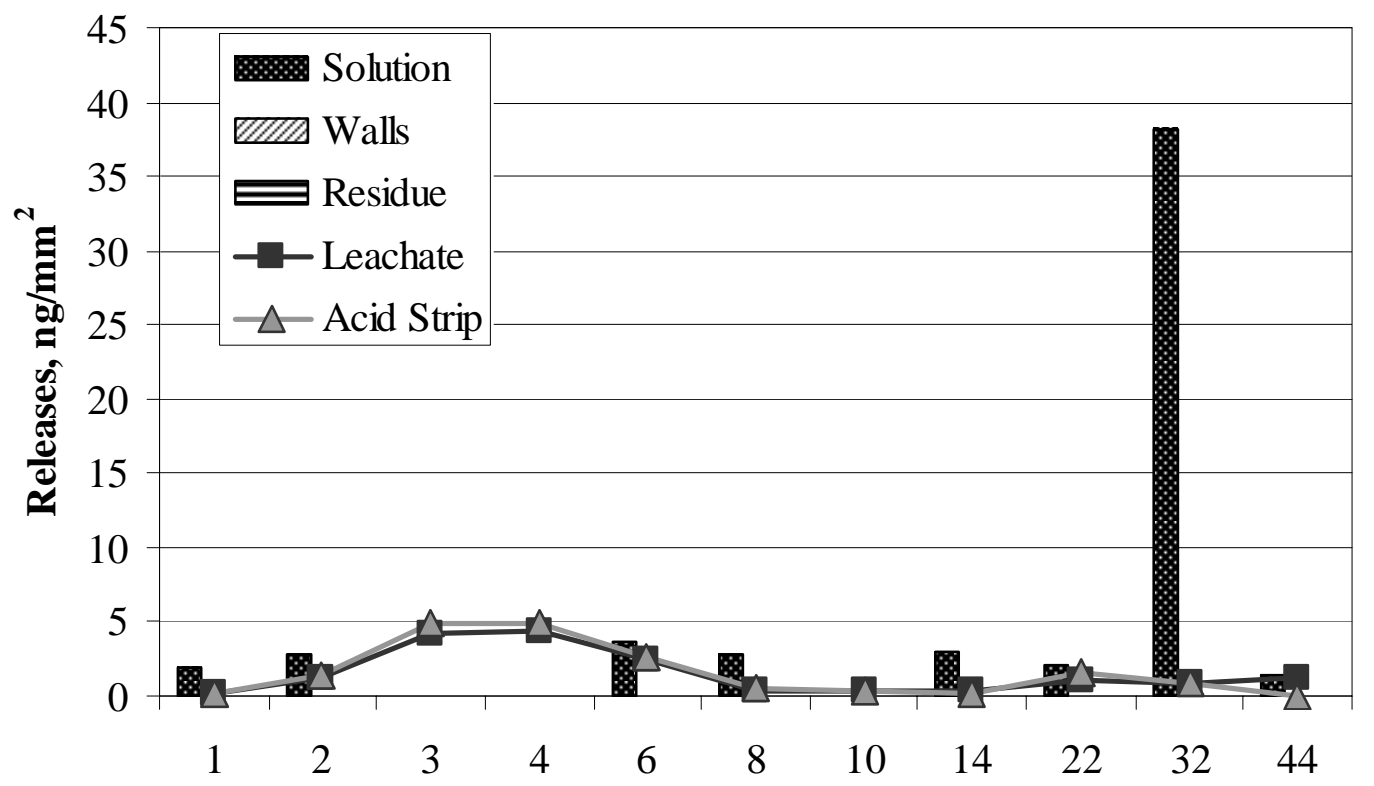

Time, weeks

Figure E-306. Vanadium Present in Solution, on Walls, and in Residue from 10KCl Control and Average Detection limits for Leachate and Acid Strip. 


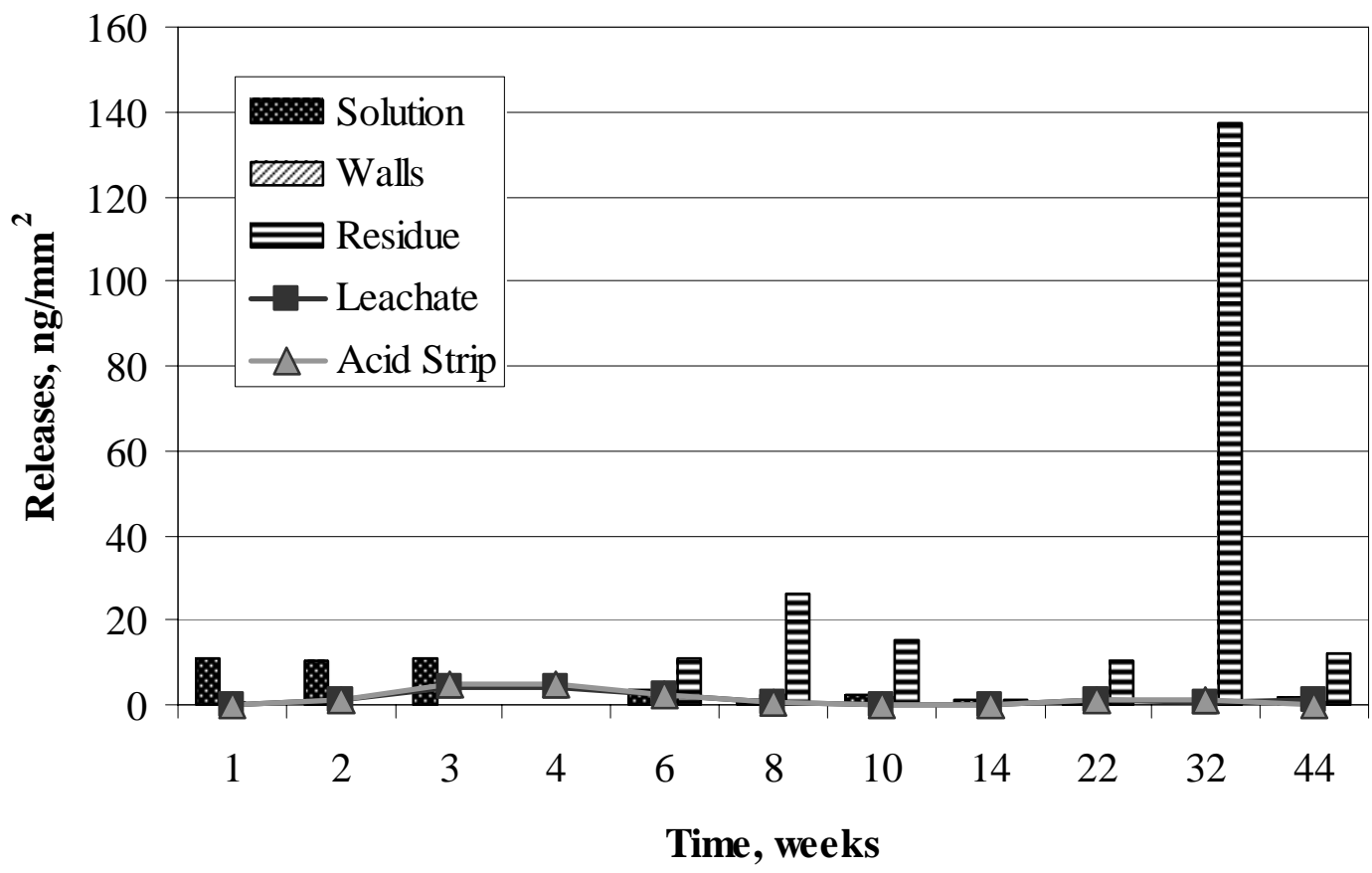

Figure E-307. Vanadium Releases in Solution, on Walls, and in Residue from Polished Sample 1 in AJ13 and Average Detection Limits for Leachate and Acid Strip.

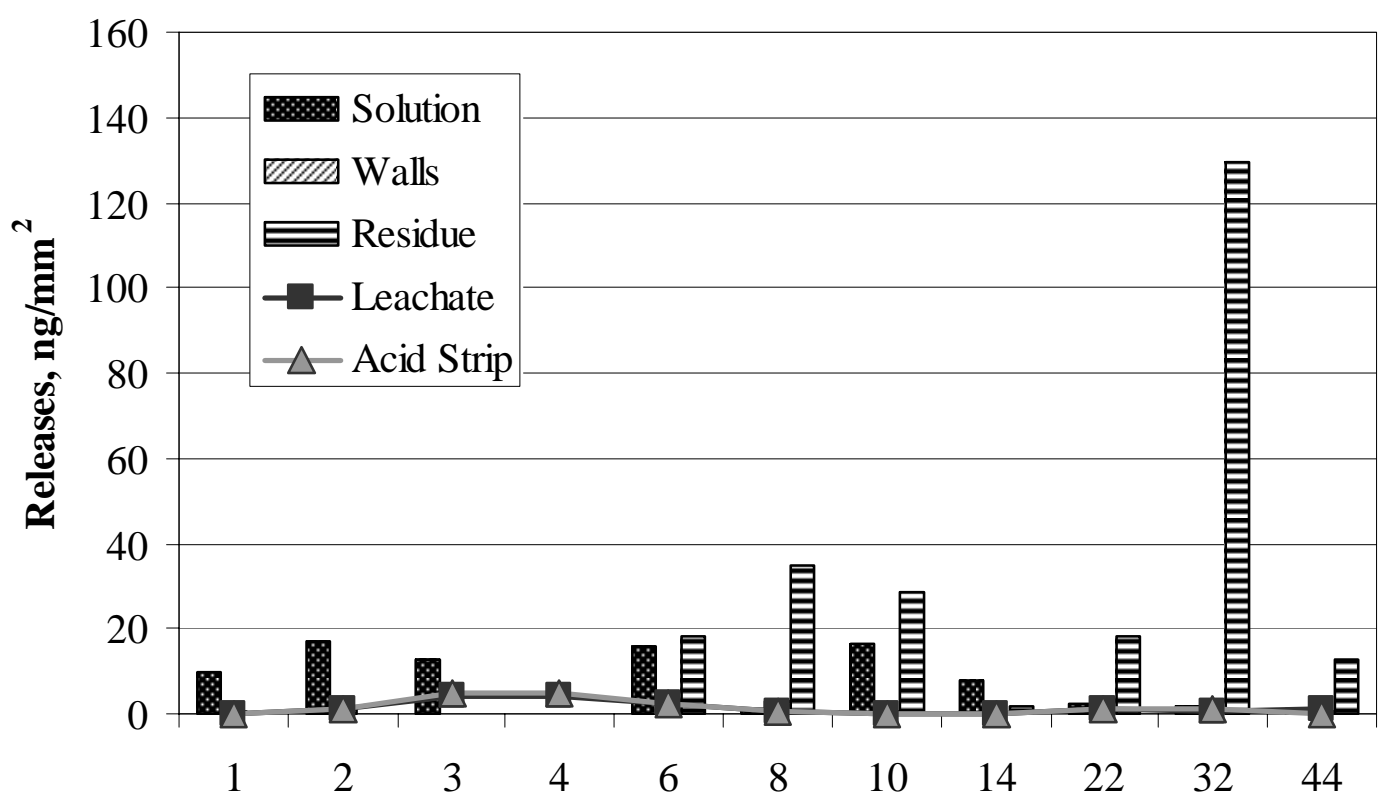

Time, weeks

Figure E-308. Vanadium Releases in Solution, on Walls, and in Residue from Polished Sample 2 in AJ13 and Average Detection Limits for Leachate and Acid Strip. 


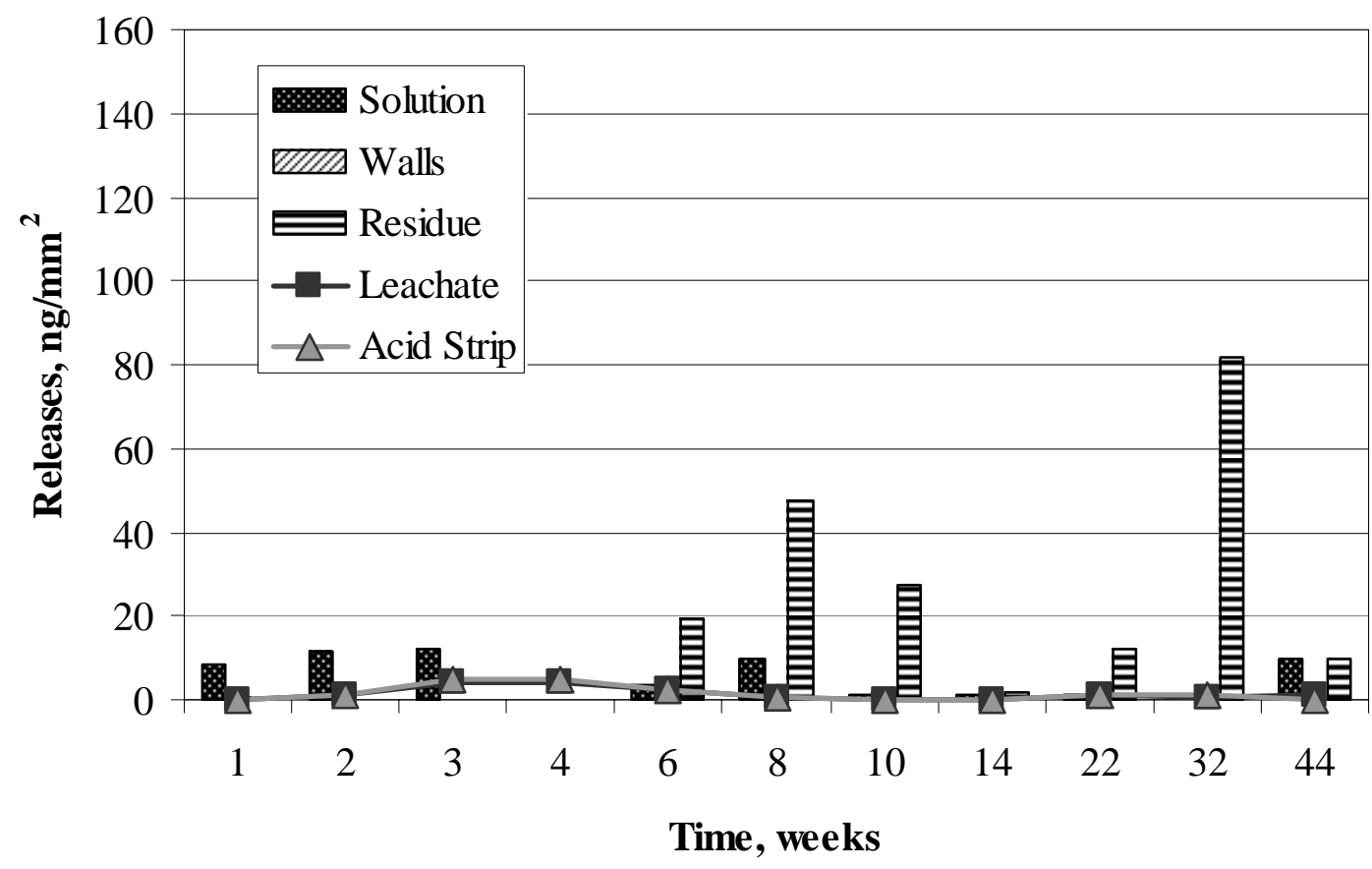

Figure E-309. Vanadium Releases in Solution, on Walls, and in Residue from Polished Sample 3 in AJ13 and Average Detection Limits for Leachate and Acid Strip.

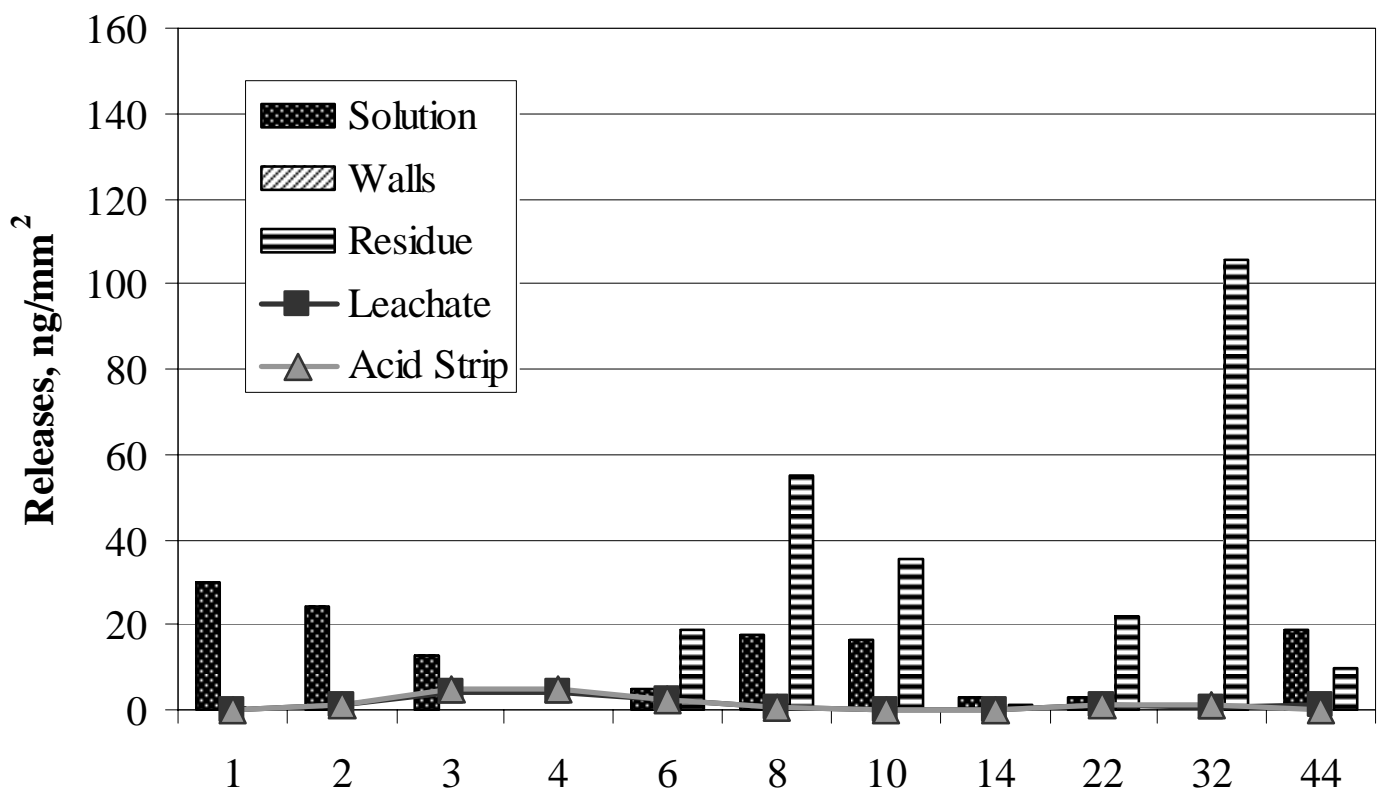

Time, weeks

Figure E-310. Vanadium Releases in Solution, on Walls, and in Residue from Oxidized Sample 4 in AJ13 and Average Detection Limits for Leachate and Acid Strip. 


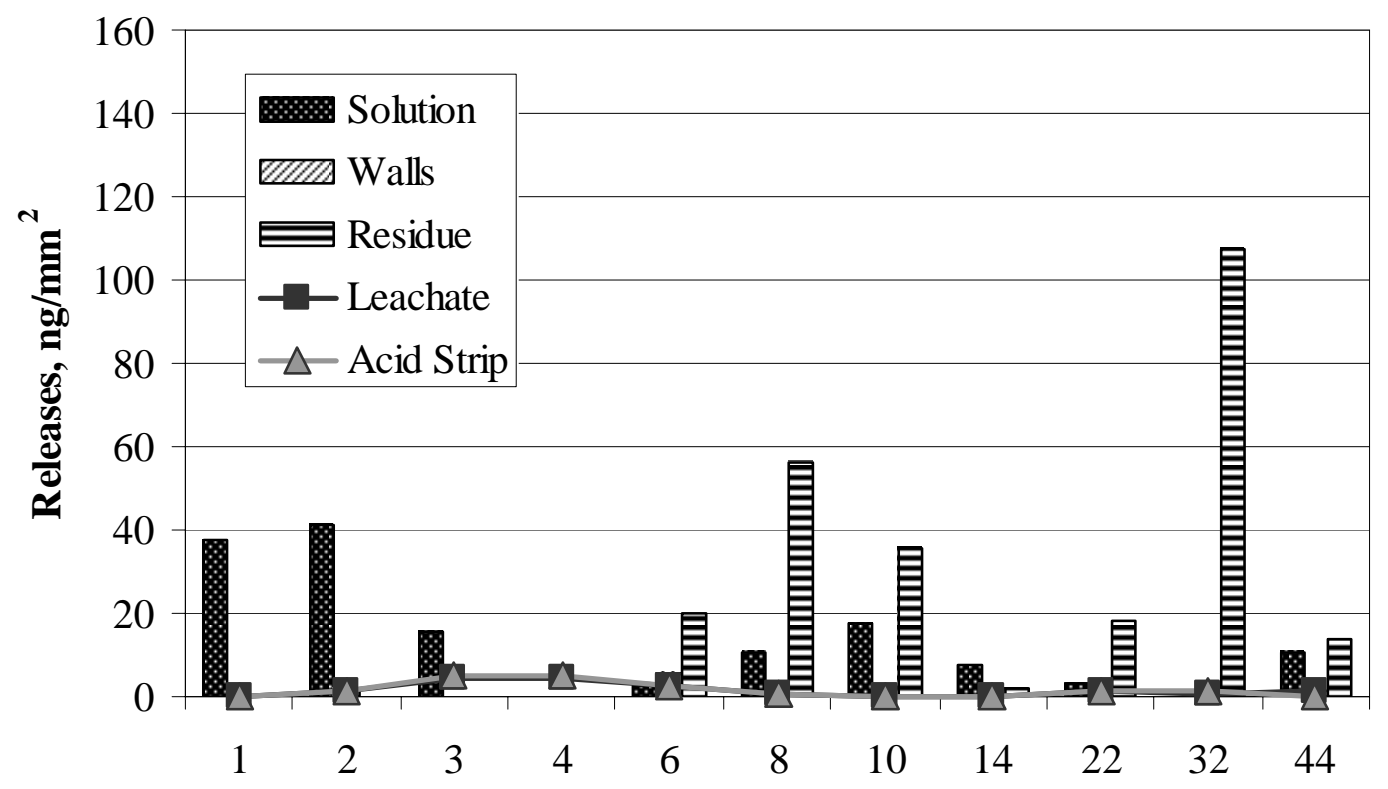

Time, weeks

Figure E-311. Vanadium Releases in Solution, on Walls, and in Residue from Oxidized Sample 5 in AJ13 and Average Detection Limits for Leachate and Acid Strip.

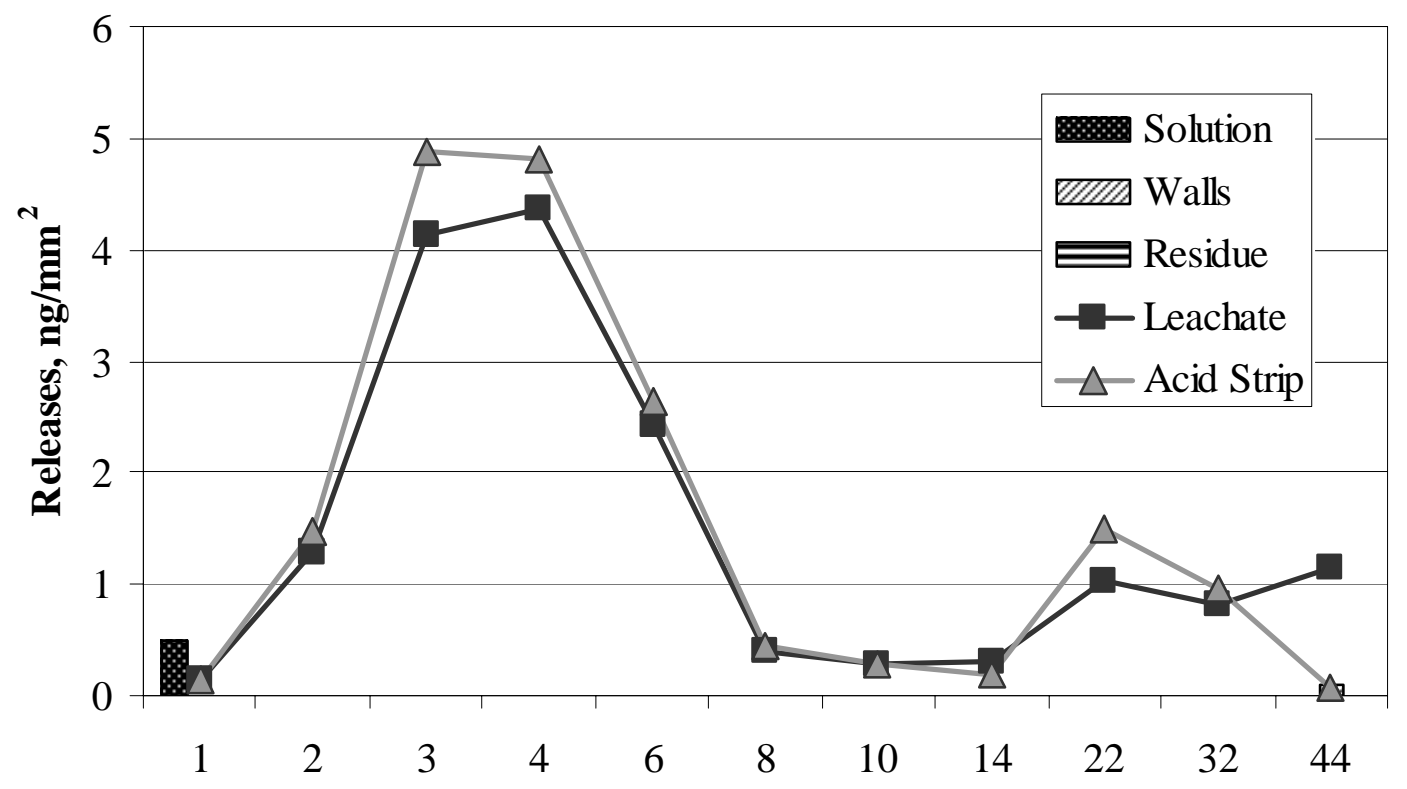

Time, weeks

Figure E-312. Vanadium Present in Solution, on Walls, and in Residue from AJ13 Control and Average Detection Limits for Leachate and Acid Strip. 


\section{F. Raw Data}

Table F-1. Leachate Data $\left(\mathrm{ng} / \mathrm{mm}^{2}\right)$ from SS15ZR26 Specimens Immersed in $363 \mathrm{~K}\left(90^{\circ} \mathrm{C}\right)$ Solution for 7 days.

\begin{tabular}{|c|c|c|c|c|c|c|c|c|c|c|c|c|c|c|}
\hline \multirow[b]{2}{*}{ Expt. ID } & \multirow[b]{2}{*}{ Ingot ID } & \multicolumn{4}{|c|}{ Major Elements } & \multicolumn{5}{|c|}{ Noble Metal Fission Products } & \multicolumn{4}{|c|}{ Minor Elements } \\
\hline & & $\mathrm{Fe}$ & $\mathrm{Cr}$ & $\mathrm{Ni}$ & $\mathrm{Zr}$ & $\mathrm{Nb}$ & $\mathrm{Pd}$ & $\mathrm{Rh}$ & $\mathrm{Ru}$ & Mo & $\mathrm{Mn}$ & $\mathrm{Co}$ & $\mathrm{Cu}$ & $\mathrm{V}$ \\
\hline \multicolumn{2}{|c|}{ Detection Limits } & 2.0 & 2.0 & 2.0 & 0.012 & 0.015 & 0.005 & 0.006 & 0.006 & 0.079 & 0.029 & 0.003 & 0.14 & 0.13 \\
\hline SJ13-1-1 & 1 & $\mathrm{a}$ & $\mathrm{a}$ & $\mathrm{a}$ & 0.084 & $\bar{a}$ & $\mathrm{a}$ & $\mathrm{a}$ & $\mathrm{a}$ & 0.693 & $\mathrm{a}$ & 0.01 & 0.36 & $\mathrm{a}$ \\
\hline SJ13-1-2 & 2 & $\bar{a}$ & $\bar{a}$ & $\bar{a}$ & 0.105 & $\bar{a}$ & $\bar{a}$ & $\bar{a}$ & $\bar{a}$ & 0.448 & $\bar{a}$ & 0.01 & 0.24 & $\bar{a}$ \\
\hline SJ13-1-3 & 3 & $a$ & $a$ & $a$ & 0.072 & $a$ & 0.007 & $\bar{a}$ & $\bar{a}$ & 1.11 & $\bar{a}$ & 0.01 & 0.23 & $\bar{a}$ \\
\hline SJ13-1-4 & 4 & $\bar{a}$ & $\mathrm{a}$ & $\mathrm{a}$ & 0.093 & $\bar{a}$ & $\bar{a}$ & $\mathrm{a}$ & $\mathrm{a}$ & 0.874 & $\bar{a}$ & $\bar{a}$ & 0.24 & $\bar{a}$ \\
\hline SJ13-1-5 & 5 & $a$ & $a$ & $\mathrm{a}$ & 0.100 & $\mathrm{a}$ & $a$ & $a$ & $a$ & 1.23 & $a$ & $a$ & 0.28 & $\mathrm{a}$ \\
\hline SJ13-1-6 & control & $\mathrm{a}$ & $\mathrm{a}$ & $\mathrm{a}$ & 0.132 & $\bar{a}$ & $\mathrm{a}$ & $\mathrm{a}$ & $\mathrm{a}$ & 0.332 & $\mathrm{a}$ & $\mathrm{a}$ & $\mathrm{a}$ & $\mathrm{a}$ \\
\hline CJ13-1-7 & 7 & 9.0 & $\mathrm{a}$ & $a$ & 2.42 & 0.152 & 0.068 & 0.062 & 0.040 & 1.40 & 0.23 & 0.05 & 0.98 & 0.25 \\
\hline CJ13-1-8 & 8 & 8.9 & $\mathrm{a}$ & $a$ & 2.65 & 0.158 & 0.069 & 0.071 & 0.045 & 1.89 & 0.25 & 0.06 & 1.21 & 0.27 \\
\hline CJ13-1-9 & 9 & 10.9 & $\bar{a}$ & $a$ & 6.66 & 0.381 & 0.219 & 0.069 & 0.130 & 2.23 & 0.29 & 0.08 & 1.59 & 0.27 \\
\hline CJ13-1-10 & 10 & $\mathrm{a}$ & $a$ & $a$ & 1.29 & 0.021 & 0.044 & 0.070 & 0.031 & 0.930 & 0.23 & 0.04 & 1.04 & 0.28 \\
\hline CJ13-1-11 & 11 & $\mathrm{a}$ & $\mathrm{a}$ & $a$ & 1.33 & 0.021 & 0.044 & 0.083 & 0.043 & 1.20 & 0.20 & 0.04 & 1.23 & 0.29 \\
\hline CJ13-1-12 & control & $a$ & $\mathrm{a}$ & $a$ & 1.05 & $a$ & 0.033 & 0.021 & $\mathrm{a}$ & 0.723 & 0.06 & 0.02 & 0.15 & 0.29 \\
\hline $10 \mathrm{KCl}-1-13$ & 13 & 18.7 & 3.9 & 19.7 & 0.029 & 0.018 & 0.070 & 0.013 & 0.019 & 0.765 & 4.84 & 0.85 & 1.02 & 1.82 \\
\hline $10 \mathrm{KCl}-1-14$ & 14 & 11.9 & 3.0 & 13.9 & 0.029 & $\mathrm{a}$ & 0.066 & 0.011 & $\mathrm{a}$ & 2.56 & 3.78 & 0.68 & 1.83 & 1.83 \\
\hline $10 \mathrm{KCl}-1-15$ & 15 & 7.0 & 2.0 & 16.9 & $\mathrm{a}$ & $\mathrm{a}$ & 0.061 & 0.012 & $\mathrm{a}$ & 2.26 & 4.49 & 0.69 & 0.54 & 1.81 \\
\hline $10 \mathrm{KCl}-1-16$ & 16 & 29.7 & 4.0 & 25.7 & $\mathrm{a}$ & 0.018 & 0.050 & 0.020 & 0.026 & 2.22 & 4.21 & 0.81 & 0.94 & 1.82 \\
\hline $10 \mathrm{KCl}-1-17$ & 17 & 11.9 & $\mathrm{a}$ & 20.9 & 0.051 & $\mathrm{a}$ & 0.049 & 0.017 & 0.009 & 2.45 & 2.85 & 0.64 & 0.64 & 1.83 \\
\hline $10 \mathrm{KCl}-1-18$ & control & $\bar{a}$ & $\bar{a}$ & $\bar{a}$ & $\bar{a}$ & $\bar{a}$ & 0.045 & 0.016 & $\bar{a}$ & 0.373 & 0.03 & 0.01 & 0.16 & 1.88 \\
\hline AJ13-1-19 & 19 & 9527 & 2250 & 650 & 0.968 & 4.39 & 0.269 & 4.89 & 20.2 & 139 & 168 & 24.7 & 31.9 & 10.9 \\
\hline AJ13-1-20 & 20 & 7959 & 1955 & 489 & 0.846 & 2.81 & 0.200 & 2.99 & 12.8 & 126 & 137 & 21.3 & 25.6 & 9.78 \\
\hline AJ13-1-21 & 21 & 6169 & 1594 & 587 & 0.231 & 0.935 & 0.044 & 0.620 & 2.78 & 75.8 & 118 & 18.5 & 19.3 & 8.31 \\
\hline AJ13-1-22 & 22 & 10751 & 2824 & 1348.7 & 1.29 & 4.19 & 0.147 & 1.56 & 7.50 & 99.7 & 222 & 82.2 & 54.7 & 29.7 \\
\hline AJ13-1-23 & 23 & 12485 & 3316 & 1063.1 & 1.62 & 10.0 & 0.546 & 8.16 & 37.0 & 204 & 225 & 82.5 & 126 & 37.1 \\
\hline AJ13-1-24 & control & 2.0 & $\bar{a}$ & $\bar{a}$ & 0.112 & 0.032 & $\bar{a}$ & 0.009 & 0.030 & 3.92 & 0.49 & 0.04 & 1.10 & 0.50 \\
\hline
\end{tabular}

${ }^{\mathrm{a}}$ Element below detection limits of measuring instrument. 
Table F-2. Acid Strip Data $\left(\mathrm{ng} / \mathrm{mm}^{2}\right)$ from SS15ZR26 Specimens Immersed in $363 \mathrm{~K}\left(90^{\circ} \mathrm{C}\right)$ Solution for 7 days.

\begin{tabular}{|c|c|c|c|c|c|c|c|c|c|c|c|c|c|c|}
\hline \multirow[b]{2}{*}{ Expt. ID } & \multirow[b]{2}{*}{ Ingot ID } & \multicolumn{4}{|c|}{ Major Elements } & \multicolumn{5}{|c|}{ Noble Metal Fission Products } & \multicolumn{4}{|c|}{ Minor Elements } \\
\hline & & $\mathrm{Fe}$ & $\mathrm{Cr}$ & $\mathrm{Ni}$ & $\mathrm{Zr}$ & $\mathrm{Nb}$ & $\mathrm{Pd}$ & $\mathrm{Rh}$ & $\mathrm{Ru}$ & Mo & $\mathrm{Mn}$ & $\mathrm{Co}$ & $\mathrm{Cu}$ & $\mathrm{V}$ \\
\hline \multicolumn{2}{|c|}{ Detection Limits } & 2.3 & 2.3 & 2.3 & 0.014 & 0.017 & 0.006 & 0.007 & 0.007 & 0.091 & 0.033 & 0.003 & 0.16 & 0.15 \\
\hline SJ13-1-1AS & 1 & 3.4 & $\mathrm{a}$ & $\mathrm{a}$ & 0.369 & $\mathrm{a}$ & $\mathrm{a}$ & $\mathrm{a}$ & $\mathrm{a}$ & 0.051 & 0.063 & 0.035 & 0.33 & $\mathrm{a}$ \\
\hline SJ13-1-2AS & 2 & $\mathrm{a}$ & $\bar{a}$ & $\bar{a}$ & 0.321 & $\bar{a}$ & $\bar{a}$ & $\bar{a}$ & $\bar{a}$ & $\mathrm{a}$ & 0.047 & 0.005 & $\mathrm{a}$ & $a$ \\
\hline SJ13-1-3AS & 3 & 5.7 & $\mathrm{a}$ & $\mathrm{a}$ & 0.420 & $\mathrm{a}$ & $\mathrm{a}$ & $\mathrm{a}$ & $\mathrm{a}$ & 0.651 & 0.131 & 0.064 & 0.36 & $\mathrm{a}$ \\
\hline SJ13-1-4AS & 4 & $\bar{a}$ & $\bar{a}$ & $\mathrm{a}$ & 0.387 & $\mathrm{a}$ & $\mathrm{a}$ & $\mathrm{a}$ & $\mathrm{a}$ & 0.132 & 0.079 & 0.006 & 0.33 & $\mathrm{a}$ \\
\hline SJ13-1-5AS & 5 & $\mathrm{a}$ & $\mathrm{a}$ & $\mathrm{a}$ & 0.413 & $\mathrm{a}$ & $\mathrm{a}$ & $\mathrm{a}$ & $\mathrm{a}$ & 0.067 & 0.074 & 0.005 & 0.40 & $\mathrm{a}$ \\
\hline SJ13-1-6AS & control & 3.4 & $\bar{a}$ & $\bar{a}$ & 0.497 & $\bar{a}$ & $\bar{a}$ & $\bar{a}$ & $\mathrm{a}$ & 0.178 & 0.036 & $\mathrm{a}$ & $\mathrm{a}$ & $\mathrm{a}$ \\
\hline CJ13-1-7AS & 7 & 2.4 & $\mathrm{a}$ & $\mathrm{a}$ & 0.153 & $\mathrm{a}$ & $\mathrm{a}$ & $\mathrm{a}$ & 0.017 & 0.138 & 0.047 & 0.011 & $\mathrm{a}$ & $\mathrm{a}$ \\
\hline CJ13-1-8AS & 8 & 9.4 & $\mathrm{a}$ & $\mathrm{a}$ & 0.185 & $\mathrm{a}$ & 0.006 & $\mathrm{a}$ & 0.008 & 0.584 & 0.135 & 0.014 & 0.24 & $\mathrm{a}$ \\
\hline CJ13-1-9AS & 9 & 11.7 & $\mathrm{a}$ & $\mathrm{a}$ & 2.78 & 0.177 & 0.102 & $\mathrm{a}$ & 0.287 & 0.343 & 0.097 & 0.022 & 0.78 & $\mathrm{a}$ \\
\hline CJ13-1-10AS & 10 & $\mathrm{a}$ & $\bar{a}$ & $\mathrm{a}$ & 0.026 & $\mathrm{a}$ & $\mathrm{a}$ & $\mathrm{a}$ & $\mathrm{a}$ & 0.048 & 0.054 & $\mathrm{a}$ & $\mathrm{a}$ & $\mathrm{a}$ \\
\hline CJ13-1-11AS & 11 & 2.2 & $\mathrm{a}$ & $\mathrm{a}$ & 0.057 & $\mathrm{a}$ & $\mathrm{a}$ & $\mathrm{a}$ & $\mathrm{a}$ & 0.036 & 0.078 & 0.005 & $\mathrm{a}$ & $\mathrm{a}$ \\
\hline CJ13-1-12AS & control & $\mathrm{a}$ & $\bar{a}$ & $\mathrm{a}$ & 0.037 & $\mathrm{a}$ & $\mathrm{a}$ & $\mathrm{a}$ & $\mathrm{a}$ & 0.046 & $\mathrm{a}$ & $\mathrm{a}$ & $\mathrm{a}$ & $\mathrm{a}$ \\
\hline $10 \mathrm{KCl}-1-13 \mathrm{AS}$ & 13 & 223 & 34.5 & 29.9 & 0.119 & 0.074 & 0.024 & 0.083 & 0.320 & 0.670 & 12.0 & 1.17 & 2.75 & $\mathrm{a}$ \\
\hline 10KCl-1-14AS & 14 & 254 & 39.1 & 26.8 & 0.069 & 0.048 & 0.020 & 0.046 & 0.176 & 0.336 & 9.90 & 1.06 & 1.96 & $\mathrm{a}$ \\
\hline $10 \mathrm{KCl}-1-15 \mathrm{AS}$ & 15 & 105 & 32.5 & 14.6 & 0.089 & 0.069 & 0.022 & 0.060 & 0.225 & 2.21 & 4.03 & 0.377 & 1.86 & $\mathrm{a}$ \\
\hline 10KCl-1-16AS & 16 & 192 & 16.6 & 48.7 & 0.066 & 0.039 & 0.009 & 0.035 & 0.136 & 1.10 & 8.99 & 1.56 & 1.98 & $\mathrm{a}$ \\
\hline 10KCl-1-17AS & 17 & 130 & 16.5 & 39.5 & 0.062 & 0.036 & 0.008 & 0.028 & 0.118 & 0.753 & 5.75 & 1.08 & 1.42 & $\mathrm{a}$ \\
\hline $10 \mathrm{KCl}-1-18 \mathrm{AS}$ & control & $\mathrm{a}$ & $\mathrm{a}$ & $\mathrm{a}$ & 0.052 & $\mathrm{a}$ & $\mathrm{a}$ & $\mathrm{a}$ & $\mathrm{a}$ & $\mathrm{a}$ & $\mathrm{a}$ & $\mathrm{a}$ & 0.20 & $\mathrm{a}$ \\
\hline AJ13-1-19AS & 19 & 499 & 123 & 34.1 & 0.839 & 0.637 & 0.104 & 0.406 & 1.64 & 11.6 & 8.59 & 1.26 & 1.72 & 0.68 \\
\hline AJ13-1-20AS & 20 & 365 & 102 & 21.9 & 5.21 & 2.05 & 0.278 & 0.501 & 2.31 & 15.5 & 6.16 & 0.892 & 1.15 & 0.68 \\
\hline AJ13-1-21AS & 21 & 356 & 94.8 & 34.0 & 1.18 & 0.668 & 0.129 & 0.159 & 0.625 & 6.71 & 7.13 & 1.06 & 1.21 & 0.50 \\
\hline AJ13-1-22AS & 22 & 267 & 68.7 & 29.8 & 1.04 & 0.532 & 0.094 & 0.113 & 0.497 & 5.91 & 5.38 & 0.897 & 0.66 & 0.52 \\
\hline AJ13-1-23AS & 23 & 14.1 & 9.4 & $\mathrm{a}$ & 0.336 & 0.466 & 0.178 & 0.173 & 0.753 & 4.76 & 0.257 & 0.038 & 0.54 & 0.30 \\
\hline AJ13-1-24AS & control & $\mathrm{a}$ & $\mathrm{a}$ & $\mathrm{a}$ & 0.700 & 0.075 & $\mathrm{a}$ & $\mathrm{a}$ & 0.011 & 0.133 & $\mathrm{a}$ & 0.007 & $\mathrm{a}$ & $\mathrm{a}$ \\
\hline
\end{tabular}

${ }^{\mathrm{a}}$ Element below detection limits of measuring instrument. 
Table F-3. Residue Data $\left(\mathrm{ng} / \mathrm{mm}^{2}\right)$ from SS15ZR26 Specimens Immersed in $363 \mathrm{~K}\left(90^{\circ} \mathrm{C}\right)$ Solution for 7 days.

\begin{tabular}{|c|c|c|c|c|c|c|c|c|c|c|c|c|c|c|}
\hline \multirow[b]{2}{*}{ Expt. ID } & \multirow[b]{2}{*}{ Ingot ID } & \multicolumn{4}{|c|}{ Major Elements } & \multicolumn{5}{|c|}{ Noble Metal Fission Products } & \multicolumn{4}{|c|}{ Minor Elements } \\
\hline & & $\mathrm{Fe}$ & $\mathrm{Cr}$ & $\mathrm{Ni}$ & $\mathrm{Zr}$ & $\mathrm{Nb}$ & $\mathrm{Pd}$ & $\mathrm{Rh}$ & $\overline{\mathrm{Ru}}$ & Mo & $\mathrm{Mn}$ & Co & $\mathrm{Cu}$ & $\mathrm{V}$ \\
\hline \multicolumn{15}{|c|}{ Detection Limits not available } \\
\hline $10 \mathrm{KCl}-1-13 \mathrm{R}$ & 13 & 727.6 & 112.8 & 28.5 & 3.03 & 0.340 & 0.094 & 0.387 & 1.387 & 32.77 & 10.79 & 9.21 & 33.97 & 18.60 \\
\hline $10 \mathrm{KCl}-1-14 \mathrm{R}$ & 14 & 627.6 & 72.8 & 43.0 & 2.94 & 0.156 & 0.096 & 0.201 & 0.746 & 28.84 & 15.51 & 3.45 & 38.43 & 25.79 \\
\hline $10 \mathrm{KCl}-1-15 \mathrm{R}$ & 15 & 237.4 & 51.8 & 14.6 & 1.63 & 0.151 & 0.052 & 0.149 & 0.482 & 11.35 & 4.52 & 2.46 & 19.37 & 26.61 \\
\hline $10 \mathrm{KCl}-1-16 \mathrm{R}$ & 16 & 459.3 & 40.2 & 58.2 & 13.99 & 0.133 & 0.097 & 0.162 & 0.555 & 14.05 & 9.80 & 4.01 & 32.09 & 29.22 \\
\hline $10 \mathrm{KCl}-1-17 \mathrm{R}$ & 17 & 340.6 & 41.1 & 34.6 & 19.09 & 0.298 & 0.121 & 0.106 & 0.367 & 11.12 & 5.37 & 2.46 & 21.88 & 28.31 \\
\hline
\end{tabular}


Table F-4. Leachate Data $\left(\mathrm{ng} / \mathrm{mm}^{2}\right)$ from SS15ZR26 Specimens Immersed in $363 \mathrm{~K}\left(90^{\circ} \mathrm{C}\right)$ Solution for 14 days.

\begin{tabular}{|c|c|c|c|c|c|c|c|c|c|c|c|c|c|c|}
\hline \multirow[b]{2}{*}{ Expt. ID } & \multirow[b]{2}{*}{ Ingot ID } & \multicolumn{4}{|c|}{ Major Elements } & \multicolumn{5}{|c|}{ Noble Metal Fission Products } & \multicolumn{4}{|c|}{ Minor Elements } \\
\hline & & $\mathrm{Fe}$ & $\mathrm{Cr}$ & $\mathrm{Ni}$ & $\mathrm{Zr}$ & $\mathrm{Nb}$ & $\mathrm{Pd}$ & $\mathrm{Rh}$ & $\mathrm{Ru}$ & Mo & $\mathrm{Mn}$ & $\mathrm{Co}$ & $\mathrm{Cu}$ & $\mathrm{V}$ \\
\hline Detection & imits & 1.9 & 1.9 & 1.9 & 0.069 & 0.007 & 0.003 & 0.006 & 0.068 & 0.10 & 0.076 & 0.007 & 0.35 & 1.3 \\
\hline SJ13-2-25 & 1 & $\mathrm{a}$ & $\mathrm{a}$ & $\mathrm{a}$ & 0.117 & $\bar{a}$ & 0.005 & $\mathrm{a}$ & $\mathrm{a}$ & 0.65 & $\bar{a}$ & $\mathrm{a}$ & $\mathrm{a}$ & $\mathrm{a}$ \\
\hline SJ13-2-26 & 2 & $\mathrm{a}$ & $\mathrm{a}$ & $\mathrm{a}$ & 0.085 & $\mathrm{a}$ & $\mathrm{a}$ & $\mathrm{a}$ & $\mathrm{a}$ & 0.29 & $\mathrm{a}$ & $\mathrm{a}$ & $a$ & $\mathrm{a}$ \\
\hline SJ13-2-27 & 3 & $a$ & $a$ & $a$ & 0.096 & $\bar{a}$ & 0.010 & $a$ & $a$ & 1.18 & $a$ & $\bar{a}$ & $a$ & $\mathrm{a}$ \\
\hline SJ13-2-28 & 4 & $\mathrm{a}$ & $\mathrm{a}$ & $a$ & 0.113 & $\mathrm{a}$ & 0.006 & $a$ & $a$ & 1.19 & $a$ & $a$ & $\mathrm{a}$ & $a$ \\
\hline SJ13-2-29 & 5 & $a$ & $a$ & $\bar{a}$ & $\bar{a}$ & $\mathrm{a}$ & $\mathrm{a}$ & $a$ & $a$ & 1.11 & $a$ & $a$ & $\mathrm{a}$ & $\mathrm{a}$ \\
\hline SJ13-2-30 & control & $\mathrm{a}$ & $\mathrm{a}$ & $\mathrm{a}$ & 0.164 & $\mathrm{a}$ & 0.003 & $\mathrm{a}$ & $\mathrm{a}$ & 0.10 & $\mathrm{a}$ & $\mathrm{a}$ & $a$ & $\mathrm{a}$ \\
\hline CJ13-2-31 & 7 & 6.1 & $\bar{a}$ & $\bar{a}$ & 3.16 & 0.219 & 0.066 & 0.030 & $a$ & 0.58 & 0.153 & 0.032 & 0.37 & $a$ \\
\hline CJ13-2-32 & 8 & 5.0 & $\mathrm{a}$ & $\mathrm{a}$ & 6.48 & 0.159 & 0.091 & 0.038 & $\mathrm{a}$ & 0.93 & 0.134 & 0.045 & 1.85 & $\mathrm{a}$ \\
\hline CJ13-2-33 & 9 & 6.0 & $\mathrm{a}$ & $\mathrm{a}$ & 6.91 & 0.182 & 0.093 & 0.035 & $a$ & 0.81 & 0.164 & 0.052 & 1.05 & $\bar{a}$ \\
\hline CJ13-2-34 & 10 & 2.0 & $\mathrm{a}$ & $\mathrm{a}$ & 2.19 & 0.074 & 0.052 & 0.021 & $a$ & 1.15 & 0.135 & 0.034 & 2.16 & $a$ \\
\hline CJ13-2-35 & 11 & 2.0 & $a$ & $a$ & 6.44 & 0.078 & 0.085 & 0.021 & $a$ & 0.75 & 0.120 & 0.035 & $a$ & $a$ \\
\hline CJ13-2-36 & control & 3.0 & $\mathrm{a}$ & $\mathrm{a}$ & 8.24 & 0.061 & 0.089 & 0.019 & $\mathrm{a}$ & 2.14 & 0.149 & 0.033 & 0.50 & $\mathrm{a}$ \\
\hline $10 \mathrm{KCl}-2-37$ & 13 & 8.0 & 3.0 & 24.9 & $\bar{a}$ & 0.013 & 0.060 & 0.009 & $a$ & 0.94 & 9.83 & 2.016 & 1.58 & 2.4 \\
\hline $10 \mathrm{KCl}-2-38$ & 14 & 6.9 & 2.0 & 24.8 & $\mathrm{a}$ & $\mathrm{a}$ & 0.061 & $a$ & $\mathrm{a}$ & 0.55 & 9.9 & 1.557 & 0.96 & 3.0 \\
\hline $10 \mathrm{KCl}-2-39$ & 15 & 7.0 & $\bar{a}$ & 24.9 & $a$ & 0.011 & 0.064 & 0.009 & $a$ & 1.62 & 9.37 & 1.812 & 1.58 & 2.9 \\
\hline $10 \mathrm{KCl}-2-40$ & 16 & 5.0 & $\mathrm{a}$ & 22.8 & $\bar{a}$ & $\mathrm{a}$ & 0.057 & 0.014 & $\mathrm{a}$ & 0.71 & 10.3 & 1.627 & 1.58 & 3.0 \\
\hline $10 \mathrm{KCl}-2-41$ & 17 & 7.0 & $\bar{a}$ & 20.0 & $\mathrm{a}$ & 0.009 & 0.068 & 0.011 & $a$ & 22.5 & 8.34 & 1.427 & 1.42 & 2.8 \\
\hline $10 \mathrm{KCl}-2-42$ & control & $\mathrm{a}$ & $\mathrm{a}$ & $\mathrm{a}$ & $a$ & $a$ & 0.050 & 0.007 & $\mathrm{a}$ & 1.64 & $\bar{a}$ & 0.032 & $\mathrm{a}$ & 2.9 \\
\hline AJ13-2-43 & 19 & 9693 & 1769 & 594 & 0.575 & 3.15 & 0.172 & 2.87 & 12.1 & 111 & 178 & 30.7 & 40.3 & 10.2 \\
\hline AJ13-2-44 & 20 & 10082 & 2800 & 671 & 1.11 & 5.77 & 0.367 & 5.62 & 24.3 & 192 & 193 & 33.6 & 53.7 & 17.2 \\
\hline AJ13-2-45 & 21 & 9465 & 2120 & 857 & 0.552 & 2.79 & 0.112 & 1.33 & 6.13 & 91 & 183 & 33.0 & 23.9 & 11.7 \\
\hline AJ13-2-46 & 22 & 8376 & 2172 & 866 & 1.02 & 3.59 & 0.176 & 1.04 & 4.28 & 89 & 167 & 60.7 & 43.8 & 24.6 \\
\hline AJ13-2-47 & 23 & 12189 & 3372 & 843 & 1.83 & 14.9 & 1.06 & 13.7 & 57.1 & 242 & 232 & 82.9 & 121 & 41.2 \\
\hline AJ13-2-48 & control & 3.9 & $\bar{a}$ & $\bar{a}$ & 0.160 & 0.015 & $\bar{a}$ & 0.010 & $\bar{a}$ & 0.78 & 0.098 & 0.015 & $\bar{a}$ & $\bar{a}$ \\
\hline
\end{tabular}

${ }^{\mathrm{a}}$ Element below detection limits of measuring instrument. 
Table F-5. Acid Strip Data $\left(\mathrm{ng} / \mathrm{mm}^{2}\right)$ from SS15ZR26 Specimens Immersed in $363 \mathrm{~K}\left(90^{\circ} \mathrm{C}\right)$ Solution for 14 days.

\begin{tabular}{|c|c|c|c|c|c|c|c|c|c|c|c|c|c|c|}
\hline \multirow[b]{2}{*}{ Expt. ID } & \multirow[b]{2}{*}{ Ingot ID } & \multicolumn{4}{|c|}{ Major Elements } & \multicolumn{5}{|c|}{ Noble Metal Fission Products } & \multicolumn{4}{|c|}{ Minor Elements } \\
\hline & & $\mathrm{Fe}$ & $\mathrm{Cr}$ & $\mathrm{Ni}$ & $\mathrm{Zr}$ & $\mathrm{Nb}$ & $\mathrm{Pd}$ & $\mathrm{Rh}$ & $\mathrm{Ru}$ & Mo & $\mathrm{Mn}$ & $\mathrm{Co}$ & $\mathrm{Cu}$ & $\mathrm{V}$ \\
\hline \multicolumn{2}{|c|}{ Detection Limits } & 2.3 & 2.3 & 2.3 & 0.080 & 0.008 & 0.003 & 0.007 & 0.079 & 0.12 & 0.089 & 0.008 & 0.41 & 1.5 \\
\hline SJ13-2-25AS & 1 & 2.3 & $\mathrm{a}$ & $\mathrm{a}$ & 0.840 & 0.038 & 0.006 & $\mathrm{a}$ & $\mathrm{a}$ & 0.20 & $\mathrm{a}$ & 0.010 & 1.38 & $\mathrm{a}$ \\
\hline SJ13-2-26AS & 2 & $\mathrm{a}$ & $\mathrm{a}$ & $\mathrm{a}$ & 0.484 & $\mathrm{a}$ & $\bar{a}$ & $\mathrm{a}$ & $\mathrm{a}$ & 0.14 & $\mathrm{a}$ & $\bar{a}$ & $\mathrm{a}$ & $\mathrm{a}$ \\
\hline SJ13-2-27AS & 3 & 2.1 & $\mathrm{a}$ & $\mathrm{a}$ & 1.97 & 0.155 & 0.021 & $\mathrm{a}$ & $\mathrm{a}$ & 0.32 & $\mathrm{a}$ & $\mathrm{a}$ & $\mathrm{a}$ & $\mathrm{a}$ \\
\hline SJ13-2-28AS & 4 & $\mathrm{a}$ & $\mathrm{a}$ & $\mathrm{a}$ & 1.42 & 0.064 & 0.012 & $\mathrm{a}$ & $\mathrm{a}$ & 0.67 & $\mathrm{a}$ & $\mathrm{a}$ & 0.69 & $\mathrm{a}$ \\
\hline SJ13-2-29AS & 5 & $\mathrm{a}$ & $\mathrm{a}$ & $\mathrm{a}$ & 0.693 & 0.034 & 0.006 & $\mathrm{a}$ & $\mathrm{a}$ & 0.35 & $\mathrm{a}$ & $\mathrm{a}$ & 9.36 & $\mathrm{a}$ \\
\hline SJ13-2-30AS & control & 2.2 & $\mathrm{a}$ & $\mathrm{a}$ & 1.21 & 0.039 & 0.008 & $\mathrm{a}$ & $a$ & $\mathrm{a}$ & $\mathrm{a}$ & $\mathrm{a}$ & 0.59 & $\mathrm{a}$ \\
\hline CJ13-2-31AS & 7 & $\mathrm{a}$ & $\mathrm{a}$ & $\mathrm{a}$ & $\mathrm{a}$ & 0.024 & 0.004 & $\mathrm{a}$ & $\mathrm{a}$ & 0.08 & $\mathrm{a}$ & $\mathrm{a}$ & $\mathrm{a}$ & $\mathrm{a}$ \\
\hline CJ13-2-32AS & 8 & 7.6 & $\mathrm{a}$ & $\mathrm{a}$ & 1.24 & 0.059 & 0.013 & $\mathrm{a}$ & $\mathrm{a}$ & 0.30 & $\mathrm{a}$ & $\mathrm{a}$ & $\mathrm{a}$ & $\mathrm{a}$ \\
\hline CJ13-2-33AS & 9 & 6.8 & $\mathrm{a}$ & $\mathrm{a}$ & 3.51 & 0.039 & 0.024 & $\mathrm{a}$ & $\mathrm{a}$ & 0.34 & $\mathrm{a}$ & $\mathrm{a}$ & $\mathrm{a}$ & $\mathrm{a}$ \\
\hline CJ13-2-34AS & 10 & 4.4 & $\mathrm{a}$ & $\mathrm{a}$ & 0.147 & 0.022 & 0.008 & $\mathrm{a}$ & $\mathrm{a}$ & 1.75 & 0.207 & 0.026 & $\mathrm{a}$ & $\mathrm{a}$ \\
\hline CJ13-2-35AS & 11 & 5.6 & $\mathrm{a}$ & $\mathrm{a}$ & 0.903 & 0.027 & 0.010 & $\mathrm{a}$ & $\mathrm{a}$ & 0.33 & $\mathrm{a}$ & $\mathrm{a}$ & $\mathrm{a}$ & $\mathrm{a}$ \\
\hline CJ13-2-36AS & control & 4.5 & $\mathrm{a}$ & $\mathrm{a}$ & 3.19 & 0.038 & 0.019 & $\mathrm{a}$ & $\mathrm{a}$ & 0.21 & 0.216 & $\mathrm{a}$ & $\mathrm{a}$ & $\mathrm{a}$ \\
\hline $10 \mathrm{KCl}-2-37 \mathrm{AS}$ & 13 & 187 & 49.9 & 18.8 & 0.652 & 0.058 & 0.026 & 0.057 & 0.256 & 0.43 & 10.3 & 0.946 & 3.91 & $\mathrm{a}$ \\
\hline $10 \mathrm{KCl}-2-38 \mathrm{AS}$ & 14 & 190 & 52.7 & 14.9 & 0.312 & 0.061 & 0.014 & 0.041 & 0.187 & 0.77 & 6.83 & 0.732 & 1.62 & $\mathrm{a}$ \\
\hline $10 \mathrm{KCl}-2-39 \mathrm{AS}$ & 15 & 221 & 27.3 & 18.2 & 0.853 & 0.128 & 0.032 & 0.042 & 0.187 & 1.14 & 9.80 & 1.03 & 3.26 & $\mathrm{a}$ \\
\hline $10 \mathrm{KCl}-2-40 \mathrm{AS}$ & 16 & 112 & 9.1 & 12.6 & 0.381 & 0.085 & 0.017 & 0.012 & $\mathrm{a}$ & 6.49 & 3.63 & 0.522 & 2.84 & $\mathrm{a}$ \\
\hline $10 \mathrm{KCl}-2-41 \mathrm{AS}$ & 17 & 109 & 26.3 & 12.6 & $\mathrm{a}$ & 0.057 & 0.012 & 0.061 & 0.262 & 0.99 & 3.98 & 0.466 & 1.69 & $\mathrm{a}$ \\
\hline $10 \mathrm{KCl}-2-42 \mathrm{AS}$ & control & 3.4 & $\mathrm{a}$ & $\mathrm{a}$ & $\mathrm{a}$ & $\mathrm{a}$ & $\mathrm{a}$ & $\mathrm{a}$ & $\mathrm{a}$ & 0.26 & $\mathrm{a}$ & $\mathrm{a}$ & $\mathrm{a}$ & $\mathrm{a}$ \\
\hline AJ13-2-43AS & 19 & 406 & 89.4 & 24.1 & 0.407 & 1.09 & 0.177 & 0.586 & 2.51 & 14.9 & 9.23 & 1.37 & 1.95 & $\mathrm{a}$ \\
\hline AJ13-2-44AS & 20 & 355 & 129 & 21.7 & 0.971 & 2.14 & 0.288 & 1.03 & 4.46 & 27.4 & 8.26 & 1.23 & 2.77 & 1.8 \\
\hline AJ13-2-45AS & 21 & 191 & 45.3 & 16.3 & 0.361 & 0.692 & 0.069 & 0.178 & 0.766 & 5.62 & 4.68 & 0.719 & 0.66 & $\mathrm{a}$ \\
\hline AJ13-2-46AS & 22 & 255 & 73.6 & 26.1 & 0.673 & 1.29 & 0.114 & 0.212 & 0.850 & 9.36 & 6.62 & 1.01 & 0.80 & $\mathrm{a}$ \\
\hline AJ13-2-47AS & 23 & 392 & 127 & 27.4 & 1.09 & 1.57 & 0.290 & 0.558 & 2.43 & 21.3 & 9.29 & 1.39 & 2.20 & 1.6 \\
\hline AJ13-2-48AS & control & 2.3 & $\mathrm{a}$ & $a$ & 0.200 & 0.022 & $\mathrm{a}$ & $\mathrm{a}$ & $\mathrm{a}$ & 0.40 & $\mathrm{a}$ & $\mathrm{a}$ & $\mathrm{a}$ & $\mathrm{a}$ \\
\hline
\end{tabular}

${ }^{\mathrm{a}}$ Element below detection limits of measuring instrument. 
Table F-6. Residue Data $\left(\mathrm{ng} / \mathrm{mm}^{2}\right)$ from SS15ZR26 Specimens Immersed in $363 \mathrm{~K}\left(90^{\circ} \mathrm{C}\right)$ Solution for 14 days.

\begin{tabular}{|c|c|c|c|c|c|c|c|c|c|c|c|c|c|c|}
\hline \multirow[b]{2}{*}{ Expt. ID } & \multirow[b]{2}{*}{ Ingot ID } & \multicolumn{4}{|c|}{ Major Elements } & \multicolumn{5}{|c|}{ Noble Metal Fission Products } & \multicolumn{4}{|c|}{ Minor Elements } \\
\hline & & $\mathrm{Fe}$ & $\mathrm{Cr}$ & $\mathrm{Ni}$ & $\mathrm{Zr}$ & $\mathrm{Nb}$ & $\mathrm{Pd}$ & $\mathrm{Rh}$ & $\mathrm{Ru}$ & Mo & $\mathrm{Mn}$ & Co & $\mathrm{Cu}$ & $\mathrm{V}$ \\
\hline \multicolumn{15}{|c|}{ Detection Limits not available } \\
\hline $10 \mathrm{KCl}-2-37 \mathrm{R}$ & 13 & 518.4 & 88.68 & 30.88 & 8.89 & 0.23 & 0.09 & 0.18 & 0.66 & 11.06 & 12.00 & 5.34 & 21.03 & 8.10 \\
\hline $10 \mathrm{KCl}-2-38 \mathrm{R}$ & 14 & 695.8 & 174.6 & 24.92 & 9.25 & 0.31 & 0.09 & 0.23 & 0.81 & 19.59 & 8.44 & 13.18 & 18.94 & 8.97 \\
\hline $10 \mathrm{KCl}-2-39 \mathrm{R}$ & 15 & 380.6 & 69.58 & 25.47 & 6.34 & 0.15 & 0.16 & 0.16 & 0.46 & 18.25 & 7.27 & 5.26 & 13.73 & 11.94 \\
\hline $10 \mathrm{KCl}-2-40 \mathrm{R}$ & 16 & 192.4 & 13.14 & 11.41 & 15.35 & 0.08 & 0.24 & 0.18 & 0.03 & 23.06 & 3.08 & 4.48 & 10.65 & 9.44 \\
\hline $10 \mathrm{KCl}-2-41 \mathrm{R}$ & 17 & 354.3 & 108.2 & 16.73 & 24.01 & 0.49 & 0.22 & 1.61 & 0.62 & 30.60 & 4.36 & 3.56 & 15.86 & 12.32 \\
\hline
\end{tabular}


Table F-7. Leachate Data $\left(\mathrm{ng} / \mathrm{mm}^{2}\right)$ from SS15ZR26 Specimens Immersed in $363 \mathrm{~K}\left(90^{\circ} \mathrm{C}\right)$ Solution for 21 days.

\begin{tabular}{|c|c|c|c|c|c|c|c|c|c|c|c|c|c|c|}
\hline \multirow[b]{2}{*}{ Expt. ID } & \multirow[b]{2}{*}{ Ingot ID } & \multicolumn{4}{|c|}{ Major Elements } & \multicolumn{5}{|c|}{ Noble Metal Fission Products } & \multicolumn{4}{|c|}{ Minor Elements } \\
\hline & & $\mathrm{Fe}$ & $\mathrm{Cr}$ & $\mathrm{Ni}$ & $\mathrm{Zr}$ & $\mathrm{Nb}$ & $\mathrm{Pd}$ & $\mathrm{Rh}$ & $\mathrm{Ru}$ & Mo & $\mathrm{Mn}$ & $\mathrm{Co}$ & $\mathrm{Cu}$ & $\mathrm{V}$ \\
\hline \multicolumn{2}{|c|}{ Detection Limits } & 1.9 & 1.9 & 1.9 & 0.056 & 0.042 & 0.037 & 0.044 & 0.20 & 0.22 & 0.14 & 0.016 & 0.25 & 4.1 \\
\hline SJ13-3-49 & 1 & $\mathrm{a}$ & $\mathrm{a}$ & $\bar{a}$ & 0.146 & $\bar{a}$ & $\mathrm{a}$ & $\mathrm{a}$ & $\mathrm{a}$ & 2.29 & $\mathrm{a}$ & $\mathrm{a}$ & $\mathrm{a}$ & $\bar{a}$ \\
\hline SJ13-3-50 & 2 & $\mathrm{a}$ & $\mathrm{a}$ & $\mathrm{a}$ & 0.076 & $\mathrm{a}$ & $\mathrm{a}$ & $\mathrm{a}$ & $\mathrm{a}$ & 2.77 & $\mathrm{a}$ & 0.080 & $\mathrm{a}$ & $\mathrm{a}$ \\
\hline SJ13-3-51 & 3 & $\mathrm{a}$ & $\mathrm{a}$ & $\mathrm{a}$ & 0.102 & $\mathrm{a}$ & $\mathrm{a}$ & $\mathrm{a}$ & $\mathrm{a}$ & 2.54 & $\mathrm{a}$ & $\mathrm{a}$ & $\mathrm{a}$ & $\mathrm{a}$ \\
\hline SJ13-3-52 & 4 & $\mathrm{a}$ & $\mathrm{a}$ & $\mathrm{a}$ & 0.103 & $\mathrm{a}$ & $\mathrm{a}$ & $\mathrm{a}$ & $\mathrm{a}$ & 4.28 & $\mathrm{a}$ & $\mathrm{a}$ & $\mathrm{a}$ & $\mathrm{a}$ \\
\hline SJ13-3-53 & 5 & $\mathrm{a}$ & $\mathrm{a}$ & $\mathrm{a}$ & 0.131 & $\mathrm{a}$ & $\mathrm{a}$ & $\mathrm{a}$ & $\mathrm{a}$ & 3.81 & $\mathrm{a}$ & $\mathrm{a}$ & $\mathrm{a}$ & $\mathrm{a}$ \\
\hline SJ13-3-54 & control & $\mathrm{a}$ & $\mathrm{a}$ & $\mathrm{a}$ & 0.132 & $\mathrm{a}$ & $\mathrm{a}$ & $\mathrm{a}$ & $\mathrm{a}$ & 1.97 & $\mathrm{a}$ & $\mathrm{a}$ & $\mathrm{a}$ & $\mathrm{a}$ \\
\hline CJ13-3-55 & 7 & 4.0 & $\bar{a}$ & $\bar{a}$ & 1.43 & 0.084 & 0.126 & $a$ & $a$ & 1.63 & $a$ & 0.045 & 0.34 & $\bar{a}$ \\
\hline CJ13-3-56 & 8 & 3.0 & $\mathrm{a}$ & $\mathrm{a}$ & 1.96 & 0.145 & 0.133 & $\mathrm{a}$ & $\mathrm{a}$ & 2.72 & $\mathrm{a}$ & 0.053 & 0.73 & $\mathrm{a}$ \\
\hline CJ13-3-57 & 9 & 4.0 & $\mathrm{a}$ & $\mathrm{a}$ & 2.27 & 0.142 & 0.140 & $\mathrm{a}$ & $\mathrm{a}$ & 4.43 & $\mathrm{a}$ & 0.053 & 0.86 & $\mathrm{a}$ \\
\hline CJ13-3-58 & 10 & 2.0 & $\mathrm{a}$ & $\mathrm{a}$ & 1.16 & $\mathrm{a}$ & 0.094 & $\mathrm{a}$ & $\mathrm{a}$ & 3.16 & $\mathrm{a}$ & 0.037 & 1.01 & $\mathrm{a}$ \\
\hline CJ13-3-59 & 11 & 2.0 & $\mathrm{a}$ & $\mathrm{a}$ & 1.10 & $\mathrm{a}$ & 0.075 & $\mathrm{a}$ & $\mathrm{a}$ & 3.45 & $\mathrm{a}$ & 0.039 & 1.15 & $\mathrm{a}$ \\
\hline CJ13-3-60 & control & 3.0 & $\mathrm{a}$ & $\mathrm{a}$ & 1.55 & 0.109 & 0.111 & $\mathrm{a}$ & $\mathrm{a}$ & 2.61 & $\mathrm{a}$ & 0.046 & $\mathrm{a}$ & $\mathrm{a}$ \\
\hline $10 \mathrm{KCl}-3-61$ & 13 & $\mathrm{a}$ & $\mathrm{a}$ & 7.0 & $\mathrm{a}$ & $\mathrm{a}$ & 0.095 & $\mathrm{a}$ & $\mathrm{a}$ & 0.86 & 2.72 & 0.409 & 1.83 & $\mathrm{a}$ \\
\hline $10 \mathrm{KCl}-3-62$ & 14 & 3.0 & $\mathrm{a}$ & 25.8 & $\mathrm{a}$ & $\mathrm{a}$ & 0.112 & $\mathrm{a}$ & $\mathrm{a}$ & 0.46 & 12.7 & 1.9 & 1.47 & $\mathrm{a}$ \\
\hline $10 \mathrm{KCl}-3-63$ & 15 & 7.0 & 3.0 & 20.8 & $\mathrm{a}$ & $\mathrm{a}$ & 0.110 & $\mathrm{a}$ & $\mathrm{a}$ & 1.31 & 8.25 & 1.5 & 2.19 & $\mathrm{a}$ \\
\hline $10 \mathrm{KCl}-3-64$ & 16 & 9.0 & 3.0 & 22.0 & $\mathrm{a}$ & $\mathrm{a}$ & 0.090 & $\mathrm{a}$ & $\mathrm{a}$ & 1.41 & 7.01 & 1.4 & 1.43 & $\mathrm{a}$ \\
\hline $10 \mathrm{KCl}-3-65$ & 17 & 3.0 & $\mathrm{a}$ & 18.4 & $\mathrm{a}$ & $\mathrm{a}$ & 0.095 & $\mathrm{a}$ & $\mathrm{a}$ & 1.40 & 9.01 & 1.4 & 1.55 & $\mathrm{a}$ \\
\hline $10 \mathrm{KCl}-3-66$ & control & $\mathrm{a}$ & $\mathrm{a}$ & $\mathrm{a}$ & $\bar{a}$ & $\mathrm{a}$ & 0.089 & $a$ & $\mathrm{a}$ & 0.26 & $\mathrm{a}$ & 0.047 & $\mathrm{a}$ & $\bar{a}$ \\
\hline AJ13-3-67 & 19 & 11567 & 2699 & 788 & 0.680 & 5.79 & 0.392 & 4.74 & 19.8 & 147 & 218 & 30 & 42.4 & 10.9 \\
\hline AJ13-3-68 & 20 & 9431 & 2763 & 623 & 0.980 & 4.63 & 0.241 & 2.55 & 12.0 & 196 & 166 & 23 & 39.5 & 12.6 \\
\hline AJ13-3-69 & 21 & 11388 & 2886 & 839 & 0.608 & 5.66 & 0.365 & 4.83 & 20.4 & 182 & 216 & 30 & 35.5 & 12.2 \\
\hline AJ13-3-70 & 22 & 10332 & 3090 & 99.4 & 0.686 & 2.90 & 0.202 & 1.47 & 6.66 & 139 & 214 & 30 & 29.1 & 12.7 \\
\hline AJ13-3-71 & 23 & 10731 & 3475 & 865 & 0.291 & 2.56 & 0.134 & 0.955 & 5.85 & 178 & 214 & 31 & 47.9 & 15.5 \\
\hline AJ13-3-72 & control & 4.9 & $\mathrm{a}$ & $\mathrm{a}$ & 0.133 & $\mathrm{a}$ & $\mathrm{a}$ & $\mathrm{a}$ & $\mathrm{a}$ & $\mathrm{a}$ & $\mathrm{a}$ & $\mathrm{a}$ & $\mathrm{a}$ & $\mathrm{a}$ \\
\hline
\end{tabular}

${ }^{a}$ Element below detection limits of measuring instrument. 
Table F-8. Acid Strip Data $\left(\mathrm{ng} / \mathrm{mm}^{2}\right)$ from SS15ZR26 Specimens Immersed in $363 \mathrm{~K}\left(90^{\circ} \mathrm{C}\right)$ Solution for 21 days.

\begin{tabular}{|c|c|c|c|c|c|c|c|c|c|c|c|c|c|c|}
\hline \multirow[b]{2}{*}{ Expt. ID } & \multirow[b]{2}{*}{ Ingot ID } & \multicolumn{4}{|c|}{ Major Elements } & \multicolumn{5}{|c|}{ Noble Metal Fission Products } & \multicolumn{4}{|c|}{ Minor Elements } \\
\hline & & $\mathrm{Fe}$ & $\mathrm{Cr}$ & $\mathrm{Ni}$ & $\mathrm{Zr}$ & $\mathrm{Nb}$ & $\mathrm{Pd}$ & $\mathrm{Rh}$ & $\mathrm{Ru}$ & Mo & $\mathrm{Mn}$ & Co & $\mathrm{Cu}$ & $\mathrm{V}$ \\
\hline \multicolumn{2}{|c|}{ Detection Limits } & 2.3 & 2.3 & 2.3 & 0.067 & 0.050 & 0.044 & 0.052 & 0.24 & 0.27 & 0.16 & 0.019 & 0.30 & 4.9 \\
\hline SJ13-3-49AS & 1 & 5.9 & $\mathrm{a}$ & $\mathrm{a}$ & 0.380 & $\mathrm{a}$ & $\mathrm{a}$ & $\bar{a}$ & $\bar{a}$ & 0.85 & $\mathrm{a}$ & $\mathrm{a}$ & $\mathrm{a}$ & $\mathrm{a}$ \\
\hline SJ13-3-50AS & 2 & 8.2 & $\mathrm{a}$ & $\mathrm{a}$ & 0.440 & $\mathrm{a}$ & $\mathrm{a}$ & $\mathrm{a}$ & $\mathrm{a}$ & 0.44 & $\mathrm{a}$ & $\mathrm{a}$ & $\mathrm{a}$ & $\mathrm{a}$ \\
\hline SJ13-3-51AS & 3 & 4.6 & $\mathrm{a}$ & $\mathrm{a}$ & 0.452 & $\mathrm{a}$ & $\mathrm{a}$ & $\mathrm{a}$ & $\mathrm{a}$ & 0.28 & $\mathrm{a}$ & $\mathrm{a}$ & 1.12 & $\mathrm{a}$ \\
\hline SJ13-3-52AS & 4 & 4.7 & $\mathrm{a}$ & $\mathrm{a}$ & 0.229 & $\mathrm{a}$ & $\mathrm{a}$ & $\mathrm{a}$ & $\mathrm{a}$ & $\mathrm{a}$ & $\mathrm{a}$ & $\mathrm{a}$ & $\mathrm{a}$ & $\mathrm{a}$ \\
\hline SJ13-3-53AS & 5 & 4.6 & $\bar{a}$ & $\bar{a}$ & 0.357 & $a$ & $\bar{a}$ & $\bar{a}$ & $\bar{a}$ & 0.44 & $\bar{a}$ & $a$ & $\bar{a}$ & $\mathrm{a}$ \\
\hline SJ13-3-54AS & control & 6.8 & $\mathrm{a}$ & $a$ & 0.605 & $\mathrm{a}$ & $\mathrm{a}$ & $\bar{a}$ & $\bar{a}$ & 0.32 & $\mathrm{a}$ & $\mathrm{a}$ & $\mathrm{a}$ & $\mathrm{a}$ \\
\hline CJ13-3-55AS & 7 & 2.3 & $\bar{a}$ & $\mathrm{a}$ & $\mathrm{a}$ & $\mathrm{a}$ & $\mathrm{a}$ & $\mathrm{a}$ & $\mathrm{a}$ & 0.30 & $\mathrm{a}$ & $\mathrm{a}$ & $\mathrm{a}$ & $\mathrm{a}$ \\
\hline CJ13-3-56AS & 8 & 7.0 & $\mathrm{a}$ & $\mathrm{a}$ & 0.168 & $\mathrm{a}$ & $\mathrm{a}$ & $\mathrm{a}$ & $\mathrm{a}$ & $\mathrm{a}$ & $\mathrm{a}$ & $\mathrm{a}$ & $\mathrm{a}$ & $\mathrm{a}$ \\
\hline CJ13-3-57AS & 9 & 7.0 & $\mathrm{a}$ & $\mathrm{a}$ & 0.147 & $\mathrm{a}$ & $\mathrm{a}$ & $\mathrm{a}$ & $\mathrm{a}$ & $\mathrm{a}$ & $\mathrm{a}$ & $\mathrm{a}$ & $\mathrm{a}$ & $\mathrm{a}$ \\
\hline CJ13-3-58AS & 10 & 4.6 & $\mathrm{a}$ & $\mathrm{a}$ & $\mathrm{a}$ & $\mathrm{a}$ & $\mathrm{a}$ & $\mathrm{a}$ & $\mathrm{a}$ & 0.82 & $\mathrm{a}$ & $\mathrm{a}$ & $\mathrm{a}$ & $\mathrm{a}$ \\
\hline CJ13-3-59AS & 11 & 3.5 & $\mathrm{a}$ & $\mathrm{a}$ & $\mathrm{a}$ & $\mathrm{a}$ & $\mathrm{a}$ & $\mathrm{a}$ & $\mathrm{a}$ & 1.26 & $\mathrm{a}$ & $\mathrm{a}$ & $\mathrm{a}$ & $\mathrm{a}$ \\
\hline CJ13-3-60AS & control & 6.0 & $\mathrm{a}$ & $\mathrm{a}$ & 0.250 & 0.129 & $\mathrm{a}$ & $\mathrm{a}$ & $\mathrm{a}$ & 0.35 & $\mathrm{a}$ & $\mathrm{a}$ & $\mathrm{a}$ & $\mathrm{a}$ \\
\hline $10 \mathrm{KCl}-3-61 \mathrm{AS}$ & 13 & 29.3 & $\mathrm{a}$ & $\mathrm{a}$ & 0.128 & 0.049 & $\mathrm{a}$ & $\mathrm{a}$ & $\mathrm{a}$ & $\mathrm{a}$ & 0.23 & 0.058 & 1.47 & $\mathrm{a}$ \\
\hline $10 \mathrm{KCl}-3-62 \mathrm{AS}$ & 14 & 130 & 40.4 & 9.2 & 0.304 & 0.149 & 0.052 & 0.094 & 0.389 & 0.52 & 4.23 & 0.403 & 3.16 & $\mathrm{a}$ \\
\hline $10 \mathrm{KCl}-3-63 \mathrm{AS}$ & 15 & 94.8 & 17.6 & 8.2 & 0.200 & 0.097 & $\mathrm{a}$ & $\mathrm{a}$ & $\mathrm{a}$ & 0.52 & 4.84 & 0.379 & 2.08 & $\mathrm{a}$ \\
\hline $10 \mathrm{KCl}-3-64 \mathrm{AS}$ & 16 & 104 & 17.5 & 10.5 & 0.263 & 0.074 & $\mathrm{a}$ & $\bar{a}$ & $\mathrm{a}$ & 0.83 & 5.92 & 0.530 & 2.28 & $\mathrm{a}$ \\
\hline $10 \mathrm{KCl}-3-65 \mathrm{AS}$ & 17 & 110 & 27.7 & 9.2 & 0.556 & 0.159 & $\mathrm{a}$ & 0.054 & 0.255 & 0.44 & 4.15 & 0.438 & 3.10 & $\mathrm{a}$ \\
\hline 10KCl-3-66AS & control & 5.9 & $\mathrm{a}$ & $\mathrm{a}$ & 0.293 & 0.064 & $\mathrm{a}$ & $\mathrm{a}$ & $\mathrm{a}$ & $\mathrm{a}$ & $\mathrm{a}$ & $\mathrm{a}$ & $\mathrm{a}$ & $\mathrm{a}$ \\
\hline AJ13-3-67AS & 19 & 601 & 138 & 37.8 & 0.640 & 0.945 & 0.309 & 0.463 & 1.96 & 13.0 & 12.8 & 1.80 & 3.16 & $\mathrm{a}$ \\
\hline AJ13-3-68AS & 20 & 538 & 170 & 34.1 & 0.822 & 1.94 & 0.163 & 0.825 & 3.66 & 22.4 & 11.1 & 1.56 & 3.38 & $\mathrm{a}$ \\
\hline AJ13-3-69AS & 21 & 388 & 104 & 24.5 & 0.414 & 1.15 & 0.303 & 0.565 & 2.36 & 15.3 & 8.25 & 1.20 & 1.70 & $\mathrm{a}$ \\
\hline AJ13-3-70AS & 22 & 272 & 81.6 & 22.5 & 2.09 & 1.22 & 0.299 & 0.453 & 1.79 & 11.3 & 6.14 & 0.891 & 1.02 & $\mathrm{a}$ \\
\hline AJ13-3-71AS & 23 & 332 & 104 & 23.1 & 0.479 & 0.816 & 0.140 & 0.179 & 0.828 & 9.79 & 7.23 & 1.02 & 1.97 & $\mathrm{a}$ \\
\hline AJ13-3-72AS & control & 3.5 & $\mathrm{a}$ & $\mathrm{a}$ & 0.250 & $\mathrm{a}$ & $\mathrm{a}$ & $\mathrm{a}$ & $\mathrm{a}$ & $\mathrm{a}$ & $\mathrm{a}$ & $\mathrm{a}$ & $\mathrm{a}$ & $\mathrm{a}$ \\
\hline
\end{tabular}

${ }^{\mathrm{a}}$ Element below detection limits of measuring instrument. 
Table F-9. Residue Data $\left(\mathrm{ng} / \mathrm{mm}^{2}\right)$ from SS15ZR26 Specimens Immersed in $363 \mathrm{~K}\left(90^{\circ} \mathrm{C}\right)$ Solution for 21 days.

\begin{tabular}{|c|c|c|c|c|c|c|c|c|c|c|c|c|c|c|}
\hline \multirow[b]{2}{*}{ Expt. ID } & \multirow[b]{2}{*}{ Ingot ID } & \multicolumn{4}{|c|}{ Major Elements } & \multicolumn{5}{|c|}{ Noble Metal Fission Products } & \multicolumn{4}{|c|}{ Minor Elements } \\
\hline & & $\mathrm{Fe}$ & $\mathrm{Cr}$ & $\mathrm{Ni}$ & $\mathrm{Zr}$ & $\mathrm{Nb}$ & $\mathrm{Pd}$ & $\mathrm{Rh}$ & $\mathrm{Ru}$ & Mo & $\mathrm{Mn}$ & Co & $\mathrm{Cu}$ & $\mathrm{V}$ \\
\hline Detection 1 & imits & $\mathrm{b}$ & $\bar{b}$ & $\bar{b}$ & $\bar{b}$ & $\bar{b}$ & $\mathrm{~b}$ & 0.02 & 0.02 & $\bar{b}$ & 2.30 & $\bar{b}$ & $\bar{b}$ & $\bar{b}$ \\
\hline $10 \mathrm{KCl}-3-61 \mathrm{R}$ & 13 & 90.95 & 8.91 & 6.73 & 1.47 & 0.04 & 0.03 & $\bar{a}$ & $\overline{\mathrm{a}}$ & 12.39 & $\bar{a}$ & 3.67 & 12.60 & 11.16 \\
\hline $10 \mathrm{KCl}-3-62 \mathrm{R}$ & 14 & 183.7 & 11.51 & 6.64 & 1.20 & 0.06 & 0.03 & 0.06 & 0.13 & 14.08 & 2.77 & 5.37 & 11.53 & 13.72 \\
\hline $10 \mathrm{KCl}-3-63 \mathrm{R}$ & 15 & 363.8 & 55.93 & 15.55 & 1.39 & 0.26 & 0.06 & 0.32 & 1.06 & 18.06 & 6.55 & 5.80 & 14.57 & 14.25 \\
\hline $10 \mathrm{KCl}-3-64 \mathrm{R}$ & 16 & 379.7 & 53.66 & 16.10 & 1.09 & 0.20 & 0.05 & 0.24 & 0.74 & 14.81 & 7.21 & 6.14 & 9.83 & 15.05 \\
\hline $10 \mathrm{KCl}-3-65 \mathrm{R}$ & 17 & 157.3 & 24.33 & 6.91 & 1.69 & 0.07 & 0.04 & 0.06 & 0.16 & 13.34 & 2.26 & 6.07 & 16.59 & 14.47 \\
\hline
\end{tabular}

${ }^{\mathrm{a}}$ Element below detection limits of measuring instrument.

${ }^{\mathrm{b}}$ Detection Limits not available. 
Table F-10. Leachate Data $\left(\mathrm{ng} / \mathrm{mm}^{2}\right)$ from SS15ZR26 Specimens Immersed in $363 \mathrm{~K}\left(90^{\circ} \mathrm{C}\right)$ Solution for 28 days.

\begin{tabular}{|c|c|c|c|c|c|c|c|c|c|c|c|c|c|c|}
\hline \multirow[b]{2}{*}{ Expt. ID } & \multirow[b]{2}{*}{ Ingot ID } & \multicolumn{4}{|c|}{ Major Elements } & \multicolumn{5}{|c|}{ Noble Metal Fission Products } & \multicolumn{4}{|c|}{ Minor Elements } \\
\hline & & $\mathrm{Fe}$ & $\mathrm{Cr}$ & $\mathrm{Ni}$ & $\mathrm{Zr}$ & $\mathrm{Nb}$ & $\mathrm{Pd}$ & $\mathrm{Rh}$ & $\mathrm{Ru}$ & Mo & $\mathrm{Mn}$ & $\mathrm{Co}$ & $\mathrm{Cu}$ & $\mathrm{V}$ \\
\hline \multicolumn{2}{|c|}{ Detection Limits } & 2.0 & 2.0 & 2.0 & 0.016 & 0.022 & 0.027 & 0.015 & 0.20 & 0.24 & 0.052 & 0.017 & 0.084 & 4.3 \\
\hline SJ13-4-73 & 1 & 2.0 & $\mathrm{a}$ & $\mathrm{a}$ & 0.123 & $\mathrm{a}$ & $\mathrm{a}$ & $\mathrm{a}$ & $\mathrm{a}$ & 1.23 & 0.074 & $\mathrm{a}$ & 0.813 & $\mathrm{a}$ \\
\hline SJ13-4-74 & 2 & 4.1 & $\mathrm{a}$ & $\mathrm{a}$ & 0.118 & $\mathrm{a}$ & $\mathrm{a}$ & $\mathrm{a}$ & $\mathrm{a}$ & 0.65 & 0.073 & $\mathrm{a}$ & 0.260 & $\bar{a}$ \\
\hline SJ13-4-75 & 3 & $\mathrm{a}$ & $\mathrm{a}$ & $\mathrm{a}$ & 0.114 & $\mathrm{a}$ & $a$ & $a$ & $\mathrm{a}$ & 0.32 & $\mathrm{a}$ & $\mathrm{a}$ & 0.147 & $\mathrm{a}$ \\
\hline SJ13-4-76 & 4 & 3.0 & $\mathrm{a}$ & $\mathrm{a}$ & 0.109 & $\mathrm{a}$ & $\mathrm{a}$ & $\mathrm{a}$ & $\mathrm{a}$ & 1.06 & $\mathrm{a}$ & $\mathrm{a}$ & 0.205 & $\mathrm{a}$ \\
\hline SJ13-4-77 & 5 & $\mathrm{a}$ & $\mathrm{a}$ & $\mathrm{a}$ & 0.096 & $\mathrm{a}$ & $\mathrm{a}$ & $\mathrm{a}$ & $\mathrm{a}$ & 0.41 & $a$ & $\mathrm{a}$ & $\mathrm{a}$ & $\mathrm{a}$ \\
\hline SJ13-4-78 & control & $\bar{a}$ & $\bar{a}$ & $\bar{a}$ & 0.139 & $\bar{a}$ & $\bar{a}$ & $\bar{a}$ & $\bar{a}$ & 0.25 & $\bar{a}$ & $\bar{a}$ & 0.086 & $\bar{a}$ \\
\hline CJ13-4-79 & 7 & 4.1 & $\mathrm{a}$ & $\mathrm{a}$ & 1.49 & 0.069 & 0.079 & 0.023 & $\mathrm{a}$ & 1.90 & 0.071 & 0.027 & 0.409 & $\mathrm{a}$ \\
\hline CJ13-4-80 & 8 & 3.1 & $\mathrm{a}$ & $\mathrm{a}$ & 2.95 & 0.094 & 0.121 & 0.029 & $\mathrm{a}$ & 1.50 & 0.088 & 0.048 & 0.532 & $\mathrm{a}$ \\
\hline CJ13-4-81 & 9 & 3.1 & $\mathrm{a}$ & $\mathrm{a}$ & 1.70 & 0.067 & 0.143 & 0.033 & $\mathrm{a}$ & 0.64 & 0.105 & 0.058 & 0.551 & $\mathrm{a}$ \\
\hline CJ13-4-82 & 10 & $\bar{a}$ & $\mathrm{a}$ & $\mathrm{a}$ & 1.10 & $\mathrm{a}$ & 0.136 & 0.017 & $\mathrm{a}$ & 0.53 & 0.078 & 0.049 & 0.697 & $\bar{a}$ \\
\hline CJ13-4-83 & 11 & 2.0 & $\mathrm{a}$ & $\mathrm{a}$ & 1.36 & 0.031 & 0.154 & 0.032 & $\mathrm{a}$ & 0.81 & 0.088 & 0.053 & 0.788 & $\bar{a}$ \\
\hline CJ13-4-84 & control & $\mathrm{a}$ & $\bar{a}$ & $\mathrm{a}$ & 1.33 & $\bar{a}$ & 0.154 & 0.018 & $\mathrm{a}$ & 0.44 & 0.086 & 0.090 & 0.553 & $a$ \\
\hline $10 \mathrm{KCl}-4-85$ & 13 & $\mathrm{a}$ & $\mathrm{a}$ & 10.1 & 0.026 & $\mathrm{a}$ & 0.174 & $\mathrm{a}$ & $a$ & 1.69 & 3.46 & 0.555 & 1.81 & $\bar{a}$ \\
\hline $10 \mathrm{KCl}-4-86$ & 14 & 4.1 & $\bar{a}$ & 13.3 & $\mathrm{a}$ & $\mathrm{a}$ & 0.154 & $a$ & $a$ & 0.69 & 7.50 & 1.09 & 1.49 & $a$ \\
\hline $10 \mathrm{KCl}-4-87$ & 15 & 4.1 & $\mathrm{a}$ & 16.3 & $\mathrm{a}$ & $\mathrm{a}$ & 0.197 & $\mathrm{a}$ & $\mathrm{a}$ & 0.65 & 9.09 & 1.30 & 1.33 & $\mathrm{a}$ \\
\hline $10 \mathrm{KCl}-4-88$ & 16 & 6.1 & 2.0 & 14.2 & $\bar{a}$ & $\bar{a}$ & 0.183 & $\bar{a}$ & $\bar{a}$ & 2.20 & 7.08 & 0.985 & 1.37 & $\mathrm{a}$ \\
\hline $10 \mathrm{KCl}-4-89$ & 17 & 3.0 & $\mathrm{a}$ & 20.2 & $\mathrm{a}$ & $\mathrm{a}$ & 0.162 & $\mathrm{a}$ & $\mathrm{a}$ & 0.49 & 10.09 & 1.55 & 1.64 & $\mathrm{a}$ \\
\hline $10 \mathrm{KCl}-4-90$ & \begin{tabular}{|l|} 
control \\
\end{tabular} & $\mathrm{a}$ & $\mathrm{a}$ & $\mathrm{a}$ & $\mathrm{a}$ & $\mathrm{a}$ & 0.164 & $\mathrm{a}$ & $\mathrm{a}$ & $\mathrm{a}$ & $\mathrm{a}$ & 0.047 & 0.137 & $\mathrm{a}$ \\
\hline AJ13-4-91 & 19 & 12241 & 2661 & 819 & 0.940 & 0.05 & 0.029 & 0.303 & 1.26 & 0.36 & 308 & 2.27 & 4.21 & $a$ \\
\hline AJ13-4-92 & 20 & 10035 & 3159 & 763 & 0.578 & 0.029 & 0.012 & 0.057 & $\mathrm{a}$ & 0.15 & 259 & 1.93 & 1.96 & $\mathrm{a}$ \\
\hline AJ13-4-93 & 21 & 10375 & 2197 & 906 & 0.426 & 0.021 & $\bar{a}$ & 0.033 & $\mathrm{a}$ & 0.09 & 275 & 2.04 & 3.32 & $\bar{a}$ \\
\hline AJ13-4-94 & 22 & 10086 & 3193 & 890 & 0.787 & 0.039 & 0.016 & 0.129 & 0.57 & 0.22 & 268 & 2.00 & 3.55 & $\mathrm{a}$ \\
\hline AJ13-4-95 & 23 & 11214 & 2909 & 902 & 2.37 & 0.119 & 0.012 & 0.111 & 0.47 & 0.18 & 304 & 2.23 & 2.63 & $\mathrm{a}$ \\
\hline AJ13-4-96 & control & $\bar{a}$ & $\bar{a}$ & $\bar{a}$ & 0.119 & $\bar{a}$ & $\bar{a}$ & $\bar{a}$ & $\bar{a}$ & $a$ & $\bar{a}$ & $\mathrm{a}$ & 0.338 & $\mathrm{a}$ \\
\hline
\end{tabular}

${ }^{\mathrm{a}}$ Element below detection limits of measuring instrument. 
Table F-11. Acid Strip Data $\left(\mathrm{ng} / \mathrm{mm}^{2}\right)$ from SS15ZR26 Specimens Immersed in $363 \mathrm{~K}\left(90^{\circ} \mathrm{C}\right)$ Solution for 28 days.

\begin{tabular}{|c|c|c|c|c|c|c|c|c|c|c|c|c|c|c|}
\hline \multirow[b]{2}{*}{ Expt. ID } & \multirow[b]{2}{*}{ Ingot ID } & \multicolumn{4}{|c|}{ Major Elements } & \multicolumn{5}{|c|}{ Noble Metal Fission Products } & \multicolumn{4}{|c|}{ Minor Elements } \\
\hline & & $\mathrm{Fe}$ & $\mathrm{Cr}$ & $\mathrm{Ni}$ & $\mathrm{Zr}$ & $\mathrm{Nb}$ & $\mathrm{Pd}$ & $\mathrm{Rh}$ & $\mathrm{Ru}$ & Mo & $\mathrm{Mn}$ & Co & $\mathrm{Cu}$ & $\mathrm{V}$ \\
\hline \multicolumn{2}{|c|}{ Detection Limits } & 2.2 & 2.2 & 2.2 & 0.018 & 0.025 & 0.030 & 0.017 & 0.22 & 0.27 & 0.058 & 0.019 & 0.095 & 4.8 \\
\hline SJ13-4-73AS & 1 & 2.3 & $\mathrm{a}$ & $\mathrm{a}$ & 1.01 & 0.184 & $\mathrm{a}$ & $\mathrm{a}$ & $\mathrm{a}$ & $\mathrm{a}$ & 0.451 & $\mathrm{a}$ & 1.64 & $\mathrm{a}$ \\
\hline SJ13-4-74AS & 2 & 6.6 & $\mathrm{a}$ & $\mathrm{a}$ & 0.487 & 0.028 & $\mathrm{a}$ & $\mathrm{a}$ & $\mathrm{a}$ & $\mathrm{a}$ & 0.156 & $\mathrm{a}$ & 1.23 & $\mathrm{a}$ \\
\hline SJ13-4-75AS & 3 & $\mathrm{a}$ & $\mathrm{a}$ & $\mathrm{a}$ & 1.13 & 0.062 & $\mathrm{a}$ & $\mathrm{a}$ & $\mathrm{a}$ & 1.18 & 0.194 & $\mathrm{a}$ & 0.343 & $\mathrm{a}$ \\
\hline SJ13-4-76AS & 4 & $\mathrm{a}$ & $\mathrm{a}$ & $\mathrm{a}$ & 3.57 & 0.035 & $\mathrm{a}$ & $\mathrm{a}$ & $\mathrm{a}$ & $\mathrm{a}$ & 0.094 & $\mathrm{a}$ & 0.301 & $\mathrm{a}$ \\
\hline SJ13-4-77AS & 5 & 3.4 & $\bar{a}$ & $\bar{a}$ & 0.824 & $\mathrm{a}$ & $\bar{a}$ & $\bar{a}$ & $\bar{a}$ & $\bar{a}$ & 0.082 & $a$ & 0.175 & $\mathrm{a}$ \\
\hline SJ13-4-78AS & control & 3.2 & $\mathrm{a}$ & $a$ & 1.05 & 0.050 & $\mathrm{a}$ & $\mathrm{a}$ & $\bar{a}$ & $\mathrm{a}$ & $\bar{a}$ & $\mathrm{a}$ & 0.416 & $\mathrm{a}$ \\
\hline CJ13-4-79AS & 7 & 8.1 & $\mathrm{a}$ & $\mathrm{a}$ & 0.112 & 0.026 & $\mathrm{a}$ & $\mathrm{a}$ & $\mathrm{a}$ & 0.89 & 0.066 & $\mathrm{a}$ & 0.178 & $\mathrm{a}$ \\
\hline CJ13-4-80AS & 8 & 3.3 & $\mathrm{a}$ & $\mathrm{a}$ & 0.264 & 0.039 & $\mathrm{a}$ & $\mathrm{a}$ & $\mathrm{a}$ & $\mathrm{a}$ & $\mathrm{a}$ & $\mathrm{a}$ & 0.109 & $\mathrm{a}$ \\
\hline CJ13-4-81AS & 9 & 1.1 & $\mathrm{a}$ & $\mathrm{a}$ & 0.046 & $\mathrm{a}$ & $\mathrm{a}$ & $\mathrm{a}$ & $\mathrm{a}$ & $\mathrm{a}$ & $\mathrm{a}$ & $\mathrm{a}$ & 0.107 & $\mathrm{a}$ \\
\hline CJ13-4-82AS & 10 & $\mathrm{a}$ & $\mathrm{a}$ & $\mathrm{a}$ & 0.069 & $\mathrm{a}$ & $\mathrm{a}$ & $\mathrm{a}$ & $\mathrm{a}$ & $\mathrm{a}$ & $\mathrm{a}$ & $\mathrm{a}$ & 0.154 & $\mathrm{a}$ \\
\hline CJ13-4-83AS & 11 & $\mathrm{a}$ & 2.3 & $\mathrm{a}$ & 0.070 & 0.039 & $\mathrm{a}$ & $\mathrm{a}$ & $\mathrm{a}$ & 0.28 & 0.087 & $\mathrm{a}$ & 0.222 & $\mathrm{a}$ \\
\hline CJ13-4-84AS & control & 2.2 & $\mathrm{a}$ & $\mathrm{a}$ & 0.057 & $\mathrm{a}$ & $\mathrm{a}$ & $\mathrm{a}$ & $\mathrm{a}$ & $\mathrm{a}$ & $\mathrm{a}$ & 0.059 & 1.25 & $\mathrm{a}$ \\
\hline $10 \mathrm{KCl}-4-85 \mathrm{AS}$ & 13 & 44.8 & 14.6 & $\mathrm{a}$ & 0.072 & 0.063 & $\mathrm{a}$ & 0.030 & $\mathrm{a}$ & 1.28 & 0.253 & 0.042 & 0.712 & $\mathrm{a}$ \\
\hline $10 \mathrm{KCl}-4-86 \mathrm{AS}$ & 14 & 87.1 & 12.6 & 4.6 & 0.124 & 0.048 & $\mathrm{a}$ & 0.023 & $\mathrm{a}$ & 0.33 & 1.85 & 0.205 & 1.75 & $\mathrm{a}$ \\
\hline $10 \mathrm{KCl}-4-87 \mathrm{AS}$ & 15 & 163 & 48.2 & 11.5 & 0.083 & 0.105 & $\mathrm{a}$ & 0.088 & 0.33 & 0.89 & 4.30 & 0.489 & 2.00 & $\mathrm{a}$ \\
\hline $10 \mathrm{KCl}-4-88 \mathrm{AS}$ & 16 & 128 & 27.9 & 8.9 & 0.070 & 0.051 & $\mathrm{a}$ & 0.041 & $\mathrm{a}$ & 0.74 & 2.18 & 0.343 & 1.54 & $\mathrm{a}$ \\
\hline 10KCl-4-89AS & 17 & 154 & 29.1 & 12.3 & 0.102 & 0.073 & $\mathrm{a}$ & 0.067 & 0.27 & 0.56 & 4.83 & 0.487 & 2.75 & $\mathrm{a}$ \\
\hline 10KCl-4-90AS & control & $\mathrm{a}$ & $\mathrm{a}$ & $\mathrm{a}$ & 0.094 & $\mathrm{a}$ & $\mathrm{a}$ & $\mathrm{a}$ & $\mathrm{a}$ & $\mathrm{a}$ & $\mathrm{a}$ & $\mathrm{a}$ & $\mathrm{a}$ & $\mathrm{a}$ \\
\hline AJ13-4-91AS & 19 & 777 & 193 & 47.0 & 0.565 & 1.99 & 0.363 & 0.942 & 4.04 & 30.7 & 15.9 & 2.31 & 4.22 & $\mathrm{a}$ \\
\hline AJ13-4-92AS & 20 & 431 & 133 & 28.2 & 1.12 & 1.92 & 0.284 & 0.487 & 2.20 & 20.0 & 9.31 & 1.34 & 1.46 & $\mathrm{a}$ \\
\hline AJ13-4-93AS & 21 & 377 & 72.4 & 27.6 & 0.298 & 0.732 & 0.083 & 0.096 & 0.43 & 6.50 & 7.81 & 1.14 & 1.52 & $\mathrm{a}$ \\
\hline AJ13-4-94AS & 22 & 343 & 101 & 25.3 & 0.474 & 0.920 & 0.171 & 0.590 & 2.34 & 10.7 & 8.02 & 1.15 & 2.04 & $\mathrm{a}$ \\
\hline AJ13-4-95AS & 23 & 232 & 61.3 & 15.8 & 0.447 & 1.24 & 0.235 & 0.675 & 2.69 & 10.8 & 5.48 & 0.793 & 1.03 & $\mathrm{a}$ \\
\hline AJ13-4-96AS & control & $\mathrm{a}$ & $\mathrm{a}$ & $\mathrm{a}$ & 0.165 & $\mathrm{a}$ & $a$ & $\mathrm{a}$ & $\mathrm{a}$ & $\mathrm{a}$ & $\mathrm{a}$ & $\mathrm{a}$ & 0.129 & $\mathrm{a}$ \\
\hline
\end{tabular}

${ }^{\mathrm{a}}$ Element below detection limits of measuring instrument. 
Table F-12. Residue Data $\left(\mathrm{ng} / \mathrm{mm}^{2}\right)$ from SS15ZR 26 Specimens Immersed in $363 \mathrm{~K}\left(90^{\circ} \mathrm{C}\right)$ Solution for 28 days.

\begin{tabular}{|c|c|c|c|c|c|c|c|c|c|c|c|c|c|c|}
\hline \multirow[b]{2}{*}{ Expt. ID } & \multirow[b]{2}{*}{ Ingot ID } & \multicolumn{4}{|c|}{ Major Elements } & \multicolumn{5}{|c|}{ Noble Metal Fission Products } & \multicolumn{4}{|c|}{ Minor Elements } \\
\hline & & $\mathrm{Fe}$ & $\mathrm{Cr}$ & $\mathrm{Ni}$ & $\mathrm{Zr}$ & $\mathrm{Nb}$ & $\mathrm{Pd}$ & $\mathrm{Rh}$ & $\mathrm{Ru}$ & Mo & $\mathrm{Mn}$ & Co & $\mathrm{Cu}$ & $\mathrm{V}$ \\
\hline \multicolumn{2}{|c|}{ Detection Limits } & $\bar{b}$ & $\bar{b}$ & 4.50 & $\bar{b}$ & 0.05 & $\mathrm{~b}$ & 0.03 & 0.45 & $\bar{b}$ & $\mathrm{~b}$ & $\mathrm{~b}$ & $\mathrm{~b}$ & 10.00 \\
\hline $10 \mathrm{KCl}-4-85 \mathrm{R}$ & 13 & 175.1 & 6.46 & $\mathrm{a}$ & 1.85 & $\mathrm{a}$ & 0.14 & $\bar{a}$ & $\mathrm{a}$ & 202.4 & 3.68 & 23.15 & 14.64 & $\mathrm{a}$ \\
\hline $10 \mathrm{KCl}-4-86 \mathrm{R}$ & 14 & 130.5 & 8.09 & 5.09 & 1.00 & $\mathrm{a}$ & 0.08 & $\mathrm{a}$ & $\mathrm{a}$ & 125.5 & 2.61 & 9.50 & 10.50 & $\mathrm{a}$ \\
\hline $10 \mathrm{KCl}-4-87 \mathrm{R}$ & 15 & 201.9 & 25.01 & 7.00 & 1.02 & 0.10 & 0.11 & 0.08 & $\mathrm{a}$ & 189.2 & 5.68 & 7.73 & 13.23 & 10.82 \\
\hline $10 \mathrm{KCl}-4-88 \mathrm{R}$ & 16 & 166.4 & 20.87 & 7.00 & 0.75 & 0.08 & 0.09 & 0.07 & $\mathrm{a}$ & 146.4 & 3.62 & 9.41 & 11.87 & 13.05 \\
\hline $10 \mathrm{KCl}-4-89 \mathrm{R}$ & 17 & 144.6 & 12.64 & $\bar{a}$ & 1.22 & 0.06 & 0.08 & 0.06 & $\bar{a}$ & 160.5 & 4.08 & 6.87 & 18.96 & 13.87 \\
\hline
\end{tabular}

${ }^{\mathrm{a}}$ Element below detection limits of measuring instrument.

${ }^{\mathrm{b}}$ Detection Limits not available. 
Table F-13. Leachate Data $\left(\mathrm{ng} / \mathrm{mm}^{2}\right)$ from SS15ZR26 Specimens Immersed in $363 \mathrm{~K}\left(90^{\circ} \mathrm{C}\right)$ Solution for 42 days.

\begin{tabular}{|c|c|c|c|c|c|c|c|c|c|c|c|c|c|c|}
\hline \multirow[b]{2}{*}{ Expt. ID } & \multirow[b]{2}{*}{ Ingot ID } & \multicolumn{4}{|c|}{ Major Elements } & \multicolumn{5}{|c|}{ Noble Metal Fission Products } & \multicolumn{4}{|c|}{ Minor Elements } \\
\hline & & $\mathrm{Fe}$ & $\mathrm{Cr}$ & $\mathrm{Ni}$ & $\mathrm{Zr}$ & $\mathrm{Nb}$ & $\mathrm{Pd}$ & $\mathrm{Rh}$ & $\mathrm{Ru}$ & Mo & $\mathrm{Mn}$ & $\mathrm{Co}$ & $\mathrm{Cu}$ & $\mathrm{V}$ \\
\hline \multicolumn{2}{|c|}{ Detection Limits } & 2.0 & 2.0 & 2.0 & 0.090 & 0.009 & 0.006 & 0.005 & 0.19 & 0.23 & 0.064 & 0.006 & 0.053 & 2.4 \\
\hline SJ13-6-97 & 1 & $\mathrm{a}$ & $\mathrm{a}$ & $\mathrm{a}$ & $\mathrm{a}$ & $\mathrm{a}$ & $\mathrm{a}$ & $\bar{a}$ & $\mathrm{a}$ & 0.79 & $\bar{a}$ & $\mathrm{a}$ & 0.216 & $\mathrm{a}$ \\
\hline SJ13-6-98 & 2 & $\mathrm{a}$ & $\bar{a}$ & $\mathrm{a}$ & $\mathrm{a}$ & $\bar{a}$ & $\mathrm{a}$ & $\mathrm{a}$ & $\mathrm{a}$ & 0.77 & $\mathrm{a}$ & $\mathrm{a}$ & 0.255 & $\mathrm{a}$ \\
\hline SJ13-6-99 & 3 & $\mathrm{a}$ & $\mathrm{a}$ & $\mathrm{a}$ & 0.109 & $\mathrm{a}$ & $\mathrm{a}$ & $\mathrm{a}$ & $\mathrm{a}$ & 0.69 & $\mathrm{a}$ & $\mathrm{a}$ & 0.162 & $\mathrm{a}$ \\
\hline SJ13-6-100 & 4 & $\mathrm{a}$ & $\mathrm{a}$ & $\mathrm{a}$ & 0.094 & $\mathrm{a}$ & $\mathrm{a}$ & $\mathrm{a}$ & $\mathrm{a}$ & 1.01 & $\mathrm{a}$ & $\mathrm{a}$ & 0.270 & $\mathrm{a}$ \\
\hline SJ13-6-101 & 5 & $\bar{a}$ & $\mathrm{a}$ & $\bar{a}$ & 0.175 & $\bar{a}$ & $\bar{a}$ & $\bar{a}$ & $\bar{a}$ & 0.32 & $\bar{a}$ & $a$ & 0.125 & $a$ \\
\hline SJ13-6-102 & control & $\mathrm{a}$ & $\mathrm{a}$ & $\mathrm{a}$ & 0.221 & $\mathrm{a}$ & $\mathrm{a}$ & $\bar{a}$ & $\mathrm{a}$ & 0.45 & $\mathrm{a}$ & $\mathrm{a}$ & 0.143 & $\mathrm{a}$ \\
\hline CJ13-6-103 & 7 & $\mathrm{a}$ & $\mathrm{a}$ & $\mathrm{a}$ & 1.74 & 0.068 & 0.095 & 0.032 & $\mathrm{a}$ & 0.48 & $\mathrm{a}$ & 0.033 & 0.264 & $\mathrm{a}$ \\
\hline CJ13-6-104 & 8 & $\mathrm{a}$ & $\mathrm{a}$ & $\mathrm{a}$ & 1.73 & 0.063 & 0.123 & 0.031 & $\mathrm{a}$ & 0.57 & $\mathrm{a}$ & 0.047 & 0.329 & $\mathrm{a}$ \\
\hline CJ13-6-105 & 9 & $\mathrm{a}$ & $\mathrm{a}$ & $\mathrm{a}$ & 1.54 & 0.048 & 0.124 & 0.031 & $\mathrm{a}$ & 6.14 & 0.077 & 0.050 & 0.683 & $\mathrm{a}$ \\
\hline CJ13-6-106 & 10 & $\mathrm{a}$ & $\mathrm{a}$ & $\mathrm{a}$ & 1.31 & 0.021 & 0.127 & 0.018 & $\mathrm{a}$ & 0.92 & 0.070 & 0.046 & 0.456 & $\mathrm{a}$ \\
\hline CJ13-6-107 & 11 & $\mathrm{a}$ & $\mathrm{a}$ & $\mathrm{a}$ & 1.08 & 0.013 & 0.113 & 0.018 & $\mathrm{a}$ & 2.08 & $\mathrm{a}$ & 0.043 & 0.775 & $\mathrm{a}$ \\
\hline CJ13-6-108 & control & $\mathrm{a}$ & $\mathrm{a}$ & $\mathrm{a}$ & 1.04 & 0.011 & 0.100 & 0.019 & $\mathrm{a}$ & 0.37 & 0.075 & 0.042 & 0.208 & $\mathrm{a}$ \\
\hline $10 \mathrm{KCl}-6-109$ & 13 & 5.1 & $a$ & 13.3 & $a$ & $\mathrm{a}$ & 0.153 & 0.006 & $\bar{a}$ & 16.6 & 7.65 & 1.011 & 4.09 & 2.5 \\
\hline $10 \mathrm{KCl}-6-110$ & 14 & 3.1 & $\mathrm{a}$ & 16.3 & $\mathrm{a}$ & $\mathrm{a}$ & 0.125 & 0.006 & $\mathrm{a}$ & 5.26 & 7.92 & 1.012 & 2.68 & 2.8 \\
\hline $10 \mathrm{KCl}-6-111$ & 15 & 4.1 & $\mathrm{a}$ & 10.2 & $\mathrm{a}$ & $\mathrm{a}$ & 0.115 & $\mathrm{a}$ & $\mathrm{a}$ & 4.43 & 4.00 & 0.621 & 3.24 & 2.7 \\
\hline $10 \mathrm{KCl}-6-112$ & 16 & 6.1 & $\mathrm{a}$ & 30.7 & 0.334 & $\mathrm{a}$ & 0.148 & $\mathrm{a}$ & $\mathrm{a}$ & 4.43 & 11.4 & 1.86 & 2.20 & 2.9 \\
\hline $10 \mathrm{KCl}-6-113$ & 17 & 5.1 & $\mathrm{a}$ & 39.0 & $\mathrm{a}$ & $\mathrm{a}$ & 0.117 & $\mathrm{a}$ & $\mathrm{a}$ & 3.53 & 13.7 & 2.14 & 2.02 & 3.5 \\
\hline $10 \mathrm{KCl}-6-114$ & control & $\mathrm{a}$ & $\mathrm{a}$ & $\mathrm{a}$ & $\mathrm{a}$ & $\mathrm{a}$ & 0.094 & $\mathrm{a}$ & $\mathrm{a}$ & 0.30 & 0.142 & 0.032 & 0.423 & 3.7 \\
\hline AJ13-6-115 & 19 & 18278 & 3716 & 1436 & 0.354 & 2.26 & 0.207 & 2.40 & 9.59 & 198 & 510 & 15.1 & 22.0 & 3.6 \\
\hline AJ13-6-116 & 20 & 15975 & 4176 & 1021 & 1.73 & 5.69 & 0.481 & 5.57 & 23.1 & 249 & 362 & 48.8 & 58.0 & 16.2 \\
\hline AJ13-6-117 & 21 & 20037 & 4027 & 1924 & 0.333 & 1.58 & 0.125 & 1.21 & 4.68 & 134 & 535 & 17.5 & 29.3 & 3.8 \\
\hline AJ13-6-118 & 22 & 18092 & 4728 & 1329 & 0.339 & 1.95 & 0.146 & 2.00 & 7.99 & 212 & 445 & 16.1 & 37.4 & 4.7 \\
\hline AJ13-6-119 & 23 & 19396 & 3618 & 1337 & 0.141 & 1.18 & 0.089 & 1.18 & 4.64 & 143 & 476 & 12.9 & 19.8 & 2.7 \\
\hline AJ13-6-120 & control & 6.1 & $\mathrm{a}$ & $\bar{a}$ & 0.174 & $\bar{a}$ & $\bar{a}$ & $\mathrm{a}$ & $\mathrm{a}$ & 0.77 & 0.125 & 0.011 & 0.541 & $\mathrm{a}$ \\
\hline
\end{tabular}

${ }^{\mathrm{a}}$ Element below detection limits of measuring instrument. 
Table F-14. Acid Strip Data $\left(\mathrm{ng} / \mathrm{mm}^{2}\right)$ from SS15ZR26 Specimens Immersed in $363 \mathrm{~K}\left(90^{\circ} \mathrm{C}\right)$ Solution for 42 days.

\begin{tabular}{|c|c|c|c|c|c|c|c|c|c|c|c|c|c|c|}
\hline \multirow[b]{2}{*}{ Expt. ID } & \multirow[b]{2}{*}{ Ingot ID } & \multicolumn{4}{|c|}{ Major Elements } & \multicolumn{5}{|c|}{ Noble Metal Fission Products } & \multicolumn{4}{|c|}{ Minor Elements } \\
\hline & & $\mathrm{Fe}$ & $\mathrm{Cr}$ & $\mathrm{Ni}$ & $\mathrm{Zr}$ & $\mathrm{Nb}$ & $\mathrm{Pd}$ & $\mathrm{Rh}$ & $\mathrm{Ru}$ & Mo & $\mathrm{Mn}$ & Co & $\mathrm{Cu}$ & $\mathrm{V}$ \\
\hline \multicolumn{2}{|c|}{ Detection Limits } & 2.2 & 2.2 & 2.2 & 0.10 & 0.010 & 0.007 & 0.006 & 0.21 & 0.25 & 0.071 & 0.007 & 0.058 & 2.6 \\
\hline SJ13-6-97AS & 1 & $\mathrm{a}$ & $\mathrm{a}$ & $\mathrm{a}$ & 0.61 & $\mathrm{a}$ & 0.008 & $\mathrm{a}$ & $\mathrm{a}$ & $\mathrm{a}$ & $\mathrm{a}$ & 0.009 & 0.317 & $\mathrm{a}$ \\
\hline SJ13-6-98AS & 2 & $\mathrm{a}$ & $\mathrm{a}$ & $\mathrm{a}$ & 0.30 & $\mathrm{a}$ & $\mathrm{a}$ & $\mathrm{a}$ & $\mathrm{a}$ & 1.12 & $\mathrm{a}$ & 0.007 & 1.19 & $\mathrm{a}$ \\
\hline SJ13-6-99AS & 3 & $\mathrm{a}$ & $\mathrm{a}$ & $\mathrm{a}$ & 0.26 & $\mathrm{a}$ & $\mathrm{a}$ & $\mathrm{a}$ & $\mathrm{a}$ & $\mathrm{a}$ & $\mathrm{a}$ & 0.008 & 0.199 & $\mathrm{a}$ \\
\hline SJ13-6-100AS & 4 & 4.1 & $\mathrm{a}$ & $\mathrm{a}$ & 0.36 & $\mathrm{a}$ & $\mathrm{a}$ & $\mathrm{a}$ & $\mathrm{a}$ & $\mathrm{a}$ & $\mathrm{a}$ & 0.006 & 0.182 & $\mathrm{a}$ \\
\hline SJ13-6-101AS & 5 & 29.8 & $\bar{a}$ & $\bar{a}$ & 0.47 & $a$ & $\bar{a}$ & $\bar{a}$ & $\bar{a}$ & $\bar{a}$ & 0.180 & $\mathrm{a}$ & 0.132 & $\mathrm{a}$ \\
\hline SJ13-6-102AS & control & 2.2 & $\mathrm{a}$ & $\mathrm{a}$ & 0.76 & 0.017 & $\mathrm{a}$ & $\mathrm{a}$ & $\mathrm{a}$ & $\mathrm{a}$ & $\mathrm{a}$ & 0.007 & 0.527 & $\mathrm{a}$ \\
\hline CJ13-6-103AS & 7 & 2.2 & $\mathrm{a}$ & $\mathrm{a}$ & 0.14 & 0.022 & $\mathrm{a}$ & $\mathrm{a}$ & $\mathrm{a}$ & 0.51 & 0.100 & 0.008 & 0.220 & $\mathrm{a}$ \\
\hline CJ13-6-104AS & 8 & $\mathrm{a}$ & $\mathrm{a}$ & $\mathrm{a}$ & $\mathrm{a}$ & $\mathrm{a}$ & $\mathrm{a}$ & $\mathrm{a}$ & $\mathrm{a}$ & $\mathrm{a}$ & $\mathrm{a}$ & $\mathrm{a}$ & 0.065 & $\mathrm{a}$ \\
\hline CJ13-6-105AS & 9 & 4.4 & $\mathrm{a}$ & $\mathrm{a}$ & $\mathrm{a}$ & $\mathrm{a}$ & $\mathrm{a}$ & $\mathrm{a}$ & $\mathrm{a}$ & 0.74 & $\mathrm{a}$ & 0.014 & 4.92 & $\mathrm{a}$ \\
\hline CJ13-6-106AS & 10 & $\mathrm{a}$ & $\mathrm{a}$ & $\mathrm{a}$ & $\mathrm{a}$ & $\mathrm{a}$ & $\mathrm{a}$ & $\mathrm{a}$ & $\mathrm{a}$ & $\mathrm{a}$ & $\mathrm{a}$ & $\mathrm{a}$ & 0.107 & $\mathrm{a}$ \\
\hline CJ13-6-107AS & 11 & 2.1 & $\mathrm{a}$ & $\mathrm{a}$ & $\mathrm{a}$ & $\mathrm{a}$ & $\mathrm{a}$ & $\mathrm{a}$ & $\mathrm{a}$ & $\mathrm{a}$ & $\mathrm{a}$ & $\mathrm{a}$ & 0.120 & $\mathrm{a}$ \\
\hline CJ13-6-108AS & control & $\mathrm{a}$ & $\mathrm{a}$ & $\mathrm{a}$ & $\mathrm{a}$ & $\mathrm{a}$ & $\mathrm{a}$ & $\mathrm{a}$ & $\mathrm{a}$ & $\mathrm{a}$ & $\mathrm{a}$ & $\mathrm{a}$ & $\mathrm{a}$ & $\mathrm{a}$ \\
\hline $10 \mathrm{KCl}-6-109 \mathrm{AS}$ & 13 & 79.1 & 11 & 2.1 & $\mathrm{a}$ & 0.024 & 0.008 & 0.010 & $\mathrm{a}$ & 0.96 & 0.473 & 0.089 & 1.07 & $\mathrm{a}$ \\
\hline $10 \mathrm{KCl}-6-110 \mathrm{AS}$ & 14 & 95.2 & 20 & 4.6 & 0.12 & 0.047 & 0.012 & 0.031 & $\mathrm{a}$ & 0.45 & 1.21 & 0.177 & 1.36 & $\mathrm{a}$ \\
\hline $10 \mathrm{KCl}-6-111 \mathrm{AS}$ & 15 & 25.8 & 8.6 & $\mathrm{a}$ & $\mathrm{a}$ & 0.023 & $\mathrm{a}$ & 0.008 & $\mathrm{a}$ & $\mathrm{a}$ & 0.312 & 0.049 & 0.657 & $\mathrm{a}$ \\
\hline $10 \mathrm{KCl}-6-112 \mathrm{AS}$ & 16 & 253 & 50 & 29.5 & $\mathrm{a}$ & 0.072 & 0.028 & 0.103 & 0.39 & 0.65 & 9.61 & 1.21 & 4.23 & $\mathrm{a}$ \\
\hline $10 \mathrm{KCl}-6-113 \mathrm{AS}$ & 17 & 264 & 41 & 23.9 & 0.13 & 0.089 & 0.021 & 0.084 & 0.33 & 0.77 & 6.76 & 0.840 & 2.86 & $\mathrm{a}$ \\
\hline $10 \mathrm{KCl}-6-114 \mathrm{AS}$ & control & 5.6 & $\mathrm{a}$ & $\mathrm{a}$ & $\mathrm{a}$ & $\mathrm{a}$ & $\mathrm{a}$ & $\mathrm{a}$ & $\mathrm{a}$ & $\mathrm{a}$ & $\mathrm{a}$ & $\mathrm{a}$ & 0.165 & $\mathrm{a}$ \\
\hline AJ13-6-115AS & 19 & 980 & 470 & 50.1 & 0.70 & 1.67 & 0.500 & 1.86 & 7.81 & 31.3 & 14.5 & 2.12 & 3.25 & 3.7 \\
\hline AJ13-6-116AS & 20 & 559 & 204 & 31.3 & 1.05 & 3.05 & 0.347 & 1.39 & 6.12 & 32.2 & 10.2 & 1.48 & 1.77 & 3.0 \\
\hline AJ13-6-117AS & 21 & 911 & 298 & 76.6 & 0.36 & 0.563 & 0.227 & 0.469 & 2.06 & 9.44 & 18.2 & 2.71 & 4.54 & $\mathrm{a}$ \\
\hline AJ13-6-118AS & 22 & 869 & 322 & 56.5 & 0.79 & 2.69 & 0.306 & 2.01 & 8.39 & 30.2 & 15.9 & 2.33 & 5.47 & 3.2 \\
\hline AJ13-6-119AS & 23 & 1200 & 580 & 55.2 & 0.73 & 2.84 & 0.400 & 2.31 & 9.88 & 54.0 & 16.8 & 2.42 & 3.87 & 5.6 \\
\hline AJ13-6-120AS & control & $\mathrm{a}$ & $\mathrm{a}$ & $\mathrm{a}$ & 0.20 & $\mathrm{a}$ & $\mathrm{a}$ & $\mathrm{a}$ & $\mathrm{a}$ & $\mathrm{a}$ & $\mathrm{a}$ & $\mathrm{a}$ & $\mathrm{a}$ & $\mathrm{a}$ \\
\hline
\end{tabular}

${ }^{\mathrm{a}}$ Element below detection limits of measuring instrument. 
Table F-15. Residue Data $\left(\mathrm{ng} / \mathrm{mm}^{2}\right)$ from SS15ZR26 Specimens Immersed in $363 \mathrm{~K}\left(90^{\circ} \mathrm{C}\right)$ Solution for 42 days.

\begin{tabular}{|c|c|c|c|c|c|c|c|c|c|c|c|c|c|c|}
\hline \multirow[b]{2}{*}{ Expt. ID } & \multirow[b]{2}{*}{ Ingot ID } & \multicolumn{4}{|c|}{ Major Elements } & \multicolumn{5}{|c|}{ Noble Metal Fission Products } & \multicolumn{4}{|c|}{ Minor Elements } \\
\hline & & $\mathrm{Fe}$ & $\mathrm{Cr}$ & $\mathrm{Ni}$ & $\mathrm{Zr}$ & $\mathrm{Nb}$ & $\mathrm{Pd}$ & $\mathrm{Rh}$ & $\mathrm{Ru}$ & Mo & $\mathrm{Mn}$ & $\mathrm{Co}$ & $\mathrm{Cu}$ & $\mathrm{V}$ \\
\hline \multicolumn{15}{|c|}{ Detection Limits not available } \\
\hline 10KCl-6-109R & 13 & 140.1 & 13.19 & 92.77 & 1.14 & 0.07 & 0.07 & 0.04 & $\mathrm{a}$ & 62.30 & 1.62 & 8.28 & 14.69 & 12.23 \\
\hline 10KCl-6-110R & 14 & 131.9 & 17.51 & 71.85 & 1.22 & 0.07 & 0.03 & 0.06 & $\mathrm{a}$ & 15.05 & 3.67 & 7.28 & 33.33 & 14.92 \\
\hline 10KCl-6-111R & 15 & 47.29 & $\bar{a}$ & 69.12 & 0.83 & $\bar{a}$ & 0.01 & $\mathrm{a}$ & $\mathrm{a}$ & 10.19 & 1.03 & 4.87 & 28.69 & 15.92 \\
\hline 10KCl-6-112R & 16 & 170.1 & 17.96 & 66.39 & 0.68 & 0.04 & 0.03 & 0.04 & $\mathrm{a}$ & 11.82 & 3.88 & 7.00 & 52.75 & 38.38 \\
\hline 10KCl-6-113R & 17 & 224.6 & 27.29 & 98.68 & 0.80 & 0.07 & 0.02 & 0.08 & $\mathrm{a}$ & 12.46 & 3.57 & 7.55 & 24.06 & $\mathrm{a}$ \\
\hline AJ13-6-115R & 19 & 3547.1 & 1236.9 & 545.7 & 1.19 & 1.60 & 0.25 & 2.10 & 5.99 & 58.66 & 27.38 & 9.50 & 55.48 & 11.01 \\
\hline AJ13-6-116R & 20 & 2296.5 & 736.7 & 586.6 & 1.01 & 1.19 & 0.16 & 1.19 & 3.62 & 66.39 & 21.74 & 8.50 & 45.48 & 18.44 \\
\hline AJ13-6-117R & 21 & 3365.2 & 1118.7 & 532.1 & 0.75 & 1.00 & 0.12 & 0.81 & 2.24 & 39.61 & 27.69 & 8.78 & 45.93 & 19.51 \\
\hline AJ13-6-118R & 22 & 3001.4 & 1045.9 & 591.2 & 0.76 & 1.07 & 0.13 & 1.06 & 2.99 & 55.48 & 26.88 & 8.32 & 54.12 & 19.20 \\
\hline AJ13-6-119R & 23 & 3137.8 & 809.5 & 654.8 & 1.33 & 0.70 & 0.11 & 0.77 & 2.21 & 81.86 & 28.97 & 9.69 & 69.12 & 20.30 \\
\hline
\end{tabular}

${ }^{\mathrm{a}}$ Element below detection limits of measuring instrument. 
Table F-16. Leachate Data $\left(\mathrm{ng} / \mathrm{mm}^{2}\right)$ from SS15ZR26 Specimens Immersed in $363 \mathrm{~K}\left(90^{\circ} \mathrm{C}\right)$ Solution for 56 days.

\begin{tabular}{|c|c|c|c|c|c|c|c|c|c|c|c|c|c|c|}
\hline \multirow[b]{2}{*}{ Expt. ID } & \multirow[b]{2}{*}{ Ingot ID } & \multicolumn{4}{|c|}{ Major Elements } & \multicolumn{5}{|c|}{ Noble Metal Fission Products } & \multicolumn{4}{|c|}{ Minor Elements } \\
\hline & & $\mathrm{Fe}$ & $\mathrm{Cr}$ & $\mathrm{Ni}$ & $\mathrm{Zr}$ & $\mathrm{Nb}$ & $\mathrm{Pd}$ & $\mathrm{Rh}$ & $\mathrm{Ru}$ & Mo & $\mathrm{Mn}$ & $\mathrm{Co}$ & $\mathrm{Cu}$ & $\mathrm{V}$ \\
\hline \multicolumn{2}{|c|}{ Detection Limits } & 2.0 & 2.0 & 2.0 & 0.007 & 0.010 & 0.008 & 0.006 & 0.24 & 0.073 & 0.063 & 0.009 & 1.6 & 0.40 \\
\hline SJ13-8-121 & 1 & $\mathrm{a}$ & $\mathrm{a}$ & $\mathrm{a}$ & 0.096 & $\mathrm{a}$ & $\mathrm{a}$ & $\mathrm{a}$ & $\mathrm{a}$ & 0.336 & $\mathrm{a}$ & $\mathrm{a}$ & $\mathrm{a}$ & $\mathrm{a}$ \\
\hline SJ13-8-122 & 2 & $\bar{a}$ & $\bar{a}$ & $\bar{a}$ & 0.116 & $\mathrm{a}$ & $\bar{a}$ & $\mathrm{a}$ & $\mathrm{a}$ & 0.092 & $\bar{a}$ & $\bar{a}$ & $\bar{a}$ & $\mathrm{a}$ \\
\hline SJ13-8-123 & 3 & $\mathrm{a}$ & $\mathrm{a}$ & $\mathrm{a}$ & 0.125 & $\mathrm{a}$ & $\mathrm{a}$ & $\mathrm{a}$ & $\mathrm{a}$ & 0.809 & $\mathrm{a}$ & $\mathrm{a}$ & $\mathrm{a}$ & $\mathrm{a}$ \\
\hline SJ13-8-124 & 4 & $\bar{a}$ & $\bar{a}$ & $\mathrm{a}$ & 0.077 & $\mathrm{a}$ & $\mathrm{a}$ & $\bar{a}$ & $\mathrm{a}$ & 0.154 & $\bar{a}$ & $\bar{a}$ & $\mathrm{a}$ & $\mathrm{a}$ \\
\hline SJ13-8-125 & 5 & $\mathrm{a}$ & $\mathrm{a}$ & $\mathrm{a}$ & 0.082 & $\mathrm{a}$ & $\mathrm{a}$ & $\mathrm{a}$ & $\mathrm{a}$ & 0.104 & $\mathrm{a}$ & $\mathrm{a}$ & $\mathrm{a}$ & $\mathrm{a}$ \\
\hline SJ13-8-126 & control & $\bar{a}$ & $\bar{a}$ & $\bar{a}$ & 0.143 & $\bar{a}$ & $\mathrm{a}$ & $\bar{a}$ & $\bar{a}$ & $\mathrm{a}$ & $\bar{a}$ & $\bar{a}$ & $\bar{a}$ & $\mathrm{a}$ \\
\hline CJ13-8-127 & 7 & $\mathrm{a}$ & $\mathrm{a}$ & $\mathrm{a}$ & 1.32 & 0.030 & 0.061 & 0.009 & $\mathrm{a}$ & 0.624 & $\mathrm{a}$ & 0.015 & $\mathrm{a}$ & 0.43 \\
\hline CJ13-8-128 & 8 & $\mathrm{a}$ & $\mathrm{a}$ & $\mathrm{a}$ & 1.31 & 0.029 & 0.068 & 0.010 & $\mathrm{a}$ & 1.06 & $\mathrm{a}$ & 0.023 & $\mathrm{a}$ & 0.73 \\
\hline CJ13-8-129 & 9 & $\mathrm{a}$ & $\mathrm{a}$ & $\mathrm{a}$ & 1.37 & 0.029 & 0.075 & 0.012 & $\mathrm{a}$ & 0.886 & 0.078 & 0.028 & 2.4 & 0.43 \\
\hline CJ13-8-130 & 10 & $\bar{a}$ & $\bar{a}$ & $\mathrm{a}$ & 1.10 & $\mathrm{a}$ & 0.065 & $\bar{a}$ & $\bar{a}$ & 0.732 & $\bar{a}$ & 0.020 & $\mathrm{a}$ & $\mathrm{a}$ \\
\hline CJ13-8-131 & 11 & $\mathrm{a}$ & $\mathrm{a}$ & $\mathrm{a}$ & 1.13 & $\mathrm{a}$ & 0.064 & $\mathrm{a}$ & $\mathrm{a}$ & 1.39 & $\mathrm{a}$ & 0.020 & $\mathrm{a}$ & $\mathrm{a}$ \\
\hline CJ13-8-132 & control & $\bar{a}$ & $\bar{a}$ & $\mathrm{a}$ & 1.08 & $\mathrm{a}$ & 0.060 & $\bar{a}$ & $\mathrm{a}$ & 0.421 & $\bar{a}$ & 0.020 & $\mathrm{a}$ & $\mathrm{a}$ \\
\hline $10 \mathrm{KCl}-8-133$ & 13 & $\mathrm{a}$ & 3.1 & 17.4 & 0.017 & $a$ & 0.112 & 0.008 & $\mathrm{a}$ & 2.70 & 6.03 & 0.975 & 1.7 & 2.36 \\
\hline $10 \mathrm{KCl}-8-134$ & 14 & $\bar{a}$ & $\mathrm{a}$ & 6.1 & 0.008 & $\mathrm{a}$ & 0.118 & 0.006 & $\bar{a}$ & 1.26 & 2.51 & 0.371 & $\mathrm{a}$ & 2.61 \\
\hline $10 \mathrm{KCl}-8-135$ & 15 & $\mathrm{a}$ & $\mathrm{a}$ & 4.2 & 0.138 & $\mathrm{a}$ & 0.110 & $\mathrm{a}$ & $\mathrm{a}$ & 1.13 & 1.41 & 0.256 & $\mathrm{a}$ & 2.82 \\
\hline $10 \mathrm{KCl}-8-136$ & 16 & $\bar{a}$ & 8.2 & 16.3 & 0.009 & 0.013 & 0.149 & 0.011 & $\bar{a}$ & 4.50 & 6.53 & 1.20 & $\bar{a}$ & 2.93 \\
\hline $10 \mathrm{KCl}-8-137$ & 17 & $\mathrm{a}$ & $\mathrm{a}$ & 11.3 & 0.012 & $\mathrm{a}$ & 0.118 & 0.007 & $\mathrm{a}$ & 1.91 & 5.68 & 0.839 & 2.1 & 2.88 \\
\hline $10 \mathrm{KCl}-8-138$ & control & $\mathrm{a}$ & $\mathrm{a}$ & $\mathrm{a}$ & $\mathrm{a}$ & $\mathrm{a}$ & 0.101 & $\mathrm{a}$ & $\mathrm{a}$ & 0.602 & $\mathrm{a}$ & 0.027 & $\mathrm{a}$ & 2.87 \\
\hline AJ13-8-139 & 19 & 12690 & 823 & 1309 & 0.165 & 0.719 & 0.219 & 1.44 & 5.43 & 4.27 & 470 & 72.6 & 81.8 & 1.51 \\
\hline AJ13-8-140 & 20 & 15960 & 600 & 1281 & 0.137 & 0.635 & 0.205 & 1.50 & 5.49 & 2.02 & 442 & 50.5 & 58.1 & 1.14 \\
\hline AJ13-8-1 & 21 & 18155 & 3002 & 1461 & 0.084 & 0.188 & 0.085 & 0.310 & 1.02 & 75.4 & 417 & 51.1 & 32.6 & 9.47 \\
\hline AJ13-8-2 & 22 & 19492 & 4363 & 1791 & 0.700 & 3.31 & 0.139 & 1.55 & 6.99 & 137 & 462 & 49.5 & 54.0 & 17.7 \\
\hline AJ13-8-3 & 23 & 15703 & 3141 & 1700 & 1.35 & 5.82 & 0.333 & 3.72 & 16.7 & 98.6 & 494 & 60.3 & 72.5 & 10.6 \\
\hline AJ13-8-4 & control & $\mathrm{a}$ & $\mathrm{a}$ & $\mathrm{a}$ & 0.639 & 4.71 & 0.477 & 5.29 & 21.2 & 0.127 & $\mathrm{a}$ & 62.3 & 96.5 & $\mathrm{a}$ \\
\hline
\end{tabular}

${ }^{\mathrm{a}}$ Element below detection limits of measuring instrument. 
Table F-17. Acid Strip Data $\left(\mathrm{ng} / \mathrm{mm}^{2}\right)$ from SS15ZR26 Specimens Immersed in $363 \mathrm{~K}\left(90^{\circ} \mathrm{C}\right)$ Solution for 56 days.

\begin{tabular}{|c|c|c|c|c|c|c|c|c|c|c|c|c|c|c|}
\hline \multirow[b]{2}{*}{ Expt. ID } & \multirow[b]{2}{*}{ Ingot ID } & \multicolumn{4}{|c|}{ Major Elements } & \multicolumn{5}{|c|}{ Noble Metal Fission Products } & \multicolumn{4}{|c|}{ Minor Elements } \\
\hline & & $\mathrm{Fe}$ & $\mathrm{Cr}$ & $\mathrm{Ni}$ & $\mathrm{Zr}$ & $\mathrm{Nb}$ & $\mathrm{Pd}$ & $\mathrm{Rh}$ & $\mathrm{Ru}$ & Mo & $\mathrm{Mn}$ & $\mathrm{Co}$ & $\mathrm{Cu}$ & $\mathrm{V}$ \\
\hline \multicolumn{2}{|c|}{ Detection Limits } & 2.2 & 2.2 & 2.2 & 0.008 & 0.011 & 0.009 & 0.007 & 0.27 & 0.081 & 0.070 & 0.010 & 1.8 & 0.44 \\
\hline SJ13-8-121AS & 1 & $\mathrm{a}$ & $\mathrm{a}$ & $\mathrm{a}$ & 0.261 & $\mathrm{a}$ & $\mathrm{a}$ & $\mathrm{a}$ & $\mathrm{a}$ & $\mathrm{a}$ & $\mathrm{a}$ & $\mathrm{a}$ & $\mathrm{a}$ & $\mathrm{a}$ \\
\hline SJ13-8-122AS & 2 & $\bar{a}$ & $\mathrm{a}$ & $\bar{a}$ & 0.318 & $\bar{a}$ & $\bar{a}$ & $\bar{a}$ & $\bar{a}$ & $\bar{a}$ & 0.093 & $\bar{a}$ & $\bar{a}$ & $\mathrm{a}$ \\
\hline SJ13-8-123AS & 3 & $\mathrm{a}$ & $\mathrm{a}$ & $\mathrm{a}$ & 0.231 & $\mathrm{a}$ & $\mathrm{a}$ & $\mathrm{a}$ & $\mathrm{a}$ & $\mathrm{a}$ & $\mathrm{a}$ & $\mathrm{a}$ & $\mathrm{a}$ & $\mathrm{a}$ \\
\hline SJ13-8-124AS & 4 & $\bar{a}$ & $\bar{a}$ & $\mathrm{a}$ & 0.351 & $\mathrm{a}$ & $\mathrm{a}$ & $\mathrm{a}$ & $\mathrm{a}$ & $\mathrm{a}$ & $\mathrm{a}$ & $\mathrm{a}$ & $\mathrm{a}$ & $\mathrm{a}$ \\
\hline SJ13-8-125AS & 5 & $\mathrm{a}$ & $\mathrm{a}$ & $\mathrm{a}$ & 0.308 & $\mathrm{a}$ & $\mathrm{a}$ & $\mathrm{a}$ & $\mathrm{a}$ & $\mathrm{a}$ & $\mathrm{a}$ & $\mathrm{a}$ & $\mathrm{a}$ & $\mathrm{a}$ \\
\hline SJ13-8-126AS & control & $\bar{a}$ & $\bar{a}$ & $\bar{a}$ & 0.563 & $\bar{a}$ & $\bar{a}$ & $\bar{a}$ & $\bar{a}$ & $\bar{a}$ & $\bar{a}$ & 0.011 & $\bar{a}$ & $\mathrm{a}$ \\
\hline CJ13-8-127AS & 7 & $\mathrm{a}$ & $\mathrm{a}$ & $\mathrm{a}$ & 0.034 & $\mathrm{a}$ & $\mathrm{a}$ & $\mathrm{a}$ & $\mathrm{a}$ & $\mathrm{a}$ & $\mathrm{a}$ & $\mathrm{a}$ & $\mathrm{a}$ & $\mathrm{a}$ \\
\hline CJ13-8-128AS & 8 & $\mathrm{a}$ & $\mathrm{a}$ & $\mathrm{a}$ & 0.022 & $\mathrm{a}$ & $\mathrm{a}$ & $\mathrm{a}$ & $\mathrm{a}$ & $\mathrm{a}$ & $\mathrm{a}$ & $\mathrm{a}$ & $\mathrm{a}$ & $\mathrm{a}$ \\
\hline CJ13-8-129AS & 9 & $\mathrm{a}$ & $\mathrm{a}$ & $\mathrm{a}$ & 0.116 & $\mathrm{a}$ & $\mathrm{a}$ & $\mathrm{a}$ & $\mathrm{a}$ & 0.509 & $\mathrm{a}$ & 0.013 & $\mathrm{a}$ & $\mathrm{a}$ \\
\hline CJ13-8-130AS & 10 & $\bar{a}$ & $\mathrm{a}$ & $\mathrm{a}$ & 0.061 & $\mathrm{a}$ & 0.013 & $\mathrm{a}$ & $\mathrm{a}$ & $\mathrm{a}$ & $\mathrm{a}$ & $\bar{a}$ & $\mathrm{a}$ & $\mathrm{a}$ \\
\hline CJ13-8-131AS & 11 & $\mathrm{a}$ & $\mathrm{a}$ & $\mathrm{a}$ & 0.025 & $\mathrm{a}$ & $\mathrm{a}$ & $\mathrm{a}$ & $\mathrm{a}$ & 0.149 & $\mathrm{a}$ & $\mathrm{a}$ & $\mathrm{a}$ & $\mathrm{a}$ \\
\hline CJ13-8-132AS & control & $\mathrm{a}$ & $\mathrm{a}$ & $\mathrm{a}$ & 0.023 & $\mathrm{a}$ & $\mathrm{a}$ & $\mathrm{a}$ & $\mathrm{a}$ & $\mathrm{a}$ & $\mathrm{a}$ & $\mathrm{a}$ & $\mathrm{a}$ & $\mathrm{a}$ \\
\hline $10 \mathrm{KCl}-8-133 \mathrm{AS}$ & 13 & 34.6 & 13.4 & 3.4 & 0.023 & 0.024 & $\mathrm{a}$ & 0.016 & $\mathrm{a}$ & 0.249 & 1.59 & 0.144 & $\mathrm{a}$ & $\mathrm{a}$ \\
\hline $10 \mathrm{KCl}-8-134 \mathrm{AS}$ & 14 & 20.6 & 6.9 & $\mathrm{a}$ & 0.018 & 0.024 & $\mathrm{a}$ & 0.011 & $\mathrm{a}$ & 0.127 & 0.317 & 0.039 & $\mathrm{a}$ & $\mathrm{a}$ \\
\hline $10 \mathrm{KCl}-8-135 \mathrm{AS}$ & 15 & 10.3 & 2.3 & $\mathrm{a}$ & 0.039 & 0.014 & $\mathrm{a}$ & $\mathrm{a}$ & $\mathrm{a}$ & 0.108 & $\mathrm{a}$ & $\mathrm{a}$ & $\mathrm{a}$ & $\mathrm{a}$ \\
\hline $10 \mathrm{KCl}-8-136 \mathrm{AS}$ & 16 & 61.4 & 23.7 & 7.5 & 0.026 & 0.072 & 0.014 & 0.080 & 0.31 & 0.461 & 3.87 & 0.299 & 1.8 & $\mathrm{a}$ \\
\hline $10 \mathrm{KCl}-8-137 \mathrm{AS}$ & 17 & 67.7 & 21.1 & 6.7 & 0.061 & 0.045 & $\mathrm{a}$ & 0.040 & $\mathrm{a}$ & 0.328 & 1.79 & 0.228 & $\mathrm{a}$ & $\mathrm{a}$ \\
\hline $10 \mathrm{KCl}-8-138 \mathrm{AS}$ & control & $\mathrm{a}$ & $\mathrm{a}$ & $\mathrm{a}$ & 0.012 & $\mathrm{a}$ & $\mathrm{a}$ & $\mathrm{a}$ & $\mathrm{a}$ & $\mathrm{a}$ & $\mathrm{a}$ & $\mathrm{a}$ & $\mathrm{a}$ & $\mathrm{a}$ \\
\hline AJ13-8-139AS & 19 & 951 & 386 & 15.7 & 0.487 & 0.493 & 0.349 & 2.47 & 10.1 & 5.54 & 5.48 & 0.819 & $\mathrm{a}$ & 2.34 \\
\hline AJ13-8-140AS & 20 & 1928 & 578 & 52.0 & 0.943 & 0.361 & 0.345 & 1.97 & 8.27 & 5.95 & 18.4 & 2.77 & 1.9 & 3.00 \\
\hline AJ13-8-1AS & 21 & 282 & 112 & 16.5 & 0.332 & 0.819 & 0.137 & 0.275 & 1.26 & 11.2 & 4.73 & 0.733 & $\mathrm{a}$ & 1.41 \\
\hline AJ13-8-2AS & 22 & 525 & 166 & 44.8 & 0.339 & 0.579 & 0.185 & 0.302 & 1.38 & 8.73 & 11.6 & 1.80 & 2.1 & 1.05 \\
\hline AJ13-8-3AS & 23 & 620 & 227 & 51.6 & 0.353 & 0.623 & 0.477 & 0.816 & 3.41 & 9.73 & 15.6 & 2.36 & 3.7 & 1.50 \\
\hline AJ13-8-4AS & control & $\mathrm{a}$ & $\mathrm{a}$ & $\mathrm{a}$ & 0.149 & $\mathrm{a}$ & $\mathrm{a}$ & $\mathrm{a}$ & $\mathrm{a}$ & 0.103 & $\mathrm{a}$ & $\mathrm{a}$ & $\mathrm{a}$ & $\mathrm{a}$ \\
\hline
\end{tabular}

${ }^{\mathrm{a}}$ Element below detection limits of measuring instrument. 
Table F-18. Residue Data $\left(\mathrm{ng} / \mathrm{mm}^{2}\right)$ from SS15ZR26 Specimens Immersed in $363 \mathrm{~K}\left(90^{\circ} \mathrm{C}\right)$ Solution for 56 days.

\begin{tabular}{|c|c|c|c|c|c|c|c|c|c|c|c|c|c|c|}
\hline \multirow[b]{2}{*}{ Expt. ID } & \multirow[b]{2}{*}{ Ingot ID } & \multicolumn{4}{|c|}{ Major Elements } & \multicolumn{5}{|c|}{ Noble Metal Fission Products } & \multicolumn{4}{|c|}{ Minor Elements } \\
\hline & & $\mathrm{Fe}$ & $\mathrm{Cr}$ & $\mathrm{Ni}$ & $\mathrm{Zr}$ & $\mathrm{Nb}$ & $\mathrm{Pd}$ & $\mathrm{Rh}$ & $\mathrm{Ru}$ & Mo & $\mathrm{Mn}$ & $\mathrm{Co}$ & $\mathrm{Cu}$ & $\mathrm{V}$ \\
\hline \multicolumn{15}{|c|}{ Detection Limits not available } \\
\hline $10 \mathrm{KCl}-8-133 \mathrm{R}$ & 13 & 119.1 & 21.33 & 4.91 & 1.96 & 0.07 & $\mathrm{a}$ & 0.06 & $\mathrm{a}$ & 19.58 & 2.18 & 2.73 & 9.22 & 11.46 \\
\hline $10 \mathrm{KCl}-8-134 \mathrm{R}$ & 14 & 37.70 & $\mathrm{a}$ & $\mathrm{a}$ & 1.06 & $\mathrm{a}$ & $\mathrm{a}$ & $\mathrm{a}$ & $\mathrm{a}$ & 9.44 & 0.74 & 2.43 & 5.14 & 10.45 \\
\hline $10 \mathrm{KCl}-8-135 \mathrm{R}$ & 15 & 25.69 & $\mathrm{a}$ & $\mathrm{a}$ & 0.90 & $\mathrm{a}$ & $\mathrm{a}$ & $\mathrm{a}$ & $\mathrm{a}$ & 8.35 & $\mathrm{a}$ & 3.26 & 4.94 & 11.75 \\
\hline $10 \mathrm{KCl}-8-136 \mathrm{R}$ & 16 & 150.1 & 18.28 & 5.73 & 1.06 & 0.08 & $\bar{a}$ & 0.12 & $\mathrm{a}$ & 10.72 & 2.72 & 2.98 & 6.58 & 12.79 \\
\hline $10 \mathrm{KCl}-8-137 \mathrm{R}$ & 17 & 88.22 & 19.05 & 6.37 & 1.17 & 0.05 & $\mathrm{a}$ & 0.05 & $\mathrm{a}$ & 8.28 & 1.39 & 2.38 & 6.45 & 12.96 \\
\hline AJ13-8-139R & 19 & 3801.7 & 715.3 & 182.4 & 2.30 & 2.06 & 0.24 & 2.61 & 7.18 & 53.67 & 55.38 & 15.06 & 26.94 & 26.53 \\
\hline AJ13-8-140R & 20 & 3483.4 & 464.8 & 188.7 & 2.05 & 0.82 & 0.14 & 1.00 & 2.87 & 33.20 & 58.35 & 14.00 & 19.31 & 34.52 \\
\hline AJ13-8-1R & 21 & 3033.2 & 754.0 & 224.2 & 1.75 & 1.56 & 0.10 & 0.75 & 2.16 & 55.54 & 54.92 & 9.43 & 21.40 & 47.69 \\
\hline AJ13-8-2R & 22 & 3628.9 & 1282.4 & 246.5 & 2.02 & 2.34 & 0.22 & 2.15 & 5.89 & 87.96 & 59.72 & 13.40 & 24.83 & 55.00 \\
\hline AJ13-8-3R & 23 & 3774.4 & 1227.8 & 259.7 & 2.20 & 2.31 & 0.22 & 2.18 & 5.60 & 84.49 & 63.25 & 14.08 & 22.87 & 56.53 \\
\hline
\end{tabular}

${ }^{\mathrm{a}}$ Element below detection limits of measuring instrument. 
Table F-19. Leachate Data $\left(\mathrm{ng} / \mathrm{mm}^{2}\right)$ from SS15ZR26 Specimens Immersed in $363 \mathrm{~K}\left(90^{\circ} \mathrm{C}\right)$ Solution for 70 days.

\begin{tabular}{|c|c|c|c|c|c|c|c|c|c|c|c|c|c|c|}
\hline \multirow[b]{2}{*}{ Expt. ID } & \multirow[b]{2}{*}{ Ingot ID } & \multicolumn{4}{|c|}{ Major Elements } & \multicolumn{5}{|c|}{ Noble Metal Fission Products } & \multicolumn{4}{|c|}{ Minor Elements } \\
\hline & & $\mathrm{Fe}$ & $\mathrm{Cr}$ & $\mathrm{Ni}$ & $\mathrm{Zr}$ & $\mathrm{Nb}$ & $\mathrm{Pd}$ & $\mathrm{Rh}$ & $\mathrm{Ru}$ & Mo & $\mathrm{Mn}$ & $\mathrm{Co}$ & $\mathrm{Cu}$ & $\mathrm{V}$ \\
\hline \multicolumn{2}{|c|}{ Detection Limits } & 2.0 & 2.0 & 2.0 & 0.010 & 0.008 & 0.004 & 0.003 & 0.24 & 0.052 & 0.087 & 0.090 & 0.10 & 0.024 \\
\hline SJ13-10-141 & 1 & $\mathrm{a}$ & $\mathrm{a}$ & $\mathrm{a}$ & 0.210 & $\mathrm{a}$ & $\mathrm{a}$ & $\mathrm{a}$ & $\mathrm{a}$ & 0.234 & $\mathrm{a}$ & $\mathrm{a}$ & $\mathrm{a}$ & 0.161 \\
\hline SJ13-10-142 & 2 & $\bar{a}$ & $\bar{a}$ & $\mathrm{a}$ & 0.101 & $\mathrm{a}$ & $\bar{a}$ & $\bar{a}$ & $\bar{a}$ & $\mathrm{a}$ & $\bar{a}$ & $\bar{a}$ & $\mathrm{a}$ & 0.108 \\
\hline SJ13-10-143 & 3 & $\mathrm{a}$ & $\mathrm{a}$ & $\mathrm{a}$ & 0.072 & $\mathrm{a}$ & $\mathrm{a}$ & $\mathrm{a}$ & $\mathrm{a}$ & 0.057 & $\mathrm{a}$ & $\mathrm{a}$ & $\mathrm{a}$ & 0.087 \\
\hline SJ13-10-144 & 4 & $\mathrm{a}$ & $\bar{a}$ & $\mathrm{a}$ & 0.115 & $\mathrm{a}$ & $\mathrm{a}$ & $\mathrm{a}$ & $\mathrm{a}$ & 0.065 & $\mathrm{a}$ & $\mathrm{a}$ & $\mathrm{a}$ & 0.065 \\
\hline SJ13-10-145 & 5 & $\mathrm{a}$ & $\mathrm{a}$ & $\mathrm{a}$ & 0.071 & $\mathrm{a}$ & $\mathrm{a}$ & $\mathrm{a}$ & $\mathrm{a}$ & 0.066 & $\mathrm{a}$ & $\mathrm{a}$ & $\mathrm{a}$ & 0.047 \\
\hline SJ13-10-146 & control & $\bar{a}$ & $\bar{a}$ & $\bar{a}$ & 0.185 & $\bar{a}$ & $\bar{a}$ & $\bar{a}$ & $\bar{a}$ & $\bar{a}$ & $\bar{a}$ & $\mathrm{a}$ & $\bar{a}$ & 0.037 \\
\hline CJ13-10-147 & 7 & $\mathrm{a}$ & $\mathrm{a}$ & $\mathrm{a}$ & 0.943 & 0.018 & 0.079 & 0.005 & $\mathrm{a}$ & 0.329 & $\mathrm{a}$ & $\mathrm{a}$ & 0.18 & 0.429 \\
\hline CJ13-10-148 & 8 & $\mathrm{a}$ & $\mathrm{a}$ & $\mathrm{a}$ & 0.991 & 0.020 & 0.116 & 0.009 & $\mathrm{a}$ & 0.343 & $\mathrm{a}$ & $\mathrm{a}$ & 0.23 & 0.376 \\
\hline CJ13-10-149 & 9 & $\mathrm{a}$ & $\mathrm{a}$ & $\mathrm{a}$ & 1.17 & 0.026 & 0.153 & 0.008 & $\mathrm{a}$ & 0.629 & $\mathrm{a}$ & $\mathrm{a}$ & 0.20 & 0.395 \\
\hline CJ13-10-150 & 10 & $\mathrm{a}$ & $\mathrm{a}$ & $\mathrm{a}$ & 1.03 & 0.010 & 0.149 & 0.004 & $\mathrm{a}$ & 0.321 & $\mathrm{a}$ & $\mathrm{a}$ & 0.20 & 0.419 \\
\hline CJ13-10-151 & 11 & $\mathrm{a}$ & $\mathrm{a}$ & $\mathrm{a}$ & 0.945 & 0.009 & 0.143 & 0.004 & $\mathrm{a}$ & 0.353 & $\mathrm{a}$ & $\mathrm{a}$ & 0.26 & 0.416 \\
\hline CJ13-10-152 & control & $\mathrm{a}$ & $\mathrm{a}$ & $\mathrm{a}$ & 0.716 & $\mathrm{a}$ & 0.122 & 0.004 & $\mathrm{a}$ & 0.294 & $\mathrm{a}$ & $\mathrm{a}$ & 0.17 & 0.414 \\
\hline $10 \mathrm{KCl}-10-153$ & 13 & $\mathrm{a}$ & $\mathrm{a}$ & 6.2 & 0.034 & $\mathrm{a}$ & 0.118 & $a$ & $\mathrm{a}$ & 0.735 & 2.34 & 0.32 & 0.46 & 3.26 \\
\hline $10 \mathrm{KCl}-10-154$ & 14 & $\mathrm{a}$ & $\mathrm{a}$ & 6.1 & $\mathrm{a}$ & $\mathrm{a}$ & 0.139 & 0.003 & $\mathrm{a}$ & 1.45 & 1.75 & 0.23 & 0.52 & 2.63 \\
\hline $10 \mathrm{KCl}-10-155$ & 15 & $\mathrm{a}$ & 2.1 & $\mathrm{a}$ & $\mathrm{a}$ & $\mathrm{a}$ & 0.146 & $\mathrm{a}$ & $\mathrm{a}$ & 0.951 & 0.36 & $\mathrm{a}$ & 0.39 & 2.72 \\
\hline $10 \mathrm{KCl}-10-156$ & 16 & $\bar{a}$ & 5.2 & 14.5 & $\mathrm{a}$ & $\mathrm{a}$ & 0.187 & 0.004 & $\bar{a}$ & 3.90 & 5.69 & 0.75 & 0.91 & 2.96 \\
\hline $10 \mathrm{KCl}-10-157$ & 17 & $\mathrm{a}$ & $\mathrm{a}$ & 21.6 & $\mathrm{a}$ & $\mathrm{a}$ & 0.148 & 0.004 & $\mathrm{a}$ & 1.65 & 7.91 & 1.09 & 0.63 & 2.84 \\
\hline $10 \mathrm{KCl}-10-158$ & control & $\mathrm{a}$ & $\mathrm{a}$ & $\mathrm{a}$ & $\mathrm{a}$ & $\mathrm{a}$ & $\mathrm{a}$ & $\mathrm{a}$ & $\mathrm{a}$ & 0.050 & $\mathrm{a}$ & $\mathrm{a}$ & $\mathrm{a}$ & $\mathrm{a}$ \\
\hline AJ13-10-159 & 19 & 13849 & 1247 & 1279 & 0.308 & 0.906 & 0.329 & 2.16 & 8.17 & 5.72 & 440 & 49.4 & 77.8 & 2.53 \\
\hline AJ13-10-160 & 20 & 18248 & 5005 & 1249 & 8.32 & 6.14 & 0.509 & 3.96 & 19.0 & 191 & 407 & 47.3 & 93.3 & 16.5 \\
\hline AJ-13-10-5 & 21 & 18130 & 1057 & 1410 & $\mathrm{a}$ & $\mathrm{a}$ & 0.012 & 0.050 & 0.076 & 0.366 & 438 & 49.3 & 23.3 & 1.09 \\
\hline AJ-13-10-6 & 22 & 18672 & 4360 & 1581 & 1.39 & 6.94 & 0.430 & 3.26 & 14.2 & 98.6 & 432 & 50.6 & 59.1 & 16.6 \\
\hline AJ-13-10-7 & 23 & 18723 & 4908 & 1449 & 1.17 & 7.72 & 0.562 & 7.05 & 28.6 & 128 & 436 & 51.9 & 110 & 17.3 \\
\hline AJ-13-10-8 & control & $\mathrm{a}$ & $\mathrm{a}$ & $\mathrm{a}$ & 0.107 & $\mathrm{a}$ & $\mathrm{a}$ & $\mathrm{a}$ & $\mathrm{a}$ & 0.060 & $\mathrm{a}$ & $\mathrm{a}$ & $\mathrm{a}$ & $\mathrm{a}$ \\
\hline
\end{tabular}

${ }^{\mathrm{a}}$ Element below detection limits of measuring instrument. 
Table F-20. Acid Strip Data $\left(\mathrm{ng} / \mathrm{mm}^{2}\right)$ from SS15ZR26 Specimens Immersed in $363 \mathrm{~K}\left(90^{\circ} \mathrm{C}\right)$ Solution for 70 days.

\begin{tabular}{|c|c|c|c|c|c|c|c|c|c|c|c|c|c|c|}
\hline \multirow[b]{2}{*}{ Expt. ID } & \multirow[b]{2}{*}{ Ingot ID } & \multicolumn{4}{|c|}{ Major Elements } & \multicolumn{5}{|c|}{ Noble Metal Fission Products } & \multicolumn{4}{|c|}{ Minor Elements } \\
\hline & & $\mathrm{Fe}$ & $\mathrm{Cr}$ & $\mathrm{Ni}$ & $\mathrm{Zr}$ & $\mathrm{Nb}$ & $\mathrm{Pd}$ & $\mathrm{Rh}$ & $\mathrm{Ru}$ & Mo & $\mathrm{Mn}$ & $\mathrm{Co}$ & $\mathrm{Cu}$ & $\mathrm{V}$ \\
\hline \multicolumn{2}{|c|}{ Detection Limits } & 2.2 & 2.2 & 2.2 & 0.011 & 0.009 & 0.004 & 0.003 & 0.27 & 0.056 & 0.094 & 0.10 & 0.11 & 0.027 \\
\hline SJ13-10-141AS & 1 & 4.3 & $\bar{a}$ & $\bar{a}$ & 0.202 & $\mathrm{a}$ & $\bar{a}$ & $\bar{a}$ & $\mathrm{a}$ & 0.117 & $\bar{a}$ & $\bar{a}$ & 0.33 & $\bar{a}$ \\
\hline SJ13-10-142AS & 2 & 2.8 & $\mathrm{a}$ & $\mathrm{a}$ & 0.347 & $\mathrm{a}$ & $\mathrm{a}$ & $\mathrm{a}$ & $\mathrm{a}$ & $\mathrm{a}$ & $\mathrm{a}$ & $\mathrm{a}$ & $\mathrm{a}$ & $\mathrm{a}$ \\
\hline SJ13-10-143AS & 3 & 3.4 & $\mathrm{a}$ & $\bar{a}$ & 0.259 & $\bar{a}$ & $\mathrm{a}$ & $\mathrm{a}$ & $\mathrm{a}$ & 0.062 & $\bar{a}$ & $\bar{a}$ & $\bar{a}$ & $\bar{a}$ \\
\hline SJ13-10-144AS & 4 & $\mathrm{a}$ & $\mathrm{a}$ & $\mathrm{a}$ & 0.379 & $\mathrm{a}$ & $\mathrm{a}$ & $\mathrm{a}$ & $\mathrm{a}$ & $\mathrm{a}$ & $\mathrm{a}$ & $\mathrm{a}$ & $\mathrm{a}$ & $\mathrm{a}$ \\
\hline SJ13-10-145AS & 5 & 3.6 & $\bar{a}$ & $\mathrm{a}$ & 0.317 & $\bar{a}$ & $\bar{a}$ & $\bar{a}$ & $\mathrm{a}$ & 0.085 & $\bar{a}$ & $\bar{a}$ & $\mathrm{a}$ & $\mathrm{a}$ \\
\hline SJ13-10-146AS & control & 3.4 & $\mathrm{a}$ & $\mathrm{a}$ & 0.464 & $\mathrm{a}$ & $\mathrm{a}$ & $\mathrm{a}$ & $\mathrm{a}$ & 0.066 & $\mathrm{a}$ & $\mathrm{a}$ & $\mathrm{a}$ & $\mathrm{a}$ \\
\hline CJ13-10-147AS & 7 & $\mathrm{a}$ & $\mathrm{a}$ & $\mathrm{a}$ & 0.037 & 0.019 & 0.008 & 0.006 & $\mathrm{a}$ & 0.080 & $\mathrm{a}$ & $\mathrm{a}$ & $\mathrm{a}$ & $\mathrm{a}$ \\
\hline CJ13-10-148AS & 8 & $\mathrm{a}$ & $\mathrm{a}$ & $\mathrm{a}$ & 0.032 & $\mathrm{a}$ & $\mathrm{a}$ & $\mathrm{a}$ & $\mathrm{a}$ & $\mathrm{a}$ & $\mathrm{a}$ & $\mathrm{a}$ & 0.42 & $\mathrm{a}$ \\
\hline CJ13-10-149AS & 9 & $\mathrm{a}$ & $\mathrm{a}$ & $\mathrm{a}$ & 0.031 & $\mathrm{a}$ & $\mathrm{a}$ & $\mathrm{a}$ & $\mathrm{a}$ & $\mathrm{a}$ & $\mathrm{a}$ & $\mathrm{a}$ & $\mathrm{a}$ & $\mathrm{a}$ \\
\hline CJ13-10-150AS & 10 & $\mathrm{a}$ & $\mathrm{a}$ & $\mathrm{a}$ & 0.026 & $\mathrm{a}$ & $\mathrm{a}$ & $\mathrm{a}$ & $\mathrm{a}$ & $\mathrm{a}$ & $\mathrm{a}$ & $\mathrm{a}$ & $\mathrm{a}$ & $\mathrm{a}$ \\
\hline CJ13-10-151AS & 11 & 4.9 & $\mathrm{a}$ & $\bar{a}$ & 0.027 & $\bar{a}$ & $\mathrm{a}$ & $\mathrm{a}$ & $\mathrm{a}$ & $\mathrm{a}$ & $\bar{a}$ & $\bar{a}$ & $\bar{a}$ & $\bar{a}$ \\
\hline CJ13-10-152AS & control & 2.7 & $\mathrm{a}$ & $\mathrm{a}$ & 0.046 & $\mathrm{a}$ & $\mathrm{a}$ & $\mathrm{a}$ & $\mathrm{a}$ & $\mathrm{a}$ & $\mathrm{a}$ & $\mathrm{a}$ & $\mathrm{a}$ & $\mathrm{a}$ \\
\hline $10 \mathrm{KCl}-10-153 \mathrm{AS}$ & 13 & 17.5 & 6.6 & $\mathrm{a}$ & 0.042 & 0.016 & $\mathrm{a}$ & 0.010 & $\mathrm{a}$ & 0.256 & 0.30 & $\mathrm{a}$ & $\mathrm{a}$ & $\bar{a}$ \\
\hline $10 \mathrm{KCl}-10-154 \mathrm{AS}$ & 14 & 13.5 & 6.8 & $\bar{a}$ & 0.017 & 0.032 & $\bar{a}$ & 0.019 & $\mathrm{a}$ & 0.213 & 0.15 & $\bar{a}$ & 0.29 & $\bar{a}$ \\
\hline $10 \mathrm{KCl}-10-155 \mathrm{AS}$ & 15 & $\mathrm{a}$ & $\bar{a}$ & $\bar{a}$ & $\mathrm{a}$ & $\bar{a}$ & $\bar{a}$ & $\mathrm{a}$ & $\mathrm{a}$ & $\mathrm{a}$ & $\bar{a}$ & $\bar{a}$ & $\bar{a}$ & $\bar{a}$ \\
\hline 10KCl-10-156AS & 16 & 62.2 & 28.4 & 5.5 & 0.060 & 0.067 & $\mathrm{a}$ & 0.065 & 0.21 & 0.536 & 1.56 & 0.16 & 1.46 & $\mathrm{a}$ \\
\hline 10KCl-10-157AS & 17 & 76.8 & 9.9 & 6.6 & 0.017 & 0.022 & $\mathrm{a}$ & 0.019 & $\mathrm{a}$ & 0.392 & 1.56 & 0.18 & 1.05 & $\mathrm{a}$ \\
\hline 10KCl-10-158AS & control & $\mathrm{a}$ & $\mathrm{a}$ & $\mathrm{a}$ & $\mathrm{a}$ & $\mathrm{a}$ & $\mathrm{a}$ & $\mathrm{a}$ & $\mathrm{a}$ & 0.185 & $\mathrm{a}$ & $\mathrm{a}$ & $\mathrm{a}$ & $\mathrm{a}$ \\
\hline AJ13-10-159AS & 19 & 624 & 255 & 12.2 & 0.555 & 0.404 & 0.220 & 1.87 & 7.72 & 6.55 & 3.52 & 0.48 & 0.91 & 1.66 \\
\hline AJ13-10-160AS & 20 & 209 & 91.1 & 12.9 & 0.447 & 0.774 & 0.117 & 0.445 & 1.97 & 10.7 & 3.35 & 0.49 & 1.02 & 0.86 \\
\hline AJ13-10-5AS & 21 & 788 & 156 & 38.1 & 0.365 & 0.121 & 0.046 & 0.151 & 0.65 & 2.10 & 10.2 & 1.48 & 0.78 & 1.74 \\
\hline AJ13-10-6AS & 22 & 285 & 88.3 & 19.0 & 0.289 & 0.401 & 0.166 & 0.160 & 0.69 & 5.97 & 4.67 & 0.65 & 1.89 & 0.61 \\
\hline AJ13-10-7AS & 23 & 593 & 195 & 43.9 & 0.329 & 0.741 & 0.204 & 0.918 & 3.70 & 10.6 & 11.3 & 1.68 & 3.58 & 1.27 \\
\hline AJ13-10-8AS & control & $\mathrm{a}$ & $\mathrm{a}$ & $\mathrm{a}$ & 0.138 & $\mathrm{a}$ & $\mathrm{a}$ & $\mathrm{a}$ & $\mathrm{a}$ & 0.050 & $\mathrm{a}$ & $\mathrm{a}$ & $\bar{a}$ & $\bar{a}$ \\
\hline
\end{tabular}

${ }^{\mathrm{a}}$ Element below detection limits of measuring instrument. 
Table F-21. Residue Data $\left(\mathrm{ng} / \mathrm{mm}^{2}\right)$ from SS15ZR26 Specimens Immersed in $363 \mathrm{~K}\left(90^{\circ} \mathrm{C}\right)$ Solution for 70 days.

\begin{tabular}{|c|c|c|c|c|c|c|c|c|c|c|c|c|c|c|}
\hline \multirow[b]{2}{*}{ Expt. ID } & \multirow[b]{2}{*}{ Ingot ID } & \multicolumn{4}{|c|}{ Major Elements } & \multicolumn{5}{|c|}{ Noble Metal Fission Products } & \multicolumn{4}{|c|}{ Minor Elements } \\
\hline & & $\mathrm{Fe}$ & $\mathrm{Cr}$ & $\mathrm{Ni}$ & $\mathrm{Zr}$ & $\mathrm{Nb}$ & $\mathrm{Pd}$ & $\mathrm{Rh}$ & $\mathrm{Ru}$ & Mo & $\mathrm{Mn}$ & $\mathrm{Co}$ & $\mathrm{Cu}$ & $\mathrm{V}$ \\
\hline \multicolumn{15}{|c|}{ Detection Limits not available } \\
\hline 10KCl-10-153R & 13 & 80.49 & 4.77 & $\mathrm{a}$ & 0.78 & $\mathrm{a}$ & $\mathrm{a}$ & $\mathrm{a}$ & $\mathrm{a}$ & 4.37 & 2.28 & 20.67 & 6.37 & 36.94 \\
\hline $10 \mathrm{KCl}-10-154 \mathrm{R}$ & 14 & 43.52 & $\mathrm{a}$ & $\mathrm{a}$ & 0.94 & $\mathrm{a}$ & $\mathrm{a}$ & $\mathrm{a}$ & $\mathrm{a}$ & 2.26 & 1.07 & 14.26 & 3.87 & 35.18 \\
\hline $10 \mathrm{KCl}-10-155 \mathrm{R}$ & 15 & 54.57 & $\mathrm{a}$ & $\mathrm{a}$ & 1.16 & $\mathrm{a}$ & $\mathrm{a}$ & $\mathrm{a}$ & $\mathrm{a}$ & 2.66 & 2.05 & 16.02 & 5.75 & 32.55 \\
\hline $10 \mathrm{KCl}-10-156 \mathrm{R}$ & 16 & 86.40 & 9.78 & 4.73 & 0.67 & $\mathrm{a}$ & $a$ & $\mathrm{a}$ & $a$ & 3.23 & 2.50 & 16.63 & 6.72 & 30.95 \\
\hline $10 \mathrm{KCl}-10-157 \mathrm{R}$ & 17 & 98.68 & 6.91 & 5.28 & 0.64 & $\mathrm{a}$ & $\mathrm{a}$ & $\mathrm{a}$ & $\mathrm{a}$ & 6.16 & 2.42 & 15.61 & 5.26 & 30.19 \\
\hline AJ13-10-159R & 19 & 1887.2 & 422.9 & 78.67 & 1.12 & 1.29 & 0.15 & 1.81 & 5.47 & 35.13 & 24.00 & 22.01 & 9.12 & 15.27 \\
\hline AJ13-10-160R & 20 & 1414.3 & 513.9 & 81.86 & 3.62 & 1.36 & 0.13 & 0.96 & 2.59 & 49.61 & 23.00 & 23.19 & 8.83 & 28.45 \\
\hline AJ-13-10-5R & 21 & 1614.4 & 157.3 & 102.3 & 0.59 & 0.14 & $\mathrm{a}$ & 0.07 & $\mathrm{a}$ & 7.18 & 27.81 & 19.40 & 4.34 & 27.67 \\
\hline AJ-13-10-6R & 22 & 1596.2 & 554.8 & 111.0 & 0.81 & 1.31 & 0.09 & 0.74 & 2.25 & 39.97 & 26.31 & 17.93 & 9.20 & 35.42 \\
\hline AJ-13-10-7R & 23 & 1787.2 & 627.6 & 97.77 & 0.58 & 1.44 & 0.13 & 1.38 & 4.08 & 51.09 & 26.30 & 17.60 & 10.98 & 35.66 \\
\hline
\end{tabular}

${ }^{\mathrm{a}}$ Element below detection limits of measuring instrument. 
Table F-22. Leachate Data $\left(\mathrm{ng} / \mathrm{mm}^{2}\right)$ from SS15ZR26 Specimens Immersed in 363K $\left(90^{\circ} \mathrm{C}\right)$ Solution for 98 days.

\begin{tabular}{|c|c|c|c|c|c|c|c|c|c|c|c|c|c|c|}
\hline \multirow[b]{2}{*}{ Expt. ID } & \multirow[b]{2}{*}{ Ingot ID } & \multicolumn{4}{|c|}{ Major Elements } & \multicolumn{5}{|c|}{ Noble Metal Fission Products } & \multicolumn{4}{|c|}{ Minor Elements } \\
\hline & & $\mathrm{Fe}$ & $\mathrm{Cr}$ & $\mathrm{Ni}$ & $\mathrm{Zr}$ & $\mathrm{Nb}$ & $\mathrm{Pd}$ & $\mathrm{Rh}$ & $\mathrm{Ru}$ & Mo & $\mathrm{Mn}$ & $\mathrm{Co}$ & $\mathrm{Cu}$ & $\mathrm{V}$ \\
\hline \multicolumn{2}{|c|}{ Detection Limits } & 2.0 & 2.0 & 2.0 & 0.017 & 0.011 & 0.009 & 0.005 & 0.15 & 0.043 & 0.108 & 0.089 & 0.17 & 0.29 \\
\hline SJ13-14-9 & 1 & $\mathrm{a}$ & $\mathrm{a}$ & $\mathrm{a}$ & 0.057 & $\mathrm{a}$ & $\mathrm{a}$ & $\mathrm{a}$ & $\mathrm{a}$ & 0.345 & $\mathrm{a}$ & $\mathrm{a}$ & $\mathrm{a}$ & $\mathrm{a}$ \\
\hline SJ13-14-10 & 2 & $\mathrm{a}$ & $\mathrm{a}$ & $\mathrm{a}$ & 0.055 & $\mathrm{a}$ & $\mathrm{a}$ & $\bar{a}$ & $\mathrm{a}$ & 0.170 & $\mathrm{a}$ & $\mathrm{a}$ & $\mathrm{a}$ & $\mathrm{a}$ \\
\hline SJ13-14-11 & 3 & $\mathrm{a}$ & $a$ & $\mathrm{a}$ & 0.055 & $\mathrm{a}$ & $\mathrm{a}$ & $\mathrm{a}$ & $a$ & 0.179 & $\mathrm{a}$ & $\mathrm{a}$ & 0.24 & $\bar{a}$ \\
\hline SJ13-14-12 & 4 & $\mathrm{a}$ & $\mathrm{a}$ & $\mathrm{a}$ & 0.037 & $\mathrm{a}$ & $\mathrm{a}$ & $\mathrm{a}$ & $\mathrm{a}$ & 0.122 & $\mathrm{a}$ & $\mathrm{a}$ & $\mathrm{a}$ & $\mathrm{a}$ \\
\hline SJ13-14-13 & 5 & 2.0 & $\mathrm{a}$ & $\mathrm{a}$ & 0.055 & $\mathrm{a}$ & $\mathrm{a}$ & $\mathrm{a}$ & $\mathrm{a}$ & 0.417 & $\mathrm{a}$ & $\mathrm{a}$ & $\mathrm{a}$ & $\bar{a}$ \\
\hline SJ13-14-14 & control & $\bar{a}$ & $\bar{a}$ & $\mathrm{a}$ & 0.121 & $\mathrm{a}$ & $\mathrm{a}$ & $\bar{a}$ & $\mathrm{a}$ & 0.159 & $\mathrm{a}$ & $\bar{a}$ & 0.14 & $\mathrm{a}$ \\
\hline CJ13-14-15 & 7 & $\bar{a}$ & $\bar{a}$ & $\bar{a}$ & 0.951 & $\bar{a}$ & 0.046 & 0.009 & $\bar{a}$ & 0.646 & $\bar{a}$ & $\bar{a}$ & 0.13 & 0.29 \\
\hline CJ13-14-16 & 8 & $\mathrm{a}$ & $\mathrm{a}$ & $\mathrm{a}$ & 0.999 & $\mathrm{a}$ & 0.065 & 0.007 & $\mathrm{a}$ & 0.441 & $\mathrm{a}$ & $\mathrm{a}$ & 0.19 & 0.32 \\
\hline CJ13-14-17 & 9 & $\mathrm{a}$ & $\mathrm{a}$ & $\mathrm{a}$ & 1.64 & 0.017 & 0.089 & 0.009 & $\mathrm{a}$ & 0.523 & $\mathrm{a}$ & $\mathrm{a}$ & 0.25 & 0.32 \\
\hline CJ13-14-18 & 10 & $\mathrm{a}$ & $\mathrm{a}$ & $\mathrm{a}$ & 0.953 & $\bar{a}$ & 0.056 & $\mathrm{a}$ & $\mathrm{a}$ & 0.302 & $\mathrm{a}$ & $\mathrm{a}$ & $\bar{a}$ & 0.33 \\
\hline CJ13-14-19 & 11 & $\mathrm{a}$ & $\mathrm{a}$ & $\mathrm{a}$ & 1.10 & $\mathrm{a}$ & 0.089 & 0.042 & 0.146 & 0.382 & $\mathrm{a}$ & $\mathrm{a}$ & 0.17 & 0.34 \\
\hline CJ13-14-20 & control & $\mathrm{a}$ & $\mathrm{a}$ & $\mathrm{a}$ & 6.50 & 0.632 & 0.165 & 0.081 & 0.415 & 0.460 & $\mathrm{a}$ & $\mathrm{a}$ & 0.17 & 0.36 \\
\hline $10 \mathrm{KCl}-14-21$ & 13 & $a$ & $a$ & 7.1 & 0.026 & $\mathrm{a}$ & 0.182 & 0.020 & $a$ & 0.735 & 3.05 & 0.44 & 1.19 & 2.92 \\
\hline $10 \mathrm{KCl}-14-22$ & 14 & $\mathrm{a}$ & $\mathrm{a}$ & $\mathrm{a}$ & 0.014 & $\mathrm{a}$ & 0.184 & 0.013 & $\mathrm{a}$ & 1.97 & 0.57 & $\mathrm{a}$ & 0.91 & 3.32 \\
\hline $10 \mathrm{KCl}-14-23$ & 15 & $\mathrm{a}$ & 3.2 & $\mathrm{a}$ & 0.018 & $\mathrm{a}$ & 0.142 & 0.017 & $\mathrm{a}$ & 1.021 & 0.28 & $\mathrm{a}$ & 0.54 & 2.75 \\
\hline $10 \mathrm{KCl}-14-24$ & 16 & $\mathrm{a}$ & 4.6 & 7.9 & $\mathrm{a}$ & $\mathrm{a}$ & 0.166 & 0.005 & $\mathrm{a}$ & 4.67 & 3.57 & 0.51 & 0.87 & 3.02 \\
\hline $10 \mathrm{KCl}-14-25$ & 17 & $\bar{a}$ & 7.9 & 15.7 & $\mathrm{a}$ & $\mathrm{a}$ & 0.160 & 0.005 & $\bar{a}$ & 4.42 & 3.87 & 0.72 & 0.47 & 2.98 \\
\hline $10 \mathrm{KCl}-14-26$ & control & $\mathrm{a}$ & $\mathrm{a}$ & $\mathrm{a}$ & $\mathrm{a}$ & $\mathrm{a}$ & 0.119 & $\mathrm{a}$ & $\mathrm{a}$ & 0.473 & $\mathrm{a}$ & $\mathrm{a}$ & $\mathrm{a}$ & 2.90 \\
\hline AJ13-14-27 & 19 & 7082 & 818 & 2703 & 0.127 & 0.874 & 0.195 & 2.76 & 12.6 & 7.88 & 886 & 94.1 & 119 & 1.29 \\
\hline AJ13-14-28 & 20 & 4974 & 3728 & 2774 & 19.3 & 4.80 & 0.637 & 8.10 & 37.6 & 49.6 & 788 & 94.7 & 94.7 & 8.14 \\
\hline AJ13-14-29 & 21 & 5756 & 1490 & 3633 & 0.309 & 1.56 & 0.248 & 4.65 & 21.9 & 8.05 & 1004 & 115 & 128 & 1.21 \\
\hline AJ13-14-30 & 22 & 4999 & 1744 & 2972 & 0.539 & 1.76 & 0.120 & 2.10 & 8.18 & 10.9 & 713 & 84.8 & 122 & 2.94 \\
\hline AJ13-14-31 & 23 & 4646 & 3334 & 2479 & 3.13 & 4.19 & 0.338 & 7.73 & 34.0 & 43.4 & 707 & 84.5 & 195 & 7.63 \\
\hline AJ13-14-32 & control & $\mathrm{a}$ & $\mathrm{a}$ & $\bar{a}$ & 0.120 & $\bar{a}$ & $\mathrm{a}$ & $\bar{a}$ & $\mathrm{a}$ & 0.049 & $\mathrm{a}$ & $\bar{a}$ & 0.27 & $\bar{a}$ \\
\hline
\end{tabular}

${ }^{\mathrm{a}}$ Element below detection limits of measuring instrument. 
Table F-23. Acid Strip Data $\left(\mathrm{ng} / \mathrm{mm}^{2}\right)$ from SS15ZR26 Specimens Immersed in $363 \mathrm{~K}\left(90^{\circ} \mathrm{C}\right)$ Solution for 98 days.

\begin{tabular}{|c|c|c|c|c|c|c|c|c|c|c|c|c|c|c|}
\hline \multirow[b]{2}{*}{ Expt. ID } & \multirow[b]{2}{*}{ Ingot ID } & \multicolumn{4}{|c|}{ Major Elements } & \multicolumn{5}{|c|}{ Noble Metal Fission Products } & \multicolumn{4}{|c|}{ Minor Elements } \\
\hline & & $\mathrm{Fe}$ & $\mathrm{Cr}$ & $\mathrm{Ni}$ & $\mathrm{Zr}$ & $\mathrm{Nb}$ & $\mathrm{Pd}$ & $\mathrm{Rh}$ & $\mathrm{Ru}$ & Mo & $\mathrm{Mn}$ & $\mathrm{Co}$ & $\mathrm{Cu}$ & $\mathrm{V}$ \\
\hline \multicolumn{2}{|c|}{ Detection Limits } & 2.3 & 2.3 & 2.3 & 0.535 & 0.031 & 0.030 & 0.115 & 0.12 & 0.044 & 0.12 & 0.125 & 0.12 & 0.18 \\
\hline SJ13-14-9AS & 1 & 3.1 & $\mathrm{a}$ & $\mathrm{a}$ & 0.438 & $\mathrm{a}$ & $\mathrm{a}$ & $\mathrm{a}$ & $\mathrm{a}$ & 0.258 & $\mathrm{a}$ & $\mathrm{a}$ & 4.296 & $\mathrm{a}$ \\
\hline SJ13-14-10AS & 2 & 18.2 & $\mathrm{a}$ & $\mathrm{a}$ & 0.374 & $\mathrm{a}$ & $\mathrm{a}$ & $\mathrm{a}$ & $\mathrm{a}$ & 0.170 & $\mathrm{a}$ & $\mathrm{a}$ & 3.222 & $\mathrm{a}$ \\
\hline SJ13-14-11AS & 3 & 10.1 & $a$ & $\mathrm{a}$ & 0.239 & $\mathrm{a}$ & $\mathrm{a}$ & $\mathrm{a}$ & $a$ & $\mathrm{a}$ & $\mathrm{a}$ & $\mathrm{a}$ & 3.338 & $\bar{a}$ \\
\hline SJ13-14-12AS & 4 & 17.2 & $\mathrm{a}$ & $\mathrm{a}$ & 0.398 & $\mathrm{a}$ & $\mathrm{a}$ & $\mathrm{a}$ & $\mathrm{a}$ & 0.068 & $\mathrm{a}$ & $\mathrm{a}$ & 2.712 & $\mathrm{a}$ \\
\hline SJ13-14-13AS & 5 & 4.7 & $\mathrm{a}$ & $\mathrm{a}$ & 0.257 & $\mathrm{a}$ & $\mathrm{a}$ & $\mathrm{a}$ & $\mathrm{a}$ & $\mathrm{a}$ & $\mathrm{a}$ & $\mathrm{a}$ & 2.825 & $\bar{a}$ \\
\hline SJ13-14-14AS & control & 24.7 & $\bar{a}$ & $\mathrm{a}$ & 0.501 & $\mathrm{a}$ & $\mathrm{a}$ & $\bar{a}$ & $\mathrm{a}$ & 0.177 & 0.139 & $\bar{a}$ & 3.096 & $\mathrm{a}$ \\
\hline CJ13-14-15AS & 7 & 18.9 & $\bar{a}$ & $\bar{a}$ & 0.029 & 0.019 & $\bar{a}$ & $\bar{a}$ & $\bar{a}$ & 0.204 & 0.102 & $\bar{a}$ & 2.860 & $\bar{a}$ \\
\hline CJ13-14-16AS & 8 & 16.4 & $\mathrm{a}$ & $\mathrm{a}$ & $\mathrm{a}$ & $\mathrm{a}$ & $\mathrm{a}$ & $\mathrm{a}$ & $\mathrm{a}$ & 0.183 & $\mathrm{a}$ & $\mathrm{a}$ & 3.090 & $\mathrm{a}$ \\
\hline CJ13-14-17AS & 9 & 13.3 & $\mathrm{a}$ & $\mathrm{a}$ & 0.177 & 0.035 & $\mathrm{a}$ & $\mathrm{a}$ & $\mathrm{a}$ & 0.194 & 0.106 & $\mathrm{a}$ & 2.771 & $\mathrm{a}$ \\
\hline CJ13-14-18AS & 10 & $\mathrm{a}$ & $\mathrm{a}$ & $\mathrm{a}$ & $\bar{a}$ & $\bar{a}$ & $\mathrm{a}$ & $\mathrm{a}$ & $\mathrm{a}$ & $a$ & $a$ & $\mathrm{a}$ & 2.723 & $\mathrm{a}$ \\
\hline CJ13-14-19AS & 11 & $\mathrm{a}$ & $\mathrm{a}$ & $\mathrm{a}$ & 0.027 & $\mathrm{a}$ & $\mathrm{a}$ & 0.010 & $\mathrm{a}$ & $\mathrm{a}$ & $\mathrm{a}$ & $\mathrm{a}$ & 2.977 & $\mathrm{a}$ \\
\hline CJ13-14-20AS & control & $\mathrm{a}$ & $\mathrm{a}$ & $\mathrm{a}$ & 0.380 & 0.588 & $\mathrm{a}$ & 0.062 & 0.264 & $\mathrm{a}$ & $\mathrm{a}$ & $\mathrm{a}$ & 2.819 & $\mathrm{a}$ \\
\hline $10 \mathrm{KCl}-14-21 \mathrm{AS}$ & 13 & 24.9 & 7.8 & $a$ & 0.307 & 0.070 & 0.022 & 0.063 & 0.263 & 0.170 & 0.158 & $\bar{a}$ & 2.279 & $\bar{a}$ \\
\hline $10 \mathrm{KCl}-14-22 \mathrm{AS}$ & 14 & 2.6 & $\mathrm{a}$ & $\mathrm{a}$ & 0.115 & 0.012 & $\mathrm{a}$ & 0.029 & $\mathrm{a}$ & 0.047 & $\mathrm{a}$ & $\mathrm{a}$ & 2.927 & $\mathrm{a}$ \\
\hline $10 \mathrm{KCl}-14-23 \mathrm{AS}$ & 15 & 7.1 & 5.8 & $\mathrm{a}$ & 0.091 & 0.022 & 0.013 & 0.048 & $\mathrm{a}$ & 0.148 & $\mathrm{a}$ & $\mathrm{a}$ & 3.242 & $\mathrm{a}$ \\
\hline $10 \mathrm{KCl}-14-24 \mathrm{AS}$ & 16 & 23.5 & 7.0 & $\mathrm{a}$ & 0.133 & 0.020 & $\mathrm{a}$ & 0.008 & $\mathrm{a}$ & 0.262 & $\mathrm{a}$ & $\mathrm{a}$ & 3.336 & $\mathrm{a}$ \\
\hline $10 \mathrm{KCl}-14-25 \mathrm{AS}$ & 17 & 80.7 & 34.0 & 5.9 & 0.044 & 0.077 & $\mathrm{a}$ & 0.092 & 0.325 & 0.863 & 2.185 & 0.159 & 3.829 & $\mathrm{a}$ \\
\hline $10 \mathrm{KCl}-14-26 \mathrm{AS}$ & control & 14.1 & $\mathrm{a}$ & $\mathrm{a}$ & $\mathrm{a}$ & $\mathrm{a}$ & $\mathrm{a}$ & $\mathrm{a}$ & $\mathrm{a}$ & $\mathrm{a}$ & $\mathrm{a}$ & $\mathrm{a}$ & 2.469 & $\mathrm{a}$ \\
\hline AJ13-14-27AS & 19 & 1393.0 & 324.3 & 83.6 & 0.598 & 0.168 & 0.377 & 1.817 & 7.645 & 0.785 & 21.063 & 3.031 & 4.692 & $\mathrm{a}$ \\
\hline AJ13-14-28AS & 20 & 160.8 & 131.9 & 31.0 & 3.315 & 0.405 & 0.328 & 1.153 & 4.613 & 4.834 & 7.329 & 1.079 & 3.482 & $\mathrm{a}$ \\
\hline AJ13-14-29AS & 21 & 991.6 & 407.1 & 58.5 & 0.175 & 0.243 & 0.140 & 2.451 & 10.892 & 1.475 & 13.310 & 1.941 & 3.305 & $\mathrm{a}$ \\
\hline AJ13-14-30AS & 22 & 147.1 & 72.3 & 28.8 & 0.192 & 0.115 & 0.069 & 0.185 & 0.756 & 1.037 & 6.082 & 0.888 & 2.167 & $\mathrm{a}$ \\
\hline AJ13-14-31AS & 23 & 145.9 & 86.5 & 26.9 & 0.390 & 0.238 & 0.094 & 0.702 & 2.754 & 2.107 & 6.957 & 1.018 & 2.897 & $\mathrm{a}$ \\
\hline AJ13-14-32AS & control & $\bar{a}$ & $\mathrm{a}$ & $\bar{a}$ & 0.320 & $\bar{a}$ & $\mathrm{a}$ & $\bar{a}$ & $\mathrm{a}$ & $\mathrm{a}$ & $\mathrm{a}$ & $\bar{a}$ & $\bar{a}$ & $\bar{a}$ \\
\hline
\end{tabular}

${ }^{\mathrm{a}}$ Element below detection limits of measuring instrument. 
Table F-24. Acid Strip Data $\left(\mathrm{ng} / \mathrm{mm}^{2}\right)$ from SS15ZR26 Specimens Immersed in $363 \mathrm{~K}\left(90^{\circ} \mathrm{C}\right)$ Solution for 98 days.

\begin{tabular}{|c|c|c|c|c|c|c|c|c|c|c|c|c|c|c|}
\hline \multirow[b]{2}{*}{ Expt. ID } & \multirow[b]{2}{*}{ Ingot ID } & \multicolumn{4}{|c|}{ Major Elements } & \multicolumn{5}{|c|}{ Noble Metal Fission Products } & \multicolumn{4}{|c|}{ Minor Elements } \\
\hline & & $\mathrm{Fe}$ & $\mathrm{Cr}$ & $\mathrm{Ni}$ & $\mathrm{Zr}$ & $\mathrm{Nb}$ & $\mathrm{Pd}$ & $\mathrm{Rh}$ & $\mathrm{Ru}$ & Mo & $\mathrm{Mn}$ & $\mathrm{Co}$ & $\mathrm{Cu}$ & $\mathrm{V}$ \\
\hline \multicolumn{15}{|c|}{ Detection Limits not available } \\
\hline $10 \mathrm{KCl}-14-21 \mathrm{R}$ & 13 & 38.93 & $\mathrm{a}$ & $\mathrm{a}$ & 0.02 & $\mathrm{a}$ & 0.00 & 0.00 & $\mathrm{a}$ & 0.06 & 0.02 & 0.09 & 0.30 & 0.50 \\
\hline $10 \mathrm{KCl}-14-22 \mathrm{R}$ & 14 & 41.43 & $\mathrm{a}$ & $\mathrm{a}$ & 0.02 & $\mathrm{a}$ & 0.00 & $\mathrm{a}$ & $\mathrm{a}$ & 0.04 & 0.01 & 0.12 & 0.36 & 0.51 \\
\hline $10 \mathrm{KCl}-14-23 \mathrm{R}$ & 15 & 30.70 & $\mathrm{a}$ & $\mathrm{a}$ & 0.02 & $\mathrm{a}$ & 0.00 & $\mathrm{a}$ & $\mathrm{a}$ & 0.04 & 0.01 & 0.15 & 0.30 & 0.42 \\
\hline $10 \mathrm{KCl}-14-24 \mathrm{R}$ & 16 & 72.76 & 4.55 & $\mathrm{a}$ & 0.03 & $a$ & 0.00 & $\mathrm{a}$ & $a$ & 0.05 & 0.02 & 0.15 & 0.32 & 0.49 \\
\hline $10 \mathrm{KCl}-14-25 \mathrm{R}$ & 17 & 247.8 & 42.84 & 8.23 & 0.03 & 0.00 & 0.00 & 0.00 & 0.01 & 0.11 & 0.07 & 0.16 & 0.60 & 0.50 \\
\hline AJ13-14-27R & 19 & 2014.6 & 311.5 & 93.68 & 0.05 & 0.04 & 0.00 & 0.05 & 0.16 & 0.93 & 1.05 & 0.37 & 0.55 & 1.47 \\
\hline AJ13-14-28R & 20 & 3979.1 & 1032.3 & 100.5 & 0.64 & 0.12 & 0.02 & 0.10 & 0.29 & 3.19 & 1.03 & 0.43 & 0.44 & 1.63 \\
\hline AJ13-14-29R & 21 & 7457.9 & 1355.2 & 146.4 & 0.03 & 0.13 & 0.01 & 0.14 & 0.43 & 2.80 & 1.52 & 0.48 & 0.65 & 1.55 \\
\hline AJ13-14-30R & 22 & 4533.9 & 1136.9 & 119.1 & 0.14 & 0.09 & 0.01 & 0.07 & 0.21 & 2.33 & 1.08 & 0.41 & 0.52 & 1.52 \\
\hline AJ13-14-31R & 23 & 3678.9 & 1018.6 & 89.13 & 0.07 & 0.10 & 0.01 & 0.09 & 0.26 & 3.41 & 0.94 & 0.38 & 0.66 & 1.58 \\
\hline
\end{tabular}

${ }^{\mathrm{a}}$ Element below detection limits of measuring instrument. 
Table F-25. Leachate Data $\left(\mathrm{ng} / \mathrm{mm}^{2}\right)$ from SS15ZR26 Specimens Immersed in $363 \mathrm{~K}\left(90^{\circ} \mathrm{C}\right)$ Solution for 154 days.

\begin{tabular}{|c|c|c|c|c|c|c|c|c|c|c|c|c|c|c|}
\hline \multirow[b]{2}{*}{ Expt. ID } & \multirow[b]{2}{*}{ Ingot ID } & \multicolumn{4}{|c|}{ Major Elements } & \multicolumn{5}{|c|}{ Noble Metal Fission Products } & \multicolumn{4}{|c|}{ Minor Elements } \\
\hline & & $\mathrm{Fe}$ & $\mathrm{Cr}$ & $\mathrm{Ni}$ & $\mathrm{Zr}$ & $\mathrm{Nb}$ & $\mathrm{Pd}$ & $\mathrm{Rh}$ & $\mathrm{Ru}$ & Mo & $\mathrm{Mn}$ & $\mathrm{Co}$ & $\mathrm{Cu}$ & $\mathrm{V}$ \\
\hline \multicolumn{2}{|c|}{ Detection Limits } & 2.0 & 2.0 & 2.0 & 0.016 & 0.024 & 0.018 & 0.023 & 0.047 & 0.9 & 0.56 & 0.070 & 0.48 & 1.0 \\
\hline SJ13-22-33 & 1 & $\mathrm{a}$ & $\mathrm{a}$ & $\mathrm{a}$ & 0.055 & $\mathrm{a}$ & $\mathrm{a}$ & $\mathrm{a}$ & $\mathrm{a}$ & $\mathrm{a}$ & $\mathrm{a}$ & $\mathrm{a}$ & $\mathrm{a}$ & $\mathrm{a}$ \\
\hline SJ13-22-34 & 2 & $\mathrm{a}$ & $\bar{a}$ & $\bar{a}$ & 0.077 & $\bar{a}$ & $\bar{a}$ & $\bar{a}$ & $\bar{a}$ & $\bar{a}$ & $\bar{a}$ & $\bar{a}$ & $\bar{a}$ & $a$ \\
\hline SJ13-22-35 & 3 & $\mathrm{a}$ & $\mathrm{a}$ & $\mathrm{a}$ & 0.062 & $\mathrm{a}$ & $\mathrm{a}$ & $\mathrm{a}$ & $\mathrm{a}$ & $\mathrm{a}$ & $\mathrm{a}$ & $\mathrm{a}$ & $\mathrm{a}$ & $\mathrm{a}$ \\
\hline SJ13-22-36 & 4 & $\mathrm{a}$ & $\bar{a}$ & $\mathrm{a}$ & 0.081 & $\mathrm{a}$ & $\mathrm{a}$ & $\mathrm{a}$ & $\mathrm{a}$ & $\mathrm{a}$ & $\mathrm{a}$ & $\mathrm{a}$ & $\mathrm{a}$ & $\mathrm{a}$ \\
\hline SJ13-22-40 & 5 & $\mathrm{a}$ & $\mathrm{a}$ & $\mathrm{a}$ & 0.113 & $\mathrm{a}$ & $\mathrm{a}$ & $\mathrm{a}$ & $\mathrm{a}$ & $\mathrm{a}$ & $\mathrm{a}$ & $\mathrm{a}$ & $\mathrm{a}$ & $\mathrm{a}$ \\
\hline SJ13-22-41 & control & $\bar{a}$ & $\bar{a}$ & $\bar{a}$ & 0.121 & $\bar{a}$ & $\bar{a}$ & $\bar{a}$ & $\mathrm{a}$ & $\bar{a}$ & $\bar{a}$ & $\mathrm{a}$ & $\bar{a}$ & $\mathrm{a}$ \\
\hline CJ13-22-42 & 7 & $\mathrm{a}$ & $\mathrm{a}$ & $\mathrm{a}$ & 1.34 & $\mathrm{a}$ & 0.050 & $\mathrm{a}$ & $\mathrm{a}$ & $\mathrm{a}$ & $\mathrm{a}$ & $\mathrm{a}$ & $\mathrm{a}$ & $\mathrm{a}$ \\
\hline CJ13-22-43 & 8 & $\mathrm{a}$ & $\mathrm{a}$ & $\mathrm{a}$ & 1.44 & $\mathrm{a}$ & 0.050 & 0.027 & 0.148 & $\mathrm{a}$ & $\mathrm{a}$ & $\mathrm{a}$ & $\mathrm{a}$ & $\mathrm{a}$ \\
\hline CJ13-22-44 & 9 & $\mathrm{a}$ & $\mathrm{a}$ & $\mathrm{a}$ & 1.24 & $\mathrm{a}$ & 0.069 & 0.043 & 0.264 & $\mathrm{a}$ & $\mathrm{a}$ & $\mathrm{a}$ & $\mathrm{a}$ & $\mathrm{a}$ \\
\hline CJ13-22-45 & 10 & $\mathrm{a}$ & $\mathrm{a}$ & $\mathrm{a}$ & 1.008 & $\mathrm{a}$ & 0.027 & $\mathrm{a}$ & 0.072 & $\mathrm{a}$ & $\mathrm{a}$ & $\mathrm{a}$ & $\mathrm{a}$ & $\mathrm{a}$ \\
\hline CJ13-22-46 & 11 & $\mathrm{a}$ & $\mathrm{a}$ & $\mathrm{a}$ & 1.13 & $\mathrm{a}$ & 0.029 & $\mathrm{a}$ & 0.137 & $\mathrm{a}$ & $\mathrm{a}$ & $\mathrm{a}$ & $\mathrm{a}$ & $\mathrm{a}$ \\
\hline CJ13-22-47 & control & $\mathrm{a}$ & $\mathrm{a}$ & $\mathrm{a}$ & 1.15 & $\mathrm{a}$ & 0.039 & 0.089 & 0.446 & $\mathrm{a}$ & $\mathrm{a}$ & $\mathrm{a}$ & 9.41 & $\mathrm{a}$ \\
\hline $10 \mathrm{KCl}-22-48$ & 13 & $\mathrm{a}$ & $\mathrm{a}$ & 9.1 & $\mathrm{a}$ & $\mathrm{a}$ & 0.030 & $\mathrm{a}$ & $\mathrm{a}$ & $\mathrm{a}$ & 3.91 & 0.556 & $\mathrm{a}$ & 2.9 \\
\hline $10 \mathrm{KCl}-22-49$ & 14 & 4.0 & 6.0 & 6.0 & $\mathrm{a}$ & $\mathrm{a}$ & 0.030 & 0.025 & 0.064 & 2.05 & 1.90 & 0.274 & $\mathrm{a}$ & 5.4 \\
\hline $10 \mathrm{KCl}-22-50$ & 15 & $\mathrm{a}$ & 8.1 & $\mathrm{a}$ & $\mathrm{a}$ & $\mathrm{a}$ & 0.031 & 0.041 & 0.046 & 3.40 & $\mathrm{a}$ & $\mathrm{a}$ & 2.58 & 3.6 \\
\hline $10 \mathrm{KCl}-22-52$ & 16 & 5.0 & 8.1 & 4.0 & $\mathrm{a}$ & $\bar{a}$ & 0.038 & 0.076 & 0.164 & 4.60 & 1.17 & 0.236 & 0.6 & 2.9 \\
\hline $10 \mathrm{KCl}-22-53$ & 17 & $\mathrm{a}$ & 2.0 & 6.1 & $\mathrm{a}$ & $\mathrm{a}$ & 0.028 & $\mathrm{a}$ & 0.035 & 8.51 & 1.84 & 0.252 & $\mathrm{a}$ & 2.2 \\
\hline $10 \mathrm{KCl}-22-54$ & control & $\mathrm{a}$ & $\mathrm{a}$ & $\mathrm{a}$ & $\mathrm{a}$ & $\mathrm{a}$ & $\mathrm{a}$ & $\mathrm{a}$ & $\mathrm{a}$ & $\mathrm{a}$ & $\mathrm{a}$ & $\mathrm{a}$ & $\mathrm{a}$ & 2.1 \\
\hline AJ13-22-55 & 19 & 3195 & 1346 & 4743 & 0.101 & 0.802 & 0.069 & 2.83 & 14.9 & 3.08 & 1330 & 191 & 196 & 0.33 \\
\hline AJ13-22-56 & 20 & 1434 & 3188 & 4321 & 3.07 & 1.91 & 0.386 & 5.30 & 24.3 & 21.5 & 1108 & 161 & 182 & 2.62 \\
\hline AJ13-22-57 & 21 & 1512 & 1925 & 5803 & 0.327 & 2.28 & 0.307 & 7.60 & 39.1 & 16.8 & 1356 & 196 & 193 & 1.46 \\
\hline AJ13-22-58 & 22 & 1607 & 3688 & 5761 & 0.623 & 3.04 & 0.390 & 8.63 & 36.4 & 29.2 & 1393 & 198 & 517 & 3.18 \\
\hline AJ13-22-59 & 23 & 1625 & 3346 & 4102 & 2.54 & 2.41 & 0.349 & 5.37 & 24.4 & 36.3 & 1063 & 152 & 203 & 2.96 \\
\hline AJ13-22-60 & control & $\mathrm{a}$ & $\mathrm{a}$ & $\mathrm{a}$ & 0.092 & $\mathrm{a}$ & $\mathrm{a}$ & $\mathrm{a}$ & $\mathrm{a}$ & $\mathrm{a}$ & $\mathrm{a}$ & $\mathrm{a}$ & $\mathrm{a}$ & $\mathrm{a}$ \\
\hline
\end{tabular}

${ }^{\mathrm{a}}$ Element below detection limits of measuring instrument. 
Table F-26. Acid Strip Data $\left(\mathrm{ng} / \mathrm{mm}^{2}\right)$ from SS15ZR26 Specimens Immersed in $363 \mathrm{~K}\left(90^{\circ} \mathrm{C}\right)$ Solution for 154 days.

\begin{tabular}{|c|c|c|c|c|c|c|c|c|c|c|c|c|c|c|}
\hline \multirow[b]{2}{*}{ Expt. ID } & \multirow[b]{2}{*}{ Ingot ID } & \multicolumn{4}{|c|}{ Major Elements } & \multicolumn{5}{|c|}{ Noble Metal Fission Products } & \multicolumn{4}{|c|}{ Minor Elements } \\
\hline & & $\mathrm{Fe}$ & $\mathrm{Cr}$ & $\mathrm{Ni}$ & $\mathrm{Zr}$ & $\mathrm{Nb}$ & $\mathrm{Pd}$ & $\mathrm{Rh}$ & $\mathrm{Ru}$ & Mo & $\mathrm{Mn}$ & $\mathrm{Co}$ & $\mathrm{Cu}$ & $\mathrm{V}$ \\
\hline \multicolumn{2}{|c|}{ Detection Limits } & 2.3 & 2.3 & 2.3 & 0.02 & 0.03 & 0.02 & 0.03 & 0.03 & 1.3 & 0.66 & 0.08 & 0.57 & 1.5 \\
\hline SJ13-22-33AS & 1 & $\mathrm{a}$ & $\mathrm{a}$ & $\mathrm{a}$ & 0.45 & $\mathrm{a}$ & $\mathrm{a}$ & $\mathrm{a}$ & $\mathrm{a}$ & $\mathrm{a}$ & $\mathrm{a}$ & $\mathrm{a}$ & $\mathrm{a}$ & $\mathrm{a}$ \\
\hline SJ13-22-34AS & 2 & $\mathrm{a}$ & $\mathrm{a}$ & $\mathrm{a}$ & 0.37 & $\mathrm{a}$ & $\mathrm{a}$ & $\mathrm{a}$ & 0.07 & $\mathrm{a}$ & $\mathrm{a}$ & $\mathrm{a}$ & $\mathrm{a}$ & $\mathrm{a}$ \\
\hline SJ13-22-35AS & 3 & $\mathrm{a}$ & $\mathrm{a}$ & $\mathrm{a}$ & 0.35 & $\mathrm{a}$ & $\mathrm{a}$ & $\mathrm{a}$ & $\mathrm{a}$ & $\mathrm{a}$ & $\mathrm{a}$ & $\mathrm{a}$ & $\mathrm{a}$ & $\mathrm{a}$ \\
\hline SJ13-22-36AS & 4 & $\mathrm{a}$ & $\mathrm{a}$ & $\mathrm{a}$ & 0.57 & $\mathrm{a}$ & $\mathrm{a}$ & $\mathrm{a}$ & $\mathrm{a}$ & $\mathrm{a}$ & $\mathrm{a}$ & $\mathrm{a}$ & $\mathrm{a}$ & $\mathrm{a}$ \\
\hline SJ13-22-40AS & 5 & 3.4 & $\mathrm{a}$ & $\mathrm{a}$ & 0.70 & $\mathrm{a}$ & $\mathrm{a}$ & $\mathrm{a}$ & $\mathrm{a}$ & $\mathrm{a}$ & $\mathrm{a}$ & $\mathrm{a}$ & $\mathrm{a}$ & $\mathrm{a}$ \\
\hline SJ13-22-41AS & control & $\mathrm{a}$ & $\mathrm{a}$ & $\mathrm{a}$ & 0.56 & $\mathrm{a}$ & $\mathrm{a}$ & $\mathrm{a}$ & $\mathrm{a}$ & $\mathrm{a}$ & $\mathrm{a}$ & $\bar{a}$ & $\mathrm{a}$ & $\mathrm{a}$ \\
\hline CJ13-22-42AS & 7 & $\mathrm{a}$ & $\mathrm{a}$ & $\mathrm{a}$ & 0.05 & $\mathrm{a}$ & $\mathrm{a}$ & $\mathrm{a}$ & $\mathrm{a}$ & $\mathrm{a}$ & $\mathrm{a}$ & $\mathrm{a}$ & $\mathrm{a}$ & $\mathrm{a}$ \\
\hline CJ13-22-43AS & 8 & $\mathrm{a}$ & $\mathrm{a}$ & $\mathrm{a}$ & 0.11 & $\mathrm{a}$ & $\mathrm{a}$ & $\mathrm{a}$ & 0.08 & $\mathrm{a}$ & $\mathrm{a}$ & $\mathrm{a}$ & $\mathrm{a}$ & $\mathrm{a}$ \\
\hline CJ13-22-44AS & 9 & $\mathrm{a}$ & $\mathrm{a}$ & $\mathrm{a}$ & 0.07 & $\mathrm{a}$ & $\mathrm{a}$ & 0.06 & 0.21 & $\mathrm{a}$ & $\mathrm{a}$ & $\mathrm{a}$ & $\mathrm{a}$ & $\mathrm{a}$ \\
\hline CJ13-22-45AS & 10 & $\mathrm{a}$ & $\mathrm{a}$ & $\mathrm{a}$ & 0.04 & $\mathrm{a}$ & $\mathrm{a}$ & $\mathrm{a}$ & 0.05 & $\mathrm{a}$ & $\mathrm{a}$ & $\mathrm{a}$ & 2.5 & $\mathrm{a}$ \\
\hline CJ13-22-46AS & 11 & $\mathrm{a}$ & $\mathrm{a}$ & $\mathrm{a}$ & 0.04 & $\mathrm{a}$ & $\mathrm{a}$ & $\mathrm{a}$ & 0.06 & $\mathrm{a}$ & $\mathrm{a}$ & $\mathrm{a}$ & $\mathrm{a}$ & $\mathrm{a}$ \\
\hline CJ13-22-47AS & control & $\mathrm{a}$ & $\mathrm{a}$ & $\mathrm{a}$ & 0.19 & $\mathrm{a}$ & $\mathrm{a}$ & 0.12 & 0.32 & $\mathrm{a}$ & $\mathrm{a}$ & $\mathrm{a}$ & 0.7 & $\mathrm{a}$ \\
\hline $10 \mathrm{KCl}-22-48 \mathrm{AS}$ & 13 & 7.0 & $\mathrm{a}$ & $\mathrm{a}$ & $\mathrm{a}$ & $\mathrm{a}$ & $\mathrm{a}$ & $\mathrm{a}$ & 0.04 & $\mathrm{a}$ & $\mathrm{a}$ & $\mathrm{a}$ & 2.6 & $\mathrm{a}$ \\
\hline $10 \mathrm{KCl}-22-49 \mathrm{AS}$ & 14 & 15.9 & 4.5 & $\mathrm{a}$ & $\mathrm{a}$ & $\mathrm{a}$ & $\mathrm{a}$ & $\mathrm{a}$ & $\mathrm{a}$ & $\mathrm{a}$ & $\mathrm{a}$ & $\mathrm{a}$ & 2.6 & $\mathrm{a}$ \\
\hline $10 \mathrm{KCl}-22-50 \mathrm{AS}$ & 15 & $\mathrm{a}$ & $\mathrm{a}$ & $\mathrm{a}$ & $\mathrm{a}$ & $\mathrm{a}$ & $\mathrm{a}$ & $\mathrm{a}$ & $\mathrm{a}$ & $\mathrm{a}$ & $\mathrm{a}$ & $\mathrm{a}$ & 2.6 & $\mathrm{a}$ \\
\hline $10 \mathrm{KCl}-22-52 \mathrm{AS}$ & 16 & 23.4 & 14.1 & $\mathrm{a}$ & $\mathrm{a}$ & $\mathrm{a}$ & $\mathrm{a}$ & $\mathrm{a}$ & 0.09 & $\mathrm{a}$ & $\mathrm{a}$ & $\mathrm{a}$ & 2.9 & $\mathrm{a}$ \\
\hline $10 \mathrm{KCl}-22-53 \mathrm{AS}$ & 17 & 11.3 & 4.5 & $\mathrm{a}$ & $\mathrm{a}$ & $\mathrm{a}$ & $\mathrm{a}$ & $\mathrm{a}$ & $\mathrm{a}$ & $\mathrm{a}$ & $\mathrm{a}$ & $\mathrm{a}$ & 2.8 & $\mathrm{a}$ \\
\hline $10 \mathrm{KCl}-22-54 \mathrm{AS}$ & \begin{tabular}{|l|} 
control \\
\end{tabular} & $\mathrm{a}$ & $\mathrm{a}$ & 2.4 & $\mathrm{a}$ & $\mathrm{a}$ & $\mathrm{a}$ & $\mathrm{a}$ & $\mathrm{a}$ & $\mathrm{a}$ & $\mathrm{a}$ & $\mathrm{a}$ & 2.5 & $\mathrm{a}$ \\
\hline AJ13-22-55AS & 19 & 431.0 & 168.9 & 92.0 & 0.33 & 0.10 & 0.13 & 1.19 & 5.38 & $\mathrm{a}$ & 22.95 & 3.23 & 3.8 & $\mathrm{a}$ \\
\hline AJ13-22-56AS & 20 & 115.5 & 102.0 & 48.2 & 16.37 & 0.38 & 0.17 & 0.73 & 2.96 & $\mathrm{a}$ & 10.77 & 1.54 & 2.2 & $\mathrm{a}$ \\
\hline AJ13-22-57AS & 21 & 187.8 & 131.4 & 117.5 & 0.14 & 0.12 & 0.07 & 0.51 & 2.39 & $\mathrm{a}$ & 24.09 & 3.41 & 3.5 & $\mathrm{a}$ \\
\hline AJ13-22-58AS & 22 & 194.3 & 138.0 & 67.8 & 0.73 & 0.17 & 0.11 & 0.57 & 2.38 & $\mathrm{a}$ & 14.37 & 2.01 & 5.4 & $\mathrm{a}$ \\
\hline AJ13-22-59AS & 23 & 148.9 & 126.4 & 63.2 & 1.10 & 0.21 & 0.09 & 0.62 & 2.55 & $\mathrm{a}$ & 15.12 & 2.12 & 2.9 & $\mathrm{a}$ \\
\hline AJ13-22-60AS & control & $\mathrm{a}$ & $\mathrm{a}$ & $\mathrm{a}$ & 0.08 & $\mathrm{a}$ & $\mathrm{a}$ & $\mathrm{a}$ & $\mathrm{a}$ & $\mathrm{a}$ & $\mathrm{a}$ & $\mathrm{a}$ & $\mathrm{a}$ & $\mathrm{a}$ \\
\hline
\end{tabular}

${ }^{\mathrm{a}}$ Element below detection limits of measuring instrument. 
Table F-27. Residue Data $\left(\mathrm{ng} / \mathrm{mm}^{2}\right)$ from SS15ZR26 Specimens Immersed in $363 \mathrm{~K}\left(90^{\circ} \mathrm{C}\right)$ Solution for 154 days.

\begin{tabular}{|c|c|c|c|c|c|c|c|c|c|c|c|c|c|c|}
\hline \multirow[b]{2}{*}{ Expt. ID } & \multirow[b]{2}{*}{ Ingot ID } & \multicolumn{4}{|c|}{ Major Elements } & \multicolumn{5}{|c|}{ Noble Metal Fission Products } & \multicolumn{4}{|c|}{ Minor Elements } \\
\hline & & $\mathrm{Fe}$ & $\mathrm{Cr}$ & $\mathrm{Ni}$ & $\mathrm{Zr}$ & $\mathrm{Nb}$ & $\mathrm{Pd}$ & $\mathrm{Rh}$ & $\mathrm{Ru}$ & Mo & $\mathrm{Mn}$ & $\mathrm{Co}$ & $\mathrm{Cu}$ & $\mathrm{V}$ \\
\hline \multicolumn{15}{|c|}{ Detection Limits not available } \\
\hline AJ13-22-55R & 19 & $\overline{59573}$ & 9050 & 809 & 1.20 & 5.08 & 0.32 & 5.13 & 17.6 & 128 & 50.7 & 9.38 & 23.9 & 10.2 \\
\hline AJ13-22-56R & 20 & 60937 & 14552 & 759 & 24.6 & 7.91 & 0.65 & 5.58 & 19.2 & 239 & 43.1 & 8.49 & 18.9 & 18.3 \\
\hline AJ13-22-57R & 21 & 70487 & 11869 & 869 & 1.71 & 5.99 & 0.26 & 3.76 & 12.2 & 147 & 44.4 & 8.51 & 21.6 & 12.1 \\
\hline AJ13-22-58R & 22 & 73215 & 17644 & 728 & 1.90 & 7.90 & 0.37 & 5.33 & 16.9 & 278 & 39.6 & 8.66 & 37.7 & 21.7 \\
\hline AJ13-22-59R & 23 & 62301 & 15189 & 991 & 8.40 & 7.01 & 0.40 & 5.03 & 15.7 & 292 & 57.0 & 12.4 & 26.2 & 18.4 \\
\hline
\end{tabular}


Table F-28. Leachate Data $\left(\mathrm{ng} / \mathrm{mm}^{2}\right)$ from SS15ZR26 Specimens Immersed in 363K $\left(90^{\circ} \mathrm{C}\right)$ Solution for 224 days.

\begin{tabular}{|c|c|c|c|c|c|c|c|c|c|c|c|c|c|c|}
\hline \multirow[b]{2}{*}{ Expt. ID } & \multirow[b]{2}{*}{ Ingot ID } & \multicolumn{4}{|c|}{ Major Elements } & \multicolumn{5}{|c|}{ Noble Metal Fission Products } & \multicolumn{4}{|c|}{ Minor Elements } \\
\hline & & $\mathrm{Fe}$ & $\mathrm{Cr}$ & $\mathrm{Ni}$ & $\mathrm{Zr}$ & $\mathrm{Nb}$ & $\mathrm{Pd}$ & $\mathrm{Rh}$ & $\mathrm{Ru}$ & Mo & $\mathrm{Mn}$ & $\mathrm{Co}$ & $\mathrm{Cu}$ & $\overline{\mathrm{V}}$ \\
\hline \multicolumn{2}{|c|}{ Detection Limits } & 2.0 & 2.0 & 2.0 & 1.2 & 0.018 & 0.017 & 0.023 & 0.032 & 0.40 & 0.10 & 0.021 & 0.10 & 0.80 \\
\hline SJ13-32-1 & 1 & $\mathrm{a}$ & $\mathrm{a}$ & $\mathrm{a}$ & $\mathrm{a}$ & $\mathrm{a}$ & $\mathrm{a}$ & $\mathrm{a}$ & $\mathrm{a}$ & $\mathrm{a}$ & $\mathrm{a}$ & $\mathrm{a}$ & 0.24 & $\mathrm{a}$ \\
\hline SJ13-32-2 & 2 & $\mathrm{a}$ & $\bar{a}$ & $\bar{a}$ & $\bar{a}$ & $\bar{a}$ & $\bar{a}$ & $\mathrm{a}$ & $\mathrm{a}$ & $\mathrm{a}$ & $\mathrm{a}$ & $\mathrm{a}$ & 0.23 & $\mathrm{a}$ \\
\hline SJ13-32-3 & 3 & $\mathrm{a}$ & $\mathrm{a}$ & $\mathrm{a}$ & $\mathrm{a}$ & $\mathrm{a}$ & $\mathrm{a}$ & $\mathrm{a}$ & $\mathrm{a}$ & $\mathrm{a}$ & $\mathrm{a}$ & $\mathrm{a}$ & 0.22 & $\mathrm{a}$ \\
\hline SJ13-32-4 & 4 & $\mathrm{a}$ & $\mathrm{a}$ & $\mathrm{a}$ & $\mathrm{a}$ & $\mathrm{a}$ & $\mathrm{a}$ & $\mathrm{a}$ & $\mathrm{a}$ & $\mathrm{a}$ & $\mathrm{a}$ & $\bar{a}$ & 0.36 & $\mathrm{a}$ \\
\hline SJ13-32-5 & 5 & $\mathrm{a}$ & $\mathrm{a}$ & $\mathrm{a}$ & $\bar{a}$ & $\bar{a}$ & $\mathrm{a}$ & $\mathrm{a}$ & $\mathrm{a}$ & $\mathrm{a}$ & $\mathrm{a}$ & $\mathrm{a}$ & 0.32 & $\mathrm{a}$ \\
\hline SJ13-32-161 & control & $\bar{a}$ & $\bar{a}$ & $\bar{a}$ & $\mathrm{a}$ & $\bar{a}$ & $\bar{a}$ & $\bar{a}$ & $\bar{a}$ & $\bar{a}$ & $\bar{a}$ & $\bar{a}$ & 0.90 & $\bar{a}$ \\
\hline CJ13-32-41 & 7 & $\mathrm{a}$ & $\mathrm{a}$ & $\mathrm{a}$ & $\mathrm{a}$ & $\mathrm{a}$ & 0.037 & $\mathrm{a}$ & $\mathrm{a}$ & 0.51 & $\mathrm{a}$ & 0.023 & 0.32 & $\mathrm{a}$ \\
\hline CJ13-32-42 & 8 & $\mathrm{a}$ & $\mathrm{a}$ & $\mathrm{a}$ & $\mathrm{a}$ & $\mathrm{a}$ & 0.046 & $\mathrm{a}$ & $\mathrm{a}$ & 0.48 & $\mathrm{a}$ & 0.025 & 0.39 & $\mathrm{a}$ \\
\hline CJ13-32-43 & 9 & $\mathrm{a}$ & $\mathrm{a}$ & $\mathrm{a}$ & $\mathrm{a}$ & $\mathrm{a}$ & 0.051 & $\mathrm{a}$ & $\mathrm{a}$ & 0.56 & $\mathrm{a}$ & 0.029 & 0.44 & $\mathrm{a}$ \\
\hline CJ13-32-44 & 10 & $\mathrm{a}$ & $\mathrm{a}$ & 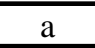 & $\mathrm{a}$ & $a$ & 0.027 & $a$ & $a$ & 0.59 & $a$ & 0.026 & 0.46 & $\mathrm{a}$ \\
\hline CJ13-32-45 & 11 & $\mathrm{a}$ & $\mathrm{a}$ & $\mathrm{a}$ & $\mathrm{a}$ & $\mathrm{a}$ & 0.026 & $\mathrm{a}$ & $\mathrm{a}$ & 0.57 & $\mathrm{a}$ & 0.024 & 0.41 & $\mathrm{a}$ \\
\hline CJ13-32-162 & control & $\mathrm{a}$ & $a$ & $\mathrm{a}$ & $\mathrm{a}$ & $a$ & 0.026 & $a$ & $\mathrm{a}$ & 0.79 & $a$ & 0.036 & 0.39 & $a$ \\
\hline $10 \mathrm{KCl}-32-81$ & 13 & $\mathrm{a}$ & $\mathrm{a}$ & 4.0 & $\bar{a}$ & $\mathrm{a}$ & 0.024 & $\mathrm{a}$ & $\mathrm{a}$ & 0.59 & 1.54 & 0.212 & 0.58 & 1.93 \\
\hline $10 \mathrm{KCl}-32-82$ & 14 & $\mathrm{a}$ & $\mathrm{a}$ & 3.0 & $a$ & $\bar{a}$ & 0.021 & $a$ & $a$ & 1.09 & 1.84 & 0.157 & 0.48 & 2.13 \\
\hline $10 \mathrm{KCl}-32-83$ & 15 & $\mathrm{a}$ & 3.0 & 4.0 & $\mathrm{a}$ & $\mathrm{a}$ & 0.028 & $\mathrm{a}$ & $\mathrm{a}$ & 1.35 & 1.36 & 0.205 & 1.49 & 2.40 \\
\hline $10 \mathrm{KCl}-32-84$ & 16 & 34.1 & 24.1 & 8.0 & $\bar{a}$ & 0.150 & 0.065 & 0.160 & 0.574 & 6.15 & 3.44 & 0.467 & 1.76 & 2.56 \\
\hline $10 \mathrm{KCl}-32-85$ & 17 & 2.0 & $\mathrm{a}$ & 12.0 & $\mathrm{a}$ & $\mathrm{a}$ & 0.671 & $\mathrm{a}$ & $\mathrm{a}$ & 65.3 & 87.1 & 11.7 & 20.8 & 39.41 \\
\hline $10 \mathrm{KCl}-32-163$ & control & $\mathrm{a}$ & $\mathrm{a}$ & $\bar{a}$ & $\mathrm{a}$ & $\mathrm{a}$ & $\mathrm{a}$ & $\mathrm{a}$ & $\mathrm{a}$ & $\mathrm{a}$ & $\mathrm{a}$ & $\mathrm{a}$ & 8.10 & 38.19 \\
\hline AJ13-32-121 & 19 & 2813 & 4709 & 5035 & 0.98 & 2.01 & 0.205 & 8.31 & 40.8 & 10.0 & 1198 & 241 & 351 & $\mathrm{a}$ \\
\hline AJ13-32-122 & 20 & 1569 & 3780 & 4921 & 7.95 & 2.19 & 0.248 & 9.51 & 46.9 & 13.3 & 1211 & 233 & 190 & 1.66 \\
\hline AJ13-32-123 & 21 & 1508 & 1304 & 5817 & $\mathrm{a}$ & 1.41 & 0.088 & 4.59 & 25.3 & 7.3 & 1218 & 243 & 231 & $\mathrm{a}$ \\
\hline AJ13-32-124 & 22 & 2896 & 3357 & 5302 & 0.63 & 2.60 & 0.159 & 4.71 & 21.5 & 13.4 & 1096 & 10.8 & 12.1 & $\mathrm{a}$ \\
\hline AJ13-32-125 & 23 & 2922 & 3500 & 5042 & 10.6 & 1.74 & 0.185 & 6.53 & 31.2 & 8.8 & 1007 & 10.04 & 16.3 & $\mathrm{a}$ \\
\hline AJ13-32-164 & control & $\bar{a}$ & $\mathrm{a}$ & $\bar{a}$ & $\bar{a}$ & $\bar{a}$ & $a$ & $\bar{a}$ & $\bar{a}$ & $\bar{a}$ & 0.15 & 0.025 & 1.72 & $\mathrm{a}$ \\
\hline
\end{tabular}

${ }^{\mathrm{a}}$ Element below detection limits of measuring instrument. 
Table F-29. Acid Strip Data $\left(\mathrm{ng} / \mathrm{mm}^{2}\right)$ from SS15ZR26 Specimens Immersed in $363 \mathrm{~K}\left(90^{\circ} \mathrm{C}\right)$ Solution for 224 days.

\begin{tabular}{|c|c|c|c|c|c|c|c|c|c|c|c|c|c|c|}
\hline \multirow[b]{2}{*}{ Expt. ID } & \multirow[b]{2}{*}{ Ingot ID } & \multicolumn{4}{|c|}{ Major Elements } & \multicolumn{5}{|c|}{ Noble Metal Fission Products } & \multicolumn{4}{|c|}{ Minor Elements } \\
\hline & & $\mathrm{Fe}$ & $\mathrm{Cr}$ & $\mathrm{Ni}$ & $\mathrm{Zr}$ & $\mathrm{Nb}$ & $\mathrm{Pd}$ & $\mathrm{Rh}$ & $\mathrm{Ru}$ & Mo & $\mathrm{Mn}$ & $\mathrm{Co}$ & $\mathrm{Cu}$ & $\mathrm{V}$ \\
\hline \multicolumn{2}{|c|}{ Detection Limits } & 2.4 & 2.4 & 2.4 & 1.4 & 0.021 & 0.020 & 0.027 & 0.038 & 0.48 & 0.12 & 0.025 & 0.12 & 0.96 \\
\hline SJ13-32-1AS & 1 & $\mathrm{a}$ & $\mathrm{a}$ & $\mathrm{a}$ & $\mathrm{a}$ & $\mathrm{a}$ & $\mathrm{a}$ & $\mathrm{a}$ & $\mathrm{a}$ & $\mathrm{a}$ & 0.17 & $\mathrm{a}$ & 0.64 & $\mathrm{a}$ \\
\hline SJ13-32-2AS & 2 & $\bar{a}$ & $\mathrm{a}$ & $\mathrm{a}$ & $\bar{a}$ & $\bar{a}$ & $\bar{a}$ & $\bar{a}$ & $\bar{a}$ & $\bar{a}$ & $\mathrm{a}$ & $\bar{a}$ & 0.29 & $\mathrm{a}$ \\
\hline SJ13-32-3AS & 3 & $\mathrm{a}$ & $\mathrm{a}$ & 2.4 & $\mathrm{a}$ & $\mathrm{a}$ & $\mathrm{a}$ & $\mathrm{a}$ & $\mathrm{a}$ & $\mathrm{a}$ & $\mathrm{a}$ & $\mathrm{a}$ & 0.28 & $\mathrm{a}$ \\
\hline SJ13-32-4AS & 4 & $\mathrm{a}$ & $\mathrm{a}$ & $\mathrm{a}$ & $\mathrm{a}$ & $\mathrm{a}$ & $\mathrm{a}$ & $\mathrm{a}$ & $\mathrm{a}$ & $\mathrm{a}$ & $\mathrm{a}$ & $\mathrm{a}$ & 0.46 & $\mathrm{a}$ \\
\hline SJ13-32-5AS & 5 & $\mathrm{a}$ & $\mathrm{a}$ & $\mathrm{a}$ & $\mathrm{a}$ & $\mathrm{a}$ & $\mathrm{a}$ & $\mathrm{a}$ & $\mathrm{a}$ & $\mathrm{a}$ & $\mathrm{a}$ & $\mathrm{a}$ & 0.45 & $\mathrm{a}$ \\
\hline SJ13-32-161AS & control & $\bar{a}$ & $\mathrm{a}$ & $\mathrm{a}$ & $\bar{a}$ & $\bar{a}$ & $\bar{a}$ & $\bar{a}$ & $\bar{a}$ & $\mathrm{a}$ & $\bar{a}$ & $\bar{a}$ & 0.69 & $\mathrm{a}$ \\
\hline CJ13-32-41AS & 7 & $\mathrm{a}$ & $\mathrm{a}$ & 3.7 & $\mathrm{a}$ & $\mathrm{a}$ & $\mathrm{a}$ & $\mathrm{a}$ & $\mathrm{a}$ & $\mathrm{a}$ & $\mathrm{a}$ & $\mathrm{a}$ & 0.29 & $\mathrm{a}$ \\
\hline CJ13-32-42AS & 8 & $\mathrm{a}$ & $\mathrm{a}$ & $\mathrm{a}$ & $\mathrm{a}$ & $\mathrm{a}$ & $\mathrm{a}$ & $\mathrm{a}$ & $\mathrm{a}$ & $\mathrm{a}$ & $\mathrm{a}$ & $\mathrm{a}$ & 0.23 & $\mathrm{a}$ \\
\hline CJ13-32-43AS & 9 & $\mathrm{a}$ & $\mathrm{a}$ & $\mathrm{a}$ & $\mathrm{a}$ & $\mathrm{a}$ & $\mathrm{a}$ & $\mathrm{a}$ & $\mathrm{a}$ & $\mathrm{a}$ & $\mathrm{a}$ & $\mathrm{a}$ & 0.27 & $\mathrm{a}$ \\
\hline CJ13-32-44AS & 10 & $\mathrm{a}$ & $\mathrm{a}$ & $\mathrm{a}$ & $\mathrm{a}$ & $\mathrm{a}$ & $\mathrm{a}$ & $\mathrm{a}$ & $\mathrm{a}$ & $\mathrm{a}$ & $\mathrm{a}$ & $\mathrm{a}$ & 0.28 & $\mathrm{a}$ \\
\hline CJ13-32-45AS & 11 & $\mathrm{a}$ & $\mathrm{a}$ & $\mathrm{a}$ & $\mathrm{a}$ & $\mathrm{a}$ & $\mathrm{a}$ & $\mathrm{a}$ & $\mathrm{a}$ & $\mathrm{a}$ & $\mathrm{a}$ & $\mathrm{a}$ & 0.44 & $\mathrm{a}$ \\
\hline CJ13-32-162AS & control & 2.4 & $\mathrm{a}$ & 3.6 & $\mathrm{a}$ & $\mathrm{a}$ & $\mathrm{a}$ & $\mathrm{a}$ & $\mathrm{a}$ & $\mathrm{a}$ & $\mathrm{a}$ & $\mathrm{a}$ & 0.34 & $\mathrm{a}$ \\
\hline $10 \mathrm{KCl}-32-81 \mathrm{AS}$ & 13 & 6.0 & $\mathrm{a}$ & $\mathrm{a}$ & $\mathrm{a}$ & $\mathrm{a}$ & $\mathrm{a}$ & $\mathrm{a}$ & $\mathrm{a}$ & $\mathrm{a}$ & $\mathrm{a}$ & $\mathrm{a}$ & 0.19 & $\mathrm{a}$ \\
\hline $10 \mathrm{KCl}-32-82 \mathrm{AS}$ & 14 & 4.8 & $\mathrm{a}$ & $\mathrm{a}$ & $\mathrm{a}$ & $\mathrm{a}$ & $\mathrm{a}$ & $\mathrm{a}$ & $\mathrm{a}$ & $\mathrm{a}$ & $\mathrm{a}$ & $\mathrm{a}$ & 0.34 & $\mathrm{a}$ \\
\hline $10 \mathrm{KCl}-32-83 \mathrm{AS}$ & 15 & 5.0 & $\mathrm{a}$ & $\mathrm{a}$ & $\mathrm{a}$ & $\mathrm{a}$ & $\mathrm{a}$ & $\mathrm{a}$ & $\mathrm{a}$ & $\mathrm{a}$ & $\mathrm{a}$ & $\mathrm{a}$ & 0.41 & $\mathrm{a}$ \\
\hline $10 \mathrm{KCl}-32-84 \mathrm{AS}$ & 16 & 29.6 & 13.7 & $\mathrm{a}$ & $\bar{a}$ & 0.030 & $\bar{a}$ & 0.038 & 0.153 & 0.93 & $\mathrm{a}$ & $\bar{a}$ & 0.60 & $\mathrm{a}$ \\
\hline $10 \mathrm{KCl}-32-85 \mathrm{AS}$ & 17 & 32.7 & 6.8 & $\bar{a}$ & $\bar{a}$ & $\mathrm{a}$ & $\bar{a}$ & $\bar{a}$ & 0.045 & 0.92 & $\mathrm{a}$ & $\bar{a}$ & 0.59 & $\mathrm{a}$ \\
\hline $10 \mathrm{KCl}-32-163 \mathrm{AS}$ & control & $\mathrm{a}$ & $\mathrm{a}$ & $\mathrm{a}$ & $\mathrm{a}$ & $\mathrm{a}$ & $\mathrm{a}$ & $\mathrm{a}$ & $\mathrm{a}$ & $\mathrm{a}$ & $\mathrm{a}$ & $\mathrm{a}$ & 0.37 & $\mathrm{a}$ \\
\hline AJ13-32-121AS & 19 & 119.4 & 87.2 & 62.1 & $\mathrm{a}$ & 0.027 & 0.049 & 0.296 & 1.134 & 1.40 & 16.72 & 2.39 & 8.60 & $\mathrm{a}$ \\
\hline AJ13-32-122AS & 20 & 77.6 & 84.9 & 47.3 & 4.7 & 0.243 & 0.070 & 0.657 & 2.559 & 1.07 & 13.46 & 1.88 & 5.54 & $\mathrm{a}$ \\
\hline AJ13-32-123AS & 21 & 117.6 & 51.8 & 82.3 & $\mathrm{a}$ & 0.024 & $\mathrm{a}$ & 0.236 & 0.929 & $\mathrm{a}$ & 19.41 & 2.73 & 4.82 & $\mathrm{a}$ \\
\hline AJ13-32-124AS & 22 & 154.7 & 124.4 & 118.8 & $\mathrm{a}$ & 0.092 & 0.047 & 0.306 & 1.300 & 1.13 & 29.59 & 4.16 & 9.69 & $\mathrm{a}$ \\
\hline AJ13-32-125AS & 23 & 118.9 & 80.0 & 59.5 & 1.2 & 0.077 & 0.023 & 0.338 & 1.353 & 0.71 & 15.48 & 2.20 & 6.26 & $\mathrm{a}$ \\
\hline AJ13-32-164AS & control & $\mathrm{a}$ & $\mathrm{a}$ & $\mathrm{a}$ & $\mathrm{a}$ & $\mathrm{a}$ & $\mathrm{a}$ & $\mathrm{a}$ & $\mathrm{a}$ & $\mathrm{a}$ & $\mathrm{a}$ & $\mathrm{a}$ & 0.29 & $\mathrm{a}$ \\
\hline
\end{tabular}

${ }^{\mathrm{a}}$ Element below detection limits of measuring instrument. 
Table F-30. Residue $\left(\mathrm{ng} / \mathrm{mm}^{2}\right)$ from SS15ZR26 Specimens Immersed in $363 \mathrm{~K}\left(90^{\circ} \mathrm{C}\right)$ Solution for 224 days.

\begin{tabular}{|c|c|c|c|c|c|c|c|c|c|c|c|c|c|c|}
\hline \multirow[b]{2}{*}{ Expt. ID } & \multirow[b]{2}{*}{ Ingot ID } & \multicolumn{4}{|c|}{ Major Elements } & \multicolumn{5}{|c|}{ Noble Metal Fission Products } & \multicolumn{4}{|c|}{ Minor Elements } \\
\hline & & $\mathrm{Fe}$ & $\mathrm{Cr}$ & $\mathrm{Ni}$ & $\mathrm{Zr}$ & $\mathrm{Nb}$ & $\mathrm{Pd}$ & $\mathrm{Rh}$ & $\mathrm{Ru}$ & Mo & $\mathrm{Mn}$ & $\mathrm{Co}$ & $\mathrm{Cu}$ & $\mathrm{V}$ \\
\hline \multicolumn{15}{|c|}{ Detection Limits not available } \\
\hline AJ13-32-121R & 19 & 71396 & 13324 & 13324 & 60.7 & 39.3 & 3.0 & 37.8 & 142 & 1092 & 325 & 65.5 & 161 & 137 \\
\hline AJ13-32-122R & 20 & 83220 & 20418 & 20418 & 98.6 & 38.9 & 3.2 & 28.5 & 112 & 1475 & 330 & 71.9 & 105 & 130 \\
\hline AJ13-32-123R & 21 & 73215 & 11414 & 11414 & 50.5 & 19.3 & 1.0 & 15.8 & 64.8 & 499 & 318 & 71.1 & 101 & 81.8 \\
\hline AJ13-32-124R & 22 & 68213 & 16553 & 16553 & 23.6 & 30.0 & 2.2 & 19.4 & 69.3 & 1013 & 300 & 70.9 & 113 & 106 \\
\hline AJ13-32-125R & 23 & 68668 & 16644 & 16644 & 134.4 & 38.1 & 2.1 & 28.4 & 98.5 & 1204 & 284 & 66.1 & 129 & 108 \\
\hline
\end{tabular}


Table F-31. Leachate Data $\left(\mathrm{ng} / \mathrm{mm}^{2}\right)$ from SS15ZR26 Specimens Immersed in $363 \mathrm{~K}\left(90^{\circ} \mathrm{C}\right)$ Solution for 308 days.

\begin{tabular}{|c|c|c|c|c|c|c|c|c|c|c|c|c|c|c|}
\hline \multirow[b]{2}{*}{ Expt. ID } & \multirow[b]{2}{*}{ Ingot ID } & \multicolumn{4}{|c|}{ Major Elements } & \multicolumn{5}{|c|}{ Noble Metal Fission Products } & \multicolumn{4}{|c|}{ Minor Elements } \\
\hline & & $\mathrm{Fe}$ & $\mathrm{Cr}$ & $\mathrm{Ni}$ & $\mathrm{Zr}$ & $\mathrm{Nb}$ & $\mathrm{Pd}$ & $\mathrm{Rh}$ & $\mathrm{Ru}$ & Mo & $\mathrm{Mn}$ & Co & $\mathrm{Cu}$ & $\mathrm{V}$ \\
\hline \multicolumn{2}{|c|}{ Detection Limits } & 2.0 & 2.0 & 2.0 & 0.020 & 0.020 & 0.020 & 0.031 & 0.031 & 0.51 & 0.31 & 0.020 & 0.41 & 1.1 \\
\hline SJ13-44-6 & 1 & $\mathrm{a}$ & $\mathrm{a}$ & $\mathrm{a}$ & 0.085 & $\mathrm{a}$ & $\mathrm{a}$ & $\mathrm{a}$ & $\mathrm{a}$ & $\mathrm{a}$ & $\mathrm{a}$ & $\mathrm{a}$ & $\mathrm{a}$ & $\mathrm{a}$ \\
\hline SJ13-44-7 & 2 & $\mathrm{a}$ & $\mathrm{a}$ & $\mathrm{a}$ & 0.108 & $\mathrm{a}$ & $\mathrm{a}$ & $\mathrm{a}$ & $\mathrm{a}$ & $\mathrm{a}$ & $\mathrm{a}$ & $\mathrm{a}$ & $\mathrm{a}$ & $\mathrm{a}$ \\
\hline SJ13-44-8 & 3 & $\mathrm{a}$ & $\mathrm{a}$ & $\mathrm{a}$ & 0.106 & $\mathrm{a}$ & $\mathrm{a}$ & $\mathrm{a}$ & $\mathrm{a}$ & $\mathrm{a}$ & $\mathrm{a}$ & $\mathrm{a}$ & $\mathrm{a}$ & $\mathrm{a}$ \\
\hline SJ13-44-9 & 4 & $\mathrm{a}$ & $\mathrm{a}$ & $\mathrm{a}$ & 0.111 & $\mathrm{a}$ & $\mathrm{a}$ & $\mathrm{a}$ & $\mathrm{a}$ & $\mathrm{a}$ & $\mathrm{a}$ & $\mathrm{a}$ & $\mathrm{a}$ & $\mathrm{a}$ \\
\hline SJ13-44-10 & 5 & $\mathrm{a}$ & $\bar{a}$ & $\bar{a}$ & 0.160 & $a$ & $\bar{a}$ & $\bar{a}$ & $\bar{a}$ & $\bar{a}$ & $\bar{a}$ & $a$ & $\mathrm{a}$ & $\mathrm{a}$ \\
\hline SJ13-44-165 & control & $\mathrm{a}$ & $\mathrm{a}$ & $\mathrm{a}$ & 0.322 & $\mathrm{a}$ & $\mathrm{a}$ & $\mathrm{a}$ & $\mathrm{a}$ & 1.04 & $\mathrm{a}$ & $\mathrm{a}$ & $\mathrm{a}$ & $\mathrm{a}$ \\
\hline CJ13-44-46 & 7 & $\mathrm{a}$ & $\mathrm{a}$ & $\mathrm{a}$ & 1.48 & $\mathrm{a}$ & 0.053 & $\mathrm{a}$ & $\mathrm{a}$ & 0.61 & $\mathrm{a}$ & 0.021 & $\mathrm{a}$ & $\mathrm{a}$ \\
\hline CJ13-44-47 & 8 & $\mathrm{a}$ & $\mathrm{a}$ & $\mathrm{a}$ & 1.47 & $\mathrm{a}$ & 0.049 & $\mathrm{a}$ & $\mathrm{a}$ & 0.98 & $\mathrm{a}$ & 0.021 & $\mathrm{a}$ & $\mathrm{a}$ \\
\hline CJ13-44-48 & 9 & $\mathrm{a}$ & $\mathrm{a}$ & $\mathrm{a}$ & 1.32 & $\mathrm{a}$ & 0.051 & $\mathrm{a}$ & $\mathrm{a}$ & 1.02 & $\mathrm{a}$ & $\mathrm{a}$ & $\mathrm{a}$ & $\mathrm{a}$ \\
\hline CJ13-44-49 & 10 & $\mathrm{a}$ & $\mathrm{a}$ & $\mathrm{a}$ & 1.61 & $\mathrm{a}$ & 0.037 & 0.033 & 0.041 & 1.44 & $\mathrm{a}$ & $\mathrm{a}$ & $\mathrm{a}$ & $\mathrm{a}$ \\
\hline CJ13-44-50 & 11 & $\mathrm{a}$ & $\mathrm{a}$ & $\mathrm{a}$ & 1.83 & $\mathrm{a}$ & 0.038 & 0.045 & 0.061 & 1.17 & $\mathrm{a}$ & 0.022 & 0.48 & $\mathrm{a}$ \\
\hline CJ13-44-166 & control & $\mathrm{a}$ & $\mathrm{a}$ & $\mathrm{a}$ & 1.22 & $\mathrm{a}$ & 0.044 & 0.035 & 0.049 & 1.30 & $\mathrm{a}$ & 0.025 & 0.45 & $\mathrm{a}$ \\
\hline $10 \mathrm{KCl}-44-86$ & 13 & $\mathrm{a}$ & $\mathrm{a}$ & 6.0 & 0.028 & $\mathrm{a}$ & 0.058 & $\mathrm{a}$ & $\mathrm{a}$ & 1.09 & 2.03 & 0.268 & 0.58 & 1.5 \\
\hline $10 \mathrm{KCl}-44-87$ & 14 & $\mathrm{a}$ & $\mathrm{a}$ & $\mathrm{a}$ & $\mathrm{a}$ & $\mathrm{a}$ & 0.052 & $\mathrm{a}$ & $\mathrm{a}$ & 1.54 & 0.82 & 0.112 & 0.45 & 1.3 \\
\hline $10 \mathrm{KCl}-44-88$ & 15 & $\mathrm{a}$ & 21.9 & $\mathrm{a}$ & $\mathrm{a}$ & $\mathrm{a}$ & 0.068 & $\mathrm{a}$ & $\mathrm{a}$ & 9.91 & $\mathrm{a}$ & 0.035 & 0.39 & 1.3 \\
\hline $10 \mathrm{KCl}-44-89$ & 16 & $\mathrm{a}$ & 9.7 & 4.1 & 0.035 & $a$ & 0.128 & $\mathrm{a}$ & $\bar{a}$ & 18.6 & 0.89 & 0.157 & 0.46 & 1.3 \\
\hline $10 \mathrm{KCl}-44-90$ & 17 & 2.3 & 4.2 & 2.3 & 0.025 & $\mathrm{a}$ & 0.065 & $\mathrm{a}$ & $\mathrm{a}$ & 13.9 & 1.00 & 0.169 & 0.61 & 1.3 \\
\hline $10 \mathrm{KCl}-44-167$ & control & $\mathrm{a}$ & $\mathrm{a}$ & $\mathrm{a}$ & $\mathrm{a}$ & $\mathrm{a}$ & 0.037 & $\mathrm{a}$ & $\mathrm{a}$ & $\mathrm{a}$ & $\mathrm{a}$ & $\mathrm{a}$ & 0.53 & 1.4 \\
\hline AJ13-44-126 & 19 & 9364 & 5766 & 7555 & 1.06 & 2.01 & 0.164 & 4.34 & 19.6 & 16.9 & 2078 & 289 & 358 & 1.5 \\
\hline AJ13-44-127 & 20 & 3730 & 3811 & 7035 & 0.955 & 2.89 & 0.361 & 6.83 & 30.2 & 21.5 & 2006 & 50.2 & 57.8 & 1.1 \\
\hline AJ13-44-128 & 21 & 4546 & 2598 & 8230 & 0.207 & 1.61 & 0.177 & 6.18 & 33.0 & 7.01 & 2184 & 51.1 & 32.6 & 9.5 \\
\hline AJ13-44-129 & 22 & 1730 & 1667 & 6072 & 0.186 & 0.953 & 0.066 & 2.85 & 13.3 & 5.41 & 1784 & 50.8 & 55.5 & 18.2 \\
\hline AJ13-44-130 & 23 & 2283 & 3910 & 6597 & 1.36 & 0.739 & 0.045 & 1.84 & 7.43 & 6.57 & 1970 & 60.3 & 72.5 & 11 \\
\hline AJ13-44-168 & control & $\mathrm{a}$ & $\mathrm{a}$ & 5.0 & 0.209 & $\mathrm{a}$ & $\mathrm{a}$ & $\mathrm{a}$ & $\mathrm{a}$ & $\mathrm{a}$ & $\mathrm{a}$ & 0.027 & 0.50 & $\mathrm{a}$ \\
\hline
\end{tabular}

${ }^{\mathrm{a}}$ Element below detection limits of measuring instrument. 
Table F-32. Acid Strip Data $\left(\mathrm{ng} / \mathrm{mm}^{2}\right)$ from SS15ZR26 Specimens Immersed in $363 \mathrm{~K}\left(90^{\circ} \mathrm{C}\right)$ Solution for 308 days.

\begin{tabular}{|c|c|c|c|c|c|c|c|c|c|c|c|c|c|c|}
\hline \multirow[b]{2}{*}{ Expt. ID } & \multirow[b]{2}{*}{ Ingot ID } & \multicolumn{4}{|c|}{ Major Elements } & \multicolumn{5}{|c|}{ Noble Metal Fission Products } & \multicolumn{4}{|c|}{ Minor Elements } \\
\hline & & $\mathrm{Fe}$ & $\mathrm{Cr}$ & $\mathrm{Ni}$ & $\overline{\mathrm{Zr}}$ & $\mathrm{Nb}$ & $\mathrm{Pd}$ & $\mathrm{Rh}$ & $\mathrm{Ru}$ & Mo & $\mathrm{Mn}$ & $\mathrm{Co}$ & $\mathrm{Cu}$ & $\mathrm{V}$ \\
\hline \multicolumn{2}{|c|}{ Detection Limits } & 2.0 & 2.0 & 2.0 & 0.02 & 0.04 & 0.03 & 0.03 & 0.04 & 0.06 & 0.05 & 0.03 & 0.06 & 0.06 \\
\hline SJ13-44-6AS & 1 & $\bar{a}$ & $\bar{a}$ & $\bar{a}$ & 0.38 & $\bar{a}$ & $\mathrm{a}$ & $\bar{a}$ & $\mathrm{a}$ & $\mathrm{a}$ & $\mathrm{a}$ & $\bar{a}$ & 0.29 & $\bar{a}$ \\
\hline SJ13-44-7AS & 2 & $\mathrm{a}$ & $\mathrm{a}$ & $\mathrm{a}$ & 0.23 & $\mathrm{a}$ & $\mathrm{a}$ & $\mathrm{a}$ & $\mathrm{a}$ & $\mathrm{a}$ & $\mathrm{a}$ & $\mathrm{a}$ & 0.30 & $\mathrm{a}$ \\
\hline SJ13-44-8AS & 3 & $\mathrm{a}$ & $\mathrm{a}$ & 3.2 & 0.30 & $\mathrm{a}$ & $\mathrm{a}$ & $\mathrm{a}$ & $\mathrm{a}$ & $\mathrm{a}$ & $\mathrm{a}$ & $\mathrm{a}$ & 0.29 & $\mathrm{a}$ \\
\hline SJ13-44-9AS & 4 & $\mathrm{a}$ & $\mathrm{a}$ & $\mathrm{a}$ & 0.37 & $\mathrm{a}$ & $\mathrm{a}$ & $\mathrm{a}$ & $\mathrm{a}$ & $\mathrm{a}$ & $\mathrm{a}$ & $\mathrm{a}$ & 0.33 & $\mathrm{a}$ \\
\hline SJ13-44-10AS & 5 & 3.1 & $\bar{a}$ & 3.8 & 0.44 & $\mathrm{a}$ & $\mathrm{a}$ & $a$ & $a$ & 0.11 & $\mathrm{a}$ & $\bar{a}$ & 17.46 & $\mathrm{a}$ \\
\hline SJ13-44-165AS & control & $\mathrm{a}$ & $\mathrm{a}$ & 4.4 & 0.42 & $\bar{a}$ & $\bar{a}$ & $\mathrm{a}$ & $\mathrm{a}$ & $\mathrm{a}$ & 0.06 & $\mathrm{a}$ & 0.66 & $\mathrm{a}$ \\
\hline CJ13-44-46AS & 7 & $\mathrm{a}$ & $\mathrm{a}$ & 4.8 & 0.09 & $\mathrm{a}$ & $\mathrm{a}$ & $\mathrm{a}$ & $\mathrm{a}$ & $\mathrm{a}$ & $\mathrm{a}$ & $\mathrm{a}$ & 0.29 & $\mathrm{a}$ \\
\hline CJ13-44-47AS & 8 & 5.9 & $\mathrm{a}$ & $\mathrm{a}$ & 0.05 & $\mathrm{a}$ & $\mathrm{a}$ & $\mathrm{a}$ & $\mathrm{a}$ & 0.10 & $\mathrm{a}$ & $\mathrm{a}$ & 0.63 & $\mathrm{a}$ \\
\hline CJ13-44-48AS & 9 & $\mathrm{a}$ & $\mathrm{a}$ & 3.4 & 0.05 & $\mathrm{a}$ & $\mathrm{a}$ & $\mathrm{a}$ & $\mathrm{a}$ & 0.19 & $\mathrm{a}$ & $\mathrm{a}$ & 0.23 & $\mathrm{a}$ \\
\hline CJ13-44-49AS & 10 & $\mathrm{a}$ & $\mathrm{a}$ & $\bar{a}$ & 0.05 & $\mathrm{a}$ & $\mathrm{a}$ & $\mathrm{a}$ & $\mathrm{a}$ & 0.08 & $\mathrm{a}$ & $\mathrm{a}$ & 0.20 & 0.09 \\
\hline CJ13-44-50AS & 11 & $\mathrm{a}$ & $\mathrm{a}$ & $\mathrm{a}$ & 0.06 & $\mathrm{a}$ & $\mathrm{a}$ & $\mathrm{a}$ & $\mathrm{a}$ & $\mathrm{a}$ & $\mathrm{a}$ & $\mathrm{a}$ & 0.18 & $\mathrm{a}$ \\
\hline CJ13-44-166AS & control & 3.2 & $\mathrm{a}$ & $\mathrm{a}$ & 0.26 & $\mathrm{a}$ & $\mathrm{a}$ & $\mathrm{a}$ & $\mathrm{a}$ & 0.08 & $\mathrm{a}$ & $\mathrm{a}$ & 0.67 & 0.13 \\
\hline $10 \mathrm{KCl}-44-86 \mathrm{AS}$ & 13 & 2.8 & $\bar{a}$ & $\bar{a}$ & 0.13 & $\bar{a}$ & $\mathrm{a}$ & $a$ & $\bar{a}$ & 0.10 & 0.06 & $\bar{a}$ & 0.27 & 1.00 \\
\hline $10 \mathrm{KCl}-44-87 \mathrm{AS}$ & 14 & 3.6 & $\mathrm{a}$ & $\mathrm{a}$ & 0.06 & $\mathrm{a}$ & $\mathrm{a}$ & $\mathrm{a}$ & $\mathrm{a}$ & 0.10 & $\mathrm{a}$ & $\mathrm{a}$ & 0.24 & 0.85 \\
\hline $10 \mathrm{KCl}-44-88 \mathrm{AS}$ & 15 & $\mathrm{a}$ & $\mathrm{a}$ & $\mathrm{a}$ & 0.09 & $\mathrm{a}$ & $\mathrm{a}$ & $\mathrm{a}$ & $\mathrm{a}$ & 0.12 & $\mathrm{a}$ & $\mathrm{a}$ & 0.20 & 0.32 \\
\hline $10 \mathrm{KCl}-44-89 \mathrm{AS}$ & 16 & 11.6 & 4.6 & $\bar{a}$ & 0.06 & $\mathrm{a}$ & $\bar{a}$ & $\mathrm{a}$ & $\mathrm{a}$ & 0.29 & 0.07 & $\bar{a}$ & 0.34 & 0.16 \\
\hline $10 \mathrm{KCl}-44-90 \mathrm{AS}$ & 17 & 9.4 & 4.4 & $\mathrm{a}$ & 0.05 & $\mathrm{a}$ & $\mathrm{a}$ & $\mathrm{a}$ & $\mathrm{a}$ & 0.22 & $\mathrm{a}$ & $\mathrm{a}$ & 0.32 & $\mathrm{a}$ \\
\hline $10 \mathrm{KCl}-44-167 \mathrm{AS}$ & control & $\mathrm{a}$ & $\mathrm{a}$ & $\mathrm{a}$ & $\mathrm{a}$ & $\mathrm{a}$ & $\mathrm{a}$ & $\mathrm{a}$ & $\mathrm{a}$ & $\mathrm{a}$ & $\mathrm{a}$ & $\mathrm{a}$ & 0.19 & $\mathrm{a}$ \\
\hline AJ13-44-126AS & 19 & 428.0 & 195.8 & 108.3 & 2.45 & 0.40 & 0.25 & 1.06 & 4.63 & 5.18 & 25.73 & 3.62 & 5.12 & 0.43 \\
\hline AJ13-44-127AS & 20 & 549.3 & 192.0 & 60.4 & 9.21 & 0.58 & 1.14 & 0.98 & 3.55 & 5.89 & 14.74 & 2.09 & 2.88 & 0.43 \\
\hline AJ13-44-128AS & 21 & 390.1 & 191.3 & 216.2 & 0.20 & 0.29 & 0.36 & 1.22 & 5.79 & 2.24 & 45.22 & 6.47 & 7.62 & 0.18 \\
\hline AJ13-44-129AS & 22 & 215.6 & 101.7 & 100.5 & 2.43 & 0.24 & 0.29 & 0.84 & 3.73 & 2.48 & 23.86 & 3.44 & 4.27 & 0.22 \\
\hline AJ13-44-130AS & 23 & 907.7 & 293.2 & 91.0 & 2.23 & 0.75 & 0.15 & 1.02 & 4.47 & 17.12 & 22.48 & 3.16 & 5.11 & 1.05 \\
\hline AJ13-44-168AS & control & $\mathrm{a}$ & $\mathrm{a}$ & $\mathrm{a}$ & 0.08 & $\mathrm{a}$ & $\mathrm{a}$ & $\mathrm{a}$ & $\mathrm{a}$ & 0.09 & $\mathrm{a}$ & $\mathrm{a}$ & 0.16 & 0.09 \\
\hline
\end{tabular}

${ }^{\mathrm{a}}$ Element below detection limits of measuring instrument. 
Table F-33. Residue $\left(\mathrm{ng} / \mathrm{mm}^{2}\right)$ from SS15ZR26 Specimens Immersed in $363 \mathrm{~K}\left(90^{\circ} \mathrm{C}\right)$ Solution for 308 days.

\begin{tabular}{|c|c|c|c|c|c|c|c|c|c|c|c|c|c|c|}
\hline \multirow[b]{2}{*}{ Expt. ID } & \multirow[b]{2}{*}{ Ingot ID } & \multicolumn{4}{|c|}{ Major Elements } & \multicolumn{5}{|c|}{ Noble Metal Fission Products } & \multicolumn{4}{|c|}{ Minor Elements } \\
\hline & & $\mathrm{Fe}$ & $\mathrm{Cr}$ & $\mathrm{Ni}$ & $\mathrm{Zr}$ & $\mathrm{Nb}$ & $\mathrm{Pd}$ & $\mathrm{Rh}$ & $\mathrm{Ru}$ & Mo & $\mathrm{Mn}$ & $\mathrm{Co}$ & $\mathrm{Cu}$ & $\mathrm{V}$ \\
\hline \multicolumn{15}{|c|}{ Detection Limits not available } \\
\hline AJ13-44-126R & 19 & 85493 & 23101 & 2383 & 2.32 & 4.58 & 0.22 & 3.67 & 15.67 & 153.9 & 58.07 & 11.01 & 21.21 & 12.26 \\
\hline AJ13-44-127R & 20 & 90041 & 23283 & 2192 & 4.15 & 4.81 & 0.40 & 4.10 & 15.88 & 164.6 & 54.05 & 10.57 & 15.06 & 13.11 \\
\hline AJ13-44-128R & 21 & 86403 & 15962 & 2715 & 0.94 & 3.30 & 0.18 & 2.94 & 13.07 & 85.99 & 59.88 & 11.56 & 18.18 & 9.60 \\
\hline AJ13-44-129R & 22 & 82765 & 18145 & 2055 & 1.61 & 3.48 & 0.21 & 2.83 & 12.16 & 100.7 & 44.65 & 8.31 & 13.18 & 9.70 \\
\hline AJ13-44-130R & 23 & 89131 & 24147 & 2233 & 8.94 & 5.12 & 0.24 & 4.61 & 18.38 & 184.4 & 54.90 & 10.30 & 19.69 & 13.92 \\
\hline
\end{tabular}




\section{G. Detection Limits}

Table G-1. Iron Detection Limits in Leachate Data $\left(\mathrm{ng} / \mathrm{mm}^{2}\right)$.

\begin{tabular}{|c|c|c|c|c|c|c|c|c|c|c|c|}
\hline Sample \# & 1 & 2 & 3 & 4 & 6 & 8 & 10 & 14 & 22 & 32 & 44 \\
\hline 1 & 1.97 & 1.96 & 1.97 & 2.01 & 2.01 & 2.03 & 2.03 & 1.97 & 2.00 & 2.06 & 2.06 \\
\hline 2 & 1.97 & 1.97 & 1.94 & 2.03 & 2.02 & 2.03 & 2.03 & 1.94 & 2.07 & 2.03 & 2.07 \\
\hline 3 & 1.97 & 1.97 & 1.96 & 2.00 & 2.02 & 2.04 & 2.04 & 1.95 & 2.00 & 2.03 & 2.06 \\
\hline 4 & 1.97 & 1.96 & 1.97 & 2.01 & 2.01 & 2.02 & 2.04 & 1.96 & 1.99 & 2.03 & 2.05 \\
\hline 5 & 1.97 & 1.97 & 1.97 & 2.02 & 2.01 & 2.01 & 2.03 & 1.96 & 2.00 & 2.04 & 2.06 \\
\hline SJ13 control & 1.98 & 1.97 & 1.98 & 2.03 & 2.02 & 2.02 & 2.04 & 1.96 & 2.00 & 2.04 & 2.05 \\
\hline 7 & 2.00 & 2.04 & 1.98 & 2.03 & 2.04 & 2.03 & 2.10 & 1.98 & 2.02 & 2.09 & 2.10 \\
\hline 8 & 2.00 & 1.99 & 2.00 & 2.05 & 2.03 & 2.05 & 2.09 & 1.98 & 2.03 & 2.07 & 2.09 \\
\hline 9 & 2.00 & 2.00 & 2.00 & 2.05 & 2.03 & 2.05 & 2.09 & 1.97 & 2.02 & 2.07 & 2.10 \\
\hline 10 & 1.99 & 1.99 & 1.99 & 2.03 & 2.04 & 2.05 & 2.10 & 1.97 & 2.03 & 2.07 & 2.10 \\
\hline 11 & 2.09 & 2.00 & 2.00 & 2.05 & 2.05 & 2.03 & 2.08 & 1.97 & 2.03 & 2.07 & 2.10 \\
\hline CJ13 control & 1.99 & 1.98 & 2.00 & 2.04 & 2.05 & 2.04 & 2.09 & 1.97 & 2.03 & 2.09 & 2.12 \\
\hline 13 & 1.98 & 2.00 & 1.79 & 2.03 & 2.04 & 2.05 & 2.06 & 1.99 & 2.02 & 1.99 & 2.07 \\
\hline 14 & 2.00 & 1.98 & 2.00 & 2.05 & 2.03 & 2.02 & 2.05 & 1.98 & 2.01 & 2.00 & 2.09 \\
\hline 15 & 2.00 & 1.99 & 2.00 & 2.04 & 2.04 & 2.10 & 2.06 & 1.98 & 2.02 & 2.00 & 2.10 \\
\hline 16 & 1.99 & 1.98 & 1.99 & 2.03 & 2.05 & 2.04 & 2.07 & 1.98 & 2.01 & 2.01 & 2.09 \\
\hline 17 & 1.99 & 2.00 & 2.00 & 2.02 & 2.05 & 2.05 & 2.06 & 1.98 & 2.02 & 2.00 & 2.10 \\
\hline $10 \mathrm{KCl}$ control & 1.99 & 1.98 & 2.00 & 2.03 & 2.02 & 2.03 & 2.07 & 1.98 & 2.01 & 2.00 & 2.09 \\
\hline 19 & 1.96 & 1.97 & 1.98 & 2.02 & 2.01 & 2.01 & 2.11 & 1.94 & 1.83 & 2.04 & 2.06 \\
\hline 20 & 1.97 & 1.96 & 1.97 & 2.03 & 2.02 & 2.03 & 2.13 & 1.95 & 1.83 & 2.04 & 2.08 \\
\hline 21 & 1.98 & 1.95 & 1.96 & 2.03 & 2.00 & 2.03 & 2.12 & 1.95 & 1.88 & 2.04 & 2.09 \\
\hline 22 & 1.97 & 1.96 & 1.97 & 2.03 & 2.00 & 1.98 & 2.12 & 1.95 & 1.90 & 2.05 & 2.09 \\
\hline 23 & 1.96 & 1.97 & 1.97 & 2.02 & 2.01 & 2.00 & 2.12 & 1.94 & 1.74 & 2.03 & 2.06 \\
\hline AJ13 control & 1.97 & 1.94 & 1.96 & 2.02 & 2.02 & 1.97 & 2.12 & 1.95 & 1.98 & 2.07 & 2.08 \\
\hline Average & 1.99 & 1.98 & 1.97 & 2.03 & 2.03 & 2.03 & 2.08 & 1.96 & 1.98 & 2.04 & 2.08 \\
\hline Standard Deviation & 0.03 & 0.02 & 0.04 & 0.01 & 0.02 & 0.03 & 0.03 & 0.02 & 0.08 & 0.03 & 0.02 \\
\hline
\end{tabular}


Table G-2. Iron Detection Limits in Acid Strip Data (ng/mm²).

\begin{tabular}{|c|c|c|c|c|c|c|c|c|c|c|c|}
\hline Sample \# & 1 & 2 & 3 & 4 & 6 & 8 & 10 & 14 & 22 & 32 & 44 \\
\hline 1 & 2.29 & 2.25 & 2.35 & 2.27 & 2.33 & 2.10 & 2.28 & 2.28 & 2.27 & 2.23 & 2.29 \\
\hline 2 & 2.30 & 2.31 & 2.35 & 2.22 & 2.23 & 2.30 & 2.28 & 2.34 & 2.30 & 2.53 & 2.38 \\
\hline 3 & 2.28 & 2.08 & 2.32 & 2.30 & 2.25 & 2.14 & 2.24 & 2.23 & 2.52 & 2.44 & 2.44 \\
\hline 4 & 2.01 & 2.21 & 2.33 & 2.26 & 2.07 & 2.24 & 2.21 & 2.30 & 2.29 & 2.30 & 2.44 \\
\hline 5 & 2.22 & 2.27 & 2.31 & 2.28 & 2.21 & 2.24 & 2.08 & 2.24 & 2.27 & 2.53 & 2.31 \\
\hline SJ13 control & 2.28 & 2.23 & 2.28 & 2.14 & 2.21 & 2.28 & 2.27 & 2.24 & 2.30 & 2.44 & 2.51 \\
\hline 7 & 2.38 & 2.28 & 2.33 & 2.33 & 2.24 & 2.17 & 2.18 & 2.23 & 2.28 & 2.49 & 2.44 \\
\hline 8 & 2.34 & 2.16 & 2.32 & 2.22 & 2.18 & 2.24 & 2.26 & 2.27 & 2.52 & 2.45 & 2.48 \\
\hline 9 & 2.34 & 2.28 & 2.33 & 2.25 & 2.20 & 2.20 & 2.19 & 2.24 & 2.36 & 2.49 & 2.29 \\
\hline 10 & 2.24 & 2.20 & 2.32 & 2.24 & 2.15 & 2.17 & 2.27 & 2.25 & 2.27 & 2.49 & 2.26 \\
\hline 11 & 2.23 & 2.24 & 2.33 & 2.30 & 2.13 & 2.24 & 2.20 & 2.31 & 2.22 & 2.46 & 2.36 \\
\hline CJ13 control & 2.14 & 2.24 & 2.40 & 2.23 & 2.25 & 2.21 & 2.30 & 2.28 & 2.31 & 2.38 & 2.46 \\
\hline 13 & 2.30 & 2.22 & 2.25 & 2.24 & 2.14 & 2.24 & 2.19 & 2.27 & 2.34 & 2.40 & 2.42 \\
\hline 14 & 2.23 & 2.29 & 2.31 & 2.29 & 2.32 & 2.29 & 2.25 & 2.27 & 2.27 & 2.38 & 2.52 \\
\hline 15 & 2.24 & 2.28 & 2.34 & 2.30 & 2.15 & 2.30 & 2.18 & 2.27 & 2.33 & 2.52 & 2.38 \\
\hline 16 & 2.21 & 2.28 & 2.33 & 2.23 & 2.11 & 2.15 & 2.18 & 2.27 & 2.34 & 2.28 & 2.40 \\
\hline 17 & 2.20 & 2.29 & 2.31 & 2.24 & 2.17 & 2.22 & 2.20 & 2.25 & 2.26 & 2.26 & 2.20 \\
\hline $10 \mathrm{KCl}$ control & 2.24 & 2.27 & 2.36 & 2.19 & 2.24 & 2.32 & 2.19 & 2.32 & 2.36 & 2.34 & 2.46 \\
\hline 19 & 2.35 & 2.29 & 2.22 & 2.19 & 2.28 & 2.24 & 2.23 & 2.23 & 2.33 & 2.39 & 2.46 \\
\hline 20 & 2.31 & 2.28 & 2.35 & 2.17 & 2.32 & 2.17 & 2.14 & 2.22 & 2.24 & 2.43 & 2.29 \\
\hline 21 & 2.34 & 2.32 & 2.34 & 2.30 & 2.22 & 2.20 & 2.12 & 2.22 & 2.30 & 2.35 & 2.48 \\
\hline 22 & 2.29 & 2.27 & 2.36 & 2.30 & 2.17 & 2.24 & 2.23 & 2.21 & 2.30 & 2.24 & 2.42 \\
\hline 23 & 2.34 & 2.28 & 2.31 & 2.11 & 2.12 & 2.20 & 2.20 & 2.19 & 2.26 & 2.05 & 2.28 \\
\hline AJ13 control & 2.34 & 2.26 & 2.31 & 2.20 & 2.22 & 2.27 & 2.26 & 2.23 & 2.30 & 2.46 & 2.54 \\
\hline Average & 2.27 & 2.25 & 2.32 & 2.24 & 2.20 & 2.22 & 2.21 & 2.26 & 2.31 & 2.39 & 2.40 \\
\hline Standard Deviation & 0.08 & 0.05 & 0.04 & 0.05 & 0.07 & 0.05 & 0.05 & 0.04 & 0.07 & 0.12 & 0.09 \\
\hline
\end{tabular}


Table G-3. Chromium Detection Limits for Leachate Data (ng/mm²).

\begin{tabular}{|c|c|c|c|c|c|c|c|c|c|c|c|}
\hline Sample \# & 1 & 2 & 3 & 4 & 6 & 8 & 10 & 14 & 22 & 32 & 44 \\
\hline 1 & 1.97 & 1.96 & 1.97 & 2.01 & 2.01 & 2.03 & 2.03 & 1.97 & 2.00 & 2.06 & 2.06 \\
\hline 2 & 1.97 & 1.97 & 1.94 & 2.03 & 2.02 & 2.03 & 2.03 & 1.94 & 2.07 & 2.03 & 2.07 \\
\hline 3 & 1.97 & 1.97 & 1.96 & 2.00 & 2.02 & 2.04 & 2.04 & 1.95 & 2.00 & 2.03 & 2.06 \\
\hline 4 & 1.97 & 1.96 & 1.97 & 2.01 & 2.01 & 2.02 & 2.04 & 1.96 & 1.99 & 2.03 & 2.05 \\
\hline 5 & 1.97 & 1.97 & 1.97 & 2.02 & 2.01 & 2.01 & 2.03 & 1.96 & 2.00 & 2.04 & 2.06 \\
\hline SJ13 control & 1.98 & 1.97 & 1.98 & 2.03 & 2.02 & 2.02 & 2.04 & 1.96 & 2.00 & 2.04 & 2.05 \\
\hline 7 & 2.00 & 2.04 & 1.98 & 2.03 & 2.04 & 2.03 & 2.10 & 1.98 & 2.02 & 2.09 & 2.10 \\
\hline 8 & 2.00 & 1.99 & 2.00 & 2.05 & 2.03 & 2.05 & 2.09 & 1.98 & 2.03 & 2.07 & 2.09 \\
\hline 9 & 2.00 & 2.00 & 2.00 & 2.05 & 2.03 & 2.05 & 2.09 & 1.97 & 2.02 & 2.07 & 2.10 \\
\hline 10 & 1.99 & 1.99 & 1.99 & 2.03 & 2.04 & 2.05 & 2.10 & 1.97 & 2.03 & 2.07 & 2.10 \\
\hline 11 & 2.09 & 2.00 & 2.00 & 2.05 & 2.05 & 2.03 & 2.08 & 1.97 & 2.03 & 2.07 & 2.10 \\
\hline CJ13 control & 1.99 & 1.98 & 2.00 & 2.04 & 2.05 & 2.04 & 2.09 & 1.97 & 2.03 & 2.09 & 2.12 \\
\hline 13 & 1.98 & 2.00 & 1.79 & 2.03 & 2.04 & 2.05 & 2.06 & 1.99 & 2.02 & 1.99 & 2.07 \\
\hline 14 & 2.00 & 1.98 & 2.00 & 2.05 & 2.03 & 2.02 & 2.05 & 1.98 & 2.01 & 2.00 & 2.09 \\
\hline 15 & 2.00 & 1.99 & 2.00 & 2.04 & 2.04 & 2.10 & 2.06 & 1.98 & 2.02 & 2.00 & 2.10 \\
\hline 16 & 1.99 & 1.98 & 1.99 & 2.03 & 2.05 & 2.04 & 2.07 & 1.98 & 2.01 & 2.01 & 2.09 \\
\hline 17 & 1.99 & 2.00 & 2.00 & 2.02 & 2.05 & 2.05 & 2.06 & 1.98 & 2.02 & 2.00 & 2.10 \\
\hline $10 \mathrm{KCl}$ control & 1.99 & 1.98 & 2.00 & 2.03 & 2.02 & 2.03 & 2.07 & 1.98 & 2.01 & 2.00 & 2.09 \\
\hline 19 & 1.96 & 1.97 & 1.98 & 2.02 & 2.01 & 2.01 & 2.11 & 1.94 & 1.83 & 2.04 & 2.06 \\
\hline 20 & 1.97 & 1.96 & 1.97 & 2.03 & 2.02 & 2.03 & 2.13 & 1.95 & 1.83 & 2.04 & 2.08 \\
\hline 21 & 1.98 & 1.95 & 1.96 & 2.03 & 2.00 & 2.03 & 2.12 & 1.95 & 1.88 & 2.04 & 2.09 \\
\hline 22 & 1.97 & 1.96 & 1.97 & 2.03 & 2.00 & 1.98 & 2.12 & 1.95 & 1.90 & 2.05 & 2.09 \\
\hline 23 & 1.96 & 1.97 & 1.97 & 2.02 & 2.01 & 2.00 & 2.12 & 1.94 & 1.74 & 2.03 & 2.06 \\
\hline AJ13 control & 1.97 & 1.94 & 1.96 & 2.02 & 2.02 & 1.97 & 2.12 & 1.95 & 1.98 & 2.07 & 2.08 \\
\hline Average & 1.99 & 1.98 & 1.97 & 2.03 & 2.03 & 2.03 & 2.08 & 1.96 & 1.98 & 2.04 & 2.08 \\
\hline Standard Deviation & 0.03 & 0.02 & 0.04 & 0.01 & 0.02 & 0.03 & 0.03 & 0.02 & 0.08 & 0.03 & 0.02 \\
\hline
\end{tabular}


Table G-4. Chromium Detection Limits for Acid Strip Data $\left(\mathbf{n g} / \mathbf{m m}^{2}\right)$.

\begin{tabular}{|c|c|c|c|c|c|c|c|c|c|c|c|}
\hline Sample \# & 1 & 2 & 3 & 4 & 6 & 8 & 10 & 14 & 22 & 32 & 44 \\
\hline 1 & 2.29 & 2.25 & 2.35 & 2.27 & 2.33 & 2.10 & 2.28 & 2.28 & 2.27 & 2.23 & 2.29 \\
\hline 2 & 2.30 & 2.31 & 2.35 & 2.22 & 2.23 & 2.30 & 2.28 & 2.34 & 2.30 & 2.53 & 2.38 \\
\hline 3 & 2.28 & 2.08 & 2.32 & 2.30 & 2.25 & 2.14 & 2.24 & 2.23 & 2.52 & 2.44 & 2.44 \\
\hline 4 & 2.01 & 2.21 & 2.33 & 2.26 & 2.07 & 2.24 & 2.21 & 2.30 & 2.29 & 2.30 & 2.44 \\
\hline 5 & 2.22 & 2.27 & 2.31 & 2.28 & 2.21 & 2.24 & 2.08 & 2.24 & 2.27 & 2.53 & 2.31 \\
\hline SJ13 control & 2.28 & 2.23 & 2.28 & 2.14 & 2.21 & 2.28 & 2.27 & 2.24 & 2.30 & 2.44 & 2.51 \\
\hline 7 & 2.38 & 2.28 & 2.33 & 2.33 & 2.24 & 2.17 & 2.18 & 2.23 & 2.28 & 2.49 & 2.44 \\
\hline 8 & 2.34 & 2.16 & 2.32 & 2.22 & 2.18 & 2.24 & 2.26 & 2.27 & 2.52 & 2.45 & 2.48 \\
\hline 9 & 2.34 & 2.28 & 2.33 & 2.25 & 2.20 & 2.20 & 2.19 & 2.24 & 2.36 & 2.49 & 2.29 \\
\hline 10 & 2.24 & 2.20 & 2.32 & 2.24 & 2.15 & 2.17 & 2.27 & 2.25 & 2.27 & 2.49 & 2.26 \\
\hline 11 & 2.23 & 2.24 & 2.33 & 2.30 & 2.13 & 2.24 & 2.20 & 2.31 & 2.22 & 2.46 & 2.36 \\
\hline CJ13 control & 2.14 & 2.24 & 2.40 & 2.23 & 2.25 & 2.21 & 2.30 & 2.28 & 2.31 & 2.38 & 2.46 \\
\hline 13 & 2.30 & 2.22 & 2.25 & 2.24 & 2.14 & 2.24 & 2.19 & 2.27 & 2.34 & 2.40 & 2.42 \\
\hline 14 & 2.23 & 2.29 & 2.31 & 2.29 & 2.32 & 2.29 & 2.25 & 2.27 & 2.27 & 2.38 & 2.52 \\
\hline 15 & 2.24 & 2.28 & 2.34 & 2.30 & 2.15 & 2.30 & 2.18 & 2.27 & 2.33 & 2.52 & 2.38 \\
\hline 16 & 2.21 & 2.28 & 2.33 & 2.23 & 2.11 & 2.15 & 2.18 & 2.27 & 2.34 & 2.28 & 2.40 \\
\hline 17 & 2.20 & 2.29 & 2.31 & 2.24 & 2.17 & 2.22 & 2.20 & 2.25 & 2.26 & 2.26 & 2.20 \\
\hline $10 \mathrm{KCl}$ control & 2.24 & 2.27 & 2.36 & 2.19 & 2.24 & 2.32 & 2.19 & 2.32 & 2.36 & 2.34 & 2.46 \\
\hline 19 & 2.35 & 2.29 & 2.22 & 2.19 & 2.28 & 2.24 & 2.23 & 2.23 & 2.33 & 2.39 & 2.46 \\
\hline 20 & 2.31 & 2.28 & 2.35 & 2.17 & 2.32 & 2.17 & 2.14 & 2.22 & 2.24 & 2.43 & 2.29 \\
\hline 21 & 2.34 & 2.32 & 2.34 & 2.30 & 2.22 & 2.20 & 2.12 & 2.22 & 2.30 & 2.35 & 2.48 \\
\hline 22 & 2.29 & 2.27 & 2.36 & 2.30 & 2.17 & 2.24 & 2.23 & 2.21 & 2.30 & 2.24 & 2.42 \\
\hline 23 & 2.34 & 2.28 & 2.31 & 2.11 & 2.12 & 2.20 & 2.20 & 2.19 & 2.26 & 2.05 & 2.28 \\
\hline AJ13 control & 2.34 & 2.26 & 2.31 & 2.20 & 2.22 & 2.27 & 2.26 & 2.23 & 2.30 & 2.46 & 2.54 \\
\hline Average & 2.27 & 2.25 & 2.32 & 2.24 & 2.20 & 2.22 & 2.21 & 2.26 & 2.31 & 2.39 & 2.40 \\
\hline Standard Deviation & 0.08 & 0.05 & 0.04 & 0.05 & 0.07 & 0.05 & 0.05 & 0.04 & 0.07 & 0.12 & 0.09 \\
\hline
\end{tabular}


Table G-5. Nickel Detection Limits for Leachate Data $\left(\mathbf{n g} / \mathbf{m m}^{2}\right)$.

\begin{tabular}{|c|c|c|c|c|c|c|c|c|c|c|c|}
\hline Sample \# & 1 & 2 & 3 & 4 & 6 & 8 & 10 & 14 & 22 & 32 & 44 \\
\hline 1 & 1.97 & 1.96 & 1.97 & 2.01 & 2.01 & 2.03 & 2.03 & 1.97 & 2.00 & 2.06 & 2.06 \\
\hline 2 & 1.97 & 1.97 & 1.94 & 2.03 & 2.02 & 2.03 & 2.03 & 1.94 & 2.07 & 2.03 & 2.07 \\
\hline 3 & 1.97 & 1.97 & 1.96 & 2.00 & 2.02 & 2.04 & 2.04 & 1.95 & 2.00 & 2.03 & 2.06 \\
\hline 4 & 1.97 & 1.96 & 1.97 & 2.01 & 2.01 & 2.02 & 2.04 & 1.96 & 1.99 & 2.03 & 2.05 \\
\hline 5 & 1.97 & 1.97 & 1.97 & 2.02 & 2.01 & 2.01 & 2.03 & 1.96 & 2.00 & 2.04 & 2.06 \\
\hline SJ13 control & 1.98 & 1.97 & 1.98 & 2.03 & 2.02 & 2.02 & 2.04 & 1.96 & 2.00 & 2.04 & 2.05 \\
\hline 7 & 2.00 & 2.04 & 1.98 & 2.03 & 2.04 & 2.03 & 2.10 & 1.98 & 2.02 & 2.09 & 2.10 \\
\hline 8 & 2.00 & 1.99 & 2.00 & 2.05 & 2.03 & 2.05 & 2.09 & 1.98 & 2.03 & 2.07 & 2.09 \\
\hline 9 & 2.00 & 2.00 & 2.00 & 2.05 & 2.03 & 2.05 & 2.09 & 1.97 & 2.02 & 2.07 & 2.10 \\
\hline 10 & 1.99 & 1.99 & 1.99 & 2.03 & 2.04 & 2.05 & 2.10 & 1.97 & 2.03 & 2.07 & 2.10 \\
\hline 11 & 2.09 & 2.00 & 2.00 & 2.05 & 2.05 & 2.03 & 2.08 & 1.97 & 2.03 & 2.07 & 2.10 \\
\hline CJ13 control & 1.99 & 1.98 & 2.00 & 2.04 & 2.05 & 2.04 & 2.09 & 1.97 & 2.03 & 2.09 & 2.12 \\
\hline 13 & 1.98 & 2.00 & 1.79 & 2.03 & 2.04 & 2.05 & 2.06 & 1.99 & 2.02 & 1.99 & 2.07 \\
\hline 14 & 2.00 & 1.98 & 2.00 & 2.05 & 2.03 & 2.02 & 2.05 & 1.98 & 2.01 & 2.00 & 2.09 \\
\hline 15 & 2.00 & 1.99 & 2.00 & 2.04 & 2.04 & 2.10 & 2.06 & 1.98 & 2.02 & 2.00 & 2.10 \\
\hline 16 & 1.99 & 1.98 & 1.99 & 2.03 & 2.05 & 2.04 & 2.07 & 1.98 & 2.01 & 2.01 & 2.09 \\
\hline 17 & 1.99 & 2.00 & 2.00 & 2.02 & 2.05 & 2.05 & 2.06 & 1.98 & 2.02 & 2.00 & 2.10 \\
\hline $10 \mathrm{KCl}$ control & 1.99 & 1.98 & 2.00 & 2.03 & 2.02 & 2.03 & 2.07 & 1.98 & 2.01 & 2.00 & 2.09 \\
\hline 19 & 1.96 & 1.97 & 1.98 & 2.02 & 2.01 & 2.01 & 2.11 & 1.94 & 1.83 & 2.04 & 2.06 \\
\hline 20 & 1.97 & 1.96 & 1.97 & 2.03 & 2.02 & 2.03 & 2.13 & 1.95 & 1.83 & 2.04 & 2.08 \\
\hline 21 & 1.98 & 1.95 & 1.96 & 2.03 & 2.00 & 2.03 & 2.12 & 1.95 & 1.88 & 2.04 & 2.09 \\
\hline 22 & 1.97 & 1.96 & 1.97 & 2.03 & 2.00 & 1.98 & 2.12 & 1.95 & 1.90 & 2.05 & 2.09 \\
\hline 23 & 1.96 & 1.97 & 1.97 & 2.02 & 2.01 & 2.00 & 2.12 & 1.94 & 1.74 & 2.03 & 2.06 \\
\hline AJ13 control & 1.97 & 1.94 & 1.96 & 2.02 & 2.02 & 1.97 & 2.12 & 1.95 & 1.98 & 2.07 & 2.08 \\
\hline Average & 1.99 & 1.98 & 1.97 & 2.03 & 2.03 & 2.03 & 2.08 & 1.96 & 1.98 & 2.04 & 2.08 \\
\hline Standard Deviation & 0.03 & 0.02 & 0.04 & 0.01 & 0.02 & 0.03 & 0.03 & 0.02 & 0.08 & 0.03 & 0.02 \\
\hline
\end{tabular}


Table G-6. Nickel Detection Limits for Acid Strip Data $\left(\mathbf{n g} / \mathrm{mm}^{2}\right)$.

\begin{tabular}{|c|c|c|c|c|c|c|c|c|c|c|c|}
\hline Sample \# & 1 & 2 & 3 & 4 & 6 & 8 & 10 & 14 & 22 & 32 & 44 \\
\hline 1 & 2.29 & 2.25 & 2.35 & 2.27 & 2.33 & 2.10 & 2.28 & 2.28 & 2.27 & 2.23 & 2.29 \\
\hline 2 & 2.30 & 2.31 & 2.35 & 2.22 & 2.23 & 2.30 & 2.28 & 2.34 & 2.30 & 2.53 & 2.38 \\
\hline 3 & 2.28 & 2.08 & 2.32 & 2.30 & 2.25 & 2.14 & 2.24 & 2.23 & 2.52 & 2.44 & 2.44 \\
\hline 4 & 2.01 & 2.21 & 2.33 & 2.26 & 2.07 & 2.24 & 2.21 & 2.30 & 2.29 & 2.30 & 2.44 \\
\hline 5 & 2.22 & 2.27 & 2.31 & 2.28 & 2.21 & 2.24 & 2.08 & 2.24 & 2.27 & 2.53 & 2.31 \\
\hline SJ13 control & 2.28 & 2.23 & 2.28 & 2.14 & 2.21 & 2.28 & 2.27 & 2.24 & 2.30 & 2.44 & 2.51 \\
\hline 7 & 2.38 & 2.28 & 2.33 & 2.33 & 2.24 & 2.17 & 2.18 & 2.23 & 2.28 & 2.49 & 2.44 \\
\hline 8 & 2.34 & 2.16 & 2.32 & 2.22 & 2.18 & 2.24 & 2.26 & 2.27 & 2.52 & 2.45 & 2.48 \\
\hline 9 & 2.34 & 2.28 & 2.33 & 2.25 & 2.20 & 2.20 & 2.19 & 2.24 & 2.36 & 2.49 & 2.29 \\
\hline 10 & 2.24 & 2.20 & 2.32 & 2.24 & 2.15 & 2.17 & 2.27 & 2.25 & 2.27 & 2.49 & 2.26 \\
\hline 11 & 2.23 & 2.24 & 2.33 & 2.30 & 2.13 & 2.24 & 2.20 & 2.31 & 2.22 & 2.46 & 2.36 \\
\hline CJ13 control & 2.14 & 2.24 & 2.40 & 2.23 & 2.25 & 2.21 & 2.30 & 2.28 & 2.31 & 2.38 & 2.46 \\
\hline 13 & 2.30 & 2.22 & 2.25 & 2.24 & 2.14 & 2.24 & 2.19 & 2.27 & 2.34 & 2.40 & 2.42 \\
\hline 14 & 2.23 & 2.29 & 2.31 & 2.29 & 2.32 & 2.29 & 2.25 & 2.27 & 2.27 & 2.38 & 2.52 \\
\hline 15 & 2.24 & 2.28 & 2.34 & 2.30 & 2.15 & 2.30 & 2.18 & 2.27 & 2.33 & 2.52 & 2.38 \\
\hline 16 & 2.21 & 2.28 & 2.33 & 2.23 & 2.11 & 2.15 & 2.18 & 2.27 & 2.34 & 2.28 & 2.40 \\
\hline 17 & 2.20 & 2.29 & 2.31 & 2.24 & 2.17 & 2.22 & 2.20 & 2.25 & 2.26 & 2.26 & 2.20 \\
\hline $10 \mathrm{KCl}$ control & 2.24 & 2.27 & 2.36 & 2.19 & 2.24 & 2.32 & 2.19 & 2.32 & 2.36 & 2.34 & 2.46 \\
\hline 19 & 2.35 & 2.29 & 2.22 & 2.19 & 2.28 & 2.24 & 2.23 & 2.23 & 2.33 & 2.39 & 2.46 \\
\hline 20 & 2.31 & 2.28 & 2.35 & 2.17 & 2.32 & 2.17 & 2.14 & 2.22 & 2.24 & 2.43 & 2.29 \\
\hline 21 & 2.34 & 2.32 & 2.34 & 2.30 & 2.22 & 2.20 & 2.12 & 2.22 & 2.30 & 2.35 & 2.48 \\
\hline 22 & 2.29 & 2.27 & 2.36 & 2.30 & 2.17 & 2.24 & 2.23 & 2.21 & 2.30 & 2.24 & 2.42 \\
\hline 23 & 2.34 & 2.28 & 2.31 & 2.11 & 2.12 & 2.20 & 2.20 & 2.19 & 2.26 & 2.05 & 2.28 \\
\hline AJ13 control & 2.34 & 2.26 & 2.31 & 2.20 & 2.22 & 2.27 & 2.26 & 2.23 & 2.30 & 2.46 & 2.54 \\
\hline Average & 2.27 & 2.25 & 2.32 & 2.24 & 2.20 & 2.22 & 2.21 & 2.26 & 2.31 & 2.39 & 2.40 \\
\hline Standard Deviation & 0.08 & 0.05 & 0.04 & 0.05 & 0.07 & 0.05 & 0.05 & 0.04 & 0.07 & 0.12 & 0.09 \\
\hline
\end{tabular}


Table G-7. Zirconium Detection Limits for Leachate Data $\left(\mathbf{n g} / \mathbf{m m}^{2}\right)$.

\begin{tabular}{|c|c|c|c|c|c|c|c|c|c|c|c|}
\hline Sample \# & 1 & 2 & 3 & 4 & 6 & 8 & 10 & 14 & 22 & 32 & 44 \\
\hline 1 & 0.01 & 0.07 & 0.06 & 0.02 & 0.09 & 0.01 & 0.01 & 0.02 & 0.02 & 1.24 & 0.02 \\
\hline 2 & 0.01 & 0.07 & 0.06 & 0.02 & 0.09 & 0.01 & 0.01 & 0.02 & 0.02 & 1.22 & 0.02 \\
\hline 3 & 0.01 & 0.07 & 0.06 & 0.02 & 0.09 & 0.01 & 0.01 & 0.02 & 0.02 & 1.22 & 0.02 \\
\hline 4 & 0.01 & 0.07 & 0.06 & 0.02 & 0.09 & 0.01 & 0.01 & 0.02 & 0.02 & 1.22 & 0.02 \\
\hline 5 & 0.01 & 0.07 & 0.06 & 0.02 & 0.09 & 0.01 & 0.01 & 0.02 & 0.02 & 1.22 & 0.02 \\
\hline SJ13 control & 0.01 & 0.07 & 0.06 & 0.02 & 0.09 & 0.01 & 0.01 & 0.02 & 0.02 & 1.22 & 0.02 \\
\hline 7 & 0.01 & 0.07 & 0.06 & 0.02 & 0.09 & 0.01 & 0.01 & 0.02 & 0.02 & 1.25 & 0.02 \\
\hline 8 & 0.01 & 0.07 & 0.06 & 0.02 & 0.09 & 0.01 & 0.01 & 0.02 & 0.02 & 1.24 & 0.02 \\
\hline 9 & 0.01 & 0.07 & 0.06 & 0.02 & 0.09 & 0.01 & 0.01 & 0.02 & 0.02 & 1.24 & 0.02 \\
\hline 10 & 0.01 & 0.07 & 0.06 & 0.02 & 0.09 & 0.01 & 0.01 & 0.02 & 0.02 & 1.24 & 0.02 \\
\hline 11 & 0.01 & 0.07 & 0.06 & 0.02 & 0.09 & 0.01 & 0.01 & 0.02 & 0.02 & 1.24 & 0.02 \\
\hline CJ13 control & 0.01 & 0.07 & 0.06 & 0.02 & 0.09 & 0.01 & 0.01 & 0.02 & 0.02 & 1.26 & 0.02 \\
\hline 13 & 0.01 & 0.07 & 0.05 & 0.02 & 0.09 & 0.01 & 0.01 & 0.01 & 0.02 & 1.20 & 0.02 \\
\hline 14 & 0.01 & 0.07 & 0.06 & 0.02 & 0.09 & 0.01 & 0.01 & 0.01 & 0.02 & 1.20 & 0.02 \\
\hline 15 & 0.01 & 0.07 & 0.06 & 0.02 & 0.09 & 0.01 & 0.01 & 0.01 & 0.02 & 1.20 & 0.02 \\
\hline 16 & 0.01 & 0.07 & 0.06 & 0.02 & 0.09 & 0.01 & 0.01 & 0.01 & 0.02 & 1.20 & 0.02 \\
\hline 17 & 0.01 & 0.07 & 0.06 & 0.02 & 0.09 & 0.01 & 0.01 & 0.01 & 0.02 & 1.20 & 0.02 \\
\hline $10 \mathrm{KCl}$ control & 0.01 & 0.07 & 0.06 & 0.02 & 0.09 & 0.01 & 0.01 & 0.01 & 0.02 & 1.20 & 0.02 \\
\hline 19 & 0.01 & 0.07 & 0.06 & 0.02 & 0.09 & 0.01 & 0.01 & 0.01 & 0.01 & 1.22 & 0.02 \\
\hline 20 & 0.01 & 0.07 & 0.06 & 0.02 & 0.09 & 0.01 & 0.01 & 0.01 & 0.01 & 1.22 & 0.02 \\
\hline 21 & 0.01 & 0.07 & 0.06 & 0.02 & 0.09 & 0.01 & 0.01 & 0.01 & 0.01 & 1.22 & 0.02 \\
\hline 22 & 0.01 & 0.07 & 0.06 & 0.02 & 0.09 & 0.01 & 0.01 & 0.01 & 0.01 & 1.23 & 0.02 \\
\hline 23 & 0.01 & 0.07 & 0.06 & 0.02 & 0.09 & 0.01 & 0.01 & 0.01 & 0.01 & 1.22 & 0.02 \\
\hline AJ13 control & 0.01 & 0.07 & 0.06 & 0.02 & 0.09 & 0.01 & 0.01 & 0.01 & 0.02 & 1.24 & 0.02 \\
\hline Average & 0.01 & 0.07 & 0.06 & 0.02 & 0.09 & 0.01 & 0.01 & 0.02 & 0.02 & 1.22 & 0.02 \\
\hline Standard Deviation & 0.0002 & 0.001 & 0.001 & 0.0001 & 0.001 & 0.0001 & 0.002 & 0.003 & 0.001 & 0.02 & 0.0002 \\
\hline
\end{tabular}


Table G-8. Zirconium Detection Limits for Acid Strip Data $\left(\mathbf{n g} / \mathbf{m m}^{2}\right)$.

\begin{tabular}{|c|c|c|c|c|c|c|c|c|c|c|c|}
\hline Sample \# & 1 & 2 & 3 & 4 & 6 & 8 & 10 & 14 & 22 & 32 & 44 \\
\hline 1 & 0.01 & 0.08 & 0.07 & 0.02 & 0.11 & 0.01 & 0.01 & 0.02 & 0.02 & 1.34 & 0.02 \\
\hline 2 & 0.01 & 0.08 & 0.07 & 0.02 & 0.10 & 0.01 & 0.01 & 0.02 & 0.02 & 1.52 & 0.02 \\
\hline 3 & 0.01 & 0.07 & 0.07 & 0.02 & 0.10 & 0.01 & 0.01 & 0.02 & 0.02 & 1.46 & 0.02 \\
\hline 4 & 0.01 & 0.08 & 0.07 & 0.02 & 0.09 & 0.01 & 0.01 & 0.02 & 0.02 & 1.38 & 0.02 \\
\hline 5 & 0.01 & 0.08 & 0.07 & 0.02 & 0.10 & 0.01 & 0.01 & 0.02 & 0.02 & 1.52 & 0.02 \\
\hline SJ13 control & 0.01 & 0.08 & 0.07 & 0.02 & 0.10 & 0.01 & 0.01 & 0.02 & 0.02 & 1.47 & 0.03 \\
\hline 7 & 0.01 & 0.08 & 0.07 & 0.02 & 0.10 & 0.01 & 0.01 & 0.02 & 0.02 & 1.50 & 0.02 \\
\hline 8 & 0.01 & 0.08 & 0.07 & 0.02 & 0.10 & 0.01 & 0.01 & 0.02 & 0.02 & 1.47 & 0.02 \\
\hline 9 & 0.01 & 0.08 & 0.07 & 0.02 & 0.10 & 0.01 & 0.01 & 0.02 & 0.02 & 1.49 & 0.02 \\
\hline 10 & 0.01 & 0.08 & 0.07 & 0.02 & 0.10 & 0.01 & 0.01 & 0.02 & 0.02 & 1.49 & 0.02 \\
\hline 11 & 0.01 & 0.08 & 0.07 & 0.02 & 0.10 & 0.01 & 0.01 & 0.02 & 0.02 & 1.48 & 0.02 \\
\hline CJ13 control & 0.01 & 0.08 & 0.07 & 0.02 & 0.10 & 0.01 & 0.01 & 0.02 & 0.02 & 1.43 & 0.02 \\
\hline 13 & 0.01 & 0.08 & 0.07 & 0.02 & 0.10 & 0.01 & 0.02 & 0.02 & 0.02 & 1.44 & 0.02 \\
\hline 14 & 0.01 & 0.08 & 0.07 & 0.02 & 0.11 & 0.01 & 0.02 & 0.02 & 0.02 & 1.43 & 0.03 \\
\hline 15 & 0.01 & 0.08 & 0.07 & 0.02 & 0.10 & 0.01 & 0.02 & 0.02 & 0.02 & 1.51 & 0.02 \\
\hline 16 & 0.01 & 0.08 & 0.07 & 0.02 & 0.10 & 0.01 & 0.02 & 0.02 & 0.02 & 1.37 & 0.02 \\
\hline 17 & 0.01 & 0.08 & 0.07 & 0.02 & 0.10 & 0.01 & 0.02 & 0.02 & 0.02 & 1.35 & 0.02 \\
\hline $10 \mathrm{KCl}$ control & 0.01 & 0.08 & 0.07 & 0.02 & 0.10 & 0.01 & 0.02 & 1.85 & 0.02 & 1.40 & 0.02 \\
\hline 19 & 0.01 & 0.08 & 0.06 & 0.02 & 0.10 & 0.01 & 0.02 & 1.78 & 0.02 & 1.43 & 0.02 \\
\hline 20 & 0.01 & 0.08 & 0.07 & 0.02 & 0.11 & 0.01 & 0.02 & 1.77 & 0.02 & 1.46 & 0.02 \\
\hline 21 & 0.01 & 0.08 & 0.07 & 0.02 & 0.10 & 0.01 & 0.01 & 1.77 & 0.02 & 1.41 & 0.02 \\
\hline 22 & 0.01 & 0.08 & 0.07 & 0.02 & 0.10 & 0.01 & 0.02 & 1.77 & 0.02 & 1.34 & 0.02 \\
\hline 23 & 0.01 & 0.08 & 0.07 & 0.02 & 0.10 & 0.01 & 0.02 & 1.76 & 0.02 & 1.23 & 0.02 \\
\hline AJ13 control & 0.01 & 0.08 & 0.07 & 0.02 & 0.10 & 0.01 & 0.02 & 1.79 & 0.02 & 1.47 & 0.03 \\
\hline Average & 0.01 & 0.08 & 0.07 & 0.02 & 0.10 & 0.01 & 0.01 & 0.54 & 0.02 & 1.43 & 0.02 \\
\hline Standard Deviation & 0.0005 & 0.002 & 0.001 & 0.0004 & 0.003 & 0.0002 & 0.002 & 0.82 & 0.001 & 0.07 & 0.001 \\
\hline
\end{tabular}


Table G-9. Niobium Detection Limits for Leachate Data $\left(\mathbf{n g} / \mathbf{m m}^{2}\right)$.

\begin{tabular}{|c|c|c|c|c|c|c|c|c|c|c|c|}
\hline Sample \# & 1 & 2 & 3 & 4 & 6 & 8 & 10 & 14 & 22 & 32 & 44 \\
\hline 1 & 0.01 & 0.01 & 0.04 & 0.02 & 0.01 & 0.01 & 0.01 & 0.01 & 0.03 & 0.02 & 0.02 \\
\hline 2 & 0.01 & 0.01 & 0.04 & 0.02 & 0.01 & 0.01 & 0.01 & 0.01 & 0.03 & 0.02 & 0.02 \\
\hline 3 & 0.01 & 0.01 & 0.04 & 0.02 & 0.01 & 0.01 & 0.01 & 0.01 & 0.03 & 0.02 & 0.02 \\
\hline 4 & 0.01 & 0.01 & 0.04 & 0.02 & 0.01 & 0.01 & 0.01 & 0.01 & 0.03 & 0.02 & 0.02 \\
\hline 5 & 0.01 & 0.01 & 0.04 & 0.02 & 0.01 & 0.01 & 0.01 & 0.01 & 0.03 & 0.02 & 0.02 \\
\hline SJ13 control & 0.01 & 0.01 & 0.04 & 0.02 & 0.01 & 0.01 & 0.01 & 0.01 & 0.03 & 0.02 & 0.02 \\
\hline 7 & 0.02 & 0.01 & 0.04 & 0.02 & 0.01 & 0.01 & 0.01 & 0.01 & 0.03 & 0.02 & 0.02 \\
\hline 8 & 0.01 & 0.01 & 0.04 & 0.02 & 0.01 & 0.01 & 0.01 & 0.01 & 0.03 & 0.02 & 0.02 \\
\hline 9 & 0.01 & 0.01 & 0.04 & 0.02 & 0.01 & 0.01 & 0.01 & 0.01 & 0.03 & 0.02 & 0.02 \\
\hline 10 & 0.01 & 0.01 & 0.04 & 0.02 & 0.01 & 0.01 & 0.01 & 0.01 & 0.03 & 0.02 & 0.02 \\
\hline 11 & 0.02 & 0.01 & 0.04 & 0.02 & 0.01 & 0.01 & 0.01 & 0.01 & 0.03 & 0.02 & 0.02 \\
\hline CJ13 control & 0.01 & 0.01 & 0.04 & 0.02 & 0.01 & 0.01 & 0.01 & 0.01 & 0.03 & 0.02 & 0.02 \\
\hline 13 & 0.01 & 0.01 & 0.04 & 0.02 & 0.01 & 0.01 & 0.01 & 0.01 & 0.03 & 0.02 & 0.02 \\
\hline 14 & 0.01 & 0.01 & 0.04 & 0.02 & 0.01 & 0.01 & 0.01 & 0.01 & 0.03 & 0.02 & 0.02 \\
\hline 15 & 0.01 & 0.01 & 0.04 & 0.02 & 0.01 & 0.01 & 0.01 & 0.01 & 0.03 & 0.02 & 0.02 \\
\hline 16 & 0.01 & 0.01 & 0.04 & 0.02 & 0.01 & 0.01 & 0.01 & 0.01 & 0.03 & 0.02 & 0.02 \\
\hline 17 & 0.01 & 0.01 & 0.04 & 0.02 & 0.01 & 0.01 & 0.01 & 0.01 & 0.03 & 0.02 & 0.02 \\
\hline $10 \mathrm{KCl}$ control & 0.01 & 0.01 & 0.04 & 0.02 & 0.01 & 0.01 & 0.01 & 0.01 & 0.03 & 0.02 & 0.02 \\
\hline 19 & 0.01 & 0.01 & 0.04 & 0.02 & 0.01 & 0.01 & 0.01 & 0.01 & 0.01 & 0.02 & 0.02 \\
\hline 20 & 0.01 & 0.01 & 0.04 & 0.02 & 0.01 & 0.01 & 0.01 & 0.01 & 0.01 & 0.02 & 0.02 \\
\hline 21 & 0.01 & 0.01 & 0.04 & 0.02 & 0.01 & 0.01 & 0.01 & 0.01 & 0.01 & 0.02 & 0.02 \\
\hline 22 & 0.01 & 0.01 & 0.04 & 0.02 & 0.01 & 0.01 & 0.01 & 0.01 & 0.01 & 0.02 & 0.02 \\
\hline 23 & 0.01 & 0.01 & 0.04 & 0.02 & 0.01 & 0.01 & 0.01 & 0.01 & 0.01 & 0.02 & 0.02 \\
\hline AJ13 control & 0.01 & 0.01 & 0.04 & 0.02 & 0.01 & 0.01 & 0.01 & 0.01 & 0.03 & 0.02 & 0.02 \\
\hline Average & 0.01 & 0.01 & 0.04 & 0.02 & 0.01 & 0.01 & 0.01 & 0.01 & 0.02 & 0.02 & 0.02 \\
\hline Standard Deviation & 0.0002 & 0.0001 & 0.001 & 0.0001 & 0.0001 & 0.0001 & 0.0001 & 0.003 & 0.01 & 0.0003 & 0.0002 \\
\hline
\end{tabular}


Table G-10. Niobium Detection Limits for Acid Strip Data (ng/mm²).

\begin{tabular}{|c|c|c|c|c|c|c|c|c|c|c|c|}
\hline Sample \# & 1 & 2 & 3 & 4 & 6 & 8 & 10 & 14 & 22 & 32 & 44 \\
\hline 1 & 0.02 & 0.01 & 0.05 & 0.03 & 0.01 & 0.01 & 0.01 & 0.02 & 0.03 & 0.02 & 0.05 \\
\hline 2 & 0.02 & 0.01 & 0.05 & 0.02 & 0.01 & 0.01 & 0.01 & 0.02 & 0.03 & 0.02 & 0.05 \\
\hline 3 & 0.02 & 0.01 & 0.05 & 0.03 & 0.01 & 0.01 & 0.01 & 0.02 & 0.03 & 0.02 & 0.05 \\
\hline 4 & 0.02 & 0.01 & 0.05 & 0.02 & 0.01 & 0.01 & 0.01 & 0.02 & 0.03 & 0.02 & 0.05 \\
\hline 5 & 0.02 & 0.01 & 0.05 & 0.03 & 0.01 & 0.01 & 0.01 & 0.02 & 0.03 & 0.02 & 0.05 \\
\hline SJ13 control & 0.02 & 0.01 & 0.05 & 0.02 & 0.01 & 0.01 & 0.01 & 0.02 & 0.03 & 0.02 & 0.05 \\
\hline 7 & 0.02 & 0.01 & 0.05 & 0.03 & 0.01 & 0.01 & 0.01 & 0.02 & 0.03 & 0.02 & 0.05 \\
\hline 8 & 0.02 & 0.01 & 0.05 & 0.02 & 0.01 & 0.01 & 0.01 & 0.02 & 0.03 & 0.02 & 0.05 \\
\hline 9 & 0.02 & 0.01 & 0.05 & 0.02 & 0.01 & 0.01 & 0.01 & 0.02 & 0.03 & 0.02 & 0.05 \\
\hline 10 & 0.02 & 0.01 & 0.05 & 0.02 & 0.01 & 0.01 & 0.01 & 0.02 & 0.03 & 0.02 & 0.05 \\
\hline 11 & 0.02 & 0.01 & 0.05 & 0.03 & 0.01 & 0.01 & 0.01 & 0.02 & 0.03 & 0.02 & 0.05 \\
\hline CJ13 control & 0.02 & 0.01 & 0.05 & 0.02 & 0.01 & 0.01 & 0.01 & 0.02 & 0.03 & 0.02 & 0.05 \\
\hline 13 & 0.02 & 0.01 & 0.05 & 0.02 & 0.01 & 0.01 & 0.01 & 0.01 & 0.03 & 0.02 & 0.05 \\
\hline 14 & 0.02 & 0.01 & 0.05 & 0.03 & 0.01 & 0.01 & 0.01 & 0.01 & 0.03 & 0.02 & 0.05 \\
\hline 15 & 0.02 & 0.01 & 0.05 & 0.03 & 0.01 & 0.01 & 0.01 & 0.01 & 0.03 & 0.02 & 0.05 \\
\hline 16 & 0.02 & 0.01 & 0.05 & 0.02 & 0.01 & 0.01 & 0.01 & 0.01 & 0.03 & 0.02 & 0.05 \\
\hline 17 & 0.02 & 0.01 & 0.05 & 0.02 & 0.01 & 0.01 & 0.01 & 0.01 & 0.03 & 0.02 & 0.04 \\
\hline $10 \mathrm{KCl}$ control & 0.02 & 0.01 & 0.05 & 0.02 & 0.01 & 0.01 & 0.01 & 0.08 & 0.03 & 0.02 & 0.05 \\
\hline 19 & 0.02 & 0.01 & 0.05 & 0.02 & 0.01 & 0.01 & 0.01 & 0.07 & 0.03 & 0.02 & 0.05 \\
\hline 20 & 0.02 & 0.01 & 0.05 & 0.02 & 0.01 & 0.01 & 0.01 & 0.07 & 0.03 & 0.02 & 0.05 \\
\hline 21 & 0.02 & 0.01 & 0.05 & 0.03 & 0.01 & 0.01 & 0.01 & 0.07 & 0.03 & 0.02 & 0.05 \\
\hline 22 & 0.02 & 0.01 & 0.05 & 0.03 & 0.01 & 0.01 & 0.01 & 0.07 & 0.03 & 0.02 & 0.05 \\
\hline 23 & 0.02 & 0.01 & 0.05 & 0.02 & 0.01 & 0.01 & 0.01 & 0.07 & 0.03 & 0.02 & 0.05 \\
\hline AJ13 control & 0.02 & 0.01 & 0.05 & 0.02 & 0.01 & 0.01 & 0.01 & 0.07 & 0.03 & 0.02 & 0.05 \\
\hline Average & 0.02 & 0.01 & 0.05 & 0.02 & 0.01 & 0.01 & 0.01 & 0.03 & 0.03 & 0.02 & 0.05 \\
\hline Standard Deviation & 0.001 & 0.0002 & 0.001 & 0.001 & 0.0003 & 0.0003 & 0.0002 & 0.03 & 0.001 & 0.001 & 0.002 \\
\hline
\end{tabular}


Table G-11. Paladium Detection Limits for Leachate Data $\left(\mathrm{ng} / \mathrm{mm}^{2}\right)$

\begin{tabular}{|c|c|c|c|c|c|c|c|c|c|c|c|}
\hline Sample \# & 1 & 2 & 3 & 4 & 6 & 8 & 10 & 14 & 22 & 32 & 44 \\
\hline 1 & 0.005 & 0.003 & 0.04 & 0.03 & 0.01 & 0.01 & 0.004 & 0.01 & 0.02 & 0.02 & 0.02 \\
\hline 2 & 0.005 & 0.003 & 0.04 & 0.03 & 0.01 & 0.01 & 0.004 & 0.01 & 0.02 & 0.02 & 0.02 \\
\hline 3 & 0.005 & 0.003 & 0.04 & 0.03 & 0.01 & 0.01 & 0.004 & 0.01 & 0.02 & 0.02 & 0.02 \\
\hline 4 & 0.005 & 0.003 & 0.04 & 0.03 & 0.01 & 0.01 & 0.004 & 0.01 & 0.02 & 0.02 & 0.02 \\
\hline 5 & 0.005 & 0.003 & 0.04 & 0.03 & 0.01 & 0.01 & 0.004 & 0.01 & 0.02 & 0.02 & 0.02 \\
\hline SJ13 control & 0.005 & 0.003 & 0.04 & 0.03 & 0.01 & 0.01 & 0.004 & 0.01 & 0.02 & 0.02 & 0.02 \\
\hline 7 & 0.01 & 0.003 & 0.04 & 0.03 & 0.01 & 0.01 & 0.004 & 0.01 & 0.02 & 0.02 & 0.02 \\
\hline 8 & 0.005 & 0.003 & 0.04 & 0.03 & 0.01 & 0.01 & 0.004 & 0.01 & 0.02 & 0.02 & 0.02 \\
\hline 9 & 0.005 & 0.003 & 0.04 & 0.03 & 0.01 & 0.01 & 0.004 & 0.01 & 0.02 & 0.02 & 0.02 \\
\hline 10 & 0.005 & 0.003 & 0.04 & 0.03 & 0.01 & 0.01 & 0.004 & 0.01 & 0.02 & 0.02 & 0.02 \\
\hline 11 & 0.005 & 0.003 & 0.04 & 0.03 & 0.01 & 0.01 & 0.004 & 0.01 & 0.02 & 0.02 & 0.02 \\
\hline CJ13 control & 0.005 & 0.003 & 0.04 & 0.03 & 0.01 & 0.01 & 0.004 & 0.01 & 0.02 & 0.02 & 0.02 \\
\hline 13 & 0.005 & 0.003 & 0.03 & 0.03 & 0.01 & 0.01 & 0.01 & 0.01 & 0.02 & 0.02 & 0.02 \\
\hline 14 & 0.005 & 0.003 & 0.04 & 0.03 & 0.01 & 0.01 & 0.01 & 0.01 & 0.02 & 0.02 & 0.02 \\
\hline 15 & 0.005 & 0.003 & 0.04 & 0.03 & 0.01 & 0.01 & 0.01 & 0.01 & 0.02 & 0.02 & 0.02 \\
\hline 16 & 0.005 & 0.003 & 0.04 & 0.03 & 0.01 & 0.01 & 0.01 & 0.01 & 0.02 & 0.02 & 0.02 \\
\hline 17 & 0.005 & 0.003 & 0.04 & 0.03 & 0.01 & 0.01 & 0.01 & 0.01 & 0.02 & 0.02 & 0.02 \\
\hline $10 \mathrm{KCl}$ control & 0.005 & 0.003 & 0.04 & 0.03 & 0.01 & 0.01 & 0.01 & 0.01 & 0.02 & 0.02 & 0.02 \\
\hline 19 & 0.005 & 0.003 & 0.04 & 0.03 & 0.01 & 0.01 & 0.01 & 0.01 & 0.01 & 0.02 & 0.02 \\
\hline 20 & 0.005 & 0.003 & 0.04 & 0.03 & 0.01 & 0.01 & 0.01 & 0.01 & 0.01 & 0.02 & 0.02 \\
\hline 21 & 0.005 & 0.003 & 0.04 & 0.03 & 0.01 & 0.01 & 0.01 & 0.01 & 0.01 & 0.02 & 0.02 \\
\hline 22 & 0.005 & 0.003 & 0.04 & 0.03 & 0.01 & 0.01 & 0.01 & 0.01 & 0.01 & 0.02 & 0.02 \\
\hline 23 & 0.005 & 0.003 & 0.04 & 0.03 & 0.01 & 0.01 & 0.01 & 0.01 & 0.01 & 0.02 & 0.02 \\
\hline AJ13 control & 0.005 & 0.003 & 0.04 & 0.03 & 0.01 & 0.01 & 0.01 & 0.01 & 0.02 & 0.02 & 0.02 \\
\hline Average & 0.005 & 0.003 & 0.04 & 0.03 & 0.01 & 0.01 & 0.01 & 0.01 & 0.02 & 0.02 & 0.02 \\
\hline Standard Deviation & 0.000 & 0.000 & 0.001 & 0.0002 & 0.0000 & 0.0001 & 0.002 & 0.002 & 0.01 & 0.0002 & 0.0002 \\
\hline
\end{tabular}


Table G-12. Paladium Detection Limits for Acid Strip Data $\left(\mathbf{n g} / \mathrm{mm}^{2}\right)$.

\begin{tabular}{|c|c|c|c|c|c|c|c|c|c|c|c|}
\hline Sample \# & 1 & 2 & 3 & 4 & 6 & 8 & 10 & 14 & 22 & 32 & 44 \\
\hline 1 & 0.01 & 0.003 & 0.04 & 0.03 & 0.01 & 0.01 & 0.005 & 0.01 & 0.02 & 0.02 & 0.03 \\
\hline 2 & 0.01 & 0.003 & 0.04 & 0.03 & 0.01 & 0.01 & 0.005 & 0.01 & 0.02 & 0.02 & 0.04 \\
\hline 3 & 0.01 & 0.003 & 0.04 & 0.03 & 0.01 & 0.01 & 0.004 & 0.01 & 0.03 & 0.02 & 0.04 \\
\hline 4 & 0.01 & 0.003 & 0.04 & 0.03 & 0.01 & 0.01 & 0.004 & 0.01 & 0.02 & 0.02 & 0.04 \\
\hline 5 & 0.01 & 0.003 & 0.04 & 0.03 & 0.01 & 0.01 & 0.004 & 0.01 & 0.02 & 0.02 & 0.03 \\
\hline SJ13 control & 0.01 & 0.003 & 0.04 & 0.03 & 0.01 & 0.01 & 0.005 & 0.01 & 0.02 & 0.02 & 0.04 \\
\hline 7 & 0.01 & 0.003 & 0.04 & 0.03 & 0.01 & 0.01 & 0.004 & 0.01 & 0.02 & 0.02 & 0.04 \\
\hline 8 & 0.01 & 0.003 & 0.04 & 0.03 & 0.01 & 0.01 & 0.005 & 0.01 & 0.03 & 0.02 & 0.04 \\
\hline 9 & 0.01 & 0.003 & 0.04 & 0.03 & 0.01 & 0.01 & 0.004 & 0.01 & 0.02 & 0.02 & 0.03 \\
\hline 10 & 0.01 & 0.003 & 0.04 & 0.03 & 0.01 & 0.01 & 0.005 & 0.01 & 0.02 & 0.02 & 0.03 \\
\hline 11 & 0.01 & 0.003 & 0.04 & 0.03 & 0.01 & 0.01 & 0.004 & 0.01 & 0.02 & 0.02 & 0.04 \\
\hline CJ13 control & 0.01 & 0.003 & 0.05 & 0.03 & 0.01 & 0.01 & 0.005 & 0.01 & 0.02 & 0.02 & 0.04 \\
\hline 13 & 0.01 & 0.003 & 0.04 & 0.03 & 0.01 & 0.01 & 0.01 & 0.01 & 0.02 & 0.02 & 0.04 \\
\hline 14 & 0.01 & 0.003 & 0.04 & 0.03 & 0.01 & 0.01 & 0.01 & 0.01 & 0.02 & 0.02 & 0.04 \\
\hline 15 & 0.01 & 0.003 & 0.04 & 0.03 & 0.01 & 0.01 & 0.01 & 0.01 & 0.02 & 0.02 & 0.04 \\
\hline 16 & 0.01 & 0.003 & 0.04 & 0.03 & 0.01 & 0.01 & 0.01 & 0.01 & 0.02 & 0.02 & 0.04 \\
\hline 17 & 0.01 & 0.003 & 0.04 & 0.03 & 0.01 & 0.01 & 0.01 & 0.01 & 0.02 & 0.02 & 0.03 \\
\hline $10 \mathrm{KCl}$ control & 0.01 & 0.003 & 0.04 & 0.03 & 0.01 & 0.01 & 0.01 & 0.08 & 0.02 & 0.02 & 0.04 \\
\hline 19 & 0.01 & 0.003 & 0.04 & 0.03 & 0.01 & 0.01 & 0.01 & 0.07 & 0.02 & 0.02 & 0.04 \\
\hline 20 & 0.01 & 0.003 & 0.04 & 0.03 & 0.01 & 0.01 & 0.01 & 0.07 & 0.02 & 0.02 & 0.03 \\
\hline 21 & 0.01 & 0.003 & 0.04 & 0.03 & 0.01 & 0.01 & 0.01 & 0.07 & 0.02 & 0.02 & 0.04 \\
\hline 22 & 0.01 & 0.003 & 0.04 & 0.03 & 0.01 & 0.01 & 0.01 & 0.07 & 0.02 & 0.02 & 0.04 \\
\hline 23 & 0.01 & 0.003 & 0.04 & 0.03 & 0.01 & 0.01 & 0.01 & 0.07 & 0.02 & 0.02 & 0.03 \\
\hline AJ13 control & 0.01 & 0.003 & 0.04 & 0.03 & 0.01 & 0.01 & 0.01 & 0.07 & 0.02 & 0.02 & 0.04 \\
\hline Average & 0.01 & 0.003 & 0.04 & 0.03 & 0.01 & 0.01 & 0.01 & 0.03 & 0.02 & 0.02 & 0.04 \\
\hline Standard Deviation & 0.0002 & 0.0001 & 0.001 & 0.001 & 0.0002 & 0.0002 & 0.002 & 0.03 & 0.001 & 0.001 & 0.001 \\
\hline
\end{tabular}


Table G-13. Ruthenium Detection Limits for Leachate Data $\left(\mathrm{ng} / \mathrm{mm}^{2}\right)$.

\begin{tabular}{|c|c|c|c|c|c|c|c|c|c|c|c|}
\hline Sample \# & 1 & 2 & 3 & 4 & 6 & 8 & 10 & 14 & 22 & 32 & 44 \\
\hline 1 & 0.01 & 0.07 & 0.21 & 0.20 & 0.19 & 0.24 & 0.24 & 0.12 & 0.03 & 0.03 & 0.03 \\
\hline 2 & 0.01 & 0.07 & 0.20 & 0.20 & 0.19 & 0.24 & 0.24 & 0.12 & 0.03 & 0.03 & 0.03 \\
\hline 3 & 0.01 & 0.07 & 0.21 & 0.20 & 0.19 & 0.24 & 0.24 & 0.12 & 0.03 & 0.03 & 0.03 \\
\hline 4 & 0.01 & 0.07 & 0.21 & 0.20 & 0.19 & 0.24 & 0.24 & 0.12 & 0.03 & 0.03 & 0.03 \\
\hline 5 & 0.01 & 0.07 & 0.21 & 0.20 & 0.19 & 0.24 & 0.24 & 0.12 & 0.03 & 0.03 & 0.03 \\
\hline SJ13 control & 0.01 & 0.07 & 0.21 & 0.20 & 0.19 & 0.24 & 0.24 & 0.12 & 0.03 & 0.03 & 0.03 \\
\hline 7 & 0.01 & 0.07 & 0.21 & 0.20 & 0.19 & 0.24 & 0.25 & 0.12 & 0.03 & 0.03 & 0.03 \\
\hline 8 & 0.01 & 0.07 & 0.21 & 0.20 & 0.19 & 0.25 & 0.25 & 0.12 & 0.03 & 0.03 & 0.03 \\
\hline 9 & 0.01 & 0.07 & 0.21 & 0.21 & 0.19 & 0.25 & 0.25 & 0.12 & 0.03 & 0.03 & 0.03 \\
\hline 10 & 0.01 & 0.07 & 0.21 & 0.20 & 0.19 & 0.25 & 0.25 & 0.12 & 0.03 & 0.03 & 0.03 \\
\hline 11 & 0.01 & 0.07 & 0.21 & 0.20 & 0.19 & 0.24 & 0.25 & 0.12 & 0.03 & 0.03 & 0.03 \\
\hline CJ13 control & 0.01 & 0.07 & 0.21 & 0.20 & 0.19 & 0.24 & 0.25 & 0.12 & 0.03 & 0.03 & 0.03 \\
\hline 13 & 0.01 & 0.07 & 0.19 & 0.20 & 0.19 & 0.25 & 0.19 & 0.18 & 0.03 & 0.03 & 0.03 \\
\hline 14 & 0.01 & 0.07 & 0.21 & 0.20 & 0.19 & 0.24 & 0.18 & 0.18 & 0.03 & 0.03 & 0.03 \\
\hline 15 & 0.01 & 0.07 & 0.21 & 0.20 & 0.19 & 0.25 & 0.19 & 0.18 & 0.03 & 0.03 & 0.03 \\
\hline 16 & 0.01 & 0.07 & 0.21 & 0.20 & 0.19 & 0.25 & 0.19 & 0.18 & 0.03 & 0.03 & 0.03 \\
\hline 17 & 0.01 & 0.07 & 0.21 & 0.20 & 0.19 & 0.25 & 0.19 & 0.18 & 0.03 & 0.03 & 0.03 \\
\hline $10 \mathrm{KCl}$ control & 0.01 & 0.07 & 0.21 & 0.20 & 0.19 & 0.24 & 0.19 & 0.18 & 0.03 & 0.03 & 0.03 \\
\hline 19 & 0.01 & 0.07 & 0.21 & 0.20 & 0.19 & 0.24 & 0.19 & 0.17 & 0.12 & 0.03 & 0.03 \\
\hline 20 & 0.01 & 0.07 & 0.21 & 0.20 & 0.19 & 0.24 & 0.19 & 0.18 & 0.12 & 0.03 & 0.03 \\
\hline 21 & 0.01 & 0.07 & 0.21 & 0.20 & 0.19 & 0.24 & 0.19 & 0.18 & 0.12 & 0.03 & 0.03 \\
\hline 22 & 0.01 & 0.07 & 0.21 & 0.20 & 0.19 & 0.24 & 0.19 & 0.18 & 0.12 & 0.03 & 0.03 \\
\hline 23 & 0.01 & 0.07 & 0.21 & 0.20 & 0.19 & 0.24 & 0.19 & 0.17 & 0.11 & 0.03 & 0.03 \\
\hline AJ13 control & 0.01 & 0.07 & 0.21 & 0.20 & 0.19 & 0.24 & 0.19 & 0.18 & 0.03 & 0.03 & 0.03 \\
\hline Average & 0.01 & 0.07 & 0.21 & 0.20 & 0.19 & 0.24 & 0.22 & 0.15 & 0.05 & 0.03 & 0.03 \\
\hline Standard Deviation & 0.0001 & 0.001 & 0.005 & 0.001 & 0.002 & 0.003 & 0.03 & 0.03 & 0.04 & 0.0005 & 0.0003 \\
\hline
\end{tabular}


Table G-14. Ruthenium Detection Limits for Acid Strip Data (ng/mm²).

\begin{tabular}{|c|c|c|c|c|c|c|c|c|c|c|c|}
\hline Sample \# & 1 & 2 & 3 & 4 & 6 & 8 & 10 & 14 & 22 & 32 & 44 \\
\hline 1 & 0.01 & 0.08 & 0.25 & 0.23 & 0.22 & 0.25 & 0.27 & 0.14 & 0.03 & 0.04 & 0.05 \\
\hline 2 & 0.01 & 0.08 & 0.25 & 0.22 & 0.21 & 0.28 & 0.27 & 0.14 & 0.03 & 0.04 & 0.05 \\
\hline 3 & 0.01 & 0.07 & 0.24 & 0.23 & 0.21 & 0.26 & 0.27 & 0.13 & 0.04 & 0.04 & 0.05 \\
\hline 4 & 0.01 & 0.08 & 0.24 & 0.23 & 0.20 & 0.27 & 0.27 & 0.14 & 0.03 & 0.04 & 0.05 \\
\hline 5 & 0.01 & 0.08 & 0.24 & 0.23 & 0.21 & 0.27 & 0.25 & 0.13 & 0.03 & 0.04 & 0.05 \\
\hline SJ13 control & 0.01 & 0.08 & 0.24 & 0.21 & 0.21 & 0.27 & 0.27 & 0.13 & 0.03 & 0.04 & 0.05 \\
\hline 7 & 0.01 & 0.08 & 0.24 & 0.23 & 0.21 & 0.26 & 0.26 & 0.13 & 0.03 & 0.04 & 0.05 \\
\hline 8 & 0.01 & 0.08 & 0.24 & 0.22 & 0.21 & 0.27 & 0.27 & 0.14 & 0.04 & 0.04 & 0.05 \\
\hline 9 & 0.01 & 0.08 & 0.24 & 0.22 & 0.21 & 0.26 & 0.26 & 0.13 & 0.03 & 0.04 & 0.05 \\
\hline 10 & 0.01 & 0.08 & 0.24 & 0.22 & 0.20 & 0.26 & 0.27 & 0.14 & 0.03 & 0.04 & 0.05 \\
\hline 11 & 0.01 & 0.08 & 0.24 & 0.23 & 0.20 & 0.27 & 0.26 & 0.14 & 0.03 & 0.04 & 0.05 \\
\hline CJ13 control & 0.01 & 0.08 & 0.25 & 0.22 & 0.21 & 0.27 & 0.28 & 0.14 & 0.03 & 0.04 & 0.05 \\
\hline 13 & 0.01 & 0.08 & 0.24 & 0.22 & 0.20 & 0.27 & 0.20 & 0.20 & 0.03 & 0.04 & 0.05 \\
\hline 14 & 0.01 & 0.08 & 0.24 & 0.23 & 0.22 & 0.27 & 0.20 & 0.20 & 0.03 & 0.04 & 0.05 \\
\hline 15 & 0.01 & 0.08 & 0.25 & 0.23 & 0.20 & 0.28 & 0.20 & 0.20 & 0.03 & 0.04 & 0.05 \\
\hline 16 & 0.01 & 0.08 & 0.24 & 0.22 & 0.20 & 0.26 & 0.20 & 0.20 & 0.03 & 0.04 & 0.05 \\
\hline 17 & 0.01 & 0.08 & 0.24 & 0.22 & 0.21 & 0.27 & 0.20 & 0.20 & 0.03 & 0.04 & 0.04 \\
\hline $10 \mathrm{KCl}$ control & 0.01 & 0.08 & 0.25 & 0.22 & 0.21 & 0.28 & 0.20 & 0.02 & 0.03 & 0.04 & 0.05 \\
\hline 19 & 0.01 & 0.08 & 0.23 & 0.22 & 0.22 & 0.27 & 0.20 & 0.02 & 0.03 & 0.04 & 0.05 \\
\hline 20 & 0.01 & 0.08 & 0.25 & 0.22 & 0.22 & 0.26 & 0.19 & 0.02 & 0.03 & 0.04 & 0.05 \\
\hline 21 & 0.01 & 0.08 & 0.25 & 0.23 & 0.21 & 0.26 & 0.19 & 0.02 & 0.03 & 0.04 & 0.05 \\
\hline 22 & 0.01 & 0.08 & 0.25 & 0.23 & 0.21 & 0.27 & 0.20 & 0.02 & 0.03 & 0.04 & 0.05 \\
\hline 23 & 0.01 & 0.08 & 0.24 & 0.21 & 0.20 & 0.26 & 0.20 & 0.02 & 0.03 & 0.03 & 0.05 \\
\hline AJ13 control & 0.01 & 0.08 & 0.24 & 0.22 & 0.21 & 0.27 & 0.20 & 0.02 & 0.03 & 0.04 & 0.05 \\
\hline Average & 0.01 & 0.08 & 0.24 & 0.22 & 0.21 & 0.27 & 0.23 & 0.12 & 0.03 & 0.04 & 0.05 \\
\hline Standard Deviation & 0.0002 & 0.002 & 0.004 & 0.01 & 0.01 & 0.01 & 0.04 & 0.07 & 0.001 & 0.002 & 0.002 \\
\hline
\end{tabular}


Table G-15. Rhodium Detection Limits for Leachate Data $\left(\mathbf{n g} / \mathrm{mm}^{2}\right)$.

\begin{tabular}{|c|c|c|c|c|c|c|c|c|c|c|c|}
\hline Sample \# & 1 & 2 & 3 & 4 & 6 & 8 & 10 & 14 & 22 & 32 & 44 \\
\hline 1 & 0.01 & 0.01 & 0.04 & 0.02 & 0.01 & 0.01 & 0.003 & 0.01 & 0.02 & 0.02 & 0.03 \\
\hline 2 & 0.01 & 0.01 & 0.04 & 0.02 & 0.01 & 0.01 & 0.003 & 0.01 & 0.02 & 0.02 & 0.03 \\
\hline 3 & 0.01 & 0.01 & 0.04 & 0.02 & 0.01 & 0.01 & 0.003 & 0.01 & 0.02 & 0.02 & 0.03 \\
\hline 4 & 0.01 & 0.01 & 0.04 & 0.02 & 0.01 & 0.01 & 0.003 & 0.01 & 0.02 & 0.02 & 0.03 \\
\hline 5 & 0.01 & 0.01 & 0.04 & 0.02 & 0.01 & 0.01 & 0.003 & 0.01 & 0.02 & 0.02 & 0.03 \\
\hline SJ13 control & 0.01 & 0.01 & 0.04 & 0.02 & 0.01 & 0.01 & 0.003 & 0.01 & 0.02 & 0.02 & 0.03 \\
\hline 7 & 0.01 & 0.01 & 0.04 & 0.02 & 0.01 & 0.01 & 0.003 & 0.01 & 0.02 & 0.02 & 0.03 \\
\hline 8 & 0.01 & 0.01 & 0.05 & 0.02 & 0.01 & 0.01 & 0.003 & 0.01 & 0.02 & 0.02 & 0.03 \\
\hline 9 & 0.01 & 0.01 & 0.05 & 0.02 & 0.01 & 0.01 & 0.003 & 0.01 & 0.02 & 0.02 & 0.03 \\
\hline 10 & 0.01 & 0.01 & 0.04 & 0.02 & 0.01 & 0.01 & 0.003 & 0.01 & 0.02 & 0.02 & 0.03 \\
\hline 11 & 0.01 & 0.01 & 0.04 & 0.02 & 0.01 & 0.01 & 0.003 & 0.01 & 0.02 & 0.02 & 0.03 \\
\hline CJ13 control & 0.01 & 0.01 & 0.05 & 0.02 & 0.01 & 0.01 & 0.003 & 0.01 & 0.02 & 0.02 & 0.03 \\
\hline 13 & 0.01 & 0.01 & 0.04 & 0.02 & 0.01 & 0.01 & 0.003 & 0.003 & 0.02 & 0.02 & 0.03 \\
\hline 14 & 0.01 & 0.01 & 0.04 & 0.02 & 0.01 & 0.01 & 0.003 & 0.003 & 0.02 & 0.02 & 0.03 \\
\hline 15 & 0.01 & 0.01 & 0.05 & 0.02 & 0.01 & 0.01 & 0.003 & 0.003 & 0.02 & 0.02 & 0.03 \\
\hline 16 & 0.01 & 0.01 & 0.04 & 0.02 & 0.01 & 0.01 & 0.003 & 0.003 & 0.02 & 0.02 & 0.03 \\
\hline 17 & 0.01 & 0.01 & 0.05 & 0.02 & 0.01 & 0.01 & 0.003 & 0.003 & 0.02 & 0.02 & 0.03 \\
\hline $10 \mathrm{KCl}$ control & 0.01 & 0.01 & 0.04 & 0.02 & 0.01 & 0.01 & 0.003 & 0.003 & 0.02 & 0.02 & 0.03 \\
\hline 19 & 0.01 & 0.01 & 0.04 & 0.02 & 0.01 & 0.01 & 0.003 & 0.003 & 0.02 & 0.02 & 0.03 \\
\hline 20 & 0.01 & 0.01 & 0.04 & 0.02 & 0.01 & 0.01 & 0.003 & 0.003 & 0.02 & 0.02 & 0.03 \\
\hline 21 & 0.01 & 0.01 & 0.04 & 0.02 & 0.01 & 0.01 & 0.003 & 0.003 & 0.02 & 0.02 & 0.03 \\
\hline 22 & 0.01 & 0.01 & 0.04 & 0.02 & 0.005 & 0.01 & 0.003 & 0.003 & 0.02 & 0.02 & 0.03 \\
\hline 23 & 0.01 & 0.01 & 0.04 & 0.02 & 0.01 & 0.01 & 0.003 & 0.003 & 0.02 & 0.02 & 0.03 \\
\hline AJ13 control & 0.01 & 0.01 & 0.04 & 0.02 & 0.01 & 0.01 & 0.003 & 0.003 & 0.02 & 0.02 & 0.03 \\
\hline Average & 0.01 & 0.01 & 0.04 & 0.02 & 0.01 & 0.01 & 0.003 & 0.005 & 0.02 & 0.02 & 0.03 \\
\hline Standard Deviation & 0.0001 & 0.0001 & 0.001 & 0.0001 & 0.0000 & 0.0001 & 0.0001 & 0.002 & 0.002 & 0.0003 & 0.0003 \\
\hline
\end{tabular}


Table G-16. Rhodium Detection Limits for Acid Strip Data (ng/mm $\left.\mathbf{m}^{2}\right)$

\begin{tabular}{|c|c|c|c|c|c|c|c|c|c|c|c|}
\hline Sample \# & 1 & 2 & 3 & 4 & 6 & 8 & 10 & 14 & 22 & 32 & 44 \\
\hline 1 & 0.01 & 0.01 & 0.05 & 0.02 & 0.01 & 0.01 & 0.003 & 0.01 & 0.03 & 0.03 & 0.03 \\
\hline 2 & 0.01 & 0.01 & 0.05 & 0.02 & 0.01 & 0.01 & 0.003 & 0.01 & 0.03 & 0.03 & 0.04 \\
\hline 3 & 0.01 & 0.01 & 0.05 & 0.02 & 0.01 & 0.01 & 0.003 & 0.01 & 0.03 & 0.03 & 0.04 \\
\hline 4 & 0.01 & 0.01 & 0.05 & 0.02 & 0.01 & 0.01 & 0.003 & 0.01 & 0.03 & 0.03 & 0.04 \\
\hline 5 & 0.01 & 0.01 & 0.05 & 0.02 & 0.01 & 0.01 & 0.003 & 0.01 & 0.03 & 0.03 & 0.03 \\
\hline SJ13 control & 0.01 & 0.01 & 0.05 & 0.02 & 0.01 & 0.01 & 0.003 & 0.01 & 0.03 & 0.03 & 0.04 \\
\hline 7 & 0.01 & 0.01 & 0.05 & 0.02 & 0.01 & 0.01 & 0.003 & 0.01 & 0.03 & 0.03 & 0.04 \\
\hline 8 & 0.01 & 0.01 & 0.05 & 0.02 & 0.01 & 0.01 & 0.003 & 0.01 & 0.03 & 0.03 & 0.04 \\
\hline 9 & 0.01 & 0.01 & 0.05 & 0.02 & 0.01 & 0.01 & 0.003 & 0.01 & 0.03 & 0.03 & 0.03 \\
\hline 10 & 0.01 & 0.01 & 0.05 & 0.02 & 0.01 & 0.01 & 0.003 & 0.01 & 0.03 & 0.03 & 0.03 \\
\hline 11 & 0.01 & 0.01 & 0.05 & 0.02 & 0.01 & 0.01 & 0.003 & 0.01 & 0.03 & 0.03 & 0.04 \\
\hline CJ13 control & 0.01 & 0.01 & 0.05 & 0.02 & 0.01 & 0.01 & 0.003 & 0.01 & 0.03 & 0.03 & 0.04 \\
\hline 13 & 0.01 & 0.01 & 0.05 & 0.02 & 0.01 & 0.01 & 0.003 & 0.003 & 0.03 & 0.03 & 0.04 \\
\hline 14 & 0.01 & 0.01 & 0.05 & 0.02 & 0.01 & 0.01 & 0.003 & 0.003 & 0.03 & 0.03 & 0.04 \\
\hline 15 & 0.01 & 0.01 & 0.05 & 0.02 & 0.01 & 0.01 & 0.003 & 0.003 & 0.03 & 0.03 & 0.04 \\
\hline 16 & 0.01 & 0.01 & 0.05 & 0.02 & 0.01 & 0.01 & 0.003 & 0.003 & 0.03 & 0.03 & 0.04 \\
\hline 17 & 0.01 & 0.01 & 0.05 & 0.02 & 0.01 & 0.01 & 0.003 & 0.003 & 0.03 & 0.03 & 0.03 \\
\hline $10 \mathrm{KCl}$ control & 0.01 & 0.01 & 0.05 & 0.02 & 0.01 & 0.01 & 0.003 & 0.39 & 0.03 & 0.03 & 0.04 \\
\hline 19 & 0.01 & 0.01 & 0.05 & 0.02 & 0.01 & 0.01 & 0.003 & 0.38 & 0.03 & 0.03 & 0.04 \\
\hline 20 & 0.01 & 0.01 & 0.05 & 0.02 & 0.01 & 0.01 & 0.003 & 0.38 & 0.03 & 0.03 & 0.03 \\
\hline 21 & 0.01 & 0.01 & 0.05 & 0.02 & 0.01 & 0.01 & 0.003 & 0.38 & 0.03 & 0.03 & 0.04 \\
\hline 22 & 0.01 & 0.01 & 0.05 & 0.02 & 0.01 & 0.01 & 0.003 & 0.38 & 0.03 & 0.03 & 0.04 \\
\hline 23 & 0.01 & 0.01 & 0.05 & 0.02 & 0.01 & 0.01 & 0.003 & 0.37 & 0.03 & 0.02 & 0.03 \\
\hline AJ13 control & 0.01 & 0.01 & 0.05 & 0.02 & 0.01 & 0.01 & 0.003 & 0.38 & 0.03 & 0.03 & 0.04 \\
\hline Average & 0.01 & 0.01 & 0.05 & 0.02 & 0.01 & 0.01 & 0.003 & 0.12 & 0.03 & 0.03 & 0.04 \\
\hline Standard Deviation & 0.0002 & 0.0002 & 0.001 & 0.0004 & 0.0002 & 0.0002 & 0.0001 & 0.17 & 0.001 & 0.001 & 0.001 \\
\hline
\end{tabular}


Table G-17. Molybdenum Detection Limits for Leachate Data $\left(\mathrm{ng} / \mathrm{mm}^{2}\right)$.

\begin{tabular}{|c|c|c|c|c|c|c|c|c|c|c|c|}
\hline Sample \# & 1 & 2 & 3 & 4 & 6 & 8 & 10 & 14 & 22 & 32 & 44 \\
\hline 1 & 0.01 & 0.01 & 0.05 & 0.02 & 0.01 & 0.01 & 0.003 & 0.01 & 0.03 & 0.03 & 0.03 \\
\hline 2 & 0.01 & 0.01 & 0.05 & 0.02 & 0.01 & 0.01 & 0.003 & 0.01 & 0.03 & 0.03 & 0.04 \\
\hline 3 & 0.01 & 0.01 & 0.05 & 0.02 & 0.01 & 0.01 & 0.003 & 0.01 & 0.03 & 0.03 & 0.04 \\
\hline 4 & 0.01 & 0.01 & 0.05 & 0.02 & 0.01 & 0.01 & 0.003 & 0.01 & 0.03 & 0.03 & 0.04 \\
\hline 5 & 0.01 & 0.01 & 0.05 & 0.02 & 0.01 & 0.01 & 0.003 & 0.01 & 0.03 & 0.03 & 0.03 \\
\hline SJ13 control & 0.01 & 0.01 & 0.05 & 0.02 & 0.01 & 0.01 & 0.003 & 0.01 & 0.03 & 0.03 & 0.04 \\
\hline 7 & 0.01 & 0.01 & 0.05 & 0.02 & 0.01 & 0.01 & 0.003 & 0.01 & 0.03 & 0.03 & 0.04 \\
\hline 8 & 0.01 & 0.01 & 0.05 & 0.02 & 0.01 & 0.01 & 0.003 & 0.01 & 0.03 & 0.03 & 0.04 \\
\hline 9 & 0.01 & 0.01 & 0.05 & 0.02 & 0.01 & 0.01 & 0.003 & 0.01 & 0.03 & 0.03 & 0.03 \\
\hline 10 & 0.01 & 0.01 & 0.05 & 0.02 & 0.01 & 0.01 & 0.003 & 0.01 & 0.03 & 0.03 & 0.03 \\
\hline 11 & 0.01 & 0.01 & 0.05 & 0.02 & 0.01 & 0.01 & 0.003 & 0.01 & 0.03 & 0.03 & 0.04 \\
\hline CJ13 control & 0.01 & 0.01 & 0.05 & 0.02 & 0.01 & 0.01 & 0.003 & 0.01 & 0.03 & 0.03 & 0.04 \\
\hline 13 & 0.01 & 0.01 & 0.05 & 0.02 & 0.01 & 0.01 & 0.003 & 0.003 & 0.03 & 0.03 & 0.04 \\
\hline 14 & 0.01 & 0.01 & 0.05 & 0.02 & 0.01 & 0.01 & 0.003 & 0.003 & 0.03 & 0.03 & 0.04 \\
\hline 15 & 0.01 & 0.01 & 0.05 & 0.02 & 0.01 & 0.01 & 0.003 & 0.003 & 0.03 & 0.03 & 0.04 \\
\hline 16 & 0.01 & 0.01 & 0.05 & 0.02 & 0.01 & 0.01 & 0.003 & 0.003 & 0.03 & 0.03 & 0.04 \\
\hline 17 & 0.01 & 0.01 & 0.05 & 0.02 & 0.01 & 0.01 & 0.003 & 0.003 & 0.03 & 0.03 & 0.03 \\
\hline $10 \mathrm{KCl}$ control & 0.01 & 0.01 & 0.05 & 0.02 & 0.01 & 0.01 & 0.003 & 0.39 & 0.03 & 0.03 & 0.04 \\
\hline 19 & 0.01 & 0.01 & 0.05 & 0.02 & 0.01 & 0.01 & 0.003 & 0.38 & 0.03 & 0.03 & 0.04 \\
\hline 20 & 0.01 & 0.01 & 0.05 & 0.02 & 0.01 & 0.01 & 0.003 & 0.38 & 0.03 & 0.03 & 0.03 \\
\hline 21 & 0.01 & 0.01 & 0.05 & 0.02 & 0.01 & 0.01 & 0.003 & 0.38 & 0.03 & 0.03 & 0.04 \\
\hline 22 & 0.01 & 0.01 & 0.05 & 0.02 & 0.01 & 0.01 & 0.003 & 0.38 & 0.03 & 0.03 & 0.04 \\
\hline 23 & 0.01 & 0.01 & 0.05 & 0.02 & 0.01 & 0.01 & 0.003 & 0.37 & 0.03 & 0.02 & 0.03 \\
\hline AJ13 control & 0.01 & 0.01 & 0.05 & 0.02 & 0.01 & 0.01 & 0.003 & 0.38 & 0.03 & 0.03 & 0.04 \\
\hline Average & 0.01 & 0.01 & 0.05 & 0.02 & 0.01 & 0.01 & 0.003 & 0.12 & 0.03 & 0.03 & 0.04 \\
\hline Standard Deviation & 0.0002 & 0.0002 & 0.001 & 0.0004 & 0.0002 & 0.0002 & 0.0001 & 0.17 & 0.001 & 0.001 & 0.001 \\
\hline
\end{tabular}


Table G-18. Molybdenum Detection Limits for Acid Strip Data (ng/mm $\left.\mathbf{m}^{2}\right)$

\begin{tabular}{|c|c|c|c|c|c|c|c|c|c|c|c|}
\hline Sample \# & 1 & 2 & 3 & 4 & 6 & 8 & 10 & 14 & 22 & 32 & 44 \\
\hline 1 & 0.09 & 0.12 & 0.27 & 0.27 & 0.27 & 0.08 & 0.06 & 0.06 & 1.25 & 0.45 & 0.07 \\
\hline 2 & 0.09 & 0.12 & 0.27 & 0.27 & 0.26 & 0.08 & 0.06 & 0.07 & 1.27 & 0.51 & 0.07 \\
\hline 3 & 0.09 & 0.11 & 0.27 & 0.28 & 0.26 & 0.08 & 0.06 & 0.06 & 1.39 & 0.49 & 0.07 \\
\hline 4 & 0.08 & 0.11 & 0.27 & 0.27 & 0.24 & 0.08 & 0.06 & 0.06 & 1.26 & 0.46 & 0.07 \\
\hline 5 & 0.09 & 0.12 & 0.27 & 0.27 & 0.25 & 0.08 & 0.05 & 0.06 & 1.25 & 0.51 & 0.07 \\
\hline SJ13 control & 0.09 & 0.11 & 0.26 & 0.26 & 0.25 & 0.08 & 0.06 & 0.06 & 1.27 & 0.49 & 0.08 \\
\hline 7 & 0.10 & 0.12 & 0.27 & 0.28 & 0.26 & 0.08 & 0.06 & 0.06 & 1.25 & 0.50 & 0.07 \\
\hline 8 & 0.09 & 0.11 & 0.27 & 0.27 & 0.25 & 0.08 & 0.06 & 0.06 & 1.39 & 0.49 & 0.07 \\
\hline 9 & 0.09 & 0.12 & 0.27 & 0.27 & 0.25 & 0.08 & 0.06 & 0.06 & 1.30 & 0.50 & 0.07 \\
\hline 10 & 0.09 & 0.11 & 0.27 & 0.27 & 0.25 & 0.08 & 0.06 & 0.06 & 1.25 & 0.50 & 0.07 \\
\hline 11 & 0.09 & 0.12 & 0.27 & 0.28 & 0.24 & 0.08 & 0.06 & 0.06 & 1.22 & 0.49 & 0.07 \\
\hline CJ13 control & 0.09 & 0.12 & 0.28 & 0.27 & 0.26 & 0.08 & 0.06 & 0.06 & 1.27 & 0.48 & 0.07 \\
\hline 13 & 0.09 & 0.11 & 0.26 & 0.27 & 0.25 & 0.08 & 0.03 & 0.04 & 1.29 & 0.48 & 0.07 \\
\hline 14 & 0.09 & 0.12 & 0.27 & 0.28 & 0.27 & 0.08 & 0.03 & 0.04 & 1.25 & 0.48 & 0.08 \\
\hline 15 & 0.09 & 0.12 & 0.27 & 0.28 & 0.25 & 0.08 & 0.03 & 0.04 & 1.28 & 0.50 & 0.07 \\
\hline 16 & 0.09 & 0.12 & 0.27 & 0.27 & 0.24 & 0.08 & 0.03 & 0.04 & 1.29 & 0.46 & 0.07 \\
\hline 17 & 0.09 & 0.12 & 0.27 & 0.27 & 0.25 & 0.08 & 0.03 & 0.04 & 1.24 & 0.45 & 0.07 \\
\hline $10 \mathrm{KCl}$ control & 0.09 & 0.12 & 0.27 & 0.26 & 0.26 & 0.08 & 0.03 & 0.02 & 1.30 & 0.47 & 0.07 \\
\hline 19 & 0.09 & 0.12 & 0.26 & 0.26 & 0.26 & 0.08 & 0.03 & 0.01 & 1.28 & 0.48 & 0.07 \\
\hline 20 & 0.09 & 0.12 & 0.27 & 0.26 & 0.27 & 0.08 & 0.03 & 0.01 & 1.23 & 0.49 & 0.07 \\
\hline 21 & 0.09 & 0.12 & 0.27 & 0.28 & 0.26 & 0.08 & 0.03 & 0.01 & 1.27 & 0.47 & 0.07 \\
\hline 22 & 0.09 & 0.12 & 0.27 & 0.28 & 0.25 & 0.08 & 0.03 & 0.01 & 1.26 & 0.45 & 0.07 \\
\hline 23 & 0.09 & 0.12 & 0.27 & 0.25 & 0.24 & 0.08 & 0.03 & 0.01 & 1.24 & 0.41 & 0.07 \\
\hline AJ13 control & 0.09 & 0.12 & 0.27 & 0.26 & 0.26 & 0.08 & 0.04 & 0.01 & 1.27 & 0.49 & 0.08 \\
\hline Average & 0.09 & 0.12 & 0.27 & 0.27 & 0.25 & 0.08 & 0.05 & 0.04 & 1.27 & 0.48 & 0.07 \\
\hline Standard Deviation & 0.003 & 0.003 & 0.004 & 0.01 & 0.01 & 0.002 & 0.01 & 0.02 & 0.04 & 0.02 & 0.003 \\
\hline
\end{tabular}


Table G-19. Manganese Detection Limits for Leachate Data (ng/mm $\left.\mathbf{m}^{2}\right)$

\begin{tabular}{|c|c|c|c|c|c|c|c|c|c|c|c|}
\hline Sample \# & 1 & 2 & 3 & 4 & 6 & 8 & 10 & 14 & 22 & 32 & 44 \\
\hline 1 & 0.03 & 0.08 & 0.14 & 0.05 & 0.06 & 0.06 & 0.09 & 0.09 & 0.57 & 0.10 & 0.31 \\
\hline 2 & 0.03 & 0.08 & 0.14 & 0.05 & 0.06 & 0.06 & 0.09 & 0.09 & 0.59 & 0.10 & 0.31 \\
\hline 3 & 0.03 & 0.08 & 0.14 & 0.05 & 0.06 & 0.06 & 0.09 & 0.09 & 0.57 & 0.10 & 0.31 \\
\hline 4 & 0.03 & 0.08 & 0.14 & 0.05 & 0.06 & 0.06 & 0.09 & 0.09 & 0.57 & 0.10 & 0.31 \\
\hline 5 & 0.03 & 0.08 & 0.14 & 0.05 & 0.06 & 0.06 & 0.09 & 0.09 & 0.57 & 0.10 & 0.31 \\
\hline SJ13 control & 0.03 & 0.08 & 0.14 & 0.05 & 0.06 & 0.06 & 0.09 & 0.09 & 0.57 & 0.10 & 0.31 \\
\hline 7 & 0.03 & 0.08 & 0.14 & 0.05 & 0.07 & 0.06 & 0.09 & 0.09 & 0.58 & 0.10 & 0.32 \\
\hline 8 & 0.03 & 0.08 & 0.14 & 0.05 & 0.07 & 0.06 & 0.09 & 0.09 & 0.58 & 0.10 & 0.31 \\
\hline 9 & 0.03 & 0.08 & 0.14 & 0.05 & 0.06 & 0.06 & 0.09 & 0.09 & 0.57 & 0.10 & 0.32 \\
\hline 10 & 0.03 & 0.08 & 0.14 & 0.05 & 0.07 & 0.06 & 0.09 & 0.09 & 0.58 & 0.10 & 0.31 \\
\hline 11 & 0.03 & 0.08 & 0.14 & 0.05 & 0.07 & 0.06 & 0.09 & 0.09 & 0.58 & 0.10 & 0.31 \\
\hline CJ13 control & 0.03 & 0.08 & 0.14 & 0.05 & 0.07 & 0.06 & 0.09 & 0.09 & 0.58 & 0.10 & 0.32 \\
\hline 13 & 0.03 & 0.08 & 0.12 & 0.05 & 0.07 & 0.06 & 0.13 & 0.13 & 0.58 & 0.10 & 0.31 \\
\hline 14 & 0.03 & 0.08 & 0.14 & 0.05 & 0.07 & 0.06 & 0.13 & 0.13 & 0.57 & 0.10 & 0.31 \\
\hline 15 & 0.03 & 0.08 & 0.14 & 0.05 & 0.07 & 0.07 & 0.13 & 0.13 & 0.57 & 0.10 & 0.31 \\
\hline 16 & 0.03 & 0.08 & 0.14 & 0.05 & 0.07 & 0.06 & 0.13 & 0.13 & 0.57 & 0.10 & 0.31 \\
\hline 17 & 0.03 & 0.08 & 0.14 & 0.05 & 0.07 & 0.06 & 0.13 & 0.13 & 0.57 & 0.10 & 0.31 \\
\hline $10 \mathrm{KCl}$ control & 0.03 & 0.08 & 0.14 & 0.05 & 0.06 & 0.06 & 0.13 & 0.13 & 0.57 & 0.10 & 0.31 \\
\hline 19 & 0.03 & 0.08 & 0.14 & 0.05 & 0.06 & 0.06 & 0.14 & 0.13 & 0.52 & 0.10 & 0.31 \\
\hline 20 & 0.03 & 0.08 & 0.14 & 0.05 & 0.06 & 0.06 & 0.14 & 0.13 & 0.52 & 0.10 & 0.31 \\
\hline 21 & 0.03 & 0.08 & 0.14 & 0.05 & 0.06 & 0.06 & 0.14 & 0.13 & 0.54 & 0.10 & 0.31 \\
\hline 22 & 0.03 & 0.08 & 0.14 & 0.05 & 0.06 & 0.06 & 0.14 & 0.13 & 0.54 & 0.10 & 0.31 \\
\hline 23 & 0.03 & 0.08 & 0.14 & 0.05 & 0.06 & 0.06 & 0.14 & 0.13 & 0.50 & 0.10 & 0.31 \\
\hline AJ13 control & 0.03 & 0.08 & 0.14 & 0.05 & 0.06 & 0.06 & 0.14 & 0.13 & 0.56 & 0.10 & 0.31 \\
\hline Average & 0.03 & 0.08 & 0.14 & 0.05 & 0.06 & 0.06 & 0.11 & 0.11 & 0.56 & 0.10 & 0.31 \\
\hline Standard Deviation & 0.0004 & 0.001 & 0.003 & 0.0003 & 0.001 & 0.001 & 0.02 & 0.02 & 0.02 & 0.001 & 0.003 \\
\hline
\end{tabular}


Table G-20. Manganese Detection Limits for Acid Strip Data (ng/mm²)

\begin{tabular}{|c|c|c|c|c|c|c|c|c|c|c|c|}
\hline Sample \# & 1 & 2 & 3 & 4 & 6 & 8 & 10 & 14 & 22 & 32 & 44 \\
\hline 1 & 0.03 & 0.09 & 0.16 & 0.06 & 0.07 & 0.07 & 0.10 & 0.10 & 0.65 & 0.11 & 0.06 \\
\hline 2 & 0.03 & 0.09 & 0.16 & 0.06 & 0.07 & 0.07 & 0.10 & 0.10 & 0.66 & 0.13 & 0.06 \\
\hline 3 & 0.03 & 0.08 & 0.16 & 0.06 & 0.07 & 0.07 & 0.10 & 0.10 & 0.72 & 0.12 & 0.06 \\
\hline 4 & 0.03 & 0.09 & 0.16 & 0.06 & 0.07 & 0.07 & 0.09 & 0.10 & 0.65 & 0.11 & 0.06 \\
\hline 5 & 0.03 & 0.09 & 0.16 & 0.06 & 0.07 & 0.07 & 0.09 & 0.10 & 0.65 & 0.13 & 0.06 \\
\hline SJ13 control & 0.03 & 0.09 & 0.16 & 0.06 & 0.07 & 0.07 & 0.10 & 0.10 & 0.66 & 0.12 & 0.06 \\
\hline 7 & 0.03 & 0.09 & 0.16 & 0.06 & 0.07 & 0.07 & 0.09 & 0.10 & 0.65 & 0.12 & 0.06 \\
\hline 8 & 0.03 & 0.09 & 0.16 & 0.06 & 0.07 & 0.07 & 0.10 & 0.10 & 0.72 & 0.12 & 0.06 \\
\hline 9 & 0.03 & 0.09 & 0.16 & 0.06 & 0.07 & 0.07 & 0.09 & 0.10 & 0.67 & 0.12 & 0.06 \\
\hline 10 & 0.03 & 0.09 & 0.16 & 0.06 & 0.07 & 0.07 & 0.10 & 0.10 & 0.65 & 0.12 & 0.06 \\
\hline 11 & 0.03 & 0.09 & 0.16 & 0.06 & 0.07 & 0.07 & 0.09 & 0.10 & 0.63 & 0.12 & 0.06 \\
\hline CJ13 control & 0.03 & 0.09 & 0.17 & 0.06 & 0.07 & 0.07 & 0.10 & 0.10 & 0.66 & 0.12 & 0.06 \\
\hline 13 & 0.03 & 0.09 & 0.16 & 0.06 & 0.07 & 0.07 & 0.14 & 0.15 & 0.67 & 0.12 & 0.06 \\
\hline 14 & 0.03 & 0.09 & 0.16 & 0.06 & 0.07 & 0.07 & 0.15 & 0.15 & 0.65 & 0.12 & 0.06 \\
\hline 15 & 0.03 & 0.09 & 0.16 & 0.06 & 0.07 & 0.07 & 0.14 & 0.15 & 0.66 & 0.13 & 0.06 \\
\hline 16 & 0.03 & 0.09 & 0.16 & 0.06 & 0.07 & 0.07 & 0.14 & 0.15 & 0.67 & 0.11 & 0.06 \\
\hline 17 & 0.03 & 0.09 & 0.16 & 0.06 & 0.07 & 0.07 & 0.14 & 0.15 & 0.64 & 0.11 & 0.06 \\
\hline $10 \mathrm{KCl}$ control & 0.03 & 0.09 & 0.17 & 0.06 & 0.07 & 0.07 & 0.14 & 0.14 & 0.67 & 0.12 & 0.06 \\
\hline 19 & 0.03 & 0.09 & 0.16 & 0.06 & 0.07 & 0.07 & 0.14 & 0.13 & 0.66 & 0.12 & 0.06 \\
\hline 20 & 0.03 & 0.09 & 0.16 & 0.06 & 0.07 & 0.07 & 0.14 & 0.13 & 0.64 & 0.12 & 0.06 \\
\hline 21 & 0.03 & 0.09 & 0.16 & 0.06 & 0.07 & 0.07 & 0.14 & 0.13 & 0.66 & 0.12 & 0.06 \\
\hline 22 & 0.03 & 0.09 & 0.17 & 0.06 & 0.07 & 0.07 & 0.15 & 0.13 & 0.66 & 0.11 & 0.06 \\
\hline 23 & 0.03 & 0.09 & 0.16 & 0.05 & 0.07 & 0.07 & 0.14 & 0.13 & 0.64 & 0.10 & 0.06 \\
\hline AJ13 control & 0.03 & 0.09 & 0.16 & 0.06 & 0.07 & 0.07 & 0.15 & 0.13 & 0.66 & 0.12 & 0.06 \\
\hline Average & 0.03 & 0.09 & 0.16 & 0.06 & 0.07 & 0.07 & 0.12 & 0.12 & 0.66 & 0.12 & 0.06 \\
\hline Standard Deviation & 0.001 & 0.002 & 0.003 & 0.001 & 0.002 & 0.002 & 0.02 & 0.02 & 0.02 & 0.01 & 0.002 \\
\hline
\end{tabular}


Table G-21. Cobalt Detection Limits for Leachate Data $\left(\mathrm{ng} / \mathrm{mm}^{2}\right)$

\begin{tabular}{|c|c|c|c|c|c|c|c|c|c|c|c|}
\hline Sample \# & 1 & 2 & 3 & 4 & 6 & 8 & 10 & 14 & 22 & 32 & 44 \\
\hline 1 & 0.003 & 0.01 & 0.02 & 0.02 & 0.01 & 0.01 & 0.09 & 0.07 & 0.07 & 0.02 & 0.02 \\
\hline 2 & 0.003 & 0.01 & 0.02 & 0.02 & 0.01 & 0.01 & 0.09 & 0.07 & 0.07 & 0.02 & 0.02 \\
\hline 3 & 0.003 & 0.01 & 0.02 & 0.02 & 0.01 & 0.01 & 0.09 & 0.07 & 0.07 & 0.02 & 0.02 \\
\hline 4 & 0.003 & 0.01 & 0.02 & 0.02 & 0.01 & 0.01 & 0.09 & 0.07 & 0.07 & 0.02 & 0.02 \\
\hline 5 & 0.003 & 0.01 & 0.02 & 0.02 & 0.01 & 0.01 & 0.09 & 0.07 & 0.07 & 0.02 & 0.02 \\
\hline SJ13 control & 0.003 & 0.01 & 0.02 & 0.02 & 0.01 & 0.01 & 0.09 & 0.07 & 0.07 & 0.02 & 0.02 \\
\hline 7 & 0.003 & 0.01 & 0.02 & 0.02 & 0.01 & 0.01 & 0.09 & 0.07 & 0.07 & 0.02 & 0.02 \\
\hline 8 & 0.003 & 0.01 & 0.02 & 0.02 & 0.01 & 0.01 & 0.09 & 0.07 & 0.07 & 0.02 & 0.02 \\
\hline 9 & 0.003 & 0.01 & 0.02 & 0.02 & 0.01 & 0.01 & 0.09 & 0.07 & 0.07 & 0.02 & 0.02 \\
\hline 10 & 0.003 & 0.01 & 0.02 & 0.02 & 0.01 & 0.01 & 0.09 & 0.07 & 0.07 & 0.02 & 0.02 \\
\hline 11 & 0.003 & 0.01 & 0.02 & 0.02 & 0.01 & 0.01 & 0.09 & 0.07 & 0.07 & 0.02 & 0.02 \\
\hline CJ13 control & 0.003 & 0.01 & 0.02 & 0.02 & 0.01 & 0.01 & 0.09 & 0.07 & 0.07 & 0.02 & 0.02 \\
\hline 13 & 0.003 & 0.01 & 0.01 & 0.02 & 0.01 & 0.01 & 0.11 & 0.11 & 0.07 & 0.02 & 0.02 \\
\hline 14 & 0.003 & 0.01 & 0.02 & 0.02 & 0.01 & 0.01 & 0.11 & 0.11 & 0.07 & 0.02 & 0.02 \\
\hline 15 & 0.003 & 0.01 & 0.02 & 0.02 & 0.01 & 0.01 & 0.11 & 0.11 & 0.07 & 0.02 & 0.02 \\
\hline 16 & 0.003 & 0.01 & 0.02 & 0.02 & 0.01 & 0.01 & 0.11 & 0.11 & 0.07 & 0.02 & 0.02 \\
\hline 17 & 0.003 & 0.01 & 0.02 & 0.02 & 0.01 & 0.01 & 0.11 & 0.11 & 0.07 & 0.02 & 0.02 \\
\hline $10 \mathrm{KCl}$ control & 0.003 & 0.01 & 0.02 & 0.02 & 0.01 & 0.01 & 0.11 & 0.11 & 0.07 & 0.02 & 0.02 \\
\hline 19 & 0.003 & 0.01 & 0.02 & 0.02 & 0.01 & 0.01 & 0.12 & 0.11 & 0.07 & 0.02 & 0.02 \\
\hline 20 & 0.003 & 0.01 & 0.02 & 0.02 & 0.01 & 0.01 & 0.12 & 0.11 & 0.06 & 0.02 & 0.02 \\
\hline 21 & 0.003 & 0.01 & 0.02 & 0.02 & 0.01 & 0.01 & 0.12 & 0.11 & 0.07 & 0.02 & 0.02 \\
\hline 22 & 0.003 & 0.01 & 0.02 & 0.02 & 0.01 & 0.01 & 0.12 & 0.11 & 0.07 & 0.02 & 0.02 \\
\hline 23 & 0.003 & 0.01 & 0.02 & 0.02 & 0.01 & 0.01 & 0.12 & 0.11 & 0.06 & 0.02 & 0.02 \\
\hline AJ13 control & 0.003 & 0.01 & 0.02 & 0.02 & 0.01 & 0.01 & 0.12 & 0.11 & 0.07 & 0.02 & 0.02 \\
\hline Average & 0.003 & 0.01 & 0.02 & 0.02 & 0.01 & 0.01 & 0.10 & 0.09 & 0.07 & 0.02 & 0.02 \\
\hline Standard Deviation & 0.0000 & 0.0001 & 0.0003 & 0.0001 & 0.0000 & 0.0001 & 0.01 & 0.02 & 0.003 & 0.0003 & 0.0002 \\
\hline
\end{tabular}


Table G-22. Cobalt Detection Limits for Acid Strip Data (ng/mm $\left.{ }^{2}\right)$

\begin{tabular}{|c|c|c|c|c|c|c|c|c|c|c|c|}
\hline Sample \# & 1 & 2 & 3 & 4 & 6 & 8 & 10 & 14 & 22 & 32 & 44 \\
\hline 1 & 0.003 & 0.01 & 0.02 & 0.02 & 0.01 & 0.01 & 0.10 & 0.08 & 0.08 & 0.02 & 0.03 \\
\hline 2 & 0.003 & 0.01 & 0.02 & 0.02 & 0.01 & 0.01 & 0.10 & 0.08 & 0.08 & 0.03 & 0.04 \\
\hline 3 & 0.003 & 0.01 & 0.02 & 0.02 & 0.01 & 0.01 & 0.10 & 0.08 & 0.09 & 0.03 & 0.04 \\
\hline 4 & 0.003 & 0.01 & 0.02 & 0.02 & 0.01 & 0.01 & 0.10 & 0.08 & 0.08 & 0.02 & 0.04 \\
\hline 5 & 0.003 & 0.01 & 0.02 & 0.02 & 0.01 & 0.01 & 0.09 & 0.08 & 0.08 & 0.03 & 0.03 \\
\hline SJ13 control & 0.003 & 0.01 & 0.02 & 0.02 & 0.01 & 0.01 & 0.10 & 0.08 & 0.08 & 0.03 & 0.04 \\
\hline 7 & 0.004 & 0.01 & 0.02 & 0.02 & 0.01 & 0.01 & 0.10 & 0.08 & 0.08 & 0.03 & 0.04 \\
\hline 8 & 0.004 & 0.01 & 0.02 & 0.02 & 0.01 & 0.01 & 0.10 & 0.08 & 0.09 & 0.03 & 0.04 \\
\hline 9 & 0.004 & 0.01 & 0.02 & 0.02 & 0.01 & 0.01 & 0.10 & 0.08 & 0.08 & 0.03 & 0.03 \\
\hline 10 & 0.003 & 0.01 & 0.02 & 0.02 & 0.01 & 0.01 & 0.10 & 0.08 & 0.08 & 0.03 & 0.03 \\
\hline 11 & 0.003 & 0.01 & 0.02 & 0.02 & 0.01 & 0.01 & 0.10 & 0.08 & 0.08 & 0.03 & 0.04 \\
\hline CJ13 control & 0.003 & 0.01 & 0.02 & 0.02 & 0.01 & 0.01 & 0.10 & 0.08 & 0.08 & 0.02 & 0.04 \\
\hline 13 & 0.003 & 0.01 & 0.02 & 0.02 & 0.01 & 0.01 & 0.12 & 0.12 & 0.08 & 0.03 & 0.04 \\
\hline 14 & 0.003 & 0.01 & 0.02 & 0.02 & 0.01 & 0.01 & 0.12 & 0.12 & 0.08 & 0.03 & 0.04 \\
\hline 15 & 0.003 & 0.01 & 0.02 & 0.02 & 0.01 & 0.01 & 0.12 & 0.13 & 0.08 & 0.03 & 0.04 \\
\hline 16 & 0.003 & 0.01 & 0.02 & 0.02 & 0.01 & 0.01 & 0.12 & 0.12 & 0.08 & 0.02 & 0.04 \\
\hline 17 & 0.003 & 0.01 & 0.02 & 0.02 & 0.01 & 0.01 & 0.12 & 0.12 & 0.08 & 0.02 & 0.03 \\
\hline $10 \mathrm{KCl}$ control & 0.003 & 0.01 & 0.02 & 0.02 & 0.01 & 0.01 & 0.12 & 0.21 & 0.08 & 0.02 & 0.04 \\
\hline 19 & 0.004 & 0.01 & 0.02 & 0.02 & 0.01 & 0.01 & 0.12 & 0.20 & 0.08 & 0.03 & 0.04 \\
\hline 20 & 0.003 & 0.01 & 0.02 & 0.02 & 0.01 & 0.01 & 0.12 & 0.20 & 0.08 & 0.03 & 0.03 \\
\hline 21 & 0.004 & 0.01 & 0.02 & 0.02 & 0.01 & 0.01 & 0.12 & 0.20 & 0.08 & 0.02 & 0.04 \\
\hline 22 & 0.003 & 0.01 & 0.02 & 0.02 & 0.01 & 0.01 & 0.12 & 0.20 & 0.08 & 0.02 & 0.04 \\
\hline 23 & 0.004 & 0.01 & 0.02 & 0.02 & 0.01 & 0.01 & 0.12 & 0.20 & 0.08 & 0.02 & 0.03 \\
\hline AJ13 control & 0.004 & 0.01 & 0.02 & 0.02 & 0.01 & 0.01 & 0.12 & 0.20 & 0.08 & 0.03 & 0.04 \\
\hline Average & 0.003 & 0.01 & 0.02 & 0.02 & 0.01 & 0.01 & 0.11 & 0.13 & 0.08 & 0.03 & 0.04 \\
\hline Standard Deviation & 0.0001 & 0.0002 & 0.0003 & 0.0005 & 0.0002 & 0.0002 & 0.01 & 0.05 & 0.003 & 0.001 & 0.001 \\
\hline
\end{tabular}


Table G-23. Copper Detection Limits and Leachate Data $\left(\mathbf{n g} / \mathrm{mm}^{2}\right)$

\begin{tabular}{|c|c|c|c|c|c|c|c|c|c|c|c|}
\hline Sample \# & 1 & 2 & 3 & 4 & 6 & 8 & 10 & 14 & 22 & 32 & 44 \\
\hline 1 & 0.14 & 0.35 & 0.26 & 0.09 & 0.05 & 1.62 & 0.10 & 0.12 & 0.49 & 0.10 & 0.41 \\
\hline 2 & 0.14 & 0.36 & 0.25 & 0.09 & 0.05 & 1.62 & 0.10 & 0.12 & 0.51 & 0.10 & 0.41 \\
\hline 3 & 0.14 & 0.35 & 0.25 & 0.09 & 0.05 & 1.63 & 0.10 & 0.12 & 0.49 & 0.10 & 0.41 \\
\hline 4 & 0.14 & 0.35 & 0.26 & 0.09 & 0.05 & 1.61 & 0.10 & 0.12 & 0.49 & 0.10 & 0.41 \\
\hline 5 & 0.14 & 0.35 & 0.26 & 0.09 & 0.05 & 1.60 & 0.10 & 0.12 & 0.49 & 0.10 & 0.41 \\
\hline SJ13 control & 0.14 & 0.35 & 0.26 & 0.09 & 0.05 & 1.62 & 0.10 & 0.12 & 0.49 & 0.10 & 0.41 \\
\hline 7 & 0.14 & 0.37 & 0.26 & 0.09 & 0.05 & 1.63 & 0.10 & 0.12 & 0.50 & 0.10 & 0.42 \\
\hline 8 & 0.14 & 0.36 & 0.26 & 0.09 & 0.05 & 1.64 & 0.10 & 0.12 & 0.50 & 0.10 & 0.42 \\
\hline 9 & 0.14 & 0.36 & 0.26 & 0.09 & 0.05 & 1.64 & 0.10 & 0.12 & 0.49 & 0.10 & 0.42 \\
\hline 10 & 0.14 & 0.36 & 0.26 & 0.09 & 0.05 & 1.64 & 0.10 & 0.12 & 0.50 & 0.10 & 0.42 \\
\hline 11 & 0.15 & 0.36 & 0.26 & 0.09 & 0.05 & 1.63 & 0.10 & 0.12 & 0.50 & 0.10 & 0.42 \\
\hline CJ13 control & 0.14 & 0.36 & 0.26 & 0.09 & 0.05 & 1.63 & 0.10 & 0.12 & 0.50 & 0.10 & 0.42 \\
\hline 13 & 0.14 & 0.36 & 0.23 & 0.09 & 0.05 & 1.64 & 0.24 & 0.23 & 0.49 & 0.10 & 0.41 \\
\hline 14 & 0.14 & 0.36 & 0.26 & 0.09 & 0.05 & 1.62 & 0.24 & 0.23 & 0.49 & 0.10 & 0.42 \\
\hline 15 & 0.14 & 0.36 & 0.26 & 0.09 & 0.05 & 1.68 & 0.24 & 0.23 & 0.49 & 0.10 & 0.42 \\
\hline 16 & 0.14 & 0.36 & 0.26 & 0.09 & 0.05 & 1.63 & 0.24 & 0.23 & 0.49 & 0.10 & 0.42 \\
\hline 17 & 0.14 & 0.36 & 0.26 & 0.09 & 0.05 & 1.64 & 0.24 & 0.23 & 0.49 & 0.10 & 0.42 \\
\hline $10 \mathrm{KCl}$ control & 0.14 & 0.36 & 0.26 & 0.09 & 0.05 & 1.63 & 0.24 & 0.23 & 0.49 & 0.10 & 0.42 \\
\hline 19 & 0.14 & 0.35 & 0.26 & 0.09 & 0.05 & 1.61 & 0.24 & 0.22 & 0.45 & 0.10 & 0.41 \\
\hline 20 & 0.14 & 0.35 & 0.26 & 0.09 & 0.05 & 1.63 & 0.25 & 0.22 & 0.45 & 0.10 & 0.42 \\
\hline 21 & 0.14 & 0.35 & 0.26 & 0.09 & 0.05 & 1.62 & 0.24 & 0.22 & 0.46 & 0.10 & 0.42 \\
\hline 22 & 0.14 & 0.35 & 0.26 & 0.09 & 0.05 & 1.58 & 0.24 & 0.22 & 0.47 & 0.10 & 0.42 \\
\hline 23 & 0.14 & 0.35 & 0.26 & 0.09 & 0.05 & 1.60 & 0.24 & 0.22 & 0.43 & 0.10 & 0.41 \\
\hline AJ13 control & 0.14 & 0.35 & 0.25 & 0.09 & 0.05 & 1.58 & 0.24 & 0.22 & 0.48 & 0.10 & 0.42 \\
\hline Average & 0.14 & 0.36 & 0.26 & 0.09 & 0.05 & 1.62 & 0.17 & 0.17 & 0.48 & 0.10 & 0.42 \\
\hline Standard Deviation & 0.002 & 0.004 & 0.01 & 0.001 & 0.0004 & 0.02 & 0.07 & 0.06 & 0.02 & 0.001 & 0.004 \\
\hline
\end{tabular}


Table G-24. Copper Detection Limits for Acid Strip Data (ng/mm²)

\begin{tabular}{|c|c|c|c|c|c|c|c|c|c|c|c|}
\hline Sample \# & 1 & 2 & 3 & 4 & 6 & 8 & 10 & 14 & 22 & 32 & 44 \\
\hline 1 & 0.16 & 0.41 & 0.31 & 0.10 & 0.06 & 1.68 & 0.11 & 0.14 & 0.56 & 0.11 & 0.07 \\
\hline 2 & 0.16 & 0.42 & 0.31 & 0.09 & 0.06 & 1.84 & 0.11 & 0.14 & 0.56 & 0.13 & 0.07 \\
\hline 3 & 0.16 & 0.37 & 0.30 & 0.10 & 0.06 & 1.71 & 0.11 & 0.13 & 0.62 & 0.12 & 0.07 \\
\hline 4 & 0.14 & 0.40 & 0.30 & 0.10 & 0.05 & 1.79 & 0.11 & 0.14 & 0.56 & 0.11 & 0.07 \\
\hline 5 & 0.16 & 0.41 & 0.30 & 0.10 & 0.06 & 1.79 & 0.10 & 0.13 & 0.56 & 0.13 & 0.07 \\
\hline SJ13 control & 0.16 & 0.40 & 0.30 & 0.09 & 0.06 & 1.82 & 0.11 & 0.13 & 0.56 & 0.12 & 0.08 \\
\hline 7 & 0.17 & 0.41 & 0.30 & 0.10 & 0.06 & 1.73 & 0.11 & 0.13 & 0.56 & 0.12 & 0.07 \\
\hline 8 & 0.16 & 0.39 & 0.30 & 0.09 & 0.06 & 1.79 & 0.11 & 0.14 & 0.62 & 0.12 & 0.07 \\
\hline 9 & 0.16 & 0.41 & 0.30 & 0.10 & 0.06 & 1.76 & 0.11 & 0.13 & 0.58 & 0.12 & 0.07 \\
\hline 10 & 0.16 & 0.40 & 0.30 & 0.10 & 0.06 & 1.74 & 0.11 & 0.14 & 0.56 & 0.12 & 0.07 \\
\hline 11 & 0.16 & 0.40 & 0.30 & 0.10 & 0.06 & 1.80 & 0.11 & 0.14 & 0.54 & 0.12 & 0.07 \\
\hline CJ13 control & 0.15 & 0.40 & 0.31 & 0.09 & 0.06 & 1.77 & 0.12 & 0.14 & 0.57 & 0.12 & 0.07 \\
\hline 13 & 0.16 & 0.40 & 0.29 & 0.10 & 0.06 & 1.79 & 0.25 & 0.26 & 0.57 & 0.12 & 0.07 \\
\hline 14 & 0.16 & 0.41 & 0.30 & 0.10 & 0.06 & 1.83 & 0.26 & 0.26 & 0.56 & 0.12 & 0.08 \\
\hline 15 & 0.16 & 0.41 & 0.30 & 0.10 & 0.06 & 1.84 & 0.25 & 0.26 & 0.57 & 0.13 & 0.07 \\
\hline 16 & 0.15 & 0.41 & 0.30 & 0.09 & 0.06 & 1.72 & 0.25 & 0.26 & 0.57 & 0.11 & 0.07 \\
\hline 17 & 0.15 & 0.41 & 0.30 & 0.10 & 0.06 & 1.78 & 0.25 & 0.26 & 0.55 & 0.11 & 0.07 \\
\hline $10 \mathrm{KCl}$ control & 0.16 & 0.41 & 0.31 & 0.09 & 0.06 & 1.86 & 0.25 & 0.01 & 0.58 & 0.12 & 0.07 \\
\hline 19 & 0.16 & 0.41 & 0.29 & 0.09 & 0.06 & 1.79 & 0.26 & 0.01 & 0.57 & 0.12 & 0.07 \\
\hline 20 & 0.16 & 0.41 & 0.31 & 0.09 & 0.06 & 1.73 & 0.25 & 0.01 & 0.55 & 0.12 & 0.07 \\
\hline 21 & 0.16 & 0.42 & 0.30 & 0.10 & 0.06 & 1.76 & 0.24 & 0.01 & 0.56 & 0.12 & 0.07 \\
\hline 22 & 0.16 & 0.41 & 0.31 & 0.10 & 0.06 & 1.79 & 0.26 & 0.01 & 0.56 & 0.11 & 0.07 \\
\hline 23 & 0.16 & 0.41 & 0.30 & 0.09 & 0.06 & 1.76 & 0.25 & 0.01 & 0.55 & 0.10 & 0.07 \\
\hline AJ13 control & 0.16 & 0.41 & 0.30 & 0.09 & 0.06 & 1.82 & 0.26 & 0.01 & 0.56 & 0.12 & 0.08 \\
\hline Average & 0.16 & 0.41 & 0.30 & 0.10 & 0.06 & 1.78 & 0.18 & 0.12 & 0.57 & 0.12 & 0.07 \\
\hline Standard Deviation & 0.01 & 0.01 & 0.005 & 0.002 & 0.002 & 0.04 & 0.07 & 0.09 & 0.02 & 0.01 & 0.003 \\
\hline
\end{tabular}


Table G-25. Vanadium Detection Limits for Leachate Data (ng/mm $\left.\mathbf{m}^{2}\right)$

\begin{tabular}{|c|c|c|c|c|c|c|c|c|c|c|c|}
\hline Sample \# & 1 & 2 & 3 & 4 & 6 & 8 & 10 & 14 & 22 & 32 & 44 \\
\hline 1 & 0.13 & 1.27 & 4.13 & 4.33 & 2.41 & 0.41 & 0.02 & 0.10 & 1.30 & 0.82 & 1.13 \\
\hline 2 & 0.13 & 1.28 & 4.08 & 4.36 & 2.42 & 0.41 & 0.02 & 0.10 & 1.35 & 0.81 & 1.14 \\
\hline 3 & 0.13 & 1.28 & 4.11 & 4.30 & 2.43 & 0.41 & 0.02 & 0.10 & 1.30 & 0.81 & 1.13 \\
\hline 4 & 0.13 & 1.27 & 4.13 & 4.33 & 2.42 & 0.40 & 0.02 & 0.10 & 1.30 & 0.81 & 1.13 \\
\hline 5 & 0.13 & 1.28 & 4.14 & 4.34 & 2.41 & 0.40 & 0.02 & 0.10 & 1.30 & 0.81 & 1.13 \\
\hline SJ13 control & 0.13 & 1.28 & 4.15 & 4.37 & 2.43 & 0.40 & 0.02 & 0.10 & 1.30 & 0.82 & 1.13 \\
\hline 7 & 0.13 & 1.33 & 4.16 & 4.36 & 2.44 & 0.41 & 0.03 & 0.10 & 1.31 & 0.83 & 1.16 \\
\hline 8 & 0.13 & 1.29 & 4.21 & 4.40 & 2.44 & 0.41 & 0.03 & 0.10 & 1.32 & 0.83 & 1.15 \\
\hline 9 & 0.13 & 1.30 & 4.21 & 4.41 & 2.44 & 0.41 & 0.03 & 0.10 & 1.31 & 0.83 & 1.16 \\
\hline 10 & 0.13 & 1.29 & 4.18 & 4.37 & 2.45 & 0.41 & 0.03 & 0.10 & 1.32 & 0.83 & 1.15 \\
\hline 11 & 0.14 & 1.30 & 4.19 & 4.41 & 2.46 & 0.41 & 0.02 & 0.10 & 1.32 & 0.83 & 1.15 \\
\hline CJ13 control & 0.13 & 1.29 & 4.21 & 4.38 & 2.46 & 0.41 & 0.03 & 0.10 & 1.32 & 0.84 & 1.17 \\
\hline 13 & 0.13 & 1.30 & 3.75 & 4.36 & 2.45 & 0.41 & 0.51 & 0.50 & 1.31 & 0.80 & 1.14 \\
\hline 14 & 0.13 & 1.29 & 4.19 & 4.40 & 2.44 & 0.40 & 0.51 & 0.50 & 1.31 & 0.80 & 1.15 \\
\hline 15 & 0.13 & 1.29 & 4.21 & 4.38 & 2.45 & 0.42 & 0.52 & 0.50 & 1.31 & 0.80 & 1.15 \\
\hline 16 & 0.13 & 1.29 & 4.19 & 4.36 & 2.46 & 0.41 & 0.52 & 0.50 & 1.31 & 0.80 & 1.15 \\
\hline 17 & 0.13 & 1.30 & 4.21 & 4.35 & 2.46 & 0.41 & 0.51 & 0.49 & 1.31 & 0.80 & 1.15 \\
\hline $10 \mathrm{KCl}$ control & 0.13 & 1.28 & 4.19 & 4.36 & 2.43 & 0.41 & 0.52 & 0.50 & 1.31 & 0.80 & 1.15 \\
\hline 19 & 0.13 & 1.28 & 4.15 & 4.35 & 2.41 & 0.40 & 0.53 & 0.48 & 0.01 & 0.82 & 1.14 \\
\hline 20 & 0.13 & 1.27 & 4.13 & 4.37 & 2.43 & 0.41 & 0.53 & 0.49 & 0.01 & 0.82 & 1.14 \\
\hline 21 & 0.13 & 1.27 & 4.12 & 4.37 & 2.40 & 0.41 & 0.53 & 0.49 & 0.01 & 0.81 & 1.15 \\
\hline 22 & 0.13 & 1.27 & 4.13 & 4.36 & 2.40 & 0.40 & 0.53 & 0.49 & 0.01 & 0.82 & 1.15 \\
\hline 23 & 0.13 & 1.28 & 4.14 & 4.34 & 2.41 & 0.40 & 0.53 & 0.49 & 0.01 & 0.81 & 1.13 \\
\hline AJ13 control & 0.13 & 1.26 & 4.12 & 4.34 & 2.43 & 0.39 & 0.53 & 0.49 & 1.29 & 0.83 & 1.14 \\
\hline Average & 0.13 & 1.29 & 4.14 & 4.36 & 2.43 & 0.41 & 0.27 & 0.29 & 1.04 & 0.82 & 1.14 \\
\hline Standard Deviation & 0.002 & 0.01 & 0.09 & 0.03 & 0.02 & 0.01 & 0.25 & 0.20 & 0.54 & 0.01 & 0.01 \\
\hline
\end{tabular}


Table G-26. Vanadium Detection Limits for Acid Strip Data $\left(\mathrm{ng} / \mathrm{mm}^{2}\right)$

\begin{tabular}{|c|c|c|c|c|c|c|c|c|c|c|c|}
\hline Sample \# & 1 & 2 & 3 & 4 & 6 & 8 & 10 & 14 & 22 & 32 & 44 \\
\hline 1 & 0.15 & 1.47 & 4.94 & 4.89 & 2.79 & 0.42 & 0.03 & 0.11 & 1.47 & 0.89 & 0.07 \\
\hline 2 & 0.15 & 1.50 & 4.93 & 4.76 & 2.68 & 0.46 & 0.03 & 0.12 & 1.50 & 1.01 & 0.07 \\
\hline 3 & 0.15 & 1.35 & 4.88 & 4.94 & 2.70 & 0.43 & 0.03 & 0.11 & 1.64 & 0.98 & 0.07 \\
\hline 4 & 0.13 & 1.43 & 4.88 & 4.86 & 2.49 & 0.45 & 0.03 & 0.11 & 1.49 & 0.92 & 0.07 \\
\hline 5 & 0.14 & 1.47 & 4.84 & 4.90 & 2.65 & 0.45 & 0.03 & 0.11 & 1.47 & 1.01 & 0.07 \\
\hline SJ13 control & 0.15 & 1.45 & 4.78 & 4.60 & 2.65 & 0.46 & 0.03 & 0.11 & 1.50 & 0.98 & 0.08 \\
\hline 7 & 0.15 & 1.48 & 4.89 & 5.00 & 2.69 & 0.43 & 0.03 & 0.11 & 1.48 & 1.00 & 0.07 \\
\hline 8 & 0.15 & 1.41 & 4.87 & 4.77 & 2.62 & 0.45 & 0.03 & 0.11 & 1.64 & 0.98 & 0.07 \\
\hline 9 & 0.15 & 1.48 & 4.90 & 4.84 & 2.63 & 0.44 & 0.03 & 0.11 & 1.53 & 1.00 & 0.07 \\
\hline 10 & 0.15 & 1.43 & 4.86 & 4.82 & 2.58 & 0.43 & 0.03 & 0.11 & 1.48 & 1.00 & 0.07 \\
\hline 11 & 0.15 & 1.45 & 4.89 & 4.95 & 2.55 & 0.45 & 0.03 & 0.11 & 1.44 & 0.99 & 0.07 \\
\hline CJ13 control & 0.14 & 1.46 & 5.04 & 4.80 & 2.70 & 0.44 & 0.03 & 0.11 & 1.50 & 0.95 & 0.07 \\
\hline 13 & 0.15 & 1.44 & 4.73 & 4.82 & 2.56 & 0.45 & 0.55 & 0.57 & 1.52 & 0.96 & 0.07 \\
\hline 14 & 0.15 & 1.49 & 4.85 & 4.93 & 2.79 & 0.46 & 0.56 & 0.57 & 1.47 & 0.95 & 0.08 \\
\hline 15 & 0.15 & 1.48 & 4.92 & 4.93 & 2.58 & 0.46 & 0.55 & 0.57 & 1.51 & 1.01 & 0.07 \\
\hline 16 & 0.14 & 1.49 & 4.90 & 4.80 & 2.53 & 0.43 & 0.55 & 0.57 & 1.52 & 0.91 & 0.07 \\
\hline 17 & 0.14 & 1.49 & 4.85 & 4.81 & 2.61 & 0.44 & 0.55 & 0.56 & 1.47 & 0.90 & 0.07 \\
\hline $10 \mathrm{KCl}$ control & 0.15 & 1.47 & 4.96 & 4.70 & 2.69 & 0.46 & 0.55 & 0.01 & 1.53 & 0.93 & 0.07 \\
\hline 19 & 0.15 & 1.49 & 4.67 & 4.70 & 2.74 & 0.45 & 0.56 & 0.01 & 1.51 & 0.96 & 0.07 \\
\hline 20 & 0.15 & 1.48 & 4.93 & 4.66 & 2.78 & 0.43 & 0.54 & 0.01 & 1.46 & 0.97 & 0.07 \\
\hline 21 & 0.15 & 1.51 & 4.90 & 4.94 & 2.66 & 0.44 & 0.53 & 0.01 & 1.50 & 0.94 & 0.07 \\
\hline 22 & 0.15 & 1.47 & 4.97 & 4.94 & 2.61 & 0.45 & 0.56 & 0.01 & 1.49 & 0.90 & 0.07 \\
\hline 23 & 0.15 & 1.48 & 4.86 & 4.54 & 2.55 & 0.44 & 0.55 & 0.01 & 1.47 & 0.82 & 0.07 \\
\hline AJ13 control & 0.15 & 1.47 & 4.85 & 4.74 & 2.67 & 0.45 & 0.57 & 0.01 & 1.50 & 0.98 & 0.08 \\
\hline Average & 0.15 & 1.46 & 4.88 & 4.82 & 2.65 & 0.44 & 0.29 & 0.18 & 1.50 & 0.96 & 0.07 \\
\hline Standard Deviation & 0.01 & 0.03 & 0.08 & 0.12 & 0.08 & 0.01 & 0.27 & 0.21 & 0.05 & 0.05 & 0.003 \\
\hline
\end{tabular}




\section{H. Sample Releases}

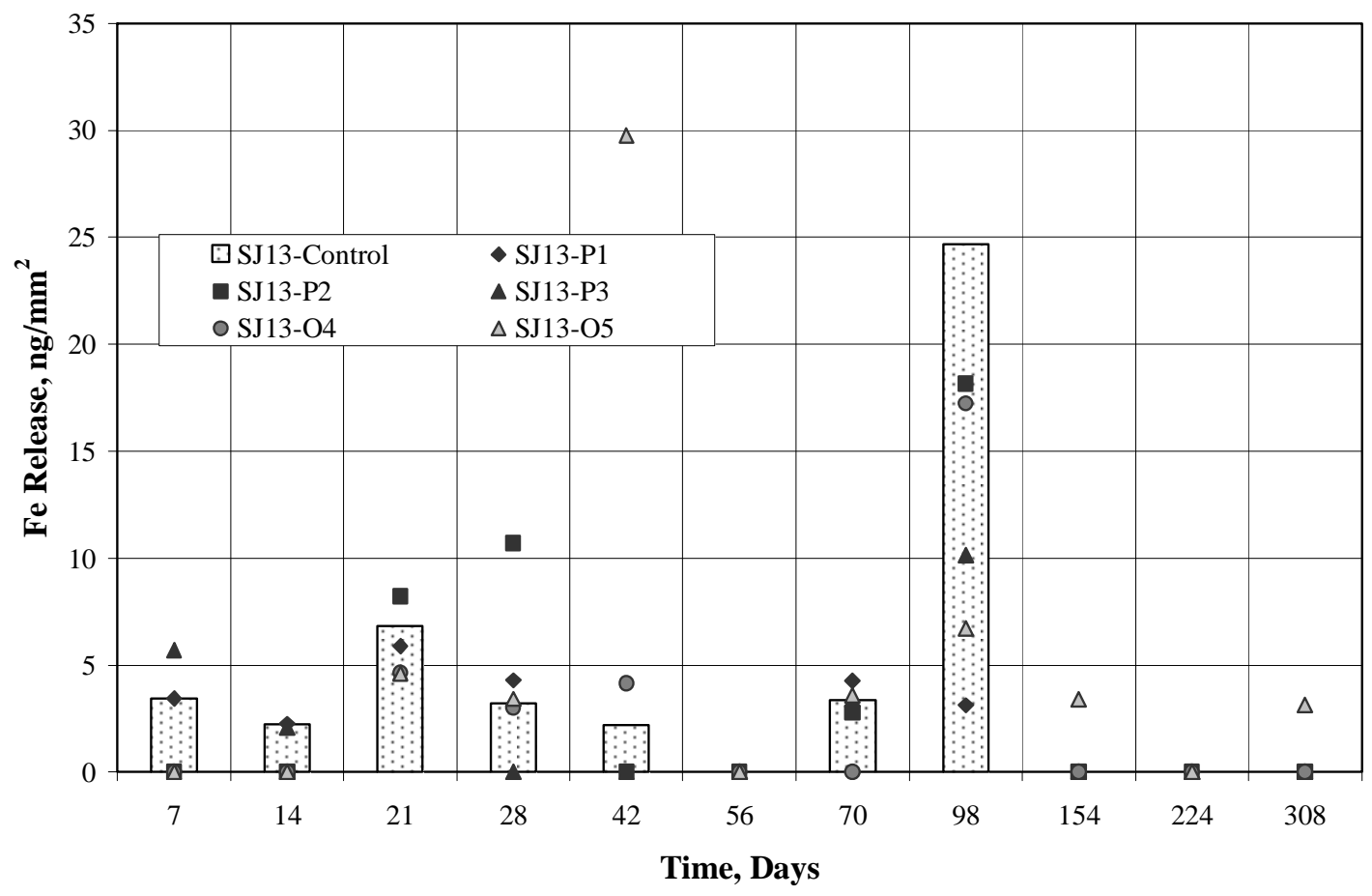

Figure H-1. Iron Releases in SJ13 solution at $90^{\circ} \mathrm{C}$.

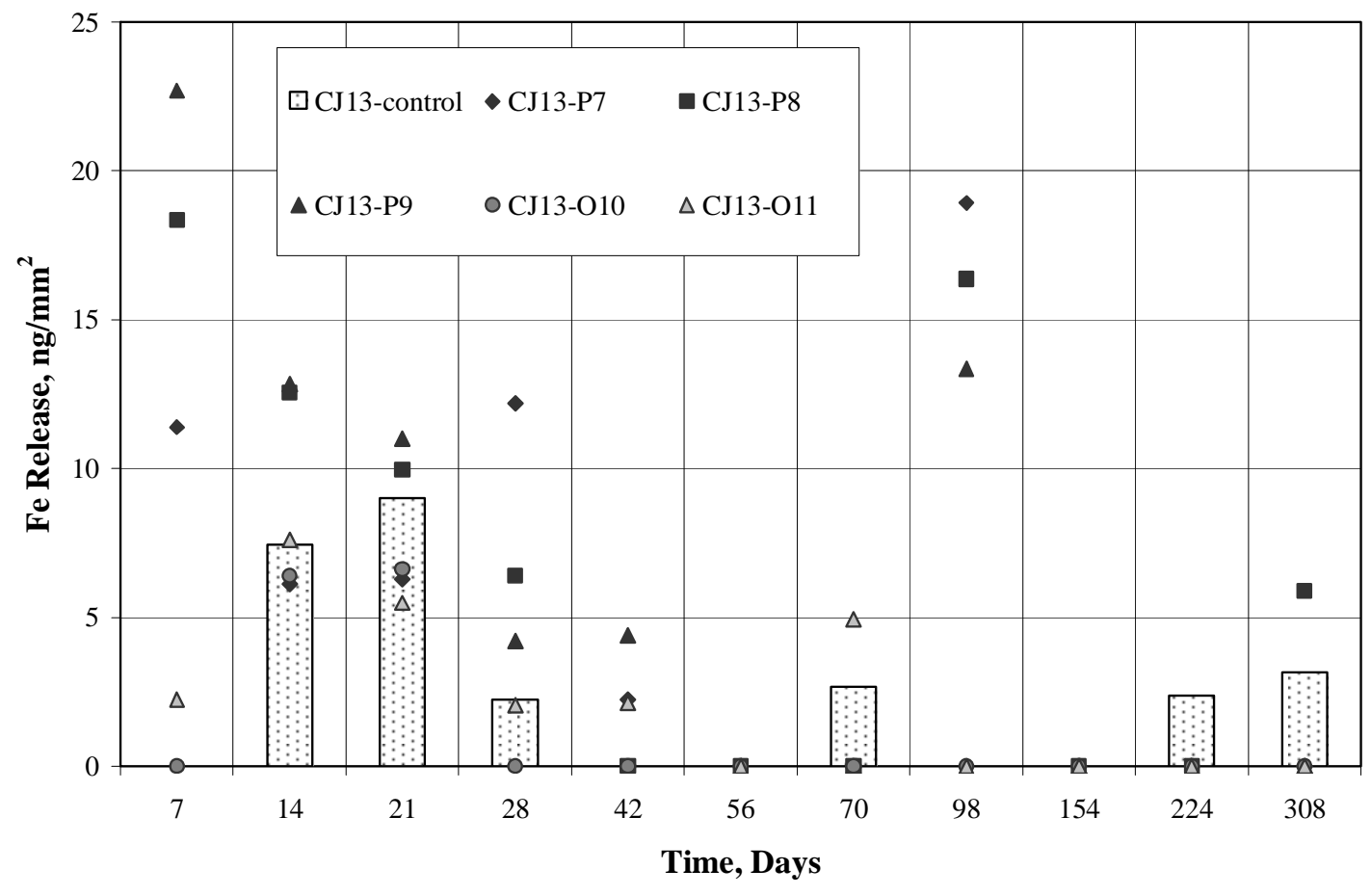

Figure H-2. Iron Releases in $\mathrm{CJ} 13$ solution at $90^{\circ} \mathrm{C}$. 


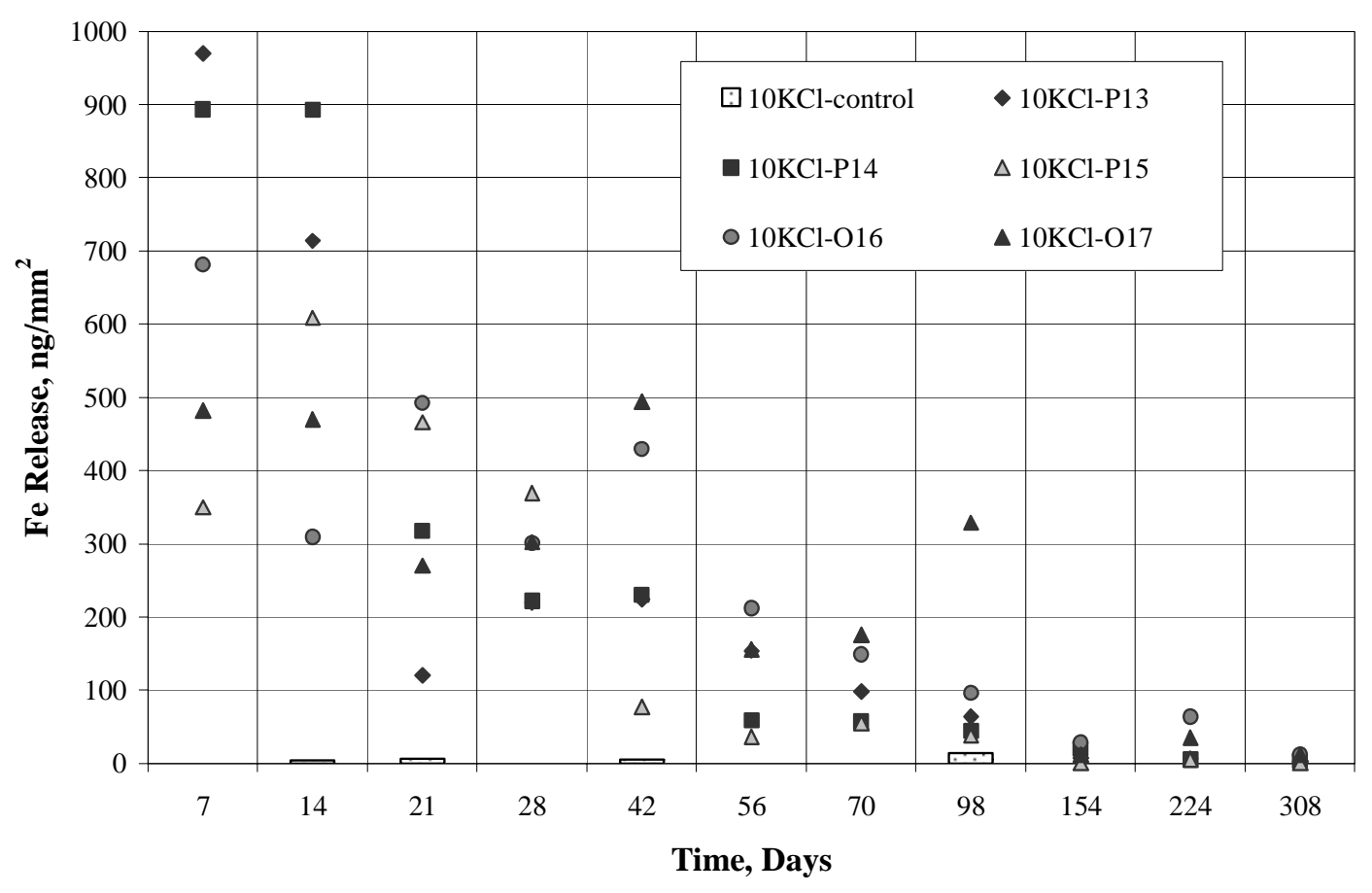

Figure H-3. Iron Releases in $10 \mathrm{KCl}$ solution at $90^{\circ} \mathrm{C}$.

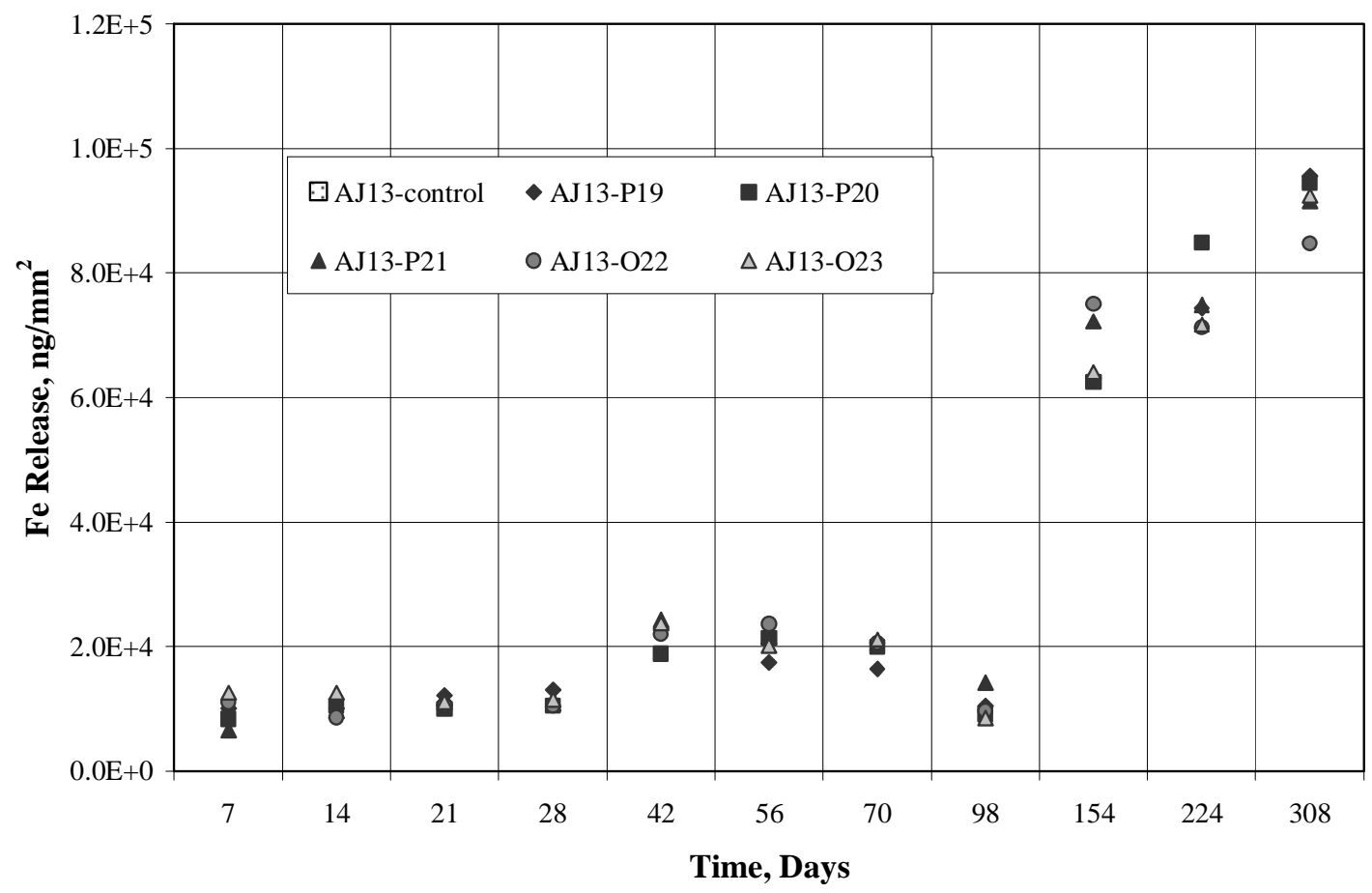

Figure H-4. Iron Releases in $\mathrm{AJ} 13$ solution at $90^{\circ} \mathrm{C}$. 


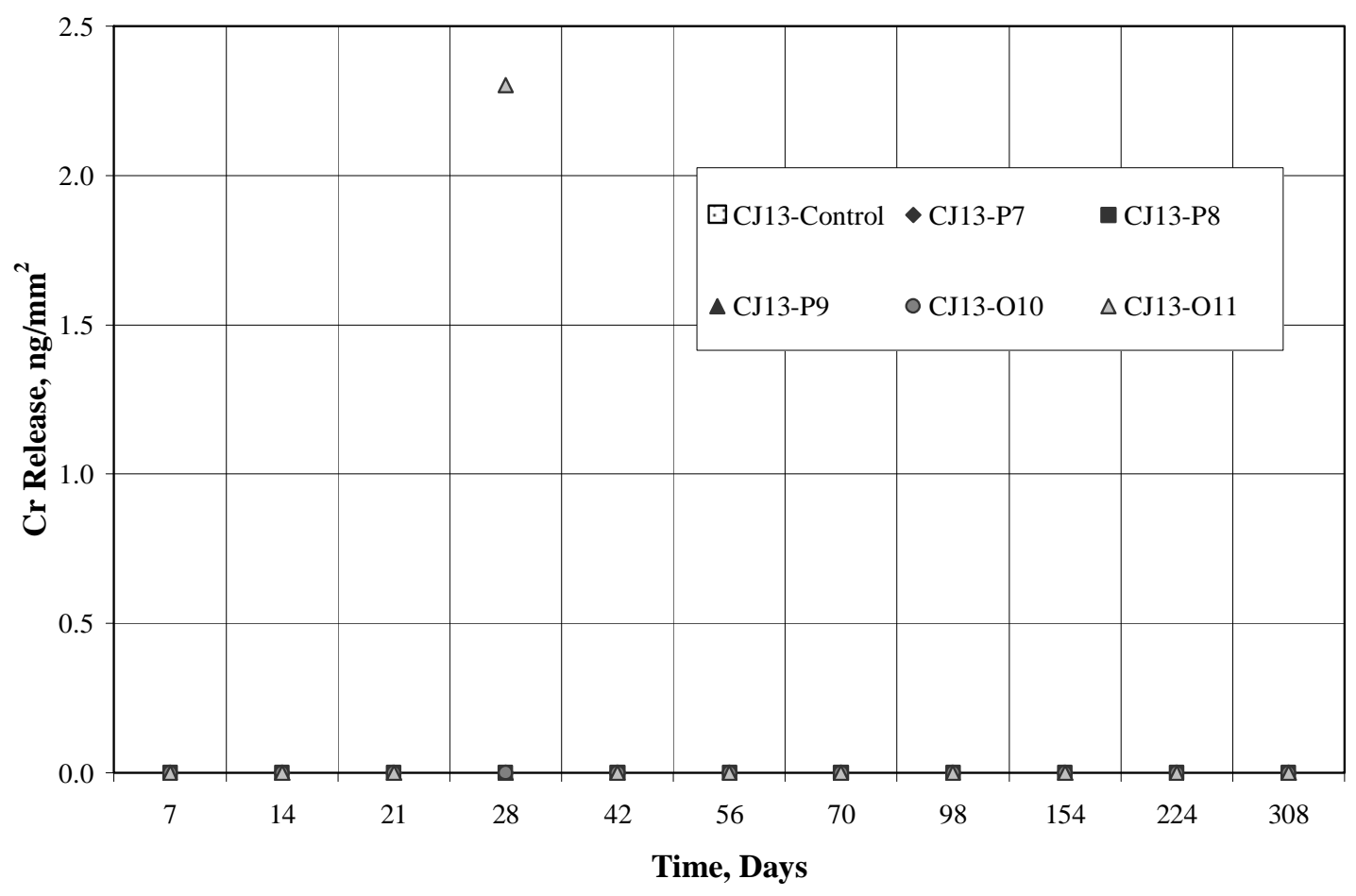

Figure H-5. Chromium Releases in CJ13 solution at $90^{\circ} \mathrm{C}$.

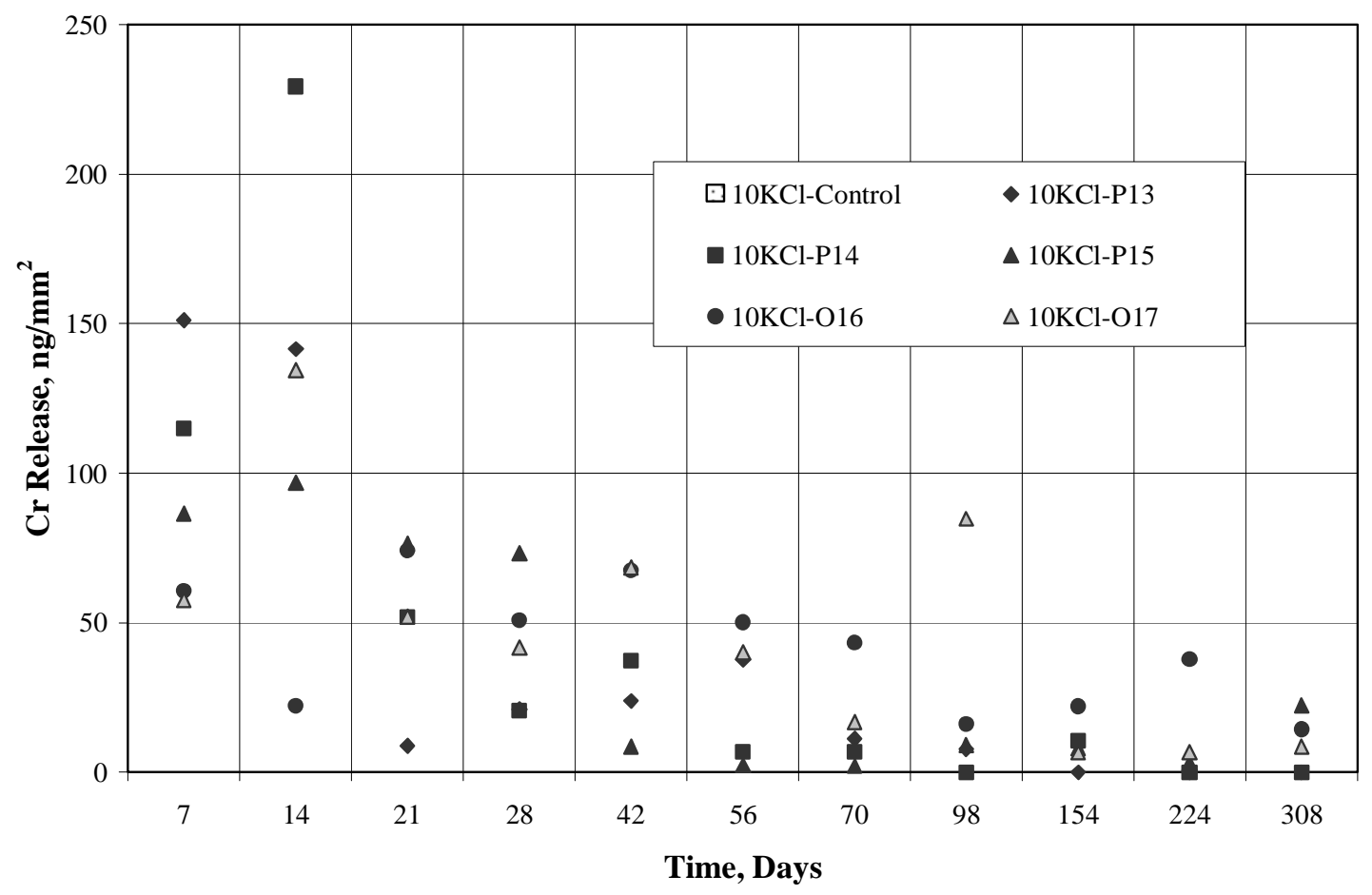

Figure H-6. Chromium Releases in $10 \mathrm{KCl}$ solution at $90^{\circ} \mathrm{C}$. 


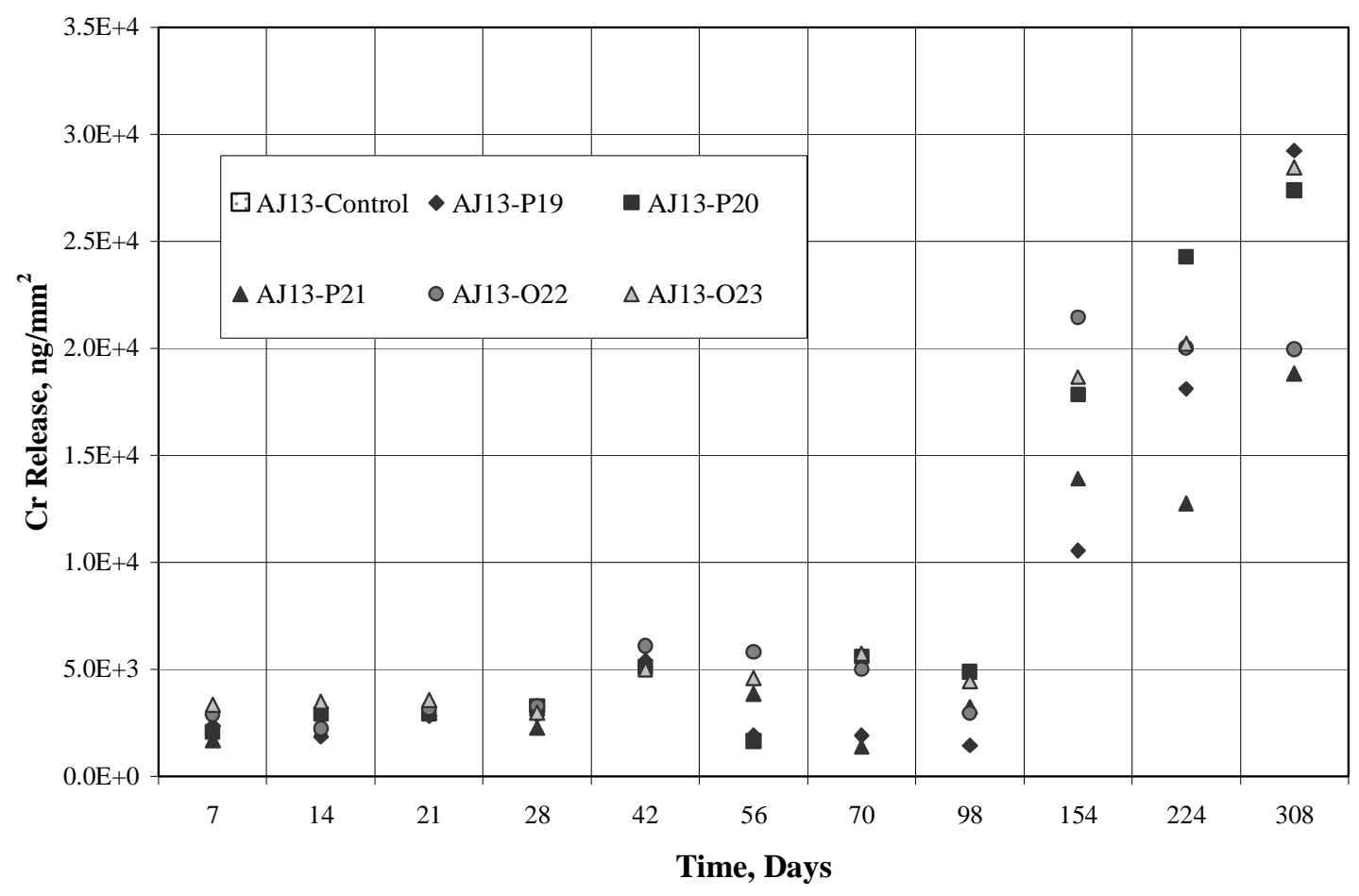

Figure H-7. Chromium Releases in AJ13 solution at $90^{\circ} \mathrm{C}$.

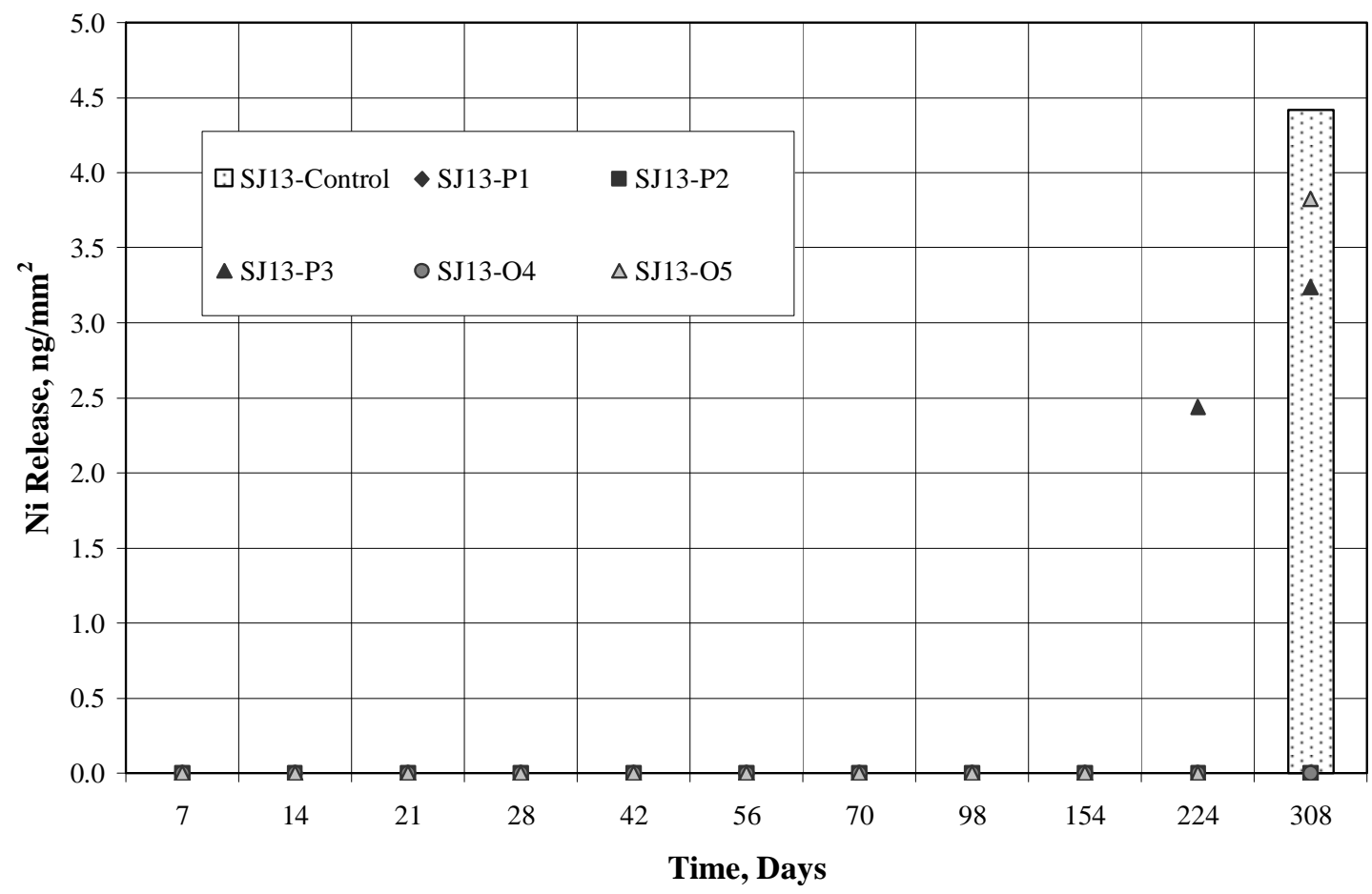

Figure H-8. Nickel Releases in $\mathrm{SJ} 13$ solution at $90^{\circ} \mathrm{C}$. 


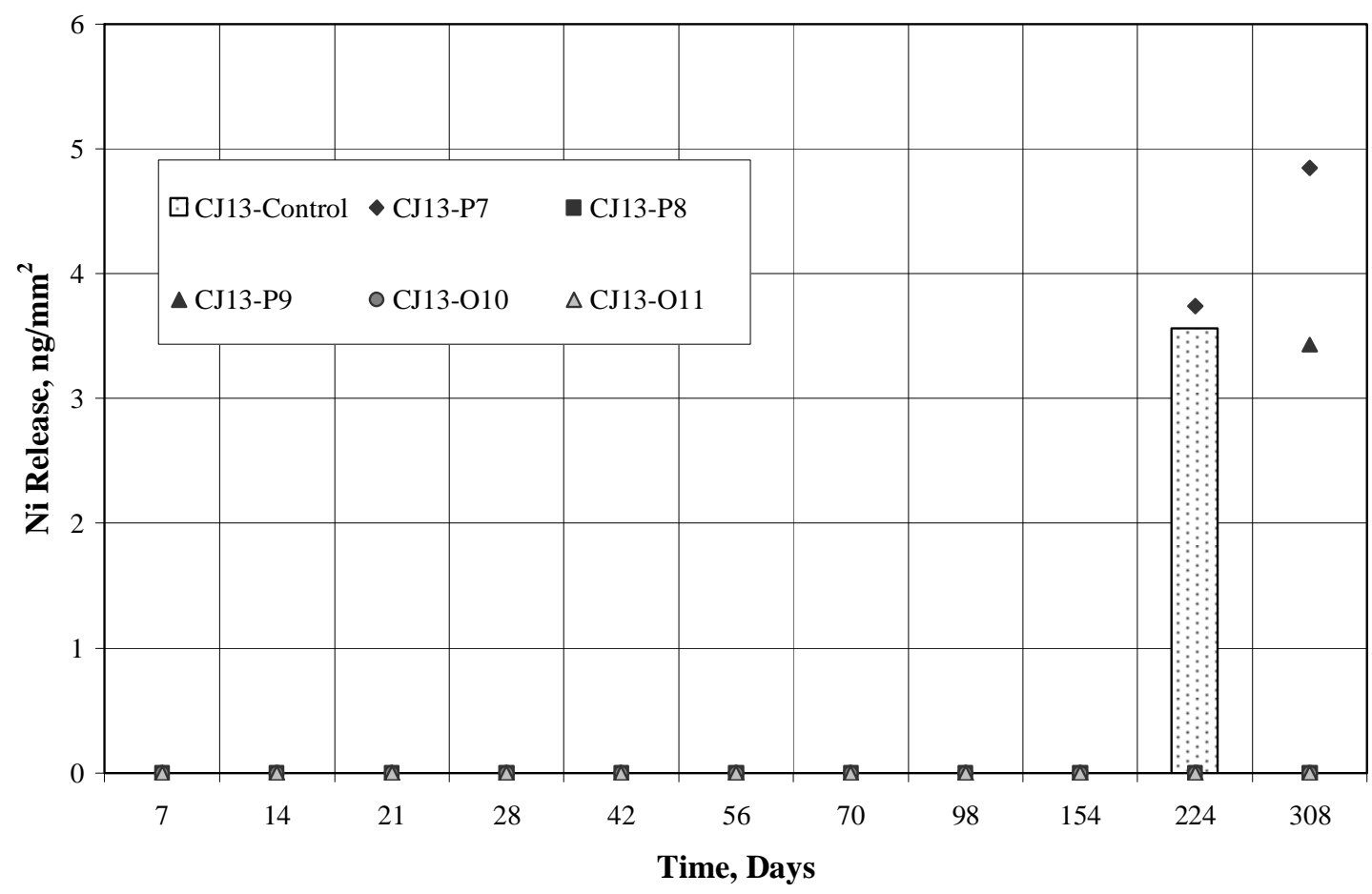

Figure H-9. Nickel Releases in $\mathrm{CJ13}$ solution at $900^{\circ} \mathrm{C}$.

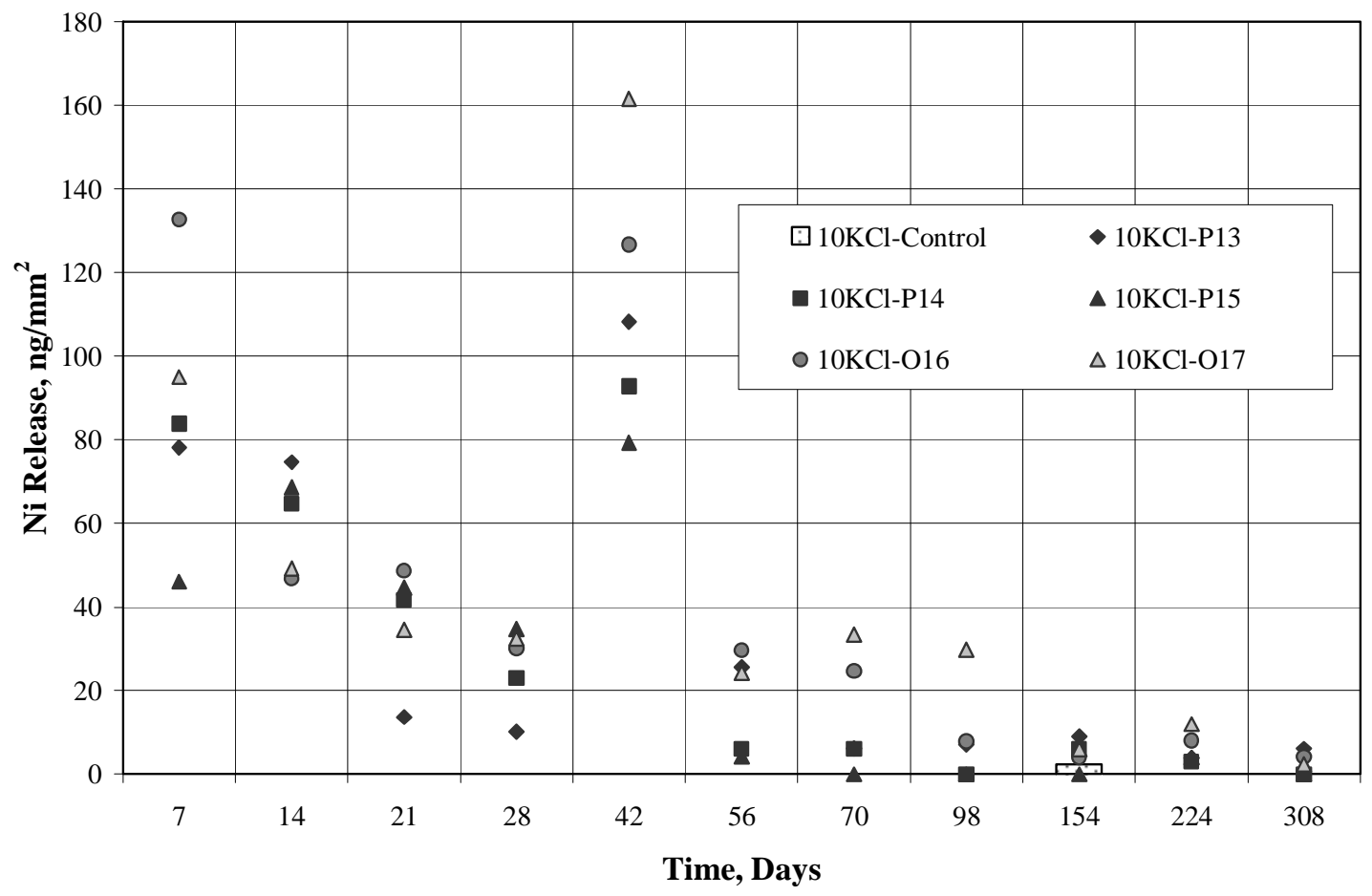

Figure $\mathrm{H}-10$. Nickel Releases in $10 \mathrm{KCl}$ solution at $90^{\circ} \mathrm{C}$. 


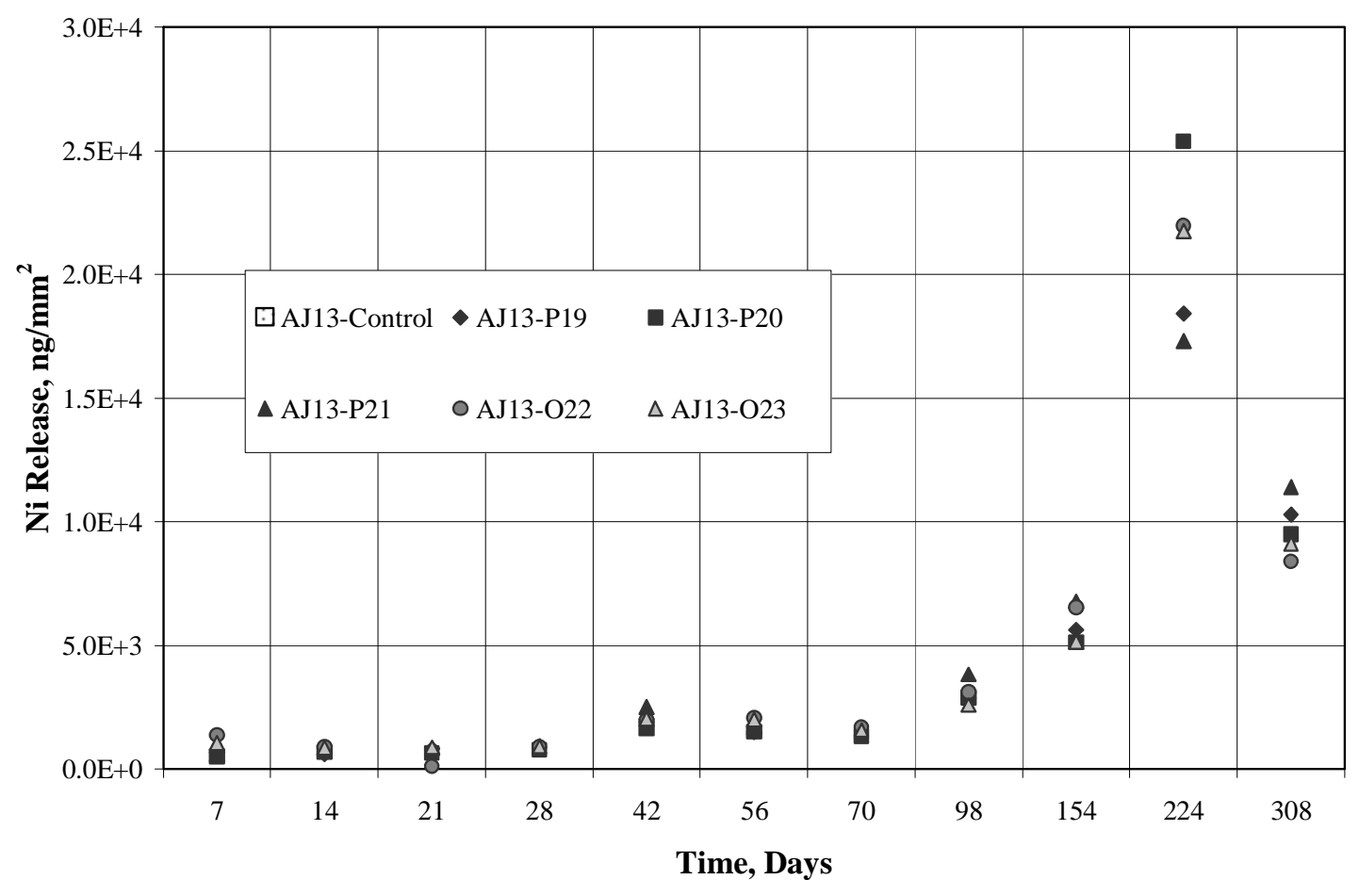

Figure H-11. Nickel Releases in $\mathrm{AJ} 13$ solution at $90^{\circ} \mathrm{C}$.

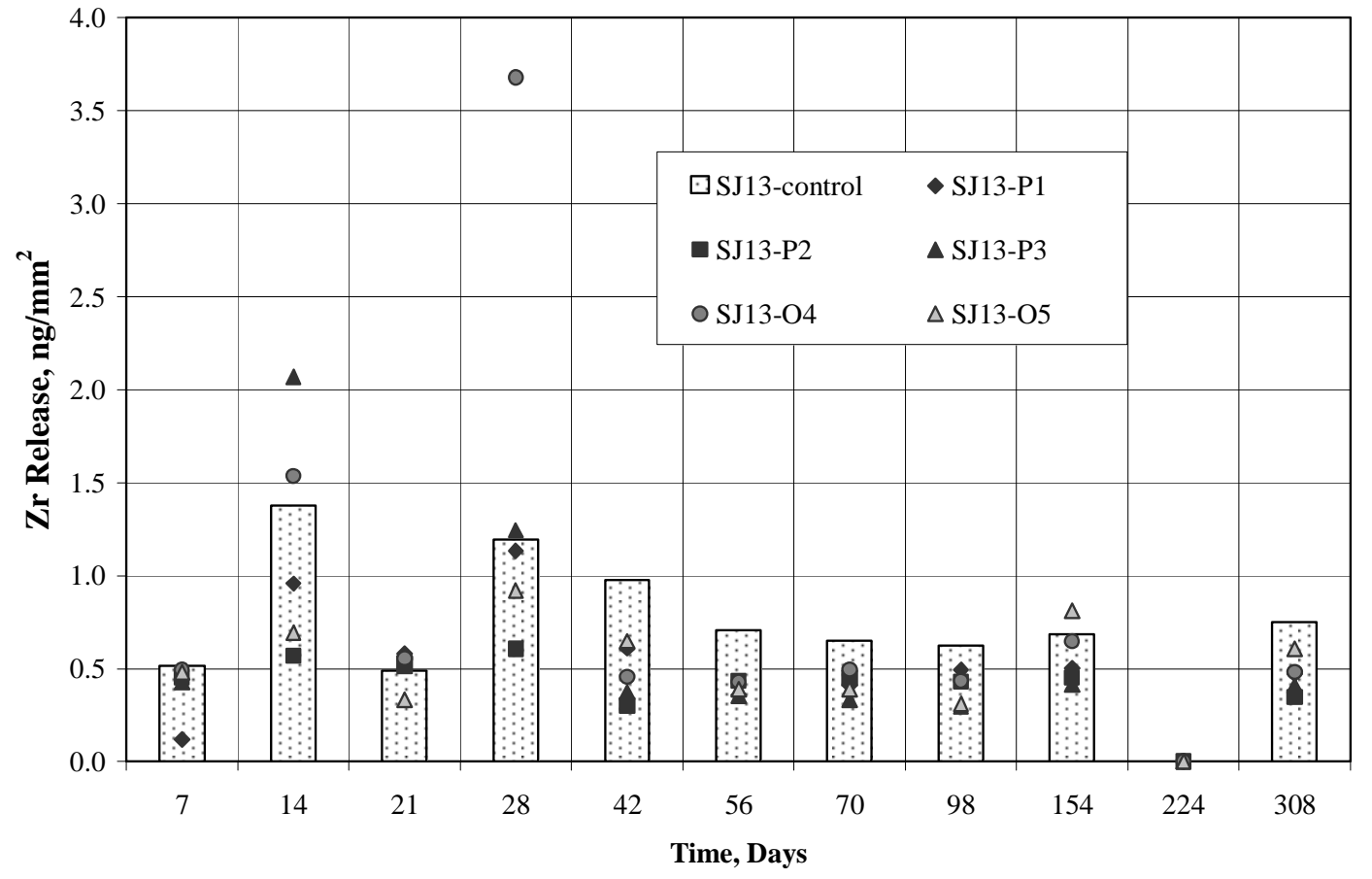

Figure H-12. Zirconium Releases in $\mathrm{SJ13}$ solution at $90^{\circ} \mathrm{C}$. 


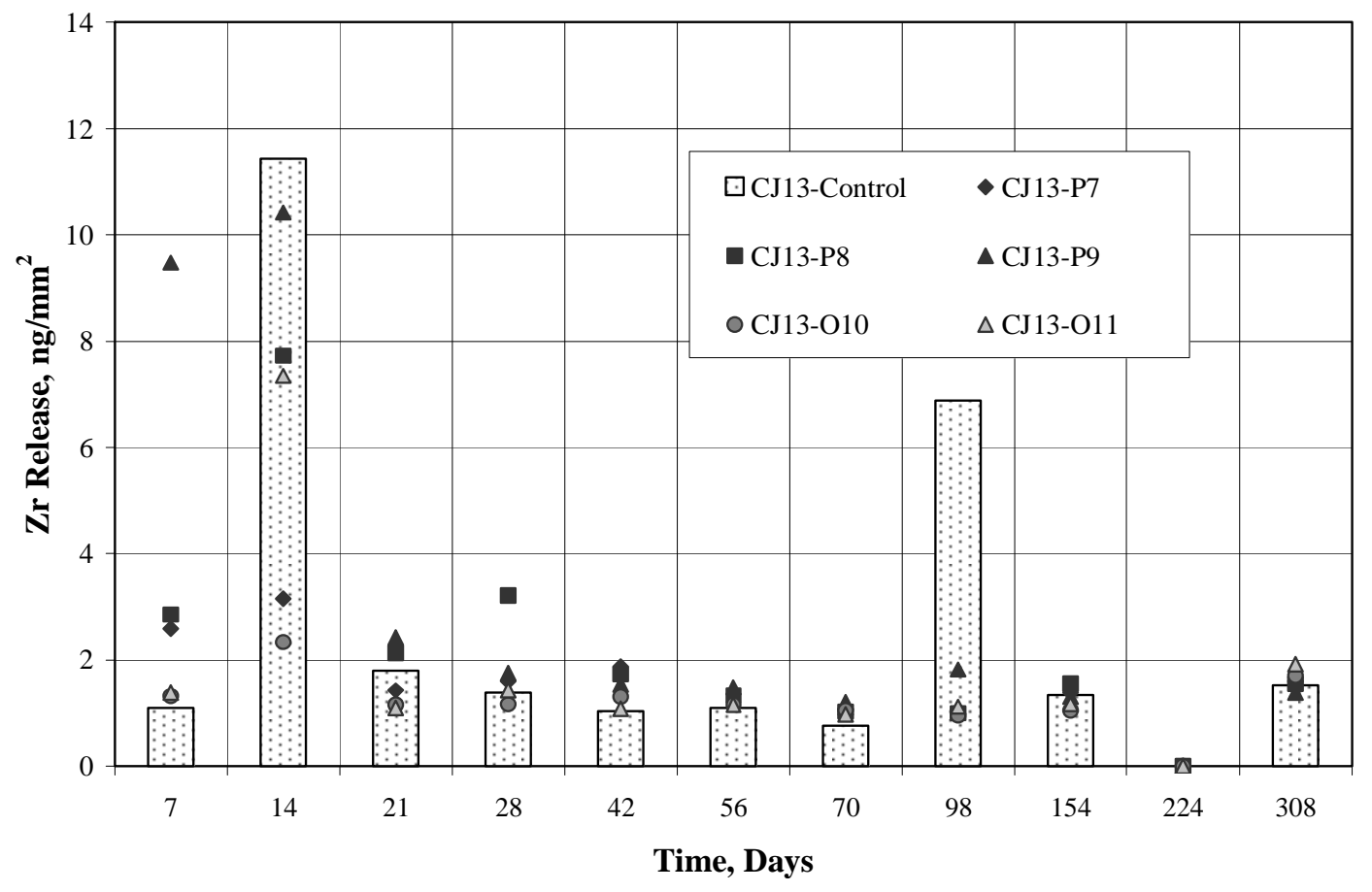

Figure H-13. Zirconium Releases in $\mathrm{CJ} 13$ solution at $90^{\circ} \mathrm{C}$.

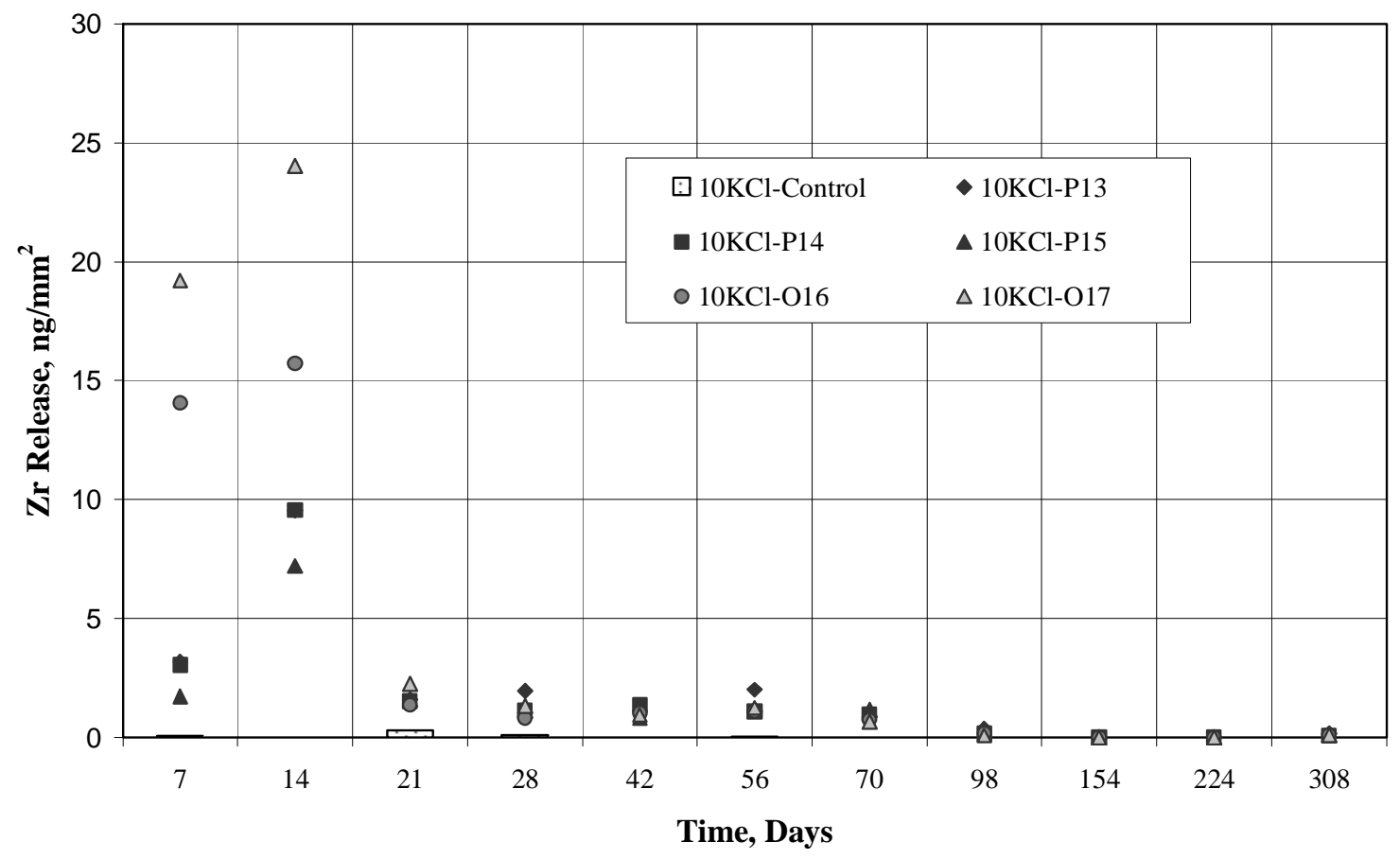

Figure H-14. Zirconium Releases in $10 \mathrm{KCl}$ solution at $90^{\circ} \mathrm{C}$. 


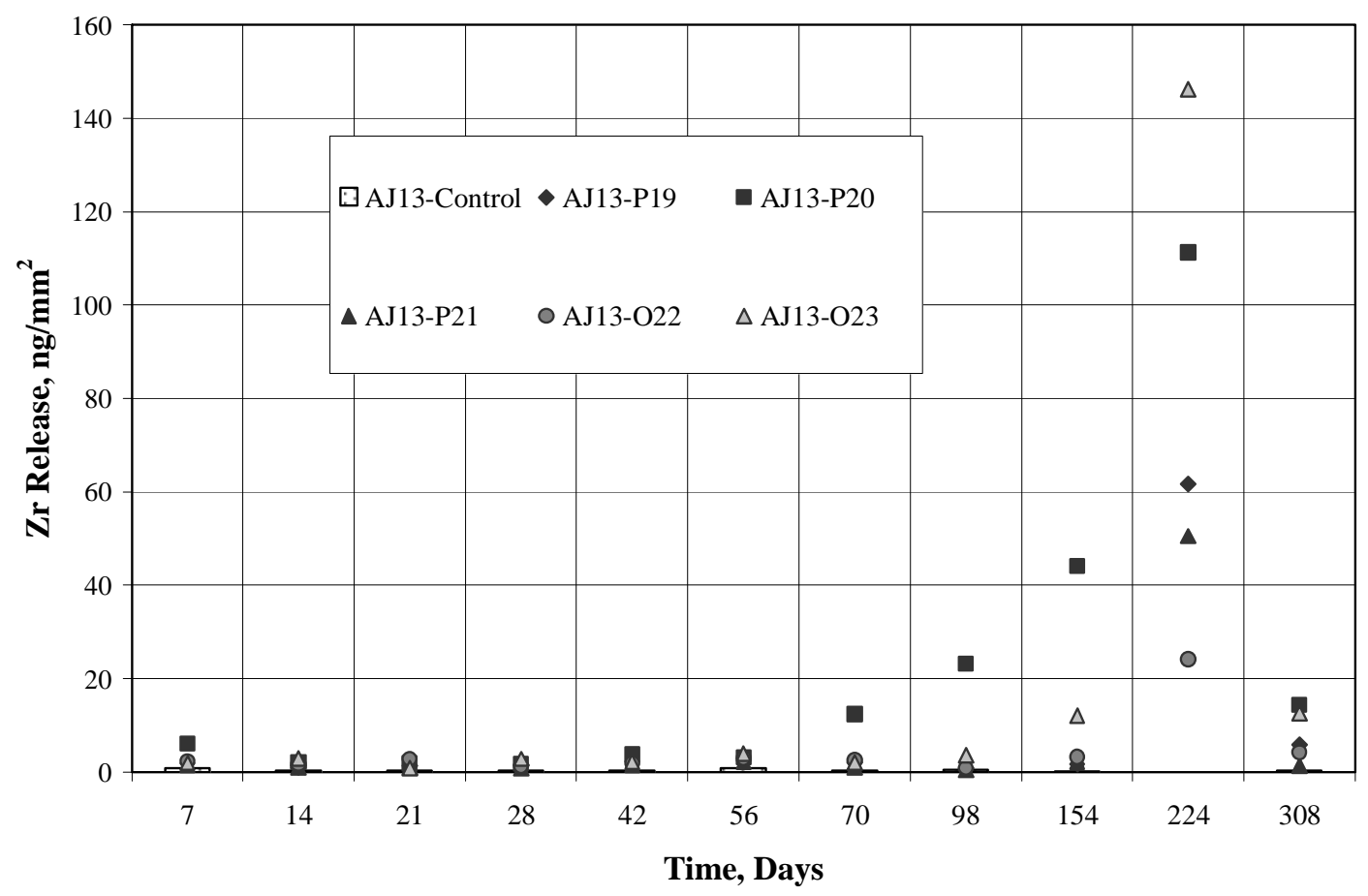

Figure H-15. Zirconium Releases in AJ13 solution at $90^{\circ} \mathrm{C}$.

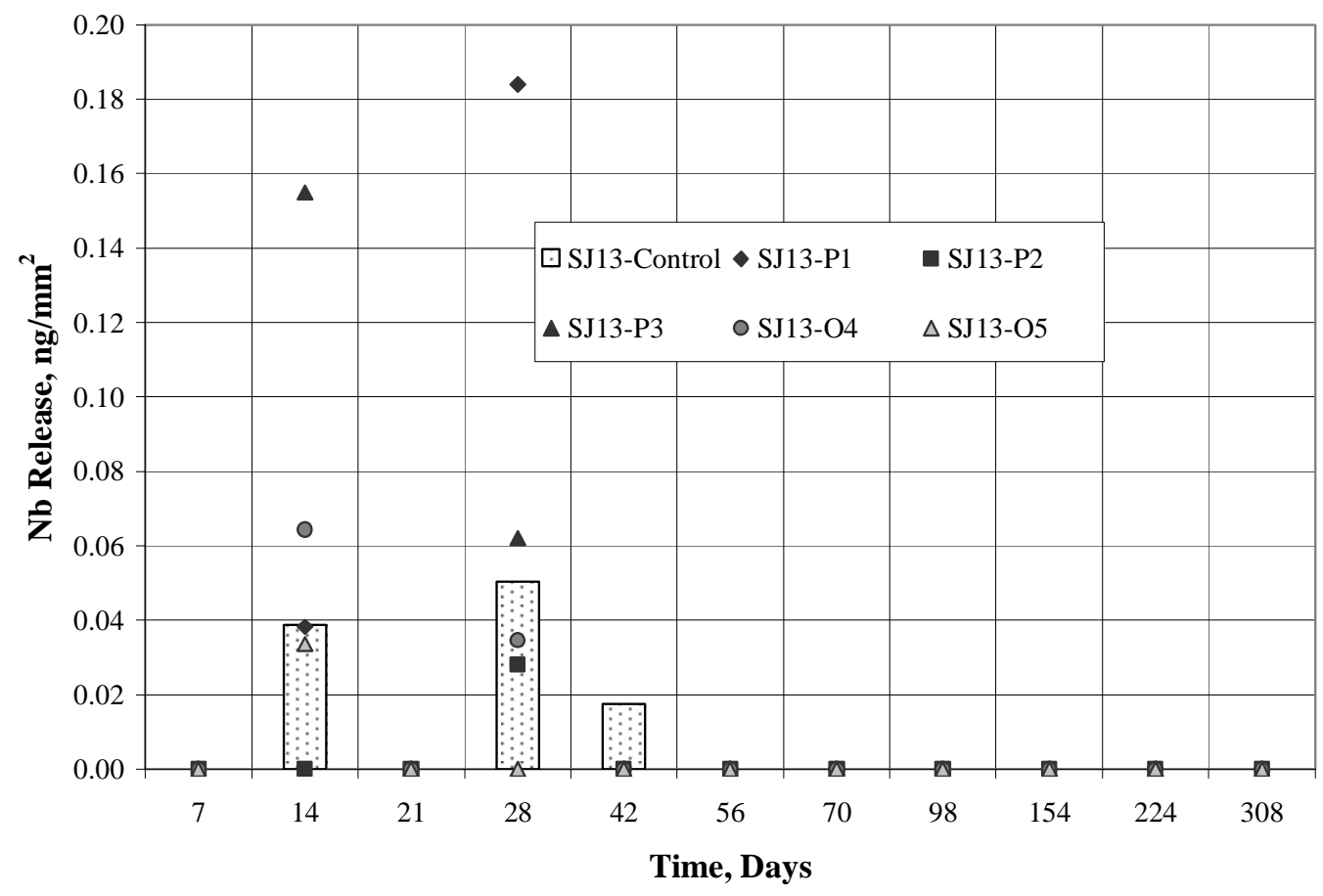

Figure H-16. Niobium Releases in $\mathrm{SJ} 13$ solution at $90^{\circ} \mathrm{C}$. 


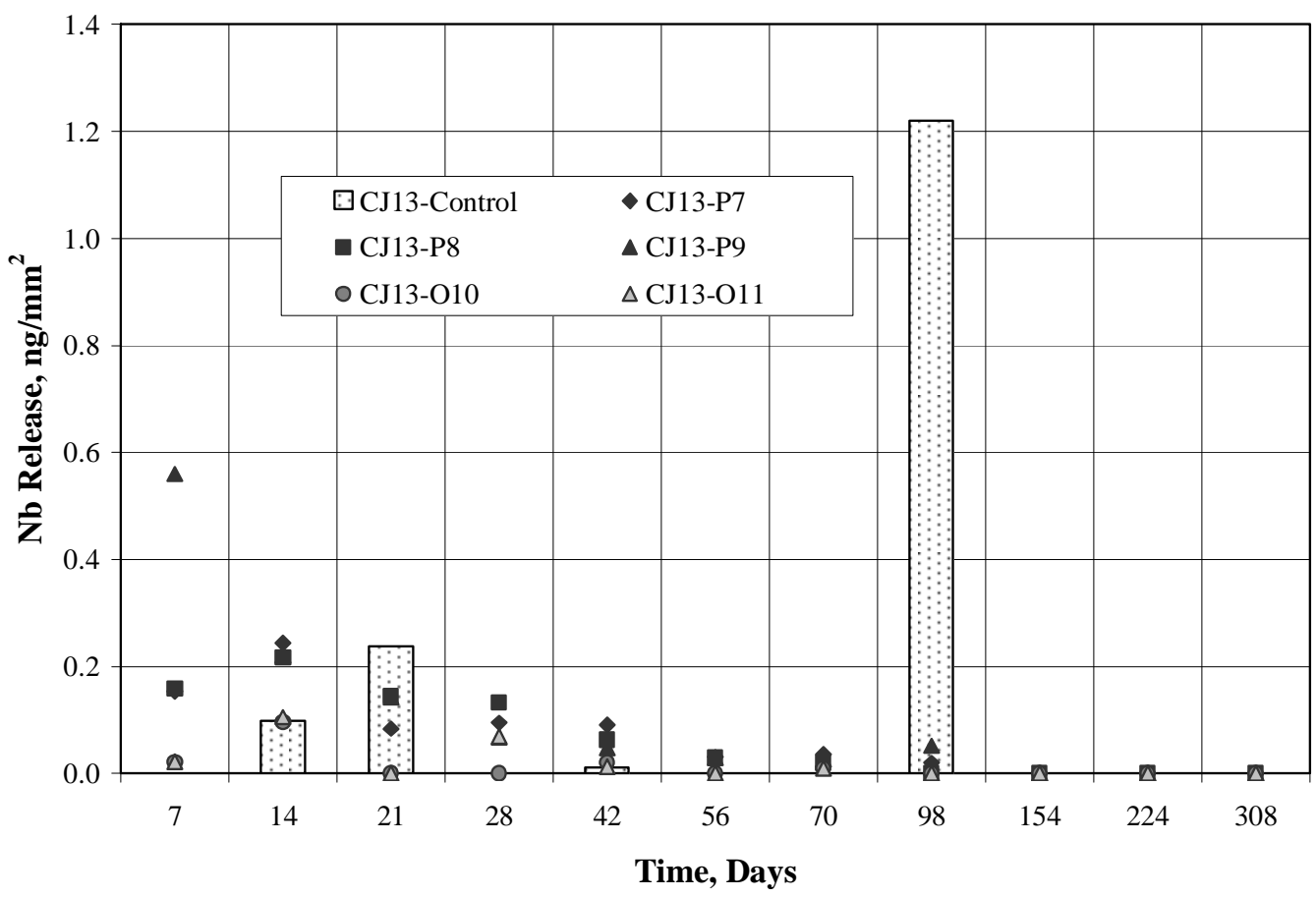

Figure H-17. Niobium Releases in $\mathrm{CJ} 13$ solution at $90^{\circ} \mathrm{C}$.

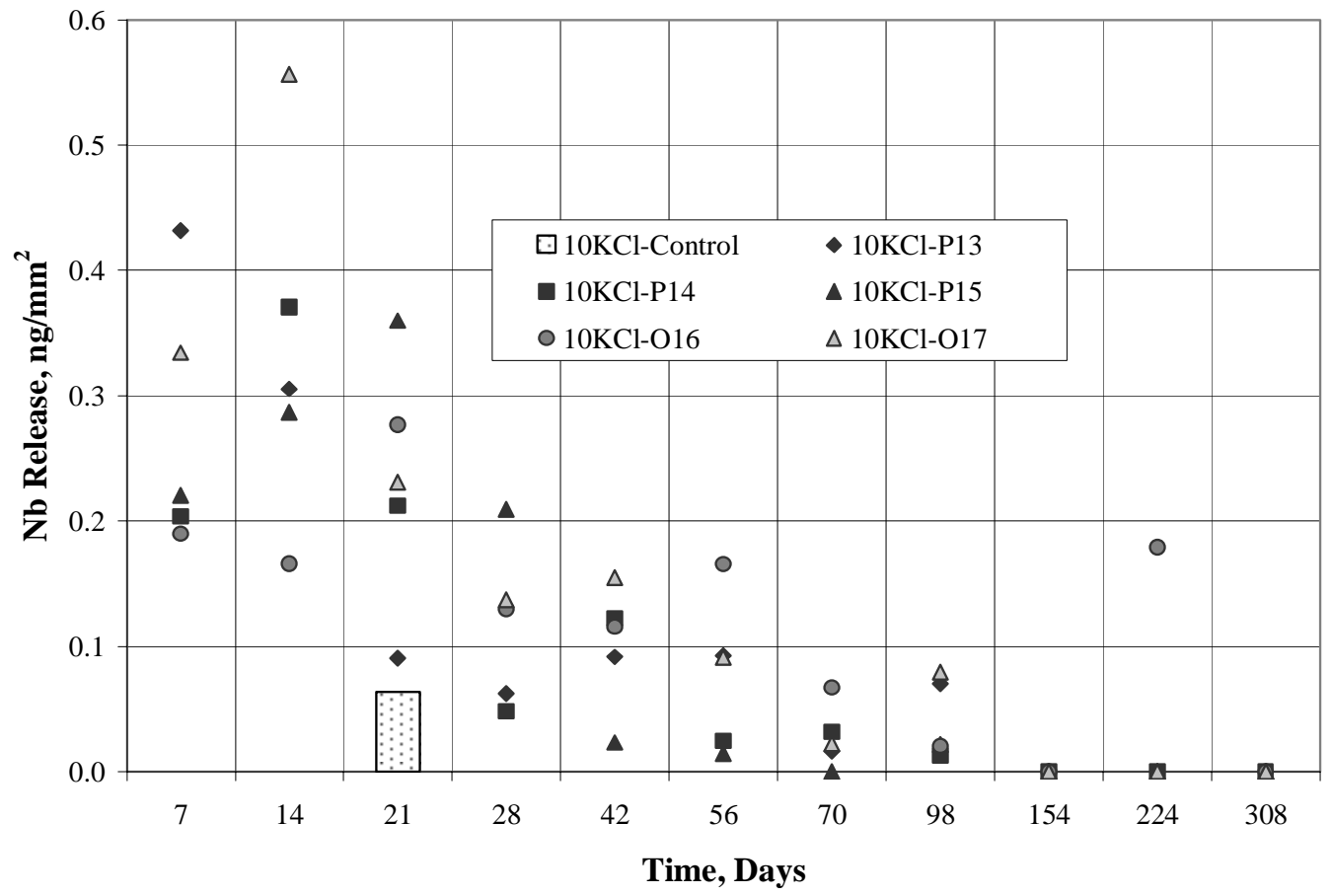

Figure H-18. Niobium Releases in $10 \mathrm{KCl}$ solution at $90^{\circ} \mathrm{C}$. 


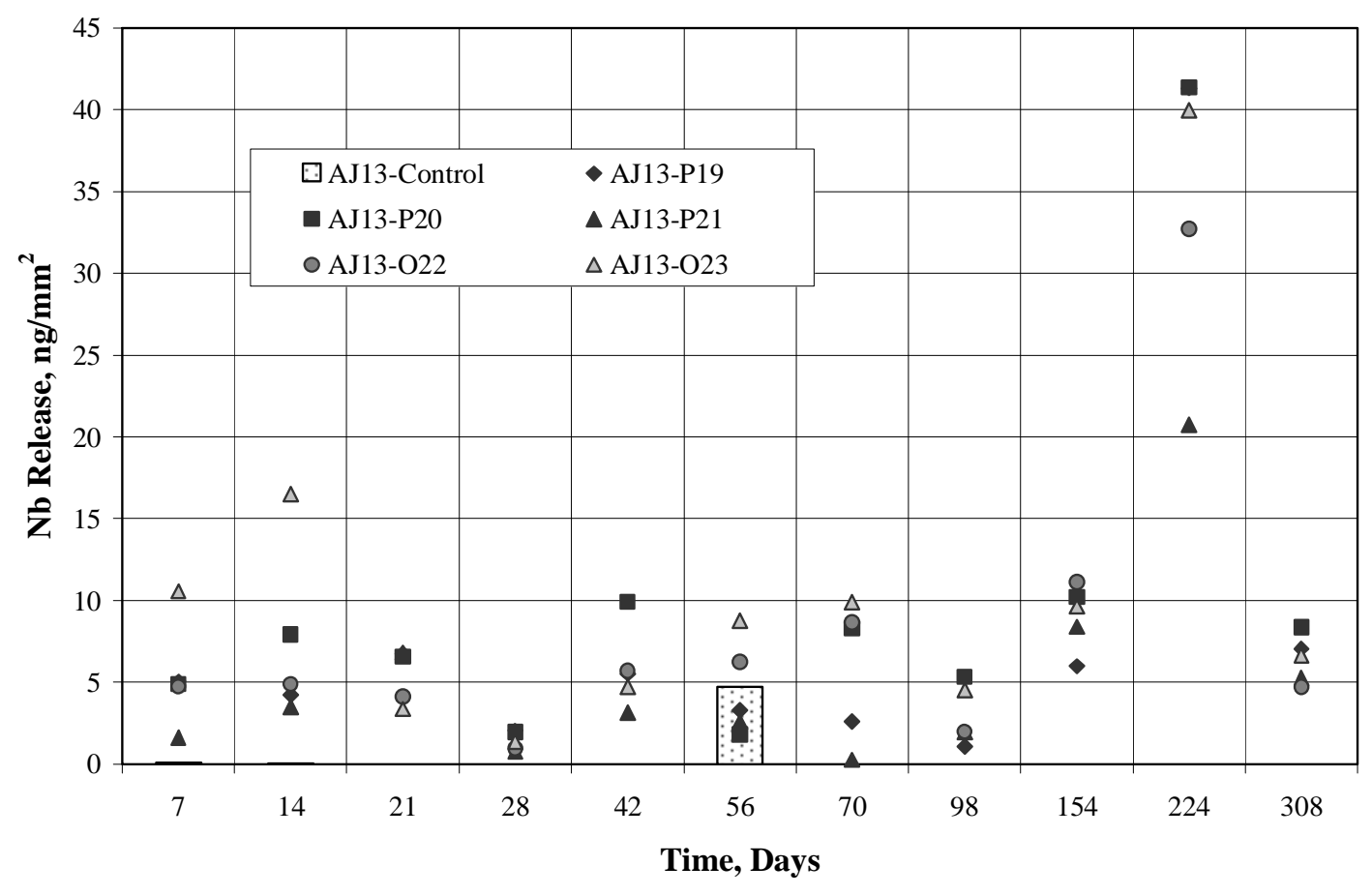

Figure H-19. Niobium Releases in AJ13 solution at $90^{\circ} \mathrm{C}$.

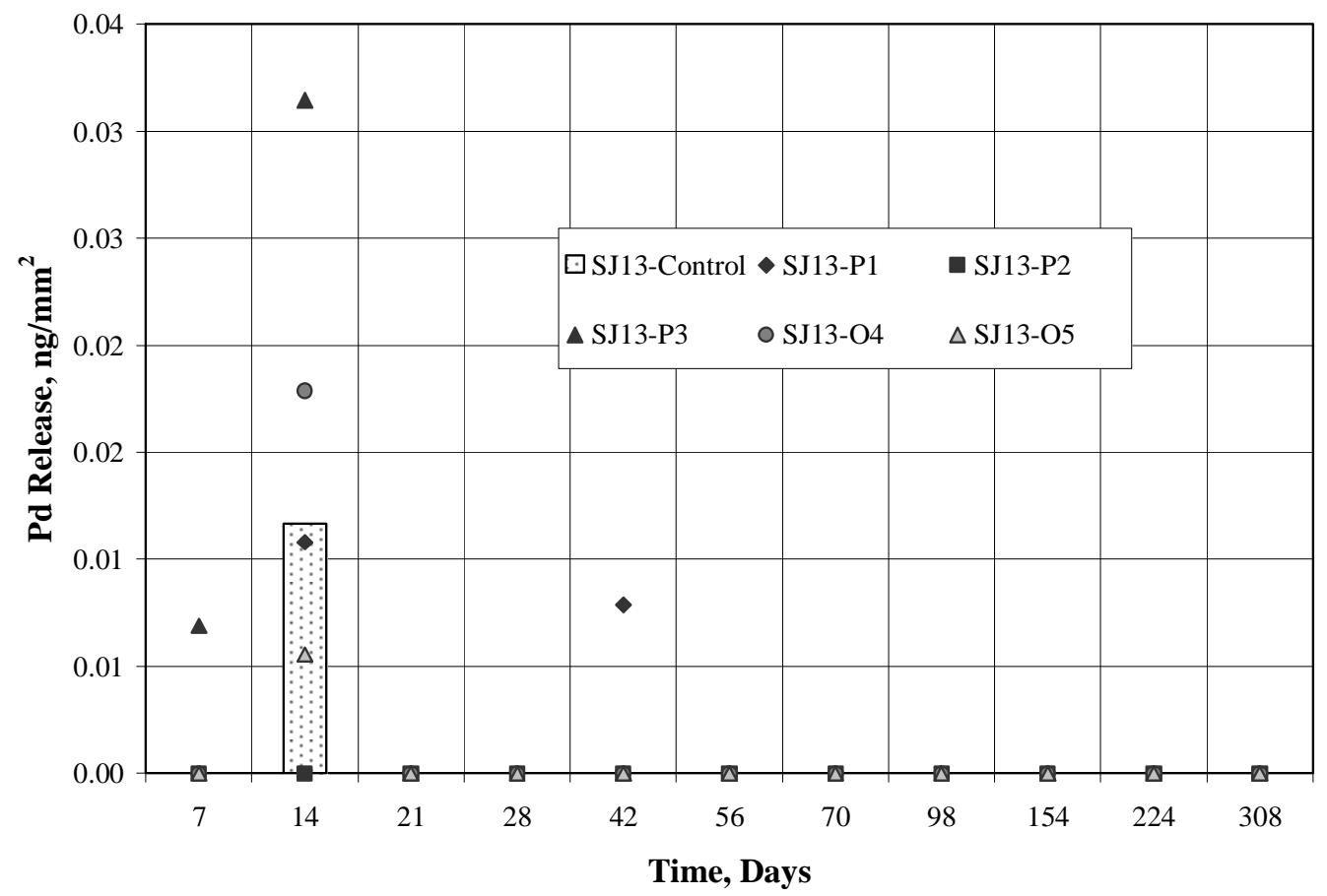

Figure H-20. Paladium Releases in $\mathrm{SJ} 13$ solution at $90^{\circ} \mathrm{C}$. 


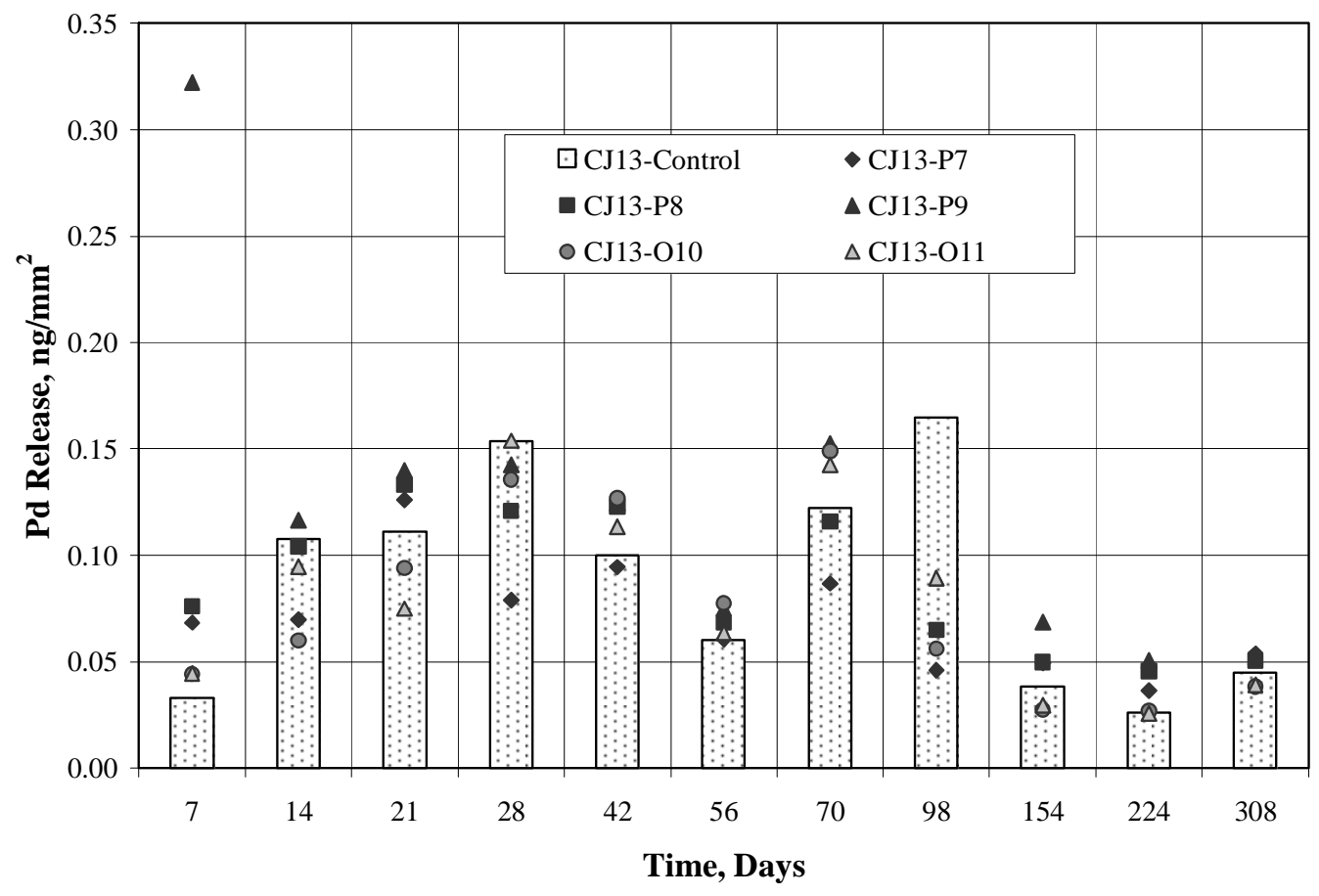

Figure H-21. Paladium Releases in $\mathrm{CJ} 13$ solution at $90^{\circ} \mathrm{C}$.

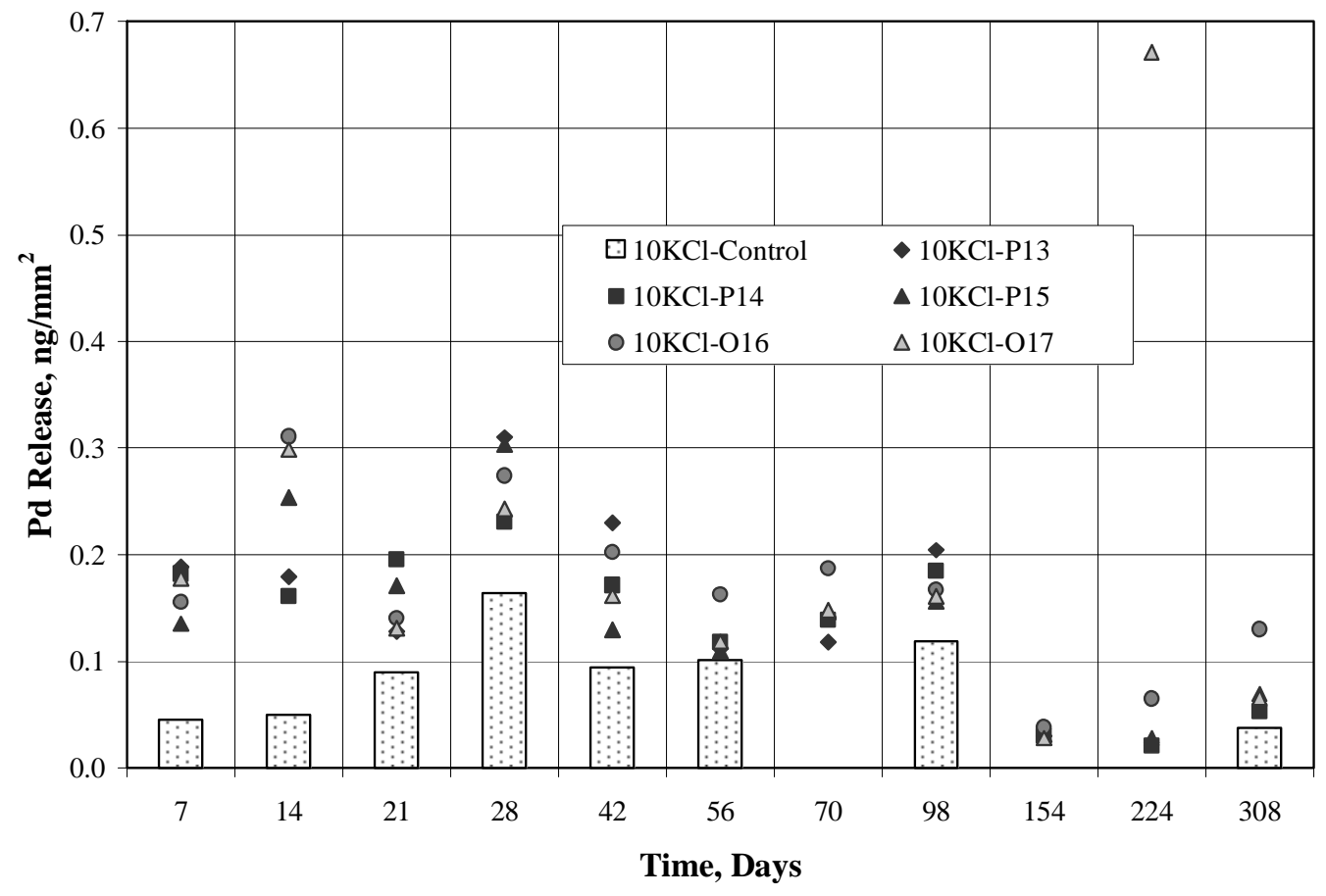

Figure H-22. Paladium Releases in $10 \mathrm{KCl}$ solution at $90^{\circ} \mathrm{C}$. 


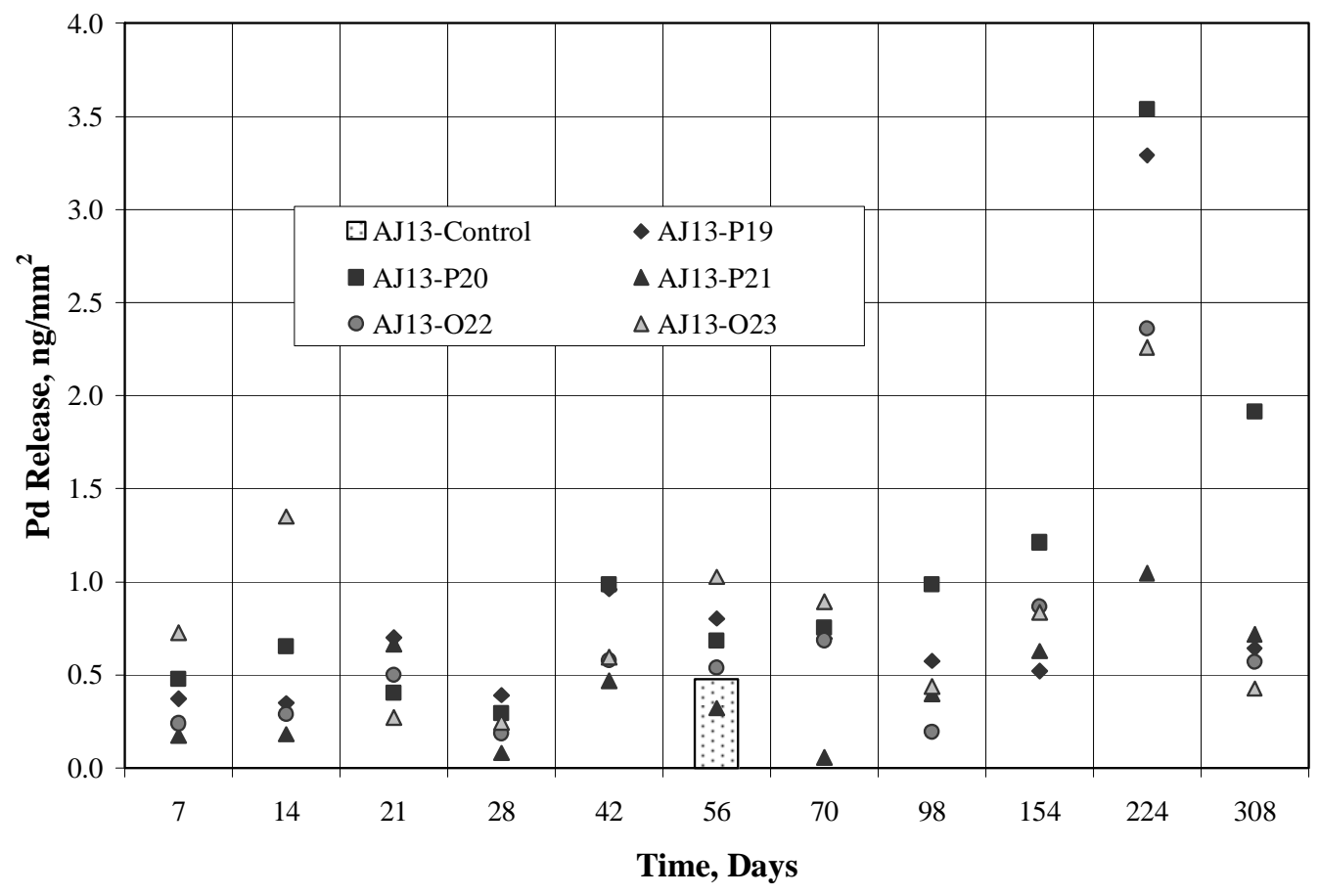

Figure H-23. Paladium Releases in AJ13 solution at $90^{\circ} \mathrm{C}$.

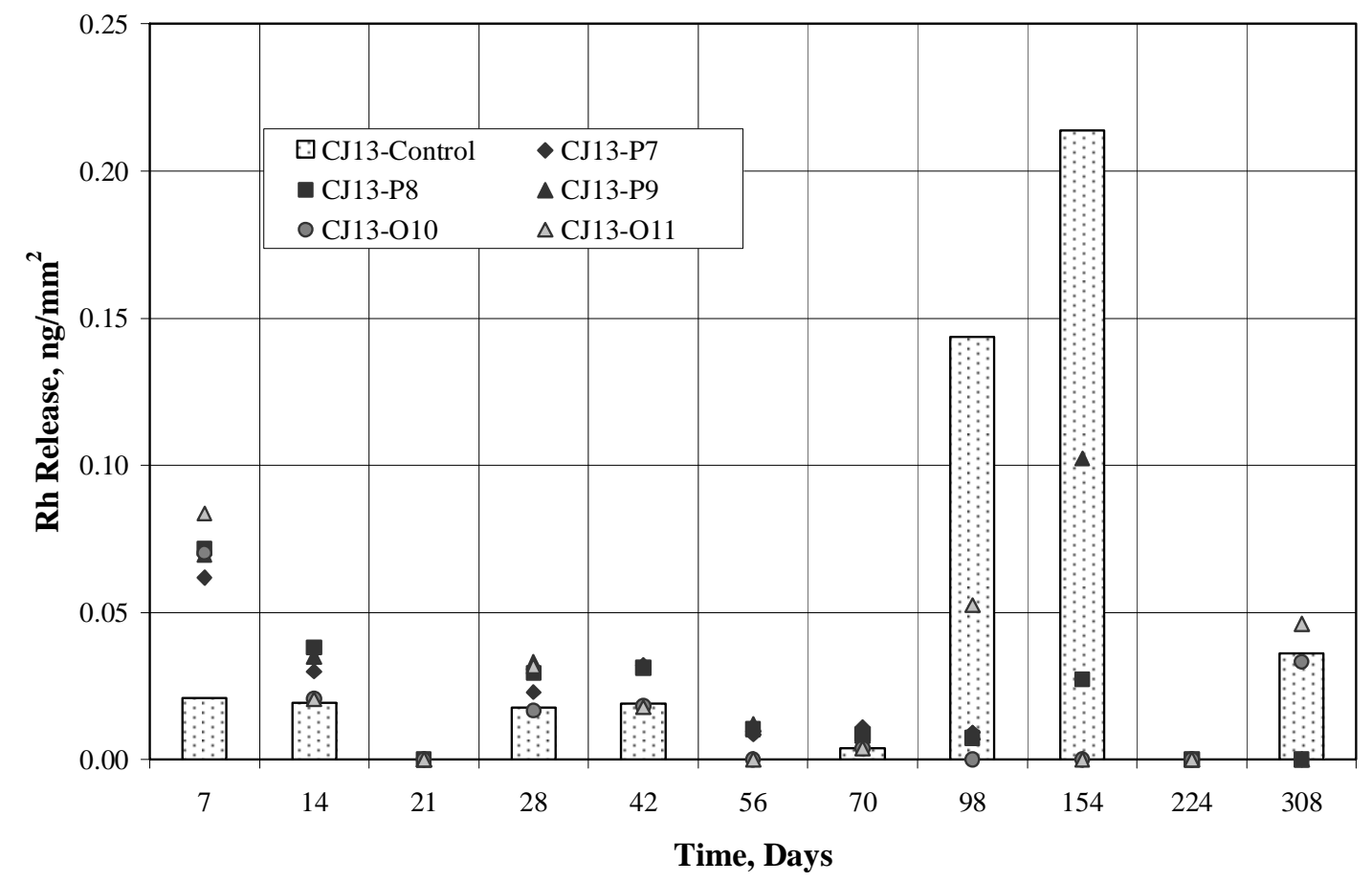

Figure H-24. Rhodium Releases in CJ13 solution at $90^{\circ} \mathrm{C}$. 


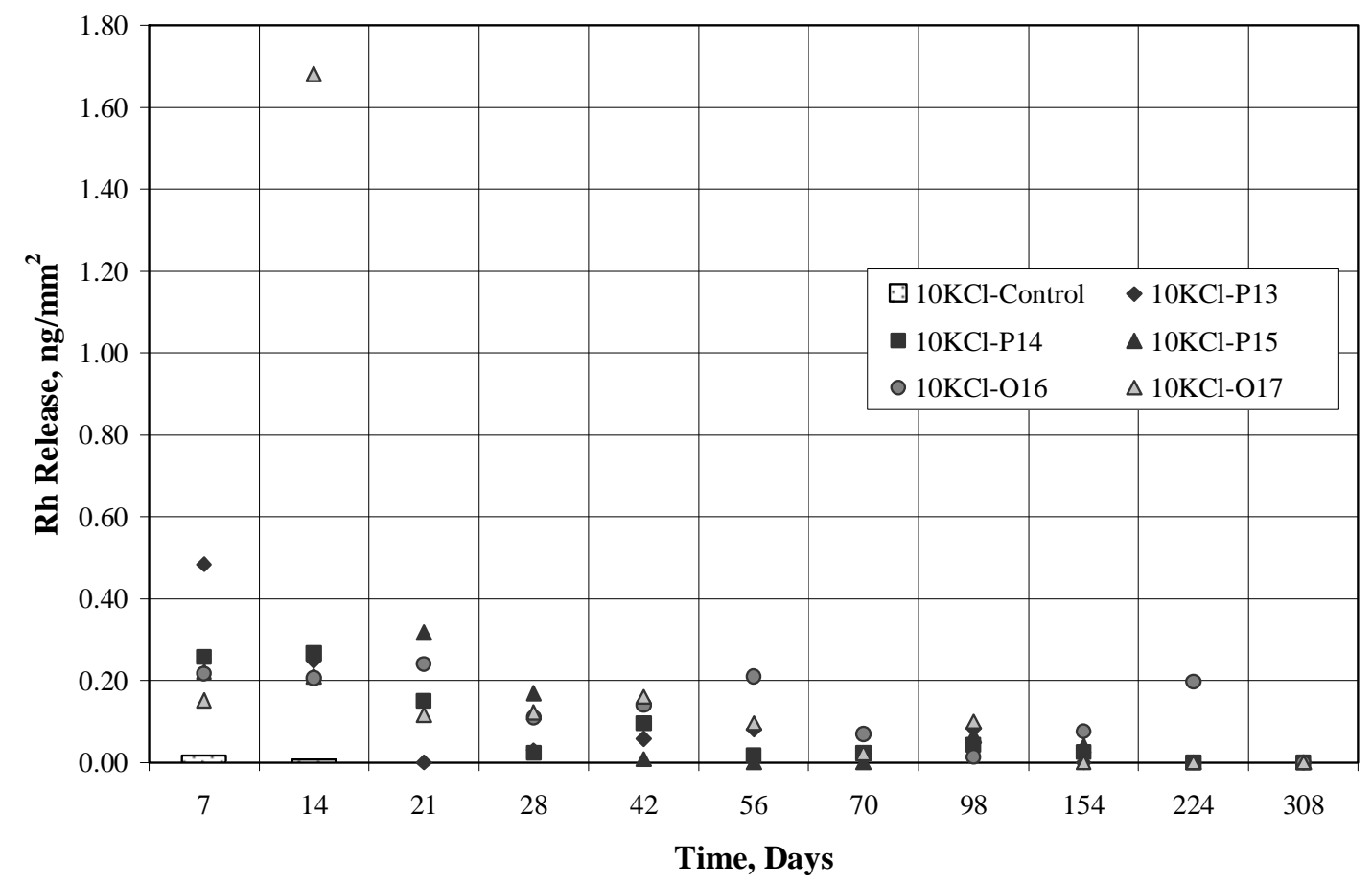

Figure H-25. Rhodium Releases in $10 \mathrm{KCl}$ solution at $90^{\circ} \mathrm{C}$.

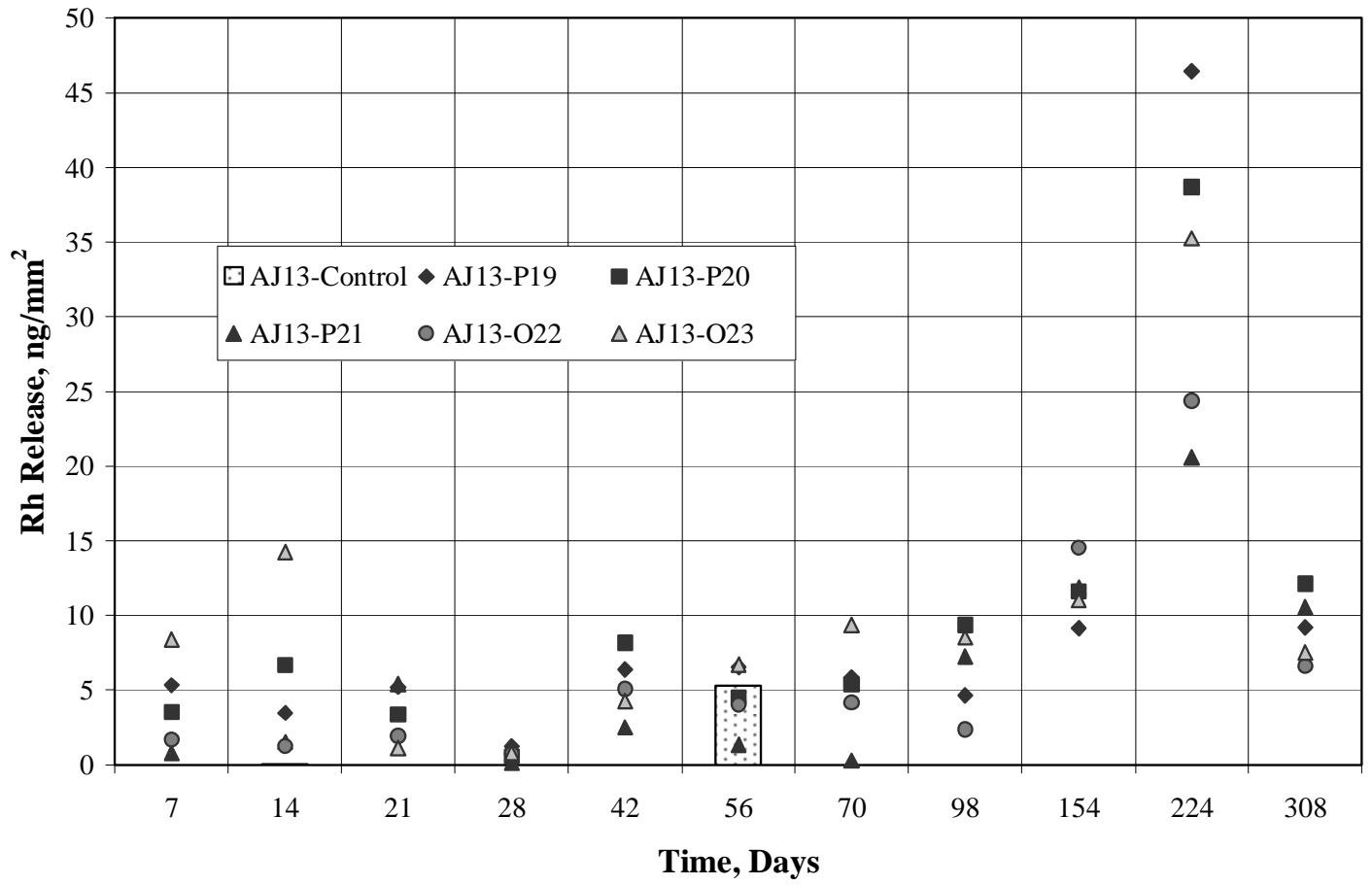

Figure H-26. Rhodium Releases in $\mathrm{AJ13}$ solution at $90^{\circ} \mathrm{C}$. 


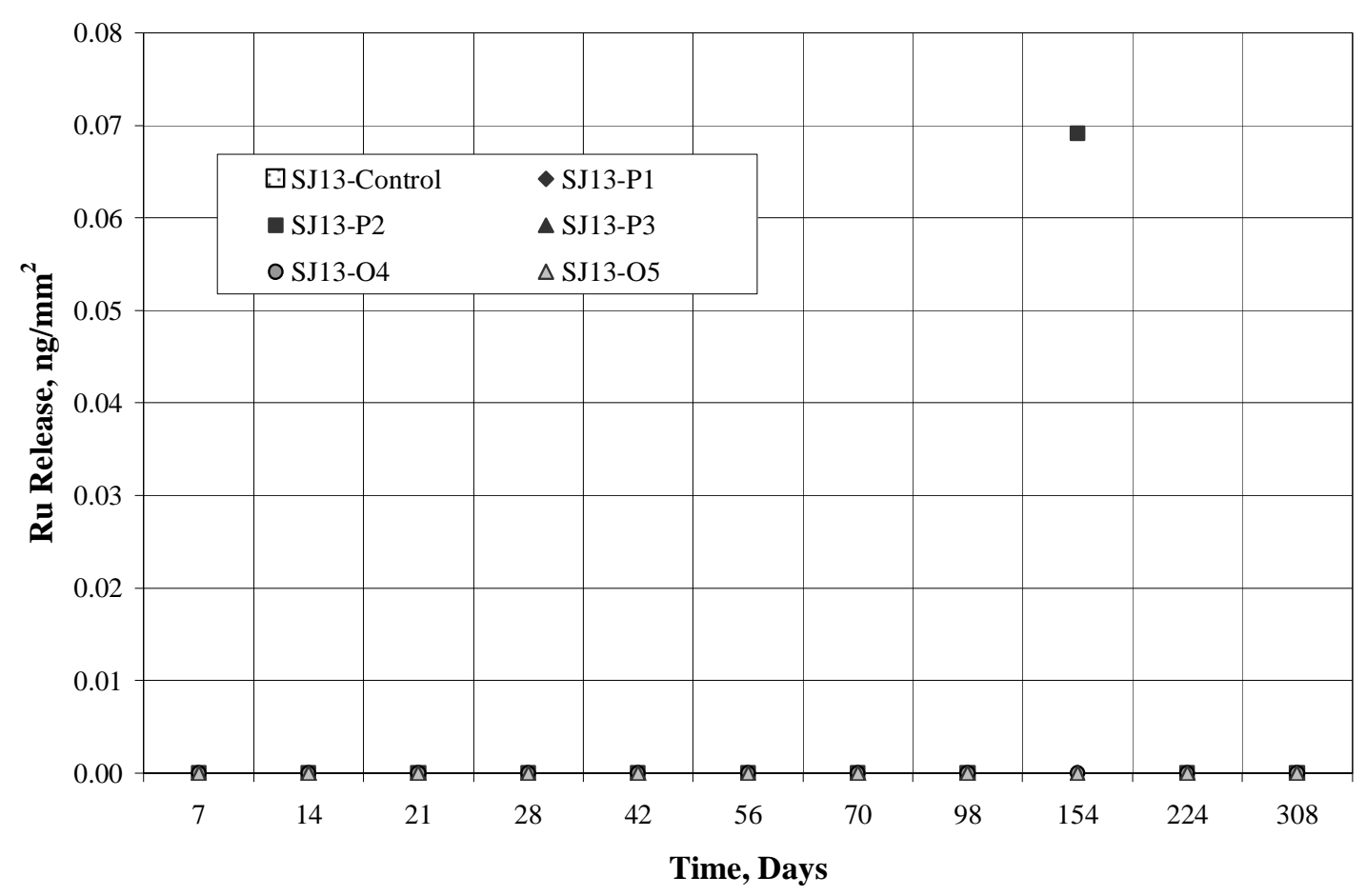

Figure H-27. Ruthenium Releases in $\mathrm{SJ13}$ solution at $90^{\circ} \mathrm{C}$.

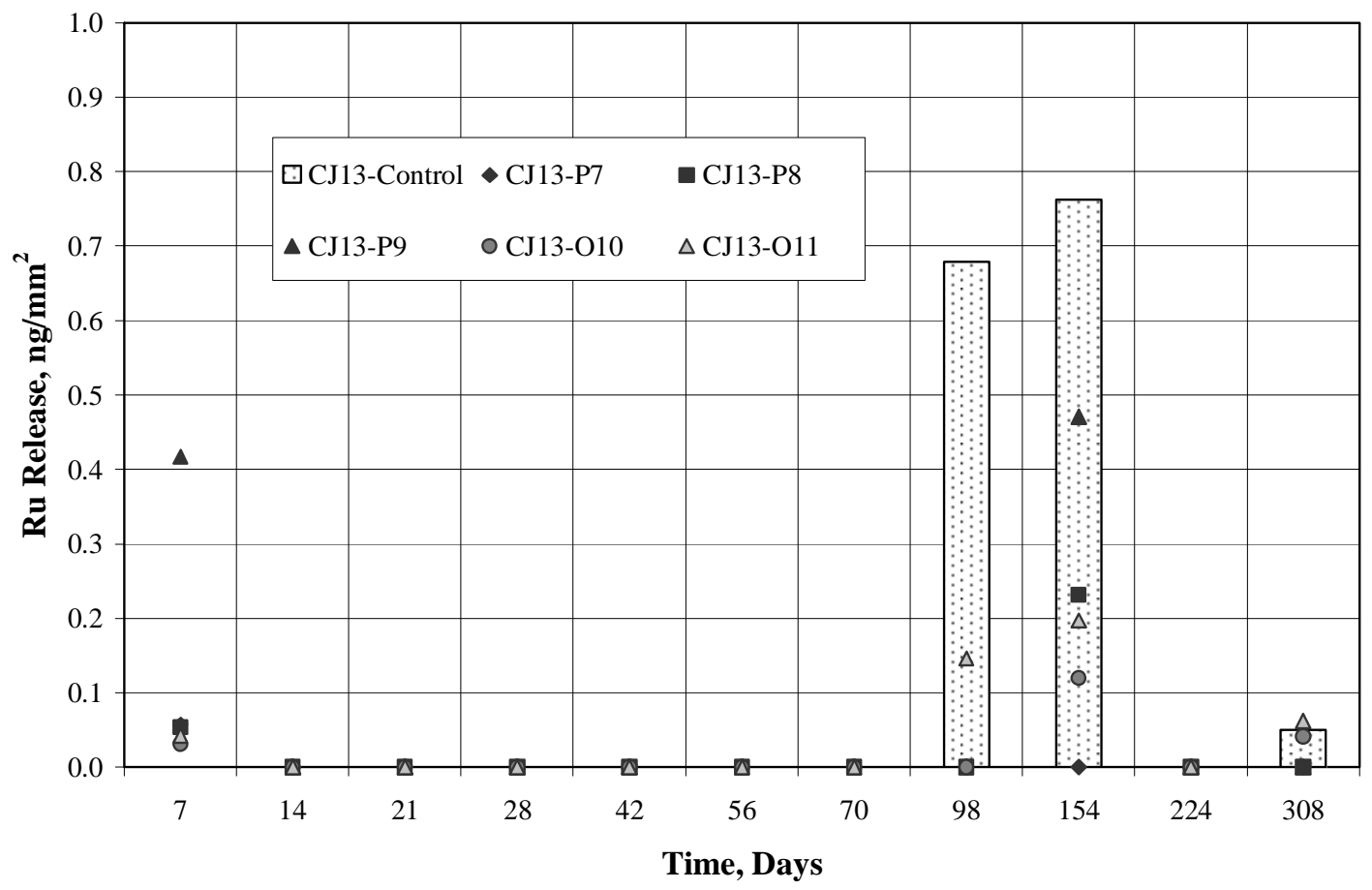

Figure H-28. Ruthenium Releases in $\mathrm{CJ} 13$ solution at $90^{\circ} \mathrm{C}$. 


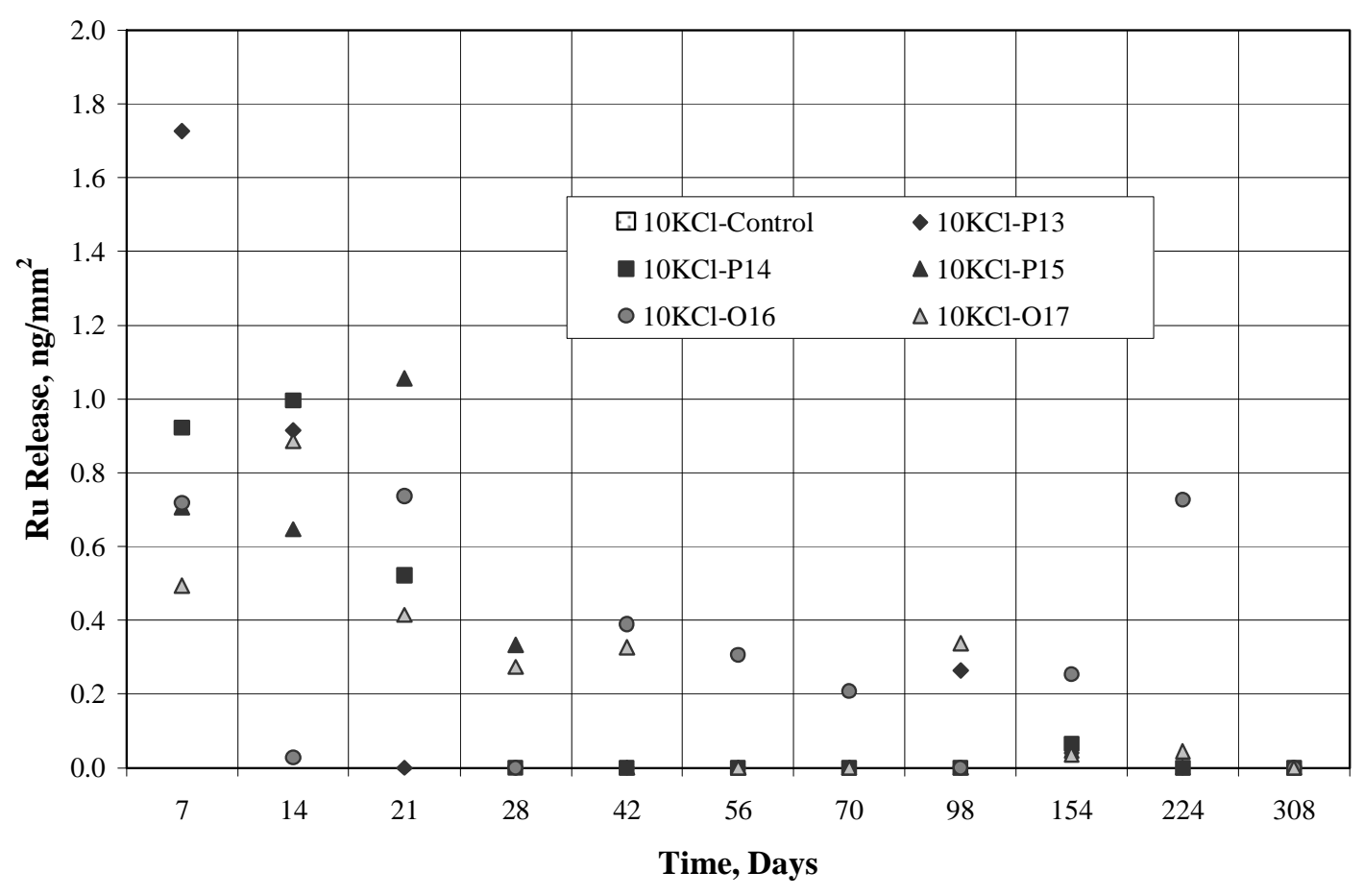

Figure H-29. Ruthenium Releases in $10 \mathrm{KCl}$ solution at $90^{\circ} \mathrm{C}$.

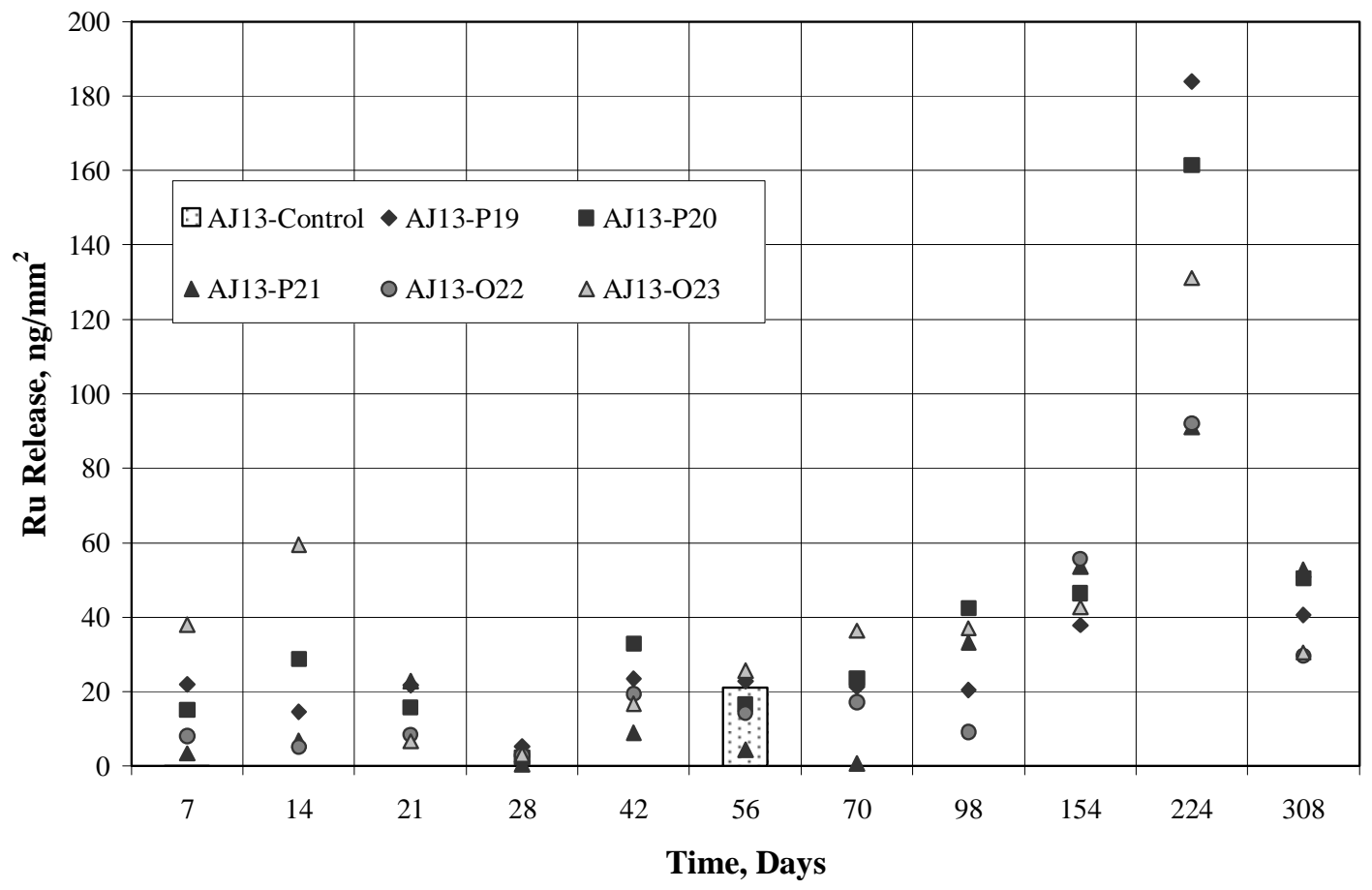

Figure H-30. Ruthenium Releases in $\mathrm{AJ} 13$ solution at $9^{\circ} \mathrm{C}$. 


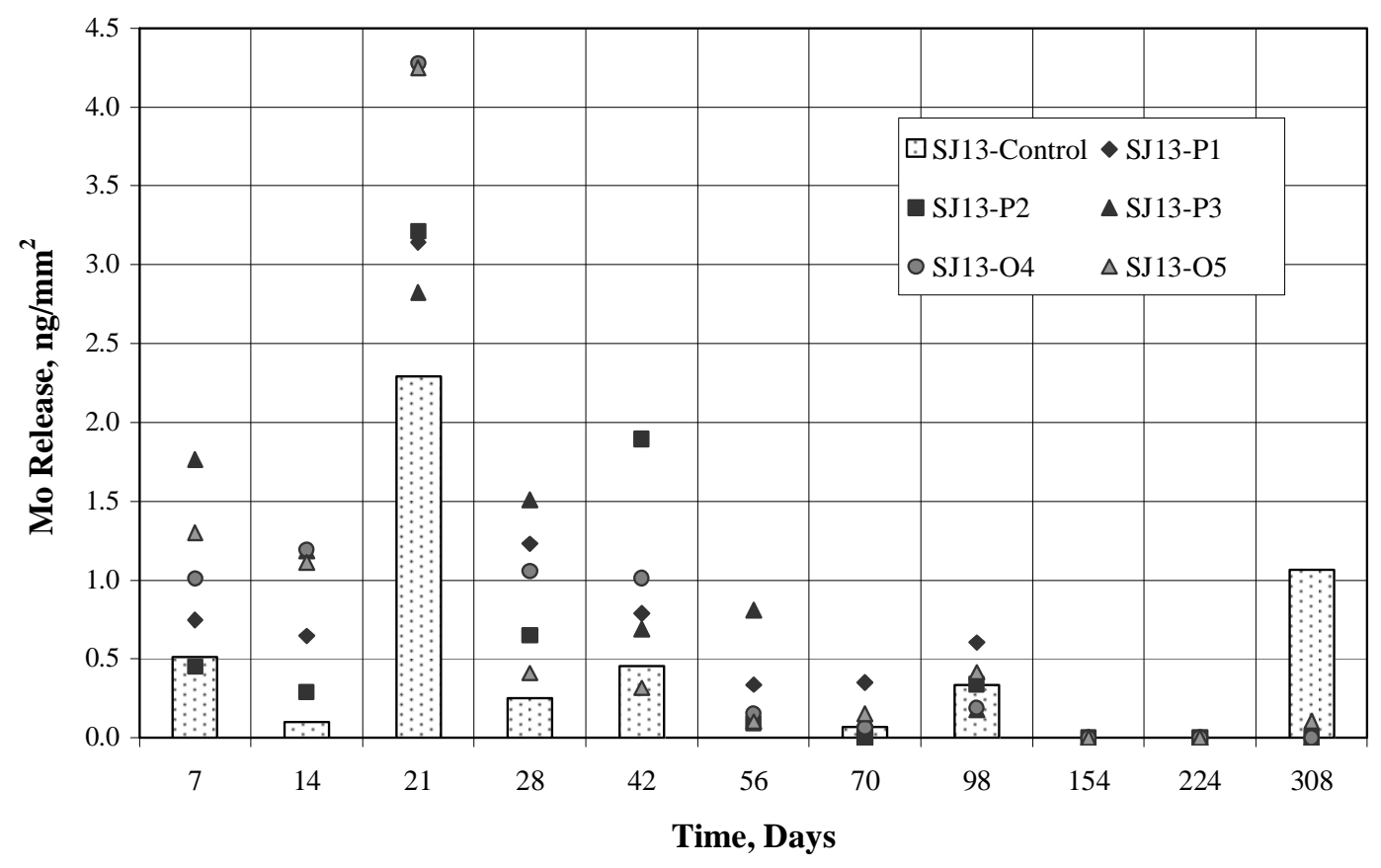

Figure H-31. Molybdenum Releases in $\mathrm{SJ13}$ solution at $90^{\circ} \mathrm{C}$.

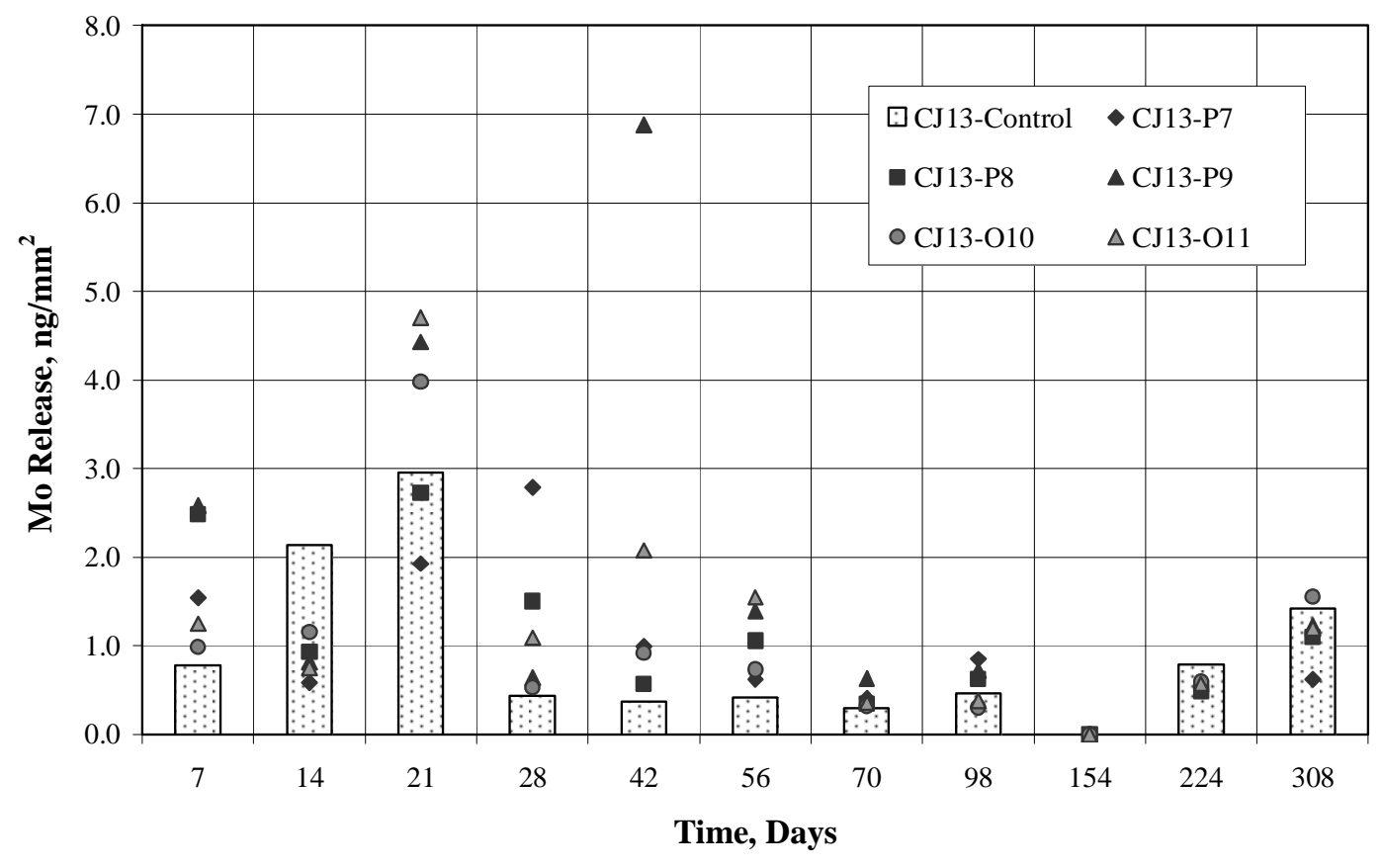

Figure H-32. Molybdenum Releases in $\mathrm{CJ13}$ solution at $90^{\circ} \mathrm{C}$. 


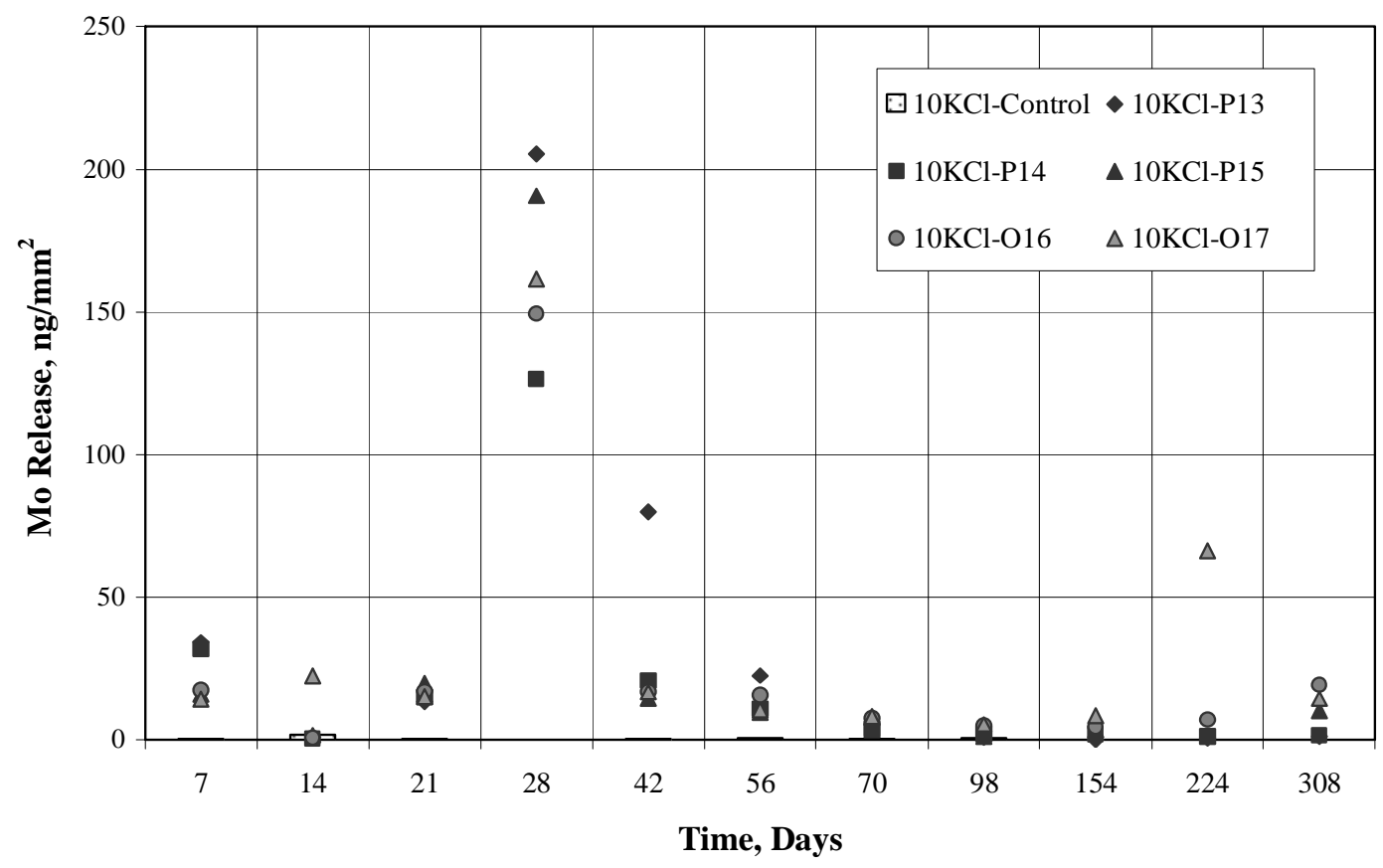

Figure H-33. Molybdenum Releases in $10 \mathrm{KCl}$ solution at $90^{\circ} \mathrm{C}$.

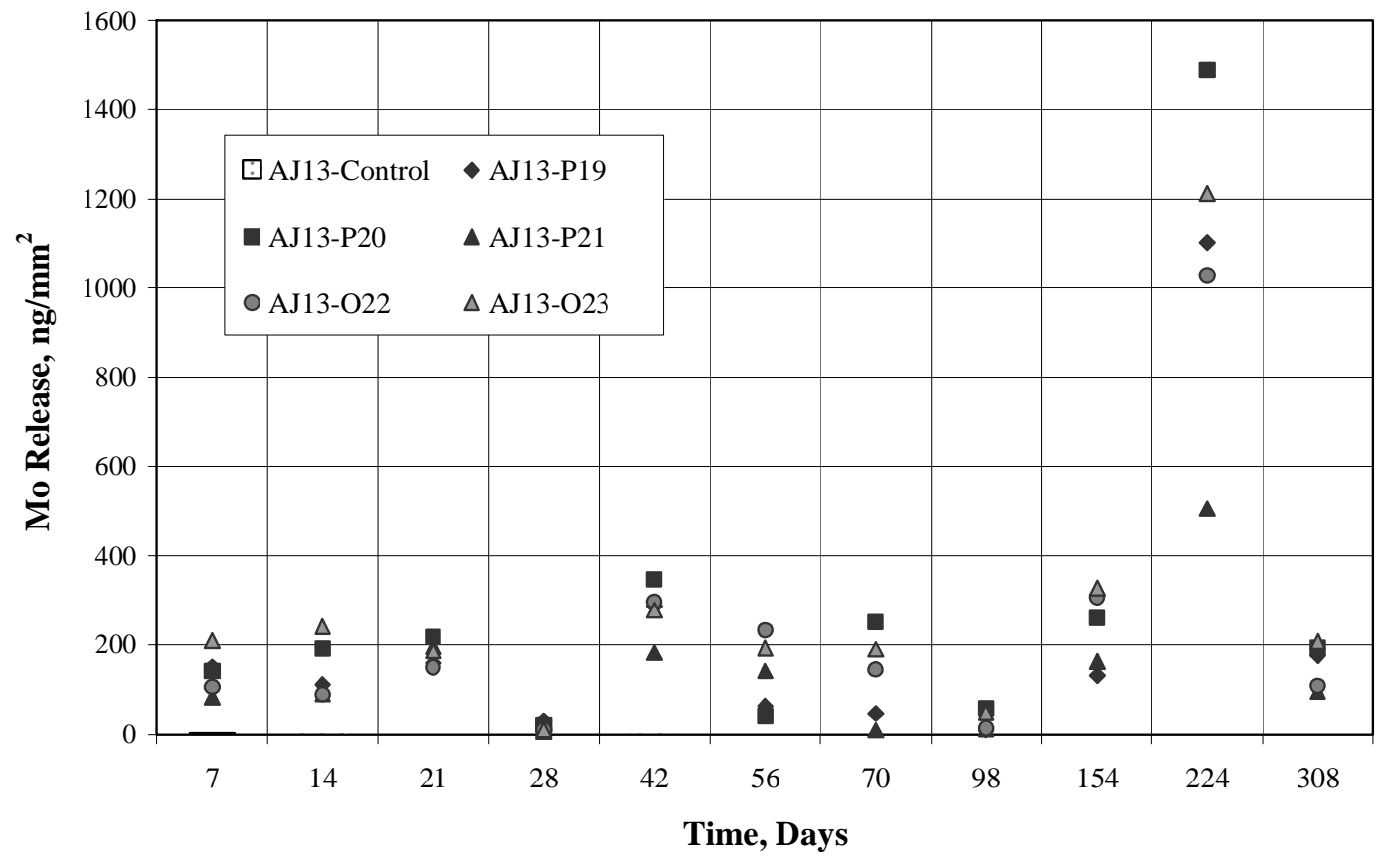

Figure H-34. Molybdenum Releases in AJ13 solution at $90^{\circ} \mathrm{C}$. 


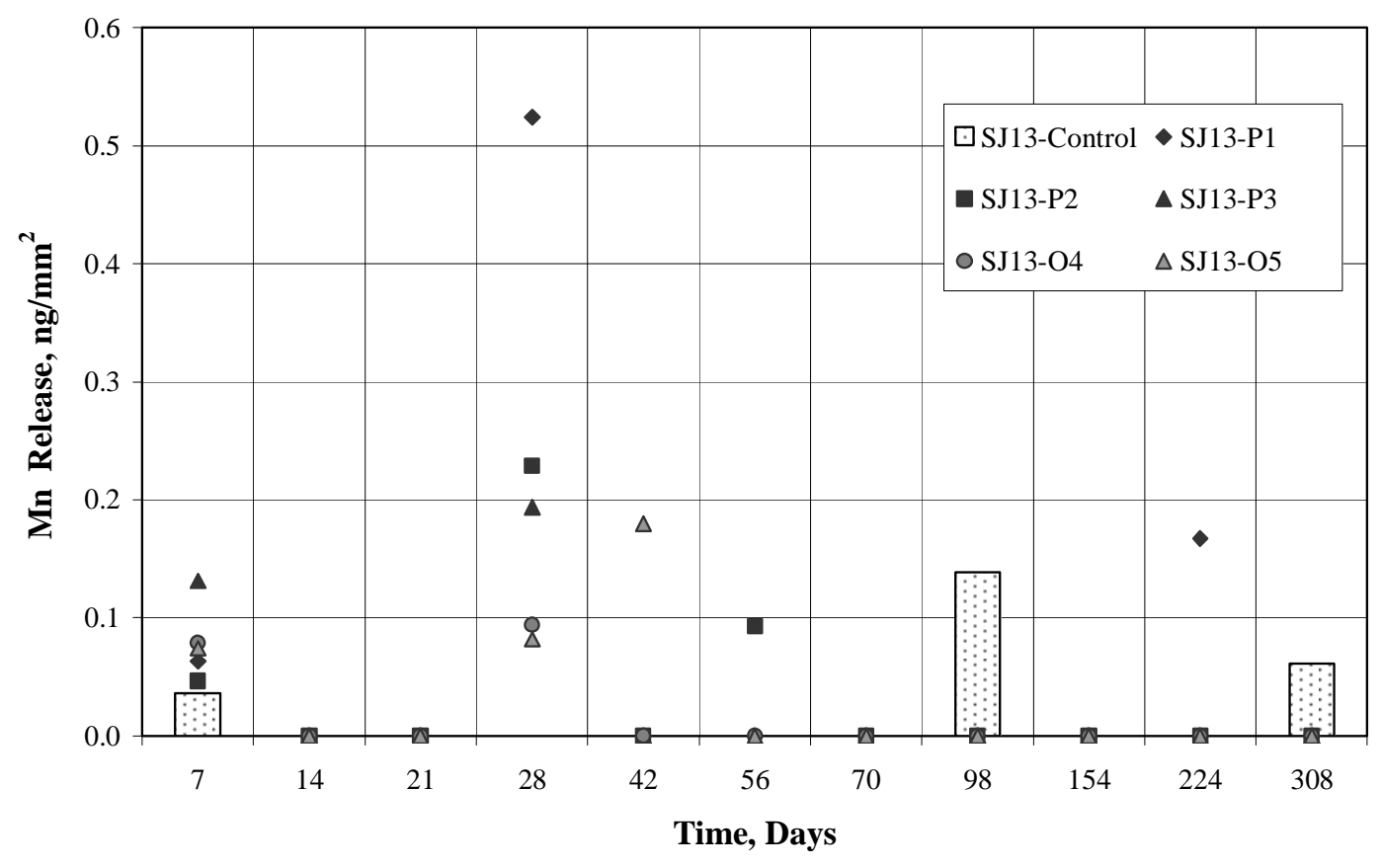

Figure H-35. Manganese Releases in $\mathrm{SJ13}$ solution at $90^{\circ} \mathrm{C}$.

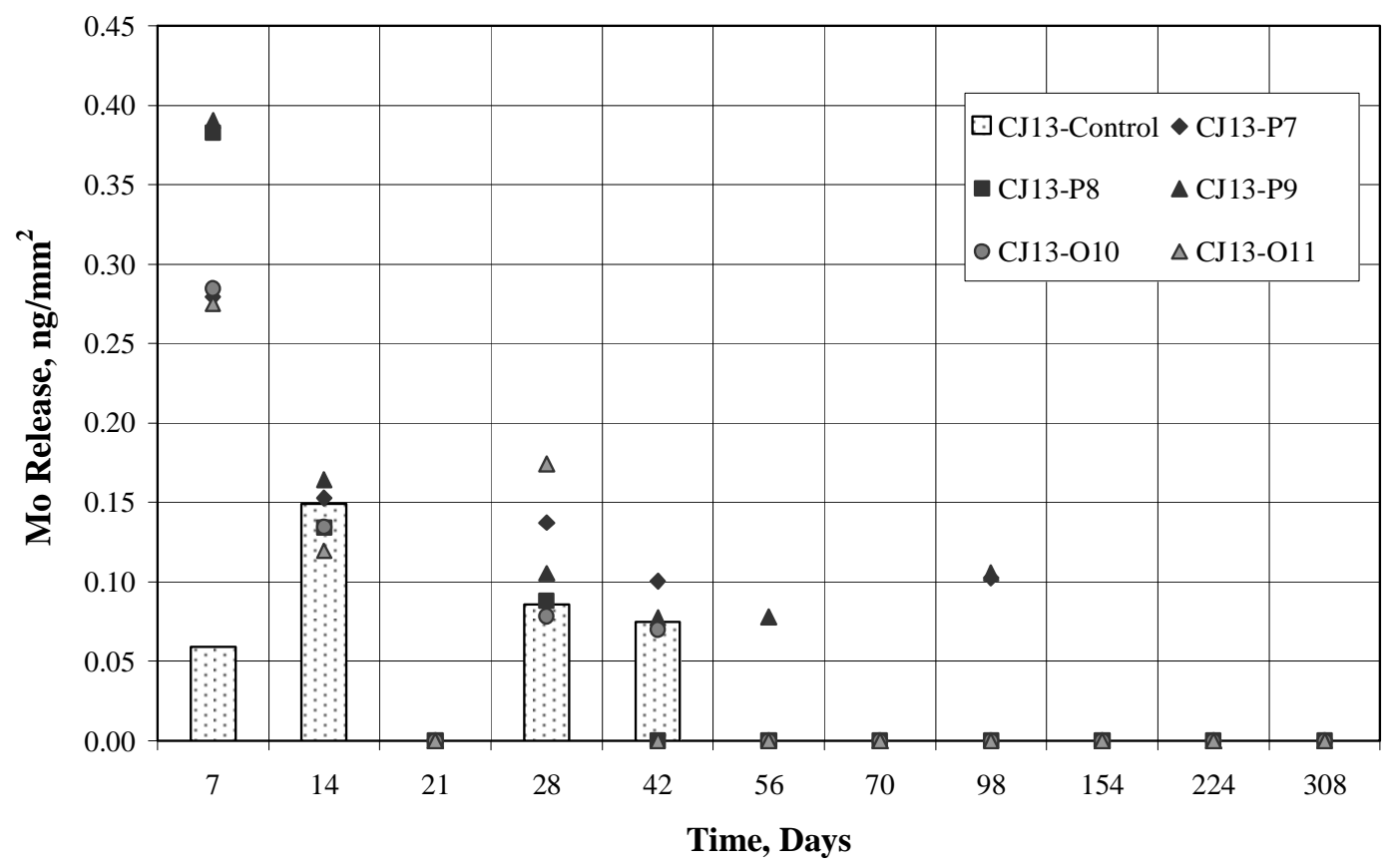

Figure H-36. Manganese Releases in $\mathrm{CJ} 13$ solution at $90^{\circ} \mathrm{C}$. 


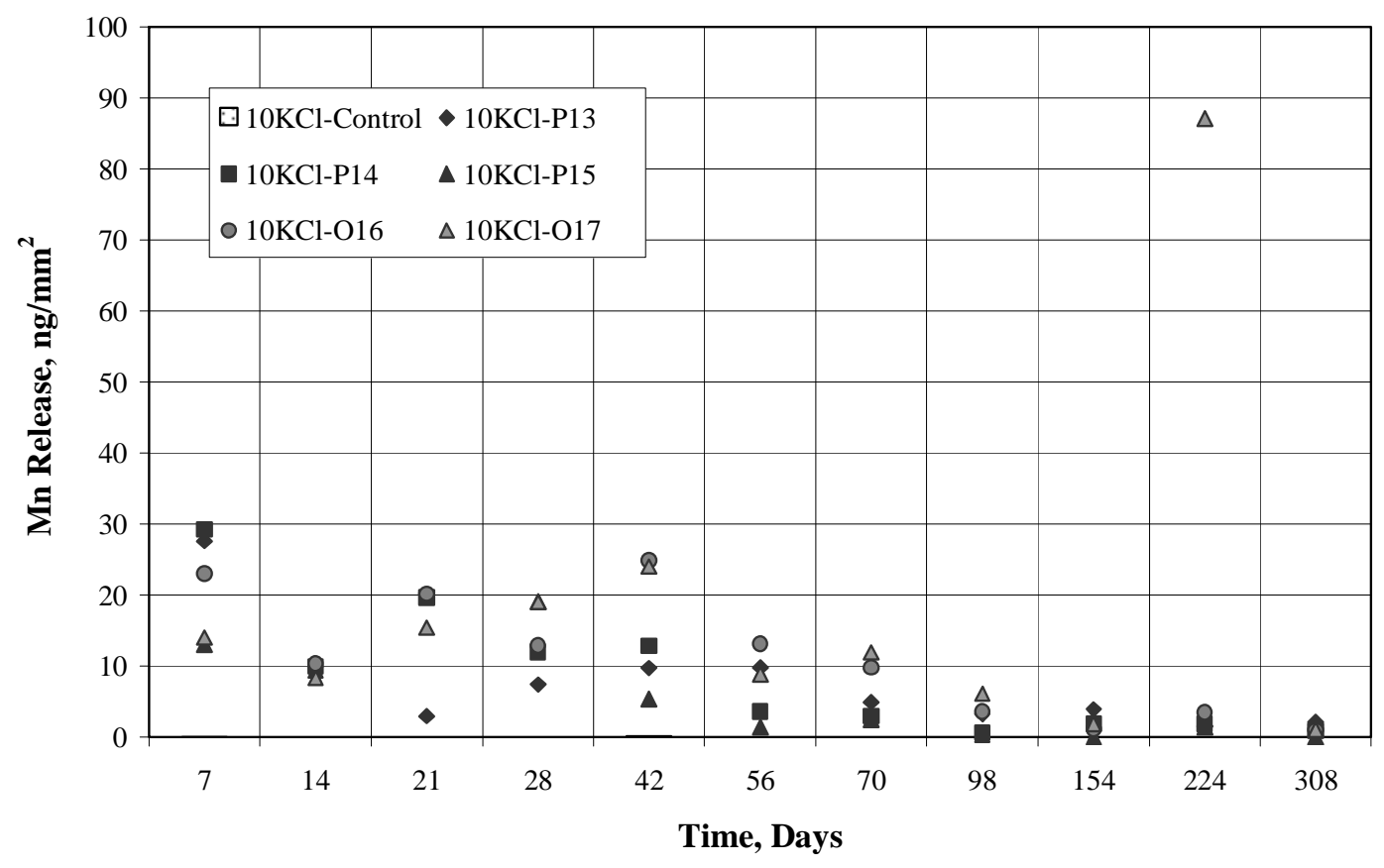

Figure $\mathrm{H}-37$. Manganese Releases in $10 \mathrm{KCl}$ solution at $90^{\circ} \mathrm{C}$.

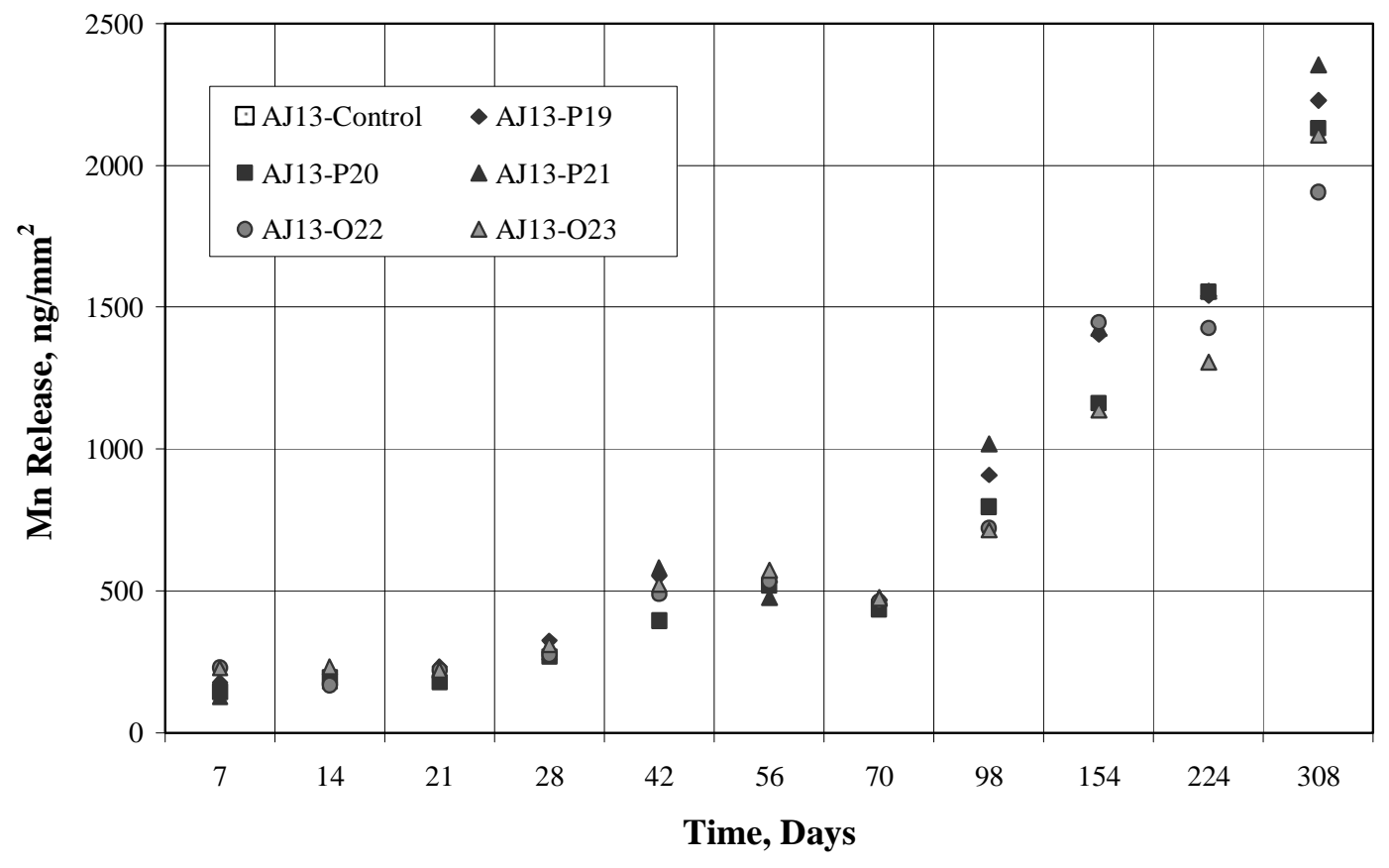

Figure H-38. Manganese Releases in AJ13 solution at $90^{\circ} \mathrm{C}$. 


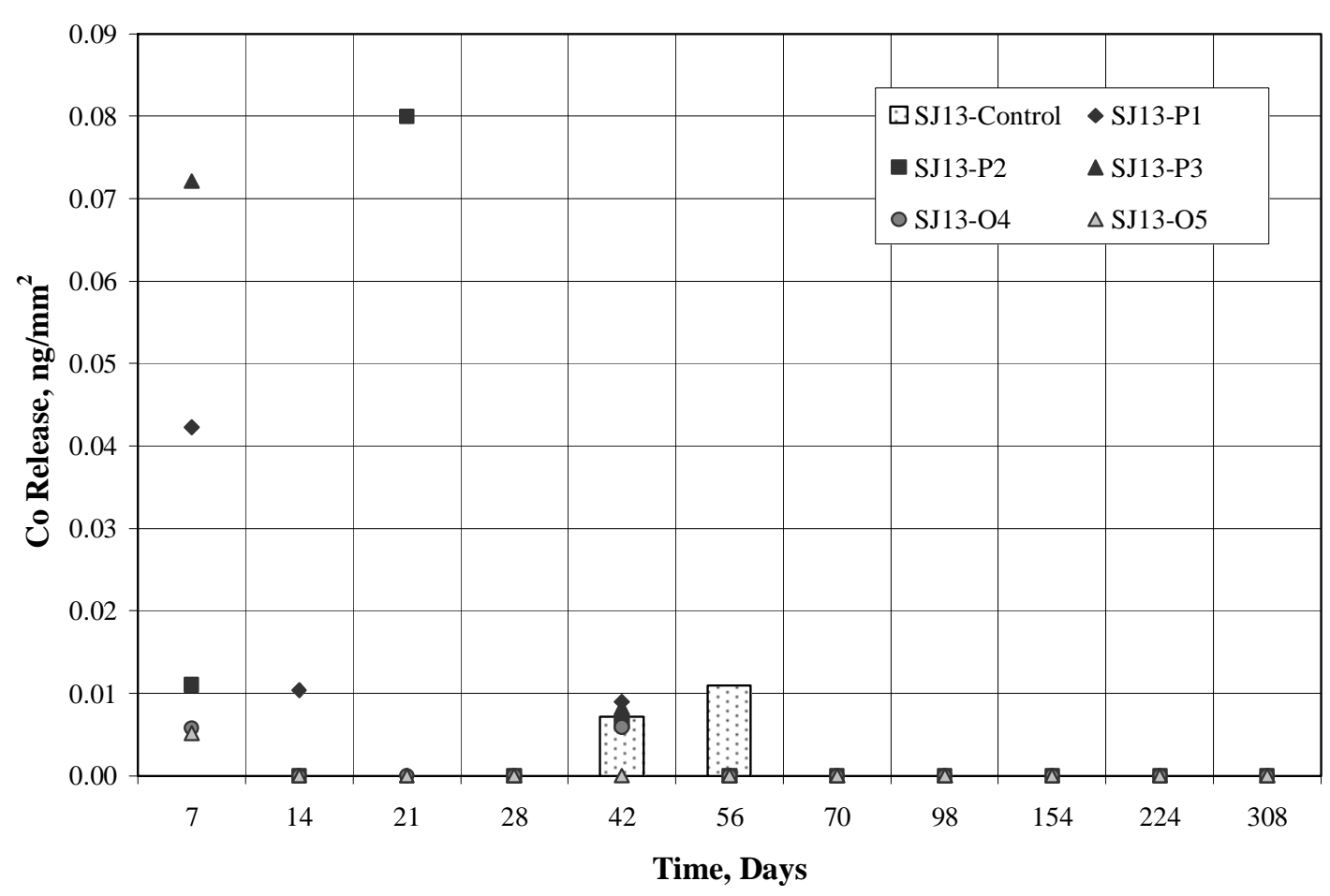

Figure H-39. Cobalt Releases in SJ13 solution at $90^{\circ} \mathrm{C}$.

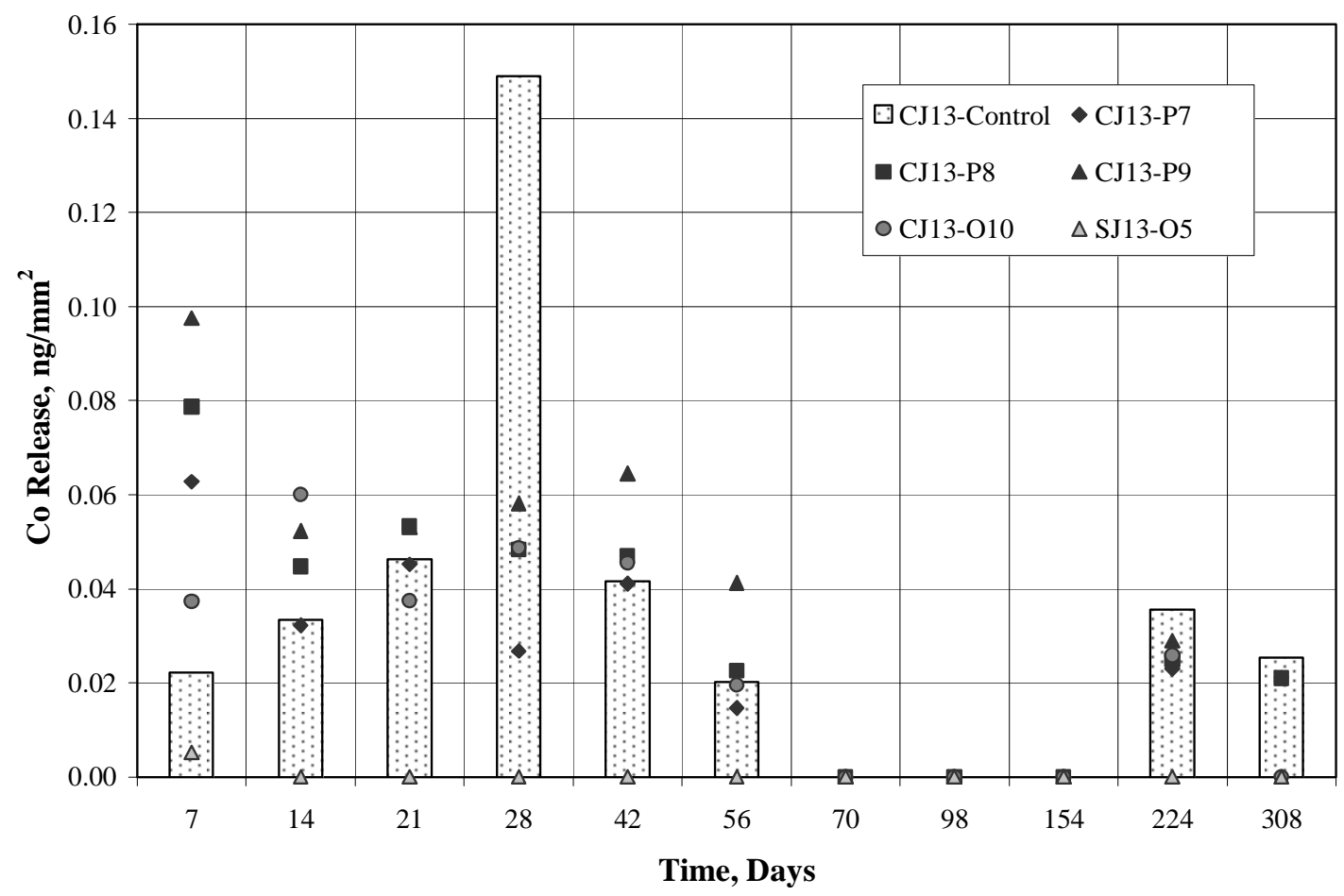

Figure H-40. Cobalt Releases in $\mathrm{CJ} 13$ solution at $90^{\circ} \mathrm{C}$. 


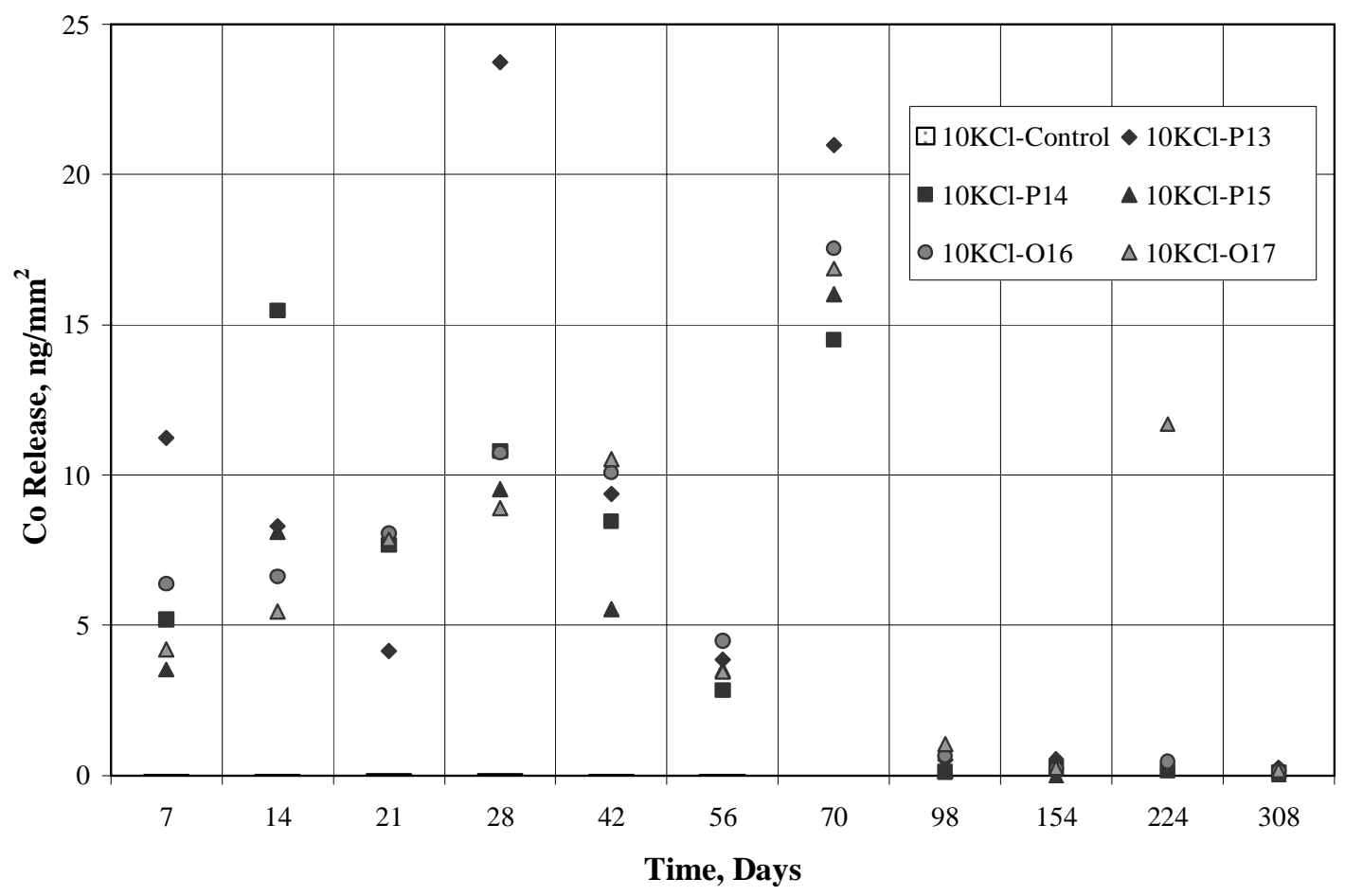

Figure H-41. Cobalt Releases in $10 \mathrm{KCl}$ solution at $90^{\circ} \mathrm{C}$.

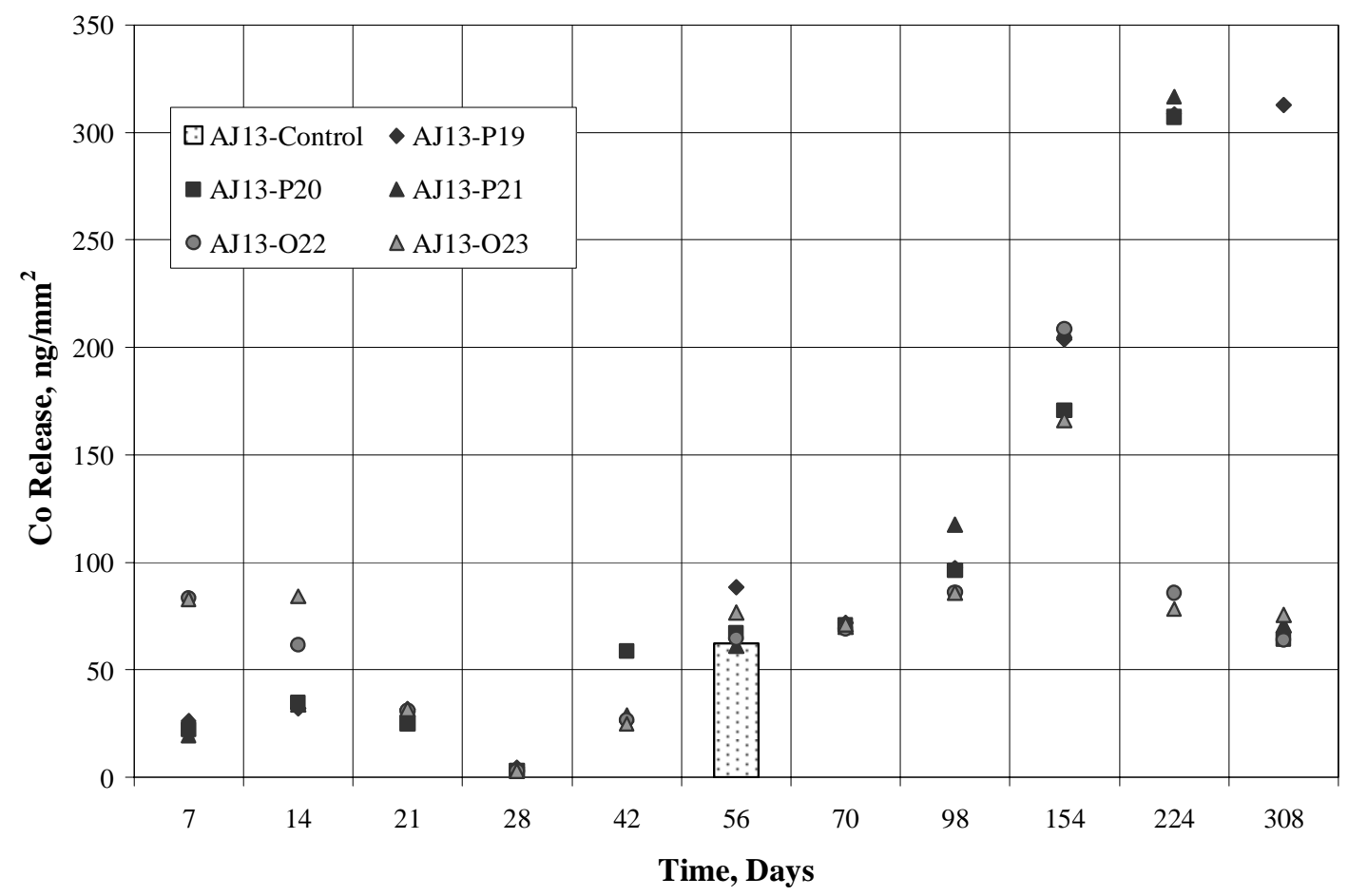

Figure H-42. Cobalt Releases in AJ13 solution at $90^{\circ} \mathrm{C}$. 


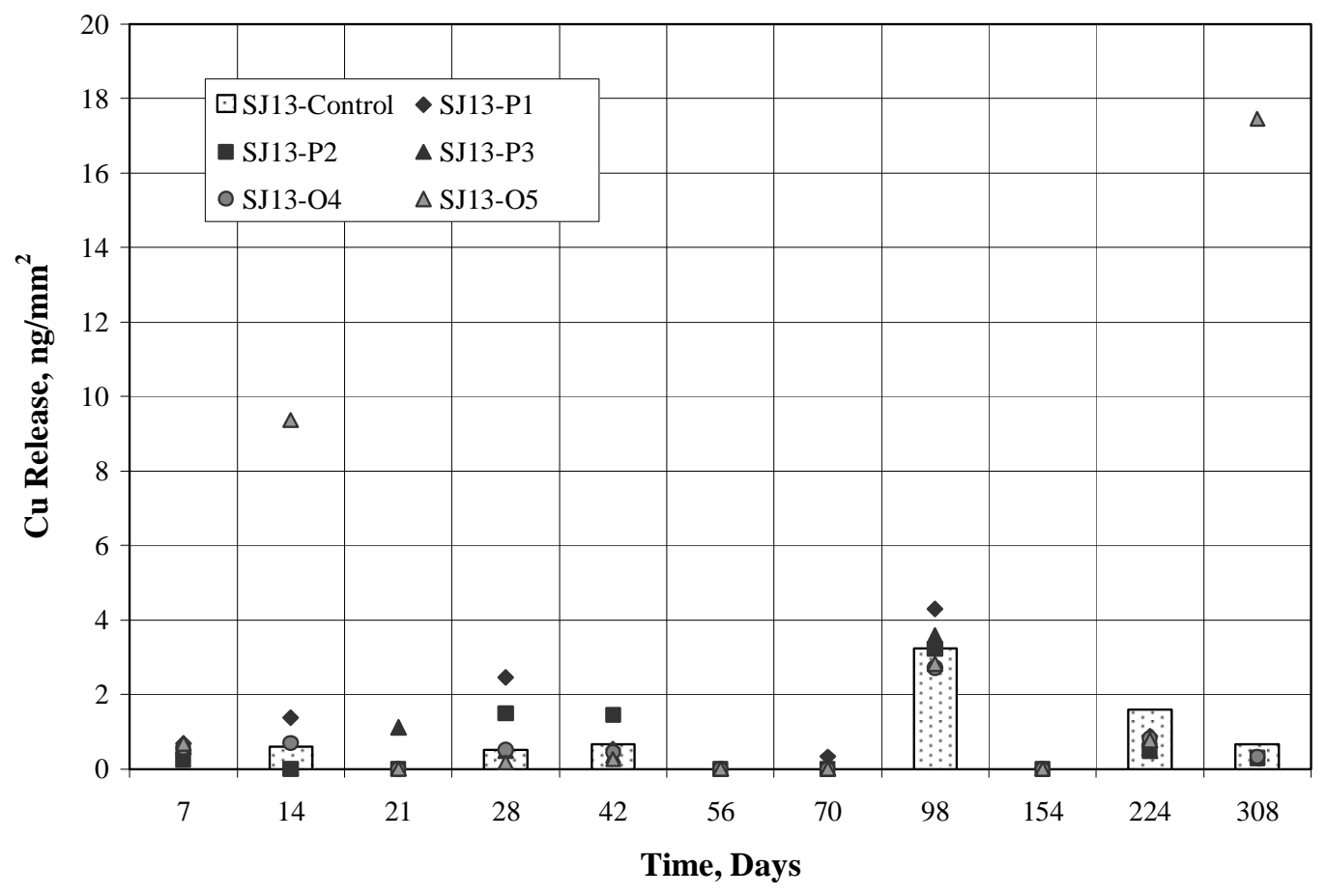

Figure H-43. Copper Releases in $\mathrm{SJ13}$ solution at $90^{\circ} \mathrm{C}$.

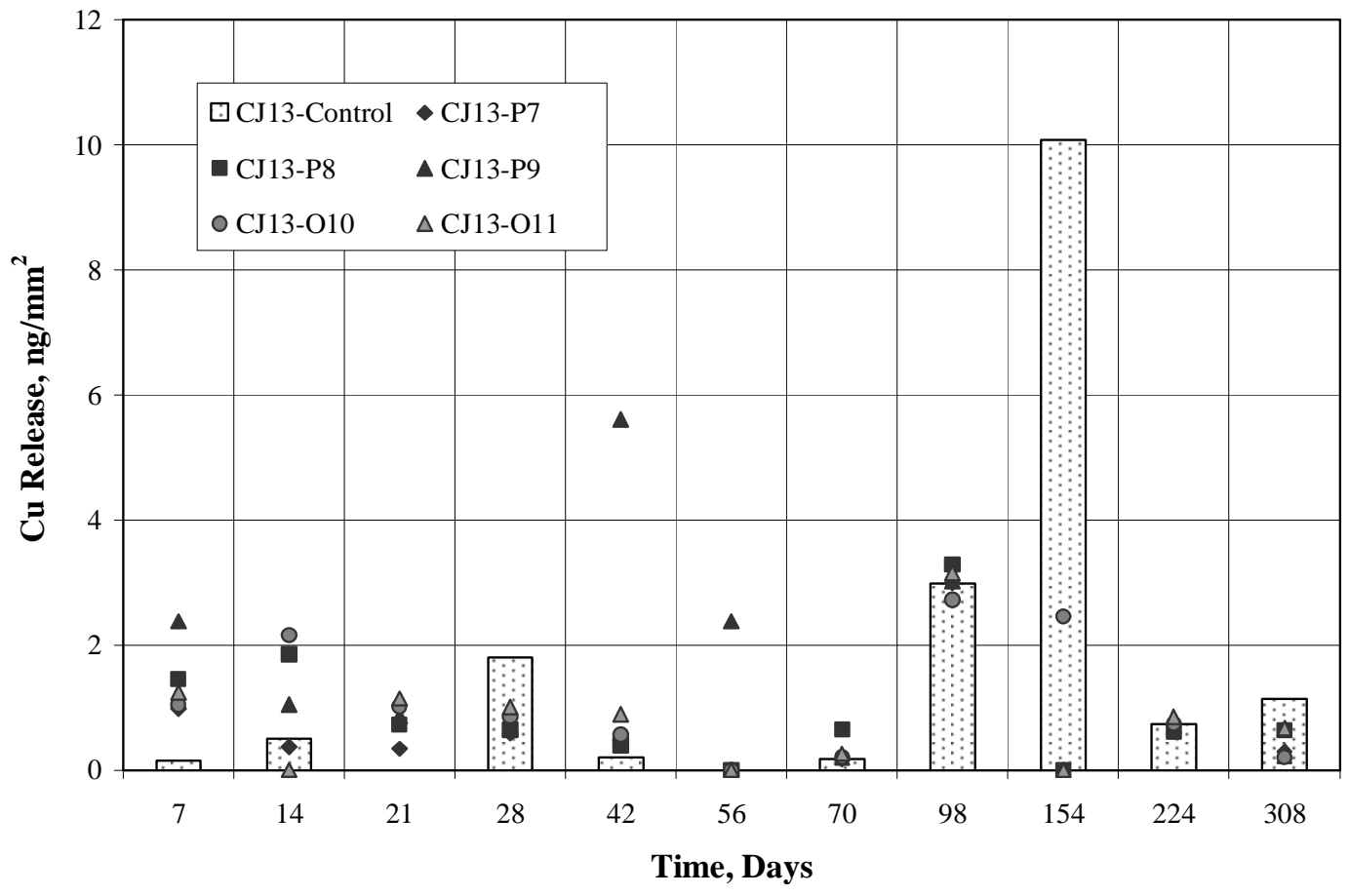

Figure H-44. Copper Releases in $\mathrm{CJ} 13$ solution at $90^{\circ} \mathrm{C}$. 


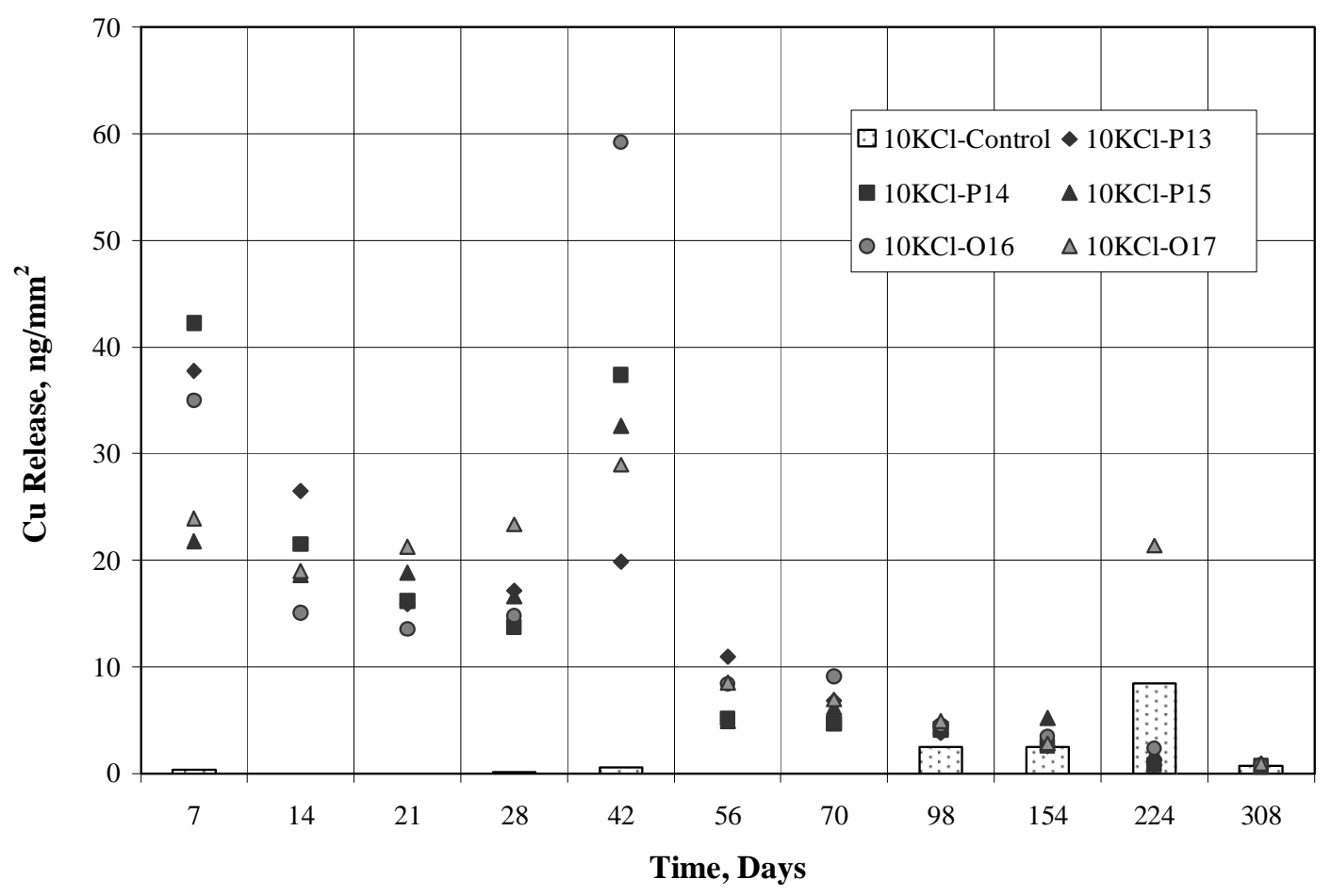

Figure H-45. Copper Releases in $10 \mathrm{KCl}$ solution at $90^{\circ} \mathrm{C}$.

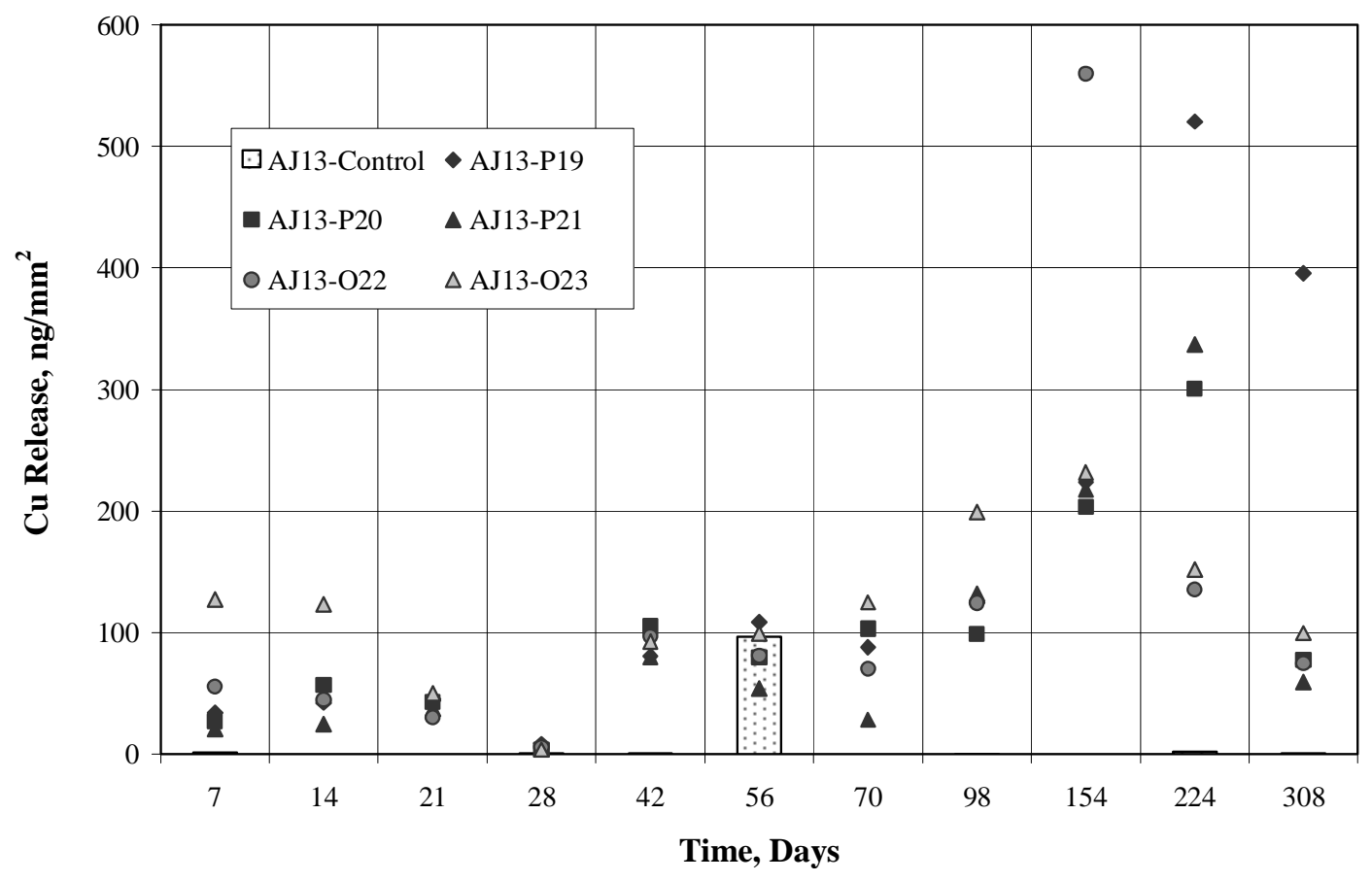

Figure H-46. Copper Releases in AJ13 solution at $90^{\circ} \mathrm{C}$. 


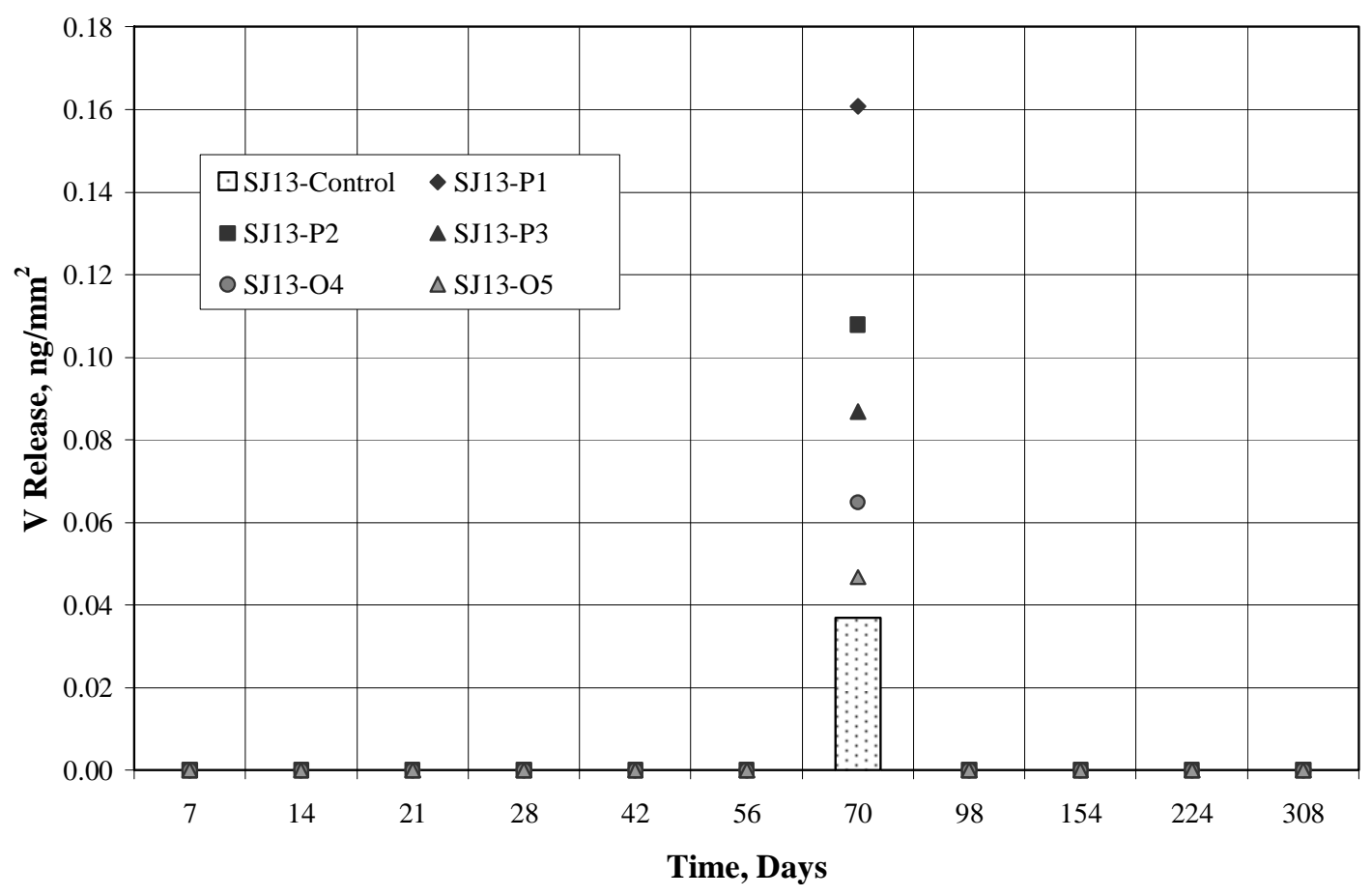

Figure H-47. Vanadium Releases in $\mathrm{SJ13}$ solution at $90^{\circ} \mathrm{C}$.

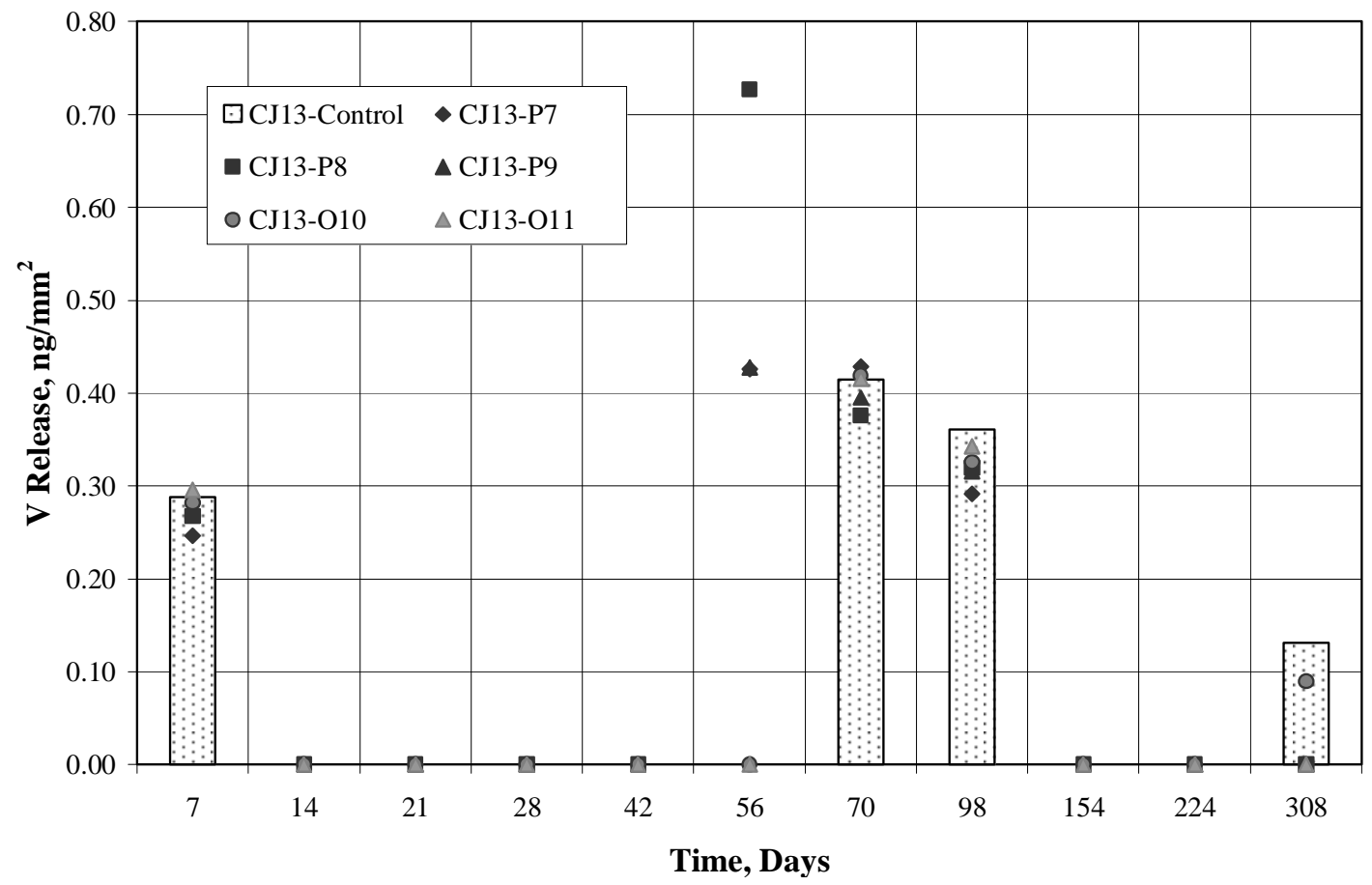

Figure H-48. Vanadium Releases in $\mathrm{CJ} 13$ solution at $90^{\circ} \mathrm{C}$. 


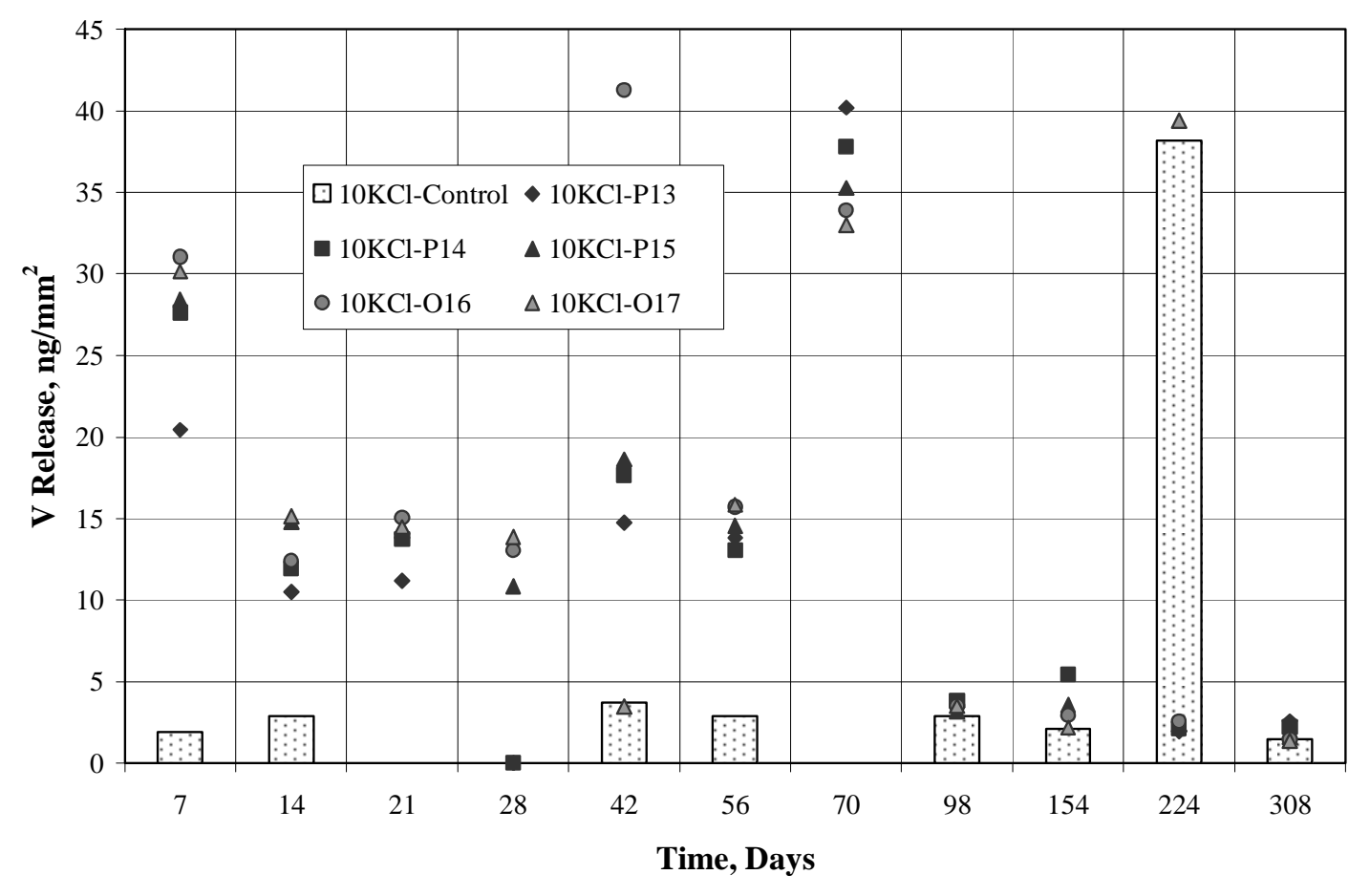

Figure H-49. Vanadium Releases in $10 \mathrm{KCl}$ solution at $90^{\circ} \mathrm{C}$.

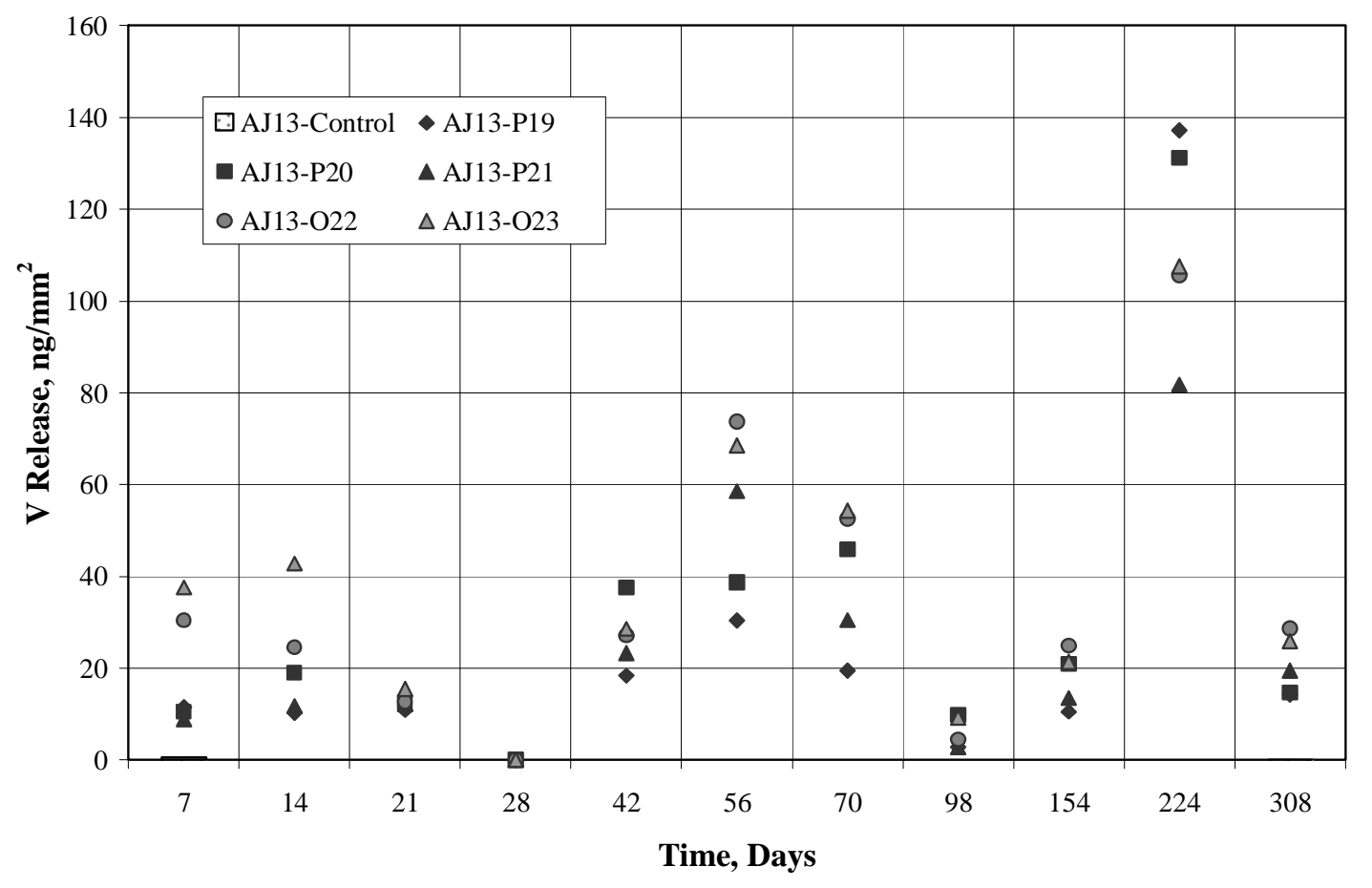

Figure H-50. Vanadium Releases in $\mathrm{AJ} 13$ solution at $90^{\circ} \mathrm{C}$. 
J. Supplementary Tests—Releases and Detection Limits

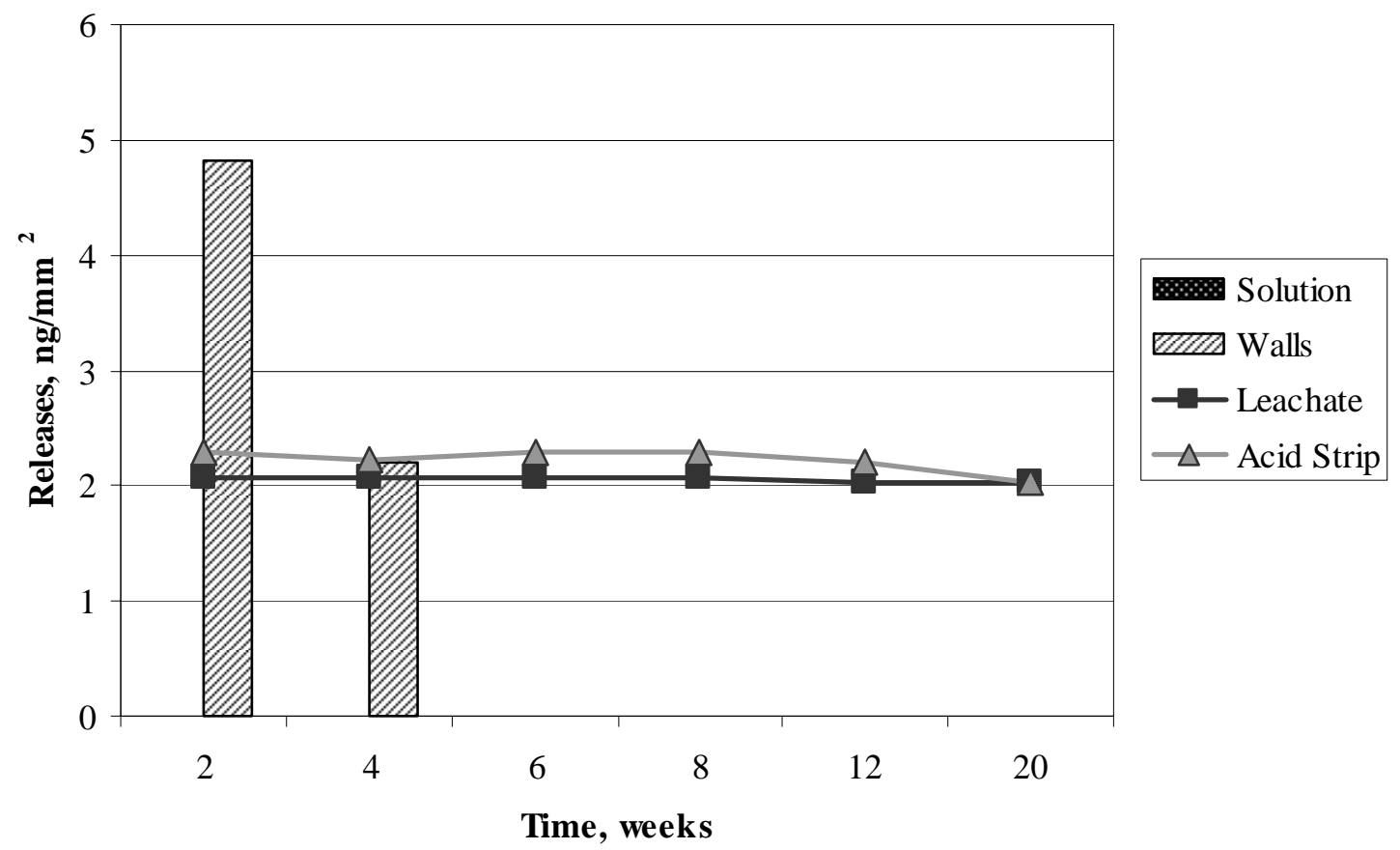

Figure J-1. Iron Releases in Solution and on Walls from Polished Sample 25 in $1 \mathrm{KCl}$ Solution at $90^{\circ} \mathrm{C}$ and Average Detection Limits for Leachate and Acid Strip.

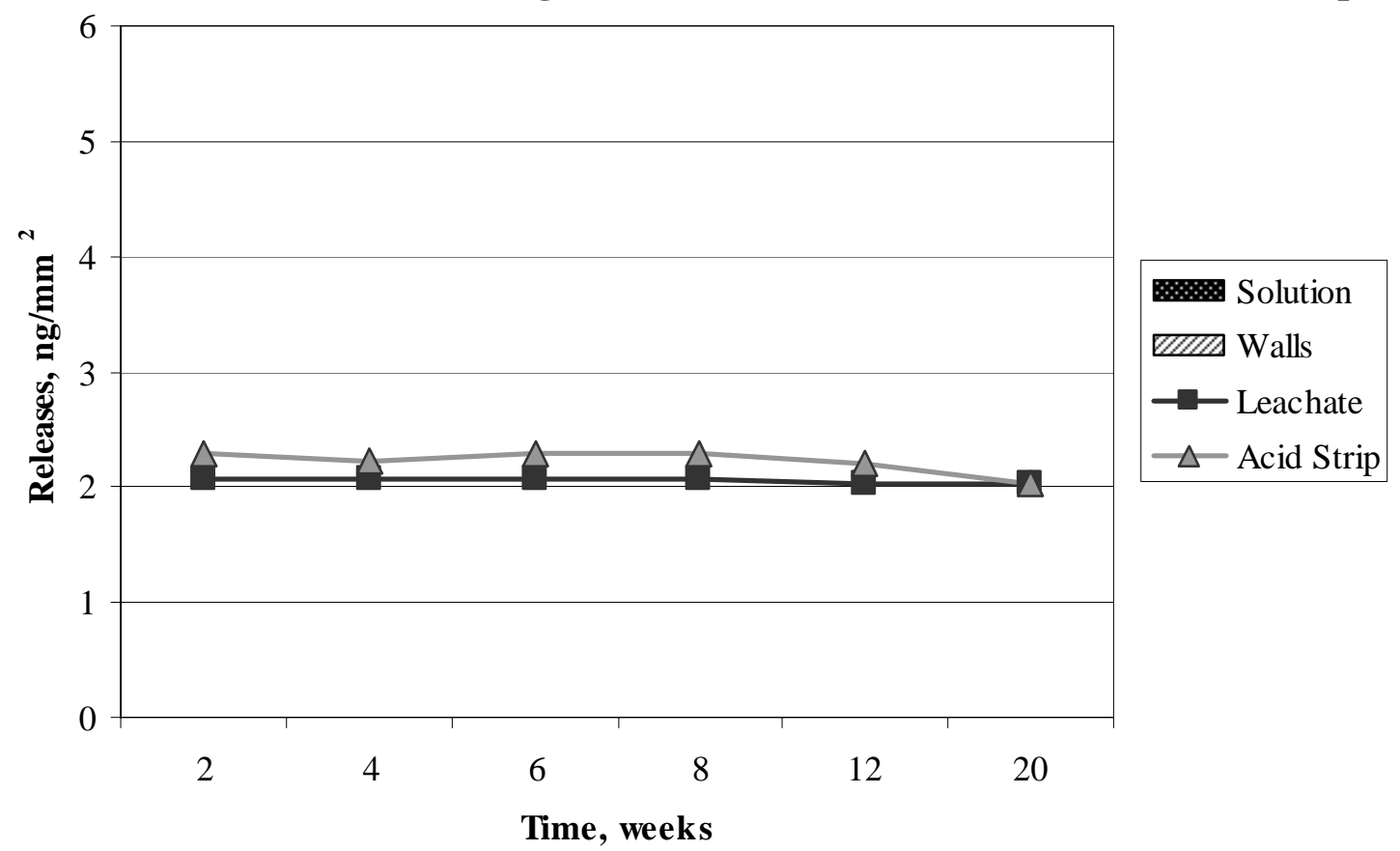

Figure J-2. Iron Present in Solutions and on Walls in $1 \mathrm{KCl}$ Solution Control at $90^{\circ} \mathrm{C}$ and Average Detection Limits for Leachate and Acid Strip. 


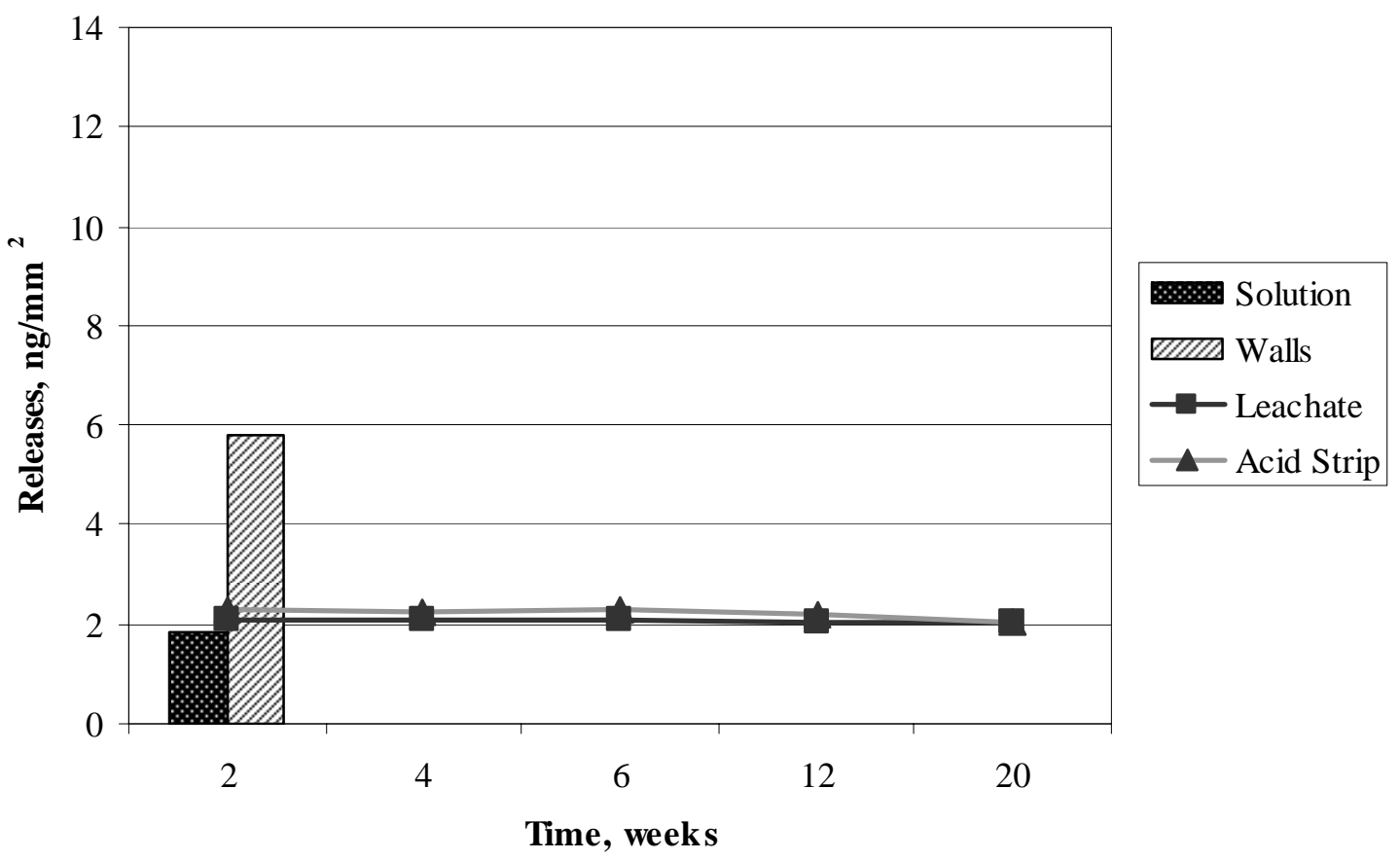

Figure J-3. Iron Releases in Solution and on Walls from Polished Sample 27 in $1 \mathrm{KCl}$ Solution at Room Temperature and Average Detection Limits for Leachate and Acid Strip.

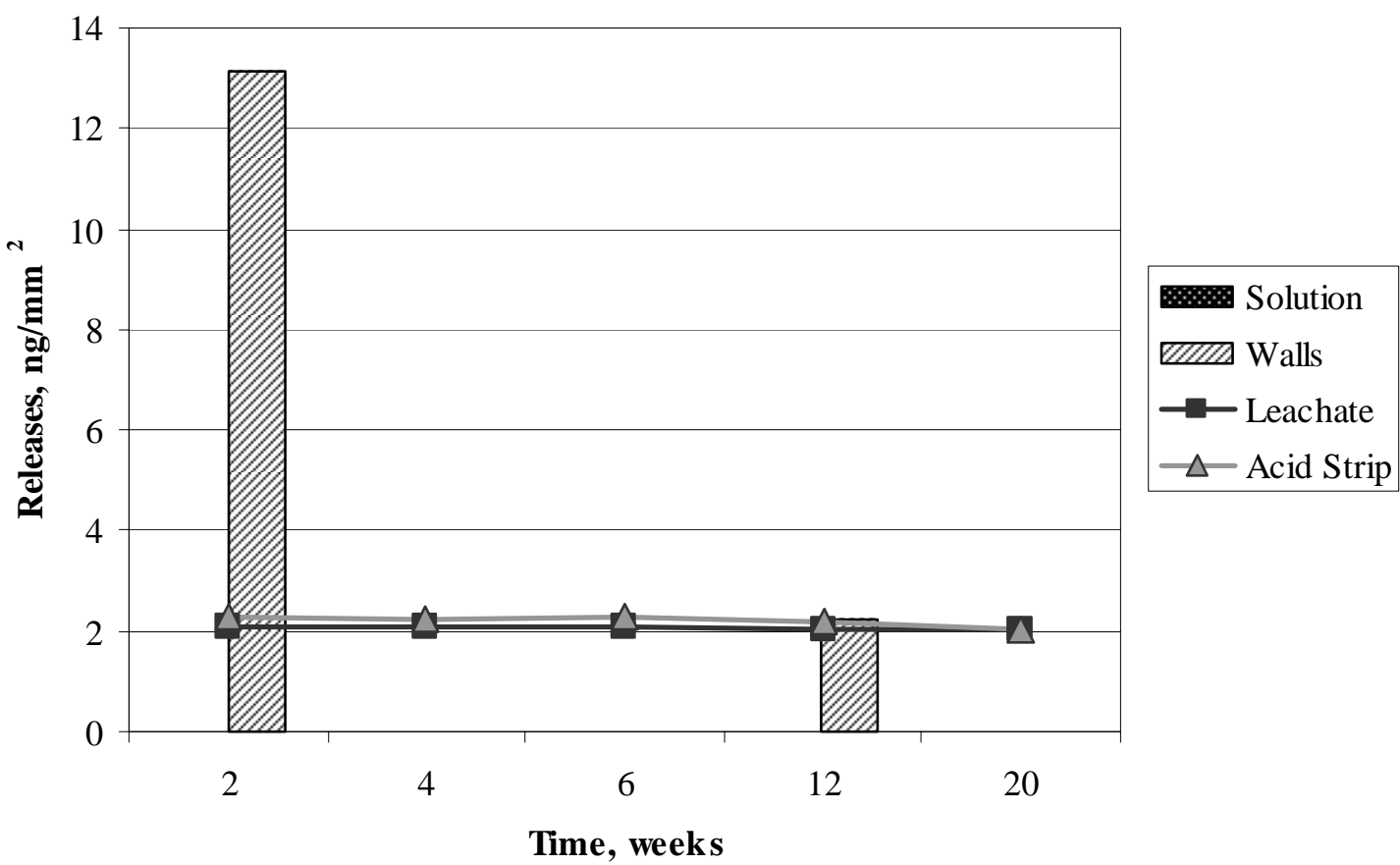

Figure J-4. Iron Present in Solution and on Walls for $1 \mathrm{KCl}$ Solution Control at Room Temperature and Average Detection Limits for Leachate and Acid Strip. 


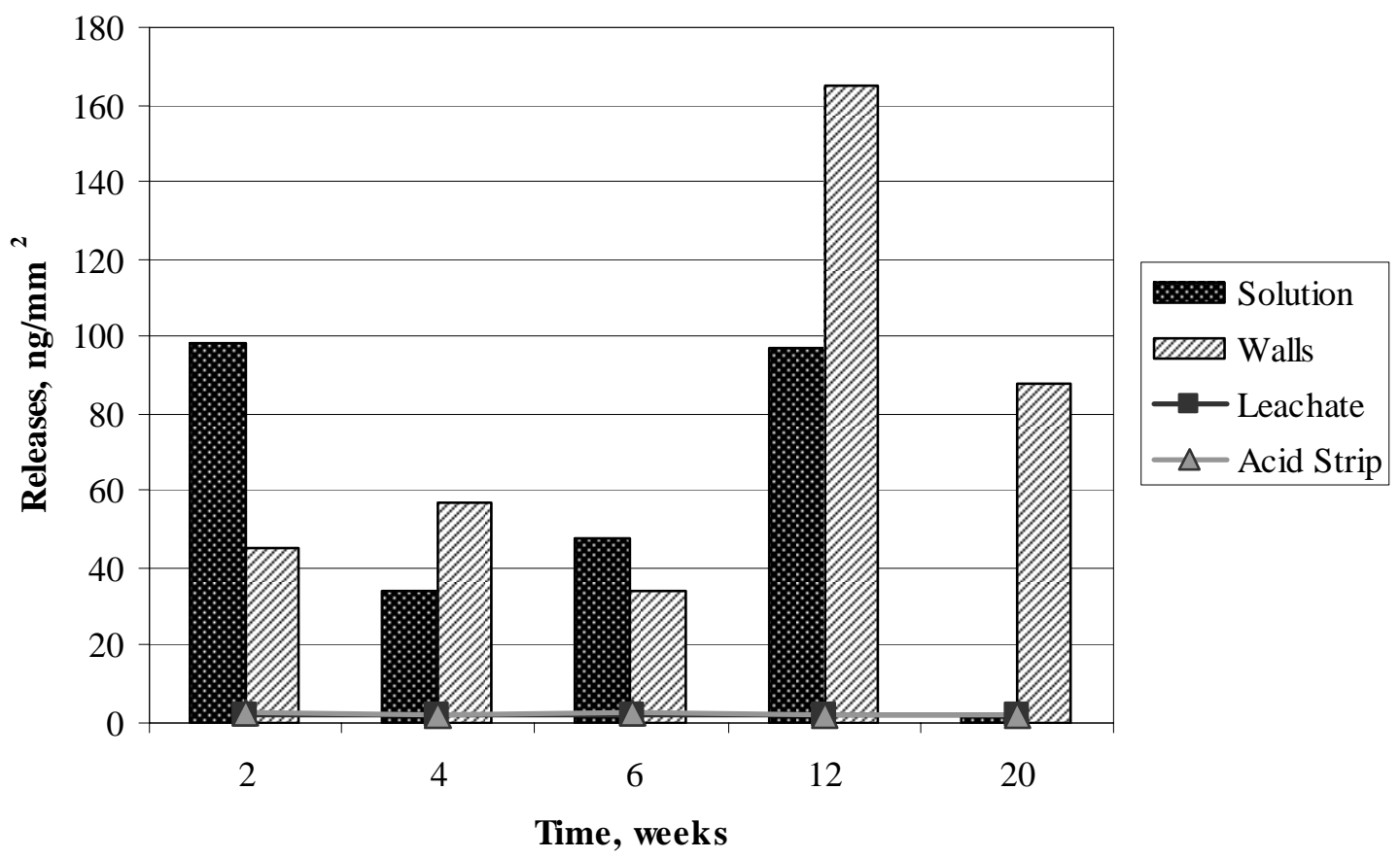

Figure J-5. Iron Releases in Solution and on Walls from Polished Sample 29 in $10 \mathrm{KCl}$ at Room Temperature and Average Detection Limits for Leachate and Acid Strip.

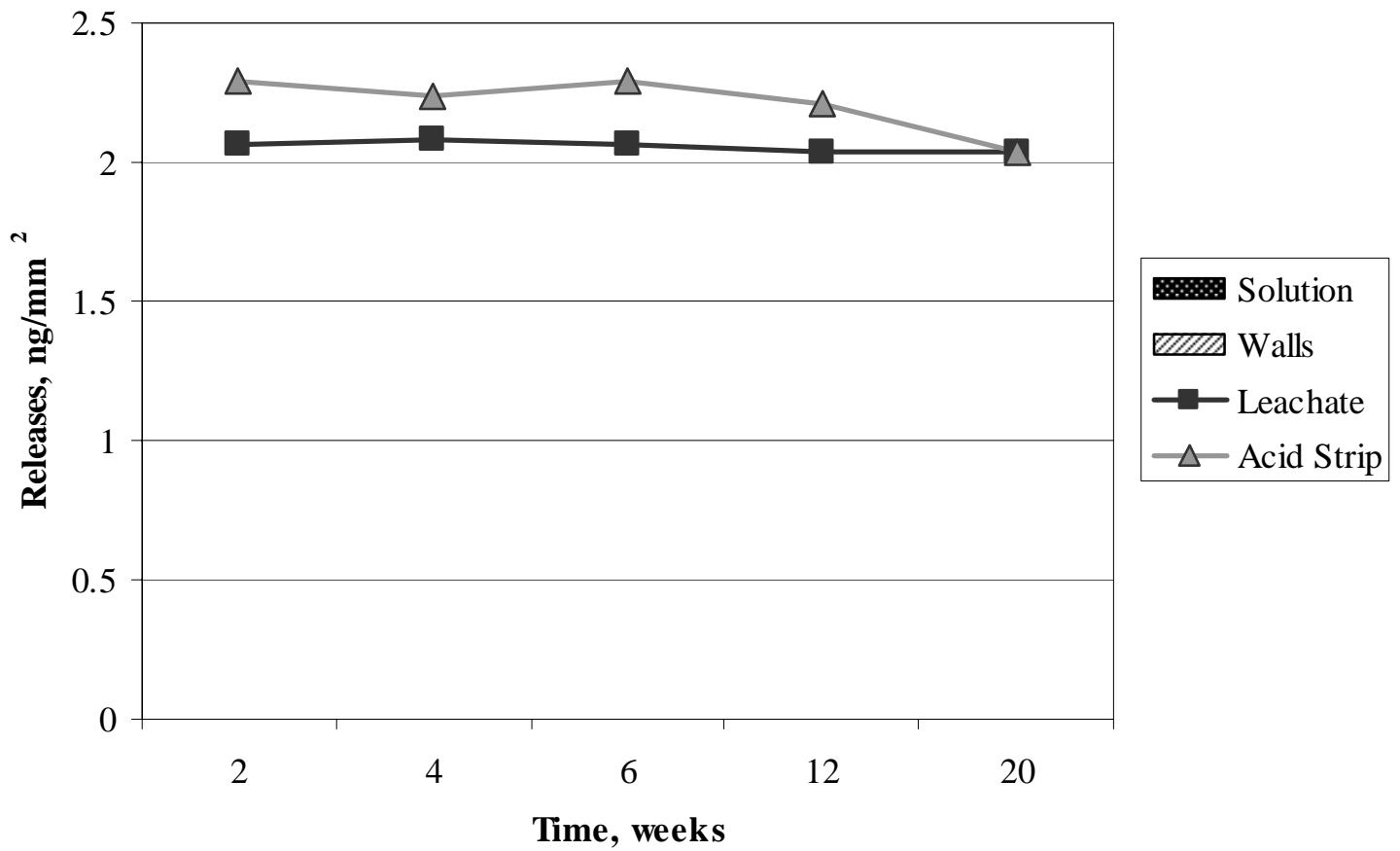

Figure J-6. Iron Present in Solution and on Walls for 10KCl Control at Room Temperature and Average Detection Limits for Leachate and Acid Strip. 


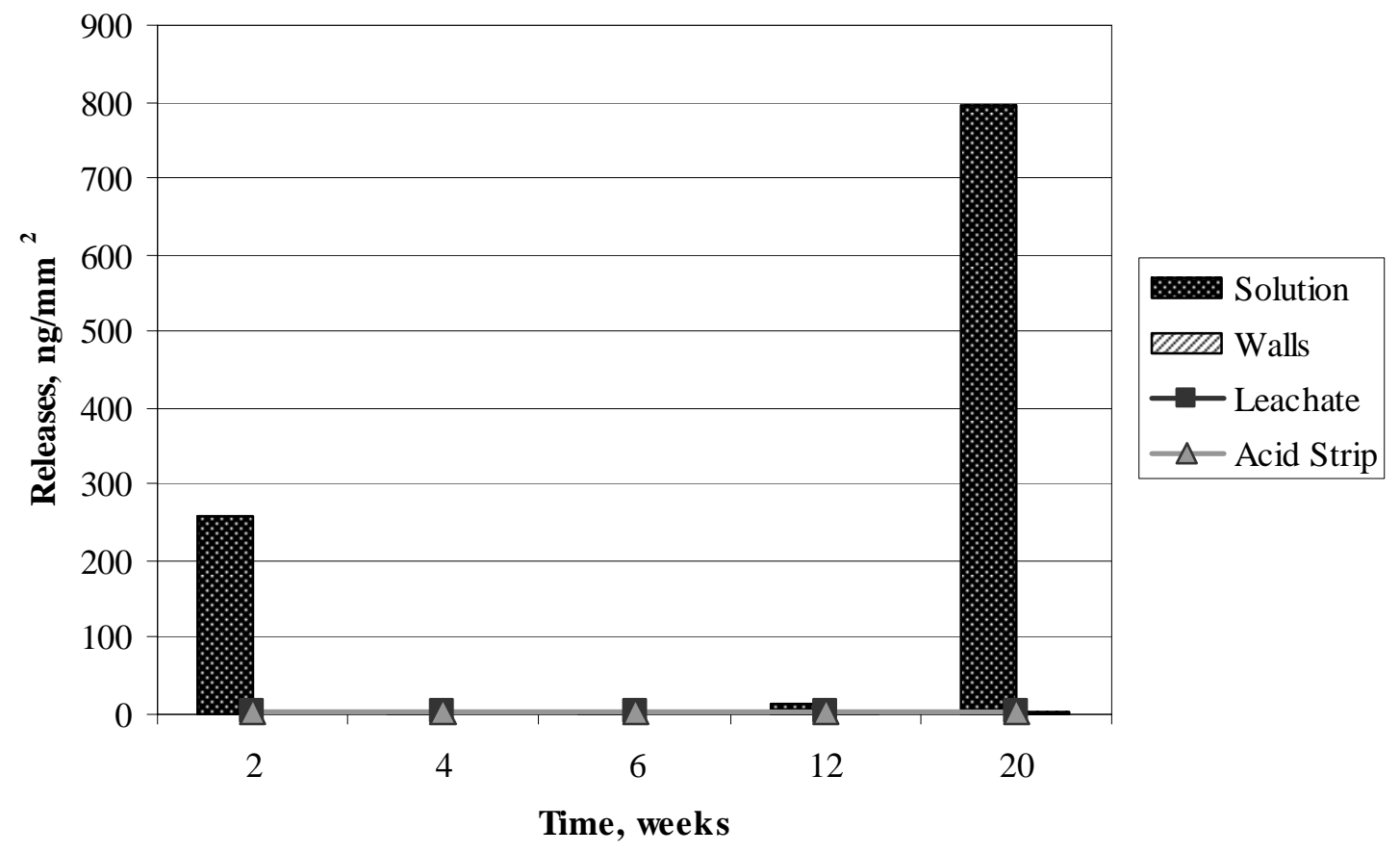

Figure J-7. Iron Releases in Solution and on Walls from Polished Sample 31 in AJ13 pH=2 at Room Temperature and Average Detection Limits for Leachate and Acid Strip.

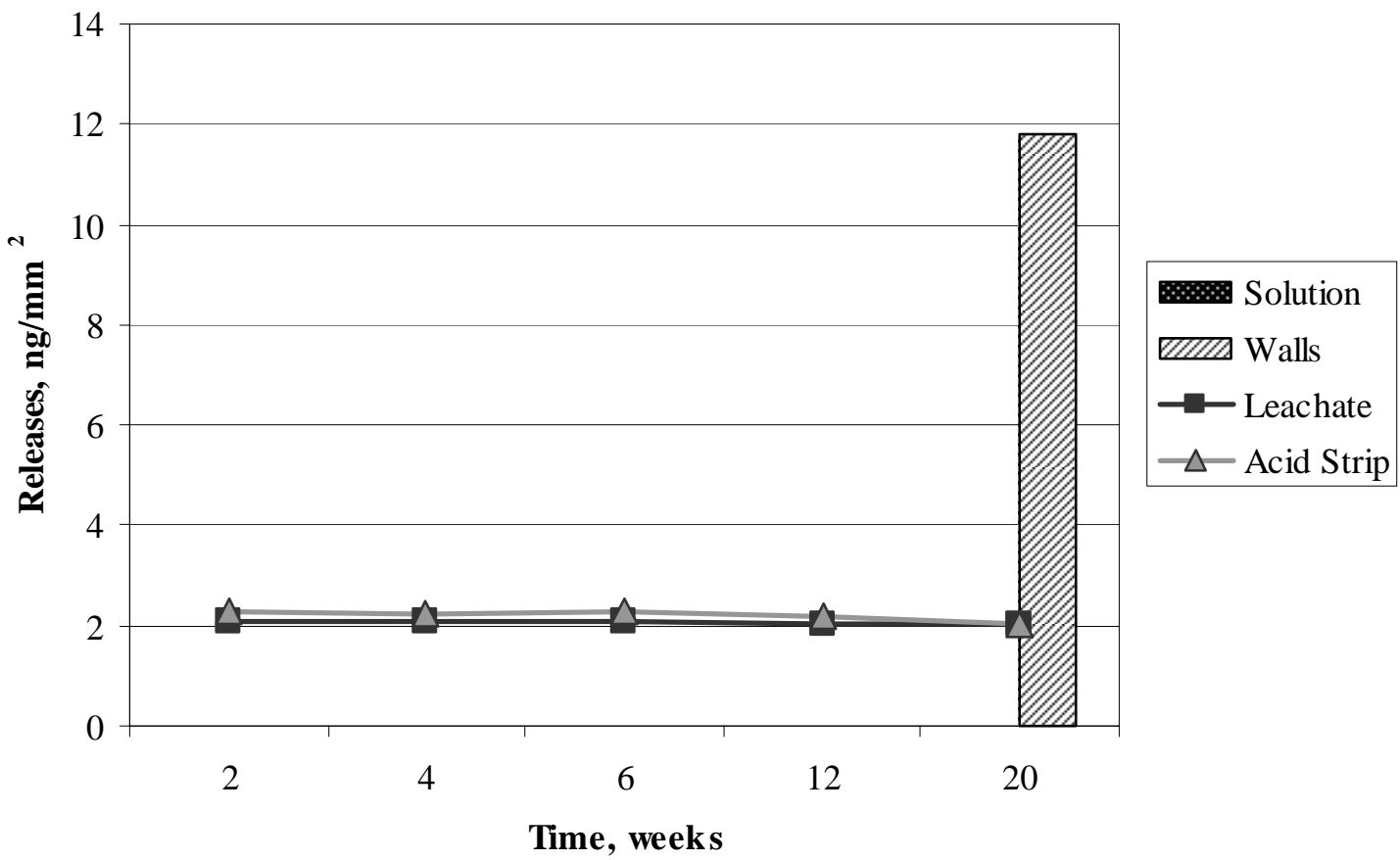

Figure J-8. Iron Present in Solution and on Walls for AJ13 pH=2 at Room Temperature and Average Detection Limits for Leachate and Acid Strip. 


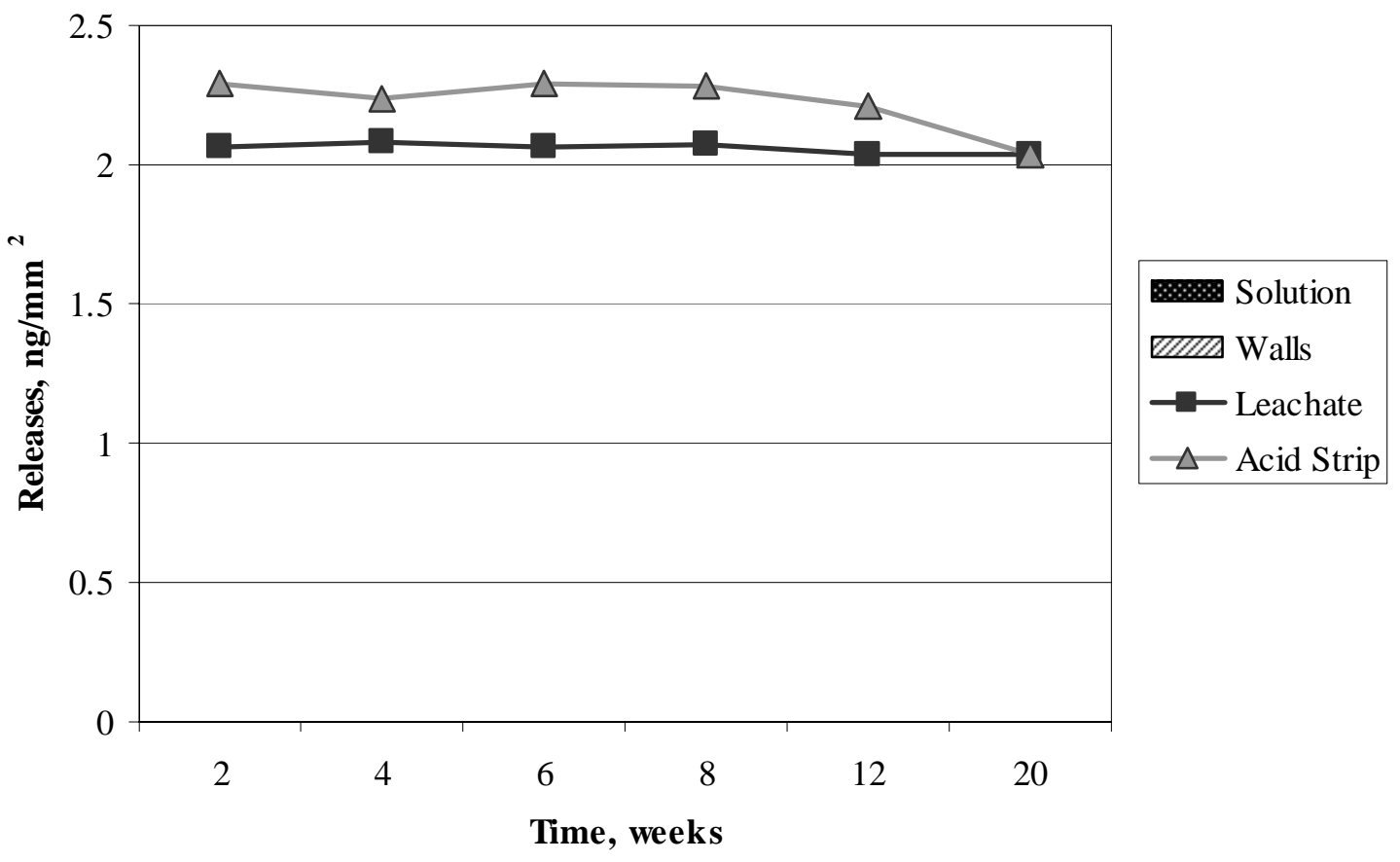

Figure J-9. Chromium Releases in Solution and on Walls from Polished Sample 25 in $1 \mathrm{KCl}$ at $90^{\circ} \mathrm{C}$ and Average Detection Limits for Leachate and Acid Strip.

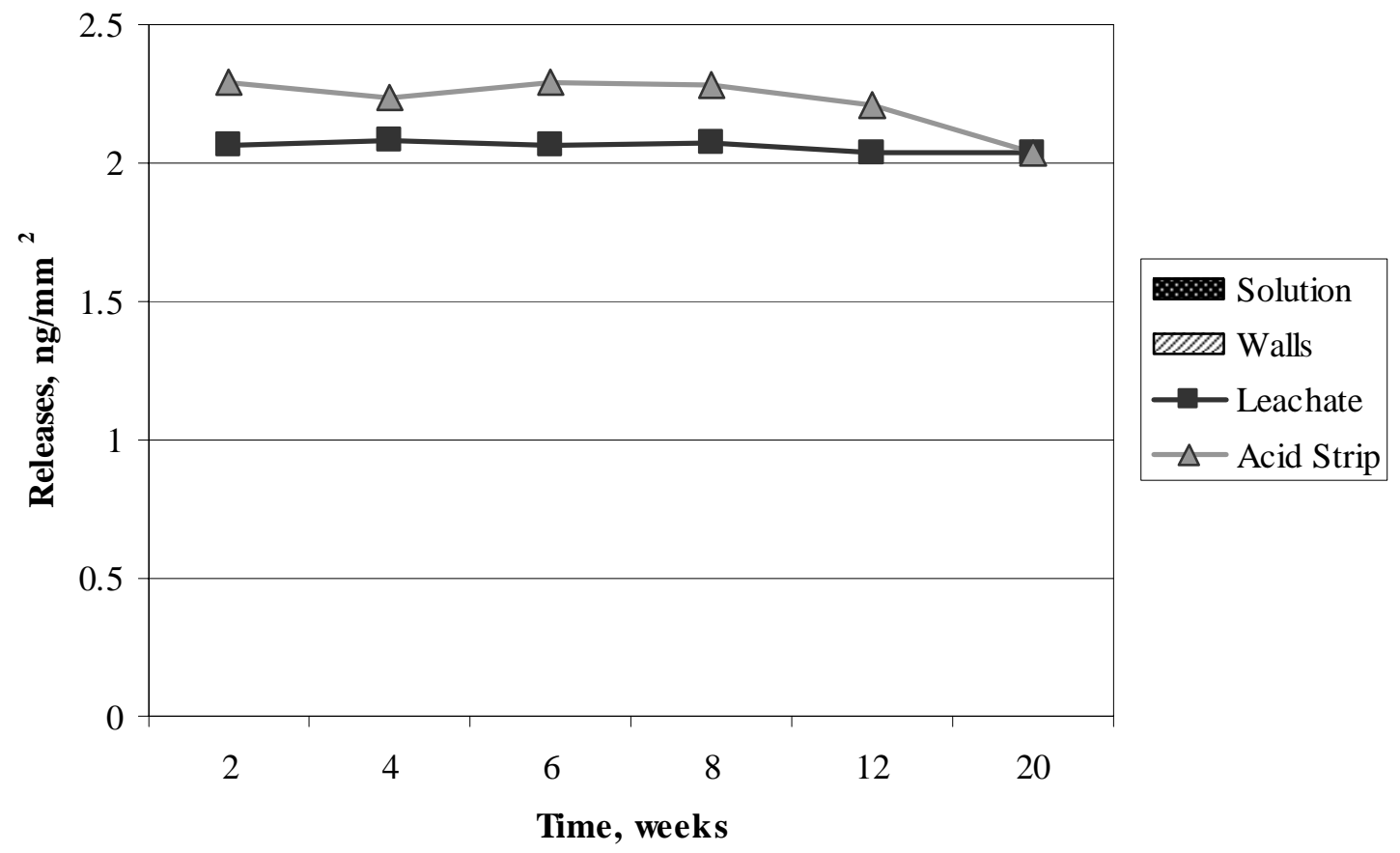

Figure J-10. Chromium Present in Solution and on Walls from 1KCl Control at $90^{\circ} \mathrm{C}$ and Average Detection Limits for Leachate and Acid Strip. 


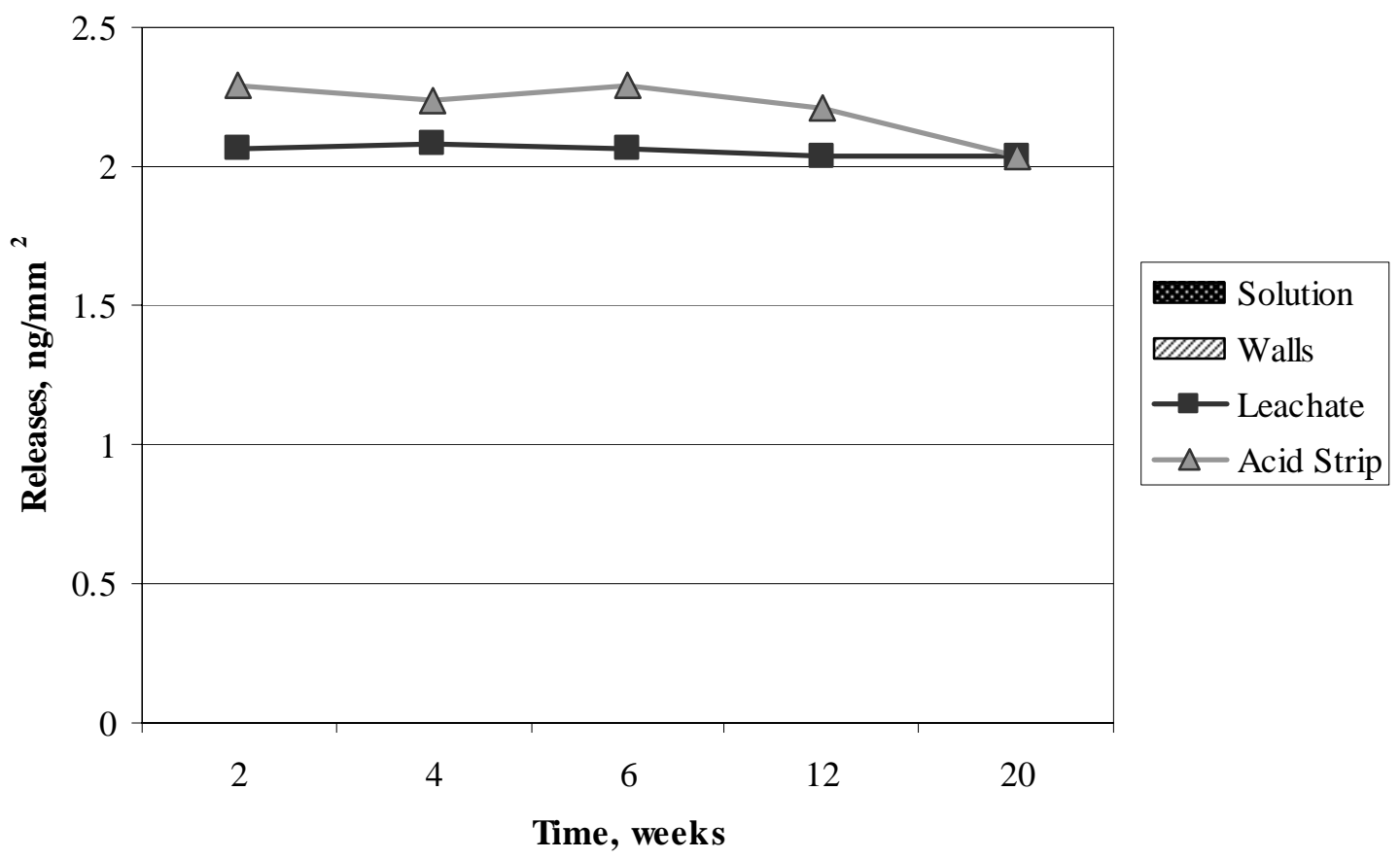

Figure J-11. Chromium Releases in Solution, on Walls, and in Residue from Polished Sample 27 in $1 \mathrm{KCl}$ at Room Temperature and Average Detection Limits for Leachate and Acid Strip.

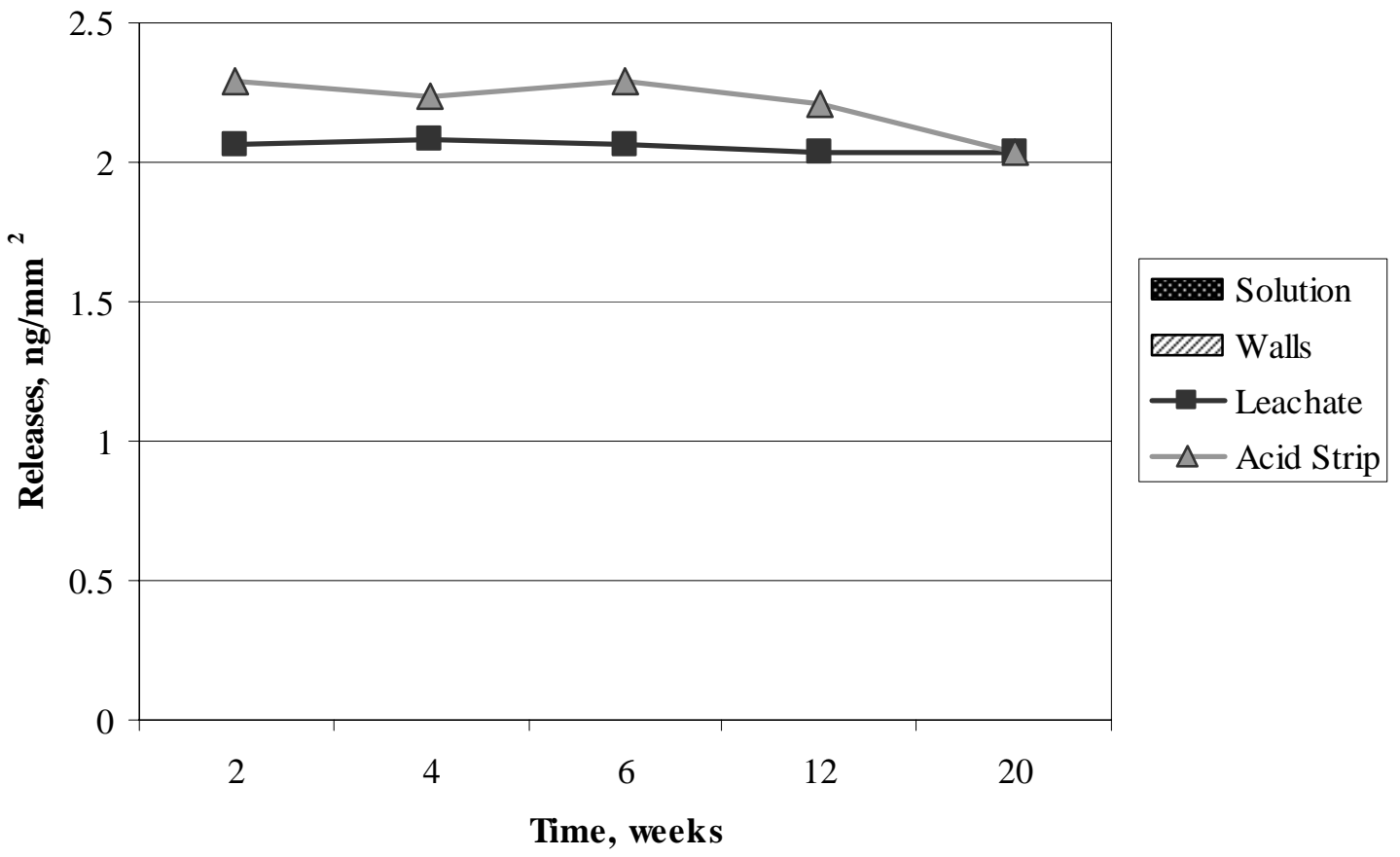

Figure J-12. Chromium Present in Solution and on Walls from 1KCl Control at Room Temperature and Average Detection Limits for Leachate and Acid Strip. 


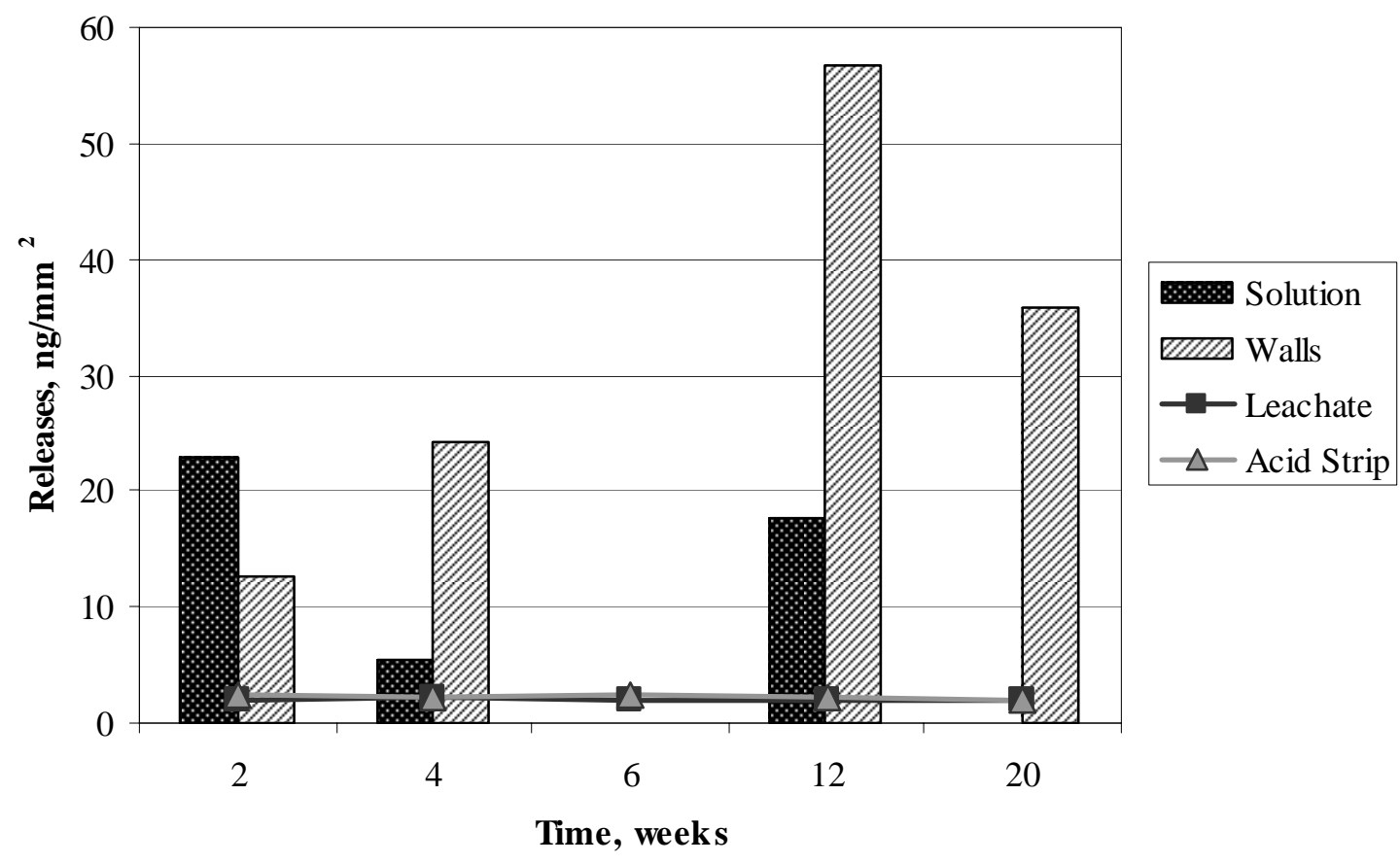

Figure J-13. Chromium Releases in Solution and on Walls from Polished Sample 29 in $10 \mathrm{KCl}$ at Room Temperature and Average Detection Limits for Leachate and Acid Strip.

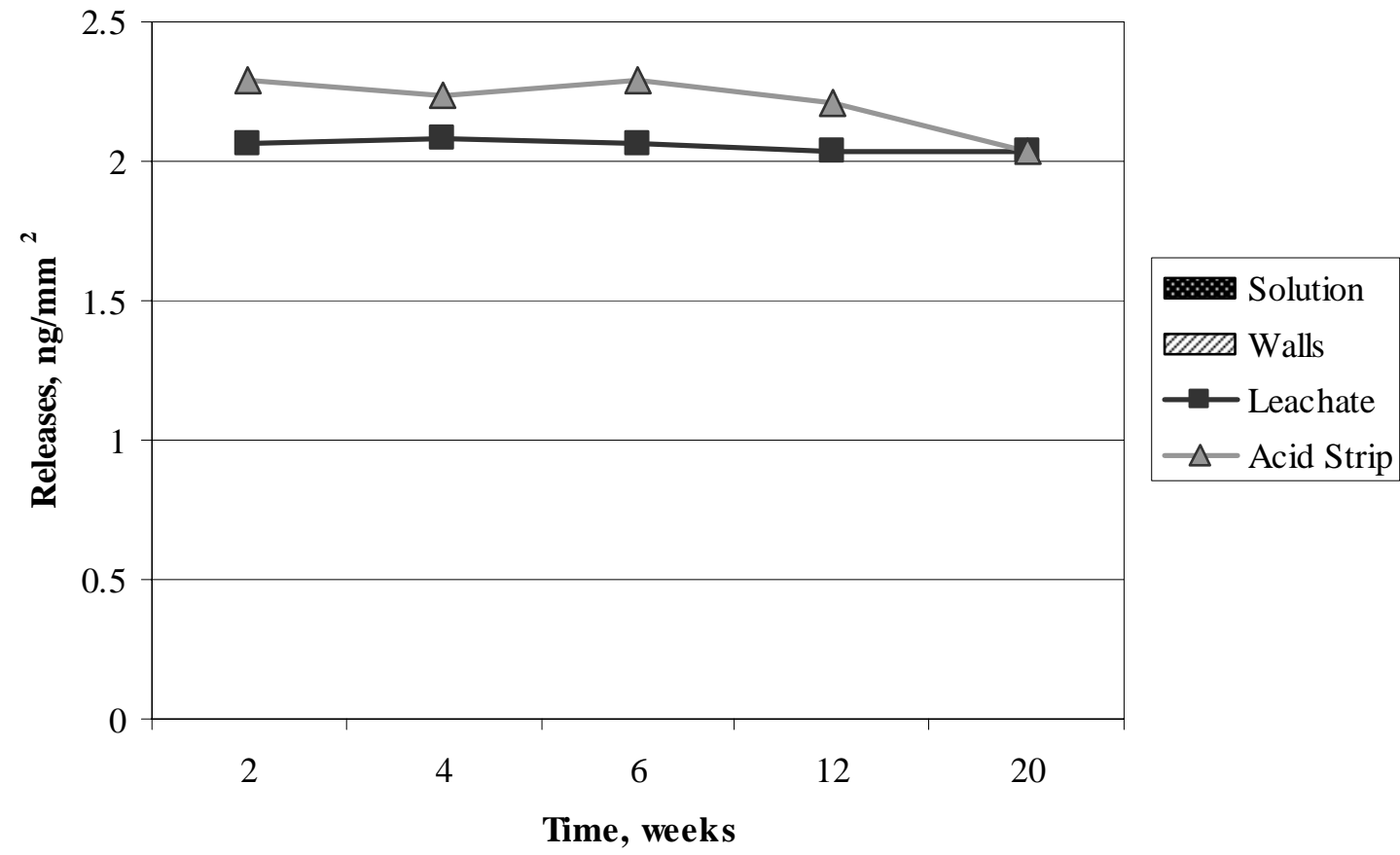

Figure J-14. Chromium Present in Solution and on Walls from $10 \mathrm{KCl}$ Control and Average Detection Limits for Leachate and Acid Strip Data. 


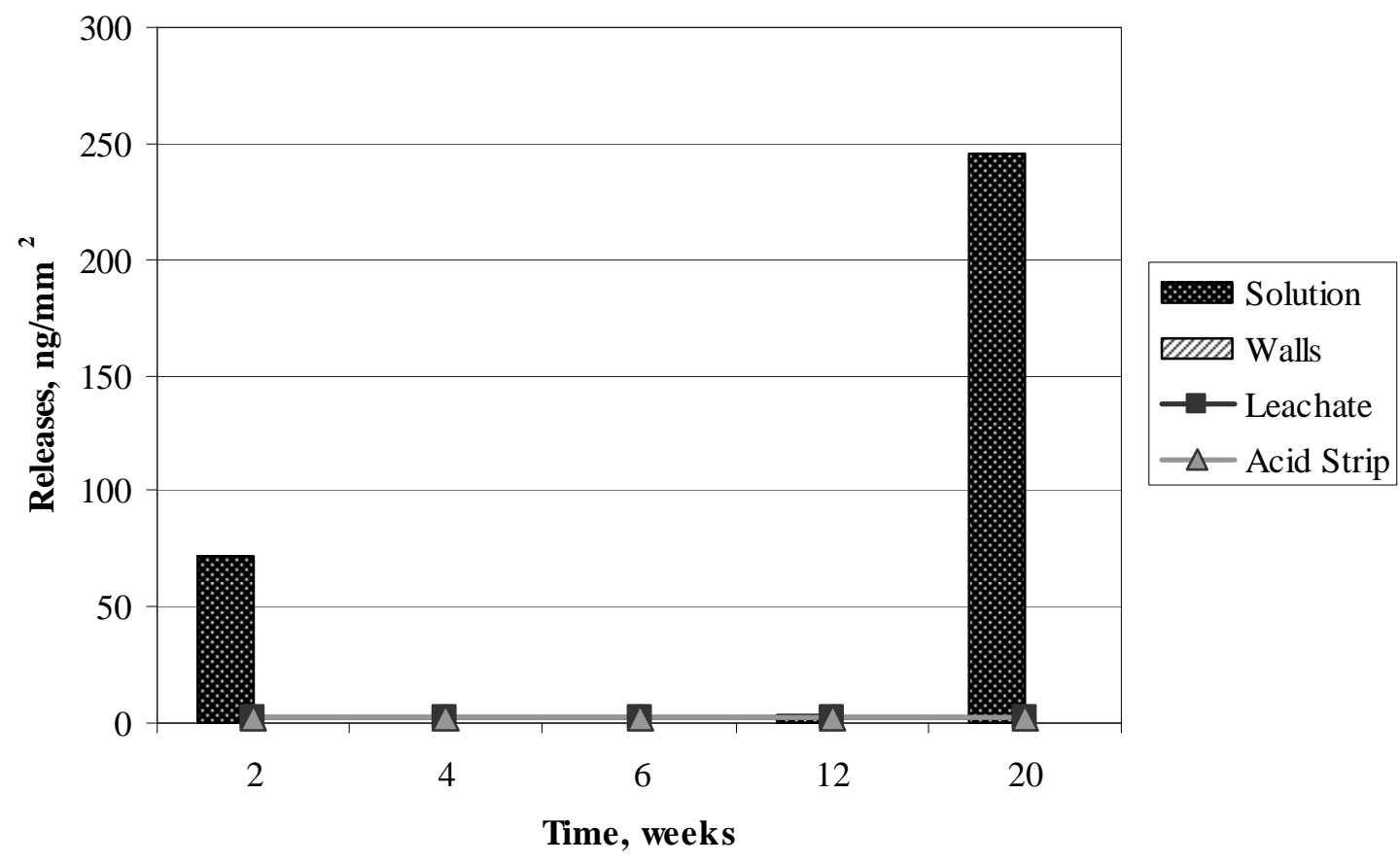

Figure J-15. Chromium Releases in Solution and on Walls from Polished Sample 31 in AJ13 at Room Temperature and Average Detection Limits for Leachate and Acid Strip.

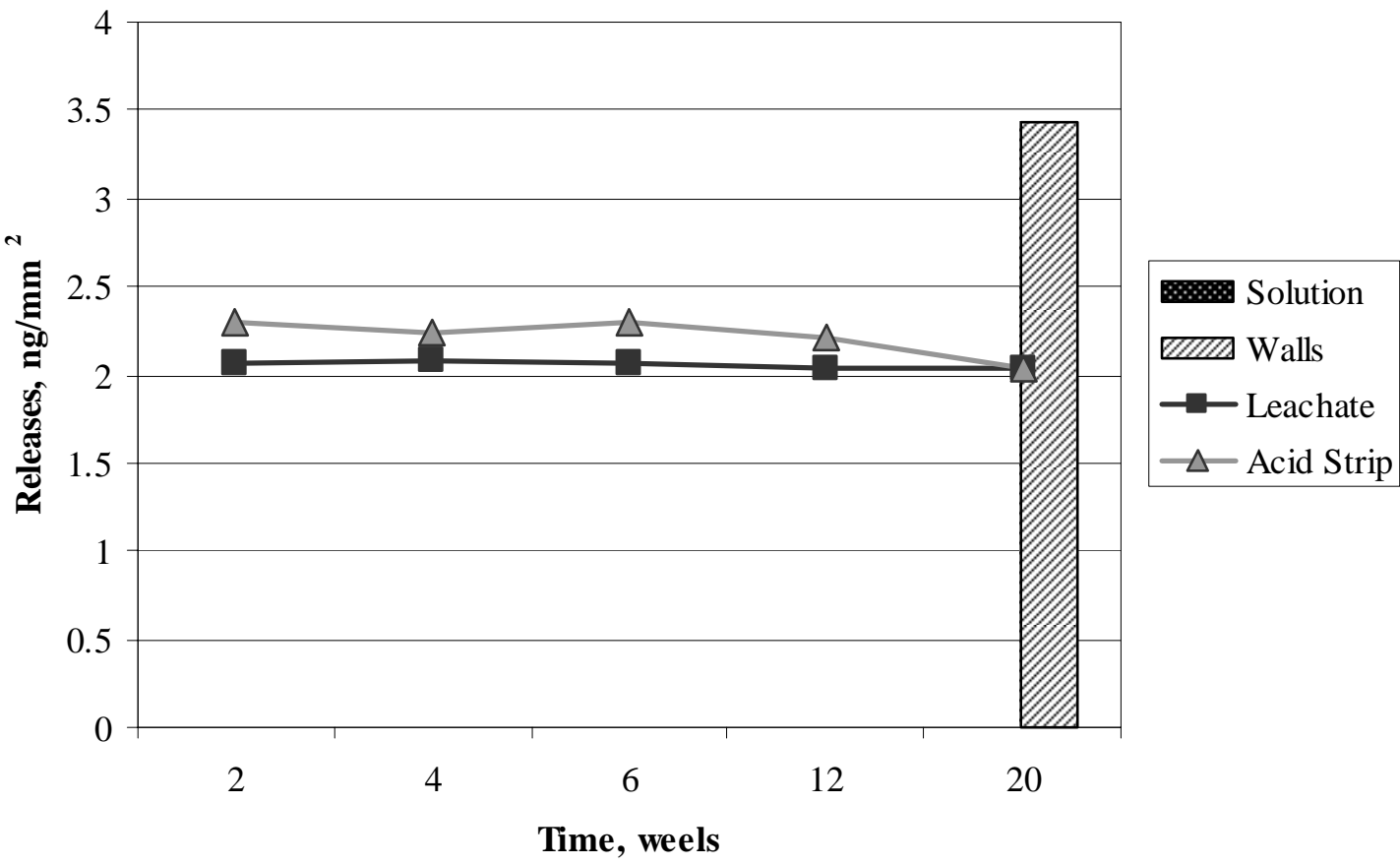

Figure J-16. Chromium Present in Solution and on Walls from AJ13 Control at Room Temperature and Average Leachate and Acid Strip Data. 


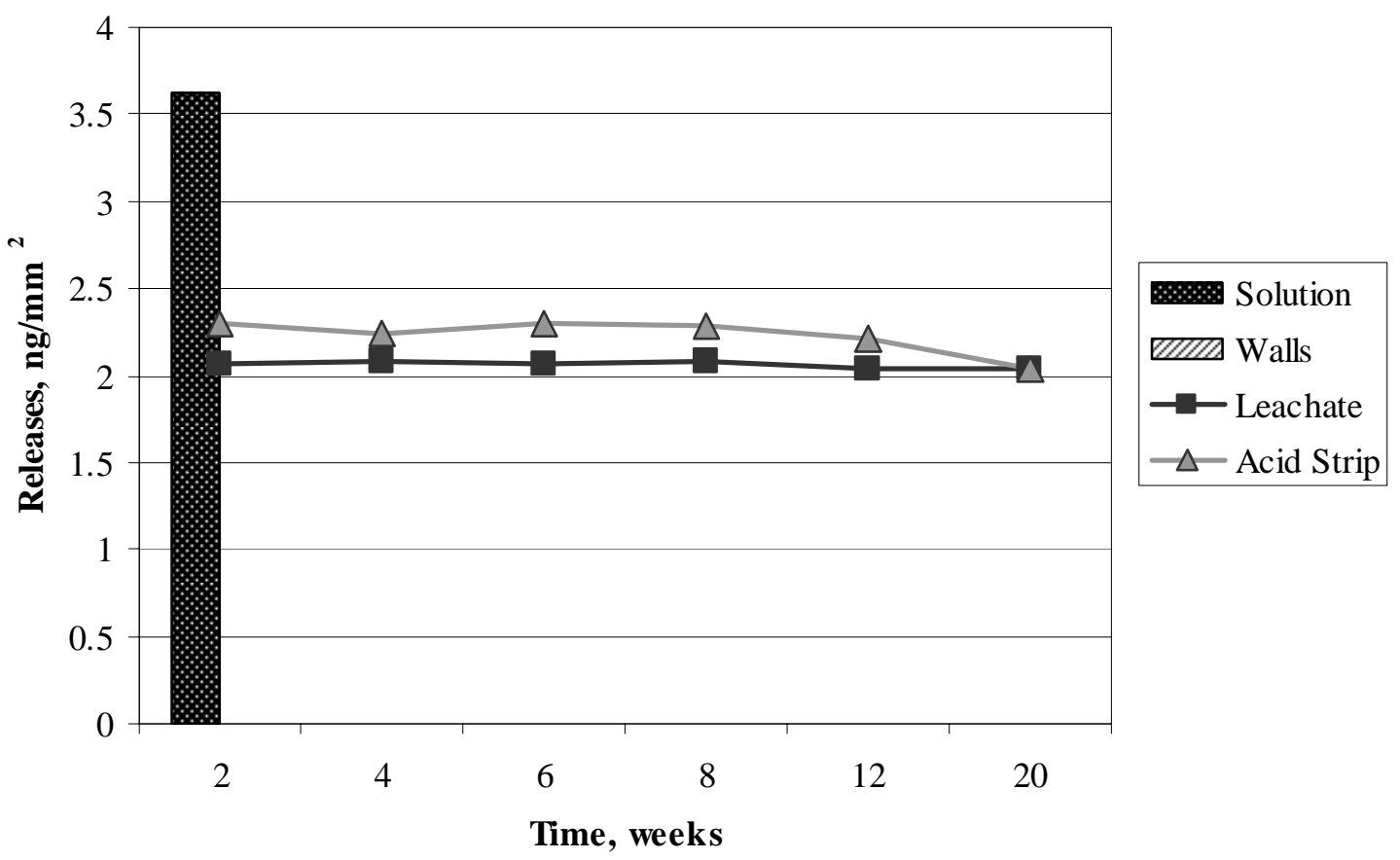

Figure J-17. Nickel Releases in Solution and on Walls from Polished Sample 25 in $1 \mathrm{KCl}$ Solution at $90^{\circ} \mathrm{C}$ and Average Detection Limits for Leachate and Acid Strip.

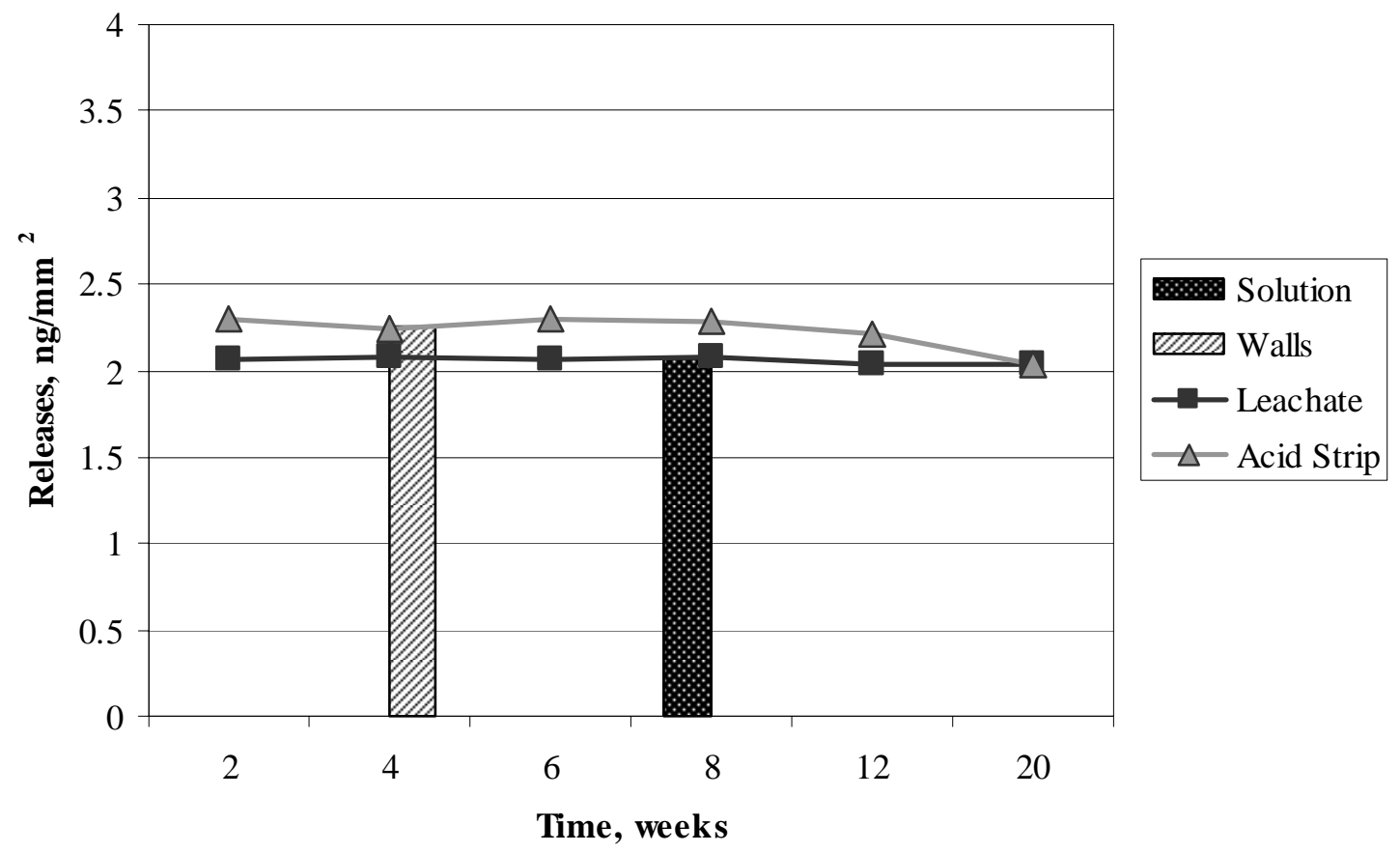

Figure J-18. Nickel Present in Solutions and on Walls in $1 \mathrm{KCl}$ Solution Control at $90^{\circ} \mathrm{C}$ and Average Detection Limits for Leachate and Acid Strip. 


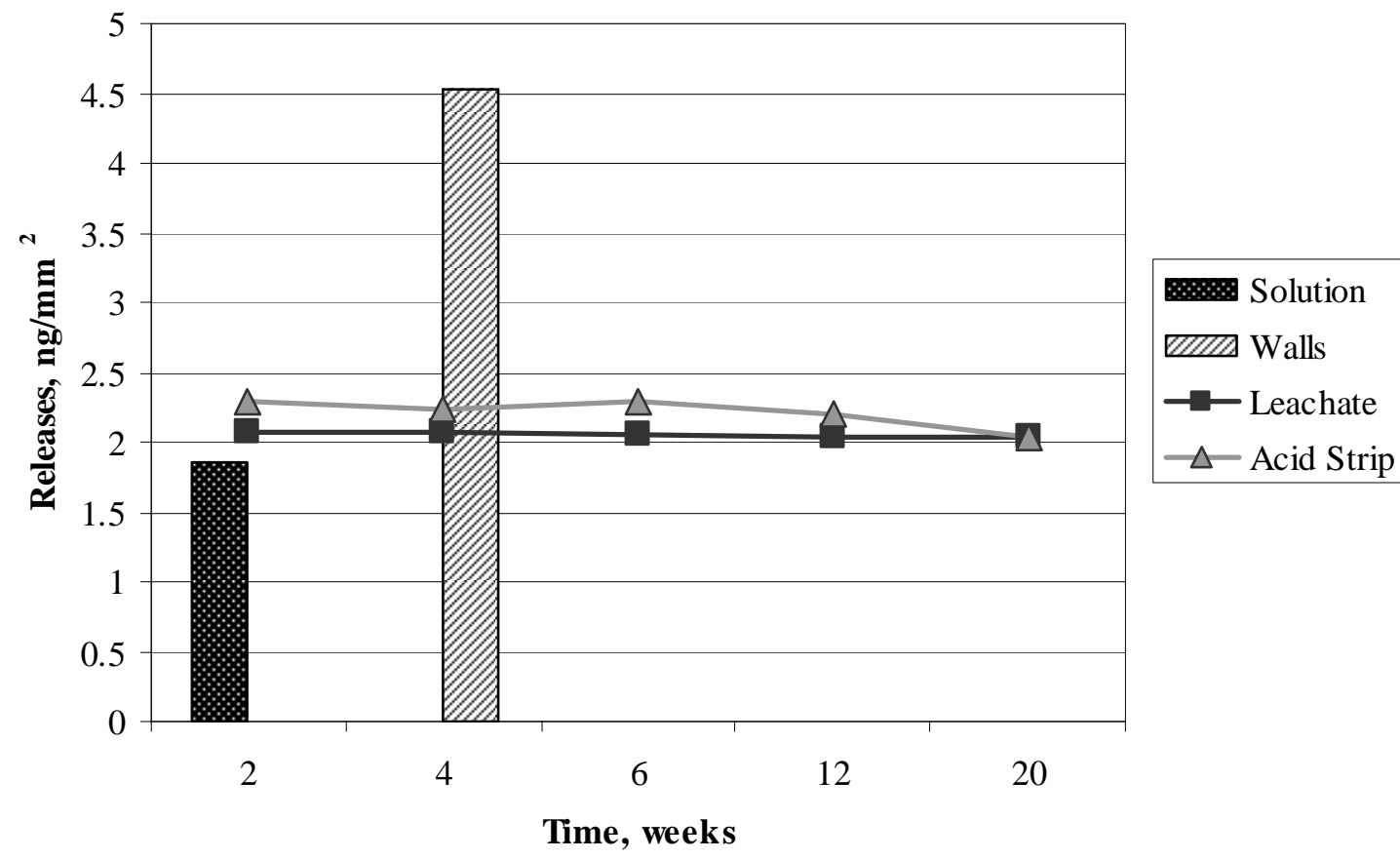

F Figure J-19. Nickel Releases in Solution and on Walls from Polished Sample 27 in $1 \mathrm{KCl}$ Solution at Room Temperature and Average Detection Limits for Leachate and Acid Strip.

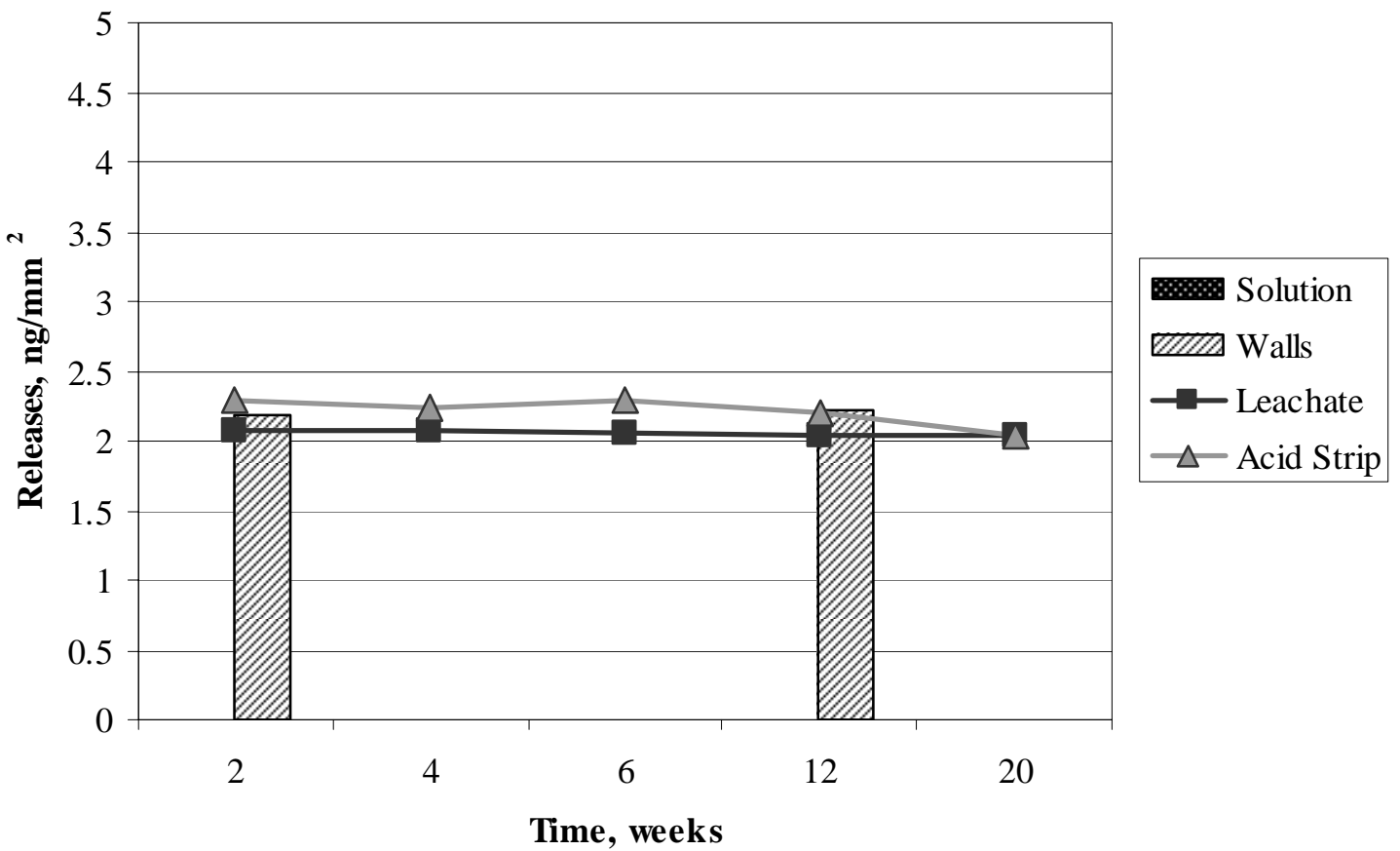

Figure J-20. Nickel Present in Solutions and on Walls in $1 \mathrm{KCl}$ Solution Control at Room Temperature and Average Detection Limits for Leachate and Acid Strip. 


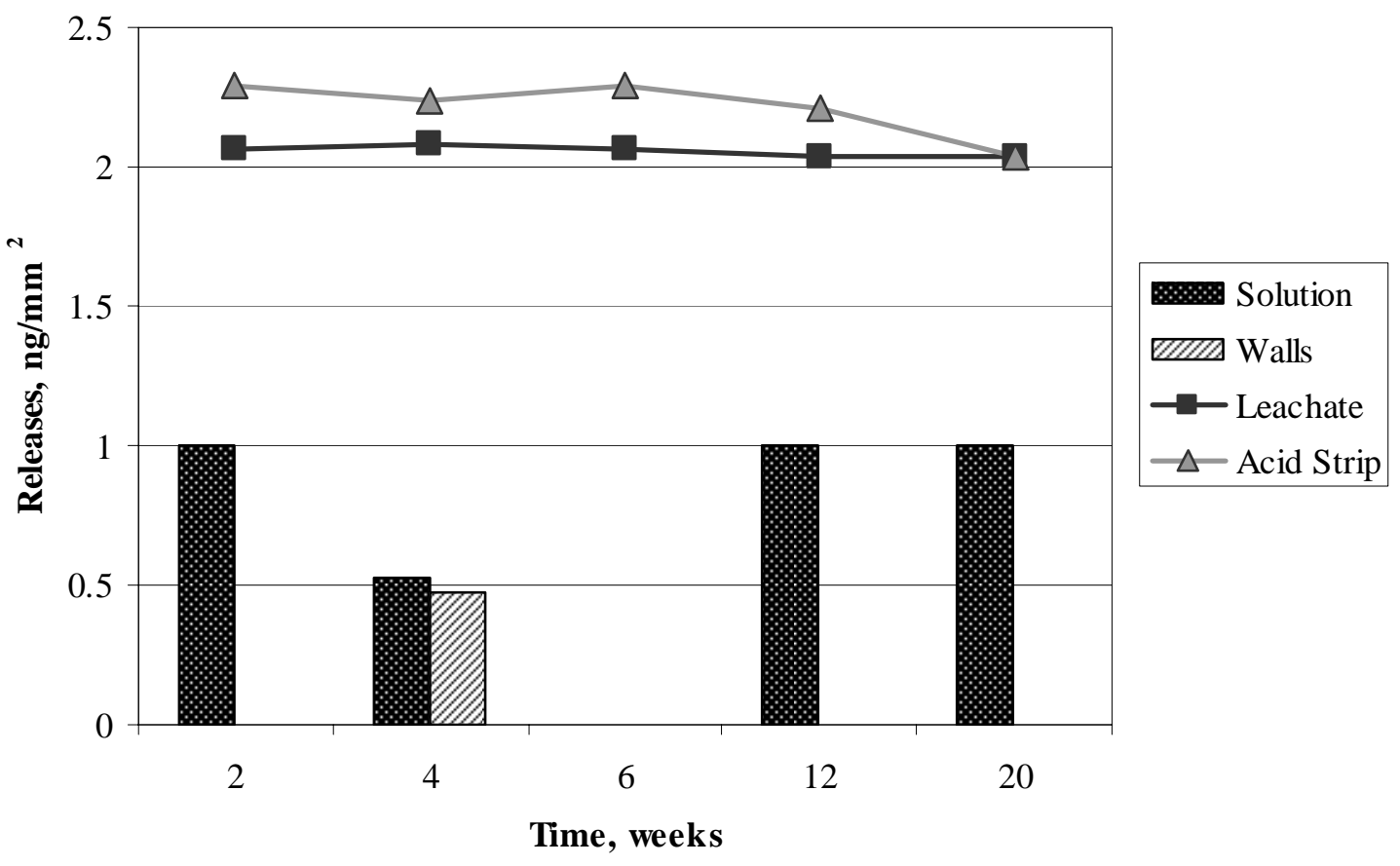

Figure J-21. Nickel Releases in Solution and on Walls from Polished Sample 29 in $10 \mathrm{KCl}$ Solution at Room Temperature and Average Detection Limits for Leachate and Acid Strip.

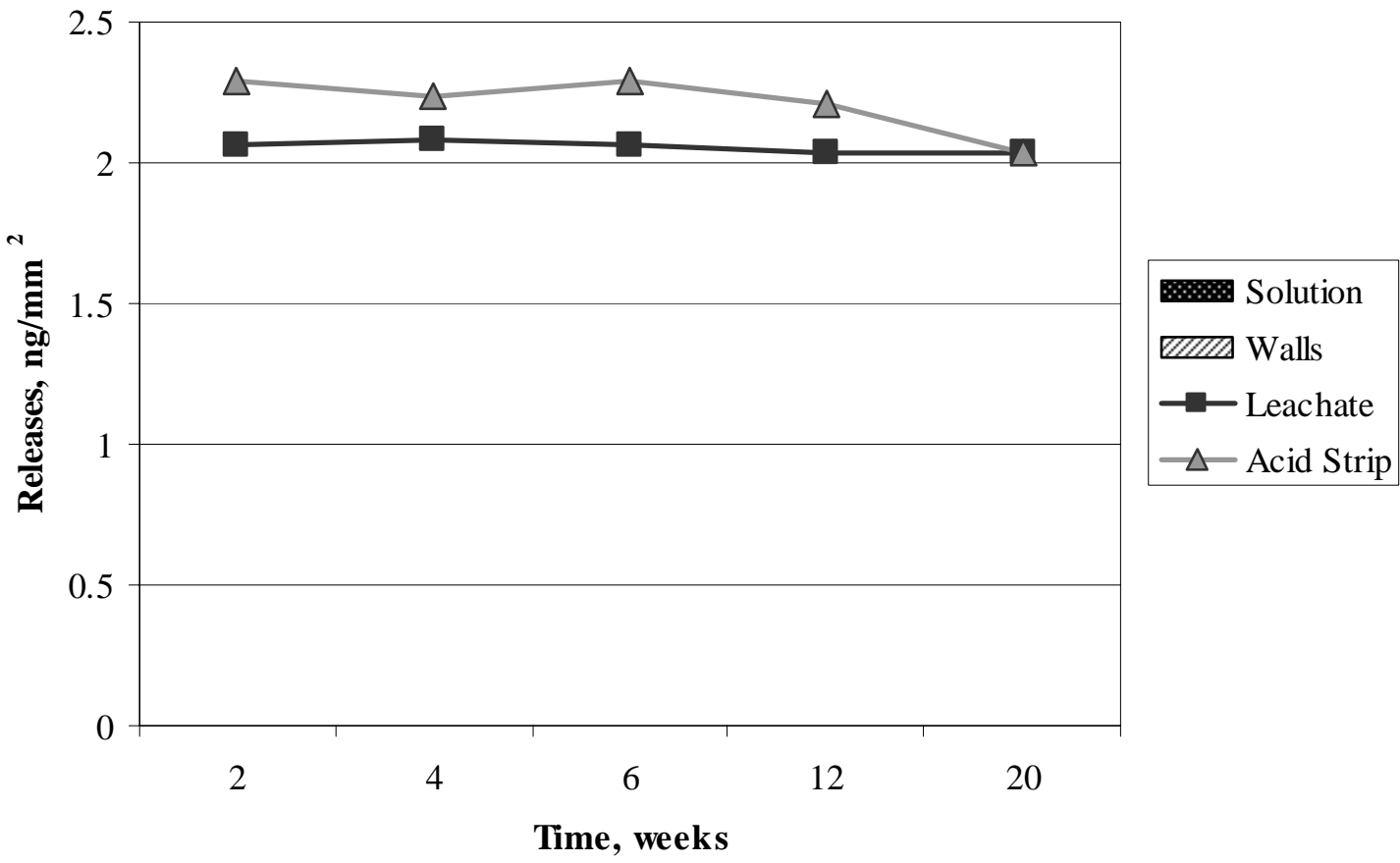

Figure J-22. Nickel Present in Solutions and on Walls in 10KCl Solution Control at Room Temperature and Average Detection Limits for Leachate and Acid Strip. 


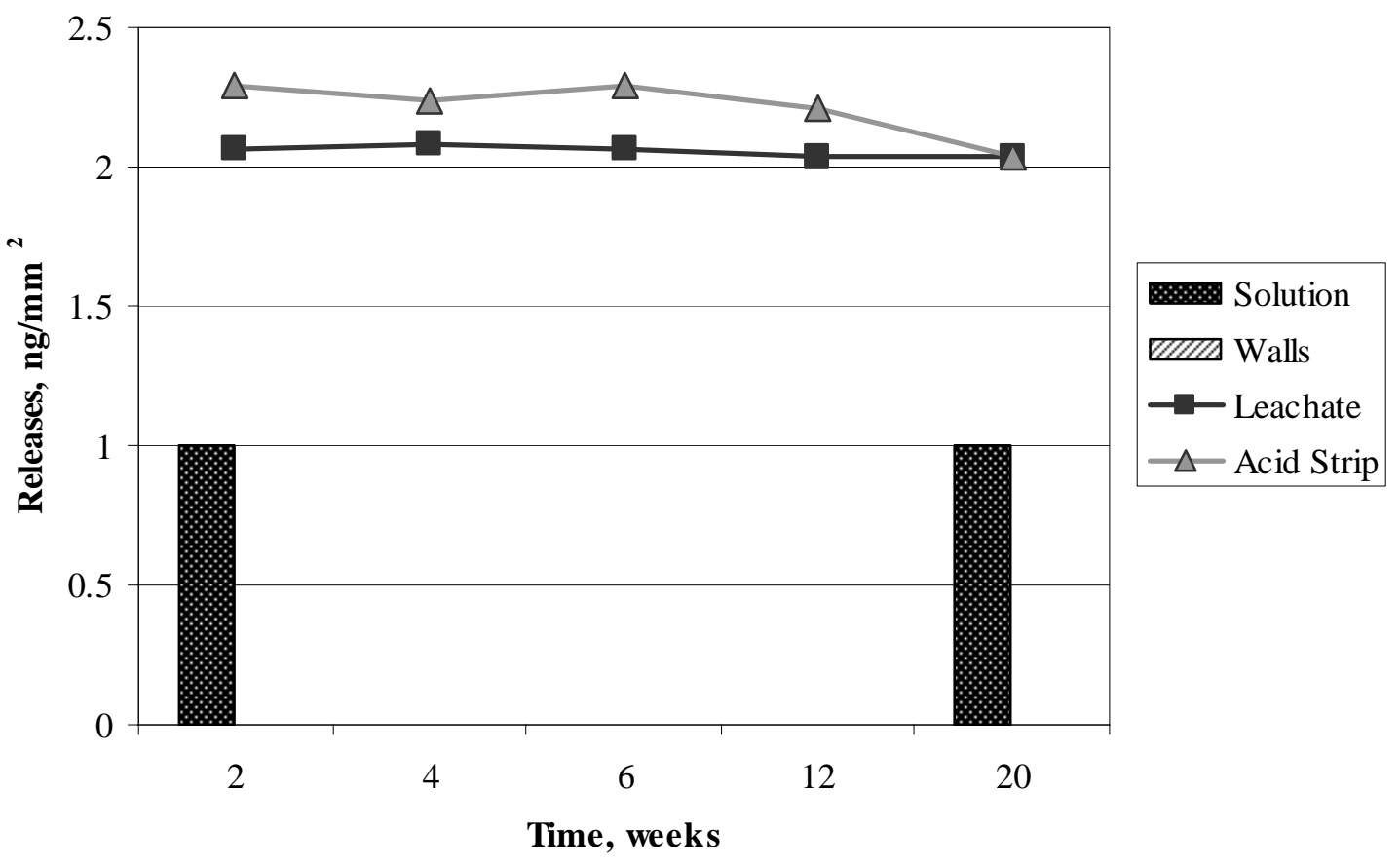

Figure J-23. Nickel Releases in Solution and on Walls from Polished Sample 31 in AJ13 Solution at Room Temperature and Average Detection Limits for Leachate and Acid Strip.

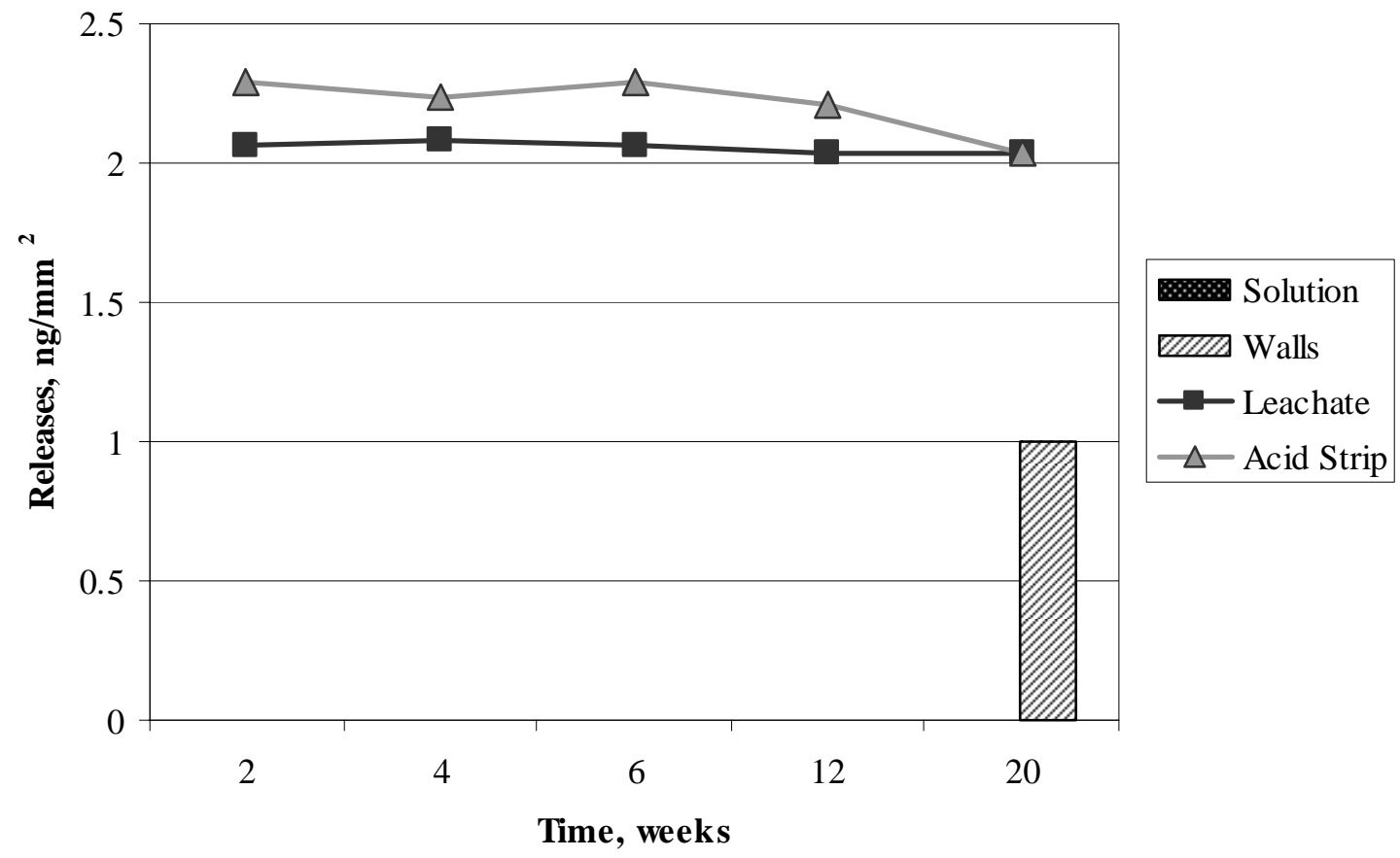

Figure J-24. Nickel Present in Solutions and on Walls in AJ13 Solution Control at Room Temperature and Average Detection Limits for Leachate and Acid Strip. 


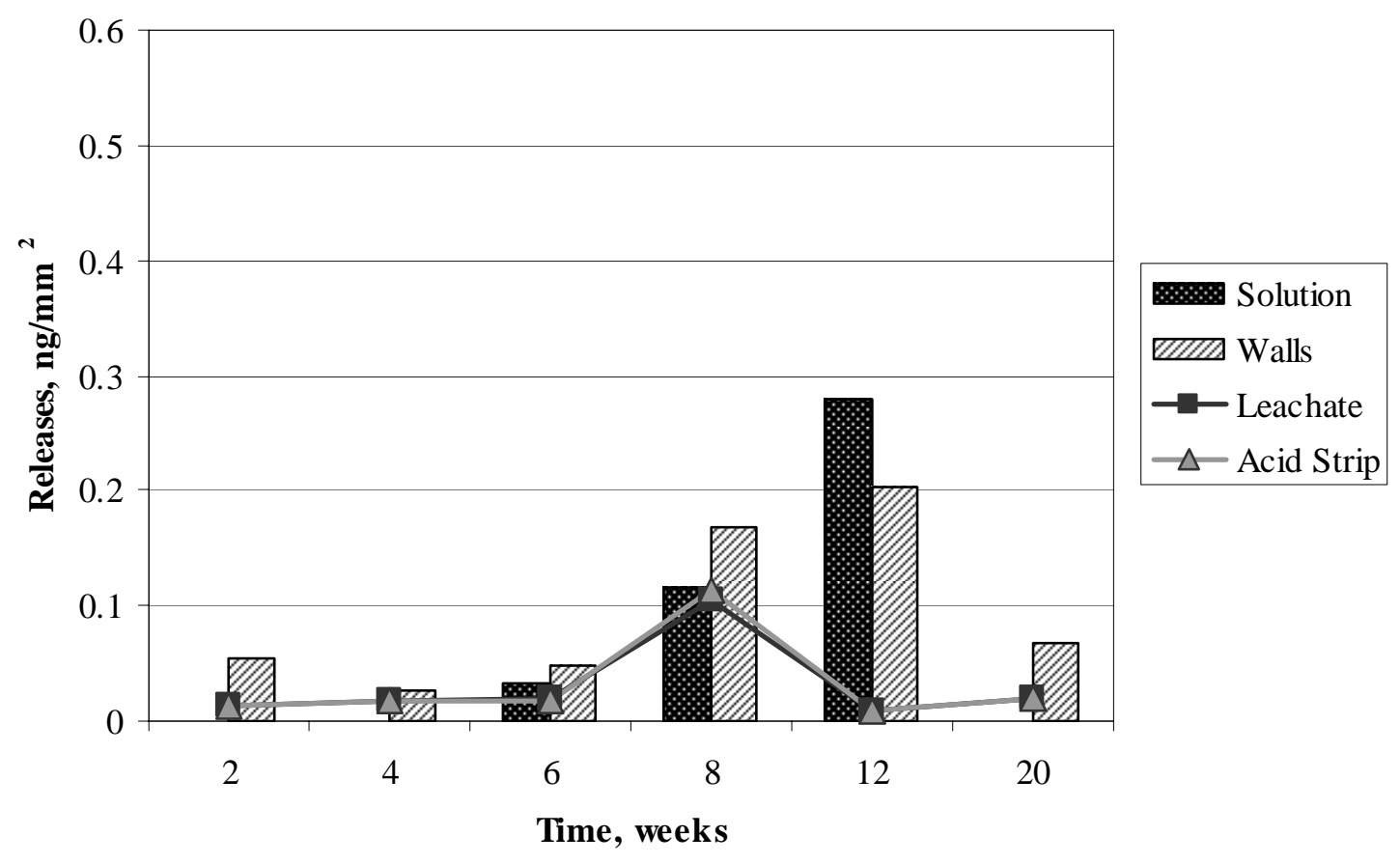

Figure J-25. Zirconium Releases in Solution and on Walls from Polished Sample 25 in $1 \mathrm{KCl}$ Solution at $90^{\circ} \mathrm{C}$ and Average Detection Limits for Leachate and Acid Strip.

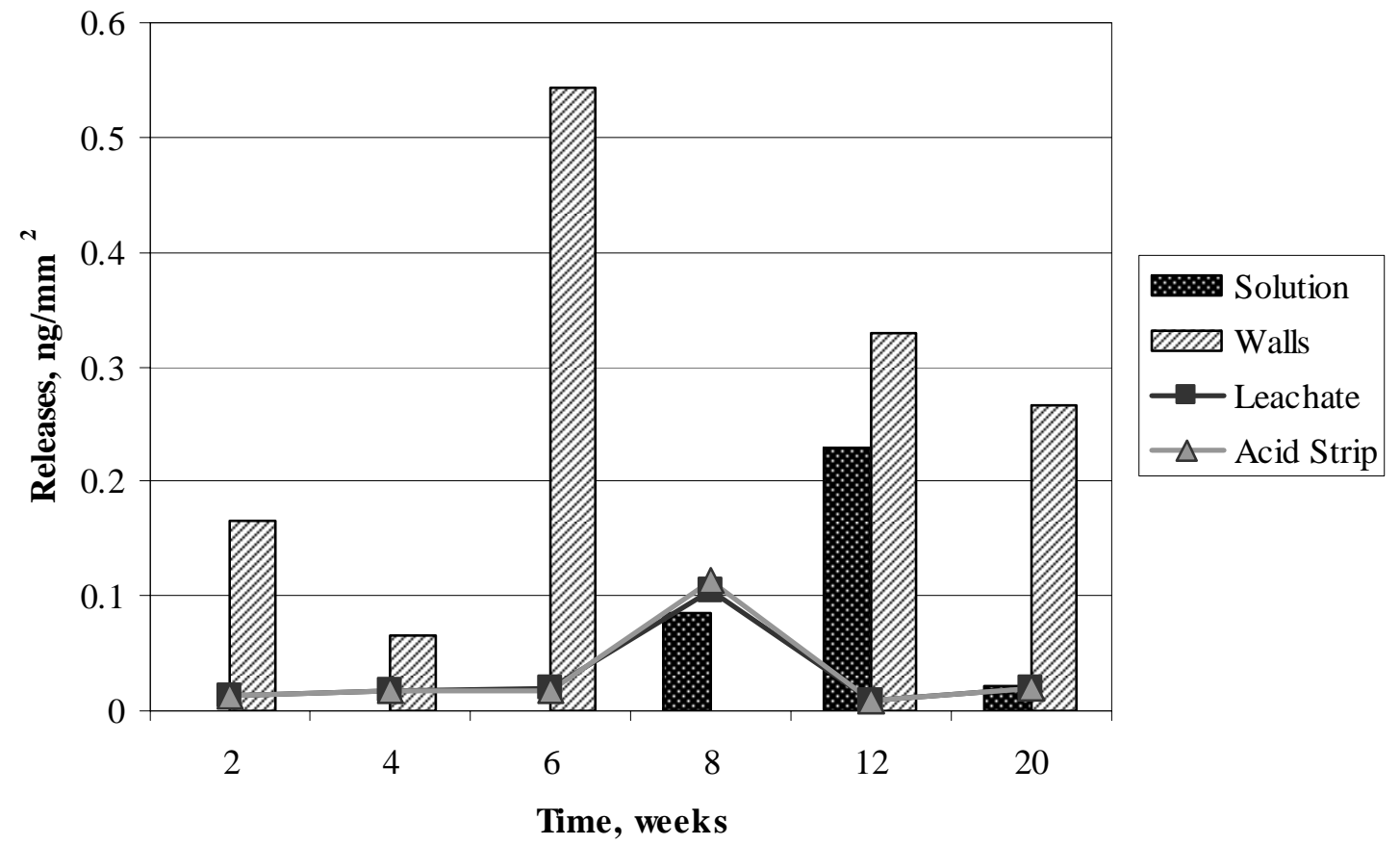

Figure J-26. Zirconium Present in Solutions and on Walls in 1KCl Solution Control at $90^{\circ} \mathrm{C}$ and Average Detection Limits for Leachate and Acid Strip. 


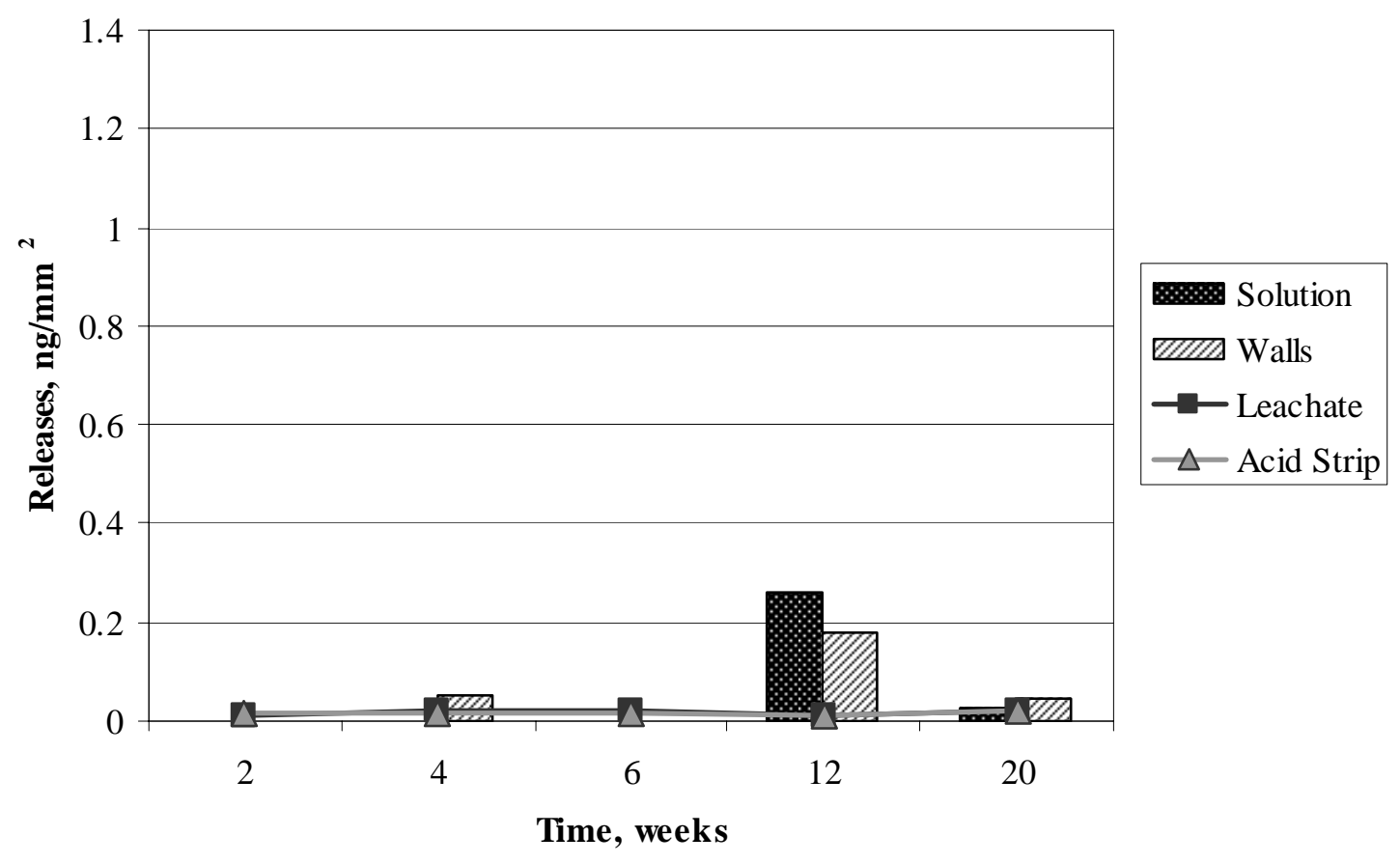

Figure J-27. Zirconium Releases in Solution and on Walls from Polished Sample 27 in $1 \mathrm{KCl}$ Solution at Room Temperature and Average Detection Limits for Leachate and Acid Strip.

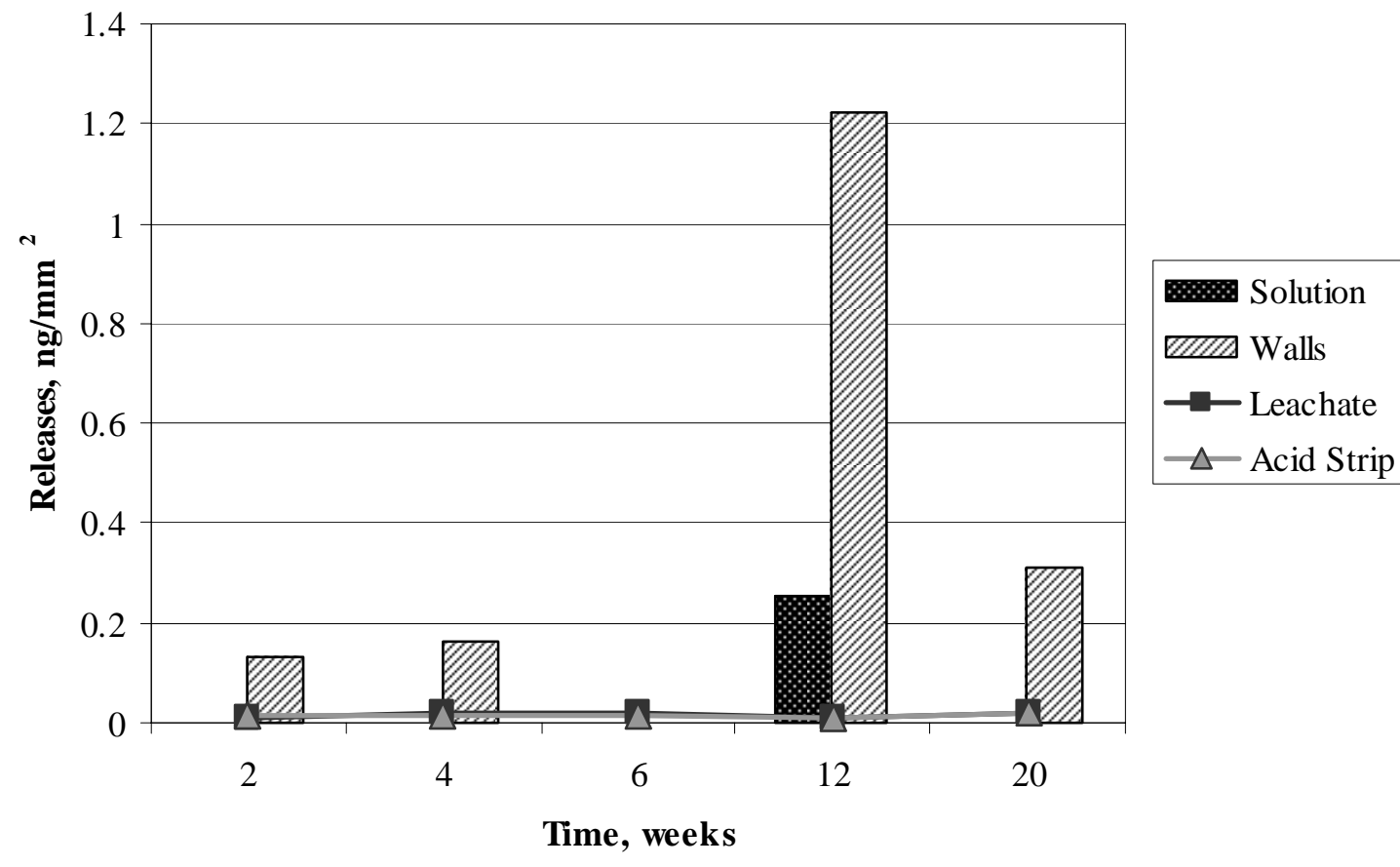

Figure J-28. Zirconium Present in Solutions and on Walls in 1KCl Solution Control at Room Temperature and Average Detection Limits for Leachate and Acid Strip. 


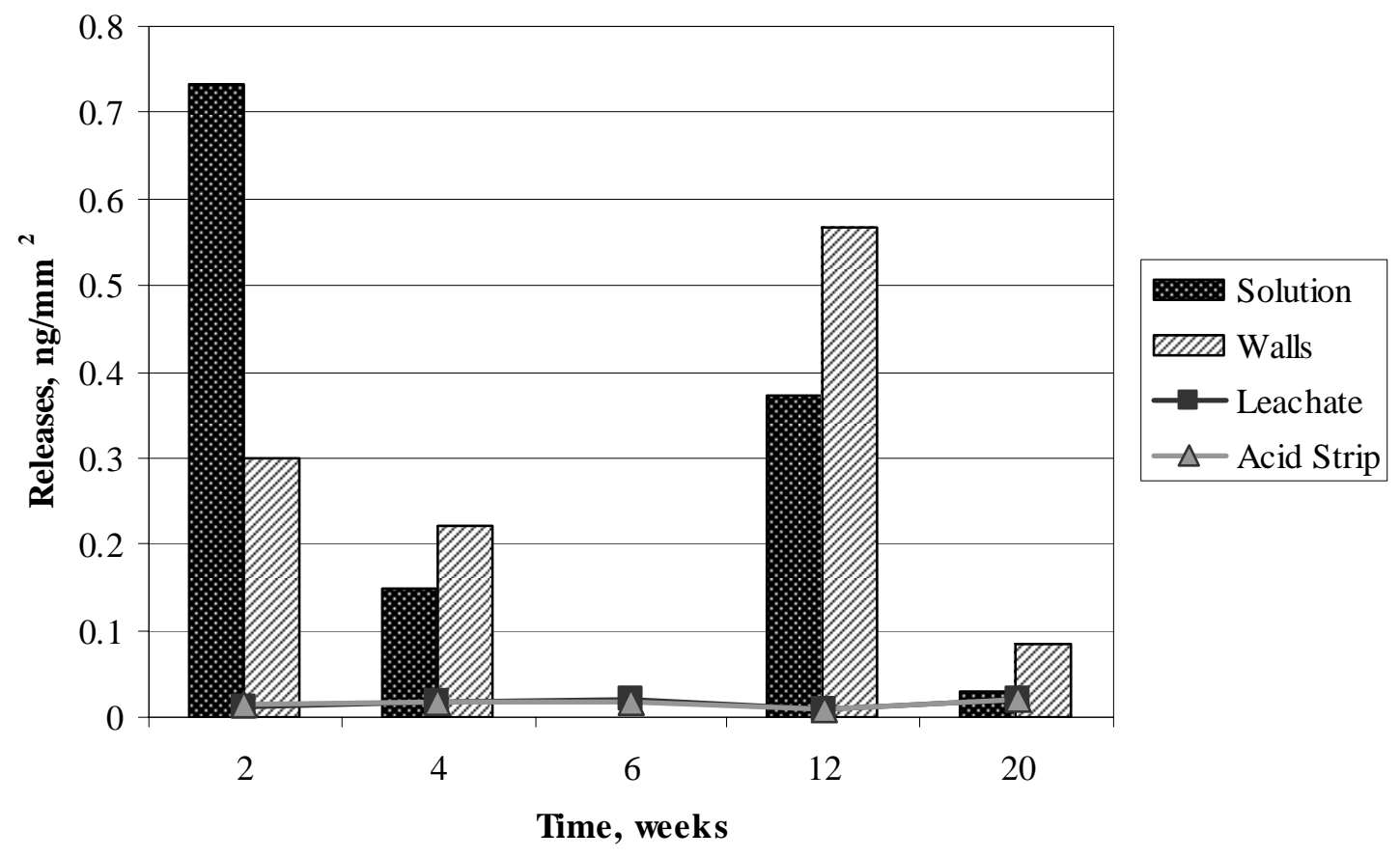

Figure J-29. Zirconium Releases in Solution and on Walls from Polished Sample 29 in 10KCl Solution at Room Temperature and Average Detection Limits for Leachate and Acid Strip.

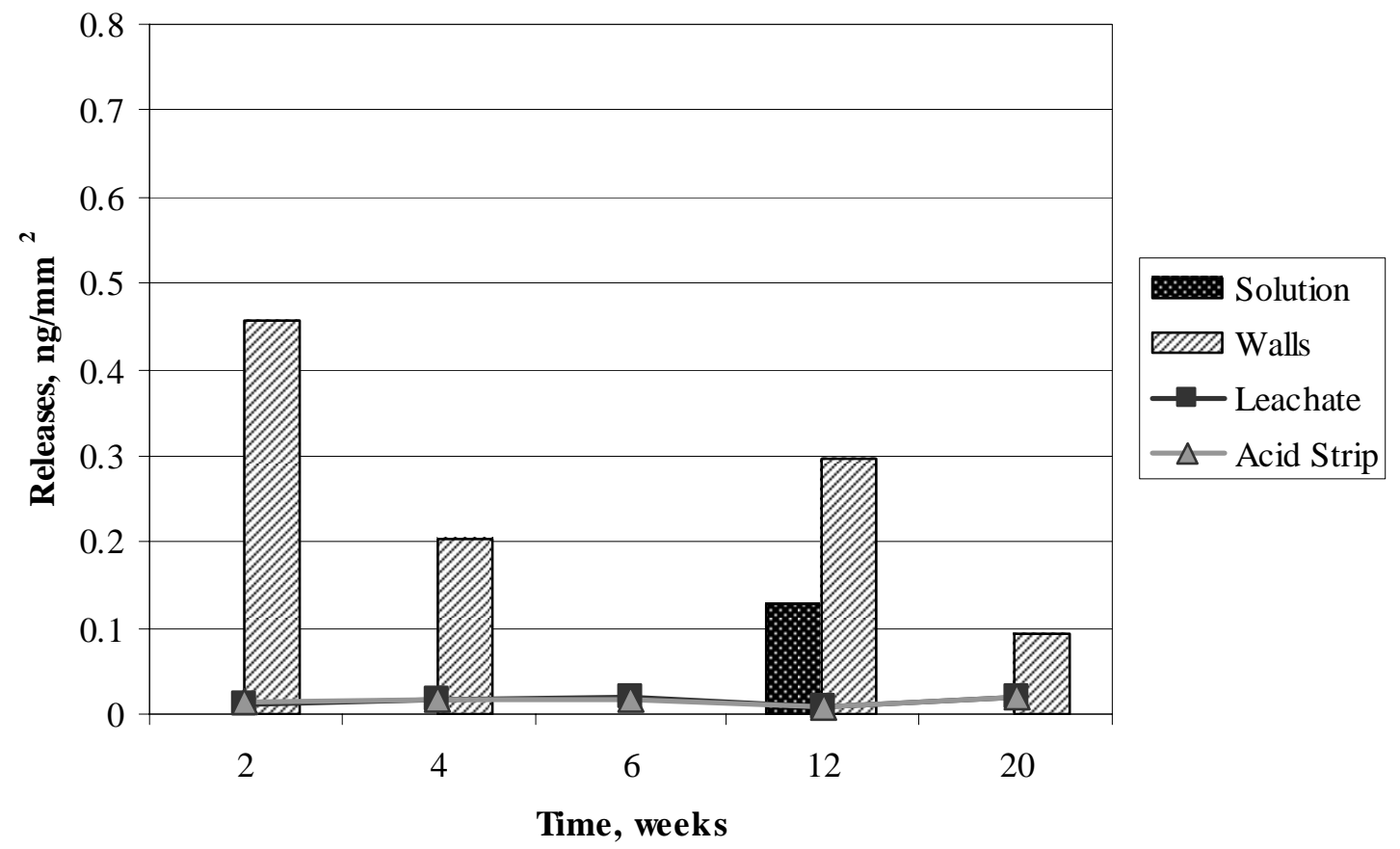

Figure J-30. Zirconium Present in Solutions and on Walls in 10KCl Solution Control at Room Temperature and Average Detection Limits for Leachate and Acid Strip. 


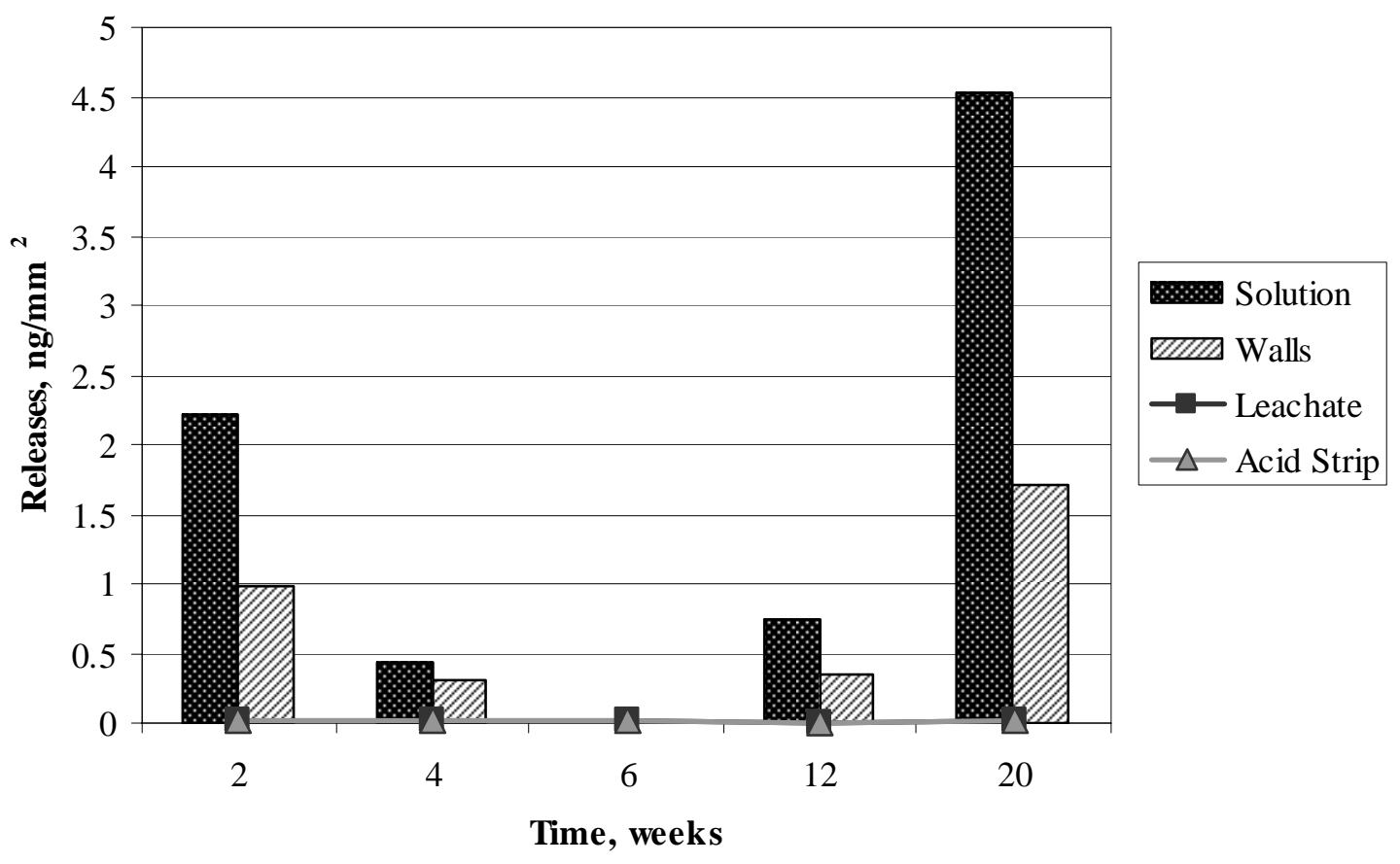

Figure J-31. Zirconium Releases in Solution and on Walls from Polished Sample 31 in AJ13 Solution at Room Temperature and Average Detection Limits for Leachate and Acid Strip.

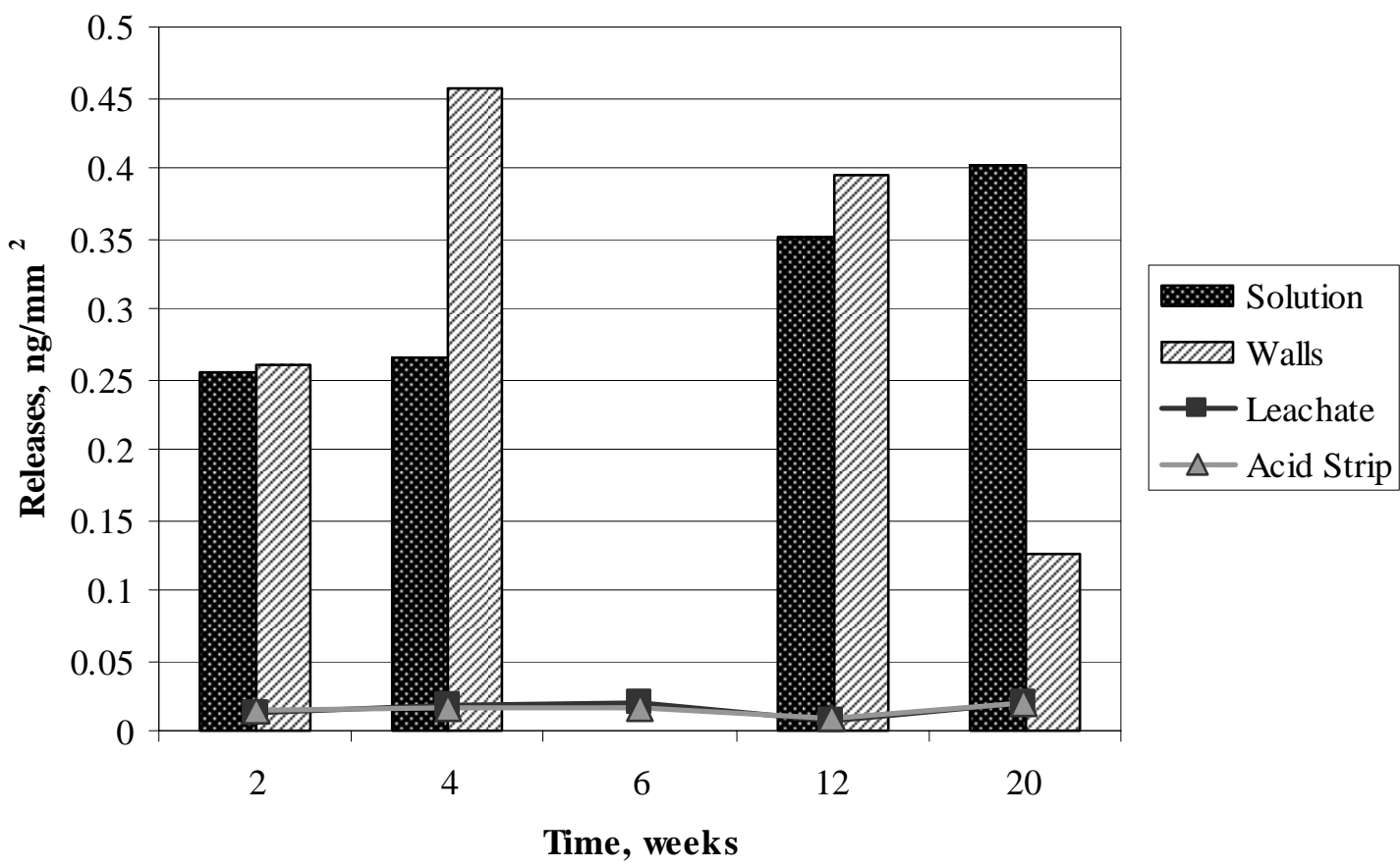

Figure J-32. Zirconium Present in Solutions and on Walls in AJ13 Solution Control at Room Temperature and Average Detection Limits for Leachate and Acid Strip. 


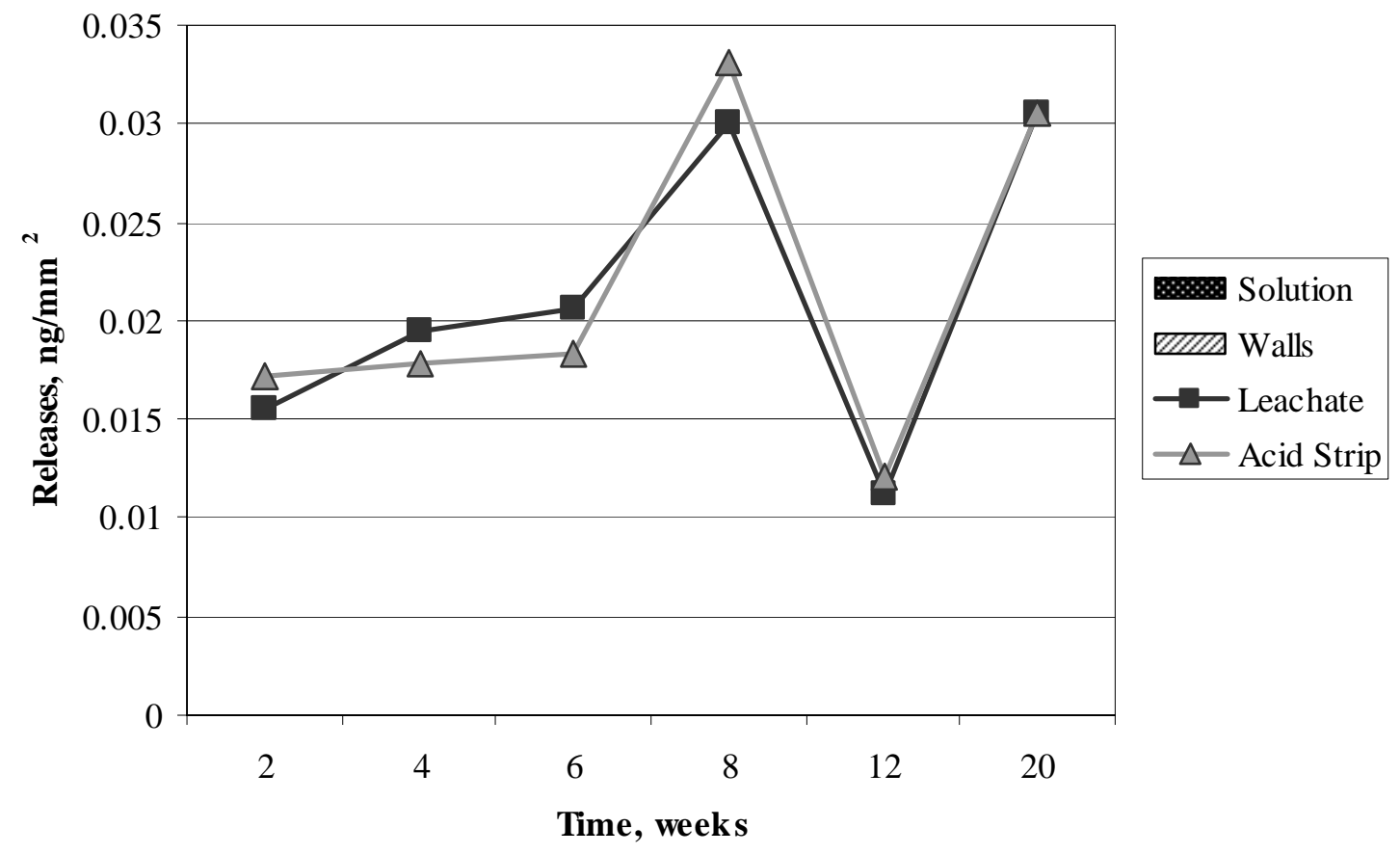

Figure J-33. Niobium Releases in Solution and on Walls from Polished Sample 25 in $1 \mathrm{KCl}$ Solution at $90^{\circ} \mathrm{C}$ and Average Detection Limits for Leachate and Acid Strip.

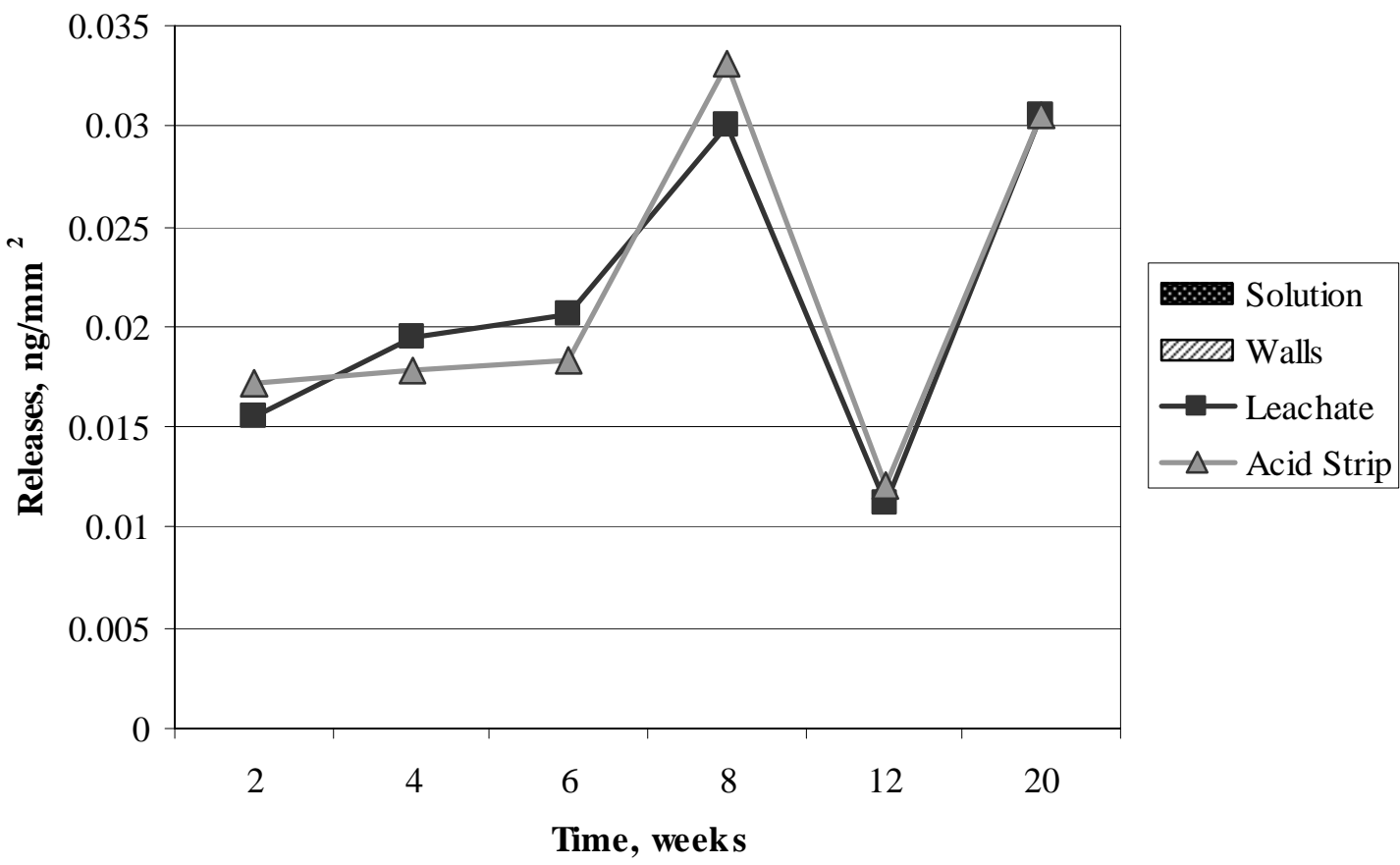

Figure J-34. Niobium Present in Solutions and on Walls in $1 \mathrm{KCl}$ Solution Control at $90^{\circ} \mathrm{C}$ and Average Detection Limits for Leachate and Acid Strip. 


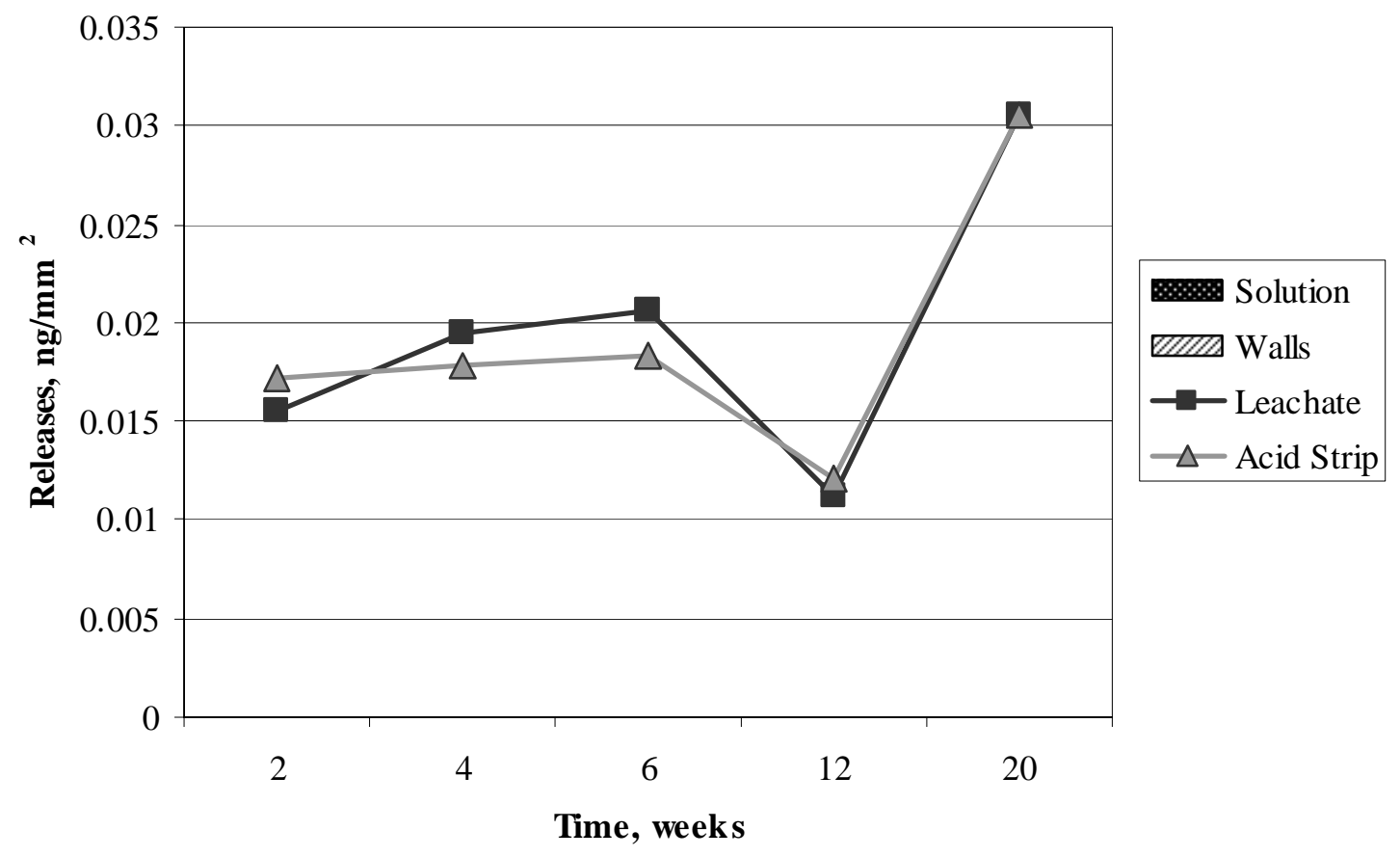

Figure J-35. Niobium Releases in Solution and on Walls from Polished Sample 27 in $1 \mathrm{KCl}$ Solution at Room Temperature and Average Detection Limits for Leachate and Acid Strip.

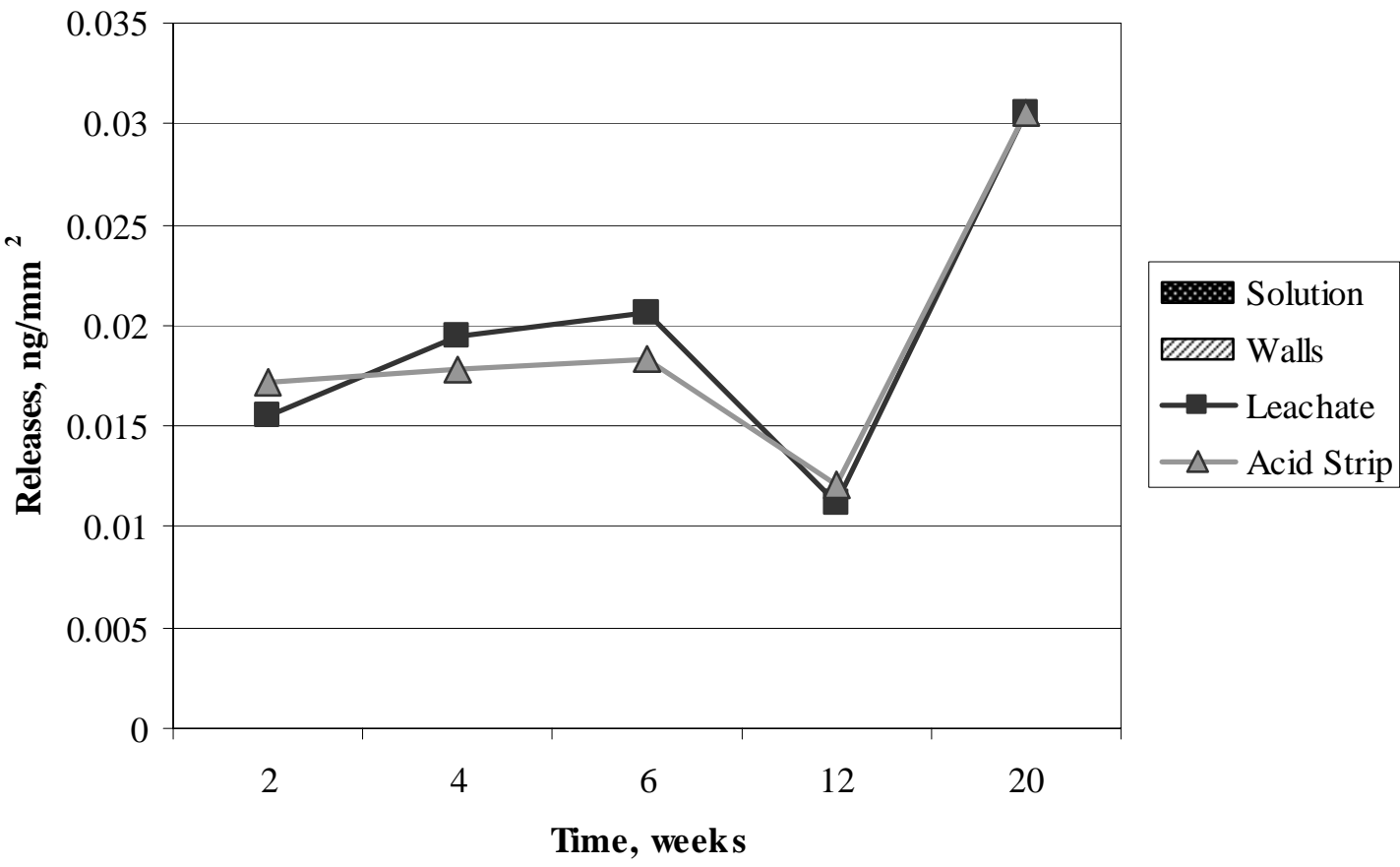

Figure J-36. Niobium Present in Solutions and on Walls in $1 \mathrm{KCl}$ Solution Control at Room Temperature and Average Detection Limits for Leachate and Acid Strip. 


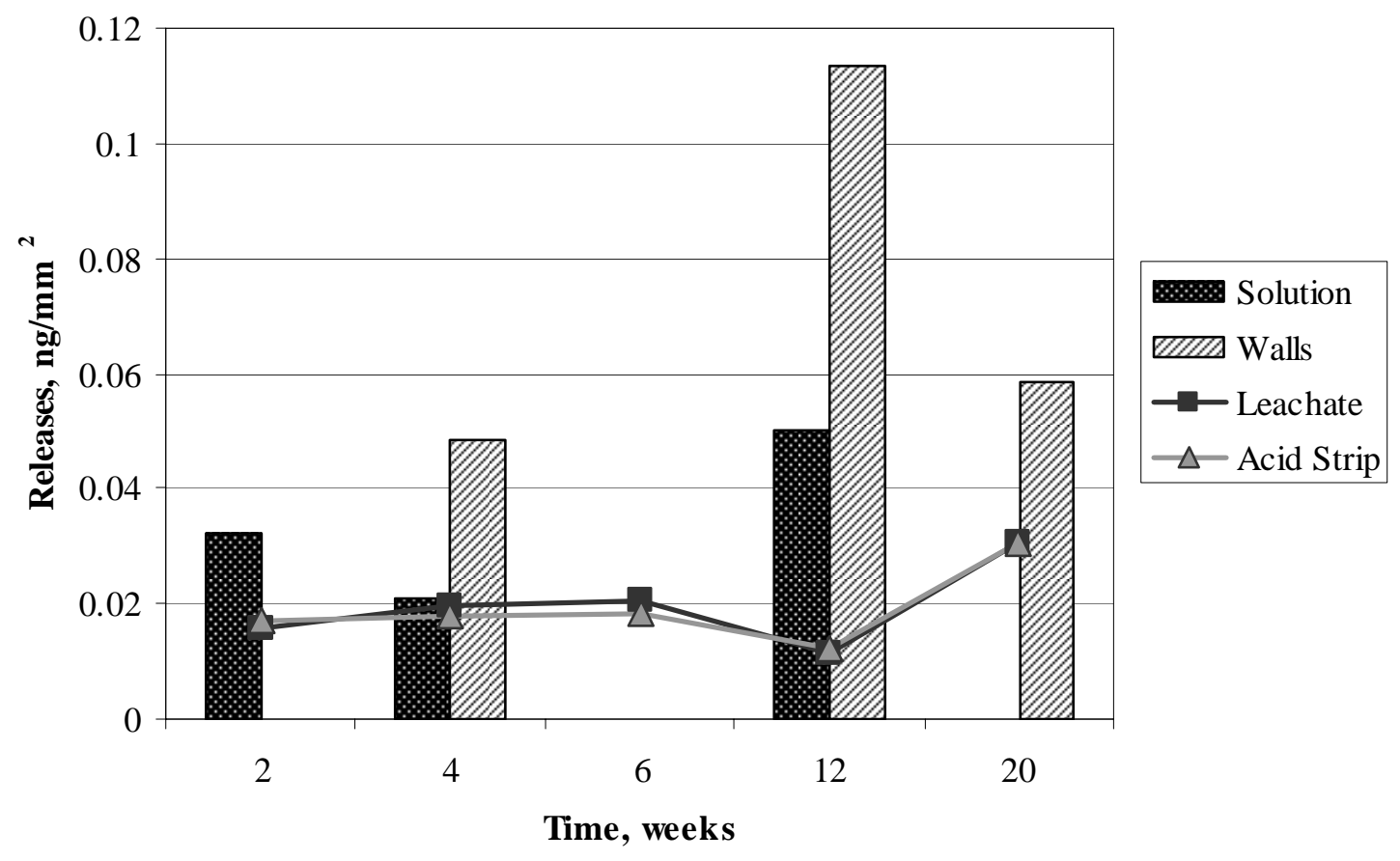

Figure J-37. Niobium Releases in Solution and on Walls from Polished Sample 29 in $10 \mathrm{KCl}$ Solution at Room Temperature and Average Detection Limits for Leachate and Acid Strip.

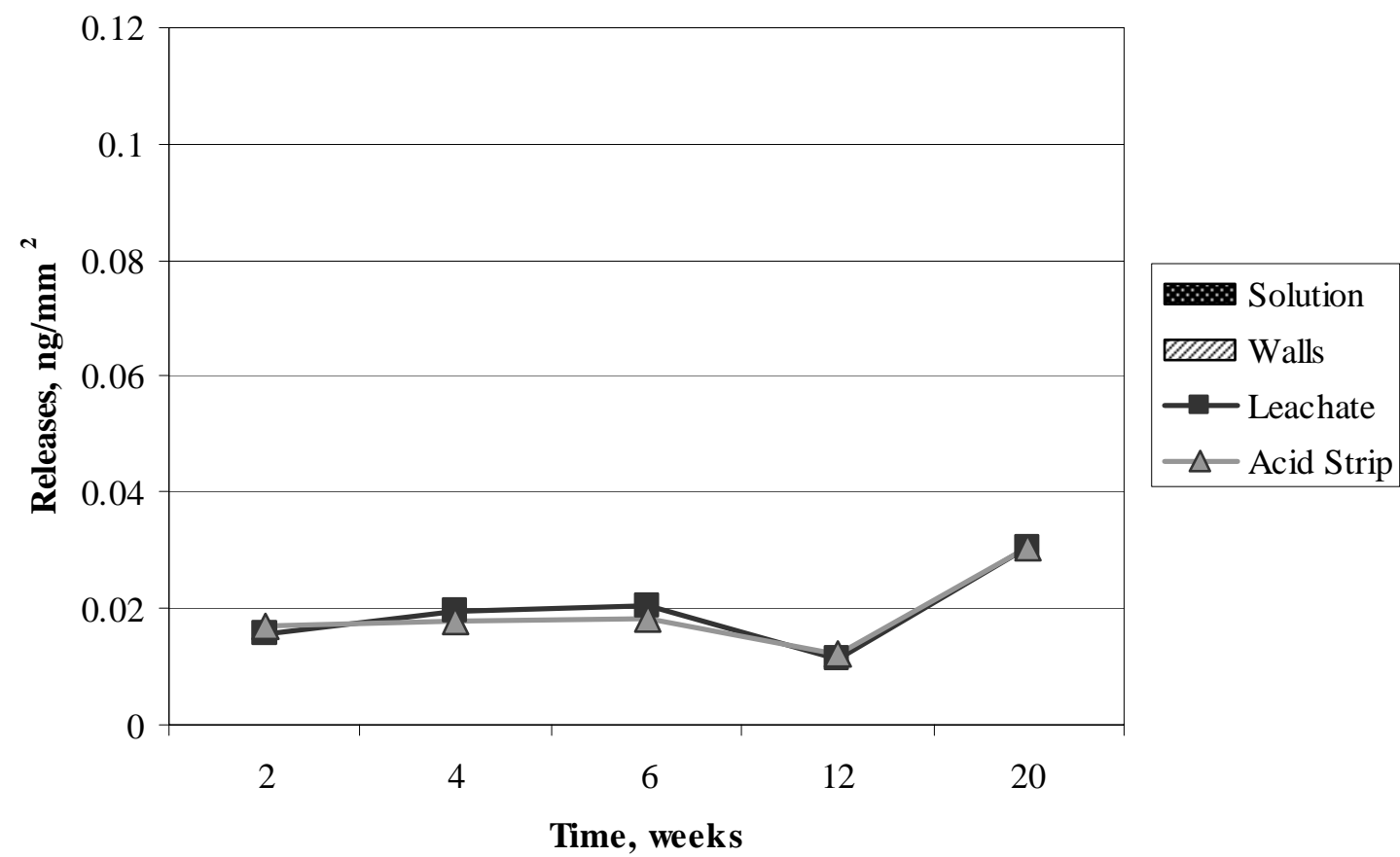

Figure J-38. Niobium Present in Solutions and on Walls in 10KCl Solution Control at Room Temperature and Average Detection Limits for Leachate and Acid Strip. 


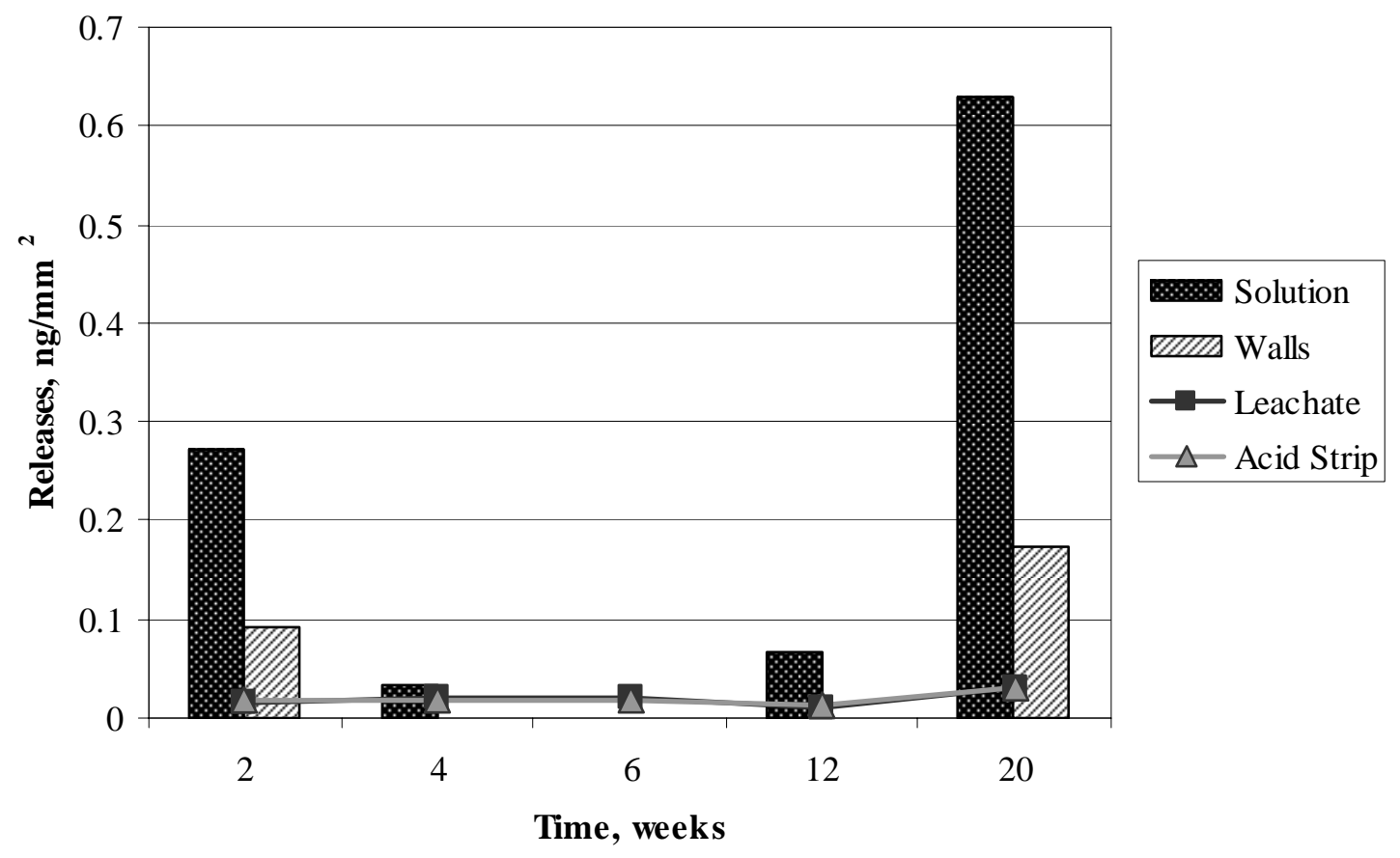

Figure J-39. Niobium Releases in Solution and on Walls from Polished Sample 31 in AJ13 Solution at Room Temperature and Average Detection Limits for Leachate and Acid Strip.

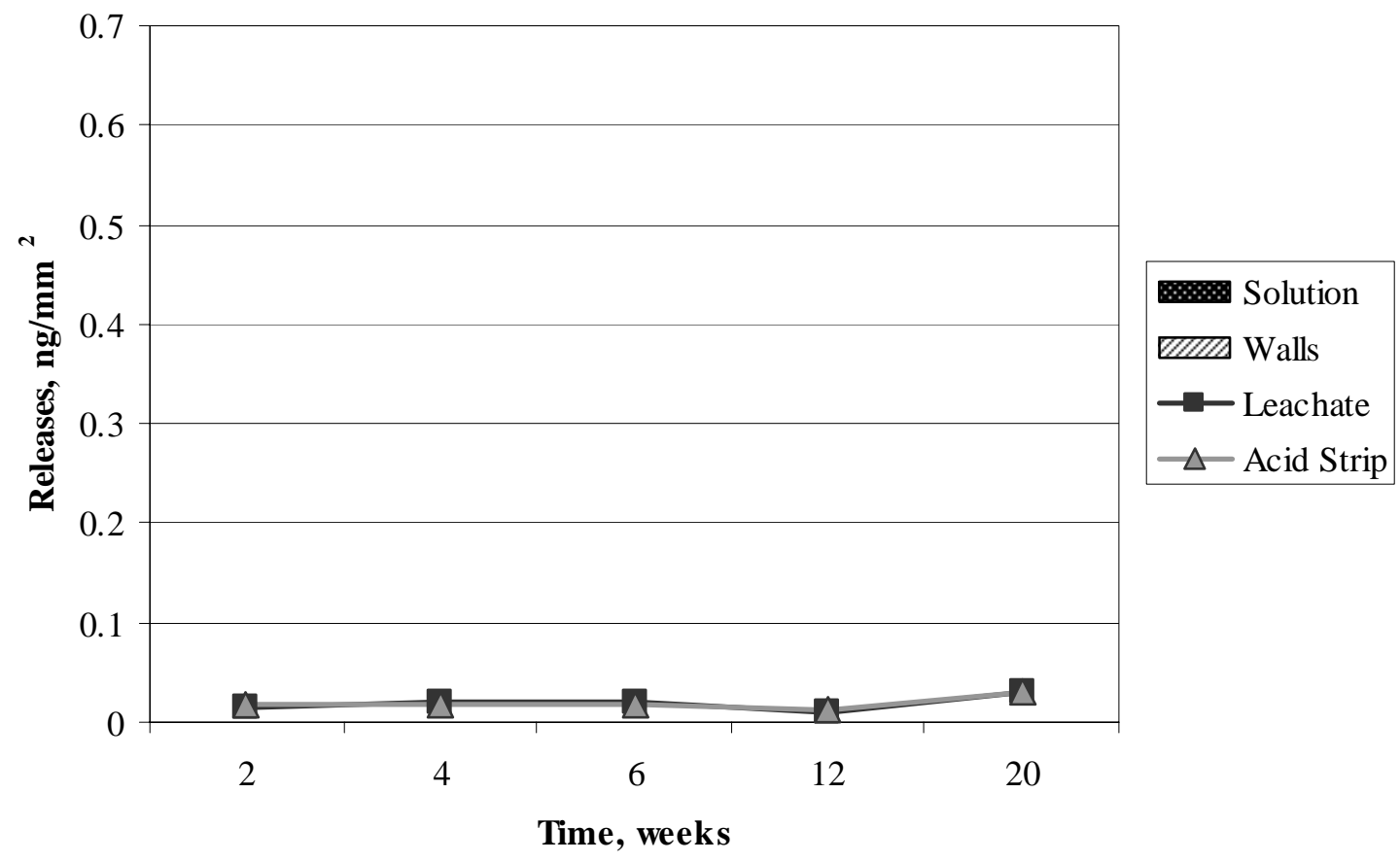

Figure J-40. Niobium Present in Solutions and on Walls in AJ13 Solution Control at Room Temperature and Average Detection Limits for Leachate and Acid Strip. 


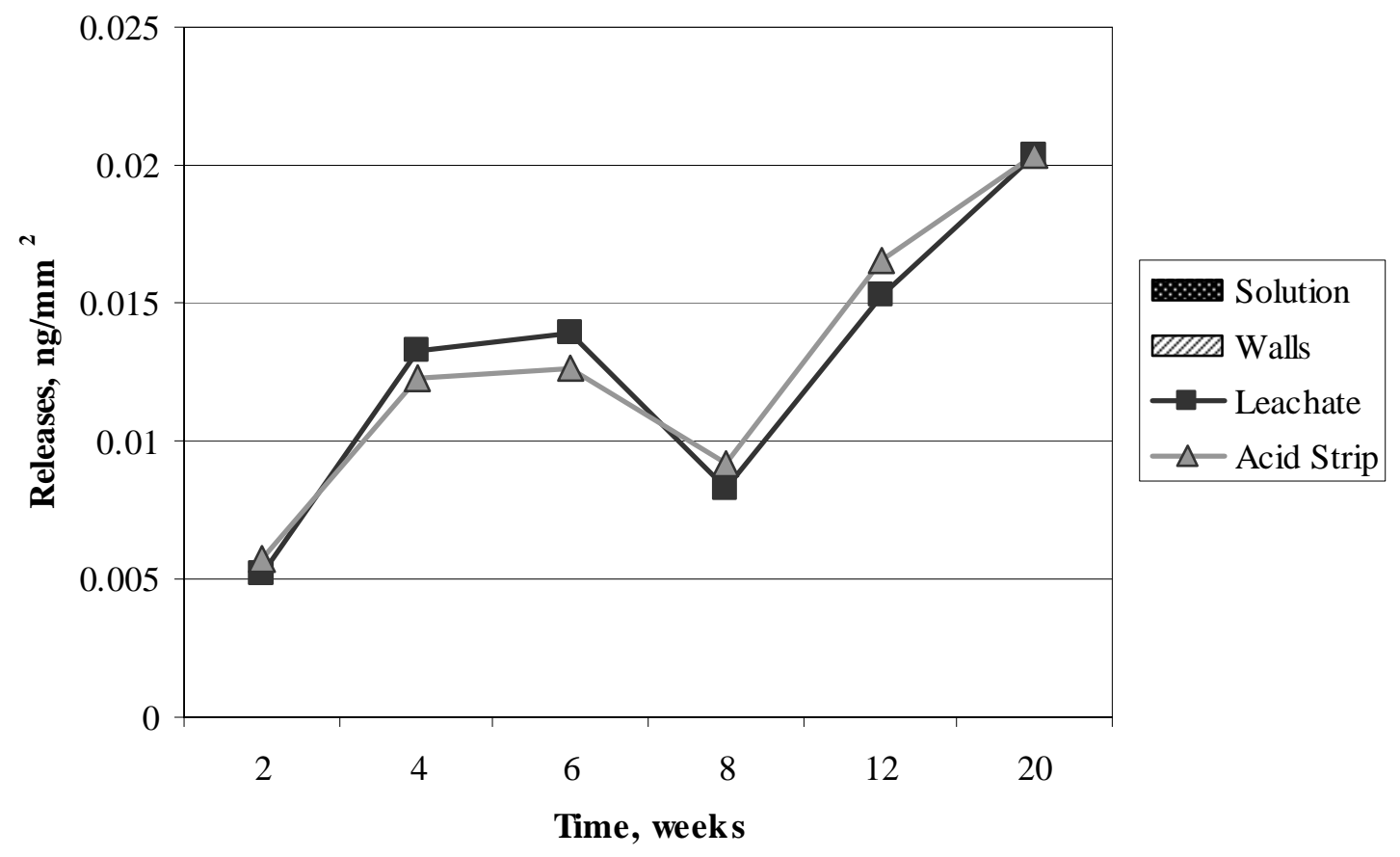

Figure J-41. Palladium Releases in Solution and on Walls from Polished Sample 25 in $1 \mathrm{KCl}$ Solution at $90^{\circ} \mathrm{C}$ and Average Detection Limits for Leachate and Acid Strip.

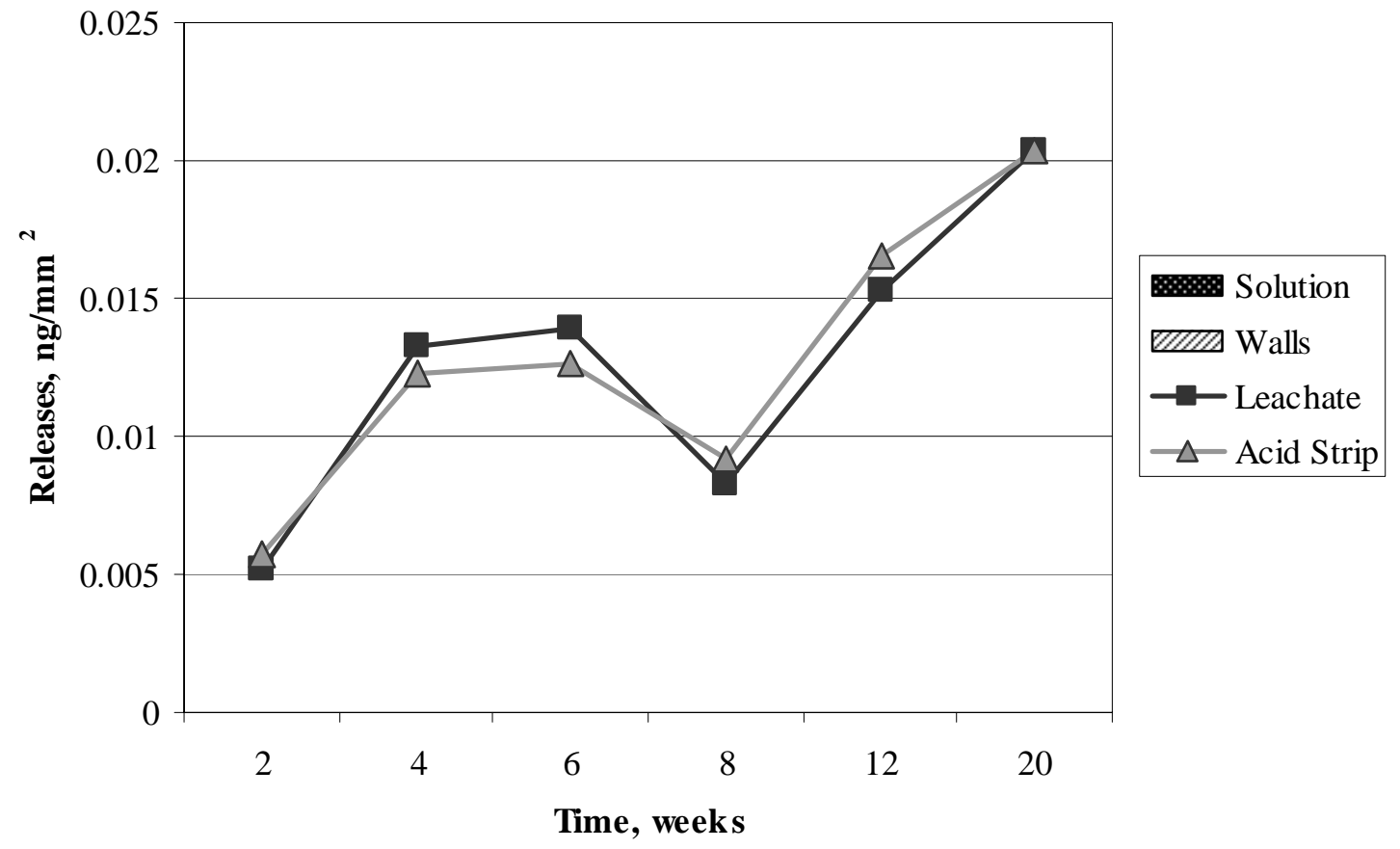

Figure J-42. Palladium Present in Solutions and on Walls in 1KCl Solution Control at $90^{\circ} \mathrm{C}$ and Average Detection Limits for Leachate and Acid Strip. 


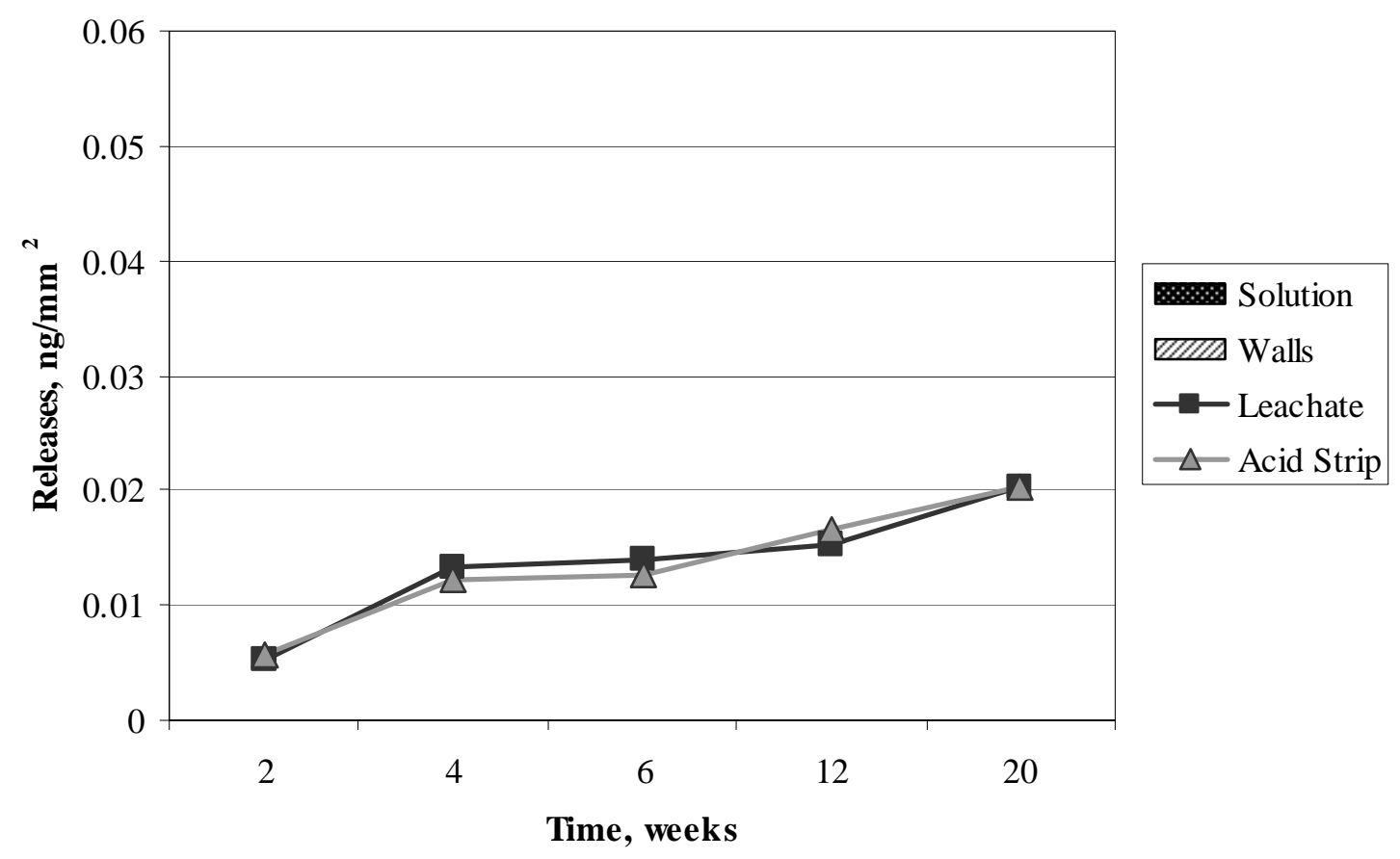

Figure J-43. Palladium Releases in Solution and on Walls from Polished Sample 27 in $1 \mathrm{KCl}$ Solution at Room Temperature and Average Detection Limits for Leachate and Acid Strip.

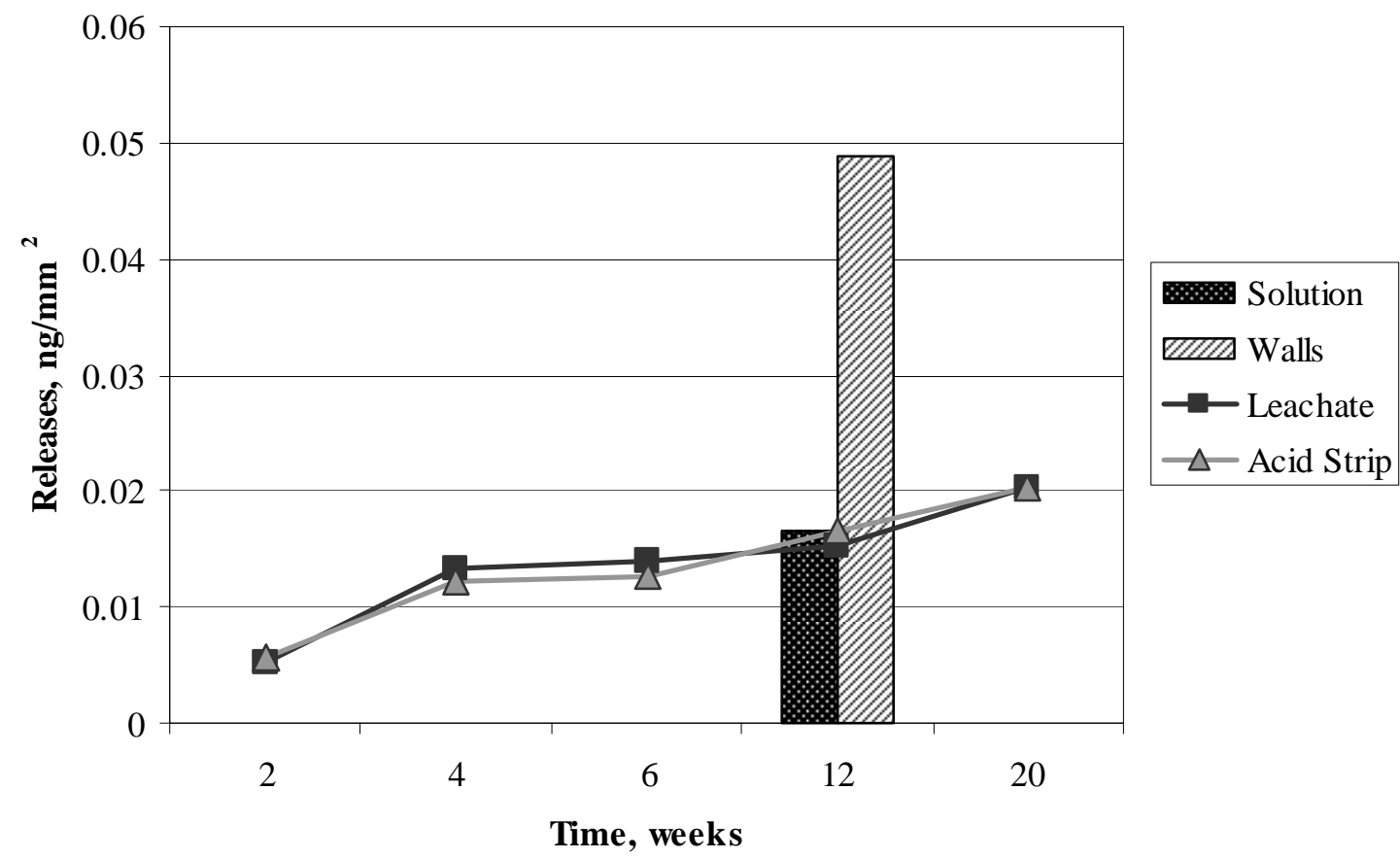

Figure J-44. Palladium Present in Solutions and on Walls in $1 \mathrm{KCl}$ Solution Control at Room Temperature and Average Detection Limits for Leachate and Acid Strip. 


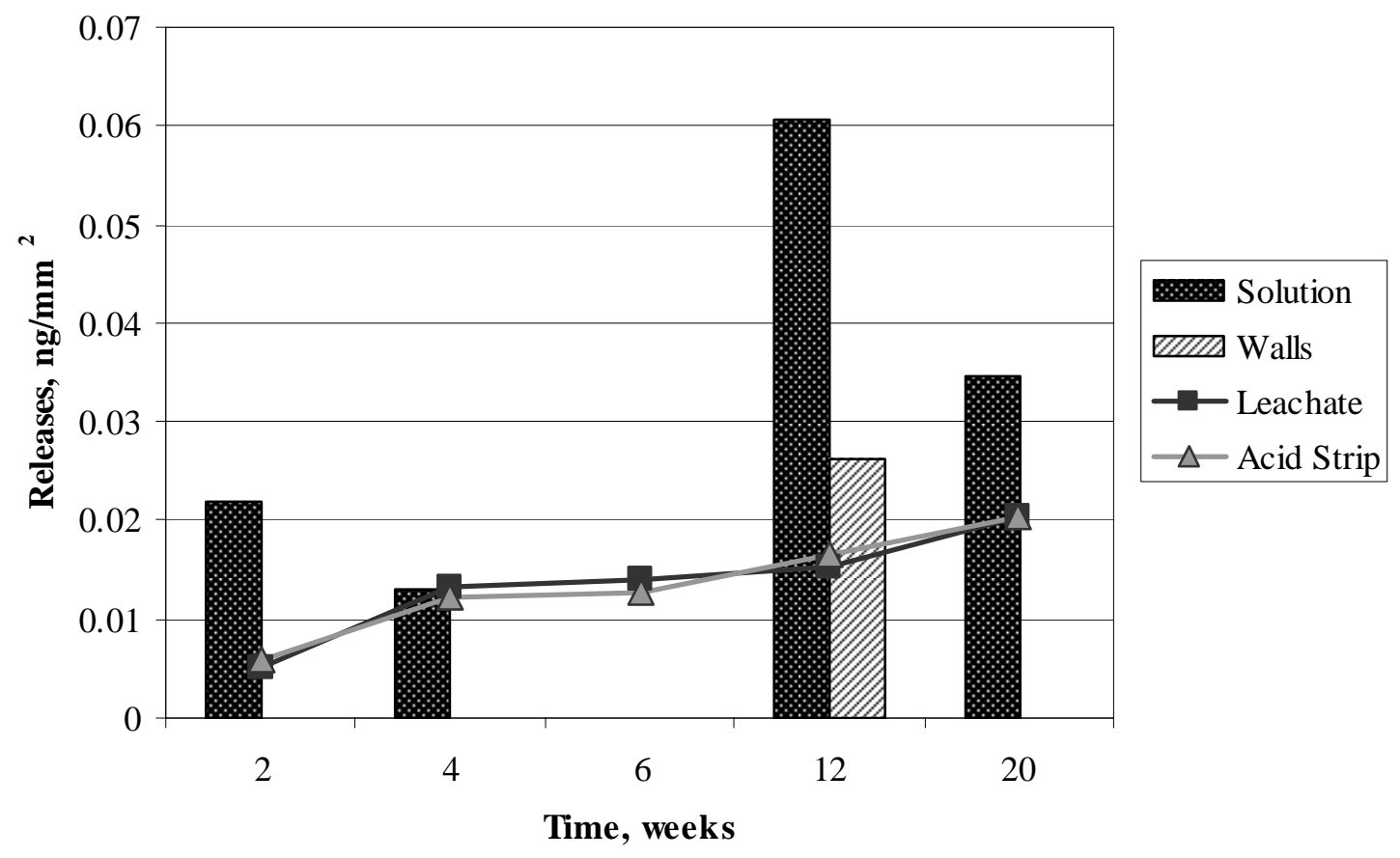

Figure J-45. Palladium Releases in Solution and on Walls from Polished Sample 29 in 10KCl Solution at Room Temperature and Average Detection Limits for Leachate and Acid Strip.

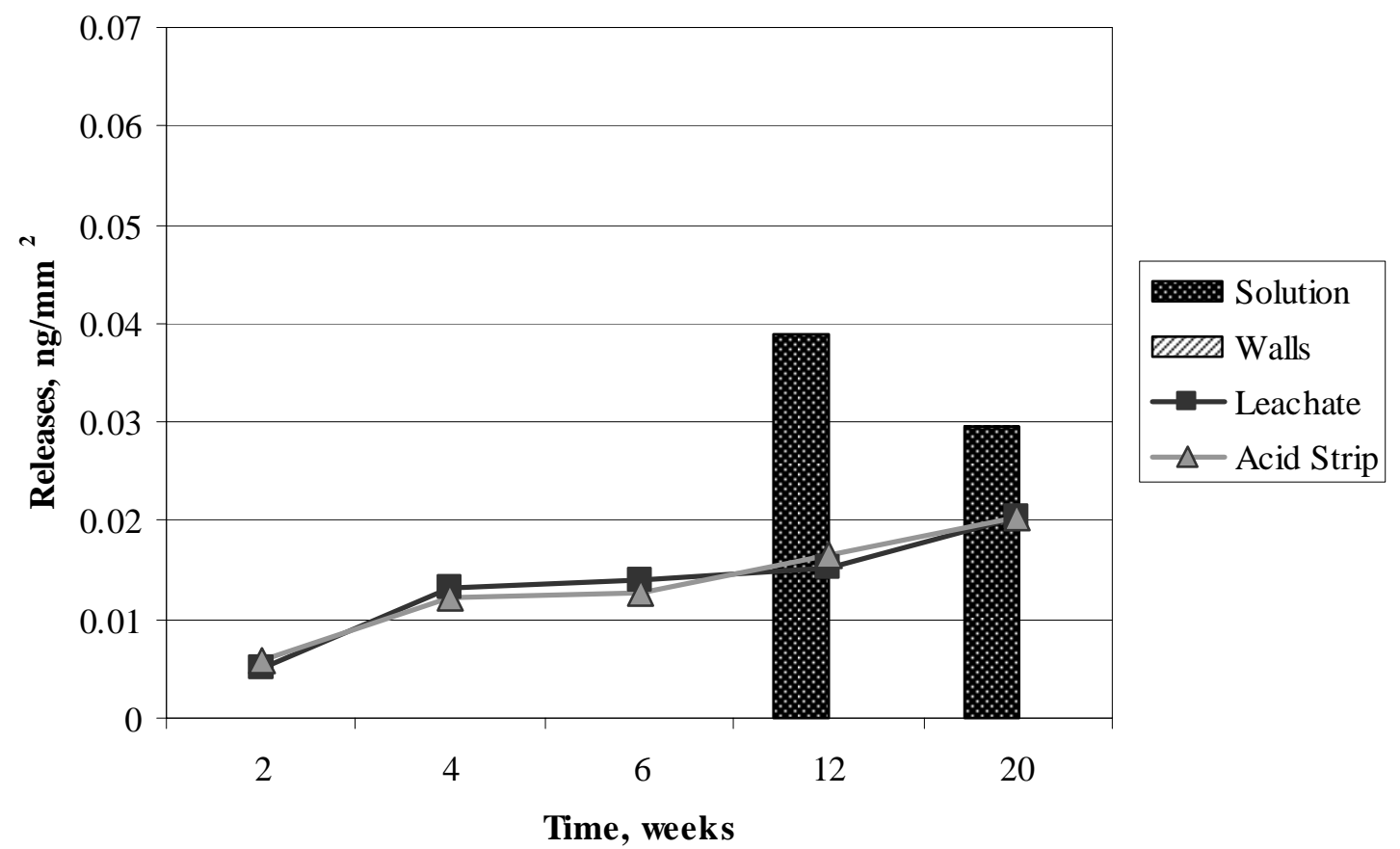

Figure J-46. Palladium Present in Solutions and on Walls in 10KCl Solution Control at Room Temperature and Average Detection Limits for Leachate and Acid Strip. 


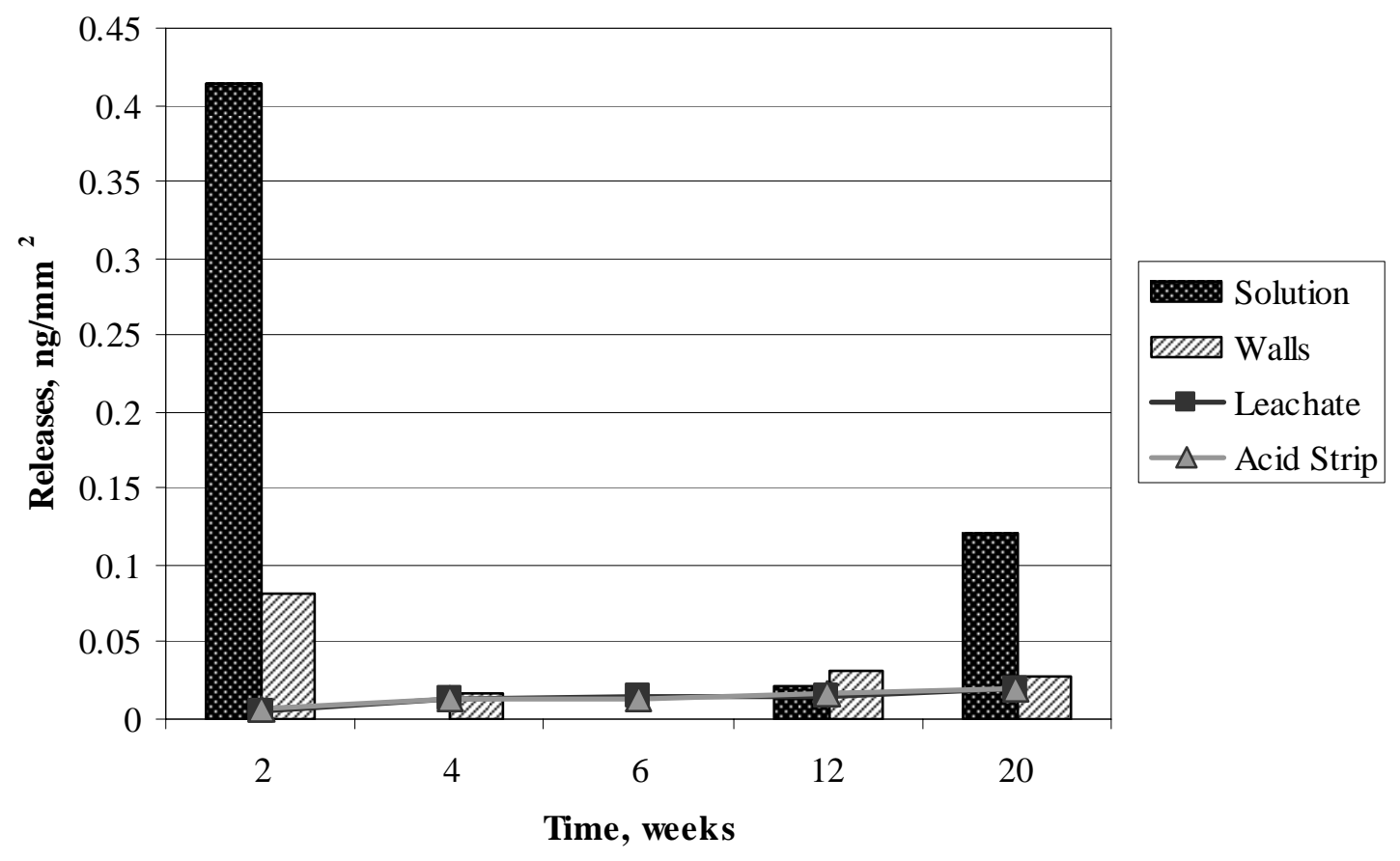

Figure J-47. Palladium Releases in Solution and on Walls from Polished Sample 31 in AJ13 Solution at Room Temperature and Average Detection Limits for Leachate and Acid Strip.

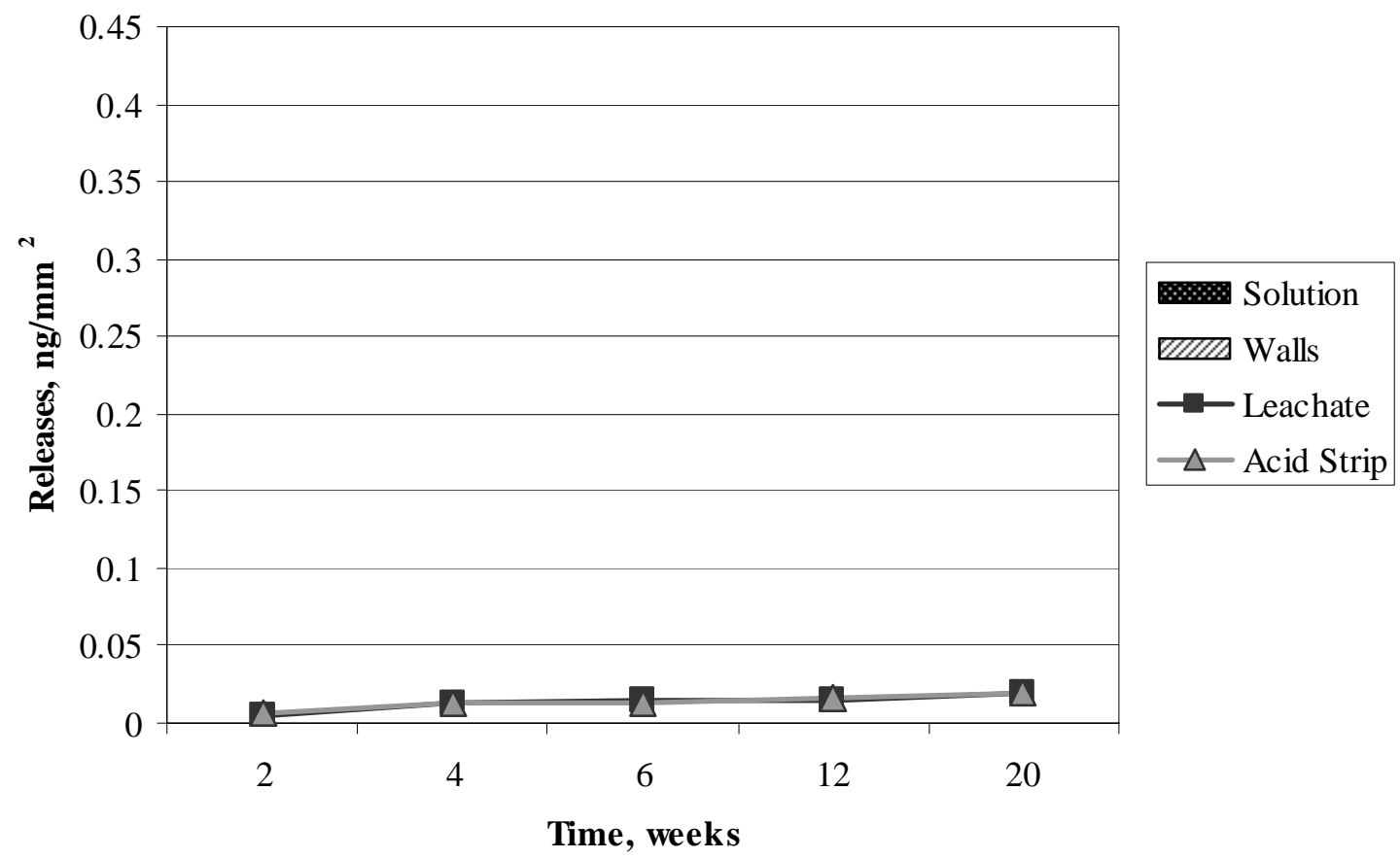

Figure J-48. Palladium Present in Solutions and on Walls in AJ13 Solution Control at Room Temperature and Average Detection Limits for Leachate and Acid Strip. 


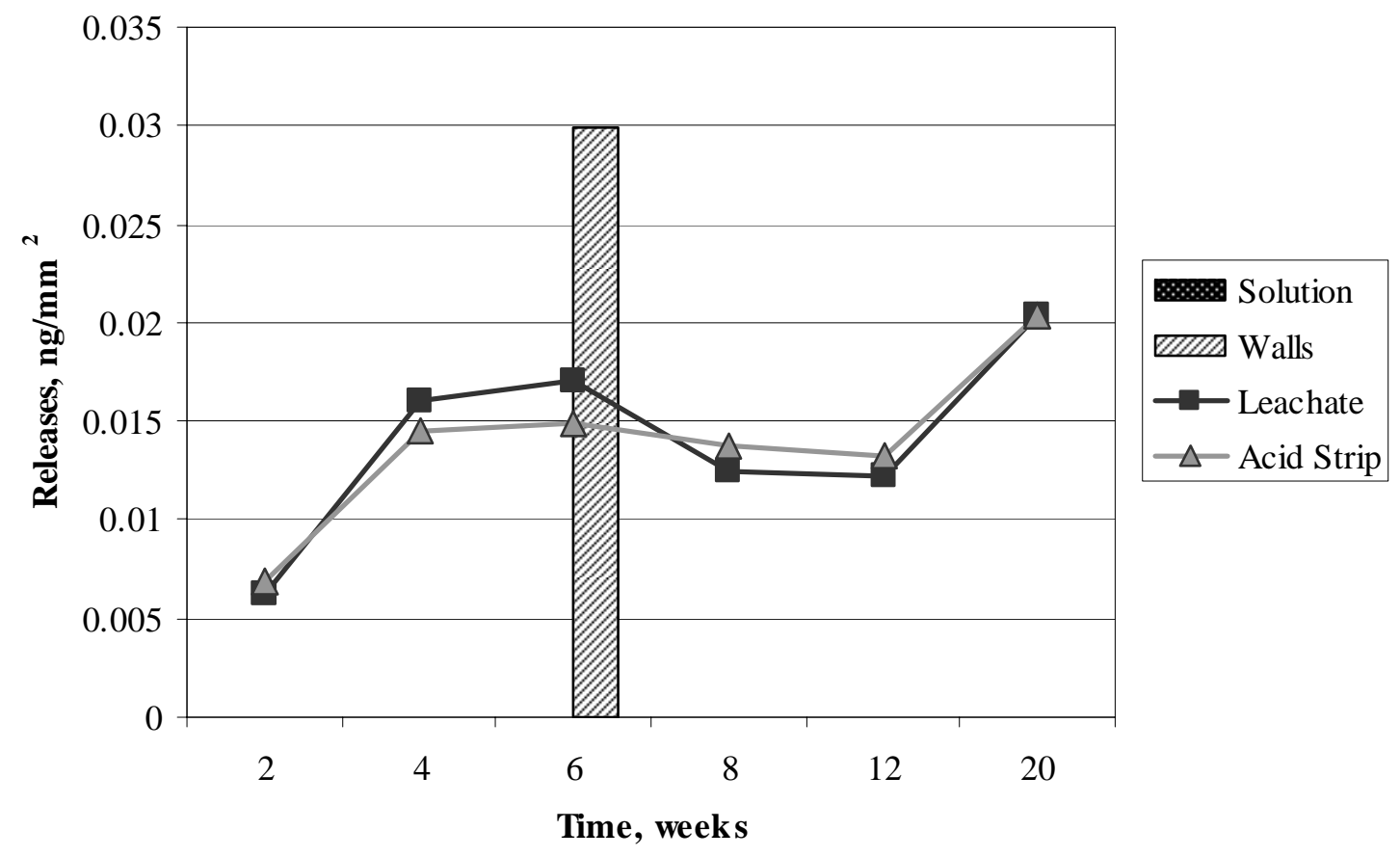

Figure J-49. Rhodium Releases in Solution and on Walls from Polished Sample 25 in $1 \mathrm{KCl}$ Solution at $90^{\circ} \mathrm{C}$ and Average Detection Limits for Leachate and Acid Strip.

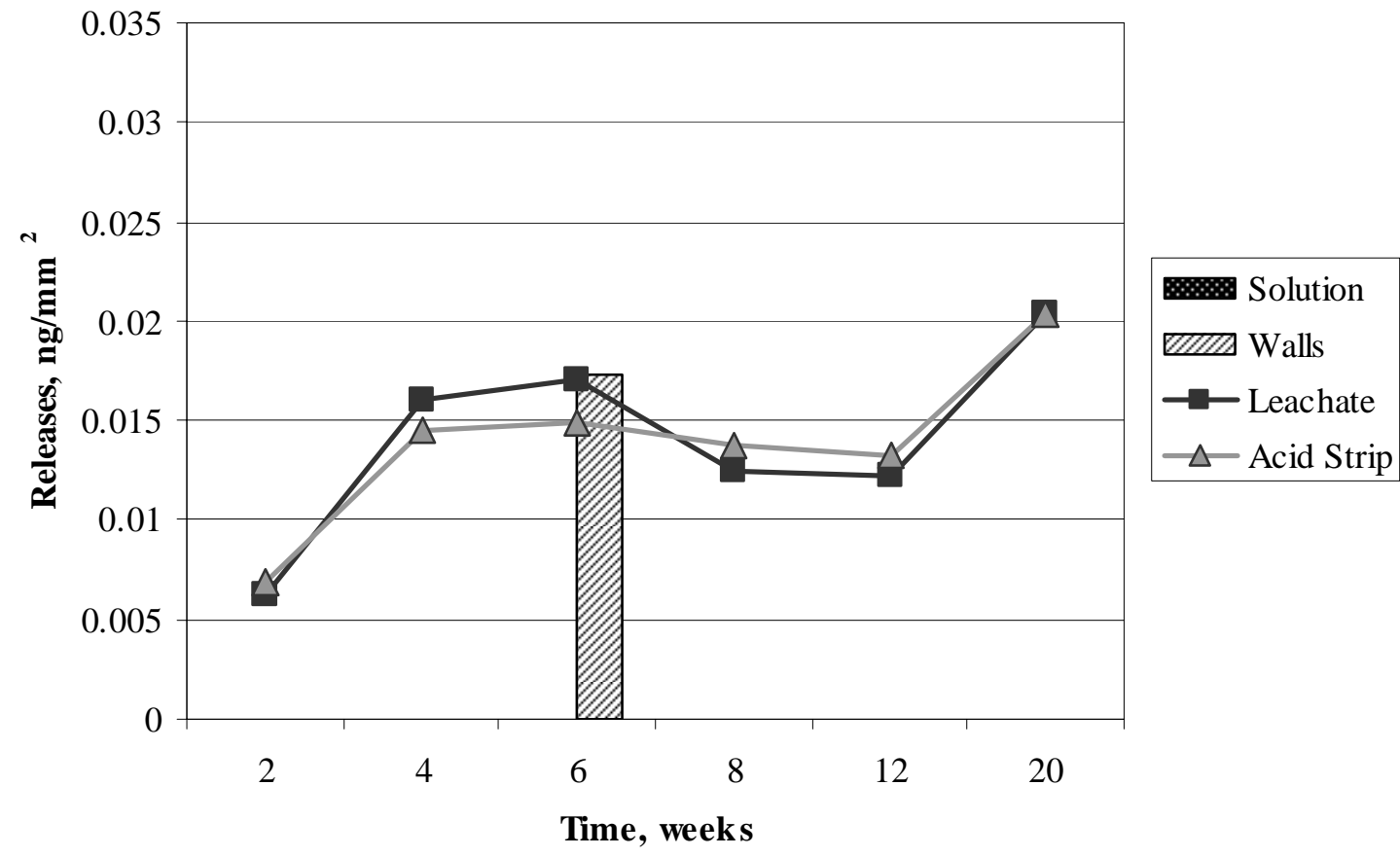

Figure J-50. Rhodium Present in Solutions and on Walls in 1KCI Solution Control at $90^{\circ} \mathrm{C}$ and Average Detection Limits for Leachate and Acid Strip. 


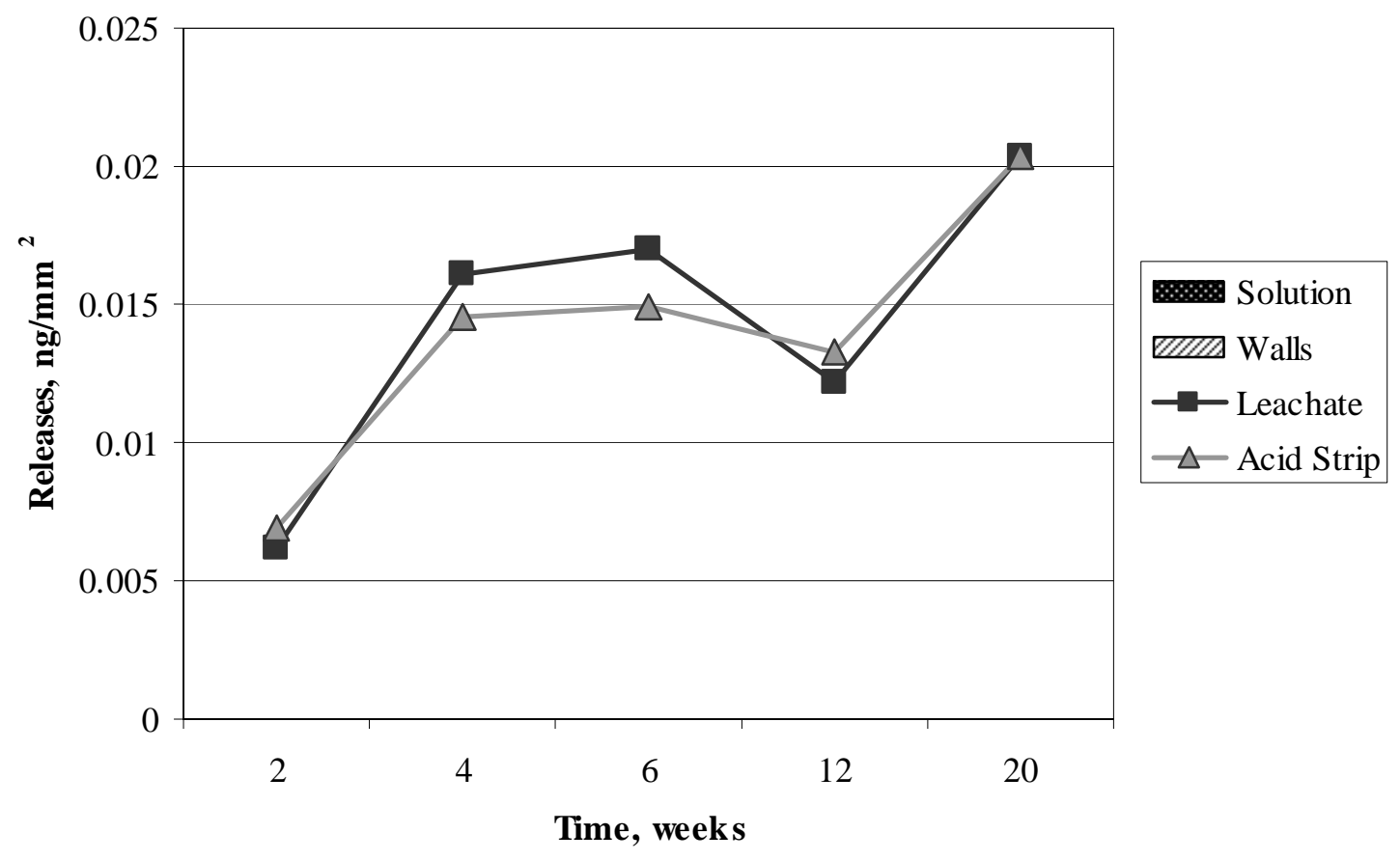

Figure J-51. Rhodium Releases in Solution and on Walls from Polished Sample 27 in $1 \mathrm{KCl}$ Solution at Room Temperature and Average Detection Limits for Leachate and Acid Strip.

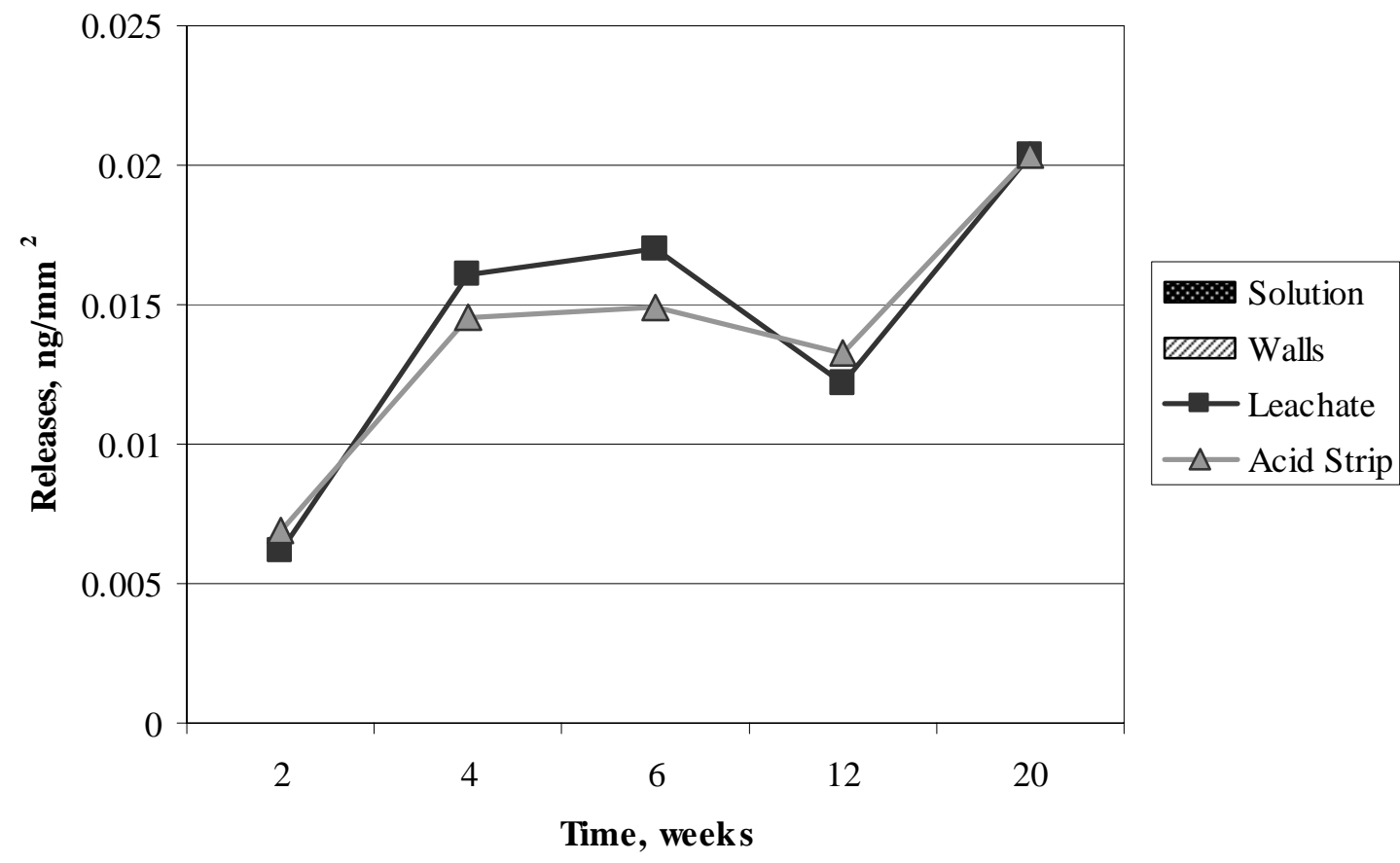

Figure J-52. Rhodium Present in Solutions and on Walls in $1 \mathrm{KCl}$ Solution Control at Room Temperature and Average Detection Limits for Leachate and Acid Strip. 


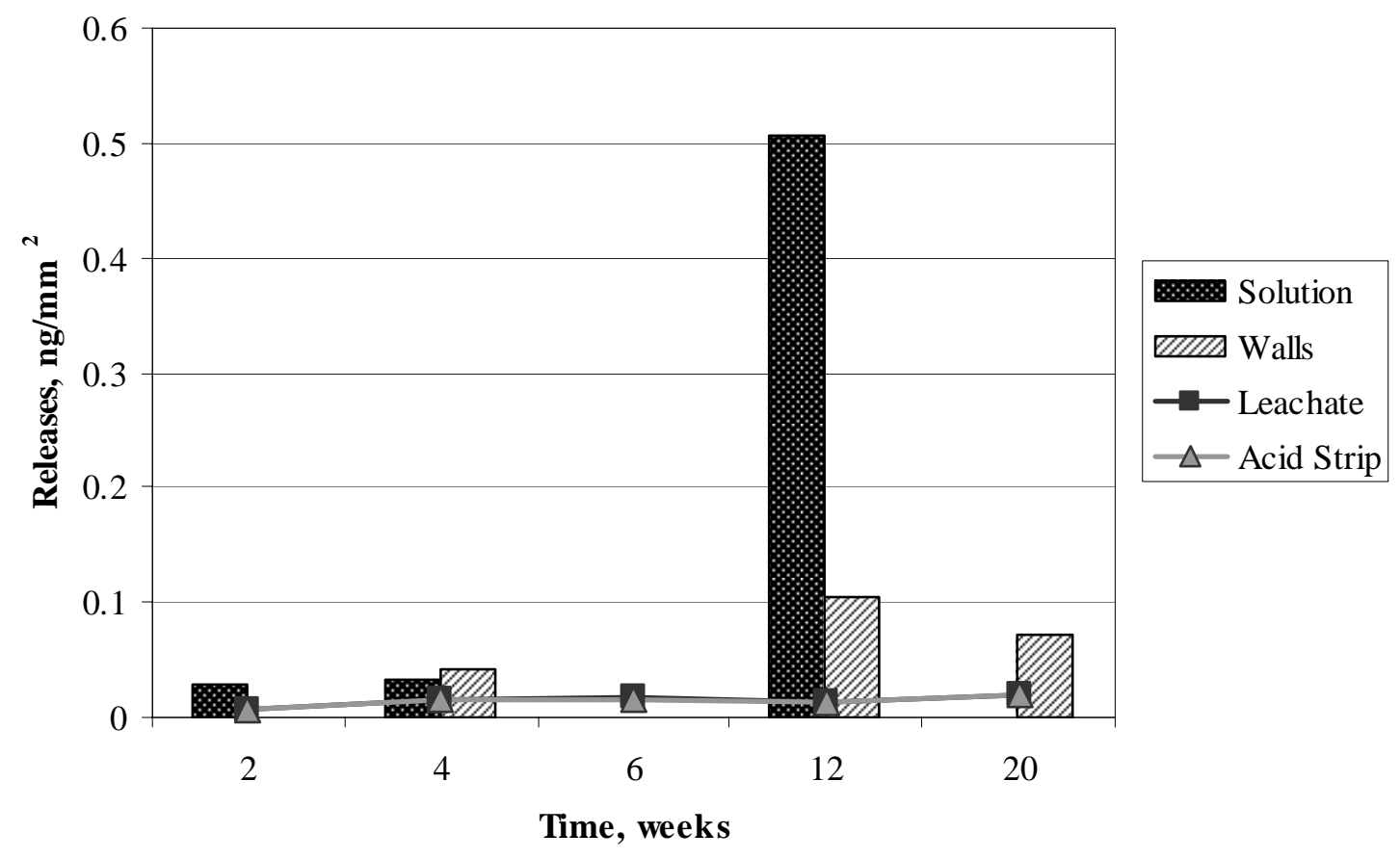

Figure J-53. Rhodium Releases in Solution and on Walls from Polished Sample 29 in 10KCl Solution at Room Temperature and Average Detection Limits for Leachate and Acid Strip.

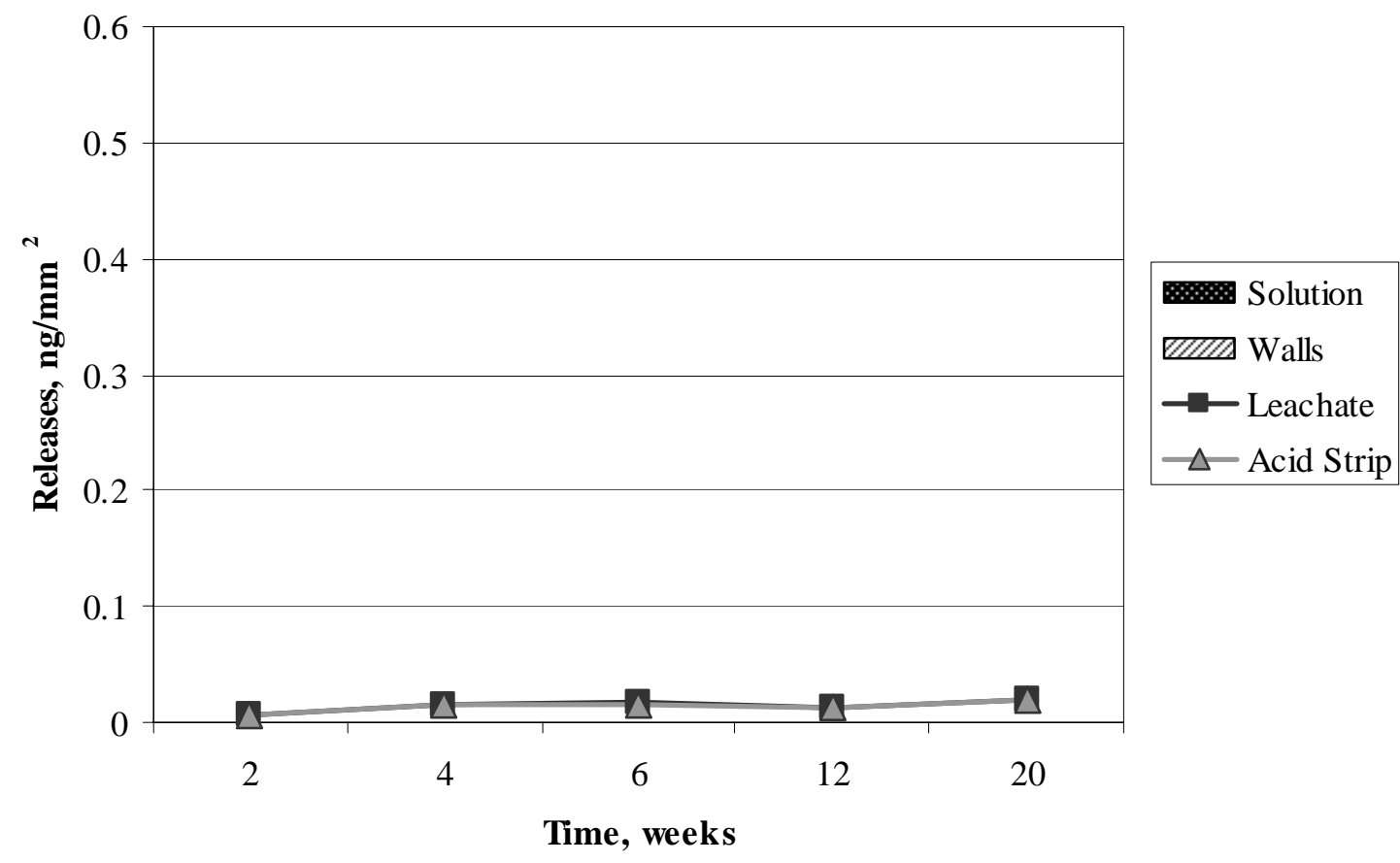

Figure J-54. Rhodium Present in Solutions and on Walls in 10KCI Solution Control at Room Temperature and Average Detection Limits for Leachate and Acid Strip. 


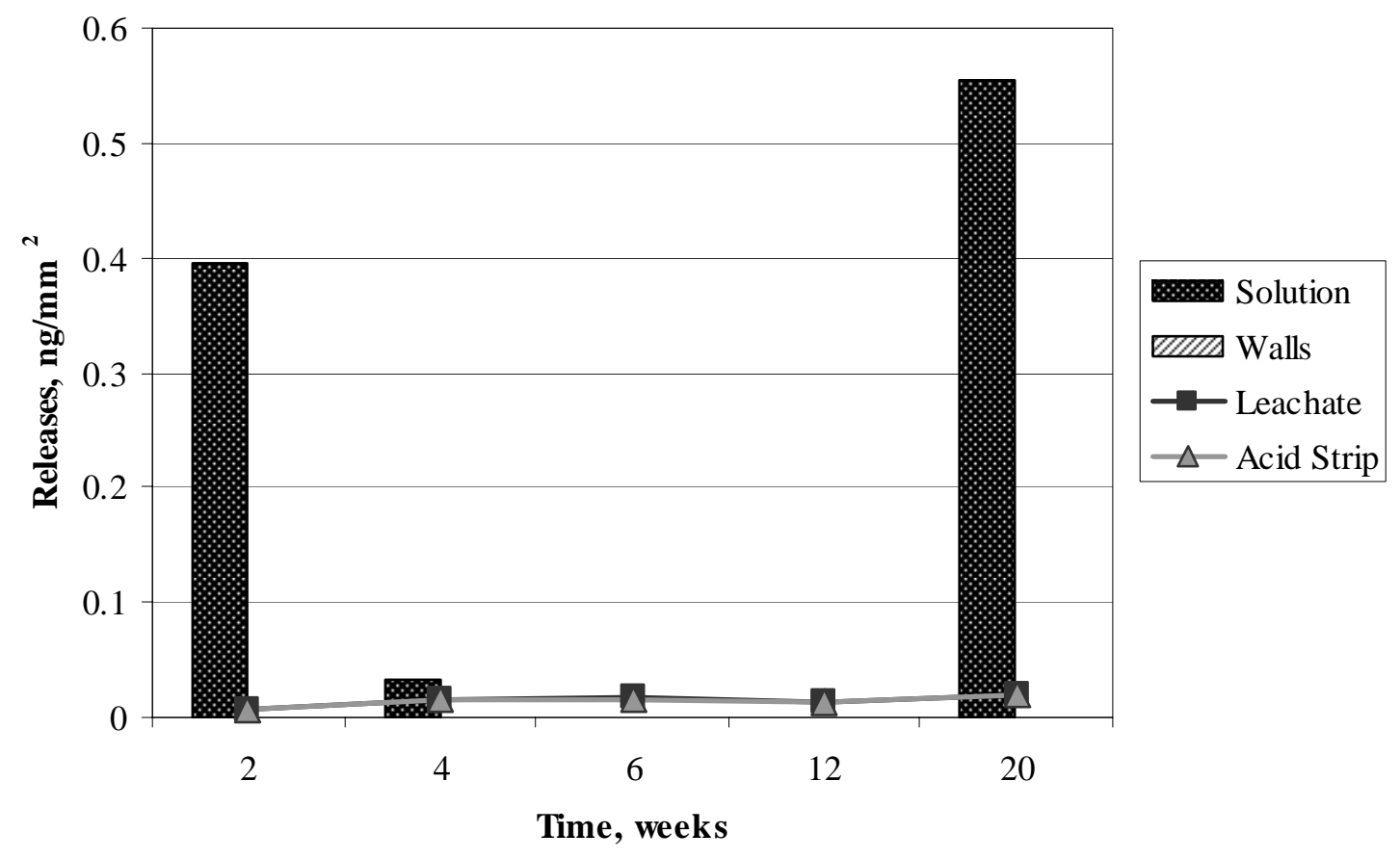

Figure J-55. Rhodium Releases in Solution and on Walls from Polished Sample 31 in AJ13 Solution at Room Temperature and Average Detection Limits for Leachate and Acid Strip.

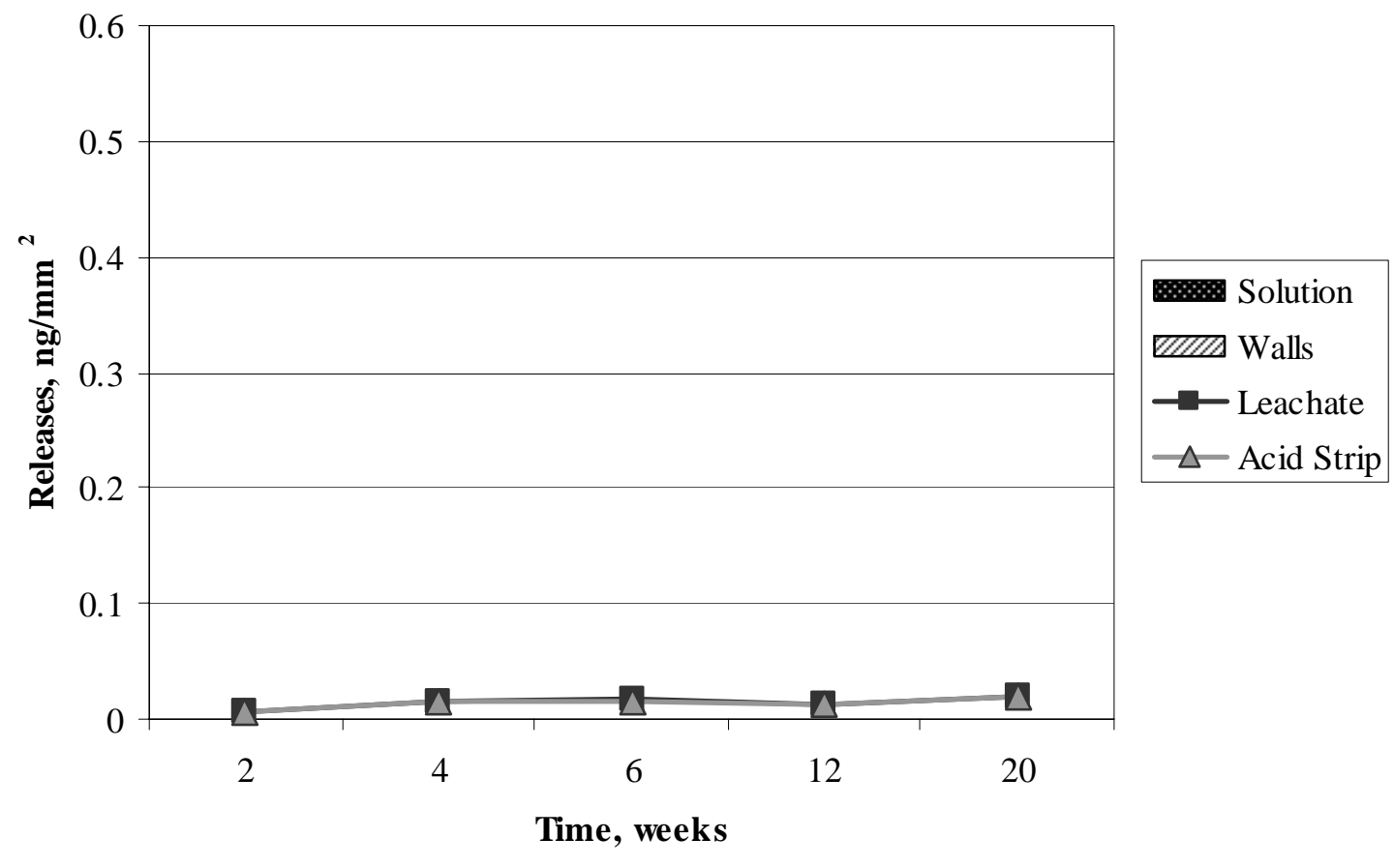

Figure J-56. Rhodium Present in Solutions and on Walls in AJ13 Solution Control at Room Temperature and Average Detection Limits for Leachate and Acid Strip. 


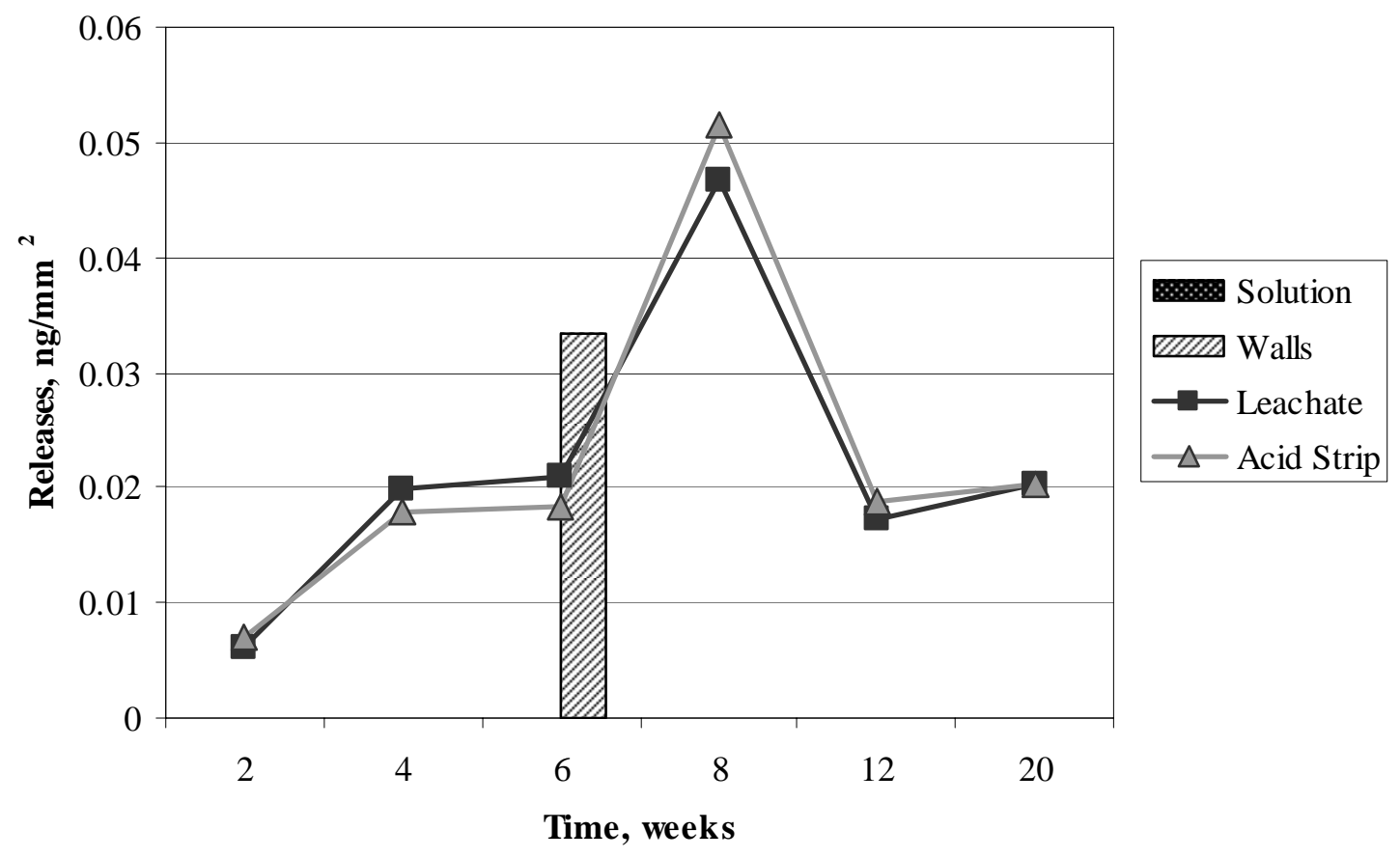

Figure J-57. Ruthenium Releases in Solution and on Walls from Polished Sample 25 in $1 \mathrm{KCl}$ Solution at $90^{\circ} \mathrm{C}$ and Average Detection Limits for Leachate and Acid Strip.

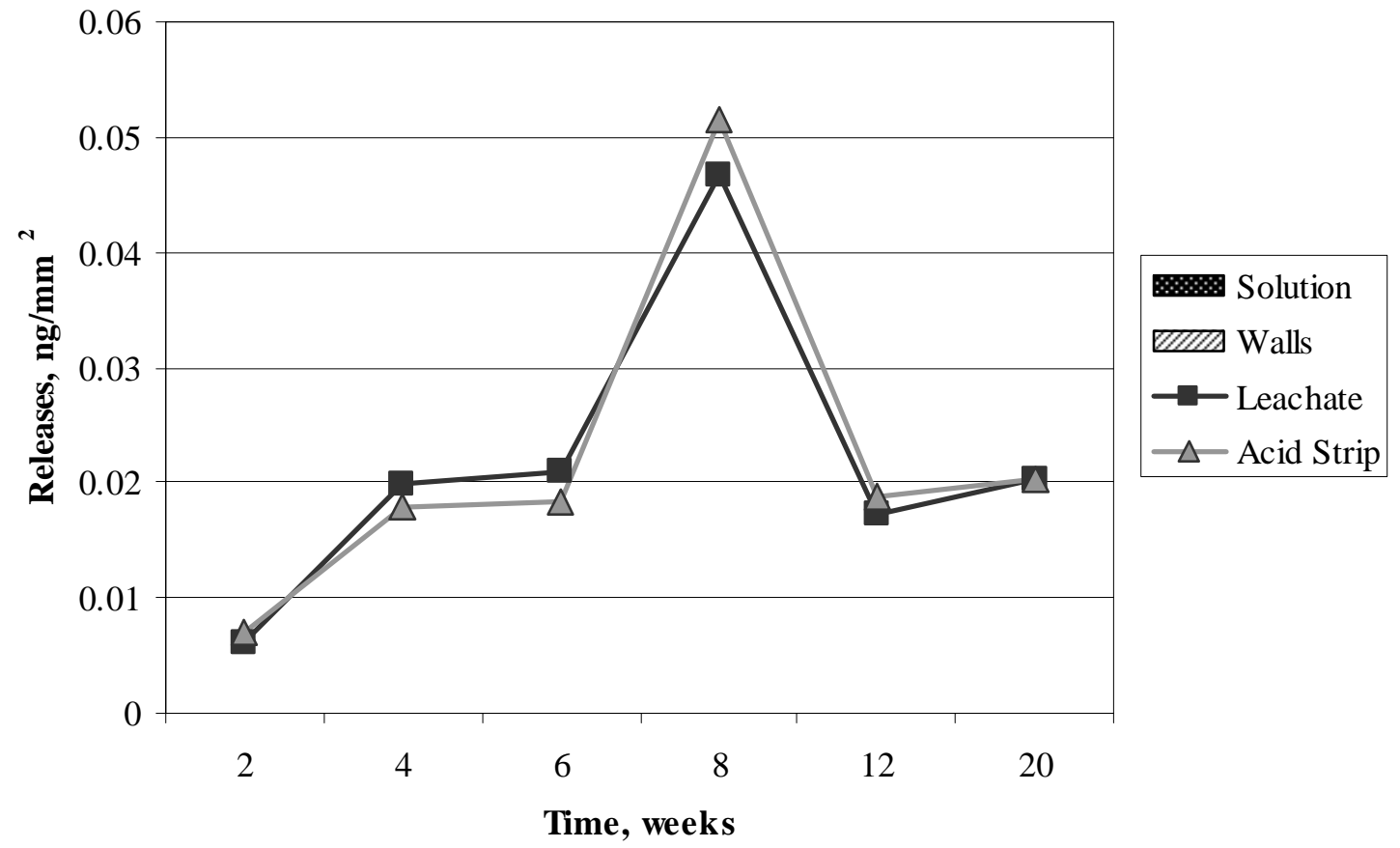

Figure J-58. Ruthenium Present in Solutions and on Walls in 1KCl Solution Control at $90^{\circ} \mathrm{C}$ and Average Detection Limits for Leachate and Acid Strip. 


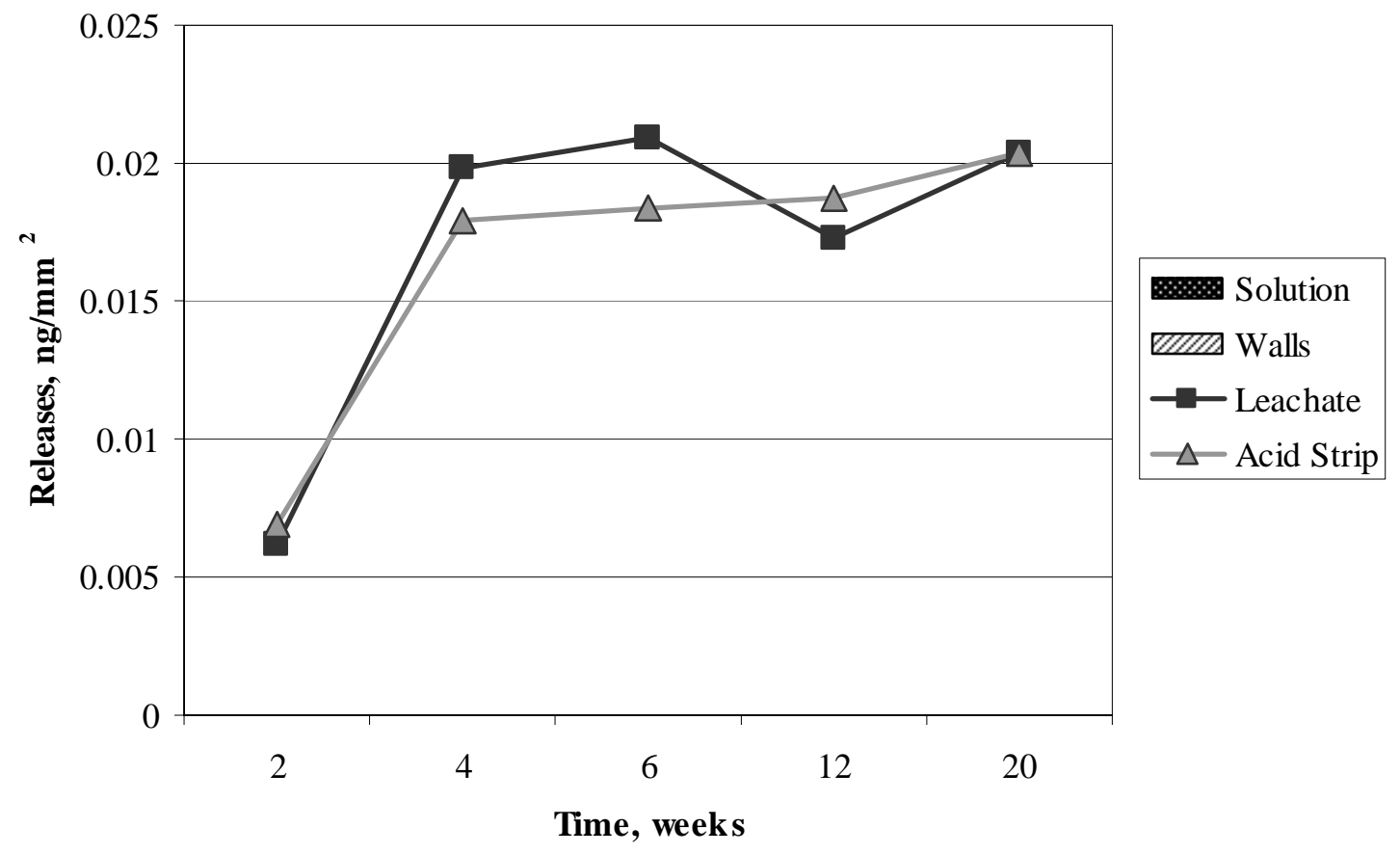

Figure J-59. Ruthenium Releases in Solution and on Walls from Polished Sample 27 in $1 \mathrm{KCl}$ Solution at Room Temperature and Average Detection Limits for Leachate and Acid Strip.

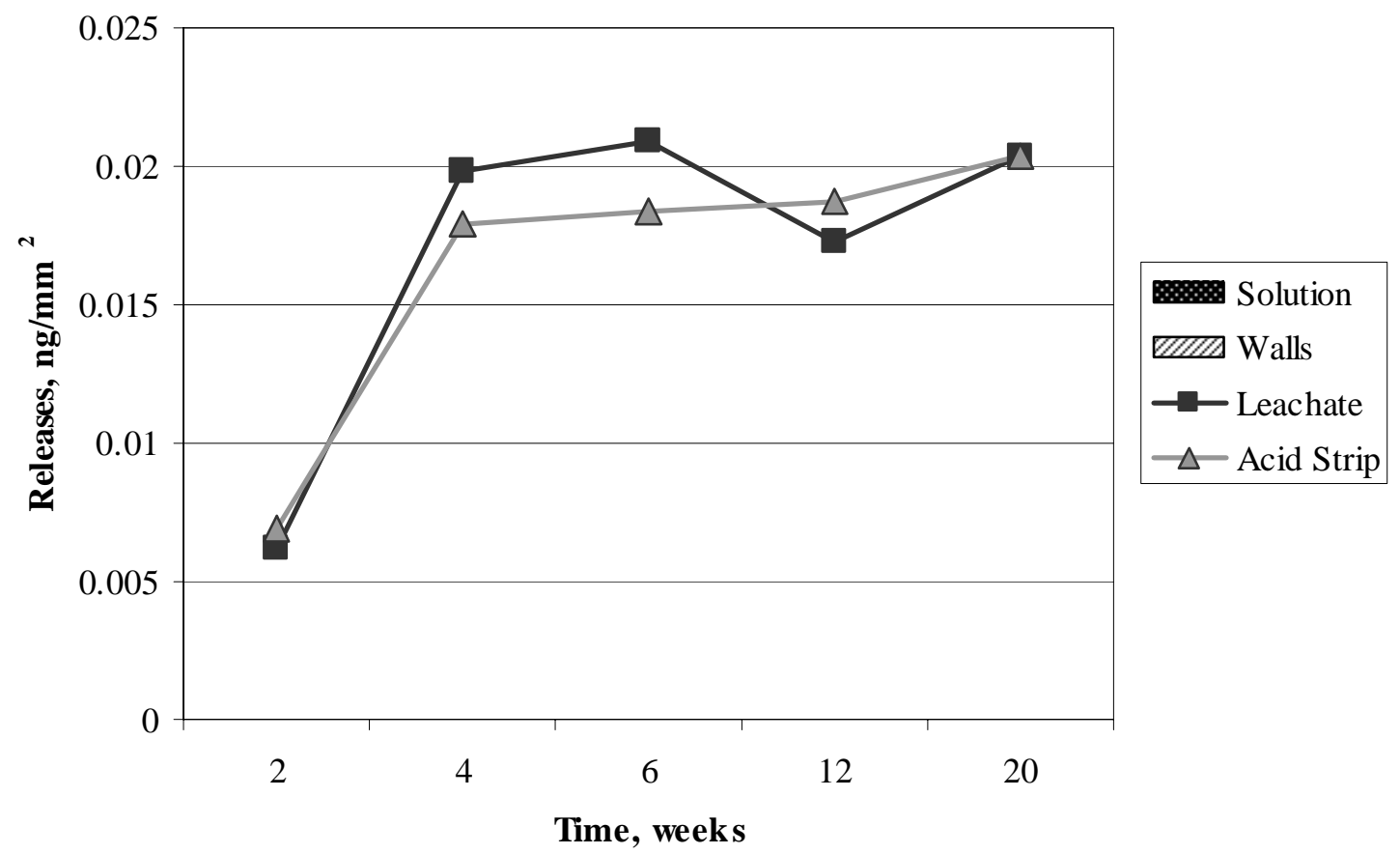

Figure J-60. Ruthenium Present in Solutions and on Walls in 1KCl Solution Control at Room Temperature and Average Detection Limits for Leachate and Acid Strip. 


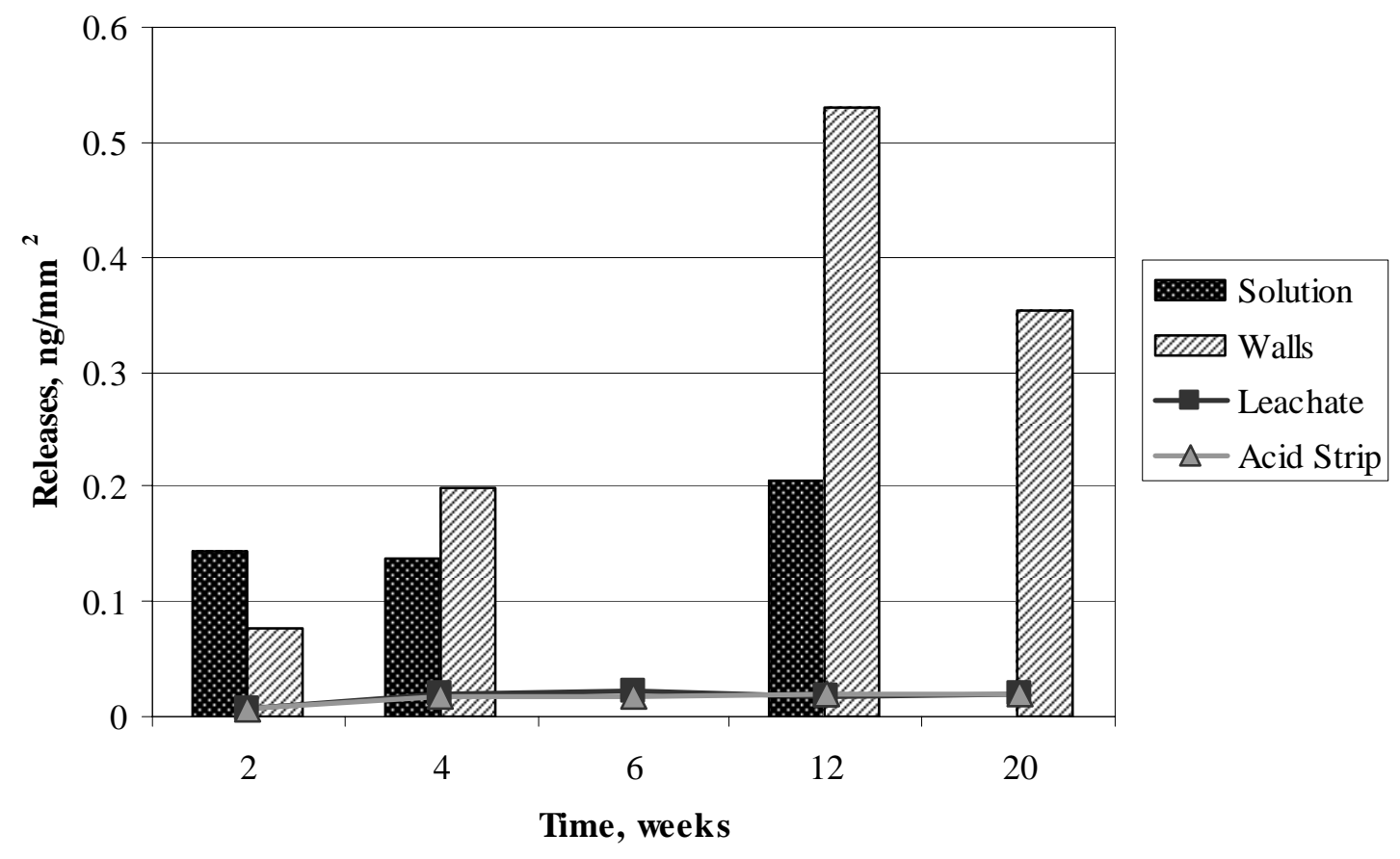

Figure J-61. Ruthenium Releases in Solution and on Walls from Polished Sample 29 in $10 \mathrm{KCl}$ Solution at Room Temperature and Average Detection Limits for Leachate and Acid Strip.

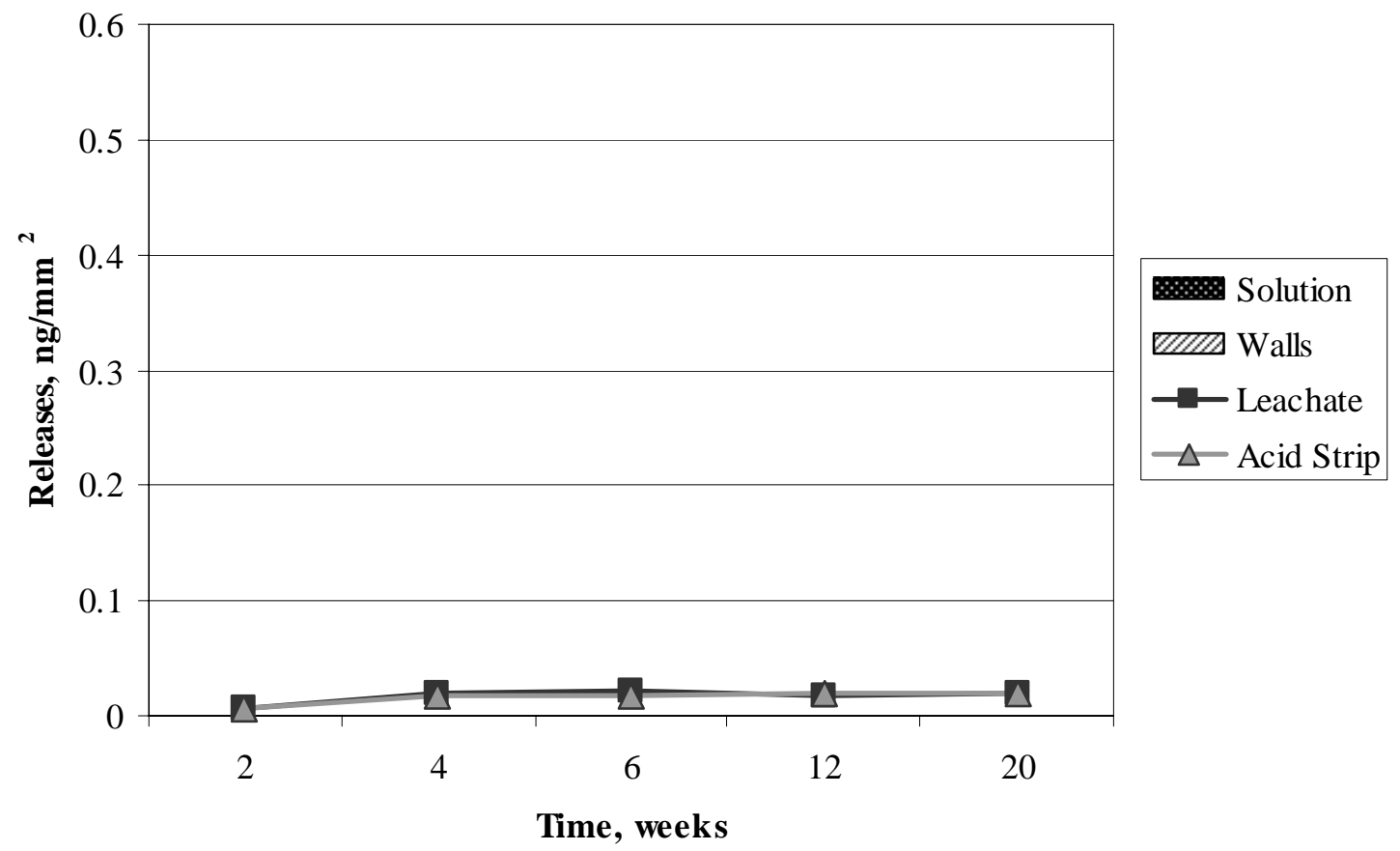

Figure J-62. Ruthenium Present in Solutions and on Walls in 10KCI Solution Control at Room Temperature and Average Detection Limits for Leachate and Acid Strip. 


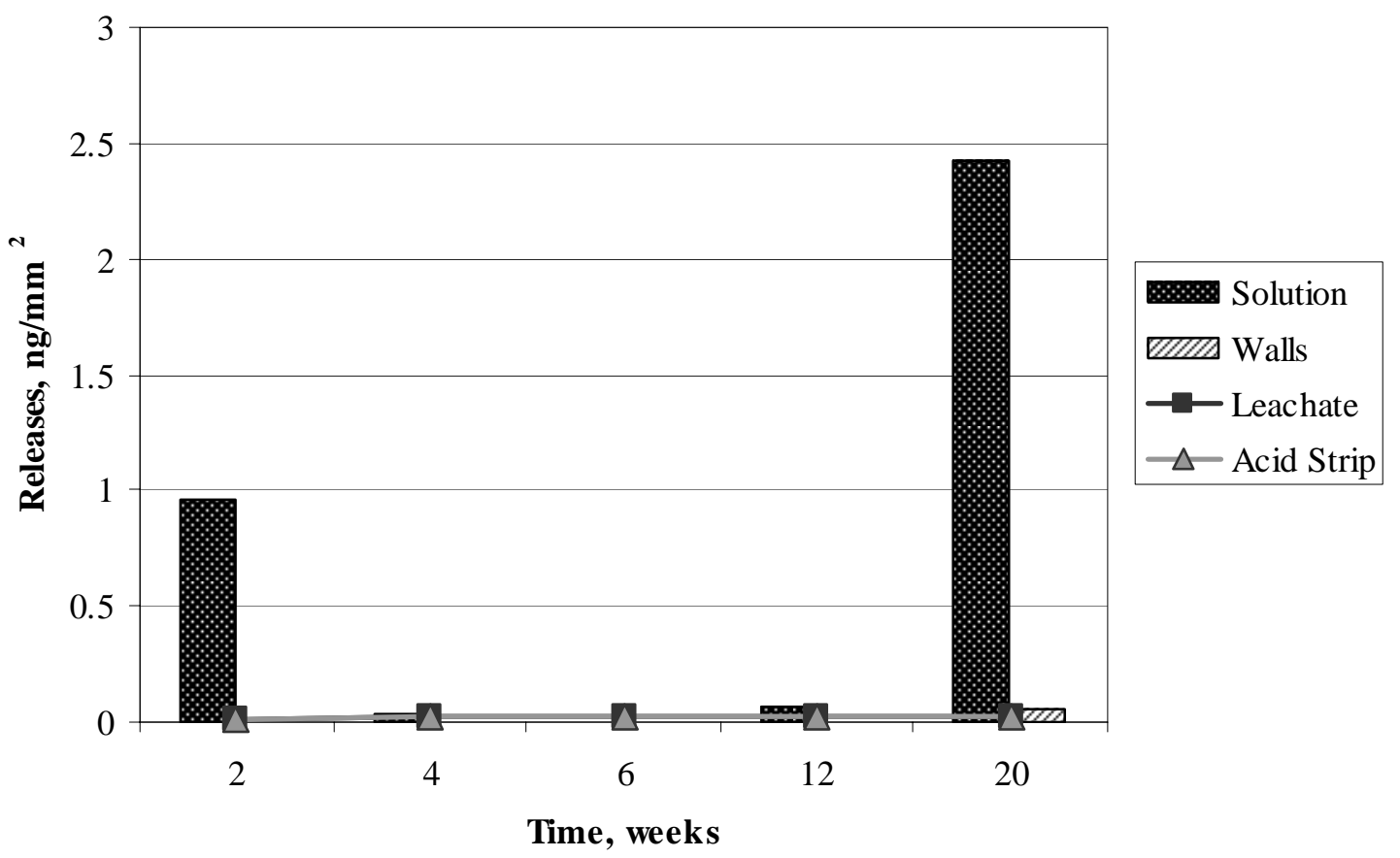

Figure J-63. Ruthenium Releases in Solution and on Walls from Polished Sample 31 in AJ13 Solution at Room Temperature and Average Detection Limits for Leachate and Acid Strip.

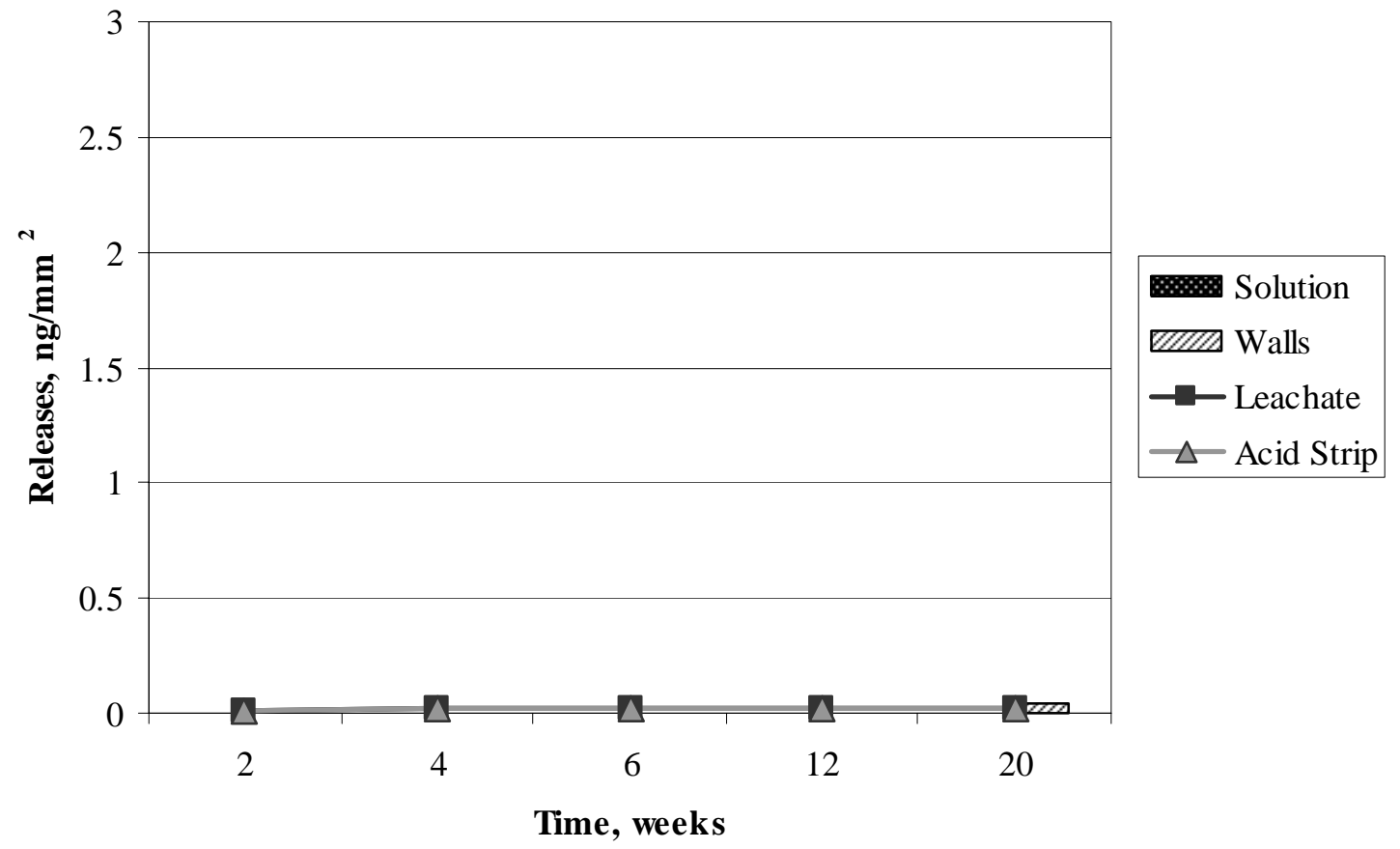

Figure J-64. Ruthenium Present in Solutions and on Walls in AJ13 Solution Control at Room Temperature and Average Detection Limits for Leachate and Acid Strip. 


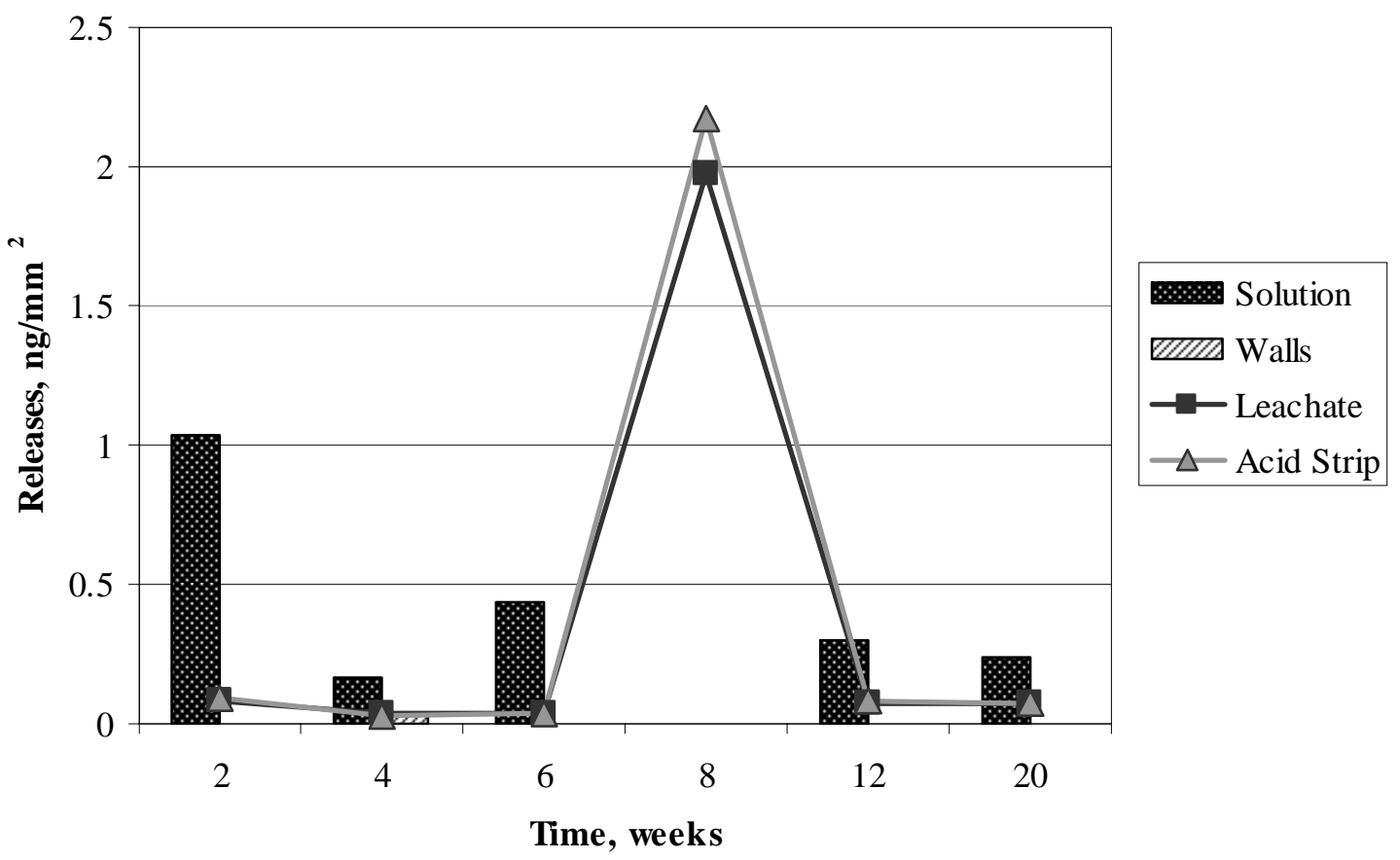

Figure J-65. Molybdenum Releases in Solution and on Walls from Polished Sample 25 in $1 \mathrm{KCl}$ Solution at $90^{\circ} \mathrm{C}$ and Average Detection Limits for Leachate and Acid Strip.

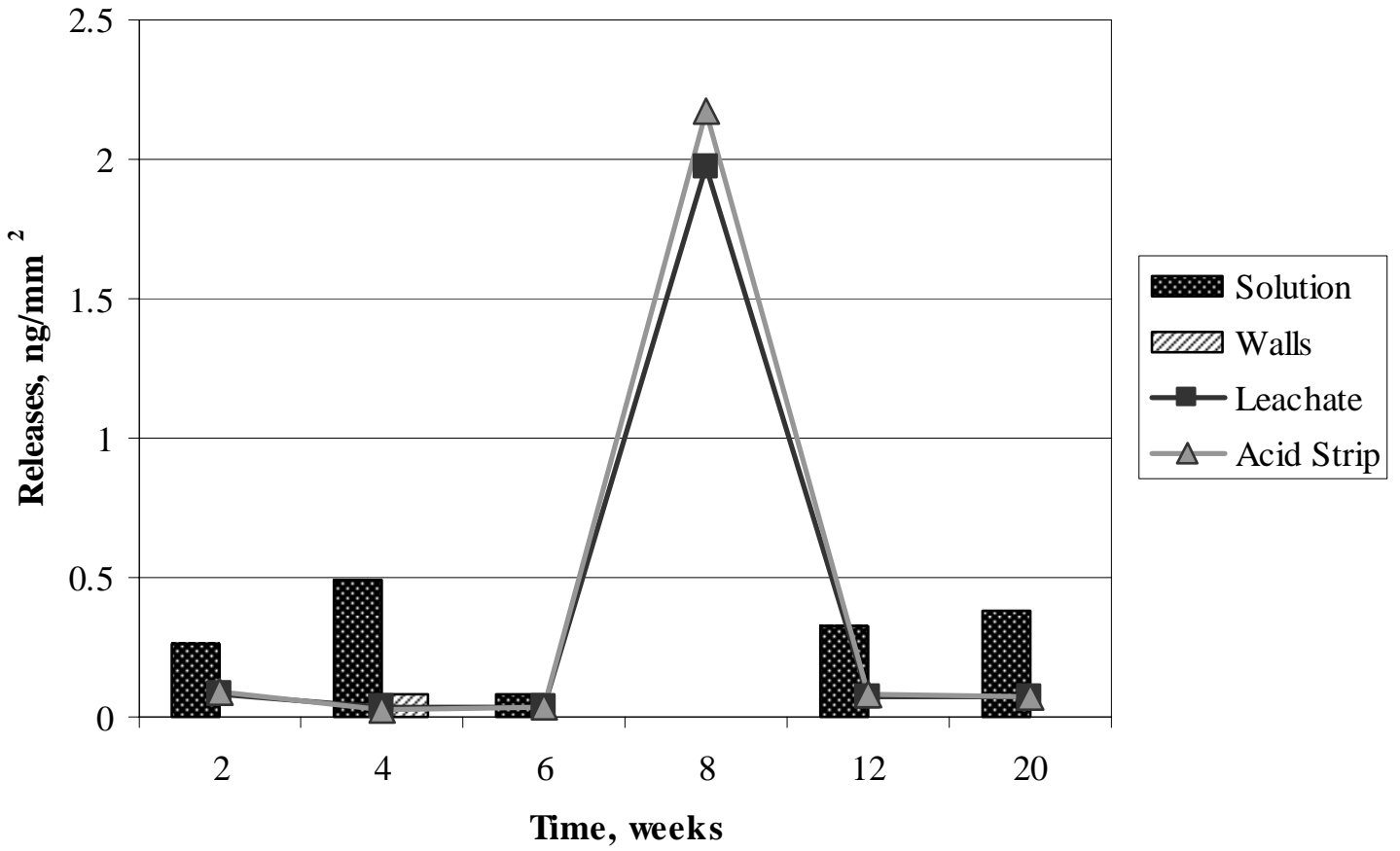

Figure J-66. Molybdenum Present in Solutions and on Walls in 1KCI Solution Control at $90^{\circ} \mathrm{C}$ and Average Detection Limits for Leachate and Acid Strip. 


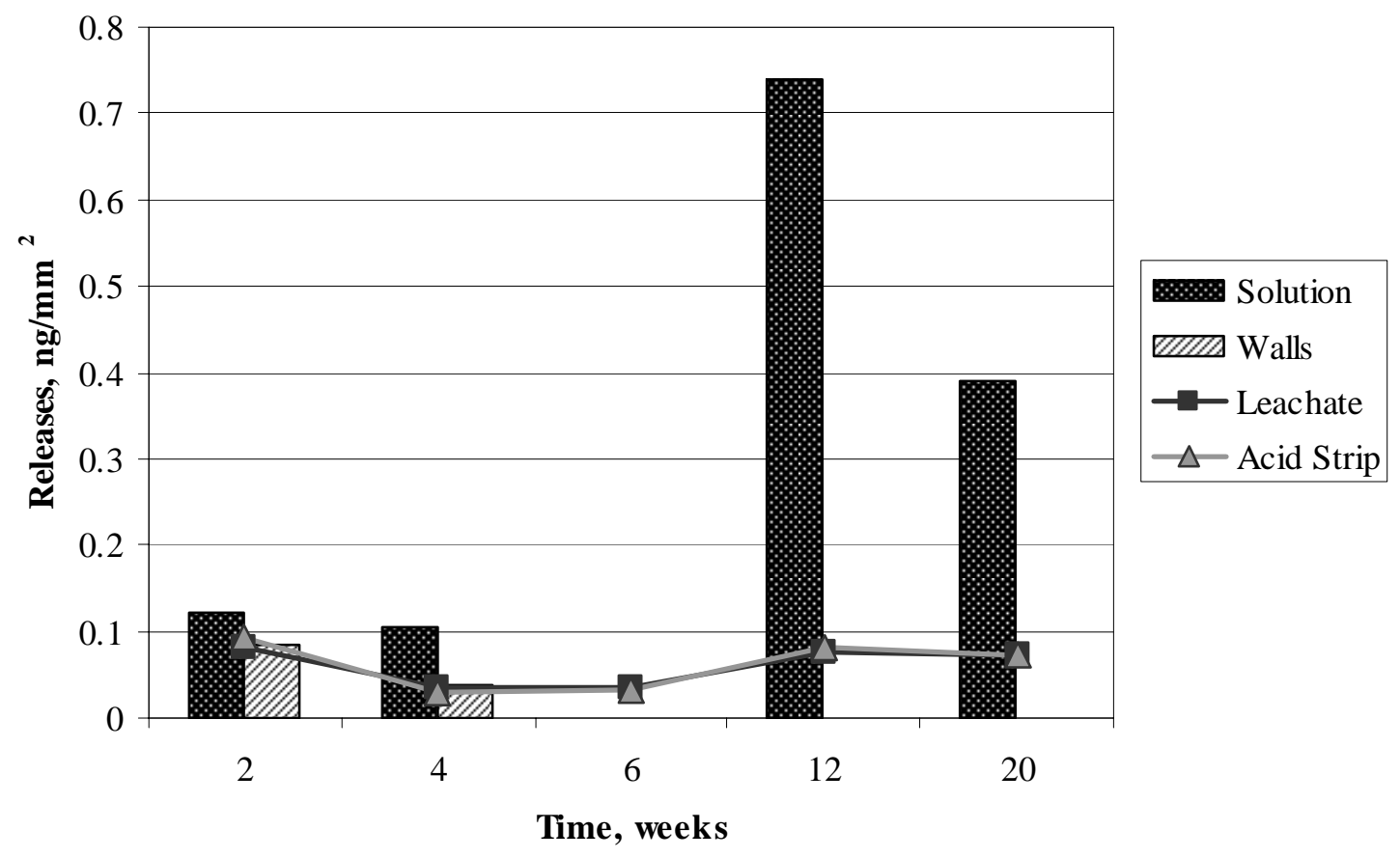

Figure J-67. Molybdenum Releases in Solution and on Walls from Polished Sample 27 in $1 \mathrm{KCl}$ Solution at Room Temperature and Average Detection Limits for Leachate and Acid Strip.

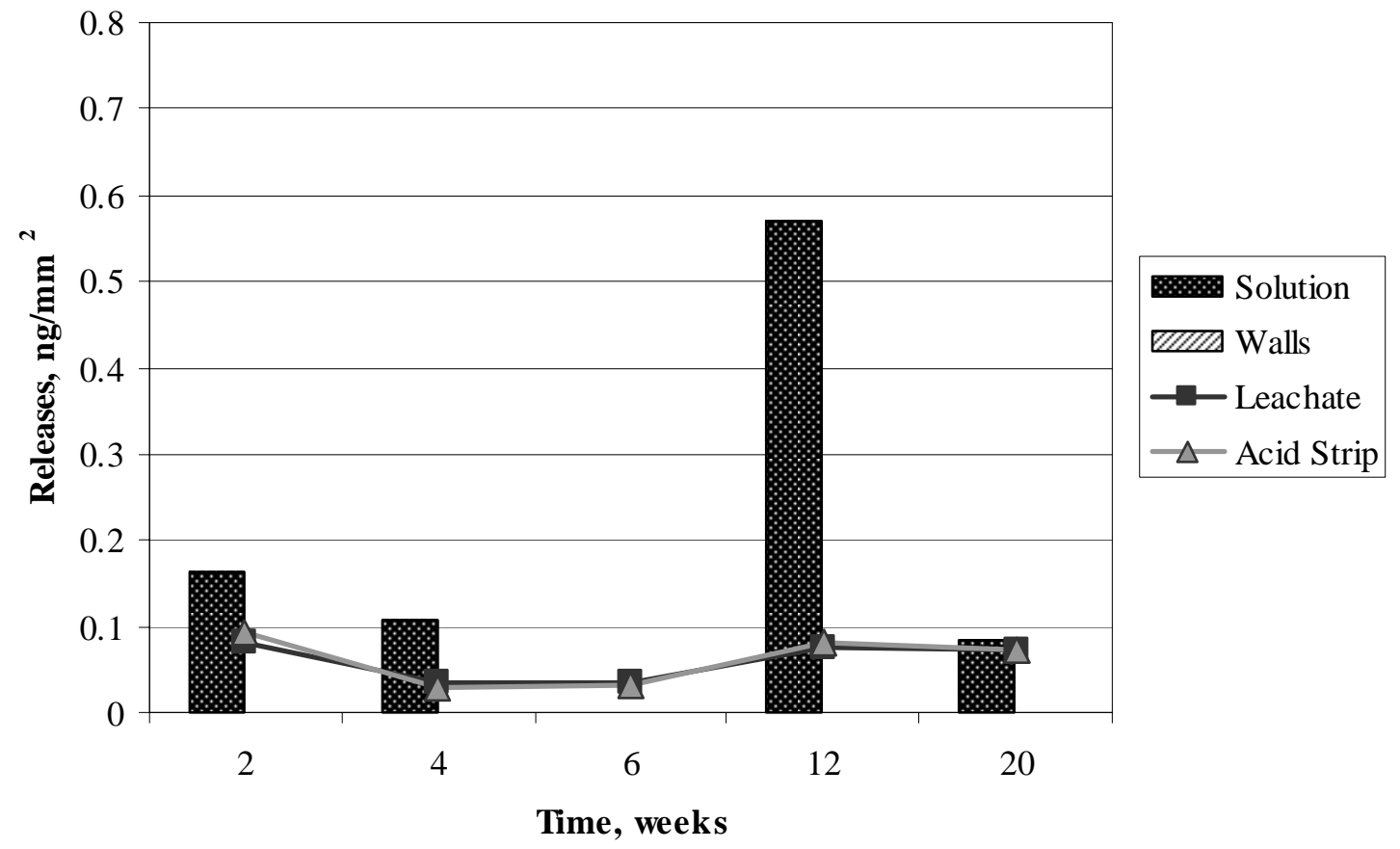

Figure J-68. Molybdenum Present in Solutions and on Walls in 1KCl Solution Control at Room Temperature and Average Detection Limits for Leachate and Acid Strip. 


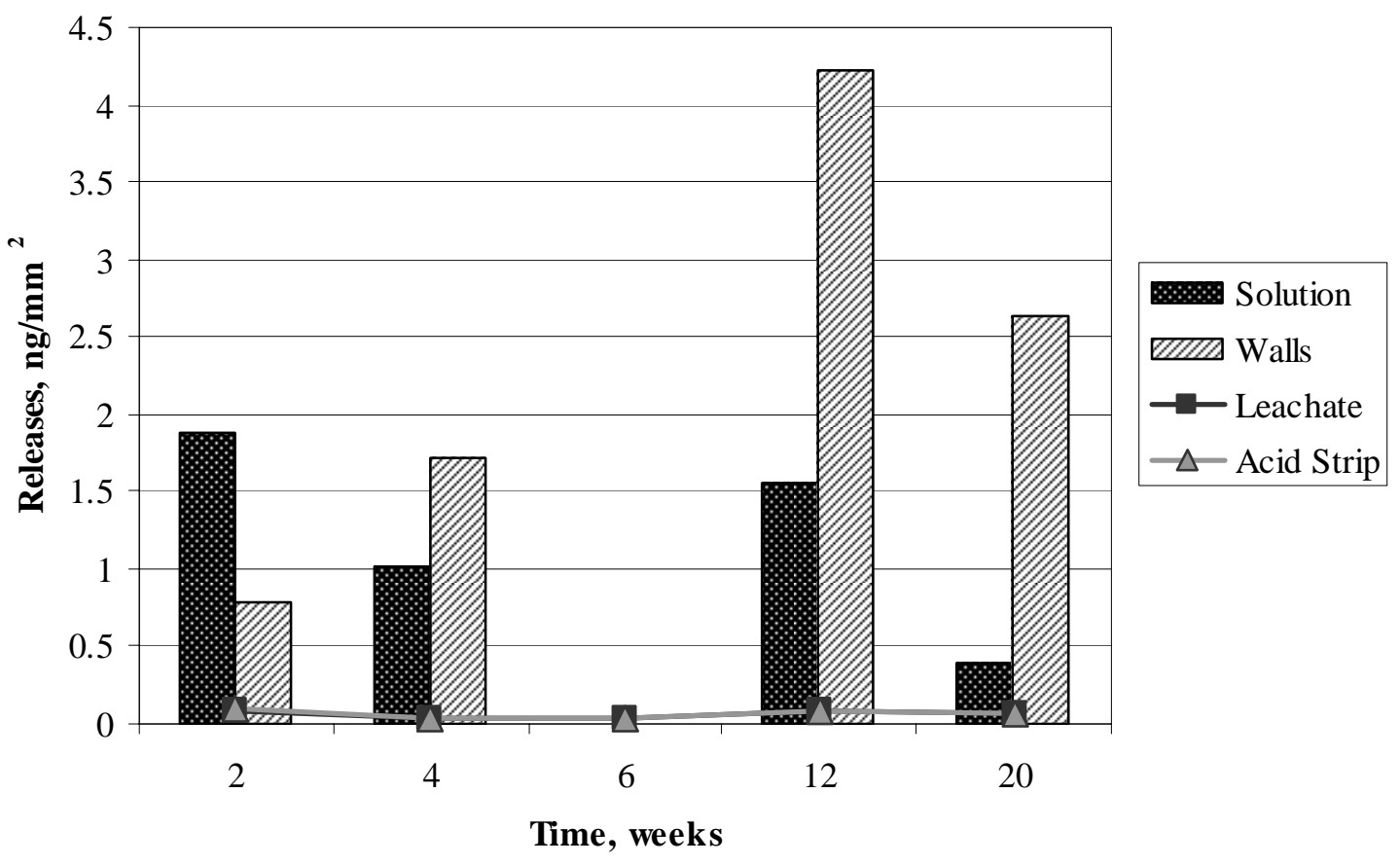

Figure J-69. Moybdenum Releases in Solution and on Walls from Polished Sample 29 in $10 \mathrm{KCl}$ Solution at Room Temperature and Average Detection Limits for Leachate and Acid Strip.

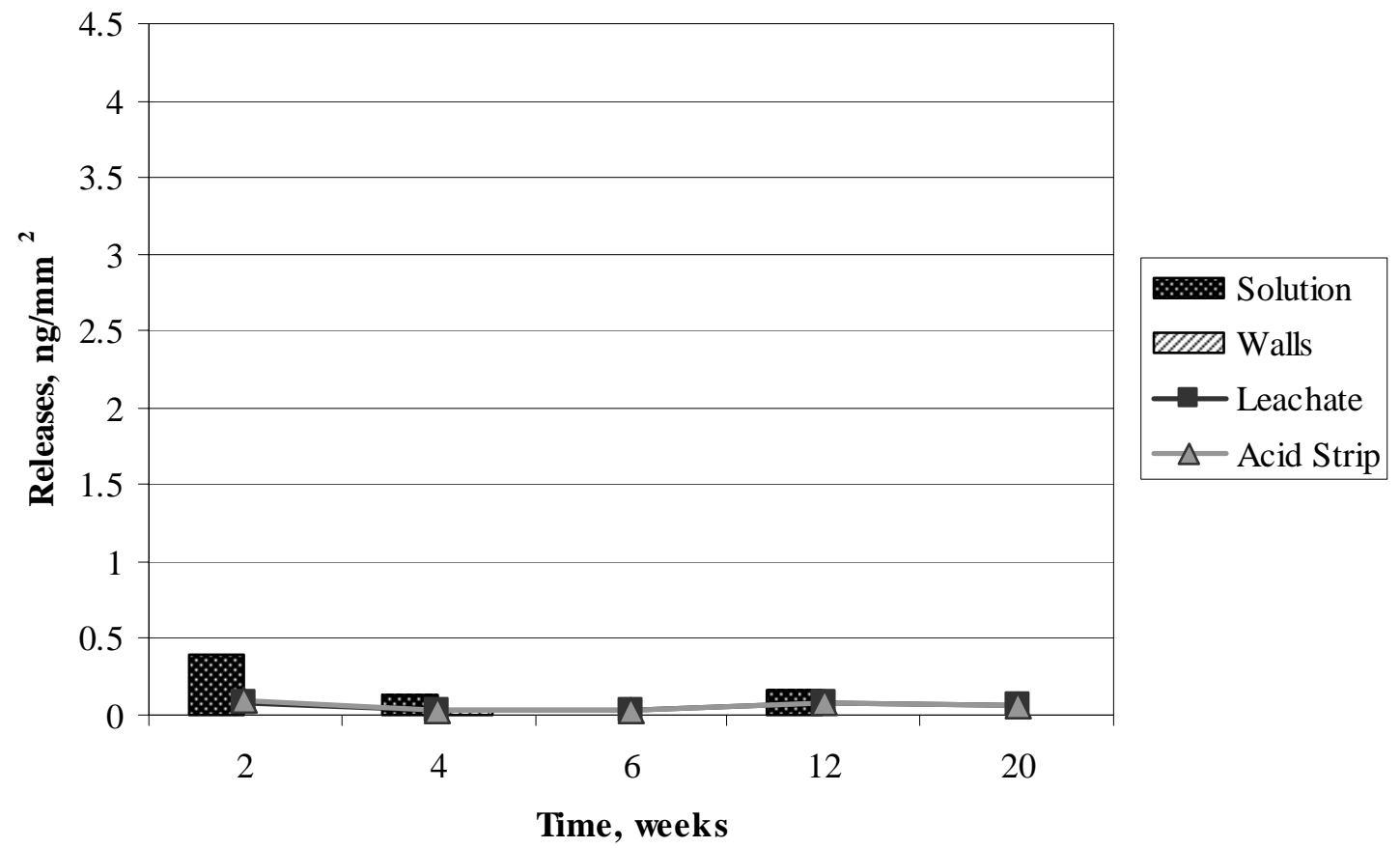

Figure J-70. Molybdenum Present in Solutions and on Walls in 10KCl Solution Control at Room Temperature and Average Detection Limits for Leachate and Acid Strip. 


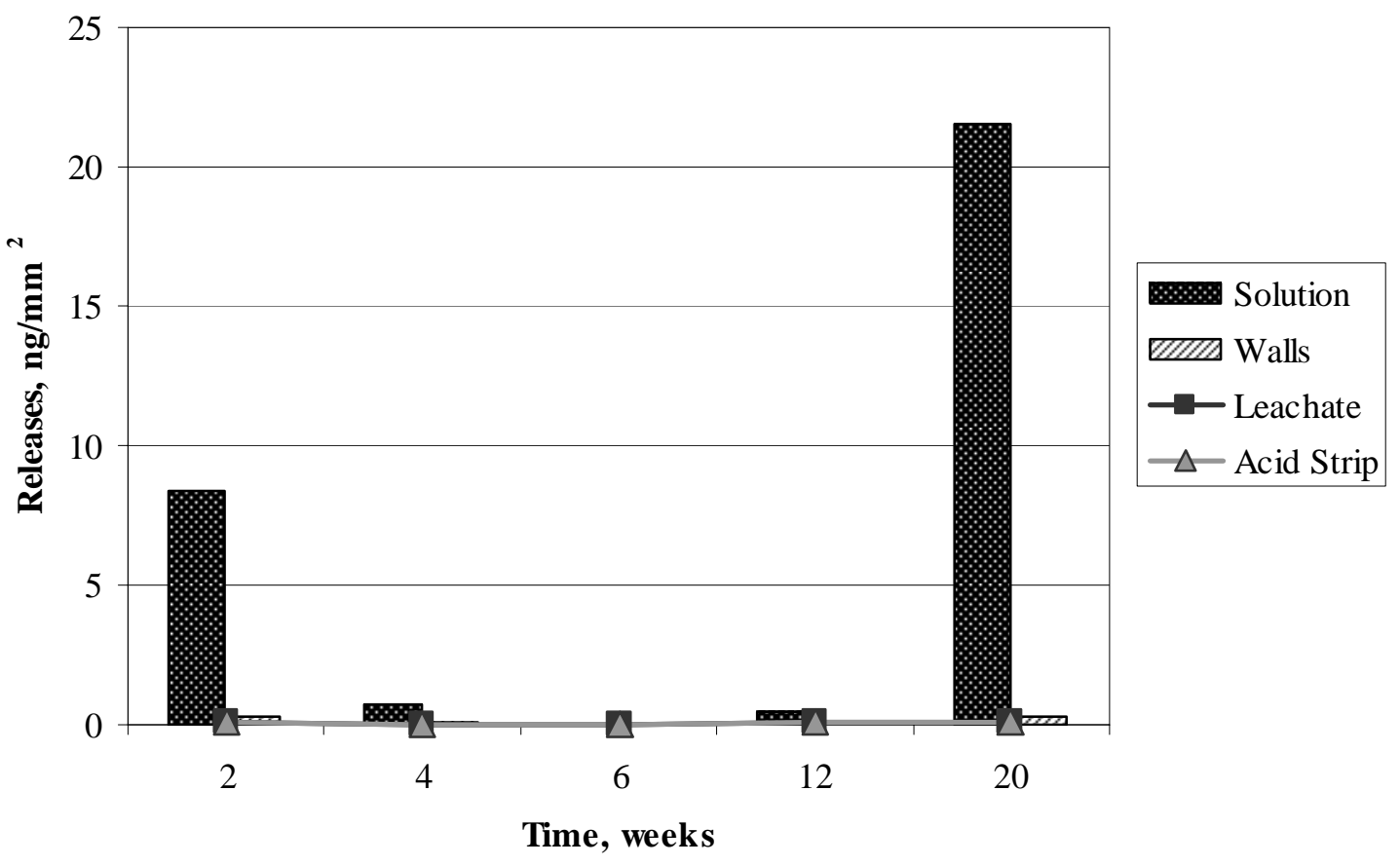

Figure J-71. Molybdenum Releases in Solution and on Walls from Polished Sample 31 in AJ13 Solution at Room Temperature and Average Detection Limits for Leachate and Acid Strip.

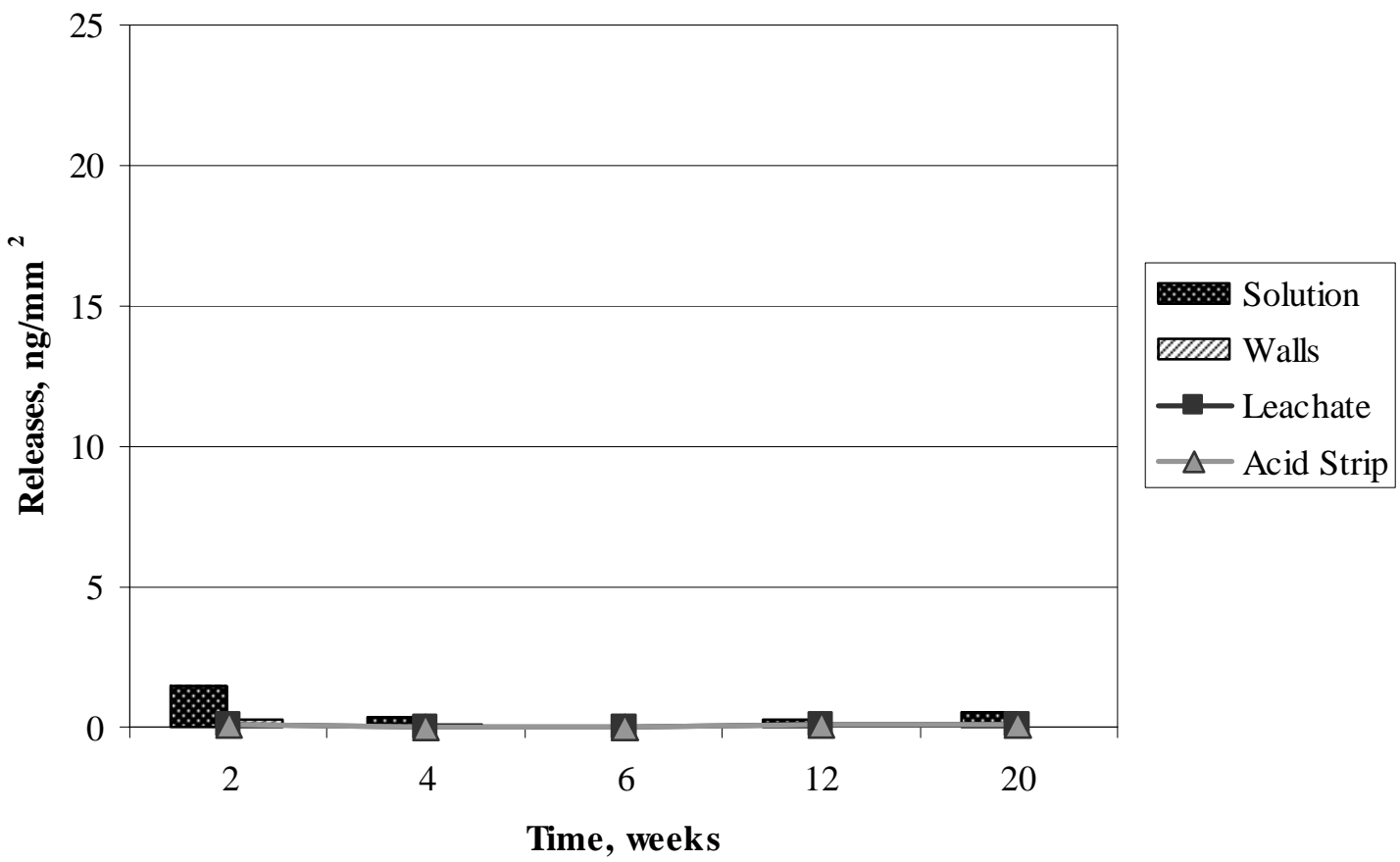

Figure J-72. Molybdenum Present in Solutions and on Walls in AJ13 Solution Control at Room Temperature and Average Detection Limits for Leachate and Acid Strip. 


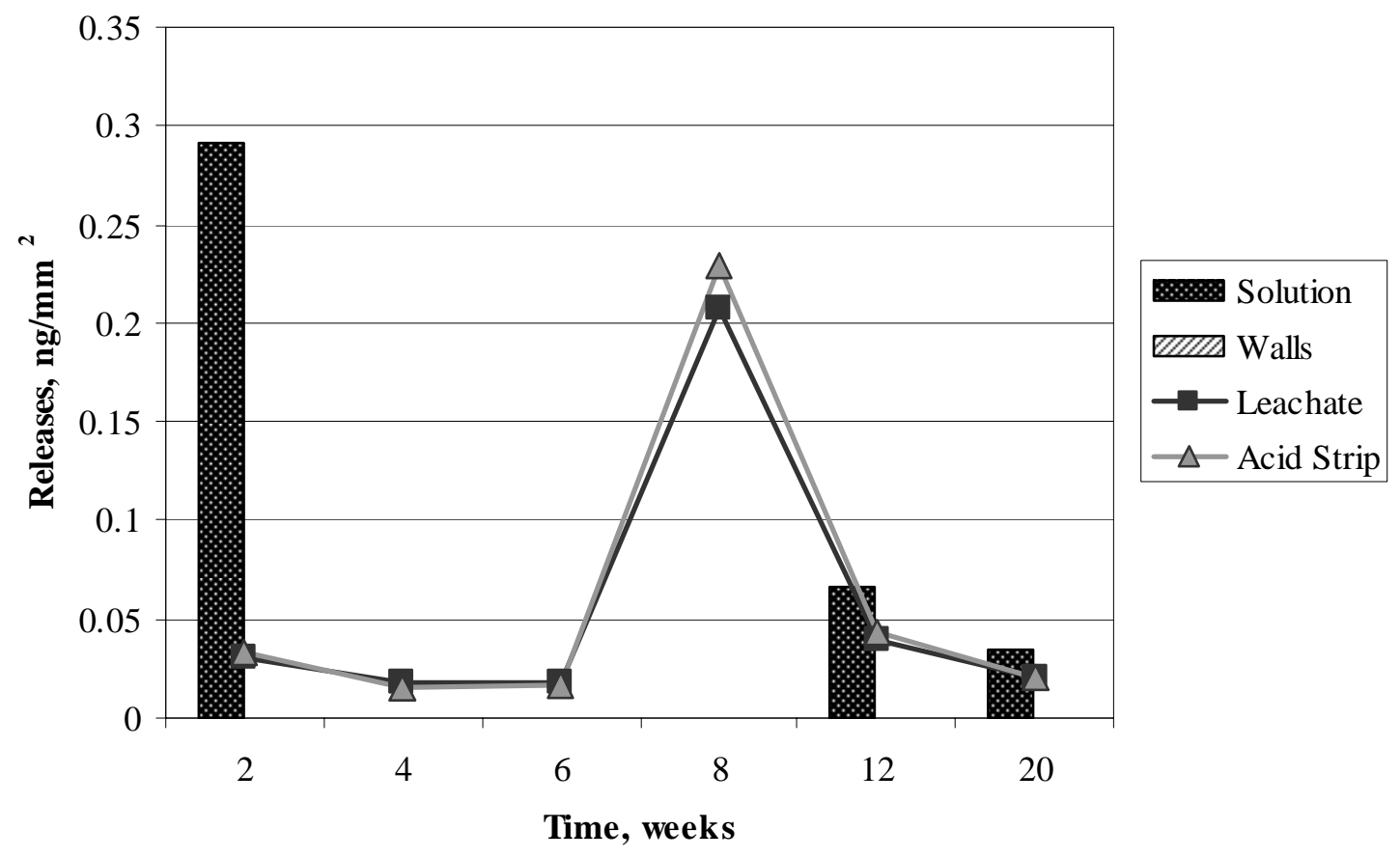

Figure J-73. Manganese Releases in Solution and on Walls from Polished Sample 25 in $1 \mathrm{KCl}$ Solution at $90^{\circ} \mathrm{C}$ and Average Detection Limits for Leachate and Acid Strip.

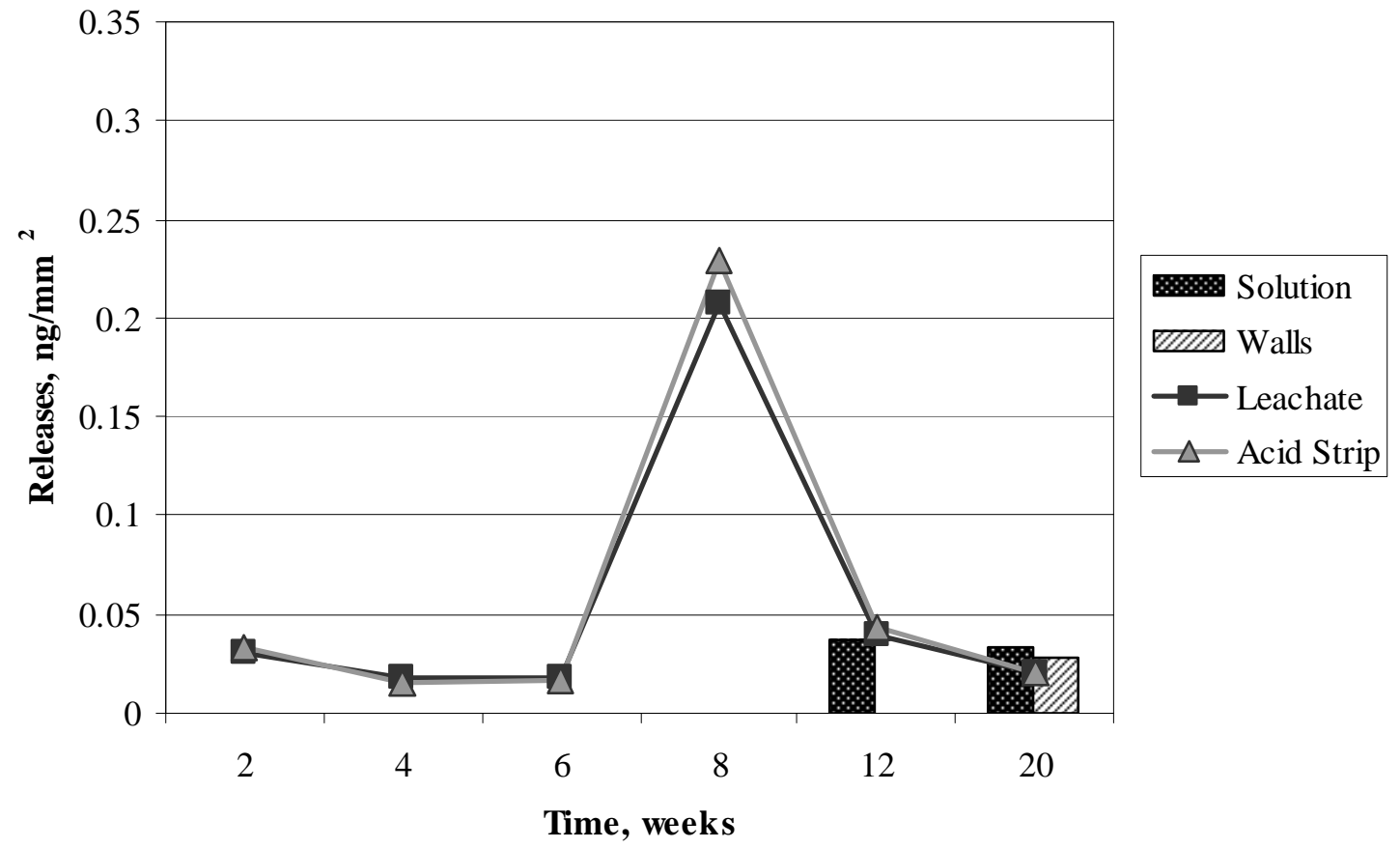

Figure J-74. Manganese Present in Solutions and on Walls in 1KCl Solution Control at $90^{\circ} \mathrm{C}$ and Average Detection Limits for Leachate and Acid Strip. 


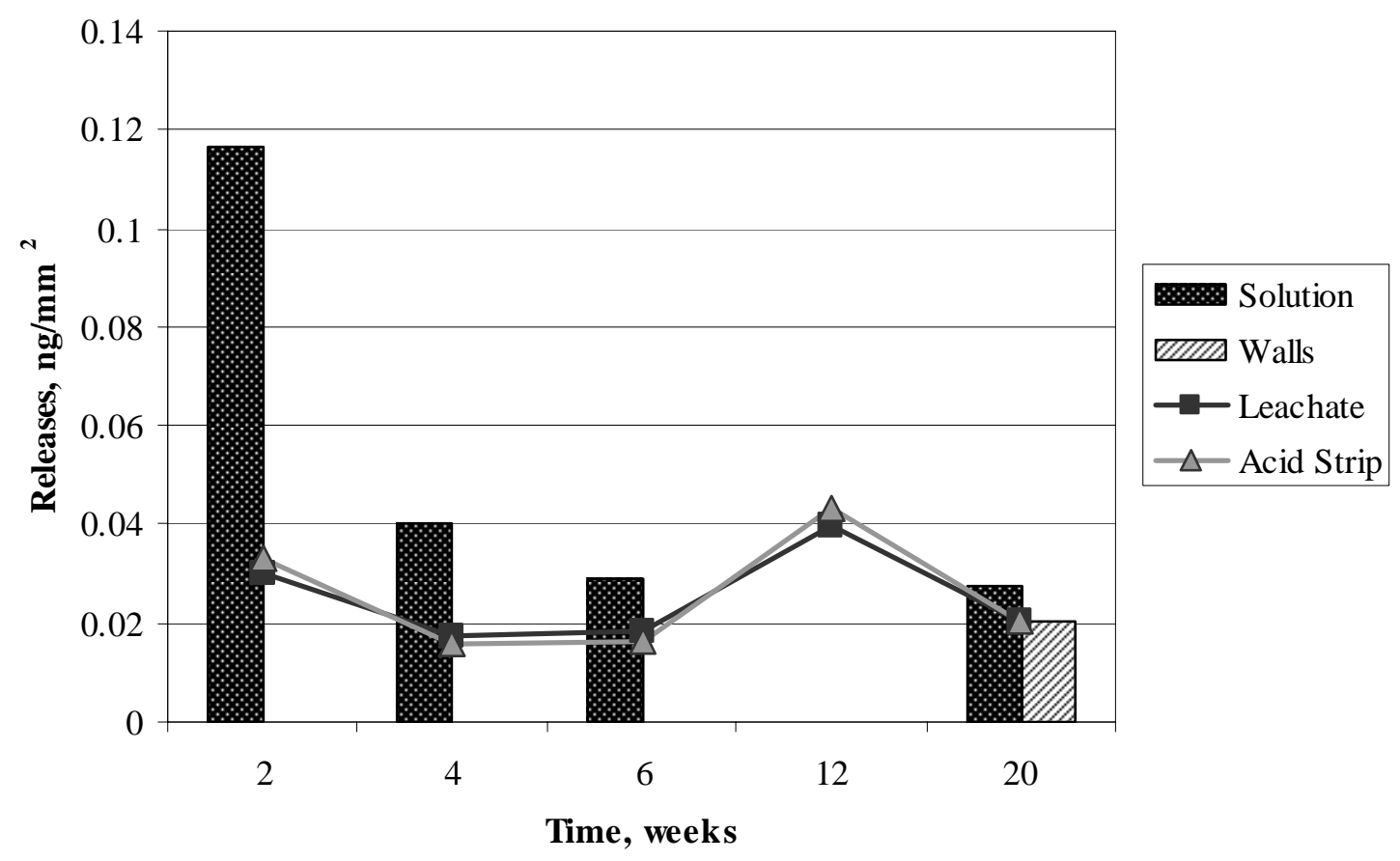

Figure J-75. Manganese Releases in Solution and on Walls from Polished Sample 27 in 1KCI Solution at Room Temperature and Average Detection Limits for Leachate and Acid Strip.

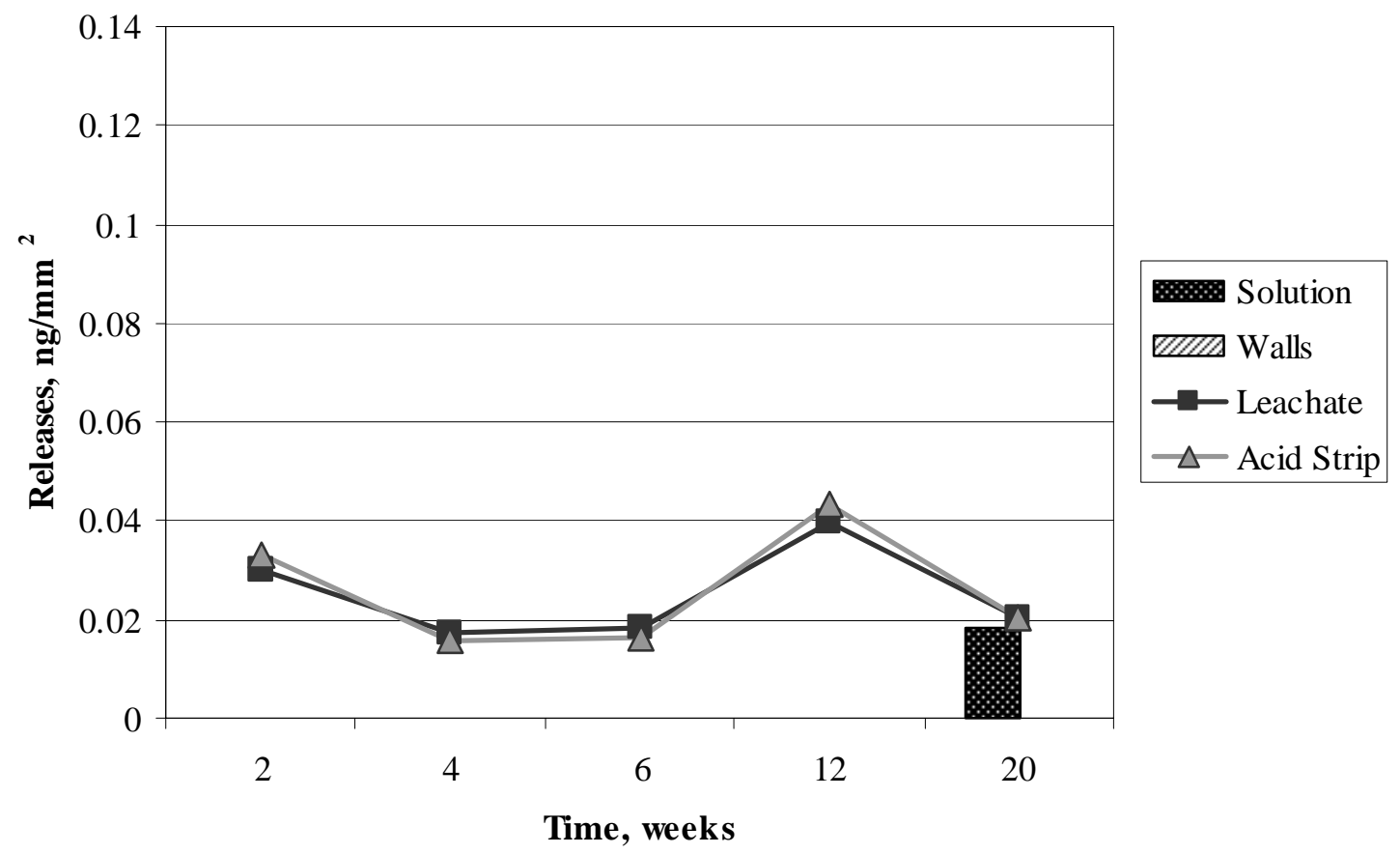

Figure J-76. Manganese Present in Solutions and on Walls in 1KCl Solution Control at Room Temperature and Average Detection Limits for Leachate and Acid Strip. 


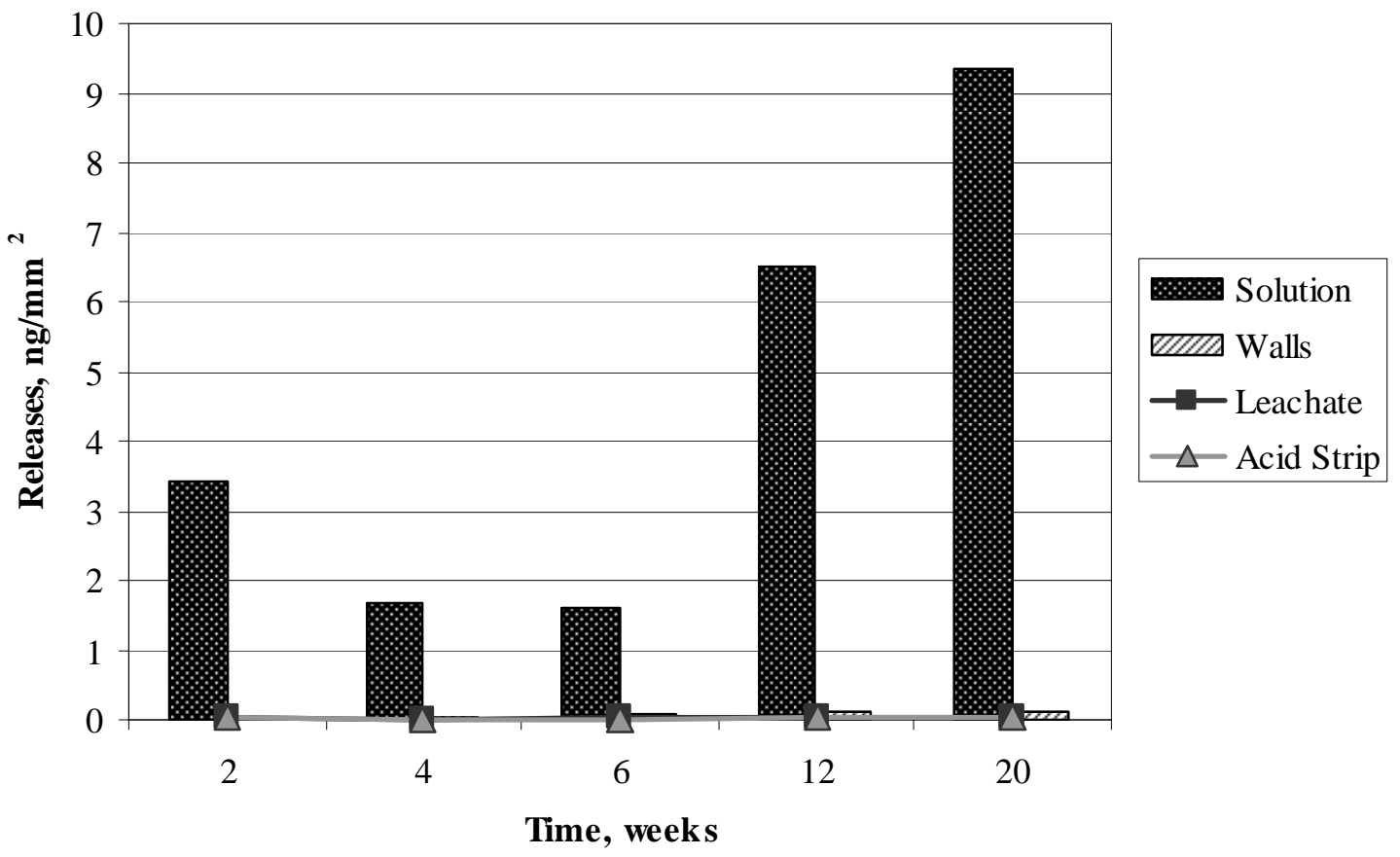

Figure J-77. Manganese Releases in Solution and on Walls from Polished Sample 29 in $10 \mathrm{KCl}$ Solution at Room Temperature and Average Detection Limits for Leachate and Acid Strip.

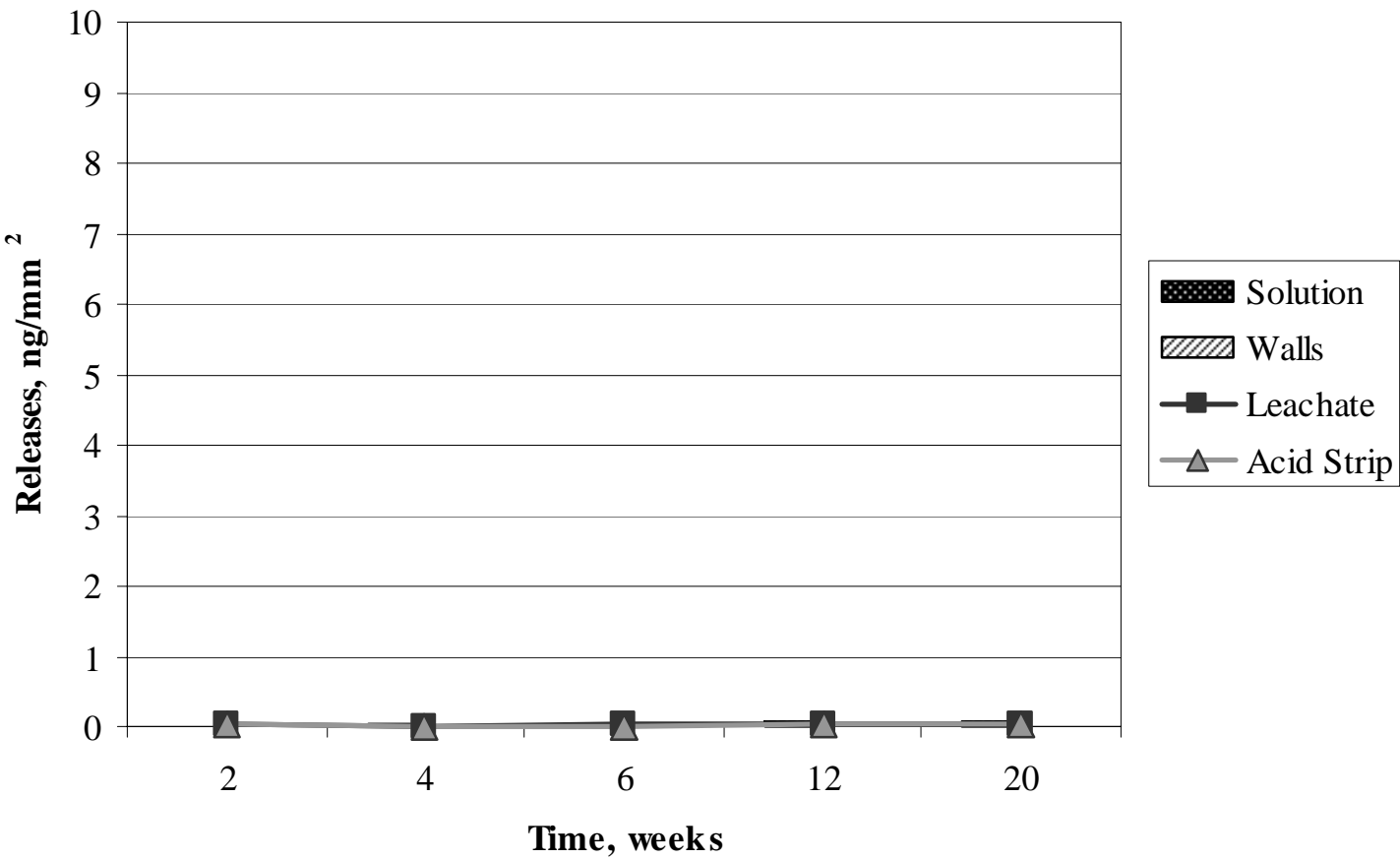

Figure J-78. Manganese Present in Solutions and on Walls in 10KCl Solution Control at Room Temperature and Average Detection Limits for Leachate and Acid Strip. 


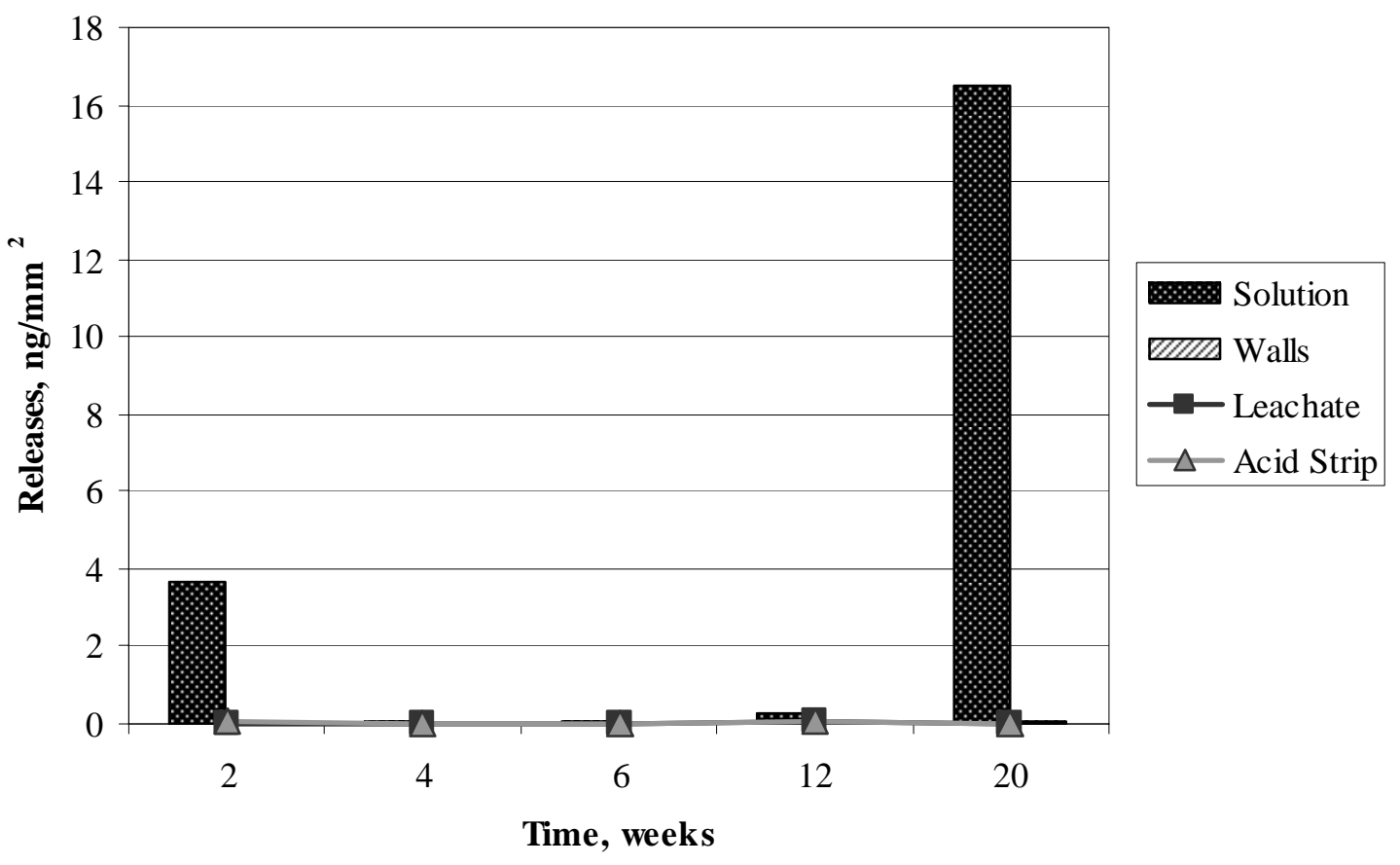

Figure J-79. Manganese Releases in Solution and on Walls from Polished Sample 31 in AJ13 Solution at Room Temperature and Average Detection Limits for Leachate and Acid Strip.

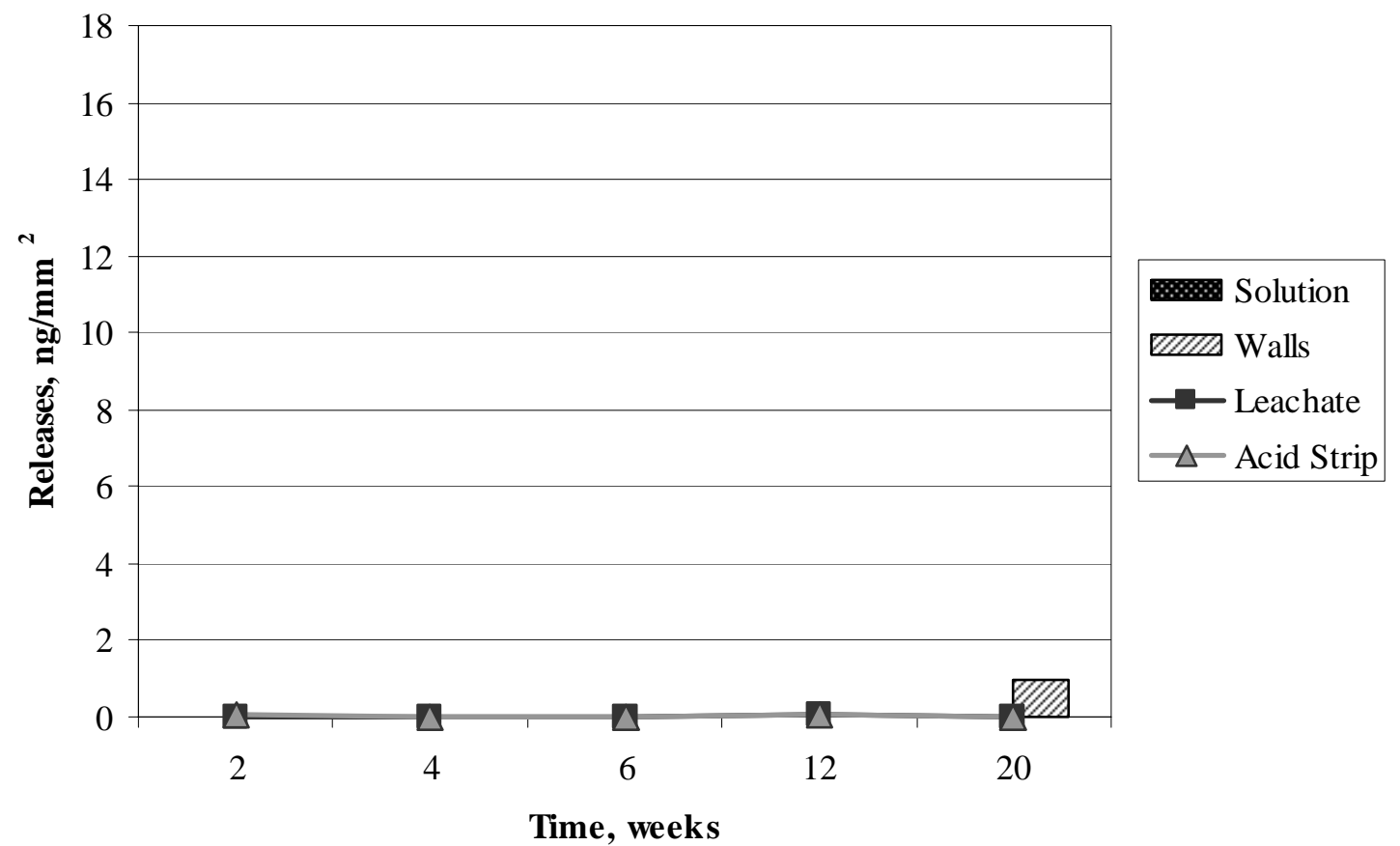

Figure J-80. Manganese Present in Solutions and on Walls in AJ13 Solution Control at Room Temperature and Average Detection Limits for Leachate and Acid Strip. 


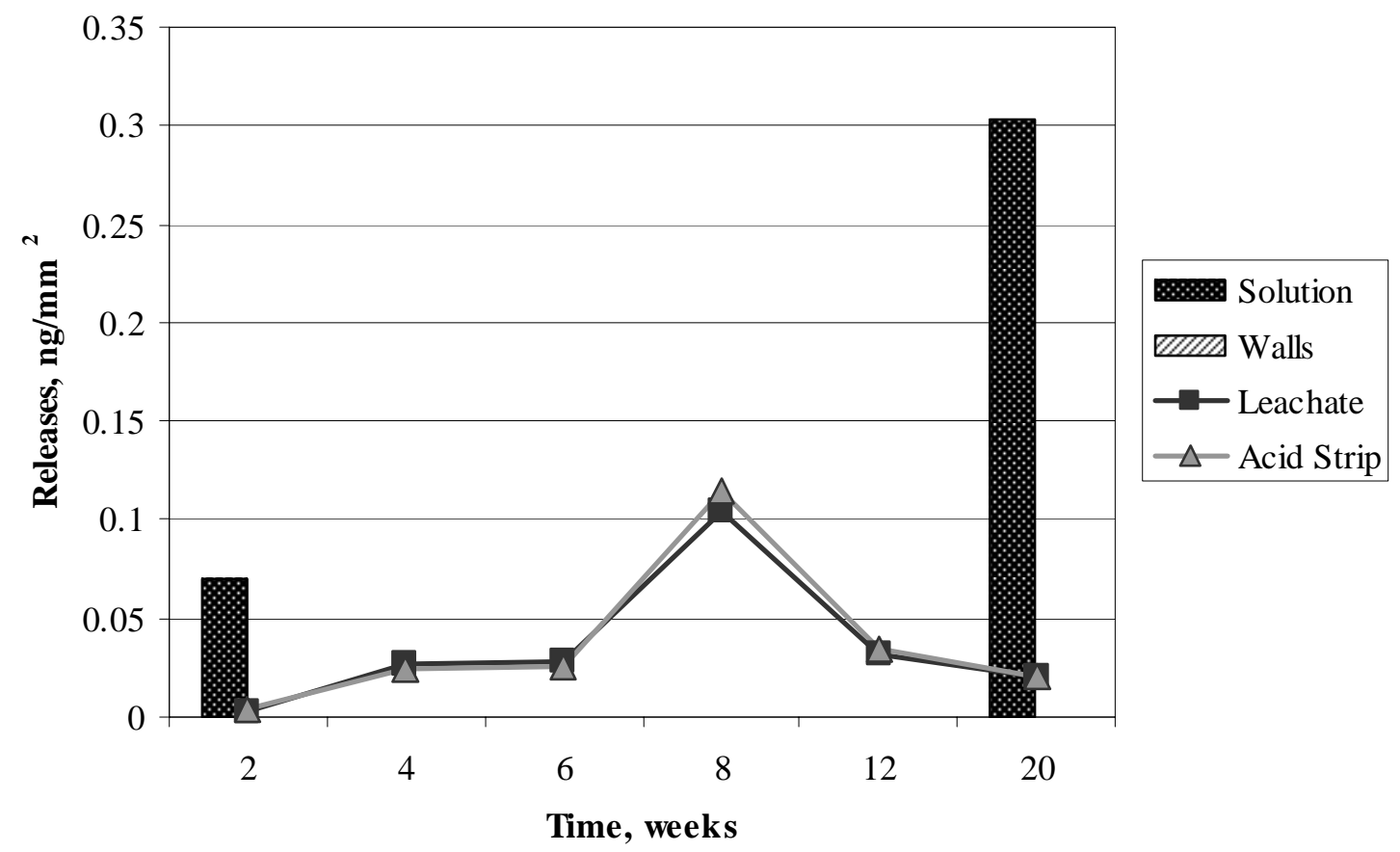

Figure J-81. Cobalt Releases in Solution and on Walls from Polished Sample 25 in $1 \mathrm{KCl}$ Solution at $90^{\circ} \mathrm{C}$ and Average Detection Limits for Leachate and Acid Strip.

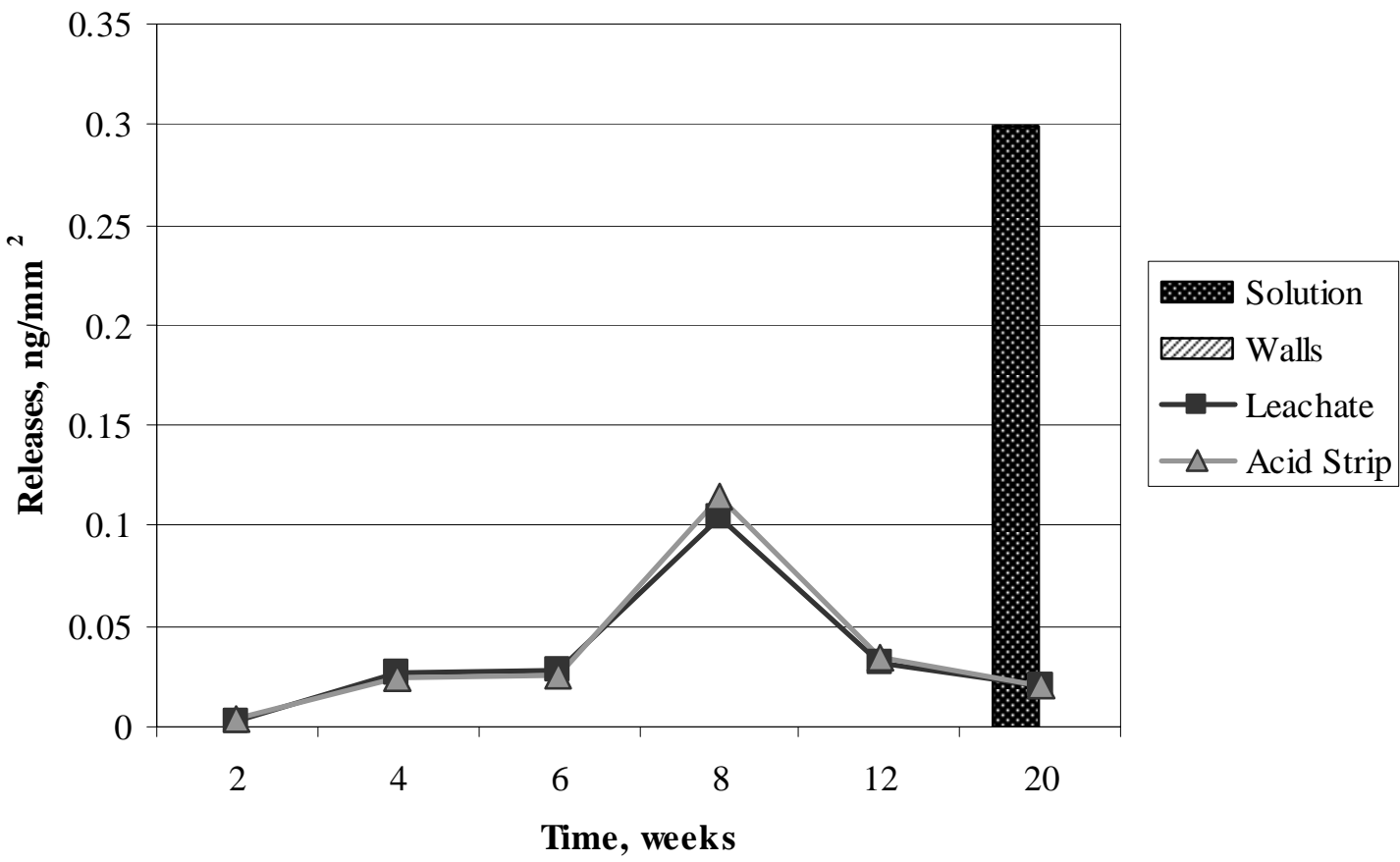

Figure J-82. Cobalt Present in Solutions and on Walls in $1 \mathrm{KCl}$ Solution Control at $90^{\circ} \mathrm{C}$ and Average Detection Limits for Leachate and Acid Strip. 


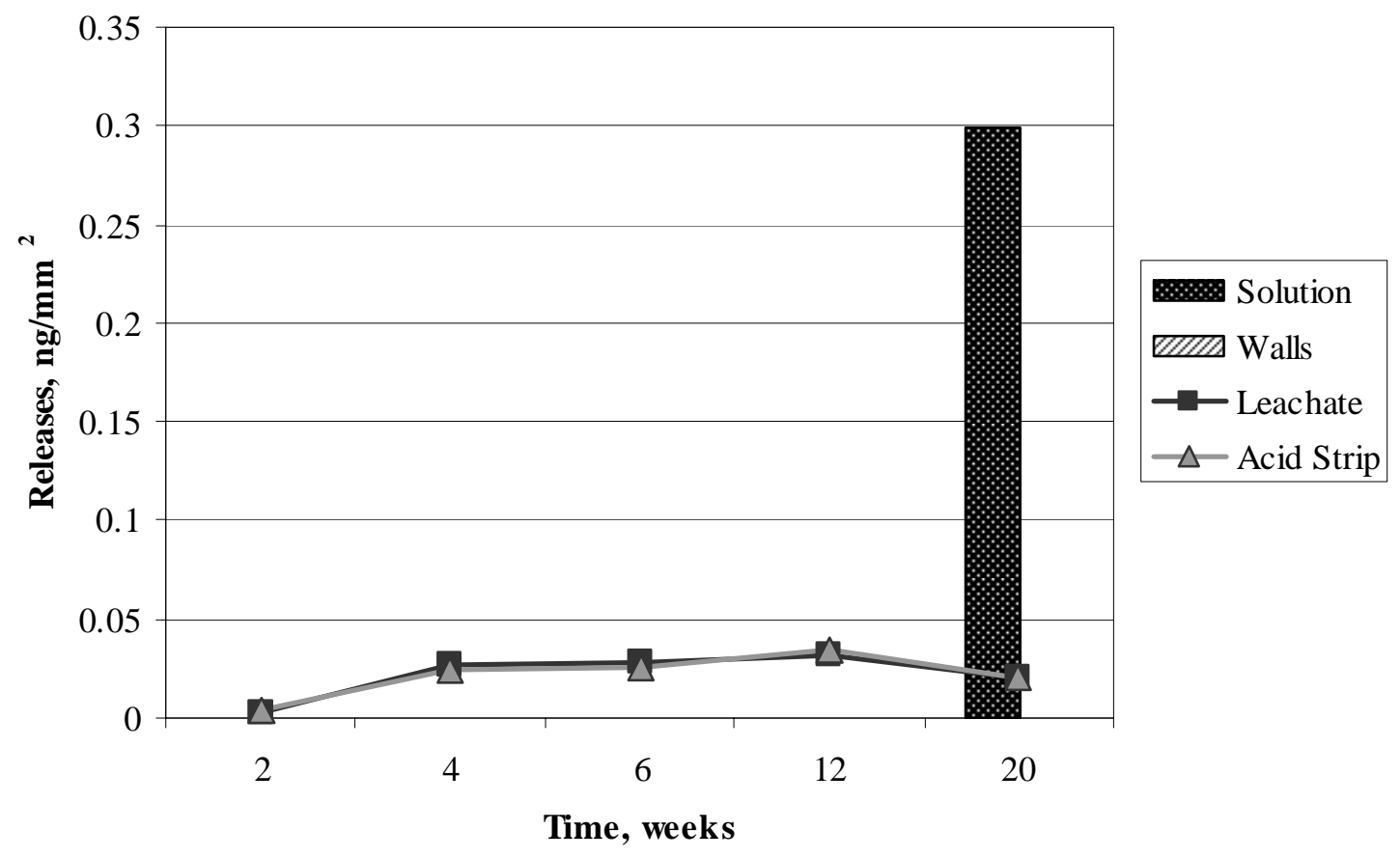

Figure J-83. Cobalt Releases in Solution and on Walls from Polished Sample 27 in $1 \mathrm{KCl}$ Solution at Room Temperature and Average Detection Limits for Leachate and Acid Strip.

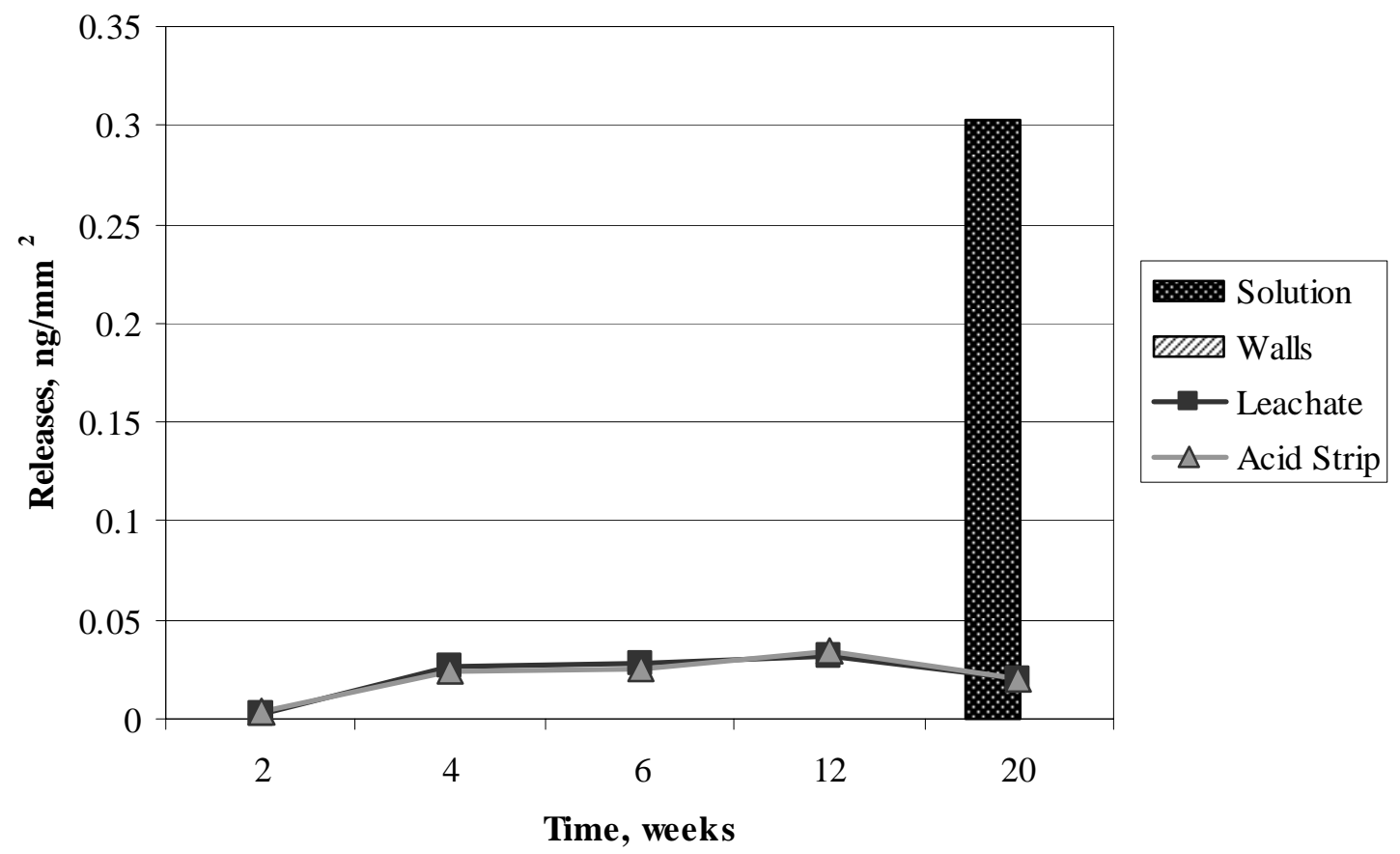

Figure J-84. Cobalt Present in Solutions and on Walls in $1 \mathrm{KCl}$ Solution Control at Room Temperature and Average Detection Limits for Leachate and Acid Strip. 


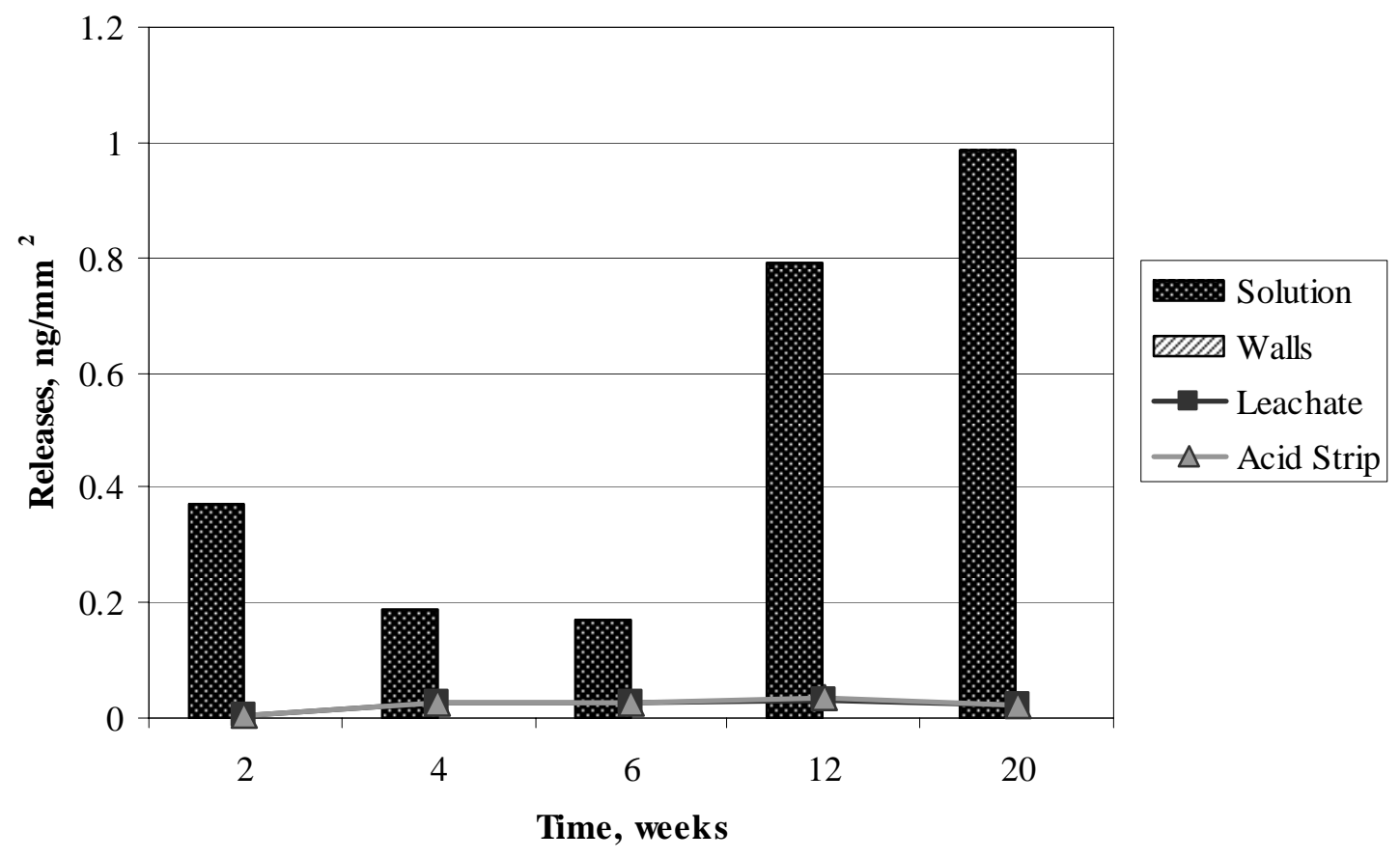

Figure J-85. Cobalt Releases in Solution and on Walls from Polished Sample 29 in $10 \mathrm{KCl}$ Solution at Room Temperature and Average Detection Limits for Leachate and Acid Strip.

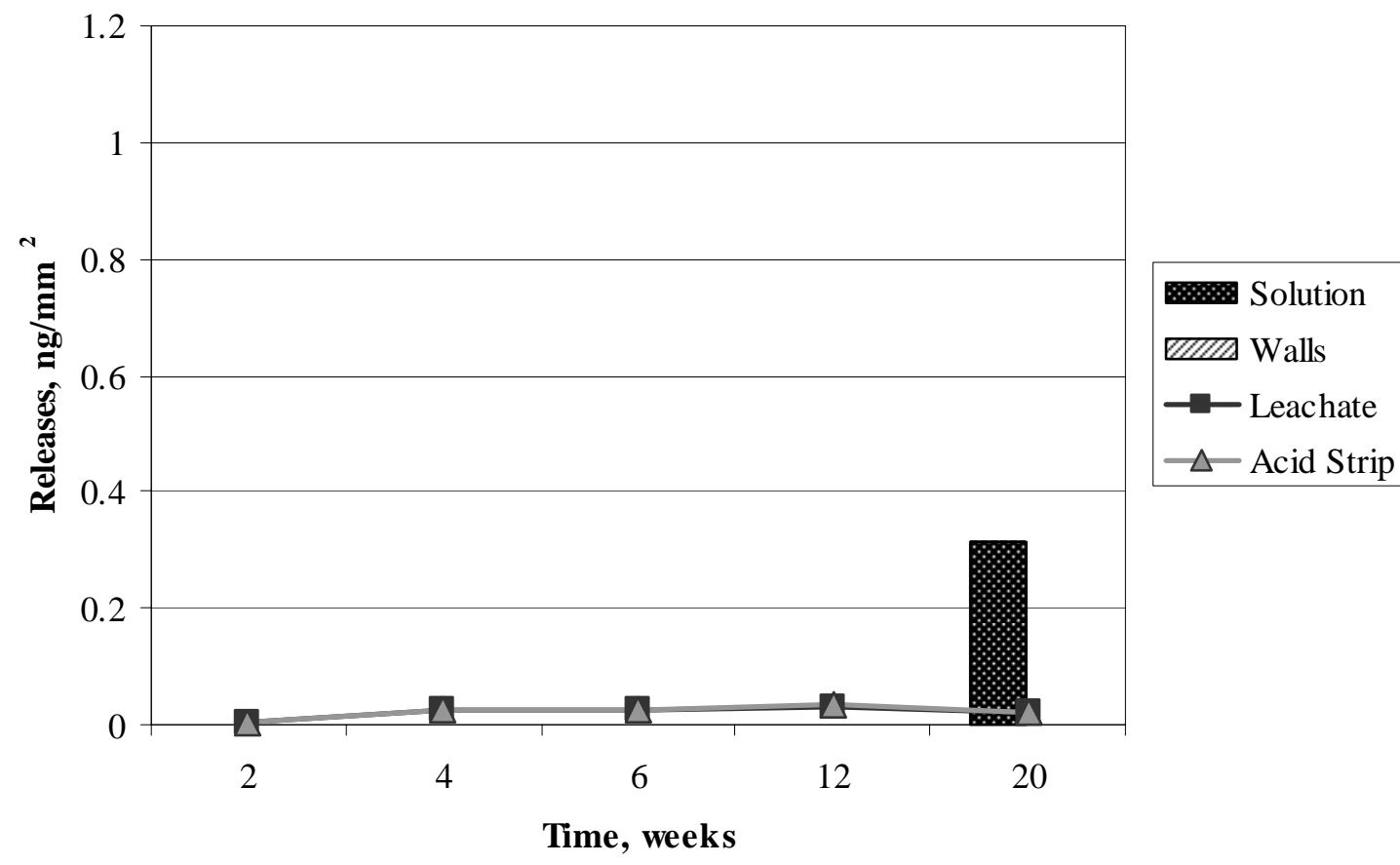

Figure J-86. Cobalt Present in Solutions and on Walls in 10KCl Solution Control at Room Temperature and Average Detection Limits for Leachate and Acid Strip. 


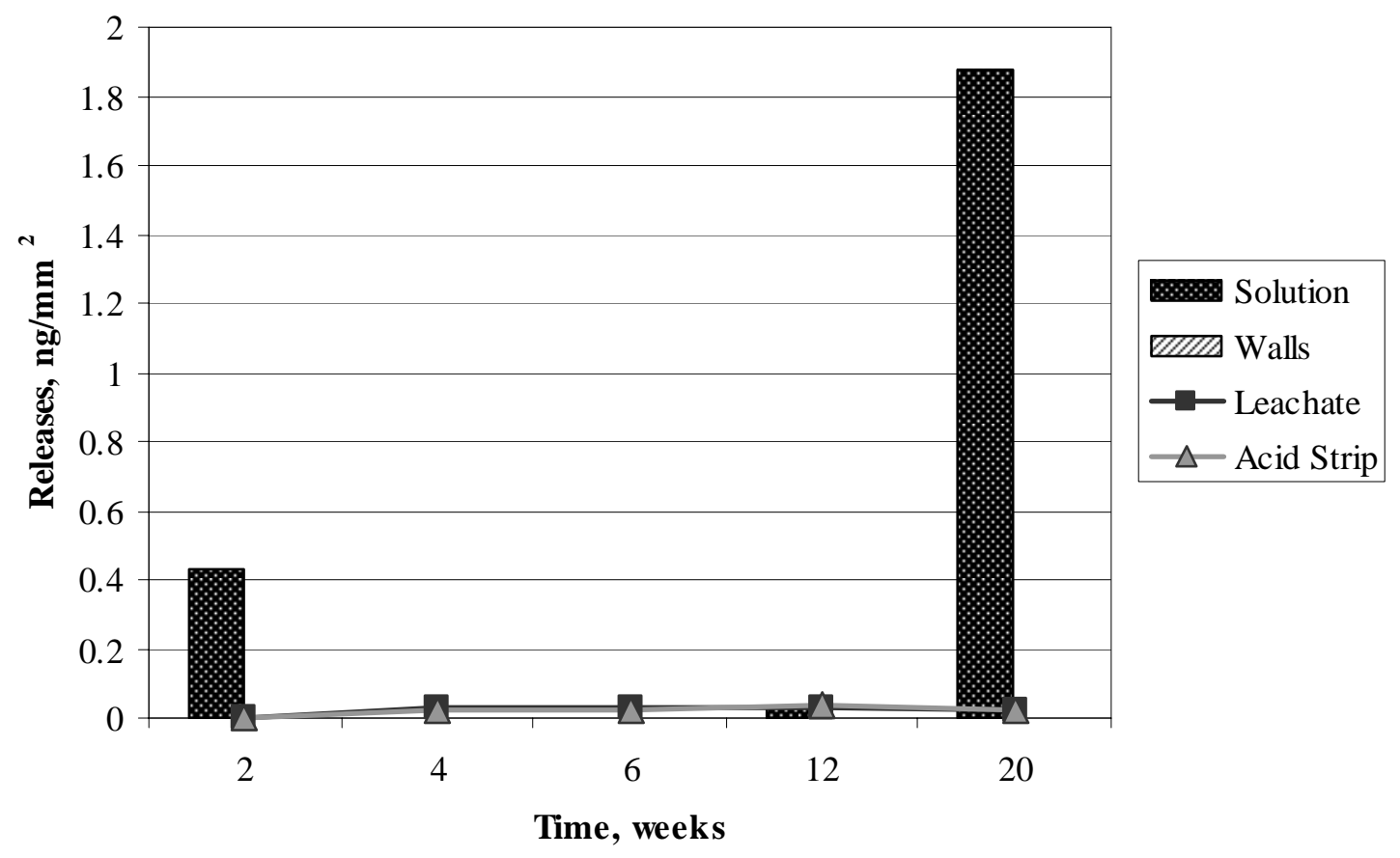

Figure J-87. Cobalt Releases in Solution and on Walls from Polished Sample 31 in AJ13 Solution at Room Temperature and Average Detection Limits for Leachate and Acid Strip.

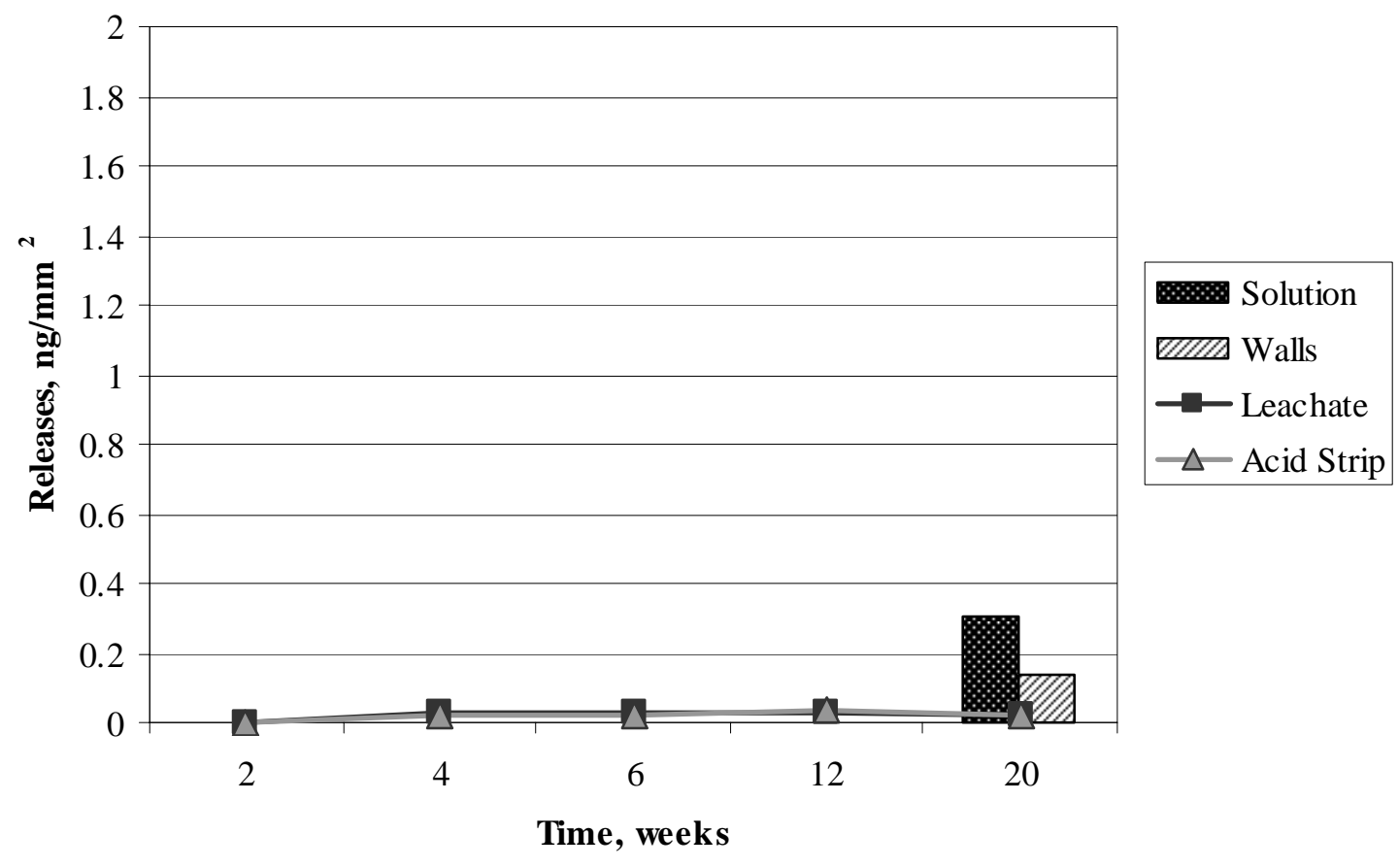

Figure J-88. Cobalt Present in Solutions and on Walls in AJ13 Solution Control at Room Temperature and Average Detection Limits for Leachate and Acid Strip. 


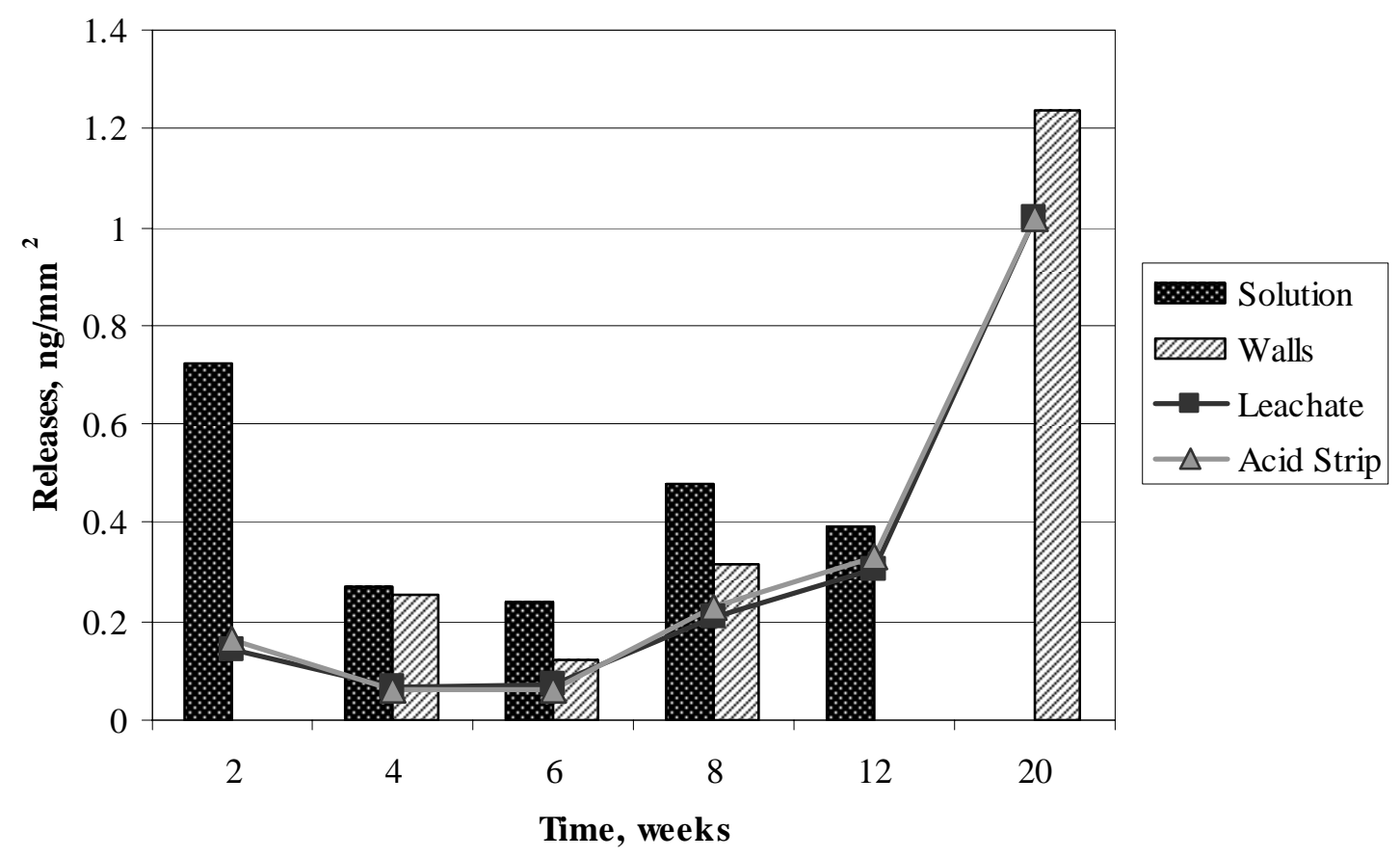

Figure J-89. Copper Releases in Solution and on Walls from Polished Sample 25 in $1 \mathrm{KCl}$ Solution at $9^{\circ} \mathrm{C}$ and Average Detection Limits for Leachate and Acid Strip.

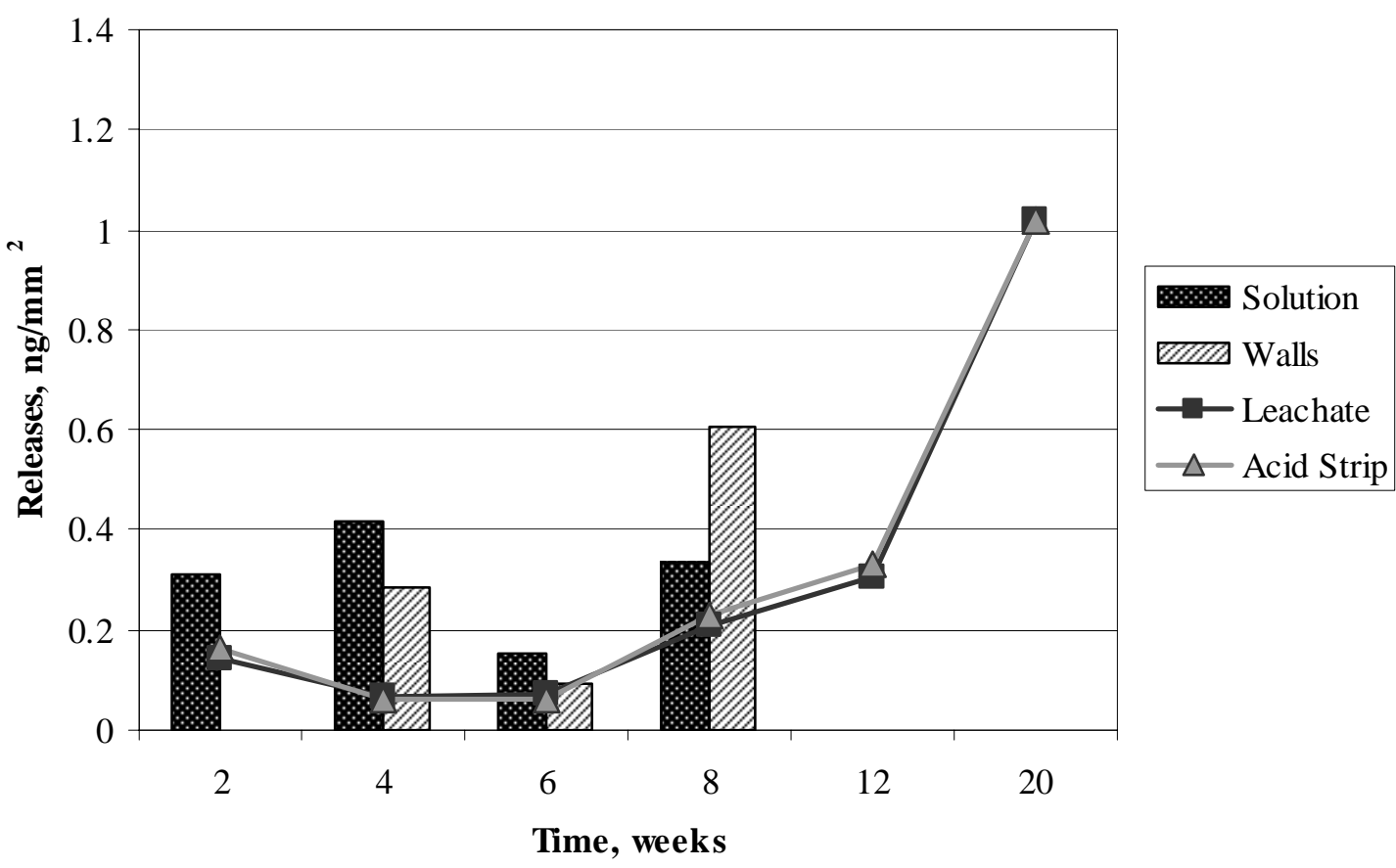

Figure J-90. Copper Present in Solutions and on Walls in $1 \mathrm{KCl}$ Solution Control at $90^{\circ} \mathrm{C}$ and Average Detection Limits for Leachate and Acid Strip. 


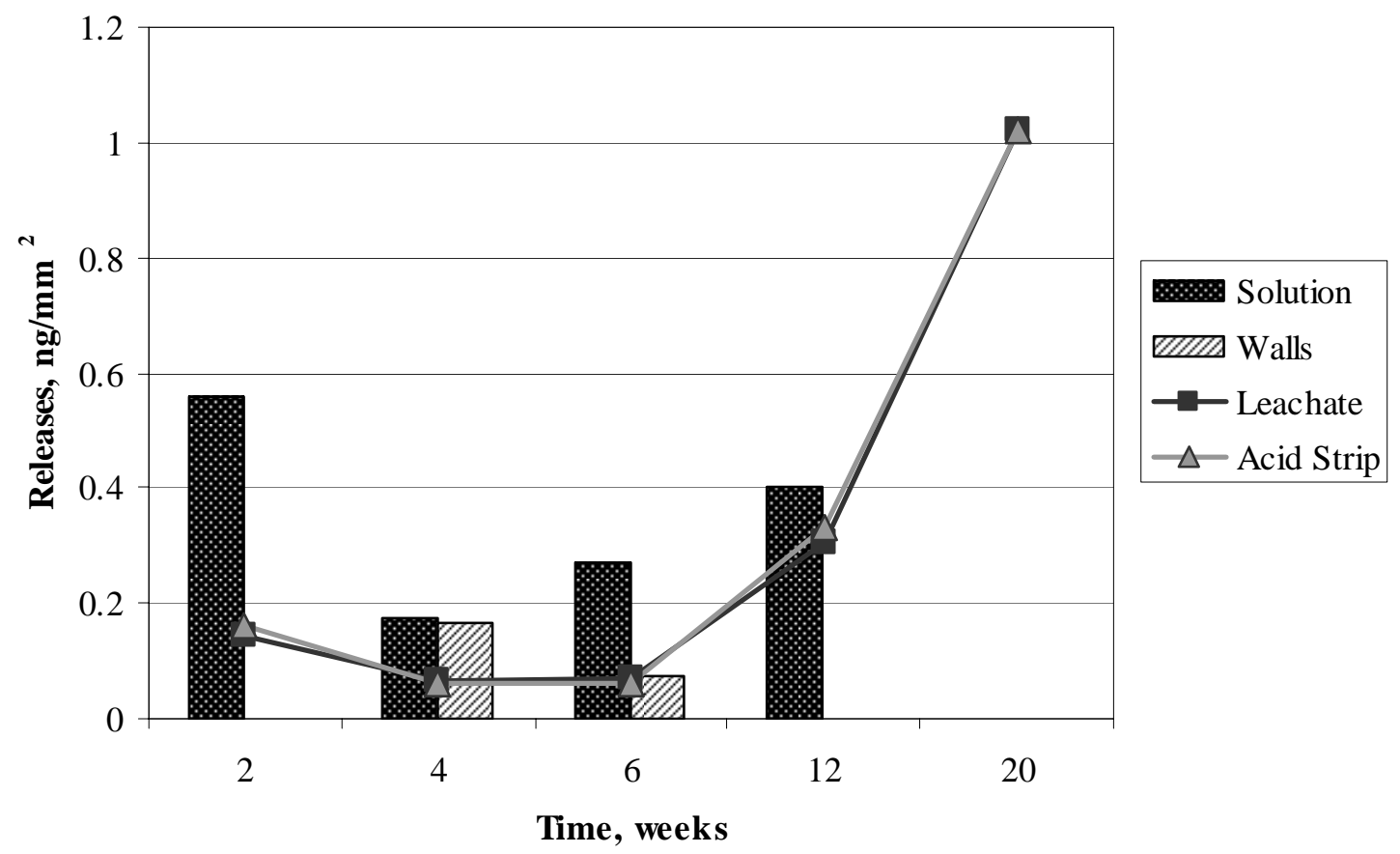

Figure J-91. Copper Releases in Solution and on Walls from Polished Sample 27 in $1 \mathrm{KCl}$ Solution at Room Temperature and Average Detection Limits for Leachate and Acid Strip.

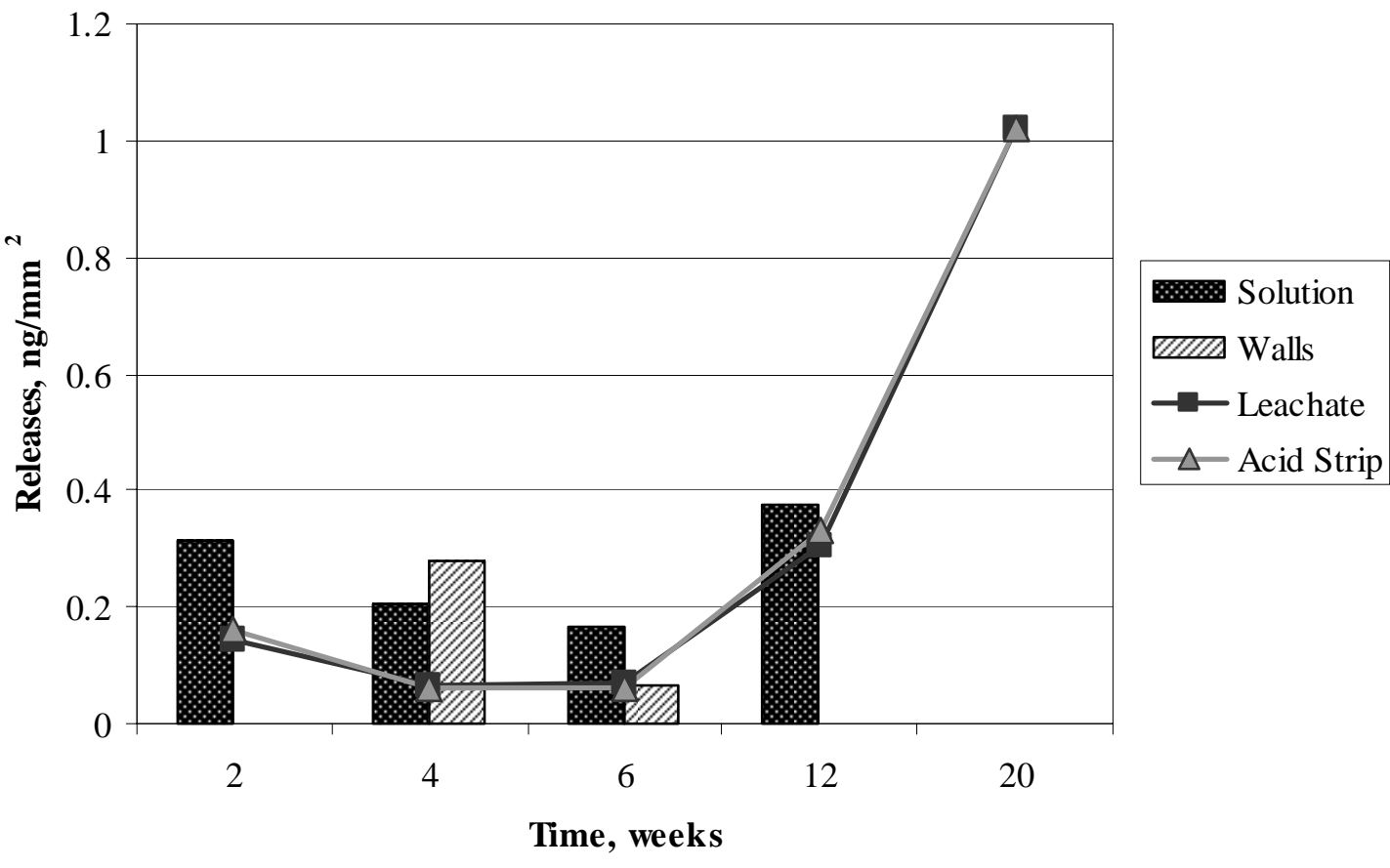

Figure J-92. Copper Present in Solutions and on Walls in 1KCI Solution Control at Room Temperature and Average Detection Limits for Leachate and Acid Strip. 


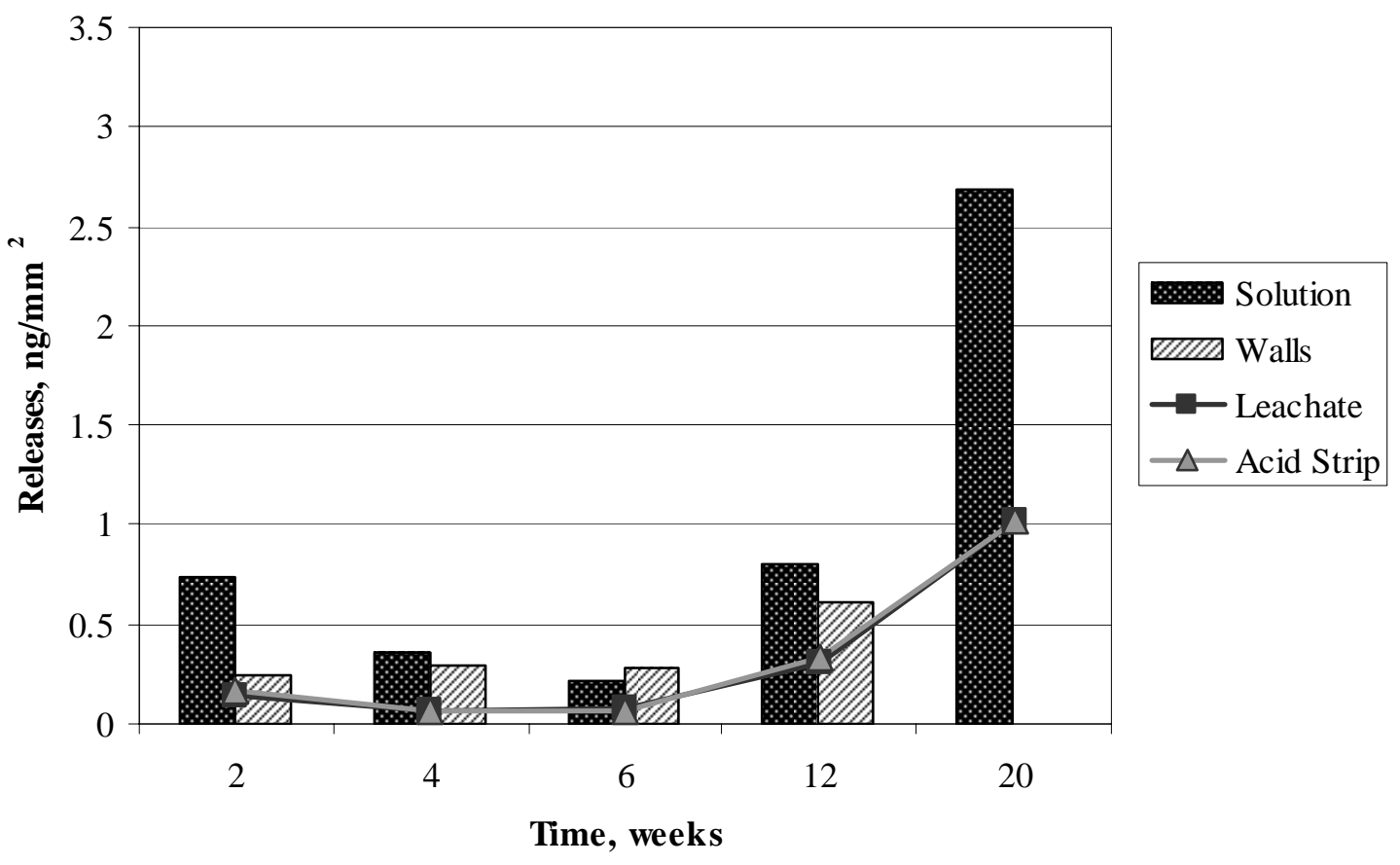

Figure J-93. Copper Releases in Solution and on Walls from Polished Sample 29 in 10KCI Solution at Room Temperature and Average Detection Limits for Leachate and Acid Strip.

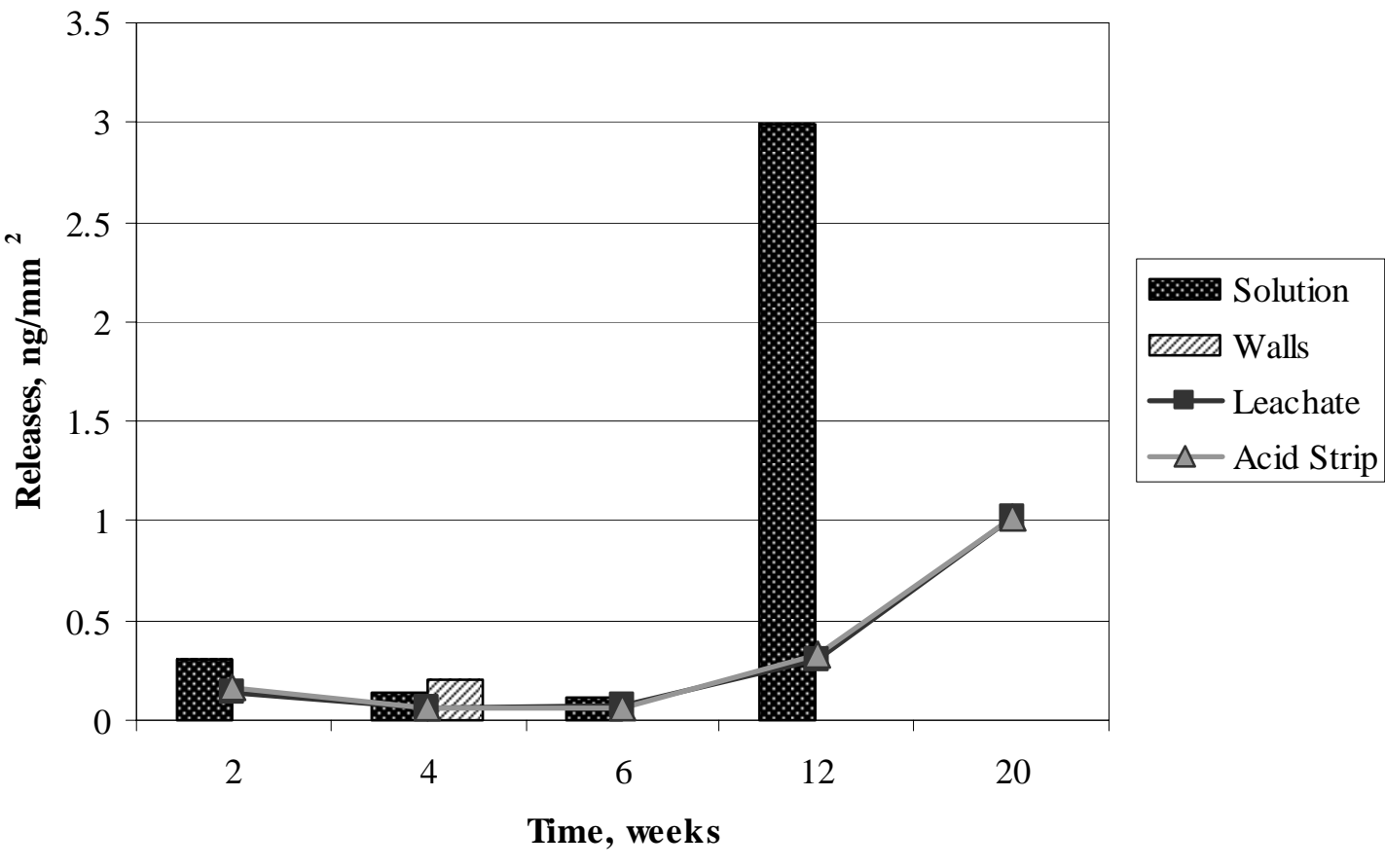

Figure J-94. Copper Present in Solutions and on Walls in 10KCl Solution Control at Room Temperature and Average Detection Limits for Leachate and Acid Strip. 


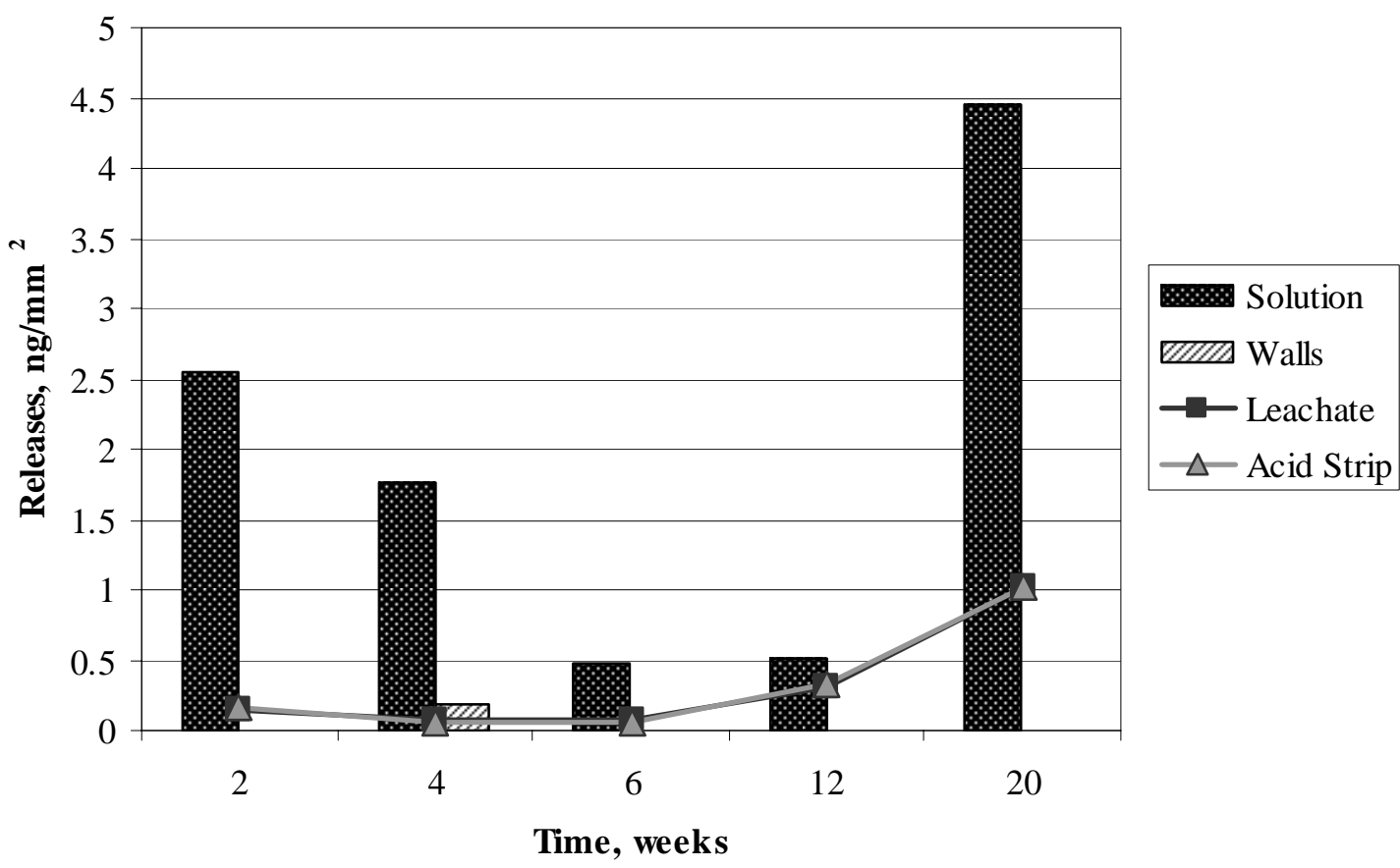

Figure J-95. Copper Releases in Solution and on Walls from Polished Sample 31 in AJ13 Solution at Room Temperature and Average Detection Limits for Leachate and Acid Strip.

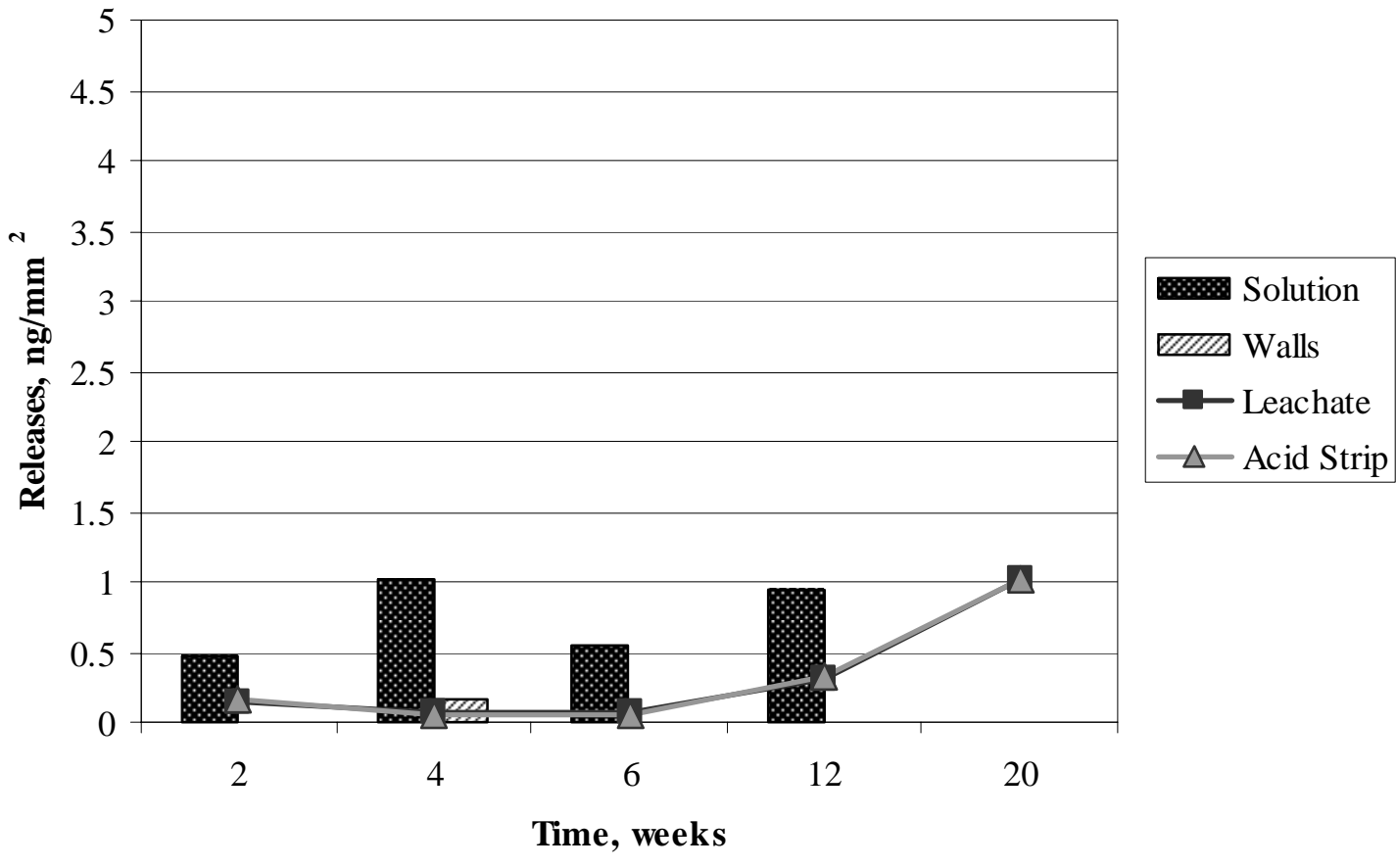

Figure J-96. Copper Present in Solutions and on Walls in AJ13 Solution Control at Room Temperature and Average Detection Limits for Leachate and Acid Strip. 


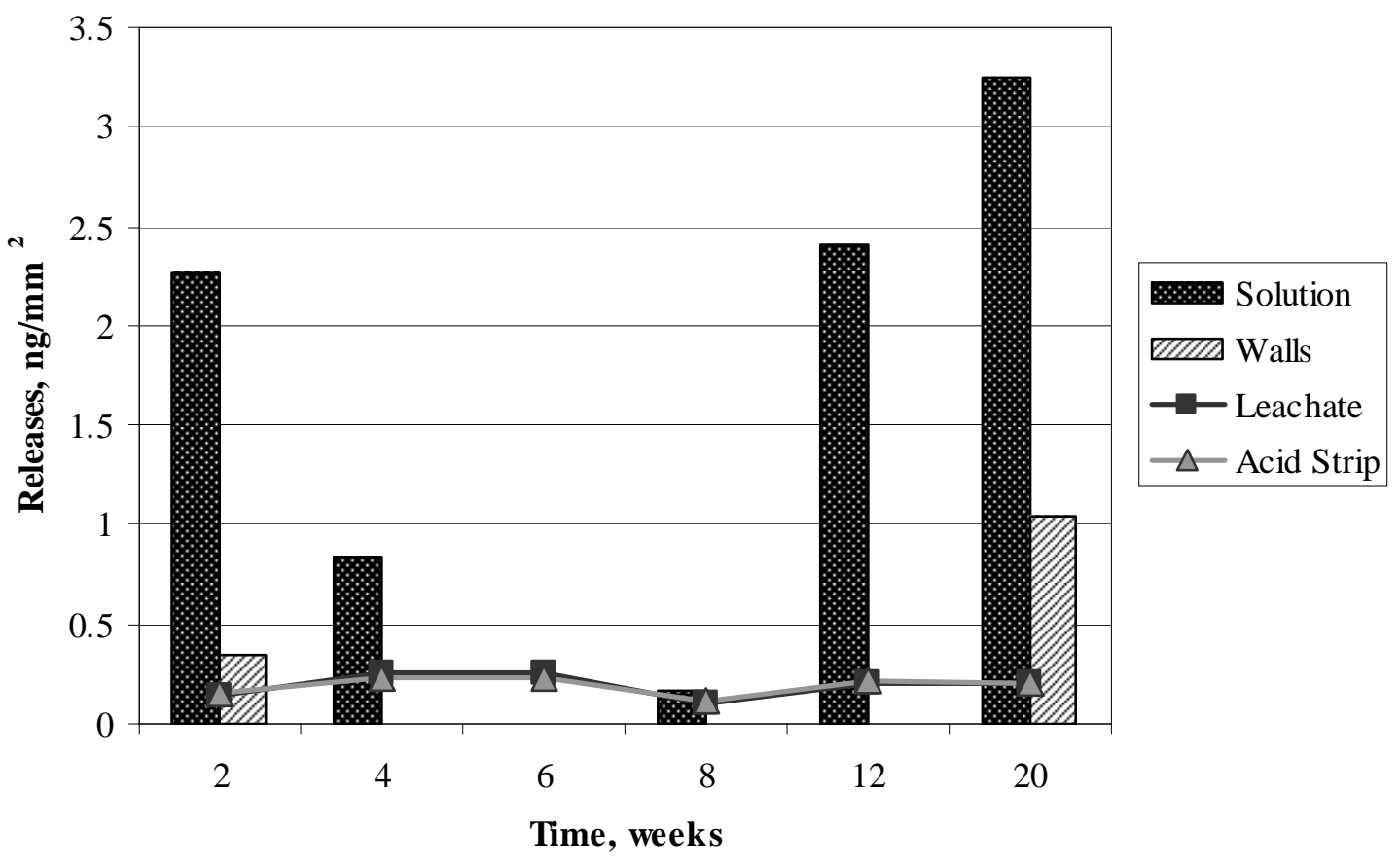

Figure J-97. Vanadium Releases in Solution and on Walls from Polished Sample 25 in $1 \mathrm{KCl}$ Solution at $90^{\circ} \mathrm{C}$ and Average Detection Limits for Leachate and Acid Strip.

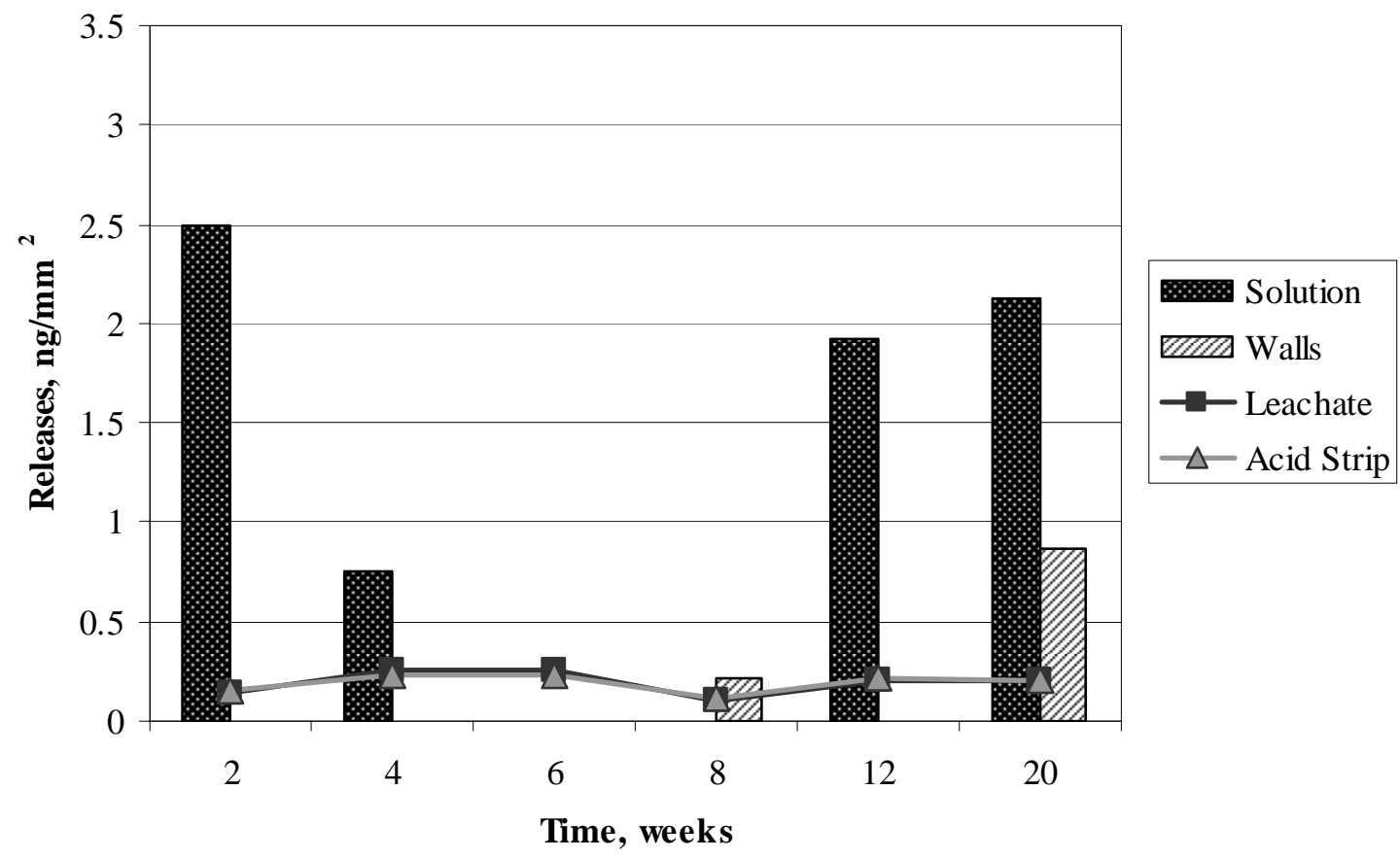

Figure J-98. Vanadium Present in Solutions and on Walls in $1 \mathrm{KCl}$ Solution Control at $90^{\circ} \mathrm{C}$ and Average Detection Limits for Leachate and Acid Strip. 


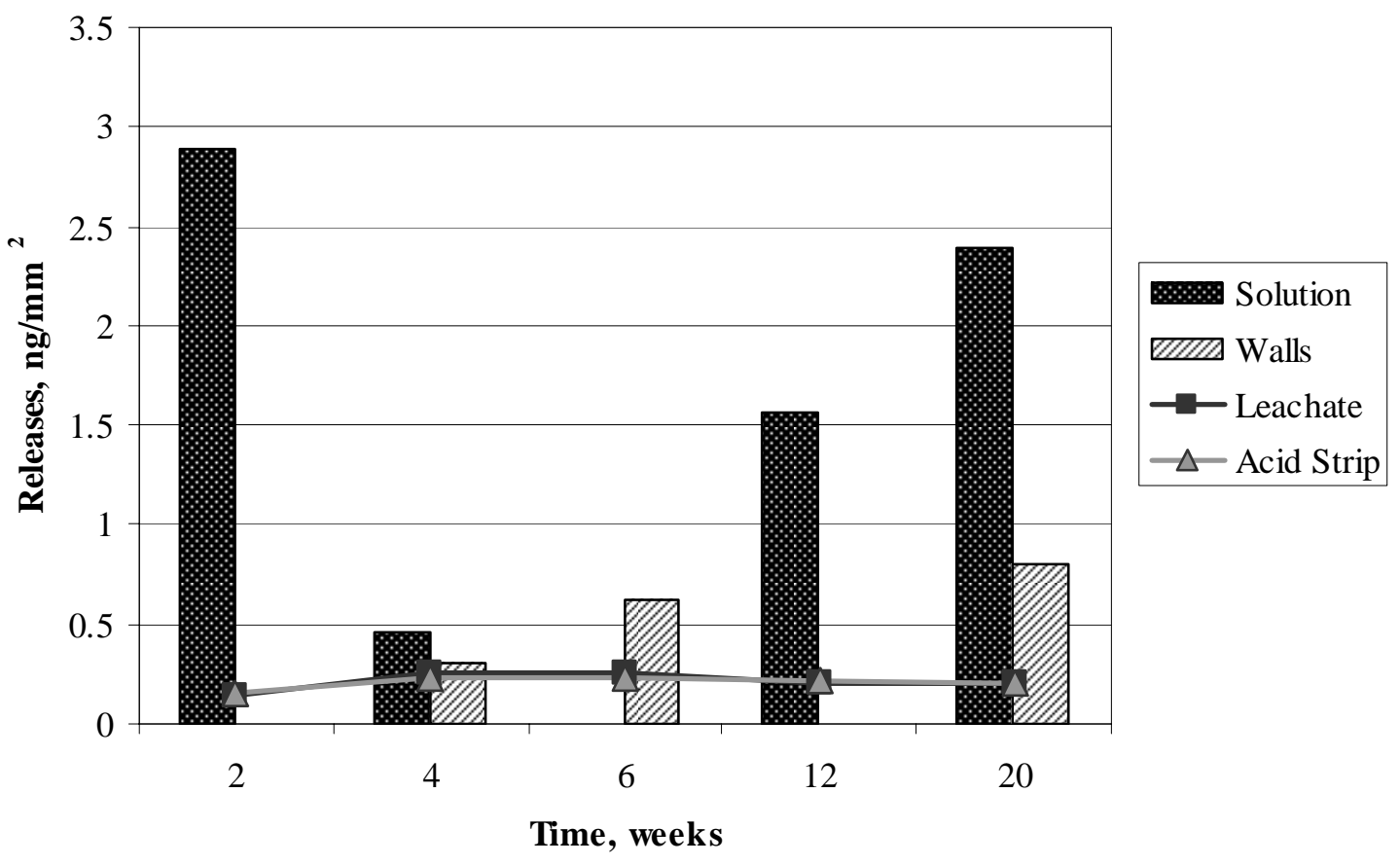

Figure J-99. Vanadium Releases in Solution and on Walls from Polished Sample 27 in $1 \mathrm{KCl}$ Solution at Room Temperature and Average Detection Limits for Leachate and Acid Strip.

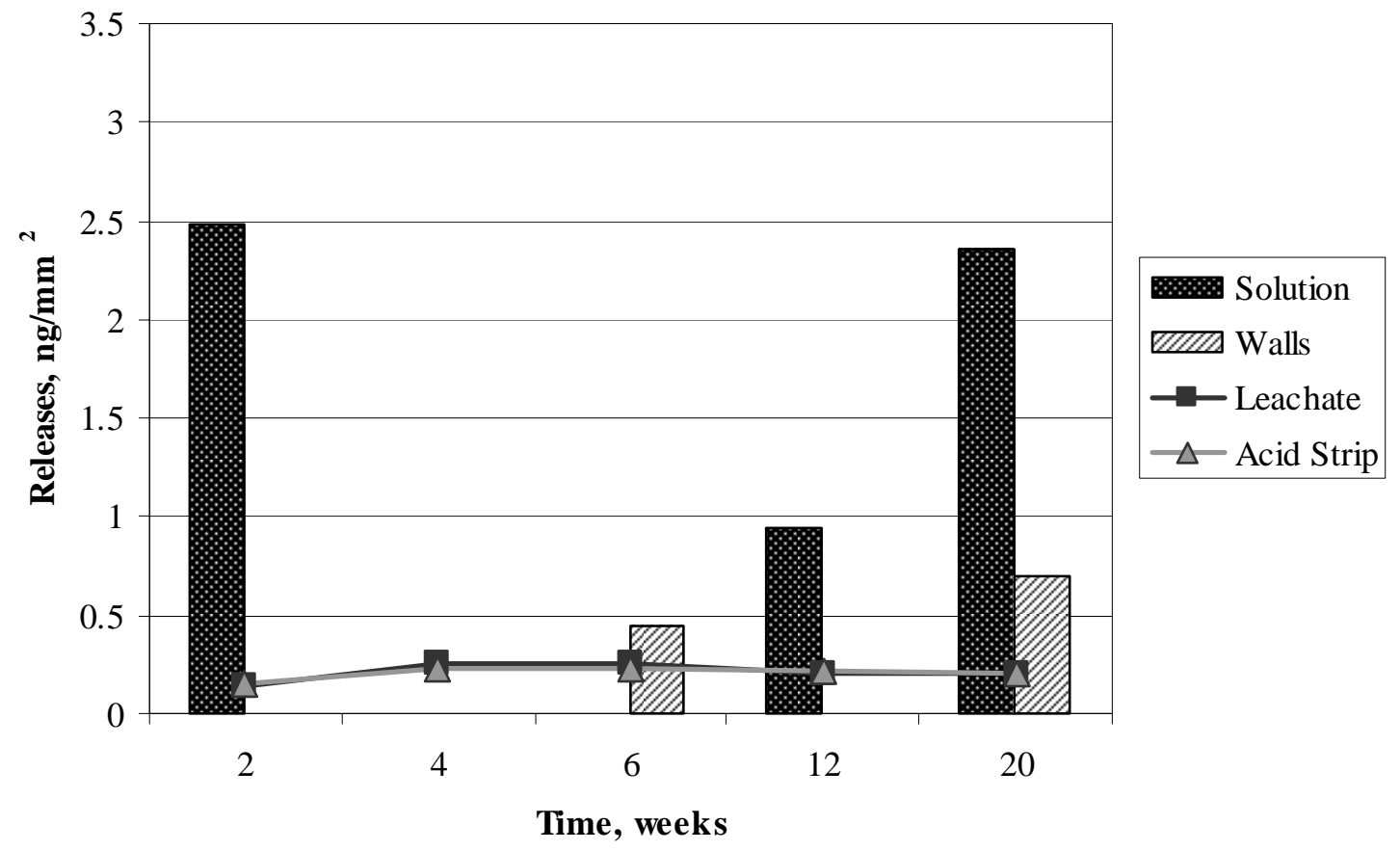

Figure J-100. Vanadium Present in Solutions and on Walls in 1KCI Solution Control at Room Temperature and Average Detection Limits for Leachate and Acid Strip. 


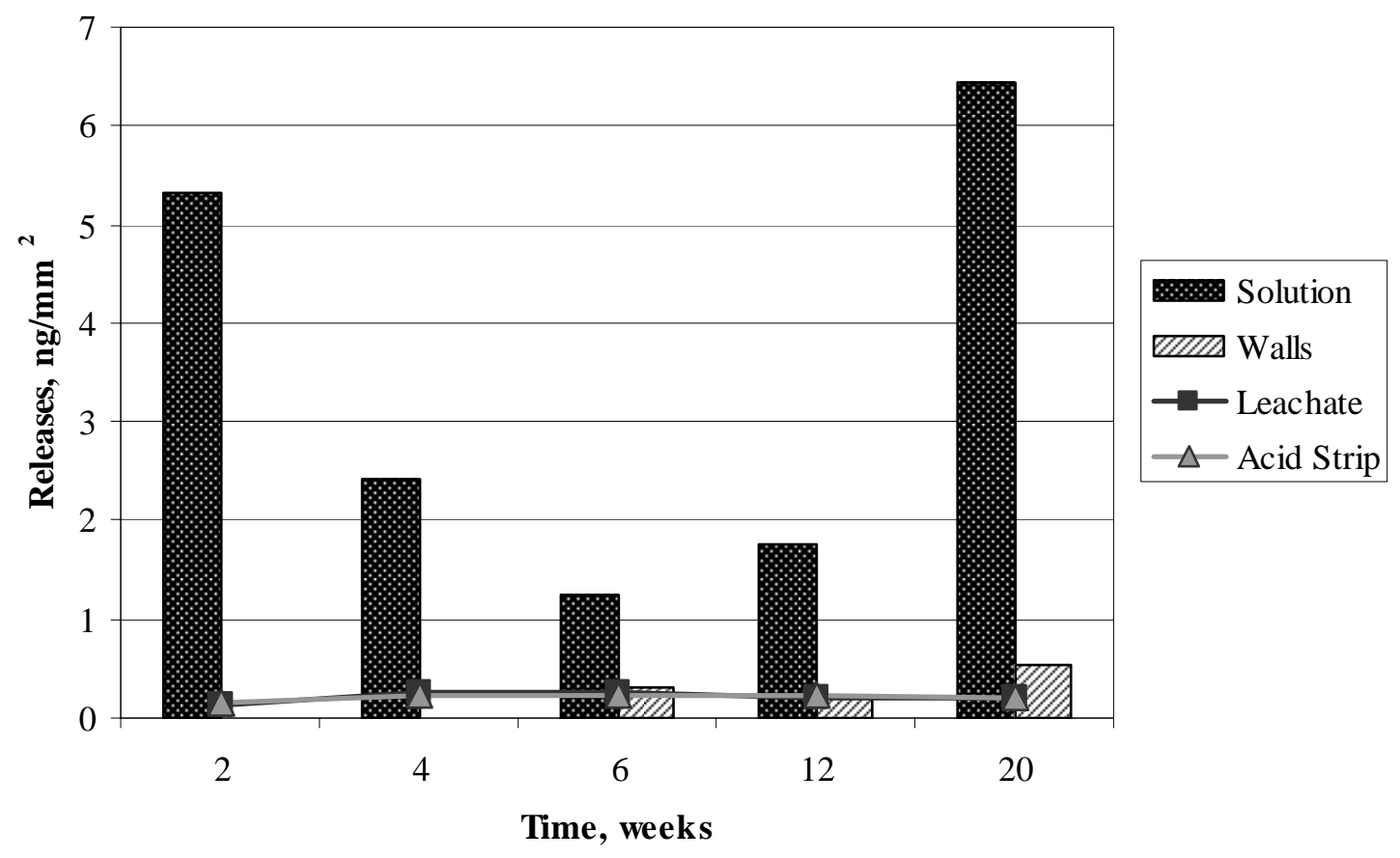

Figure J-101. Vanadium Releases in Solution and on Walls from Polished Sample 29 in $10 \mathrm{KCl}$ Solution at Room Temperature and Average Detection Limits for Leachate and Acid Strip.

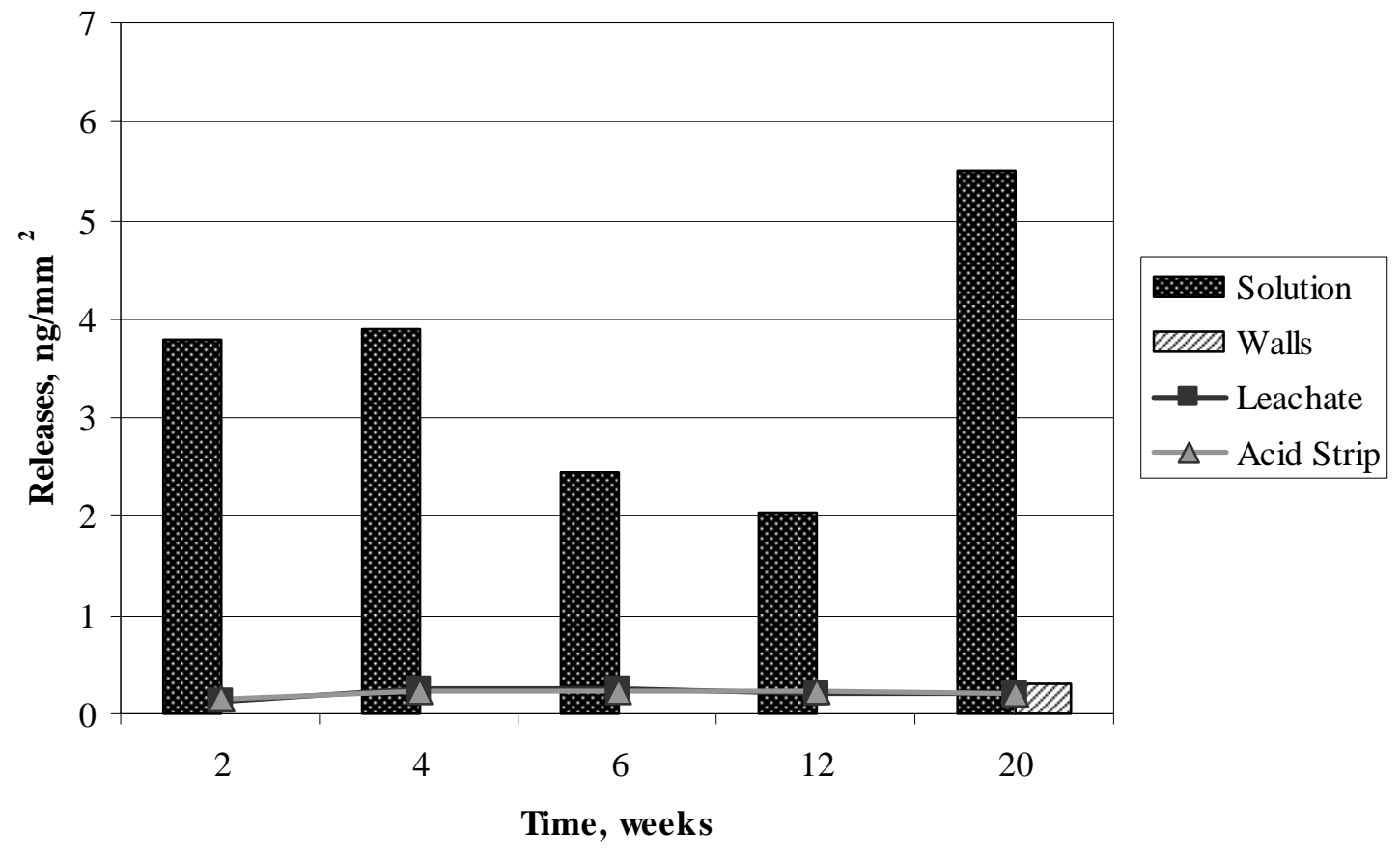

Figure J-102. Vanadium Present in Solutions and on Walls in 10KCI Solution Control at Room Temperature and Average Detection Limits for Leachate and Acid Strip. 


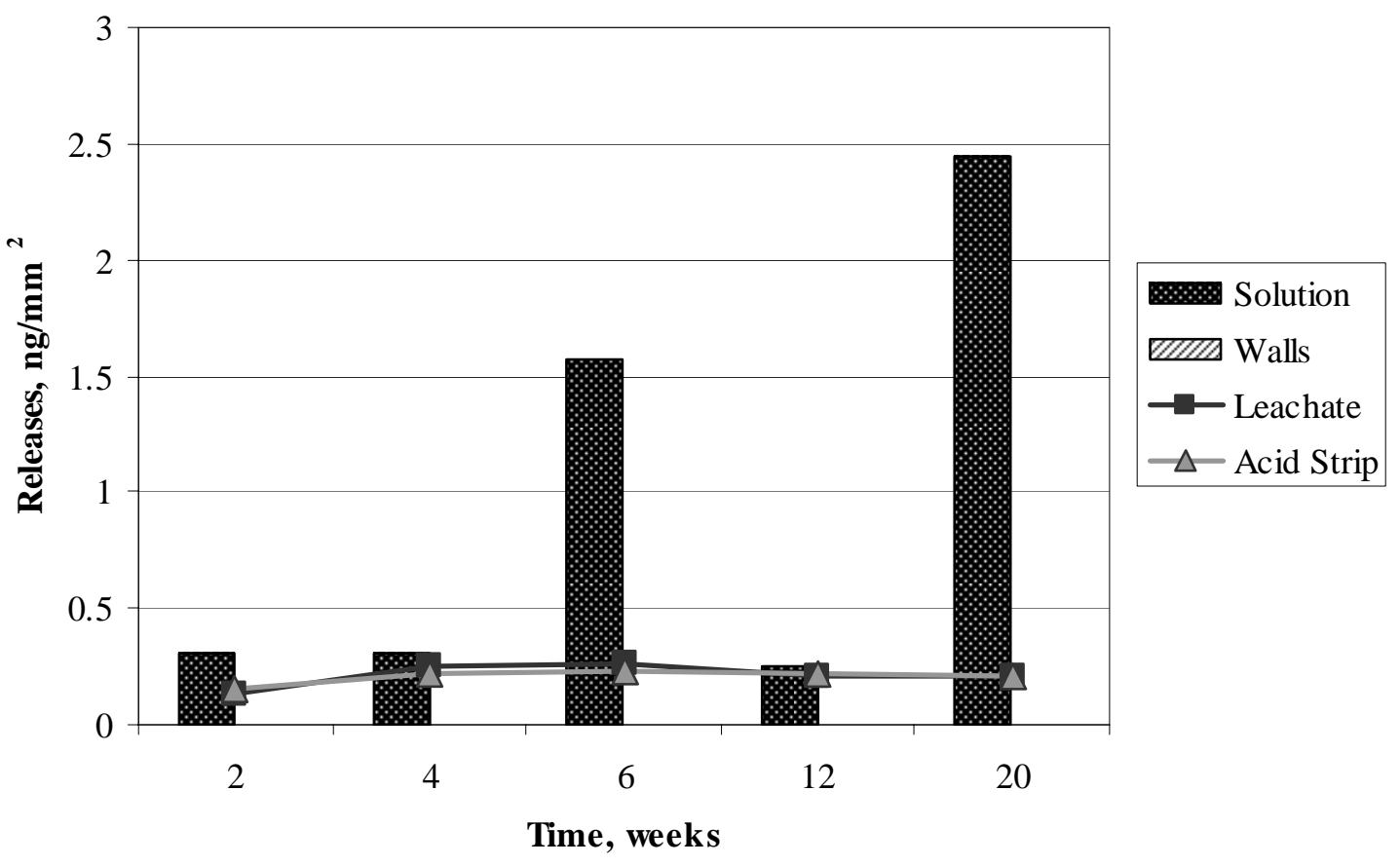

Figure J-103. Vanadium Releases in Solution and on Walls from Polished Sample 31 in AJ13 Solution at Room Temperature and Average Detection Limits for Leachate and Acid Strip.

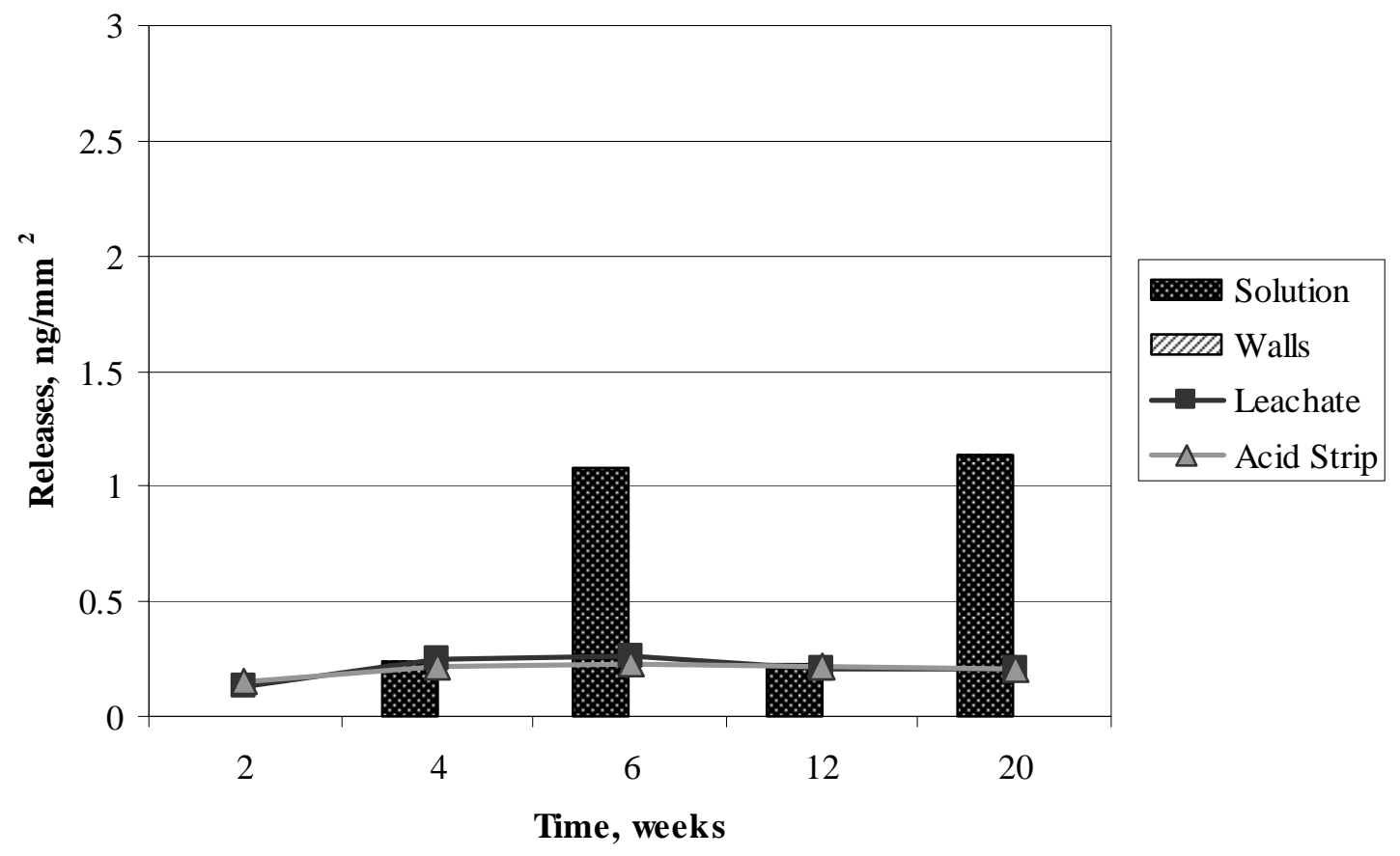

Figure J-104. Vanadium Present in Solutions and on Walls in AJ13 Solution Control at Room Temperature and Average Detection Limits for Leachate and Acid Strip. 


\section{K. Supplementary Tests-Raw Data}

Table K-1. Leachate data $\left(\mathrm{ng} / \mathrm{mm}^{2}\right)$ from SS15ZR26 specimens immersed in room temperature solution for 14 days.

\begin{tabular}{|c|c|c|c|c|c|c|c|c|c|c|c|c|c|c|}
\hline \multirow[b]{2}{*}{ Expt. ID } & \multirow[b]{2}{*}{ Ingot ID } & \multicolumn{4}{|c|}{ Major Elements } & \multicolumn{5}{|c|}{ Noble Metal Fission Products } & \multicolumn{4}{|c|}{ Minor Elements } \\
\hline & & $\mathrm{Fe}$ & $\mathrm{Cr}$ & $\mathrm{Ni}$ & $\mathrm{Zr}$ & $\mathrm{Nb}$ & $\mathrm{Pd}$ & $\mathrm{Rh}$ & $\mathrm{Ru}$ & Mo & $\mathrm{Mn}$ & $\mathrm{Co}$ & $\mathrm{Cu}$ & $\mathrm{V}$ \\
\hline \multicolumn{2}{|c|}{ Detection Limits } & 2.07 & 2.07 & 2.07 & 0.01 & 0.02 & 0.01 & 0.01 & 0.01 & 0.08 & 0.03 & 0.00 & 0.14 & 0.13 \\
\hline $1 \mathrm{KCl} 90-2-328$ & 25 & $\mathrm{a}$ & $\mathrm{a}$ & 3.63 & $\mathrm{a}$ & $\mathrm{a}$ & $\mathrm{a}$ & $\mathrm{a}$ & $\mathrm{a}$ & 1.03 & 0.29 & 0.07 & 0.73 & 2.27 \\
\hline $1 \mathrm{KCl} 90-2-388$ & control & $\mathrm{a}$ & $\mathrm{a}$ & $\mathrm{a}$ & $\mathrm{a}$ & $\mathrm{a}$ & $\mathrm{a}$ & $\mathrm{a}$ & $\mathrm{a}$ & 0.27 & $\mathrm{a}$ & $\mathrm{a}$ & 0.31 & 2.49 \\
\hline 1KClRT-2-329 & 27 & 1.85 & $\mathrm{a}$ & 1.85 & $\mathrm{a}$ & $\mathrm{a}$ & $\mathrm{a}$ & $\mathrm{a}$ & $\mathrm{a}$ & 0.12 & 0.12 & $\mathrm{a}$ & 0.56 & 2.88 \\
\hline 1KClRT-2-389 & control & $\mathrm{a}$ & $\mathrm{a}$ & $\mathrm{a}$ & $\mathrm{a}$ & $\mathrm{a}$ & $\mathrm{a}$ & $\mathrm{a}$ & $\mathrm{a}$ & 0.16 & $\mathrm{a}$ & $\mathrm{a}$ & 0.32 & 2.48 \\
\hline 10KClRT-2-353 & 29 & 98.30 & 22.91 & 12.41 & 0.73 & 0.03 & 0.02 & 0.03 & 0.14 & 1.89 & 3.41 & 0.37 & 0.74 & 5.32 \\
\hline 10KCIRT-2-390 & control & $\mathrm{a}$ & $\mathrm{a}$ & $\mathrm{a}$ & $\mathrm{a}$ & $\mathrm{a}$ & $\mathrm{a}$ & $\mathrm{a}$ & $\mathrm{a}$ & 0.40 & $\mathrm{a}$ & $\mathrm{a}$ & 0.30 & 3.80 \\
\hline $\mathrm{AJ} 13 \mathrm{pH}=2 \mathrm{RT}-2-278$ & 31 & 257.14 & 72.00 & 27.12 & 2.23 & 0.27 & 0.41 & 0.39 & 0.96 & 8.34 & 3.67 & 0.43 & 2.55 & 0.30 \\
\hline $\mathrm{AJ} 13 \mathrm{pH}=2 \mathrm{RT}-2-391$ & control & $\mathrm{a}$ & $\mathrm{a}$ & $\mathrm{a}$ & 0.25 & $\mathrm{a}$ & $\mathrm{a}$ & $a$ & $\mathrm{a}$ & 1.43 & $\mathrm{a}$ & $\mathrm{a}$ & 0.47 & $\mathrm{a}$ \\
\hline
\end{tabular}

${ }^{\mathrm{a}}$ Element below detectablility limits of measuring instrument.

Table K-2. Acid Strip data $\left(\mathrm{ng} / \mathrm{mm}^{2}\right)$ from SS15ZR26 specimens immersed in room temperature solution for 14 days.

\begin{tabular}{|c|c|c|c|c|c|c|c|c|c|c|c|c|c|c|}
\hline \multirow[b]{2}{*}{ Expt. ID } & \multirow[b]{2}{*}{ Ingot ID } & \multicolumn{4}{|c|}{ Major Elements } & \multicolumn{5}{|c|}{ Noble Metal Fission Products } & \multicolumn{4}{|c|}{ Minor Elements } \\
\hline & & $\mathrm{Fe}$ & $\mathrm{Cr}$ & $\mathrm{Ni}$ & $\mathrm{Zr}$ & $\mathrm{Nb}$ & $\mathrm{Pd}$ & $\mathrm{Rh}$ & $\mathrm{Ru}$ & Mo & $\mathrm{Mn}$ & $\mathrm{Co}$ & $\mathrm{Cu}$ & $\mathrm{V}$ \\
\hline \multicolumn{2}{|l|}{ Detection Limits } & 2.29 & 2.29 & 2.29 & 0.01 & 0.02 & 0.01 & 0.01 & 0.01 & 0.09 & 0.03 & 0.003 & 0.16 & 0.15 \\
\hline $1 \mathrm{KCl} 90-2-328 \mathrm{AS}$ & 25 & 4.83 & $\mathrm{a}$ & $\mathrm{a}$ & 0.05 & $\mathrm{a}$ & $\mathrm{a}$ & $\mathrm{a}$ & $\mathrm{a}$ & $\mathrm{a}$ & $\mathrm{a}$ & $\mathrm{a}$ & $\mathrm{a}$ & 0.34 \\
\hline $1 \mathrm{KCl} 90-2-388 \mathrm{AS}$ & control & $\mathrm{a}$ & $\mathrm{a}$ & $\mathrm{a}$ & 0.17 & $\mathrm{a}$ & $\mathrm{a}$ & $\mathrm{a}$ & $\mathrm{a}$ & $\mathrm{a}$ & $\mathrm{a}$ & $\mathrm{a}$ & $\mathrm{a}$ & $\mathrm{a}$ \\
\hline 1KClRT-2-329AS & 27 & 5.83 & $\mathrm{a}$ & $\mathrm{a}$ & $\mathrm{a}$ & $\mathrm{a}$ & $\mathrm{a}$ & $\mathrm{a}$ & $\mathrm{a}$ & 0.08 & $\mathrm{a}$ & $\bar{a}$ & $\mathrm{a}$ & $\mathrm{a}$ \\
\hline 1KClRT-2-389AS & control & 13.12 & $\mathrm{a}$ & 2.19 & 0.13 & $\mathrm{a}$ & $\mathrm{a}$ & $\mathrm{a}$ & $\mathrm{a}$ & $\mathrm{a}$ & $\mathrm{a}$ & $\mathrm{a}$ & $\mathrm{a}$ & $\mathrm{a}$ \\
\hline 10KClRT-2-353AS & 29 & 45.01 & 12.56 & $\mathrm{a}$ & 0.30 & $\mathrm{a}$ & $\mathrm{a}$ & $\mathrm{a}$ & 0.08 & 0.79 & $\mathrm{a}$ & $\mathrm{a}$ & 0.24 & $\mathrm{a}$ \\
\hline $\mathrm{AJ} 13 \mathrm{pH}=2 \mathrm{RT}-2-278 \mathrm{AS}$ & 31 & $\mathrm{a}$ & $\mathrm{a}$ & $\mathrm{a}$ & 0.99 & 0.09 & 0.08 & $\mathrm{a}$ & $\mathrm{a}$ & 0.28 & $\mathrm{a}$ & $\bar{a}$ & $\mathrm{a}$ & $\mathrm{a}$ \\
\hline $\mathrm{AJ} 13 \mathrm{pH}=2 \mathrm{RT}-2-391 \mathrm{AS}$ & control & $\mathrm{a}$ & $\mathrm{a}$ & $\bar{a}$ & 0.26 & $\bar{a}$ & $\bar{a}$ & $\mathrm{a}$ & $\mathrm{a}$ & 0.30 & $\mathrm{a}$ & $\mathrm{a}$ & $\mathrm{a}$ & $\mathrm{a}$ \\
\hline
\end{tabular}

${ }^{\mathrm{a}}$ Element below detectablility limits of measuring instrument. 
Table K-3. Leachate data $\left(\mathrm{ng} / \mathrm{mm}^{2}\right)$ from SS15ZR26 specimens immersed in room temperature solution for 28 days.

\begin{tabular}{|c|c|c|c|c|c|c|c|c|c|c|c|c|c|c|}
\hline \multirow[b]{2}{*}{ Expt. ID } & \multirow[b]{2}{*}{ Ingot ID } & \multicolumn{4}{|c|}{ Major Elements } & \multicolumn{5}{|c|}{ Noble Metal Fission Products } & \multicolumn{4}{|c|}{ Minor Elements } \\
\hline & & $\mathrm{Fe}$ & $\mathrm{Cr}$ & $\mathrm{Ni}$ & $\mathrm{Zr}$ & $\mathrm{Nb}$ & $\mathrm{Pd}$ & $\mathrm{Rh}$ & $\mathrm{Ru}$ & Mo & $\mathrm{Mn}$ & $\mathrm{Co}$ & $\mathrm{Cu}$ & $\mathrm{V}$ \\
\hline \multicolumn{2}{|c|}{ Detection Limits } & 2.08 & 2.08 & 2.08 & 0.02 & 0.02 & 0.01 & 0.02 & 0.02 & 0.03 & 0.02 & 0.03 & 0.07 & 0.25 \\
\hline $1 \mathrm{KCl} 90-4-330$ & 25 & $\mathrm{a}$ & $\mathrm{a}$ & $\mathrm{a}$ & $\bar{a}$ & $\mathrm{a}$ & $\mathrm{a}$ & $\mathrm{a}$ & $\bar{a}$ & 0.16 & $\mathrm{a}$ & $\mathrm{a}$ & 0.27 & 0.84 \\
\hline $1 \mathrm{KCl} 90-4-392$ & control & $\mathrm{a}$ & $\mathrm{a}$ & $\mathrm{a}$ & $\mathrm{a}$ & $\mathrm{a}$ & $\mathrm{a}$ & $\mathrm{a}$ & $\mathrm{a}$ & 0.49 & $\mathrm{a}$ & $\mathrm{a}$ & 0.42 & 0.75 \\
\hline 1KClRT-4-331 & 27 & $\bar{a}$ & $\bar{a}$ & $\bar{a}$ & $\bar{a}$ & $\bar{a}$ & $\bar{a}$ & $\bar{a}$ & $\bar{a}$ & 0.10 & 0.04 & $\bar{a}$ & 0.17 & 0.46 \\
\hline 1KClRT-4-393 & control & $\mathrm{a}$ & $\mathrm{a}$ & $\mathrm{a}$ & $\mathrm{a}$ & $\mathrm{a}$ & $\mathrm{a}$ & $\mathrm{a}$ & $\mathrm{a}$ & 0.11 & $\mathrm{a}$ & $\mathrm{a}$ & 0.20 & $\mathrm{a}$ \\
\hline 10KClRT-4-354 & 29 & 34.00 & 5.51 & 3.68 & 0.15 & 0.02 & 0.01 & 0.03 & 0.14 & 1.02 & 1.68 & 0.19 & 0.36 & 2.42 \\
\hline 10KClRT-4-394 & control & $\bar{a}$ & $\bar{a}$ & $\bar{a}$ & $\bar{a}$ & $\bar{a}$ & $\bar{a}$ & $\bar{a}$ & $\mathrm{a}$ & 0.14 & 0.02 & $\bar{a}$ & 0.14 & 3.91 \\
\hline $\mathrm{AJ} 13 \mathrm{pH}=2 \mathrm{RT}-4-279$ & 31 & 2.79 & $\mathrm{a}$ & $\mathrm{a}$ & 0.44 & 0.03 & $\mathrm{a}$ & 0.03 & 0.03 & 0.68 & 0.08 & $\mathrm{a}$ & 1.76 & 0.31 \\
\hline $\mathrm{AJ} 13 \mathrm{pH}=2 \mathrm{RT}-4-395$ & control & $\bar{a}$ & $\bar{a}$ & $a$ & 0.27 & $\bar{a}$ & $a$ & $\bar{a}$ & $\bar{a}$ & 0.37 & 0.02 & $\mathrm{a}$ & 1.02 & 0.24 \\
\hline
\end{tabular}

${ }^{\mathrm{a}}$ Element below detectablility limits of measuring instrument.

Table K-4. Acid Strip data $\left(\mathrm{ng} / \mathrm{mm}^{2}\right)$ from SS15ZR26 specimens immersed in room temperature solution for 28 days.

\begin{tabular}{|c|c|c|c|c|c|c|c|c|c|c|c|c|c|c|}
\hline \multirow[b]{2}{*}{ Expt. ID } & \multirow[b]{2}{*}{ Ingot ID } & \multicolumn{4}{|c|}{ Major Elements } & \multicolumn{5}{|c|}{ Noble Metal Fission Products } & \multicolumn{4}{|c|}{ Minor Elements } \\
\hline & & $\mathrm{Fe}$ & $\mathrm{Cr}$ & $\mathrm{Ni}$ & $\mathrm{Zr}$ & $\mathrm{Nb}$ & $\mathrm{Pd}$ & $\mathrm{Rh}$ & $\mathrm{Ru}$ & Mo & $\mathrm{Mn}$ & $\mathrm{Co}$ & $\mathrm{Cu}$ & $\mathrm{V}$ \\
\hline \multicolumn{2}{|l|}{ Detection Limits } & 2.24 & 2.24 & 2.24 & 0.02 & 0.02 & 0.01 & 0.01 & 0.02 & 0.03 & 0.02 & 0.02 & 0.06 & 0.22 \\
\hline 1KCl90-4-330AS & 25 & 2.21 & $\mathrm{a}$ & $\mathrm{a}$ & 0.03 & $\mathrm{a}$ & $\mathrm{a}$ & $\mathrm{a}$ & $\bar{a}$ & 0.04 & $\bar{a}$ & $\bar{a}$ & 0.26 & $\mathrm{a}$ \\
\hline $1 \mathrm{KCl} 90-4-392 \mathrm{AS}$ & control & $\mathrm{a}$ & $\mathrm{a}$ & 2.26 & 0.07 & $\mathrm{a}$ & $\mathrm{a}$ & $\mathrm{a}$ & $\mathrm{a}$ & 0.08 & $\mathrm{a}$ & $\mathrm{a}$ & 0.29 & $\mathrm{a}$ \\
\hline 1KClRT-4-331AS & 27 & $\mathrm{a}$ & $\mathrm{a}$ & 4.54 & 0.05 & $\mathrm{a}$ & $\mathrm{a}$ & $\mathrm{a}$ & $\mathrm{a}$ & 0.04 & $\mathrm{a}$ & $\mathrm{a}$ & 0.17 & 0.30 \\
\hline 1KClRT-4-393AS & control & $\mathrm{a}$ & $\mathrm{a}$ & $\mathrm{a}$ & 0.16 & $\mathrm{a}$ & $\mathrm{a}$ & $\bar{a}$ & $\bar{a}$ & $\mathrm{a}$ & $\bar{a}$ & $\bar{a}$ & 0.28 & $\mathrm{a}$ \\
\hline 10KCIRT-4-354AS & 29 & 57.25 & 24.22 & 3.30 & 0.22 & 0.05 & $\mathrm{a}$ & 0.04 & 0.20 & 1.73 & 0.03 & $\mathrm{a}$ & 0.29 & $\mathrm{a}$ \\
\hline 10KCIRT-4-394AS & control & $\mathrm{a}$ & $\mathrm{a}$ & $\mathrm{a}$ & 0.20 & $\mathrm{a}$ & $\mathrm{a}$ & $\mathrm{a}$ & $\mathrm{a}$ & 0.03 & $\mathrm{a}$ & $\mathrm{a}$ & 0.20 & $\mathrm{a}$ \\
\hline AJ13pH=2RT-4-279AS & 31 & $\bar{a}$ & $\bar{a}$ & $\bar{a}$ & 0.31 & $\bar{a}$ & 0.02 & $\bar{a}$ & $\mathrm{a}$ & 0.07 & $\mathrm{a}$ & $\mathrm{a}$ & 0.19 & $\mathrm{a}$ \\
\hline $\mathrm{AJ} 13 \mathrm{pH}=2 \mathrm{RT}-4-395 \mathrm{AS}$ & control & $\bar{a}$ & $\bar{a}$ & $\bar{a}$ & 0.46 & $\bar{a}$ & $\bar{a}$ & $\bar{a}$ & $\mathrm{a}$ & 0.07 & $\bar{a}$ & $\bar{a}$ & 0.16 & $\mathrm{a}$ \\
\hline
\end{tabular}

${ }^{\mathrm{a}}$ Element below detectablility limits of measuring instrument. 
Table K-5. Leachate data $\left(\mathrm{ng} / \mathrm{mm}^{2}\right)$ from SS15ZR26 specimens immersed in room temperature solution for 42 days.

\begin{tabular}{|c|c|c|c|c|c|c|c|c|c|c|c|c|c|c|}
\hline \multirow[b]{2}{*}{ Expt. ID } & \multirow[b]{2}{*}{ Ingot ID } & \multicolumn{4}{|c|}{ Major Elements } & \multicolumn{5}{|c|}{ Noble Metal Fission Products } & \multicolumn{4}{|c|}{ Minor Elements } \\
\hline & & $\mathrm{Fe}$ & $\mathrm{Cr}$ & $\mathrm{Ni}$ & $\mathrm{Zr}$ & $\mathrm{Nb}$ & $\mathrm{Pd}$ & $\mathrm{Rh}$ & $\mathrm{Ru}$ & Mo & $\mathrm{Mn}$ & $\mathrm{Co}$ & $\mathrm{Cu}$ & $\mathrm{V}$ \\
\hline \multicolumn{2}{|c|}{ Detection Limits } & 2.06 & 2.06 & 2.06 & 0.02 & 0.02 & 0.01 & 0.02 & 0.02 & 0.04 & 0.02 & 0.03 & 0.07 & 0.26 \\
\hline $1 \mathrm{KCl} 90-6-332$ & 25 & 0 & 0 & 0 & 0.0329 & 0 & 0 & 0 & 0 & 0.4372 & 0 & 0 & 0.2397 & 0 \\
\hline $1 \mathrm{KCl} 90-6-396$ & control & 0 & 0 & 0 & 0 & 0 & 0 & 0 & 0 & 0.0784 & 0 & 0 & 0.1517 & 0 \\
\hline 1KClRT-6-333 & 27 & 0 & 0 & 0 & 0.0154 & 0 & 0 & 0 & 0 & 0.7086 & 0.0288 & 0 & 0.2698 & 0 \\
\hline 1KClRT-6-397 & control & 0 & 0 & 0 & 0 & 0 & 0 & 0 & 0 & 0.0454 & 0 & 0 & 0.1653 & 0 \\
\hline 10KClRT-6-355 & 29 & 47.742 & 10.379 & 5.1894 & 0.0488 & 0.0187 & 0.0156 & 0.0259 & 0.1017 & 0.7348 & 1.5879 & 0.1723 & 0.2117 & 1.2454 \\
\hline 10KClRT-6-398 & control & 0 & 0 & 0 & 0 & 0 & 0 & 0 & 0 & 0.0703 & 0.0217 & 0 & 0.1158 & 2.4512 \\
\hline $\mathrm{AJ} 13 \mathrm{pH}=2 \mathrm{RT}-6-280$ & 31 & 4.1032 & 0 & 0 & 0.4893 & 0.0277 & 0 & 0.0236 & 0.0215 & 0.1744 & 0.0657 & 0 & 0.4739 & 1.5695 \\
\hline $\mathrm{AJ} 13 \mathrm{pH}=2 \mathrm{RT}-6-399$ & control & 0 & 0 & 0 & 0.2313 & 0 & 0 & 0 & 0 & 0.0596 & 0 & 0 & 0.5398 & 1.0795 \\
\hline
\end{tabular}

${ }^{\mathrm{a}}$ Element below detectablility limits of measuring instrument.

Table K-6. Acid Strip data $\left(\mathrm{ng} / \mathrm{mm}^{2}\right)$ from SS15ZR26 specimens immersed in room temperature solution for 42 days.

\begin{tabular}{|c|c|c|c|c|c|c|c|c|c|c|c|c|c|c|}
\hline \multirow[b]{2}{*}{ Expt. ID } & \multirow[b]{2}{*}{ Ingot ID } & \multicolumn{4}{|c|}{ Major Elements } & \multicolumn{5}{|c|}{ Noble Metal Fission Products } & \multicolumn{4}{|c|}{ Minor Elements } \\
\hline & & $\mathrm{Fe}$ & $\mathrm{Cr}$ & $\mathrm{Ni}$ & $\mathrm{Zr}$ & $\mathrm{Nb}$ & $\mathrm{Pd}$ & $\mathrm{Rh}$ & $\mathrm{Ru}$ & Mo & $\mathrm{Mn}$ & Co & $\mathrm{Cu}$ & $\mathrm{V}$ \\
\hline \multicolumn{2}{|l|}{ Detection Limits } & 2.29 & 2.29 & 2.29 & 0.02 & 0.02 & 0.01 & 0.01 & 0.02 & 0.03 & 0.02 & 0.03 & 0.06 & 0.23 \\
\hline $1 \mathrm{KCl} 90-6-332 \mathrm{AS}$ & 25 & $\mathrm{a}$ & $\mathrm{a}$ & $\bar{a}$ & 0.05 & $\bar{a}$ & $\bar{a}$ & 0.03 & 0.03 & $\bar{a}$ & $\mathrm{a}$ & $\bar{a}$ & 0.12 & $\mathrm{a}$ \\
\hline $1 \mathrm{KCl} 90-6-396 \mathrm{AS}$ & control & $\mathrm{a}$ & $\mathrm{a}$ & $\mathrm{a}$ & 0.54 & $\mathrm{a}$ & $\mathrm{a}$ & 0.02 & $\mathrm{a}$ & $\mathrm{a}$ & $\mathrm{a}$ & $\mathrm{a}$ & 0.09 & $\mathrm{a}$ \\
\hline 1KCIRT-6-333AS & 27 & $\mathrm{a}$ & $\mathrm{a}$ & $\mathrm{a}$ & 0.06 & $\mathrm{a}$ & $\mathrm{a}$ & $\mathrm{a}$ & $\mathrm{a}$ & 0.21 & $\mathrm{a}$ & $\mathrm{a}$ & 0.07 & 0.63 \\
\hline 1KCIRT-6-397AS & control & $\mathrm{a}$ & $\mathrm{a}$ & $\mathrm{a}$ & 0.11 & $\mathrm{a}$ & $\mathrm{a}$ & $\mathrm{a}$ & $\bar{a}$ & $\mathrm{a}$ & $\mathrm{a}$ & $\mathrm{a}$ & 0.06 & 0.45 \\
\hline 10KCIRT-6-355AS & 29 & 34.01 & 14.74 & $\mathrm{a}$ & 0.08 & 0.03 & $\bar{a}$ & 0.04 & 0.17 & 1.08 & 0.06 & $\mathrm{a}$ & 0.28 & 0.32 \\
\hline 10KCIRT-6-398AS & control & $\mathrm{a}$ & $\mathrm{a}$ & $\mathrm{a}$ & 0.04 & $\mathrm{a}$ & $\mathrm{a}$ & $\mathrm{a}$ & $\mathrm{a}$ & $\mathrm{a}$ & $\mathrm{a}$ & $\mathrm{a}$ & $\mathrm{a}$ & $\mathrm{a}$ \\
\hline $\mathrm{AJ} 13 \mathrm{pH}=2 \mathrm{RT}-6-280 \mathrm{AS}$ & 31 & $\mathrm{a}$ & $\bar{a}$ & $\mathrm{a}$ & 0.14 & $\bar{a}$ & $\bar{a}$ & $\bar{a}$ & $\bar{a}$ & $\bar{a}$ & $\bar{a}$ & $\bar{a}$ & $\bar{a}$ & $\mathrm{a}$ \\
\hline $\mathrm{AJ} 13 \mathrm{pH}=2 \mathrm{RT}-6-399 \mathrm{AS}$ & control & $\mathrm{a}$ & $\mathrm{a}$ & $\mathrm{a}$ & 0.16 & $\mathrm{a}$ & $\mathrm{a}$ & $\mathrm{a}$ & $\mathrm{a}$ & $\mathrm{a}$ & $\mathrm{a}$ & $\mathrm{a}$ & $\mathrm{a}$ & $\mathrm{a}$ \\
\hline
\end{tabular}

${ }^{\mathrm{a}}$ Element below detectablility limits of measuring instrument. 
Table K-7. Leachate data $\left(\mathrm{ng} / \mathrm{mm}^{2}\right)$ from SS15ZR26 specimens immersed in room temperature solution for 56 days.

\begin{tabular}{|c|c|c|c|c|c|c|c|c|c|c|c|c|c|c|}
\hline \multirow[b]{2}{*}{ Expt. ID } & \multirow[b]{2}{*}{ Ingot ID } & \multicolumn{4}{|c|}{ Major Elements } & \multicolumn{5}{|c|}{ Noble Metal Fission Products } & \multicolumn{4}{|c|}{ Minor Elements } \\
\hline & & $\mathrm{Fe}$ & $\mathrm{Cr}$ & $\mathrm{Ni}$ & $\mathrm{Zr}$ & $\mathrm{Nb}$ & $\mathrm{Pd}$ & $\mathrm{Rh}$ & $\mathrm{Ru}$ & Mo & $\mathrm{Mn}$ & Co & $\mathrm{Cu}$ & V \\
\hline Detection I & & 2.08 & 2.08 & 2.08 & 0.10 & 0.03 & 0.01 & 0.01 & 0.05 & 1.97 & 0.21 & 0.10 & 0.21 & 0.10 \\
\hline $1 \mathrm{KCl} 90-6-332$ & 25 & $\mathrm{a}$ & $\mathrm{a}$ & $\mathrm{a}$ & 0.12 & $\mathrm{a}$ & $\mathrm{a}$ & $\mathrm{a}$ & $\mathrm{a}$ & $\mathrm{a}$ & $\mathrm{a}$ & $\mathrm{a}$ & 0.48 & 0.17 \\
\hline $1 \mathrm{KCl} 90-6-396$ & control & $\mathrm{a}$ & $\mathrm{a}$ & 2.08 & 0.09 & $\mathrm{a}$ & $\mathrm{a}$ & $\mathrm{a}$ & $\mathrm{a}$ & $\bar{a}$ & $\mathrm{a}$ & $\mathrm{a}$ & 0.34 & $\mathrm{a}$ \\
\hline
\end{tabular}

${ }^{a}$ Element below detectablility limits of measuring instrument.

Table K-8. Acid Strip data $\left(\mathrm{ng} / \mathrm{mm}^{2}\right)$ from SS15ZR26 specimens immersed in room temperature solution for 56 days.

\begin{tabular}{|c|c|c|c|c|c|c|c|c|c|c|c|c|c|c|}
\hline \multirow[b]{2}{*}{ Expt. ID } & \multirow[b]{2}{*}{ Ingot ID } & \multicolumn{4}{|c|}{ Major Elements } & \multicolumn{5}{|c|}{ Noble Metal Fission Products } & \multicolumn{4}{|c|}{ Minor Elements } \\
\hline & & $\mathrm{Fe}$ & $\mathrm{Cr}$ & $\mathrm{Ni}$ & $\mathrm{Zr}$ & $\mathrm{Nb}$ & $\mathrm{Pd}$ & $\mathrm{Rh}$ & $\mathrm{Ru}$ & Mo & $\mathrm{Mn}$ & $\mathrm{Co}$ & $\mathrm{Cu}$ & $\mathrm{V}$ \\
\hline \multicolumn{2}{|c|}{ Detection Limits } & 2.29 & 2.29 & 2.29 & 0.11 & 0.03 & 0.01 & 0.01 & 0.05 & 2.17 & 0.23 & 0.11 & 0.23 & 0.11 \\
\hline $1 \mathrm{KCl} 90-6-332 \mathrm{AS}$ & 25 & $\mathrm{a}$ & $\bar{a}$ & $\mathrm{a}$ & 0.17 & $\mathrm{a}$ & $\mathrm{a}$ & $\bar{a}$ & $\mathrm{a}$ & $\mathrm{a}$ & $\bar{a}$ & $\mathrm{a}$ & 0.32 & $\mathrm{a}$ \\
\hline $1 \mathrm{KCl} 90-6-396 \mathrm{AS}$ & control & $\mathrm{a}$ & $\mathrm{a}$ & $\mathrm{a}$ & $\mathrm{a}$ & $\mathrm{a}$ & $\mathrm{a}$ & $\mathrm{a}$ & $\mathrm{a}$ & $\mathrm{a}$ & $\mathrm{a}$ & $\mathrm{a}$ & 0.60 & 0.21 \\
\hline
\end{tabular}

${ }^{a}$ Element below detectablility limits of measuring instrument. 
Table K-9. Leachate data $\left(\mathrm{ng} / \mathrm{mm}^{2}\right)$ from SS15ZR26 specimens immersed in room temperature solution for 84 days.

\begin{tabular}{|c|c|c|c|c|c|c|c|c|c|c|c|c|c|c|}
\hline \multirow[b]{2}{*}{ Expt. ID } & \multirow[b]{2}{*}{ Ingot ID } & \multicolumn{4}{|c|}{ Major Elements } & \multicolumn{5}{|c|}{ Noble Metal Fission Products } & \multicolumn{4}{|c|}{ Minor Elements } \\
\hline & & $\mathrm{Fe}$ & $\mathrm{Cr}$ & $\mathrm{Ni}$ & $\mathrm{Zr}$ & $\mathrm{Nb}$ & $\mathrm{Pd}$ & $\mathrm{Rh}$ & $\mathrm{Ru}$ & Mo & $\mathrm{Mn}$ & $\mathrm{Co}$ & $\mathrm{Cu}$ & $\mathrm{V}$ \\
\hline \multicolumn{2}{|c|}{ Detection Limits } & 2.04 & 2.04 & 2.04 & 0.01 & 0.01 & 0.02 & 0.01 & 0.02 & 0.08 & 0.04 & 0.03 & 0.31 & 0.20 \\
\hline $1 \mathrm{KCl} 90-12-336$ & 25 & $\mathrm{a}$ & $\bar{a}$ & $\bar{a}$ & 0.28 & $\mathrm{a}$ & $\mathrm{a}$ & $\bar{a}$ & $\mathrm{a}$ & 0.30 & 0.07 & $\bar{a}$ & 0.39 & 2.40 \\
\hline 1KClRT-12-335 & 27 & $\mathrm{a}$ & $\mathrm{a}$ & $\mathrm{a}$ & 0.26 & $\mathrm{a}$ & $\mathrm{a}$ & $\mathrm{a}$ & $\mathrm{a}$ & 0.74 & $\mathrm{a}$ & $\mathrm{a}$ & 0.40 & 1.57 \\
\hline 1KClRT-12-376 & control & $\mathrm{a}$ & $\mathrm{a}$ & $\mathrm{a}$ & 0.26 & $\mathrm{a}$ & 0.02 & $\mathrm{a}$ & $\mathrm{a}$ & 0.57 & $\mathrm{a}$ & $\mathrm{a}$ & 0.38 & 0.95 \\
\hline 10KClRT-12-356 & 29 & 97.17 & 17.76 & 15.67 & 0.37 & 0.05 & 0.06 & 0.51 & 0.21 & 1.55 & 6.52 & 0.79 & 0.80 & 1.74 \\
\hline $\mathrm{AJ} 13 \mathrm{pH}=2 \mathrm{RT}-12-281$ & 31 & 12.42 & 3.10 & $\mathrm{a}$ & 0.75 & 0.07 & 0.02 & $\mathrm{a}$ & 0.07 & 0.42 & 0.23 & 0.03 & 0.51 & 0.26 \\
\hline $\mathrm{AJ} 13 \mathrm{pH}=2 \mathrm{RT}-12-378$ & control & $\mathrm{a}$ & $\mathrm{a}$ & $\mathrm{a}$ & 0.35 & $\mathrm{a}$ & $\mathrm{a}$ & $\bar{a}$ & $\mathrm{a}$ & 0.25 & $\mathrm{a}$ & $\mathrm{a}$ & 0.94 & 0.23 \\
\hline
\end{tabular}

${ }^{\mathrm{a}}$ Element below detectablility limits of measuring instrument.

Table K-10. Acid Strip data (ng/mm2) from SS15ZR26 specimens immersed in room temperature solution for 84 days.

\begin{tabular}{|c|c|c|c|c|c|c|c|c|c|c|c|c|c|c|}
\hline \multirow[b]{2}{*}{ Expt. ID } & \multirow[b]{2}{*}{ Ingot ID } & \multicolumn{4}{|c|}{ Major Elements } & \multicolumn{5}{|c|}{ Noble Metal Fission Products } & \multicolumn{4}{|c|}{ Minor Elements } \\
\hline & & $\mathrm{Fe}$ & $\mathrm{Cr}$ & $\mathrm{Ni}$ & $\mathrm{Zr}$ & $\mathrm{Nb}$ & $\mathrm{Pd}$ & $\mathrm{Rh}$ & $\mathrm{Ru}$ & Mo & $\mathrm{Mn}$ & $\mathrm{Co}$ & $\mathrm{Cu}$ & $\overline{\mathrm{V}}$ \\
\hline \multicolumn{2}{|l|}{ Detection Limits } & 2.21 & 2.21 & 2.21 & 0.01 & 0.01 & 0.02 & 0.01 & 0.02 & 0.08 & 0.04 & 0.03 & 0.33 & 0.22 \\
\hline $1 \mathrm{KCl} 90-12-336 \mathrm{AS}$ & 25 & $\bar{a}$ & $\bar{a}$ & $\bar{a}$ & 0.20 & $\bar{a}$ & $\bar{a}$ & $\bar{a}$ & $\mathrm{a}$ & $\mathrm{a}$ & $\mathrm{a}$ & $\mathrm{a}$ & $\mathrm{a}$ & $\bar{a}$ \\
\hline $1 \mathrm{KCl} 90-12-388 \mathrm{AS}$ & control & $\mathrm{a}$ & $\mathrm{a}$ & $\mathrm{a}$ & 0.33 & $\mathrm{a}$ & $\mathrm{a}$ & $\mathrm{a}$ & $\mathrm{a}$ & $\mathrm{a}$ & $\mathrm{a}$ & $\mathrm{a}$ & $\mathrm{a}$ & $\mathrm{a}$ \\
\hline 1KCIRT-12-335AS & 27 & $\mathrm{a}$ & $\mathrm{a}$ & $\mathrm{a}$ & 0.18 & $\mathrm{a}$ & $\mathrm{a}$ & $\mathrm{a}$ & $\mathrm{a}$ & $\mathrm{a}$ & $\mathrm{a}$ & $\mathrm{a}$ & $\mathrm{a}$ & $\mathrm{a}$ \\
\hline 1KCIRT-12-376AS & control & 2.22 & $\mathrm{a}$ & 2.22 & 1.22 & $\mathrm{a}$ & 0.05 & $\mathrm{a}$ & $\mathrm{a}$ & $\mathrm{a}$ & $\mathrm{a}$ & $\mathrm{a}$ & $\mathrm{a}$ & $\mathrm{a}$ \\
\hline 10KClRT-12-356AS & 29 & 164.79 & 56.75 & $\mathrm{a}$ & 0.57 & 0.11 & 0.03 & 0.10 & 0.53 & 4.22 & 0.12 & $\mathrm{a}$ & 0.61 & 0.22 \\
\hline 10KClRT-12-377AS & control & $\mathrm{a}$ & $\bar{a}$ & $\mathrm{a}$ & 0.30 & $\bar{a}$ & $\bar{a}$ & $\bar{a}$ & $\bar{a}$ & $\mathrm{a}$ & $\bar{a}$ & $\mathrm{a}$ & $\mathrm{a}$ & $\mathrm{a}$ \\
\hline $\mathrm{AJ} 13 \mathrm{pH}=2 \mathrm{RT}-12-281 \mathrm{AS}$ & 31 & 2.01 & $\mathrm{a}$ & $\mathrm{a}$ & 0.35 & $\mathrm{a}$ & 0.03 & $\mathrm{a}$ & $\mathrm{a}$ & $\mathrm{a}$ & $\mathrm{a}$ & $\mathrm{a}$ & $\mathrm{a}$ & $\mathrm{a}$ \\
\hline $\mathrm{AJ} 13 \mathrm{pH}=2 \mathrm{RT}-12-378 \mathrm{AS}$ & control & $\mathrm{a}$ & $\bar{a}$ & $\mathrm{a}$ & 0.39 & $\mathrm{a}$ & $\mathrm{a}$ & $\mathrm{a}$ & $\mathrm{a}$ & $\mathrm{a}$ & $\mathrm{a}$ & $\mathrm{a}$ & $\mathrm{a}$ & $\mathrm{a}$ \\
\hline
\end{tabular}

${ }^{\mathrm{a}}$ Element below detectablility limits of measuring instrument. 
Table K-11. Leachate data $\left(\mathrm{ng} / \mathrm{mm}^{2}\right)$ from SS15ZR26 specimens immersed in room temperature solution for 140 days.

\begin{tabular}{|c|c|c|c|c|c|c|c|c|c|c|c|c|c|c|}
\hline \multirow[b]{2}{*}{ Expt. ID } & \multirow[b]{2}{*}{ Ingot ID } & \multicolumn{4}{|c|}{ Major Elements } & \multicolumn{5}{|c|}{ Noble Metal Fission Products } & \multicolumn{4}{|c|}{ Minor Elements } \\
\hline & & $\mathrm{Fe}$ & $\mathrm{Cr}$ & $\mathrm{Ni}$ & $\mathrm{Zr}$ & $\mathrm{Nb}$ & $\mathrm{Pd}$ & $\mathrm{Rh}$ & $\mathrm{Ru}$ & Mo & $\mathrm{Mn}$ & $\mathrm{Co}$ & $\mathrm{Cu}$ & $\mathrm{V}$ \\
\hline \multicolumn{2}{|c|}{ Detection Limits } & 2.04 & 2.04 & 2.04 & 0.02 & 0.03 & 0.02 & 0.02 & 0.02 & 0.07 & 0.02 & 0.02 & 1.02 & 0.20 \\
\hline $1 \mathrm{KC190-12-336}$ & 25 & $\bar{a}$ & $\bar{a}$ & $\bar{a}$ & $\bar{a}$ & $\bar{a}$ & $\bar{a}$ & $\bar{a}$ & $\bar{a}$ & 0.24 & 0.03 & 0.30 & $\bar{a}$ & 3.25 \\
\hline $1 \mathrm{KCl} 90-12-388$ & control & $\mathrm{a}$ & $\mathrm{a}$ & $\mathrm{a}$ & 0.02 & $\mathrm{a}$ & $\mathrm{a}$ & $\mathrm{a}$ & $\mathrm{a}$ & 0.38 & 0.03 & 0.30 & $\mathrm{a}$ & 2.13 \\
\hline 1KClRT-12-335 & 27 & $\bar{a}$ & $\bar{a}$ & $\bar{a}$ & 0.02 & $\bar{a}$ & $\bar{a}$ & $\bar{a}$ & $\mathrm{a}$ & 0.39 & 0.03 & 0.30 & $\bar{a}$ & 2.40 \\
\hline 1KClRT-12-376 & control & $\mathrm{a}$ & $\mathrm{a}$ & $\mathrm{a}$ & $\mathrm{a}$ & $\mathrm{a}$ & $\mathrm{a}$ & $\mathrm{a}$ & $\mathrm{a}$ & 0.08 & 0.02 & 0.30 & $\mathrm{a}$ & 2.35 \\
\hline 10KCIRT-12-356 & 29 & 2.10 & $\mathrm{a}$ & 23.80 & 0.03 & $\mathrm{a}$ & 0.03 & $\mathrm{a}$ & $\mathrm{a}$ & 0.39 & 9.34 & 0.98 & 2.69 & 6.45 \\
\hline 10KClRT-12-377 & control & $\bar{a}$ & $\bar{a}$ & $\bar{a}$ & $\bar{a}$ & $\mathrm{a}$ & 0.03 & $\bar{a}$ & $\bar{a}$ & $\mathrm{a}$ & 0.09 & 0.31 & $\bar{a}$ & 5.50 \\
\hline AJ13pH=2RT-12-281 & 31 & 794.69 & 245.49 & 57.40 & 4.53 & 0.63 & 0.12 & 0.55 & 2.42 & 21.53 & 16.50 & 1.88 & 4.46 & 2.44 \\
\hline AJ13pH=2RT-12-378 & control & $\mathrm{a}$ & $\mathrm{a}$ & $\mathrm{a}$ & 0.40 & $\mathrm{a}$ & $\mathrm{a}$ & $\mathrm{a}$ & $\bar{a}$ & 0.51 & 0.03 & 0.31 & $\mathrm{a}$ & 1.13 \\
\hline
\end{tabular}

${ }^{\mathrm{a}}$ Element below detectablility limits of measuring instrument.

Table K-12. Acid Strip data $\left(\mathrm{ng} / \mathrm{mm}^{2}\right)$ from SS15ZR26 specimens immersed in room temperature solution for 140 days.

\begin{tabular}{|c|c|c|c|c|c|c|c|c|c|c|c|c|c|c|}
\hline \multirow[b]{2}{*}{ Expt. ID } & \multirow[b]{2}{*}{ Ingot ID } & \multicolumn{4}{|c|}{ Major Elements } & \multicolumn{5}{|c|}{ Noble Metal Fission Products } & \multicolumn{4}{|c|}{ Minor Elements } \\
\hline & & $\mathrm{Fe}$ & $\mathrm{Cr}$ & $\mathrm{Ni}$ & $\mathrm{Zr}$ & $\mathrm{Nb}$ & $\mathrm{Pd}$ & $\mathrm{Rh}$ & $\mathrm{Ru}$ & Mo & $\mathrm{Mn}$ & $\mathrm{Co}$ & $\mathrm{Cu}$ & $\mathrm{V}$ \\
\hline \multicolumn{2}{|l|}{ Detection Limits } & 2.04 & 2.04 & 2.04 & 0.02 & 0.03 & 0.02 & 0.02 & 0.02 & 0.07 & 0.02 & 0.02 & 1.02 & 0.20 \\
\hline $1 \mathrm{KCl} 90-20-337 \mathrm{AS}$ & 25 & $\bar{a}$ & $\bar{a}$ & $\mathrm{a}$ & 0.07 & $\mathrm{a}$ & $\bar{a}$ & $\bar{a}$ & $\mathrm{a}$ & $\bar{a}$ & $\mathrm{a}$ & $\mathrm{a}$ & 1.24 & 1.04 \\
\hline $1 \mathrm{KCl} 90-20-389 \mathrm{AS}$ & control & $\mathrm{a}$ & $\mathrm{a}$ & $\mathrm{a}$ & 0.27 & $\mathrm{a}$ & $\bar{a}$ & $\mathrm{a}$ & $\mathrm{a}$ & $\mathrm{a}$ & 0.03 & $\mathrm{a}$ & $\mathrm{a}$ & 0.86 \\
\hline 1KCIRT-20-338AS & 27 & $\mathrm{a}$ & $\mathrm{a}$ & $\mathrm{a}$ & 0.04 & $\mathrm{a}$ & $\mathrm{a}$ & $\mathrm{a}$ & $\mathrm{a}$ & $\mathrm{a}$ & 0.02 & $\mathrm{a}$ & $\mathrm{a}$ & 0.80 \\
\hline 1KCIRT-20-390AS & control & $\mathrm{a}$ & $\mathrm{a}$ & $\mathrm{a}$ & 0.31 & $\mathrm{a}$ & $\mathrm{a}$ & $\mathrm{a}$ & $\mathrm{a}$ & $\mathrm{a}$ & $\mathrm{a}$ & $\mathrm{a}$ & $\mathrm{a}$ & 0.70 \\
\hline 10KClRT-20-357AS & 29 & 87.93 & 35.87 & $\mathrm{a}$ & 0.08 & 0.06 & $\mathrm{a}$ & 0.07 & 0.35 & 2.63 & 0.10 & $\mathrm{a}$ & $\mathrm{a}$ & 0.52 \\
\hline 10KClRT-20-391AS & control & $\bar{a}$ & $\mathrm{a}$ & $\bar{a}$ & 0.09 & $\mathrm{a}$ & $\mathrm{a}$ & $\mathrm{a}$ & $\bar{a}$ & $\mathrm{a}$ & $\mathrm{a}$ & $\mathrm{a}$ & $\mathrm{a}$ & 0.31 \\
\hline $\mathrm{AJ} 13 \mathrm{pH}=2 \mathrm{RT} 20-282 \mathrm{AS}$ & 31 & 2.31 & $\mathrm{a}$ & $\mathrm{a}$ & 1.71 & 0.17 & 0.03 & $\mathrm{a}$ & 0.06 & 0.30 & 0.06 & $\mathrm{a}$ & $\mathrm{a}$ & $\mathrm{a}$ \\
\hline AJ13Ph=2RT-20-392AS & control & 11.83 & 3.43 & 2.81 & 0.12 & $\bar{a}$ & $\bar{a}$ & $\mathrm{a}$ & 0.04 & $\bar{a}$ & 1.01 & 0.14 & $\mathrm{a}$ & $\mathrm{a}$ \\
\hline
\end{tabular}

${ }^{a}$ Element below detectablility limits of measuring instrument. 


\section{Supplementary Tests-Detection Limits}

Table L-1. Iron Detection Limits in Leachate Data $\left(\mathrm{ng} / \mathrm{mm}^{2}\right)$.

\begin{tabular}{|c|c|c|c|c|c|c|}
\hline Sample \# & 2 & 4 & 6 & 8 & 12 & 20 \\
\hline 25 & 2.05 & 2.07 & 2.06 & 2.07 & 2.06 & 2.02 \\
\hline 1KCl90 Control & 2.08 & 2.06 & 2.06 & 2.08 & 1.78 & 1.99 \\
\hline 27 & 2.07 & 2.07 & 2.06 & $\mathrm{a}$ & 2.07 & 2.00 \\
\hline 1KClRT control & 2.06 & 2.04 & 2.07 & $\mathrm{a}$ & 2.07 & 2.02 \\
\hline 29 & 2.08 & 2.15 & 2.08 & $\mathrm{a}$ & 2.09 & 2.10 \\
\hline 10KClRT control & 2.07 & 2.09 & 2.07 & $\mathrm{a}$ & 2.10 & 2.08 \\
\hline 31 & 2.06 & 2.07 & 2.05 & $\mathrm{a}$ & 2.07 & 2.05 \\
\hline AJ13pH=2RT Control & 2.06 & 2.07 & 2.06 & $\mathrm{a}$ & 2.06 & 2.06 \\
\hline Average & 2.07 & 2.08 & 2.06 & 2.08 & 2.04 & 2.04 \\
\hline Standard Deviation & 0.01 & 0.03 & 0.01 & 0.01 & 0.11 & 0.04 \\
\hline
\end{tabular}

${ }^{\mathrm{a}}$ Sample not terminated

Table L-2. Iron Detection Limits in Acid Strip Data $\left(\mathbf{n g} / \mathrm{mm}^{2}\right)$.

\begin{tabular}{|c|c|c|c|c|c|c|}
\hline Sample \# & 2 & 4 & 6 & 8 & 12 & 20 \\
\hline 25 & 2.41 & 2.21 & 2.30 & 2.17 & 2.29 & 2.02 \\
\hline 1KCl90 Control & 2.40 & 2.26 & 2.31 & 2.40 & 2.28 & 1.99 \\
\hline 27 & 2.33 & 2.27 & 2.31 & $\mathrm{a}$ & 2.24 & 2.00 \\
\hline 1KClRT control & 2.19 & 2.23 & 2.29 & $\mathrm{a}$ & 2.22 & 2.02 \\
\hline 29 & 2.09 & 2.20 & 2.27 & $\mathrm{a}$ & 2.18 & 2.10 \\
\hline 10KClRT control & 2.26 & 2.24 & 2.32 & $\mathrm{a}$ & 2.14 & 2.08 \\
\hline 31 & 2.38 & 2.25 & 2.22 & $\mathrm{a}$ & 2.01 & 2.05 \\
\hline AJ13pH=2RT Control & 2.28 & 2.23 & 2.30 & $\mathrm{a}$ & 2.27 & 2.06 \\
\hline Average & 2.29 & 2.24 & 2.29 & 2.29 & 2.21 & 2.04 \\
\hline Standard Deviation & 0.11 & 0.02 & 0.03 & 0.16 & 0.09 & 0.04 \\
\hline
\end{tabular}

${ }^{\mathrm{a}}$ Sample not terminated

\section{Table L-3. Chromium Detection Limits in Leachate Data $\left(\mathbf{n g} / \mathrm{mm}^{2}\right)$.}

\begin{tabular}{|c|c|c|c|c|c|c|}
\hline Sample \# & 2 & 4 & 6 & 8 & 12 & 20 \\
\hline 25 & 2.05 & 2.07 & 2.06 & 2.07 & 2.06 & 2.02 \\
\hline 1KCl90 Control & 2.08 & 2.06 & 2.06 & 2.08 & 1.78 & 1.99 \\
\hline 27 & 2.07 & 2.07 & 2.06 & $\mathrm{a}$ & 2.07 & 2.00 \\
\hline 1KClRT control & 2.06 & 2.04 & 2.07 & $\mathrm{a}$ & 2.07 & 2.02 \\
\hline 29 & 2.08 & 2.15 & 2.08 & $\mathrm{a}$ & 2.09 & 2.10 \\
\hline 10KClRT control & 2.07 & 2.09 & 2.07 & $\mathrm{a}$ & 2.10 & 2.08 \\
\hline 31 & 2.06 & 2.07 & 2.05 & $\mathrm{a}$ & 2.07 & 2.05 \\
\hline AJ13pH=2RT Control & 2.06 & 2.07 & 2.06 & $\mathrm{a}$ & 2.06 & 2.06 \\
\hline Average & 2.07 & 2.08 & 2.06 & 2.08 & 2.04 & 2.04 \\
\hline Standard Deviation & 0.01 & 0.03 & 0.01 & 0.01 & 0.11 & 0.04 \\
\hline
\end{tabular}

${ }^{\mathrm{a}}$ Sample not terminated 
Table L-4. Chromium Detection Limits in Acid Strip Data (ng/mm $\mathbf{m}^{2}$.

\begin{tabular}{|c|c|c|c|c|c|c|}
\hline Sample \# & 2 & 4 & 6 & 8 & 12 & 20 \\
\hline 25 & 2.41 & 2.21 & 2.30 & 2.17 & 2.29 & 2.02 \\
\hline 1KCl90 Control & 2.40 & 2.26 & 2.31 & 2.40 & 2.28 & 1.99 \\
\hline 27 & 2.33 & 2.27 & 2.31 & $\mathrm{a}$ & 2.24 & 2.00 \\
\hline 1KClRT control & 2.19 & 2.23 & 2.29 & $\mathrm{a}$ & 2.22 & 2.02 \\
\hline 29 & 2.09 & 2.20 & 2.27 & $\mathrm{a}$ & 2.18 & 2.10 \\
\hline 10KClRT control & 2.26 & 2.24 & 2.32 & $\mathrm{a}$ & 2.14 & 2.08 \\
\hline 31 & 2.38 & 2.25 & 2.22 & $\mathrm{a}$ & 2.01 & 2.05 \\
\hline AJ13pH=2RT Control & 2.28 & 2.23 & 2.30 & $\mathrm{a}$ & 2.27 & 2.06 \\
\hline Average & 2.29 & 2.24 & 2.29 & 2.29 & 2.21 & 2.04 \\
\hline Standard Deviation & 0.11 & 0.02 & 0.03 & 0.16 & 0.09 & 0.04 \\
\hline
\end{tabular}

${ }^{\mathrm{a}}$ Sample not terminated

Table L-5. Nickel Detection Limits in Leachate Data $\left(\mathrm{ng} / \mathrm{mm}^{2}\right)$.

\begin{tabular}{|c|c|c|c|c|c|c|}
\hline Sample \# & 2 & 4 & 6 & 8 & 12 & 20 \\
\hline 25 & 2.05 & 2.07 & 2.06 & 2.07 & 2.06 & 2.02 \\
\hline 1KCl90 Control & 2.08 & 2.06 & 2.06 & 2.08 & 1.78 & 1.99 \\
\hline 27 & 2.07 & 2.07 & 2.06 & $\mathrm{a}$ & 2.07 & 2.00 \\
\hline 1KClRT control & 2.06 & 2.04 & 2.07 & $\mathrm{a}$ & 2.07 & 2.02 \\
\hline 29 & 2.08 & 2.15 & 2.08 & $\mathrm{a}$ & 2.09 & 2.10 \\
\hline 10KClRT control & 2.07 & 2.09 & 2.07 & $\mathrm{a}$ & 2.10 & 2.08 \\
\hline 31 & 2.06 & 2.07 & 2.05 & $\mathrm{a}$ & 2.07 & 2.05 \\
\hline AJ13pH=2RT Control & 2.06 & 2.07 & 2.06 & $\mathrm{a}$ & 2.06 & 2.06 \\
\hline Average & 2.07 & 2.08 & 2.06 & 2.08 & 2.04 & 2.04 \\
\hline Standard Deviation & 0.01 & 0.03 & 0.01 & 0.01 & 0.11 & 0.04 \\
\hline
\end{tabular}

${ }^{\mathrm{a}}$ Sample not terminated

Table L-6. Nickel Detection Limits in Acid Strip Data $\left(\mathbf{n g} / \mathrm{mm}^{2}\right)$.

\begin{tabular}{|c|c|c|c|c|c|c|}
\hline Sample \# & 2 & 4 & 6 & 8 & 12 & 20 \\
\hline 25 & 2.41 & 2.21 & 2.30 & 2.17 & 2.29 & 2.02 \\
\hline 1KC190 Control & 2.40 & 2.26 & 2.31 & 2.40 & 2.28 & 1.99 \\
\hline 27 & 2.33 & 2.27 & 2.31 & $\mathrm{a}$ & 2.24 & 2.00 \\
\hline 1KClRT control & 2.19 & 2.23 & 2.29 & $\mathrm{a}$ & 2.22 & 2.02 \\
\hline 29 & 2.09 & 2.20 & 2.27 & $\mathrm{a}$ & 2.18 & 2.10 \\
\hline 10KClRT control & 2.26 & 2.24 & 2.32 & $\mathrm{a}$ & 2.14 & 2.08 \\
\hline 31 & 2.38 & 2.25 & 2.22 & $\mathrm{a}$ & 2.01 & 2.05 \\
\hline AJ13pH=2RT Control & 2.28 & 2.23 & 2.30 & $\mathrm{a}$ & 2.27 & 2.06 \\
\hline Average & 2.29 & 2.24 & 2.29 & 2.29 & 2.21 & 2.04 \\
\hline Standard Deviation & 0.11 & 0.02 & 0.03 & 0.16 & 0.09 & 0.04 \\
\hline
\end{tabular}

${ }^{\mathrm{a}}$ Sample not terminated 
Table L-7. Zirconium Detection Limits in Leachate Data (ng/mm2).

\begin{tabular}{|c|c|c|c|c|c|c|}
\hline Sample \# & 2 & 4 & 6 & 8 & 12 & 20 \\
\hline 25 & 0.01 & 0.02 & 0.03 & 0.10 & 0.01 & 0.02 \\
\hline 1KCl90 Control & 0.01 & 0.02 & 0.03 & 0.10 & 0.01 & 0.02 \\
\hline 27 & 0.01 & 0.03 & 0.02 & $\mathrm{a}$ & 0.01 & 0.02 \\
\hline 1KClRT control & 0.01 & 0.02 & 0.02 & $\mathrm{a}$ & 0.01 & 0.02 \\
\hline 29 & 0.01 & 0.02 & 0.02 & $\mathrm{a}$ & 0.01 & 0.02 \\
\hline 10KClRT control & 0.01 & 0.02 & 0.02 & $\mathrm{a}$ & 0.01 & 0.02 \\
\hline 31 & 0.01 & 0.02 & 0.02 & $\mathrm{a}$ & 0.01 & 0.02 \\
\hline AJ13pH=2RT Control & 0.01 & 0.02 & 0.02 & $\mathrm{a}$ & 0.01 & 0.02 \\
\hline Average & 0.01 & 0.02 & 0.02 & 0.10 & 0.01 & 0.02 \\
\hline Standard Deviation & 0.00 & 0.01 & 0.01 & 0.00 & 0.00 & 0.00 \\
\hline
\end{tabular}

${ }^{\mathrm{a}}$ Sample not terminated

Table L-8. Zirconium Detection Limits in Acid Strip Data $\left(\mathbf{n g} / \mathrm{mm}^{2}\right)$.

\begin{tabular}{|c|c|c|c|c|c|c|}
\hline Sample \# & 2 & 4 & 6 & 8 & 12 & 20 \\
\hline 25 & 0.01 & 0.02 & 0.02 & 0.11 & 0.01 & 0.02 \\
\hline 1KCl90 Control & 0.01 & 0.02 & 0.02 & 0.12 & 0.01 & 0.02 \\
\hline 27 & 0.01 & 0.02 & 0.02 & $\mathrm{a}$ & 0.01 & 0.02 \\
\hline 1KClRT control & 0.01 & 0.02 & 0.02 & $\mathrm{a}$ & 0.01 & 0.02 \\
\hline 29 & 0.01 & 0.02 & 0.02 & $\mathrm{a}$ & 0.01 & 0.02 \\
\hline 10KClRT control & 0.01 & 0.02 & 0.02 & $\mathrm{a}$ & 0.01 & 0.02 \\
\hline 31 & 0.01 & 0.02 & 0.02 & $\mathrm{a}$ & 0.01 & 0.02 \\
\hline AJ13pH=2RT Control & 0.01 & 0.02 & 0.02 & $\mathrm{a}$ & 0.01 & 0.02 \\
\hline Average & 0.01 & 0.02 & 0.02 & 0.11 & 0.01 & 0.02 \\
\hline Standard Deviation & 0.00 & 0.00 & 0.00 & 0.01 & 0.00 & 0.00 \\
\hline
\end{tabular}

${ }^{\mathrm{a}}$ Sample not terminated

Table L-9. Niobium Detection Limits in Leachate Data $\left(\mathbf{n g} / \mathbf{m m}^{2}\right)$.

\begin{tabular}{|c|c|c|c|c|c|c|}
\hline Sample \# & 2 & 4 & 6 & 8 & 12 & 20 \\
\hline 25 & 0.02 & 0.02 & 0.03 & 0.03 & 0.01 & 0.03 \\
\hline 1KC190 Control & 0.02 & 0.02 & 0.03 & 0.03 & 0.01 & 0.03 \\
\hline 27 & 0.02 & 0.03 & 0.02 & $\mathrm{a}$ & 0.01 & 0.03 \\
\hline 1KClRT control & 0.02 & 0.02 & 0.02 & $\mathrm{a}$ & 0.01 & 0.03 \\
\hline 29 & 0.02 & 0.02 & 0.02 & $\mathrm{a}$ & 0.01 & 0.03 \\
\hline 10KClRT control & 0.02 & 0.02 & 0.02 & $\mathrm{a}$ & 0.01 & 0.03 \\
\hline 31 & 0.02 & 0.02 & 0.02 & $\mathrm{a}$ & 0.01 & 0.03 \\
\hline AJ13pH=2RT Control & 0.02 & 0.02 & 0.02 & $\mathrm{a}$ & 0.01 & 0.03 \\
\hline Average & 0.02 & 0.02 & 0.02 & 0.03 & 0.01 & 0.03 \\
\hline Standard Deviation & 0.00 & 0.01 & 0.01 & 0.00 & 0.00 & 0.00 \\
\hline
\end{tabular}

${ }^{\mathrm{a}}$ Sample not terminated 
Table L-10. Niobium Detection Limits in Acid Strip Data $\left(\mathbf{n g} / \mathrm{mm}^{2}\right)$.

\begin{tabular}{|c|c|c|c|c|c|c|}
\hline Sample \# & 2 & 4 & 6 & 8 & 12 & 20 \\
\hline 25 & 0.02 & 0.02 & 0.02 & 0.03 & 0.01 & 0.03 \\
\hline 1KCl90 Control & 0.02 & 0.02 & 0.02 & 0.03 & 0.01 & 0.03 \\
\hline 27 & 0.02 & 0.02 & 0.02 & $\mathrm{a}$ & 0.01 & 0.03 \\
\hline 1KClRT control & 0.02 & 0.02 & 0.02 & $\mathrm{a}$ & 0.01 & 0.03 \\
\hline 29 & 0.02 & 0.02 & 0.02 & $\mathrm{a}$ & 0.01 & 0.03 \\
\hline 10KClRT control & 0.02 & 0.02 & 0.02 & $\mathrm{a}$ & 0.01 & 0.03 \\
\hline 31 & 0.02 & 0.02 & 0.02 & $\mathrm{a}$ & 0.01 & 0.03 \\
\hline AJ13pH=2RT Control & 0.02 & 0.02 & 0.02 & $\mathrm{a}$ & 0.01 & 0.03 \\
\hline Average & 0.02 & 0.02 & 0.02 & 0.03 & 0.01 & 0.03 \\
\hline Standard Deviation & 0.00 & 0.00 & 0.00 & 0.00 & 0.00 & 0.00 \\
\hline
\end{tabular}

${ }^{\mathrm{a}}$ Sample not terminated

Table L-11. Paladium Detection Limits in Leachate Data $\left(\mathrm{ng} / \mathrm{mm}^{2}\right)$.

\begin{tabular}{|c|c|c|c|c|c|c|}
\hline Sample \# & 2 & 4 & 6 & 8 & 12 & 20 \\
\hline 25 & 0.01 & 0.01 & 0.02 & 0.01 & 0.02 & 0.02 \\
\hline 1KCl90 Control & 0.01 & 0.01 & 0.02 & 0.01 & 0.01 & 0.02 \\
\hline 27 & 0.01 & 0.02 & 0.01 & $\mathrm{a}$ & 0.02 & 0.02 \\
\hline 1KClRT control & 0.01 & 0.01 & 0.01 & $\mathrm{a}$ & 0.02 & 0.02 \\
\hline 29 & 0.01 & 0.01 & 0.01 & $\mathrm{a}$ & 0.02 & 0.02 \\
\hline 10KClRT control & 0.01 & 0.01 & 0.01 & $\mathrm{a}$ & 0.02 & 0.02 \\
\hline 31 & 0.01 & 0.01 & 0.01 & $\mathrm{a}$ & 0.02 & 0.02 \\
\hline AJ13pH=2RT Control & 0.01 & 0.01 & 0.01 & $\mathrm{a}$ & 0.02 & 0.02 \\
\hline Average & 0.01 & 0.01 & 0.01 & 0.01 & 0.02 & 0.02 \\
\hline Standard Deviation & 0.00 & 0.00 & 0.00 & 0.00 & 0.00 & 0.00 \\
\hline
\end{tabular}

${ }^{\mathrm{a}}$ Sample not terminated

Table L-12. Paladium Detection Limits in Acid Strip Data $\left(\mathrm{ng} / \mathrm{mm}^{2}\right)$.

\begin{tabular}{|c|c|c|c|c|c|c|}
\hline Sample \# & 2 & 4 & 6 & 8 & 12 & 20 \\
\hline 25 & 0.01 & 0.01 & 0.01 & 0.01 & 0.02 & 0.02 \\
\hline 1KC190 Control & 0.01 & 0.01 & 0.01 & 0.01 & 0.02 & 0.02 \\
\hline 27 & 0.01 & 0.01 & 0.01 & $\mathrm{a}$ & 0.02 & 0.02 \\
\hline 1KClRT control & 0.01 & 0.01 & 0.01 & $\mathrm{a}$ & 0.02 & 0.02 \\
\hline 29 & 0.01 & 0.01 & 0.01 & $\mathrm{a}$ & 0.02 & 0.02 \\
\hline 10KClRT control & 0.01 & 0.01 & 0.01 & $\mathrm{a}$ & 0.02 & 0.02 \\
\hline 31 & 0.01 & 0.01 & 0.01 & $\mathrm{a}$ & 0.02 & 0.02 \\
\hline AJ13pH=2RT Control & 0.01 & 0.01 & 0.01 & $\mathrm{a}$ & 0.02 & 0.02 \\
\hline Average & 0.01 & 0.01 & 0.01 & 0.01 & 0.02 & 0.02 \\
\hline Standard Deviation & 0.00 & 0.00 & 0.00 & 0.00 & 0.00 & 0.00 \\
\hline
\end{tabular}

${ }^{\mathrm{a}}$ Sample not terminated 
Table L-13. Rhodium Detection Limits in Leachate Data $\left(\mathrm{ng} / \mathrm{mm}^{2}\right)$.

\begin{tabular}{|c|c|c|c|c|c|c|}
\hline Sample \# & 2 & 4 & 6 & 8 & 12 & 20 \\
\hline 25 & 0.01 & 0.02 & 0.03 & 0.01 & 0.01 & 0.02 \\
\hline 1KCl90 Control & 0.01 & 0.02 & 0.03 & 0.01 & 0.01 & 0.02 \\
\hline 27 & 0.01 & 0.03 & 0.01 & $\mathrm{a}$ & 0.01 & 0.02 \\
\hline 1KClRT control & 0.01 & 0.01 & 0.01 & $\mathrm{a}$ & 0.01 & 0.02 \\
\hline 29 & 0.01 & 0.01 & 0.01 & $\mathrm{a}$ & 0.01 & 0.02 \\
\hline 10KClRT control & 0.01 & 0.01 & 0.01 & $\mathrm{a}$ & 0.01 & 0.02 \\
\hline 31 & 0.01 & 0.01 & 0.01 & $\mathrm{a}$ & 0.01 & 0.02 \\
\hline AJ13pH=2RT Control & 0.01 & 0.01 & 0.01 & $\mathrm{a}$ & 0.01 & 0.02 \\
\hline Average & 0.01 & 0.02 & 0.02 & 0.01 & 0.01 & 0.02 \\
\hline Standard Deviation & 0.00 & 0.00 & 0.01 & 0.00 & 0.00 & 0.00 \\
\hline
\end{tabular}

${ }^{\mathrm{a}}$ Sample not terminated

Table L-14. Rhodium Detection Limits in Acid Strip Data (ng/mm²).

\begin{tabular}{|c|c|c|c|c|c|c|}
\hline Sample \# & 2 & 4 & 6 & 8 & 12 & 20 \\
\hline 25 & 0.01 & 0.01 & 0.01 & 0.01 & 0.01 & 0.02 \\
\hline 1KCl90 Control & 0.01 & 0.01 & 0.02 & 0.01 & 0.01 & 0.02 \\
\hline 27 & 0.01 & 0.01 & 0.02 & $\mathrm{a}$ & 0.01 & 0.02 \\
\hline 1KClRT control & 0.01 & 0.01 & 0.01 & $\mathrm{a}$ & 0.01 & 0.02 \\
\hline 29 & 0.01 & 0.01 & 0.01 & $\mathrm{a}$ & 0.01 & 0.02 \\
\hline 10KClRT control & 0.01 & 0.01 & 0.02 & $\mathrm{a}$ & 0.01 & 0.02 \\
\hline 31 & 0.01 & 0.01 & 0.01 & $\mathrm{a}$ & 0.01 & 0.02 \\
\hline AJ13pH=2RT Control & 0.01 & 0.01 & 0.01 & $\mathrm{a}$ & 0.01 & 0.02 \\
\hline Average & 0.01 & 0.01 & 0.01 & 0.01 & 0.01 & 0.02 \\
\hline Standard Deviation & 0.00 & 0.00 & 0.00 & 0.00 & 0.00 & 0.00 \\
\hline
\end{tabular}

${ }^{\mathrm{a}}$ Sample not terminated

Table L-15. Ruthenium Detection Limits in Leachate Data (ng/mm ${ }^{2}$ ).

\begin{tabular}{|c|c|c|c|c|c|c|}
\hline Sample \# & 2 & 4 & 6 & 8 & 12 & 20 \\
\hline 25 & 0.01 & 0.02 & 0.03 & 0.05 & 0.02 & 0.02 \\
\hline 1KC190 Control & 0.01 & 0.02 & 0.03 & 0.05 & 0.02 & 0.02 \\
\hline 27 & 0.01 & 0.03 & 0.02 & $\mathrm{a}$ & 0.02 & 0.02 \\
\hline 1KClRT control & 0.01 & 0.02 & 0.02 & $\mathrm{a}$ & 0.02 & 0.02 \\
\hline 29 & 0.01 & 0.02 & 0.02 & $\mathrm{a}$ & 0.02 & 0.02 \\
\hline 10KClRT control & 0.01 & 0.02 & 0.02 & $\mathrm{a}$ & 0.02 & 0.02 \\
\hline 31 & 0.01 & 0.02 & 0.02 & $\mathrm{a}$ & 0.02 & 0.02 \\
\hline AJ13pH=2RT Control & 0.01 & 0.02 & 0.02 & $\mathrm{a}$ & 0.02 & 0.02 \\
\hline Average & 0.01 & 0.02 & 0.02 & 0.05 & 0.02 & 0.02 \\
\hline Standard Deviation & 0.00 & 0.01 & 0.01 & 0.00 & 0.00 & 0.00 \\
\hline
\end{tabular}

${ }^{\mathrm{a}}$ Sample not terminated 
Table L-16. Ruthenium Detection Limits in Acid Strip Data (ng/mm²).

\begin{tabular}{|c|c|c|c|c|c|c|}
\hline Sample \# & 2 & 4 & 6 & 8 & 12 & 20 \\
\hline 25 & 0.01 & 0.02 & 0.02 & 0.05 & 0.02 & 0.02 \\
\hline 1KC190 Control & 0.01 & 0.02 & 0.02 & 0.05 & 0.02 & 0.02 \\
\hline 27 & 0.01 & 0.02 & 0.02 & $\mathrm{a}$ & 0.02 & 0.02 \\
\hline 1KClRT control & 0.01 & 0.02 & 0.02 & $\mathrm{a}$ & 0.02 & 0.02 \\
\hline 29 & 0.01 & 0.02 & 0.02 & $\mathrm{a}$ & 0.02 & 0.02 \\
\hline 10KClRT control & 0.01 & 0.02 & 0.02 & $\mathrm{a}$ & 0.02 & 0.02 \\
\hline 31 & 0.01 & 0.02 & 0.02 & $\mathrm{a}$ & 0.02 & 0.02 \\
\hline AJ13pH=2RT Control & 0.01 & 0.02 & 0.02 & $\mathrm{a}$ & 0.02 & 0.02 \\
\hline Average & 0.01 & 0.02 & 0.02 & 0.05 & 0.02 & 0.02 \\
\hline Standard Deviation & 0.00 & 0.00 & 0.00 & 0.00 & 0.00 & 0.00 \\
\hline
\end{tabular}

${ }^{\mathrm{a}}$ Sample not terminated

Table L-17. Molybdenum Detection Limits in Leachate Data $\left(\mathrm{ng} / \mathrm{mm}^{2}\right)$.

\begin{tabular}{|c|c|c|c|c|c|c|}
\hline Sample \# & 2 & 4 & 6 & 8 & 12 & 20 \\
\hline 25 & 0.08 & 0.04 & 0.06 & 1.97 & 0.08 & 0.07 \\
\hline 1KCl90 Control & 0.08 & 0.04 & 0.06 & 1.98 & 0.07 & 0.07 \\
\hline 27 & 0.08 & 0.06 & 0.03 & $\mathrm{a}$ & 0.08 & 0.07 \\
\hline 1KClRT control & 0.08 & 0.03 & 0.03 & $\mathrm{a}$ & 0.08 & 0.07 \\
\hline 29 & 0.08 & 0.03 & 0.03 & $\mathrm{a}$ & 0.08 & 0.07 \\
\hline 10KClRT control & 0.08 & 0.03 & 0.03 & $\mathrm{a}$ & 0.08 & 0.07 \\
\hline 31 & 0.08 & 0.03 & 0.03 & $\mathrm{a}$ & 0.08 & 0.07 \\
\hline AJ13pH=2RT Control & 0.08 & 0.03 & 0.03 & $\mathrm{a}$ & 0.08 & 0.07 \\
\hline Average & 0.08 & 0.03 & 0.04 & 1.97 & 0.08 & 0.07 \\
\hline Standard Deviation & 0.00 & 0.01 & 0.01 & 0.01 & 0.00 & 0.00 \\
\hline
\end{tabular}

${ }^{\mathrm{a}}$ Sample not terminated

Table L-18. Molybdenum Detection Limits in Acid Strip Data (ng/mm²).

\begin{tabular}{|c|c|c|c|c|c|c|}
\hline Sample \# & 2 & 4 & 6 & 8 & 12 & 20 \\
\hline 25 & 0.10 & 0.03 & 0.03 & 2.06 & 0.09 & 0.07 \\
\hline 1KC190 Control & 0.10 & 0.03 & 0.03 & 2.28 & 0.09 & 0.07 \\
\hline 27 & 0.09 & 0.03 & 0.03 & $\mathrm{a}$ & 0.08 & 0.07 \\
\hline 1KClRT control & 0.09 & 0.03 & 0.03 & $\mathrm{a}$ & 0.08 & 0.07 \\
\hline 29 & 0.08 & 0.03 & 0.03 & $\mathrm{a}$ & 0.08 & 0.07 \\
\hline 10KClRT control & 0.09 & 0.03 & 0.03 & $\mathrm{a}$ & 0.08 & 0.07 \\
\hline 31 & 0.10 & 0.03 & 0.03 & $\mathrm{a}$ & 0.08 & 0.07 \\
\hline AJ13pH=2RT Control & 0.09 & 0.03 & 0.03 & $\mathrm{a}$ & 0.09 & 0.07 \\
\hline Average & 0.09 & 0.03 & 0.03 & 2.17 & 0.08 & 0.07 \\
\hline Standard Deviation & 0.00 & 0.00 & 0.00 & 0.15 & 0.00 & 0.00 \\
\hline
\end{tabular}

${ }^{\mathrm{a}}$ Sample not terminated 
Table L-19. Manganese Detection Limits in Leachate Data $\left(\mathrm{ng} / \mathrm{mm}^{2}\right)$.

\begin{tabular}{|c|c|c|c|c|c|c|}
\hline Sample \# & 2 & 4 & 6 & 8 & 12 & 20 \\
\hline 25 & 0.03 & 0.02 & 0.03 & 0.21 & 0.04 & 0.02 \\
\hline 1KCl90 Control & 0.03 & 0.02 & 0.03 & 0.21 & 0.03 & 0.02 \\
\hline 27 & 0.03 & 0.03 & 0.01 & $\mathrm{a}$ & 0.04 & 0.02 \\
\hline 1KClRT control & 0.03 & 0.01 & 0.01 & $\mathrm{a}$ & 0.04 & 0.02 \\
\hline 29 & 0.03 & 0.02 & 0.01 & $\mathrm{a}$ & 0.04 & 0.02 \\
\hline 10KClRT control & 0.03 & 0.01 & 0.01 & $\mathrm{a}$ & 0.04 & 0.02 \\
\hline 31 & 0.03 & 0.01 & 0.01 & $\mathrm{a}$ & 0.04 & 0.02 \\
\hline AJ13pH=2RT Control & 0.03 & 0.01 & 0.01 & $\mathrm{a}$ & 0.04 & 0.02 \\
\hline Average & 0.03 & 0.02 & 0.02 & 0.21 & 0.04 & 0.02 \\
\hline Standard Deviation & 0.00 & 0.01 & 0.01 & 0.00 & 0.00 & 0.00 \\
\hline
\end{tabular}

${ }^{\mathrm{a}}$ Sample not terminated

Table L-20. Manganese Detection Limits in Acid Strip Data (ng/mm²).

\begin{tabular}{|c|c|c|c|c|c|c|}
\hline Sample \# & 2 & 4 & 6 & 8 & 12 & 20 \\
\hline 25 & 0.04 & 0.02 & 0.02 & 0.22 & 0.04 & 0.02 \\
\hline 1KCl90 Control & 0.03 & 0.02 & 0.02 & 0.24 & 0.04 & 0.02 \\
\hline 27 & 0.03 & 0.02 & 0.02 & $\mathrm{a}$ & 0.04 & 0.02 \\
\hline 1KClRT control & 0.03 & 0.02 & 0.02 & $\mathrm{a}$ & 0.04 & 0.02 \\
\hline 29 & 0.03 & 0.02 & 0.02 & $\mathrm{a}$ & 0.04 & 0.02 \\
\hline 10KClRT control & 0.03 & 0.02 & 0.02 & $\mathrm{a}$ & 0.04 & 0.02 \\
\hline 31 & 0.03 & 0.02 & 0.02 & $\mathrm{a}$ & 0.04 & 0.02 \\
\hline AJ13pH=2RT Control & 0.03 & 0.02 & 0.02 & $\mathrm{a}$ & 0.04 & 0.02 \\
\hline Average & 0.03 & 0.02 & 0.02 & 0.23 & 0.04 & 0.02 \\
\hline Standard Deviation & 0.00 & 0.00 & 0.00 & 0.02 & 0.00 & 0.00 \\
\hline
\end{tabular}

${ }^{\mathrm{a}}$ Sample not terminated

Table L-21. Cobalt Detection Limits in Leachate Data (ng/mm²).

\begin{tabular}{|c|c|c|c|c|c|c|}
\hline Sample \# & 2 & 4 & 6 & 8 & 12 & 20 \\
\hline 25 & 0.00 & 0.03 & 0.04 & 0.10 & 0.03 & 0.02 \\
\hline 1KC190 Control & 0.00 & 0.03 & 0.04 & 0.10 & 0.03 & 0.02 \\
\hline 27 & 0.00 & 0.04 & 0.02 & $\mathrm{a}$ & 0.03 & 0.02 \\
\hline 1KClRT control & 0.00 & 0.02 & 0.02 & $\mathrm{a}$ & 0.03 & 0.02 \\
\hline 29 & 0.00 & 0.02 & 0.02 & $\mathrm{a}$ & 0.03 & 0.02 \\
\hline 10KClRT control & 0.00 & 0.02 & 0.02 & $\mathrm{a}$ & 0.03 & 0.02 \\
\hline 31 & 0.00 & 0.02 & 0.02 & $\mathrm{a}$ & 0.03 & 0.02 \\
\hline AJ13pH=2RT Control & 0.00 & 0.02 & 0.02 & $\mathrm{a}$ & 0.03 & 0.02 \\
\hline Average & 0.00 & 0.03 & 0.03 & 0.10 & 0.03 & 0.02 \\
\hline Standard Deviation & 0.00 & 0.01 & 0.01 & 0.00 & 0.00 & 0.00 \\
\hline
\end{tabular}

${ }^{\mathrm{a}}$ Sample not terminated 
Table L-22. Cobalt Detection Limits in Acid Strip Data (ng/mm²).

\begin{tabular}{|c|c|c|c|c|c|c|}
\hline Sample \# & 2 & 4 & 6 & 8 & 12 & 20 \\
\hline 25 & 0.00 & 0.02 & 0.03 & 0.11 & 0.04 & 0.02 \\
\hline 1KCl90 Control & 0.00 & 0.02 & 0.03 & 0.12 & 0.04 & 0.02 \\
\hline 27 & 0.00 & 0.02 & 0.03 & $\mathrm{a}$ & 0.03 & 0.02 \\
\hline 1KClRT control & 0.00 & 0.02 & 0.03 & $\mathrm{a}$ & 0.03 & 0.02 \\
\hline 29 & 0.00 & 0.02 & 0.02 & $\mathrm{a}$ & 0.03 & 0.02 \\
\hline 10KClRT control & 0.00 & 0.02 & 0.03 & $\mathrm{a}$ & 0.03 & 0.02 \\
\hline 31 & 0.00 & 0.02 & 0.02 & $\mathrm{a}$ & 0.03 & 0.02 \\
\hline AJ13pH=2RT Control & 0.00 & 0.02 & 0.03 & $\mathrm{a}$ & 0.04 & 0.02 \\
\hline Average & 0.00 & 0.02 & 0.03 & 0.11 & 0.03 & 0.02 \\
\hline Standard Deviation & 0.00 & 0.00 & 0.00 & 0.01 & 0.00 & 0.00 \\
\hline
\end{tabular}

${ }^{\mathrm{a}}$ Sample not terminated

Table L-23. Copper Detection Limits in Leachate Data $\left(\mathrm{ng} / \mathrm{mm}^{2}\right)$.

\begin{tabular}{|c|c|c|c|c|c|c|}
\hline Sample \# & 2 & 4 & 6 & 8 & 12 & 20 \\
\hline 25 & 0.14 & 0.07 & 0.11 & 0.21 & 0.31 & 1.01 \\
\hline 1KCl90 Control & 0.15 & 0.07 & 0.11 & 0.21 & 0.27 & 1.00 \\
\hline 27 & 0.15 & 0.11 & 0.06 & $\mathrm{a}$ & 0.31 & 1.00 \\
\hline 1KClRT control & 0.14 & 0.06 & 0.06 & $\mathrm{a}$ & 0.31 & 1.01 \\
\hline 29 & 0.15 & 0.06 & 0.06 & $\mathrm{a}$ & 0.31 & 1.05 \\
\hline 10KClRT control & 0.15 & 0.06 & 0.06 & $\mathrm{a}$ & 0.32 & 1.04 \\
\hline 31 & 0.14 & 0.06 & 0.06 & $\mathrm{a}$ & 0.31 & 1.03 \\
\hline AJ13pH=2RT Control & 0.14 & 0.06 & 0.06 & $\mathrm{a}$ & 0.31 & 1.03 \\
\hline Average & 0.14 & 0.07 & 0.07 & 0.21 & 0.31 & 1.02 \\
\hline Standard Deviation & 0.00 & 0.02 & 0.03 & 0.00 & 0.02 & 0.02 \\
\hline
\end{tabular}

${ }^{\mathrm{a}}$ Sample not terminated

Table L-24. Copper Detection Limits in Acid Strip Data (ng/mm²).

\begin{tabular}{|c|c|c|c|c|c|c|}
\hline Sample \# & 2 & 4 & 6 & 8 & 12 & 20 \\
\hline 25 & 0.17 & 0.06 & 0.06 & 0.22 & 0.34 & 1.01 \\
\hline 1KCl90 Control & 0.17 & 0.06 & 0.06 & 0.24 & 0.34 & 1.00 \\
\hline 27 & 0.16 & 0.06 & 0.06 & $\mathrm{a}$ & 0.34 & 1.00 \\
\hline 1KClRT control & 0.15 & 0.06 & 0.06 & $\mathrm{a}$ & 0.33 & 1.01 \\
\hline 29 & 0.15 & 0.06 & 0.06 & $\mathrm{a}$ & 0.33 & 1.05 \\
\hline 10KClRT control & 0.16 & 0.06 & 0.06 & $\mathrm{a}$ & 0.32 & 1.04 \\
\hline 31 & 0.17 & 0.06 & 0.06 & $\mathrm{a}$ & 0.30 & 1.03 \\
\hline AJ13pH=2RT Control & 0.16 & 0.06 & 0.06 & $\mathrm{a}$ & 0.34 & 1.03 \\
\hline Average & 0.16 & 0.06 & 0.06 & 0.23 & 0.33 & 1.02 \\
\hline Standard Deviation & 0.01 & 0.00 & 0.00 & 0.02 & 0.01 & 0.02 \\
\hline
\end{tabular}

${ }^{\mathrm{a}}$ Sample not terminated 
Table L-25. Vanadium Detection Limits in Leachate Data $\left(\mathrm{ng} / \mathrm{mm}^{2}\right)$.

\begin{tabular}{|c|c|c|c|c|c|c|}
\hline Sample \# & 2 & 4 & 6 & 8 & 12 & 20 \\
\hline 25 & 0.13 & 0.26 & 0.41 & 0.10 & 0.21 & 0.20 \\
\hline 1KCl90 Control & 0.14 & 0.26 & 0.41 & 0.10 & 0.18 & 0.20 \\
\hline 27 & 0.13 & 0.43 & 0.21 & $\mathrm{a}$ & 0.21 & 0.20 \\
\hline 1KClRT control & 0.13 & 0.20 & 0.21 & $\mathrm{a}$ & 0.21 & 0.20 \\
\hline 29 & 0.14 & 0.21 & 0.21 & $\mathrm{a}$ & 0.21 & 0.21 \\
\hline 10KClRT control & 0.13 & 0.21 & 0.21 & $\mathrm{a}$ & 0.21 & 0.21 \\
\hline 31 & 0.13 & 0.21 & 0.21 & $\mathrm{a}$ & 0.21 & 0.21 \\
\hline AJ13pH=2RT Control & 0.13 & 0.21 & 0.21 & $\mathrm{a}$ & 0.21 & 0.21 \\
\hline Average & 0.13 & 0.25 & 0.26 & 0.10 & 0.20 & 0.20 \\
\hline Standard Deviation & 0.00 & 0.08 & 0.10 & 0.00 & 0.01 & 0.00 \\
\hline
\end{tabular}

${ }^{\mathrm{a}}$ Sample not terminated

Table L-26. Vanadium Detection Limits in Acid Strip Data $\left(\mathbf{n g} / \mathrm{mm}^{2}\right)$.

\begin{tabular}{|c|c|c|c|c|c|c|}
\hline Sample \# & 2 & 4 & 6 & 8 & 12 & 20 \\
\hline 25 & 0.16 & 0.22 & 0.23 & 0.11 & 0.23 & 0.20 \\
\hline 1KCl90 Control & 0.16 & 0.23 & 0.23 & 0.12 & 0.23 & 0.20 \\
\hline 27 & 0.15 & 0.23 & 0.23 & $\mathrm{a}$ & 0.22 & 0.20 \\
\hline 1KClRT control & 0.14 & 0.22 & 0.23 & $\mathrm{a}$ & 0.22 & 0.20 \\
\hline 29 & 0.14 & 0.22 & 0.23 & $\mathrm{a}$ & 0.22 & 0.21 \\
\hline 10KClRT control & 0.15 & 0.22 & 0.23 & $\mathrm{a}$ & 0.21 & 0.21 \\
\hline 31 & 0.15 & 0.22 & 0.22 & $\mathrm{a}$ & 0.20 & 0.21 \\
\hline AJ13pH=2RT Control & 0.15 & 0.22 & 0.23 & $\mathrm{a}$ & 0.23 & 0.21 \\
\hline Average & 0.15 & 0.22 & 0.23 & 0.11 & 0.22 & 0.20 \\
\hline Standard Deviation & 0.01 & 0.00 & 0.00 & 0.01 & 0.01 & 0.00 \\
\hline
\end{tabular}

${ }^{\mathrm{a}}$ Sample not terminated 
M. Supplementary Tests—Sample Releases

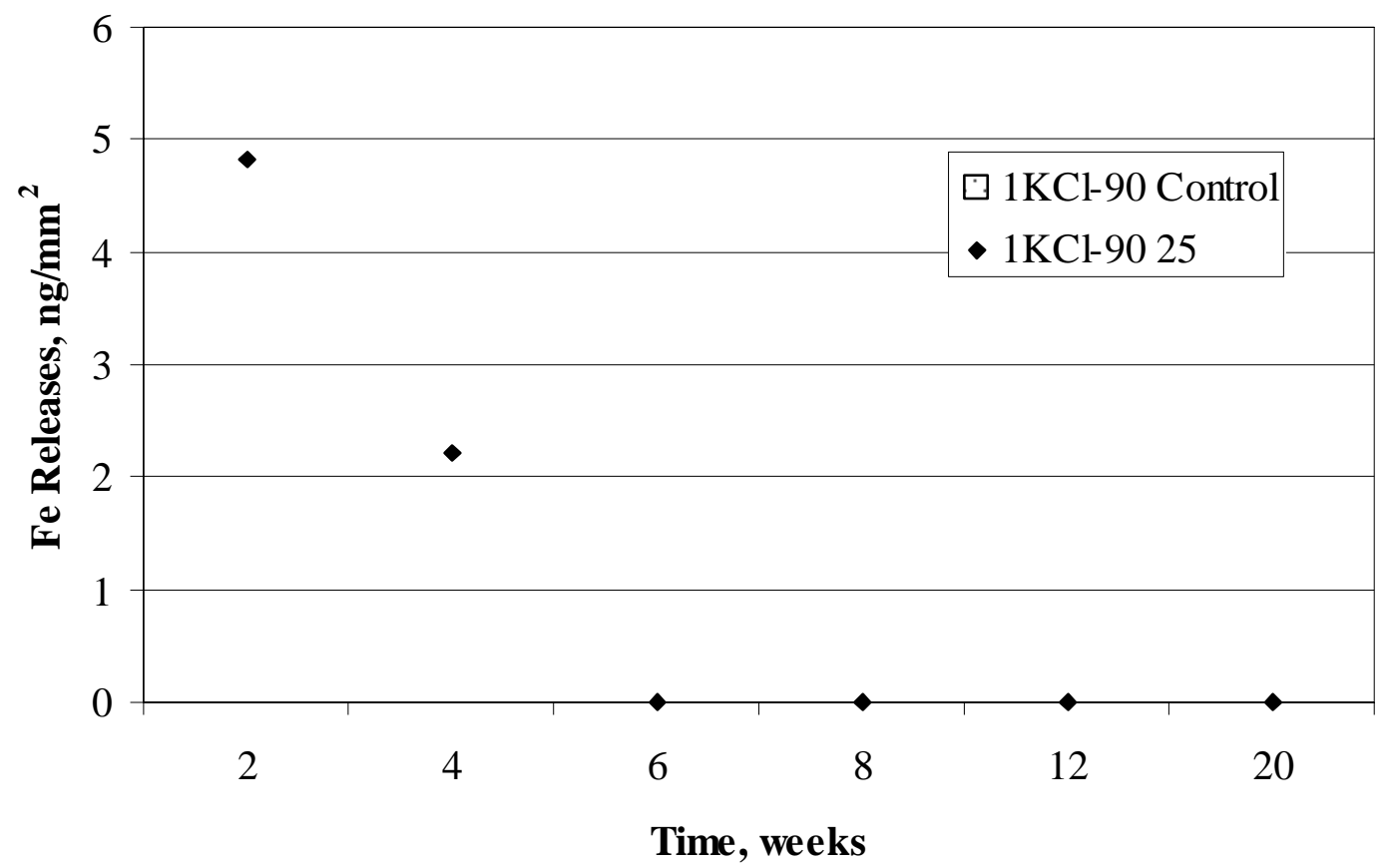

Figure M-1. Iron Releases in $1 \mathrm{KCl}$ solution at $90^{\circ} \mathrm{C}$.

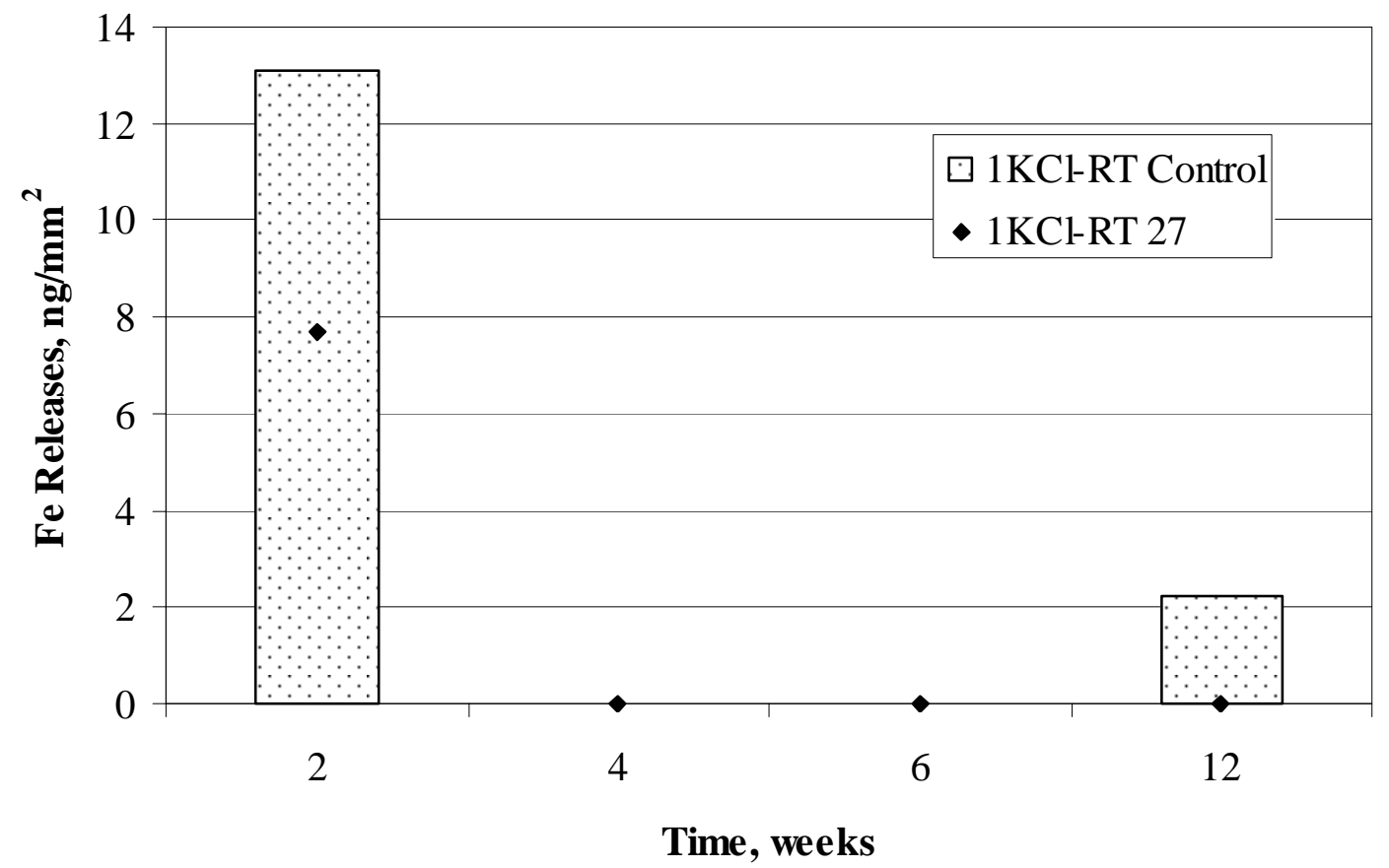

Figure M-2. Iron Releases in $1 \mathrm{KCl}$ solution at room temperature. 


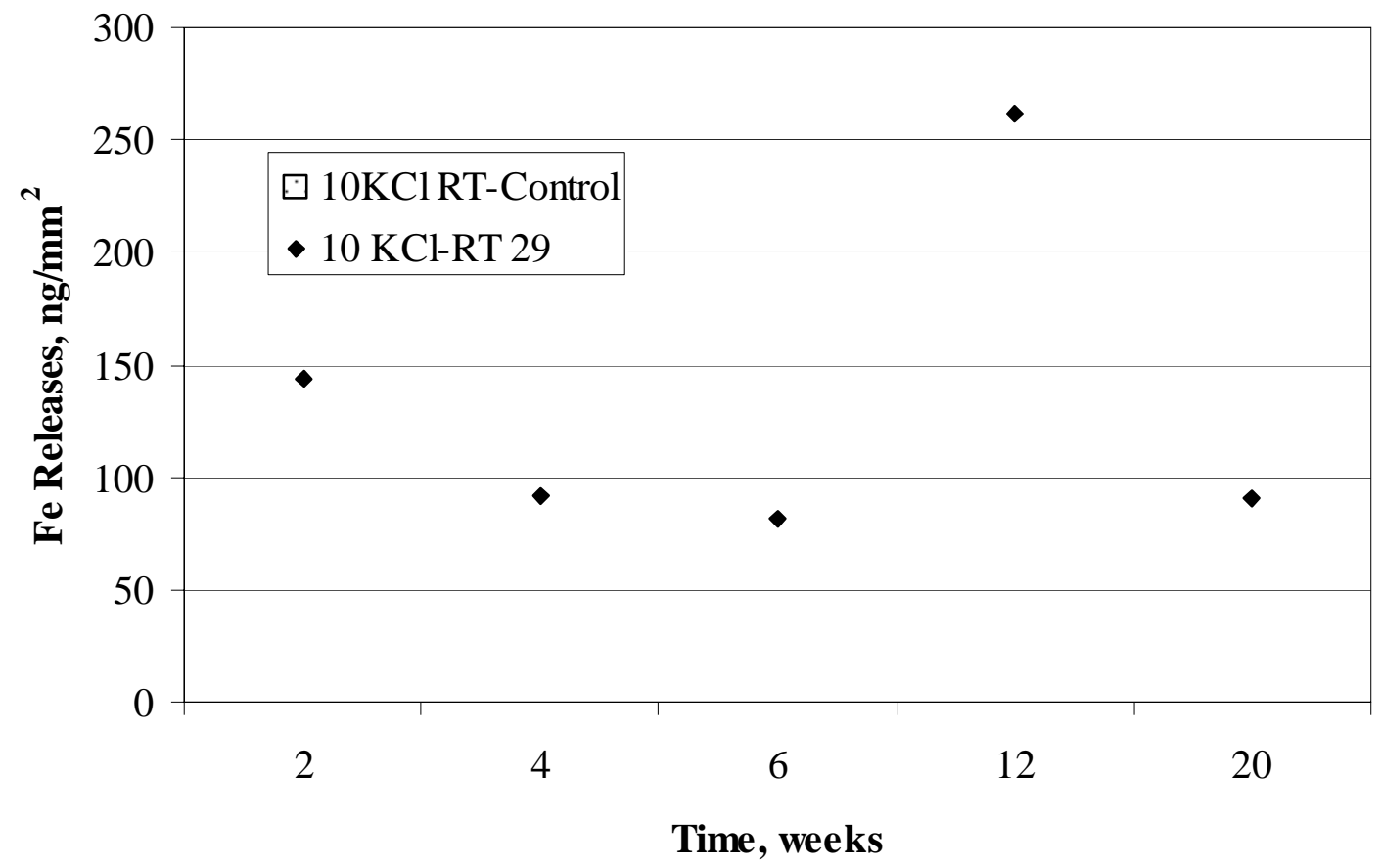

Figure M-3. Iron Releases in $10 \mathrm{KCl}$ Solution at room temperature.

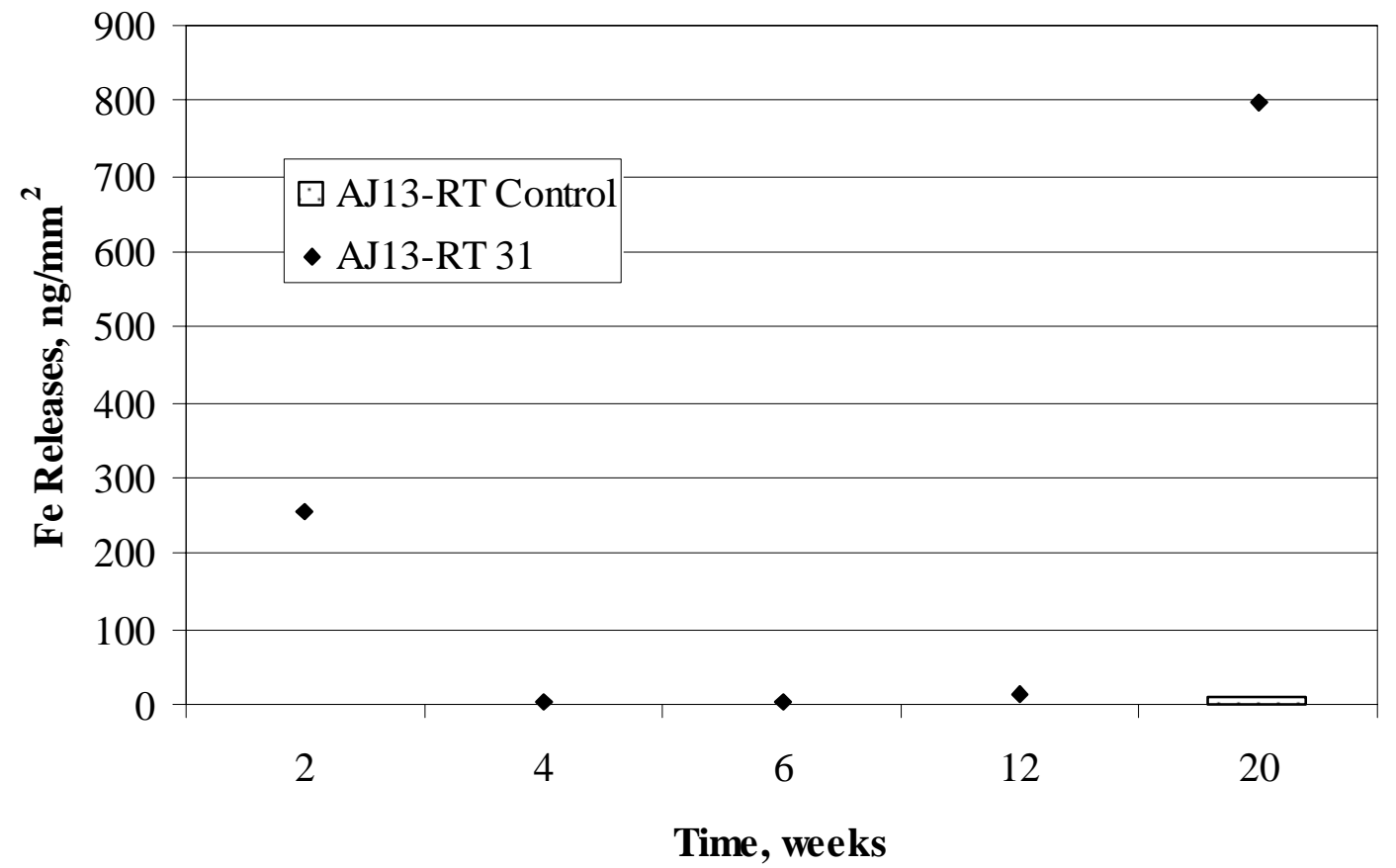

Figure M-4. Iron Releases in AJ13 Solution at room temperature. 


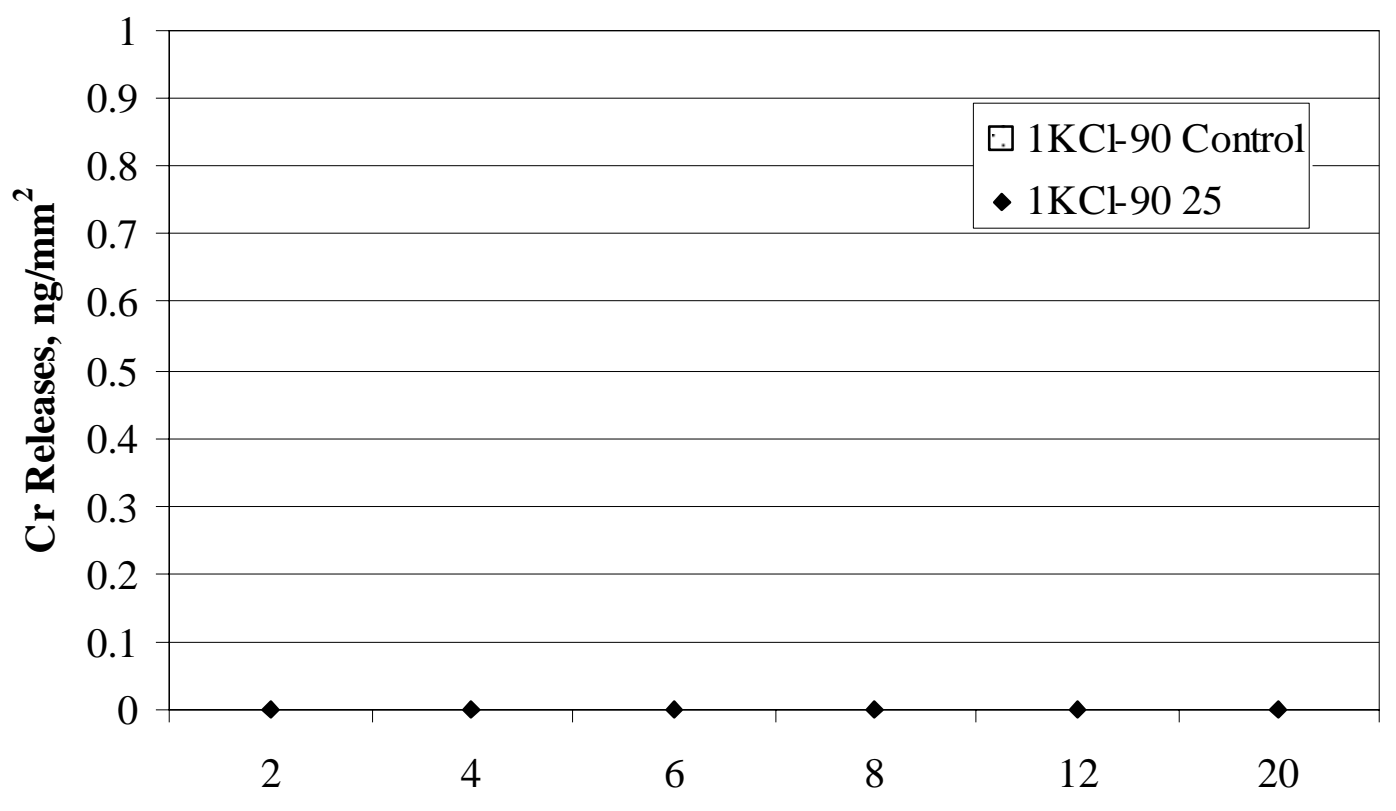

Time, weeks

Figure M-5. Chromium Releases in $1 \mathrm{KCl}$ solution at $90^{\circ} \mathrm{C}$.

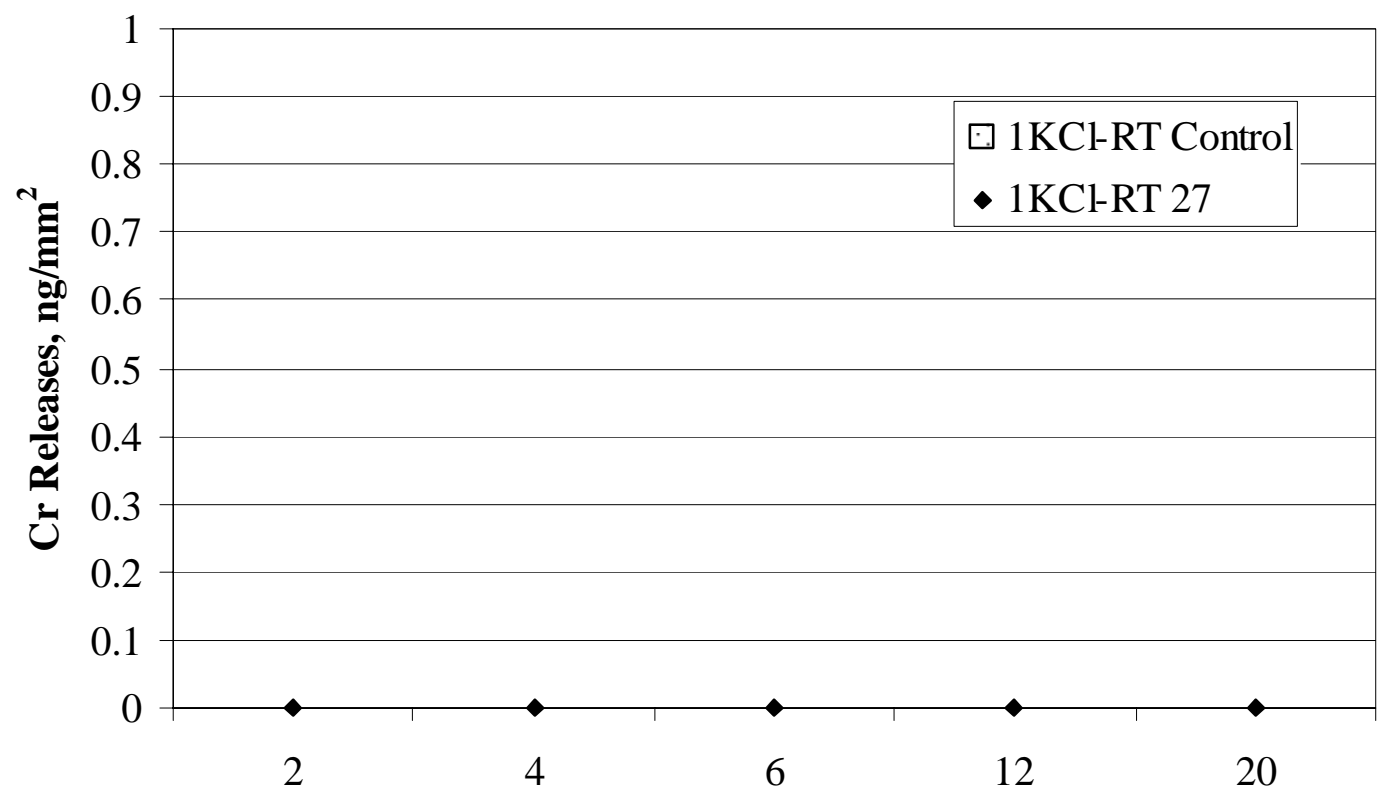

Time, weeks

Figure M-6. Chromium Releases in $1 \mathrm{KCl}$ solution at room temperature. 


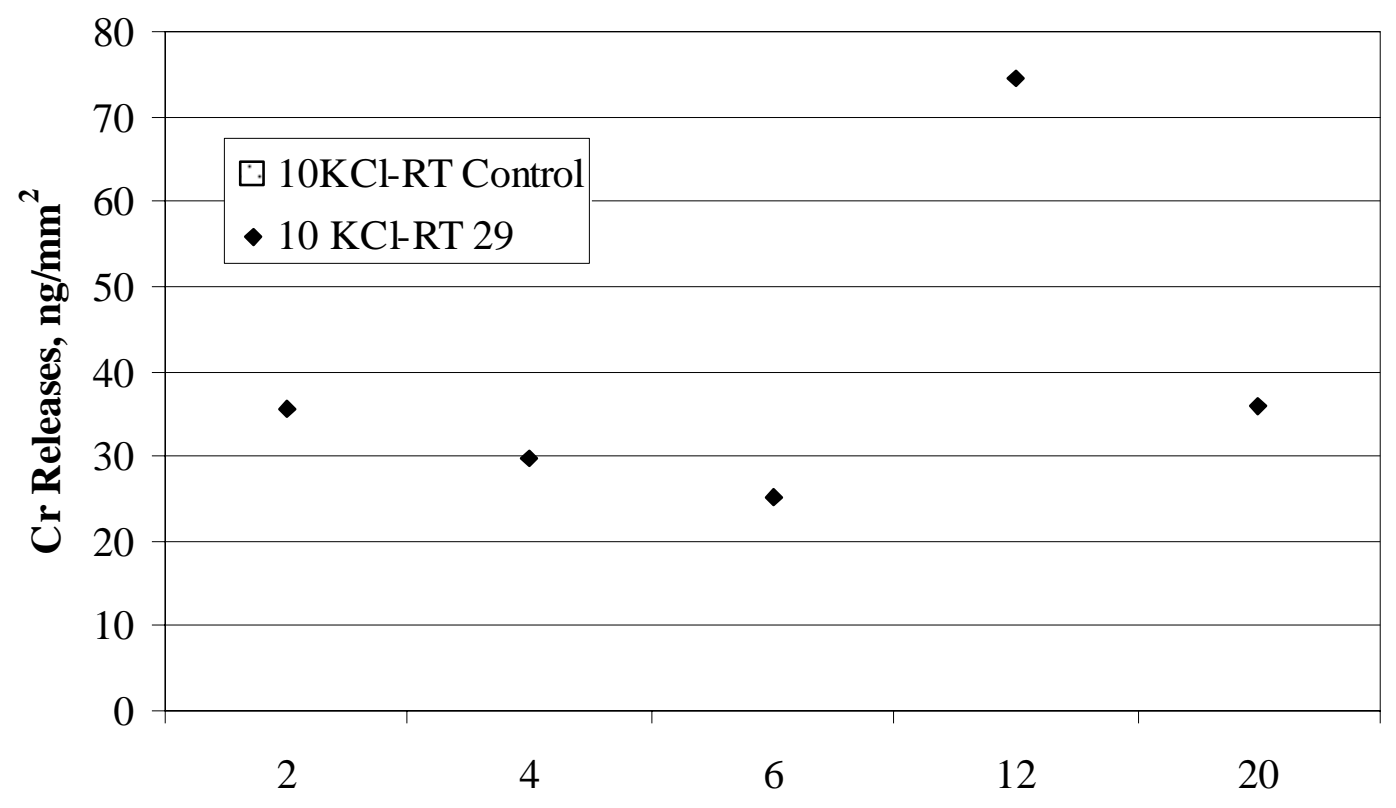

Time, weeks

Figure M-7. Chromium Releases in $10 \mathrm{KCl}$ solution at room temperature.

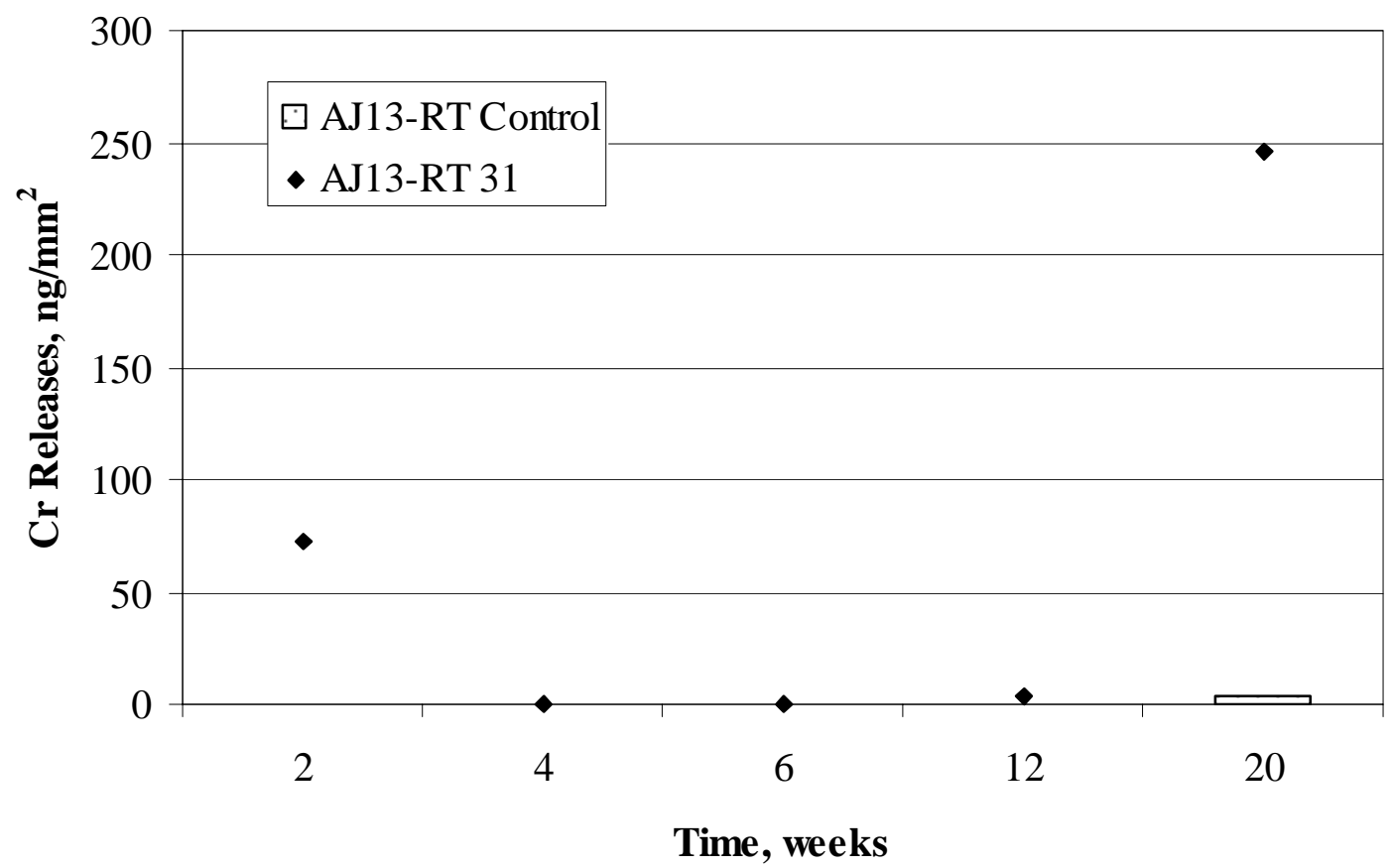

Figure M-8. Chromium Releases in AJ13 solution at room temperature. 


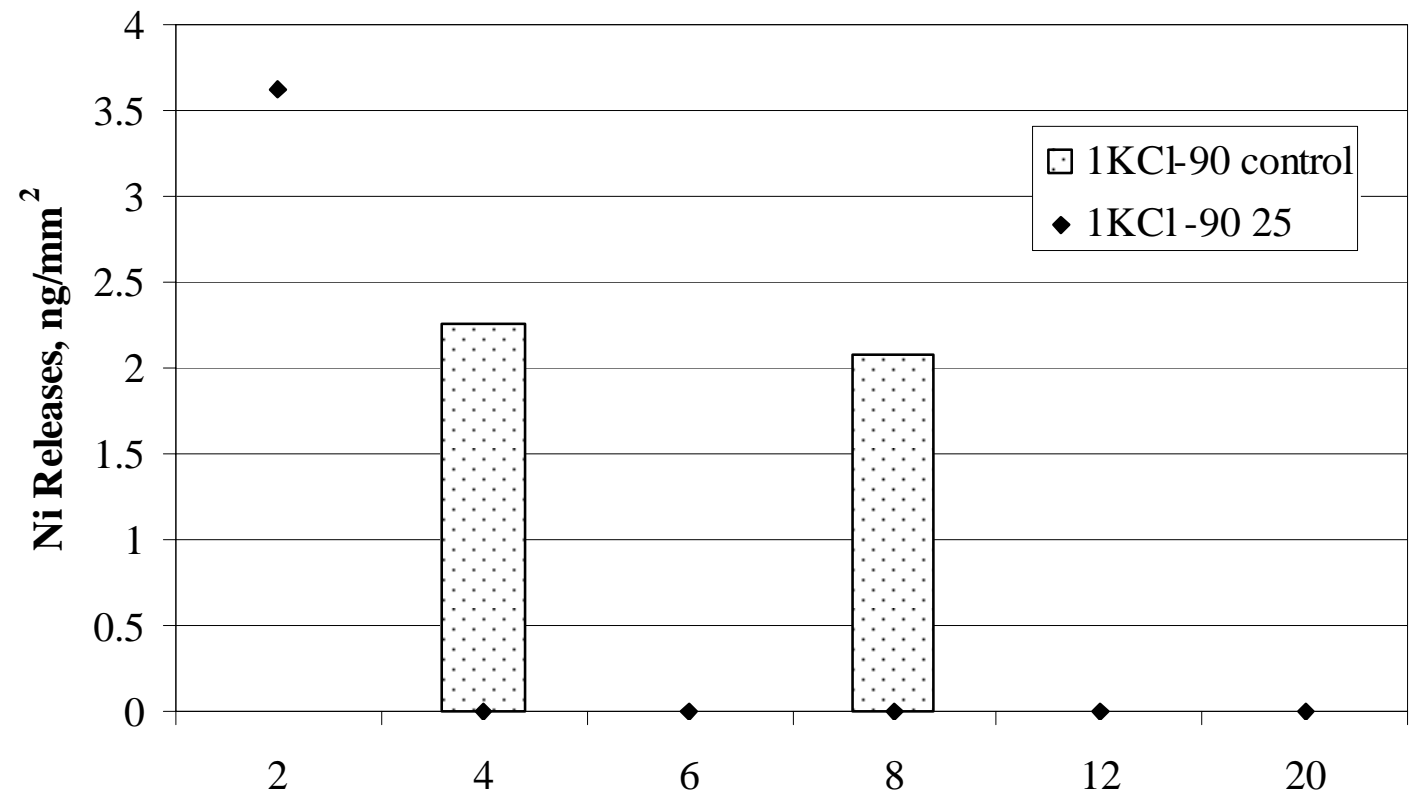

Time, weeks

Figure M-9. Nickel Releases in $1 \mathrm{KCl}$ solution at $90^{\circ} \mathrm{C}$.

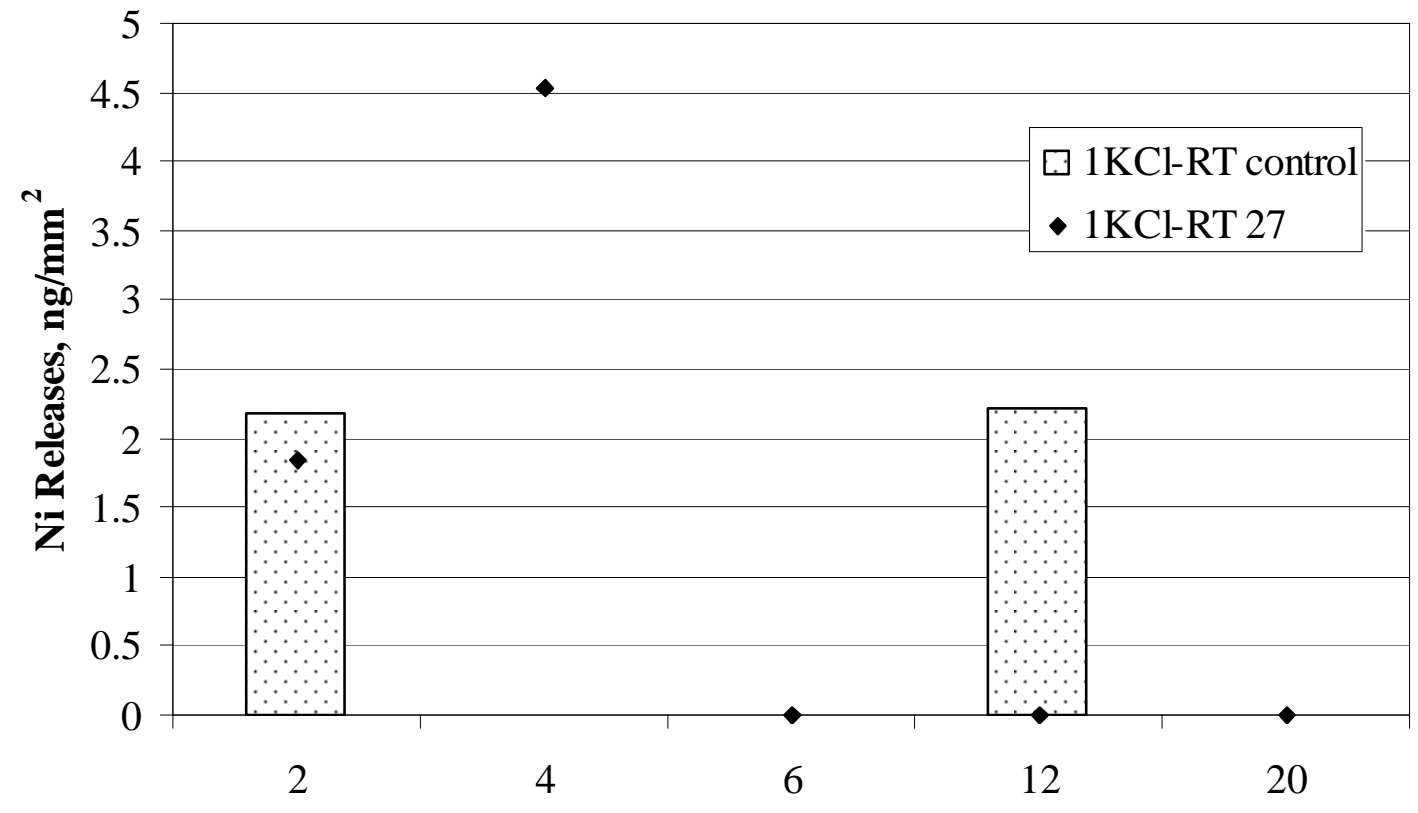

Time, weeks

Figure M-10. Nickel Releases in $1 \mathrm{KCl}$ solution at room temperature. 


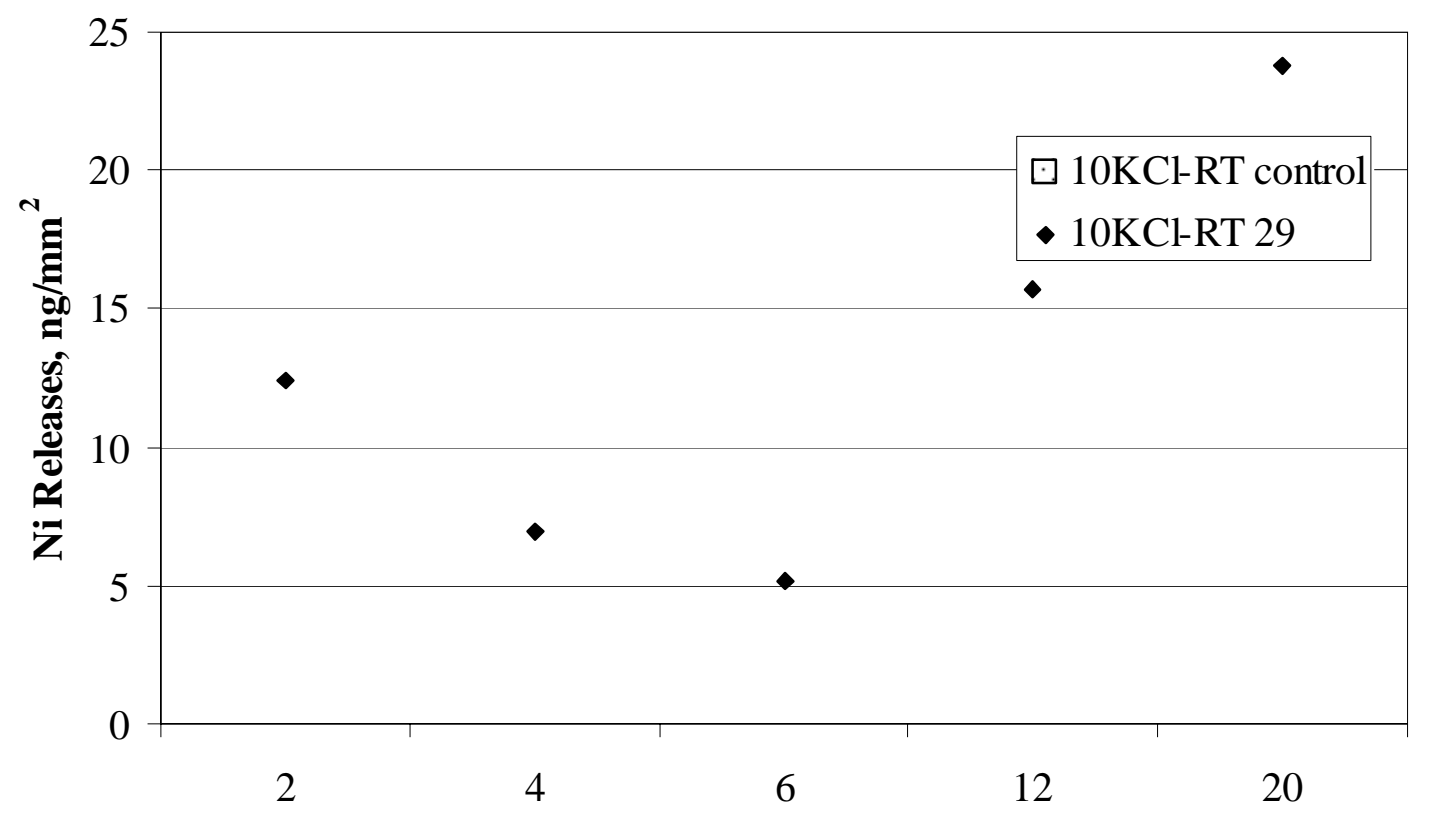

Time, weeks

Figure M-11. Nickel Releases in $10 \mathrm{KCl}$ solution at room temperature.

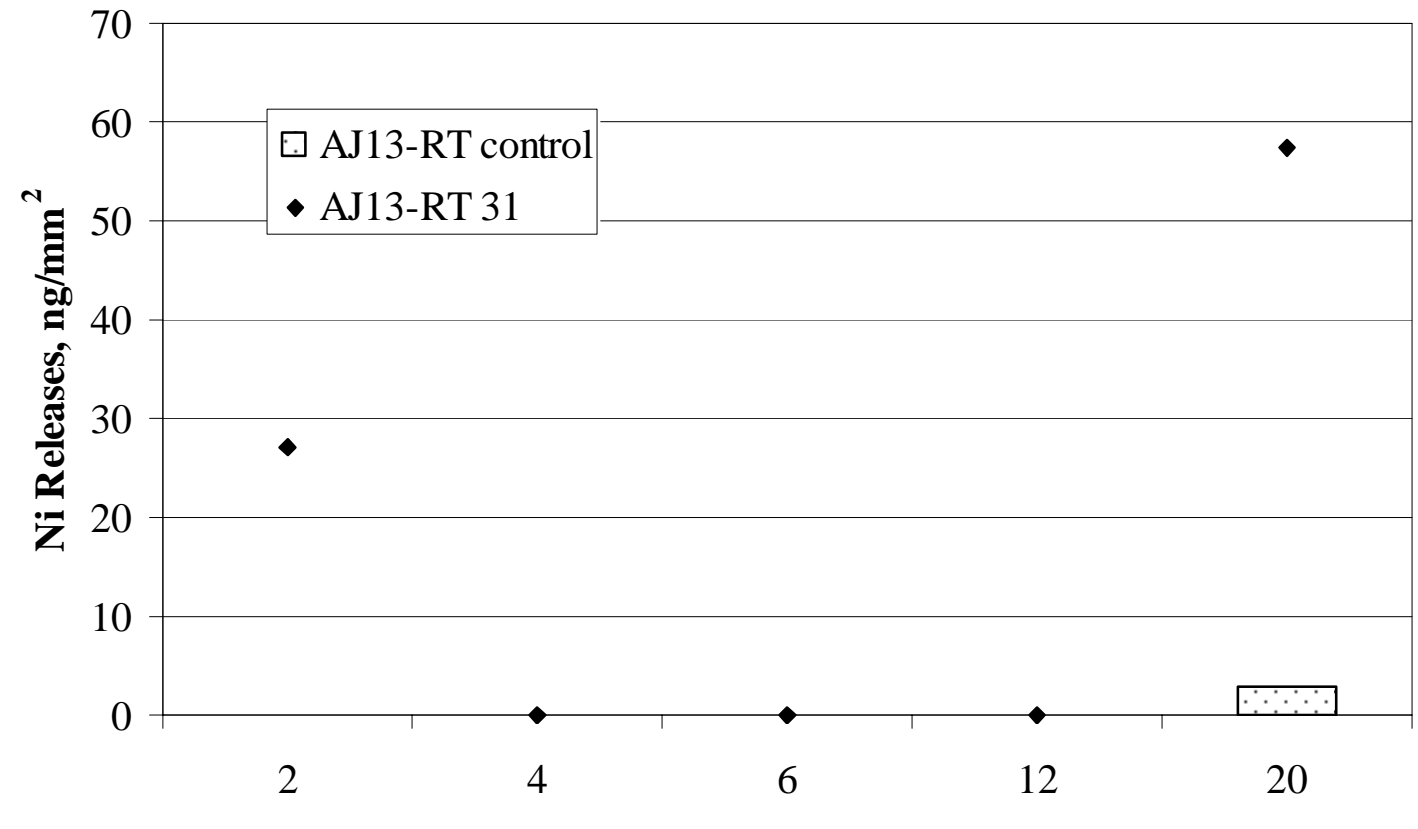

Time, weeks

Figure M-12. Nickel Releases in AJ13 solution at room temperature. 


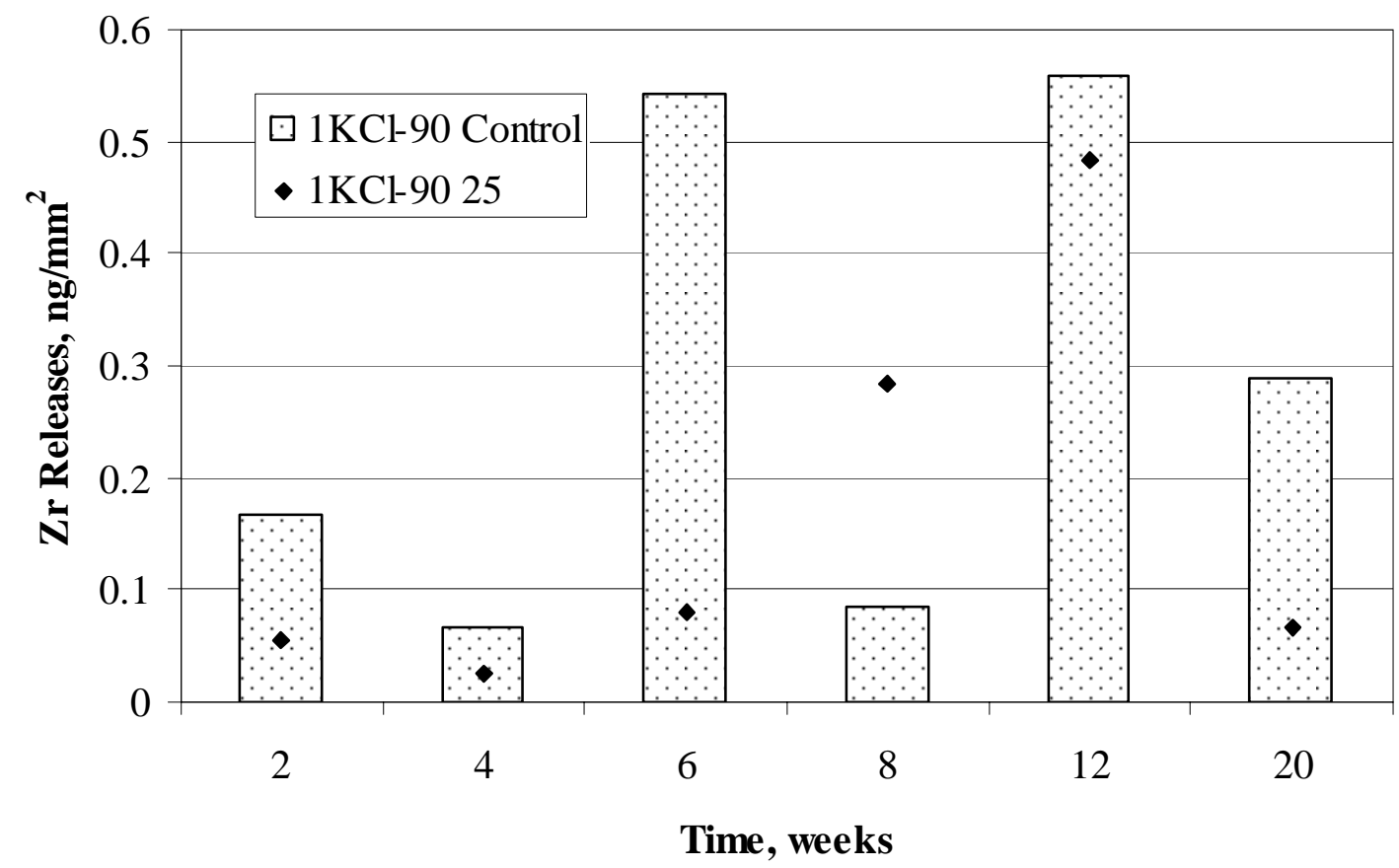

Figure M-13. Zirconium Releases in $1 \mathrm{KCl}$ solution at $90^{\circ} \mathrm{C}$.

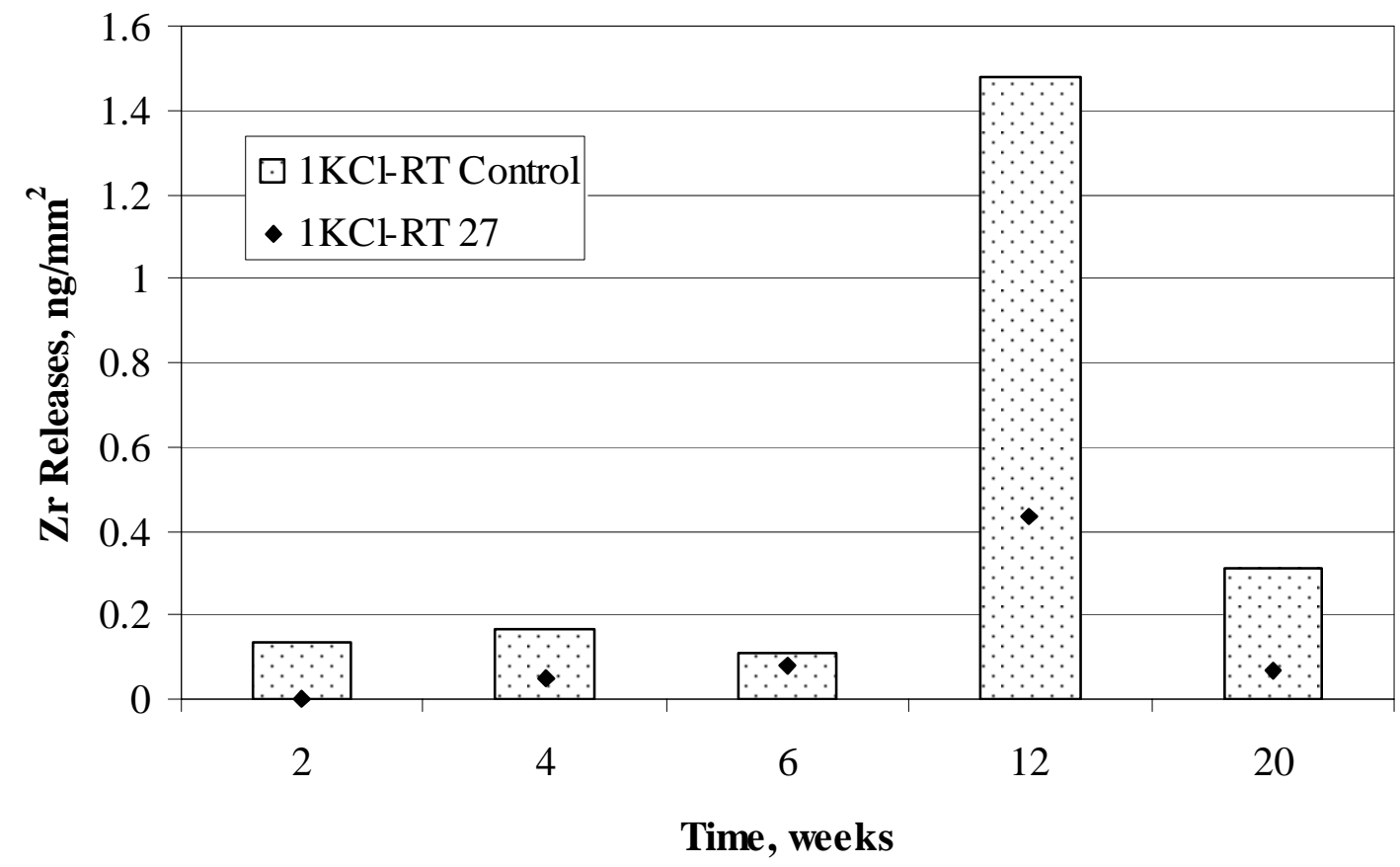

Figure M-14. Zirconium Releases in $1 \mathrm{KCl}$ solution at room temperature. 


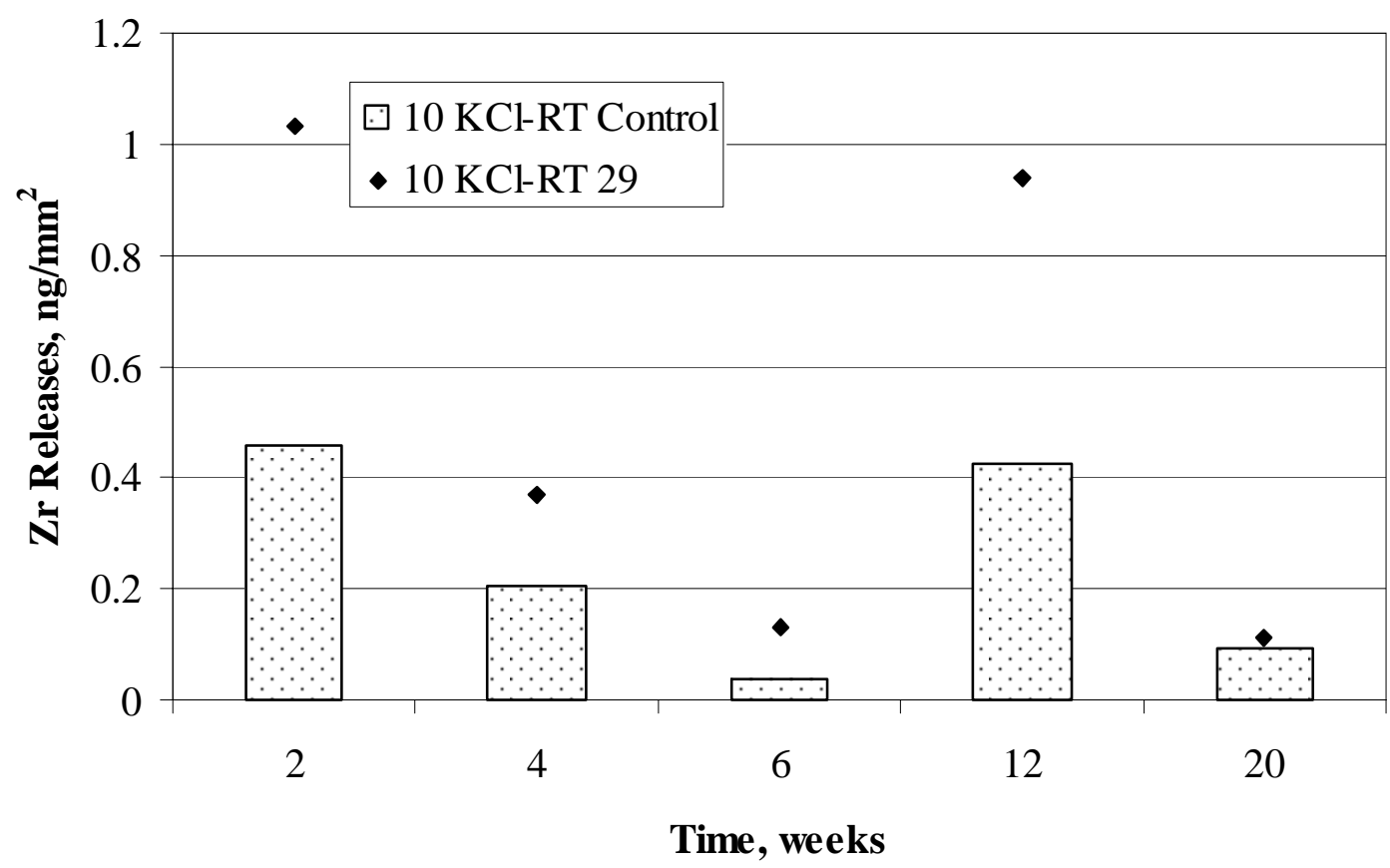

Figure M-15. Zirconium Releases in $10 \mathrm{KCl}$ solution at room temperature.

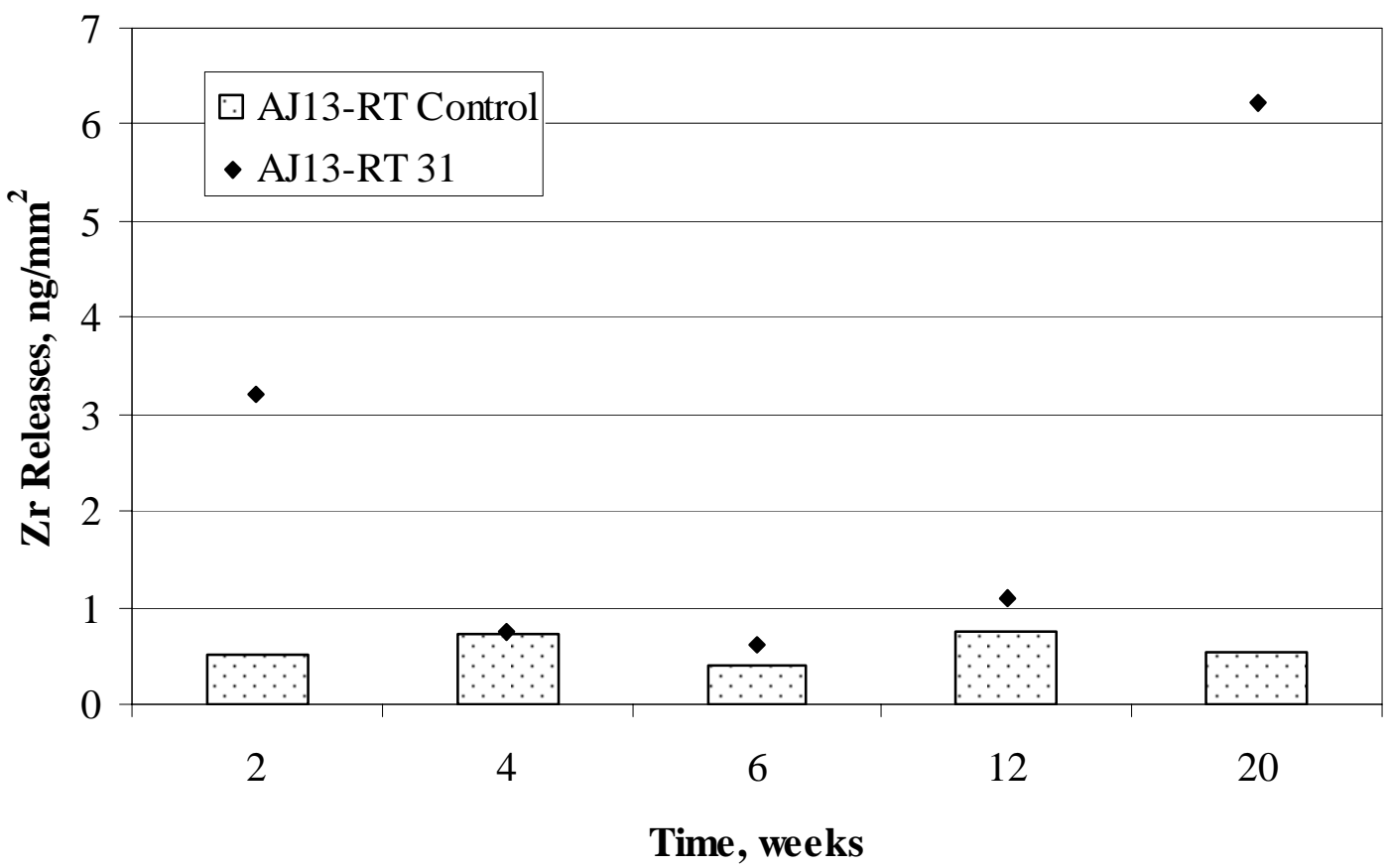

Figure M-16. Zirconium Releases in AJ13 solution at room temperature. 


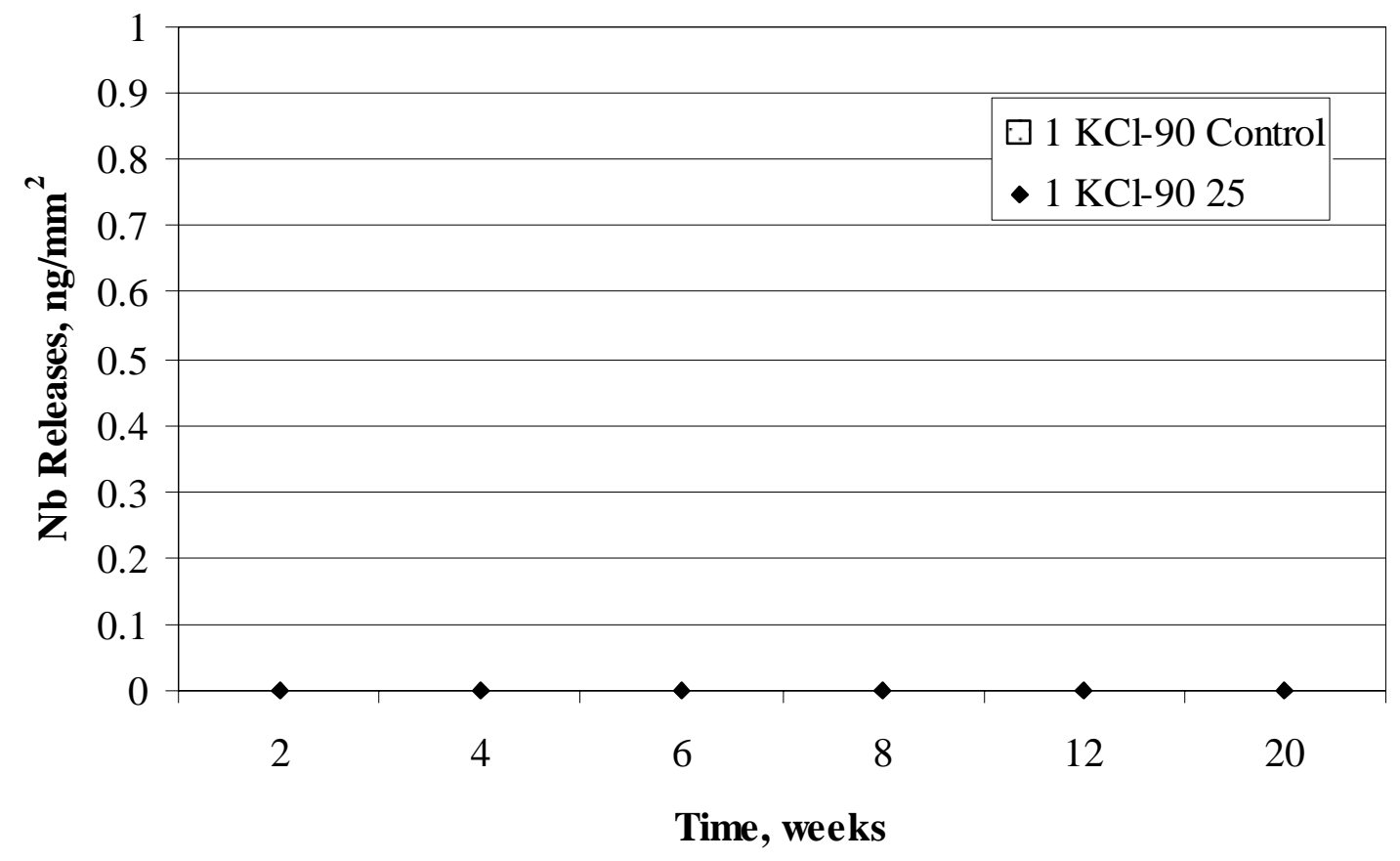

Figure M-17. Niobium Releases in $1 \mathrm{KCl}$ solution at $90^{\circ} \mathrm{C}$.

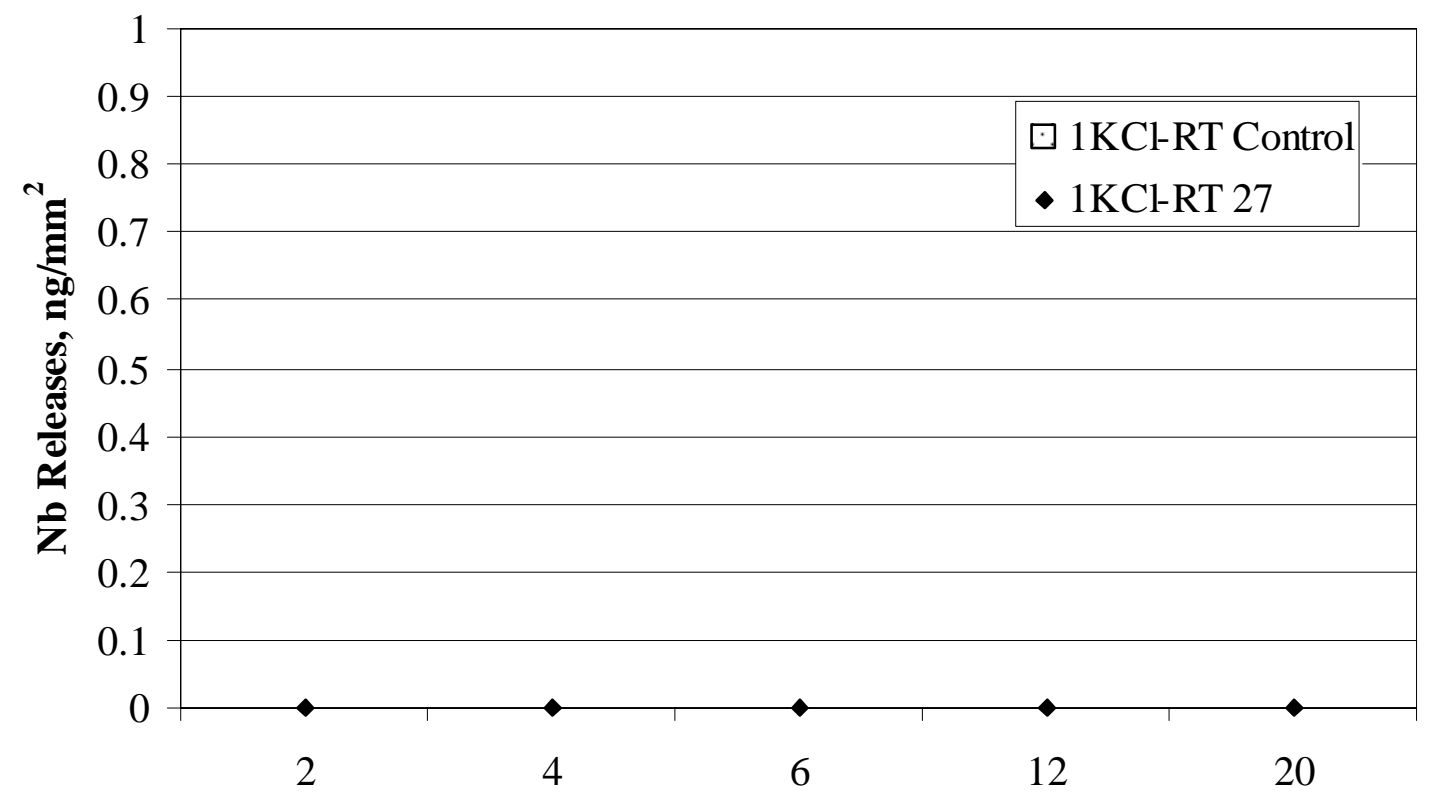

Time, weeks

Figure M-18. Niobium Releases in $1 \mathrm{KCl}$ solution at room temperature. 


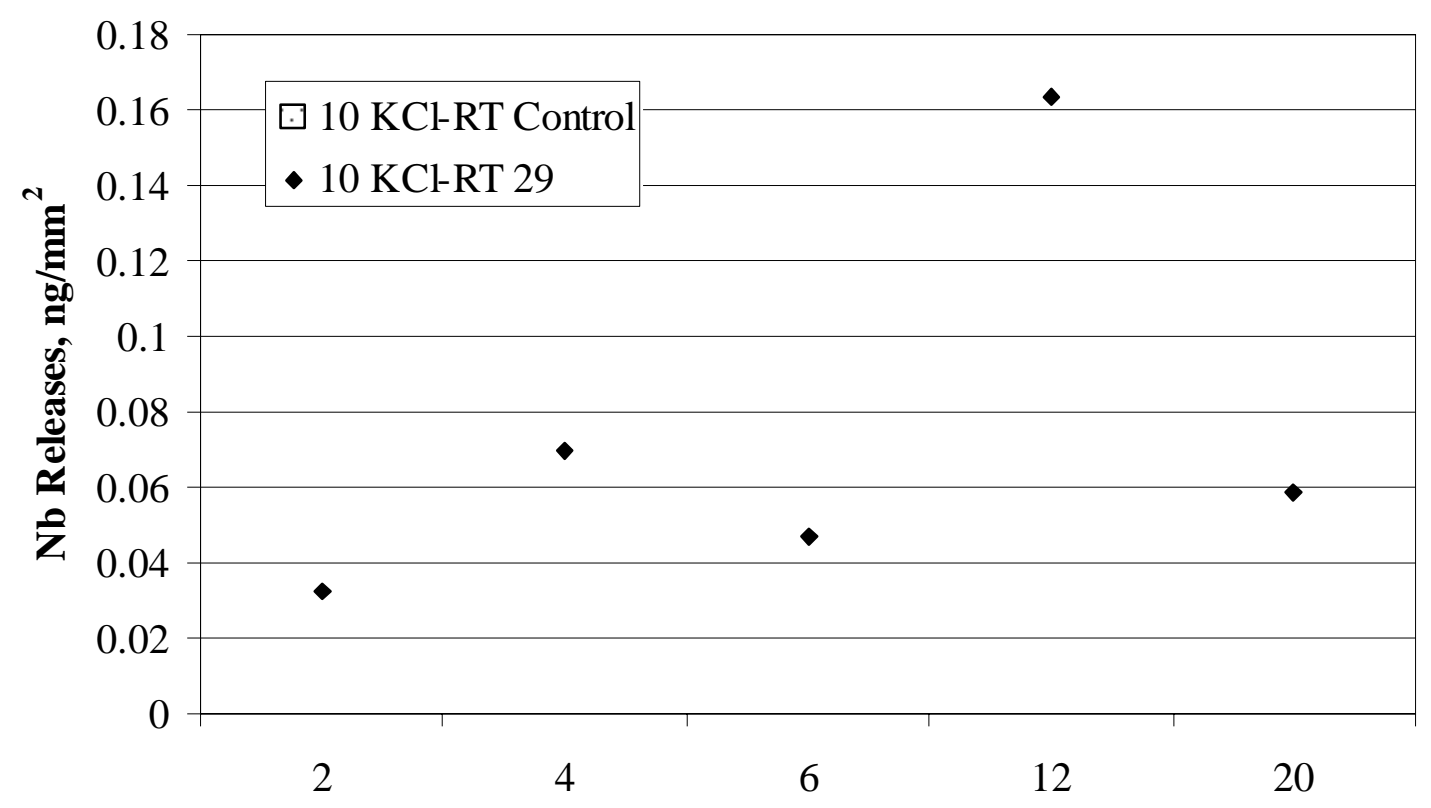

Time, weeks

Figure M-19. Niobium Releases in $10 \mathrm{KCl}$ solution at room temperature.

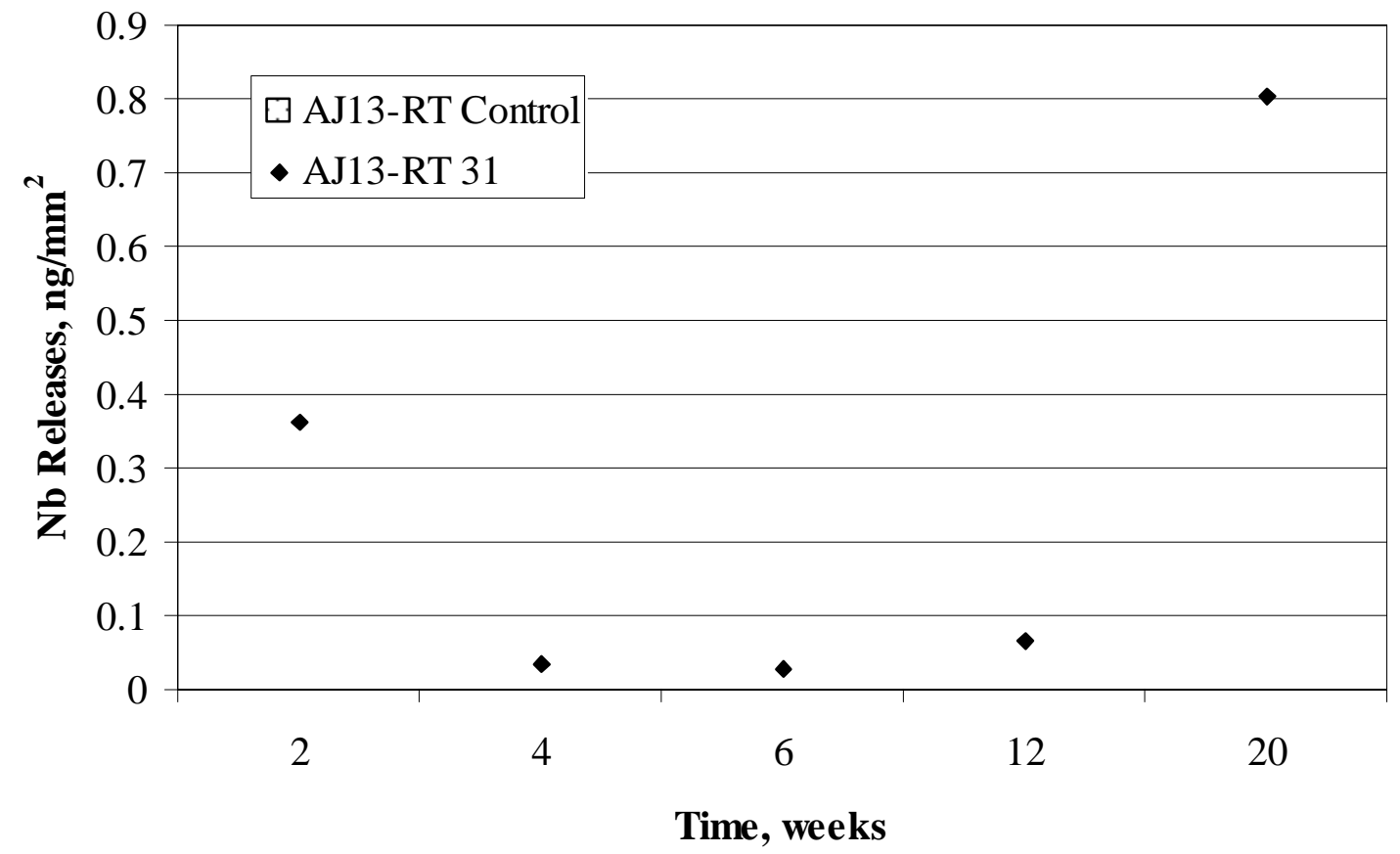

Figure M-20. Niobium Releases in AJ13 solution at room temperature. 


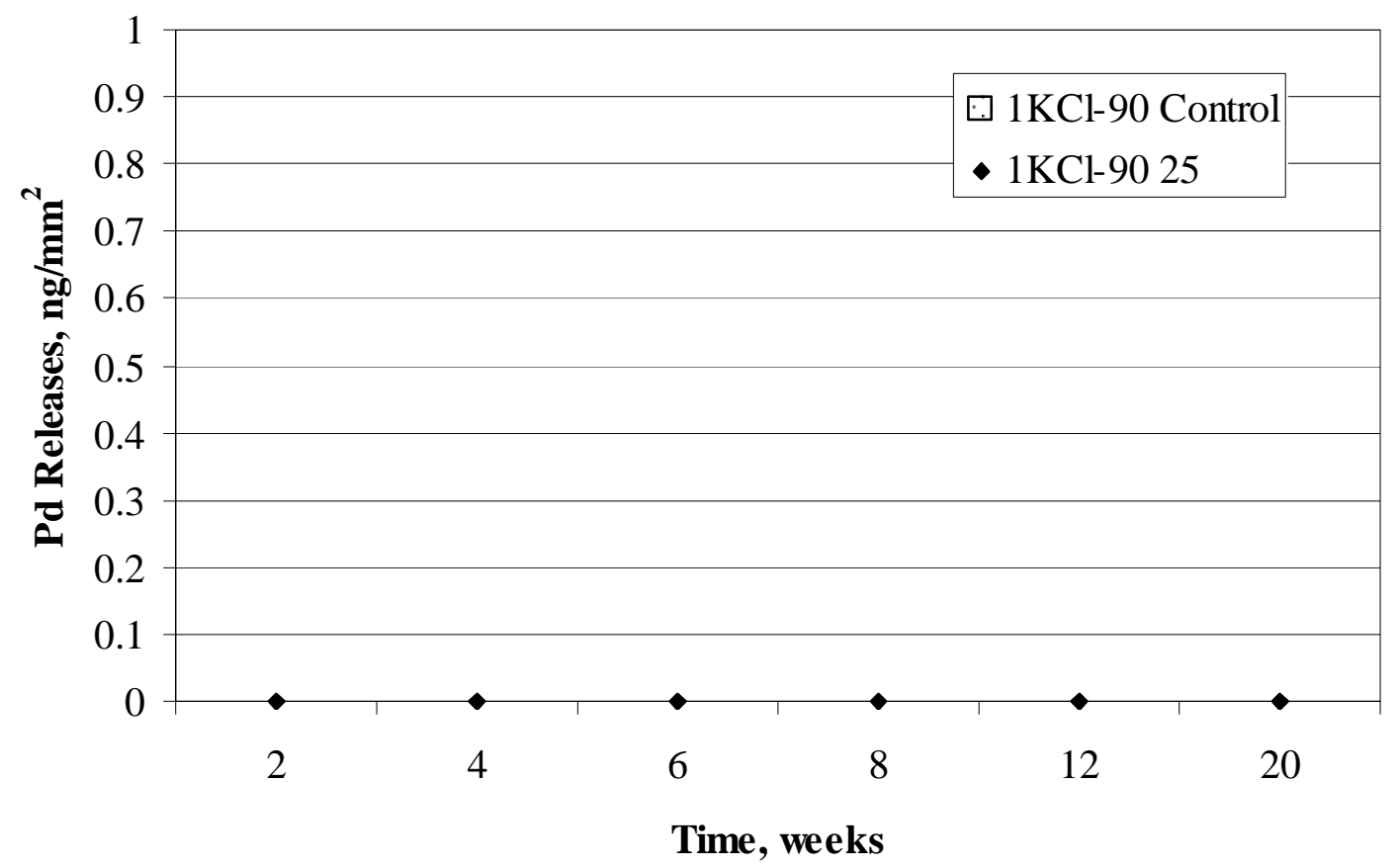

Figure M-21. Palladium Releases in $1 \mathrm{KCl}$ solution at $90^{\circ} \mathrm{C}$.

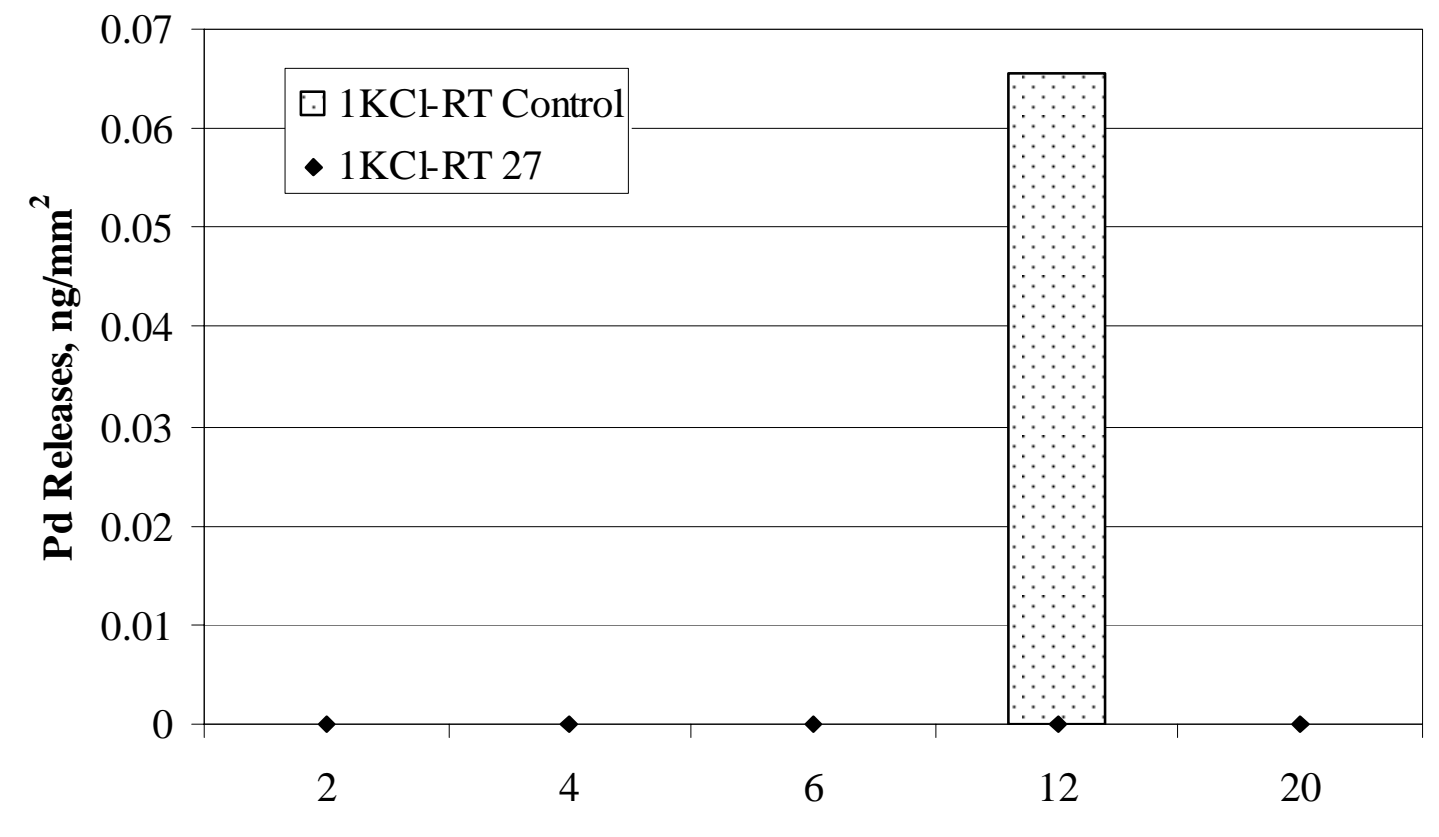

Time, weeks

Figure M-22. Palladium Releases in $1 \mathrm{KCl}$ solution at room temperature. 


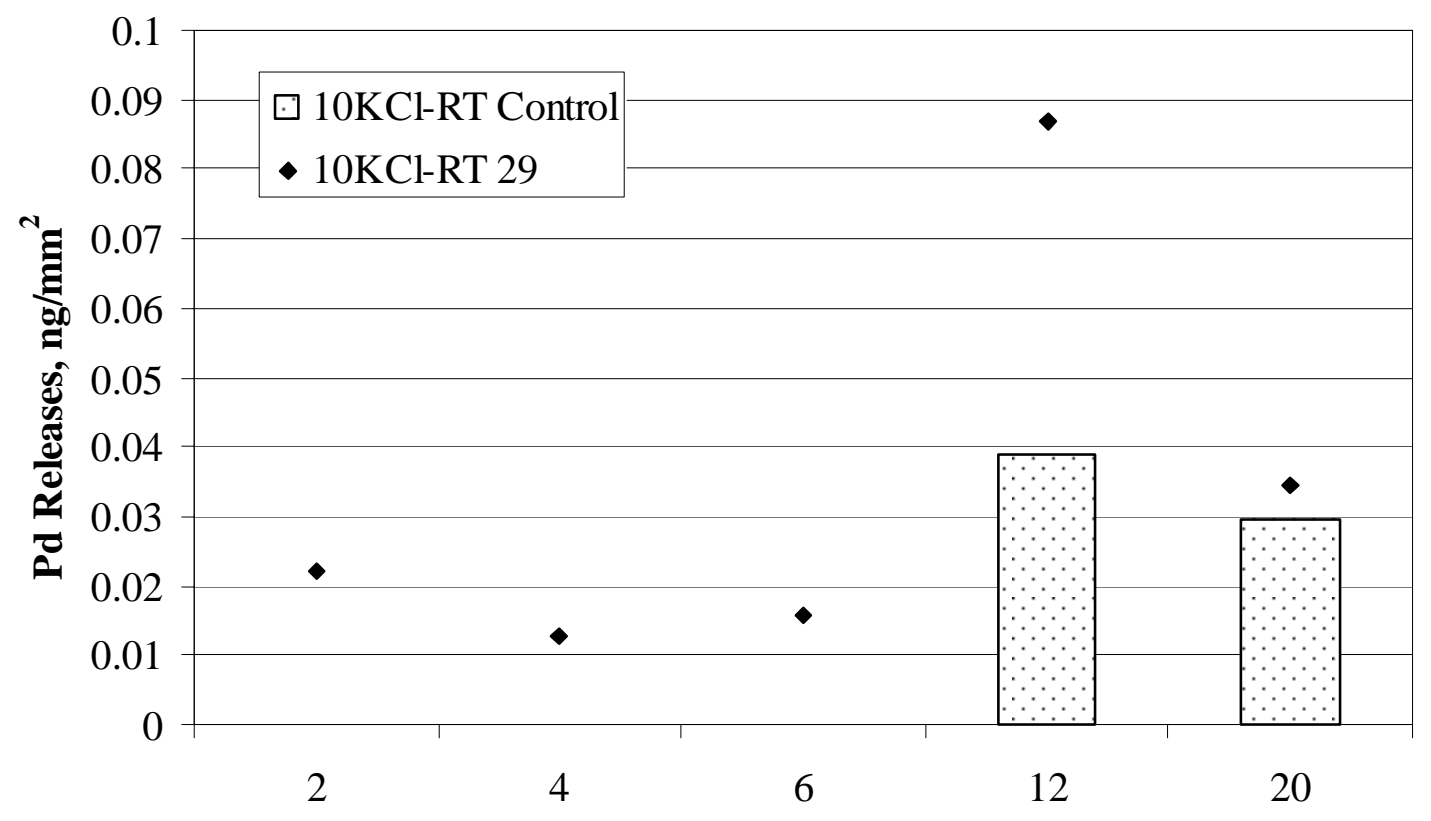

Time, weeks

Figure M-23. Palladium Releases in 10KCl solution at room temperature.

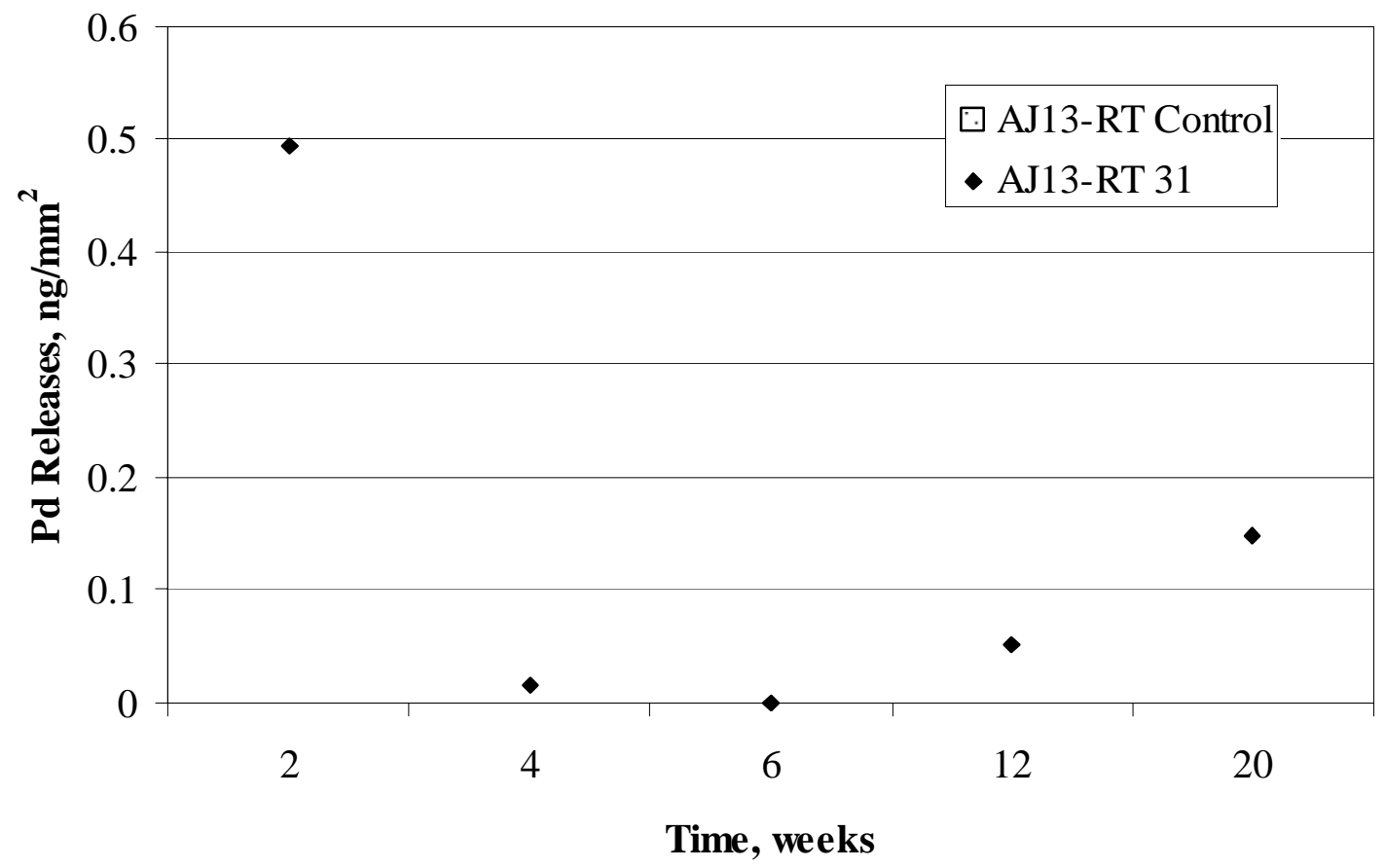

Figure M-24. Palladium Releases in AJ13 solution at room temperature. 


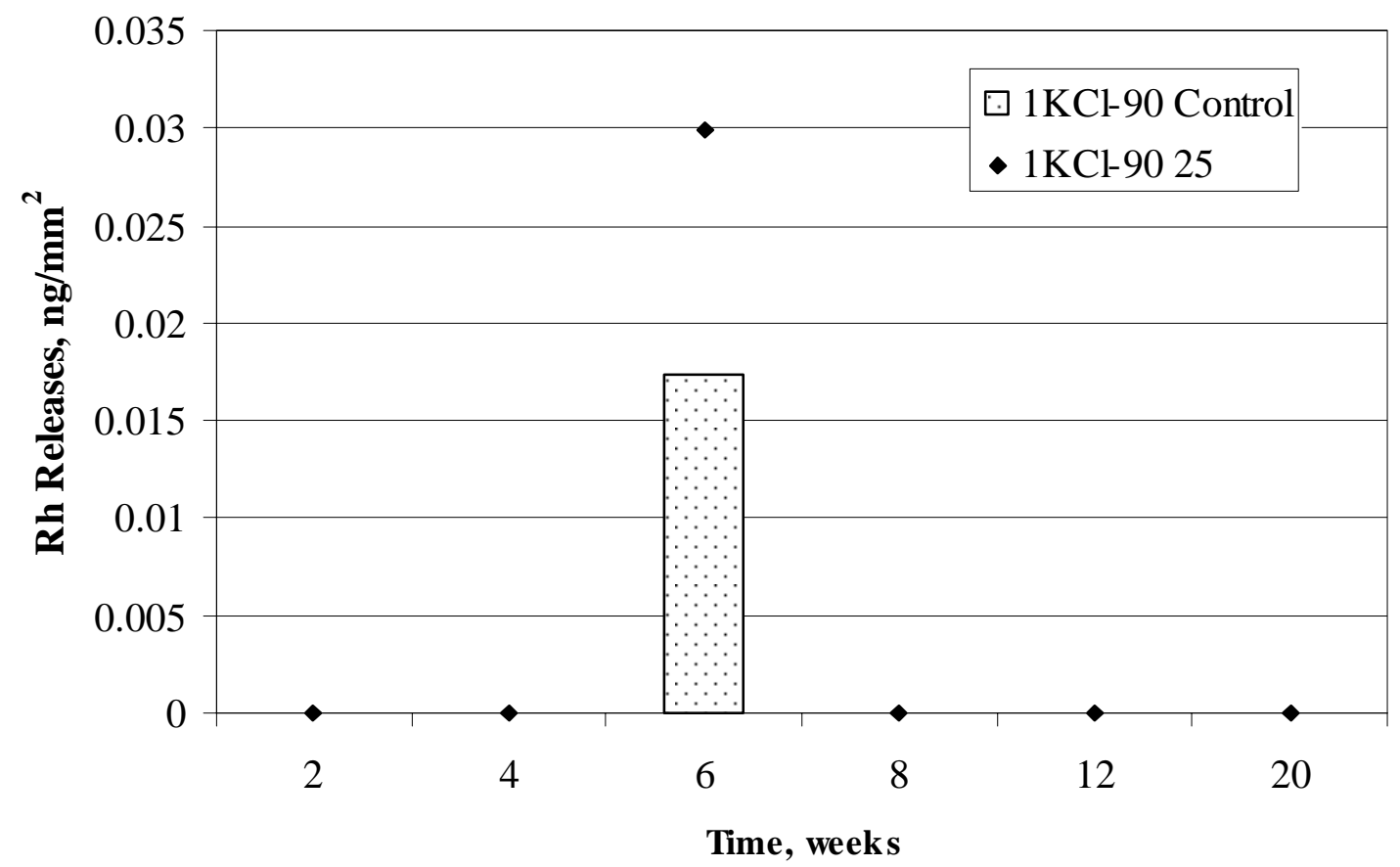

Figure M-25. Rhodium Releases in $1 \mathrm{KCl}$ solution at $90^{\circ} \mathrm{C}$.

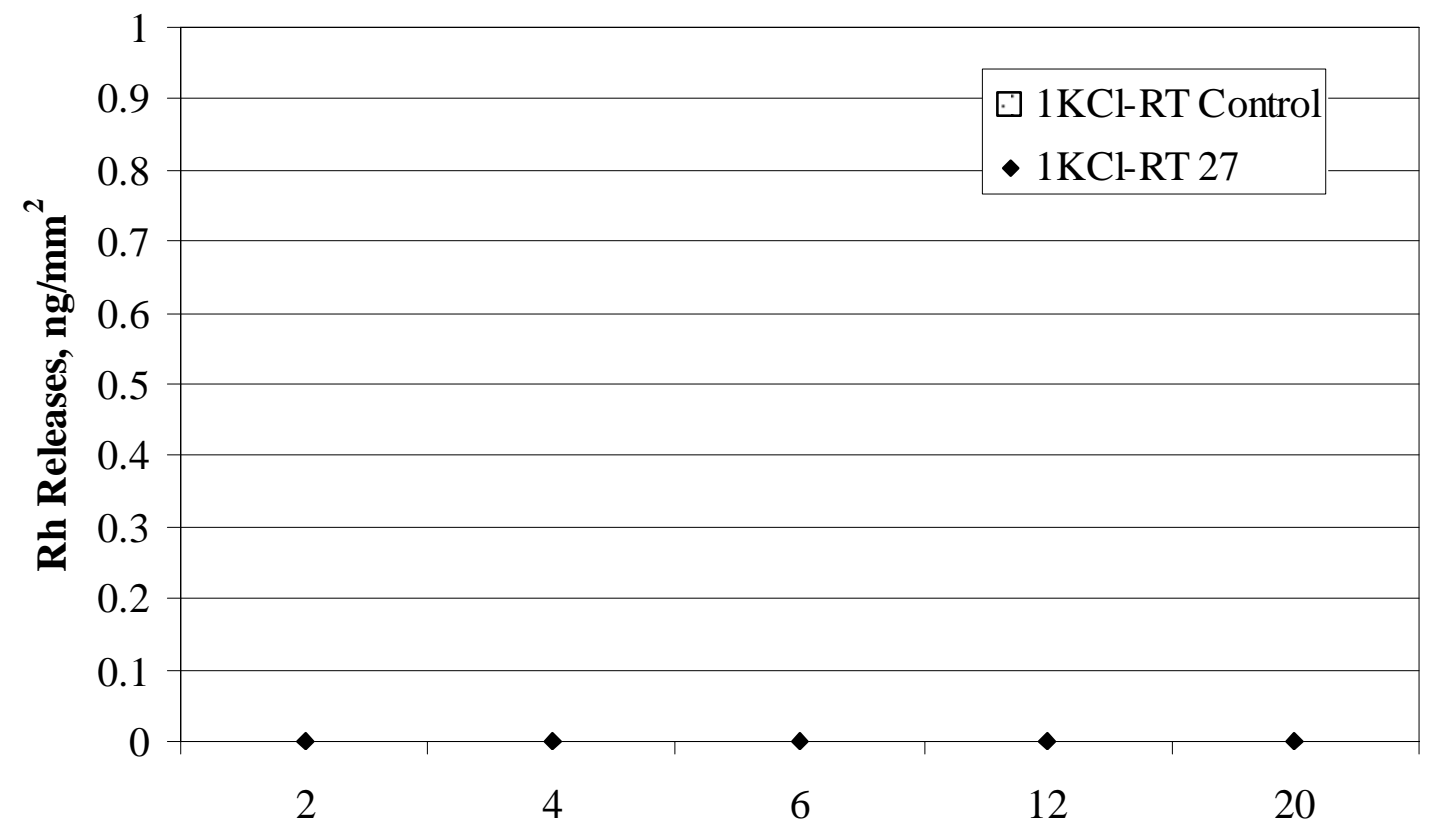

Time, weeks

Figure M-26. Rhodium Releases in $1 \mathrm{KCl}$ solution at room temperature. 


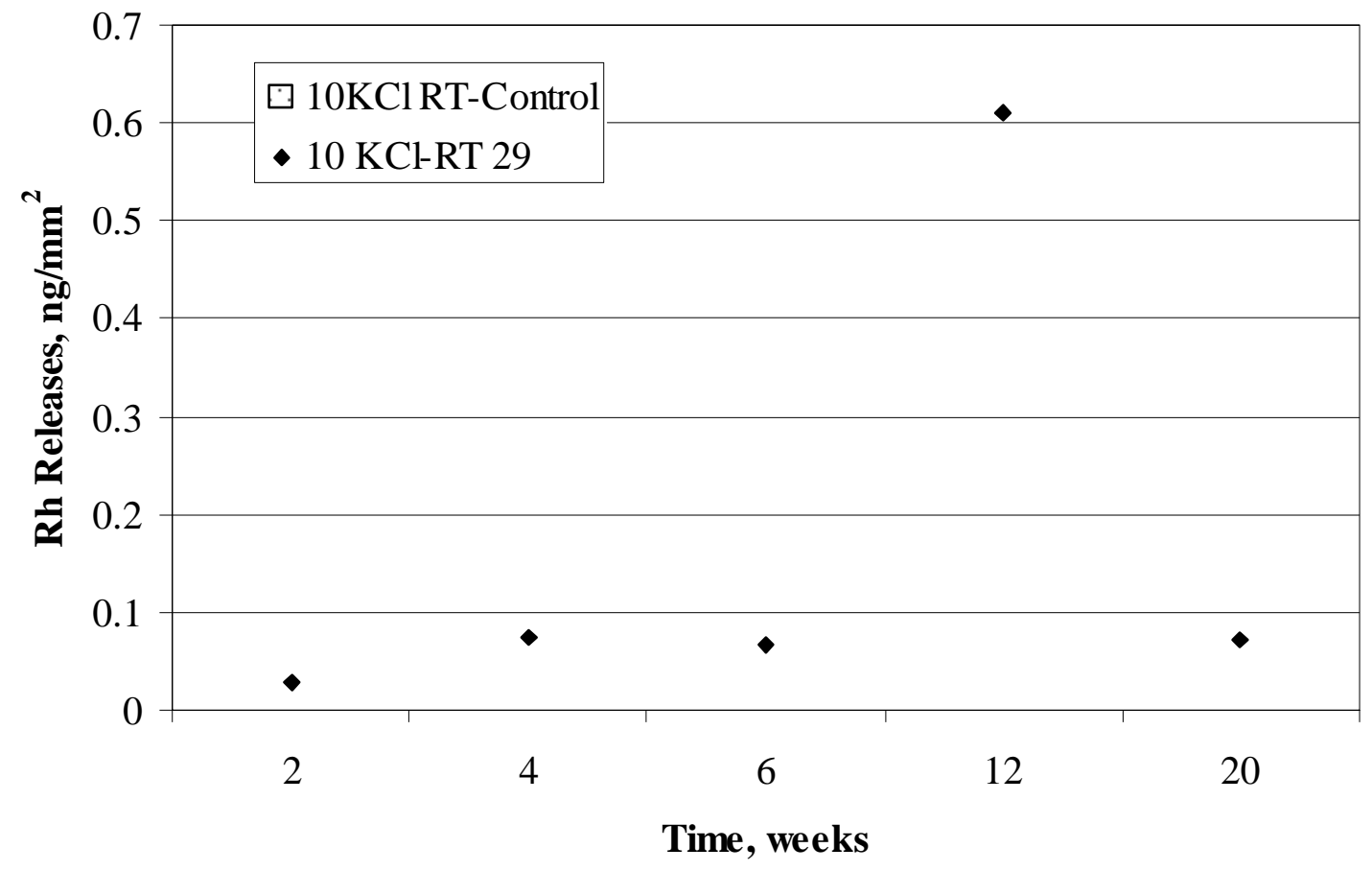

Figure M-27. Rhodium Releases in $10 \mathrm{KCl}$ solution at room temperature.

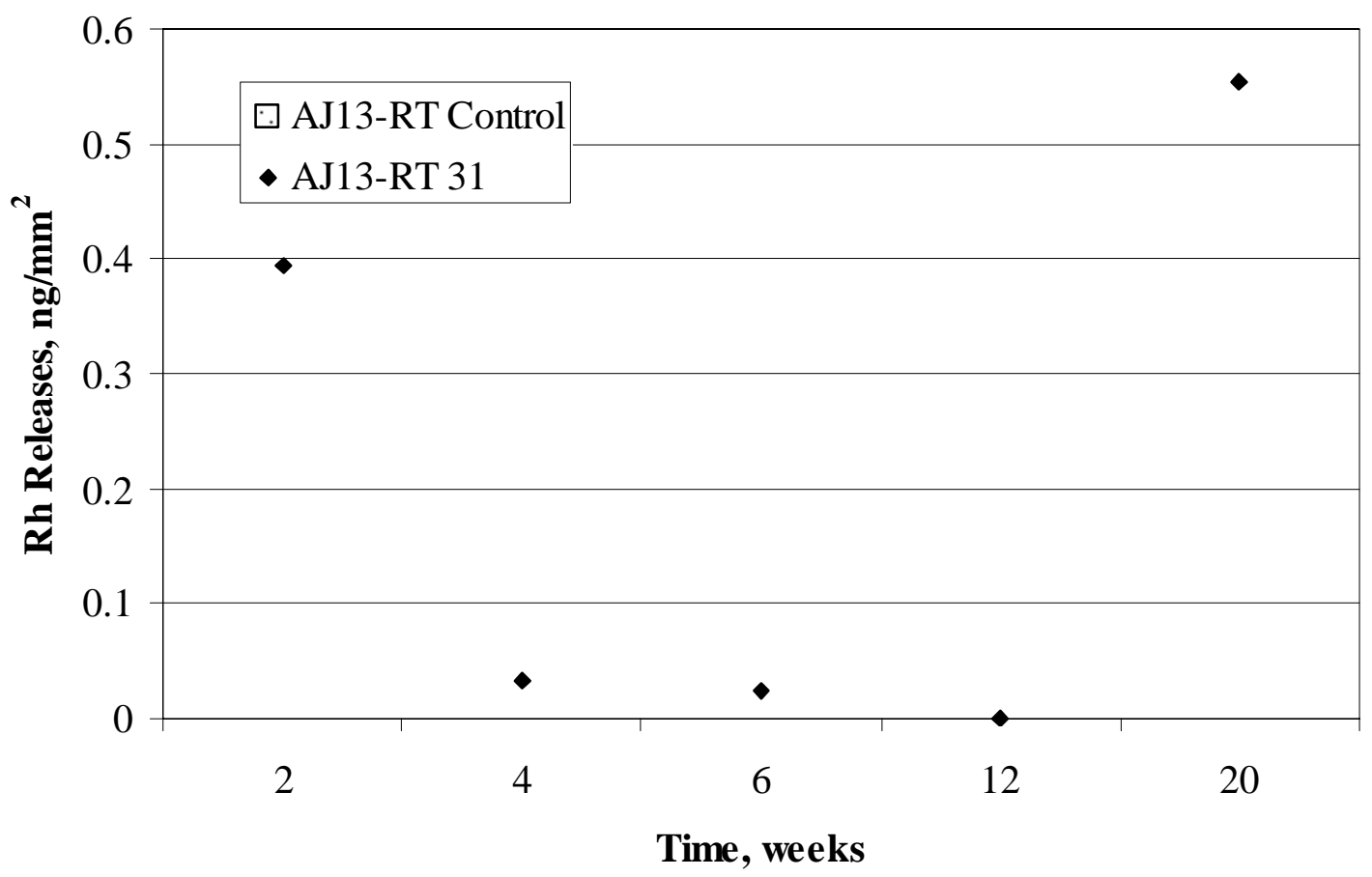

Figure M-28. Rhodium Releases in AJ13 solution at room temperature. 


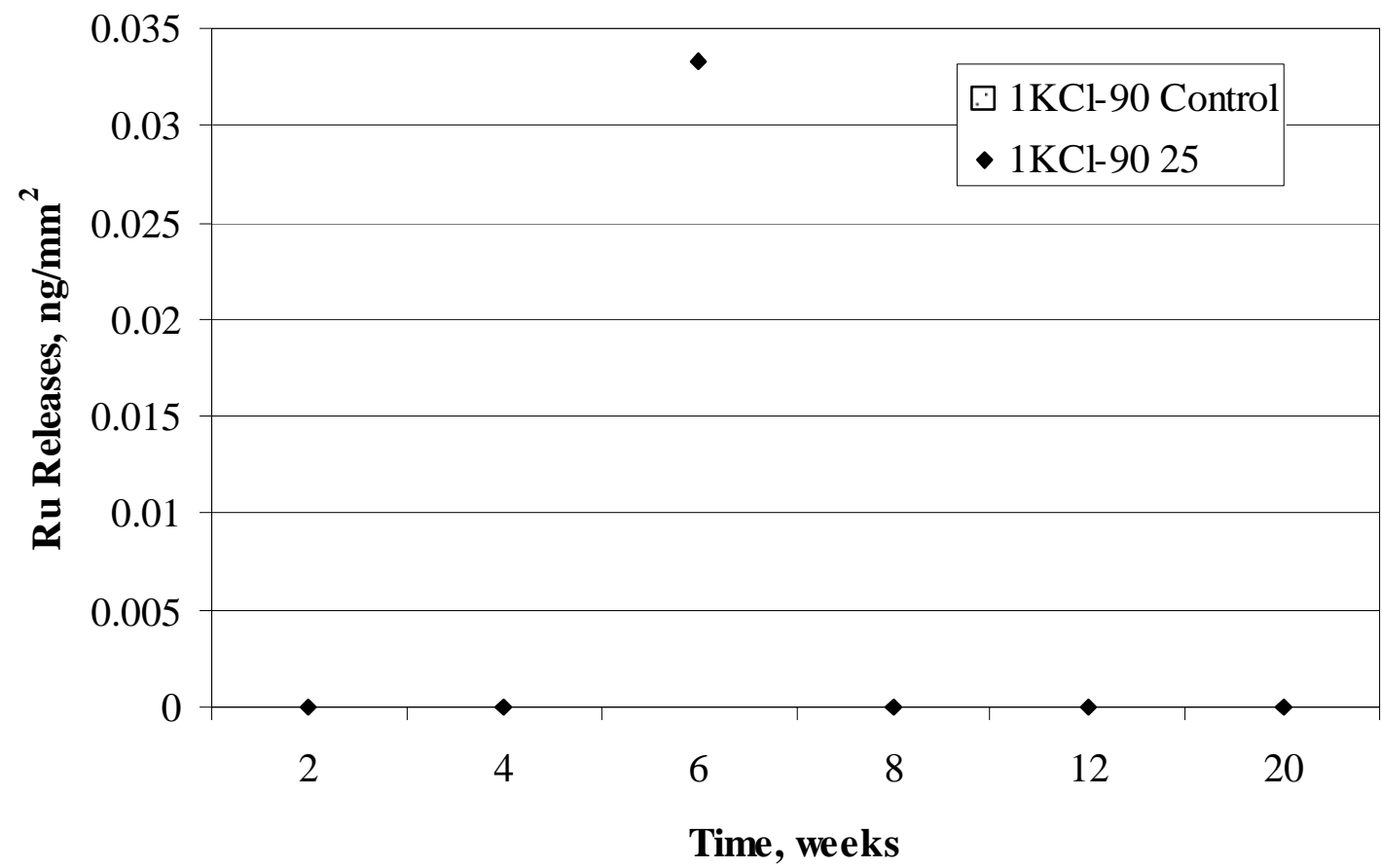

Figure M-29. Ruthenium Releases in $1 \mathrm{KCl}$ solution at $90^{\circ} \mathrm{C}$.

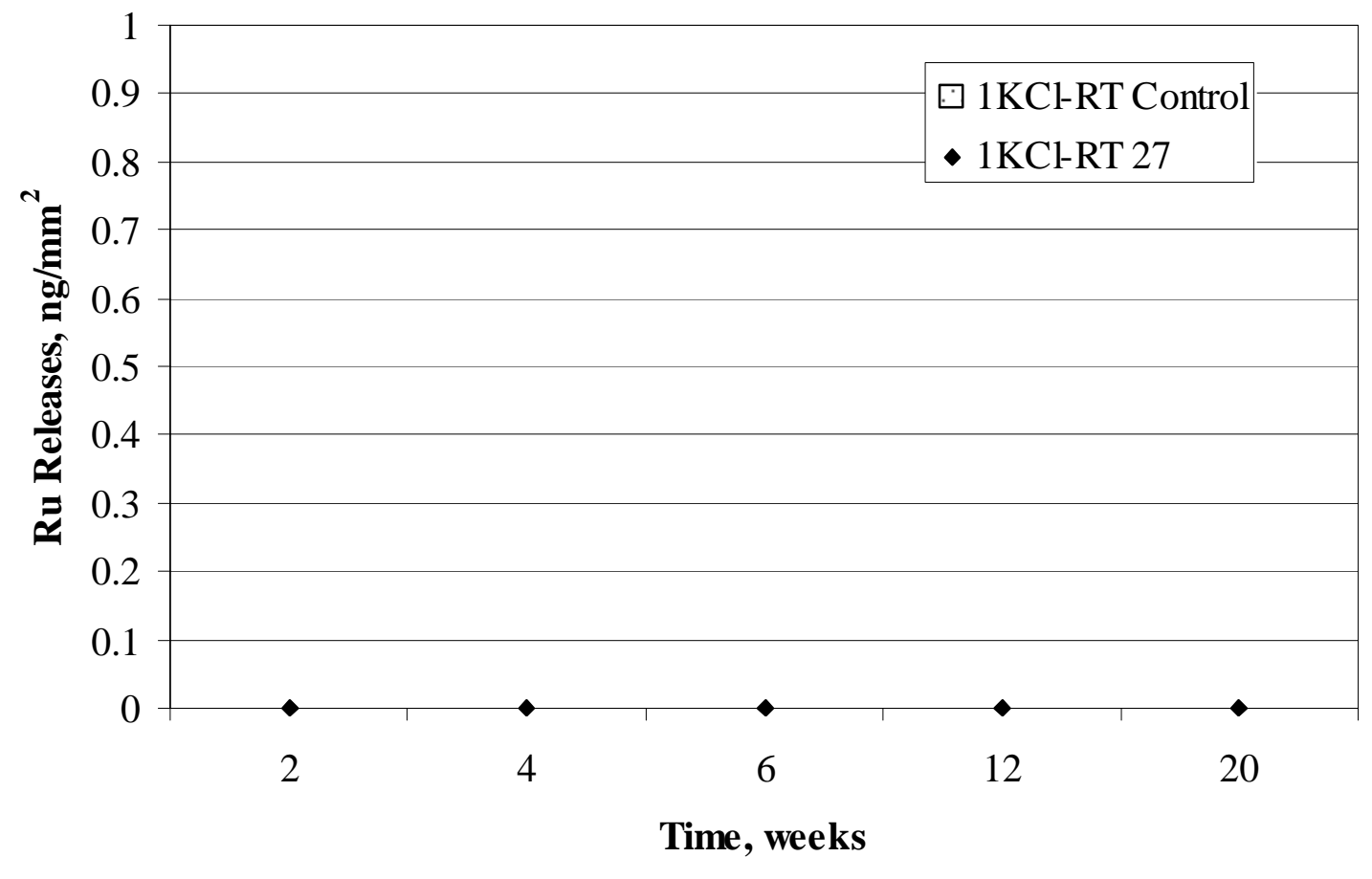

Figure M-30. Ruthenium Releases in $1 \mathrm{KCl}$ solution at room temperature. 


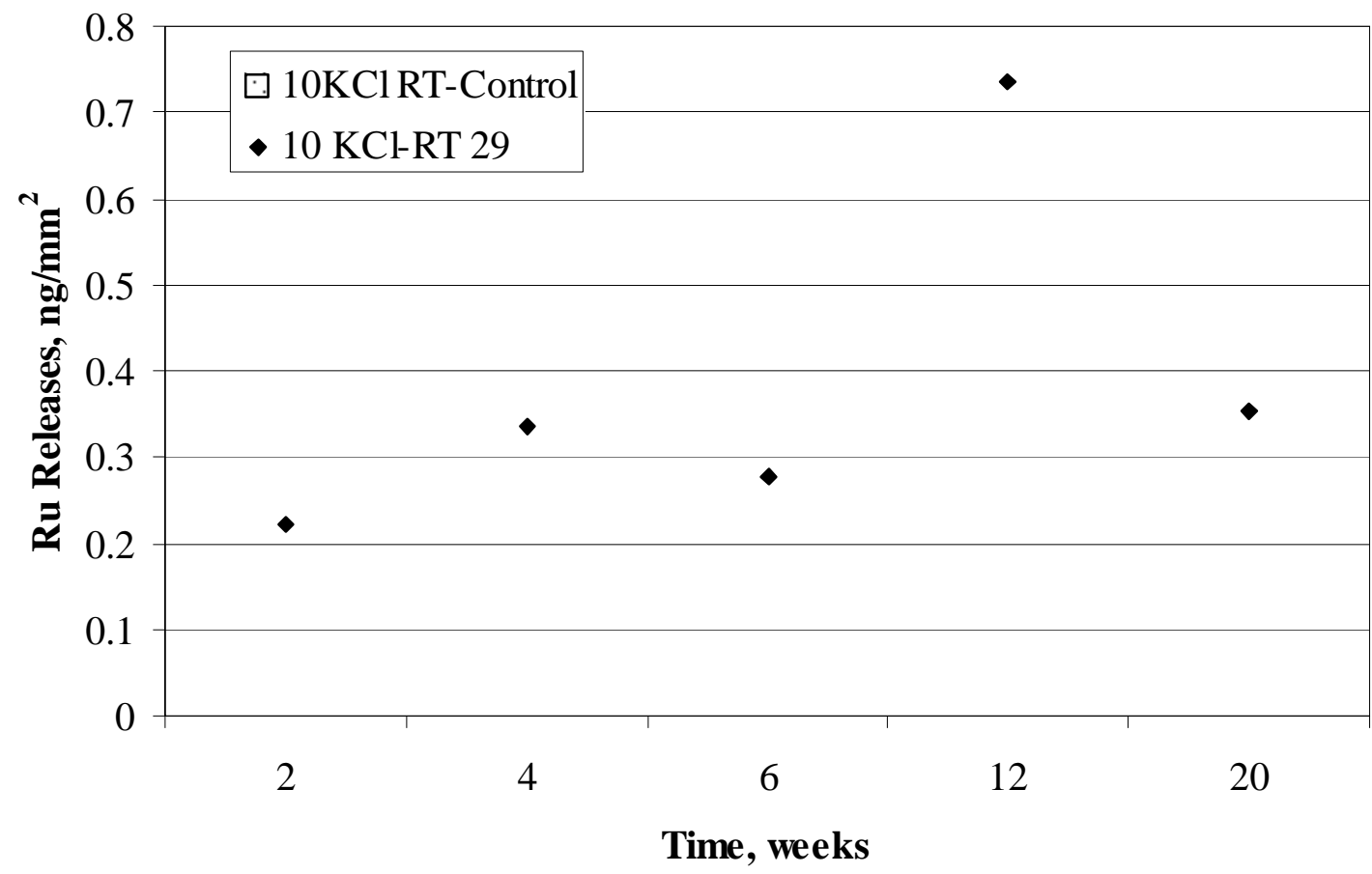

Figure M-31. Ruthenium Releases in $10 \mathrm{KCl}$ solution at room temperature.

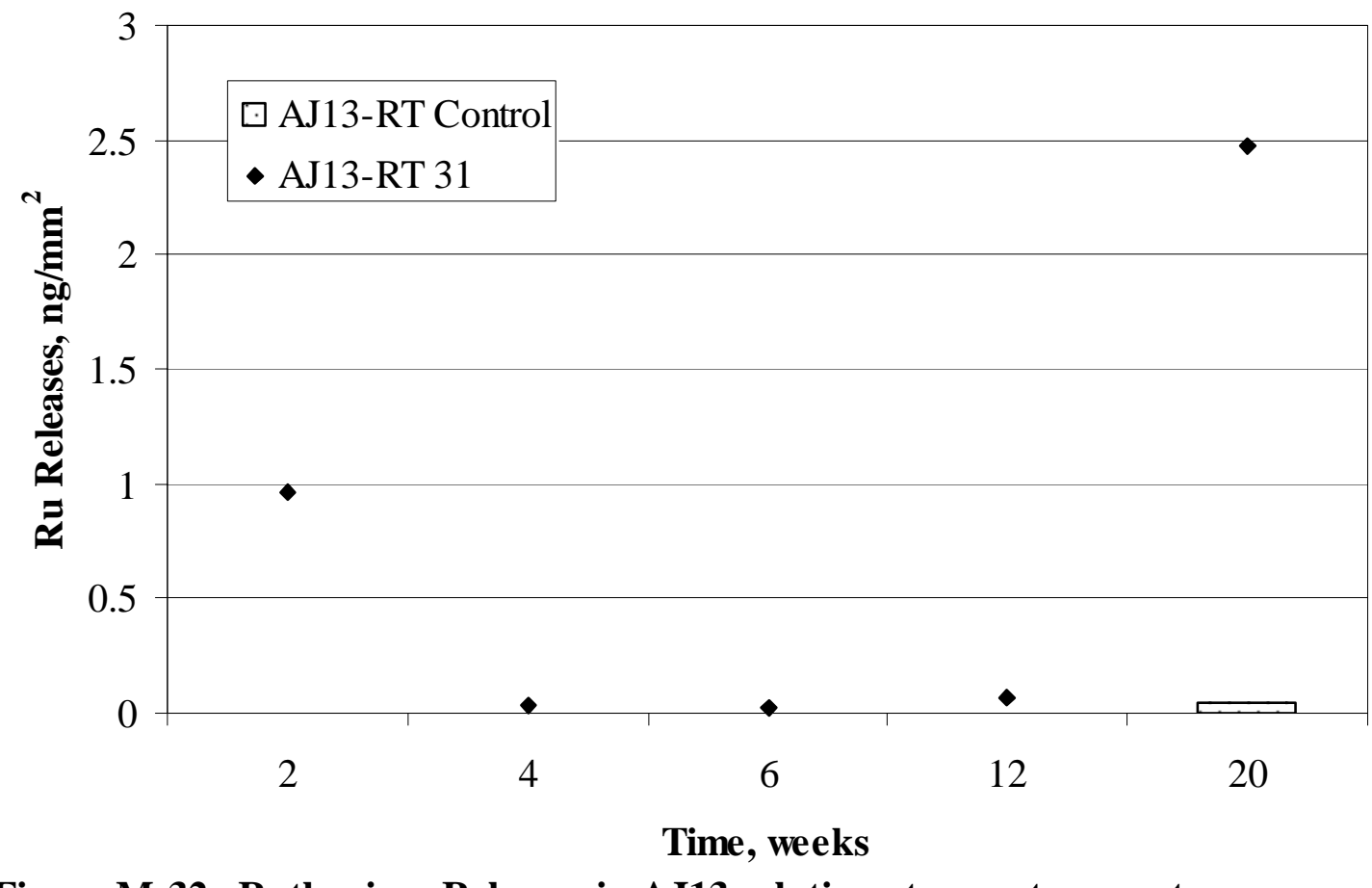

Figure M-32. Ruthenium Releases in AJ13 solution at room temperature. 


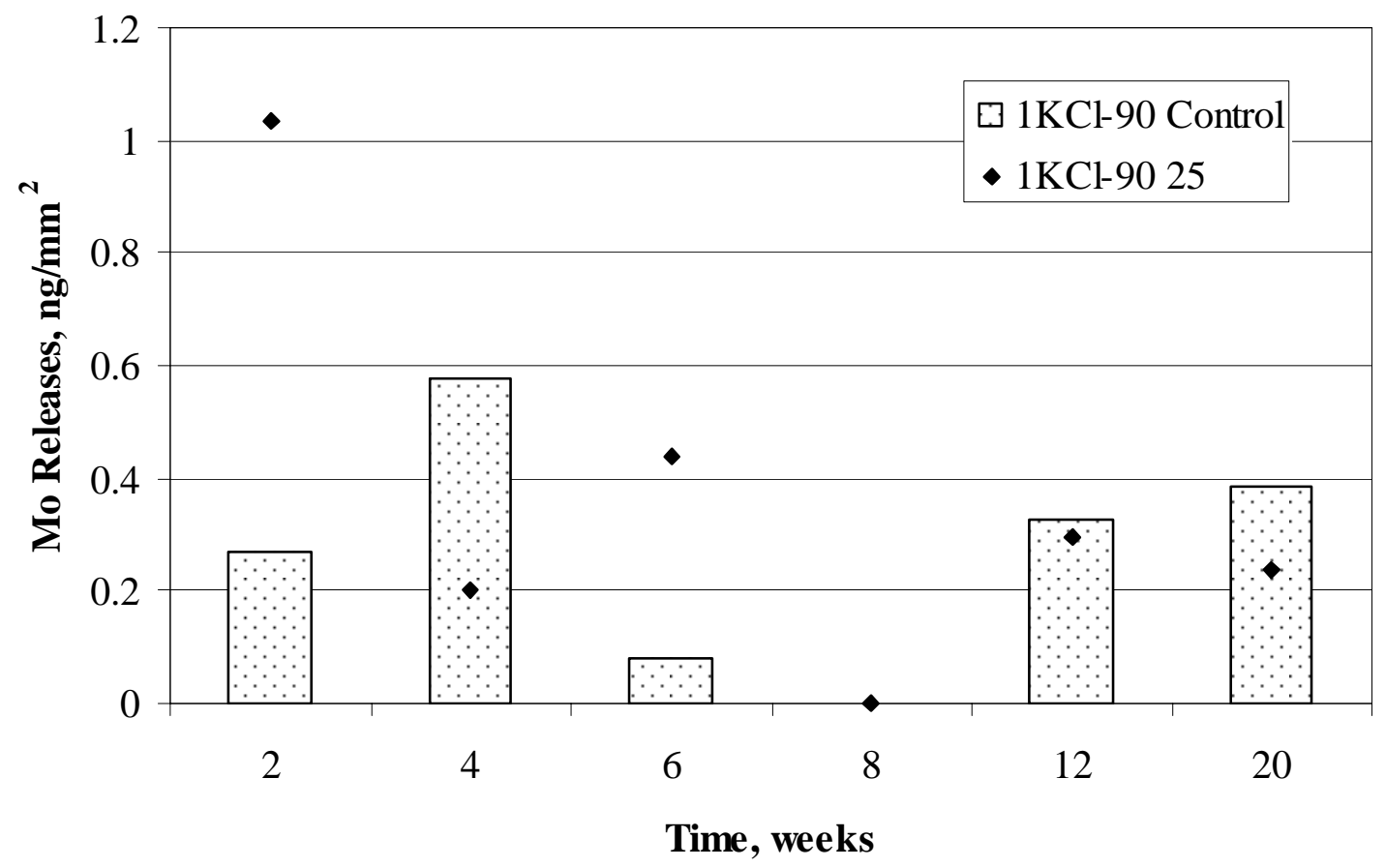

Figure M-33. Molybdenum Releases in $1 \mathrm{KCl}$ solution at $90^{\circ} \mathrm{C}$.

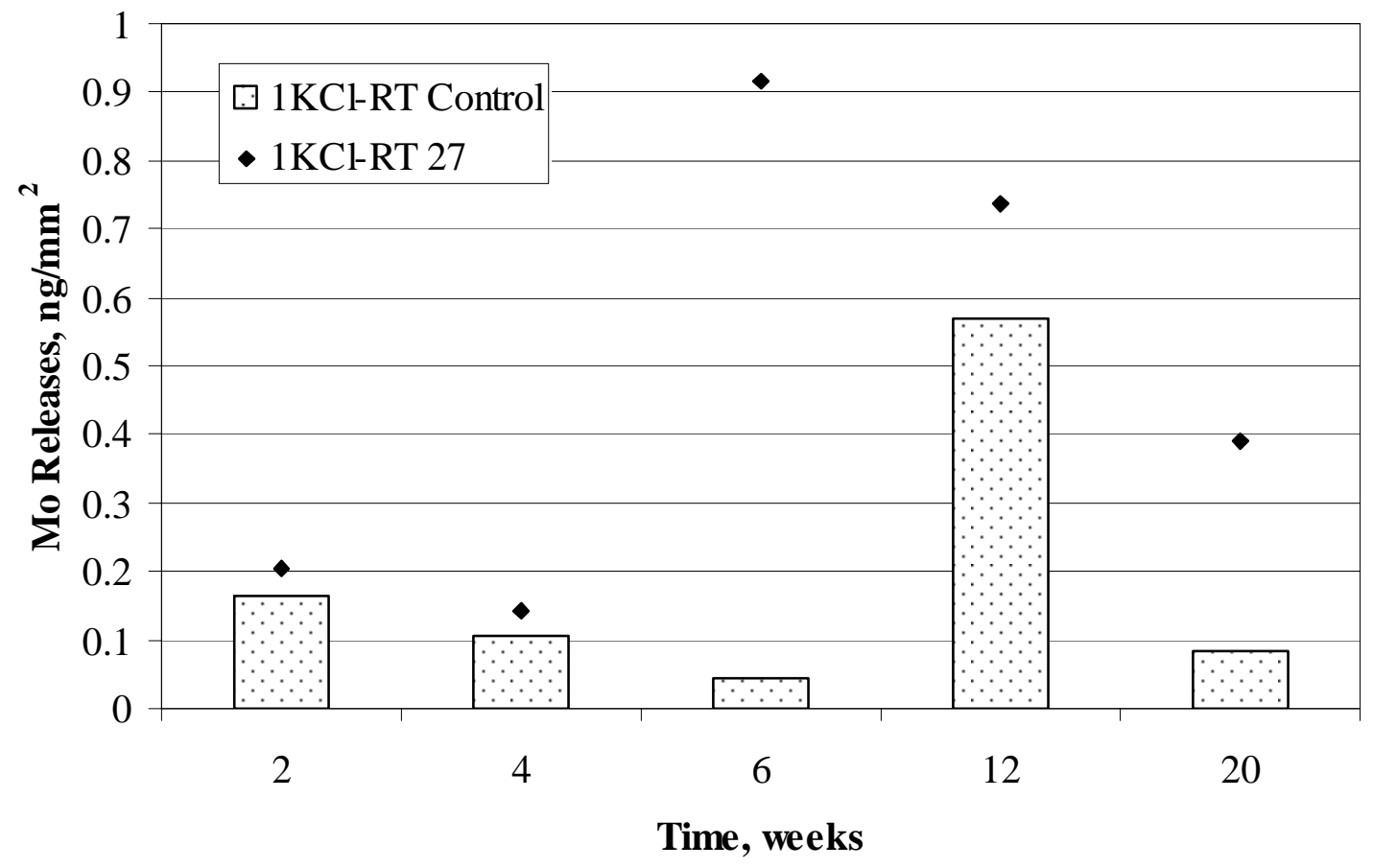

Figure M-34. Molybdenum Releases in $1 \mathrm{KCl}$ solution at room temperature. 


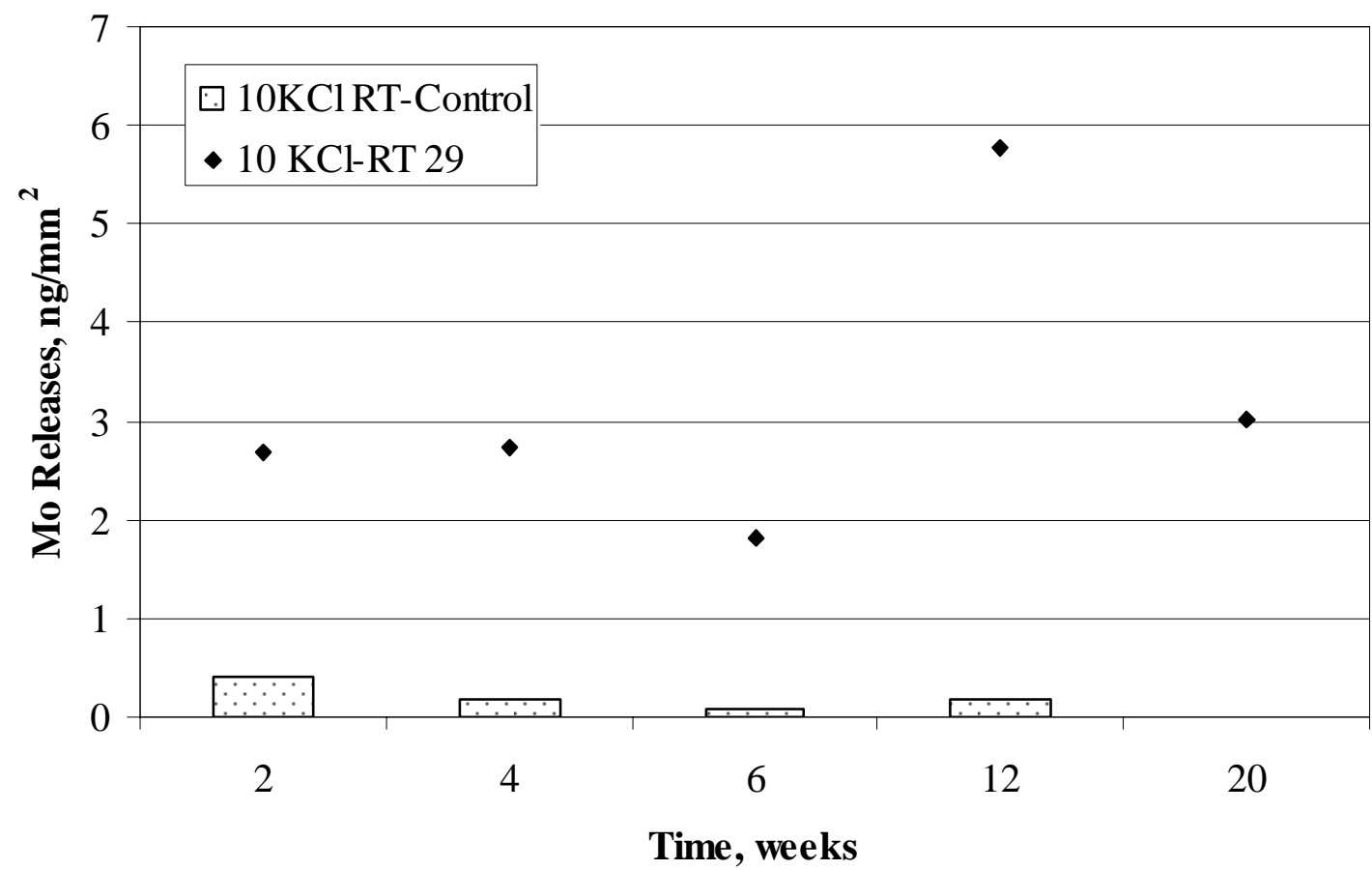

Figure M-35. Molybdenum Releases in $10 \mathrm{KCl}$ solution at room temperature.

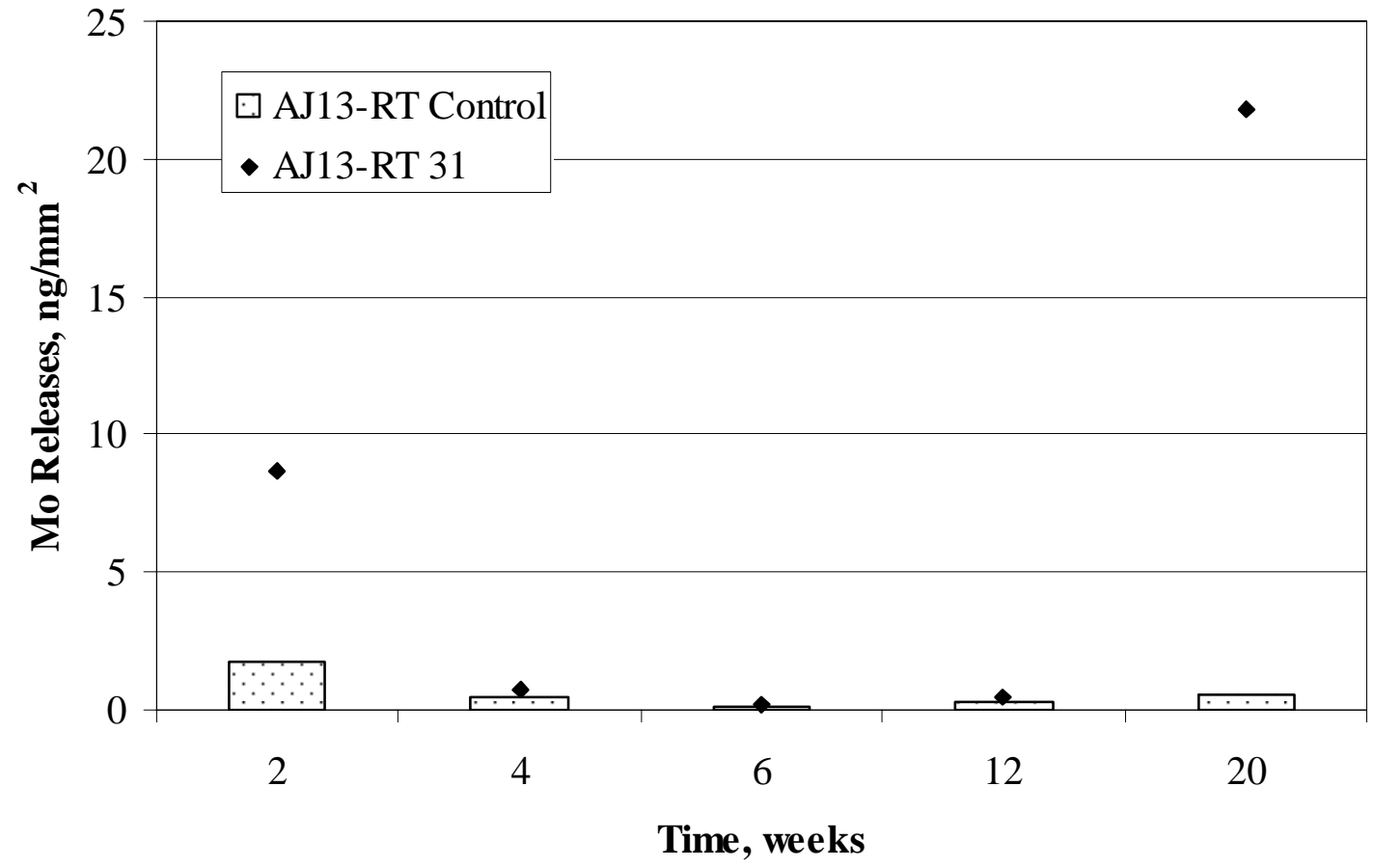

Figure M-36. Molybdenum Releases in AJ13 solution at room temperature. 


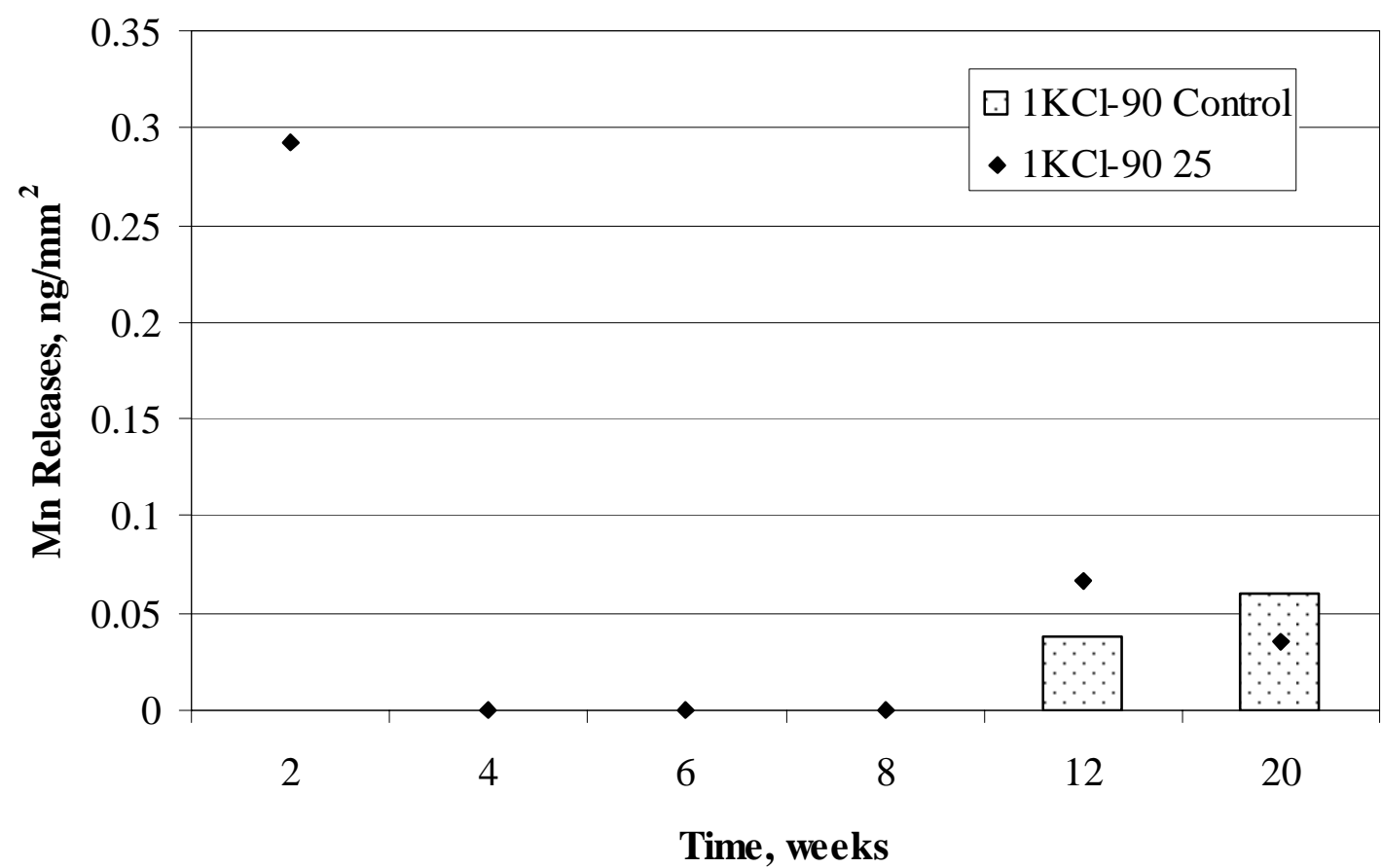

Figure M-37. Manganese Releases in $1 \mathrm{KCl}$ solution at $90^{\circ} \mathrm{C}$.

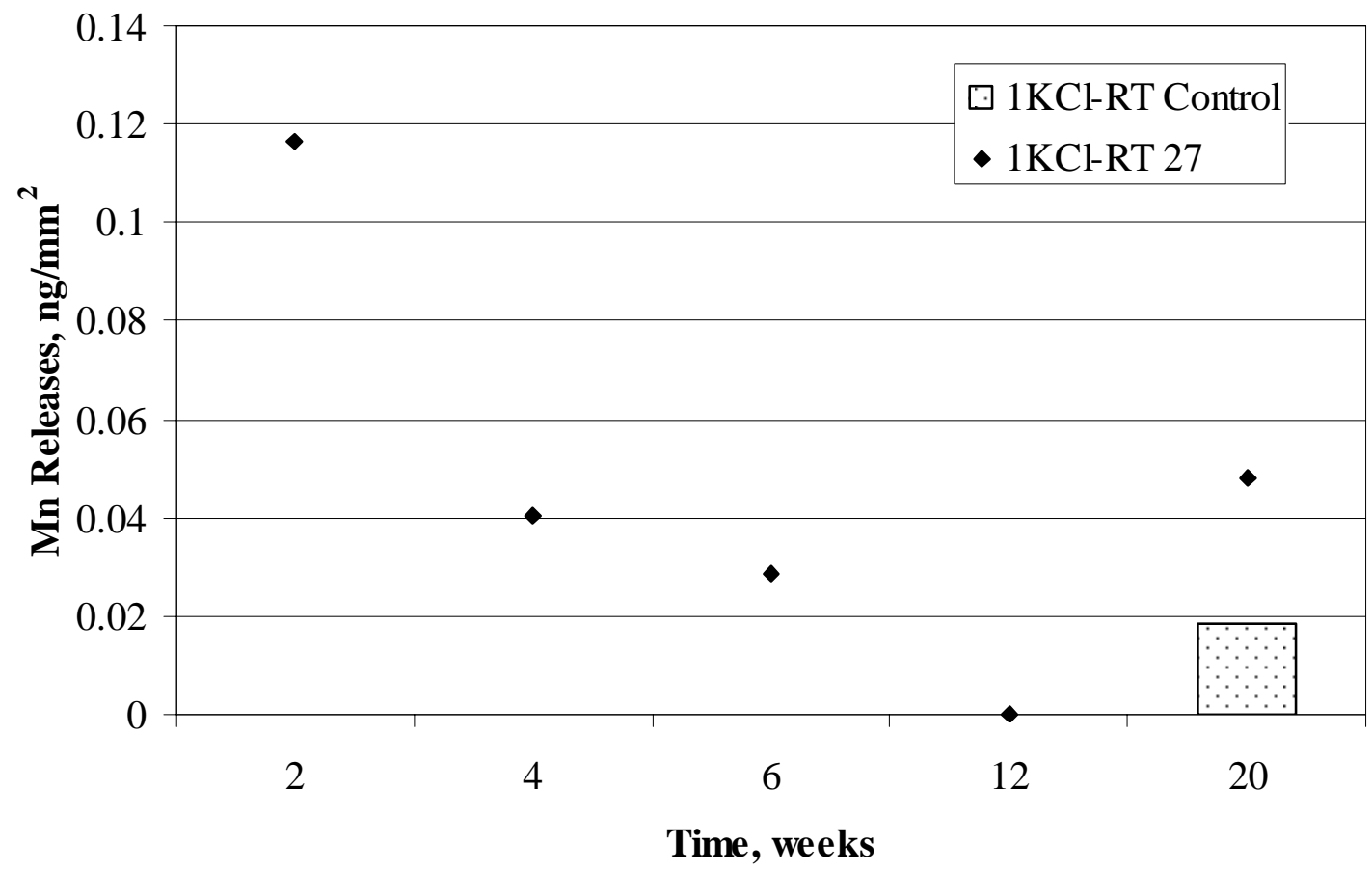

Figure M-38. Manganese Releases in $1 \mathrm{KCl}$ solution at room temperature. 


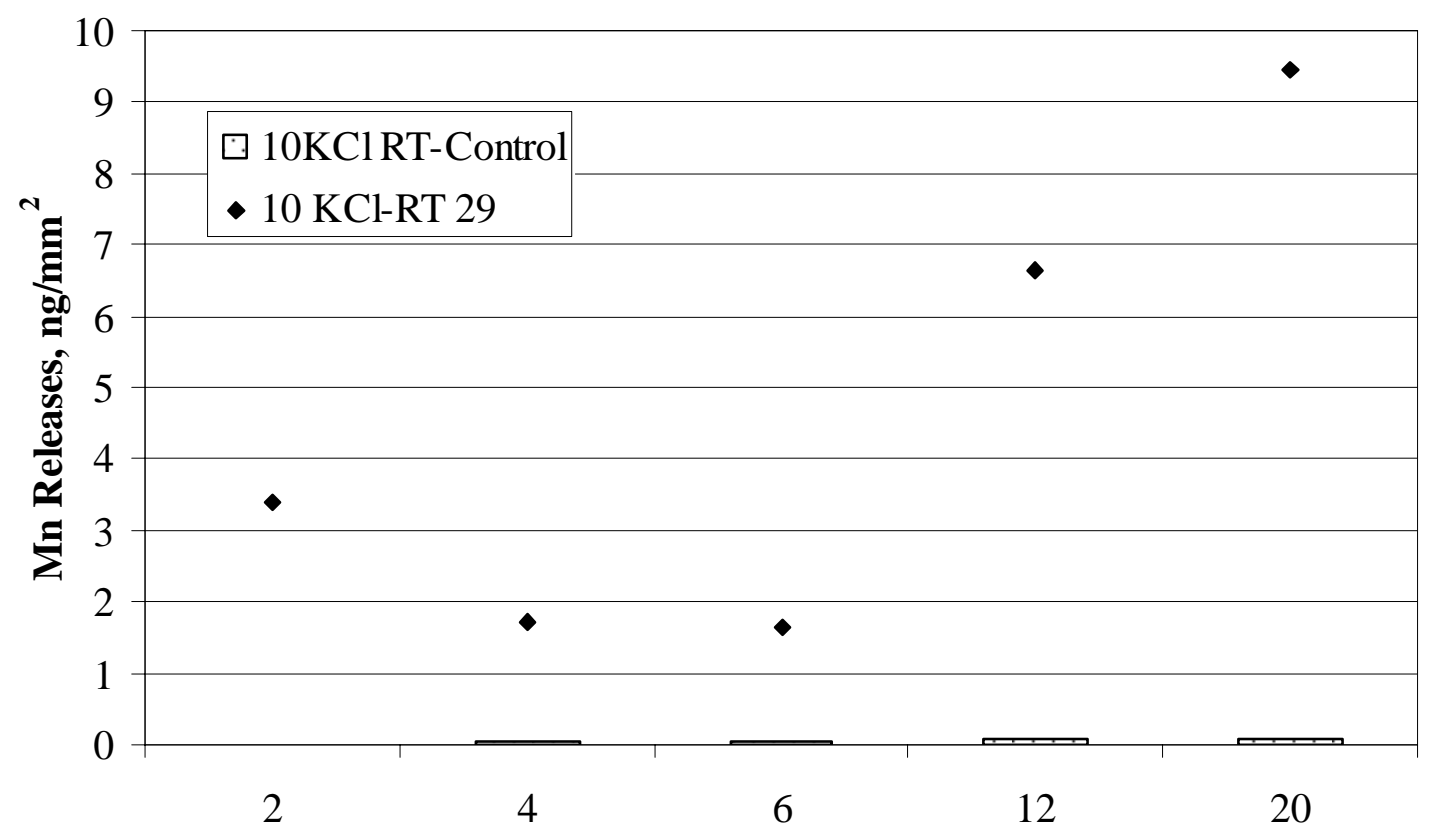

Time, weeks

Figure M-39. Manganese Releases in $10 \mathrm{KCl}$ solution at room temperature.

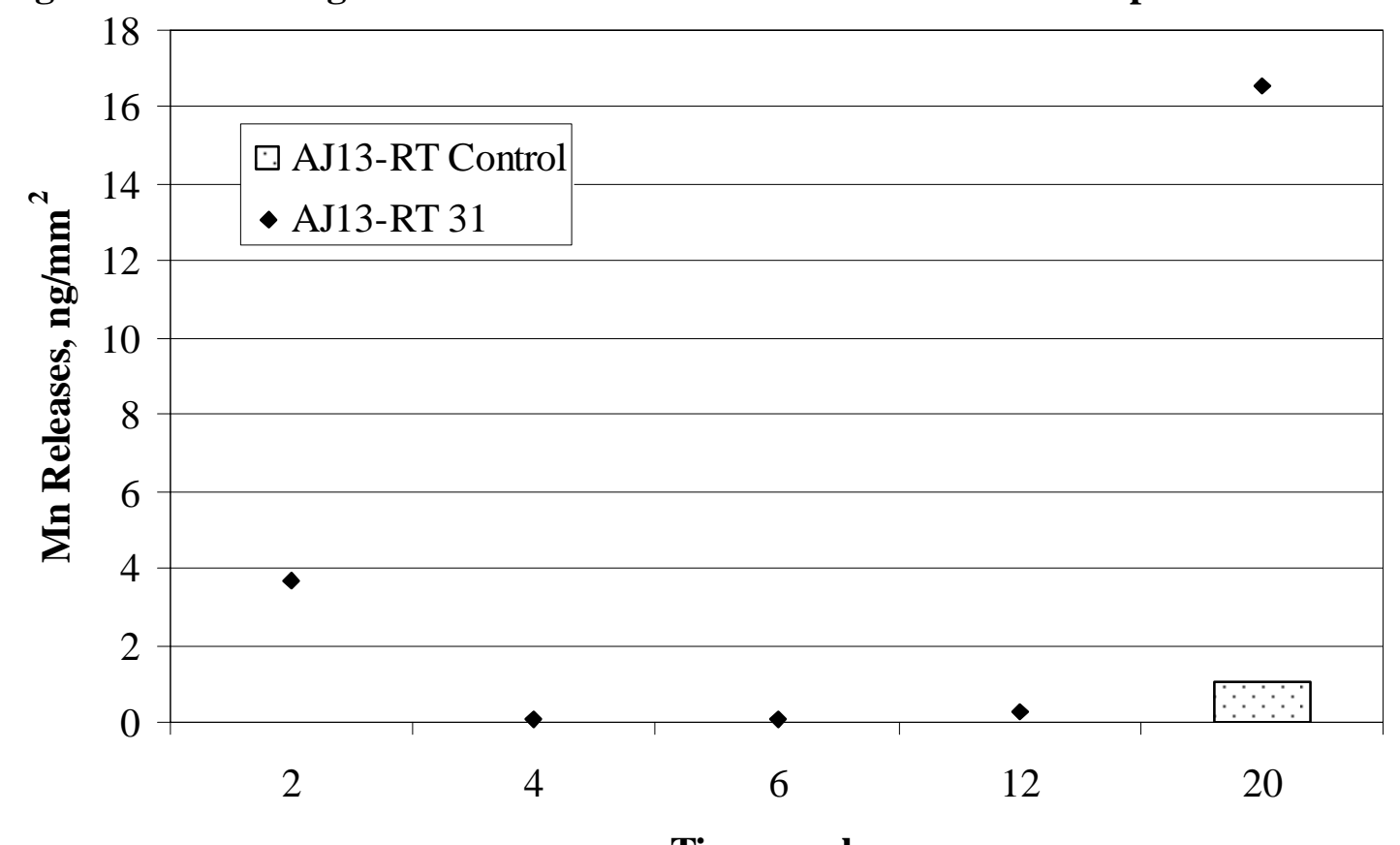

Time, weeks

Figure M-40. Manganese Releases in AJ13 solution at room temperature. 


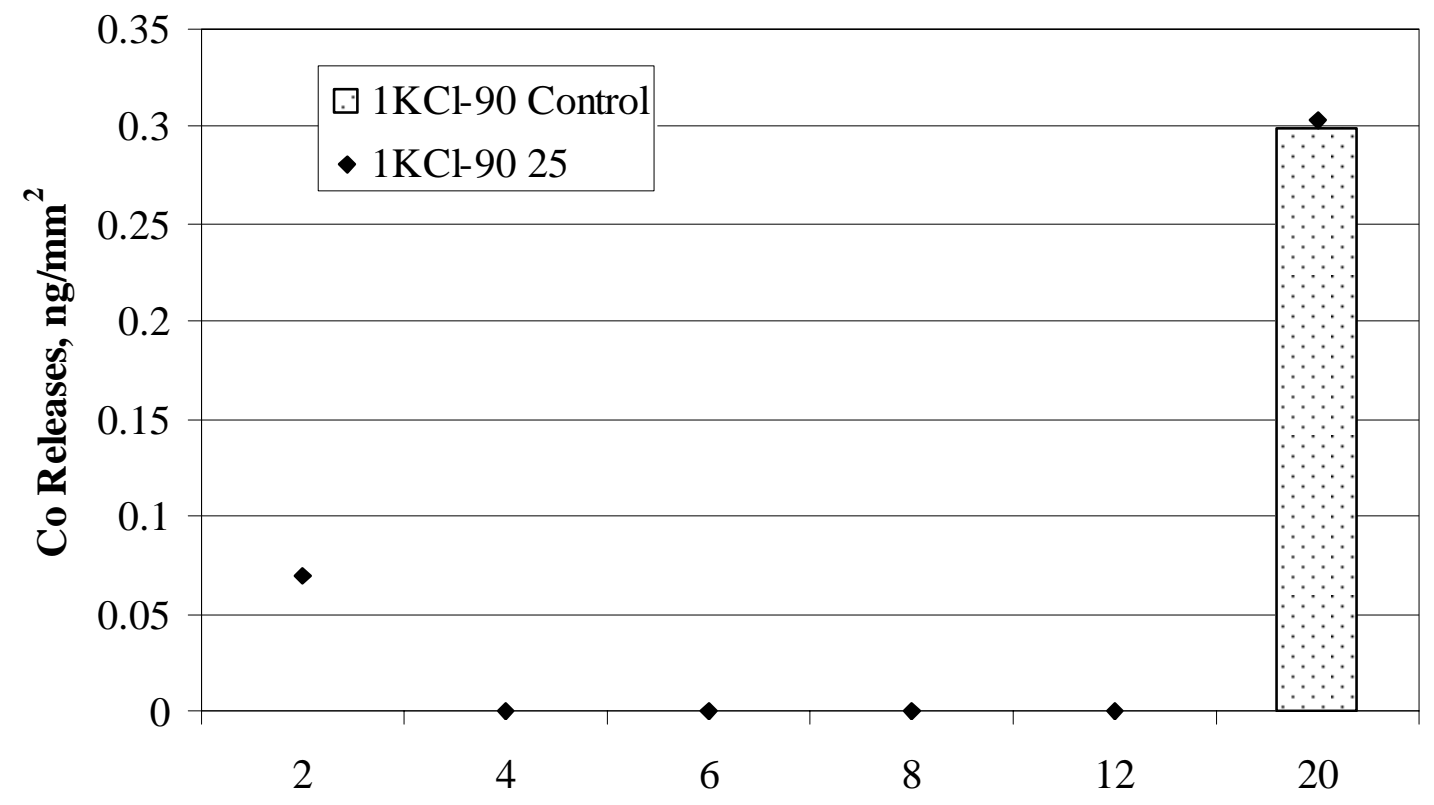

Time, weeks

Figure M-41. Cobalt Releases in $1 \mathrm{KCl}$ solution at $90^{\circ} \mathrm{C}$.

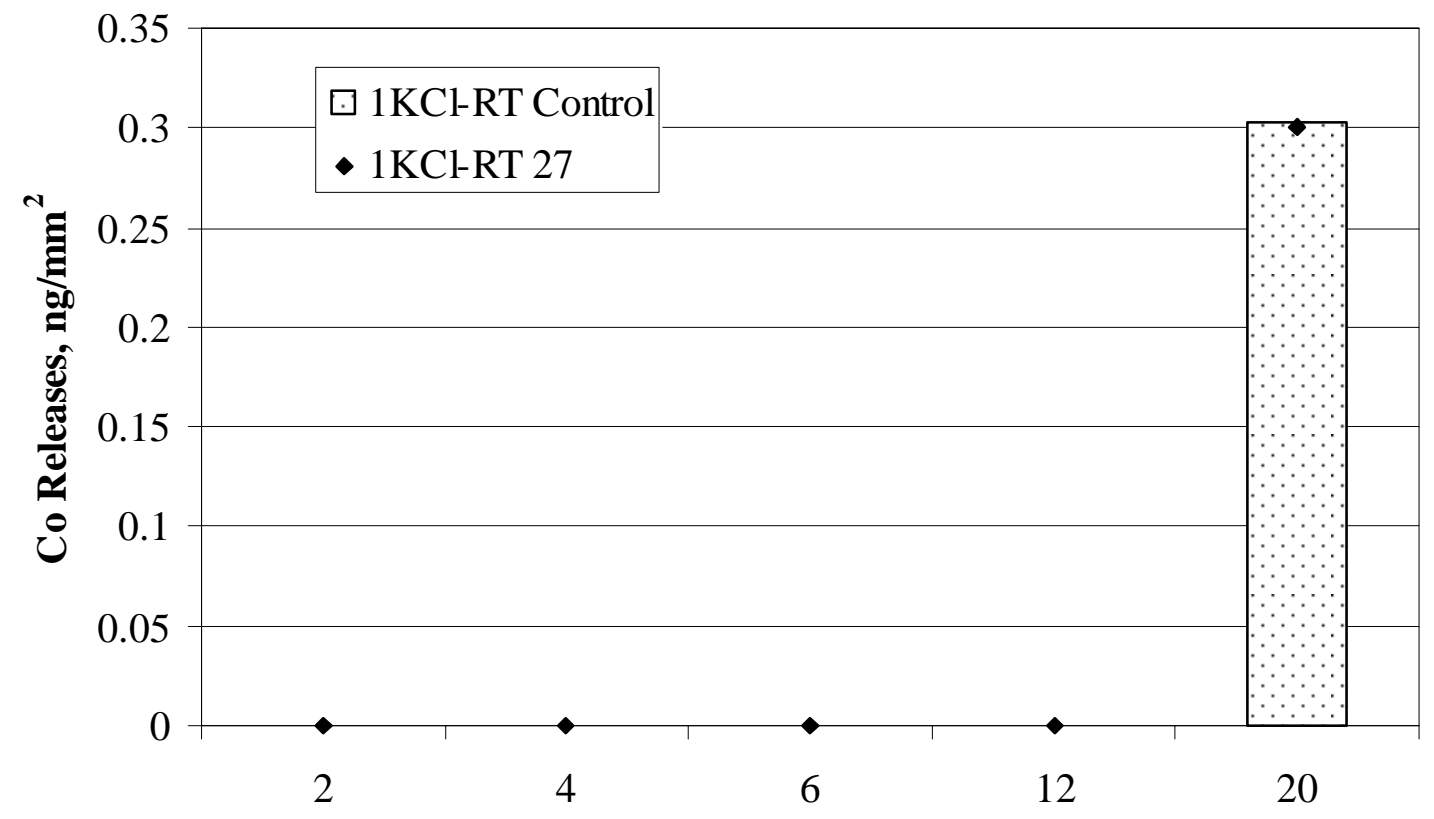

Time, weeks

Figure M-42. Cobalt Releases in $1 \mathrm{KCl}$ solution at room temperature. 


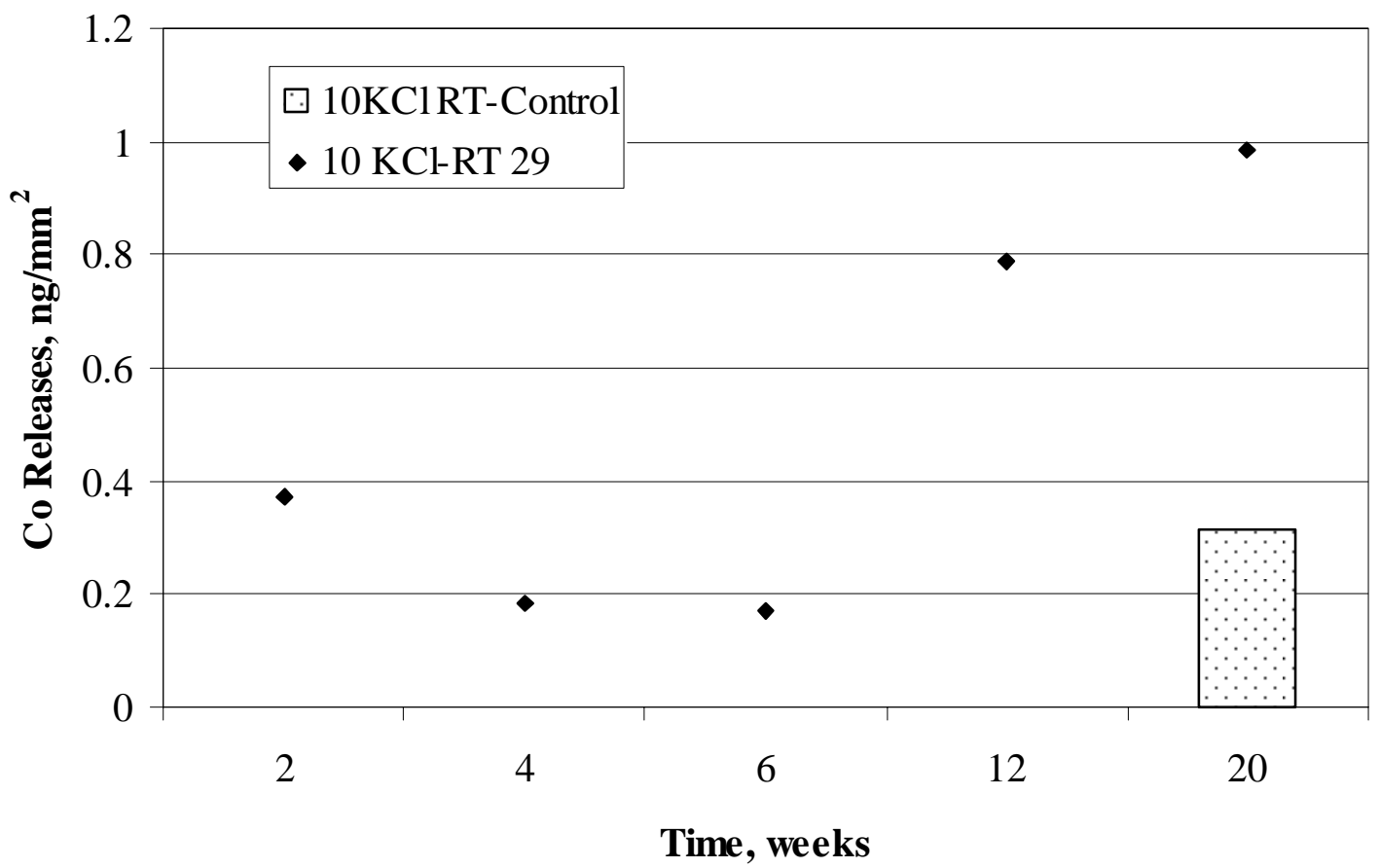

Figure M-43. Cobalt Releases in $10 \mathrm{KCl}$ solution at room temperature.

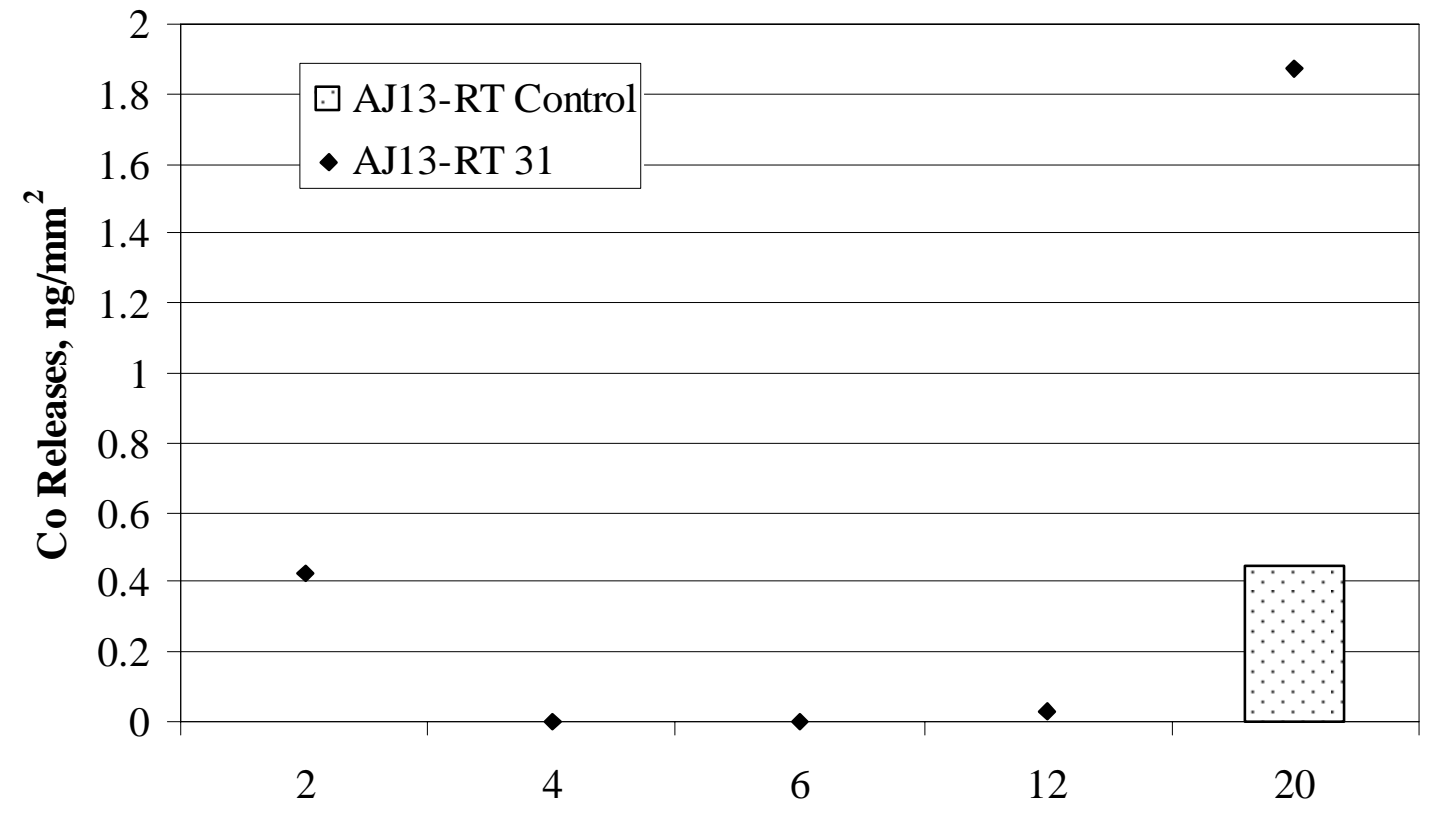

Time, weeks

Figure M-44. Cobalt Releases in AJ13 solution at room temperature. 


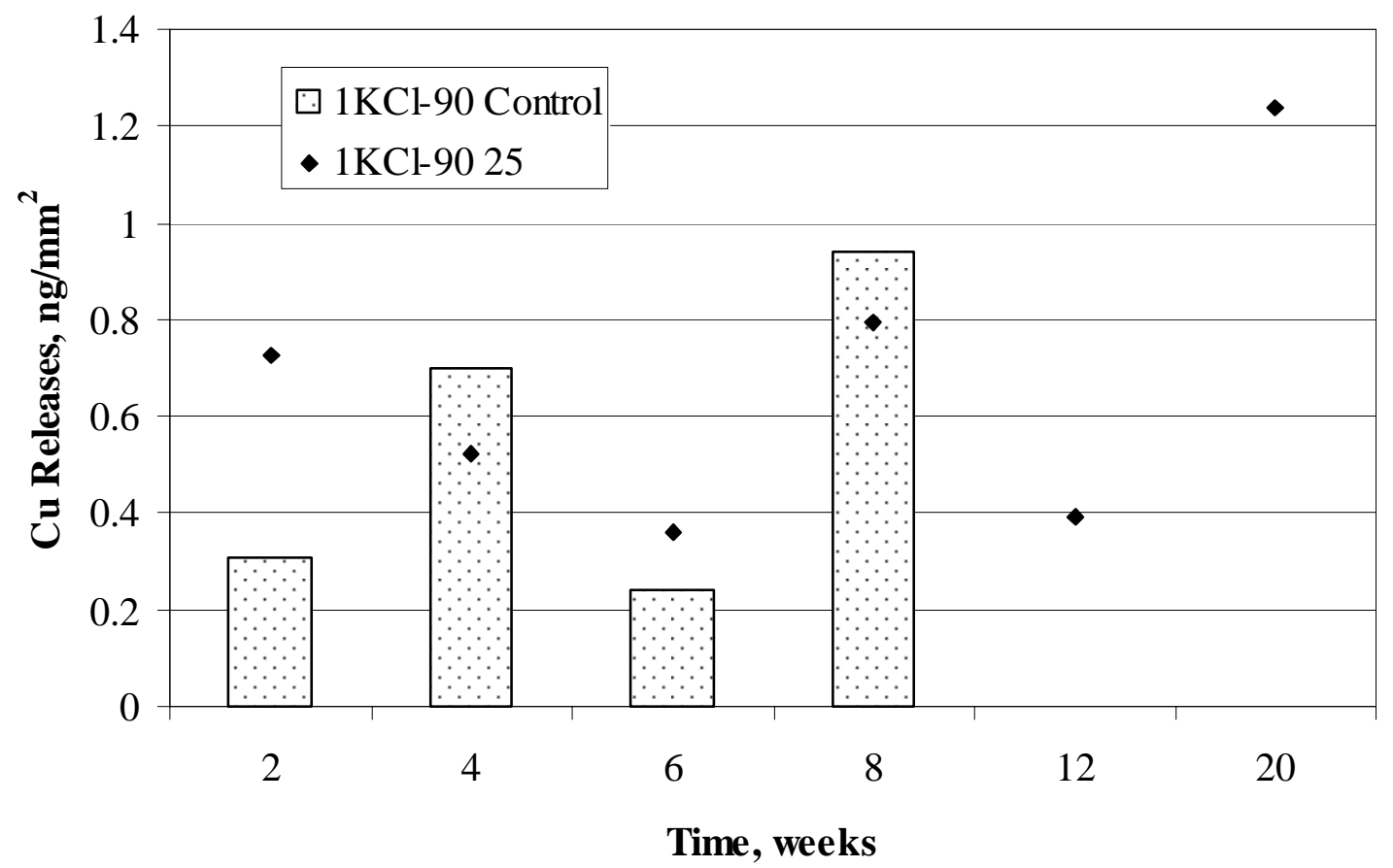

Figure M-45. Copper Releases in $1 \mathrm{KCl}$ solution at $90^{\circ} \mathrm{C}$.

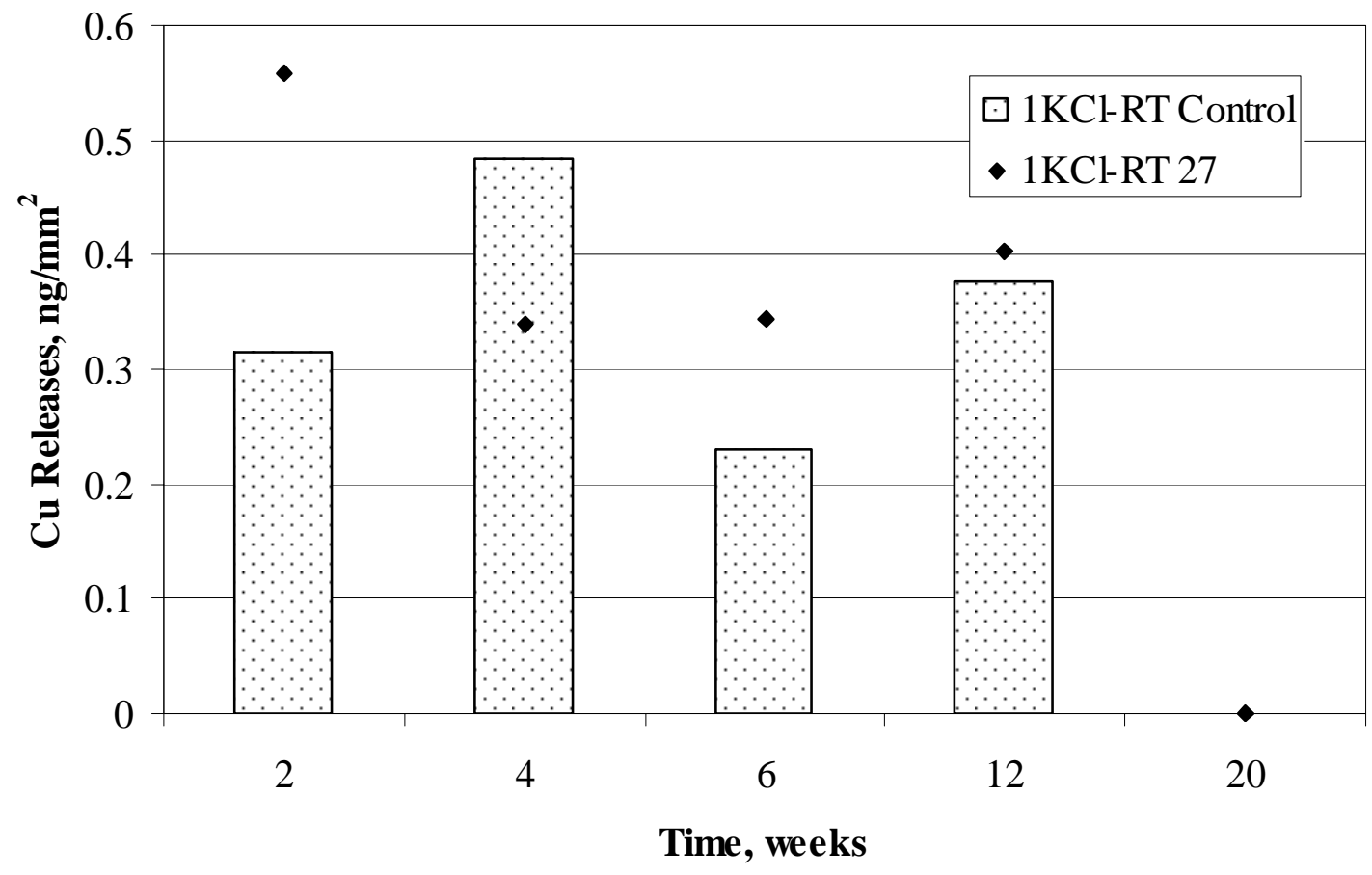

Figure M-46. Copper Releases in $1 \mathrm{KCl}$ solution at room temperature. 


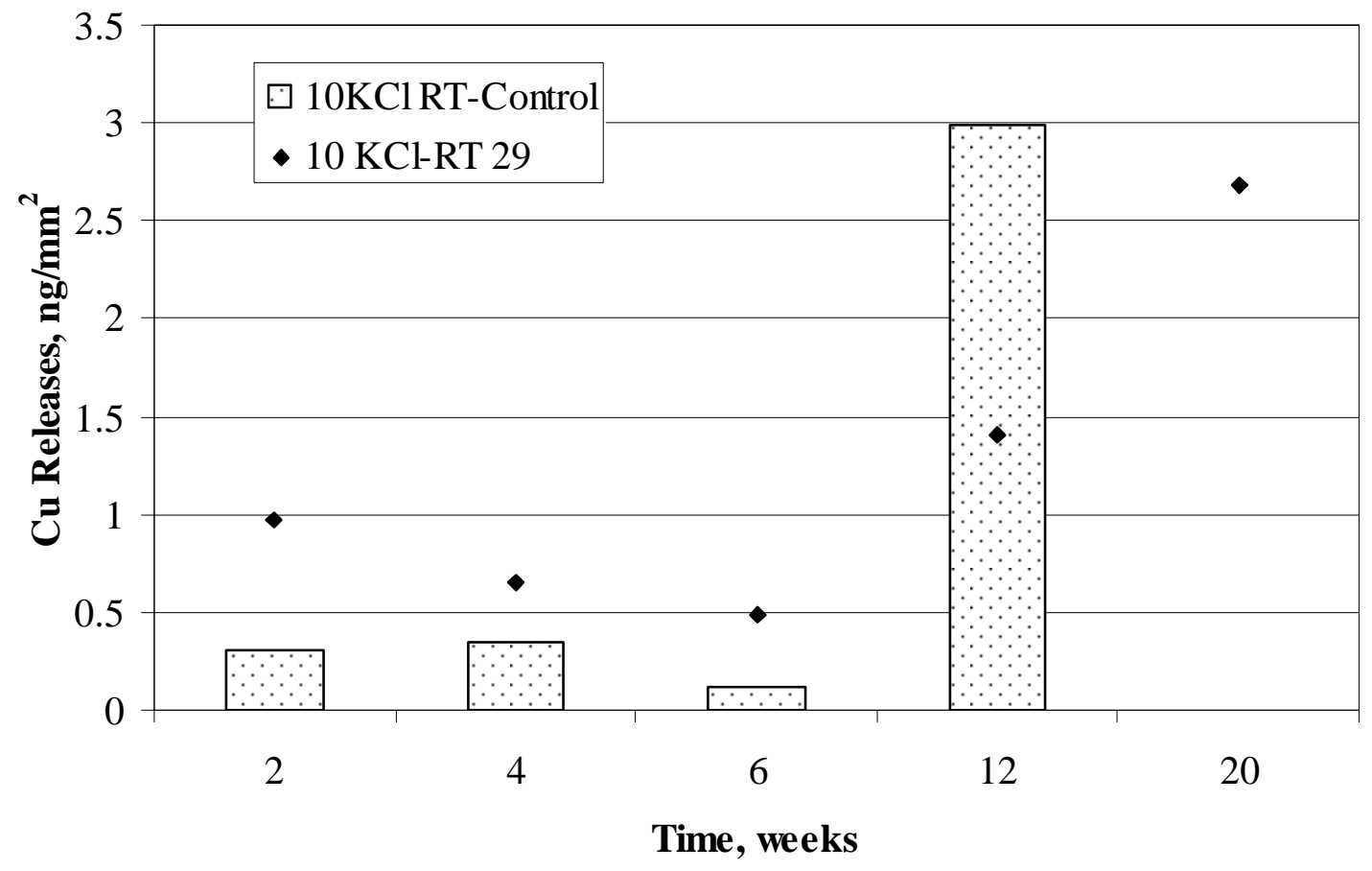

Figure M-47. Copper Releases in $10 \mathrm{KCl}$ solution at room temperature.

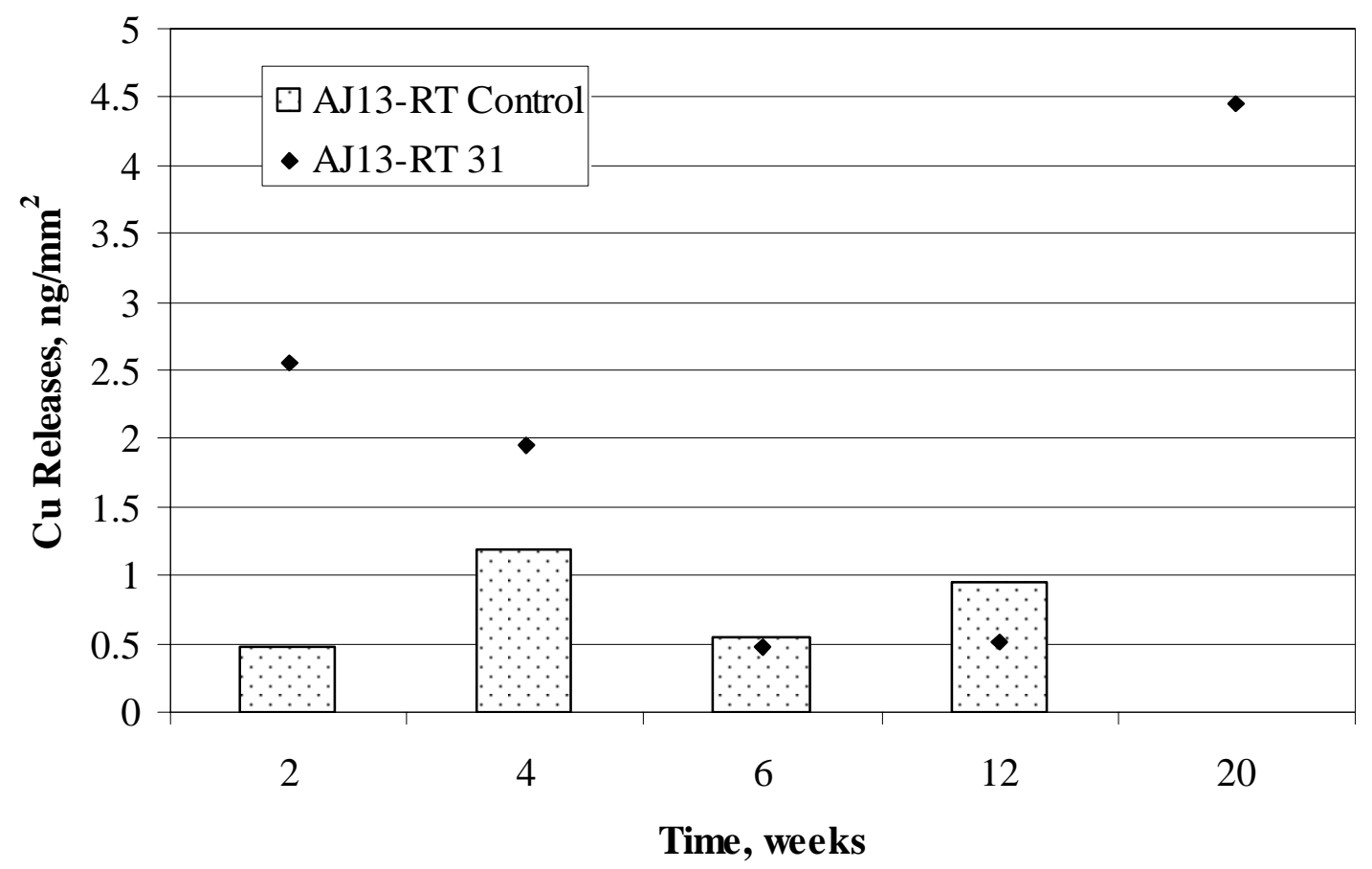

Figure M-48. Copper Releases in AJ13 solution at room temperature. 


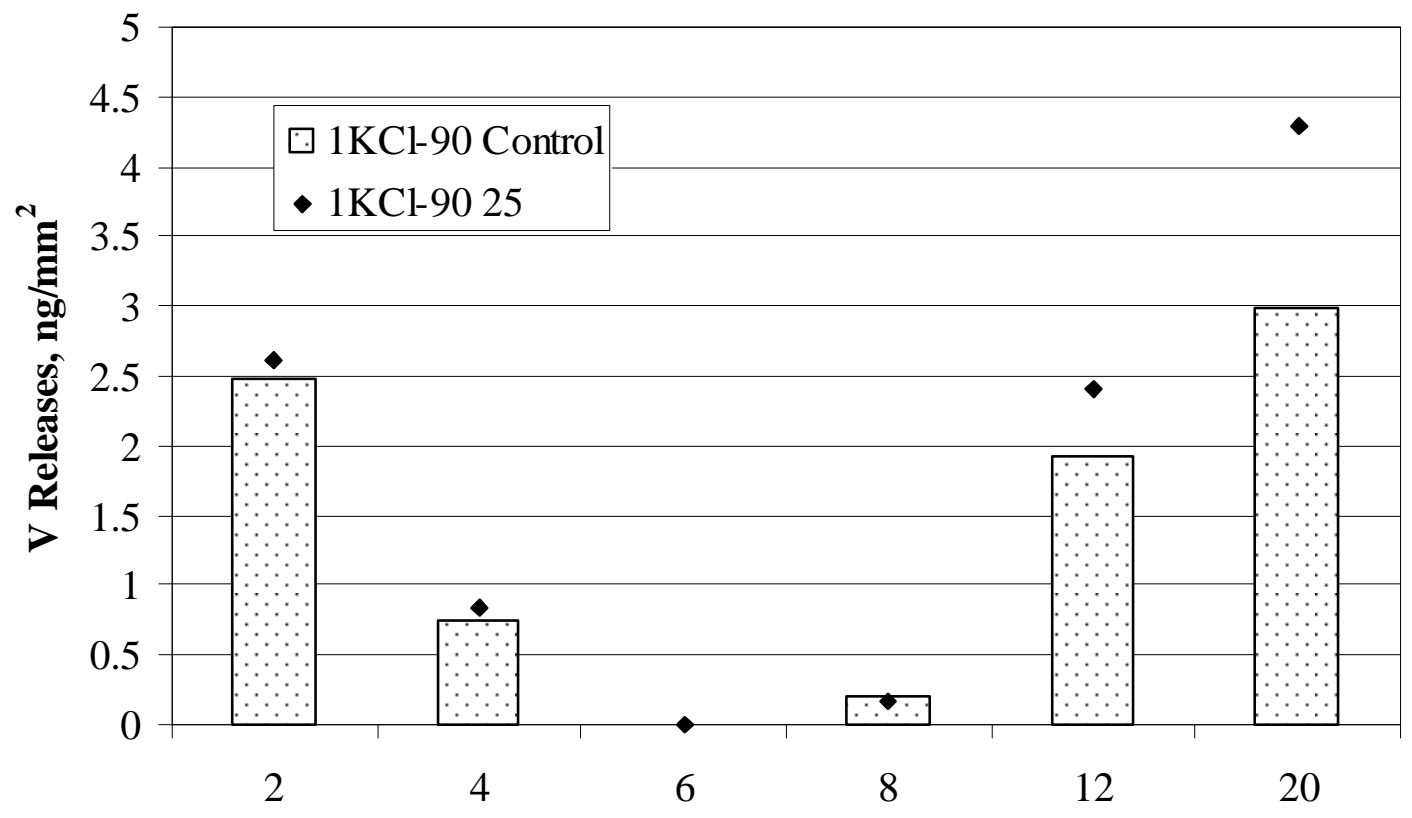

Time, weeks

Figure M-49. Vanadium Releases in $1 \mathrm{KCl}$ solution at $90^{\circ} \mathrm{C}$.

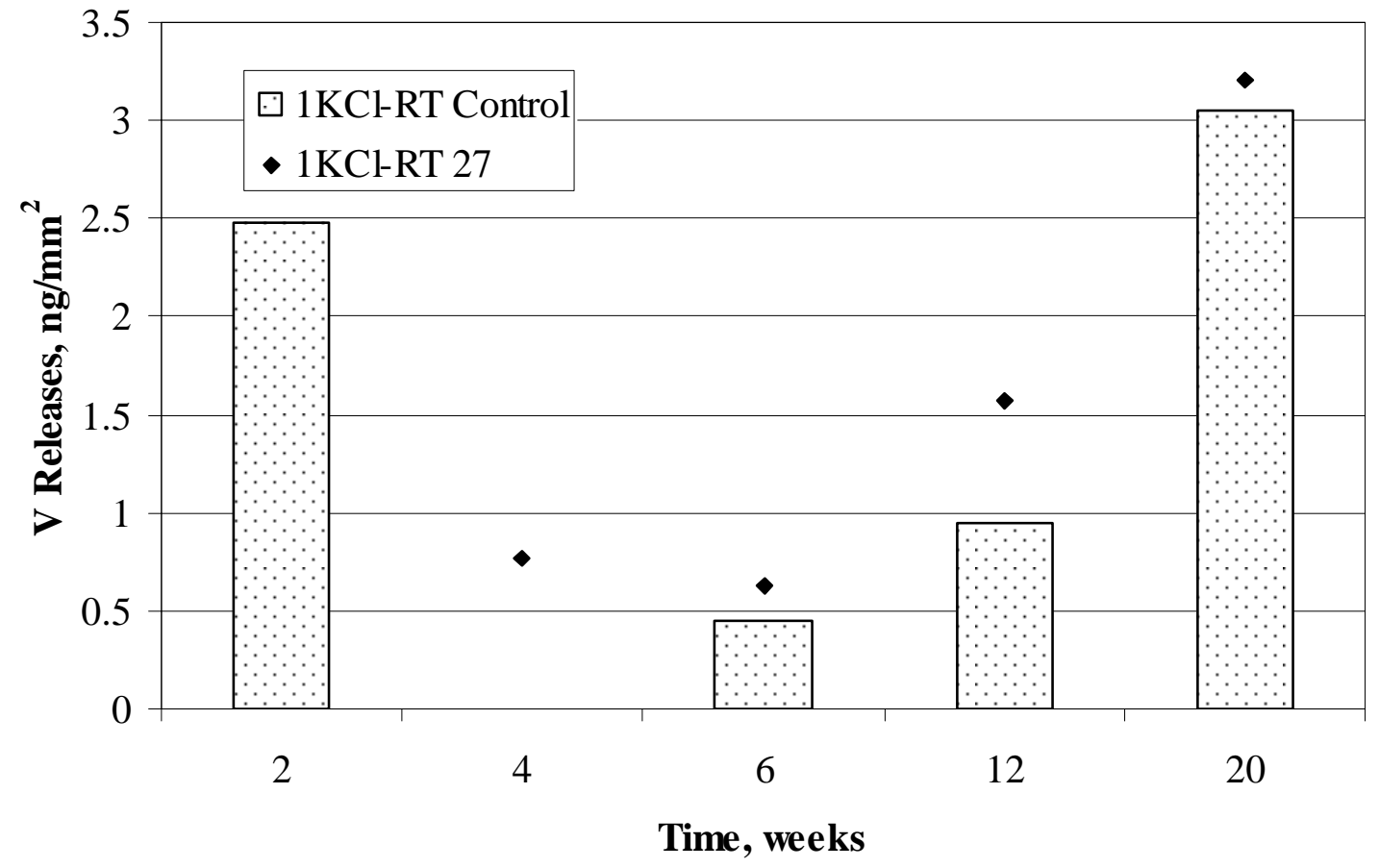

Figure M-50. Vanadium Releases in $1 \mathrm{KCl}$ solution at room temperature. 


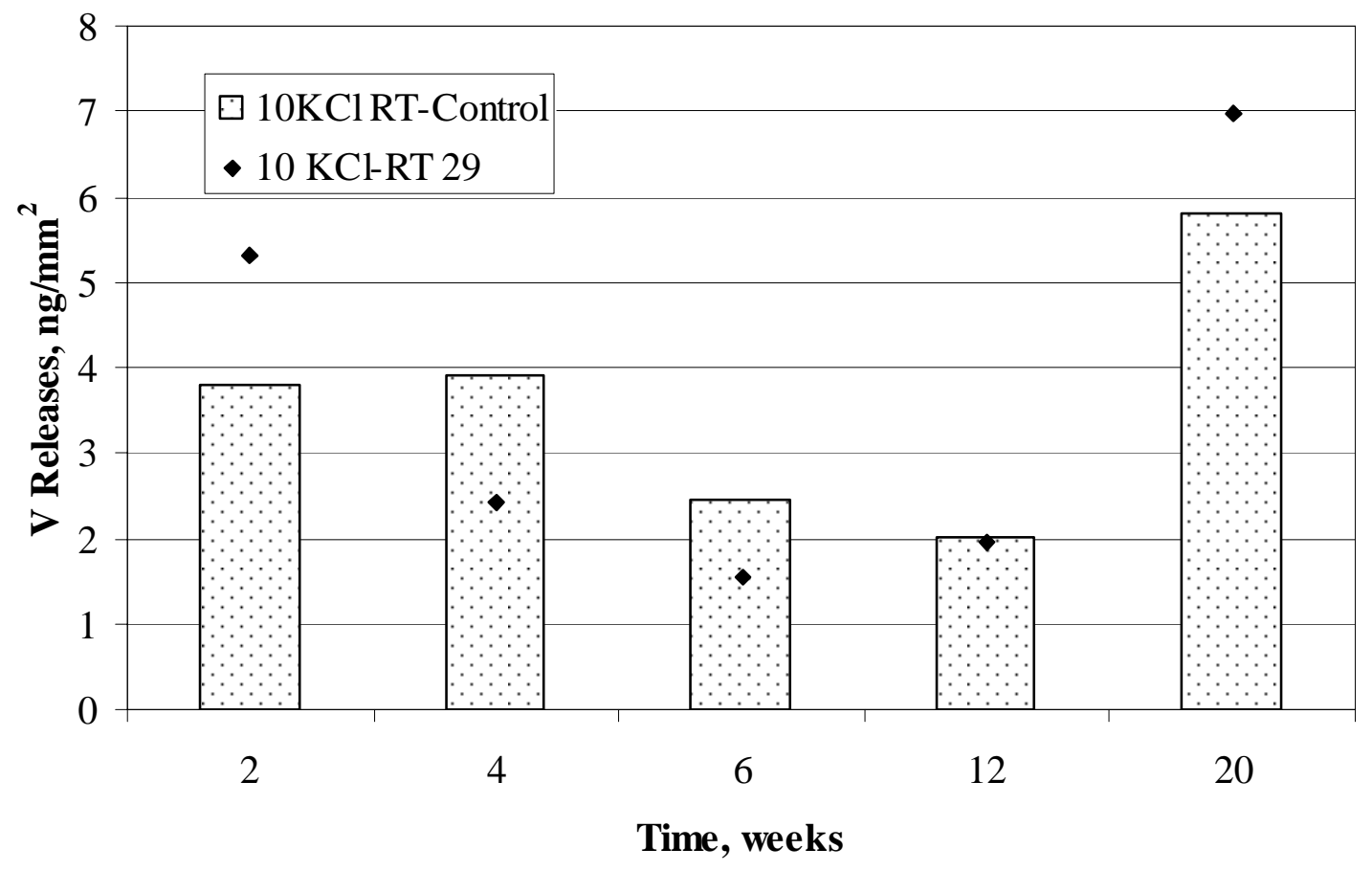

Figure M-51. Vanadium Releases in $10 \mathrm{KCl}$ solution at room temperature.

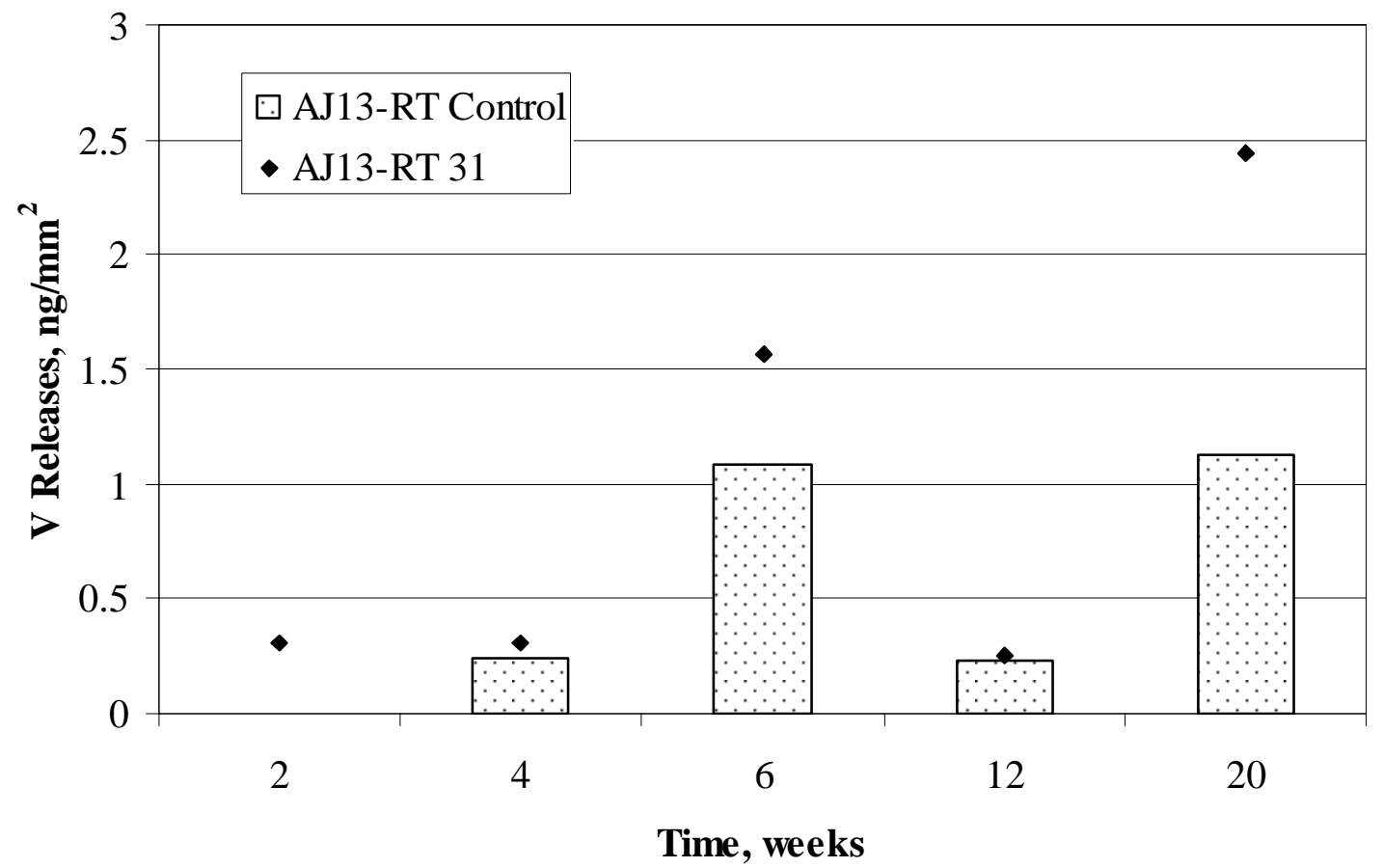

Figure M-52. Vanadium Releases in AJ13 solution at room temperature. 


\section{N. Normalized Loss Formula with No Correction for Blanks}

\section{Used for Comparing Fe Normalized Loss with High Level Glass Waste}

$\mathrm{NL}=\frac{\left[\frac{\left(\mathrm{C}_{\mathrm{idi}} \mathrm{V}_{\mathrm{i}}\right)+\left(\mathrm{CiV}_{\mathrm{i}}\right)_{\mathrm{AS}}}{\mathrm{V}_{\mathrm{i}}}+C_{R}\right] * \mathrm{~V}_{\mathrm{i}} * 0.001}{\mathrm{~A} * \mathrm{f}_{\mathrm{i}}}$

$\mathrm{NL}_{\mathrm{i}}=$ Normalized Loss $\left(\mathrm{g} / \mathrm{m}^{2}\right)$

$\mathrm{C}_{\mathrm{i}}=$ Concentration of ith element in solution $(\mu \mathrm{g} / \mathrm{L})$

$\mathrm{d}_{\mathrm{i}}=$ dilution factor for test solution containing ith element (because solution is acidified)

$\mathrm{V}_{\mathrm{i}}=$ Volume of test solution containing ith element $(\mathrm{mL})$

$\mathrm{AS}=$ Acid Strip (refers to elemental concentration and volume of acid strip solutions)

$\mathrm{A}=$ area of specimen $\left(\mathrm{mm}^{2}\right)$

$\mathrm{f}_{\mathrm{i}}=$ fraction of ith element in specimen

$\mathrm{C}_{\mathrm{R}}=$ Concentration of ith element in residue $(\mu \mathrm{g} / \mathrm{L})$

Notes:

1. The $1^{\text {st }}$ term in the equation gives the elemental content in the test and acid strip solutions.

3. The multiplication factor 0.001 is used to convert the normalized loss value to $\mathrm{g} / \mathrm{m}^{2}$. 
Distribution for ANL-04/15

\author{
Internal (Electronic Copies): \\ D. Abraham \\ L. A. Barnes \\ T. H. Bauer \\ W. L. Ebert \\ J. K. Fink \\ L. Leibowitz \\ D. Lewis \\ C. T. Snyder \\ M. A. Williamson \\ Internal (Electronic Copy):
}

M. R. Hale, TIS

External (Electronic Copies Only):

M. A. Buckley, ANL Library-E

E. Sackett, ANL Library-W 